\title{
24 M METEOROLOGICAL TOWER DATA REPORT PERIOD: JANUARY THROUGH DECEMBER, 1994
}

\author{
Submitted to: \\ John Spahn \\ Department of Energy \\ Nevada Operations Office \\ P.O. Box 98518 \\ Las Vegas, NV 89193-8519
}

RECPED

noy 121997

$0.5 \%$

\author{
Prepared by: \\ Daniel Freeman, John Bowen, Richard Egami, William Coulombe, \\ Dale Crow, Brenda Cristani, Steve Schmidt \\ Desert Research Institute \\ University and Community College System of Nevada \\ P.O. Box 60220 \\ Reno, NV 89506
}

August 1997

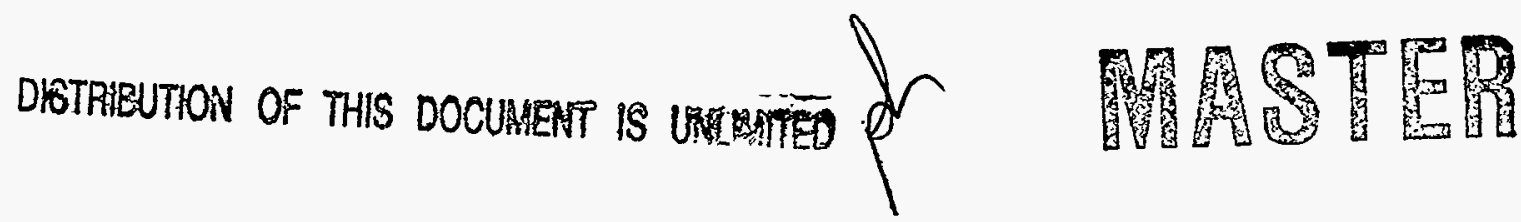




\section{DISCLAIMER}

Portions of this document may be illegible electronic image products. Images are produced from the best available original document. 


\section{TABLE OF CONTENTS}

Page

Table of Contents

i

$\begin{array}{ll}\text { List of Figures } & \text { ii }\end{array}$

$\begin{array}{ll}\text { List of Tables } & \text { ii }\end{array}$

$\begin{array}{ll}1.0 \text { INTRODUCTION } & 1\end{array}$

$\begin{array}{ll}\text { 2.0 MEASUREMENT METHODS } & 1\end{array}$

3.0 OPERATIONAL STATUS 5

$\begin{array}{ll}\text { 4.0 DATA QUALITY ASSURANCE } & 7\end{array}$

5.0 MEASSUREMENT RESULTS

6.0 STABILITY CALCULATIONS 31

$\begin{array}{ll}\text { 7.0 REFERENCES } & 33\end{array}$

APPENDIX A Selected Time Series Plots, Two and Eight Meters $\quad$ A-1 - A-48

APPENDIX B Monthly Wind Roses, Two and Eight Meters B-1 - B-264

APPENDIX C Monthly Wind Frequency Distributions, Two and Eight C-1 - C-264 Meters

APPENDIX D Tabulated Hourly Richardson Numbers, Monin-Obukhov D-1 - D-96

Lengths Estimated from Richardson Numbers,

Temperature Differences Two to Sixteen Meters, and Sigma Theta Stability Classes 


\section{LIST OF FIGURES}

Page

Figure 1-1 Location of Project

\section{LIST OF TABLES}

Page

Table 2-1 Instrument Design and Actual Height (m) from Ground to Center of Sensor

Table 3-1 Operational Summary

Table 3-2 Data Recovery for Each Measurement by Month 6

Table 4-1a Accuracy of Meteorological Data Based on Calibration Data, $\quad 8$ April, 1994

Table 4-1b Accuracy of Meteorological Data Based on Calibration Data, September, 1994

Table 4-2a Results of April 1994 Temperature Water Bath Calibrations

Table 4-2b Results of September 1994 Temperature Water Bath Calibrations (Before Program Change)

Table 4-2c Results of September 1994 Temperature Water Bath Calibrations (After Program Change)

Table 4-3a Calibration of Thermometers versus HP Quartz Thermometer 4-5 April 1994

Table 4-3b Calibration of Thermometers versus HP Quartz Thermometer September 20, 1994

Table 4-4a Results of April 1994 Wind Speed Calibrations

Table 4-4b Results of September 1994 Wind Speed Calibrations 16

Table 4-5a Results of April 1994 Wind Direction Calibrations 


\subsection{INTRODUCTION}

This report was prepared by the Desert Research Institute (DRI) for the U. S. Department of Energy (DOE). It summarizes meteorological data collected at the 24 meter tower at the Nevada Test Site Hazardous Material Spill Center (HAZMAT) located at Frenchman Flat near Mercury, Nevada, approximately 75 miles northwest of Las Vegas, Nevada (Figure 1-1). The tower was originally installed in July, 1993 to characterize baseline conditions for an EPA sponsored experimental research program at the HAZMAT.

This report presents results of the monitoring for January-December, 1994, providing:

- a status of the measurement systems (including any quality assurance activities) during the report period and

- a summary of the meteorological conditions at the HAZMAT during the report period.

The scope of the report is limited to summary data analyses and does not include extensive meteorological analysis

\subsection{MEASUREMENT METHODS}

Detailed measurement methods are described in a QA Plan written for operation of the met tower (DRI/Western Research Institute, 1993). The plan covers data processing, validation and reporting of the tower data as well as operation and maintenance of the instruments.

For convenience, the design characteristics of the met tower are repeated in Table 2-1. In summary, the tower was instrumented at eight levels. Wind speed, wind direction, and temperature were measured at all 8 levels: $1 / 4,1 / 2,1,2,4,8,16$, and 24 meters above the ground. Relative humidity was measured at 3 levels: 1,4 , and 16 meters above the ground. Solar and net radiation were measured 2 meters above the ground, approximately 20 meters to the south of the tower. Barometric pressure was measured at the base of the tower, soil temperature was measured near the base of the tower. Wind sensors were mounted on retractable arms at about $2.5 \mathrm{~m}$ from the tower. Temperature sensors were housed in aspirated radiation shields near the wind sensors. Relative humidity sensors were mounted in passive radiation shields. Data were collected using a Campbell Scientific, model $21 \mathrm{X}$, data acquisition system (DAS) with multiplexer, interval timer, and 32 analog outputs.

During the EPA dense gas dispersion experiments, wind speed and direction sensors were modified to have faster response characteristics. For year round operation, the threshold value for wind speed is $0.4 \mathrm{mps}$ and $0.5 \mathrm{mps}$ for wind direction at $10^{\circ}$ displacement. During experiments, the threshold value for wind speed was $0.2 \mathrm{mps}$ and for wind direction it was 0.4 mps at $10^{\circ}$ displacement. No experiments requiring a change in sensors occurred during the report period. 


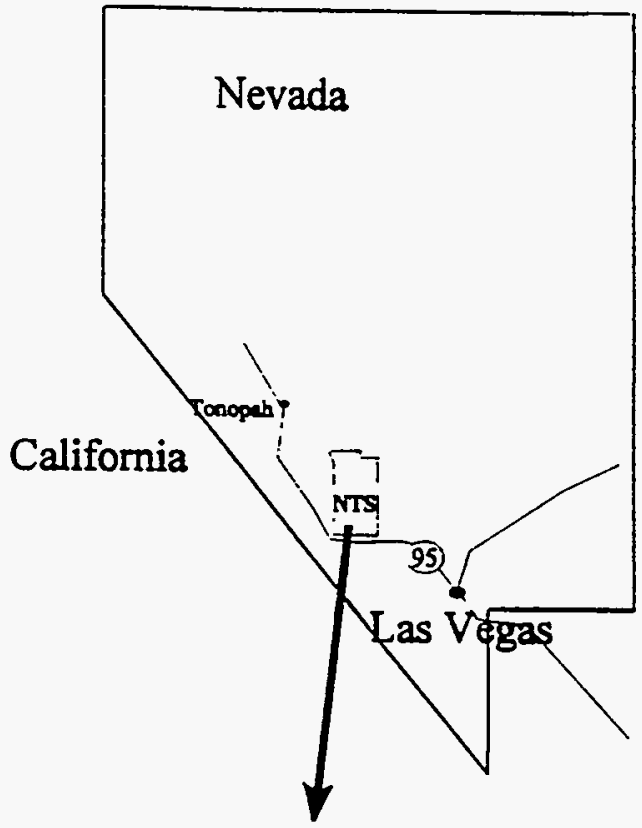

Utah

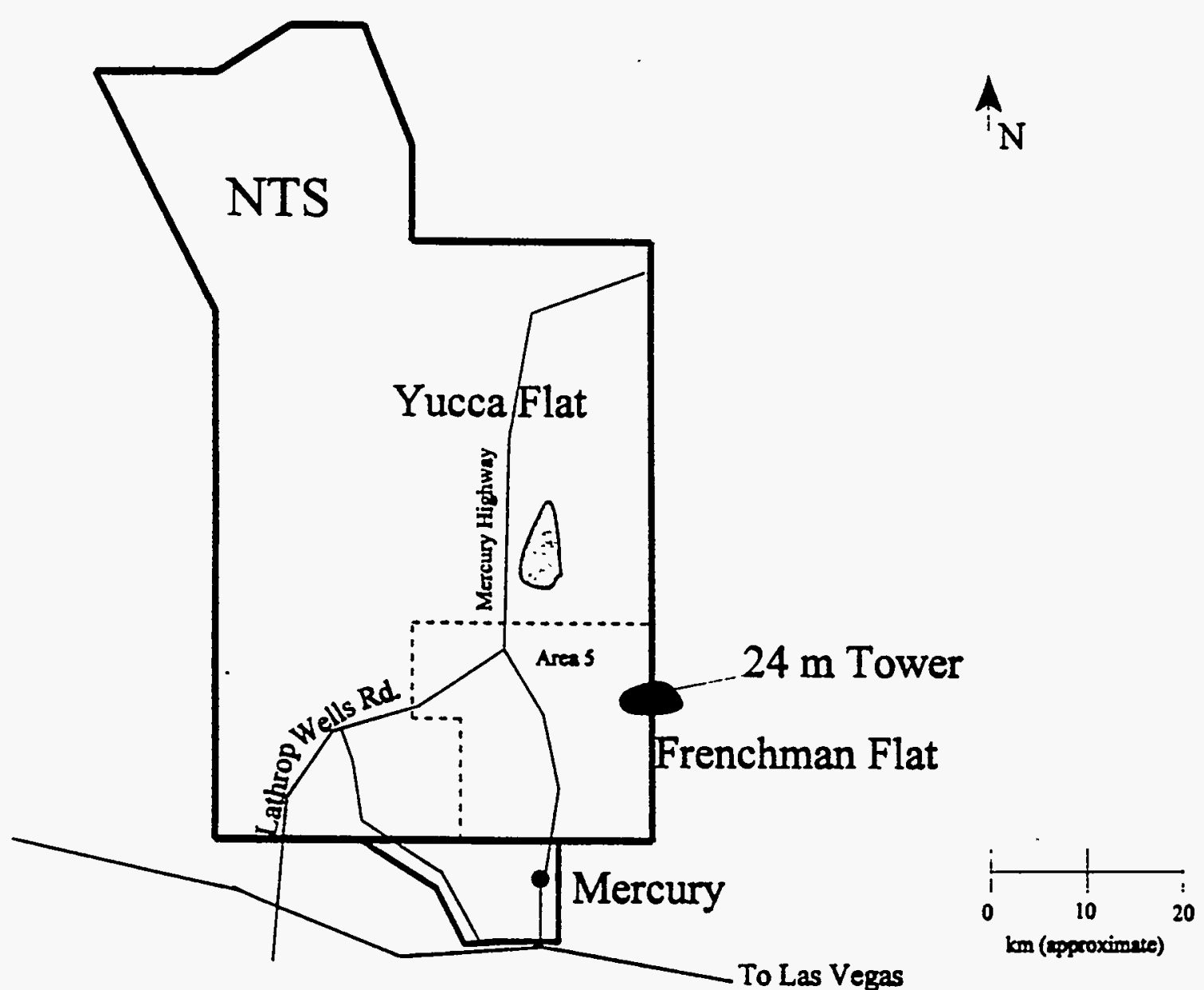

Figure 1-1 Location of Project 
Table 2-1 Instrument Design

\begin{tabular}{|c|c|c|c|c|c|c|c|}
\hline Parameter & Units & Range & Method & Manufacturer & Model & Precision & Accuracy \\
\hline Wind Speed & mps & 0 to 44.7 & Anemometer & R.M. Young & AQ-5305 & $0.1 \mathrm{mps}$ & $0.1 \mathrm{mps}$ \\
\hline Wind Direction & degrees & 0 to 360 & Wind Vane & R.M. Young & $A Q-5305$ & 3 degrees & 3 degrees \\
\hline Temperature-air & ${ }^{\circ} \mathrm{C}$ & -30 to 50 & $\begin{array}{l}\text { platinum } \\
\text { resistance } \\
\text { Thermometer }\end{array}$ & R.M. Young & none & $0.1^{\circ} \mathrm{C}$ & $0.2^{\circ} \mathrm{C}$ \\
\hline Temperature-soil & ${ }^{\circ} \mathrm{C}$ & -30 to 50 & $\begin{array}{l}\text { Fenwal } \\
\text { Thermistor }\end{array}$ & $\begin{array}{l}\text { Campbell } \\
\text { Sci. }\end{array}$ & $107 \mathrm{~B}$ & $0.1^{\circ} \mathrm{C}$ & $0.2^{\circ} \mathrm{C}$ \\
\hline Relative Humid. & percent & 0 to 100 & Capacitive & Vaisala & HMP-35C & $5 \%$ & $5 \%$ \\
\hline $\begin{array}{l}\text { Barometric } \\
\text { Pressure }\end{array}$ & $\mathrm{mb}$ & $\begin{array}{l}800 \text { to } \\
1060\end{array}$ & $\begin{array}{l}\text { Silicon } \\
\text { Capacitive }\end{array}$ & Vaisala & PTA-427 & $2 \mathrm{mb}$ & $2 \mathrm{mb}$ \\
\hline Solar Radiation & $\mathrm{w} / \mathrm{m}^{2}$ & 0 to 1396 & $\begin{array}{l}\text { Silicon } \\
\text { Photodiode }\end{array}$ & LI-COR & LI200 & $25 \mathrm{w} / \mathrm{m}^{2}$ & $25 \mathrm{w} / \mathrm{m}^{2}$ \\
\hline Net Radiation & $\mathrm{w} / \mathrm{m}^{2}$ & $\begin{array}{l}-200 \text { to } \\
1396 \\
\end{array}$ & $\begin{array}{l}\text { Differential } \\
\text { Thermopile }\end{array}$ & REBS & none & $25 \mathrm{w} / \mathrm{m}^{2}$ & $25 \mathrm{w} / \mathrm{m}^{2}$ \\
\hline
\end{tabular}

\begin{tabular}{|l|l|l|l|l|l|l|}
\hline \multicolumn{7}{|c|}{ Actual Height (m) From Ground to Center of Sensor } \\
\hline $\begin{array}{l}\text { Nominal } \\
\text { Level (m) }\end{array}$ & $\begin{array}{l}\text { Wind } \\
\text { Speed }\end{array}$ & $\begin{array}{l}\text { Wind } \\
\text { Direction }\end{array}$ & Temperature & $\begin{array}{l}\text { Relative } \\
\text { Humidity }\end{array}$ & $\begin{array}{l}\text { Solar } \\
\text { Radiation * }\end{array}$ & $\begin{array}{l}\text { Net } \\
\text { Radiation }\end{array}$ \\
\hline 24 & 24.31 & 24.31 & 23.99 & & & \\
\hline 16 & 16.01 & 16.01 & 15.95 & 16.40 & & \\
\hline 8 & 7.81 & 7.81 & 7.78 & & & \\
\hline 4 & 4.12 & 4.12 & 4.08 & 4.53 & & \\
\hline 2 & 2.01 & 2.01 & 1.98 & & 1.88 & 1.71 \\
\hline 1 & 0.95 & 0.95 & 1.02 & 1.25 & & \\
\hline 0.50 & 0.50 & 0.50 & 0.57 & & & \\
\hline 0.25 & 0.26 & 0.26 & 0.25 & & & \\
\hline soil & & & -0.07 & & & \\
\hline
\end{tabular}

* Radiation sensors are actually on separate towers approximately $20 \mathrm{~m}$ south of the main tower.

\subsection{Computations}

Sensor voltages were processed by the Campbell Scientific Data Acquisition System (DAS) at a sampling rate of once every 10 seconds and stored in engineering units as 15 minute averages. Data were automatically downloaded daily from the DAS by telephone to a personal computer at DRI's Data Processing Center in Reno. Proper data downloading was verified daily (Monday through Friday), and daily files were concatenated into weekly files for weekly evaluation of measurement system integrity.

Weekly files were concatenated into monthly files of 15 minute averages. In addition to the 15 minute data, files of hourly averaged data were constructed from validated 15 minute data. Wind 
frequency distributions and stability classes were calculated from the hourly data (Section 6.0). All times are Pacific Standard Time (PST) and the time stamp represents the beginning of the averaging period (e.g., 0900 is the average from 0900-0915). 


\subsection{OPERATIONAL STATUS}

A summary of problems and changes to instruments occurring during the report period is provided in Table 3-1 and the percent data recovery in Table 3-2.

Table 3-1 Operational Summary

\begin{tabular}{|l|l|l|l|}
\hline $\begin{array}{l}\text { Start } \\
\text { Date }\end{array}$ & Event & $\begin{array}{l}\text { End } \\
\text { Date }\end{array}$ & Action \\
\hline $1 / 1 / 94$ & $\begin{array}{l}24 \mathrm{~m} \mathrm{temperature} \mathrm{sensor} \\
\text { failure }\end{array}$ & $2 / 12 / 94$ & Replaced 24 m sensor \\
\hline $1 / 25 / 94$ & $\begin{array}{l}\text { Datalogger malfunction } \\
\text { (all output off scale high) }\end{array}$ & $2 / 1 / 94$ & Replaced datalogger \\
\hline $1 / 25 / 94$ & $\begin{array}{l}16 \mathrm{~m} \mathrm{temperature} \mathrm{sensor} \\
\text { failure }\end{array}$ & $2 / 12 / 94$ & Switched 0.5 m sensor to 16 m \\
\hline $2 / 11 / 94$ & $\begin{array}{l}\text { Installed new power supply } \\
\text { and voltage regulator for } \\
\text { datalogger }\end{array}$ & $\begin{array}{l}\text { Not } \\
\text { applicable }\end{array}$ & $\begin{array}{l}\text { Not } \\
\text { Applicable }\end{array}$ \\
\hline $2 / 12 / 94$ & $\begin{array}{l}0.5 \mathrm{~m} \mathrm{temperature} \mathrm{sensor} \\
\text { moved to 16 m }\end{array}$ & $2 / 20 / 94$ & Replaced 0.5 m sensor \\
\hline $3 / 6 / 94$ & $\begin{array}{l}24 \mathrm{~m} \mathrm{temperature} \mathrm{sensor} \\
\text { failure }\end{array}$ & $4 / 5 / 94$ & Replaced 24 m sensor \\
\hline $4 / 5 / 94$ & DRI calibration & $\begin{array}{l}\text { Not } \\
\text { Applicable }\end{array}$ & $\begin{array}{l}\text { Not } \\
\text { Applicable }\end{array}$ \\
\hline $9 / 19-20 / 94$ & DRI calibration & $\begin{array}{l}\text { Not } \\
\text { Applicable }\end{array}$ & $\begin{array}{l}\text { Not } \\
\text { Applicable }\end{array}$ \\
\hline
\end{tabular}


Table 3-2 Data Recovery for Each Measurement by Month

\begin{tabular}{|c|c|c|c|c|c|c|c|c|c|c|c|c|}
\hline Measurement & January & February & March & April & May & June & July & August & September & October & November & December \\
\hline \multicolumn{13}{|c|}{ Wind Speed and Direction } \\
\hline $24 m$ & 78.0 & 85.4 & 100.0 & 99.9 & 96.9 & 100.0 & 98.5 & 98.3 & 98.1 & 100.0 & 100.0 & 64.8 \\
\hline $16 \mathrm{~m}$ & 78.0 & 85.4 & 100.0 & 99.9 & 96.9 & 100.0 & 100.0 & 100.0 & 99.3 & 100.0 & 100.0 & 64.8 \\
\hline $8 \mathrm{~m}$ & 78.0 & 85.4 & 100.0 & 99.9 & 96.9 & 100.0 & 100.0 & 100.0 & 99.2 & 98.5 & 99.7 & 64.8 \\
\hline $4 \mathrm{~m}$ & 78.0 & 85.4 & 100.0 & 99.4 & 96.9 & 100.0 & 100.0 & 100.0 & 99.7 & 100.0 & 99.9 & 64.8 \\
\hline $2 m$ & 78.0 & 85.4 & 100.0 & 99.6 & 96.9 & 100.0 & 100.0 & 100.0 & 99.7 & 100.0 & 100.0 & 64.8 \\
\hline $1 \mathrm{~m}$ & 78.0 & 85.4 & 100.0 & 99.6 & 96.9 & 100.0 & 100.0 & 100.0 & 99.7 & 100.0 & 99.4 & 64.8 \\
\hline $0.5 \mathrm{~m}$ & 78.0 & 85.4 & 100.0 & 99.6 & 96.9 & 100.0 & 100.0 & 100.0 & 99.7 & 100.0 & 100.0 & 64.8 \\
\hline $0.25 \mathrm{~m}$ & 78.0 & 85.4 & 100.0 & 99.6 & 96.9 & 100.0 & 100.0 & 100.0 & 99.7 & 100.0 & 100.0 & 64.8 \\
\hline \multicolumn{13}{|l|}{ Temperature } \\
\hline $24 m$ & 0.0 & 52.1 & 18.8 & 84.7 & 96.9 & 99.9 & 99.9 & 100 & 98.6 & 100.0 & 100 & 64.8 \\
\hline $16 \mathrm{~m}$ & 78.0 & 52.1 & 99.9 & 99.3 & 96.9 & 99.9 & 99.9 & 100 & 98.6 & 100.0 & 100 & 64.8 \\
\hline $8 m$ & 78.0 & 75.1 & 99.9 & 99.3 & 96.9 & 99.9 & 99.9 & 100 & 98.6 & 100.0 & 100 & 64.8 \\
\hline $4 m$ & 78.0 & 75.1 & 99.9 & 99.3 & 96.9 & 99.9 & 99.9 & 100 & 98.6 & 100.0 & 100 & 64.8 \\
\hline $2 m$ & 78.0 & 75.1 & 99.9 & 99.3 & 96.9 & 99.9 & 99.9 & 100 & 98.6 & 100.0 & 100 & 64.8 \\
\hline $1 \mathrm{~m}$ & 78.0 & 75.1 & 99.9 & 99.3 & 96.9 & 99.9 & 99.9 & 100 & 98.6 & 100.0 & 100 & 64.8 \\
\hline $0.5 \mathrm{~m}$ & 78.0 & 50.7 & 99.9 & 99.3 & 96.9 & 99.9 & 99.9 & 100 & 98.6 & 100.0 & 100 & 64.8 \\
\hline $\begin{array}{c}0.25 \mathrm{~m} \\
\text { Soil }\end{array}$ & 78.0 & 75.1 & 99.9 & 99.3 & 96.9 & 99.9 & 99.9 & 100 & 98.6 & 100.0 & 100 & 64.8 \\
\hline \multicolumn{13}{|l|}{ Relative Humidity } \\
\hline $16 \mathrm{~m}$ & 78 & 85 & 100 & 99 & 97 & 100 & 100 & 100 & 99 & 100 & 100 & 65 \\
\hline $4 m$ & 78 & 85 & 100 & 100 & 97 & 100 & 100 & 100 & 99 & 100 & 100 & 65 \\
\hline $1 \mathrm{~m}$ & 78 & 85 & 100 & 100 & 97 & 100 & 100 & 100 & 99 & 100 & 100 & 65 \\
\hline Solar Radiation & 78 & 85 & 100 & 99 & 97 & 99 & 100 & 100 & 99 & 100 & 100 & 65 \\
\hline Net Radiation & 78 & 85 & 100 & 99 & 96 & 99 & 66 & & 38 & 100 & 100 & 65 \\
\hline Barometric Pressure & 78 & 85 & 100 & 100 & 97 & 100 & 100 & 100 & 100 & 100 & 100 & 65 \\
\hline
\end{tabular}




\subsection{DATA QUALITY ASSURANCE}

In accordance with the QA Plan (DRI/WRI, 1993), calibrations were performed semiannually. For this report period, calibrations were performed in April and September.

Calibration procedures are detailed in the QA Plan (DRI/WRI, 1994). In summary, temperature sensors were calibrated by side by side comparison with an audit thermometer in the field. Wind speed was checked using a constant speed motor. Wind direction was verified against targets of known direction. Relative humidity and barometric pressure were verified against a psychrometer and altimeter, respectively. Solar radiation was verified against a Precision Spectral Pyranometer run side by side.

Accuracy of the sensors, in terms of the difference between the calibration target and the value measured by each sensor, is summarized in Table 4-1. More detailed calibration results for each measurement are provided in Tables 4-2 through 4-6. 
Table 4-1a. Accuracy of Meteorological Data Based on Calibration Data, April, 1994

\begin{tabular}{|c|c|c|c|c|c|c|c|c|c|}
\hline \multicolumn{10}{|c|}{ DIFFERENCE FROM CALIBRATION STANDARD } \\
\hline \multirow{2}{*}{$\begin{array}{c}\text { Level } \\
\text { (meters) }\end{array}$} & \multicolumn{2}{|c|}{$\begin{array}{c}\text { Temperature }\left({ }^{\circ} \mathrm{C}\right) \\
\text { Water Bath }\end{array}$} & \multicolumn{2}{|c|}{$\begin{array}{l}\text { Wind Speed (mps) } \\
\text { Constant Motor }\end{array}$} & \multicolumn{2}{|c|}{$\begin{array}{l}\text { Wind Direction } \\
\text { (degrees) } \\
\text { Orientation }\end{array}$} & \multirow{2}{*}{$\begin{array}{c}\text { Relative } \\
\text { Humidity } \\
\text { Psychrometer } \\
\% \\
\end{array}$} & \multirow{2}{*}{$\begin{array}{l}\text { Barometric } \\
\text { Pressure } \\
\text { (mb) }\end{array}$} & \multirow{2}{*}{$\begin{array}{c}\text { Solar } \\
\text { Radiation } \\
\left(W / \mathrm{m}^{2}\right)\end{array}$} \\
\hline & Mean & Sid Dev & Mean & Sid Dev & Mean & Std Dev & & & \\
\hline 24 & -0.69 & 0.49 & 0.00 & 0.00 & -0.7 & 1.4 & & & \\
\hline 6 & -0.67 & 0.65 & 0.00 & 0.00 & 0.9 & 0.9 & N/A & & \\
\hline 8 & -0.22 & 0.63 & 0.00 & 0.01 & 2.1 & 1.0 & & & \\
\hline 4 & -0.62 & 0.62 & 0.00 & 0.00 & $4.4^{11}$ & $1.6^{11}$ & N/A & & \\
\hline 2 & -0.51 & 0.58 & 0.00 & 0.00 & -0.5 & 1.9 & & & \\
\hline 1 & -0.63 & 0.53 & 0.00 & 0.00 & 1.7 & 1.2 & N/A & -1.6 & 32.2 \\
\hline 0.5 & -0.74 & 0.45 & 0.00 & 0.00 & -0.5 & 1.1 & & & \\
\hline 0.25 & -0.86 & 0.49 & 0.00 & 0.00 & 1.0 & 1.3 & & & \\
\hline
\end{tabular}

* Temperature values shown in this table were used to prepare linear regression calibration relationships, as detailed in Table 4-3.

1. Alter adjustment, $4 \mathrm{~m}$ wind direction had mean difference -0.1 , standard deviation 0.0 .

- See note in Table 4-6.

N/A IIII avisilialile 
Table 4-1b. Accuracy of Meteorological Data Based on Calibration Data, September, 1994

\begin{tabular}{|c|c|c|c|c|c|c|c|c|c|c|c|}
\hline \multicolumn{12}{|c|}{ DIFFERENCE FROM CALIBRATION STANDARD } \\
\hline \multirow{2}{*}{$\begin{array}{c}\text { Level } \\
\text { (meters) }\end{array}$} & \multicolumn{2}{|c|}{$\begin{array}{c}\text { Temperature }\left({ }^{\circ} \mathrm{C}\right) \\
\text { Water Bath } \\
\text { (Before Program Change) }\end{array}$} & \multicolumn{2}{|c|}{$\begin{array}{c}\text { Temperature }\left({ }^{\circ} \mathrm{C} \text { ) }\right. \\
\text { Water Bath } \\
\text { (After Program Change) }\end{array}$} & \multicolumn{2}{|c|}{$\begin{array}{l}\text { Wind Speed (mps) } \\
\text { Constant Motor }\end{array}$} & \multicolumn{2}{|c|}{$\begin{array}{c}\text { Wind Direction } \\
\text { (degrees) } \\
\text { Orientation }\end{array}$} & \multirow{2}{*}{$\begin{array}{c}\text { Relative } \\
\text { Humidity } \\
\text { Psychrometer } \\
\%\end{array}$} & \multirow{2}{*}{$\begin{array}{c}\text { Barometric } \\
\text { Pressure } \\
\text { (mb) }\end{array}$} & \multirow{2}{*}{$\begin{array}{c}\text { Solar } \\
\text { Radiation } \\
\left(\mathrm{W} / \mathrm{m}^{2}\right)\end{array}$} \\
\hline & Mean & Std Dev & Mean & Std Dev & Mean & Std Dev & Mean & Std Dev & & & \\
\hline 24 & -0.76 & 0.45 & -0.16 & 0.03 & 0.00 & 0.00 & -1.1 & 1.6 & & & \\
\hline 16 & -0.74 & 0.55 & -0.09 & 0.14 & 0.00 & 0.00 & 1.4 & 1.6 & 2.2 & & \\
\hline 8 & -0.24 & 0.54 & -0.54 & 0.13 & 0.00 & 0.01 & 1.8 & 1.1 & & & \\
\hline 4 & -0.66 & 0.57 & -0.26 & 0.19 & 0.01 & 0.01 & 0.1 & 0.8 & 0.1 & & \\
\hline 2 & -0.50 & 0.48 & -0.18 & 0.09 & 0.00 & 0.00 & -2.2 & 1.6 & & & \\
\hline 1 & -0.65 & 0.47 & -0.06 & 0.11 & 0.00 & 0.01 & 0.2 & 0.7 & -0.7 & -0.4 & 13.4 \\
\hline 0.5 & -0.78 & 0.40 & -0.09 & 0.04 & 0.00 & 0.00 & -0.6 & 1.0 & & & . \\
\hline 0.25 & -0.91 & 0.47 & -0.05 & 0.05 & 0.00 & 0.02 & 0.7 & 1.8 & & & \\
\hline Soil & -0.05 & 0.10 & -0.07 & 0.08 & & & & & & & \\
\hline
\end{tabular}

a Temperature values shown in this table were used to prepare linear regression calibration relationships, as detailed in Table 4-3. 


\begin{tabular}{|c|c|c|c|c|c|c|c|c|c|}
\hline $\begin{array}{l}\bar{\Xi} \\
\bar{\Xi}\end{array}$ & $\stackrel{?}{\stackrel{7}{=}}$ & 总 & $\stackrel{\leftrightarrow}{=}$ & $\stackrel{3}{=}$ & $\begin{array}{l}\stackrel{n}{n} \\
\stackrel{=}{=}\end{array}$ & $\stackrel{\overbrace \circ}{=}$ & $\stackrel{\text { ? }}{=}$ & $\begin{array}{l}\stackrel{T}{T} \\
=\end{array}$ & $\stackrel{9}{=}$ \\
\hline E & $\stackrel{2}{\overline{1}}$ & 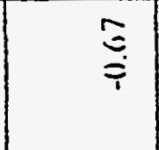 & $\begin{array}{c}\hat{1} \\
\stackrel{i}{i}\end{array}$ & $\stackrel{!}{\leftrightarrows}$ & $\stackrel{\bar{n}}{\bar{i}}$ & $\stackrel{9}{=}$ & $\begin{array}{l}\vec{T} \\
\stackrel{1}{5} \\
\end{array}$ & 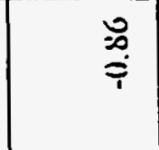 & $\begin{array}{l}\equiv \\
\overline{\mathbf{i}}\end{array}$ \\
\hline$\infty$ & 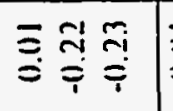 & 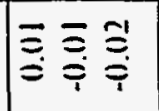 & 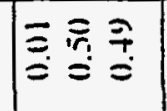 & 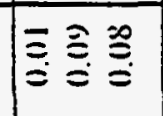 & 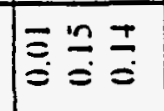 & $\begin{array}{l}\equiv \equiv \equiv \\
\equiv \equiv\end{array}$ & 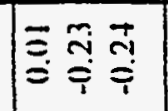 & 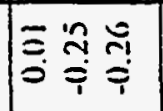 & 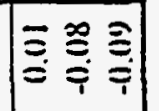 \\
\hline$r$ & 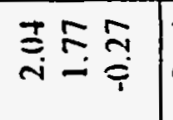 & 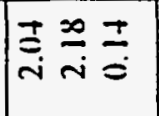 & 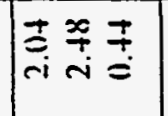 & ì & 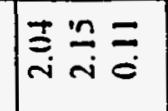 & 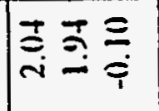 & 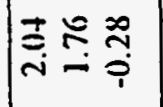 & $\stackrel{\vec{\Xi}}{\sim} \underset{\sim}{\stackrel{m}{i}}$ & 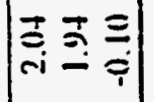 \\
\hline 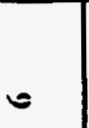 & 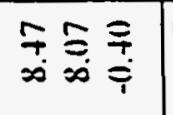 & 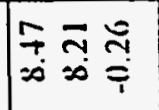 & 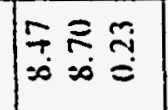 & 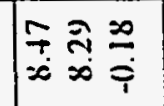 & 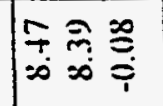 & 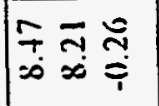 & 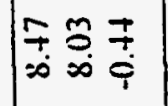 & 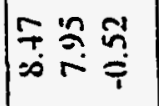 & 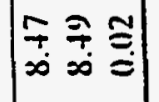 \\
\hline in & 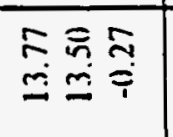 & 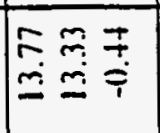 & 趈 & 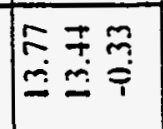 & 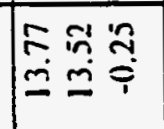 & 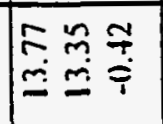 & 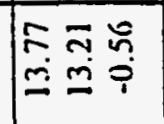 & 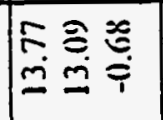 & 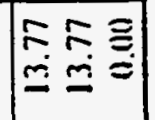 \\
\hline$T$ & 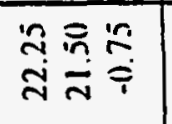 & 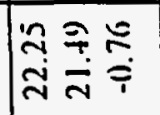 & 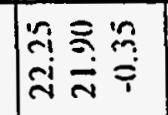 & 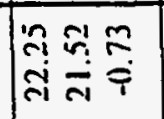 & 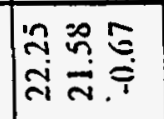 & 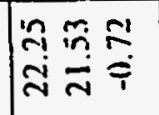 & 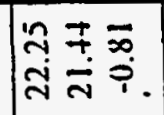 & 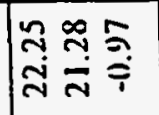 & 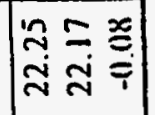 \\
\hline m & 言商 & 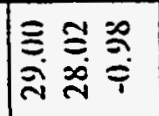 & 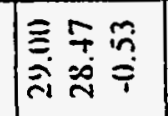 & 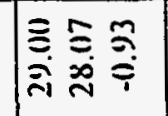 & 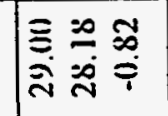 & 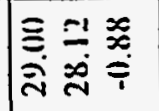 & 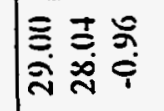 & 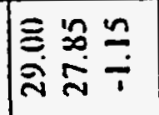 & 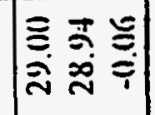 \\
\hline r & 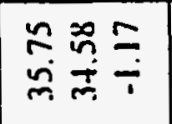 & 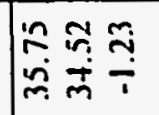 & 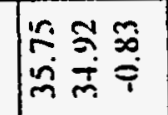 & $\mid \begin{array}{l}n=0 \\
n \\
n \\
m\end{array}$ & 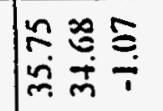 & 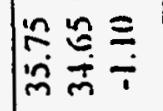 & 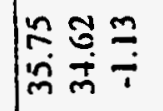 & 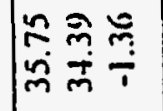 & 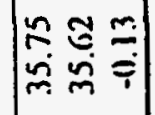 \\
\hline- & 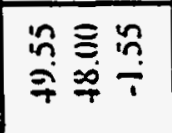 & 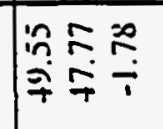 & 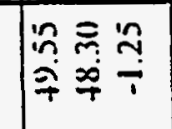 & 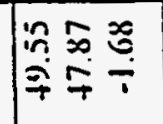 & 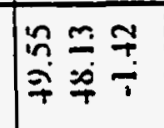 & 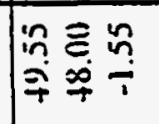 & 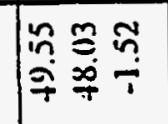 & 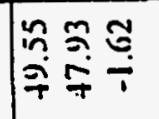 & 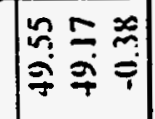 \\
\hline 0 & 㺼䓂 & 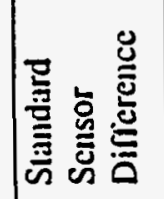 & | & 逽总总 & 苾总 & 鹿总 & 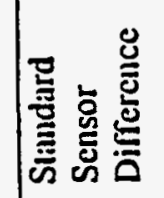 & 总嶽 & 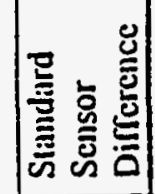 \\
\hline 可矛 & $\bar{N}$ & 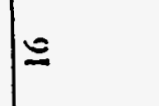 & $=0$ & + & $N$ & $1-$ & $\stackrel{n}{=}$ & $\stackrel{\overbrace{}}{\stackrel{2}{=}}$ & $\overline{\bar{c}}$ \\
\hline
\end{tabular}

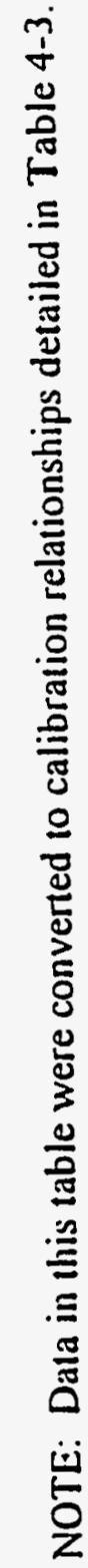


Table 4-2b. Results of September 1994 Temperature Water Bath Calibrations

Before Program Change

\begin{tabular}{|c|c|c|c|c|c|c|c|c|c|c|}
\hline $\begin{array}{l}\text { Level } \\
\text { (m) }\end{array}$ & $\left({ }^{\circ} \mathrm{C}\right)$ & 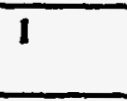 & 2 & 3 & 4 & 5 & 6 & 7 & Mean & Std Dev \\
\hline 24 & $\begin{array}{l}\text { Standard } \\
\text { Sensor } \\
\text { Difference }\end{array}$ & $\begin{array}{l}43.61 \\
42.24 \\
-1.37\end{array}$ & $\begin{array}{r}35.19 \\
34.04 \\
-1.15\end{array}$ & $\begin{array}{r}28.05 \\
27.10 \\
-0.95\end{array}$ & $\begin{array}{r}20.72 \\
19.95 \\
-0.77\end{array}$ & $\begin{array}{r}14.03 \\
13.43 \\
-0.60\end{array}$ & $\begin{array}{r}7.14 \\
6.76 \\
-0.38\end{array}$ & $\begin{array}{l}-0.01 \\
-0.09 \\
-0.08\end{array}$ & -0.76 & 0.45 \\
\hline 16 & $\begin{array}{l}\text { Standard } \\
\text { Sensor } \\
\text { Difference }\end{array}$ & $\begin{array}{l}43.61 \\
42.08 \\
-1.53\end{array}$ & $\begin{array}{r}35.19 \\
33.97 \\
-1.22\end{array}$ & $\begin{array}{l}28.05 \\
27.06 \\
-0.99\end{array}$ & $\begin{array}{r}20.72 \\
20.00 \\
-0.72\end{array}$ & $\begin{array}{r}14.03 \\
13.53 \\
-0.50\end{array}$ & $\begin{array}{r}7.14 \\
6.88 \\
-0.26\end{array}$ & $\begin{array}{r}-0.01 \\
0.02 \\
0.03\end{array}$ & -0.74 & 0.55 \\
\hline 8 & $\begin{array}{l}\text { Standard } \\
\text { Sensor } \\
\text { Difference }\end{array}$ & $\begin{array}{l}43.61 \\
42.59 \\
-1.02\end{array}$ & $\begin{array}{r}35.19 \\
34.46 \\
-0.73\end{array}$ & $\begin{array}{r}28.05 \\
27.58 \\
-0.47\end{array}$ & $\begin{array}{r}20.72 \\
20.50 \\
-0.22\end{array}$ & $\begin{array}{r}14.03 \\
14.03 \\
0.00\end{array}$ & $\begin{array}{l}7.14 \\
7.37 \\
0.23\end{array}$ & $\begin{array}{r}-0.01 \\
0.52 \\
0.53\end{array}$ & -0.24 & 0.54 \\
\hline 4 & $\begin{array}{l}\text { Standard } \\
\text { Sensor } \\
\text { Difference }\end{array}$ & $\begin{array}{l}43.61 \\
42.16 \\
-1.45\end{array}$ & $\begin{array}{l}35.19 \\
34.00 \\
-1.19\end{array}$ & $\begin{array}{r}28.05 \\
27.14 \\
-0.91\end{array}$ & $\begin{array}{l}20.72 \\
20.07 \\
-0.65\end{array}$ & $\begin{array}{r}14.03 \\
13.63 \\
-0.40\end{array}$ & $\begin{array}{r}7.14 \\
6.94 \\
-0.20\end{array}$ & $\begin{array}{r}-0.01 \\
0.17 \\
0.18\end{array}$ & -0.66 & 0.57 \\
\hline 2 & $\begin{array}{l}\text { Standard } \\
\text { Sensor } \\
\text { Difference }\end{array}$ & $\begin{array}{r}43.61 \\
42.43 \\
-1.18\end{array}$ & $\begin{array}{r}35.19 \\
34.26 \\
-0.93\end{array}$ & $\begin{array}{l}28.05 \\
27.34 \\
-0.71\end{array}$ & $\begin{array}{l}20.72 \\
20.24 \\
-0.48\end{array}$ & $\begin{array}{r}14.03 \\
13.73 \\
-0.30\end{array}$ & $\begin{array}{r}7.14 \\
7.05 \\
-0.09\end{array}$ & $\begin{array}{r}-0.01 \\
0.18 \\
0.19\end{array}$ & -0.50 & 0.48 \\
\hline 1 & $\begin{array}{l}\text { Standard } \\
\text { Sensor } \\
\text { Difference }\end{array}$ & \begin{tabular}{r|}
43.61 \\
42.30 \\
-1.31
\end{tabular} & $\begin{array}{r}35.19 \\
34.11 \\
-1.08\end{array}$ & $\begin{array}{r}28.05 \\
27.18 \\
-0.87\end{array}$ & $\begin{array}{l}20.72 \\
20.06 \\
-0.66\end{array}$ & $\begin{array}{r}14.03 \\
13.58 \\
-0.45\end{array}$ & $\begin{array}{r}7.14 \\
6.90 \\
-0.24\end{array}$ & $\begin{array}{r}-0.01 \\
0.02 \\
0.03\end{array}$ & -0.65 & 0.47 \\
\hline 0.5 & $\begin{array}{l}\text { Standard } \\
\text { Sensor } \\
\text { Difference }\end{array}$ & \begin{tabular}{r|}
43.61 \\
42.28 \\
-1.33
\end{tabular} & $\begin{array}{l}35.19 \\
34.06 \\
-1.13\end{array}$ & $\begin{array}{r}28.05 \\
27.09 \\
-0.96\end{array}$ & $\begin{array}{r}20.72 \\
19.94 \\
-0.78\end{array}$ & $\begin{array}{r}14.03 \\
13.42 \\
-0.61\end{array}$ & $\begin{array}{r}7.14 \\
6.70 \\
-0.44\end{array}$ & $\begin{array}{l}-0.01 \\
-0.20 \\
-0.19\end{array}$ & -0.78 & 0.40 \\
\hline 0.25 & $\begin{array}{l}\text { Standard } \\
\text { Sensor } \\
\text { Difference }\end{array}$ & $\begin{array}{l}43.61 \\
42.03 \\
-1.58\end{array}$ & $\begin{array}{l}35.19 \\
33.88 \\
-1.31\end{array}$ & $\begin{array}{l}28.05 \\
26.94 \\
-1.11\end{array}$ & $\begin{array}{l}20.72 \\
19.81 \\
-0.91\end{array}$ & $\begin{array}{r}14.03 \\
13.32 \\
-0.71\end{array}$ & $\begin{array}{r}7.14 \\
6.63 \\
-0.51\end{array}$ & $\begin{array}{l}-0.01 \\
-0.22 \\
-0.21\end{array}$ & -0.91 & 0.47 \\
\hline Soil & $\begin{array}{l}\text { Standard } \\
\text { Sensor } \\
\text { Difference } \\
\end{array}$ & \begin{tabular}{r|}
43.61 \\
43.46 \\
-0.15 \\
\end{tabular} & \begin{tabular}{r|}
35.19 \\
35.11 \\
-0.08 \\
\end{tabular} & $\begin{array}{r}28.05 \\
27.89 \\
-0.16 \\
\end{array}$ & $\begin{array}{r}20.72 \\
20.65 \\
-0.07 \\
\end{array}$ & $\begin{array}{r}4.03 \\
14.06 \\
0.03 \\
\end{array}$ & $\begin{array}{r}7.14 \\
7.13 \\
-0.01 \\
\end{array}$ & $\begin{array}{r}-0.01 \\
0.11 \\
0.12 \\
\end{array}$ & -0.05 & 0.10 \\
\hline
\end{tabular}

NOTE: Data in this table were converted to calibration relationships detailed in Table 4-3. 
Table 4-2c. Results of September 1994 Temperature Water Bath Calibrations

After Program Change

\begin{tabular}{|c|c|c|c|c|c|c|c|c|c|c|}
\hline $\begin{array}{c}\text { Level } \\
\text { (m) }\end{array}$ & $\left({ }^{\circ} \mathrm{C}\right)$ & 1 & 2 & 3 & 4 & 5 & 6 & 7 & Mean & Sid Dev \\
\hline 24 & $\begin{array}{l}\text { Standard } \\
\text { Sensor } \\
\text { Difference' }\end{array}$ & $\begin{array}{r}43.03 \\
42.82 \\
-0.21\end{array}$ & $\begin{array}{l}35.49 \\
35.33 \\
-0.16\end{array}$ & $\begin{array}{l}28.54 \\
28.37 \\
-0.17\end{array}$ & $\begin{array}{r}21.47 \\
21.32 \\
-0.15\end{array}$ & $\begin{array}{r}14.42 \\
14.26 \\
-0.16\end{array}$ & $\begin{array}{r}7.32 \\
7.17 \\
-0.15\end{array}$ & $\begin{array}{r}0.20 \\
0.08 \\
-0.12\end{array}$ & -0.16 & 0.03 \\
\hline 16 & $\begin{array}{l}\text { Standard } \\
\text { Sensor } \\
\text { Difference }\end{array}$ & $\begin{array}{r}43.03 \\
42.75 \\
-0.28\end{array}$ & $\begin{array}{r}35.49 \\
35.26 \\
-0.23\end{array}$ & $\begin{array}{l}28.54 \\
28.37 \\
-0.17\end{array}$ & $\begin{array}{r}21.47 \\
21.40 \\
-0.07\end{array}$ & $\begin{array}{r}14.42 \\
14.39 \\
-0.03\end{array}$ & $\begin{array}{l}7.32 \\
7.36 \\
0.04\end{array}$ & $\begin{array}{l}0.20 \\
0.31 \\
0.11\end{array}$ & -0.09 & 0.14 \\
\hline 8 & $\begin{array}{l}\text { Standard } \\
\text { Sensor } \\
\text { Difference }\end{array}$ & $\begin{array}{r}43.03 \\
43.40 \\
0.37\end{array}$ & $\begin{array}{r}35.49 \\
35.90 \\
0.41\end{array}$ & $\begin{array}{r}28.54 \\
29.02 \\
0.48\end{array}$ & $\begin{array}{r}21.47 \\
22.00 \\
0.53\end{array}$ & $\begin{array}{r}14.42 \\
14.99 \\
0.57\end{array}$ & $\begin{array}{l}7.32 \\
8.01 \\
0.69\end{array}$ & $\begin{array}{l}0.20 \\
0.93 \\
0.73\end{array}$ & 0.54 & 0.13 \\
\hline 4 & $\begin{array}{l}\text { Standard } \\
\text { Sensor } \\
\text { Difference }\end{array}$ & $\begin{array}{r}43.03 \\
42.54 \\
-0.49\end{array}$ & $\begin{array}{l}35.49 \\
35.04 \\
-0.45\end{array}$ & $\begin{array}{r}28.54 \\
28.18 \\
-0.36\end{array}$ & $\begin{array}{r}21.47 \\
21.20 \\
-0.27\end{array}$ & $\begin{array}{r}14.42 \\
14.21 \\
-0.21\end{array}$ & $\begin{array}{r}7.32 \\
7.29 \\
-0.03\end{array}$ & $\begin{array}{l}0.20 \\
0.21 \\
0.01\end{array}$ & -0.26 & 0.19 \\
\hline 2 & $\begin{array}{l}\text { Standard } \\
\text { Sensor } \\
\text { Difference }\end{array}$ & $\begin{array}{r}43.03 \\
42.74 \\
-0.29\end{array}$ & $\begin{array}{l}35.49 \\
35.22 \\
-0.27\end{array}$ & $\begin{array}{r}28.54 \\
28.32 \\
-0.22\end{array}$ & $\begin{array}{r}21.47 \\
21.29 \\
-0.18\end{array}$ & $\begin{array}{r}14.42 \\
14.28 \\
-0.14\end{array}$ & $\begin{array}{r}7.32 \\
7.20 \\
-0.12\end{array}$ & $\begin{array}{r}0.20 \\
0.17 \\
-0.03\end{array}$ & -0.18 & 0.09 \\
\hline 1 & $\begin{array}{l}\text { Standard } \\
\text { Sensor } \\
\text { Difference }\end{array}$ & $\begin{array}{r}43.03 \\
42.87 \\
-0.16\end{array}$ & $\begin{array}{l}35.49 \\
35.33 \\
-0.16\end{array}$ & $\begin{array}{r}28.54 \\
28.44 \\
-0.10\end{array}$ & $\begin{array}{r}21.47 \\
21.41 \\
-0.06\end{array}$ & $\begin{array}{r}14.42 \\
14.36 \\
-0.06\end{array}$ & $\begin{array}{l}7.32 \\
7.33 \\
0.01\end{array}$ & $\begin{array}{l}0.20 \\
0.34 \\
0.14\end{array}$ & -0.06 & 0.11 \\
\hline 0.5 & $\begin{array}{l}\text { Standard } \\
\text { Sensor } \\
\text { Difference }\end{array}$ & $\begin{array}{r}43.03 \\
43.00 \\
-0.03\end{array}$ & $\begin{array}{l}35.49 \\
35.41 \\
-0.08\end{array}$ & $\begin{array}{l}28.54 \\
28.45 \\
-0.09\end{array}$ & $\begin{array}{r}21.47 \\
21.35 \\
-0.12\end{array}$ & $\begin{array}{r}14.42 \\
14.32 \\
-0.10\end{array}$ & $\begin{array}{r}7.32 \\
7.17 \\
-0.15\end{array}$ & $\begin{array}{r}0.20 \\
0.13 \\
-0.07\end{array}$ & -0.09 & 0.04 \\
\hline 0.25 & $\begin{array}{l}\text { Standard } \\
\text { Sensor } \\
\text { Difference }\end{array}$ & $\begin{array}{r}43.03 \\
42.93 \\
-0.10\end{array}$ & $\begin{array}{r}35.49 \\
35.39 \\
-0.10\end{array}$ & $\begin{array}{r}28.54 \\
28.48 \\
-0.06\end{array}$ & $\begin{array}{r}21.47 \\
21.40 \\
-0.07\end{array}$ & $\begin{array}{r}14.42 \\
14.35 \\
-0.07\end{array}$ & $\begin{array}{r}7.32 \\
7.28 \\
-0.04\end{array}$ & $\begin{array}{l}0.20 \\
0.26 \\
0.06\end{array}$ & -0.05 & 0.05 \\
\hline Soil & $\begin{array}{l}\text { Standard } \\
\text { Sensor } \\
\text { Difference }\end{array}$ & $\begin{array}{r}43.03 \\
42.94 \\
-0.09\end{array}$ & $\begin{array}{r}35.49 \\
35.39 \\
-0.10\end{array}$ & $\begin{array}{l}28.54 \\
28.34 \\
-0.20\end{array}$ & $\begin{array}{r}21.47 \\
21.39 \\
-0.08\end{array}$ & $\begin{array}{r}14.42 \\
14.43 \\
0.01\end{array}$ & $\begin{array}{l}7.32 \\
7.34 \\
0.02\end{array}$ & $\begin{array}{r}0.20 \\
0.17 \\
-0.03\end{array}$ & -0.07 & 0.08 \\
\hline
\end{tabular}

NOTE: Data in this table were converted to calibration relationships detailed in Table 4-3. 
Table 4-3a

Calibration of Thermometers versus HP Quartz Thermometer 4-5 April 1994

\author{
LINEAR REGRESSION \\ SENSOR $=M^{*} Q U A R T Z+B$ \\ TO CORRECT SENSOR \\ $T C O R R=(S E N S O R-B) / M$ \\ CALIBRATION DATE: $t / 5 / 94$
}

\begin{tabular}{|c|c|c|c|c|c|}
\hline Level $(\mathrm{m})$ & $\mathrm{il}$ & $\mathrm{B}$ & $\mathrm{R}^{2}$ & $\mathrm{I} / \mathrm{M}$ & $-\mathrm{B} / \mathrm{M}$ \\
\hline 24 & 0.9738 & -0.162 & 0.999962 & 1.0269 & 0.167 \\
\hline 16 & 0.9636 & 0.069 & 0.999985 & 1.0378 & -0.072 \\
\hline 8 & 0.9643 & 0.501 & 0.999995 & 1.0371 & -0.520 \\
\hline+ & 09641 & 0.104 & 0.999997 & 1.0372 & -0.108 \\
\hline 2 & 0.9665 & 0.160 & 0.999991 & 1.0347 & -0.166 \\
\hline 1 & 0.9683 & 0.003 & 0.999998 & 1.0328 & -0.004 \\
\hline 0.5 & 0.9729 & -0.207 & 0.999998 & 1.0279 & 0.213 \\
\hline 0.25 & 0.9698 & -0.267 & 0.999996 & 1.0311 & 0.275 \\
\hline Soil & 0.9969 & -0.030 & 0.999981 & 1.0032 & 0.030 \\
\hline
\end{tabular}


Table 4-3b

Calibration of Thermometers versus HP Quartz Thermometer

September 20, 1994

LINEAR REGRESSION

SENSOR $=M^{*}$ QUARTZ + B

TO CORRECT SENSOR

$T C O R R=($ SENSOR $-B) / M$

CALIBRATION DATE: 09/20/94

Before Program Change

\begin{tabular}{|c|c|c|c|c|c|}
\hline Level $(\mathbf{m})$ & $\mathbf{M}$ & $\mathbf{B}$ & $\mathbf{R}^{2}$ & $\mathbf{1} \mathbf{M}$ & $-\mathbf{B} / \mathbf{M}$ \\
\hline 24 & 0.9727 & -0.166 & 0.999991 & 1.0281 & 0.171 \\
\hline 16 & 0.9660 & -0.008 & 0.999999 & 1.0352 & 0.009 \\
\hline 8 & 0.9646 & 0.508 & 0.999999 & 1.0367 & -0.527 \\
\hline 4 & 0.9629 & 0.124 & 0.999995 & 1.0385 & -0.128 \\
\hline 2 & 0.9687 & 0.161 & 0.999999 & 1.0323 & -0.166 \\
\hline 1 & 0.9676 & 0.015 & 1.000000 & 1.0335 & -0.015 \\
\hline 0.5 & 0.9723 & -0.210 & 1.000000 & 1.0284 & 0.216 \\
\hline 0.25 & 0.9674 & -0.237 & 0.999998 & 1.0336 & 0.245 \\
\hline Soil & 0.9956 & 0.059 & 0.999988 & 1.0044 & -0.059 \\
\hline
\end{tabular}

After Program Change

\begin{tabular}{|c|c|c|c|c|c|}
\hline Level $(\mathbf{m})$ & $\mathbf{M}$ & $\mathbf{B}$ & $\mathbf{R}^{2}$ & $1 / \mathbf{M}$ & $-\mathbf{B} / \mathbf{M}$ \\
\hline 24 & 0.9996 & -0.134 & 0.999999 & 1.0004 & 0.134 \\
\hline 16 & 0.9919 & 0.101 & 0.999999 & 1.0081 & -0.102 \\
\hline 8 & 0.9906 & 0.737 & 0.999999 & 1.0095 & -0.744 \\
\hline 4 & 0.9868 & 0.019 & 0.999995 & 1.0133 & -0.019 \\
\hline 2 & 0.9935 & -0.045 & 0.999999 & 1.0065 & 0.046 \\
\hline 1 & 0.9908 & 0.113 & 0.999999 & 1.0093 & -0.114 \\
\hline 0.5 & 0.9987 & -0.093 & 0.999999 & 1.0013 & 0.093 \\
\hline 0.25 & 0.9943 & 0.038 & 1.000000 & 1.0057 & -0.038 \\
\hline Soil & 0.9980 & -0.006 & 0.999986 & 1.0020 & 0.006 \\
\hline
\end{tabular}


Table 4-4a. Results of April 1994 Wind Speed Calibrations

\begin{tabular}{|c|c|c|c|c|c|c|c|c|}
\hline Level (m) & (mps) & 1 & 2 & 3 & 4 & 5 & Mean & Std Dev \\
\hline \multirow{3}{*}{27} & Target & 0 & 147 & 294 & 8.82 & 17.64 & & \\
\hline & Found & 0 & 1.46 & 2.94 & 8.82 & 17.64 & & \\
\hline & Difference & 0 & -0.01 & 0 & 0 & 0 & 0 & 0 \\
\hline & & & & & & & & \\
\hline \multirow[t]{3}{*}{16} & Target & 0 & 1.47 & 2.94 & 8.82 & 17.64 & & \\
\hline & Found & 0 & 1.47 & 2.94 & 8.82 & 17.64 & & \\
\hline & Difference & 0 & 0 & 0 & 0 & 0 & 0 & 0 \\
\hline \multirow[t]{3}{*}{8} & Target & $\overline{0}$ & 1.65 & 2.94 & 8.82 & 17.64 & & \\
\hline & Found & 0 & 1.64 & 2.95 & 8.82 & 17.64 & & \\
\hline & Difference & 0 & -0.01 & 0.01 & 0 & 0 & 0 & 0.01 \\
\hline \multirow{4}{*}{4} & & & & & & & & \\
\hline & Target & 0 & 1.52 & 2.94 & 8.82 & 1.7 .64 & & \\
\hline & Found & 0 & 1.52 & 2.95 & 8.82 & 17.64 & & \\
\hline & Difference & 0 & 0 & 0.01 & 0 & 0 & 0 & 0 \\
\hline & & & & & & & & \\
\hline \multirow[t]{3}{*}{2} & Target & 0 & 1.57 & 2.94 & 8.82 & 17.64 & & \\
\hline & Found & 0 & 1.57 & 2.94 & 8.82 & 17.64 & & \\
\hline & Difference & 0 & 0 & 0 & 0 & 0 & 0 & 0 \\
\hline & & & & & & & & \\
\hline \multirow[t]{3}{*}{1} & Target & 0 & 1.57 & 2.94 & 8.82 & 17.64 & & \\
\hline & Found & 0 & 1.57 & 2.94 & 8.82 & 17.64 & & \\
\hline & Difference & 0 & 0 & 0 & 0 & 0 & 0 & 0 \\
\hline \multirow{4}{*}{0.5} & & & & & & & & \\
\hline & Target & 0 & 1.57 & 2.94 & 8.82 & 17.64 & & \\
\hline & Found & 0 & 1.57 & 2.94 & 8.82 & 17.64 & & \\
\hline & Difference & 0 & 0 & 0 & 0 & 0 & 0 & 0 \\
\hline \multirow{4}{*}{0.25} & & & & & & & & \\
\hline & Target & 0 & 1.50 & 2.94 & 8.82 & 17.64 & & \\
\hline & Found & 0 & 1.50 & 2.94 & 8.82 & 17.64 & & \\
\hline & Difference & 0 & 0 & 0 & 0 & 0 & 0 & 0 \\
\hline
\end{tabular}


Table 4-4b. Results of September 1994 Wind Speed Calibrations

\begin{tabular}{|c|c|c|c|c|c|c|c|c|}
\hline Level (m) & (mps) & 1 & 2 & 3 & 4 & 5 & Mean & Std Dev \\
\hline \multirow[t]{3}{*}{24} & Target & 0 & 1.59 & 2.94 & 8.82 & 17.64 & & \\
\hline & Found & 0 & 1.59 & 2.94 & 8.82 & 17.64 & & \\
\hline & Difference & 0 & 0 & 0 & 0 & 0 & 0 & 0 \\
\hline & & & & & & & & \\
\hline \multirow[t]{3}{*}{16} & Target & 0 & 1.62 & 2.94 & 8.82 & 17.64 & & \\
\hline & Found & 0 & 1.62 & 2.94 & 8.82 & 17.64 & & \\
\hline & Difference & 0 & 0 & 0 & 0 & 0 & 0 & 0 \\
\hline & & & & & & & & \\
\hline \multirow[t]{3}{*}{8} & Target & 0 & 1.49 & 2.94 & 8.82 & 17.64 & & \\
\hline & Found & 0 & 1.50 & 2.94 & 8.82 & 17.64 & & \\
\hline & Difference & 0 & 0.01 & 0 & 0 & 0 & 0.003 & 0.005 \\
\hline \multirow[t]{3}{*}{4} & Target & 0 & 1.60 & 2.94 & 8.82 & 17.64 & & \\
\hline & Found & 0 & 1.62 & 2.94 & 8.82 & 17.64 & & \\
\hline & Difference & 0 & 0.02 & 0 & 0 & 0 & 0.005 & 0.010 \\
\hline \multirow[t]{4}{*}{2} & Target & 0 & 1.47 & 2.94 & 8.82 & 17.64 & & \\
\hline & Found & 0 & 1.47 & 2.94 & 8.82 & 17.64 & & \\
\hline & Difference & 0 & 0 & 0 & 0 & 0 & 0 & 0 \\
\hline & & & & & & & & \\
\hline \multirow[t]{3}{*}{1} & Target & 0 & 1.51 & 2.94 & 8.82 & 17.64 & & \\
\hline & Found & 0 & 1.52 & 2.94 & 8.82 & 17.64 & & \\
\hline & Difference & 0 & 0.01 & 0 & 0 & 0 & 0.003 & 0.005 \\
\hline \multirow[t]{3}{*}{0.5} & Target & 0 & 1.47 & 2.94 & 8.82 & 17.64 & & \\
\hline & Found & 0 & 1.47 & 2.94 & 8.82 & 17.64 & & \\
\hline & Difference & 0 & 0 & 0 & 0 & 0 & 0 & 0 \\
\hline \multirow{4}{*}{0.25} & Target & & 152 & 204 & 887 & 1761 & & \\
\hline & Found & $\frac{0}{0}$ & 1.02 & 2.74 & 8.82 & 17.64 & & \\
\hline & & $\frac{0}{0}$ & 1.53 & 2.93 & 8.82 & 17.64 & & \\
\hline & Ditterence & 0 & 0.01 & -0.01 & 0 & 0 & 0 & 0.008 \\
\hline
\end{tabular}


Table 4-5a. Results of April 1994 Wind Direction Calibrations

\begin{tabular}{|c|c|c|c|c|c|}
\hline Level & & & (Degrees) & & \\
\hline$(\mathrm{m})$ & Target & Found & Difference & Mean & Std Dev \\
\hline 24 & $\begin{array}{r}2+9.1 \\
69.1 \\
317.6 \\
137.6\end{array}$ & $\begin{array}{r}248.6 \\
68.3 \\
318.5 \\
135.1\end{array}$ & $\begin{array}{r}-0.5 \\
-0.8 \\
0.9 \\
-2.5\end{array}$ & -0.7 & 1.4 \\
\hline 16 & $\begin{array}{r}249.1 \\
69.1 \\
317.6 \\
137.6\end{array}$ & $\begin{array}{r}250.6 \\
69.9 \\
319.1 \\
137.3\end{array}$ & $\begin{array}{r}1.5 \\
0.8 \\
1.5 \\
-0.3\end{array}$ & 0.9 & 0.9 \\
\hline 8 & $\begin{array}{r}2+9.1 \\
69.1 \\
317.6 \\
137.6\end{array}$ & $\begin{array}{r}251.8 \\
71.4 \\
320.2 \\
138.2\end{array}$ & $\begin{array}{l}2.7 \\
2.3 \\
2.6 \\
0.6\end{array}$ & 2.1 & 1.0 \\
\hline$t$ & $\begin{array}{r}249.1 \\
69.1 \\
317.6 \\
137.6\end{array}$ & $\begin{array}{r}254.6 \\
74.3 \\
322.4 \\
139.6\end{array}$ & $\begin{array}{l}5.5 \\
5.2 \\
4.8 \\
2.0\end{array}$ & 4.4 & 1.6 \\
\hline 2 & $\begin{array}{r}2+9.1 \\
69.1 \\
317.6 \\
137.6\end{array}$ & $\begin{array}{r}250.6 \\
69.3 \\
317.0 \\
134.6\end{array}$ & $\begin{array}{r}1.5 \\
0.2 \\
-0.6 \\
-3.0\end{array}$ & -0.5 & 1.9 \\
\hline$T$ & $\begin{array}{r}249.1 \\
69.1 \\
317.6 \\
137.6\end{array}$ & $\begin{array}{r}251.3 \\
70.6 \\
317.6 \\
1+0.5\end{array}$ & $\begin{array}{l}2.2 \\
1.5 \\
0.0 \\
2.9\end{array}$ & 1.7 & 1.2 \\
\hline$\overline{0.5}$ & $\begin{array}{r}249.1 \\
69.1 \\
317.6 \\
137.6\end{array}$ & $\begin{array}{r}2+9.9 \\
68.2 \\
317.4 \\
135.9\end{array}$ & $\begin{array}{r}0.8 \\
-0.9 \\
-0.2 \\
-1.7\end{array}$ & -0.5 & 1.1 \\
\hline 0.25 & $\begin{array}{r}2+9.1 \\
69.1 \\
317.6 \\
137.6\end{array}$ & $\begin{array}{r}252.0 \\
69.6 \\
318.4 \\
137.4\end{array}$ & $\begin{array}{r}2.9 \\
0.5 \\
0.8 \\
-0.2\end{array}$ & 1.0 & 1.3 \\
\hline$t^{4}$ & $\begin{array}{r}2+9.1 \\
69.1 \\
\end{array}$ & $\begin{array}{r}2+8.6 \\
69.5 \\
\end{array}$ & $\begin{array}{r}-(1.5 \\
0.4\end{array}$ & -0.1 & 0.6 \\
\hline
\end{tabular}

- After adjustment. 
Table 4-5b. Results of September 1994 Wind Direction Calibrations

\begin{tabular}{|c|c|c|c|c|c|}
\hline Level & & & (Degrees) & & \\
\hline$(\mathrm{m})$ & Target & Found & Difference & Mean & Std Dev \\
\hline 24 & $\begin{array}{r}249.1 \\
69.1 \\
317.6 \\
137.6\end{array}$ & $\begin{array}{r}249.0 \\
67.1 \\
318.1 \\
134.8\end{array}$ & $\begin{array}{r}-0.1 \\
-2.0 \\
0.5 \\
-2.8\end{array}$ & -1.1 & 1.6 \\
\hline 16 & $\begin{array}{r}249.1 \\
69.1 \\
317.6 \\
137.6\end{array}$ & $\begin{array}{r}251.6 \\
70.2 \\
320.4 \\
136.8\end{array}$ & $\begin{array}{r}2.5 \\
1.1 \\
2.8 \\
-0.8\end{array}$ & 1.4 & 1.6 \\
\hline 8 & $\begin{array}{r}249.1 \\
69.1 \\
317.6 \\
137.6\end{array}$ & $\begin{array}{r}251.2 \\
71.5 \\
320.0 \\
137.8\end{array}$ & $\begin{array}{l}2.1 \\
2.4 \\
2.4 \\
0.2\end{array}$ & 1.8 & 1.1 \\
\hline 4 & $\begin{array}{r}249.1 \\
69.1 \\
317.6 \\
137.6\end{array}$ & $\begin{array}{r}250.3 \\
68.6 \\
317.8 \\
137.1\end{array}$ & $\begin{array}{r}1.2 \\
-0.5 \\
0.2 \\
-0.5\end{array}$ & 0.1 & 0.8 \\
\hline 2 & $\begin{array}{r}249.1 \\
69.1 \\
317.6 \\
137.6\end{array}$ & $\begin{array}{r}248.0 \\
68.0 \\
315.6 \\
133.1\end{array}$ & $\begin{array}{l}-1.1 \\
-1.1 \\
-2.0 \\
-4.5\end{array}$ & -2.2 & 1.6 \\
\hline 1 & $\begin{array}{r}249.1 \\
69.1 \\
317.6 \\
137.6\end{array}$ & $\begin{array}{r}249.6 \\
69.8 \\
318.0 \\
136.8\end{array}$ & $\begin{array}{r}0.5 \\
0.7 \\
0.4 \\
-0.8\end{array}$ & 0.2 & 0.7 \\
\hline$\overline{0.5}$ & $\begin{array}{r}249.1 \\
69.1 \\
317.6 \\
137.6\end{array}$ & $\begin{array}{r}249.5 \\
69.0 \\
316.9 \\
135.7\end{array}$ & $\begin{array}{r}0.4 \\
-0.1 \\
-0.7 \\
-1.9\end{array}$ & -0.6 & 1.0 \\
\hline 0.25 & $\begin{array}{r}249.1 \\
69.1 \\
317.6 \\
137.6\end{array}$ & $\begin{array}{r}251.4 \\
69.3 \\
319.4 \\
136.0\end{array}$ & $\begin{array}{r}2.3 \\
0.2 \\
1.8 \\
-1.6\end{array}$ & 0.7 & 1.8 \\
\hline
\end{tabular}


Table 4-6a

\section{Results of April 1994 Checks on Relative Humidity, Barometric Pressure} and Solar Radiation

NOTE: There were some problems in using saturated salts to check the relative humidity sensors during the April, 1994 calibration checks. While readings were within $5 \%$ of the expected value, some readings appeared to be affected by not having a good seal between the sensor and the calibrator. The ambient reading for the three levels $(16 \mathrm{~m}, 4 \mathrm{~m}$, and $1 \mathrm{~m})$ were very close over the range of $8 \%$ to $30 \%$ seen during the checks.

Barometric Pressure

\begin{tabular}{|c|c|c|c|c|}
\hline Level & Altimeter & Sensor & Difference & . Mean \\
\hline$(\mathrm{m})$ & $(\mathrm{mb})$ & $(\mathrm{mb})$ & $(\mathrm{mb})$ & $(\mathrm{mb})$ \\
\hline & & & & \\
\hline 1 & 905.0 & 903.8 & -1.2 & \\
\hline & 908.0 & 906.0 & -2.0 & -1.6 \\
\hline
\end{tabular}

Solar Radiation

\begin{tabular}{|c|c|c|c|c|}
\hline Level & Pyranometer & Sensor & Difference & Mean \\
\hline$(\mathrm{m})$ & $\left(\mathrm{W} / \mathrm{m}^{2}\right)$ & $\left(\mathrm{W} / \mathrm{m}^{-}\right)$ & $\left(W / m^{2}\right)$ & $\left(\mathrm{V} / \mathrm{m}^{2}\right)$ \\
\hline 2 & 919.4 & 931.6 & 12.2 & \\
\hline & 828.1 & 890.8 & 12.7 & . \\
\hline & 371.9 & 406.1 & 34.2 & \\
\hline & 243.8 & 216.9 & -26.9 & 32.2 \\
\hline
\end{tabular}


Table 4-6b

Results of September 1994 Checks on Relative Humidity, Barometric Pressure and Solar Radiation

Relative Humidity

\begin{tabular}{|c|c|c|c|c|c|c|}
\hline Level & \multicolumn{2}{|c|}{ Altimeter } & & & \\
\hline$(\mathbf{m})$ & Dry Bulb C & Wet Bulb C & RH \% & Sensor \% & Difference & Mean \\
\hline & & & & & & \\
\hline 16 & 29.4 & 25.0 & 22.7 & 25.0 & 2.3 & \\
\hline & 29.0 & 25.0 & 23.0 & 25.0 & 2.0 & 2.2 \\
\hline & & & & & & \\
\hline 4 & 29.0 & 15.8 & 24.7 & 24.8 & 0.1 & 0.1 \\
\hline & & & & & & \\
\hline 1 & 30.0 & 16.3 & 24.0 & 23.3 & -0.7 & -0.7 \\
\hline
\end{tabular}

Barometric Pressure

\begin{tabular}{|c|c|c|c|c|}
\hline Level & Altimeter & Sensor & Difference & Mean \\
\hline$(\mathbf{m})$ & $(\mathbf{m b})$ & $(\mathbf{m b})$ & $(\mathbf{m b})$ & $(\mathbf{m b})$ \\
\hline & & & & \\
\hline 1 & 908.0 & 907.6 & -0.4 & -0.4 \\
\hline
\end{tabular}

Solar Radiation

\begin{tabular}{|c|c|c|c|c|}
\hline Level & Pyranometer & Sensor & Difference & Mean \\
\hline$(\mathbf{m})$ & $\left(\mathbf{W} / \mathbf{m}^{2}\right)$ & $\left(\mathbf{W} / \mathbf{m}^{2}\right)$ & $\left(\mathbf{W} / \mathbf{m}^{2}\right)$ & $\left(\mathbf{W} / \mathbf{m}^{2}\right)$ \\
\hline & & & & \\
\hline 2 & 793.3 & 806.7 & 13.4 & 13.4 \\
\hline
\end{tabular}




\subsection{MEASUREMENT RESULTS}

Measurement results are available on disk for both the 15 minute and hourly data sets (refer to Section 1.0). A summary of the contents of data on disk are provided in Table 5-1. Summary statistics for wind speed and temperature are provided in Tables 5-2 and 5-3, respectively. Two types of wind direction are provided, unit vector and resultant vector (named just "vector wind direction"). The vector wind direction is wind speed weighted while the unit vector calculation uses a wind speed of one (unity). Relative humidity, solar radiation and barometric pressure summaries are provided in Table 5-4.

For convenience in analysis of overall temporal trends, time series plots are provided in Appendix A. For measurements made at multiple levels, the two meter and eight meter levels are presented. The two meter data are of particular interest for very low level dispersion of heavy gases, while eight meter data provides added information for more general interest.

Monthly wind roses are provided in graphic form in Appendix B and in tabular form (wind frequency distributions) in Appendix C. In addition to distributions based on total hours, distributions are provided for morning transition (0600-1000), late midday (1000-1600), evening transition (1600-2000), nighttime (2000-0600), and for Pasquill-Gifford stability classes A-F. 


\section{Table 5-1 Data Base Description}

Note! The 15 minute data base contains variables 1-57 only.

\begin{tabular}{|c|c|c|c|}
\hline Order & Variable & Units & Description \\
\hline 1 & Date & $\mathrm{mm} / \mathrm{dd} / \mathrm{yy}$ & Date \\
\hline 2 & Starthr & PST & Pacific Standard Time \\
\hline 3 & swsqtmps & mps & scalar wind speed, quarter meter level \\
\hline 4 & unwdqtdg & degrees & unit vector wind direction, quarter meter level \\
\hline 5 & ytdsqtdg & degrees & standard deviation (sigma theta) of wind direction, quarter meter \\
\hline 6 & swshfmps & mps & scalar wind speed, half meter level \\
\hline 7 & unwdhfdg & degrees & unit vector wind direction, half meter level \\
\hline 8 & ytdshfdg & degrees & standard deviation (sigma theta) of wind direction, half meter level \\
\hline 9 & sws01mps & mps & scalar wind speed, 1 meter level \\
\hline 10 & unwd01dg & degrees & unit vector wind direction, 1 meter level \\
\hline 11 & ytds01dg & degrees & standard deviation (sigma theta) of wind direction, 1 meter level \\
\hline 12 & sws02mps & mps & scalar wind speed, 2 meter level \\
\hline 13 & unwd02dg & degrees & unit vector wind direction, 2 meter level \\
\hline 14 & ytds02dg & degrees & standard deviation (sigma theta) of wind direction, 2 meter level \\
\hline 15 & sws04mps & mps & scalar wind speed, 4 meter level \\
\hline 16 & unwd04dg & degrees & unit vector wind direction, 4 meter level \\
\hline 17 & ytds04dg & degrees & standard deviation (sigma theta) of wind direction, 4 meter level \\
\hline 18 & sws08mps & mps & scalar wind speed, 8 meter level \\
\hline 19 & unw08fdg & degrees & unit vector wind direction, 8 meter level \\
\hline 20 & ytds08dg & degrees & standard deviation (sigma theta) of wind direction, 8 meter level \\
\hline 21 & sws $16 \mathrm{mps}$ & mps & scalar wind speed, 16 meter level \\
\hline 22 & unwl6tdg & degrees & unit vector wind direction, 16 meter level \\
\hline 23 & ytds $16 \mathrm{dg}$ & degrees & standard deviation (sigma theta) of wind direction, 16 meter level \\
\hline 24 & sws24mps & mps & scalar wind speed, 24 meter level \\
\hline 25 & unw24fdg & degrees & unit vector wind direction, 24 meter level \\
\hline 26 & ytds24dg & degrees & standard deviation (sigma theta) of wind direction, 24 meter level \\
\hline 27 & vwsqtmps & $\mathrm{mps}$ & vector wind speed, quarter meter level \\
\hline 28 & vwdqtdg & degrees & vector wind direction, quarter meter level \\
\hline 29 & vwshfmps & mps & vector wind speed, half meter level \\
\hline 30 & vwdhfdg & degrees & vector wind direction, half meter level \\
\hline 31 & vws01mps & $\mathrm{mps}$ & vector wind speed, 1 meter level \\
\hline 32 & vwd01dg & degrees & vector wind direction, I meter level \\
\hline 33 & vws02mps & $\mathrm{mps}$ & vector wind speed, 2 meter level \\
\hline 34 & vwd02dg & degrees & vector wind direction, 2 meter level \\
\hline 35 & vws04mps & mps & vector wind speed, 4 meter level \\
\hline 36 & vwd04dg & degrees & vector wind direction, 4 meter level \\
\hline 37 & vws08mps & $\mathrm{mps}$ & vector wind speed, 8 meter level \\
\hline 38 & vwd08dg & degrees & vector wind direction, 8 meter level \\
\hline 39 & vws16mps & $\mathrm{mps}$ & vector wind speed, 16 meter level \\
\hline 40 & vwd16dg & degrees & vector wind direction, 16 meter level \\
\hline 41 & vws $24 \mathrm{mps}$ & mps & vector wind speed, 24 meter level \\
\hline 42 & vwd24dg & degrees & vector wind direction, 24 meter level \\
\hline
\end{tabular}


Table 5-1 Data Base Description (continued)

\begin{tabular}{|l|l|l|l|}
\hline Order & Variable & Units & Description \\
\hline 43 & tmpqtdgc & degrees C & ambient temperature, quarter meter level \\
\hline 44 & tmphfdgc & degrees C & ambient temperature, half meter level \\
\hline 45 & tmp 1 dgc & degrees C & ambient temperature, 1 meter level \\
\hline 46 & tmp2dgc & degrees C & ambient temperature, 2 meter level \\
\hline 47 & tmp4dgc & degrees C & ambient temperature, 4 meter level \\
\hline 48 & tmp8dgc & degrees C & ambient temperature, 8 meter level \\
\hline 49 & tmp16dgc & degrees C & ambient temperature, 16 meter level \\
\hline 50 & tmp24dgc & degrees C & ambient temperature, 24 meter level \\
\hline 51 & rhi01pc & percent & relative humidity, l meter level \\
\hline 52 & rhi04pc & percent & relative humidity, 4 meter level \\
\hline 53 & rhi16pc & percent & relative humidity, 16 meter level \\
\hline 54 & sradwm2 & w/m2 & solar radiation \\
\hline 55 & nradwm2 & w/m2 & net radiation \\
\hline 56 & stmpdgc & degrees C & soil temperature \\
\hline 57 & bprmb & mb & barometric pressure \\
\hline 58 & rinum 1 & --- & Richardson number, quarter meter to 2 meter layer \\
\hline 59 & rinum 2 & ---- & Richardson number, half meter to 4 meter layer \\
\hline 60 & rinum 3 & --- & Richardson number, 2 meter to 16 meter layer \\
\hline 61 & monin 1 & --- & Monin-Obukhov Length, quarter meter to 2 meter layer \\
\hline 62 & monin 2 & --- & Monin-Obukhov Length, half meter to 4 meter layer \\
\hline 63 & monin 3 & ---- & Monin-Obukhov Length, 2 meter to 16 meter layer \\
\hline 64 & stbsig8 & --- & stability class based on sigma theta at 8 m \\
\hline
\end{tabular}


Table 5-2 Summary Wind Speed Data - January - December, 1994

\begin{tabular}{|c|c|c|c|c|c|c|c|}
\hline \multirow[b]{2}{*}{ Month } & \multirow{2}{*}{$\begin{array}{c}\text { Tower } \\
\text { Height }(\mathrm{m})\end{array}$} & \multicolumn{3}{|c|}{ Monthly } & \multicolumn{2}{|c|}{ Mean Daily } & \multirow{2}{*}{$\begin{array}{c}\% \text { Data } \\
\text { Recovery }\end{array}$} \\
\hline & & Mean & $\operatorname{Max}$ & Min & $\operatorname{Max}$ & $\operatorname{Min}$ & \\
\hline \multirow[t]{8}{*}{ January } & 24 & 1.79 & 13.60 & 0.07 & 4.88 & 0.63 & 78.0 \\
\hline & 16 & 1.83 & 13.06 & 0.03 & 4.75 & 0.63 & 78.0 \\
\hline & 8 & 1.67 & 12.27 & 0.08 & 4.28 & 0.58 & 78.0 \\
\hline & 4 & 1.55 & 11.64 & 0.08 & 3.94 & 0.57 & 78.0 \\
\hline & 2 & 1.40 & 10.80 & 0.26 & 3.54 & 0.59 & 78.0 \\
\hline & 1 & 1.22 & 10.03 & 0.09 & 3.19 & 0.46 & 78.0 \\
\hline & 0.5 & 1.12 & 9.37 & 0.24 & 2.89 & 0.50 & 78.0 \\
\hline & 0.25 & 1.01 & 8.83 & 0.08 & 2.65 & 0.40 & 78.0 \\
\hline \multirow[t]{8}{*}{ February } & 24 & 2.47 & 11.30 & 0.10 & 5.57 & 0.84 & 85.4 \\
\hline & 16 & 2.40 & 10.81 & 0.06 & 5.24 & 0.84 & 85.4 \\
\hline & 8 & 2.19 & 10.18 & 0.18 & 4.74 & 0.78 & 85.4 \\
\hline & 4 & 2.05 & 9.69 & 0.21 & 4.42 & 0.77 & 85.4 \\
\hline & 2 & 1.88 & 9.06 & 0.31 & 4.04 & 0.75 & 85.4 \\
\hline & 1 & 1.69 & 8.49 & 0.12 & 3.71 & 0.61 & 85.4 \\
\hline & 0.5 & 1.57 & 7.92 & 0.28 & 3.43 & 0.59 & 85.4 \\
\hline & 0.25 & 1.44 & 7.51 & 0.05 & 3.22 & 0.47 & 85.4 \\
\hline \multirow{8}{*}{ March } & 24 & 3.33 & 19.50 & 0.20 & 7.49 & 0.81 & 100.0 \\
\hline & 16 & 3.21 & 18.80 & 0.20 & 7.18 & 0.78 & 100.0 \\
\hline & 8 & 2.97 & 17.50 & 0.30 & 6.66 & 0.73 & 100.0 \\
\hline & 4 & 2.80 & 16.80 & 0.30 & 6.30 & 0.75 & 100.0 \\
\hline & 2 & 2.58 & 15.90 & 0.40 & 5.86 & 0.73 & 100.0 \\
\hline & 1 & 2.36 & 14.80 & 0.30 & 5.44 & 0.62 & 100.0 \\
\hline & 0.5 & 2.18 & 13.60 & 0.30 & 5.00 & 0.62 & 100.0 \\
\hline & 0.25 & 2.03 & 12.70 & 0.20 & 4.70 & 0.52 & 100.0 \\
\hline \multirow[t]{8}{*}{ April } & 24 & 3.71 & 16.46 & 0.27 & 8.36 & 0.83 & 99.9 \\
\hline & 16 & 3.58 & 15.93 & 0.26 & 8.00 & 0.80 & 99.9 \\
\hline & 8 & 3.32 & 14.88 & 0.26 & 7.48 & 0.74 & 99.9 \\
\hline & 4 & 3.11 & 14.35 & 0.32 & 7.13 & 0.73 & 99.4 \\
\hline & 2 & 2.92 & 13.67 & 0.39 & 6.73 & 0.72 & 99.6 \\
\hline & 1 & 2.68 & 12.71 & 0.18 & 6.27 & 0.66 & 99.6 \\
\hline & 0.5 & 2.48 & 11.73 & 0.30 & 5.82 & 0.62 & 99.6 \\
\hline & 0.25 & 2.30 & 10.96 & 0.18 & 5.48 & 0.49 & 99.6 \\
\hline \multirow[t]{8}{*}{ May } & 24 & 3.94 & 15.91 & 0.25 & 8.63 & 0.72 & 96.9 \\
\hline & 16 & 3.78 & 15.38 & 0.16 & 8.31 & 0.71 & 96.9 \\
\hline & 8 & 3.52 & 14.27 & 0.25 & 7.76 & 0.69 & 96.9 \\
\hline & 4 & 3.31 & 13.69 & 0.19 & 7.42 & 0.69 & 96.9 \\
\hline & 2 & 3.09 & 12.94 & 0.09 & 7.03 & 0.65 & 96.9 \\
\hline & 1 & 2.85 & 12.04 & 0.09 & 6.51 & 0.59 & 96.9 \\
\hline & 0.5 & 2.66 & 11.11 & 0.02 & 6.07 & 0.58 & 96.9 \\
\hline & 0.25 & 2.48 & 10.34 & 0.24 & 5.73 & 0.50 & 96.9 \\
\hline \multirow[t]{8}{*}{ June } & 24 & 4.44 & 14.96 & 0.00 & 9.38 & 0.69 & 100.0 \\
\hline & 16 & 4.28 & 14.63 & 0.15 & 9.12 & 0.73 & 100.0 \\
\hline & 8 & 3.96 & 13.79 & 0.19 & 8.56 & 0.68 & 100.0 \\
\hline & 4 & 3.77 & 13.26 & 0.24 & 8.25 & 0.69 & 100.0 \\
\hline & 2 & 3.52 & 12.49 & 0.25 & 7.79 & 0.68 & 100.0 \\
\hline & 1 & 3.24 & 11.60 & 0.22 & 7.25 & 0.63 & 100.0 \\
\hline & 0.5 & 2.97 & 10.73 & 0.19 & 6.69 & 0.60 & 100.0 \\
\hline & 0.25 & 2.75 & 10.01 & 0.18 & 6.27 & 0.51 & 100.0 \\
\hline
\end{tabular}


Table 5-2 Summary Wind Speed Data - January - December, 1994 Cont.

\begin{tabular}{|c|c|c|c|c|c|c|c|}
\hline \multirow[b]{2}{*}{ Month } & \multirow{2}{*}{$\begin{array}{c}\text { Tower } \\
\text { Height }(\mathrm{m})\end{array}$} & \multicolumn{3}{|c|}{ Monthly } & \multicolumn{2}{|c|}{ Mean Daily } & \multirow{2}{*}{$\begin{array}{c}\% \text { Data } \\
\text { Recovery }\end{array}$} \\
\hline & & Mean & Max & Min & Max & Min & \\
\hline \multirow[t]{8}{*}{ July } & 24 & 3.58 & 12.70 & 0.10 & 8.35 & 0.39 & 98.5 \\
\hline & 16 & 3.47 & 12.40 & 0.20 & 8.10 & 0.59 & 100.0 \\
\hline & 8 & 3.22 & 11.70 & 0.20 & 7.55 & 0.58 & 100.0 \\
\hline & 4 & 3.05 & 11.30 & 0.30 & 7.25 & 0.60 & 100.0 \\
\hline & 2 & 2.83 & 10.70 & 0.30 & 6.87 & 0.59 & 100.0 \\
\hline & 1 & 2.60 & 10.00 & 0.30 & 6.40 & 0.53 & 100.0 \\
\hline & 0.5 & 2.40 & 9.20 & 0.30 & 5.92 & 0.51 & 100.0 \\
\hline & 0.25 & 2.22 & 8.60 & 0.20 & 5.56 & 0.40 & 100.0 \\
\hline \multirow[t]{8}{*}{ August } & 24 & 3.68 & 12.50 & 0.03 & 8.63 & 0.37 & 98.3 \\
\hline & 16 & 3.57 & 12.20 & 0.10 & 8.31 & 0.56 & 100.0 \\
\hline & 8 & 3.31 & 11.50 & 0.10 & 7.81 & 0.57 & 100.0 \\
\hline & 4 & 3.14 & 11.10 & 0.20 & 7.53 & 0.60 & 100.0 \\
\hline & 2 & 2.93 & 10.50 & 0.30 & 7.12 & 0.59 & 100.0 \\
\hline & 1 & 2.69 & 9.80 & 0.20 & 6.62 & 0.54 & 100.0 \\
\hline & 0.5 & 2.49 & 9.00 & 0.20 & 6.18 & 0.52 & 100.0 \\
\hline & 0.25 & 2.31 & 8.50 & 0.20 & 5.78 & 0.45 & 100.0 \\
\hline \multirow[t]{8}{*}{ September } & 24 & 3.34 & 15.62 & 0.01 & 7.54 & 0.51 & 98.1 \\
\hline & 16 & 3.18 & 15.26 & 0.00 & 7.27 & 0.47 & 99.3 \\
\hline & 8 & 2.87 & 14.35 & 0.00 & 6.79 & 0.29 & 99.2 \\
\hline & 4 & 2.86 & 13.81 & 0.29 & 6.50 & 0.57 & 99.7 \\
\hline & 2 & 2.65 & 13.07 & 0.34 & 6.14 & 0.59 & 99.7 \\
\hline & 1 & 2.42 & 12.18 & 0.29 & 5.74 & 0.53 & 99.7 \\
\hline & 0.5 & 2.23 & 11.24 & 0.34 & 5.32 & 0.54 & 99.7 \\
\hline & 0.25 & 2.05 & 10.54 & 0.07 & 5.00 & 0.40 & 99.7 \\
\hline \multirow[t]{8}{*}{ October } & 24 & 2.54 & 14.39 & 0.22 & 6.35 & 0.60 & 100.0 \\
\hline & 16 & 2.44 & 13.94 & 0.14 & 6.07 & 0.58 & 100.0 \\
\hline & 8 & 2.08 & 12.92 & 0.00 & 5.54 & 0.22 & 98.5 \\
\hline & 4 & 2.14 & 12.38 & 0.15 & 5.19 & 0.60 & 100.0 \\
\hline & 2 & 1.97 & 11.59 & 0.29 & 4.75 & 0.64 & 100.0 \\
\hline & 1 & 1.78 & 10.90 & 0.19 & 4.42 & 0.50 & 100.0 \\
\hline & 0.5 & 1.64 & 10.03 & 0.29 & 4.05 & 0.55 & 100.0 \\
\hline & 0.25 & 1.51 & 9.42 & 0.19 & 3.80 & 0.41 & 100.0 \\
\hline \multirow[t]{8}{*}{ November } & 24 & 2.94 & 17.08 & 0.22 & 6.39 & 0.77 & 100.0 \\
\hline & 16 & 2.82 & 16.37 & 0.20 & 6.11 & 0.75 & 100.0 \\
\hline & 8 & 2.56 & 14.97 & 0.05 & 5.57 & 0.58 & 99.7 \\
\hline & 4 & 2.42 & 14.27 & 0.01 & 5.21 & 0.58 & 99.9 \\
\hline & 2 & 2.24 & 13.31 & 0.22 & 4.75 & 0.69 & 100.0 \\
\hline & 1 & 1.96 & 12.48 & 0.02 & 4.36 & 0.42 & 99.4 \\
\hline & 0.5 & 1.86 & 11.41 & 0.25 & 4.05 & 0.55 & 100.0 \\
\hline & 0.25 & 1.73 & 10.70 & 0.09 & 3.80 & 0.45 & 100.0 \\
\hline \multirow[t]{8}{*}{ December } & 24 & 2.17 & 8.27 & 0.14 & 5.12 & 0.65 & 64.8 \\
\hline & 16 & 2.07 & 8.10 & 0.20 & 4.81 & 0.63 & 64.8 \\
\hline & 8 & 1.89 & 7.71 & 0.18 & 4.35 & 0.58 & 64.8 \\
\hline & 4 & 1.77 & 7.40 & 0.21 & 4.00 & 0.61 & 64.8 \\
\hline & 2 & 1.60 & 6.84 & 0.20 & 3.59 & 0.58 & 64.8 \\
\hline & 1 & 1.45 & 6.41 & 0.11 & 3.28 & 0.53 & 64.8 \\
\hline & 0.5 & 1.32 & 5.96 & 0.10 & 3.03 & 0.45 & 64.8 \\
\hline & 0.25 & 1.21 & 5.57 & 0.06 & 2.82 & 0.36 & 64.8 \\
\hline
\end{tabular}


Table 5-3 Summary Temperature Data - January - December, 1994

\begin{tabular}{|c|c|c|c|c|c|c|c|}
\hline \multirow[b]{2}{*}{ Month } & \multirow{2}{*}{$\begin{array}{c}\text { Tower } \\
\text { Height }(m)\end{array}$} & \multicolumn{3}{|c|}{ Monthly } & \multicolumn{2}{|c|}{ Mean Daily } & \multirow{2}{*}{$\begin{array}{c}\% \text { Data } \\
\text { Recovery }\end{array}$} \\
\hline & & Mean & Max & Min & $\operatorname{Max}$ & Min & \\
\hline \multirow[t]{8}{*}{ January } & 24 & & & & & & 0.0 \\
\hline & 16 & 4.72 & 21.16 & -9.55 & 14.75 & -3.35 & 78.0 \\
\hline & 8 & 4.42 & 21.56 & -9.88 & 15.11 & -4.04 & 78.0 \\
\hline & 4 & 3.33 & 20.84 & -11.19 & 14.37 & -5.18 & 78.0 \\
\hline & 2 & 3.02 & 20.77 & -11.25 & 14.35 & -5.45 & 78.0 \\
\hline & 1 & 2.71 & 20.43 & -11.32 & 14.24 & -5.65 & 78.0 \\
\hline & 0.5 & 2.64 & 20.21 & -11.11 & 14.13 & -5.55 & 78.0 \\
\hline & $\begin{array}{l}0.25 \\
\text { soil }\end{array}$ & 2.33 & 19.81 & -11.21 & 13.95 & -5.75 & 78.0 \\
\hline \multirow[t]{9}{*}{ February } & 24 & 6.56 & 23.36 & -7.31 & 13.50 & 0 & 52.1 \\
\hline & 16 & 6.59 & 23.60 & -7.48 & 13.75 & -0.18 & 52.1 \\
\hline & 8 & 5.76 & 23.50 & -9.72 & 12.66 & -0.25 & 75.1 \\
\hline & 4 & 5.10 & 23.37 & -10.92 & 12.20 & -1.04 & 75.1 \\
\hline & 2 & 4.98 & 23.39 & -10.94 & 12.26 & -1.16 & 75.1 \\
\hline & 1 & 4.81 & 23.52 & -11.02 & 12.23 & -1.28 & 75.1 \\
\hline & 0.5 & 5.89 & 23.57 & -10.81 & 13.34 & 0.60 & 50.7 \\
\hline & 0.25 & 4.62 & 23.66 & -10.94 & 12.16 & -1.32 & 75.1 \\
\hline & soil & & & & & & \\
\hline \multirow[t]{8}{*}{ March } & 24 & 12.11 & 22.33 & 0.86 & 20.69 & 4.99 & 18.8 \\
\hline & 16 & 12.91 & 26.04 & 0.60 & 20.09 & 5.58 & 99.9 \\
\hline & 8 & 12.37 & 26.16 & -0.72 & 20.19 & 4.56 & 99.9 \\
\hline & 4 & 12.01 & 26.12 & -1.35 & 20.21 & 3.95 & 99.9 \\
\hline & 2 & 11.90 & 26.31 & -1.54 & 20.46 & 3.66 & 99.9 \\
\hline & 1 & 11.78 & 26.59 & -1.73 & 20.69 & 3.42 & 99.9 \\
\hline & 0.5 & 11.70 & 26.67 & -1.76 & 20.78 & 3.34 & 99.9 \\
\hline & $\begin{array}{l}0.25 \\
\text { soil }\end{array}$ & 11.68 & 27.01 & -1.71 & 21.03 & 3.30 & 99.9 \\
\hline \multirow[t]{9}{*}{ April } & 24 & 15.29 & 30.73 & 1.26 & 21.33 & 8.22 & 84.7 \\
\hline & 16 & 14.96 & 30.94 & 1.07 & 21.43 & 7.32 & 99.3 \\
\hline & 8 & 14.72 & 31.24 & 0.34 & 21.67 & 6.59 & 99.3 \\
\hline & 4 & 14.23 & 30.60 & -0.69 & 21.45 & 5.82 & 99.3 \\
\hline & 2 & 14.43 & 31.87 & -0.92 & 22.08 & 5.72 & 99.3 \\
\hline & 1 & 14.35 & 32.28 & -1.11 & 22.41 & 5.53 & 99.3 \\
\hline & 0.5 & 14.36 & 32.60 & -1.14 & 22.67 & 5.50 & 99.3 \\
\hline & 0.25 & 14.39 & 33.15 & -1.14 & 23.08 & 5.46 & 99.3 \\
\hline & soil & & & & & & \\
\hline \multirow[t]{8}{*}{ May } & 24 & 19.96 & 33.08 & 4.99 & 25.71 & 12.19 & 96.9 \\
\hline & 16 & 19.86 & 33.30 & 4.22 & 25.88 & 11.70 & 96.9 \\
\hline & 8 & 19.70 & 33.58 & 3.28 & 26.10 & 10.95 & 96.9 \\
\hline & 4 & 19.24 & 33.74 & 2.32 & 25.88 & 10.21 & 96.9 \\
\hline & 2 & 19.49 & 34.18 & 1.77 & 26.57 & 10.05 & 96.9 \\
\hline & 1 & 19.47 & 34.68 & 1.69 & 26.95 & 9.83 & 96.9 \\
\hline & 0.5 & 19.51 & 35.04 & 1.73 & 27.26 & 9.77 & 96.9 \\
\hline & $\begin{array}{l}0.25 \\
\text { soil }\end{array}$ & 19.59 & 35.58 & 1.78 & 27.76 & 9.67 & 96.9 \\
\hline
\end{tabular}


Table 5-3 Summary Temperature Data - January - December, 1994 Cont.

\begin{tabular}{|c|c|c|c|c|c|c|c|}
\hline \multirow[b]{2}{*}{ Month } & \multirow{2}{*}{$\begin{array}{c}\text { Tower } \\
\text { Height }(\mathrm{m})\end{array}$} & \multicolumn{3}{|c|}{ Monthly } & \multicolumn{2}{|c|}{ Mean Daily } & \multirow{2}{*}{$\begin{array}{c}\% \text { Data } \\
\text { Recovery }\end{array}$} \\
\hline & & Mean & Max & Min & $\operatorname{Max}$ & Min & \\
\hline \multirow[t]{8}{*}{ June } & 24 & 27.59 & 40.41 & 11.73 & 34.57 & 17.87 & 99.9 \\
\hline & 16 & 27.37 & 40.63 & 11.03 & 34.76 & 17.13 & 99.9 \\
\hline & 8 & 27.05 & 40.85 & 10.35 & 35.00 & 16.29 & 99.9 \\
\hline & 4 & 26.72 & 41.00 & 8.94 & 35.12 & 15.57 & 99.9 \\
\hline & 2 & 26.59 & 41.42 & 7.78 & 35.48 & 15.01 & 99.9 \\
\hline & 1 & 26.47 & 41.77 & 7.40 & 35.85 & 14.64 & 99.9 \\
\hline & 0.5 & 26.46 & 42.04 & 7.33 & 36.13 & 14.52 & 99.9 \\
\hline & $\begin{array}{l}0.25 \\
\text { soil }\end{array}$ & 26.47 & 42.49 & 7.25 & 36.59 & 14.38 & 99.9 \\
\hline \multirow[t]{9}{*}{ July } & 24 & 29.72 & 38.99 & 16.50 & 36.27 & 20.59 & 99.9 \\
\hline & 16 & 29.49 & 39.24 & 15.98 & 36.48 & 19.87 & 99.9 \\
\hline & 8 & 29.12 & 39.55 & 14.88 & 36.74 & 18.95 & 99.9 \\
\hline & 4 & 28.77 & 39.72 & 13.56 & 36.87 & 18.20 & 99.9 \\
\hline & 2 & 28.66 & 40.21 & 12.29 & 37.26 & 17.69 & 99.9 \\
\hline & 1 & 28.54 & 40.69 & 12.00 & 37.64 & 17.3 & 99.9 \\
\hline & 0.5 & 28.53 & 41.04 & 11.98 & 37.97 & 17.19 & 99.9 \\
\hline & 0.25 & 28.55 & 41.58 & 11.97 & 38.47 & 17.01 & 99.9 \\
\hline & soil & & & & & & \\
\hline \multirow[t]{9}{*}{ August } & 24 & 28.90 & 39.49 & 12.30 & 35.71 & 19.86 & 100.0 \\
\hline & 16 & 28.70 & 39.69 & 11.13 & 35.91 & 19.31 & 100.0 \\
\hline & 8 & 28.38 & 39.88 & 9.17 & 36.18 & 18.52 & 100.0 \\
\hline & 4 & 28.09 & 39.98 & 8.44 & 36.31 & 17.91 & 100.0 \\
\hline & 2 & 28.00 & 40.32 & 8.13 & 36.70 & 17.51 & 100.0 \\
\hline & 1 & 27.88 & 40.67 & 8.04 & 37.09 & 17.18 & 100.0 \\
\hline & 0.5 & 27.87 & 41.03 & 7.98 & 37.41 & 17.08 & 100.0 \\
\hline & 0.25 & 27.88 & 41.65 & 7.98 & 37.91 & 16.94 & 100.0 \\
\hline & soil & & & & & & \\
\hline \multirow[t]{9}{*}{ September } & 24 & 22.86 & 34.70 & 7.89 & 30.22 & 13.95 & 98.6 \\
\hline & 16 & 22.59 & 34.91 & 7.36 & 30.36 & 13.24 & 98.6 \\
\hline & 8 & 22.19 & 35.17 & 6.86 & 30.58 & 12.26 & 98.6 \\
\hline & 4 & 21.83 & 35.29 & 6.26 & 30.72 & 11.57 & 98.6 \\
\hline & 2 & 21.61 & 35.72 & 5.57 & 30.99 & 11.15 & 98.6 \\
\hline & 1 & 21.45 & 36.11 & 5.19 & 31.33 & 10.88 & 98.6 \\
\hline & 0.5 & 21.38 & 36.45 & 5.12 & 31.54 & 10.79 & 98.6 \\
\hline & 0.25 & 21.34 & 36.96 & 4.99 & 31.93 & 10.67 & 98.6 \\
\hline & soil & & & & & & \\
\hline \multirow[t]{9}{*}{ October } & 24 & 14.55 & 28.22 & -0.10 & 22.38 & 6.50 & 100.0 \\
\hline & 16 & 14.21 & 28.27 & -1.71 & 22.47 & 5.74 & 100.0 \\
\hline & 8 & 13.65 & 28.36 & -2.81 & 22.60 & 4.72 & 100.0 \\
\hline & 4 & 13.23 & 28.59 & -3.22 & 22.70 & 4.09 & 100.0 \\
\hline & 2 & 12.94 & 28.79 & -3.71 & 22.83 & 3.60 & 100.0 \\
\hline & 1 & 12.75 & 29.19 & -3.98 & 23.05 & 3.29 & 100.0 \\
\hline & 0.5 & 12.68 & 29.38 & -3.92 & 23.18 & 3.24 & 100.0 \\
\hline & 0.25 & 12.62 & 29.71 & -3.93 & 23.44 & 3.12 & 100.0 \\
\hline & soil & & & & & & \\
\hline
\end{tabular}


Table 5-3 Summary Temperature Data - January - December, 1994 Cont.

\begin{tabular}{|c|c|c|c|c|c|c|c|}
\hline \multirow[b]{2}{*}{ Month } & \multirow{2}{*}{$\begin{array}{c}\text { Tower } \\
\text { Height }(m)\end{array}$} & \multicolumn{3}{|c|}{ Monthly } & \multicolumn{2}{|c|}{ Mean Daily } & \multirow{2}{*}{$\begin{array}{c}\% \text { Data } \\
\text { Recovery }\end{array}$} \\
\hline & & Mean & $\operatorname{Max}$ & Min & Max & Min & \\
\hline \multirow[t]{8}{*}{ November } & 24 & 4.55 & 23.42 & -9.43 & 11.47 & -1.67 & 100.0 \\
\hline & 16 & 4.27 & 23.45 & -10.90 & 11.52 & -2.28 & 100.0 \\
\hline & 8 & 3.79 & 23.58 & -11.91 & 11.56 & -3.25 & 100.0 \\
\hline & 4 & 3.43 & 23.65 & -12.72 & 11.56 & -3.86 & 100.0 \\
\hline & 2 & 3.21 & 23.71 & -13.10 & 11.62 & -4.15 & 100.0 \\
\hline & 1 & 2.99 & 23.81 & -13.49 & 11.66 & -4.44 & 100.0 \\
\hline & 0.5 & 2.92 & 23.84 & -13.59 & 11.65 & -4.44 & 100.0 \\
\hline & $\begin{array}{l}0.25 \\
\text { soil }\end{array}$ & 2.81 & 23.88 & -13.86 & 11.68 & -4.54 & 100.0 \\
\hline \multirow[t]{9}{*}{ December } & 24 & 5.43 & 16.48 & -6.15 & 11.92 & 0.47 & 64.8 \\
\hline & 16 & 5.11 & 16.33 & -7.13 & 11.89 & -0.05 & 64.8 \\
\hline & 8 & 4.55 & 15.91 & -9.08 & 11.77 & -0.93 & 64.8 \\
\hline & 4 & 4.42 & 15.87 & -9.38 & 11.90 & -1.17 & 64.8 \\
\hline & 2 & 4.23 & 15.69 & -9.63 & 11.92 & -1.48 & 64.8 \\
\hline & 1 & 3.84 & 15.42 & -10.17 & 11.72 & -1.92 & 64.8 \\
\hline & 0.5 & 3.69 & 15.27 & -10.19 & 11.59 & -1.99 & 64.8 \\
\hline & 0.25 & 3.46 & 14.98 & -10.40 & 11.43 & -2.19 & 64.8 \\
\hline & soil & & & & & & \\
\hline
\end{tabular}


Table 5-4 Summary of Relatlve Humidity, Radlation and

Barometric Pressure - January through December, 1994

\begin{tabular}{|c|c|c|c|c|c|c|c|c|c|c|c|c|c|c|c|c|c|c|}
\hline \multirow[b]{2}{*}{ Relatlve Humidity (\%) } & \multicolumn{3}{|c|}{ January } & \multicolumn{3}{|c|}{ February } & \multicolumn{3}{|c|}{ March } & \multicolumn{3}{|c|}{ April } & \multicolumn{3}{|c|}{ May } & \multicolumn{2}{|c|}{ June } & \multirow[b]{2}{*}{$1 \mathrm{~m}$} \\
\hline & $16 \mathrm{~m}$ & $4 m$ & $9 m$ & $16 \mathrm{~m}$ & $4 m$ & $1 \mathrm{~m}$ & $16 \mathrm{~m}$ & $4 m$ & $1 \mathrm{~m}$ & $16 \mathrm{~m}$ & $4 m$ & $1 \mathrm{~m}$ & $16 \mathrm{~m}$ & $4 \mathrm{~m}$ & $1 \mathrm{~m}$ & $16 \mathrm{~m}$ & $4 m$ & \\
\hline Mean & 42 & 45 & 47 & 49 & 52 & 55 & 33 & 35 & 35 & 31 & 32 & 32 & 27 & 28 & 27 & 13 & 13 & 12 \\
\hline Maximum & 96 & 92 & 87 & 100 & 100 & 100 & 99 & 99 & 99 & 93 & 96 & 97 & 88 & 91 & 95 & 70 & 74 & 76 \\
\hline Minimum & 8 & 8 & 9 & 7 & 7 & 7 & 7 & 7 & 7 & 6 & 6 & 6 & 2 & 2 & 2 & 3 & 2 & 2 \\
\hline Mean Daily Max & 67 & 71 & 71 & 71 & 74 & 76 & 55 & 59 & 60 & 50 & 53 & 53 & 44 & 45 & 45 & 22 & 23 & 22 \\
\hline Mean Dally Min & 19 & 20 & 20 & 28 & 29 & 31 & 16 & 16 & 15 & 16 & 16 & 15 & 14 & 14 & 13 & 7 & 6 & 6 \\
\hline Data Recovery (\%) & 78 & 78 & 78 & 85 & 85 & 85 & 100 & 100 & 100 & 99 & 100 & 100 & 97 & 97 & 97 & 100 & 100 & 100 \\
\hline $\begin{array}{l}\text { Solar Radlation }\left(W / \mathrm{m}^{2}\right) \\
\text { Mean } \\
\text { Maximum } \\
\text { Minimum } \\
\text { Mean Dailly Max } \\
\text { Mean Dally Min } \\
\text { Data Recovery }(\%)\end{array}$ & & & $\begin{array}{c}130 \\
629 \\
0 \\
515 \\
0 \\
78\end{array}$ & & & $\begin{array}{c}146 \\
783 \\
0 \\
527 \\
17 \\
85\end{array}$ & & & $\begin{array}{c}232 \\
938 \\
0 \\
824 \\
0 \\
100\end{array}$ & & & $\begin{array}{c}273 \\
1004 \\
0 \\
916 \\
0 \\
99\end{array}$ & & & $\begin{array}{c}320 \\
1113 \\
0 \\
952 \\
0 \\
97\end{array}$ & & & $\begin{array}{c}360 \\
1060 \\
0 \\
1008 \\
0 \\
99 \\
\end{array}$ \\
\hline $\begin{array}{l}\text { Net Radlation }\left(\mathrm{W} / \mathrm{m}^{2}\right) \\
\text { Mean } \\
\text { Maximum } \\
\text { Minimum } \\
\text { Mean Daily Max } \\
\text { Mean Daily Min } \\
\text { Data Recovery (\%) }\end{array}$ & & & $\begin{array}{l}10 \\
179 \\
-60 \\
154 \\
-42 \\
78\end{array}$ & & & $\begin{array}{c}32 \\
335 \\
-65 \\
205 \\
-38 \\
85 \\
\end{array}$ & & & $\begin{array}{l}55 \\
454 \\
-66 \\
310 \\
-51 \\
100\end{array}$ & & & $\begin{array}{c}59 \\
364 \\
-99 \\
309 \\
-54 \\
99\end{array}$ & & & $\begin{array}{l}40 \\
359 \\
-74 \\
255 \\
-52 \\
96\end{array}$ & & & $\begin{array}{c}20 \\
356 \\
-87 \\
226 \\
-72 \\
99\end{array}$ \\
\hline $\begin{array}{l}\text { Atmosphoric Prossure (mb) } \\
\text { Mean } \\
\text { Maximum } \\
\text { Minlmum } \\
\text { Mean Dally Max } \\
\text { Mean Dally Min } \\
\text { Data Recovery (\%) }\end{array}$ & & & $\begin{array}{l}914 \\
923 \\
901 \\
916 \\
911 \\
78\end{array}$ & & & $\begin{array}{l}910 \\
924 \\
843 \\
913 \\
905 \\
85\end{array}$ & & & $\begin{array}{l}908 \\
922 \\
894 \\
911 \\
905 \\
100\end{array}$ & & & $\begin{array}{l}905 \\
915 \\
894 \\
908 \\
903 \\
100\end{array}$ & & & $\begin{array}{l}904 \\
910 \\
895 \\
906 \\
902 \\
97\end{array}$ & & & $\begin{array}{l}\mathbf{5 0 4} \\
910 \\
895 \\
906 \\
902 \\
100\end{array}$ \\
\hline
\end{tabular}


Tablo 5\& Summary of Rolative Humldity, Radlation and

Barometric Pressure - January through Decomber, 1994 Con't

\begin{tabular}{|c|c|c|c|c|c|c|c|c|c|c|c|c|c|c|c|c|c|c|}
\hline \multirow{2}{*}{ Relative Humldity (\%) } & \multicolumn{3}{|c|}{ July } & \multicolumn{3}{|c|}{ August } & \multicolumn{3}{|c|}{ September } & \multicolumn{3}{|c|}{ October } & \multicolumn{3}{|c|}{ November } & \multicolumn{3}{|c|}{ Decomber } \\
\hline & $16 \mathrm{~m}$ & $4 \mathrm{~m}$ & $1 \mathrm{~m}$ & $16 \mathrm{~m}$ & $4 m$ & $1 \mathrm{~m}$ & $16 m$ & $4 m$ & $1 \mathrm{~m}$ & $16 \mathrm{~m}$ & $4 \mathrm{~m}$ & $1 \mathrm{~m}$ & $16 \mathrm{~m}$ & $4 \mathrm{~m}$ & $1 \mathrm{~m}$ & $16 m$ & $4 \mathrm{~m}$ & $1 \mathrm{~m}$ \\
\hline Mean & 17 & 17 & 17 & 20 & 21 & 20 & 21 & 22 & 20 & 29 & 29 & 28 & 47 & 50 & 51 & 61 & 63 & 64 \\
\hline Maximum & 83 & 88 & 85 & 87 & 88 & 90 & 71 & 80 & 85 & 73 & 69 & 71 & 100 & 100 & 100 & 100 & 100 & 100 \\
\hline Minimum & 3 & 3 & 2 & 3 & 3 & 2 & 5 & 5 & 4 & 4 & 4 & 4 & 8 & 8 & 8 & 12 & 12 & 12 \\
\hline Mean Dally Max & 27 & 28 & 28 & 31 & 32 & 31 & 33 & 33 & 31 & 44 & 42 & 40 & 69 & 72 & 72 & 79 & 81 & 81 \\
\hline Mean Daily Min & $\theta$ & 9 & 9 & 11 & 11 & 10 & 12 & 12 & 11 & 17 & 17 & 16 & 25 & 26 & 26 & 35 & 36 & 36 \\
\hline Data Recovery (\%) & & & 100 & 100 & 100 & 100 & 99 & 99 & 99 & 100 & 100 & 100 & 100 & 100 & 100 & 65 & 65 & 65 \\
\hline \multicolumn{19}{|l|}{$\begin{array}{l}\text { Solar Radiation }\left(W / m^{2}\right) \\
\text { Mean }\end{array}$} \\
\hline Maximum & & & 1072 & & & $\begin{array}{ll}302 \\
1004\end{array}$ & & & $\begin{array}{l}253 \\
1001\end{array}$ & & & $\begin{array}{l}196 \\
804\end{array}$ & & & $\begin{array}{l}139 \\
727\end{array}$ & & & $\begin{array}{l}104 \\
566\end{array}$ \\
\hline Minimum & & & 0 & & & 0 & & & 0 & & & 0 & & & 0 & & & 0 \\
\hline Mean Daily Max & & & 983 & & & 941 & & & 846 & & & 719 & & & 578 & & & 438 \\
\hline $\begin{array}{l}\text { Mean Daily Min } \\
\text { Data Recovery (\%) }\end{array}$ & & & $\begin{array}{c}0 \\
100\end{array}$ & & & $\begin{array}{c}0 \\
100\end{array}$ & & & $\begin{array}{c}0 \\
99\end{array}$ & & & $\begin{array}{c}0 \\
100\end{array}$ & & & $\begin{array}{c}0 \\
100\end{array}$ & & & $\begin{array}{c}1 \\
65\end{array}$ \\
\hline \multicolumn{19}{|l|}{ Net Radlation $\left(W / m^{2}\right)$} \\
\hline Mean & & & 28 & & & & & & 26 & & & 13 & & & 5 & & & 10 \\
\hline Maximum & & & 324 & & & & & & 288 & & & 256 & & & 285 & & & 298 \\
\hline Minimum & & & -83 & & & & & & -97 & & & -88 & & & -89 & & & -80 \\
\hline Mean Daily Max & & & 238 & & & & & & 254 & & & 212 & & & 177 & & & 163 \\
\hline $\begin{array}{l}\text { Mean Dally Min } \\
\text { Data Recovery (\%) }\end{array}$ & & & $\begin{array}{l}-66 \\
66\end{array}$ & & & & & & $\begin{array}{l}-77 \\
38\end{array}$ & & & $\begin{array}{l}-73 \\
100\end{array}$ & & & $\begin{array}{r}-64 \\
100\end{array}$ & & & $\begin{array}{l}-55 \\
65\end{array}$ \\
\hline \multicolumn{19}{|c|}{ Atmospheric Pressure (mb) } \\
\hline Mean & & & 905 & & & 906 & & & 907 & & & 906 & & & 908 & & & 909 \\
\hline Maximum & & & 910 & & & 912 & & & 913 & & & 917 & & & 922 & & & 920 \\
\hline Minimum & & & 898 & & & 899 & & & 900 & & & 888 & & & 894 & & & 902 \\
\hline Mean Daily Max & & & 907 & & & 908 & & & 909 & & & 908 & & & 912 & & & 912 \\
\hline Mean Daily Min & & & 903 & & & 903 & & & 905 & & & 903 & & & 905 & & & 907 \\
\hline Data Recovery (\%) & & & 100 & & & 100 & & & 100 & & & 100 & & & 100 & & & 65 \\
\hline
\end{tabular}




\subsection{STABILITY CALCULATIONS}

Pasquill Gifford Stability Classes were calculated using the Yamartino Sigma Theta method (EPA, 1990) to look at diurnal stability trends at the STF. Tower data were also used to calculate Richardson Numbers (Ri) and corresponding Monin-Obukhov lengths (L) for 3 different height intervals, as described in the following paragraphs.

Richardson number $(\mathrm{Ri})$ is defined according to equation 2-1,

$$
R i=\frac{g}{\theta}\left(\frac{\partial \theta}{\partial z}\right) /\left(\frac{\partial u}{\partial z}\right)^{2}
$$

where,

$$
\begin{aligned}
& \mathrm{g}=9.8 \mathrm{~m} / \mathrm{sec}^{2} \\
& \theta=\text { potential temperature }\left({ }^{\circ} \mathrm{K}\right) \\
& \mathrm{u}=\text { wind speed }(\mathrm{mps}) \\
& \mathrm{z}=\text { height }(\mathrm{m})
\end{aligned}
$$

or, in the finite difference form, according to equation 2-2.

$$
\mathrm{Ri}=\frac{\mathrm{g}}{\theta_{1}} \frac{\left(\theta_{2}-\theta_{1}\right)}{\left(\mathrm{u}_{2}-\mathrm{u}_{1}\right)^{2}}\left(\mathrm{z}_{2}-\mathrm{z}_{1}\right)
$$

where,

$\theta_{1}, \mathrm{u}_{\mathrm{l}}=$ potential temperature $\left({ }^{\circ} \mathrm{K}\right)$ and wind speed (mps) at height $\mathrm{z}_{1}$

$\theta_{2}, u_{2}=$ potential temperature $\left({ }^{\circ} \mathrm{K}\right)$ and wind speed (mps) at height $z_{2}$

$\mathrm{z}_{1} \quad$.= height of lower level

$\mathrm{z}_{2} \quad=$ height of upper level

Golder (1972) gives curves that relate Pasquill stability classes to the Monin-Obukhov length $L$ and the roughness length $z_{0}$. Extrapolation of Golder's curves to $z_{0}=0.2 \mathrm{~mm}$, the approximate roughness length at the STF, gives the relationships shown in Table 6-1. Ri was calculated from profile laws given by Högström (1988) using 3 different tower intervals and used to calculate corresponding values of $\mathrm{L}$. These may be used to assign stability classes according to $\mathrm{Ri}$ based on these three levels. Ri stability classes include the "extremely stable" $G$ (class 7 ) category. 
Table 6-1

Stability Classes Based on Monin-Obukhov

Length (L) and Richardson Number (Ri)

\begin{tabular}{|l|l|l|l|l|}
\hline $\begin{array}{l}\text { Stability } \\
\text { Class }\end{array}$ & \multicolumn{1}{|c|}{$\mathrm{L}(\mathrm{m})$} & $\mathrm{Ri}(0.25-2.0 \mathrm{~m})$ & $\mathrm{Ri}(0.5-4.0 \mathrm{~m})$ & \multicolumn{1}{c|}{$\mathrm{Ri}(2.0-16.0 \mathrm{~m})$} \\
\hline $\mathrm{A}$ & $-5 \leq \mathrm{L}<0$ & $\mathrm{Ri} \leq-0.2$ & $\mathrm{Ri} \leq-0.4$ & $\mathrm{Ri} \leq-1.6$ \\
\hline $\mathrm{B}$ & $-10 \leq \mathrm{L}<-5$ & $-0.2<\mathrm{Ri} \leq-0.1$ & $-0.4<\mathrm{Ri} \leq-0.2$ & $-1.6<\mathrm{Ri} \leq-0.8$ \\
\hline $\mathrm{C}$ & $-20 \leq \mathrm{L}<-10$ & $-0.1<\mathrm{Ri} \leq-0.05$ & $-0.2<\mathrm{Ri} \leq-0.1$ & $-0.8<\mathrm{Ri} \leq-0.4$ \\
\hline $\mathrm{D}$ & $\mathrm{L}<-20, \mathrm{~L} \geq+15$ & $-0.05<\mathrm{Ri} \leq+0.05$ & $-0.1<\mathrm{Ri}+0.09$ & $-0.4<\mathrm{Ri} \leq+0.2$ \\
\hline $\mathrm{E}$ & $+5 \leq \mathrm{L}<+15$ & $+0.05<\mathrm{Ri} \leq+0.12$ & $+0.09<\mathrm{Ri} \leq+0.18$ & $+0.2<\mathrm{Ri} \leq+0.28$ \\
\hline $\mathrm{F}$ & $+1.7 \leq \mathrm{L}<+5$ & $+0.12<\mathrm{Ri} \leq+0.21$ & $+0.18<\mathrm{Ri} \leq+0.26$ & $+0.28<\mathrm{Ri} \leq+0.315$ \\
\hline $\mathrm{G}$ & $0 \leq \mathrm{L}<+1.7$ & $\mathrm{Ri}>+0.21$ & $\mathrm{Ri}>+0.26$ & $\mathrm{Ri}>0.315$ \\
\hline
\end{tabular}

Tabulations of the Pasquill-Gifford stability classes estimated using the Yamartino Sigma Theta method, of Ri calculated from equation 2-1, and of value of $L$ based on Högström (1988) profile laws, are provided in Appendix D. Values of $L$ tabulated in Appendix D are given as $\left\langle 4 z_{1}\right.$ (where $z_{1}$ is the lower level) when $R i>0.25$. This was done to eliminate artificial values of $L$ when $\mathrm{Ri}$ approaches its critical value, $\mathrm{Ri}_{\mathrm{c}} \sim 0.3385$. At supercritical values of $\mathrm{Ri}$, stability suppresses turbulence to the point that turbulence is no longer the primary mechanism for transfer of heat and momentum, and profile laws are no longer valid.

Table 6-1 could be used to assign stability classes according to $\mathrm{Ri}$ and $\mathrm{L}$. However, it should be noted that stability classes based on $\mathrm{Ri}$ are very susceptible to biases in temperature measurements at the two levels. Biases of the magnitude of those suspected in Table 4-2 could cause a reversal of the sign of the temperature gradient, and a corresponding change from Class 6 to Class 1 , or vice versa, during low wind speeds. Appendix D includes tabulations of temperature differences between the two and sixteen meter tower levels as an aid to identify hours for which $\theta_{2}-\theta_{1}$ in equation 2-2 may be close to an uncertainty level suggested by Table 4-2. 


\subsection{REFERENCES}

Desert Research Institute and Western Research Institute, 1993: "Quality Assurance Project Plan Operation of the STF 24 Meter Meteorological Tower." DRI Document No. 94-3304.D2, Desert Research Institute, Reno, Nevada

Desert Research Institute and Western Research Institute, 1994: "Characterization of Carbon Dioxide Releases Under Stable Meteorological Conditions." DRI Document No. 93-3305.3D1, Desert Research Institute, Reno, Nevada.

Environmental Protection Agency, 1987: "On-Site Meteorological Program Guidance for Regulatory Modeling Applications." EPA-450/4-87-013, June 1987, with February, 1993 revisions. OAQPS, U.S.EPA, Research Triangle Park, North Carolina 27711.

Environmental Protection Agency, 1990: "Guidelines on Air Quality Models, with Supplements A and B." EPA-450/2-78-027r. OAQPS, U.S.EPA, Research Triangle Park, North Carolina 27711.

Golder, D. 1972: "Relations Among Stability Parameters in the Surface Layer." Boundary Layer Meteorol., 3, 47-58.

Högström, U., 1988: "Non-Dimensional Wind and Temperature Profiles in the Atmospheric Surface Layer: A Re-Evaluation." Boundary Layer Meteorol., 42, 55-78. 


\section{APPENDICES}

Appendix A Selected Time Series Plots, Two and Eight Meters

Appendix B

Monthly Wind Roses, Two and Eight Meters

Appendix C

Monthly Wind Frequency Distributions, Two and Eight Meters

Appendix D

Tabulated Hourly Richardson Numbers, Monin-Obukhov Lengths

Estimated from Richardson Numbers, Temperature Differences Two

to Sixteen Meters, and Sigma Theta Stability Classes 


\section{APPENDIX A: TIME SERIES PLOTS --15 MINUTE AVERAGES}

\section{Each Month, January - December, 1994}

1. Two Meter Air Temperature

2. Eight Meter Air Temperature

3. Temperature Difference, Two to Sixteen Meter

4. Solar Radiation

5. Net Radiation

6. Two Meter Wind Speed / Wind Direction

7. Eight Meter Wind Speed / Wind Direction 


\section{METER TEMPERATURE}

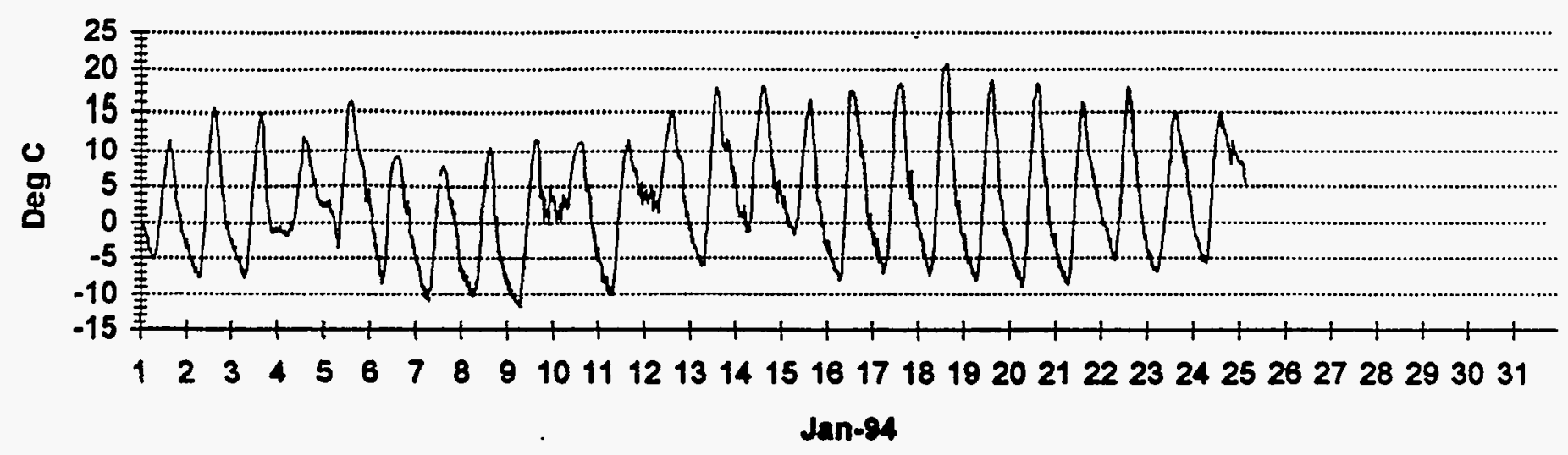

\section{METER TEMPERATURE}

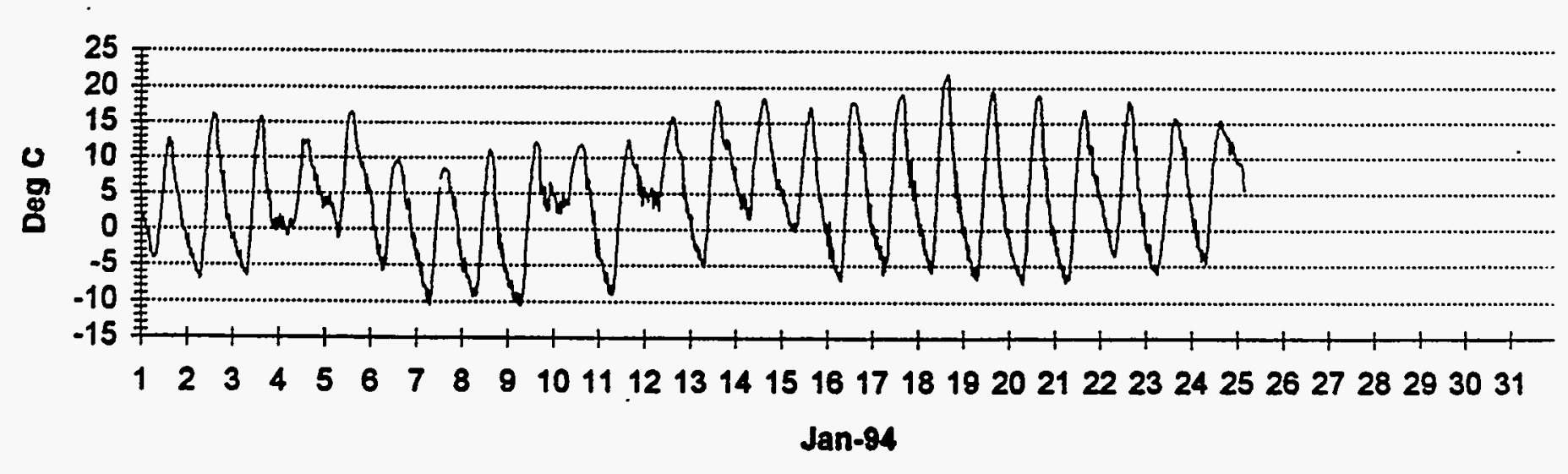

\section{TEMPERATURE DIFFERENCE, 2 TO 16 METER}

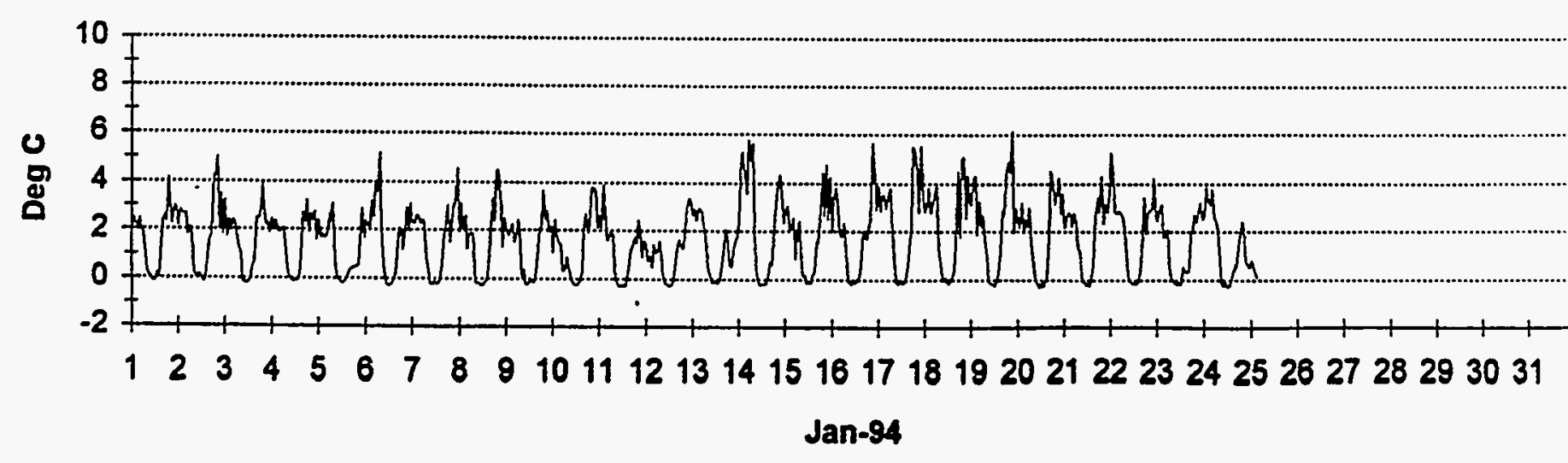




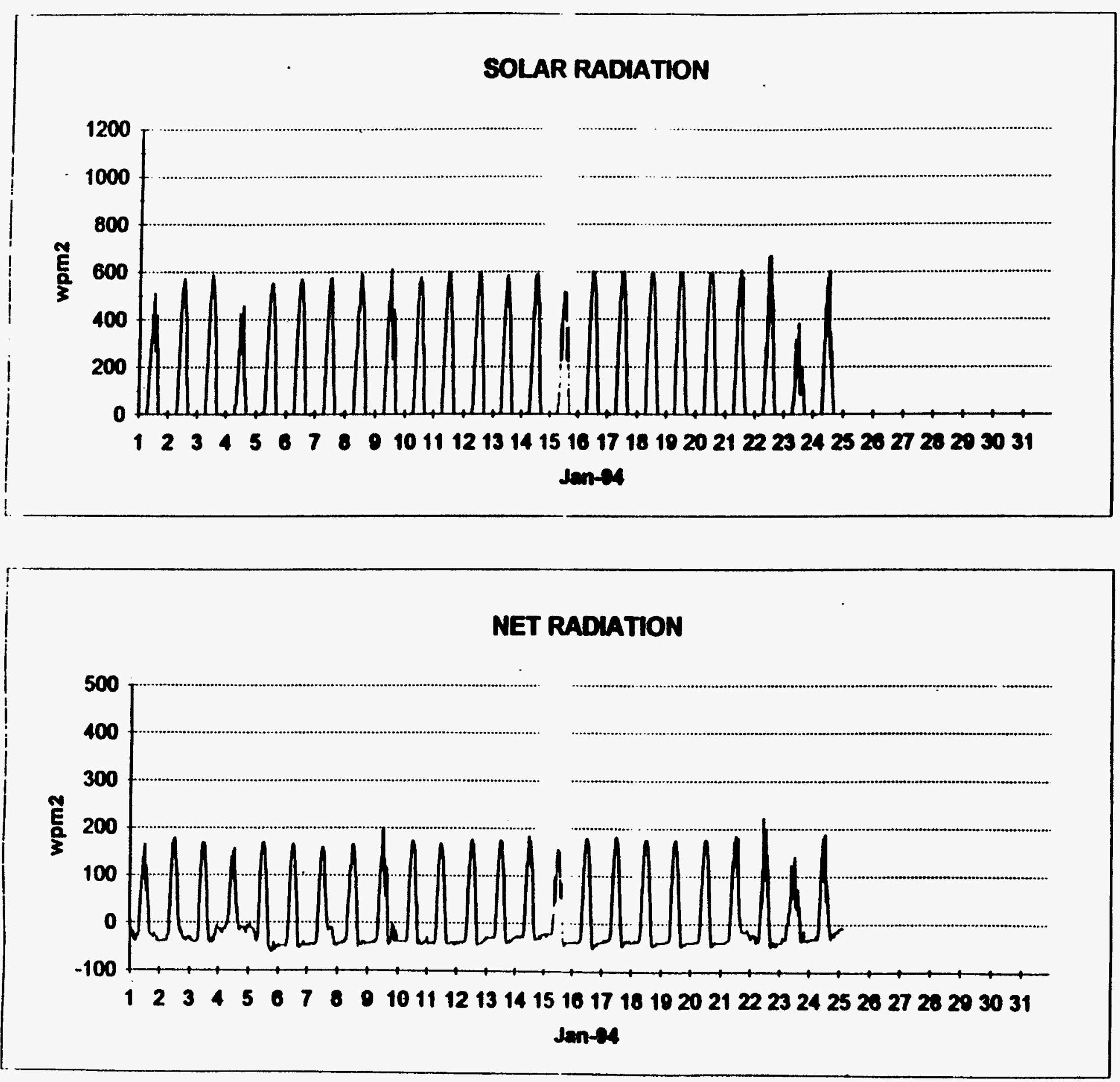



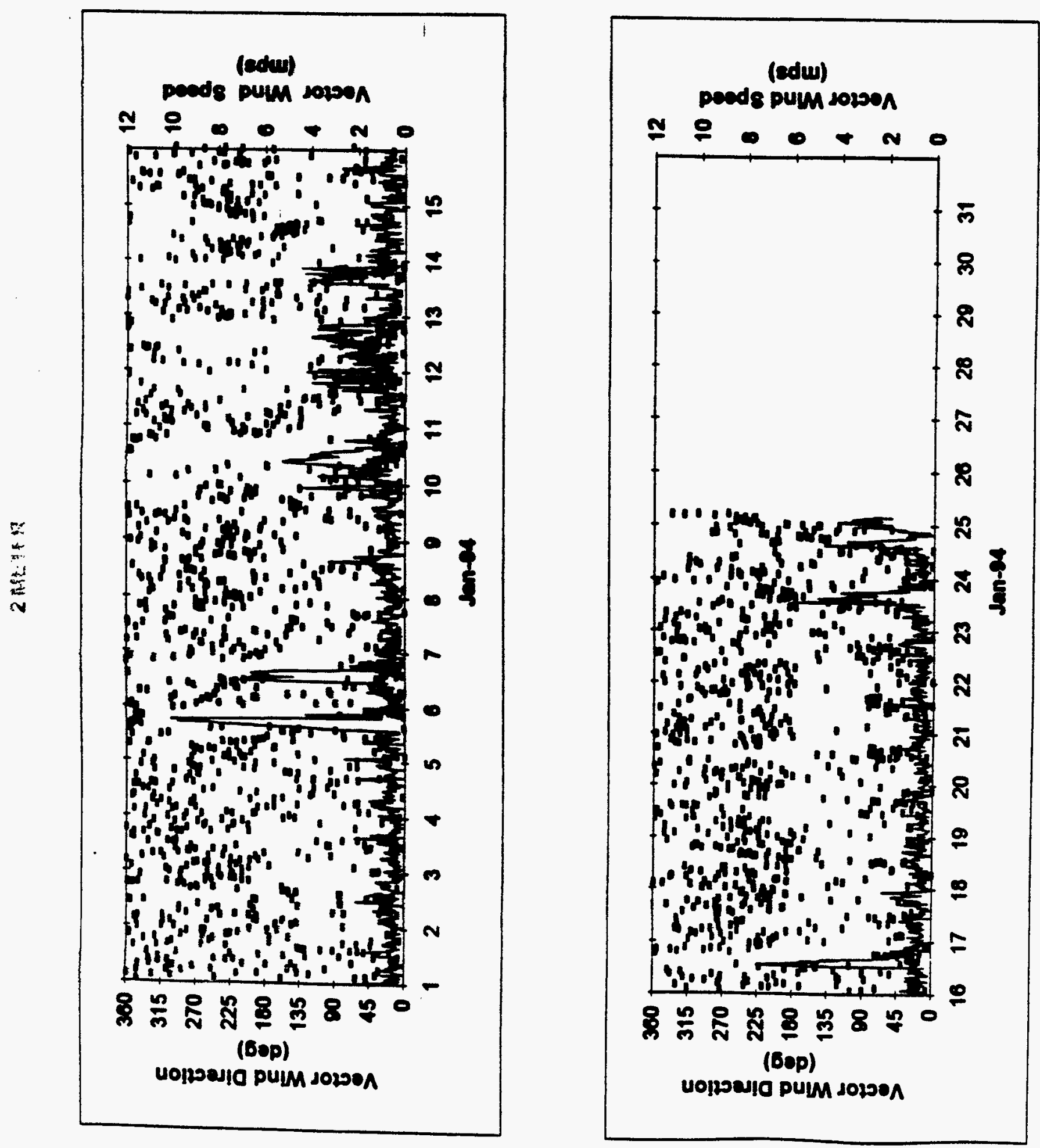

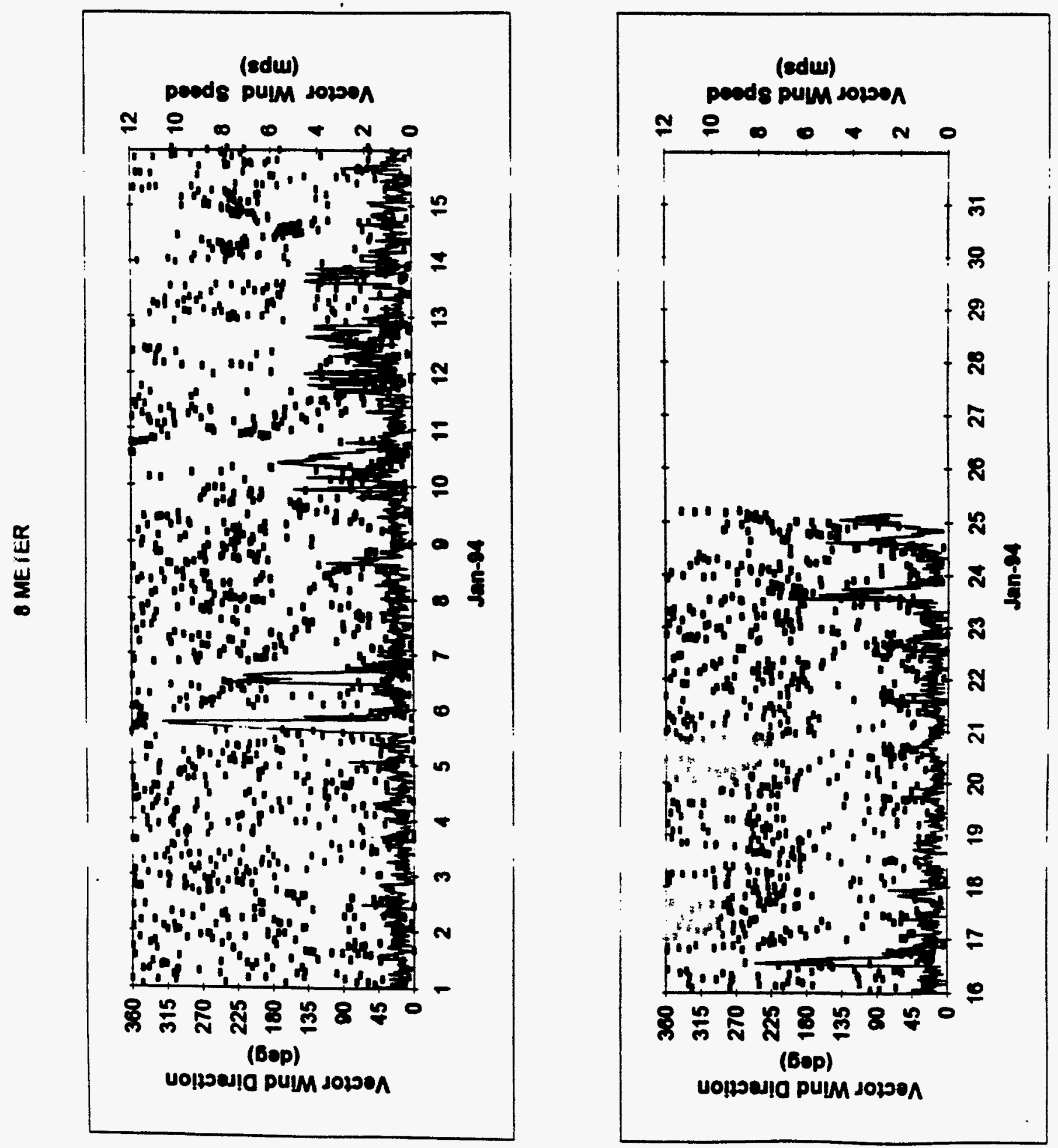


\section{METER TEMPERATURE}

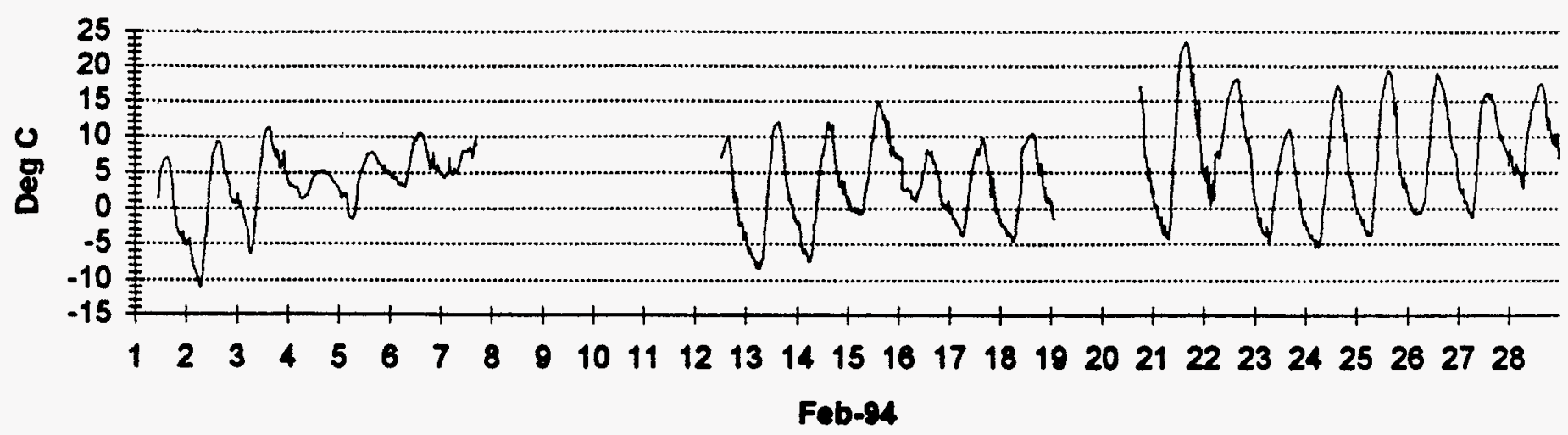

\section{METER TEMPERATURE}

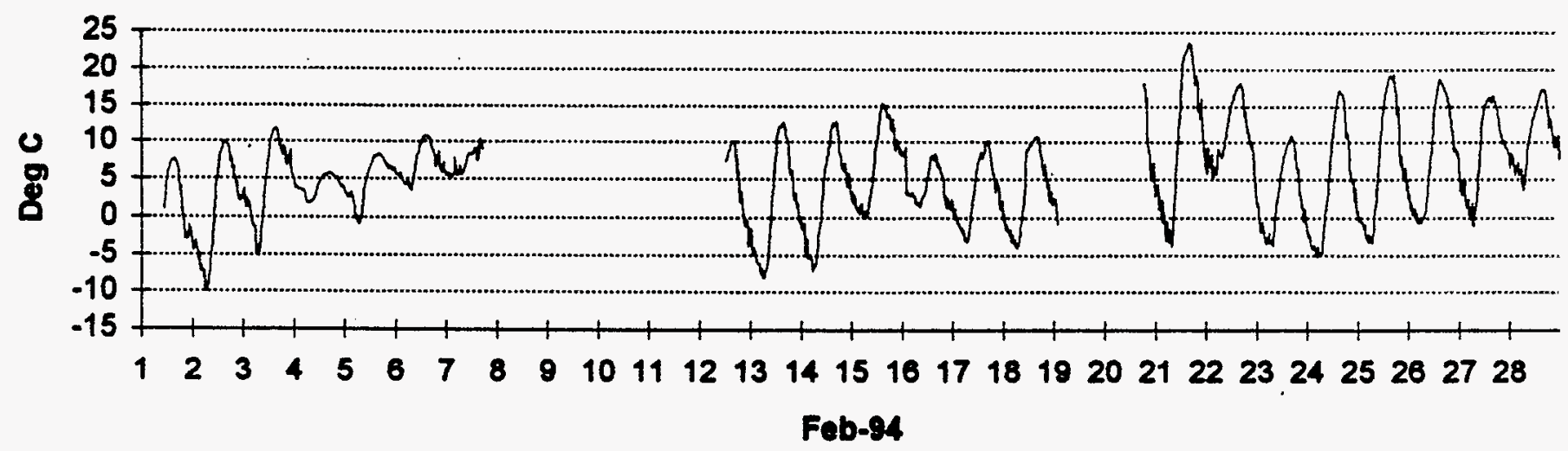

\section{TEMPERATURE DIFFERENCE, 2 TO 16 METER}

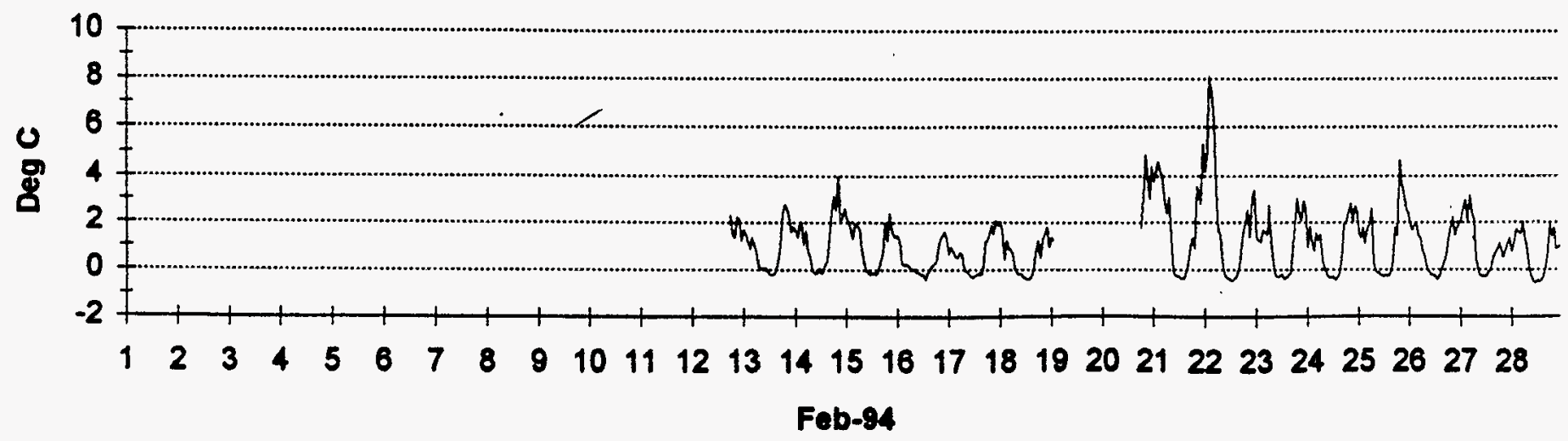



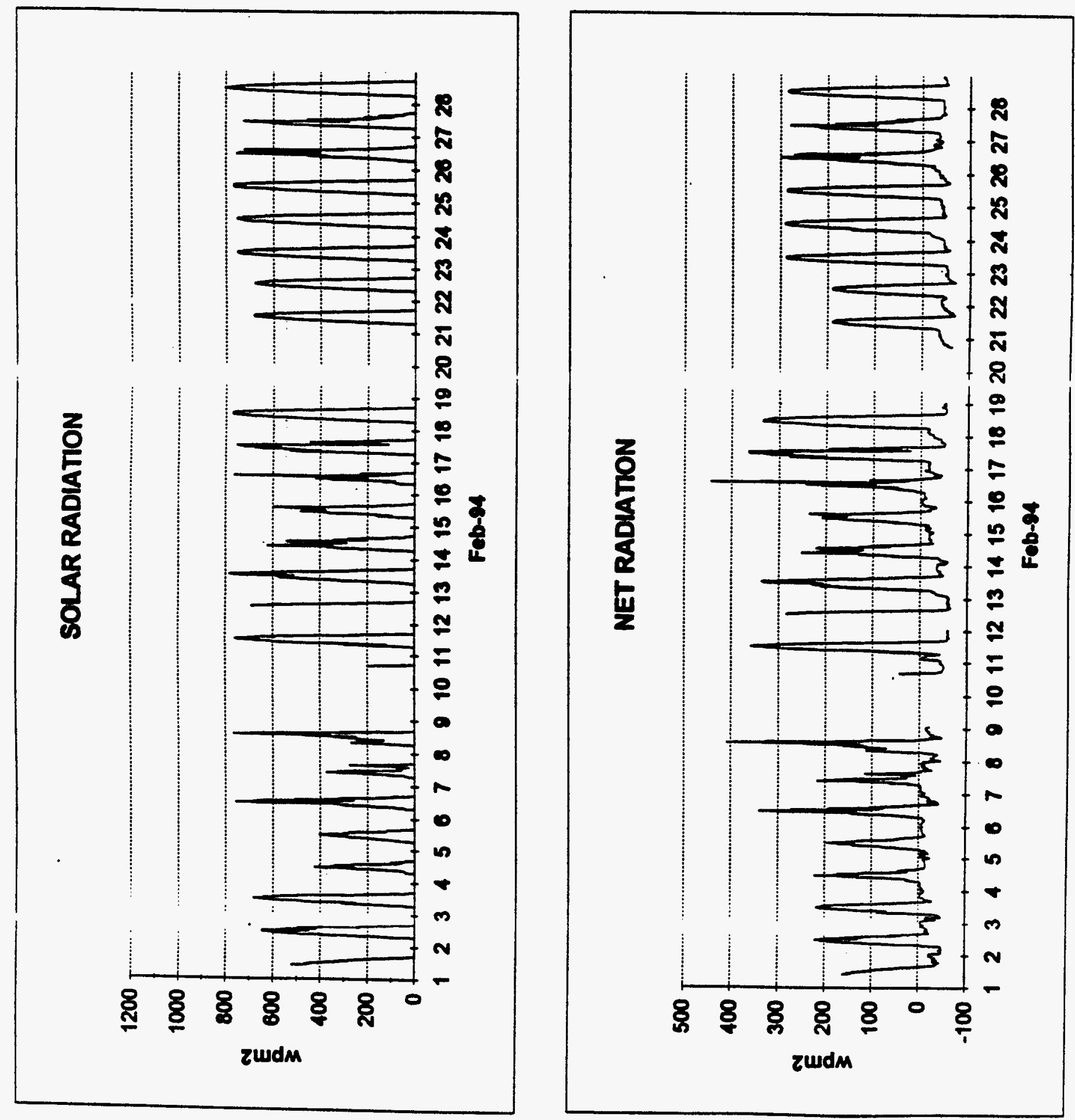

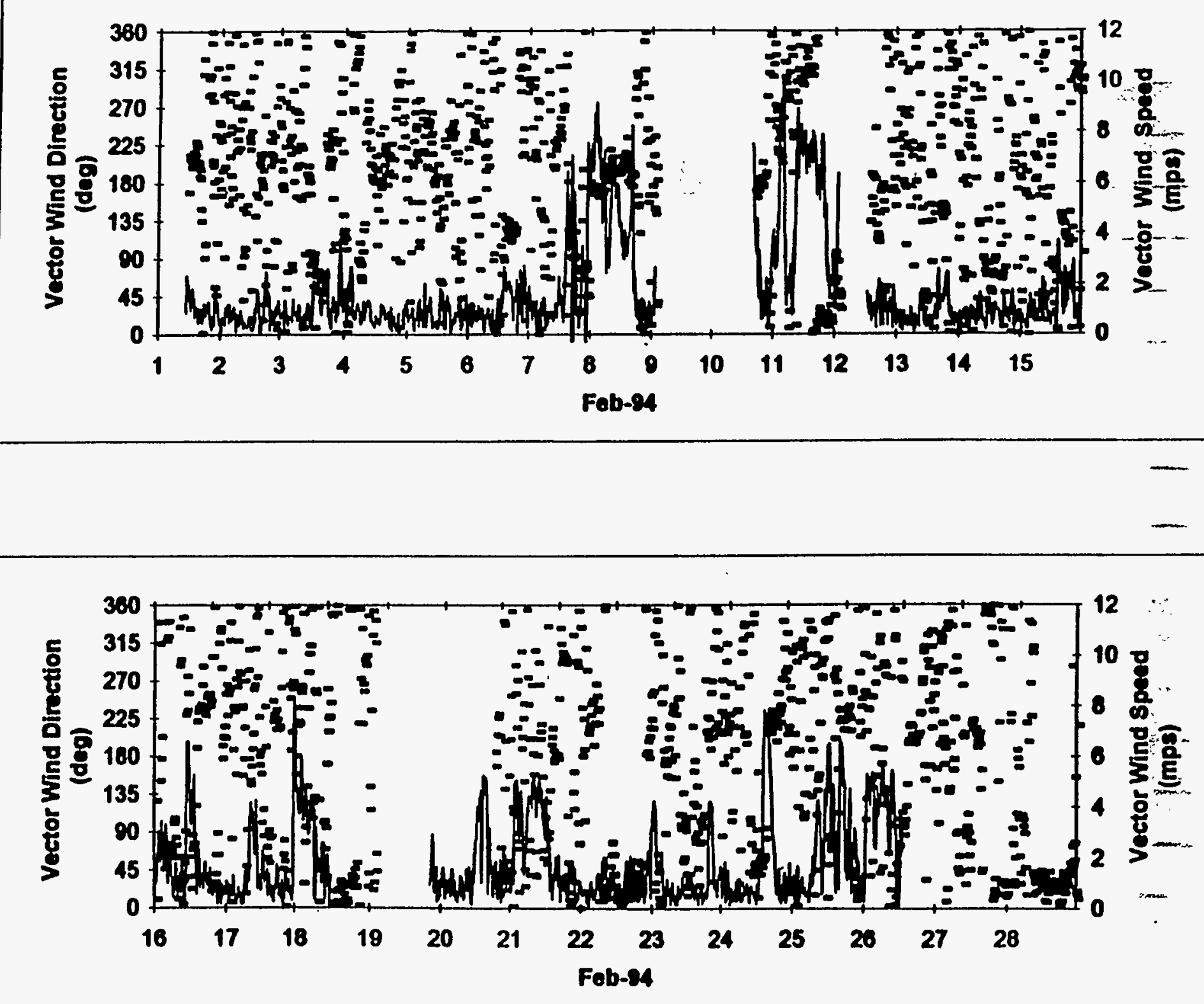

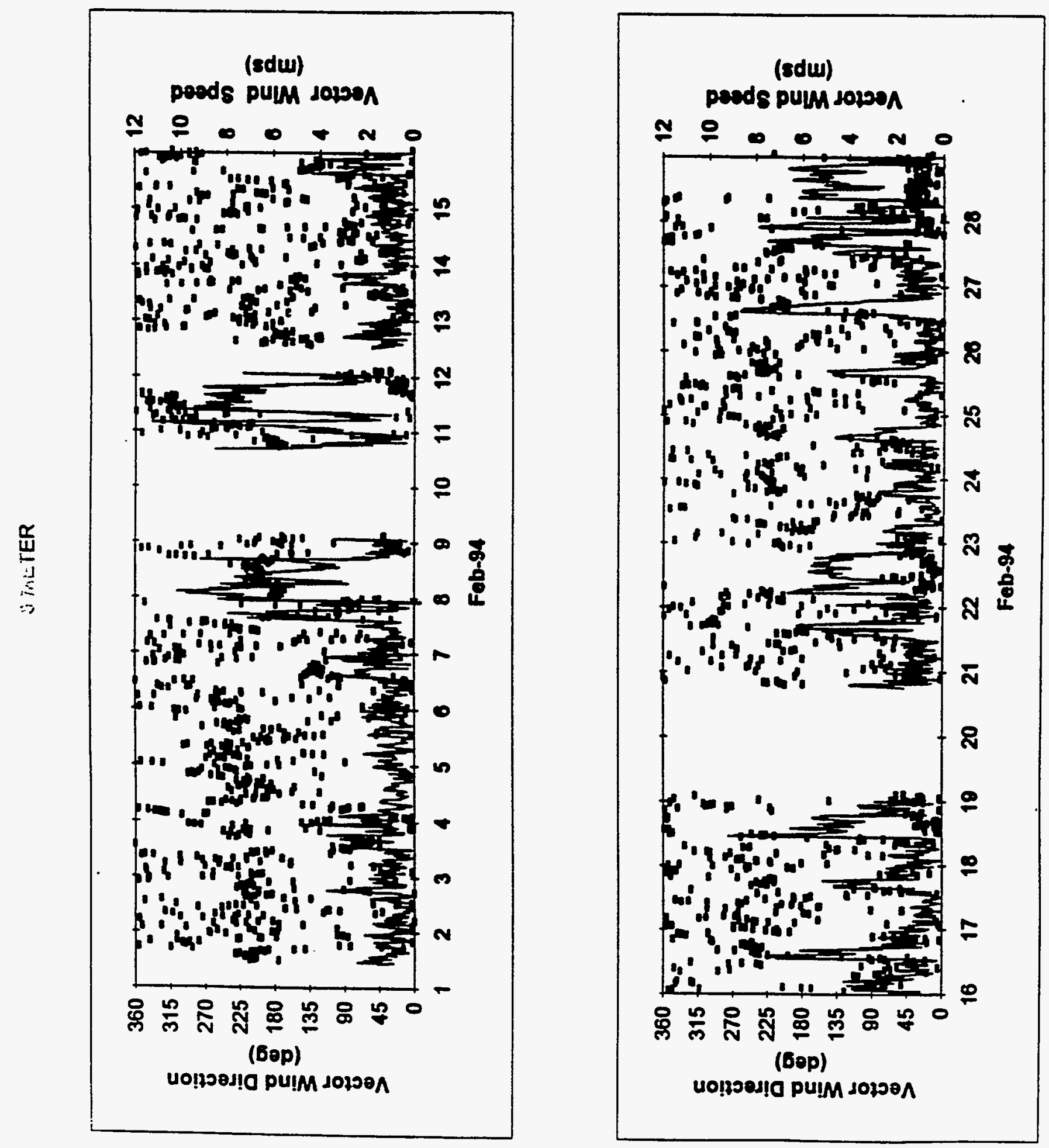


\section{METER TEMPERATURE}

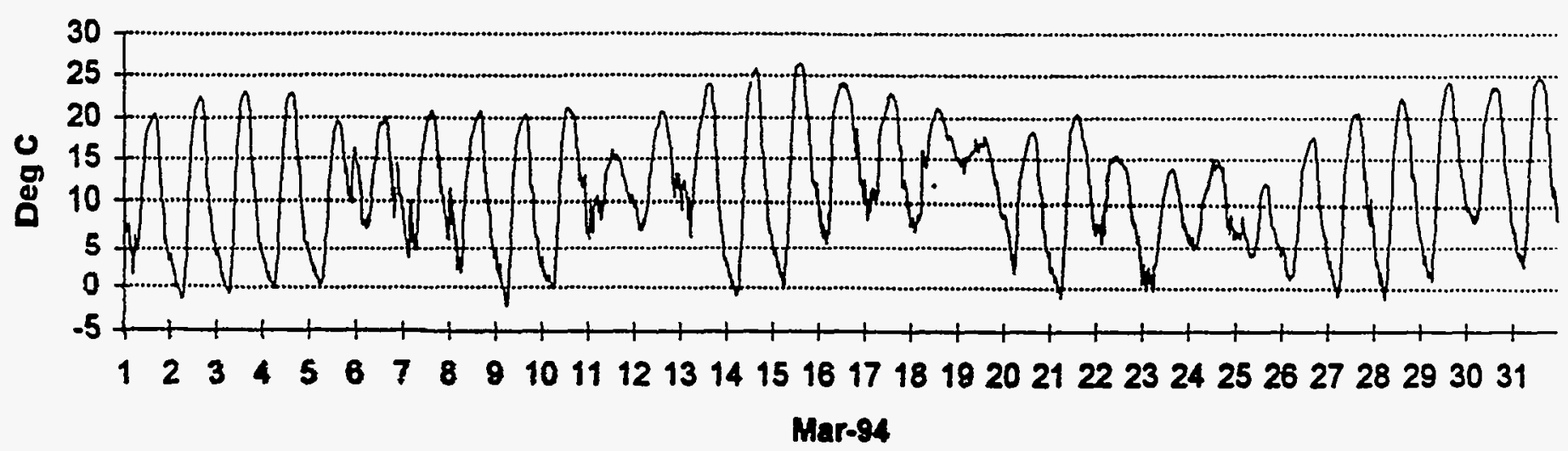

\section{METER TEMPERATURE}

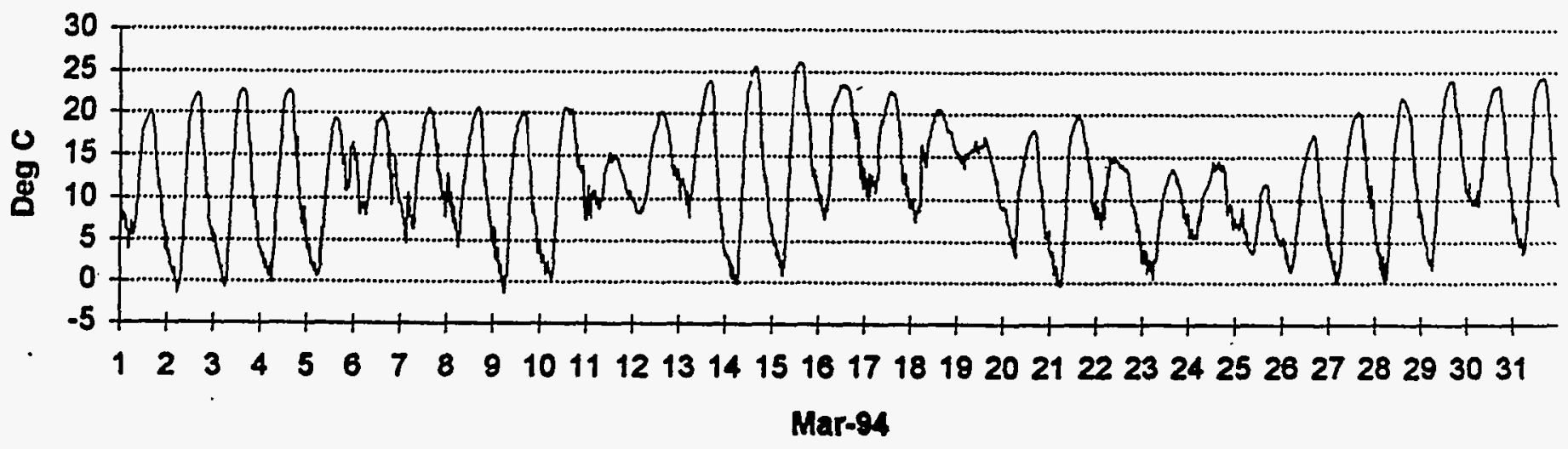

\section{TEMPERATURE DIFFERENCE, 2 TO 16 METER}

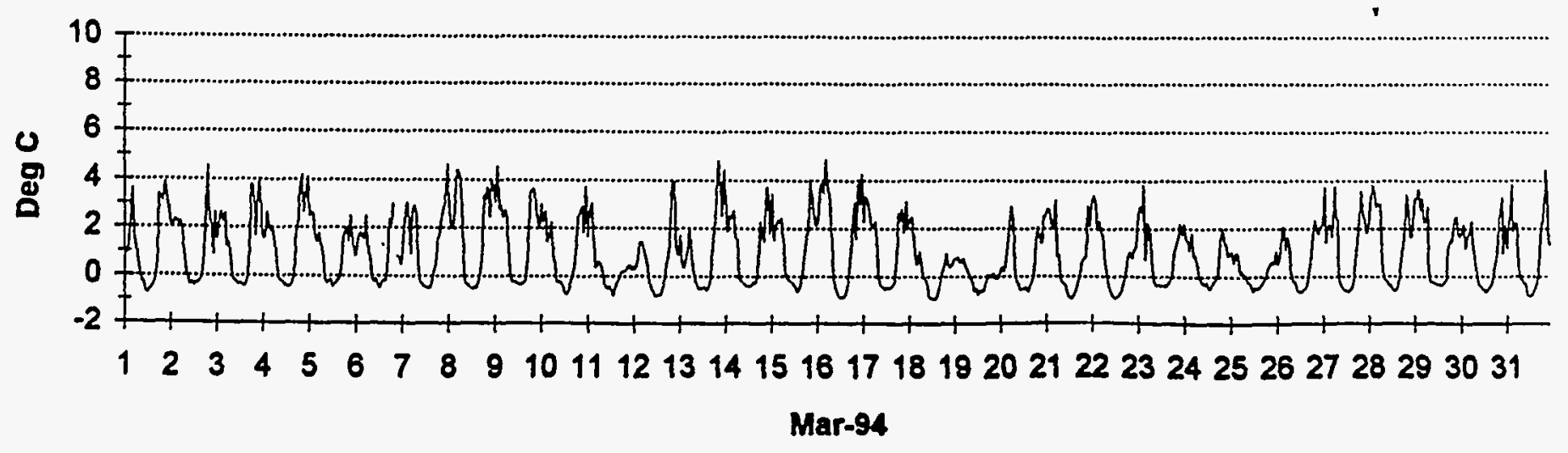



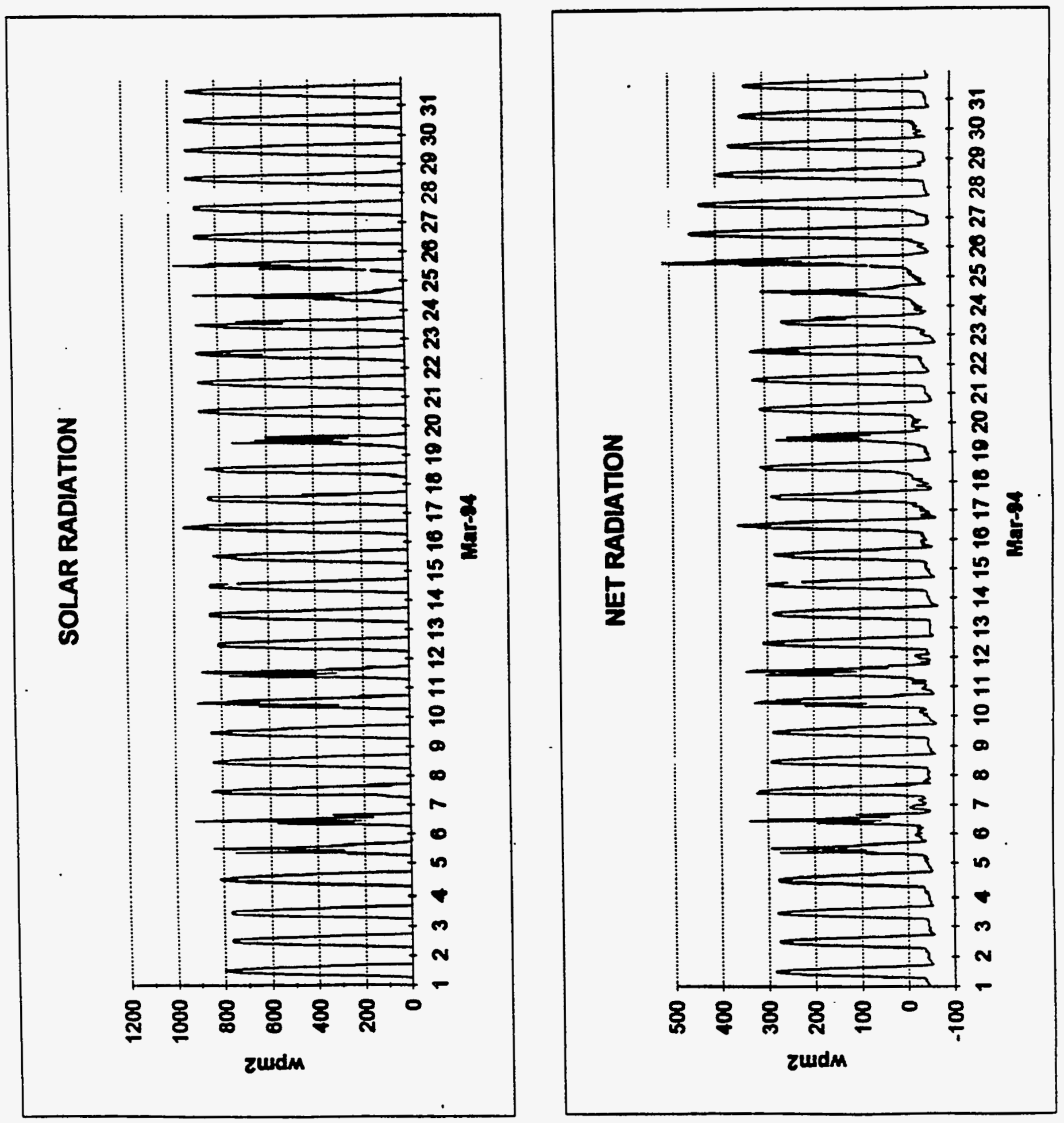

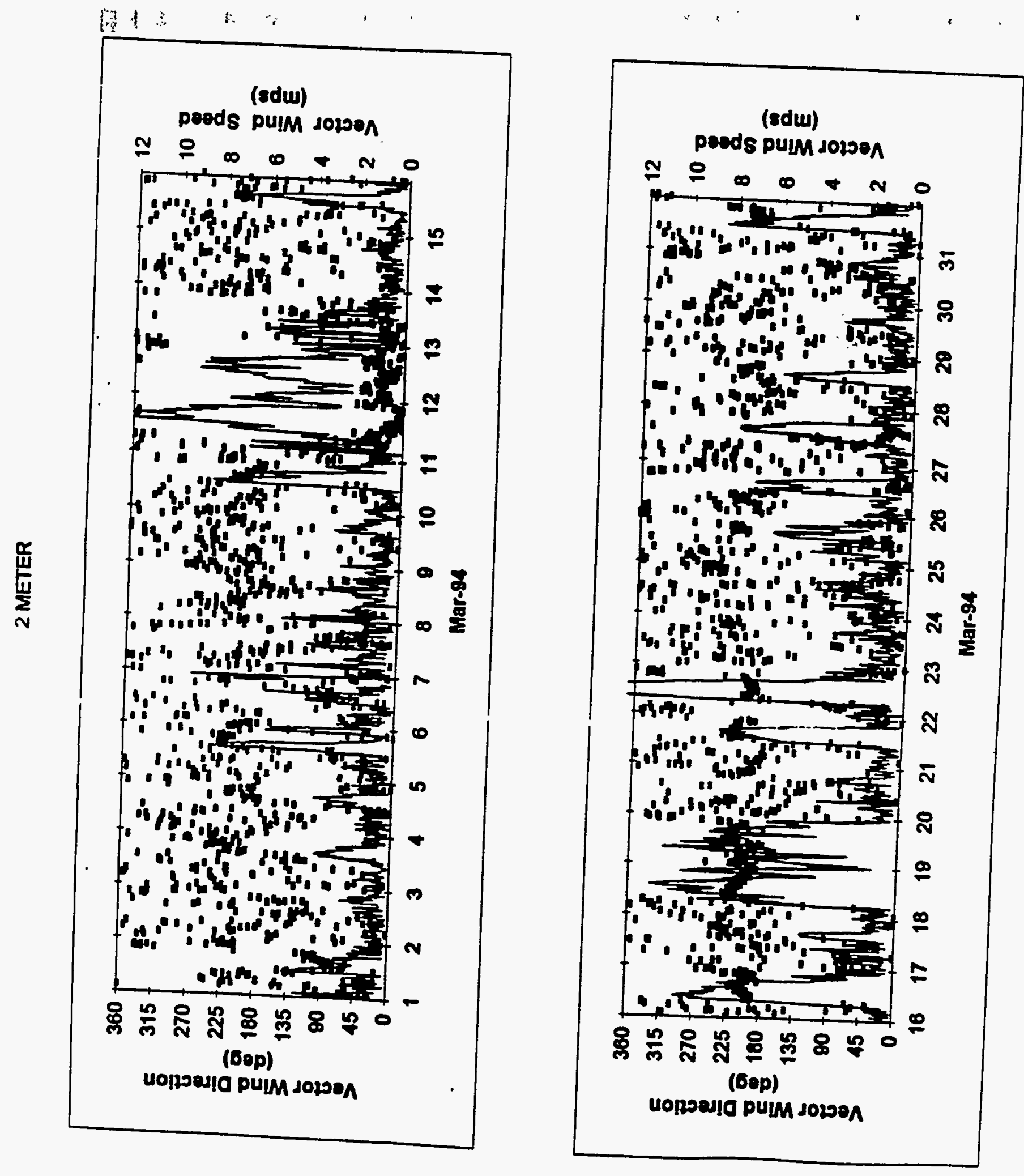

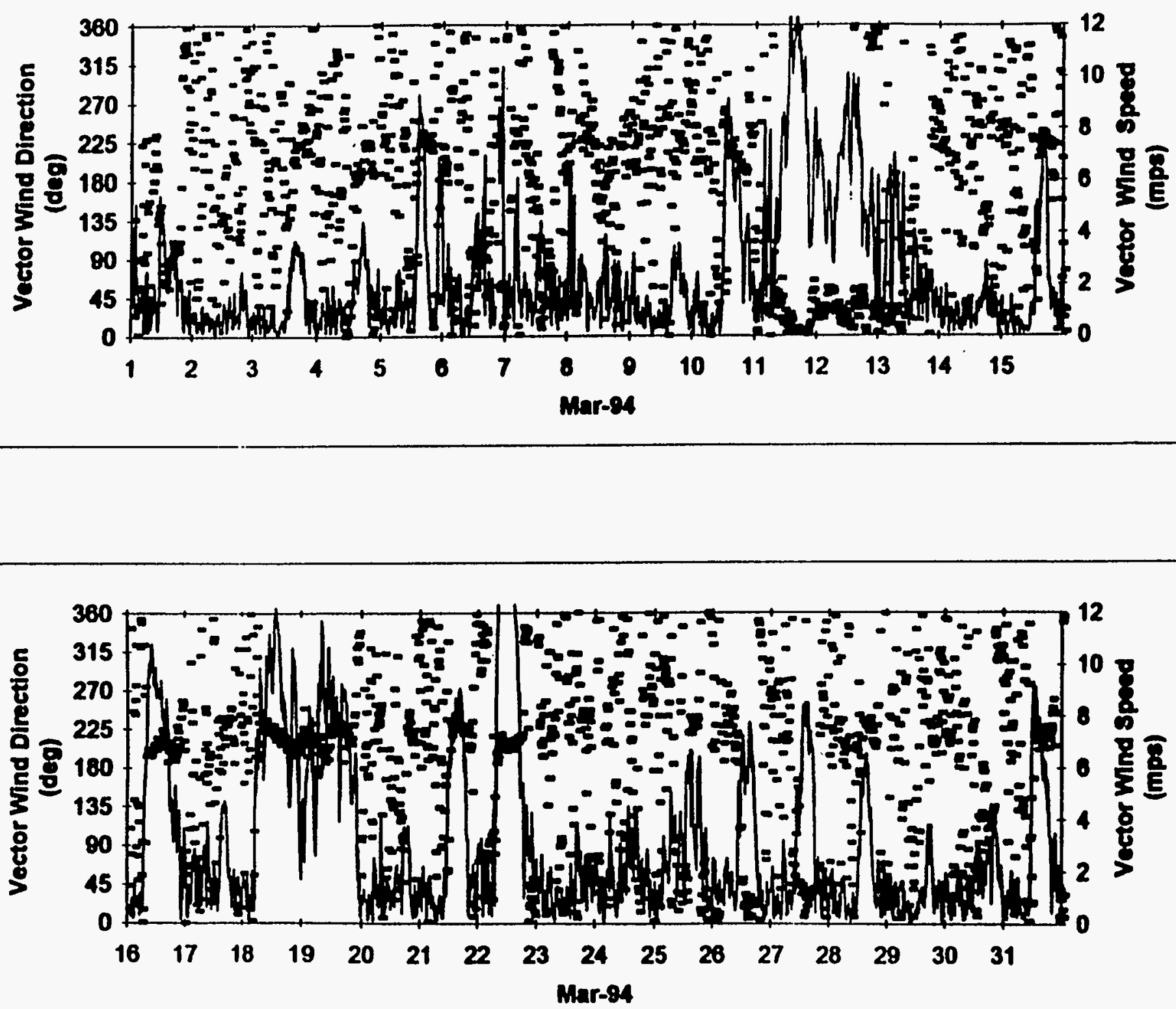


\section{METER TEMPERATURE}

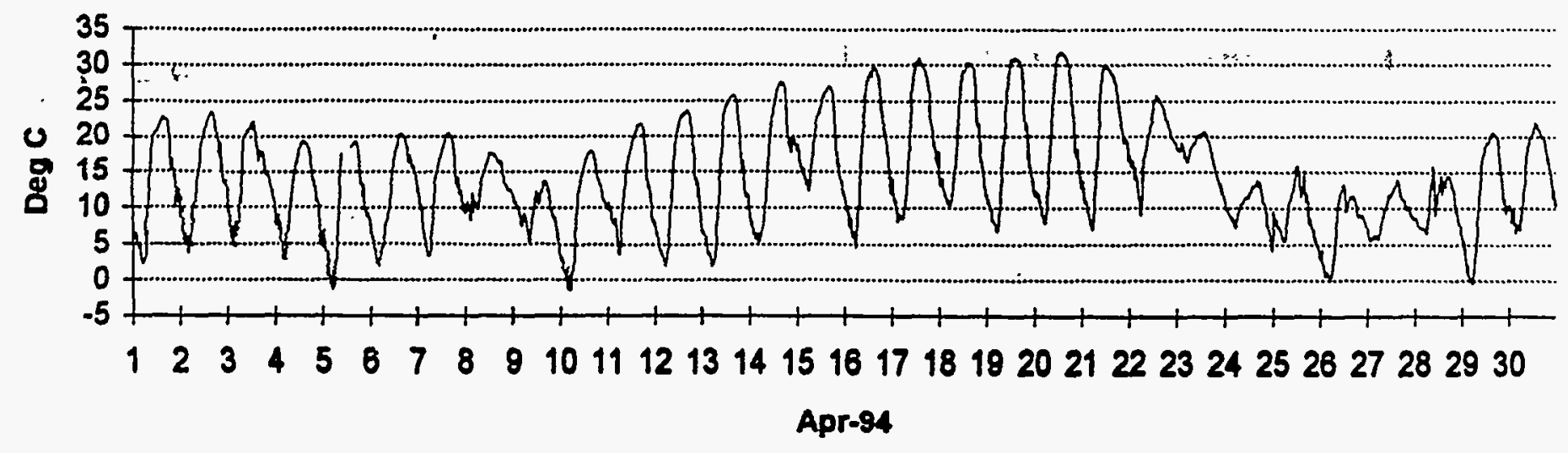

\section{METER TEMPERATURE}

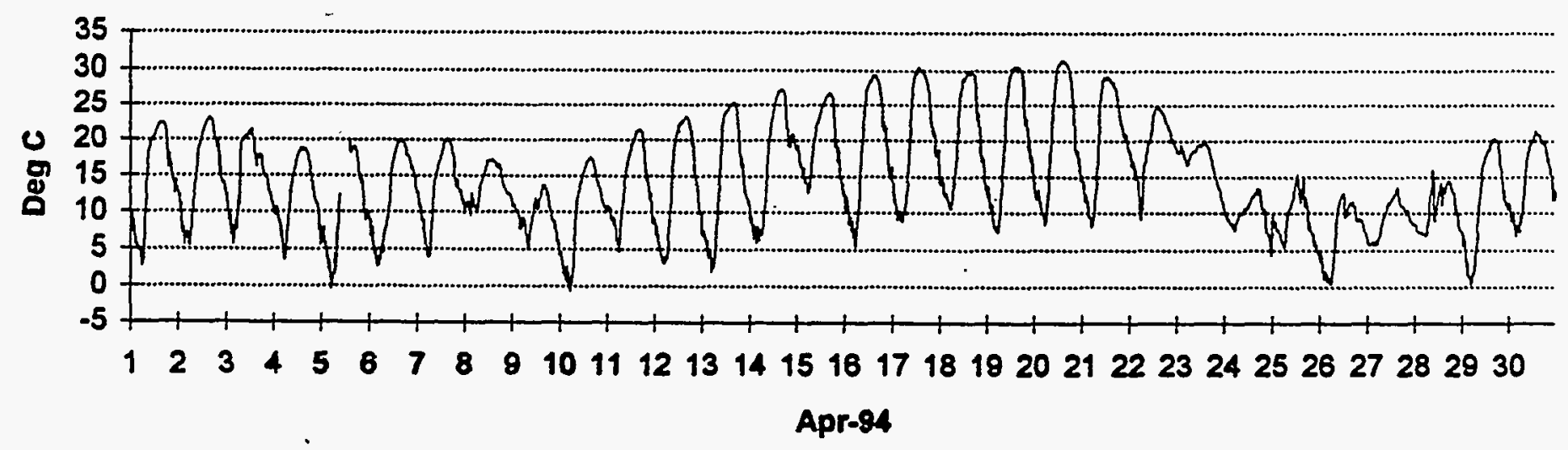

TEMPERATURE DIFFERENCE, 2 TO 16 METER

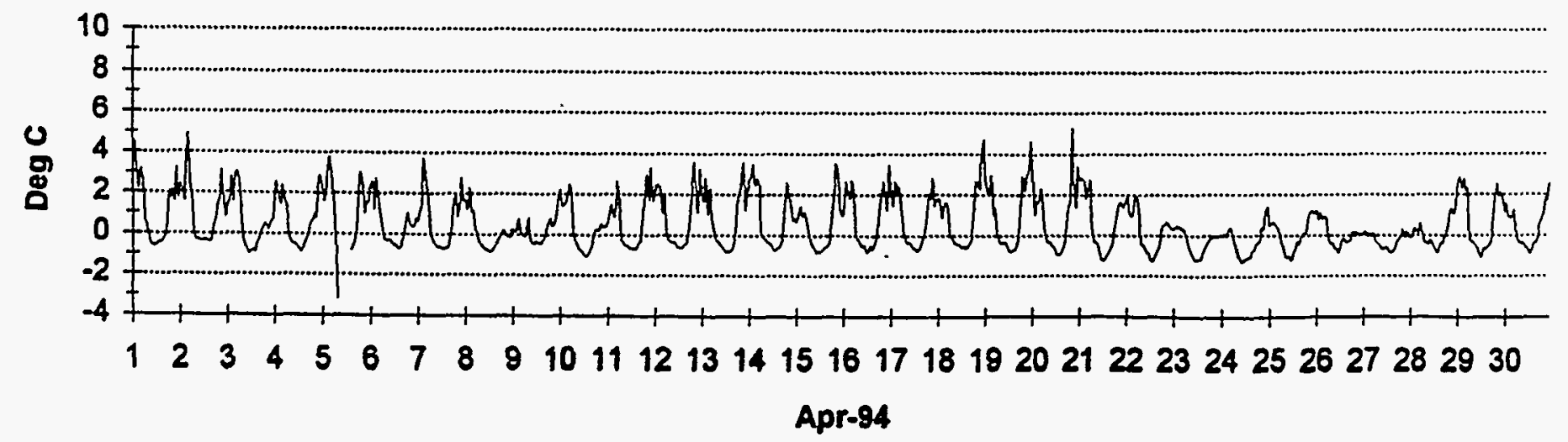



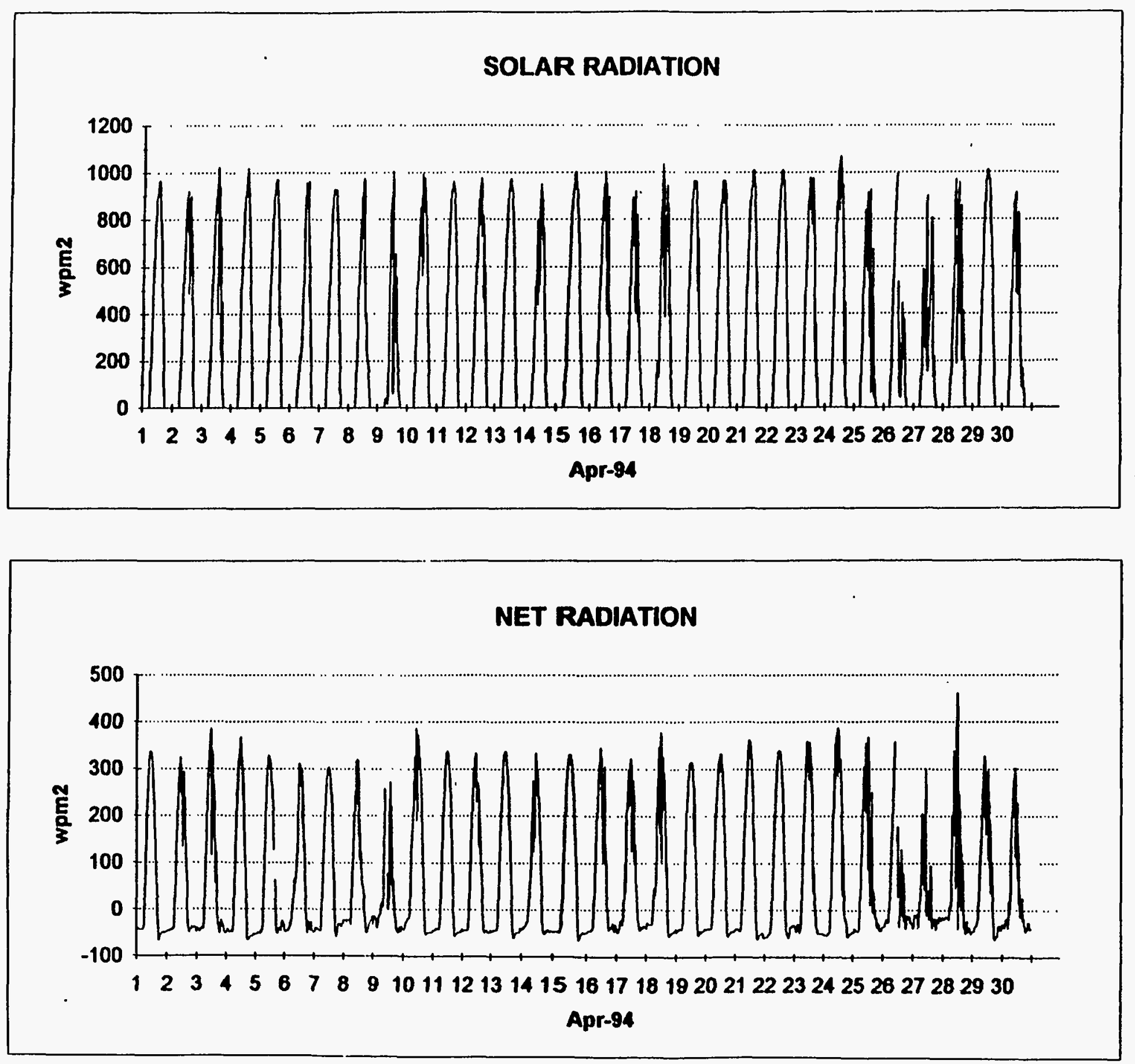

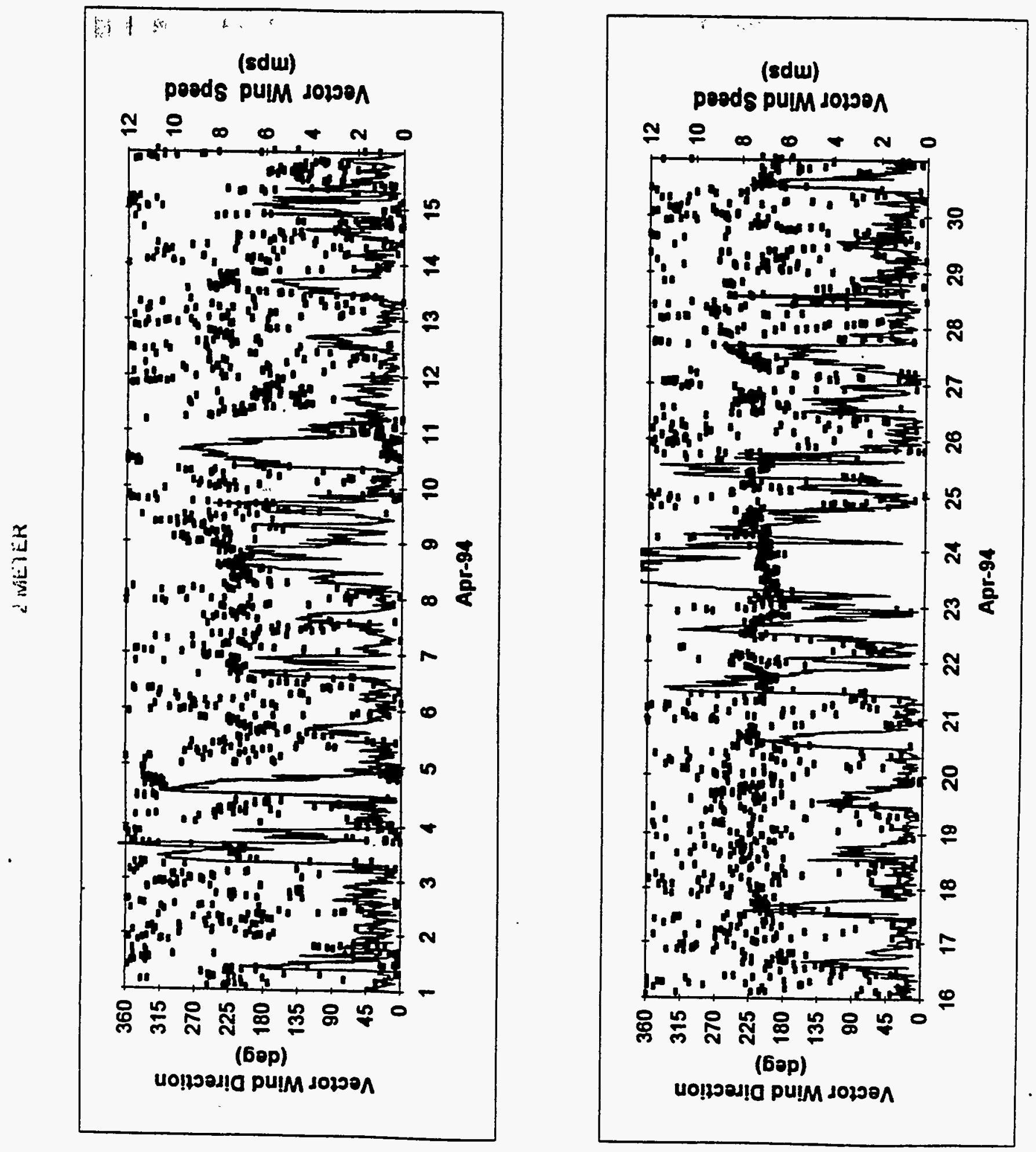
(sdui)

poods puIM dopoon

$\sim$ N $00-N \quad$

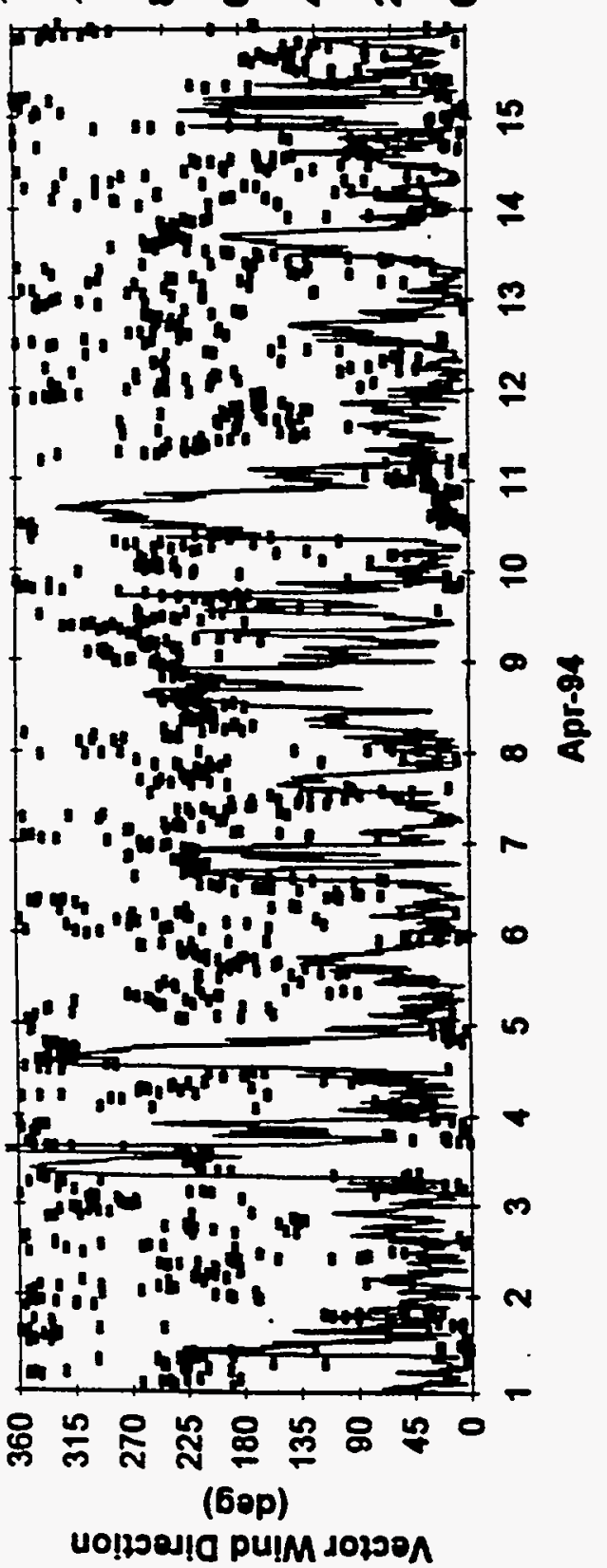

(sdui)

poods puim 102001

$\sim 0 \infty \omega+N$

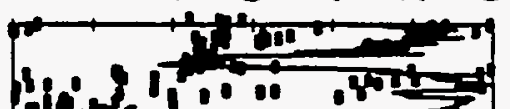

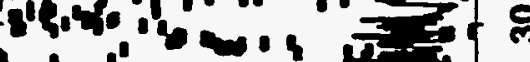

:

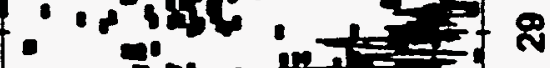

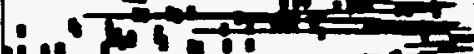

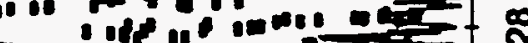

๑ :

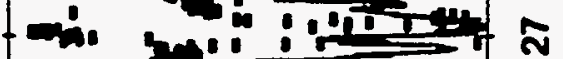

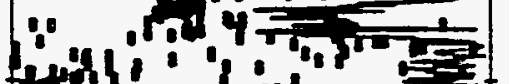

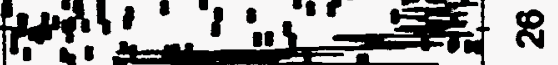

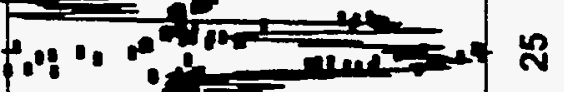

$\sum_{\infty}^{\frac{n}{w}}$

$\frac{⿱ 4}{\omega}$ 


\section{METER TEMPERATURE}

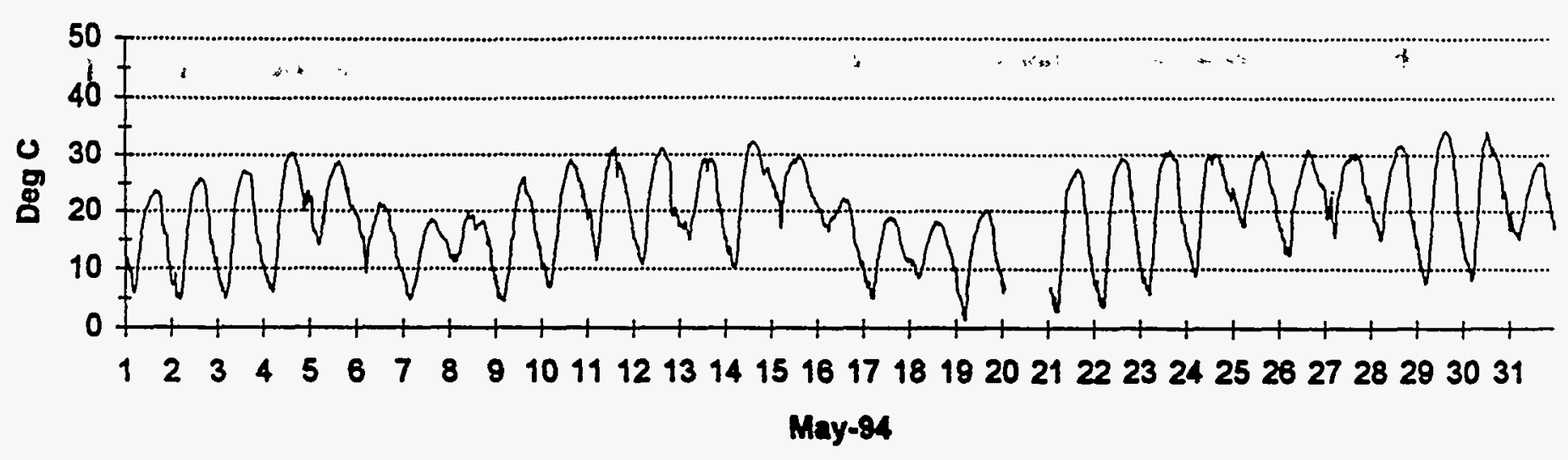

\section{METER TEMPERATURE}

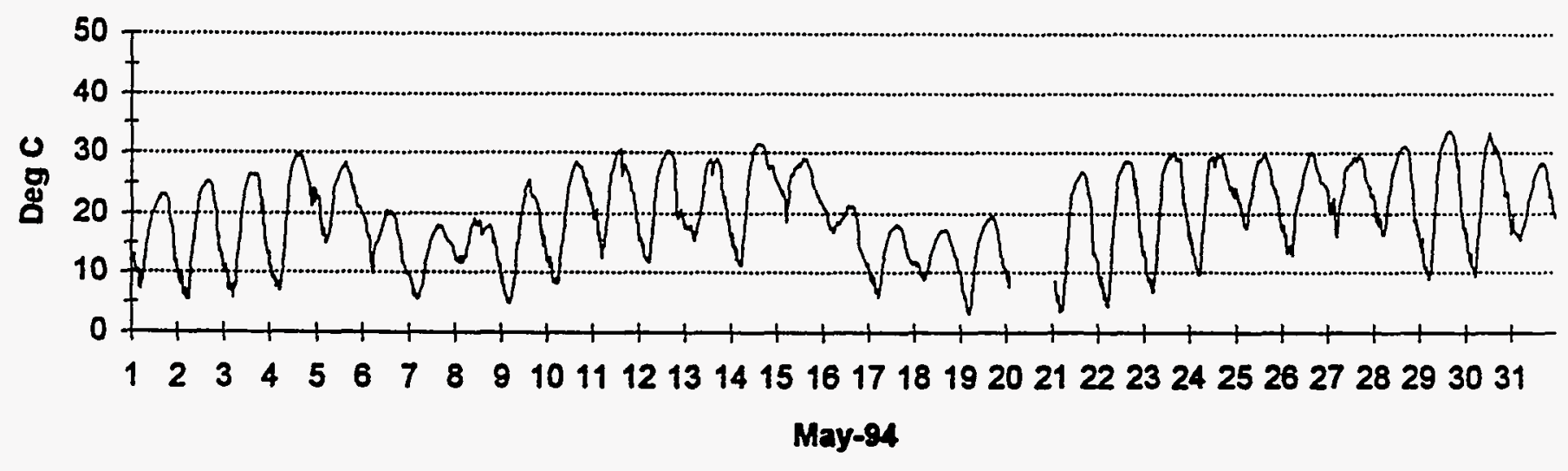

\section{TEMPERATURE DIFFERENCE, 2 TO 16 METER}

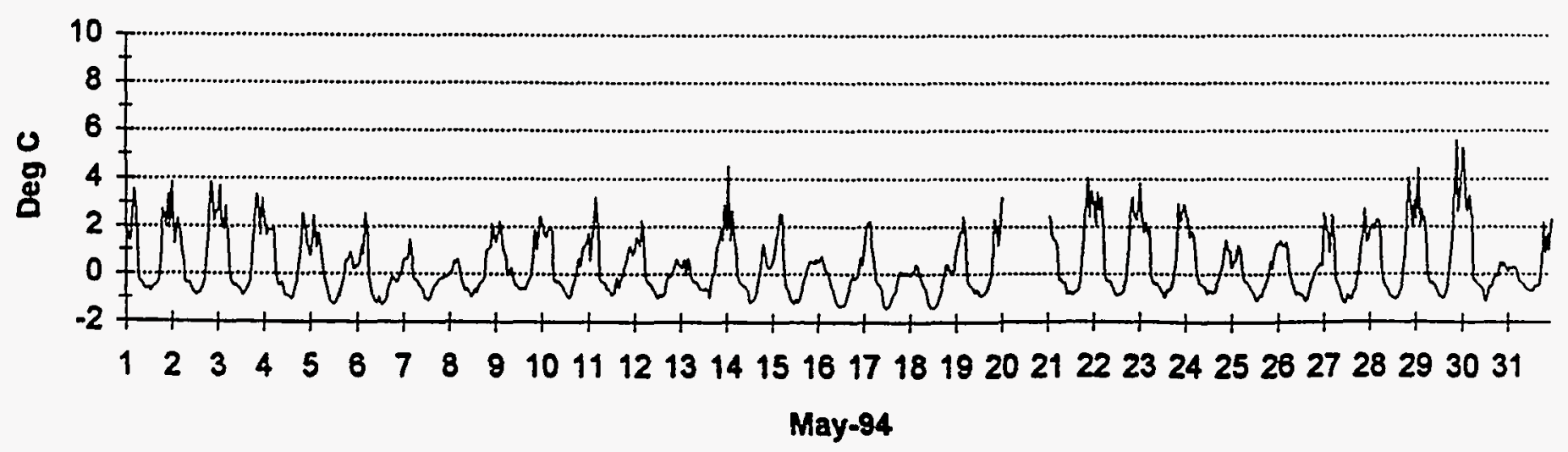


2 METER TEMPERATURE

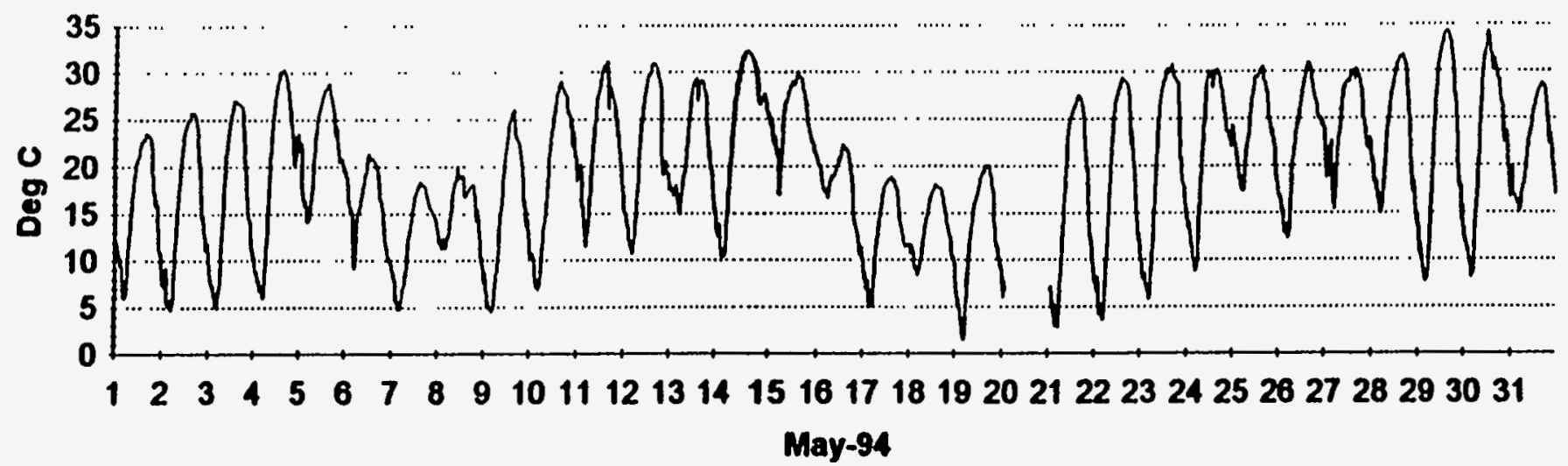

TEMPERATURE DIFFERENCE, 2 TO 16 METER

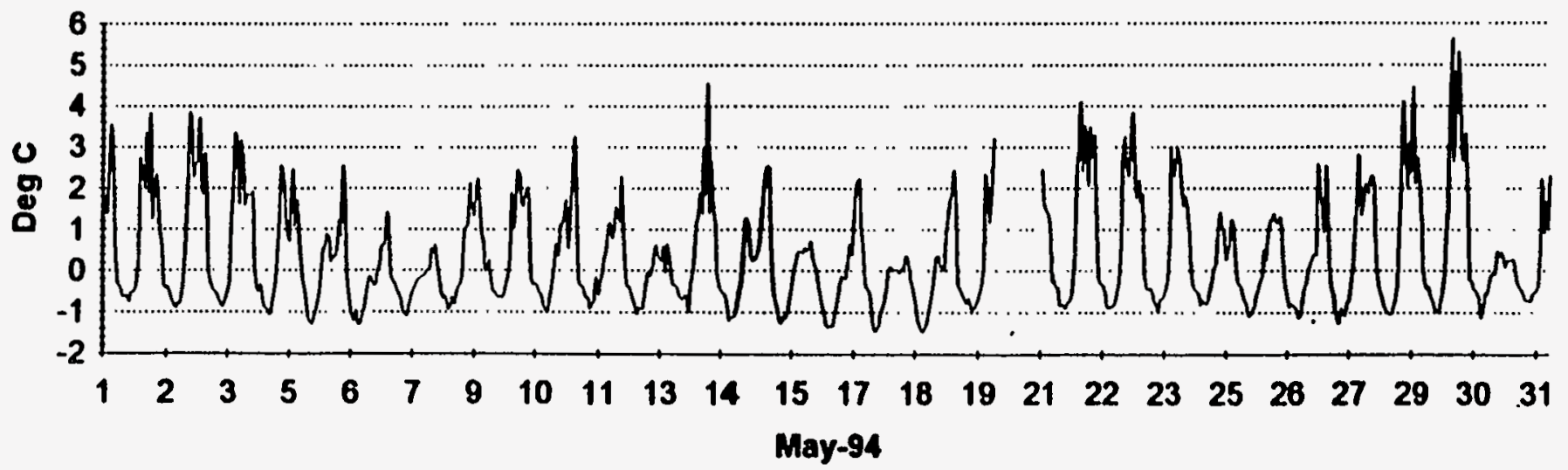



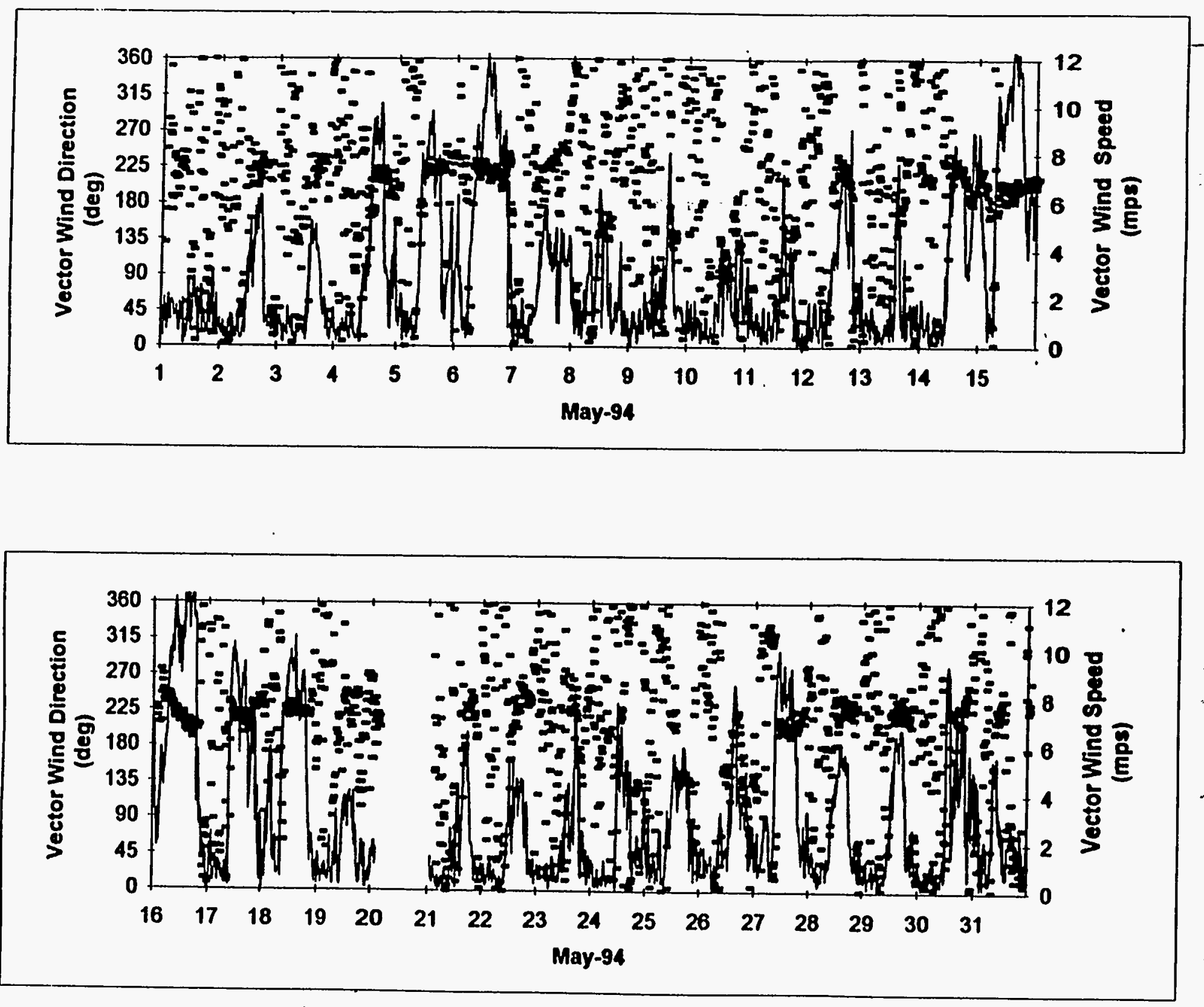
(sdw)

poods pulm jomon

$\div \quad \infty \quad \infty \quad N \quad 0$

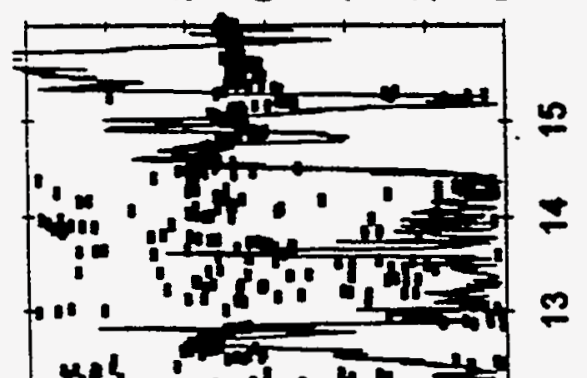

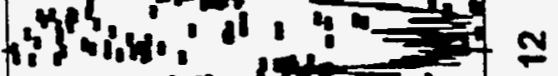

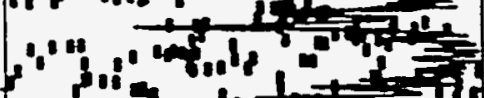

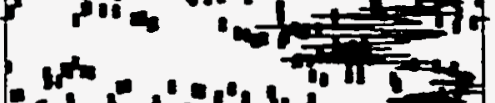

$6.1 \% 1 \% 1 \%$ \%

: :14.

$\therefore$ ac: 10

f in $\mathrm{a}_{0} \mathrm{~m}^{\mathrm{m}}$

1. 1801,10

a $110.15=$

$\frac{8}{2}$

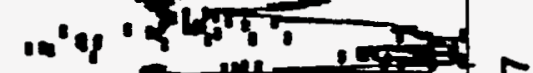

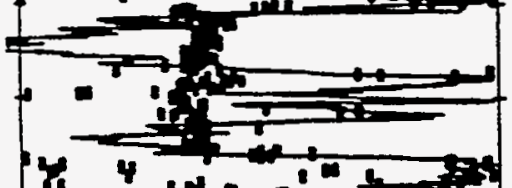

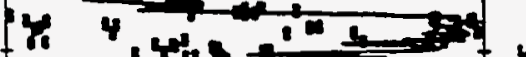

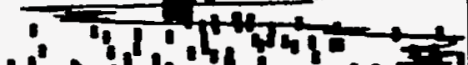

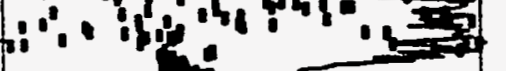

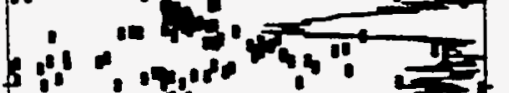

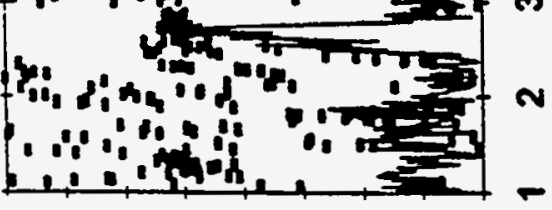

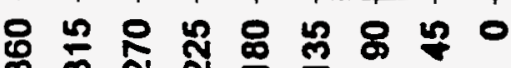

m $\mathrm{N} N$

(6op)

Uo!zo0נ! PU!M LO150八 (sduw)

poeds pum dosoen

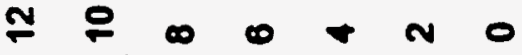

$\because$ :

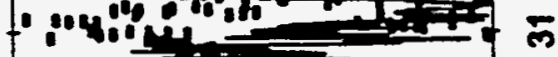

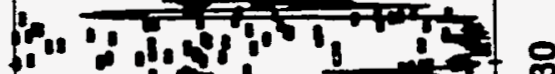

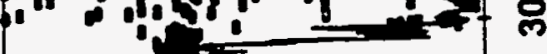

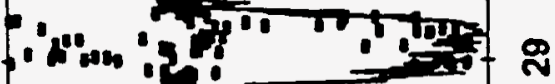

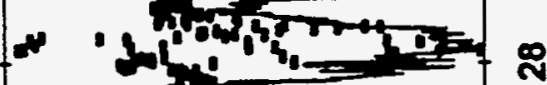

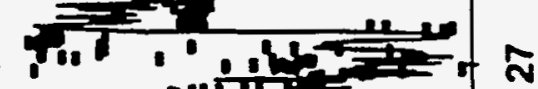

100 -

fyok $1:$ :

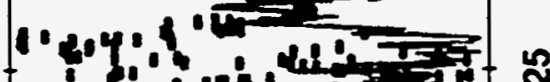

to: 018

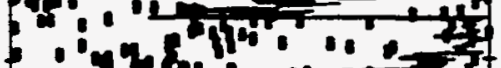

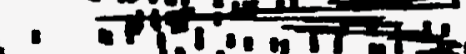

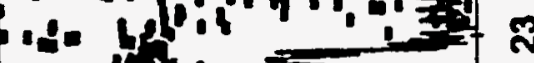

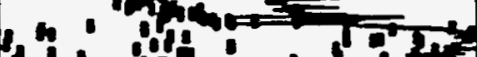

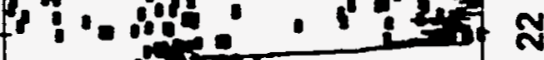

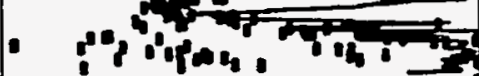

f Thas

- 0 if:

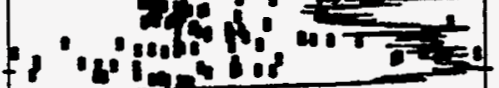

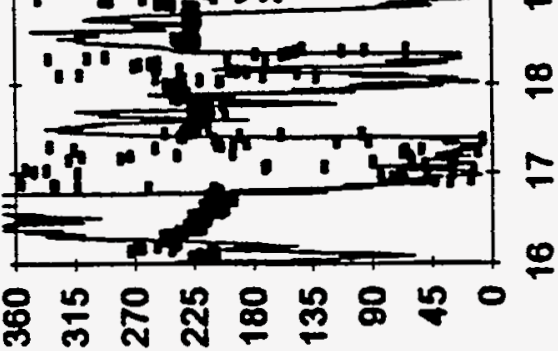

(6әp)

uolposia puyM dospan 


\section{METER TEMPERATURE}

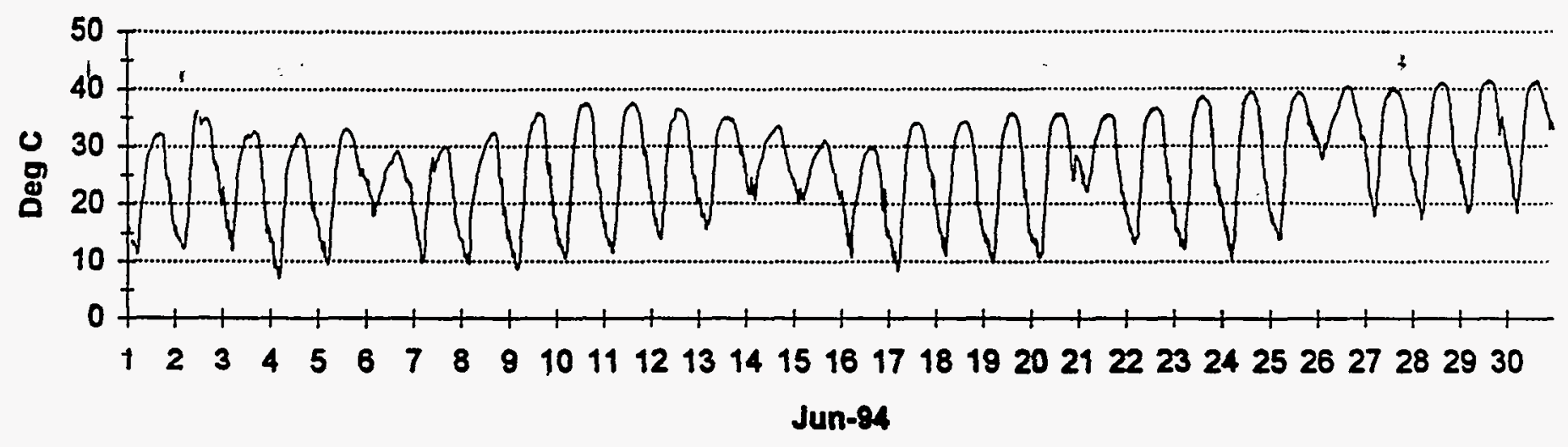

\section{METER TEMPERATURE}

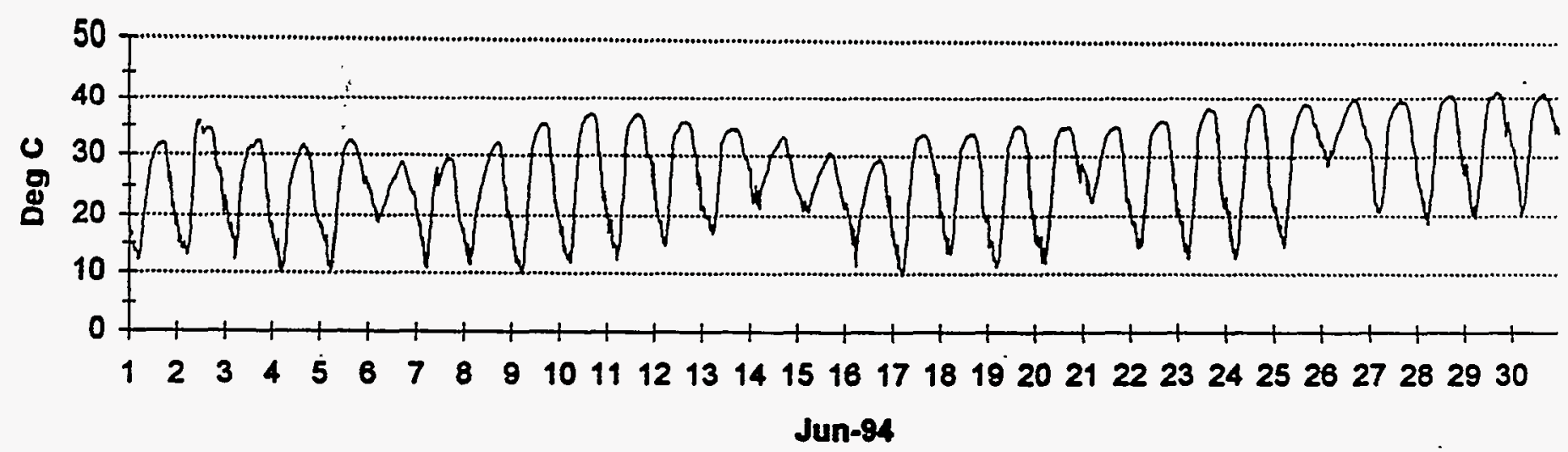

\section{TEMPERATURE DIFFERENCE, 2 TO 16 METER}

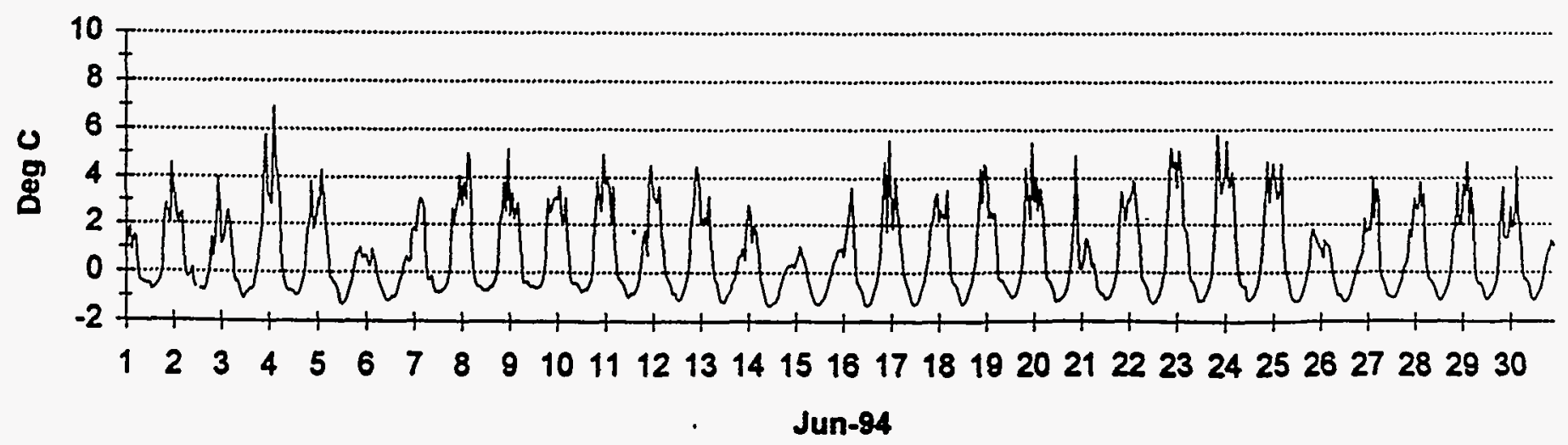



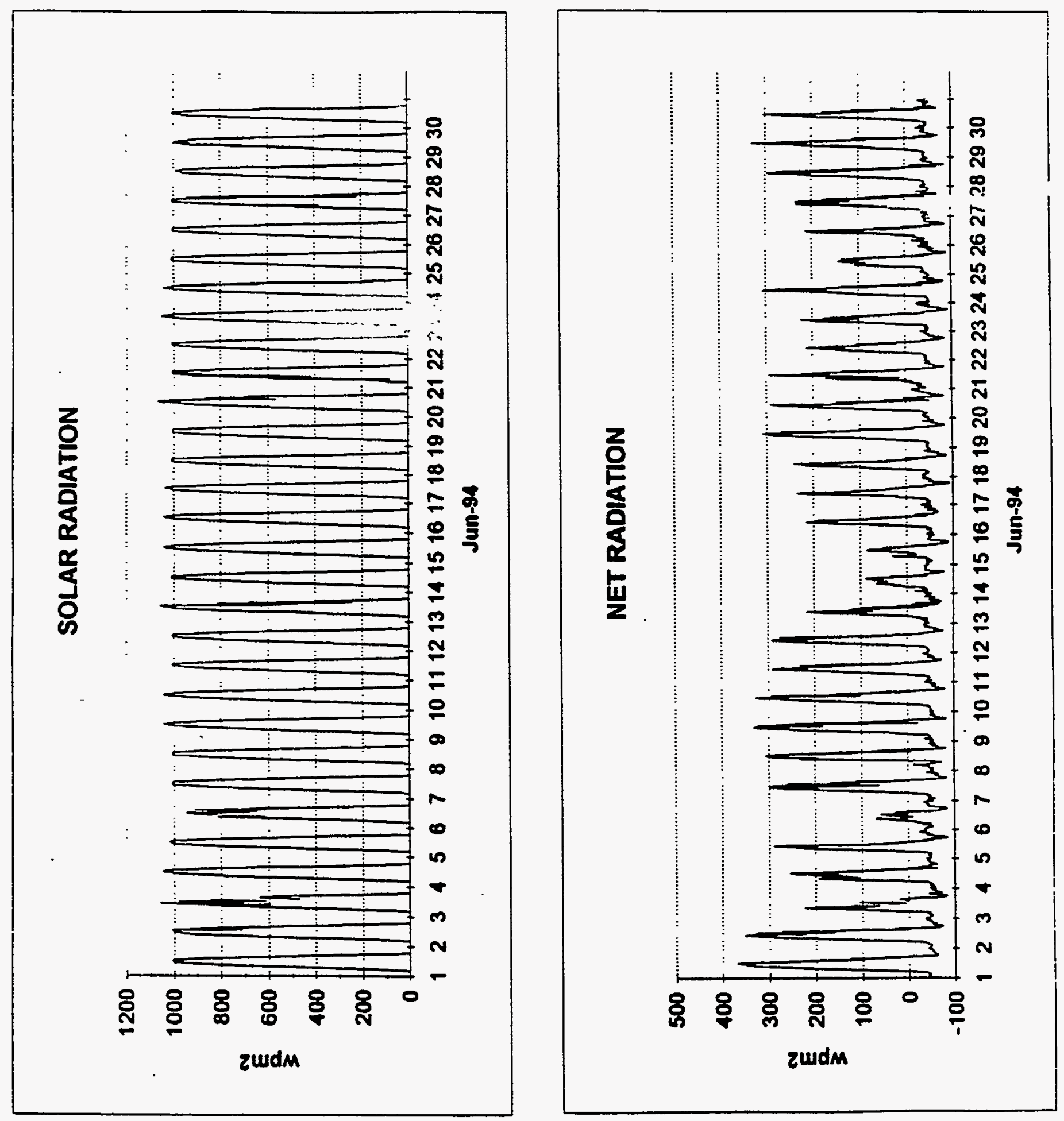

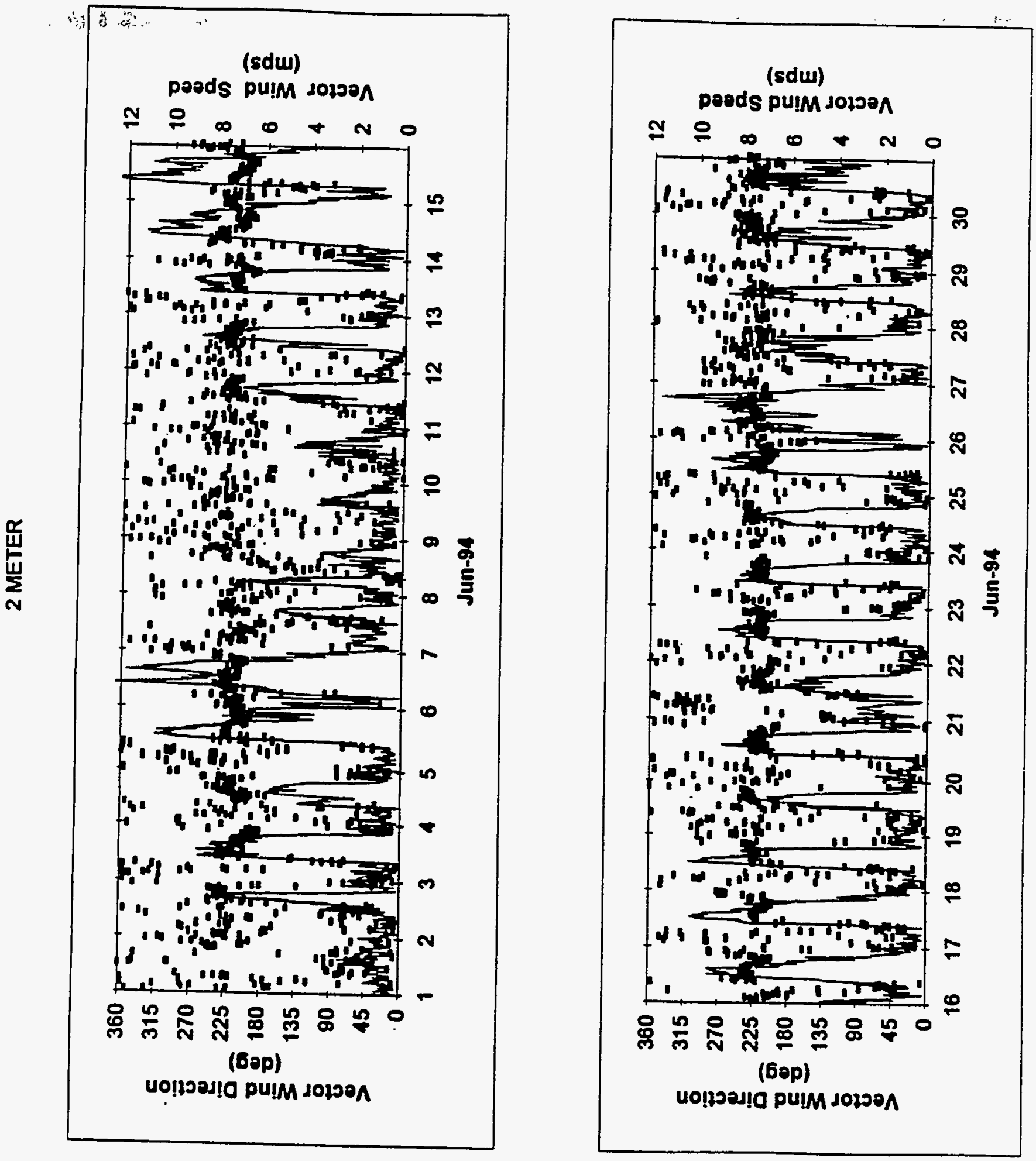
(sdw)

poads pu!M doroon

$\simeq$ $\simeq 0+N 0$

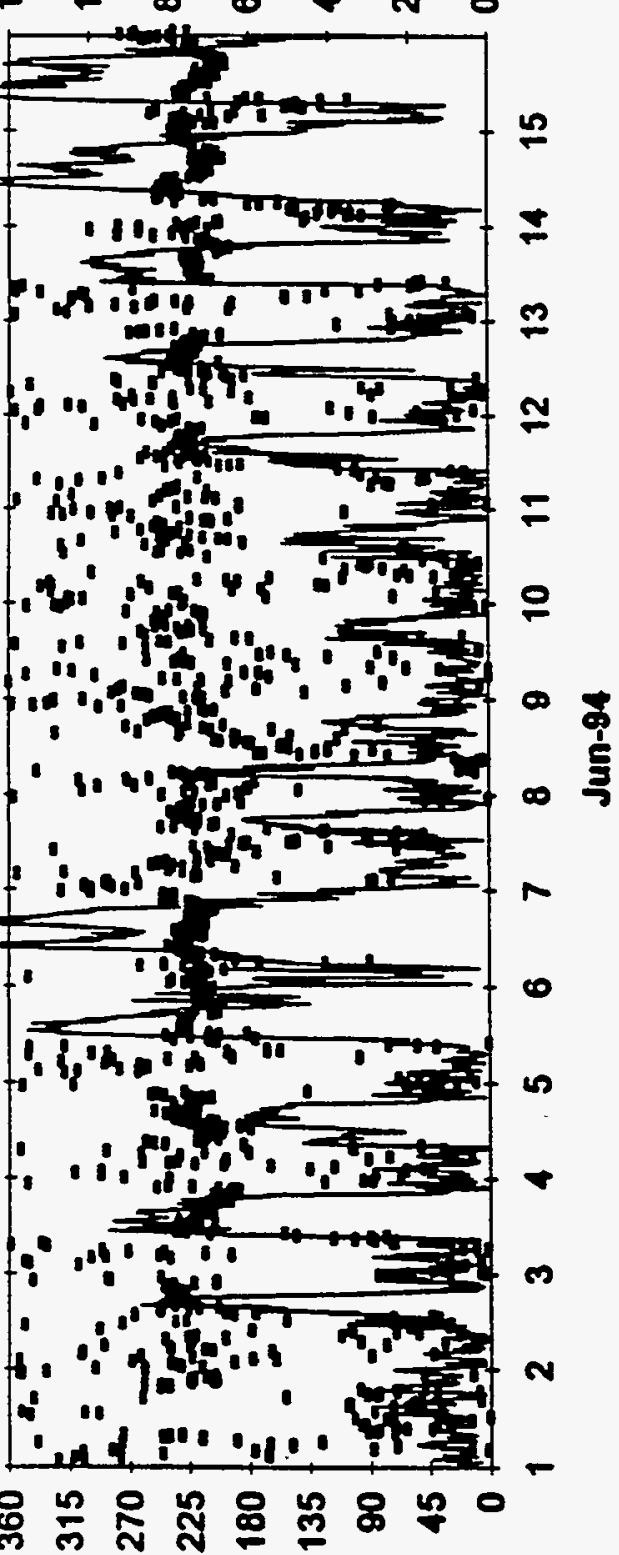

(Бop)

uo!zวa!d pu!M LO200n (sdw)

poods pu!M J0150八

$\simeq$ $\sim 0+N$ 。

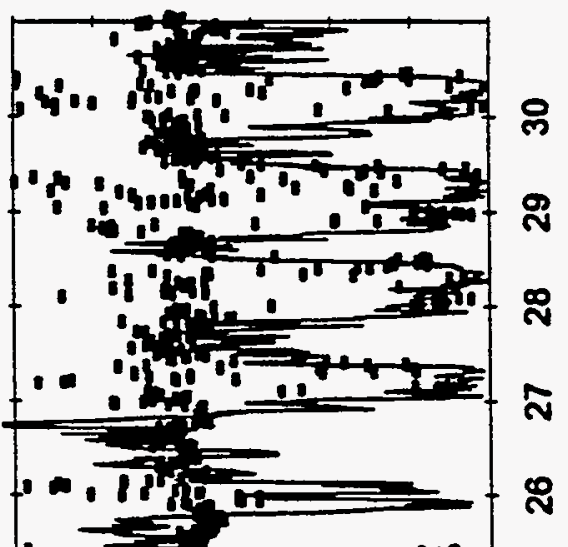

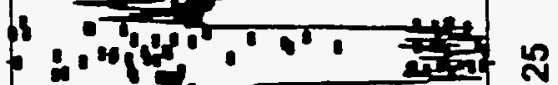

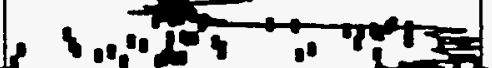

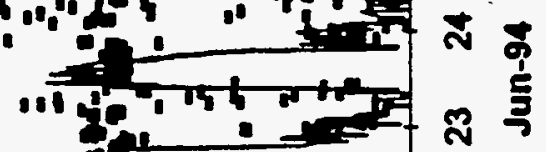

$\rightarrow 2$

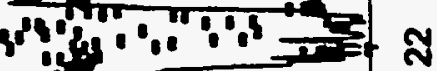

9hin $=2$

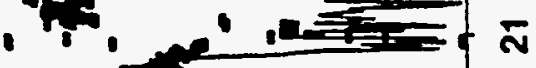

- 14 -

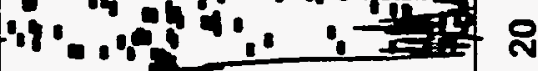

$\because:$ afy

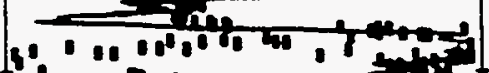

8. "Q p -

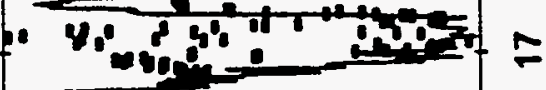

- Thin 1010

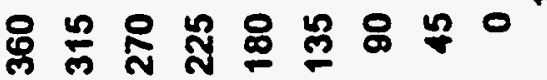

(bop)

uo!252!! PU!M JOL50^ 


\section{METER TEMPERATURE}

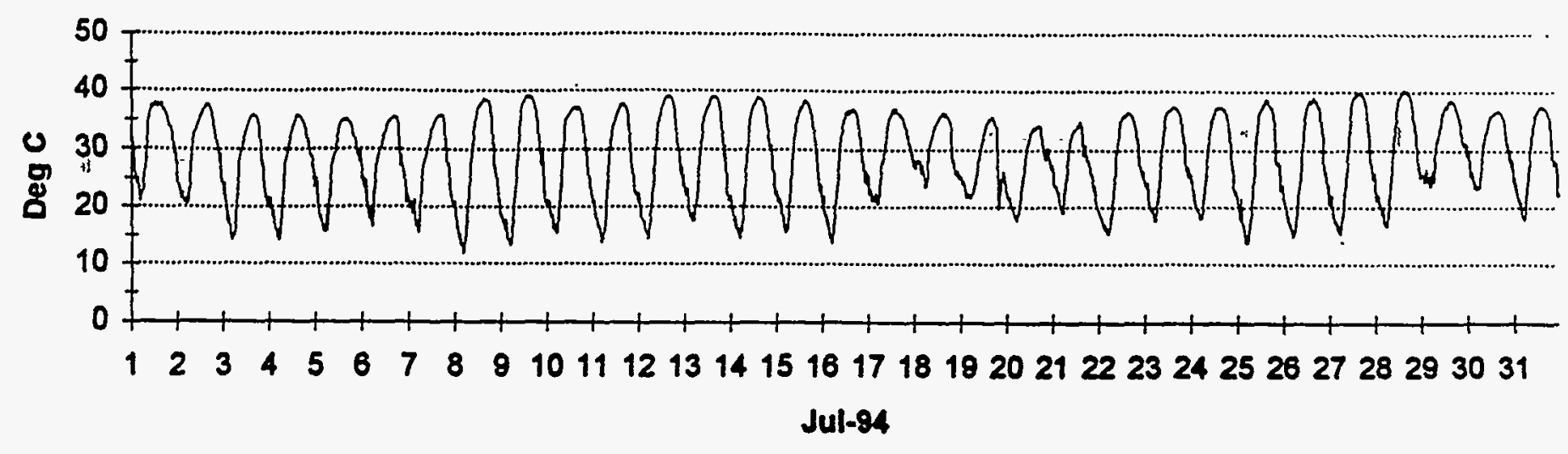

\section{METER TEMPERATURE}

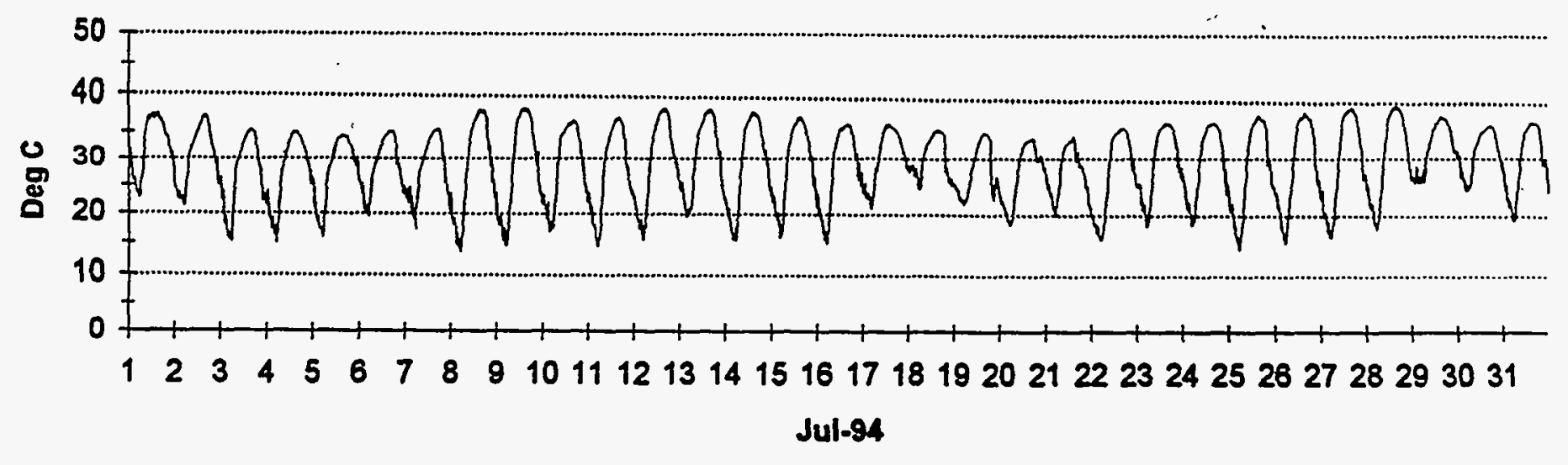

TEMPERATURE DIFFERENCE, 2 TO 16 METER

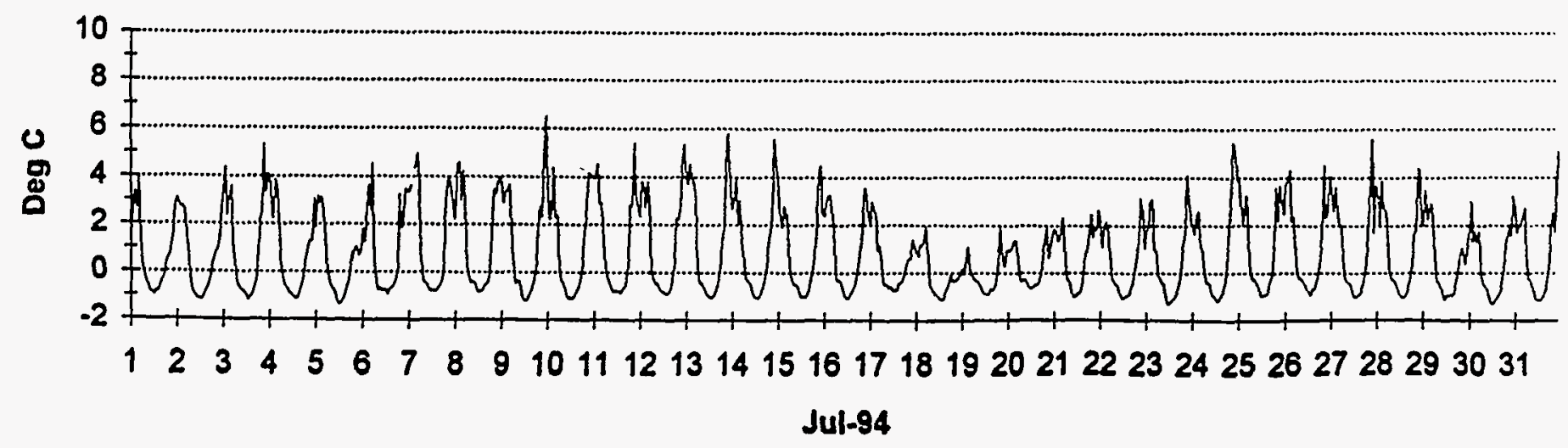



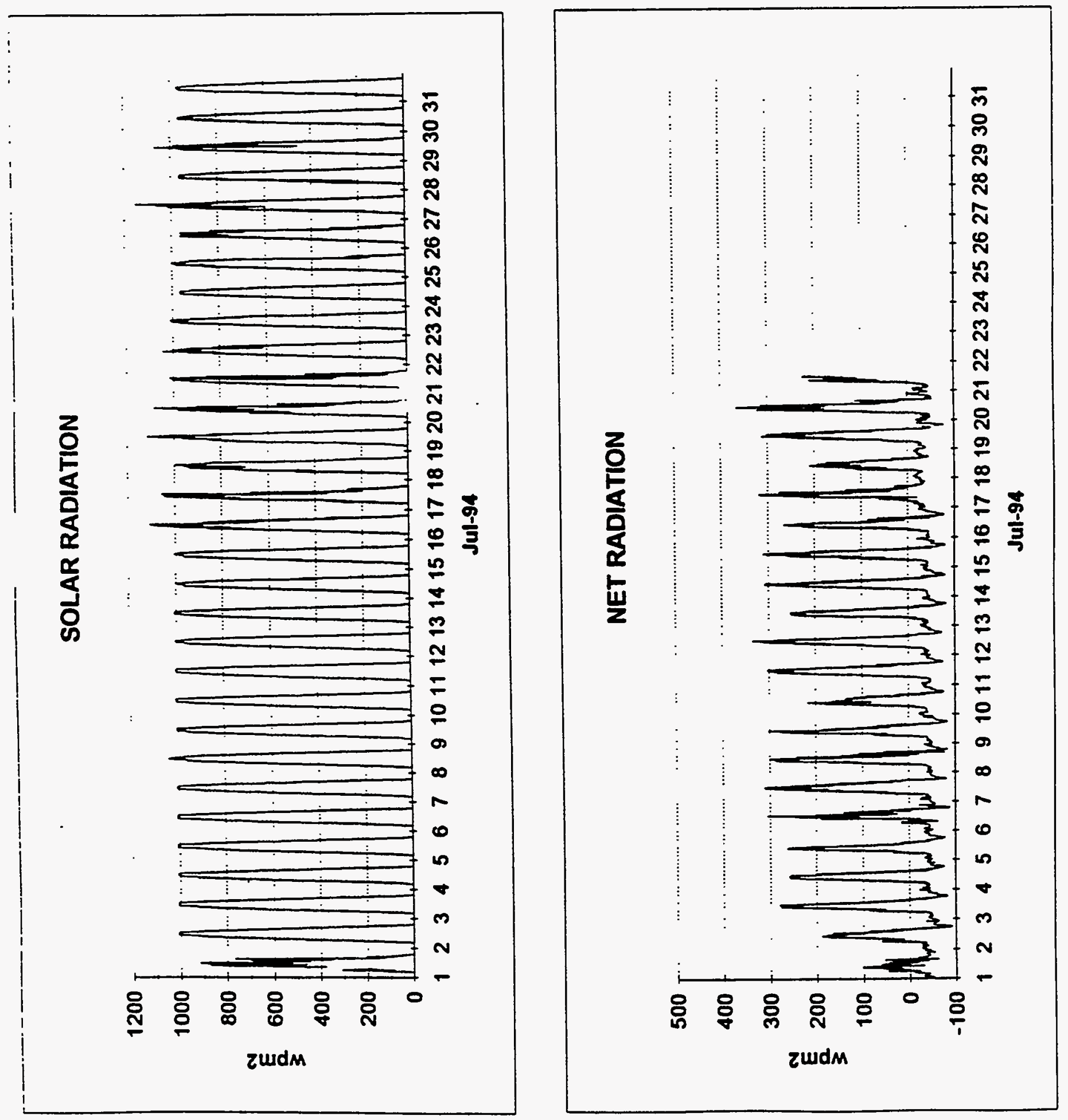

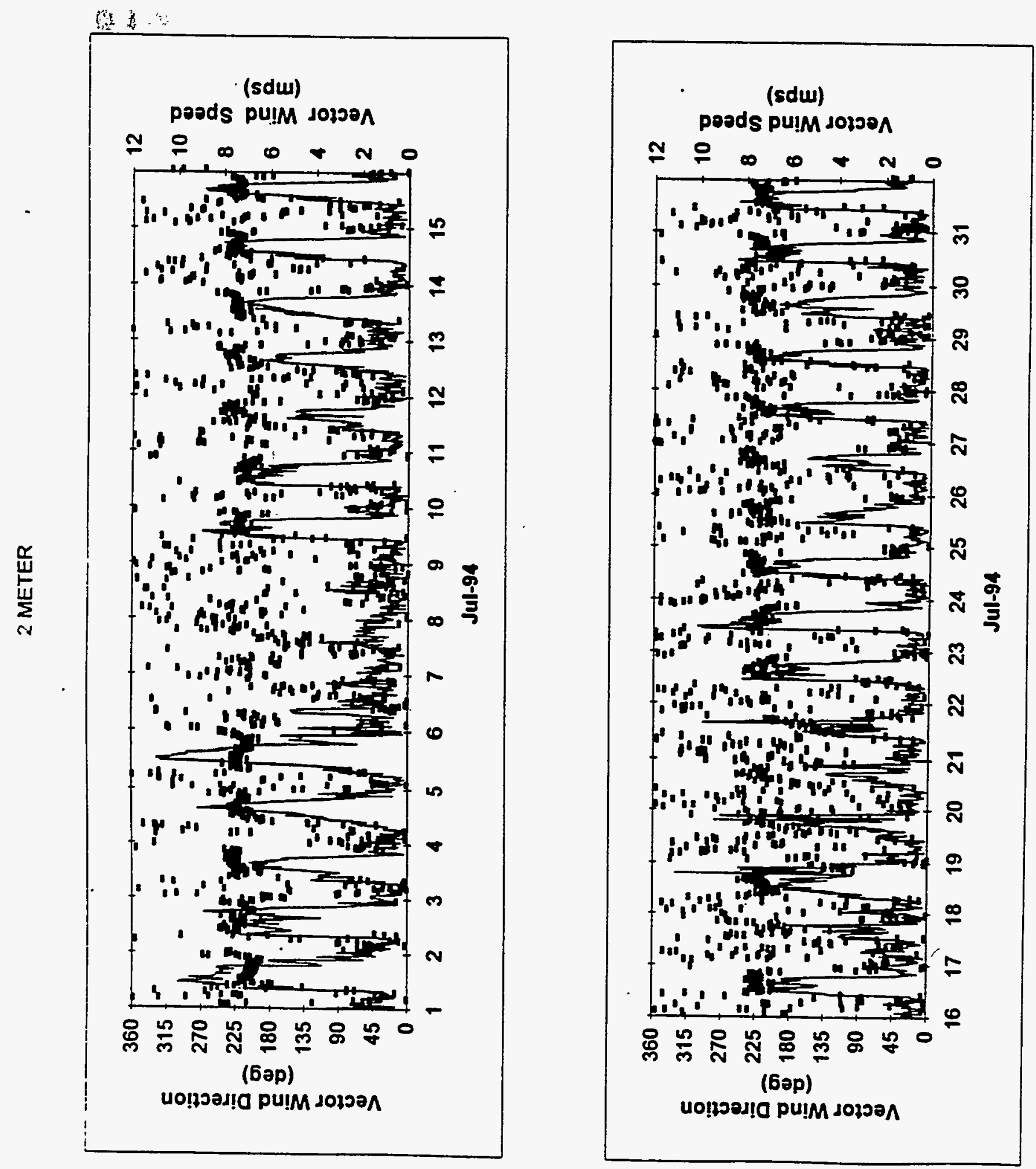

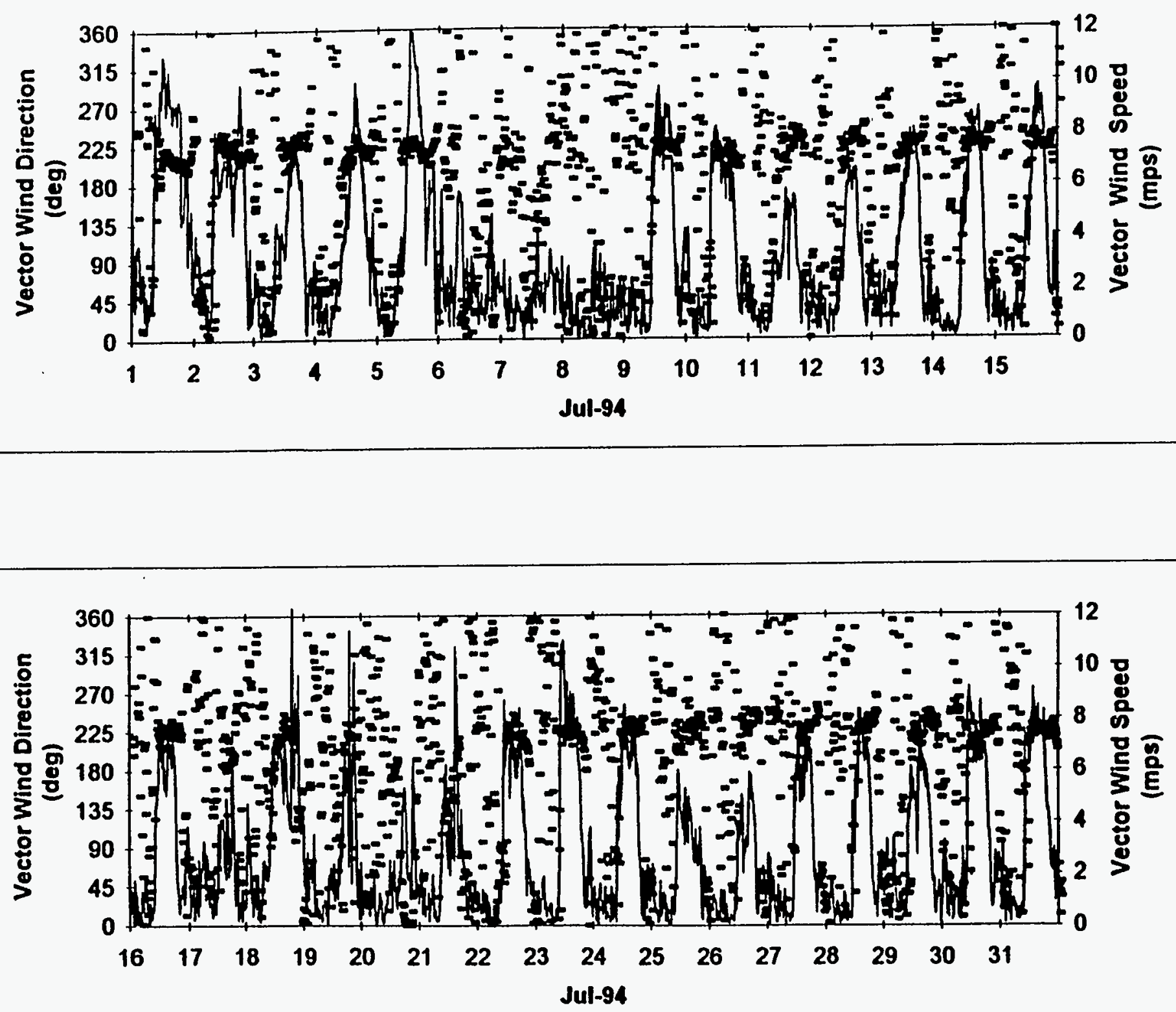


\section{METER TEMPERATURE}

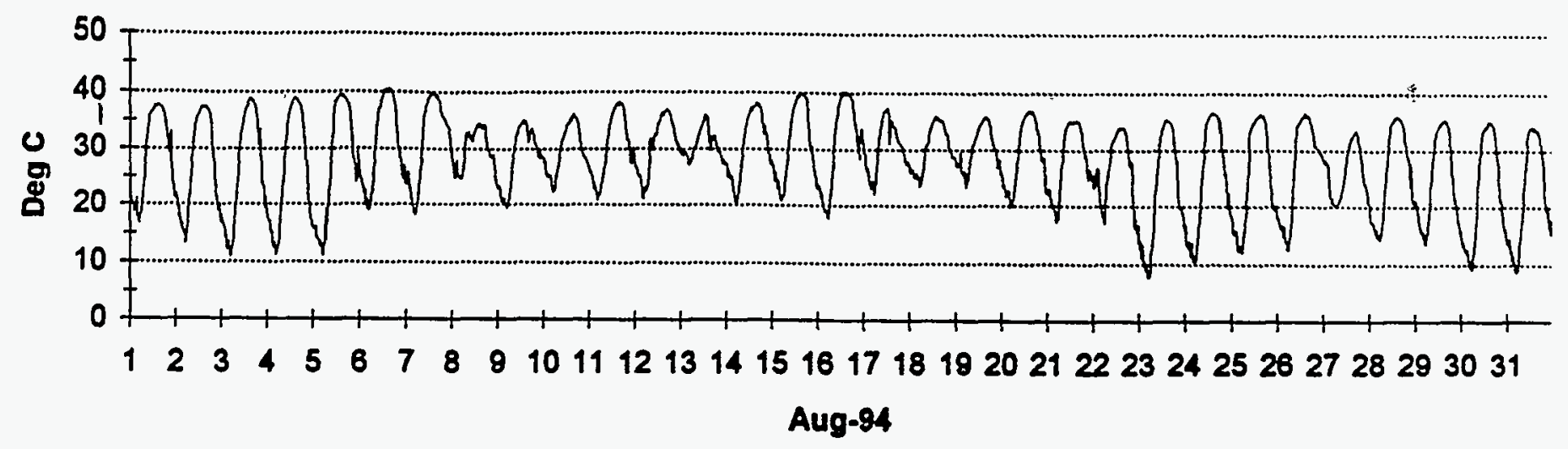

\section{METER TEMPERATURE}

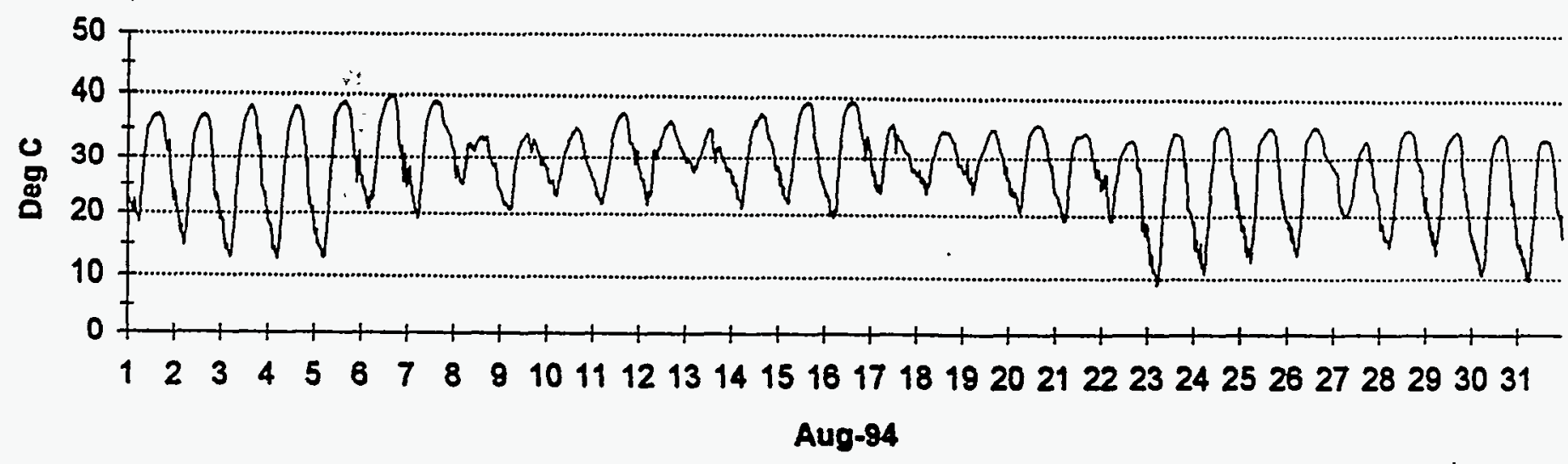

\section{TEMPERATURE DIFFERENCE, 2 TO 16 METER}

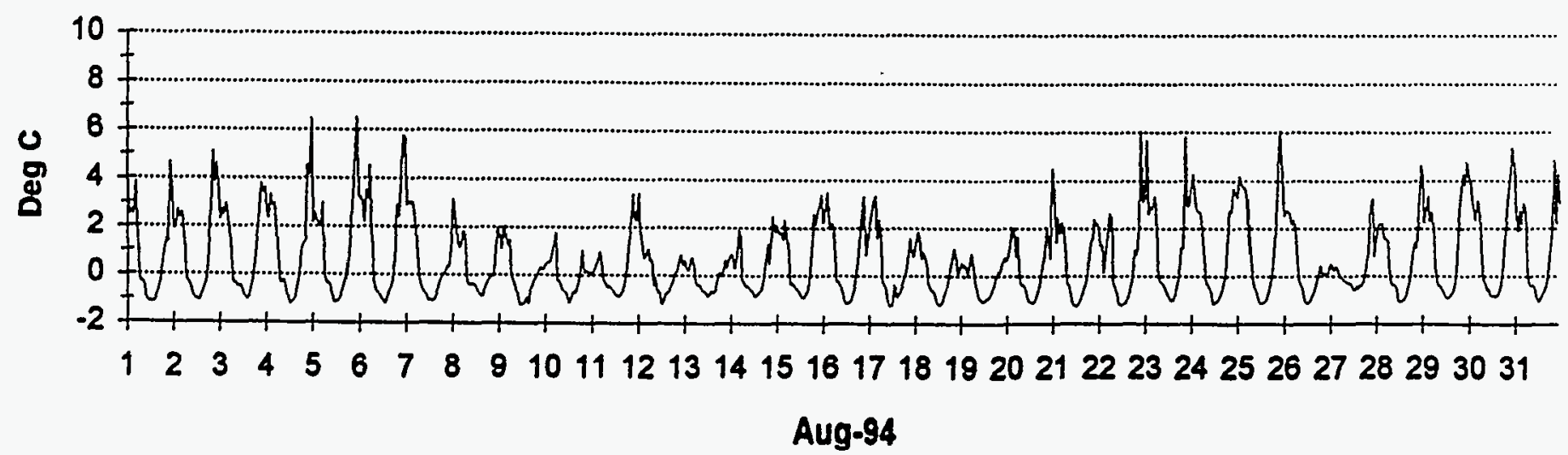



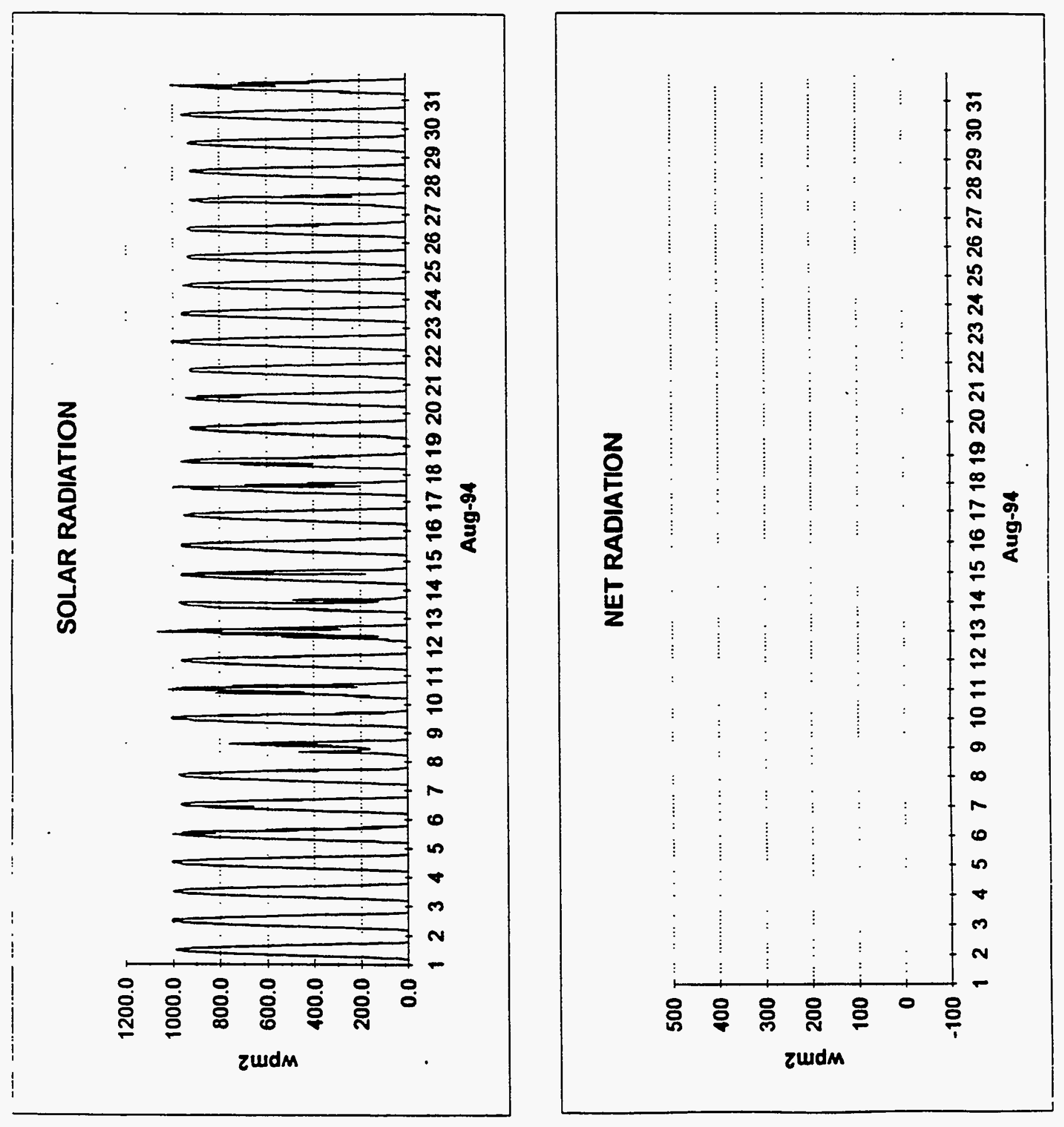

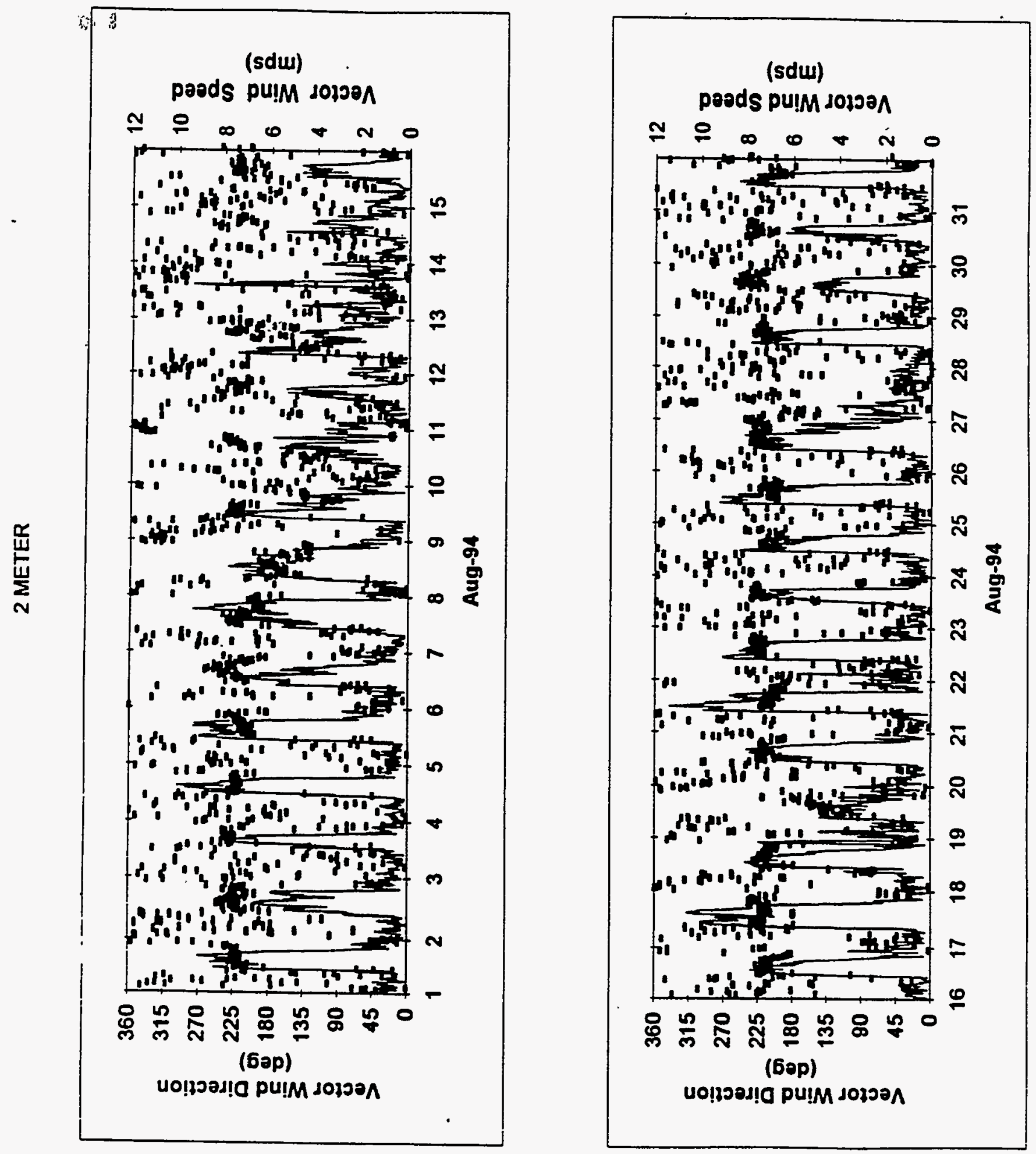

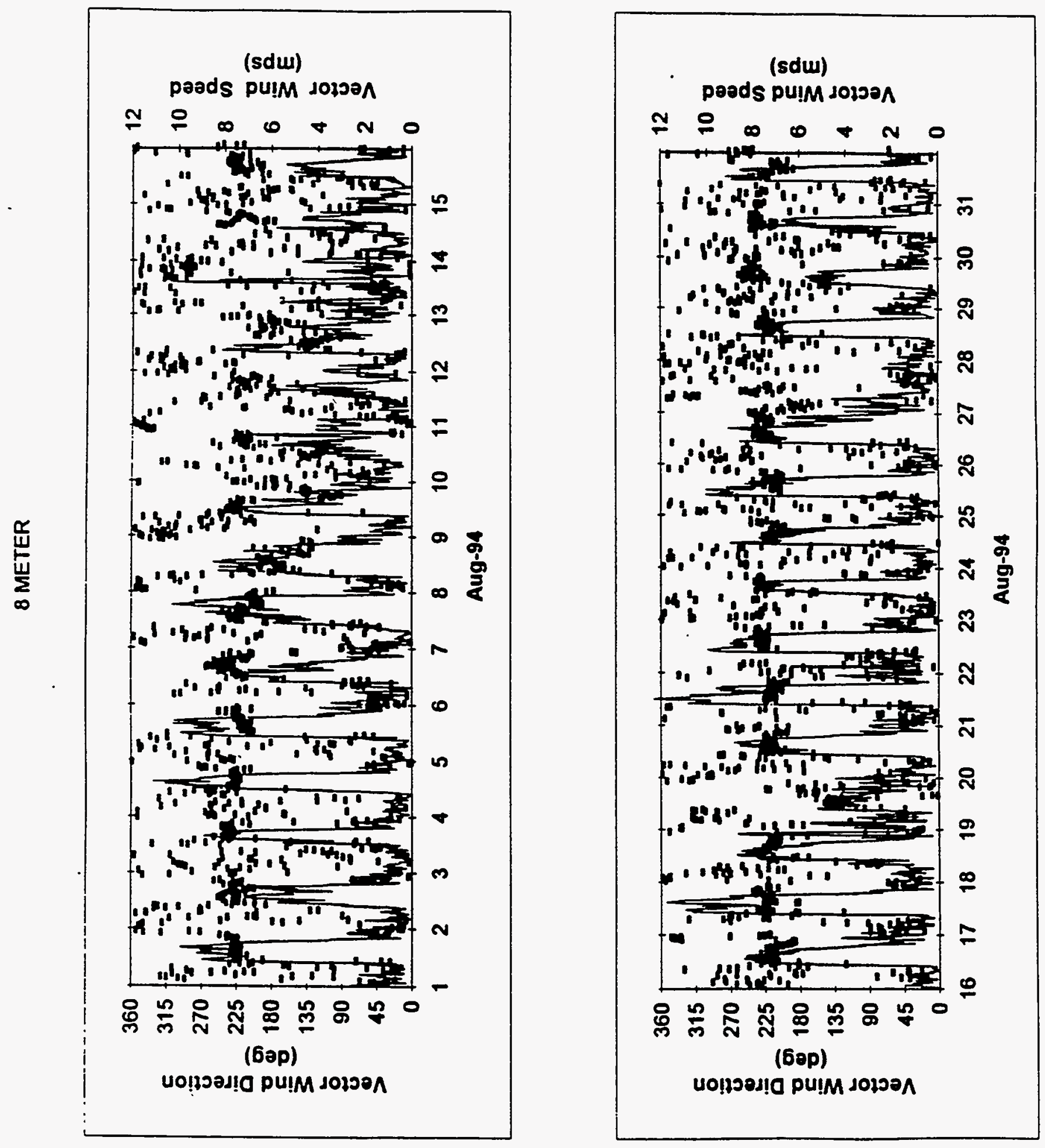


\section{METER TEMPERATURE}

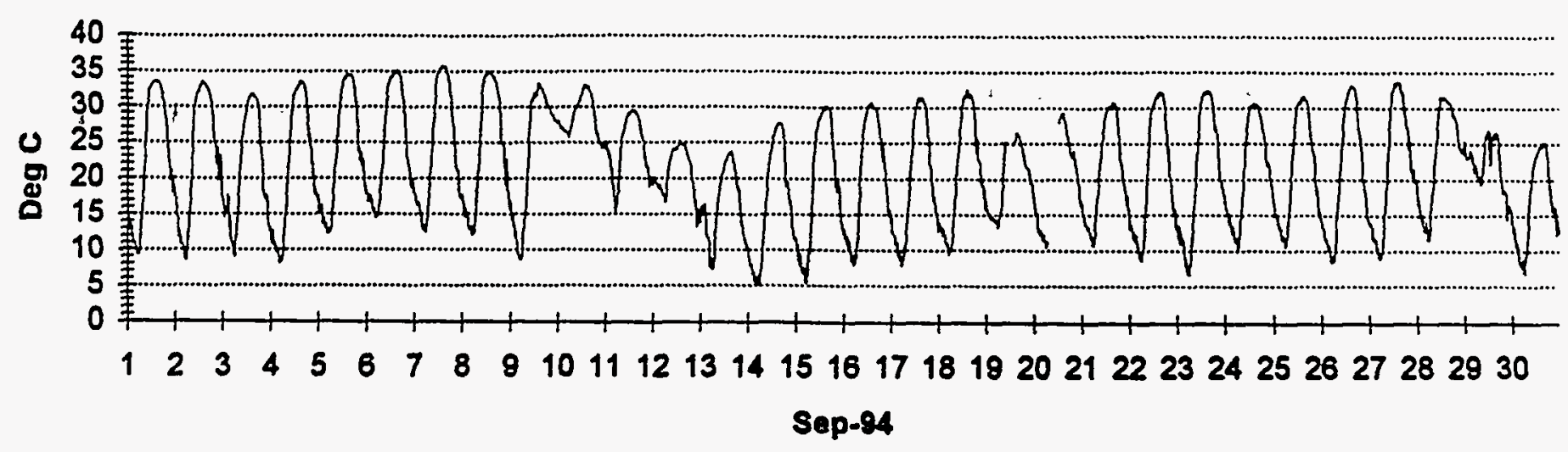

\section{METER TEMPERATURE}

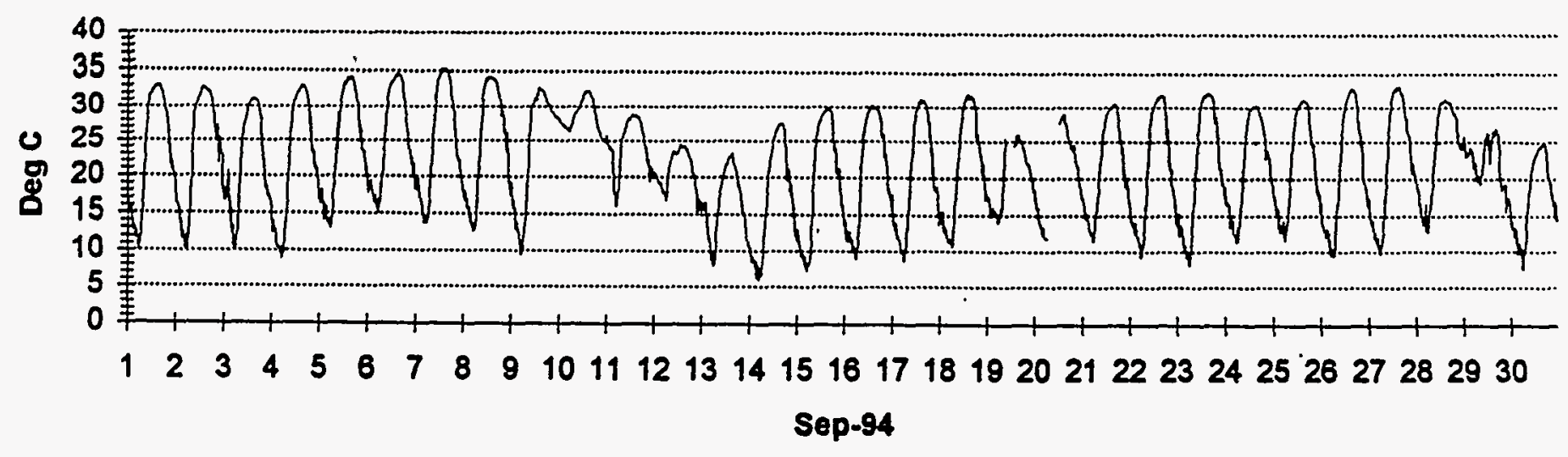

\section{TEMPERATURE DIFFERENCE, 2 TO 16 METER}

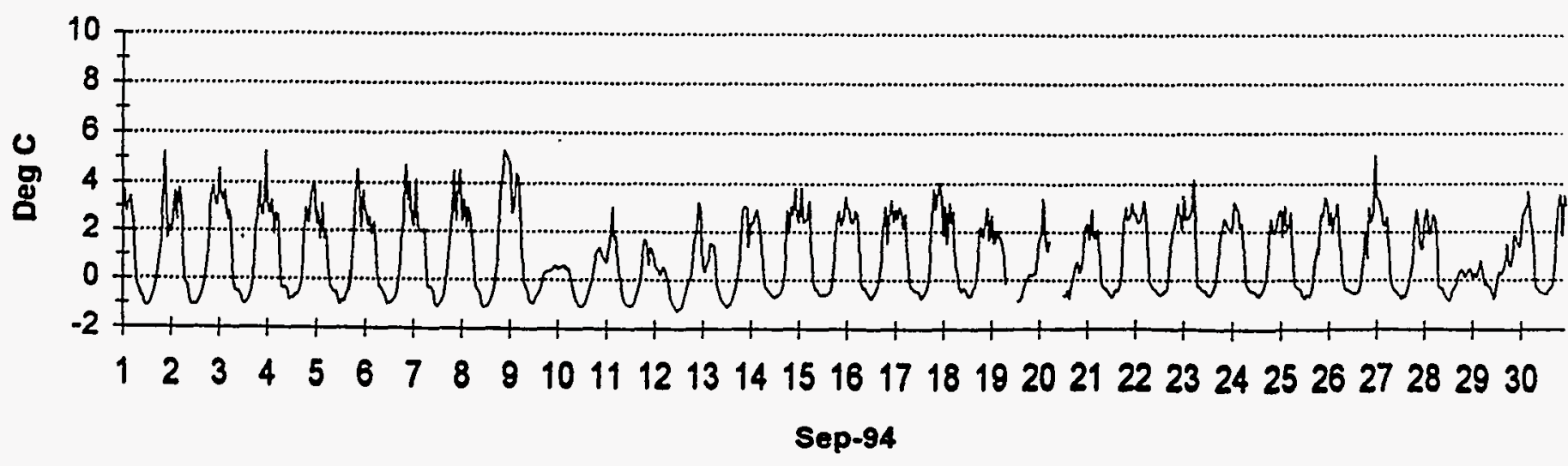



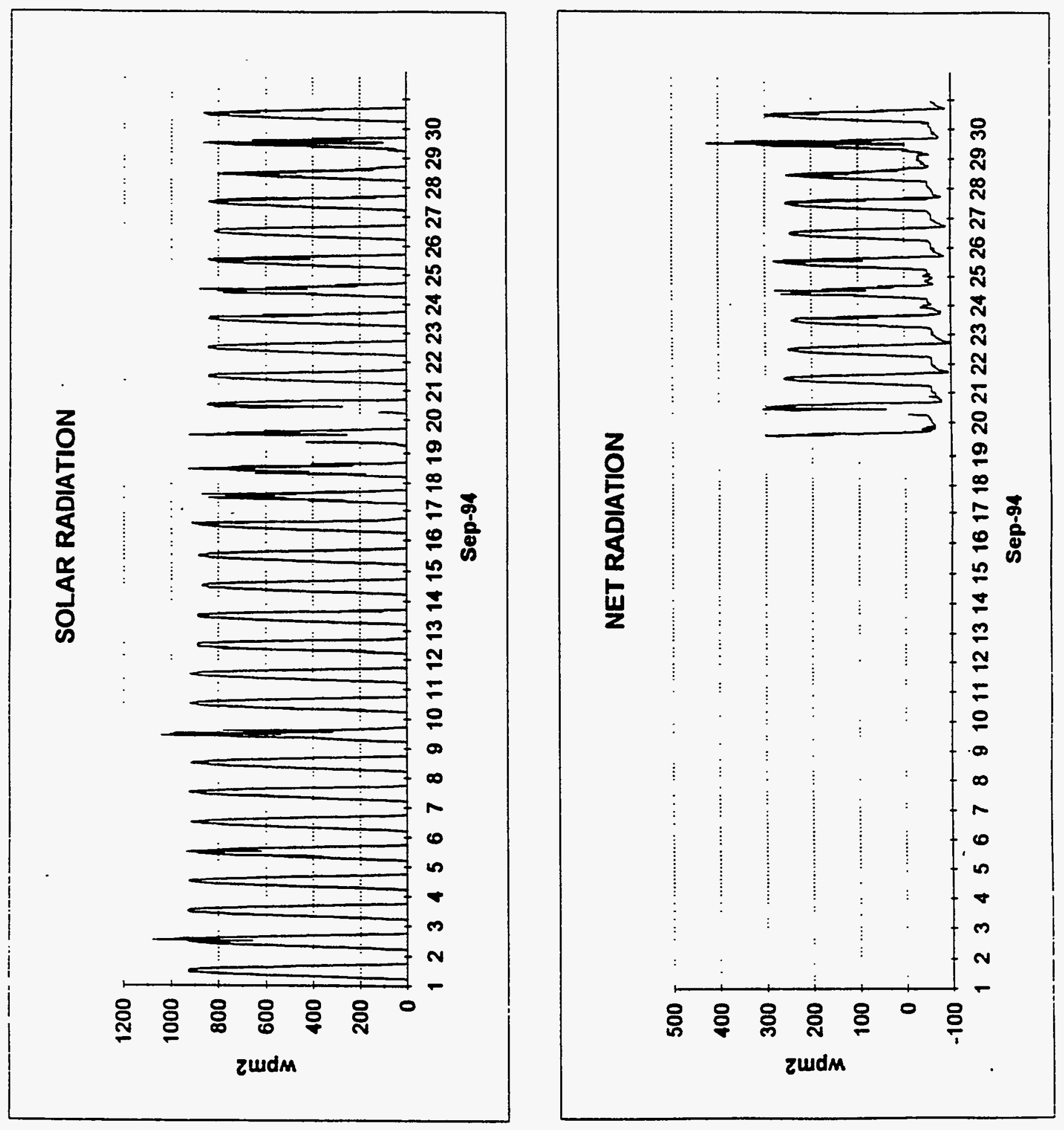

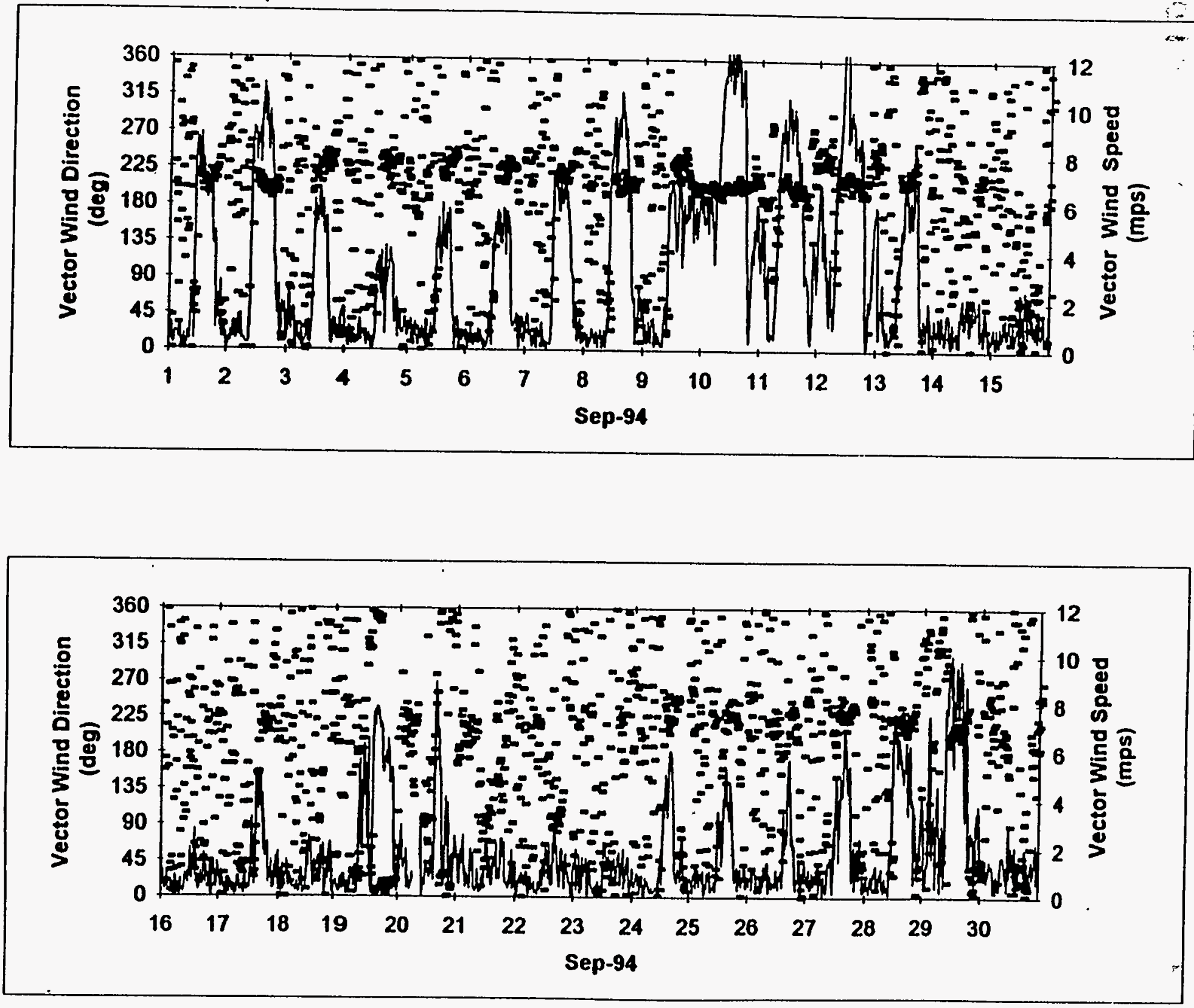
(sdu)

poods pu!M soloon

$\cong$ ㅇ $0+N \quad$

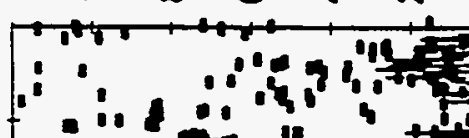

$\because \therefore 1 \therefore 11 \%$

!

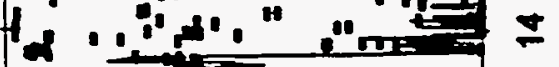

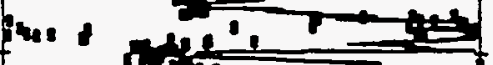

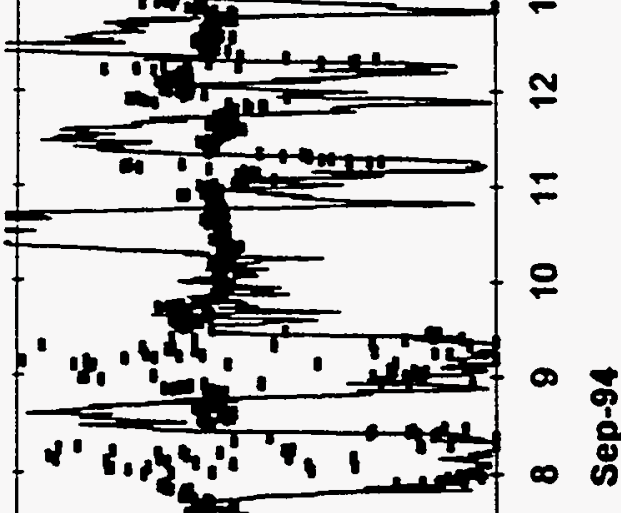

1:

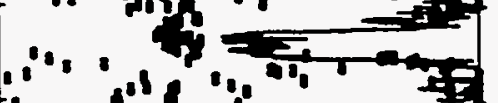

$\because$ ol in 0

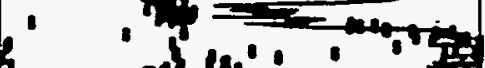

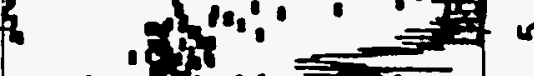

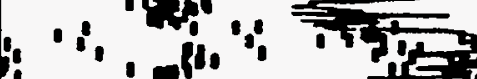

1

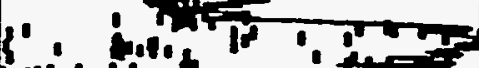

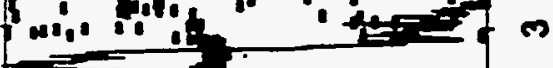

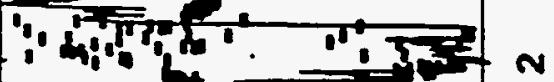

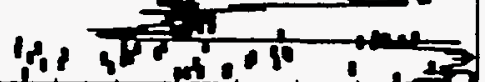

品 的 슟

(6op)

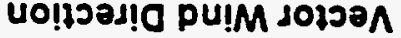

(sdu)

poeds pu!M J0100n

บ $\infty 0<v 0$

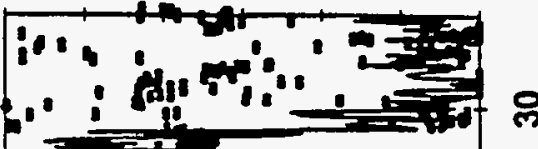

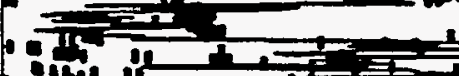

p.60.

$\because$ dic

14 4.

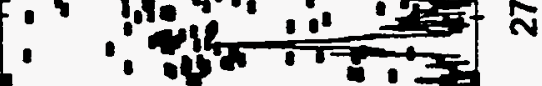

[1, 4h, 1. =0 :

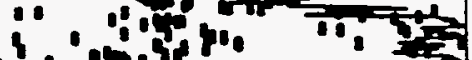

- 0 -

:

1.75 4:

: :3.:1:

.

. . : $4 \mathrm{x}^{\circ}$

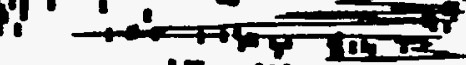

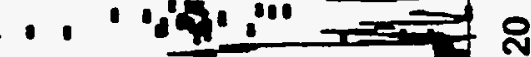

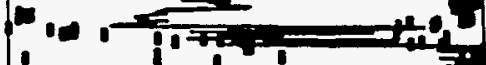

tio. $=1 ?, ?$ ?

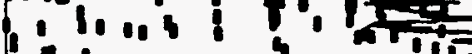

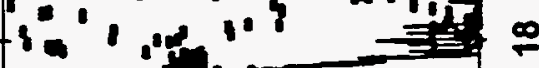

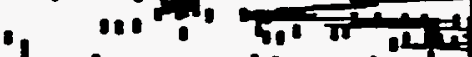

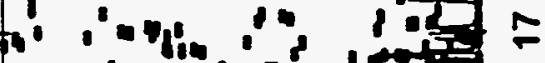

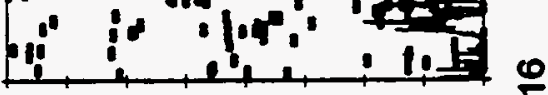

㝦 只 N

(6op)

Uo!too!d pu!M doloon 


\section{METER TEMPERATURE}

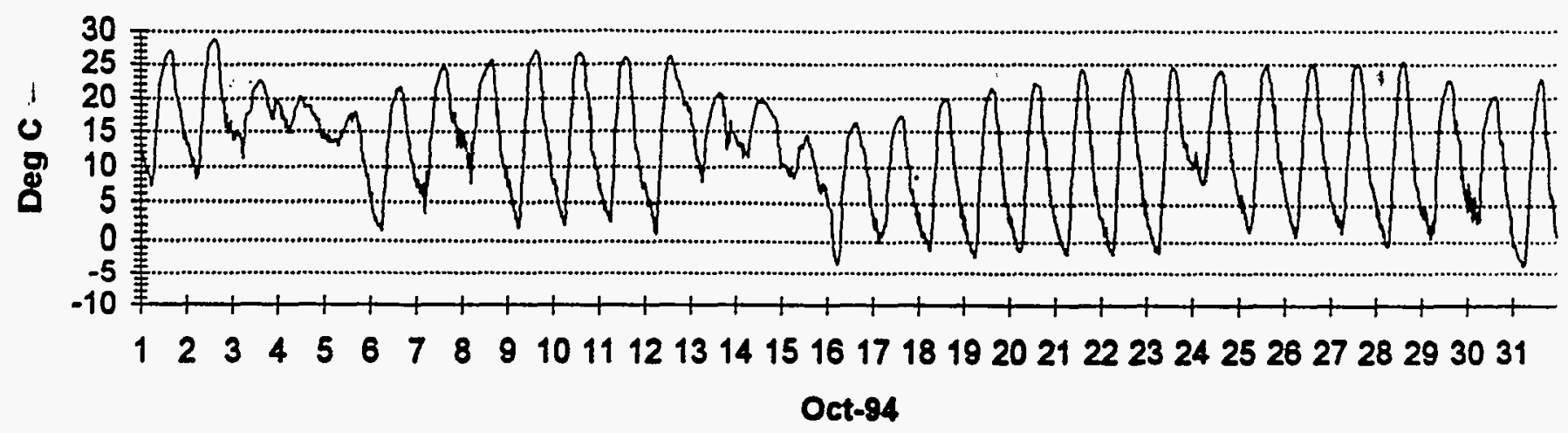

\section{METER TEMPERATURE}

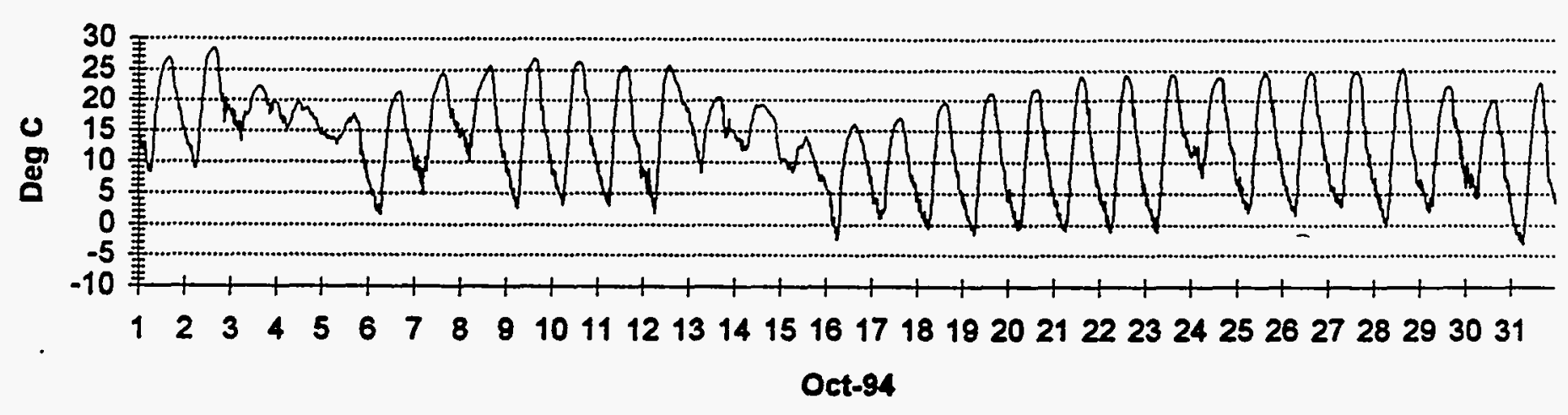

\section{TEMPERATURE DIFFERENCE, 2 TO 16 METER}

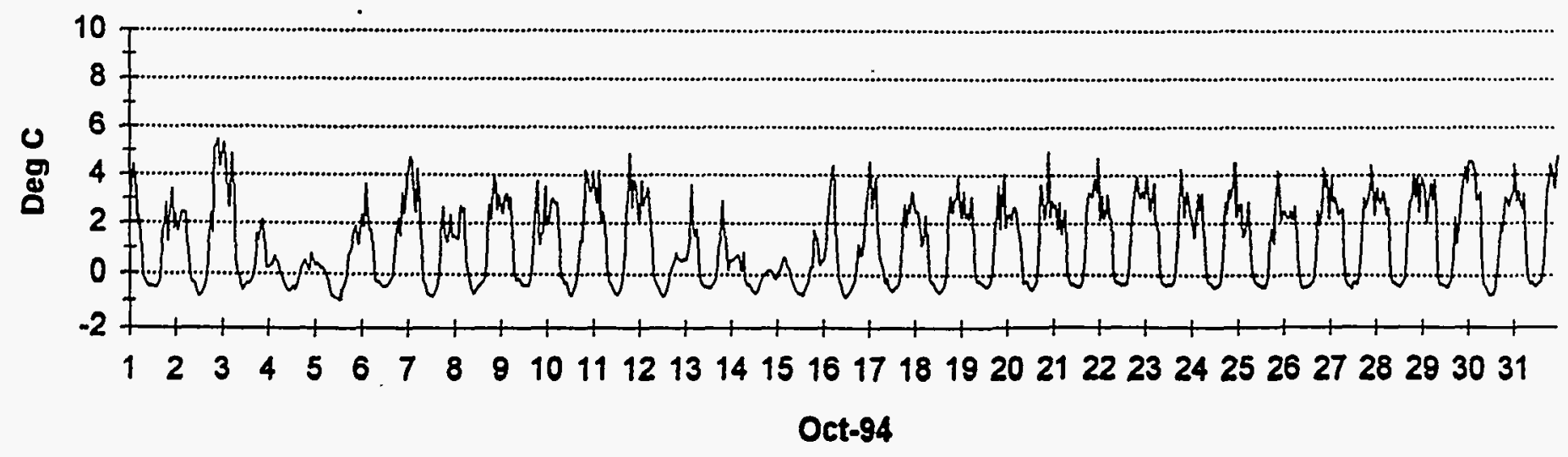



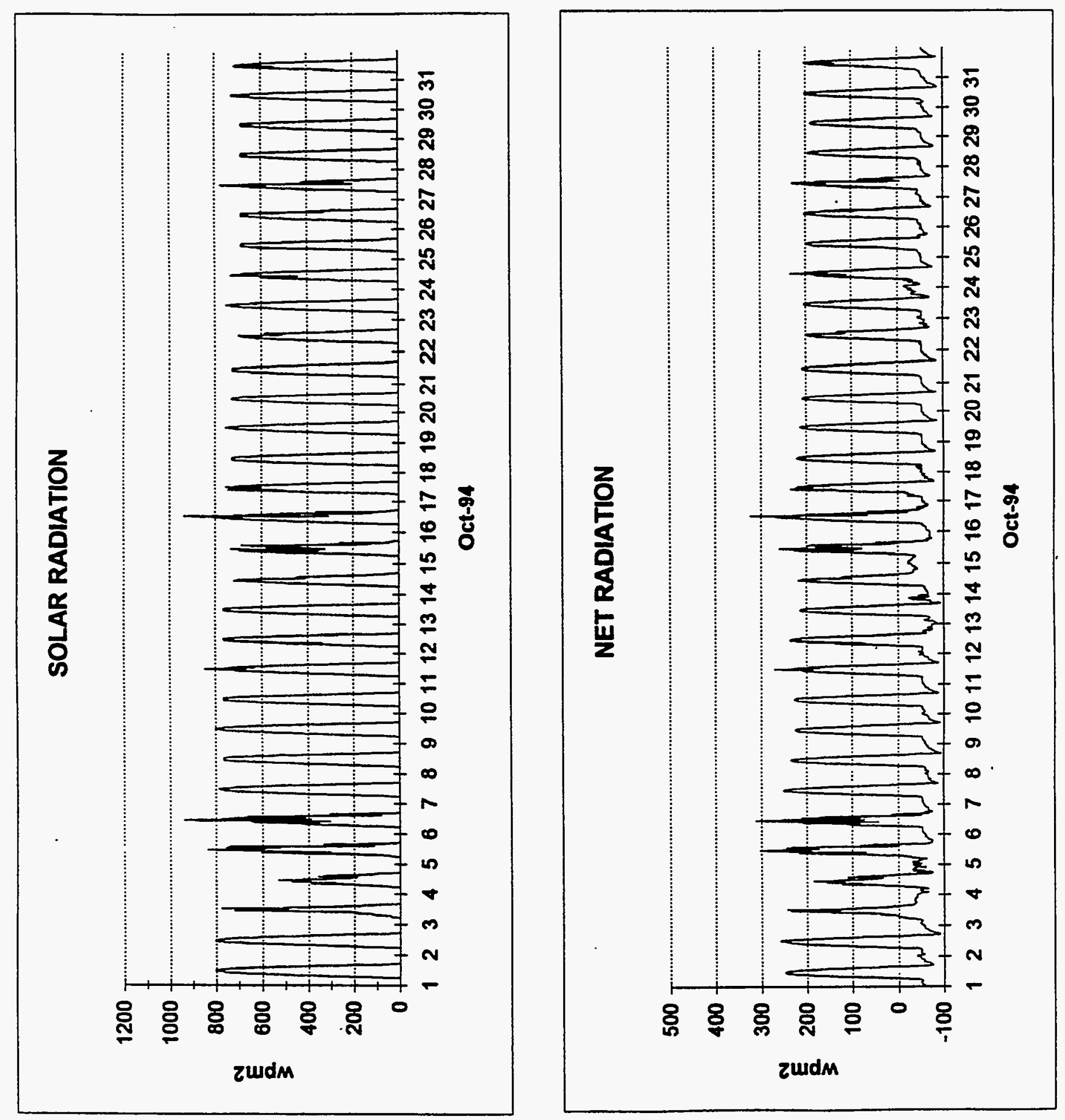

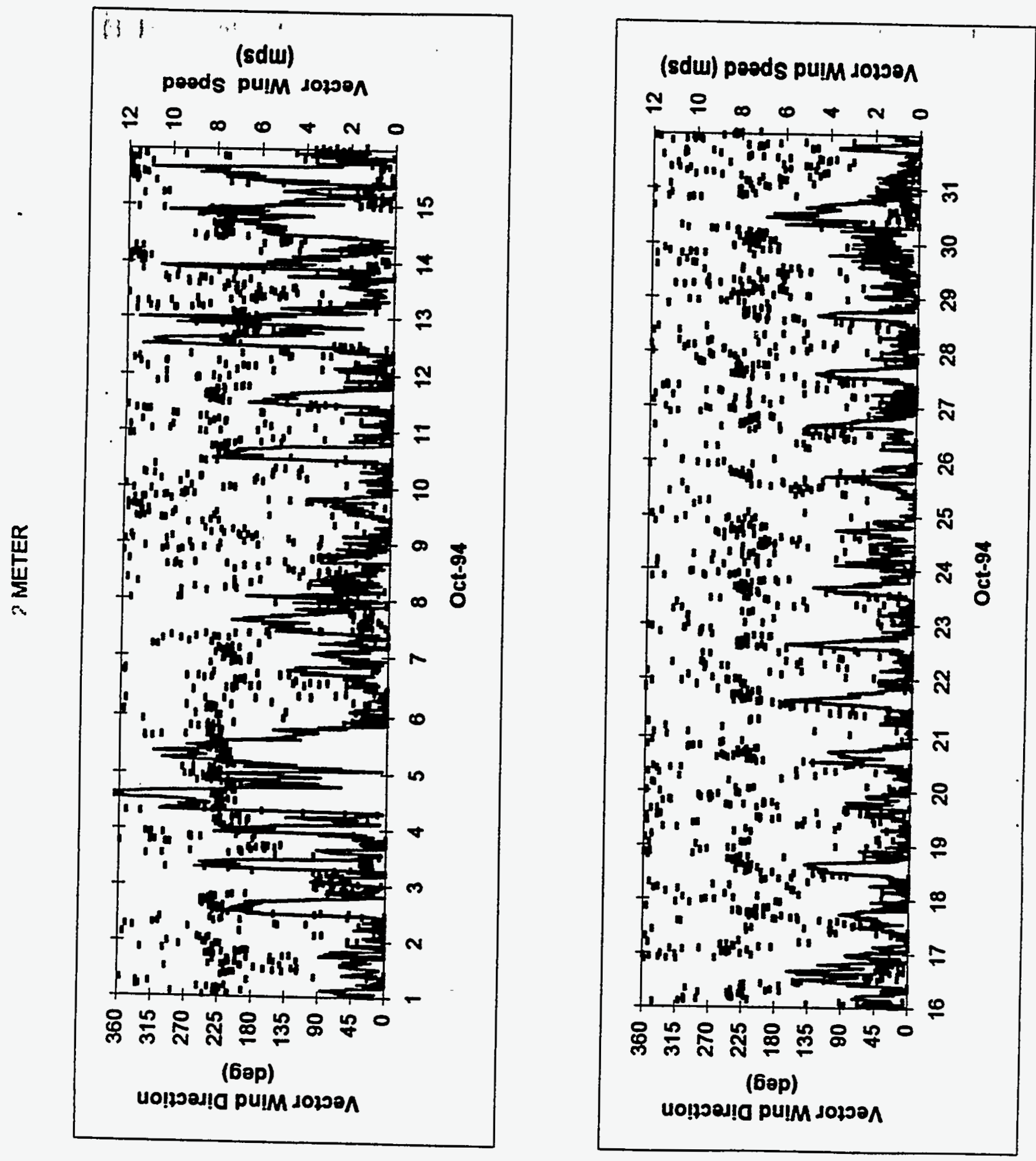

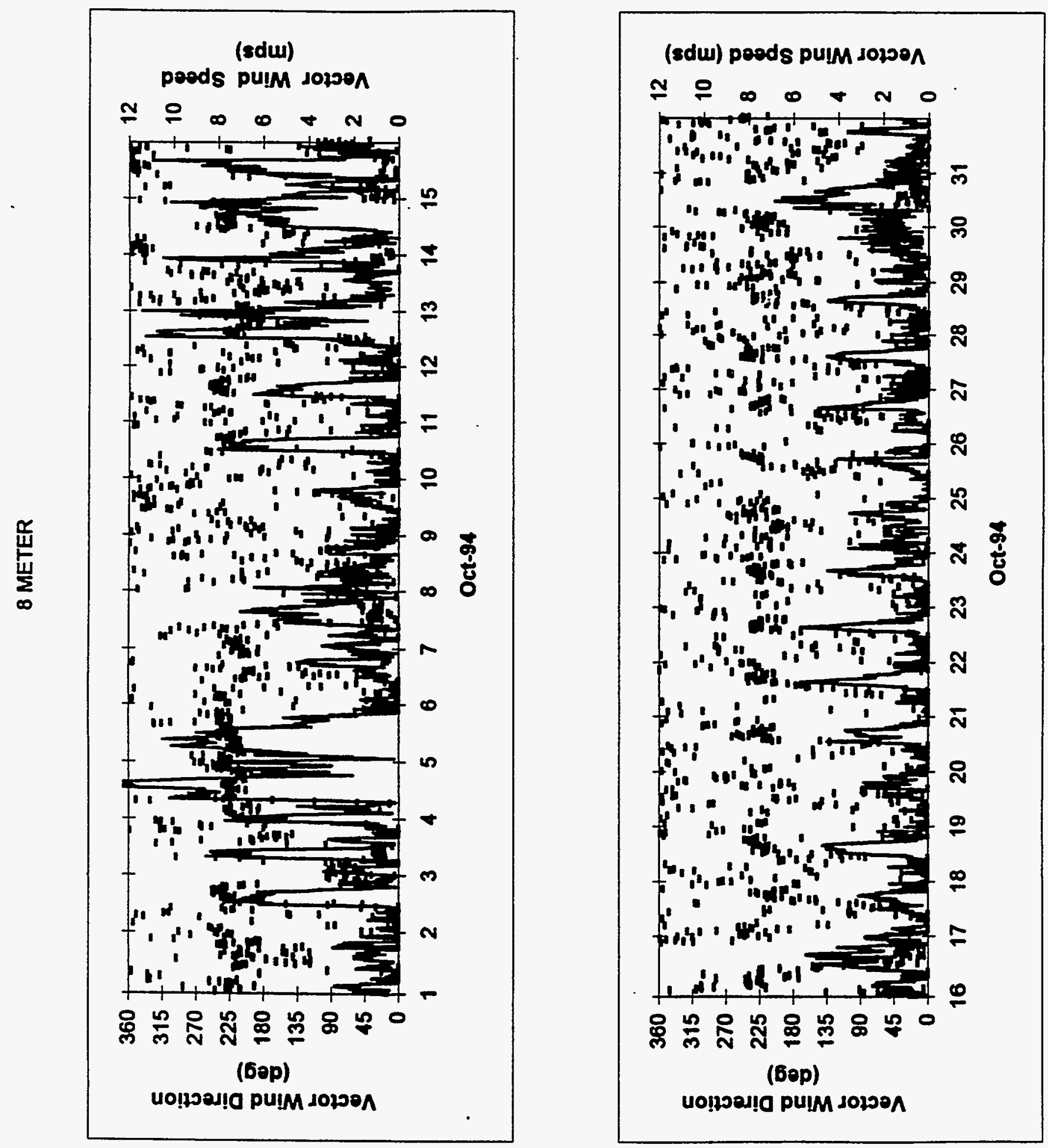


\section{METER TEMPERATURE}

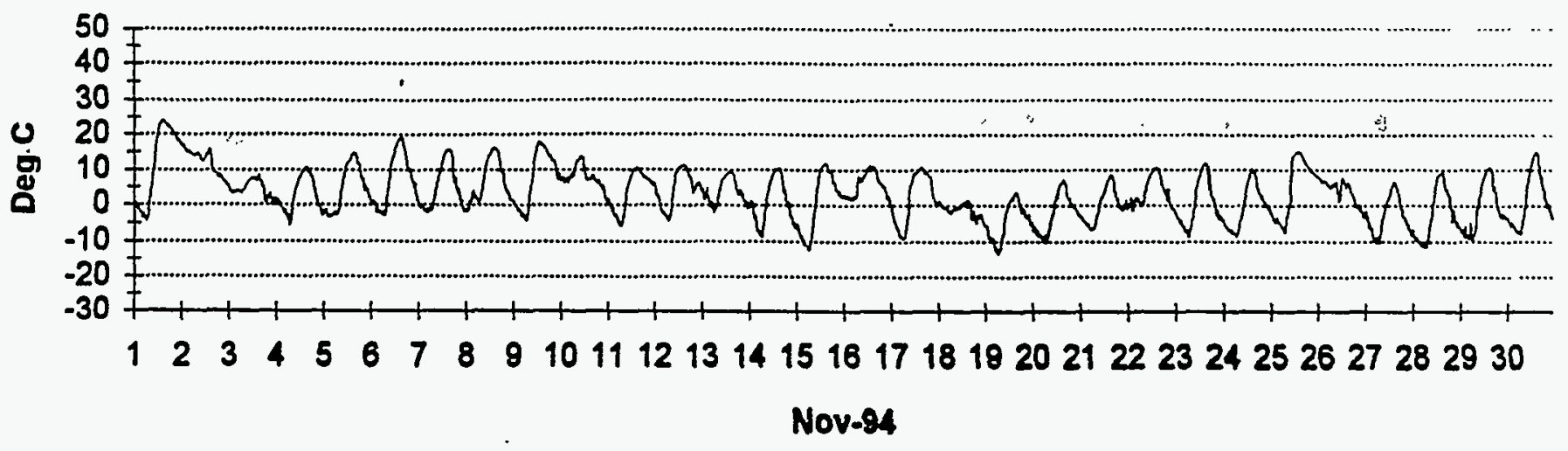

\section{METER TEMPERATURE}

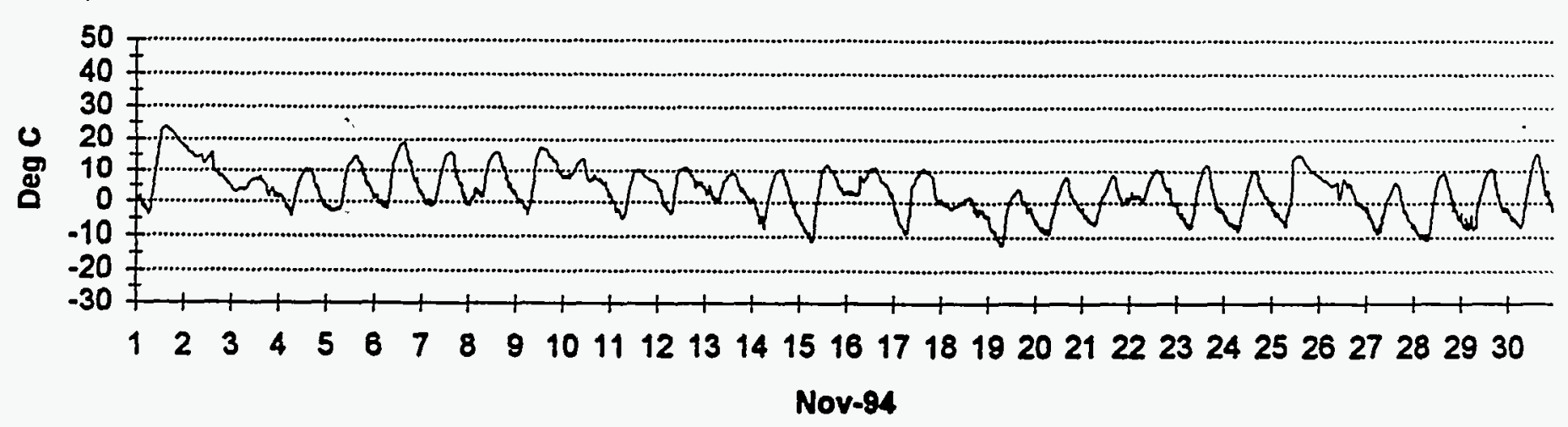

\section{TEMPERATURE DIFFERENCE, 2 TO 16 METER}

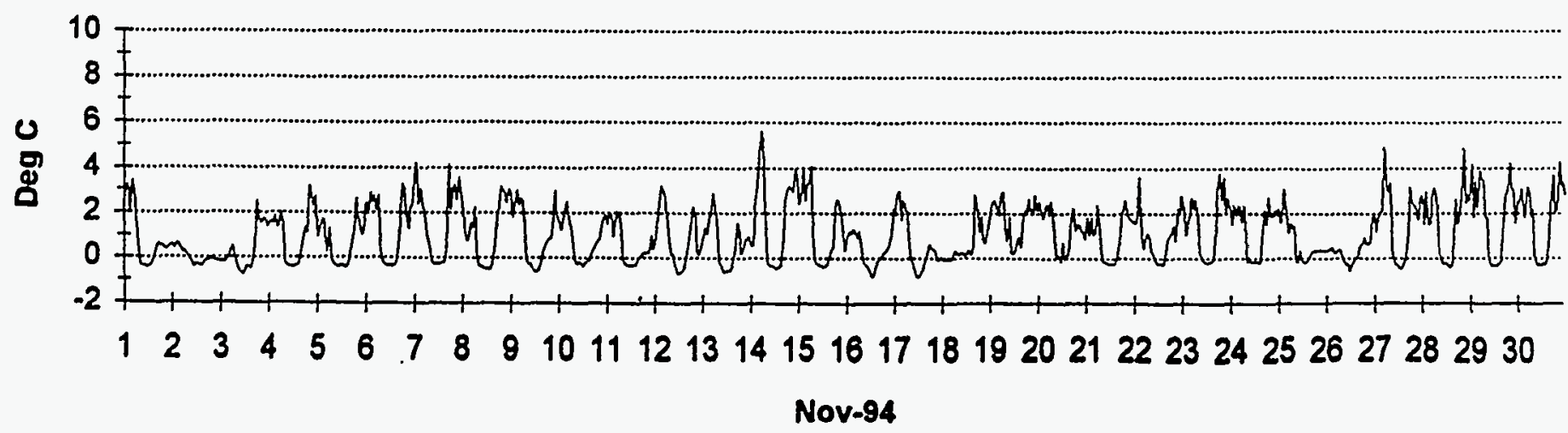



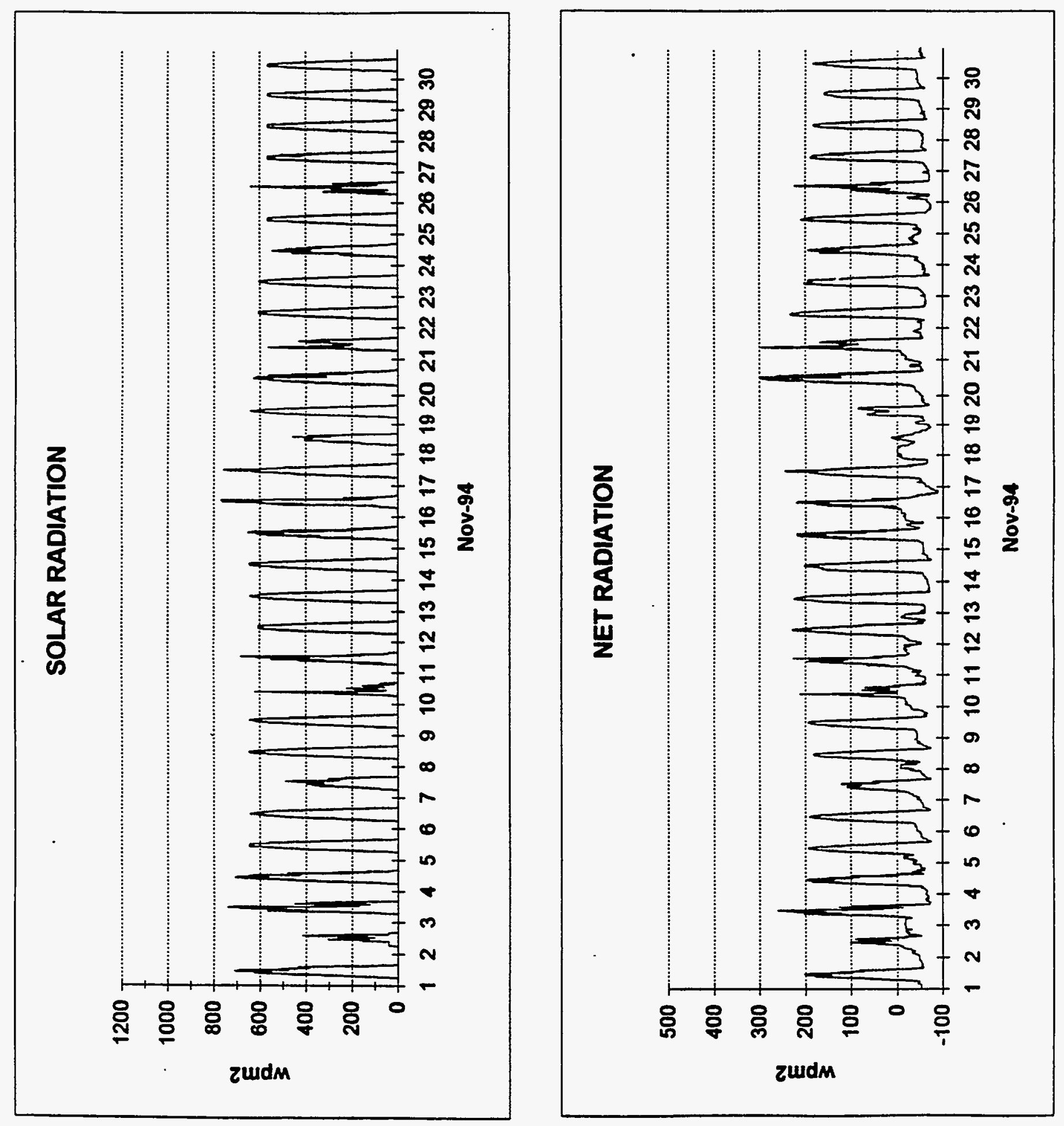

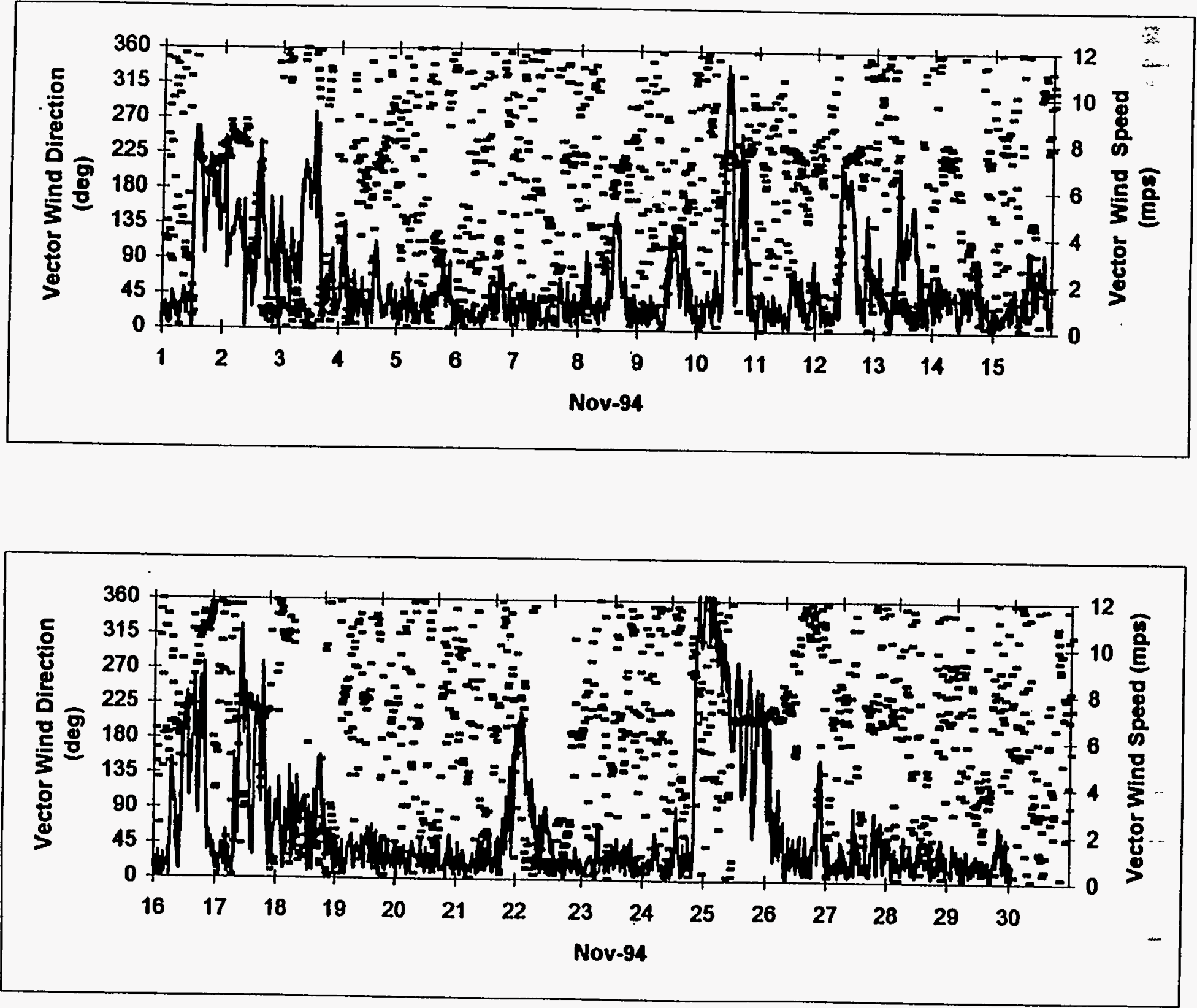
(sdw)

poods puIM sozoen

N $=\infty \infty+N o$

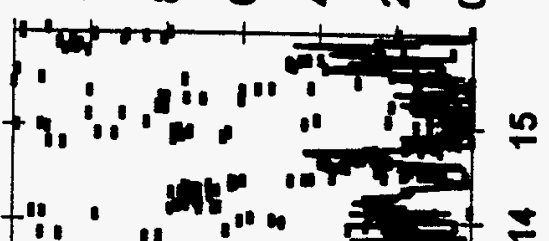

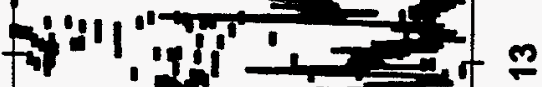

4... 1 =

-

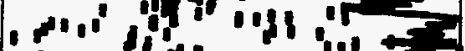

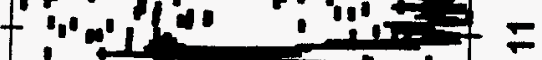

1.

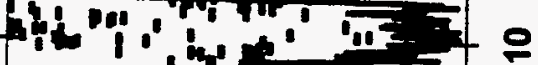

Pin

f.1.

a.: 1. THE

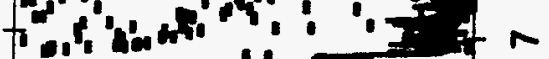

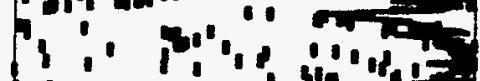

In

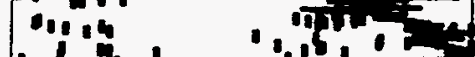

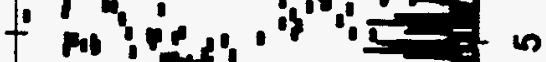

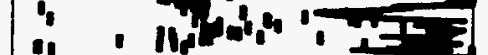

f"in! :1,
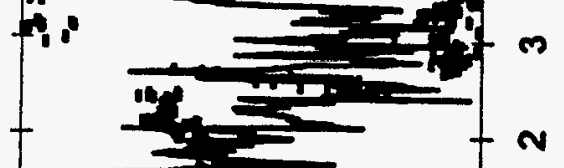

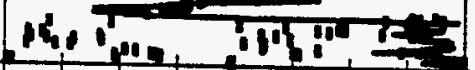

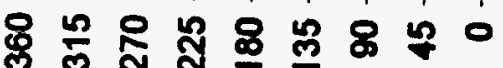

(6op)

Uo!łoes!a pu!M doł00A (sdu) peods pu!m s0200n

$\simeq$ 우 $0+N \quad$

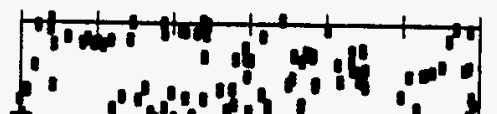

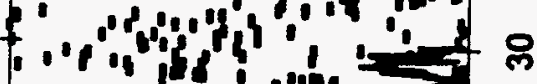

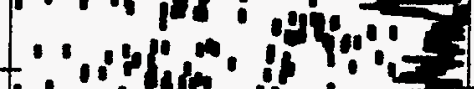

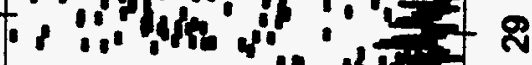

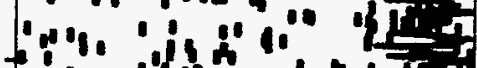

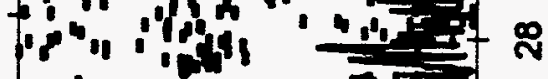

- ! "1, Int '11

अyd

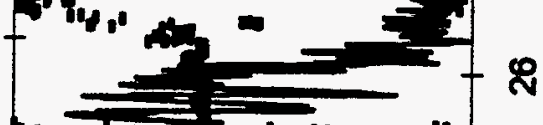

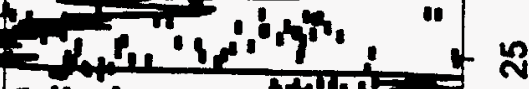

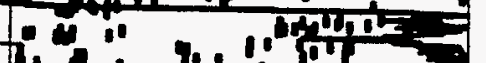

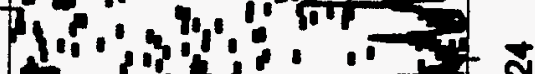

4.

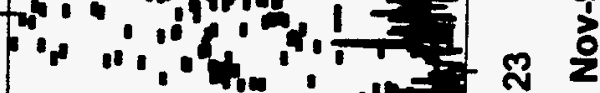

$+$

4i. . ก

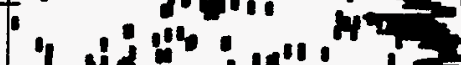

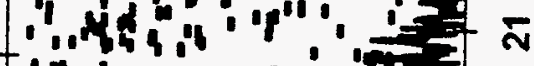

7.

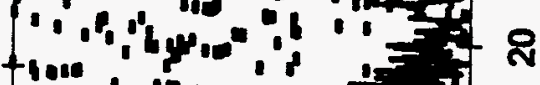

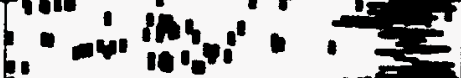

8' $\because 10.610$

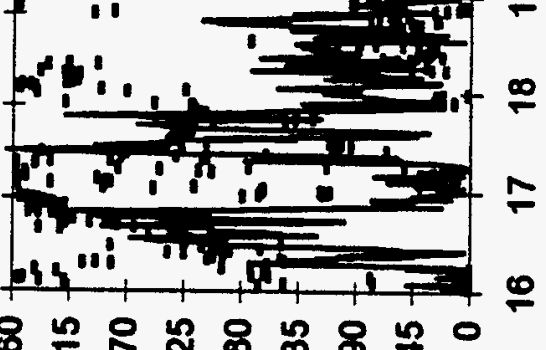

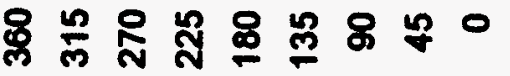

(Bop)

Uo!roed! pu!M JOzoon 


\section{METER TEMPERATURE}

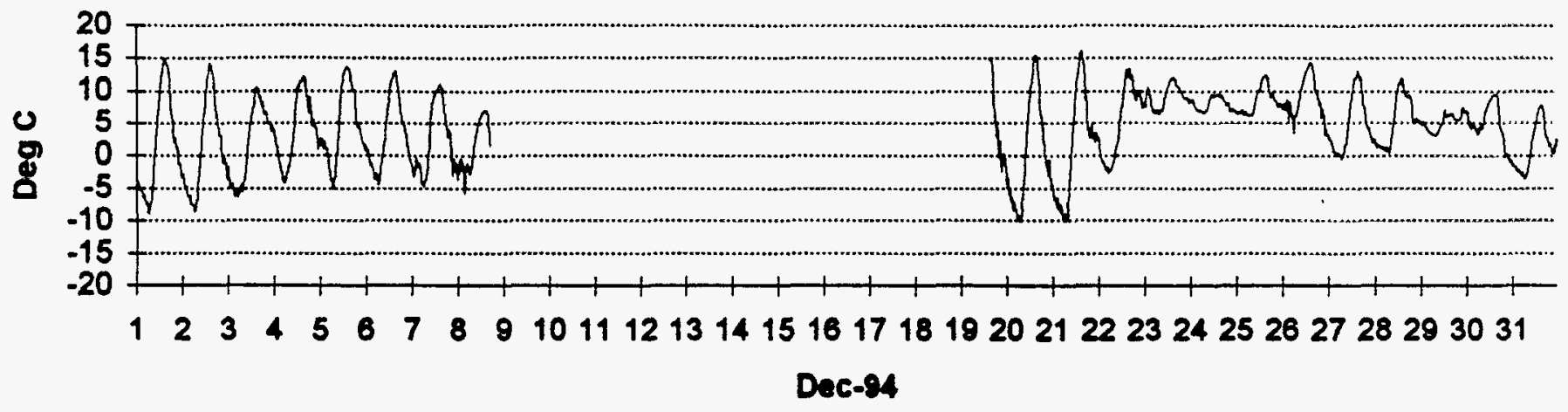

\section{METER TEMPERATURE}

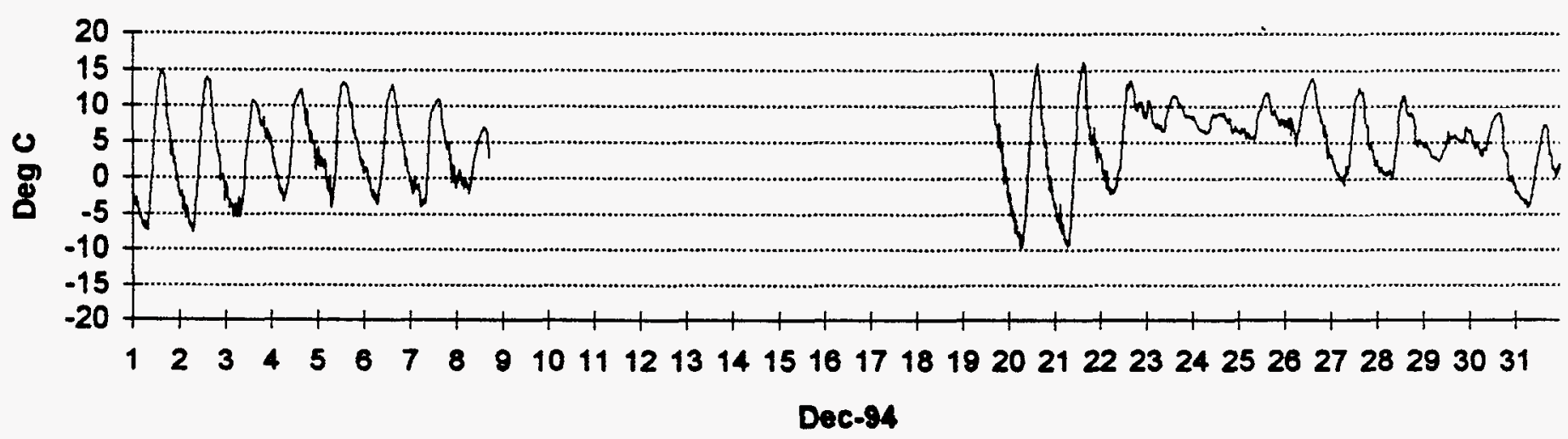

TEMPERATURE DIFFERENCE, 2 TO 16 METER

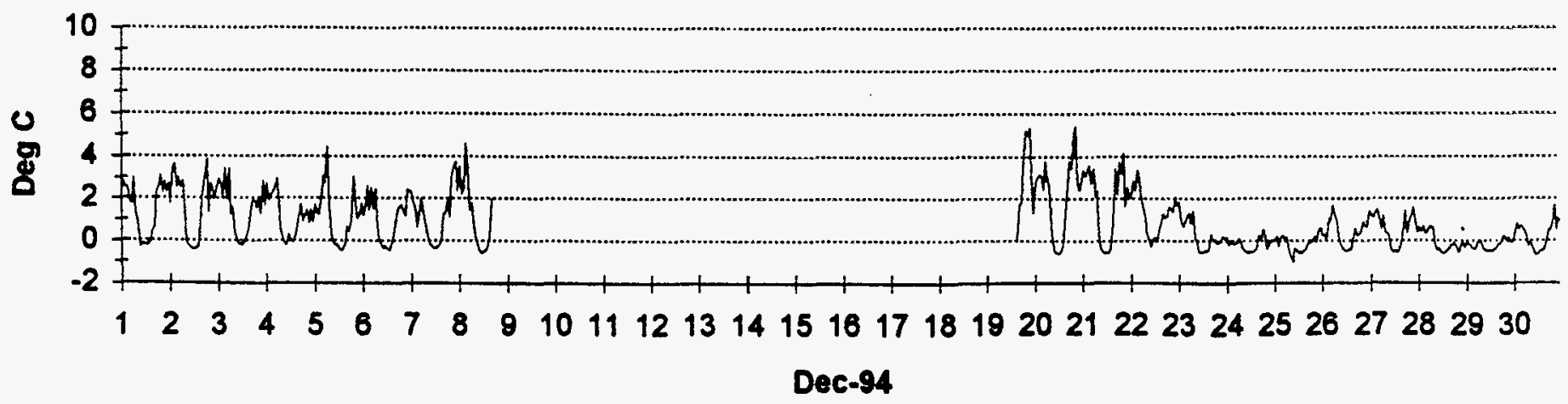



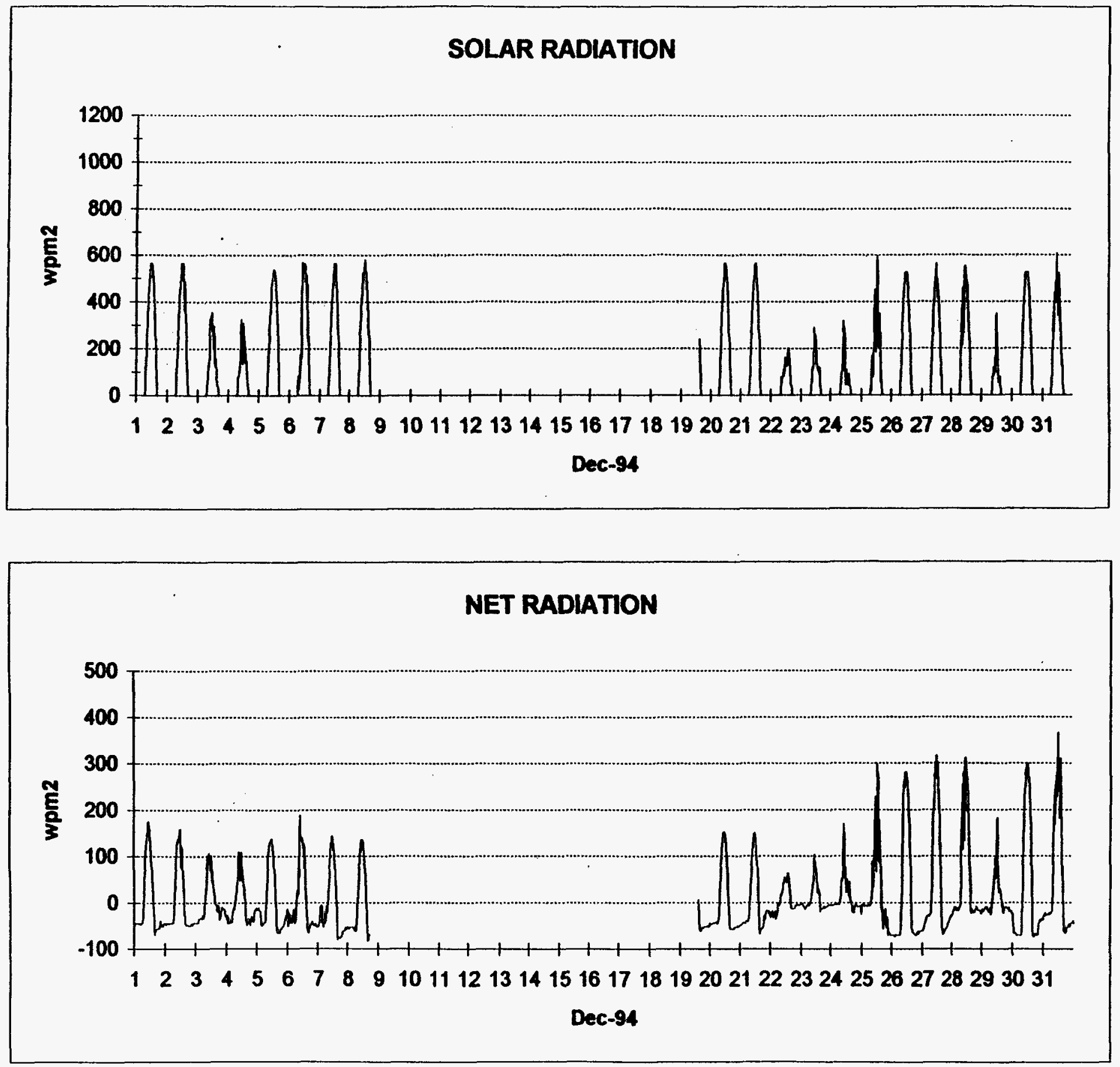


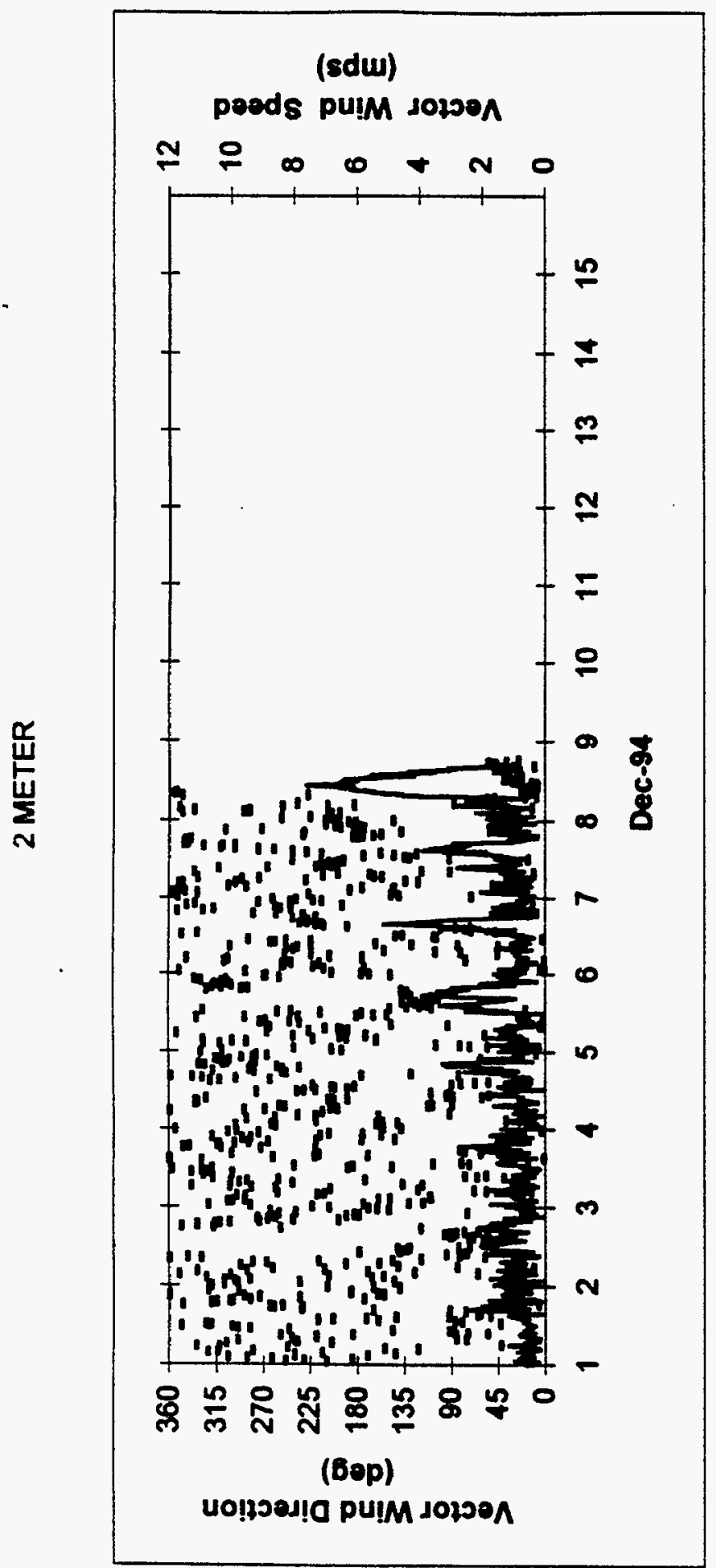

(sdw) poeds pu!M J0200/

N. 에 $\infty+N o$

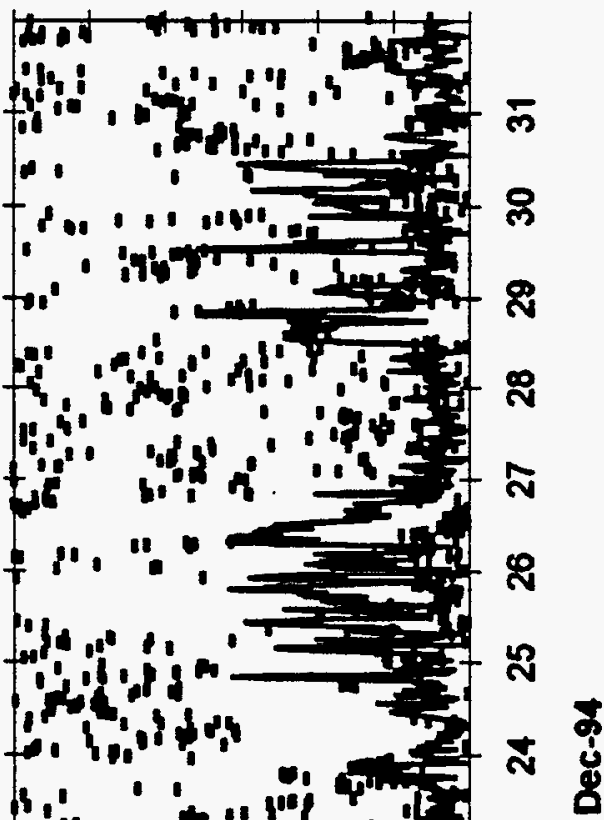

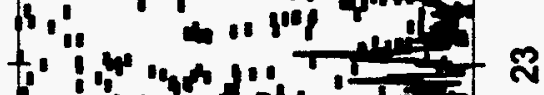

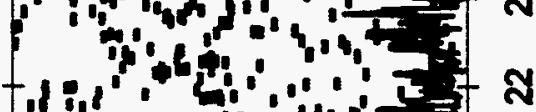

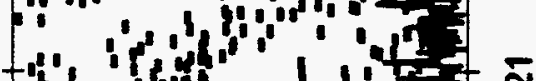

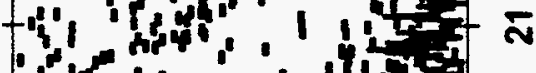

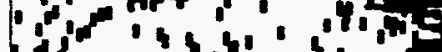

f

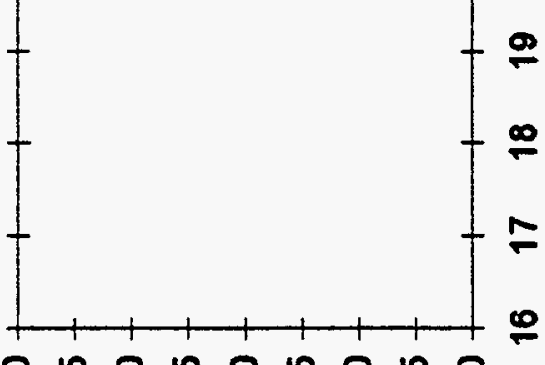

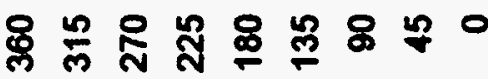

(bop)

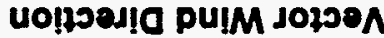



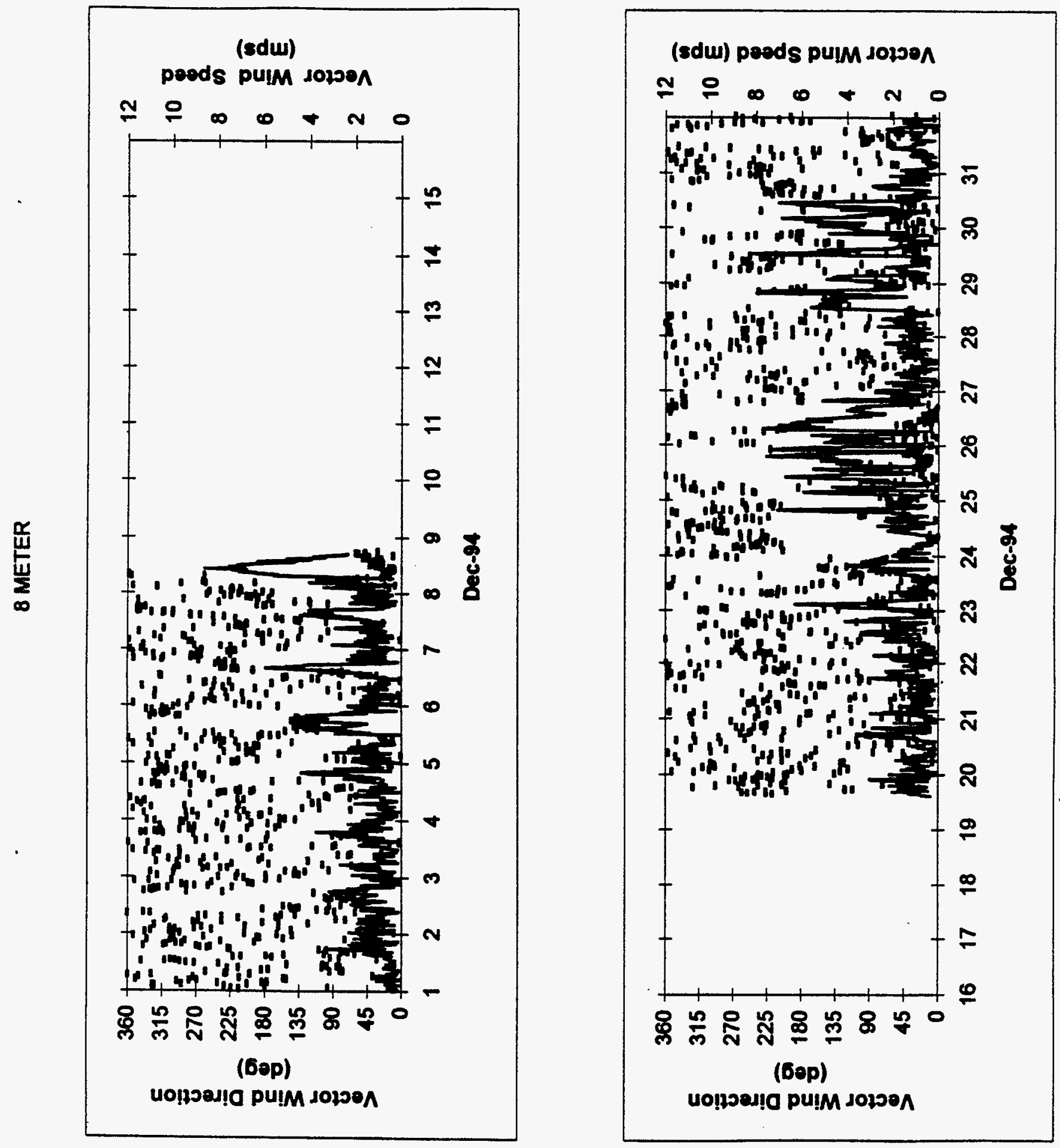


\section{APPENDIX B: MONTHLY WIND ROSES, TWO AND EIGHT METERS}

\section{Two Meters}

1-12 Total Hours (0000-2400), January-December, 1994

13-24 Morning Transition (0600-1000), January-December, 1994

25-36 Late Mid-day (1000-1600), January-December, 1994

37-48 Evening Transition (1600-2000), January-December, 1994

49-60 Night Time (2000-0600), January-December, 1994

61-72 All Stability Class A, January-December, 1994

73-84 All Stability Class B, January-December, 1994

85-96 All Stability Class C, January-December, 1994

97-108 All Stability Class D, January-December, 1994

109-120 All Stability Class E, January-December, 1994

121-132 All Stability Class F, January-December, 1994

Eight Meters

133-144 Total Hours (0000-2400),

145-156 Morning Transition (0600-1000), January-December, 1994

157-168 Late Mid-day (1000-1600), January-December, 1994

169-180 Evening Transition (1600-2000), January-December, 1994

181-192 Night Time (2000-0600), January-December, 1994

193-204 All Stability Class A, January-December, 1994

205-216 All Stability Class B, January-December, 1994

217-228 All Stability Class C, January-December, 1994 
APPENDIX B: MONTHLY WIND ROSES, TWO AND EIGHT METERS (con't.)

229-240 All Stability Class D, January-December, 1994

241-252 All Stability Class E, January-December, 1994

253-264 All Stability Class F, January-December, 1994 


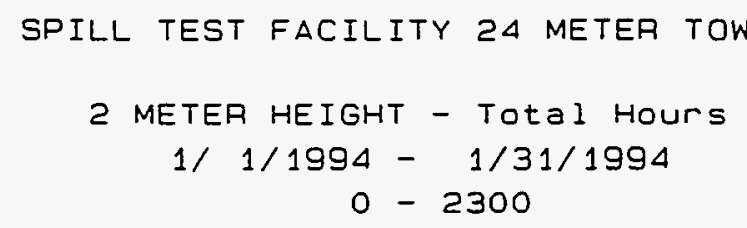

$N$

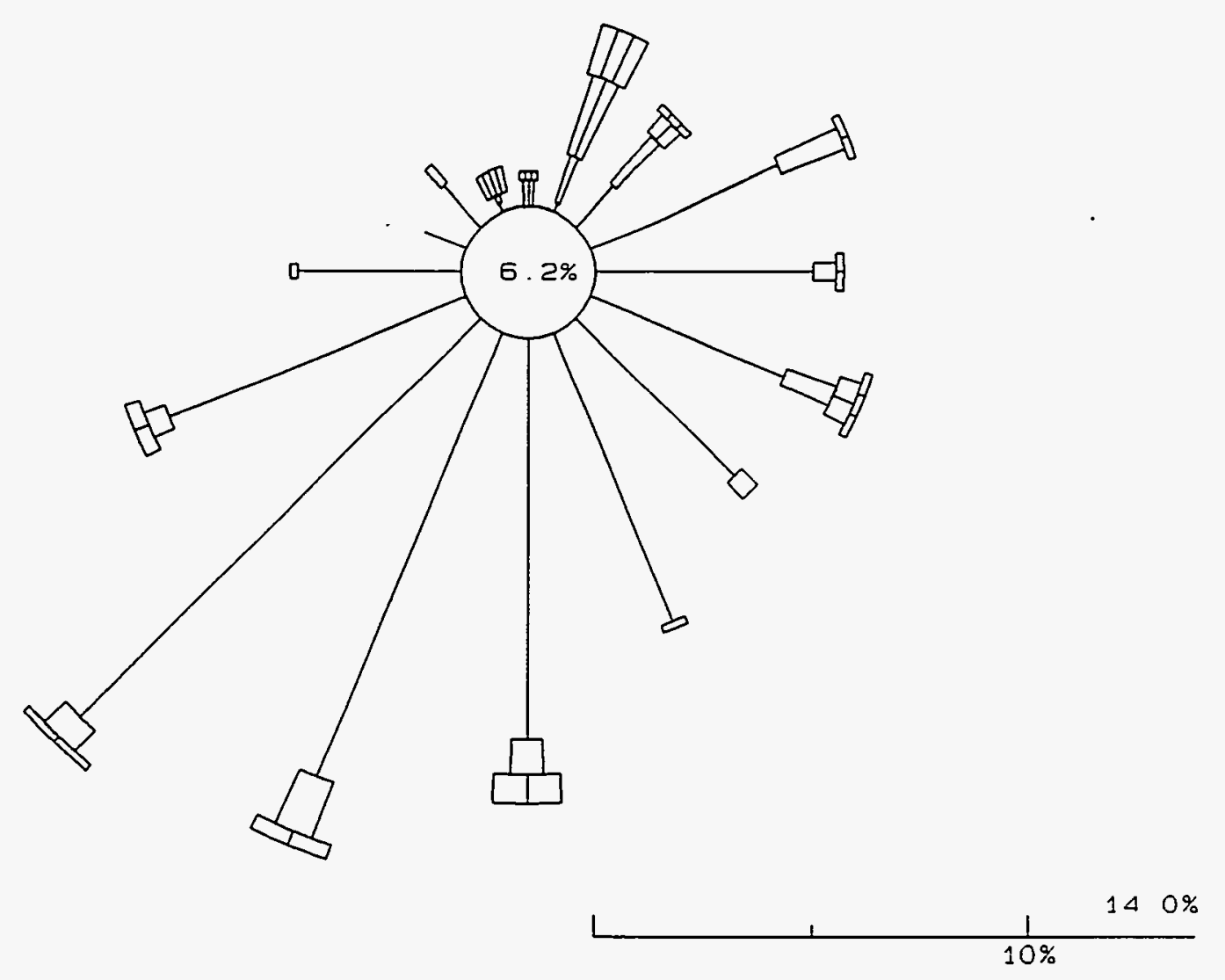

78. O\% DATA RECOVERED

OF WHICH $100.0 \%$ IS

REPOATED ABOVE 
SPILL TEST FACILITY 24 METER TOWER

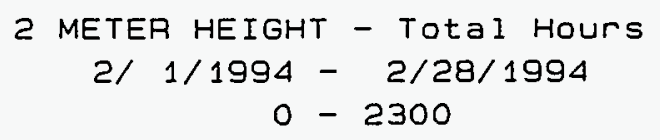

N

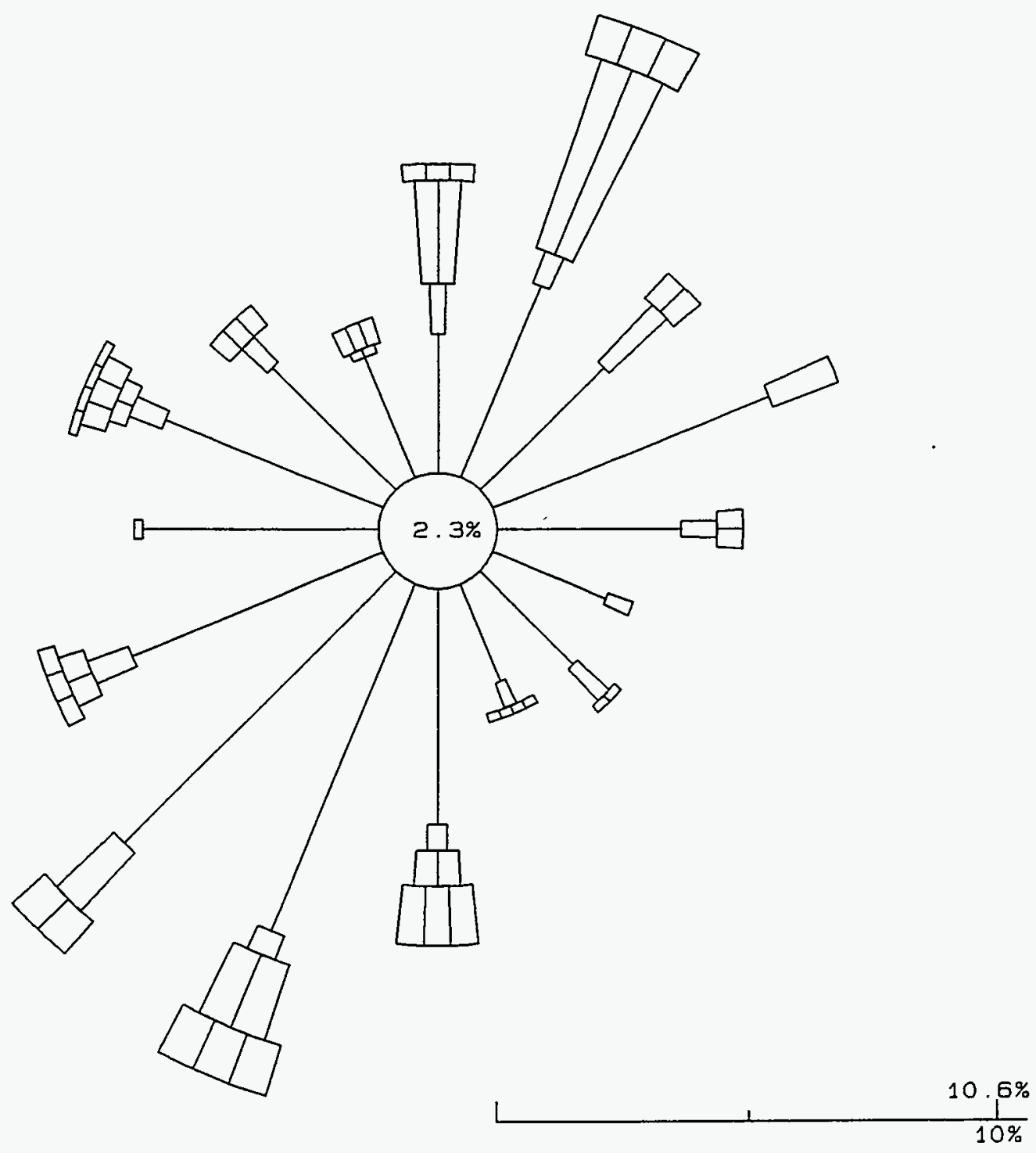

WIND SPEED CLASSES (MRS)

CALM O

11

20

$3 \square$

4 पात

5 메다

6 पाता
WS $<=.5$

$.5<W S<=1.8$

$1.8<$ WS $<=3.3$

$3.3<$ WS $<=5.4$

5. $4<$ WS $<=8.5$

8. $5<$ WS $<=10.8$

$10.8<W S$
85. 4\% DATA RECOVERED

OF WHICH $100.0 \%$ IS

REPORTED ABOVE 


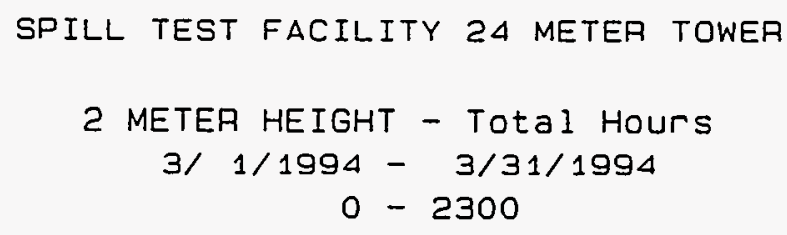

$N$

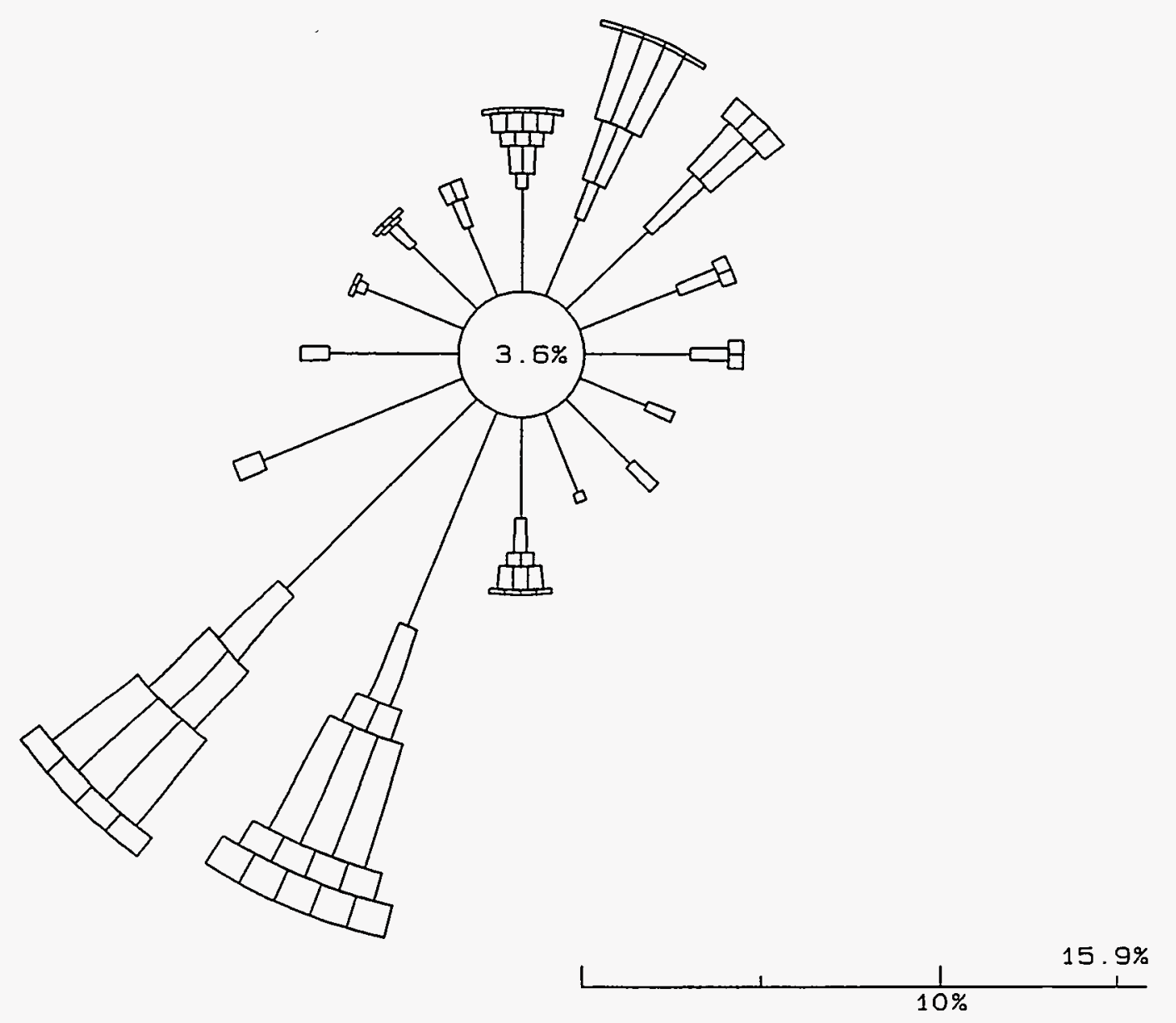

100. O\% DATA RECOVERED

OF WHICH $100.0 \%$ IS

REPORTED ABOVE 


\section{SPILL TEST FACILITY 24 METER TOWER \\ 2 METER HEIGHT - Total Hours \\ $4 / 1 / 1994$ - 4/30/1994 \\ o - 2300}

N

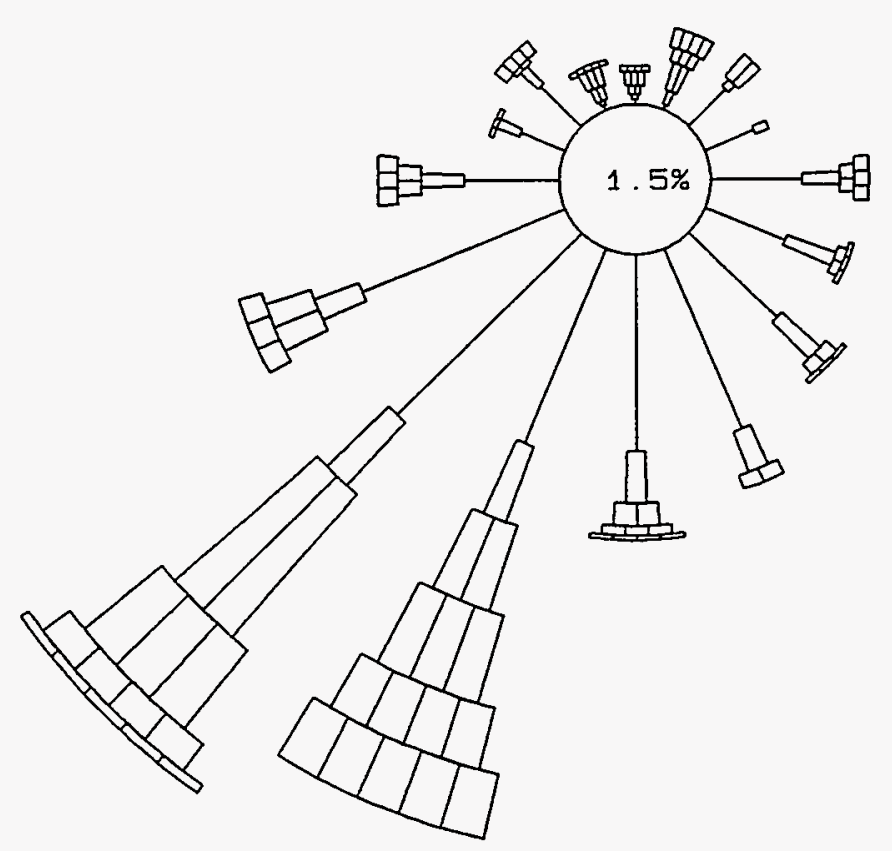

$20.0 \%$

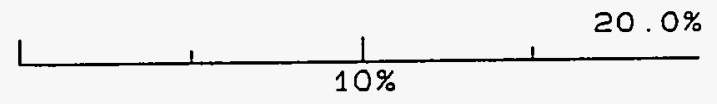

99.4\% DATA RECOVERED

OF WHICH $100.0 \%$ IS

REPORTED ABOVE 


\section{SPILL TEST FACILITY 24 METER TOWER \\ . \\ 2 METER HEIGHT - Total Hours \\ 5/ $1 / 1994$ - 5/31/1994 \\ $0-2300$}

$N$

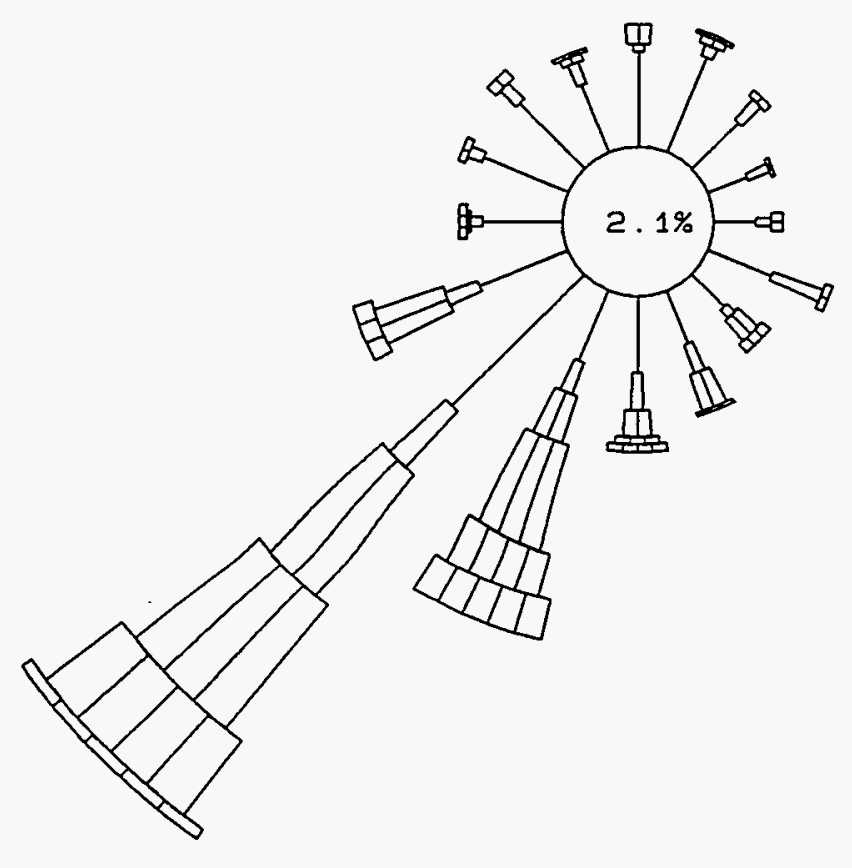

\begin{tabular}{|c|c|c|c|c|}
\hline IND & SPE & $\mathrm{ED} \mathrm{Cl}$ & (2) & $S$ (MPS \\
\hline CALM & 10 & & WS & $<=$ \\
\hline 1 & 1 & $5<$ & WS & $<=1.8$ \\
\hline 2 & ㅁ & $1.8<$ & WS & $<=3.3$ \\
\hline 3 & ש & $3.3<$ & WS & $<=5.4$ \\
\hline 4 & שس & $5.4<$ & WS & $<=8.5$ \\
\hline 5 & שחש & $8.5<$ & WS & $<=10.8$ \\
\hline 65 & סणाप & $10.8<$ & WS & \\
\hline
\end{tabular}

96.9\% DATA RECOVERED

OF WHICH $100.0 \%$ IS

REPORTED ABOVE 


\section{SPILL TEST FACILITY 24 METER TOWER \\ 2 METER HEIGHT - Total Hours \\ 6/ $1 / 1994$ - 6/30/1994 \\ $0-2300$}

$N$
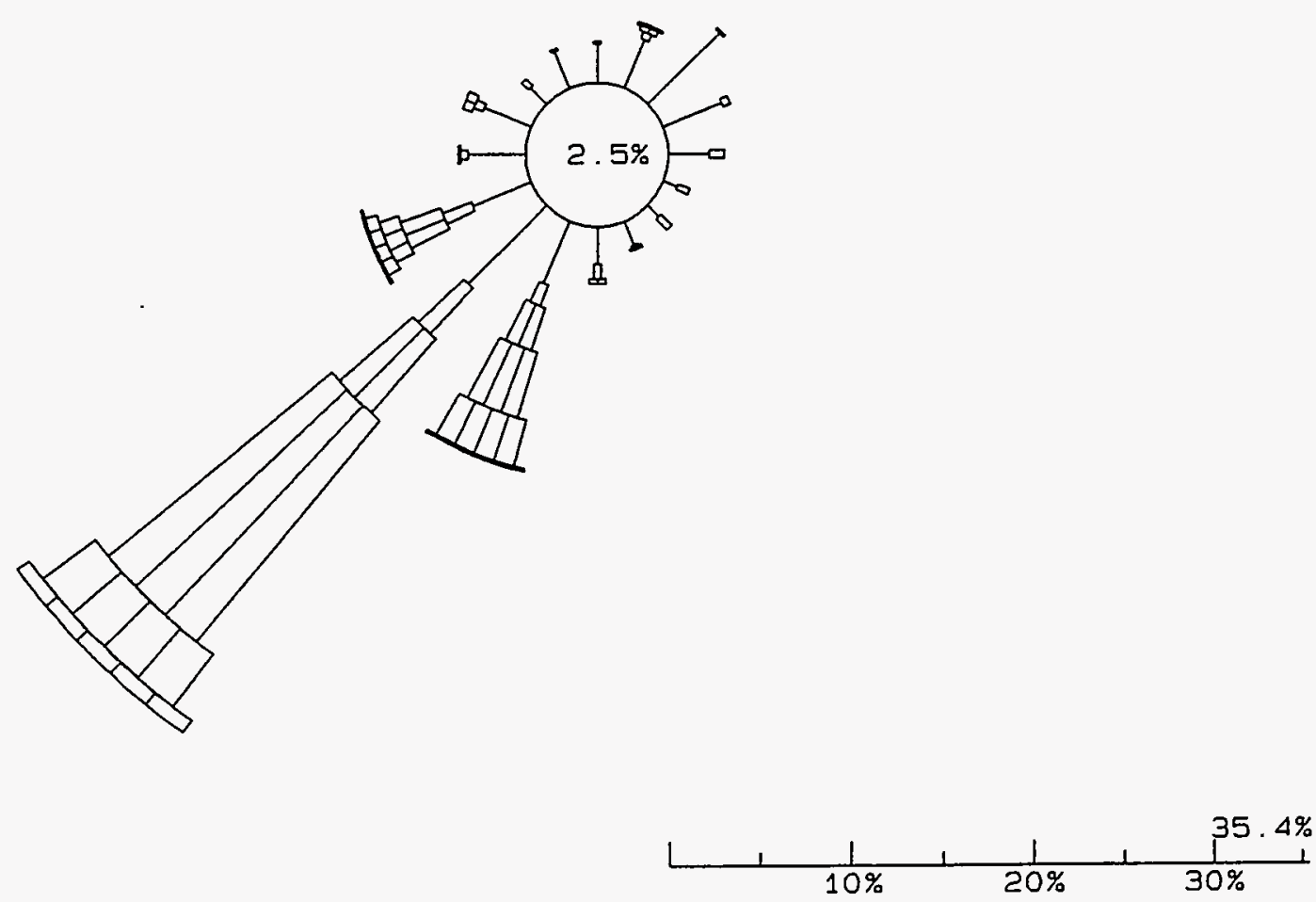

\begin{tabular}{|c|c|c|c|c|}
\hline \multirow{2}{*}{ WIND } & \multicolumn{4}{|c|}{ SPEED CLASSES (MPS) } \\
\hline & 10 & & WS & $<=$ \\
\hline 1 & 1 & $5<$ & WS & $<=1$. \\
\hline 2 & $\square$ & $1.8<$ & ws & $<=3$. \\
\hline 3 & Ф & $3.3<$ & WS & $<=5$. \\
\hline$\Delta$ & سم & $5.4<$ & WS & $<=8$. \\
\hline 5 & هய" & $8.5<$ & WS & $<=10$. \\
\hline 6 & & $108<$ & WS & \\
\hline
\end{tabular}

100. O\% DATA RECOVERED

OF WHICH $100.0 \%$ IS

REPORTED ABOVE 


\section{SPILL TEST FACILITY 24 METER TOWER \\ 2 METER HEIGHT - Total Hours \\ $7 / 1 / 1994-7 / 31 / 1994$ \\ $0-2300$}

$N$
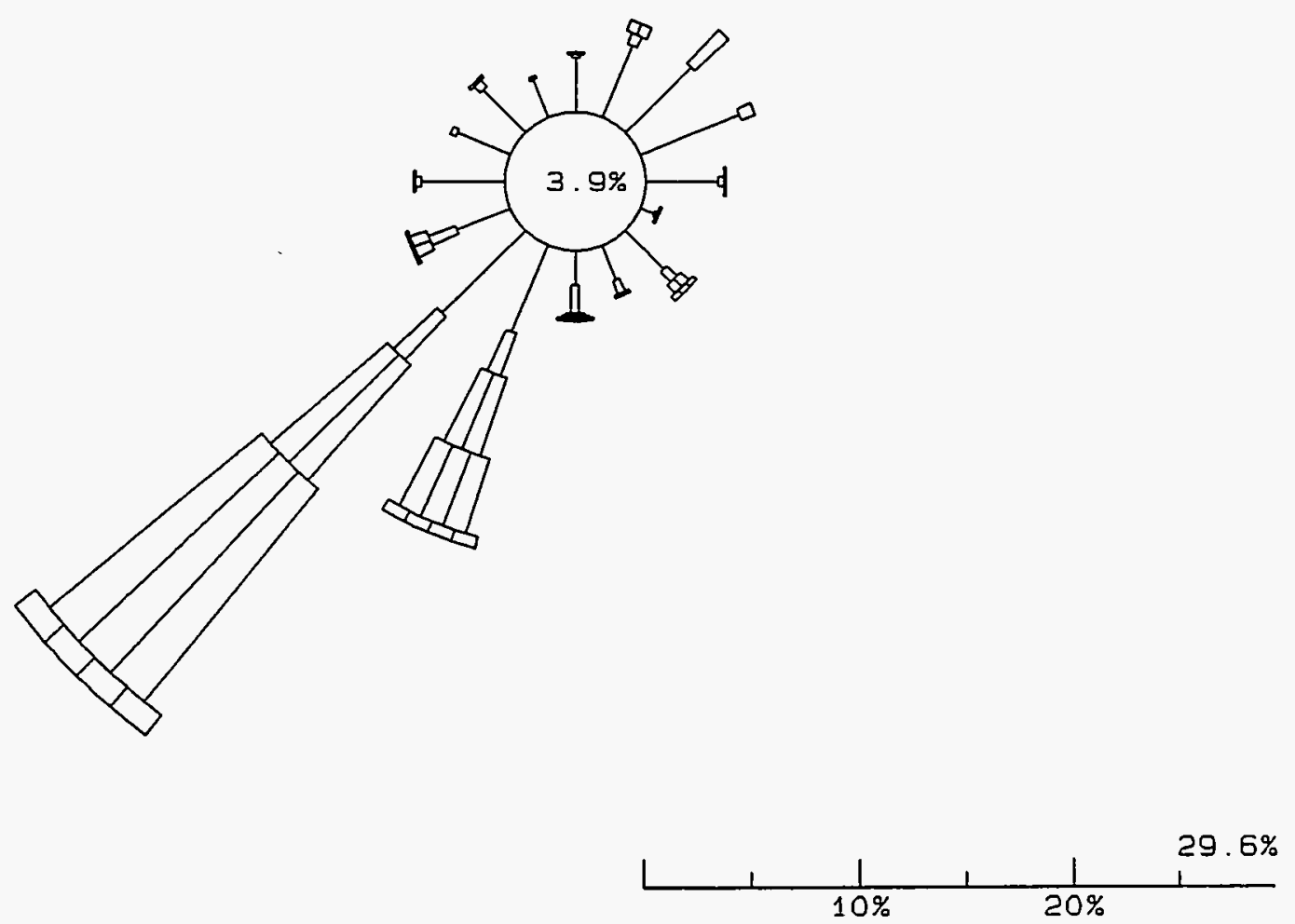

100.0\% DATA RECOVERED

OF WHICH $100.0 \%$ IS

REPORTED ABOVE 


\section{SPILL TEST FACILITY 24 METER TOWER \\ 2 METER HEIGHT - Total Hours \\ 8/ $1 / 1994-8 / 31 / 1994$ \\ $0-2300$}

N
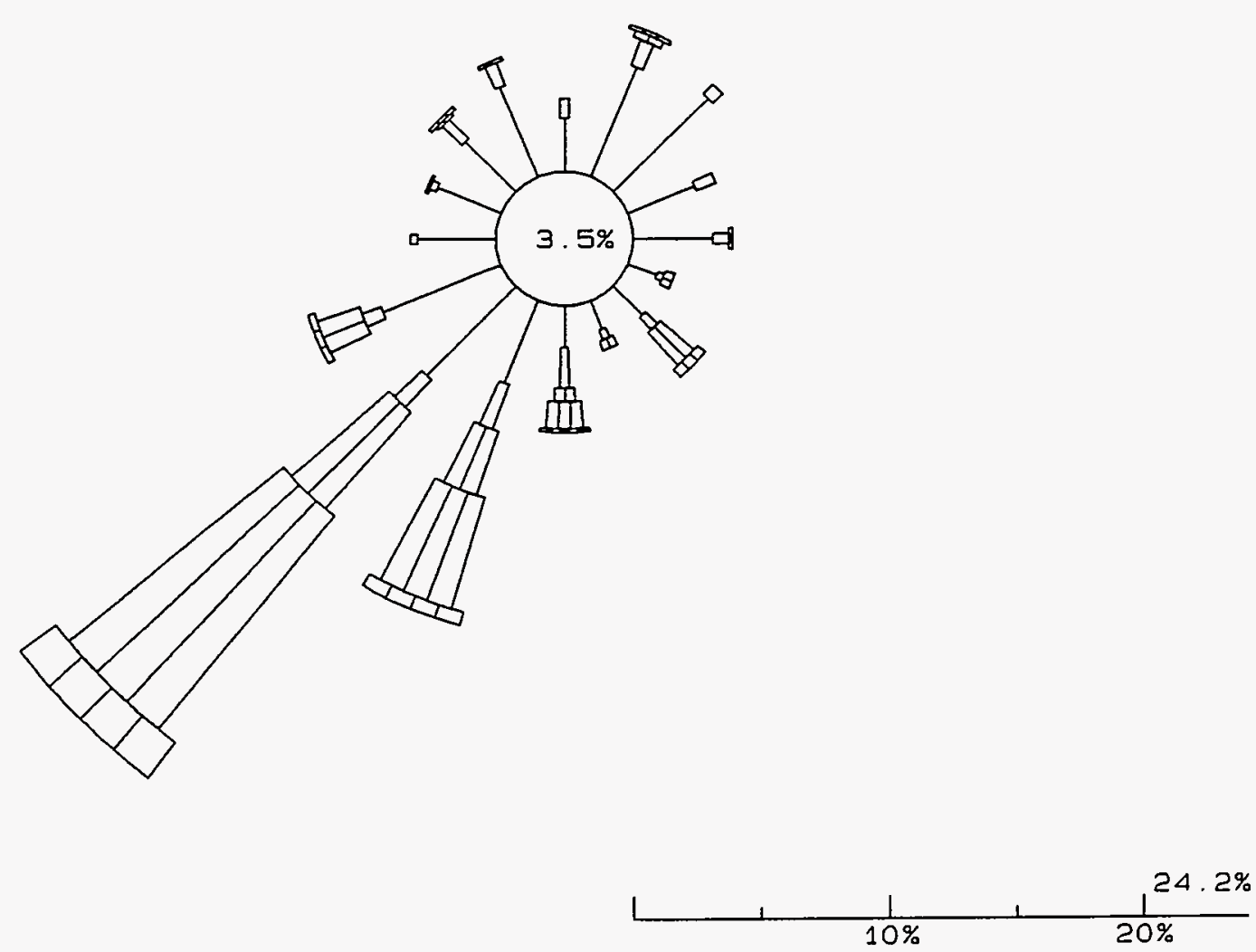

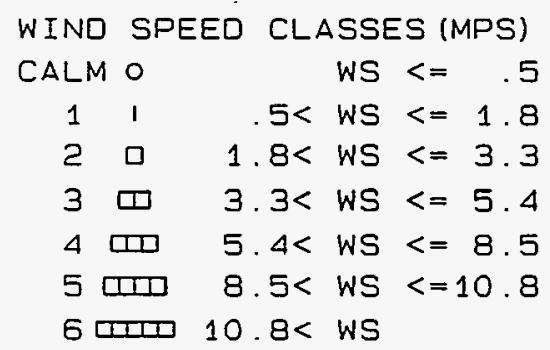

100.0\% DATA RECOVERED

OF WHICH $100.0 \%$ IS

REPORTED ABOVE 


\section{SPILL TEST FACILITY 24 METER TOWER \\ 2 METER HEIGHT - Total Hours \\ 9/ $1 / 1994-9 / 30 / 1994$ \\ $0-2300$}

$N$

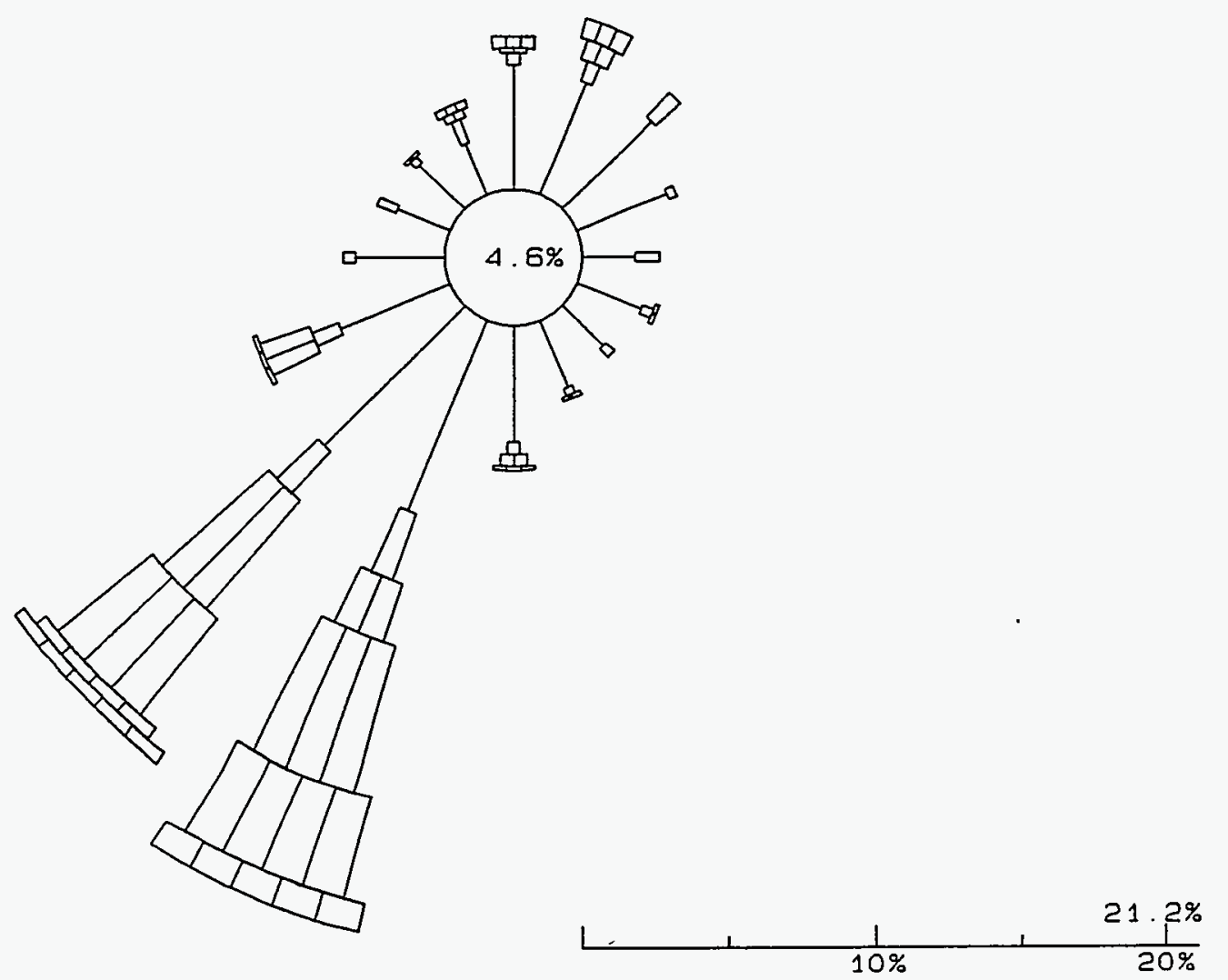

99.7\% DATA RECOVERED

OF WHICH $100.0 \%$ IS REPOATED ABOVE 
SPILL TEST FACILITY 24 METER TOWER
2 METER HEIGHT - Total Hours
$10 / 1 / 1994-10 / 31 / 1994$
$0-2300$

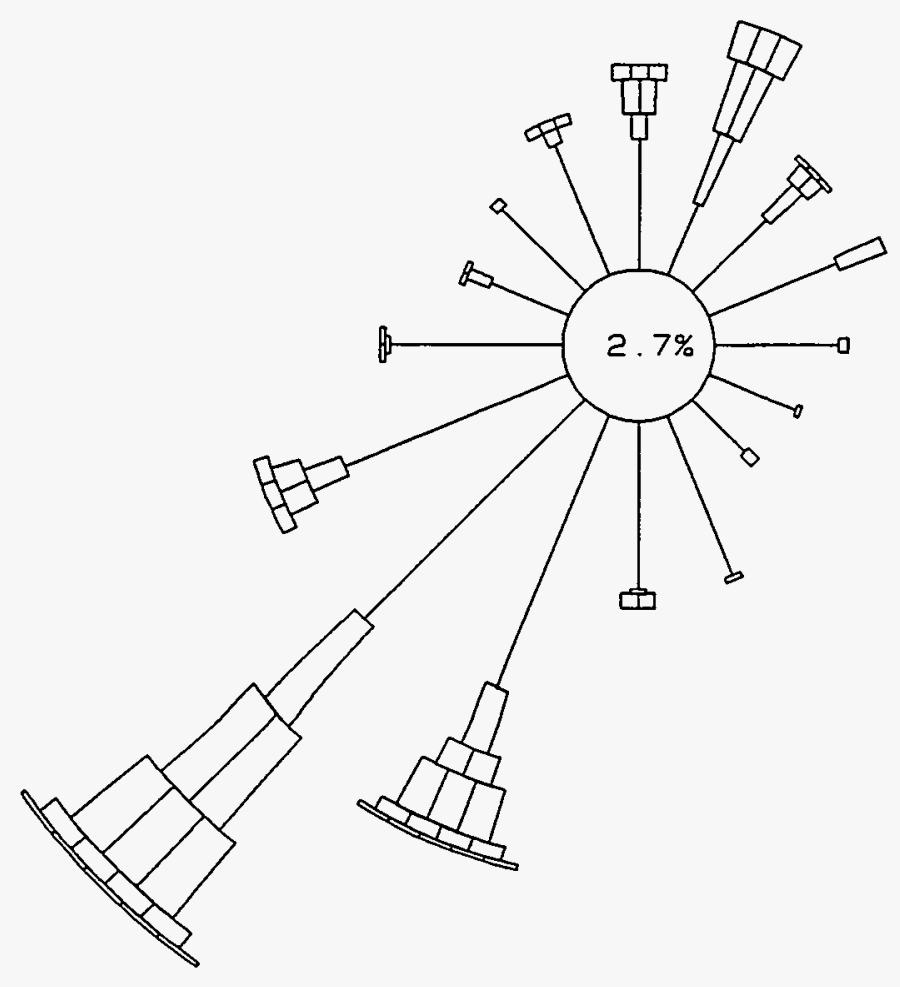

\begin{tabular}{|c|c|c|c|c|}
\hline \multirow{2}{*}{$\begin{array}{l}\text { WINO } \\
\text { CALM }\end{array}$} & SPEED & \multicolumn{3}{|c|}{ CLASSES (MPS) } \\
\hline & 10 & & WS & $<=$ \\
\hline 1 & 1 & $.5<$ & WS & $<=1.8$ \\
\hline 2 & $\square$ & $1.8<$ & WS & $<=3.3$ \\
\hline 3 & ש & $3.3<$ & WS & $<=5.4$ \\
\hline 4 & שם & $5.4<$ & WS & $<=8.5$ \\
\hline 50 & पा1ग & $8.5<$ & WS & $<=10.8$ \\
\hline 65 & IIII & $10.8<$ & WS & \\
\hline
\end{tabular}




\section{SPILL TEST FACILITY 24 METER TOWER \\ 2 METER HEIGHT - Total Hours $11 / 1 / 1994$ - $11 / 30 / 1994$ \\ $0-2300$}

$N$

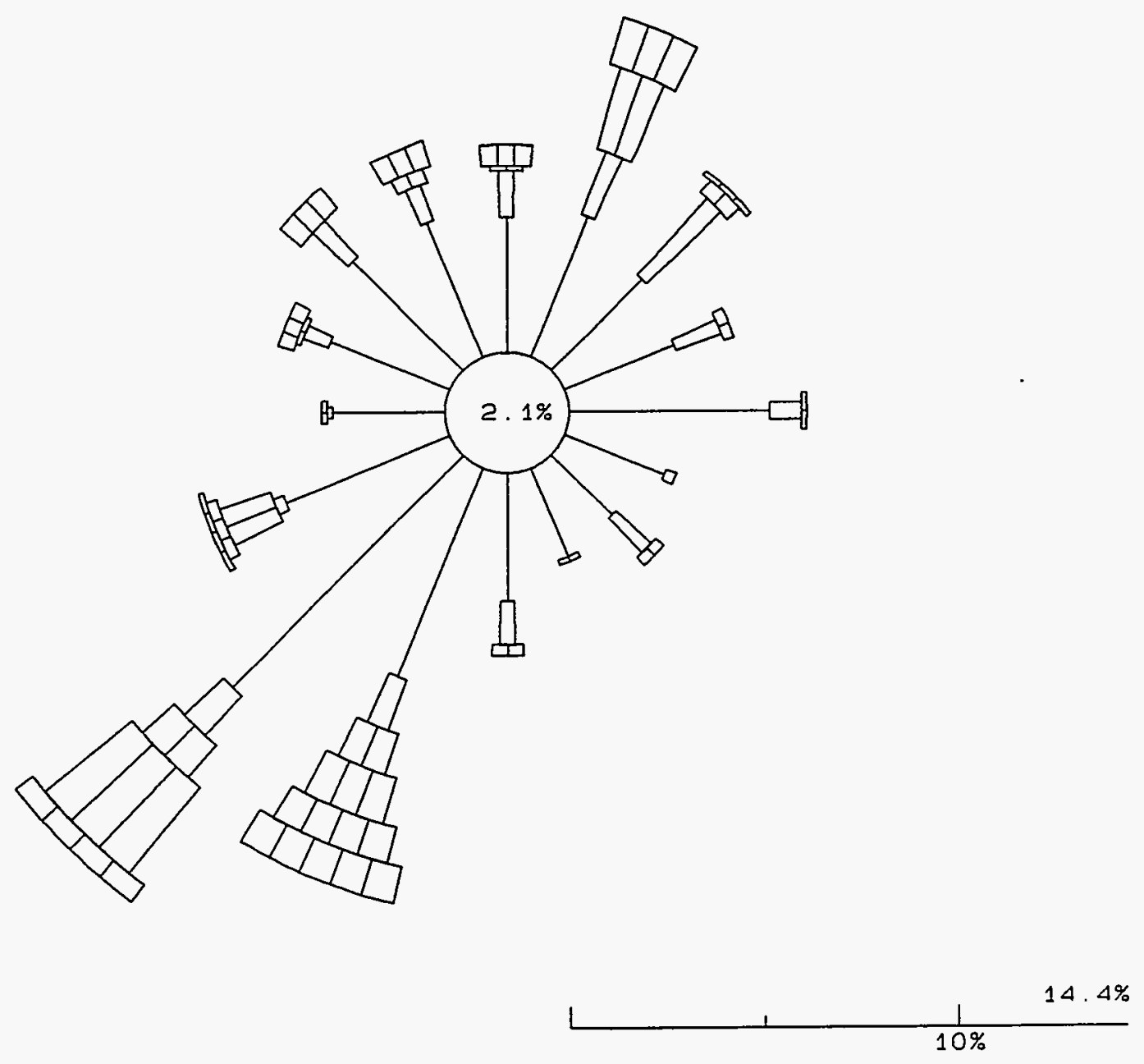

100.0\% DATA RECOVERED

OF WHICH $100.0 \%$ IS

REPORTED ABOVE

$11.5<$ WS $<=1.8$

$2 \square \quad 1.8<$ WS $<=3.3$

3 口 $3.3<$ WS $<=5.4$

4 पा $5.4<$ WS $<=8.5$

5 पाया $8.5<W S<=10.8$

6 10.8< WS 
SPILL TEST FACILITy 24 METER TOWER

2 METER HEIGHT - Tota 1 Hours

$12 / 1 / 1994-12 / 31 / 1994$

$0-2300$

$N$
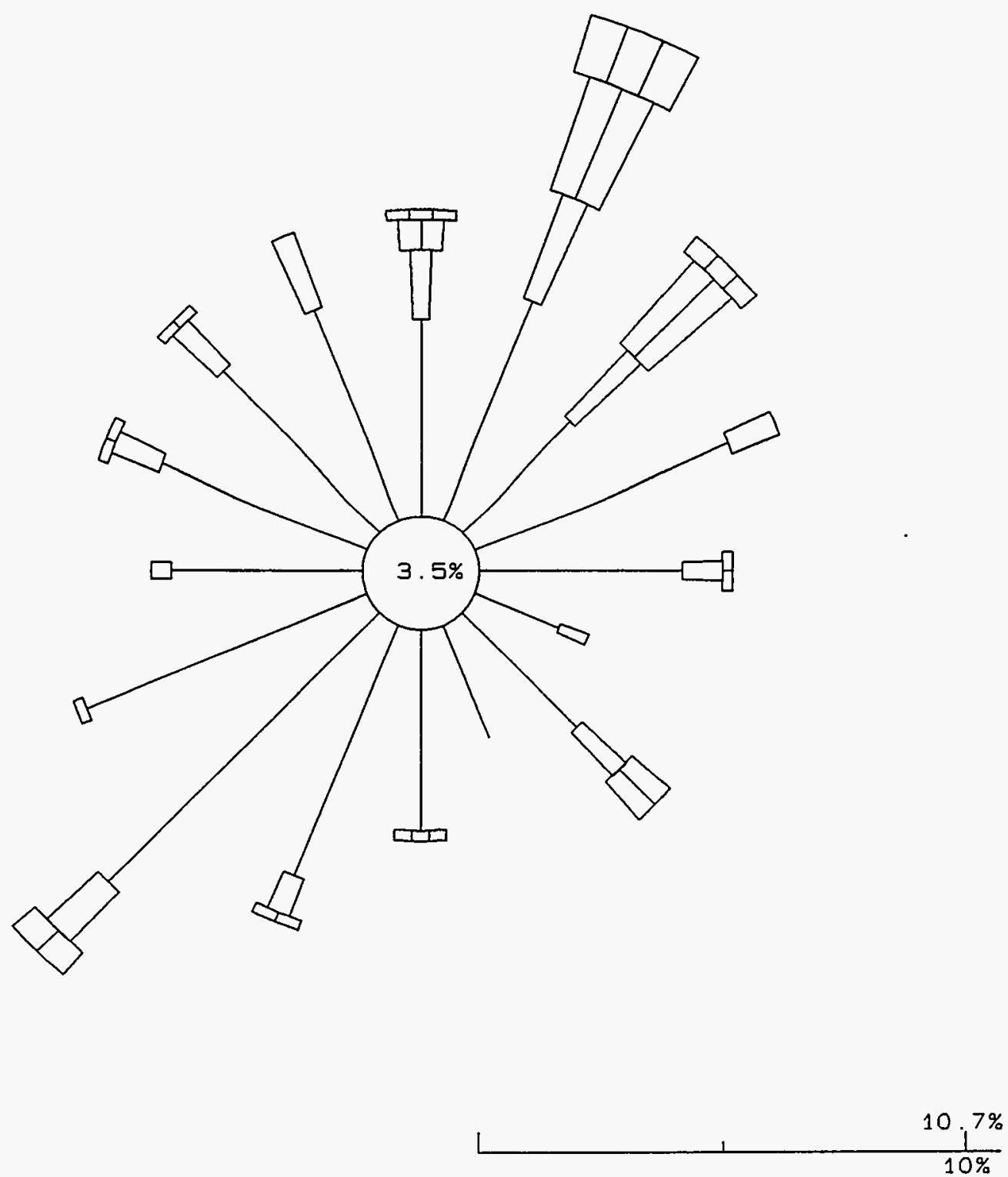

65. $1 \%$ DATA RECOVERED

OF WHICH $100.0 \%$ IS

REPORTED ABOVE 
SPILL TEST FACILITY 24 METER TOWEA

2 METER HEIGHT - Morning Transition

2/ $1 / 1994$ - 2/28/1994

$600-1000$

$N$

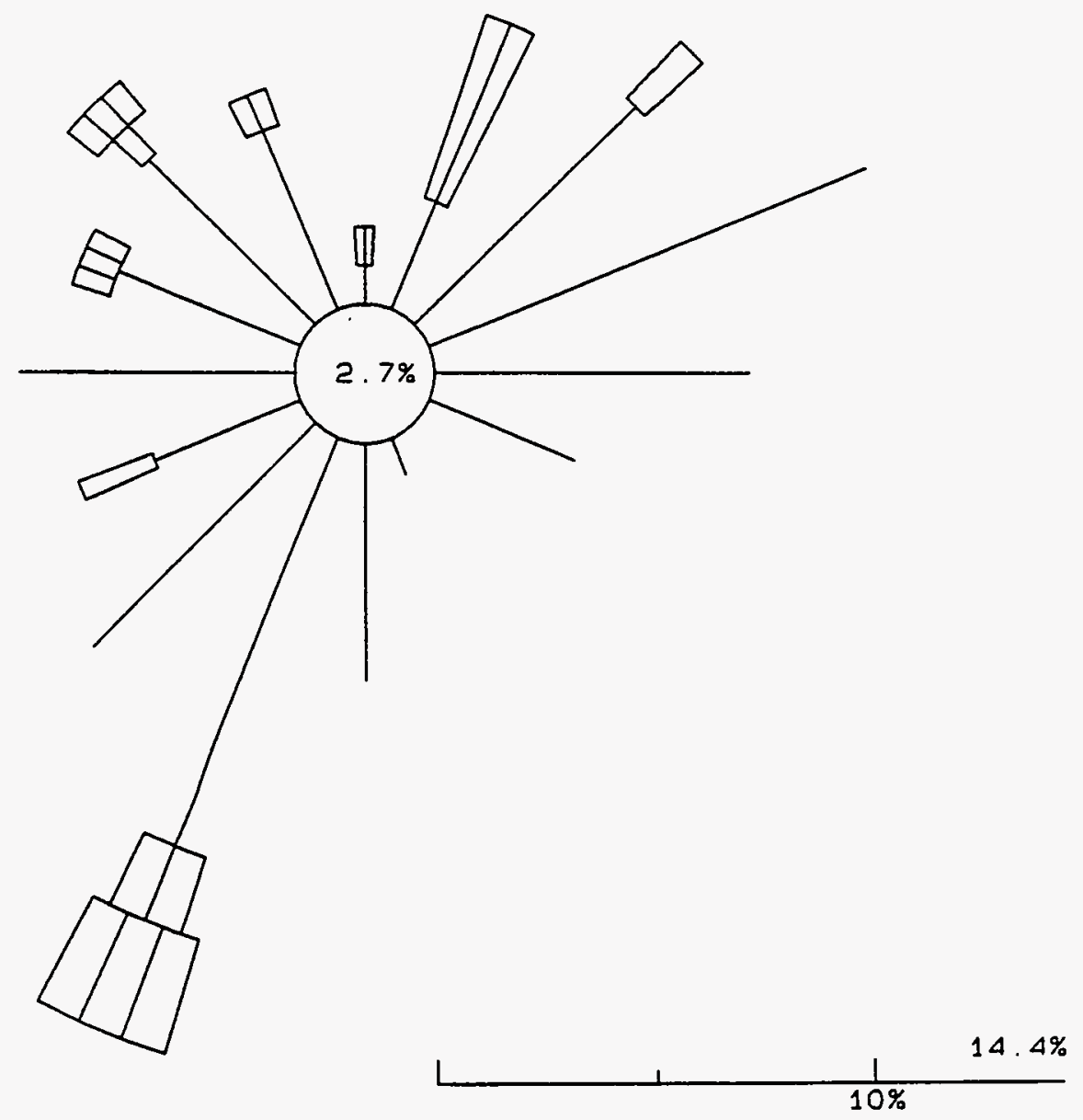

\begin{tabular}{|c|c|c|c|c|c|}
\hline WIND & SP & EED & CL & ASS & ES (MPS) \\
\hline CALM & 10 & & & WS & $<=$ \\
\hline 1 & 1 & & $.5<$ & wS & $<=1.8$ \\
\hline 2 & 口 & 1 & $.8<$ & WS & $<=3.3$ \\
\hline 3 & ه & 3 & $.3<$ & WS & $<=5.4$ \\
\hline 4 & שח & 5 & $.4<$ & WS & $<=8.5$ \\
\hline 5 & صणा & 8 & $.5<$ & WS & $<=10.8$ \\
\hline $6 c$ & هיחם & 10 & $.8<$ & WS & \\
\hline
\end{tabular}

85. $4 \%$ DATA RECOVERED

OF WHICH $19.3 \%$ IS

REPOATED ABOVE 

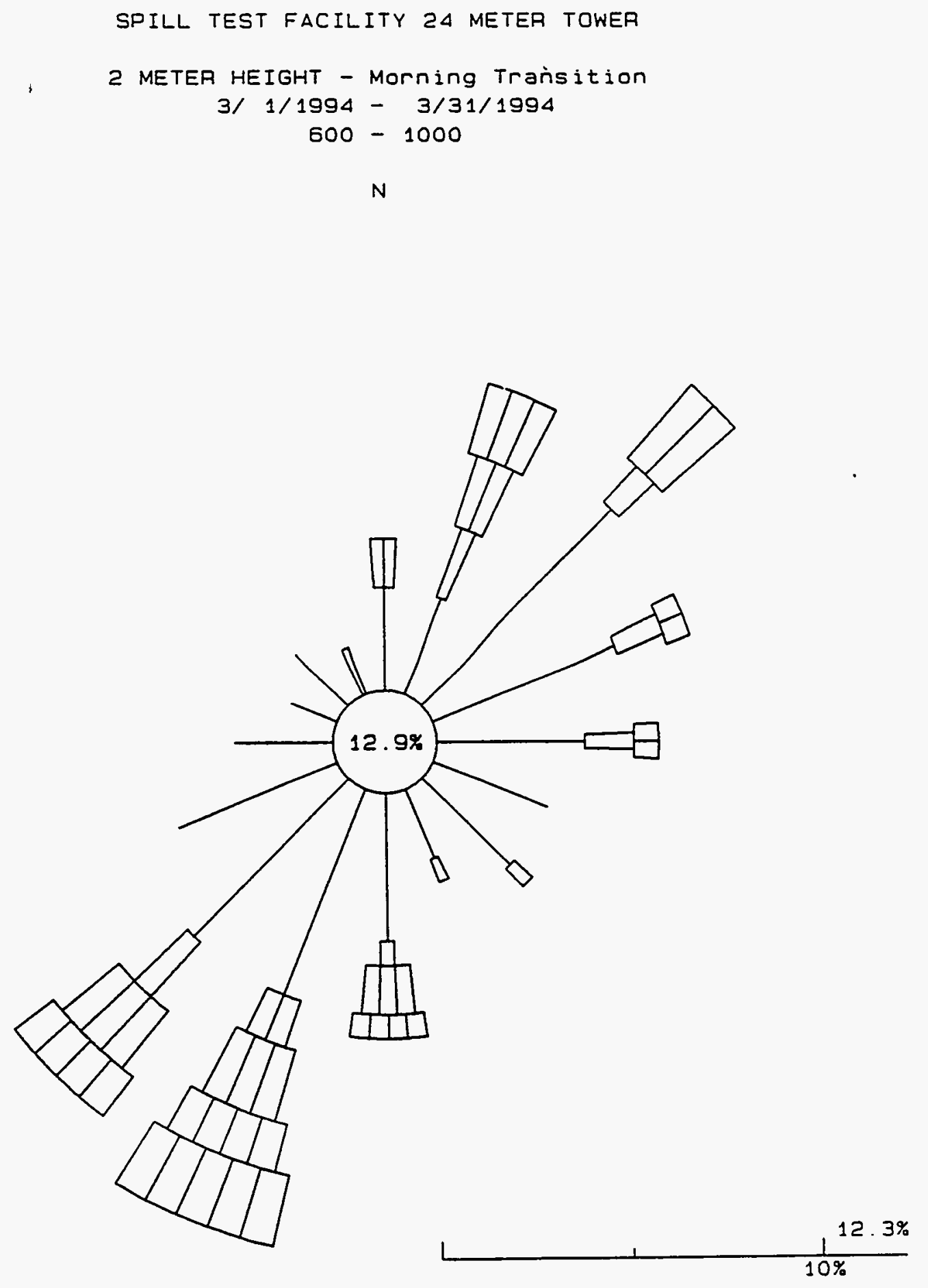

100.0\% DATA RECOVERED OF WHICH $20.8 \%$ IS REPORTED ABOVE 
SPILL TEST FACILITY 24 METER TOWER

2 METER HEIGHT - MOrning Transition

$4 / 1 / 1994-4 / 30 / 1994$

$600-1000$

$N$

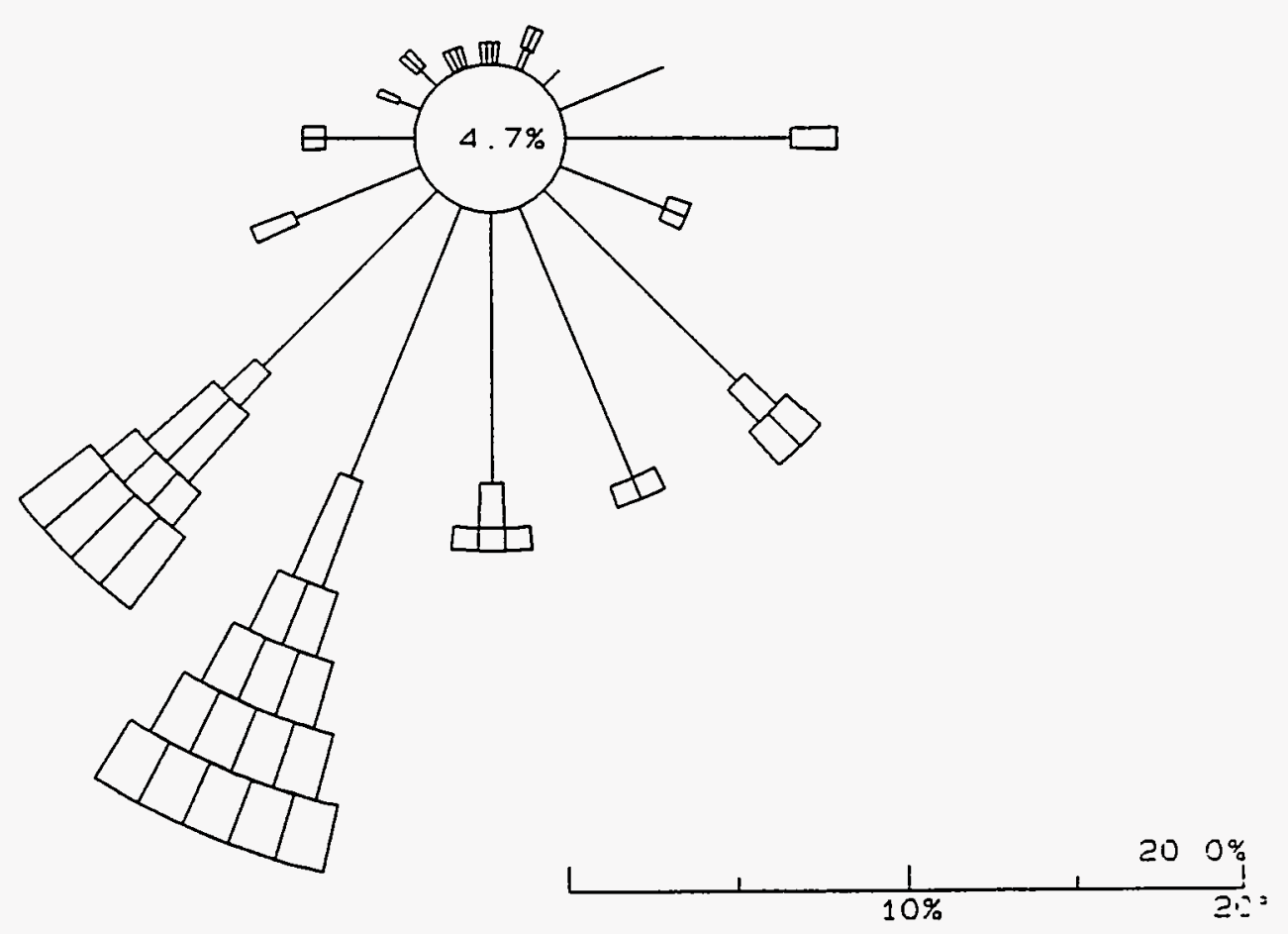

\begin{tabular}{|c|c|c|c|c|c|}
\hline WIND & \multicolumn{2}{|c|}{ SPEED } & \multicolumn{3}{|c|}{ CLASSES (MPS) } \\
\hline CALM & 10 & & & WS & $<=$ \\
\hline 1 & 1 & & $5<$ & WS & $<=1.8$ \\
\hline 2 & $\square$ & 1 & $.8<$ & WS & $<=3.3$ \\
\hline 3 & ש & 3 & $3<$ & WS & $<=5.4$ \\
\hline 4 & שם & 5 & $4<$ & WS & $<=8.5$ \\
\hline 5 & דाम & 8 & $5<$ & WS & $<=10.8$ \\
\hline 60 & पाम & 10 & $8<$ & WS & \\
\hline
\end{tabular}

99. 4\% DATA RECOVERED

OF WHICH $20.9 \%$ IS

REPOATED ABOVE

\section{B- 16}




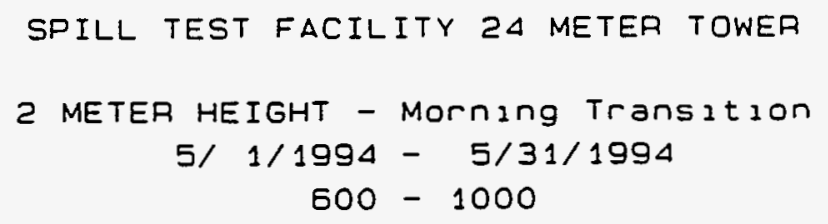

N

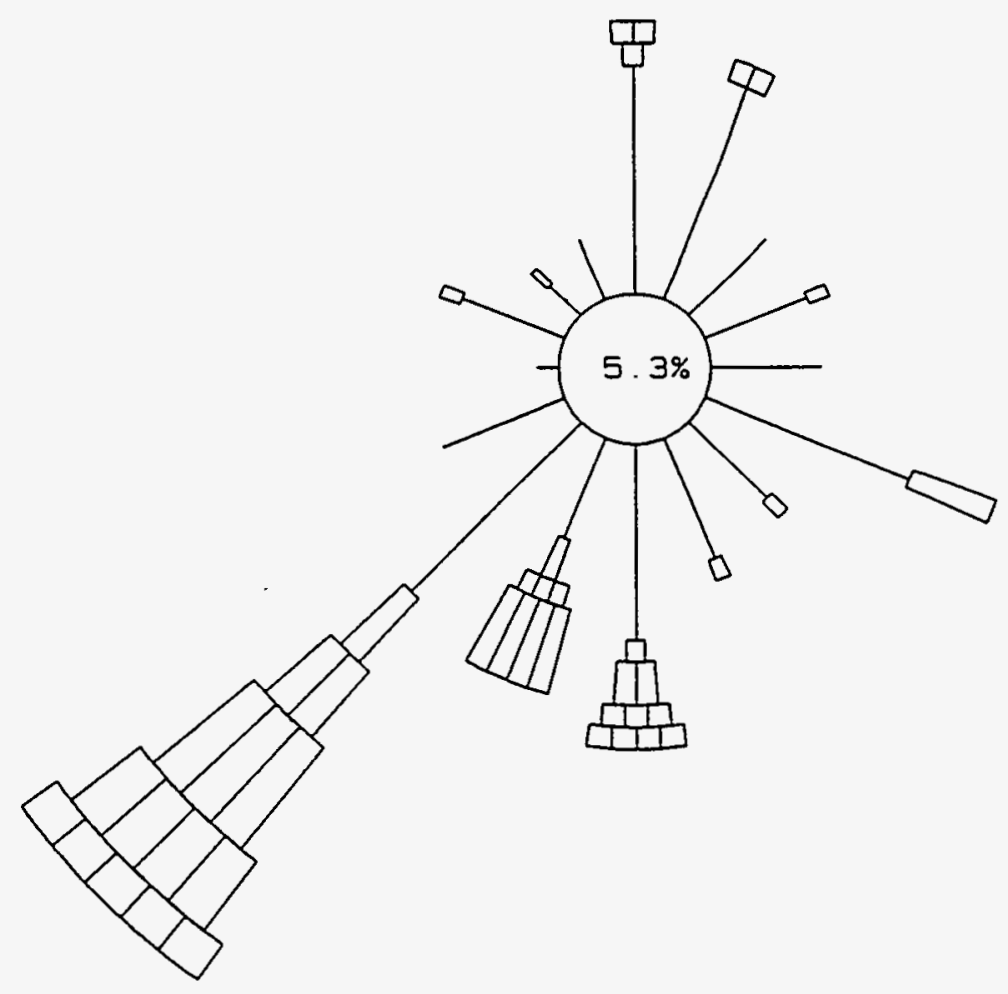

\begin{tabular}{|c|c|c|c|c|c|c|c|}
\hline WIND & SPE & ED & CL & $\Delta S S$ & $S I M$ & APS & \\
\hline CALM & 10 & & & WS & $<=$ & & 5 \\
\hline 1 & 1 & & $5<$ & WS & $<=$ & 1 & 8 \\
\hline 2 & D & 1 & $8<$ & WS & $<=$ & 3. & 3 \\
\hline 3 & س & 3 & $3<$ & WS & $<=$ & & 4 \\
\hline 4 & סד & 5 & $\Delta<$ & WS & $<=$ & 8 & 5 \\
\hline 5 & שा & 8 & $.5<$ & WS & $<=1$ & & 8 \\
\hline 6 & דחים & 10 & $.8<$ & WS & & & \\
\hline
\end{tabular}

96.9\% DATA AECOVERED

OF WHICH $20.8 \%$ IS

REPORTED ABOVE 


\section{SPILL TEST FACILITY $2 \triangle$ METER TOWEA \\ 2 METER HEIGHT - Morning Transition \\ 6/ $1 / 1994-6 / 30 / 1994$ \\ $600-1000$}

$N$

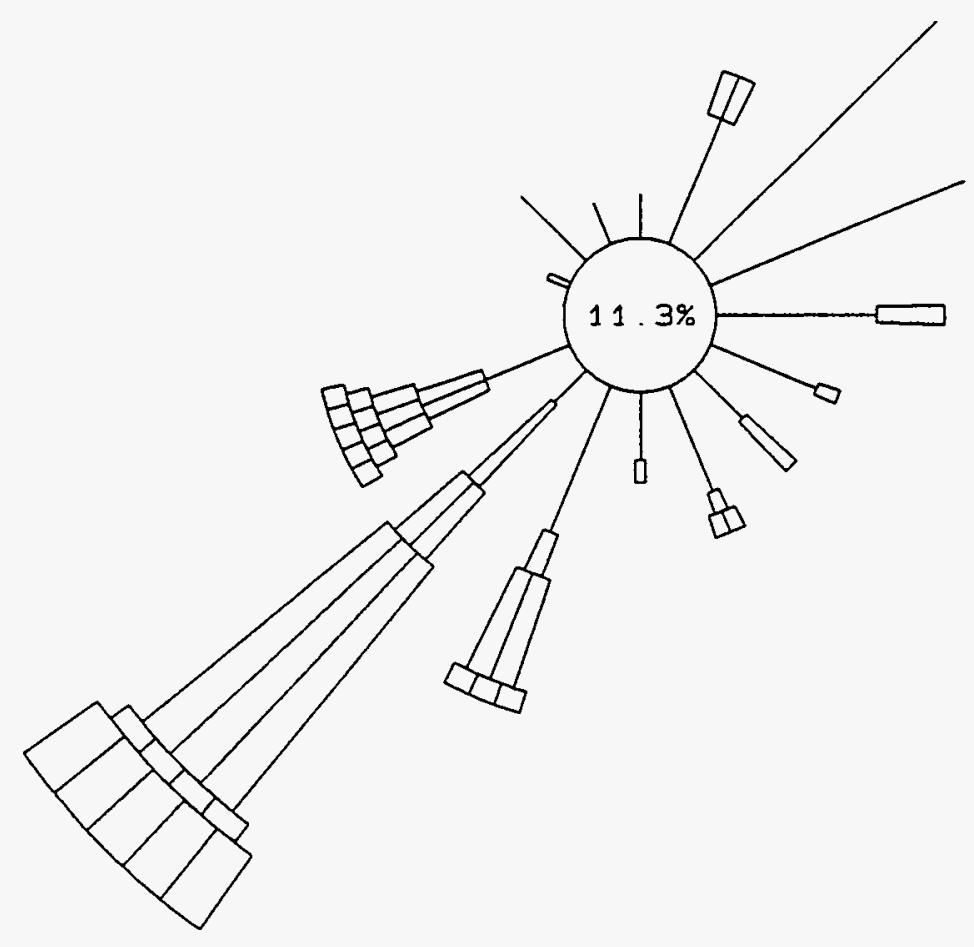

\begin{tabular}{|c|c|c|c|c|c|}
\hline WIND & $S P E$ & ED & $C L$ & $A S S$ & $S$ (MPS) \\
\hline CALM & 10 & & & WS & $<=$ \\
\hline 1 & 1 & & $5<$ & WS & $<=1.8$ \\
\hline 2 & $\square$ & 1 & $8<$ & WS & $c=3.3$ \\
\hline 3 & ש & 3 & $3<$ & WS & $<=5.4$ \\
\hline$\Delta$ & שा & 5 & $\Delta<$ & WS & $<=8.5$ \\
\hline 5 & דוד & 8 & $5<$ & WS & $<=10.8$ \\
\hline 65 & סחדבי & 10 & $8<$ & WS & \\
\hline
\end{tabular}

100.0\% DATA RECOVERED

OF WHICH 20.8\% IS

REPORTED ABOVE 


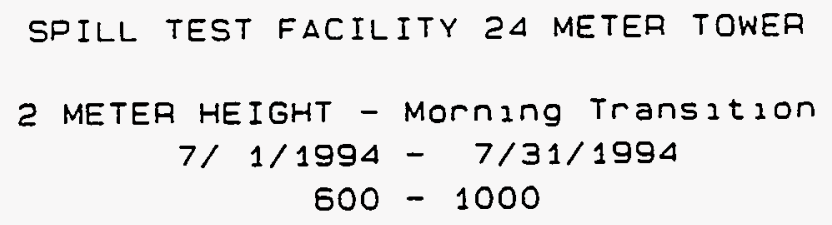

$N$

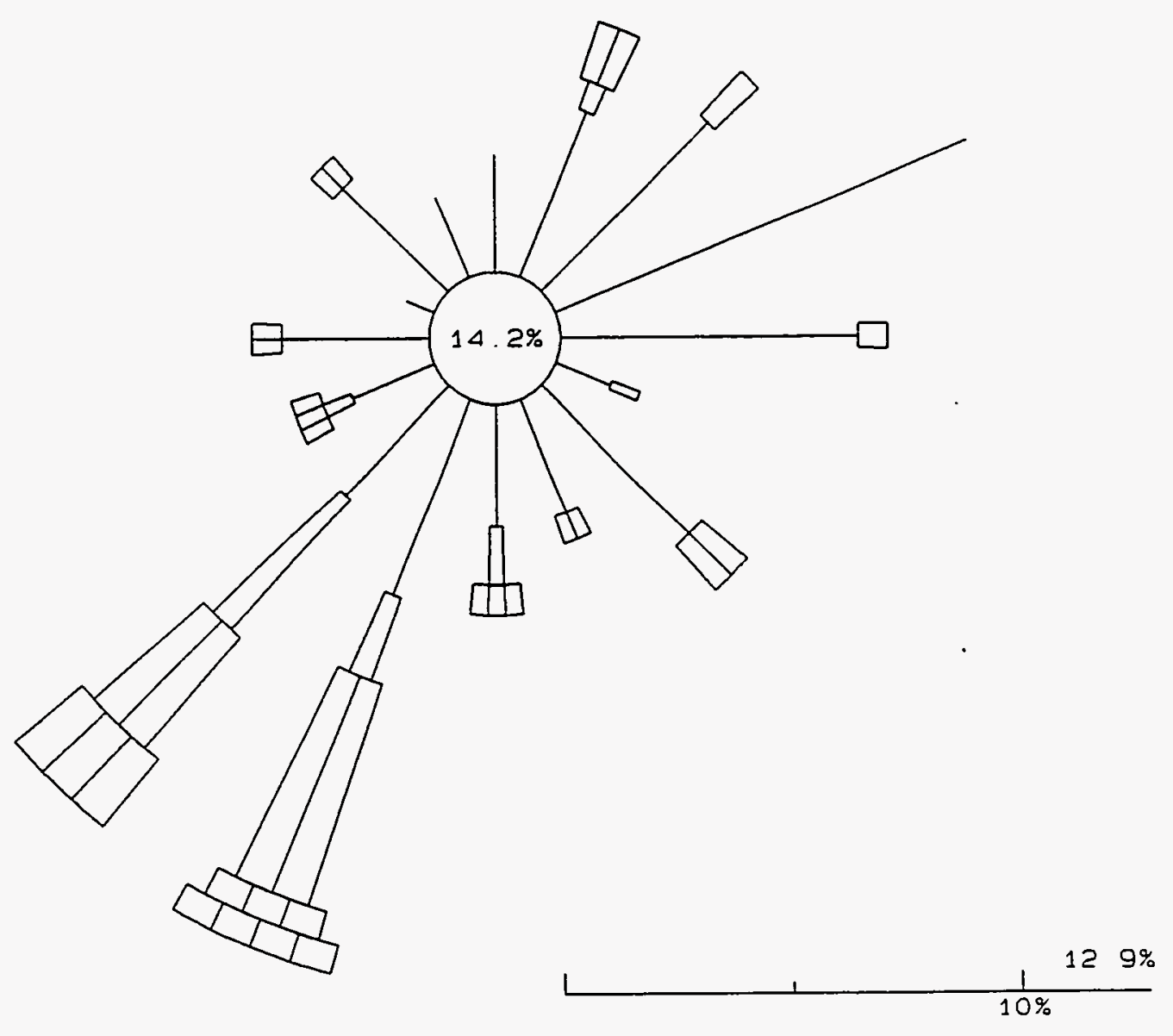

WIND SPEED CLASSES (MPS) CALM O

11

$20 \quad 1,8<$ WS $<=33$

$3 \square 3.3<$ WS $<=54$

4 대 $5.4<$ WS $<=8.5$

5 매 $8.5<$ WS $<=10.8$

6 10. $8<$ WS
100.0\% DATA RECOVERED

OF WHICH $20.8 \%$ IS

REPORTED ABOVE 


\section{SPILL TEST FACILITY $2 \triangle$ METER TOWER}

12 METER HEIGHT - Morning Transition

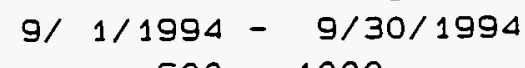

$600-1000$

$N$

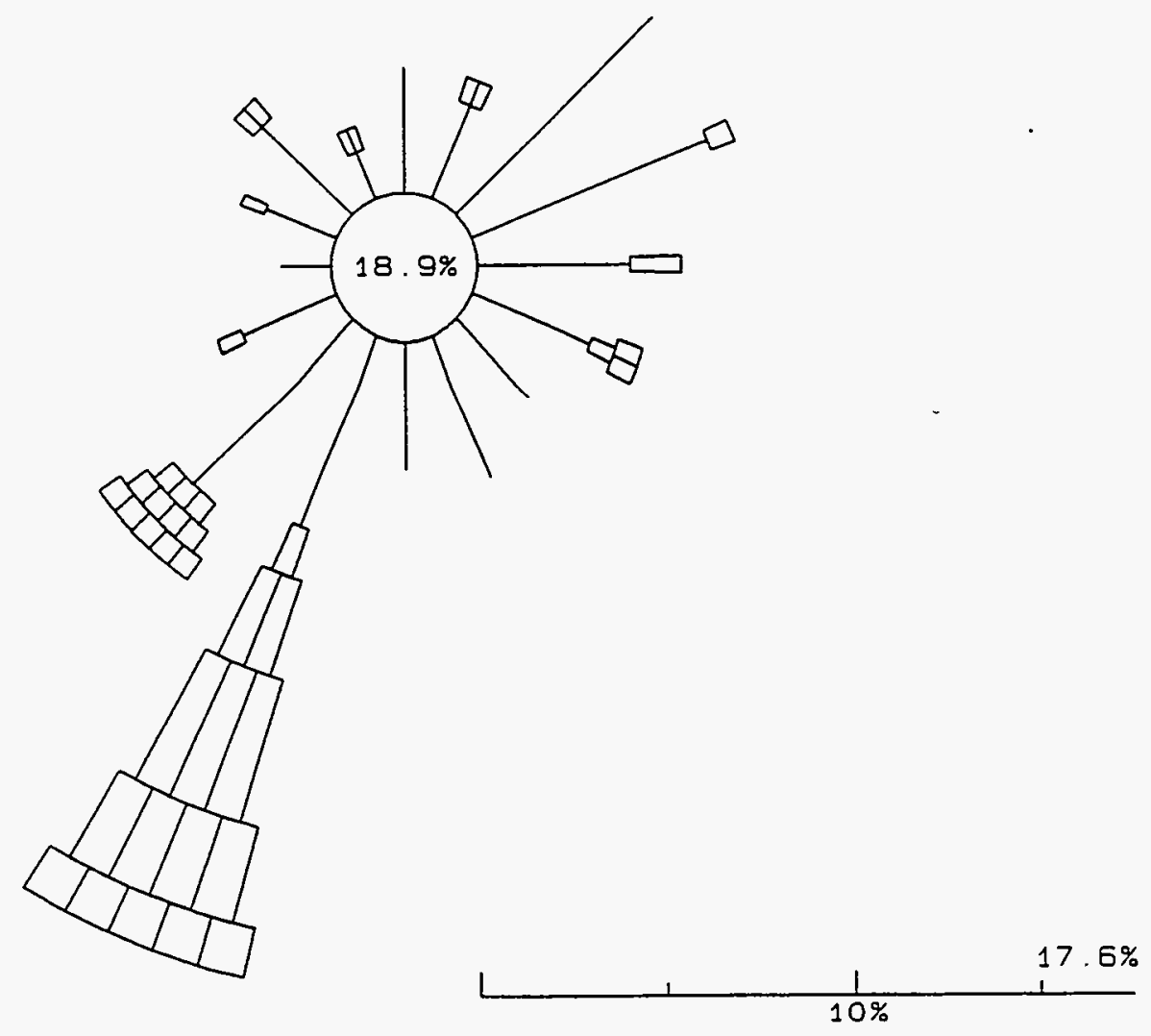

$99.7 \%$ DATA RECOVERED

OF WHICH $20.6 \%$ IS REPORTED ABOVE 

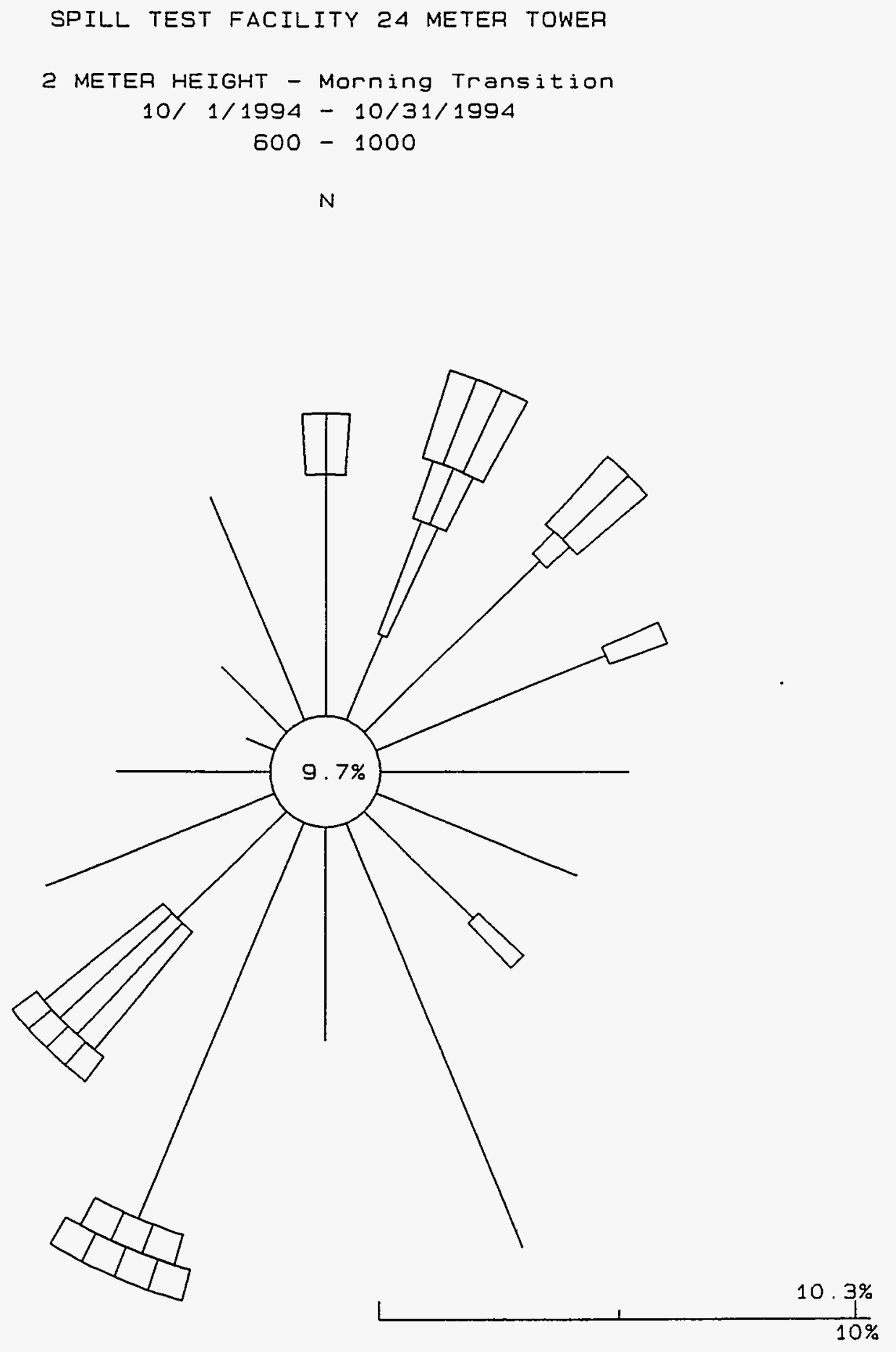

WIND SPEED CLASSES (MPS)

$$
\begin{aligned}
& \text { CALM O WS }<=.5 \\
& 11.5<W S<=1.8 \\
& 2 \square \quad 1.8<W S<=3.3 \\
& 3 \text { पा } 3.3<\text { WS }<=5.4 \\
& 4 \text { पा } 5.4<\text { WS }<=8.5 \\
& 5 \text { 패 } 8.5<\text { WS }<=10.8 \\
& 6 \text { पाया } 10.8<\text { WS }
\end{aligned}
$$

$100.0 \%$ DATA RECOVERED

OF WHICH 20.8\% IS REPORTED ABOVE 

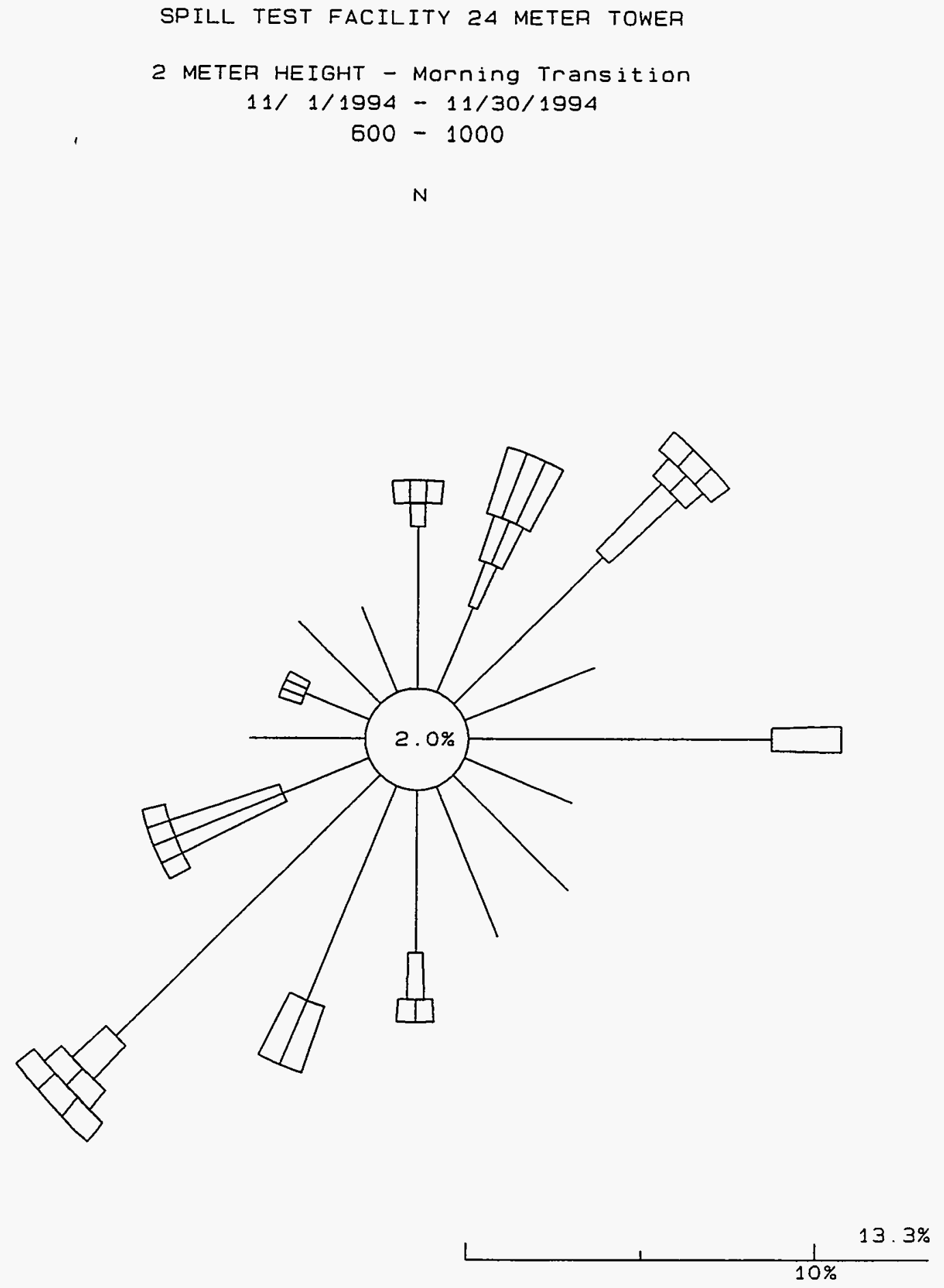

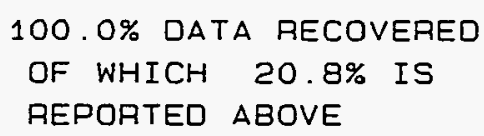




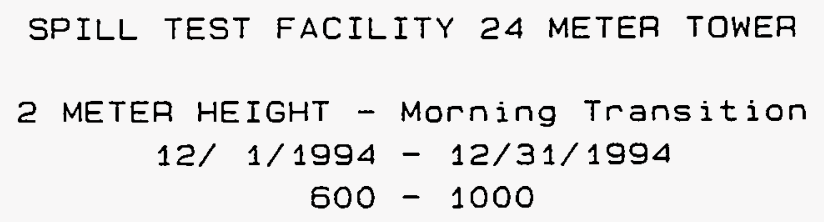

$N$
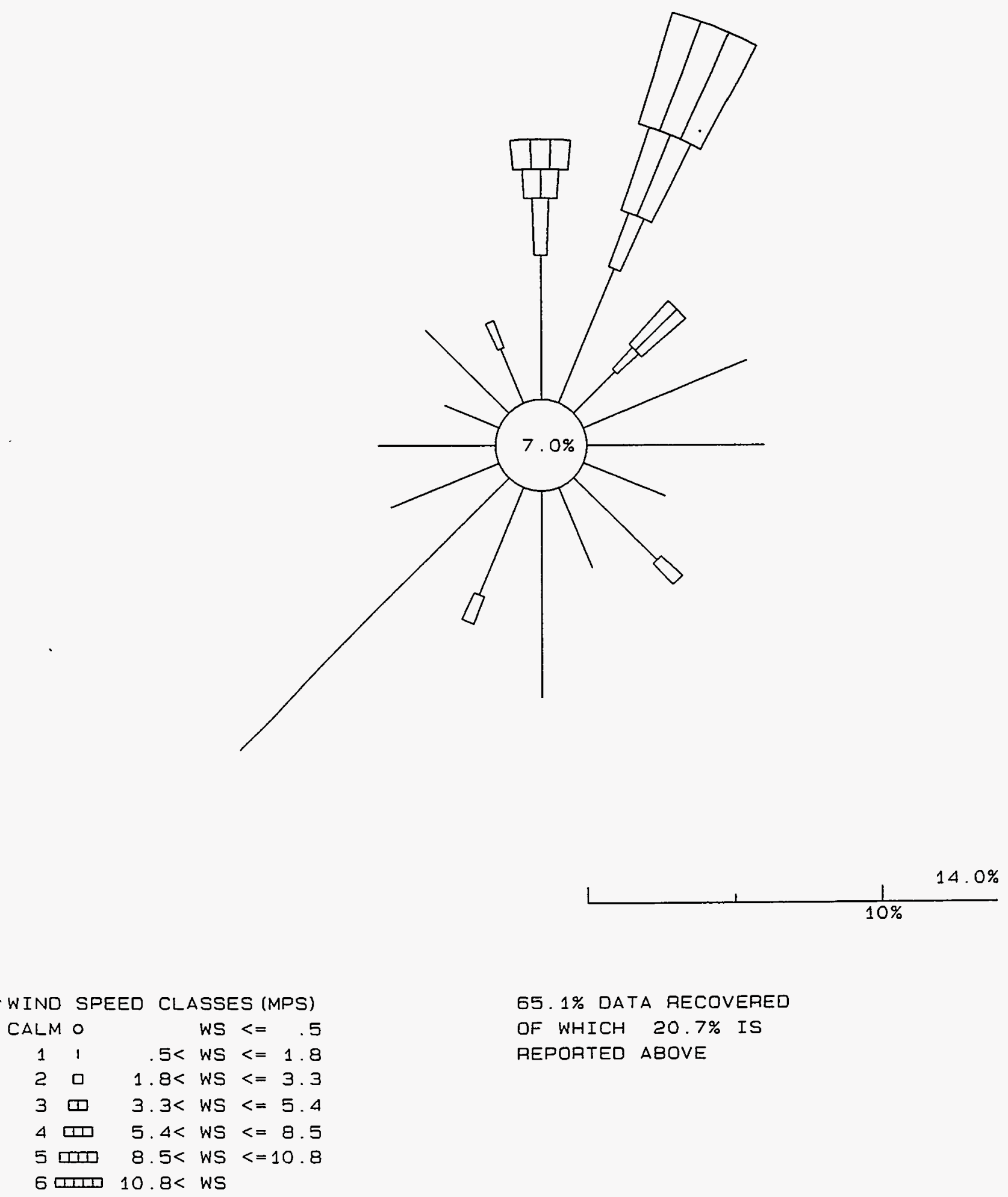


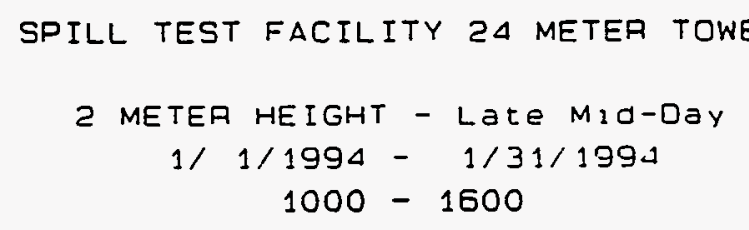

$N$
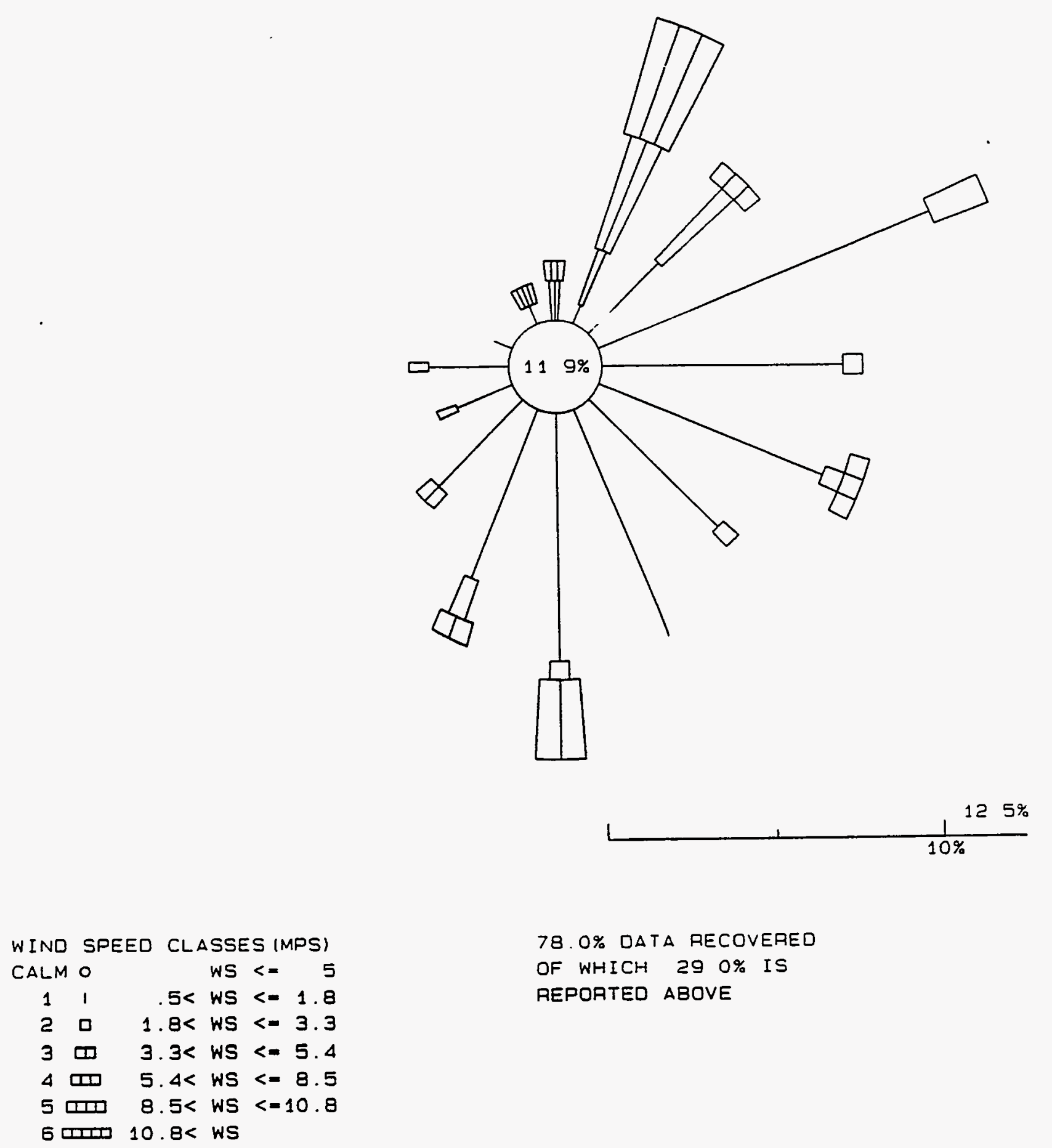

78. O\% DATA RECOVERED

OF WHICH 29 O\% IS

REPORTED ABOVE 
SPILL TEST FACILITY 24 METER TOWEA

2 METER HEIGHT - Late Mid-Day

2/ $1 / 1994-2 / 28 / 1994$

$1000-1600$

$N$
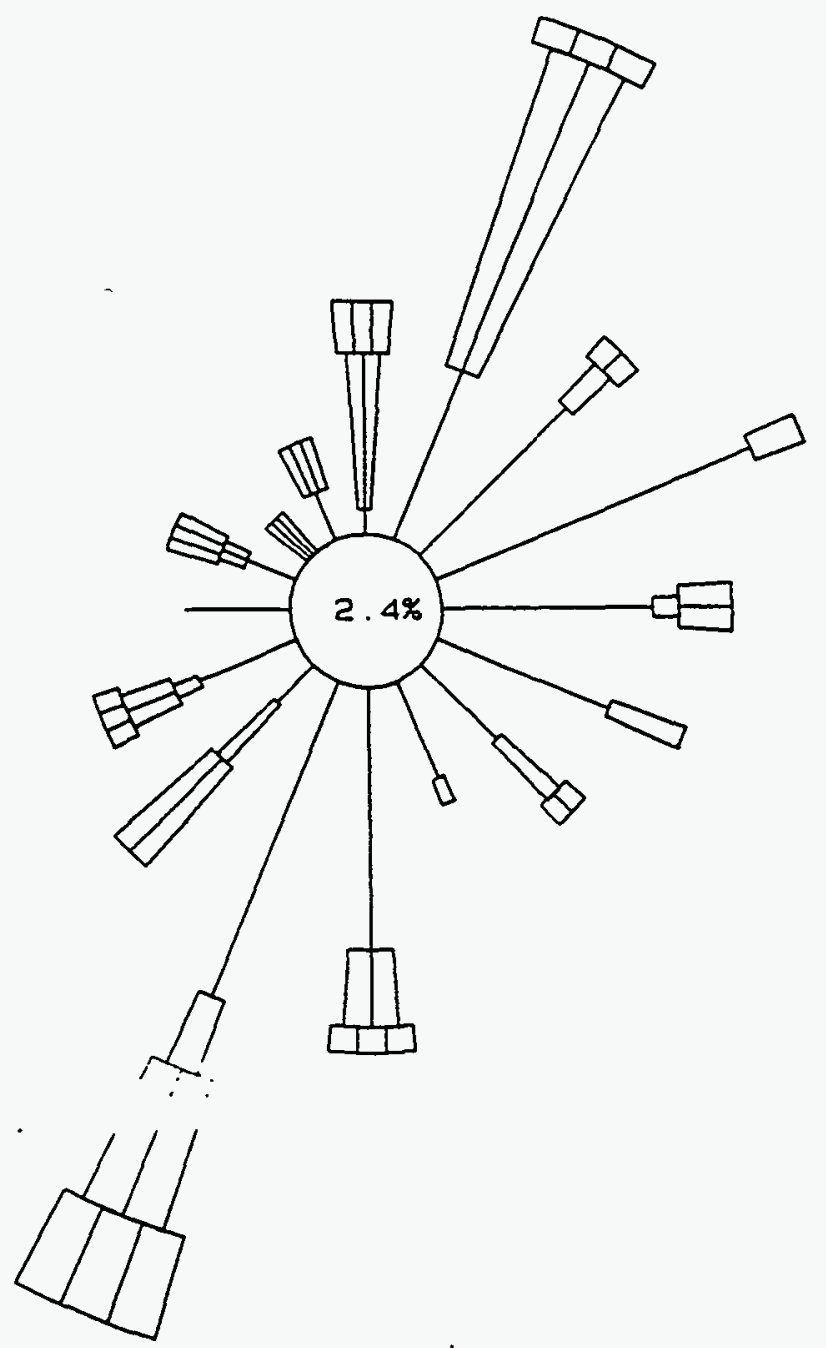

$15.6 \%$
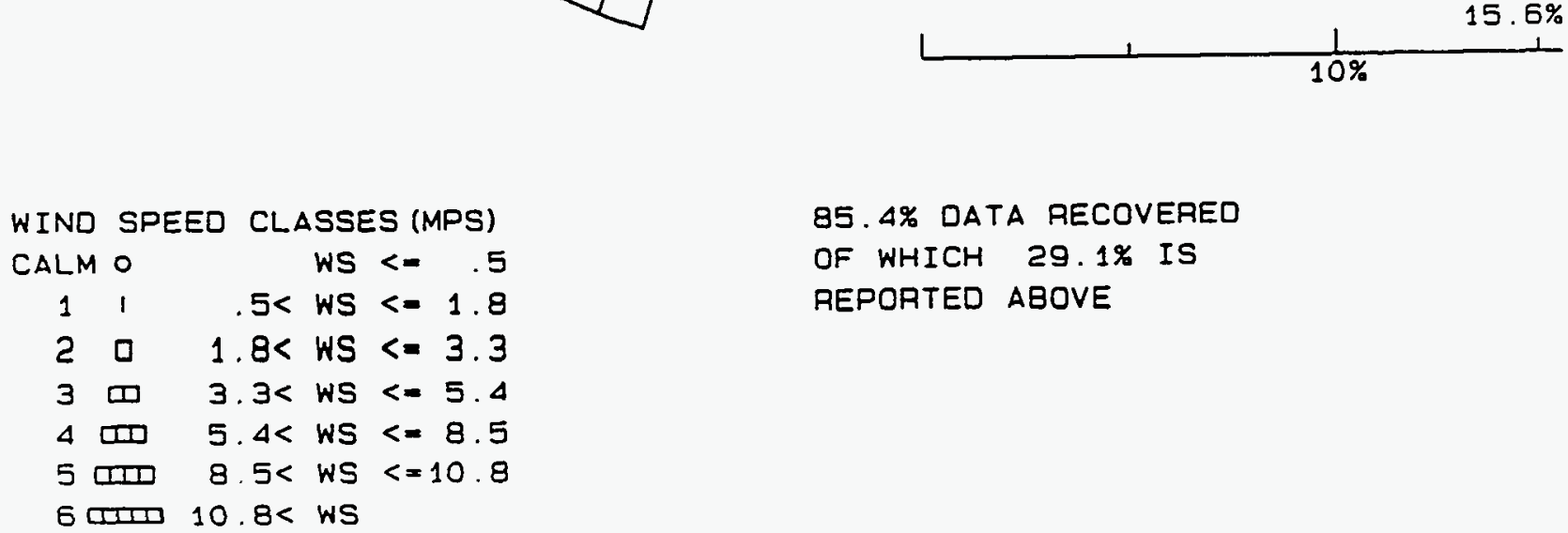

85. $4 \%$ DATA RECOVERED

OF WHICH 29.1\% IS

REPORTED ABOVE 
SPILL TEST FACILITY 24 METER TOWER

2 METER HEIGHT - Late Mid-Day

3/ $1 / 1994-3 / 31 / 1994$

$1000-1600$

$N$
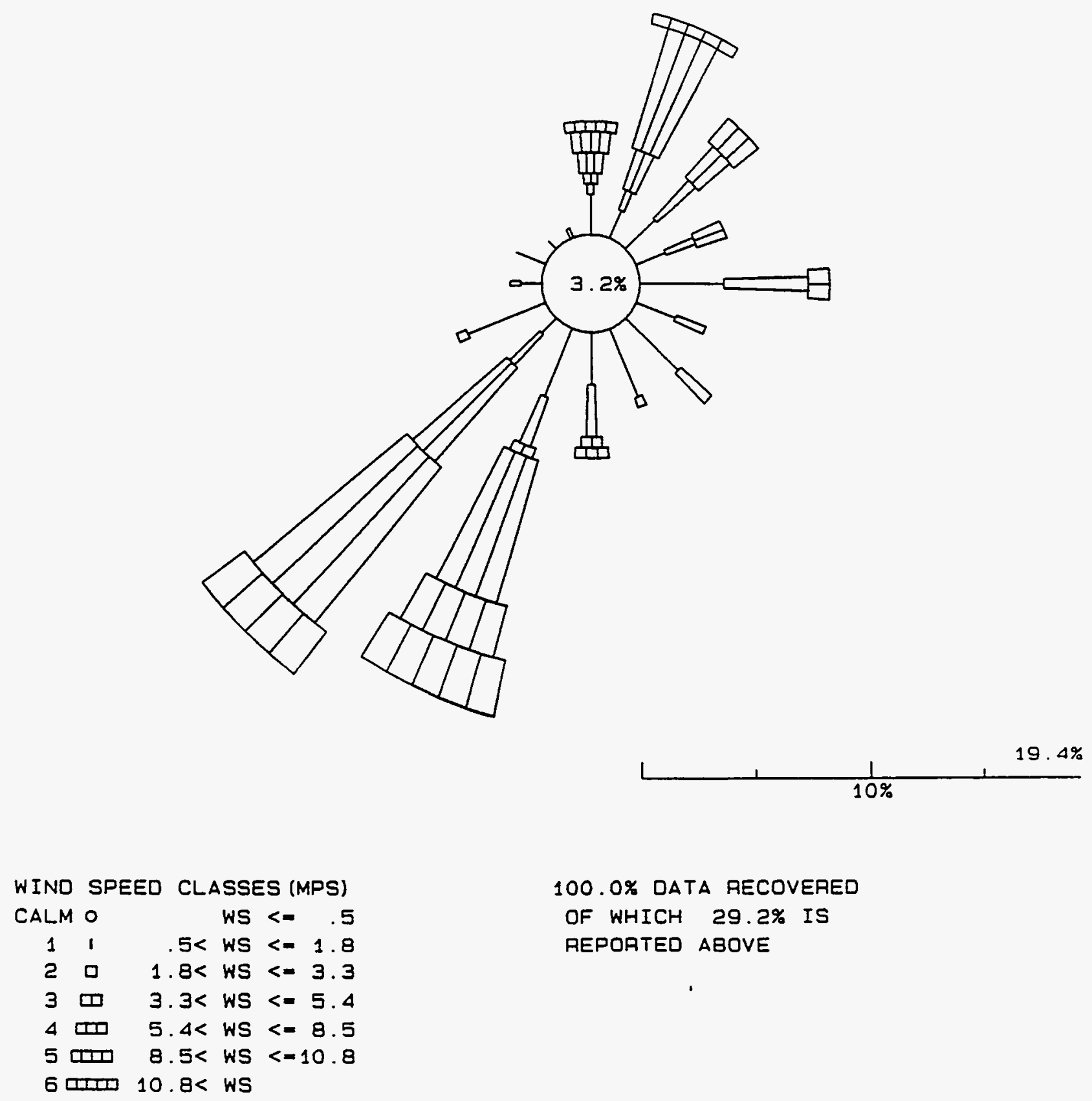

100. O\% DATA RECOVERED

OF WHICH $29.2 \%$ IS

REPORTED ABOVE 


\section{SPILL TEST FACILITY 24 METER TOWER

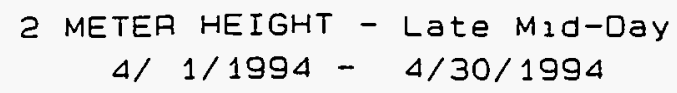

$N$
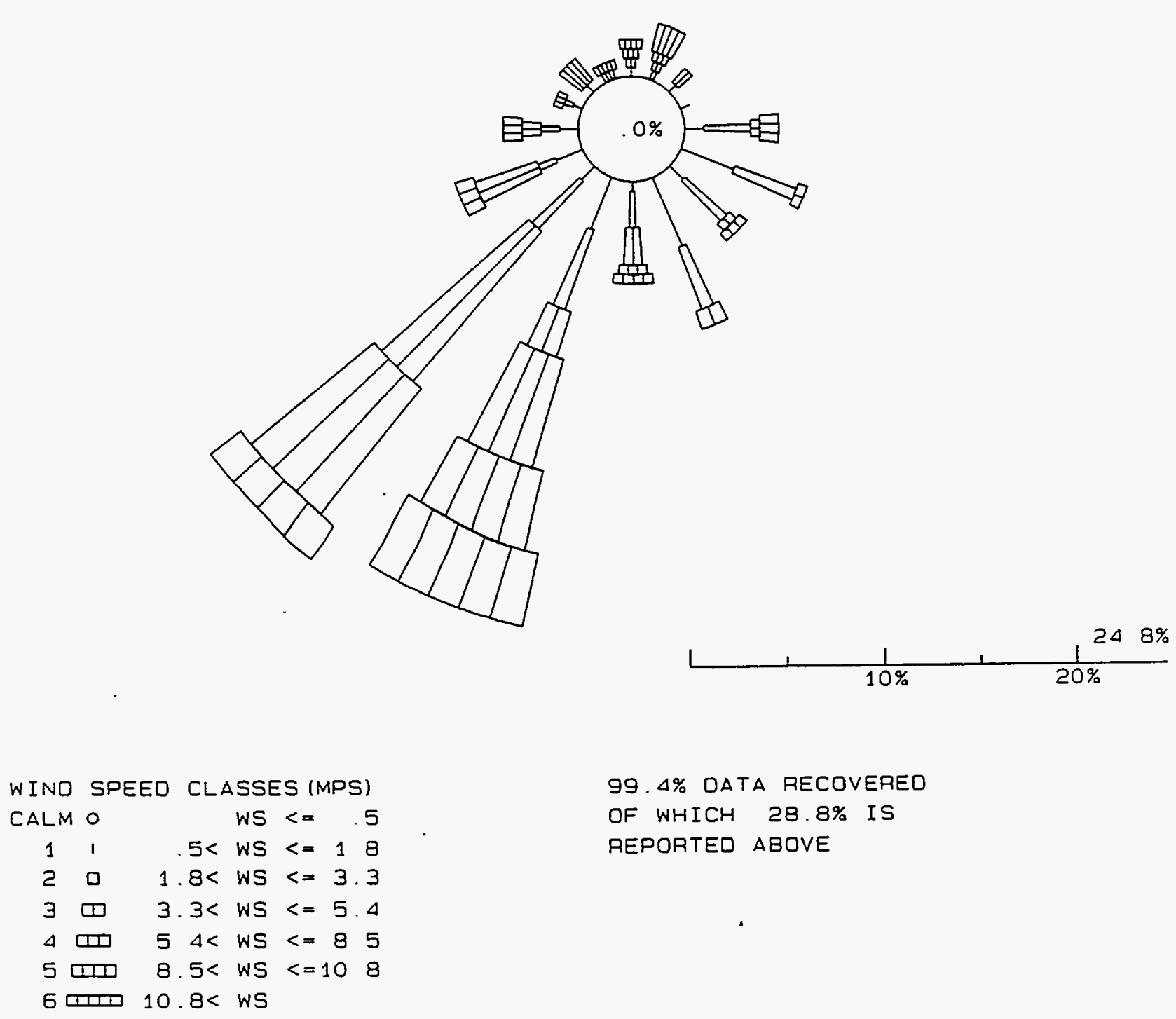

99. 4\% DATA RECOVERED

OF WHICH 28.8\% IS

REPORTED ABOVE 


\section{SPILL TEST FACILITY $2 \triangle$ METER TOWER \\ 2 METER HEIGHT - Late M 20 -Day \\ $5 / 1 / 1994-5 / 31 / 1994$ \\ $1000-1600$}

N
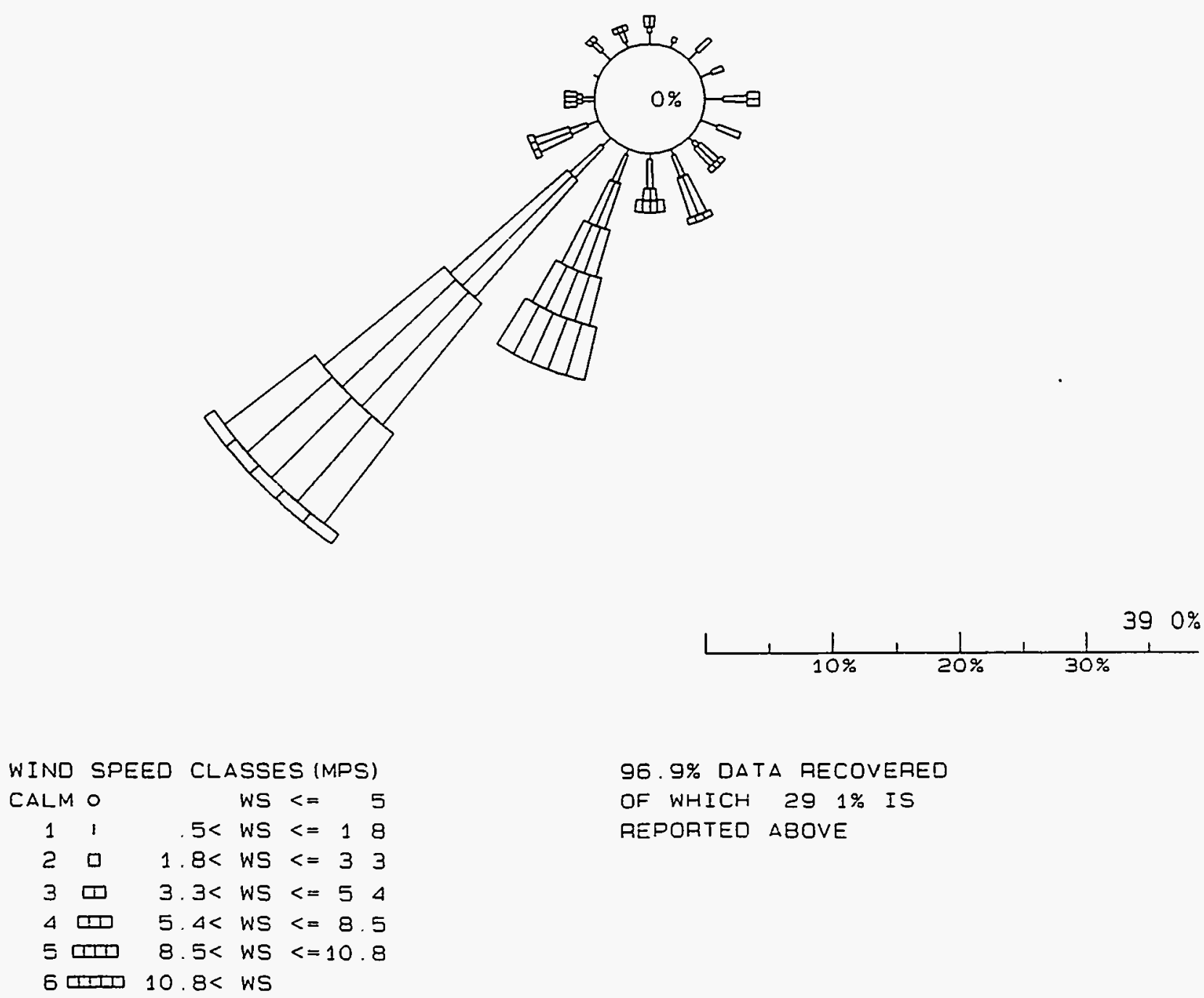

96.9\% DATA RECOVERED

OF WHICH $291 \%$ IS

REPORTED ABOVE 


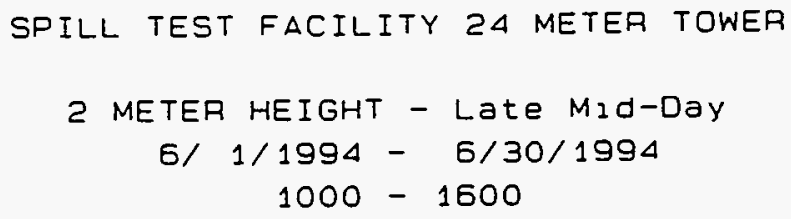

$N$

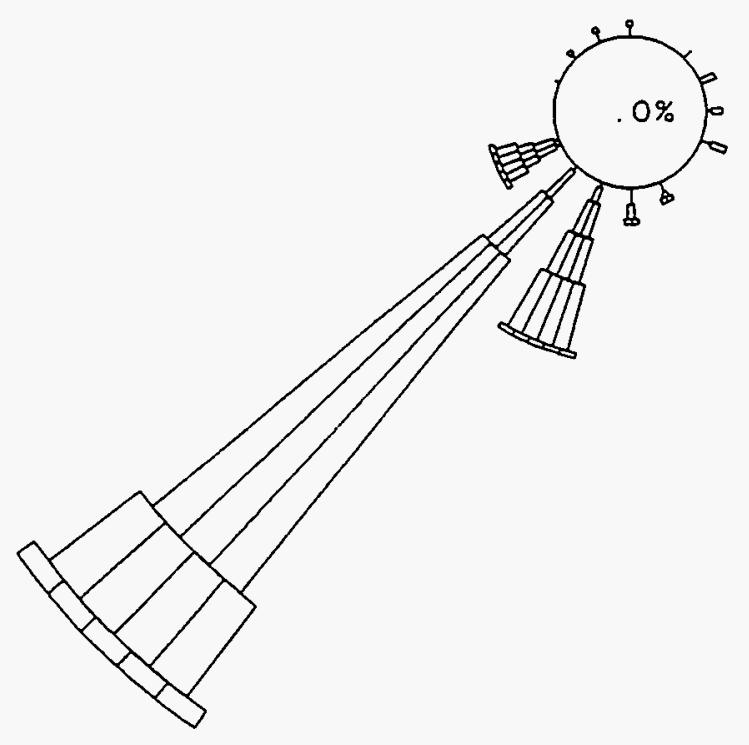

\begin{tabular}{|c|c|c|c|c|c|c|}
\hline WIND & SPE & $E D$ & $\mathrm{CL}$ & $\Delta S S$ & $E S$ (MPS) & \\
\hline CALM & 10 & & & WS & $<=$ & 5 \\
\hline 1 & 1 & & $.5<$ & WS & $<=1.8$ & 8 \\
\hline 2 & 0 & 1 & $.8<$ & WS & $<=3$. & 3 \\
\hline 3 & ש & 3 & $.3<$ & WS & $<=5$ & 4 \\
\hline 4 & पात्र & 5 & $\Delta<$ & WS & $<=8$ & 5 \\
\hline 5 & पाI & 8 & $.5<$ & WS & $<=10$. & 8 \\
\hline 6 & טעتص & 10 & $.8<$ & WS & & \\
\hline
\end{tabular}

100.0\% DATA RECOVERED

OF WHICH $29.2 \%$ IS

REPORTED ABOVE 


\section{SPILL TEST FACILITY $2 \triangle$ METER TOWER \\ 2 METER HEIGHT - Late MId-Day \\ 7/ $1 / 1994-7 / 31 / 1994$ \\ $1000-1600$}

$N$
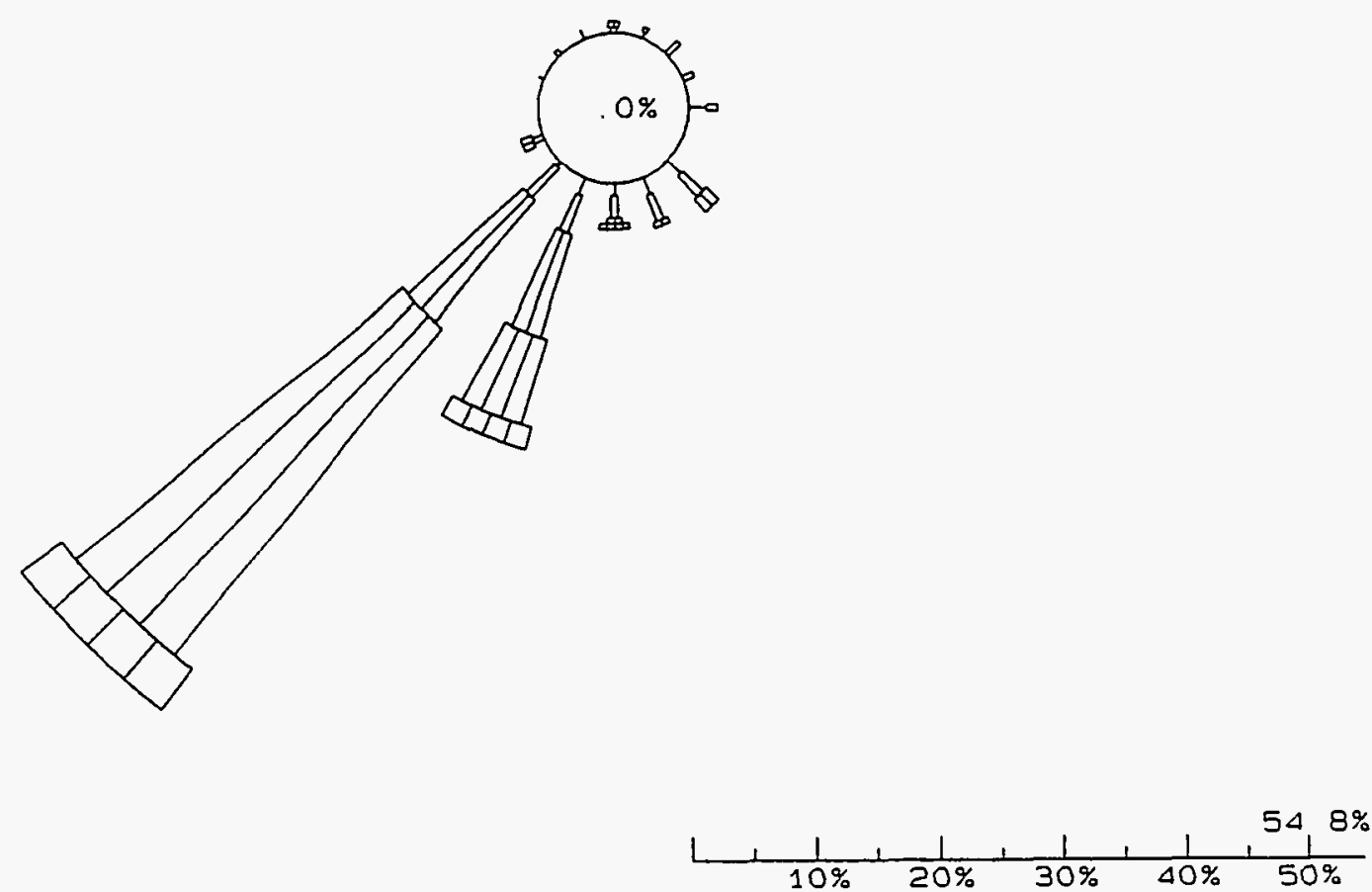

100 O\% DATA RECOVERED

OF WHICH $29.2 \%$ IS

REPORTED ABOVE 


\section{SPILL TEST FACILITY 24 METER TOWER \\ 2 METER HEIGHT - Late MId-Day \\ $8 / 1 / 1994-8 / 31 / 1994$ \\ $1000-1500$}

$N$
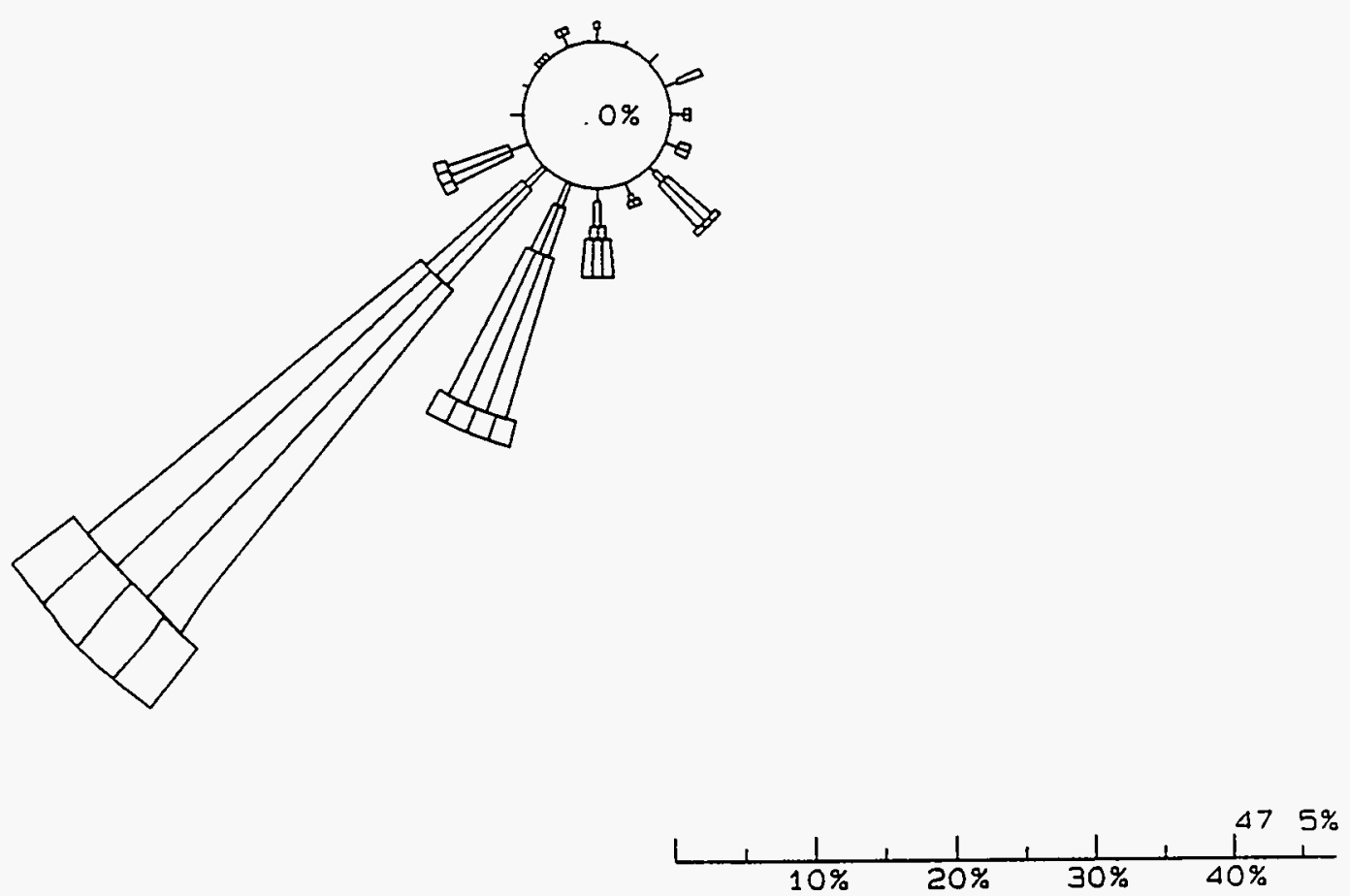

100 O\% DATA RECOVERED

OF WHICH $29.2 \%$ IS

REPORTED ABOVE 


\section{SPILL TEST FACILITY $2 \triangle$ METER TOWER \\ 2 METER HEIGHT - Late MJd-Day \\ 9/ $1 / 1994-9 / 30 / 1994$ \\ $1000-1600$}

$N$

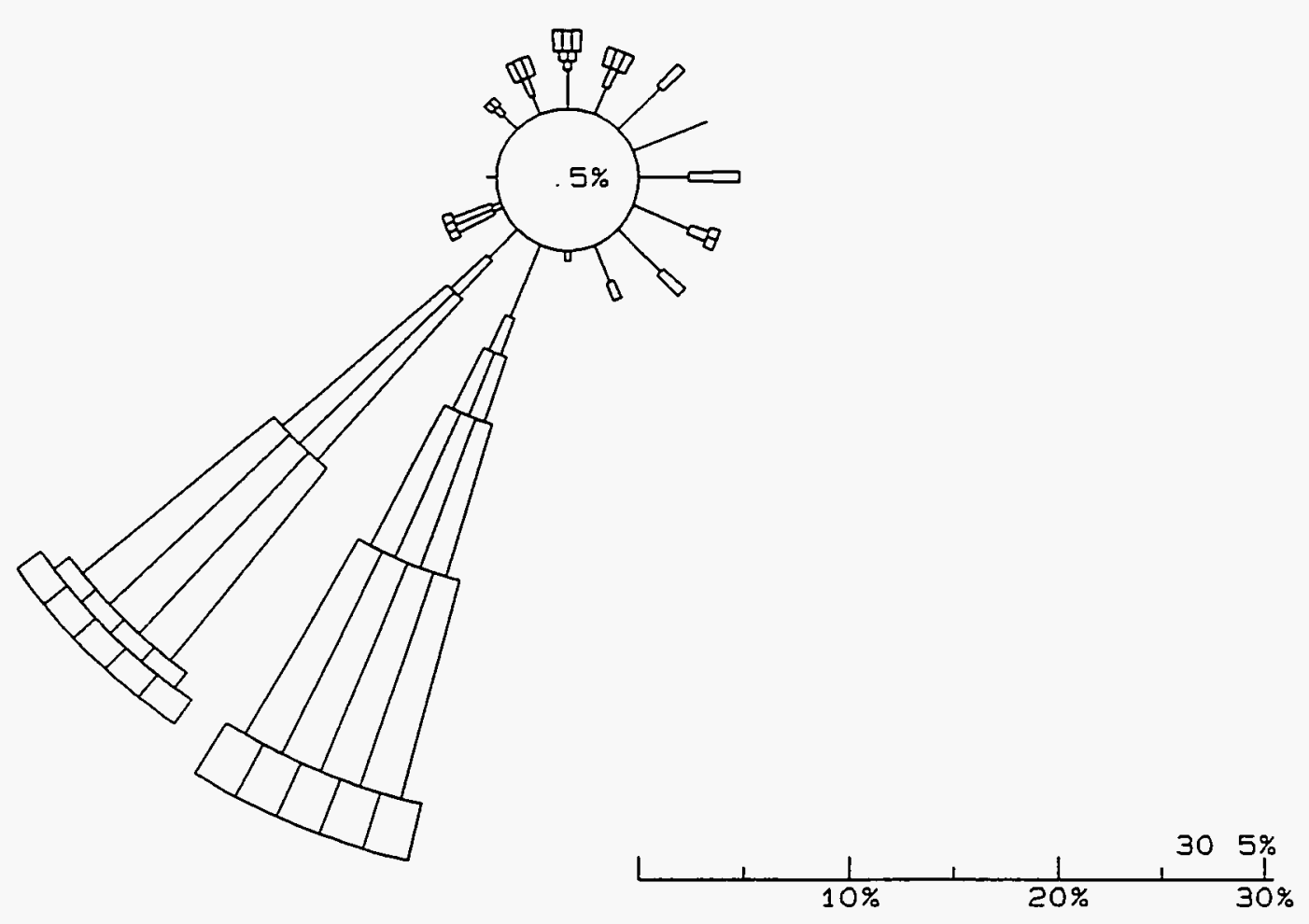

$99.7 \%$ DATA RECOVERED

OF WHICH 29.2\% IS

REPORTED ABOVE 


\section{SPILL TEST FACILITY 24 METER TOWEA \\ 2 METEA HEIGHT - Late Mid-Day \\ $10 / 1 / 1994$ - $10 / 31 / 1994$ \\ $1000-1600$}

$N$
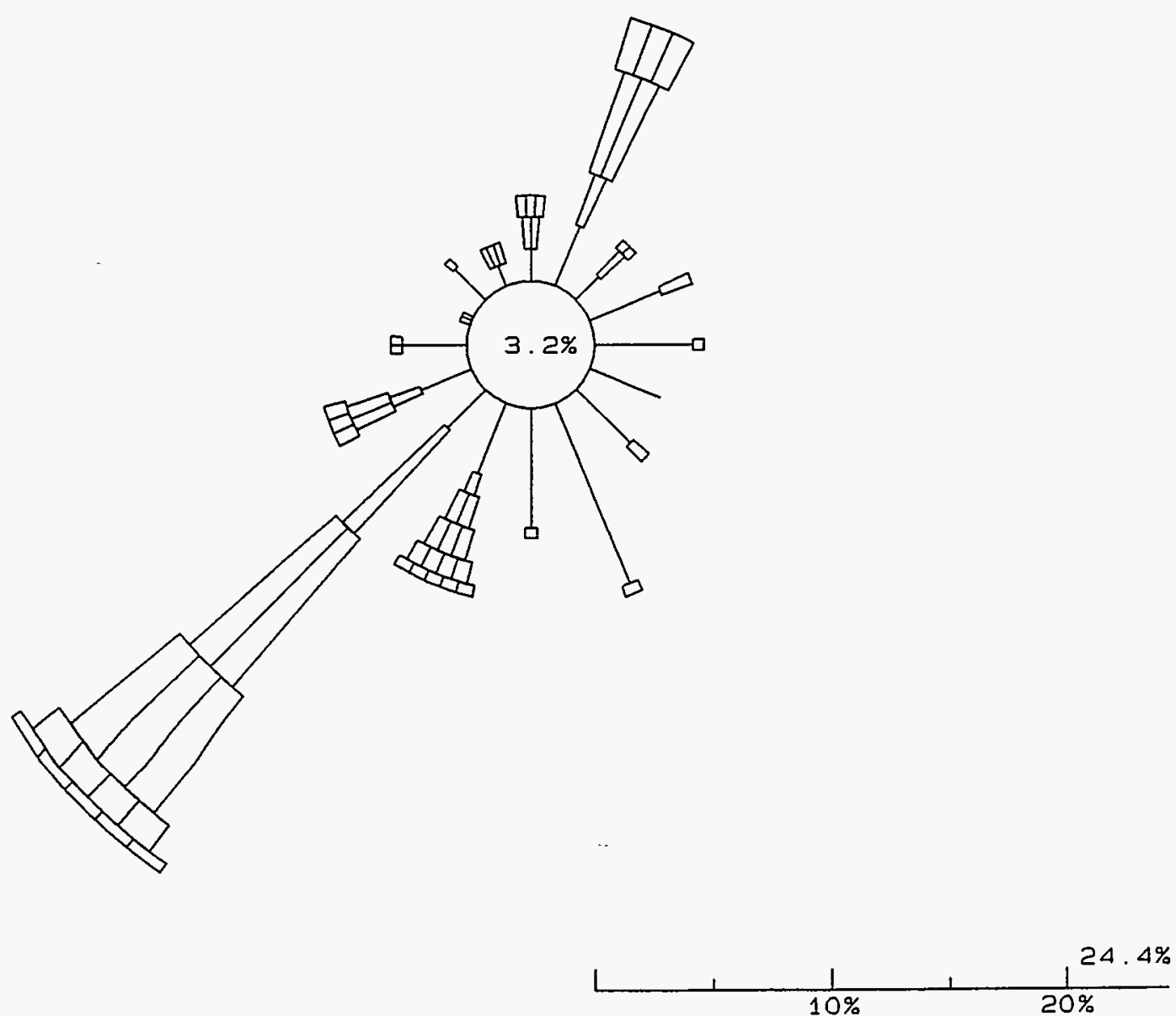

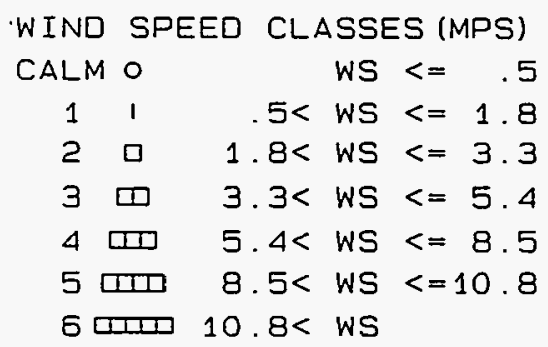

100.0\% DATA RECOVERED

OF WHICH 29.2\% IS

REPORTED $\triangle B O V E$ 


\section{SPILL TEST FACILITY 24 METER TOWEA \\ 2 METER HEIGHT - Late Mid-Day \\ $11 / 1 / 1994-11 / 30 / 1994$ \\ $1000-1600$}

$N$
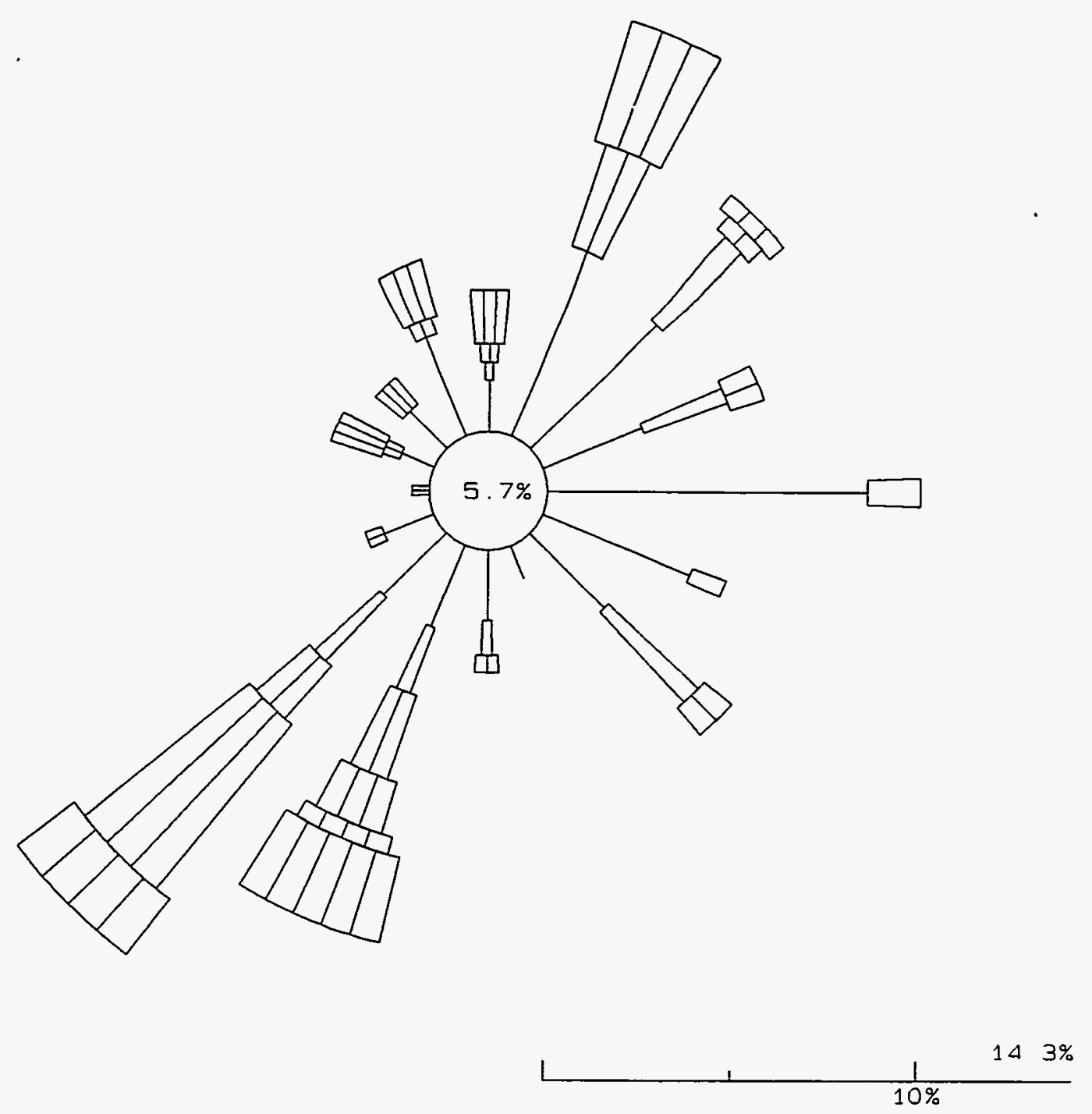

$100.0 \%$ DATA RECOVERED

OF WHICH $292 \%$ IS

REPORTED ABOVE 
SPILL TEST FACILITY 24 METER TOWER

2 METER HEIGHT - Evening Trarisition

1/ $1 / 1994$ - $1 / 31 / 1994$

$1600-2000$

N

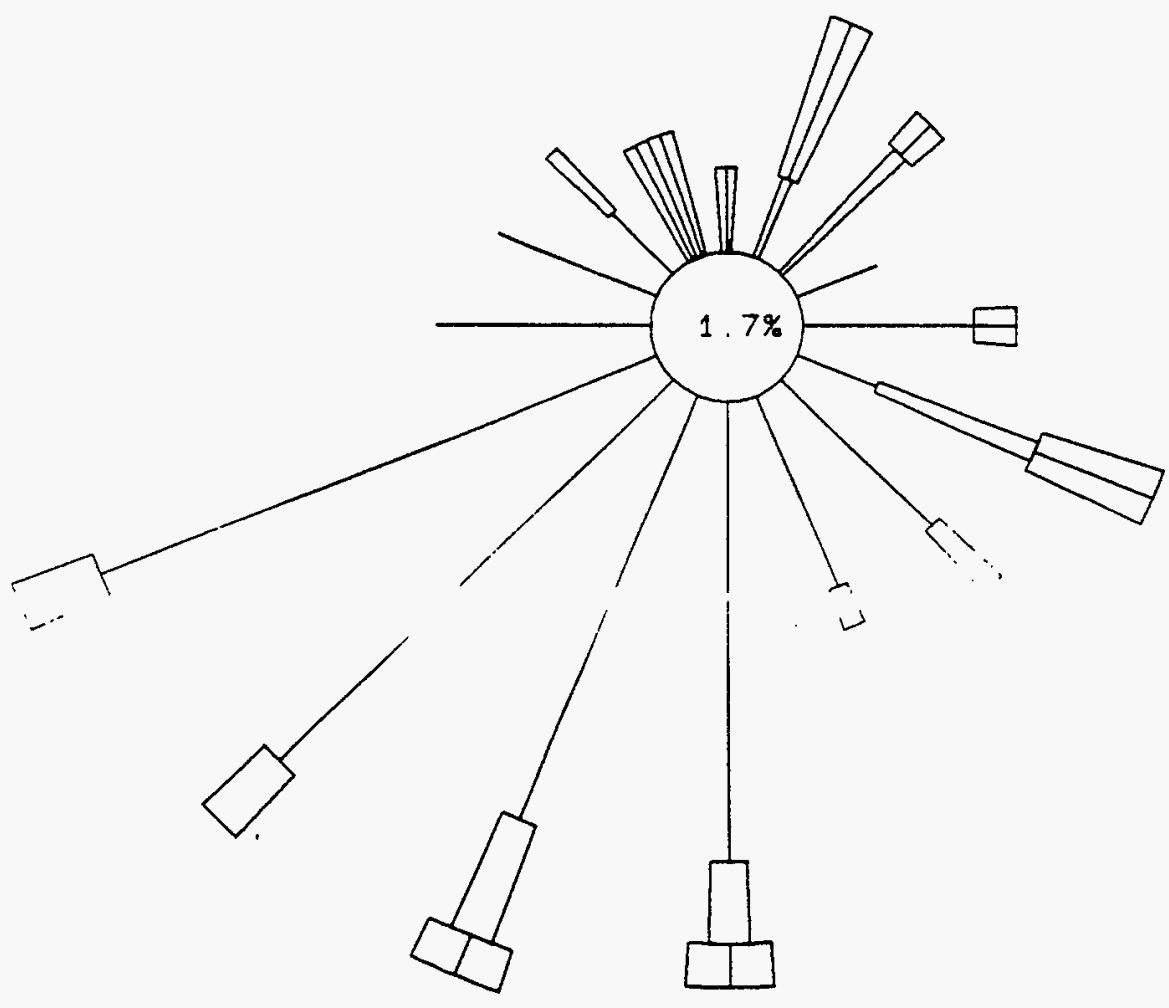

$13.3 \%$

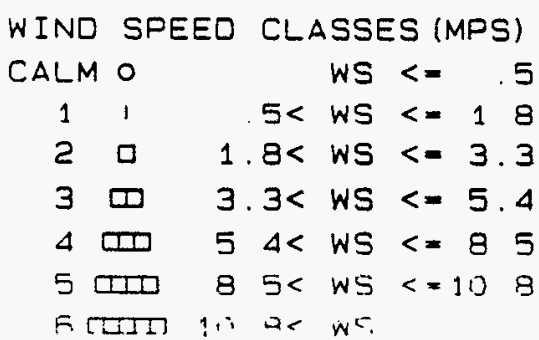

78. O\% DATA RECOVERED

OF WHICH $20.7 \%$ IS

REPOATED ABOVE 
SPILL TEST FACILITY 24 METER TOWEA

2 METER HEIGHT - Evening Transition

$$
\begin{gathered}
\text { 2/ } 1 / 1994-2 / 28 / 1994 \\
1600-2000
\end{gathered}
$$

$N$

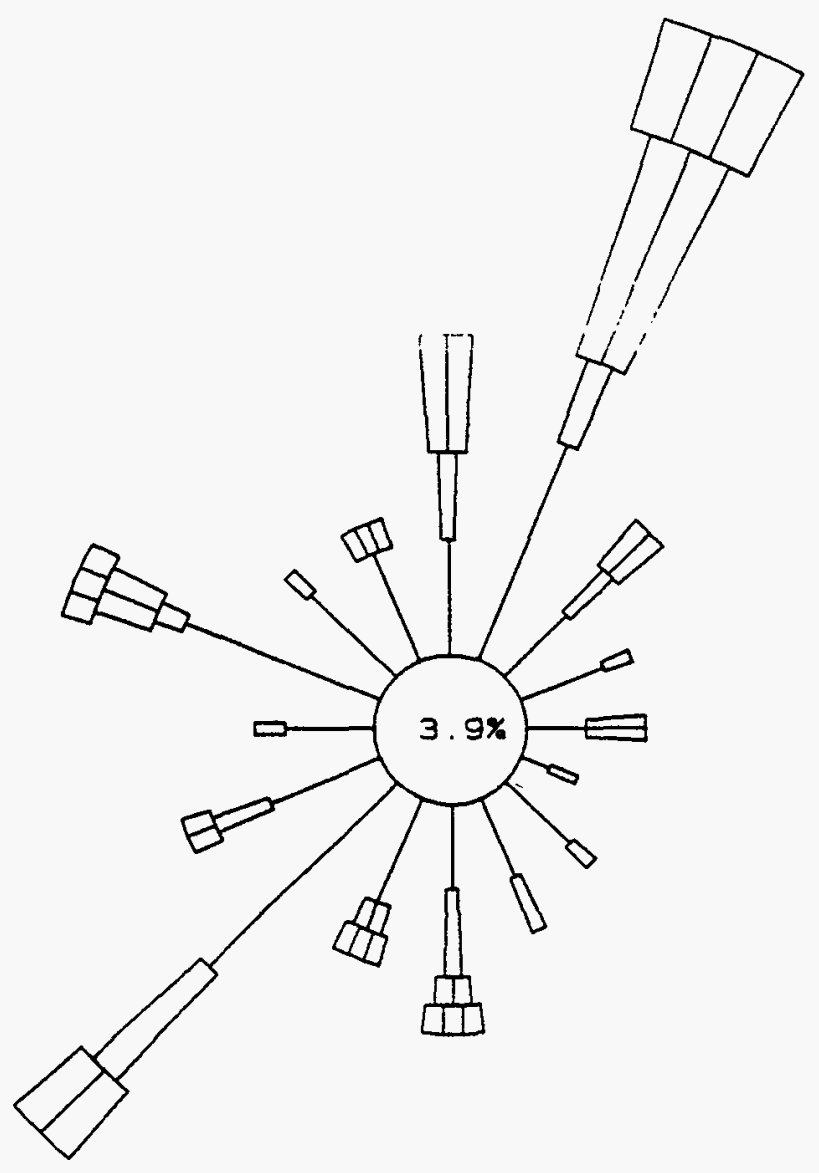

$18.0 \%$

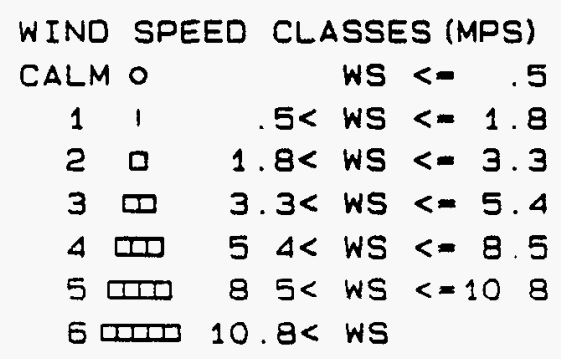

85. 4\% DATA RECOVERED

OF WHICH $22.3 \times$ IS REPOATED ABOVE 
SPILL TEST FACILITY 24 METEA TOWEA

2 METER HEIGHT - Evening Transition

$3 / 1 / 1994-3 / 31 / 1994$

$1600-2000$

N
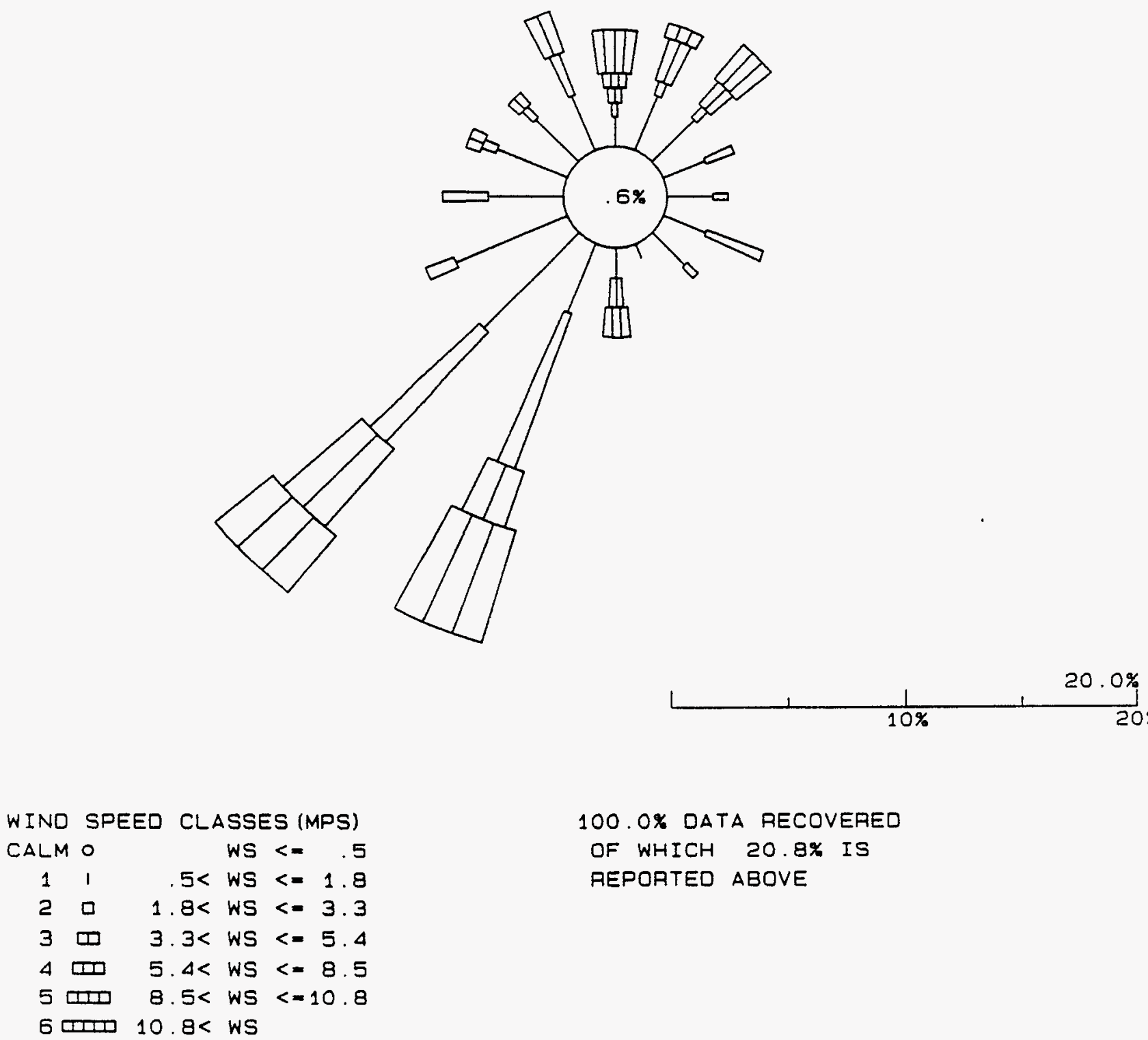

100. OX DATA RECOVEAED

OF WHICH $20.8 \%$ IS

REPORTED ABOVE 


\section{SPILL TEST FACILITY 24 METER TOWER \\ 2 METEA HEIGHT - Evening Transition$$
\text { 4/ } 1 / 1994-4 / 30 / 1994
$$$$
1600-2000
$$

N

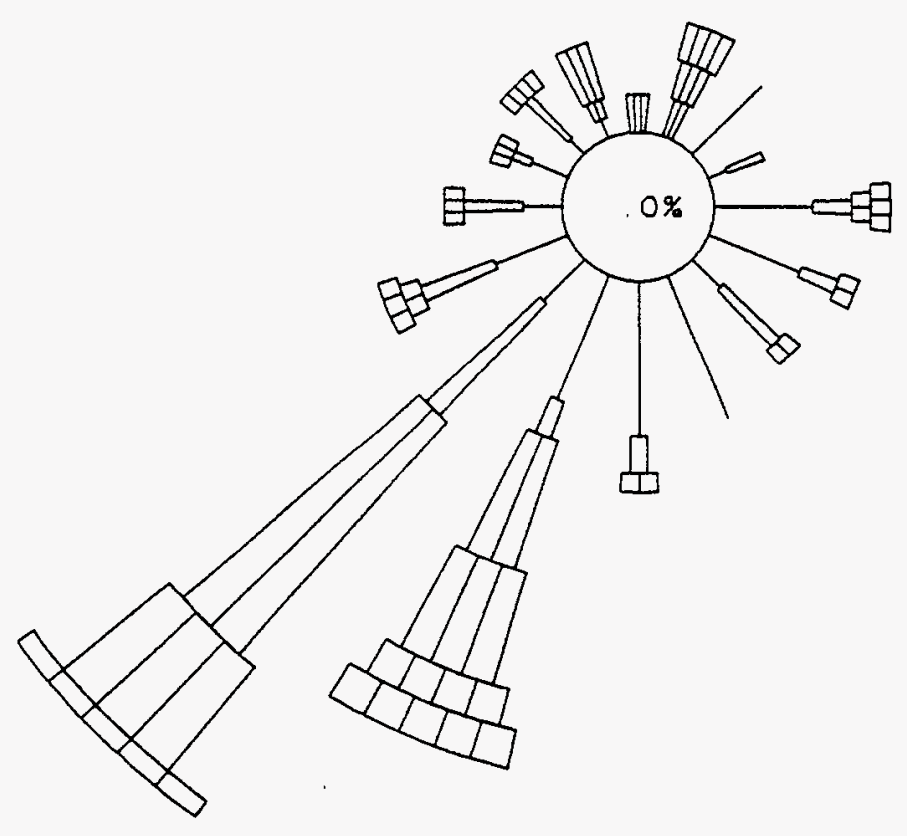

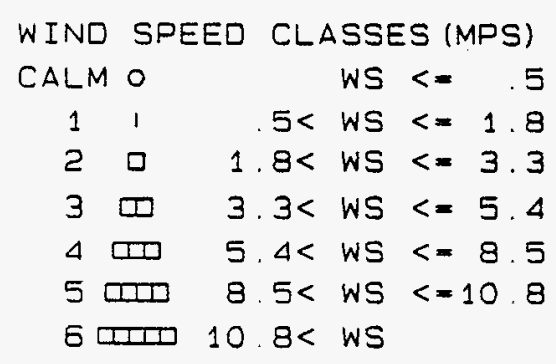

99. 4\% DATA RECOVERED

OF WHICH $20.9 \%$ IS

REPORTED ABOVE 
SPILL TEST FACILITY 24 METER TOWEP

2 METER. HEIGHT - Evening Transition

$$
\begin{gathered}
5 / 1 / 1994-5 / 31 / 1994 \\
1600-2000
\end{gathered}
$$

N
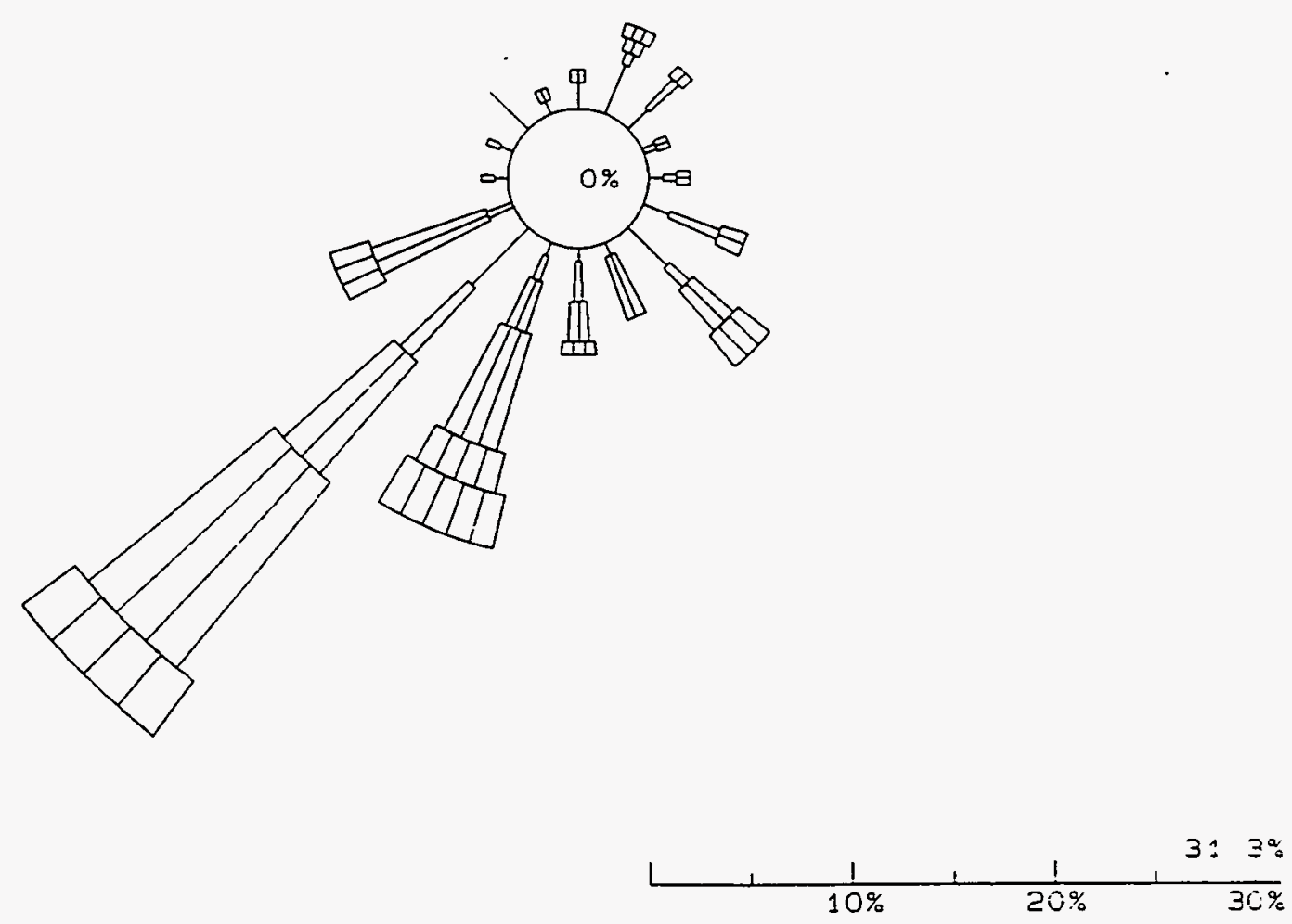

96 9\% DATA RECOVEAED

OF WLICH $20 \%$ IS

REPOITED ABOVE 


\section{SPILL TEST FACILITY 24 METER TOWER \\ 2 METER HEIGHT - Evening Transitzon \\ 6/ $1 / 1994$ - 6/30/1994 \\ $1600-2000$}
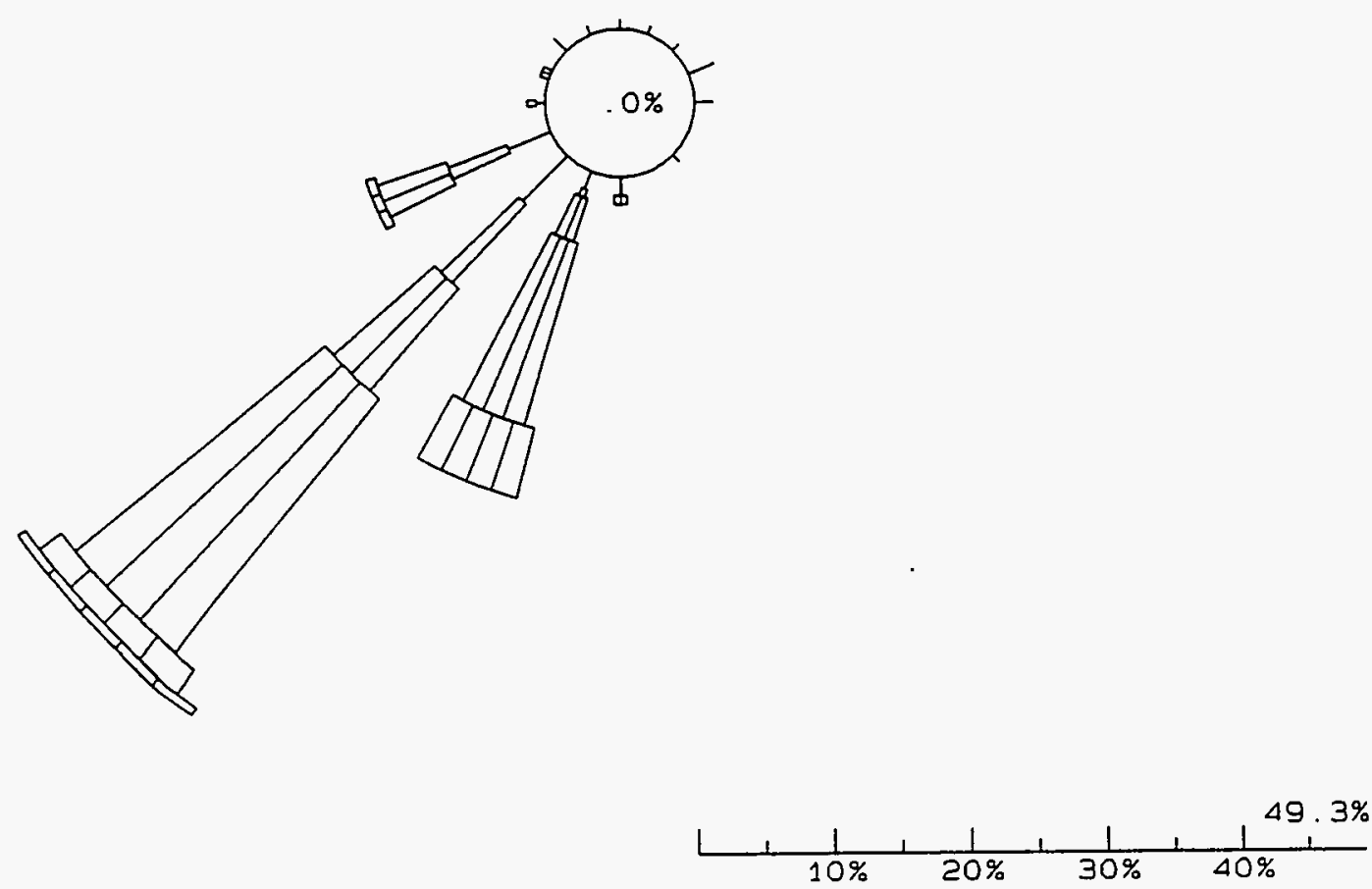

100.0\% DATA RECOVERED

OF WHICH $20.8 \%$ IS

REPORTED ABOVE 


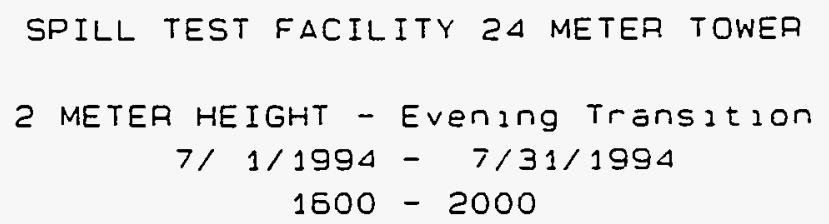

$N$
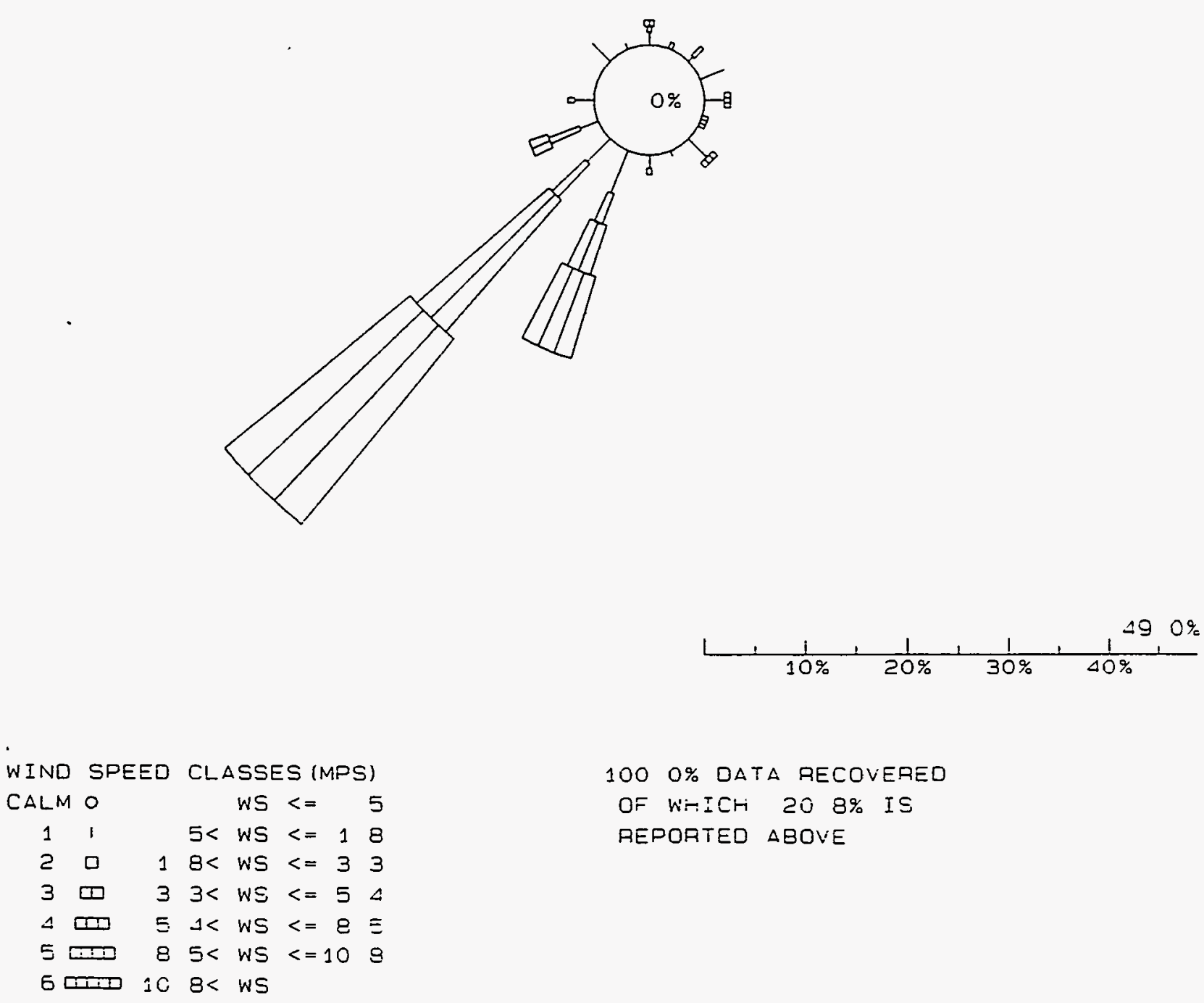


\section{SPILL TEST FACILITY 24 METER TOWER \\ 2 METER HEIGHT - Evening Transition \\ 8/ $1 / 1994-8 / 31 / 1994$ \\ $1600-2000$}

N
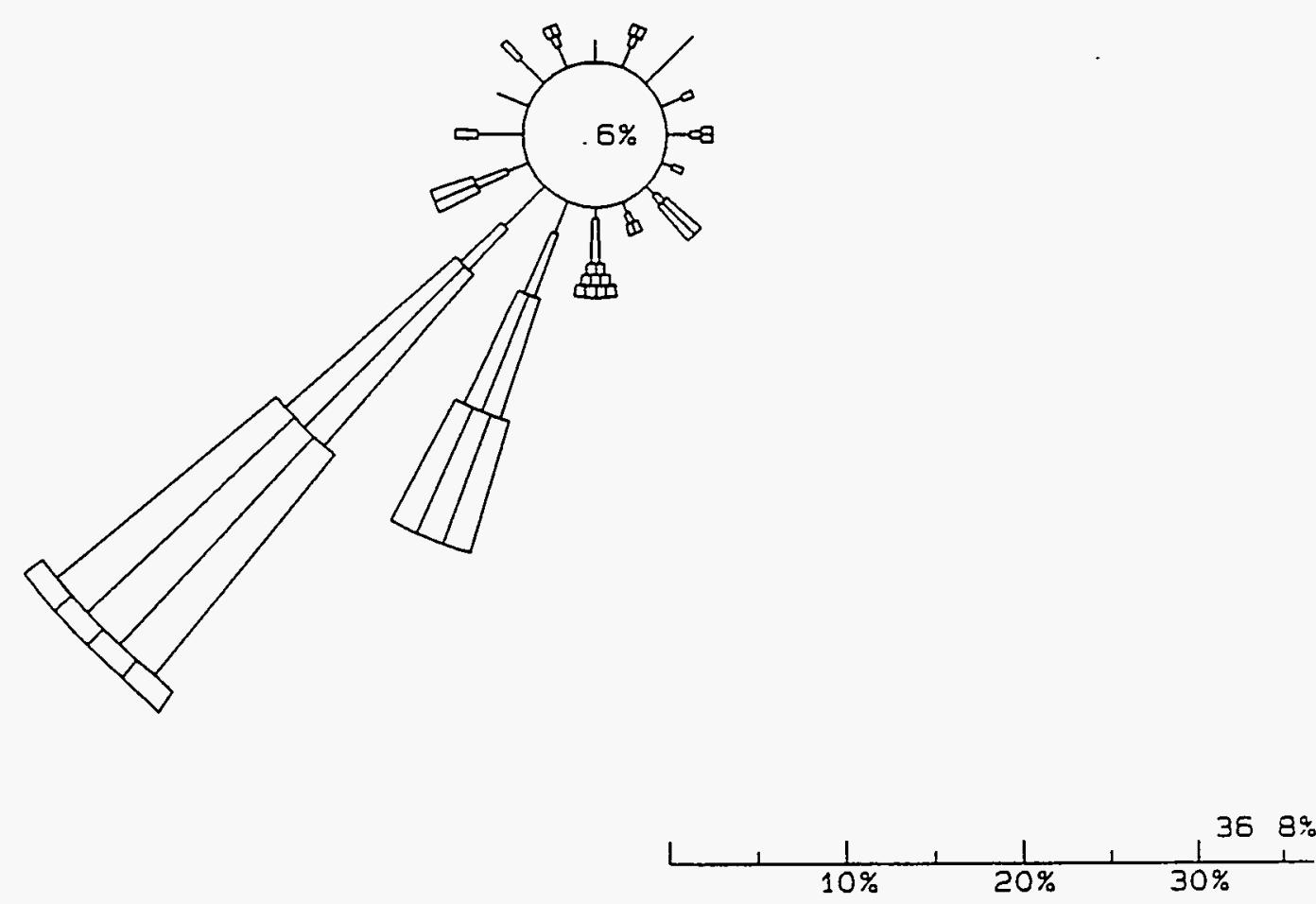

\begin{tabular}{|c|c|c|c|c|c|c|c|}
\hline WINO & \multicolumn{2}{|c|}{ SPEED } & \multicolumn{5}{|c|}{ CLASSES (MPS) } \\
\hline CALM & 10 & & & WS & $<=$ & & 5 \\
\hline 1 & 1 & & $5<$ & WS & $<=$ & 1 & 8 \\
\hline 2 & ם & 1 & $8<$ & WS & $<=$ & 3 & 3 \\
\hline 3 & $\square$ & 3 & $3<$ & WS & $<=$ & 5 & 4 \\
\hline$\Delta$ & סד & 5 & $\Delta<$ & WS & $<=$ & 8 & 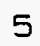 \\
\hline 5 & ס्पम & 8 & $5<$ & WS & $<=1$ & & 8 \\
\hline$\tau$ & III & 10 & $8<$ & WS & & & \\
\hline
\end{tabular}

100. O\% DATA RECOVERED

OF WHICH $20.8 \%$ IS

REPORTEO ABOVE 


\section{SPILL TEST FACILITY 24 METER TOWER \\ 2 METER HEIGHT - Evening Transition \\ $9 / 1 / 1994$ - $9 / 30 / 1994$ \\ $1600-2000$}

N

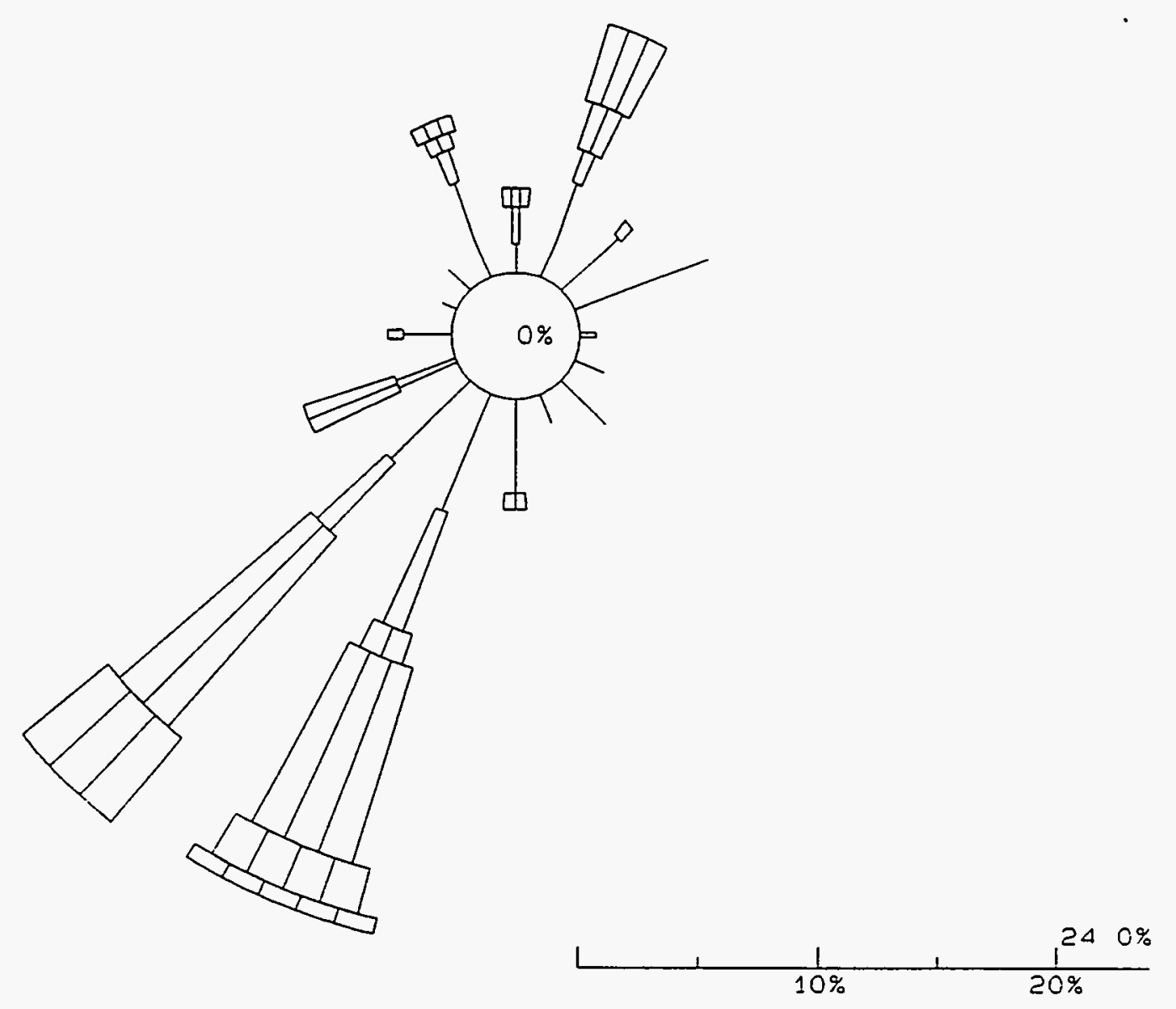

$99.7 \%$ DATA RECOVERED

OF WHICH $209 \%$ IS

REPORTED ABOVE 


\section{SPILL TEST FACILITY 24 METER TOWER \\ 2 METER HEIGHT - Evening Transition \\ $10 / 1 / 1994$ - 10/31/1994 \\ $1600-2000$}

$N$
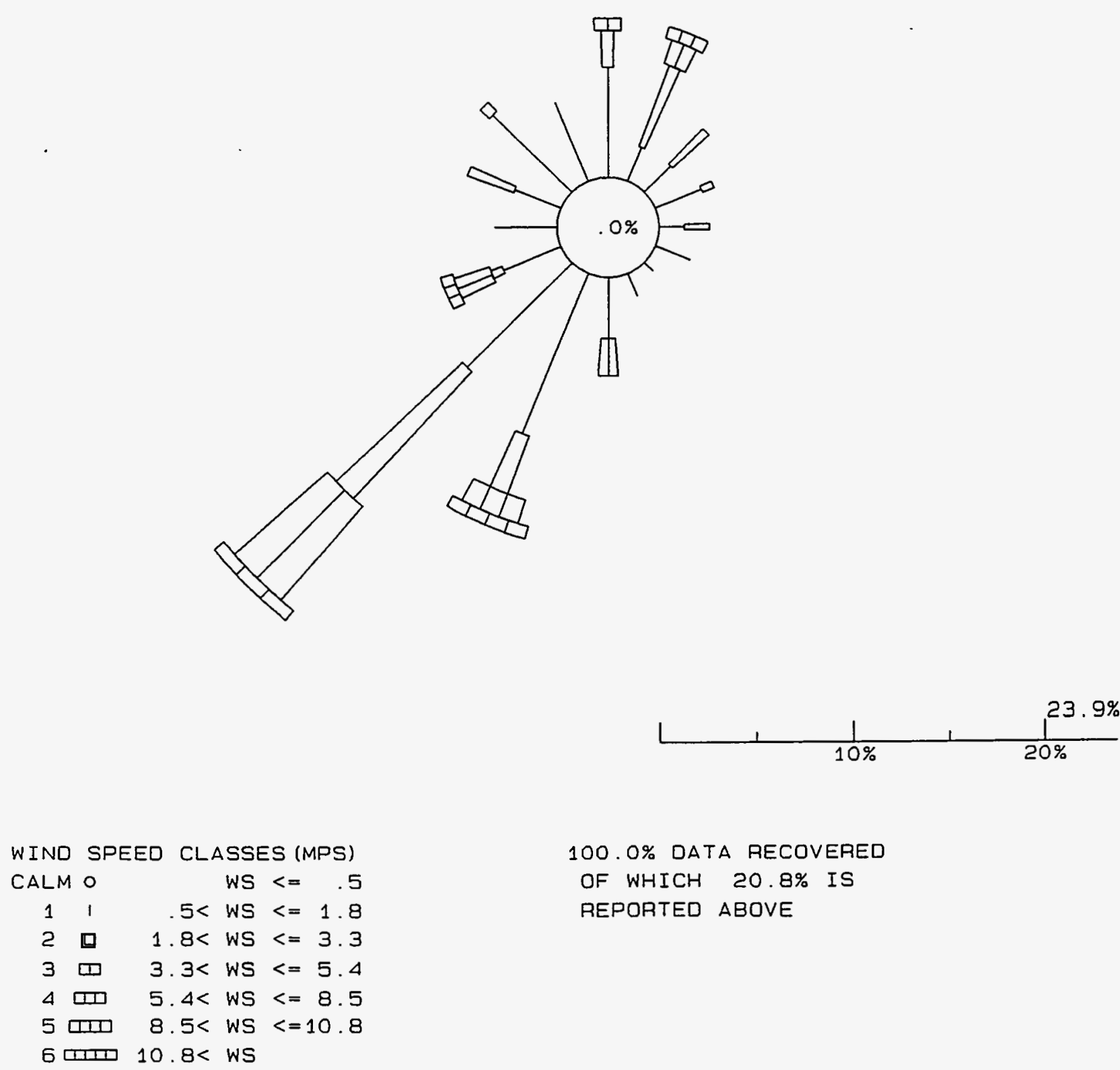

$100.0 \%$ DATA RECQVERED

OF WHICH 20.8\% IS

REPORTED ABOVE 


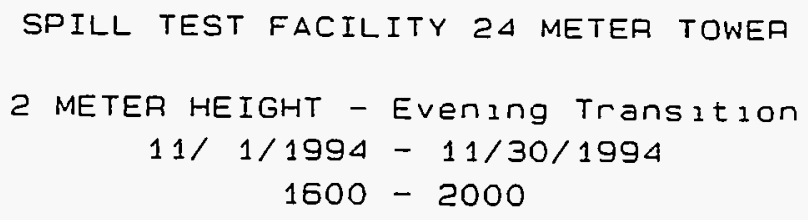

$N$

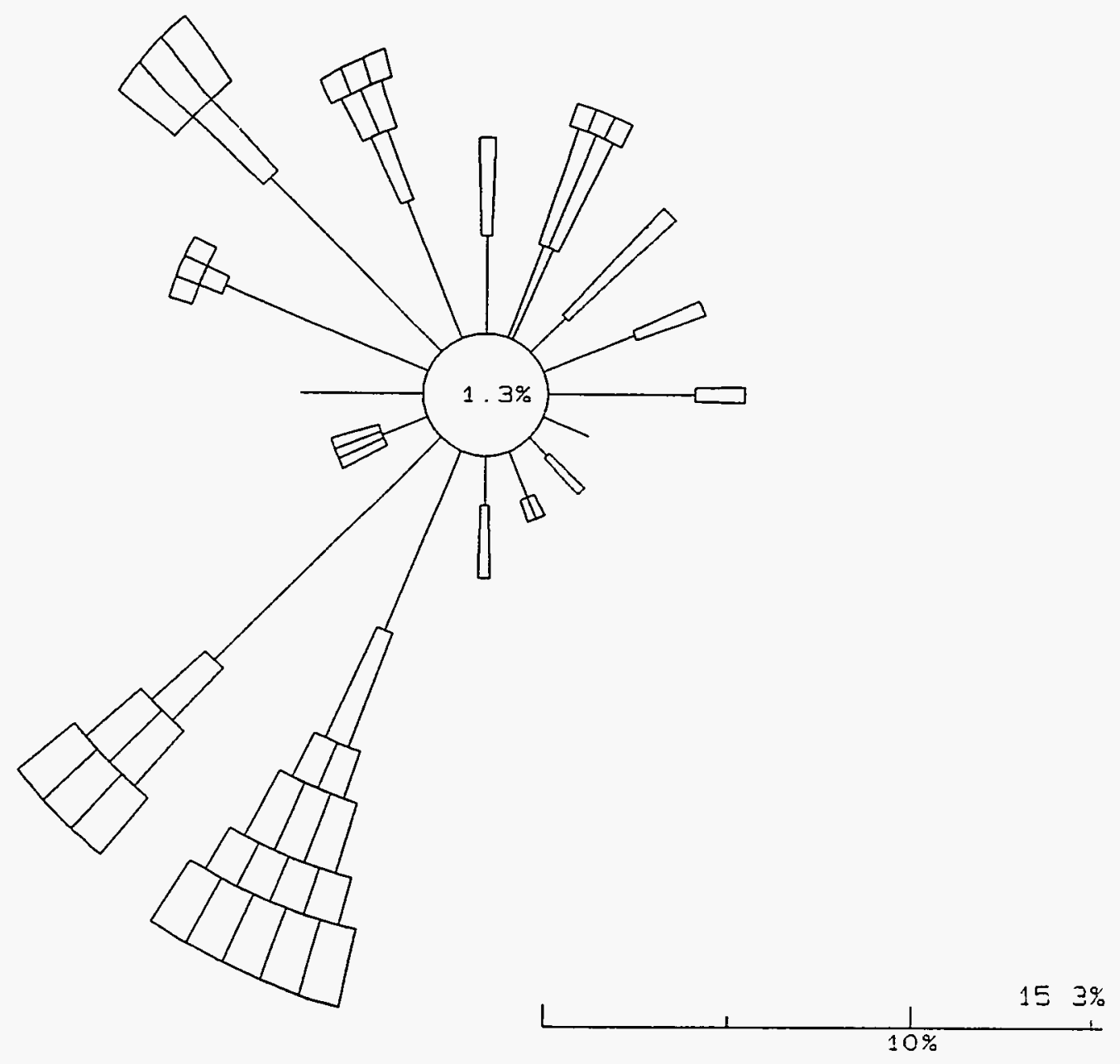

\begin{tabular}{|c|c|c|c|c|c|c|}
\hline WIND & $S P$ & EED & $C L$ & ASS & $E S(M$ & (PS) \\
\hline CALM & 10 & & & WS & $<=$ & 5 \\
\hline 1 & 1 & & $5<$ & WS & $<=$ & 1.8 \\
\hline 2 & D & 1 & $8<$ & WS & $<=$ & 3.3 \\
\hline 3 & $\square$ & 3 & $3<$ & WS & $<=$ & 5.4 \\
\hline 4 & प्ष & 5 & $4<$ & WS & $<=$ & 8.5 \\
\hline 50 & पात्म & 8 & $5<$ & WS & $<=1$ & 10.8 \\
\hline $6 \square$ & טחדי & 10 & $.8<$ & WS & & \\
\hline
\end{tabular}




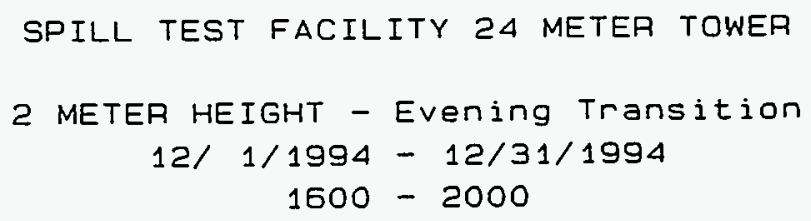

$N$

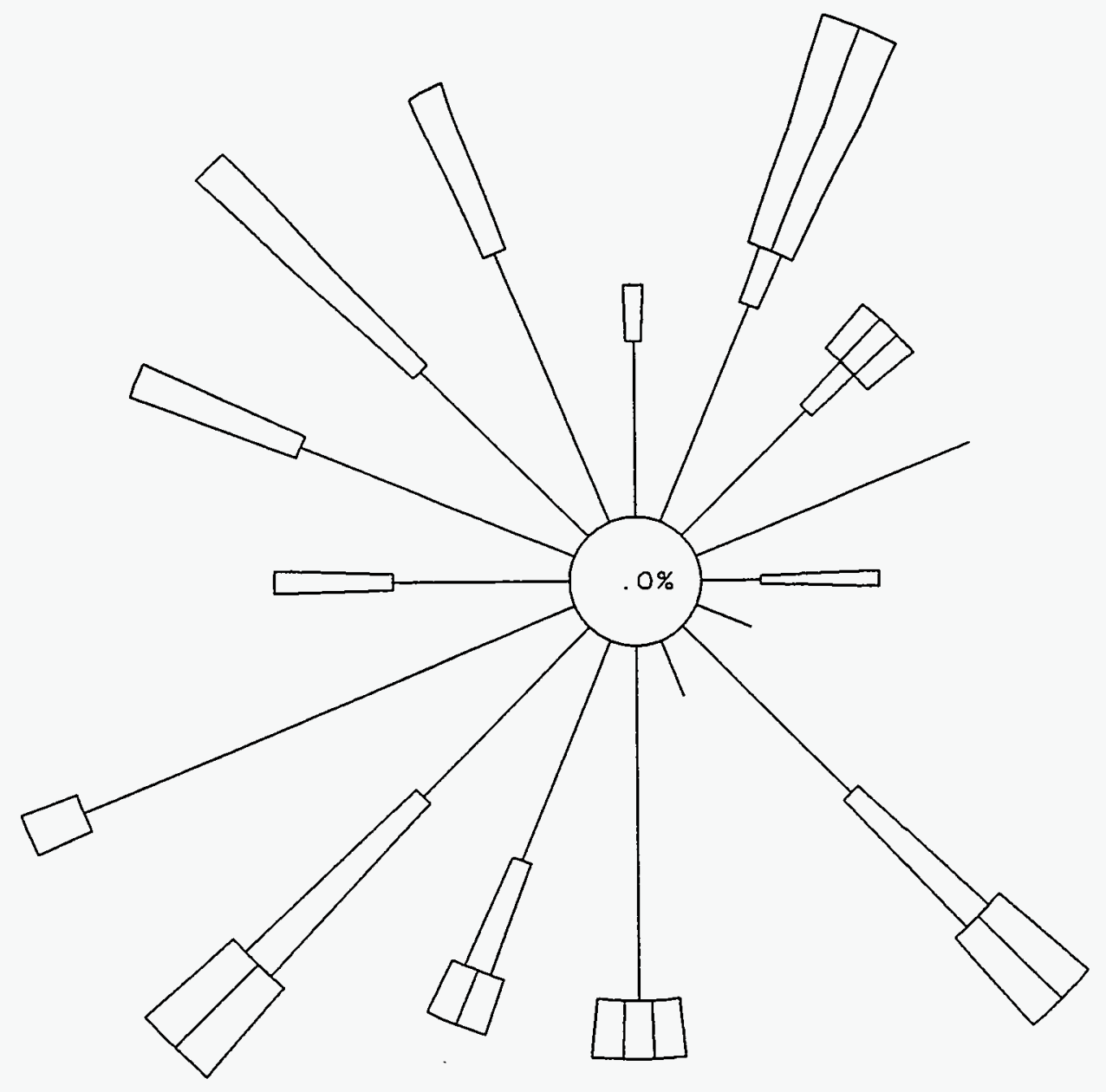

\begin{tabular}{|c|c|c|c|c|c|}
\hline WIND & $S P E$ & $E D$ & CLS & ASSE & S (MPS) \\
\hline CALM & 10 & & & WS & $<=$ \\
\hline 1 & 1 & & $.5<$ & WS & $<=1.8$ \\
\hline 2 & $\square$ & 1 & $.8<$ & WS & $<=3.3$ \\
\hline 3 & एᄆ & 3 & $.3<$ & WS & $<=5.4$ \\
\hline 4 & पाप & 5 & $.4<$ & WS & $<=8.5$ \\
\hline 5 & חाप & 8 & $.5<$ & WS & $<=10.8$ \\
\hline 65 & דII & 10 & $.8<$ & WS & \\
\hline
\end{tabular}

65. 1\% DATA RECOVERED OF WHICH $20.9 \%$ IS REPOATED ABOVE 


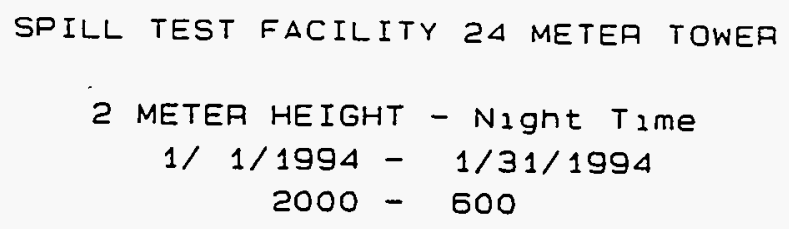

$N$

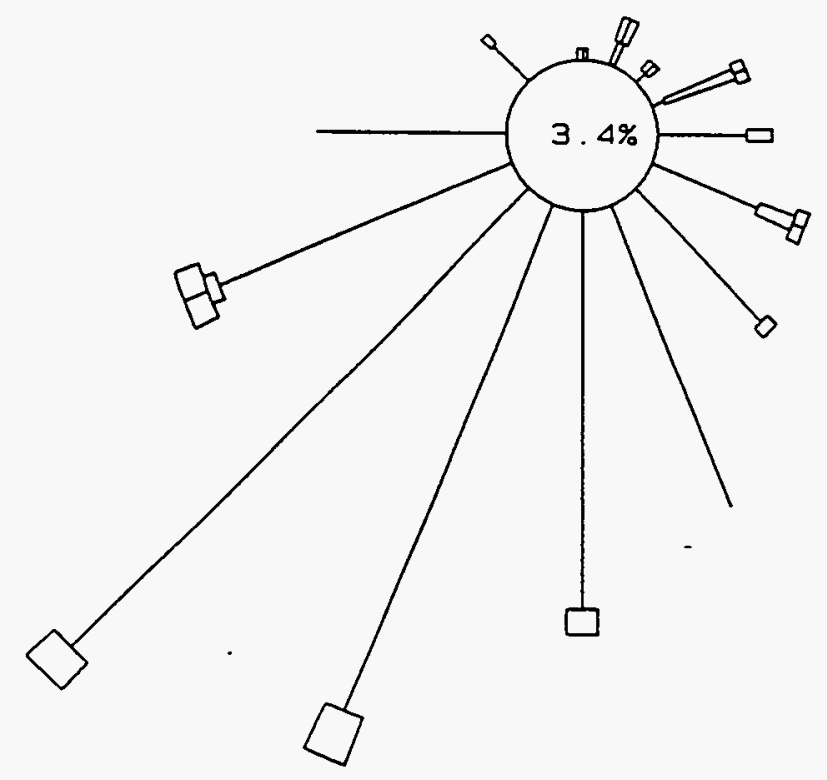

WIND SPEED CLASSES (MPS)

CALM O

$11 \quad .5<$ WS $<=1.8$

2 ㅁ $1.8<$ WS $<=3.3$

3 पा $3.3<$ WS $<-5.4$

4 पा $5.4<W S<=8.5$

5 पाI $8.5<$ WS $<=10.8$

6 10.8< WS
78.0\% DATA RECOVERED

OF WHICH $46.2 \%$ IS

AEPORTED ABOVE 
SPILL TEST FACILITY 24 METER TOWER

2 METER HEIGHT - Night Time

2/ $1 / 1994-2 / 28 / 1994$

$2000-600$

$N$

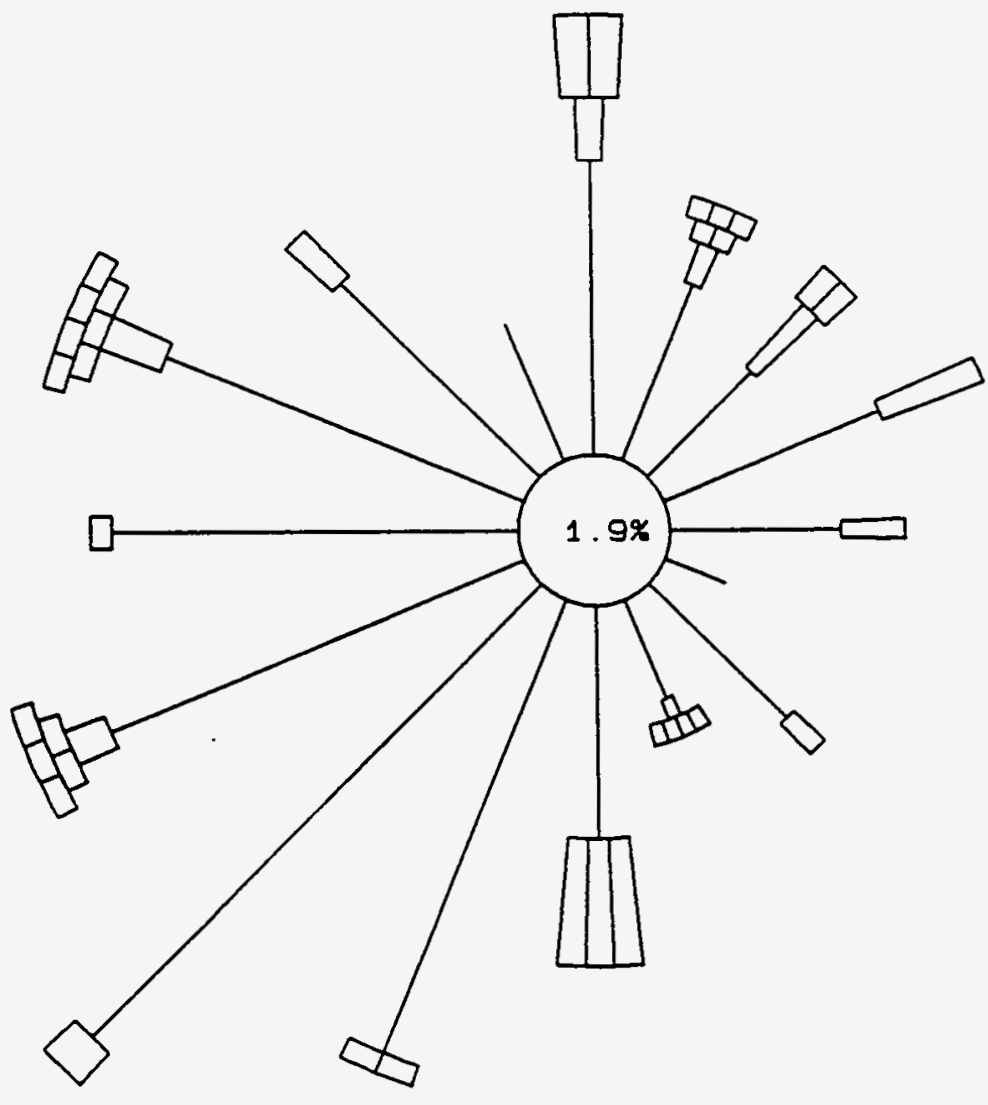

$12.1 \%$

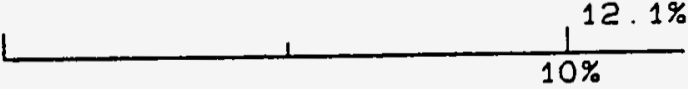

85. 4\% DATA RECOVERED

OF WHICH $46.0 \%$ IS REPORTED ABOVE 
SPILL TEST FACILITY $2 \triangle$ METEA TOWEA

2 METER HEIGHT - Night Time

$3 / 1 / 1994-3 / 31 / 1994$

$2000-600$

$N$
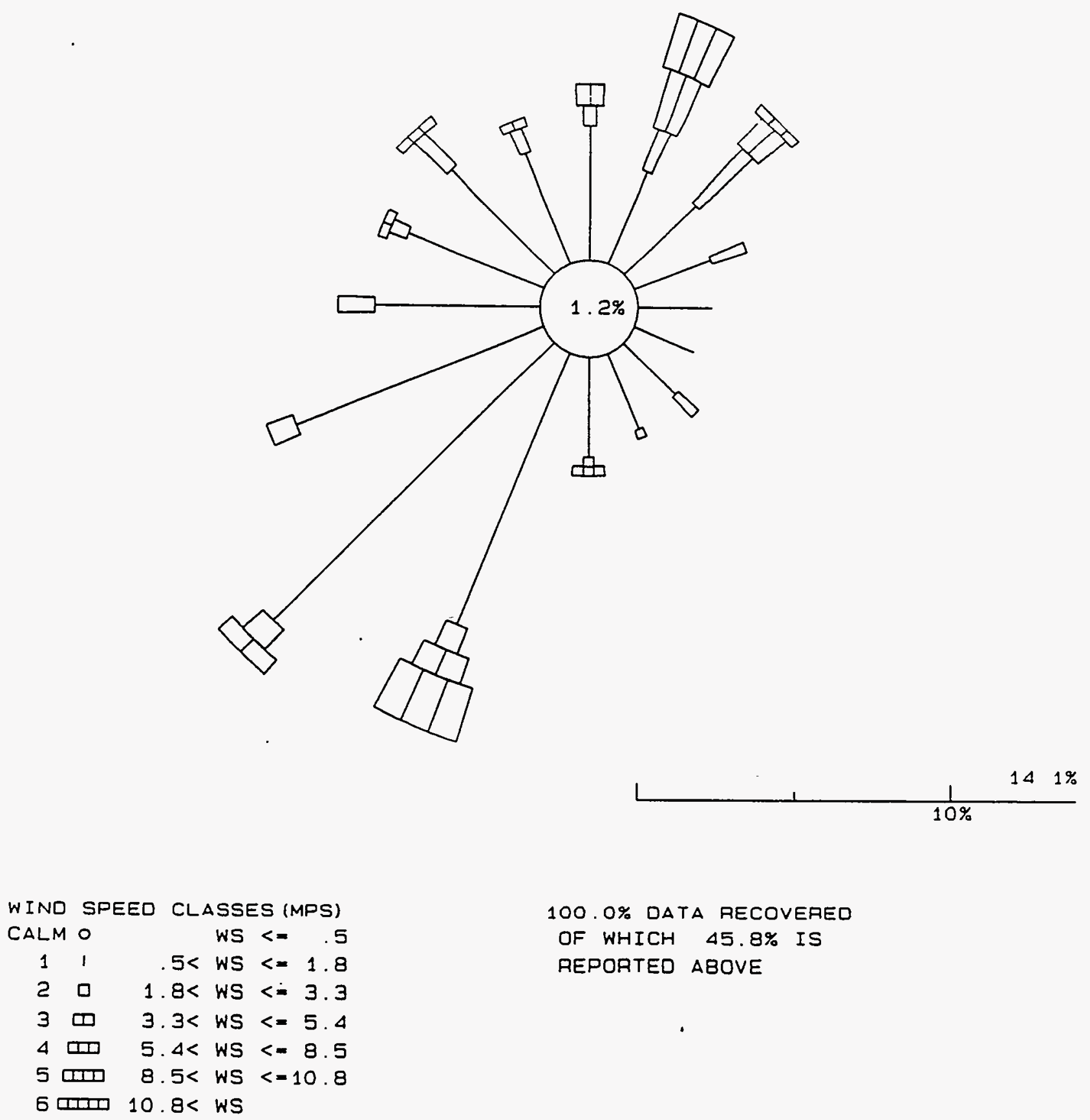

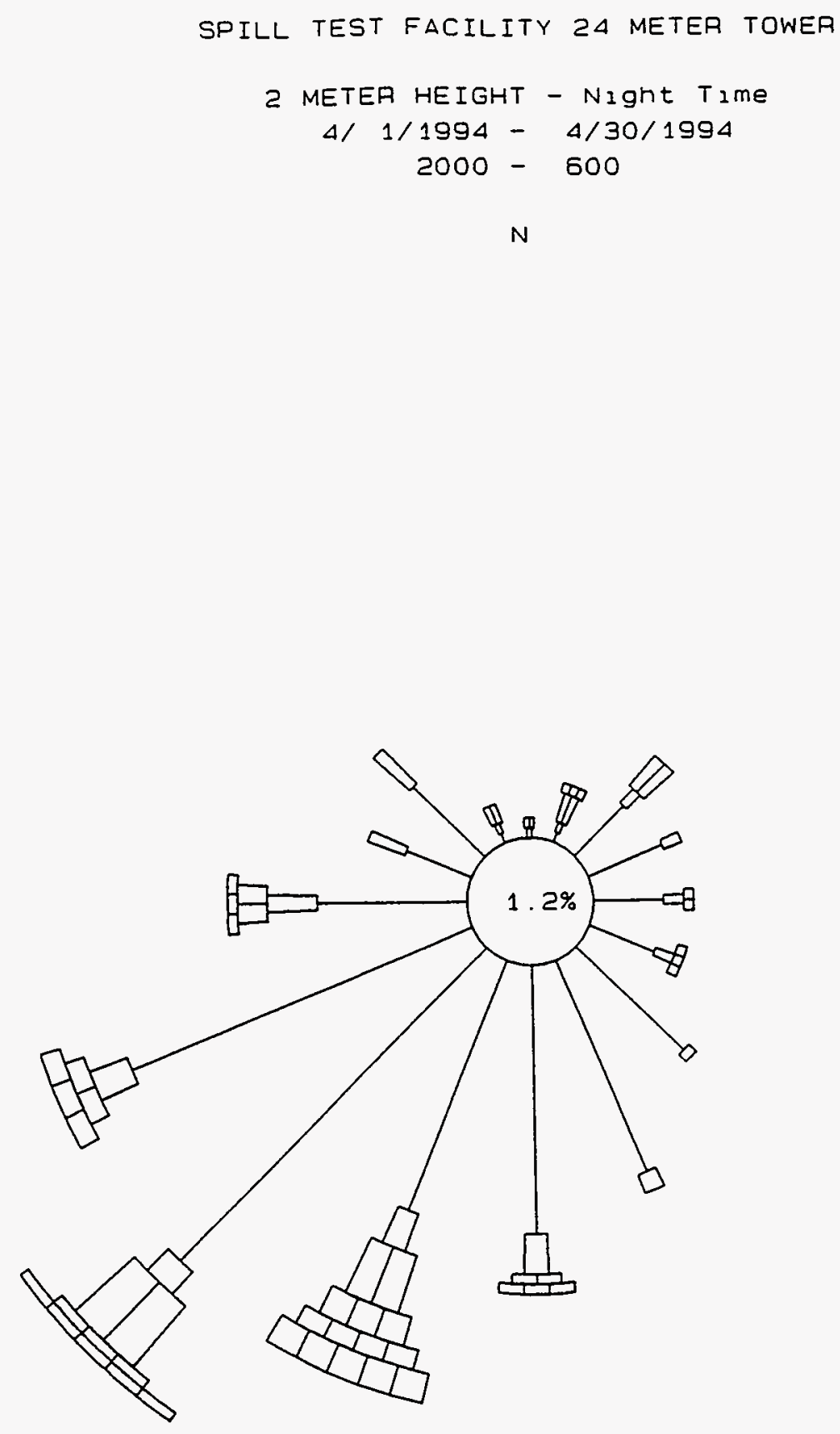

$173 \%$

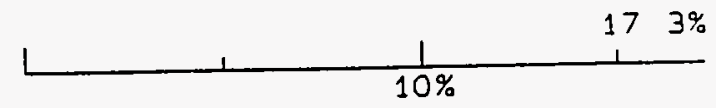

99. $4 \%$ DATA RECOVERED

OF WHICH $\triangle 6.1 \%$ IS

REPORTED ABOVE 


\section{SPILL TEST FACILITY $2 \triangle$ METEF TOWEA \\ 2 METER HEIGHT - Night Time \\ $5 / 1 / 1994-5 / 31 / 1994$ \\ $2000-600$}

N
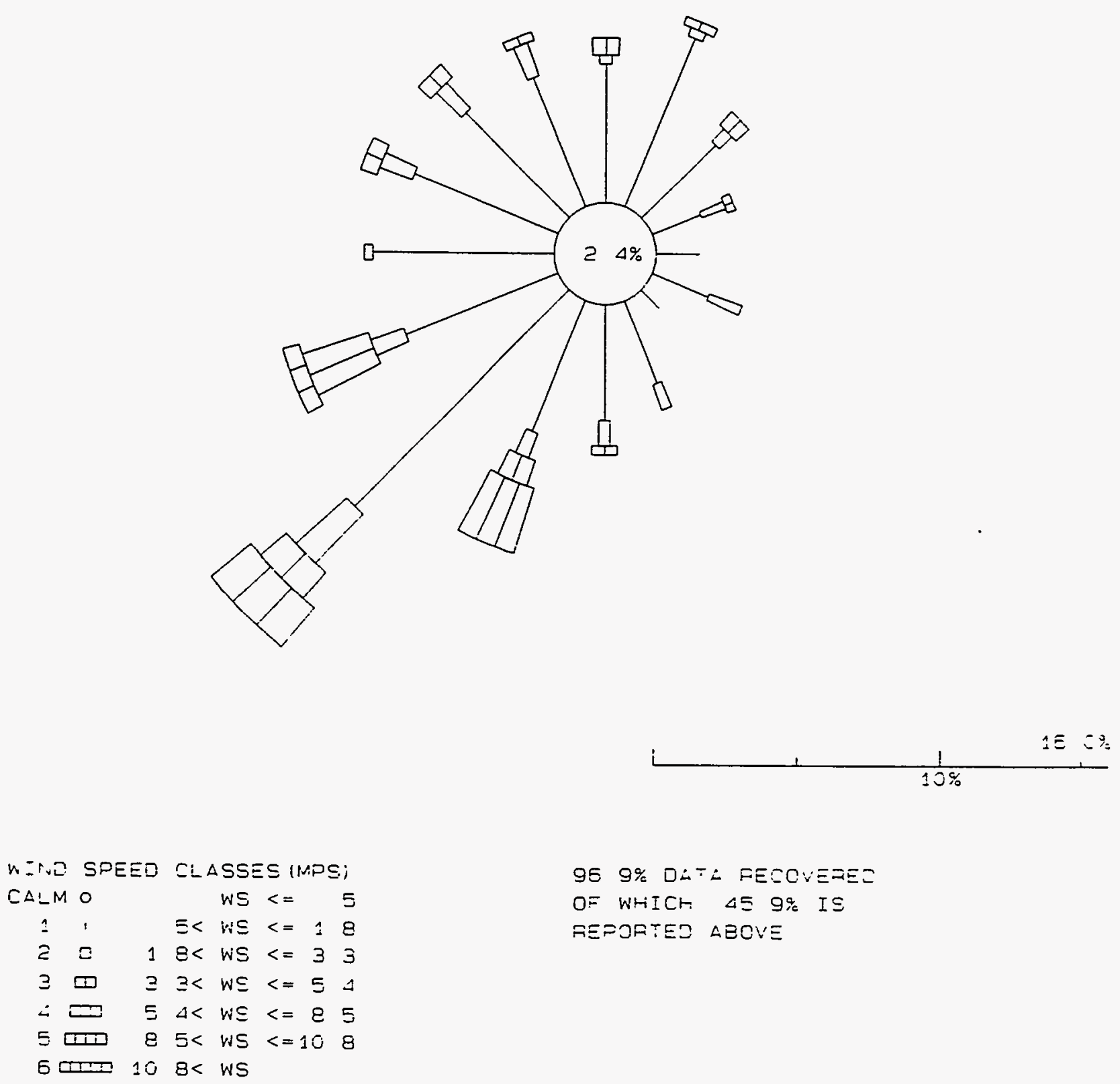

$959 \%$ DLT: FECCVシニEこ

OF WHICH 45 9\% IS

REPOFTED $\triangle E O V E$ 


\section{SPILL TEST FACILITY $2 \triangle$ METER TOWER \\ 2 METER HEIGHT - Night TIME \\ E/ $1 / 1994$ - E/30/1994 \\ $2000-600$}

$N$
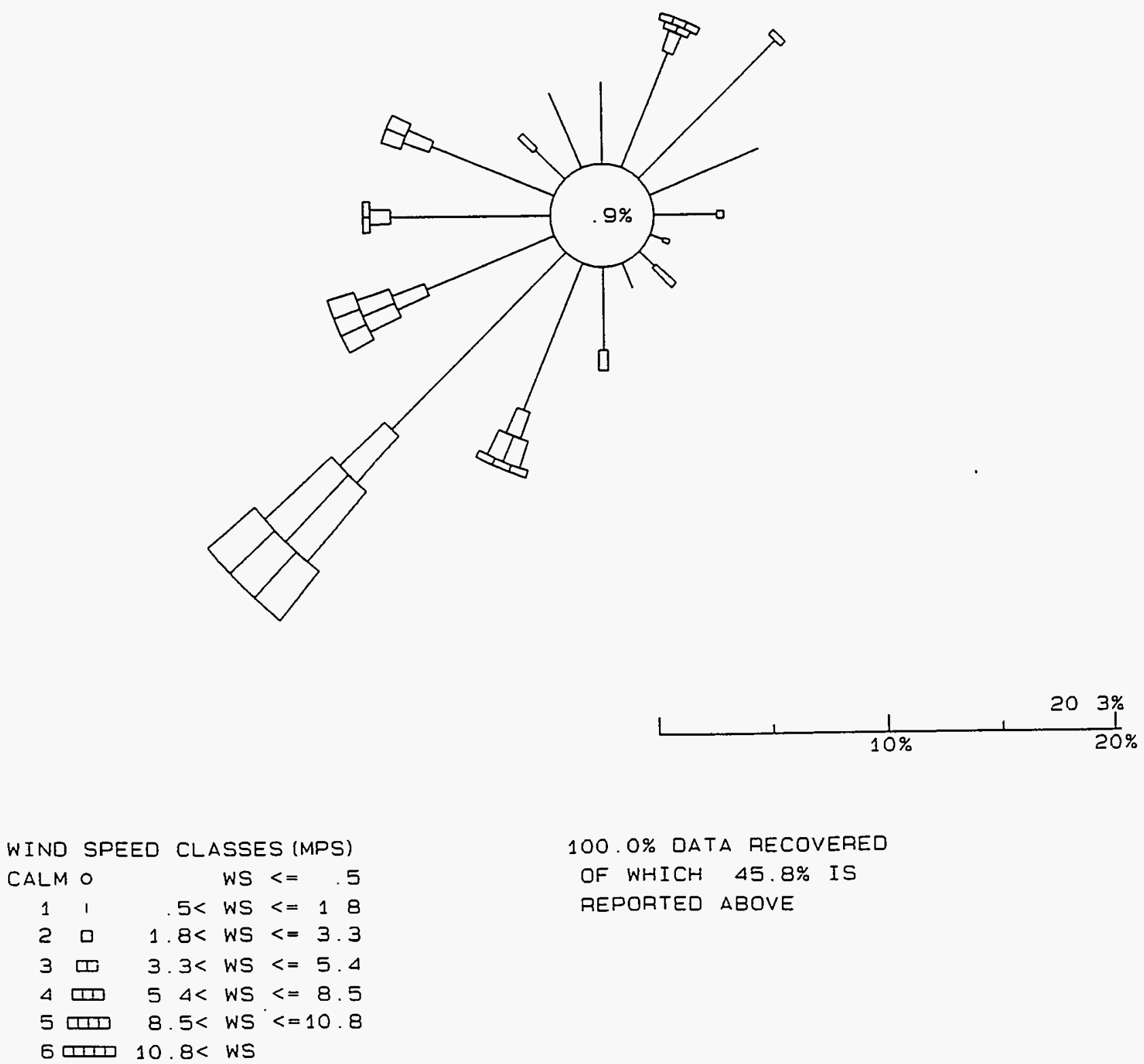

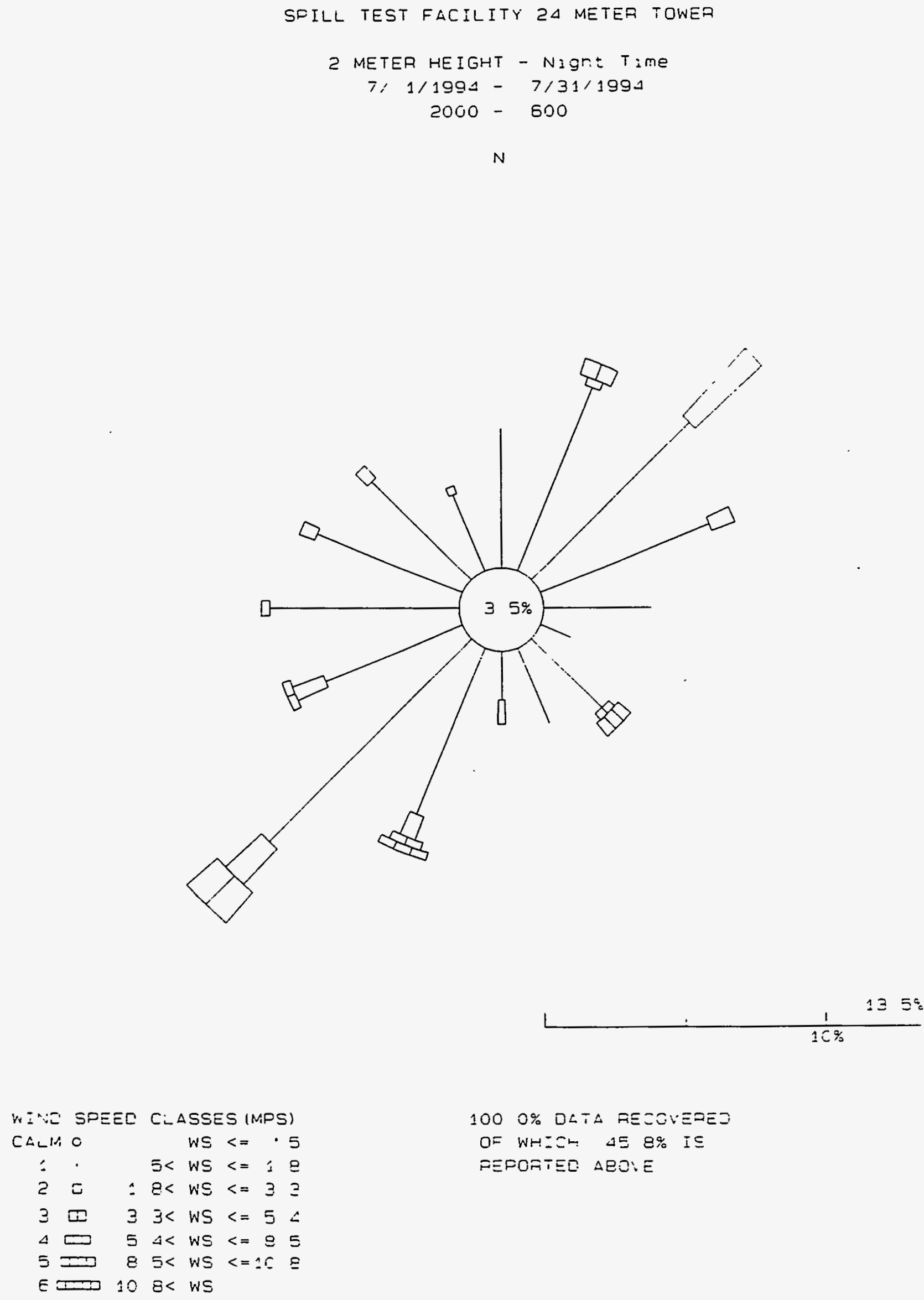


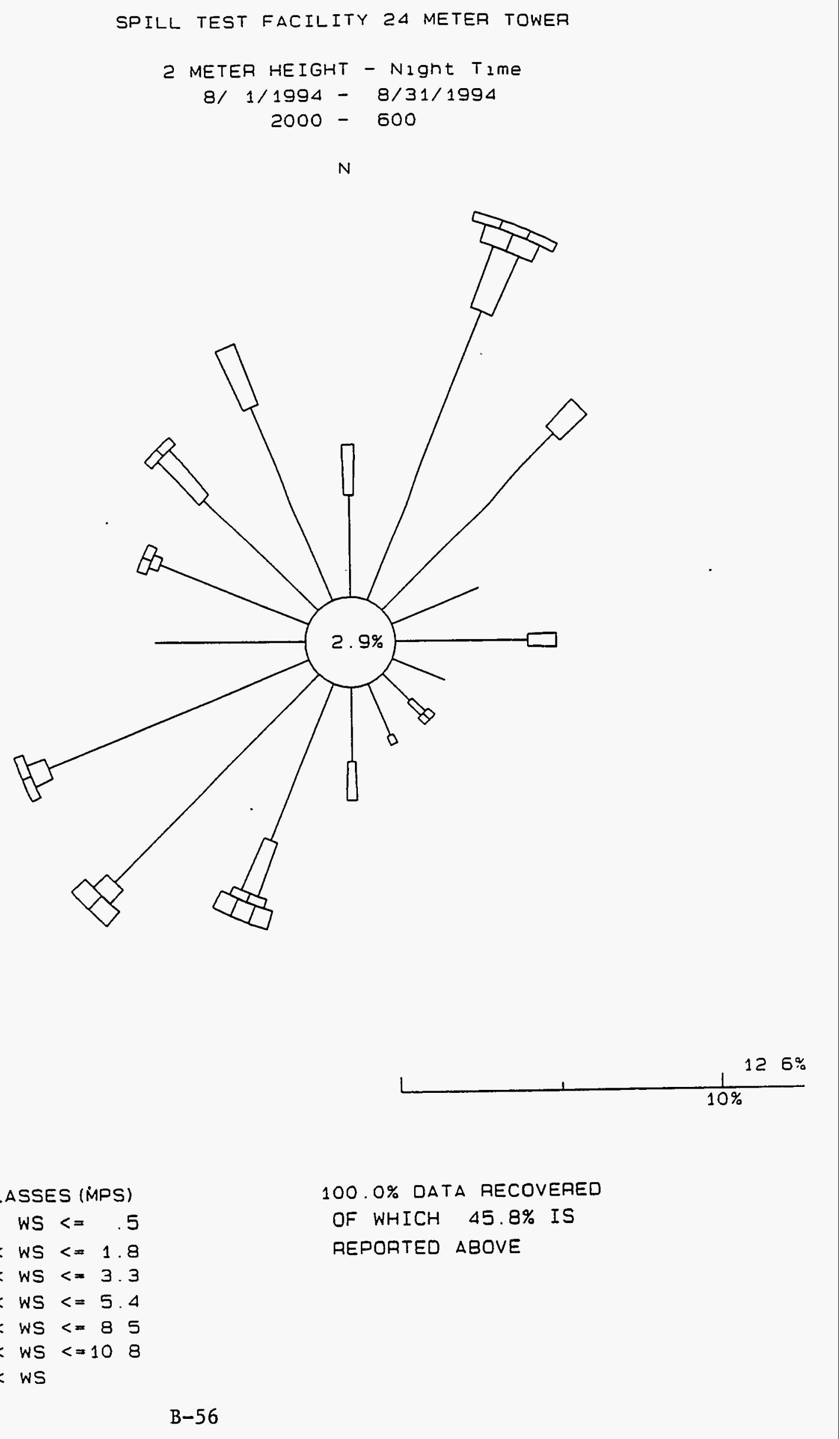




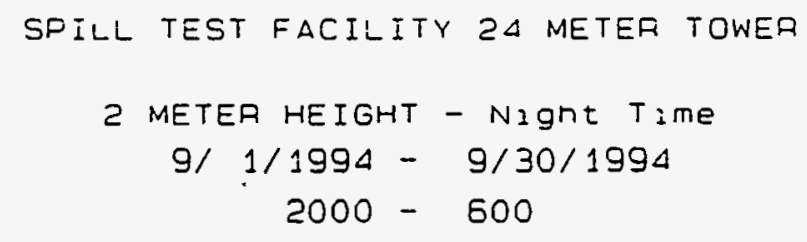

$N$
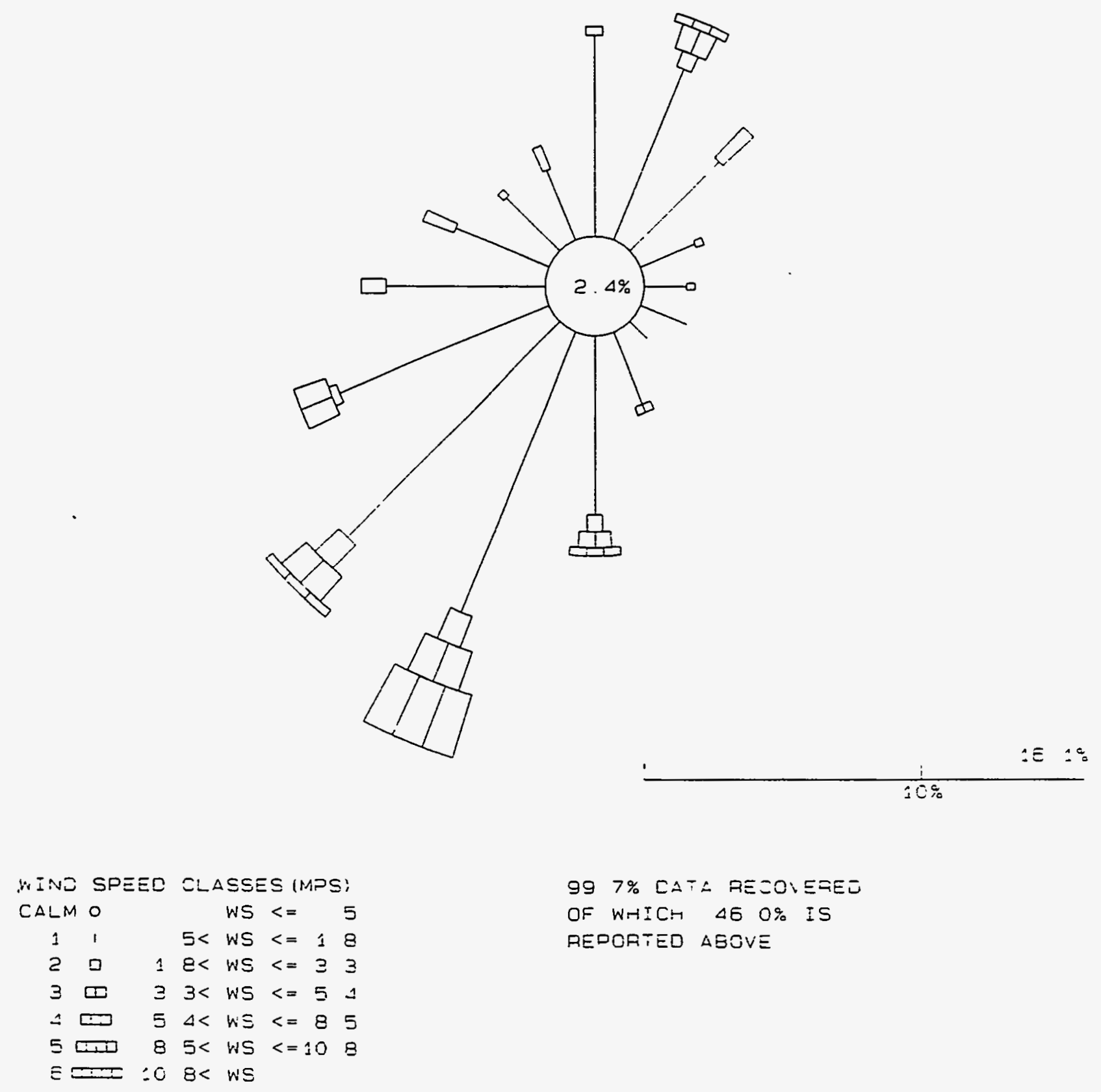

99 7\% CATA REこOVEAEU

OF WHICH $\triangle 5$ O\% IS

AEDOATED AEGVE 
SPILL TEST FACILITY 24 METER TOWER

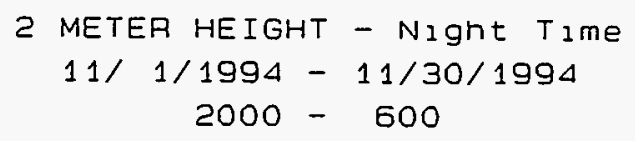

$N$

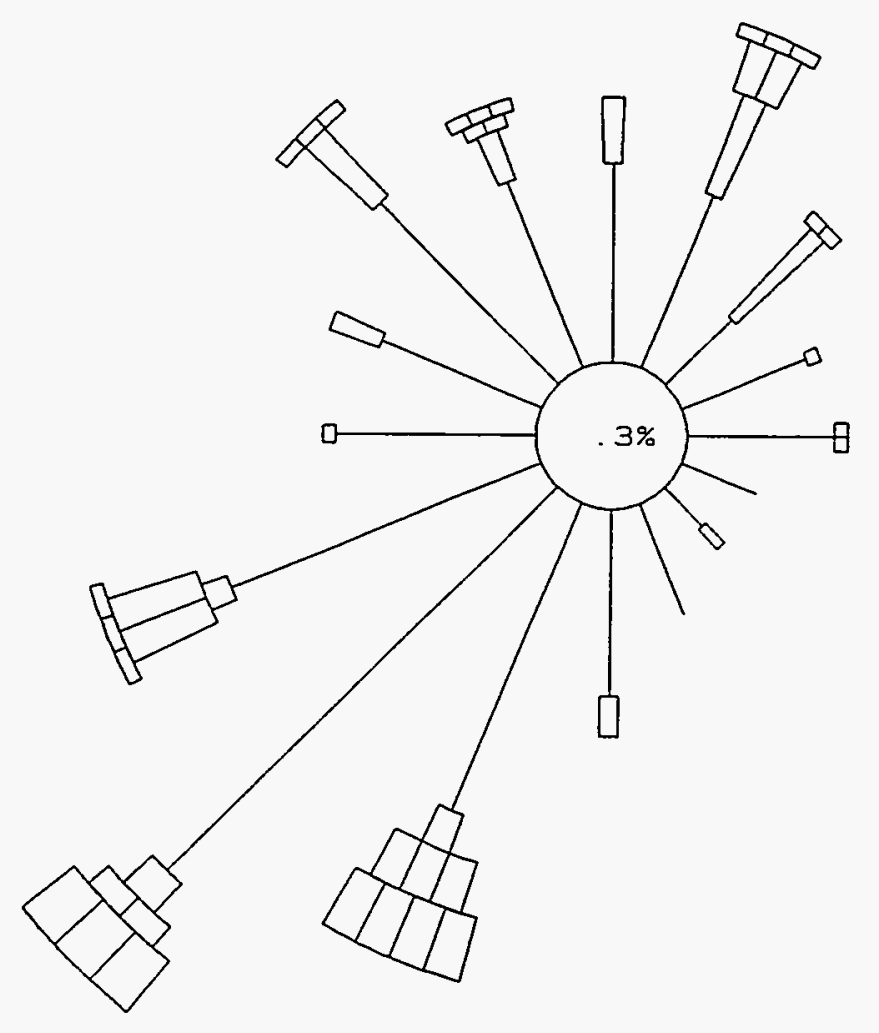

\begin{tabular}{|c|c|c|c|c|c|c|}
\hline WIND & $S P$ & EED & $\mathrm{CL}$ & $\mathrm{ASSE}$ & ES (MF & PS) \\
\hline CALM & 10 & & & WS & $<=$ & \\
\hline 1 & i & & $5<$ & WS & $<=$ & 1 \\
\hline 2 & $\square$ & 1 & $.8<$ & WS & $<=3$ & 3 \\
\hline 3 & पם & 3 & $.3<$ & WS & $<=5$ & 5 \\
\hline 4 & Dण & 5 & $.4<$ & WS & $<=\varepsilon$ & 8 \\
\hline 50 & पाम & 8 & $.5<$ & WS & $<=10$ & \\
\hline $6 \square$ & טחII & 10 & $.8<$ & WS & & \\
\hline
\end{tabular}

$100.0 \%$ DATA RECOVERED

OF WHICH $45.8 \%$ IS

REPORTED ABOVE 
SPILL TEST FACILITY 24 METER TOWEA

2 METER HEIGHT - Night Time

$12 / 1 / 1994-12 / 31 / 1994$

$2000-600$

$N$

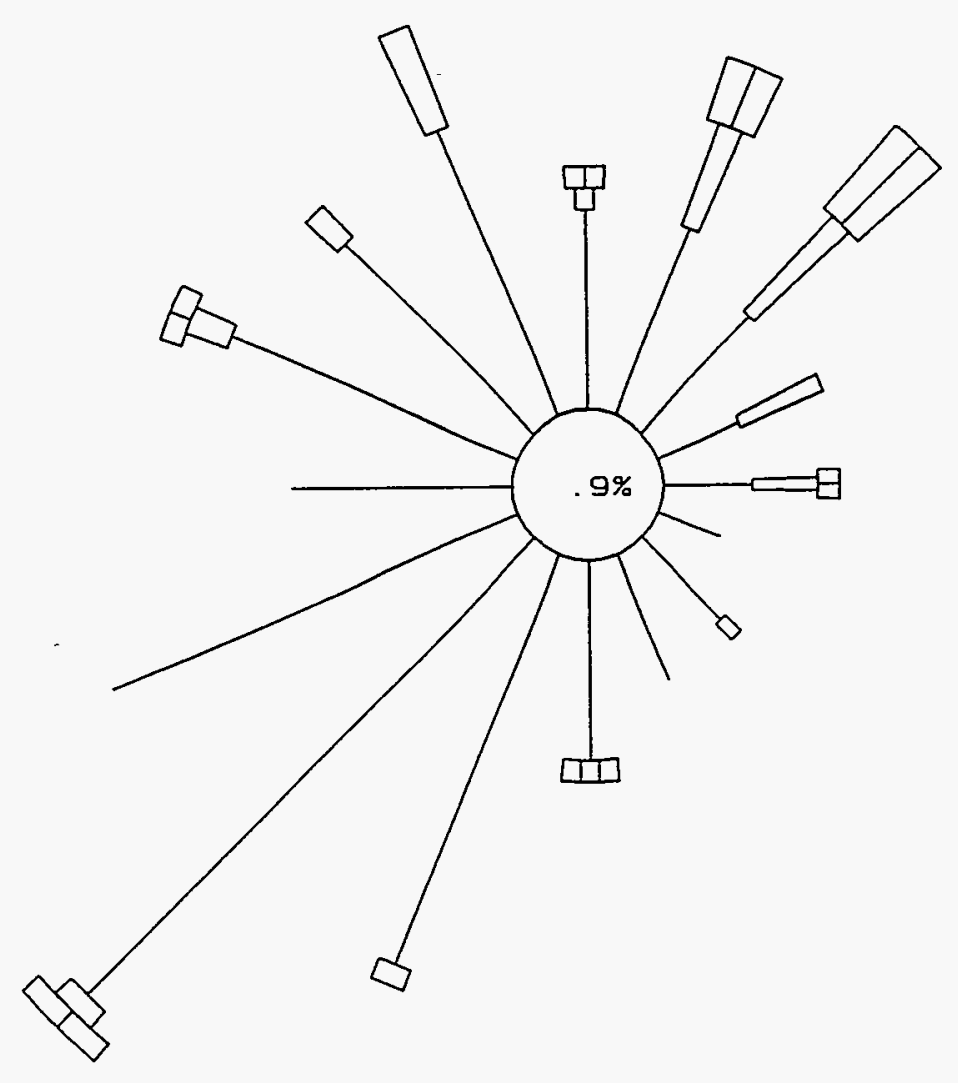

\begin{tabular}{|c|c|c|c|c|}
\hline WIND & $S P$ & $=0 \quad C L$ & $5=$ & $S$ IMF \\
\hline CALM & 10 & & WS & $<=$ \\
\hline 1 & 1 & $5<$ & WS & $<=1.8$ \\
\hline 2 & 口 & $1.8<$ & WS & $c=3.3$ \\
\hline 3 & ص & $3.3<$ & WS & $<=5.4$ \\
\hline 4 & पात & $5.4<$ & WS & $<=8.5$ \\
\hline 5 & סा1 & $8.5<$ & WS & $<=10.8$ \\
\hline 65 & סד口 & $10.8<$ & WS & \\
\hline
\end{tabular}

65. 1\% DATA RECOVERED

OF WHICH $45.7 \%$ IS

REPORTED ABOVE

$14.0 \%$

$10 \%$ 
SPILL TEST FACILITY 24 METER TOWER

STABILITY CLASS A

2 METER HEIGHT - Total Hours

$1 / 1 / 1994-1 / 31 / 1994$

$0-2300$

N
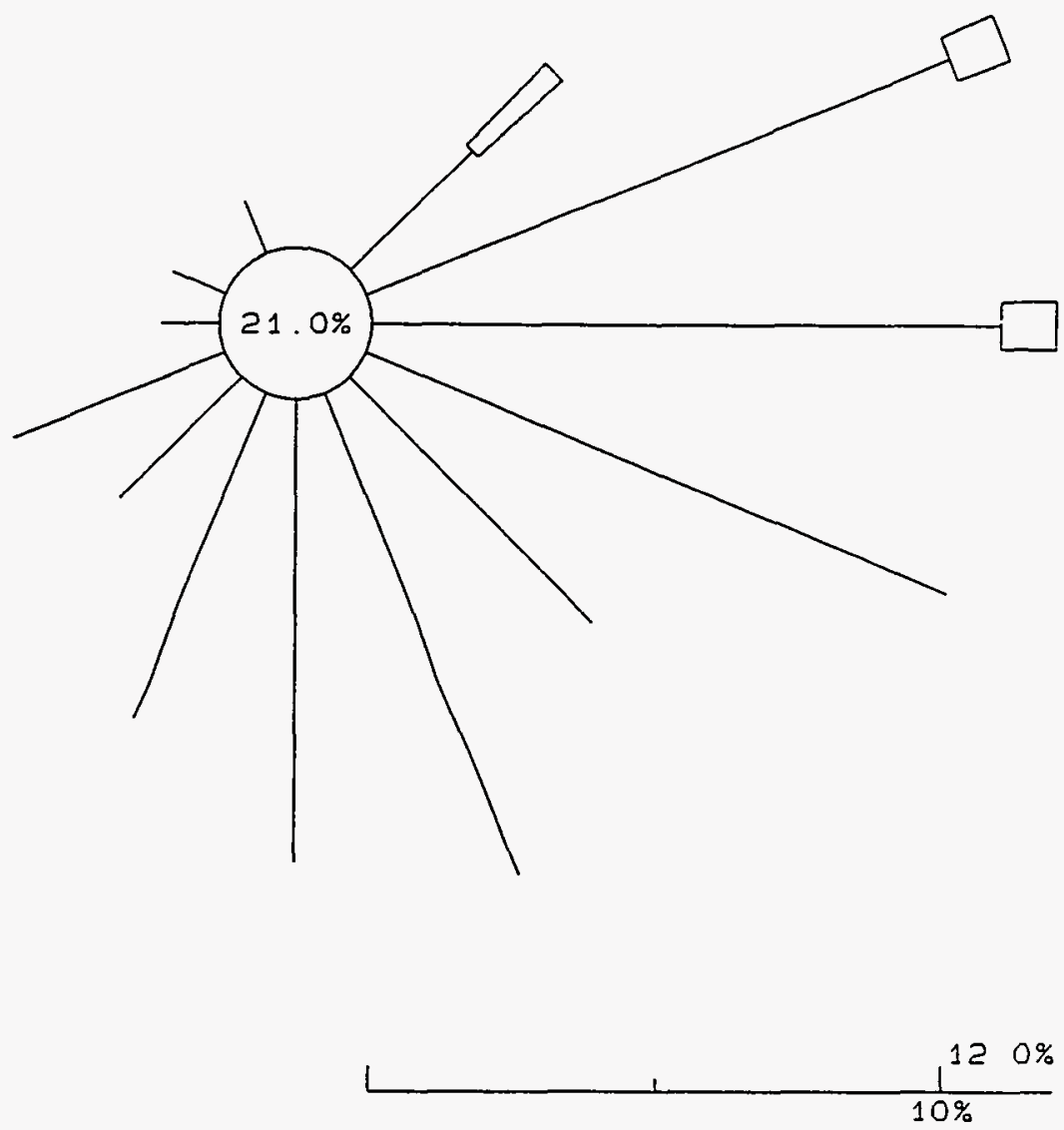

WIND SPEED CLASSES (MPS) CALM $O \quad W S<=.5$ $11.5<$ WS $<=1.8$ 2 ㅁ $1.8<$ WS $<=3.3$ 3 का $3.3<$ WS $<=5.4$ 4 एा $5.4<W S<=8.5$ 5 페 $8.5<W S<=10.8$ 6 10.8< WS
$78.0 \%$ DATA RECOVERED

OF WHICH $17.2 \%$ IS REPORTED ABOVE 


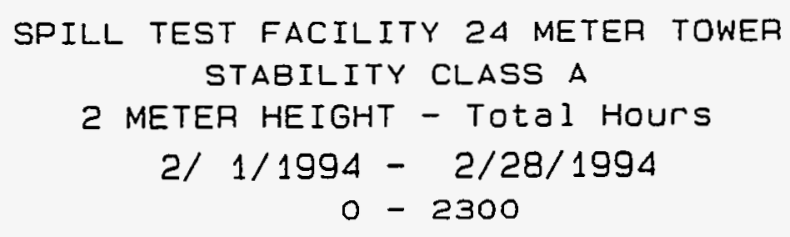

$N$
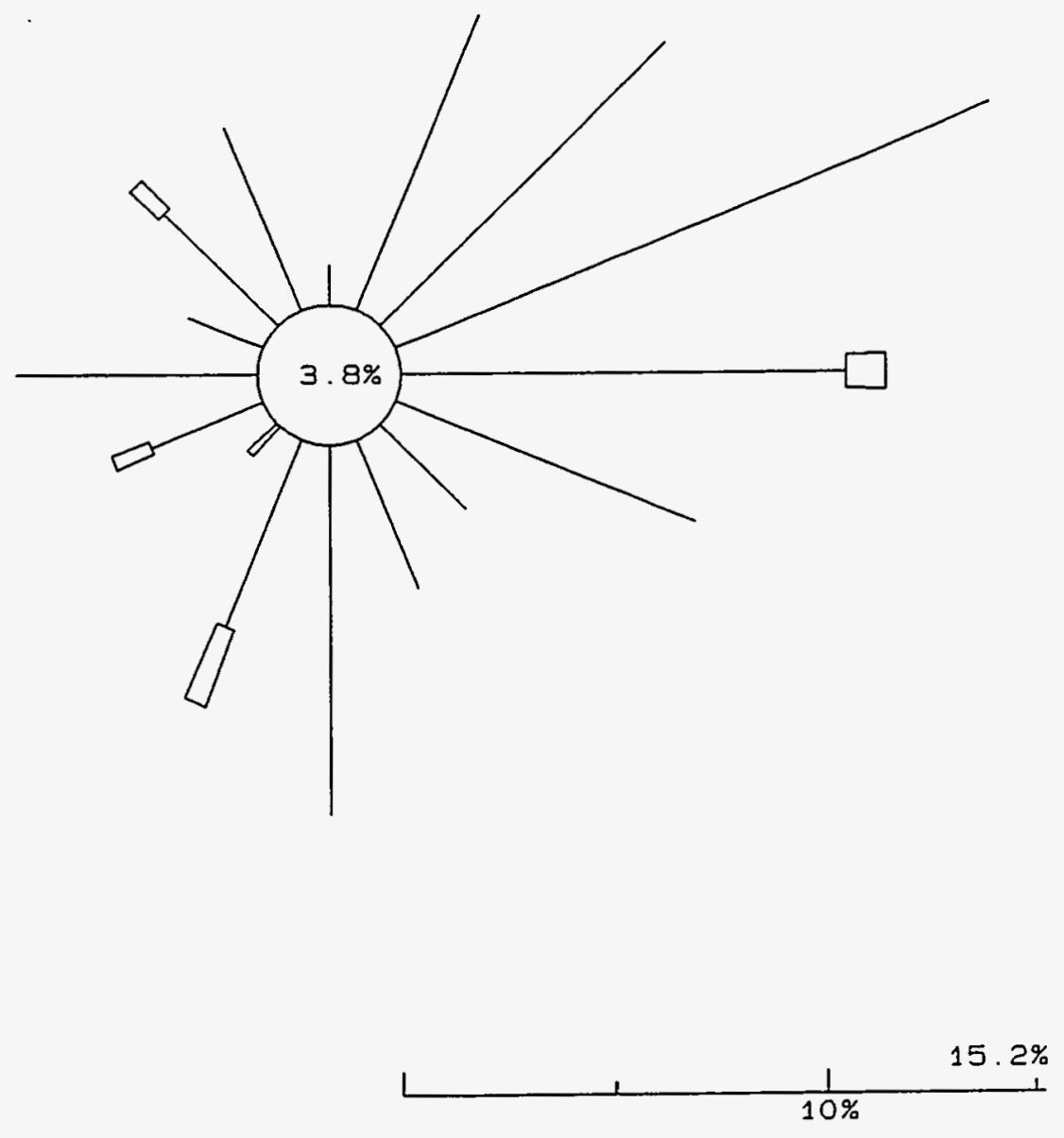

85. 4\% DATA RECOVERED

OF WHICH 18.3\% IS

REPORTED ABOVE 


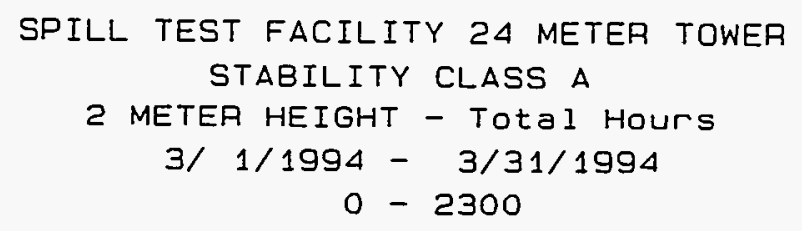

N
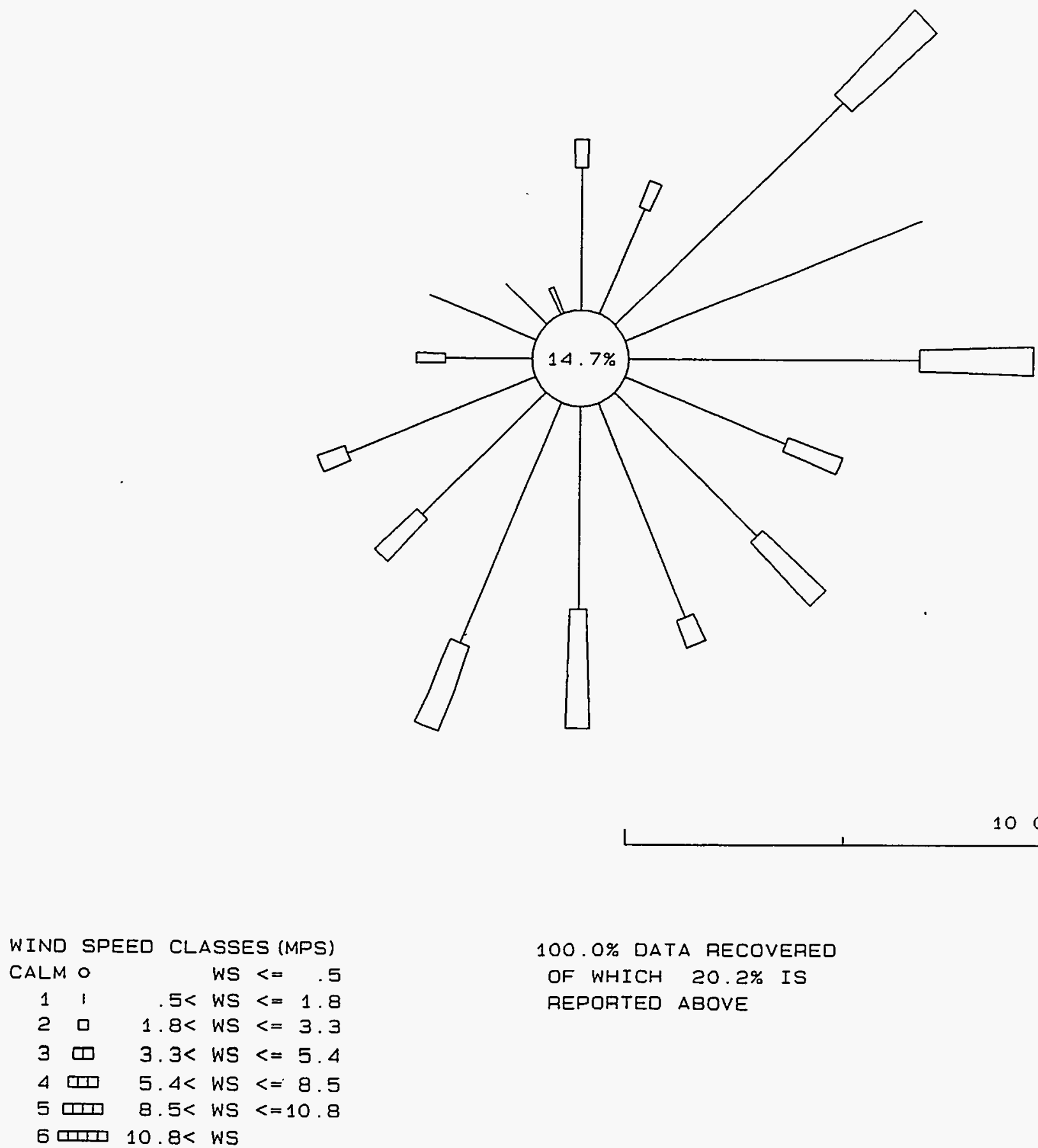


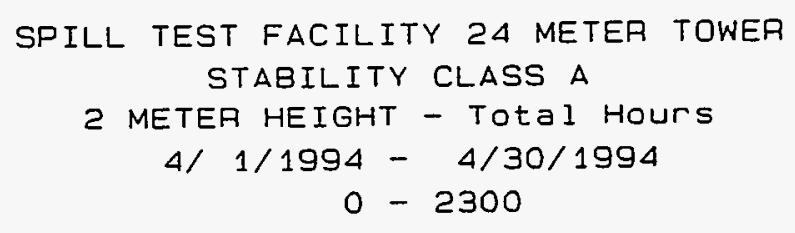

$N$
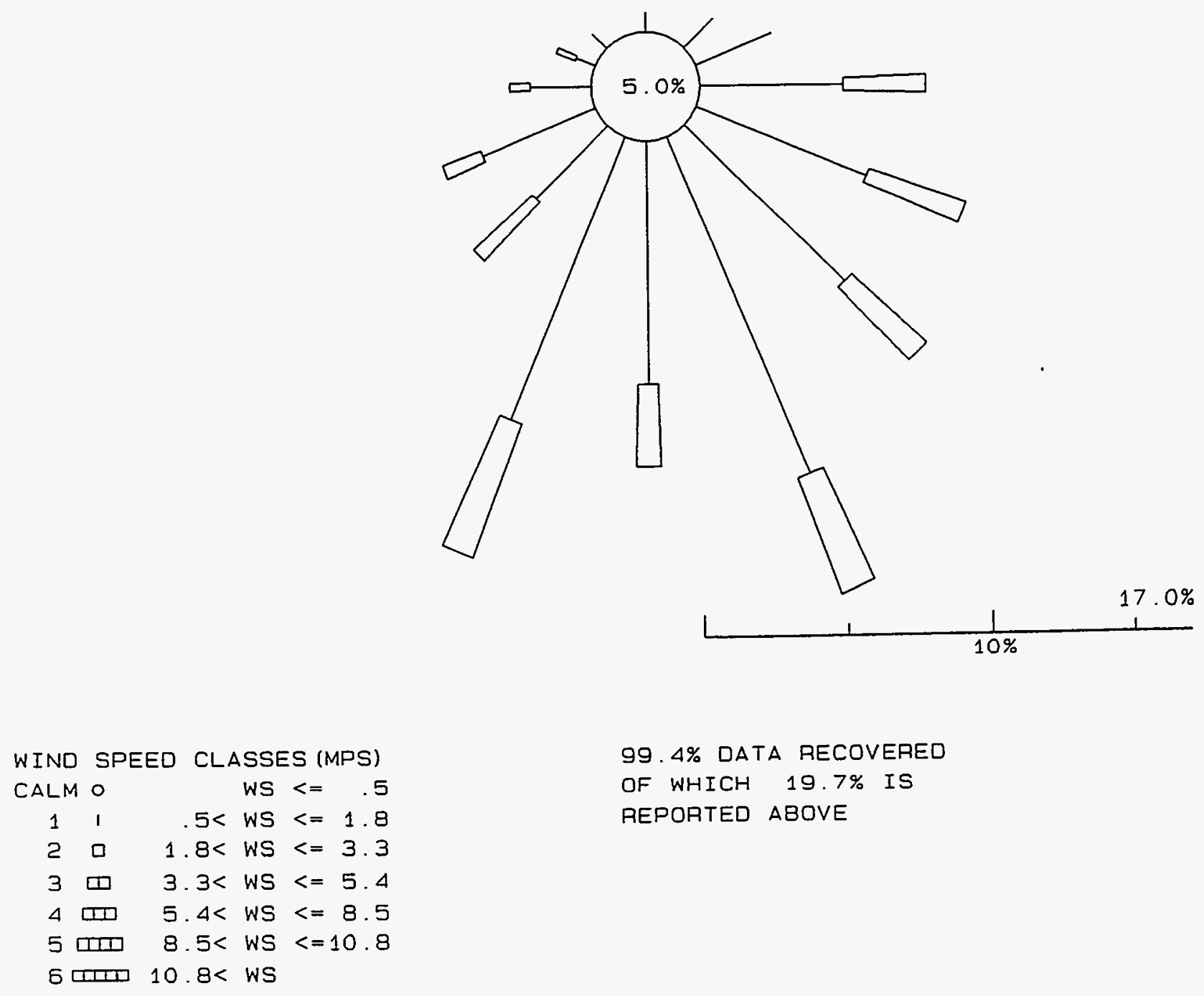

99. 4\% DATA RECOVERED

OF WHICH 19.7\% IS

REPORTED ABOVE 


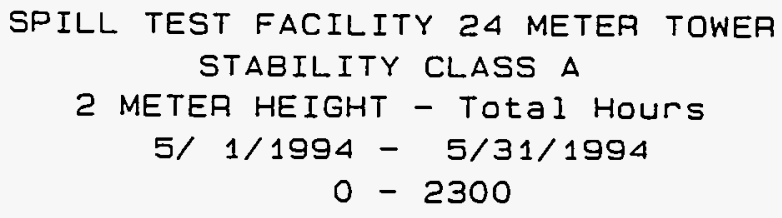

$N$

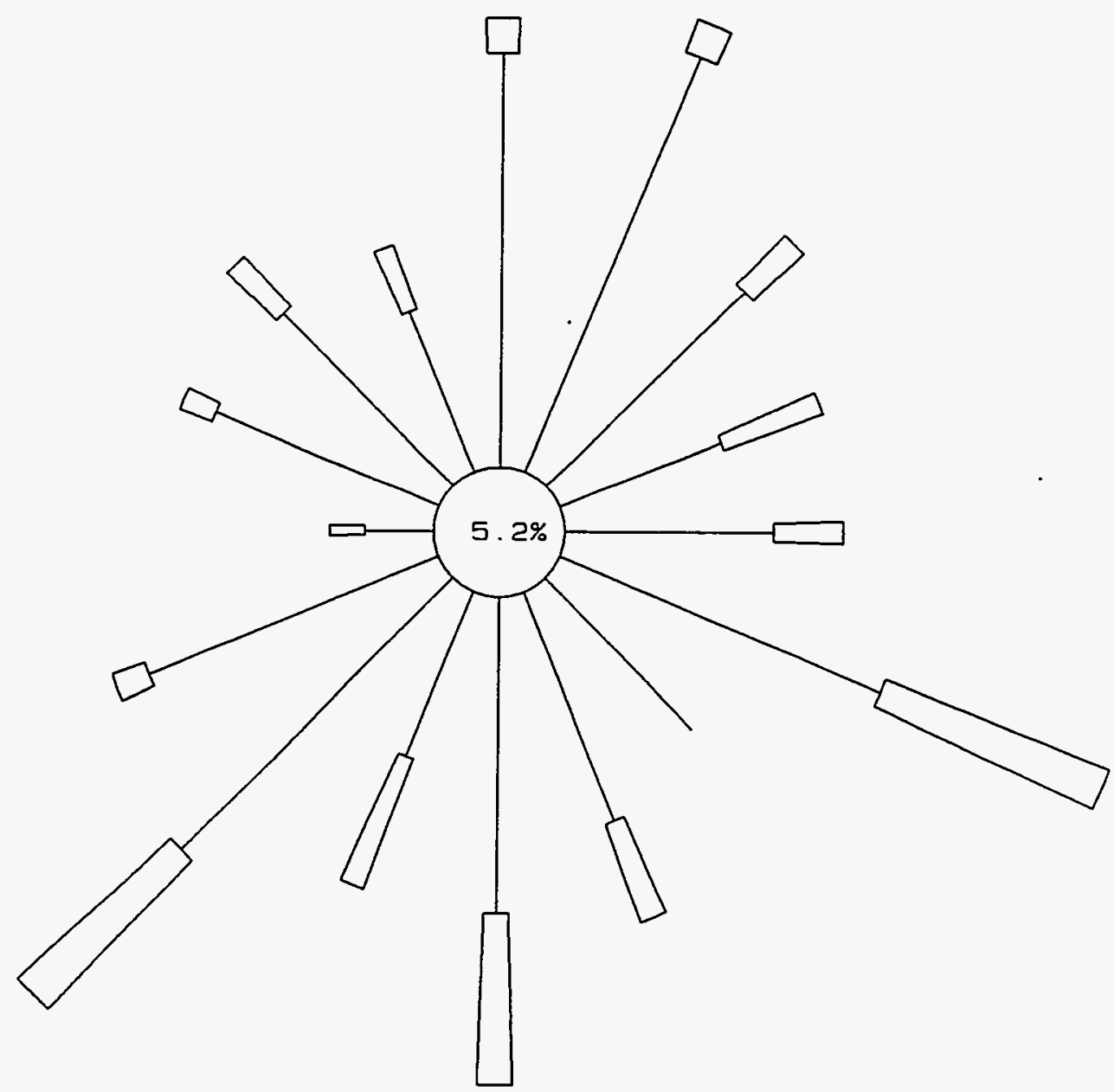

\begin{tabular}{|c|c|c|c|c|c|}
\hline IND & $S P R$ & $E D$ & CL & $\Delta S S E$ & ES (MPS \\
\hline CALM & 10 & & & WS & $<=$. \\
\hline 1 & I & & $5<$ & WS & $<=1.8$ \\
\hline 2 & ם & 1 & $.8<$ & WS & $<=3.3$ \\
\hline 3 & שי & 3 & $.3<$ & WS & $<=5$. \\
\hline 4 & שי & 5 & $.4<$ & WS & $<=8$. \\
\hline 5 & דाI & 0 & $.5<$ & WS & $<=10$. \\
\hline & & & & & \\
\hline
\end{tabular}




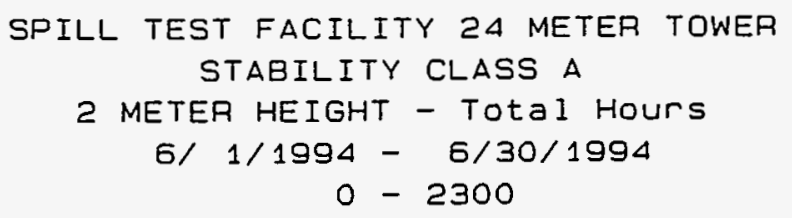

$N$
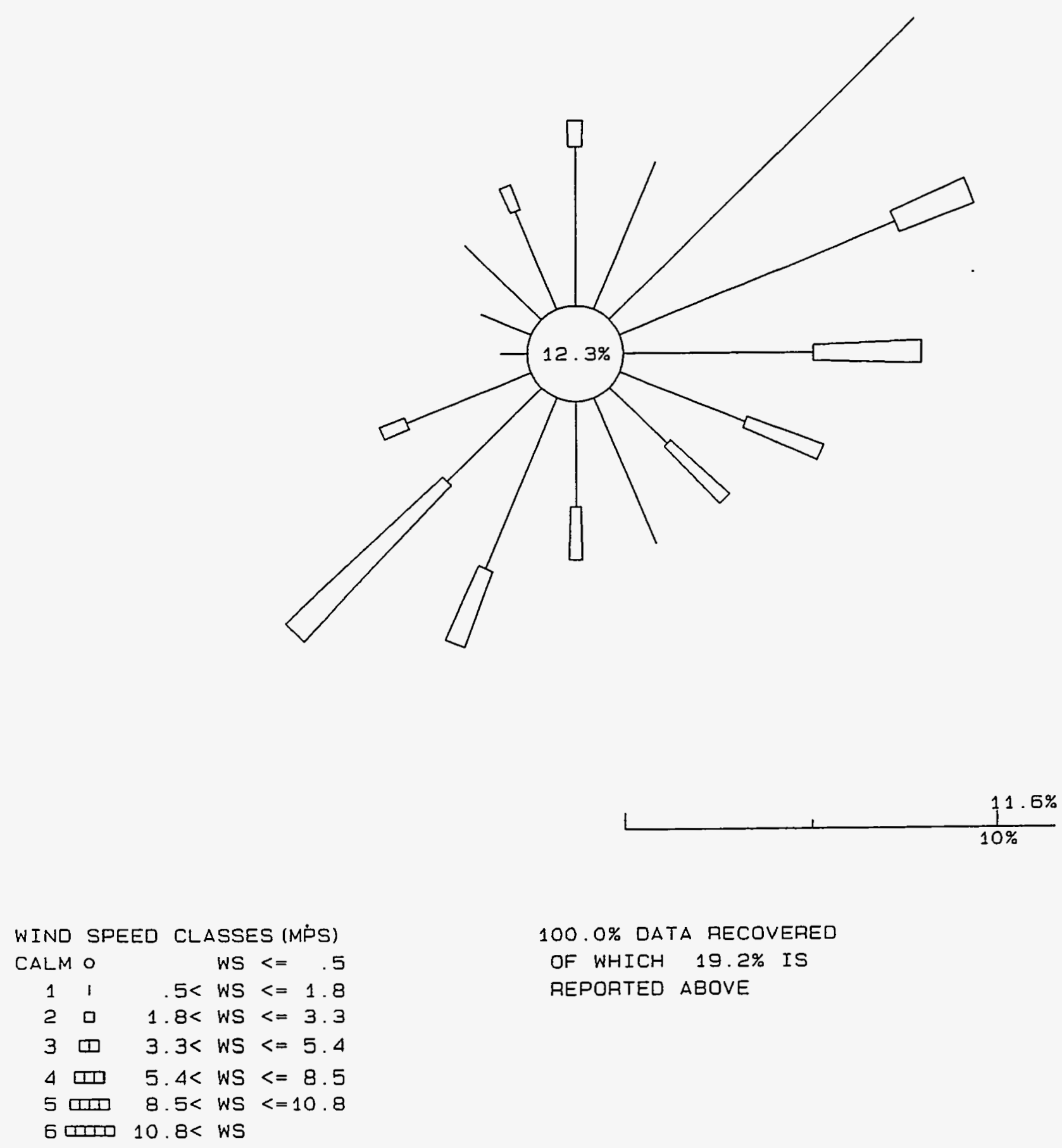

$100.0 \%$ DATA RECOVERED

OF WHICH $19.2 \%$ IS

REPORTED ABOVE 


\section{SPILL TEST FACILITY 24 METER TOWER \\ STABILITY CLASS A \\ 2 METER HEIGHT - Total Hours \\ $7 / 1 / 1994-7 / 31 / 1994$ \\ $0-2300$}

N

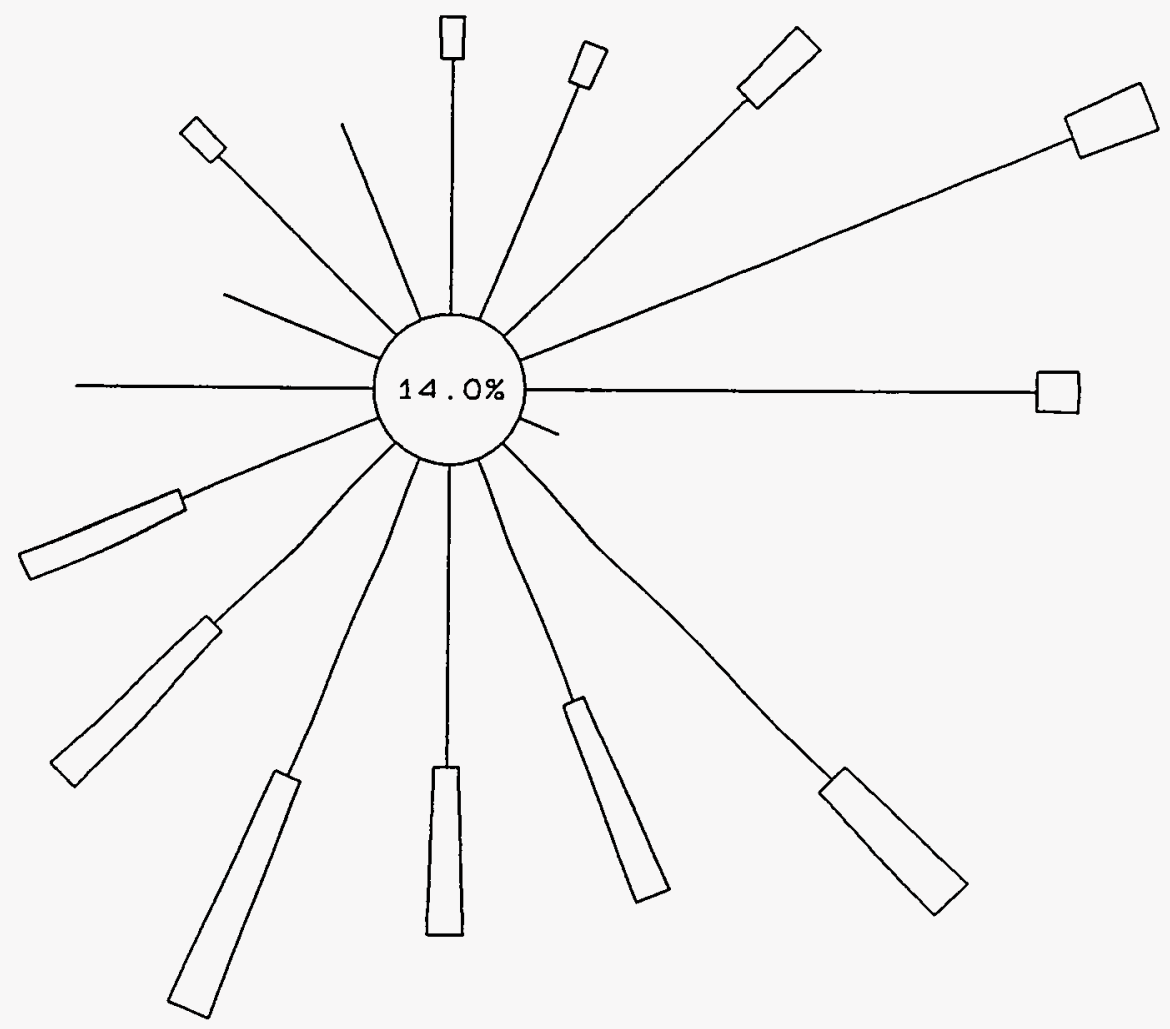

\begin{tabular}{|c|c|c|c|c|c|}
\hline WIND & $S P$ & ED & $C L$ & ASS & $S$ (MPS) \\
\hline CALM & 10 & & & WS & $<=$ \\
\hline 1 & 1 & & $5<$ & WS & $<=1.8$ \\
\hline 2 & 口 & 1 & $8<$ & WS & $<=3.3$ \\
\hline 3 & प & 3 & $.3<$ & WS & $<=5.4$ \\
\hline 4 & סם & 5 & $.4<$ & WS & $<=8.5$ \\
\hline 5 & שणप & 8 & $.5<$ & WS & $<=10.8$ \\
\hline 6 & סחד] & 10 & $.8<$ & WS & \\
\hline
\end{tabular}

$100.0 \%$ DATA RECOVERED

OF WHICH 23.1\% IS

REPORTED ABOVE 


\section{SPILL TEST FACILITY 24 METEA TOWER \\ STABILITY CLASS A \\ 2 METER HEIGHT - Total Hours \\ 9/ $1 / 1994-9 / 30 / 1994$ \\ $0-2300$}

N
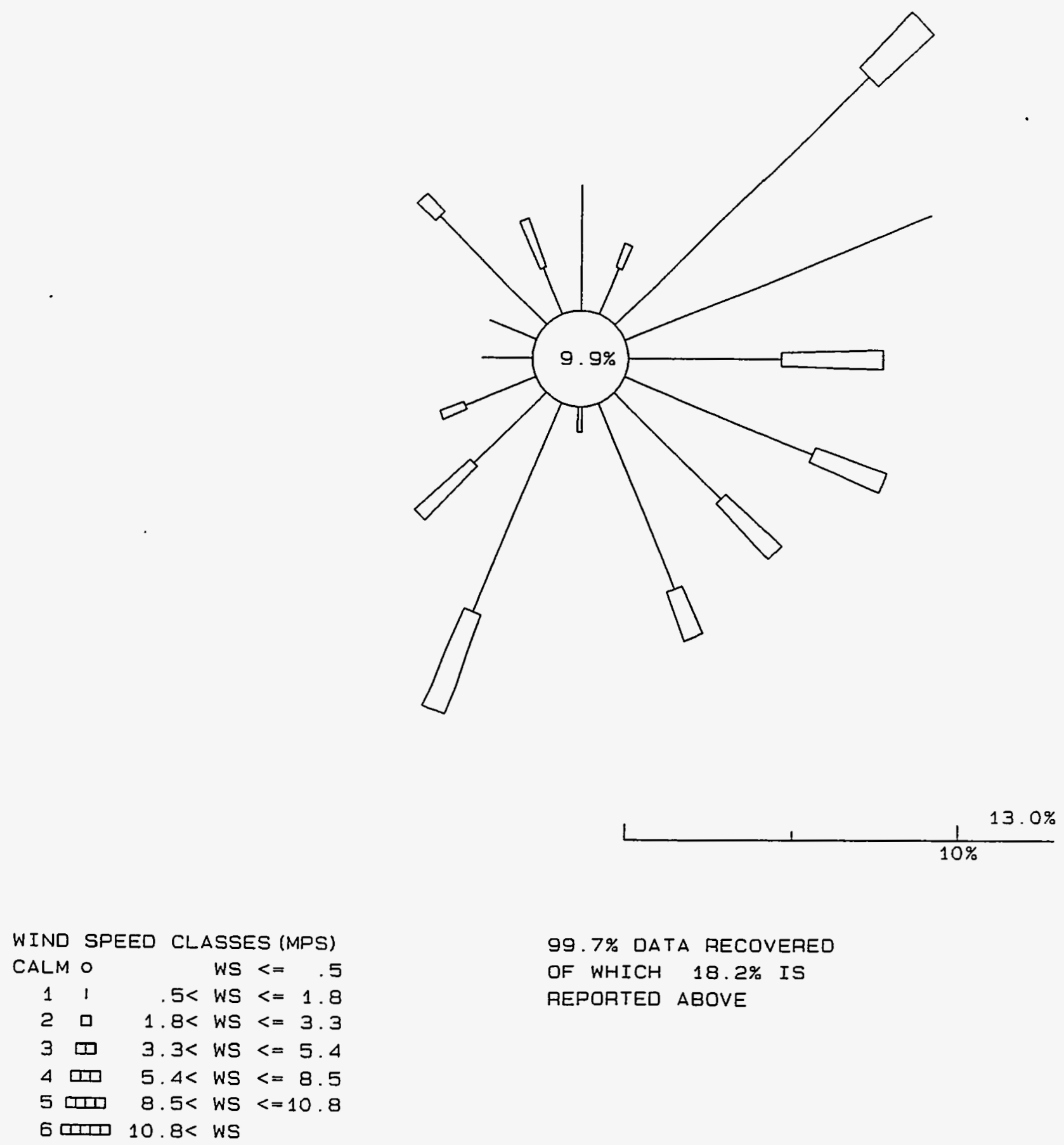

99.7\% DATA RECOVERED

OF WHICH 18.2\% IS

REPORTED ABOVE 


\section{SPILL TEST FACILITY 24 METER TOWER STABILITY CLASS A \\ 2 METER HEIGHT - Total Hours \\ $10 / 1 / 1994-10 / 31 / 1994$ \\ $0-2300$}

$N$
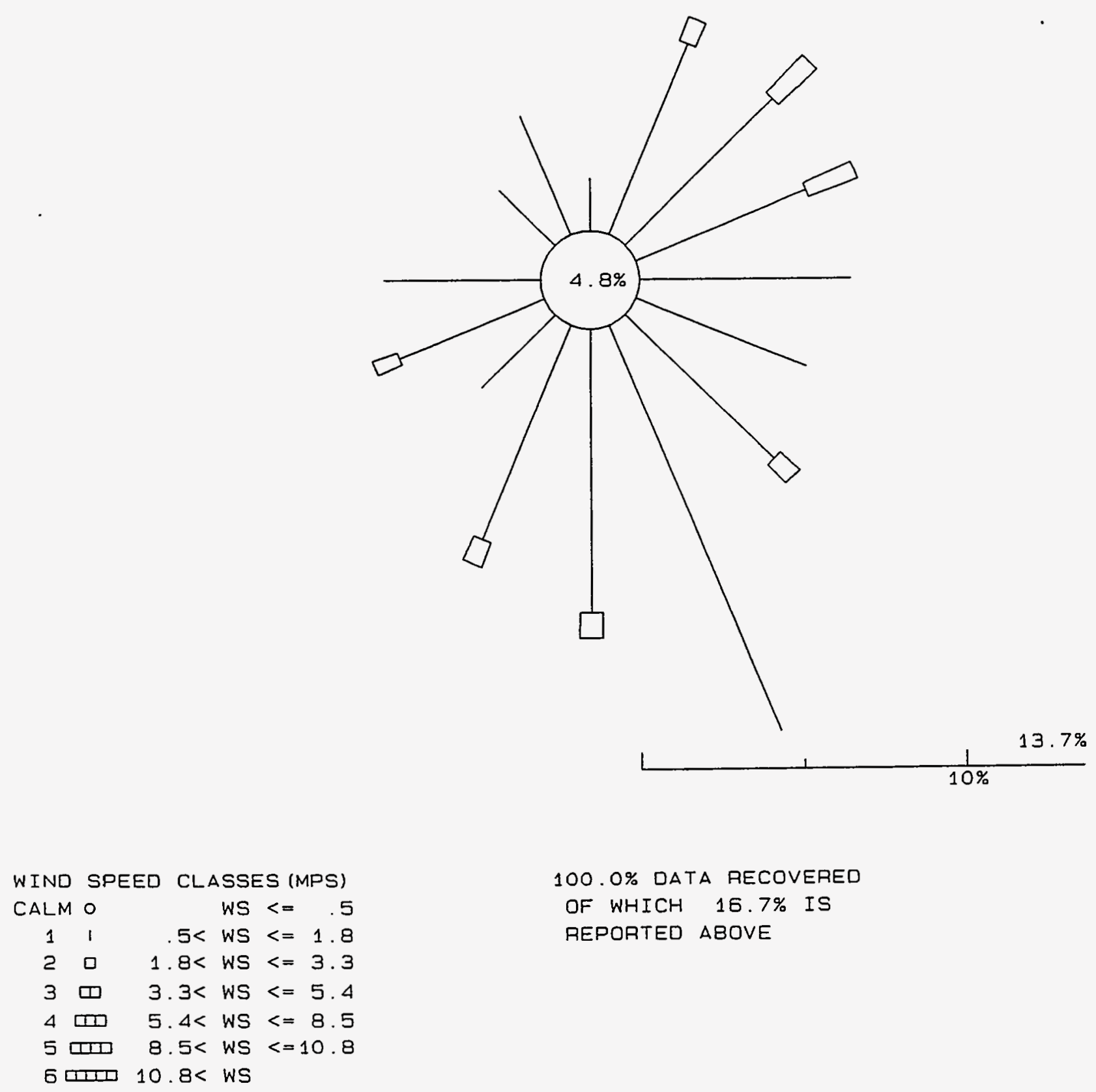

$100.0 \%$ DATA RECOVERED

OF WHICH $16.7 \%$ IS

REPORTED ABOVE 


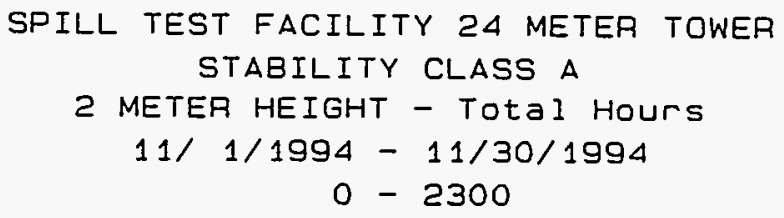

N

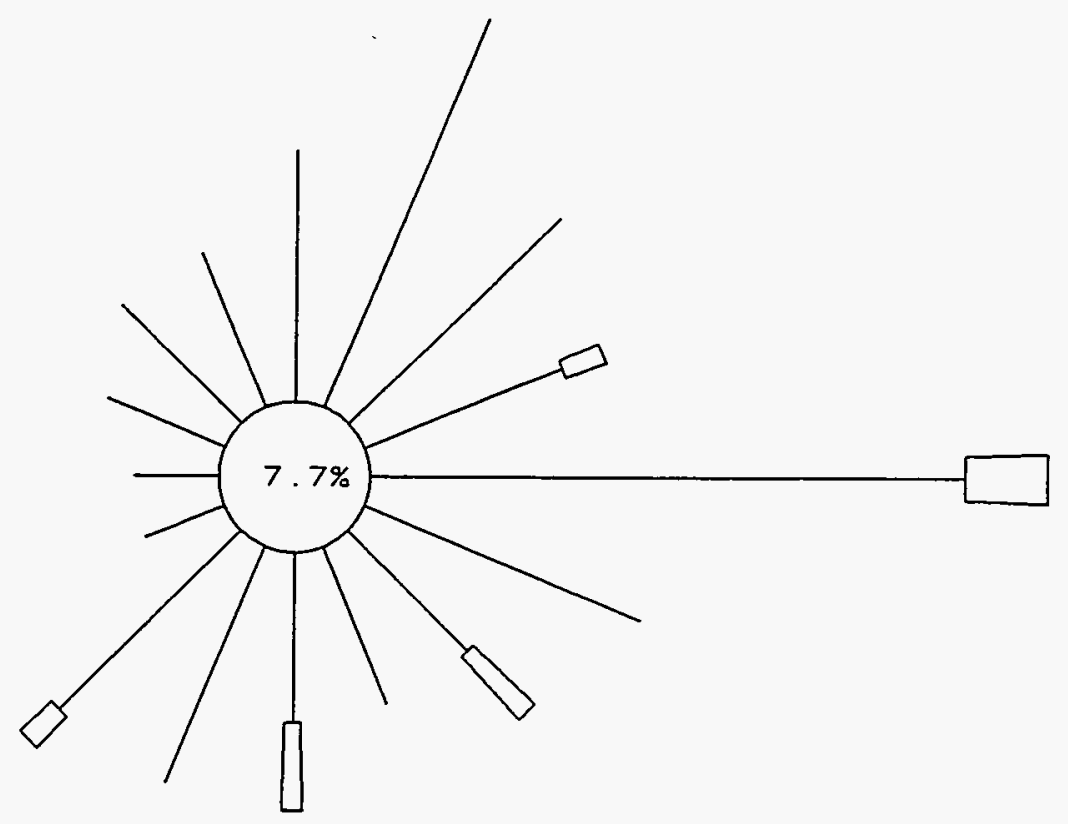

\begin{tabular}{|c|c|c|c|c|}
\hline NINO & SPE & ED CL & $\triangle S S E$ & $S$ (MPS) \\
\hline CALM & 10 & & WS & $<=$ \\
\hline 1 & I & $5<$ & WS & $<=1.8$ \\
\hline 2 & $\square$ & $1.8<$ & WS & $c=3.3$ \\
\hline 3 & שם & $3.3<$ & WS & $<=5.4$ \\
\hline 4 & هח & $5.4<$ & WS & $<=8.5$ \\
\hline 5 & סד口ם & $8.5<$ & WS & $<=10.8$ \\
\hline 65 & סדप & $10.8<$ & WS & \\
\hline
\end{tabular}

100.0\% DATA AECOVERED

OF WHICH 14.4\% IS

REPORTED ABOVE 


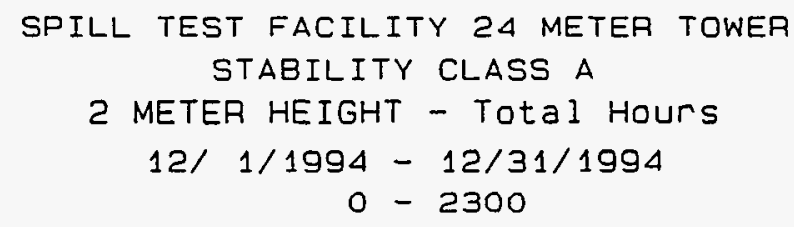

$N$
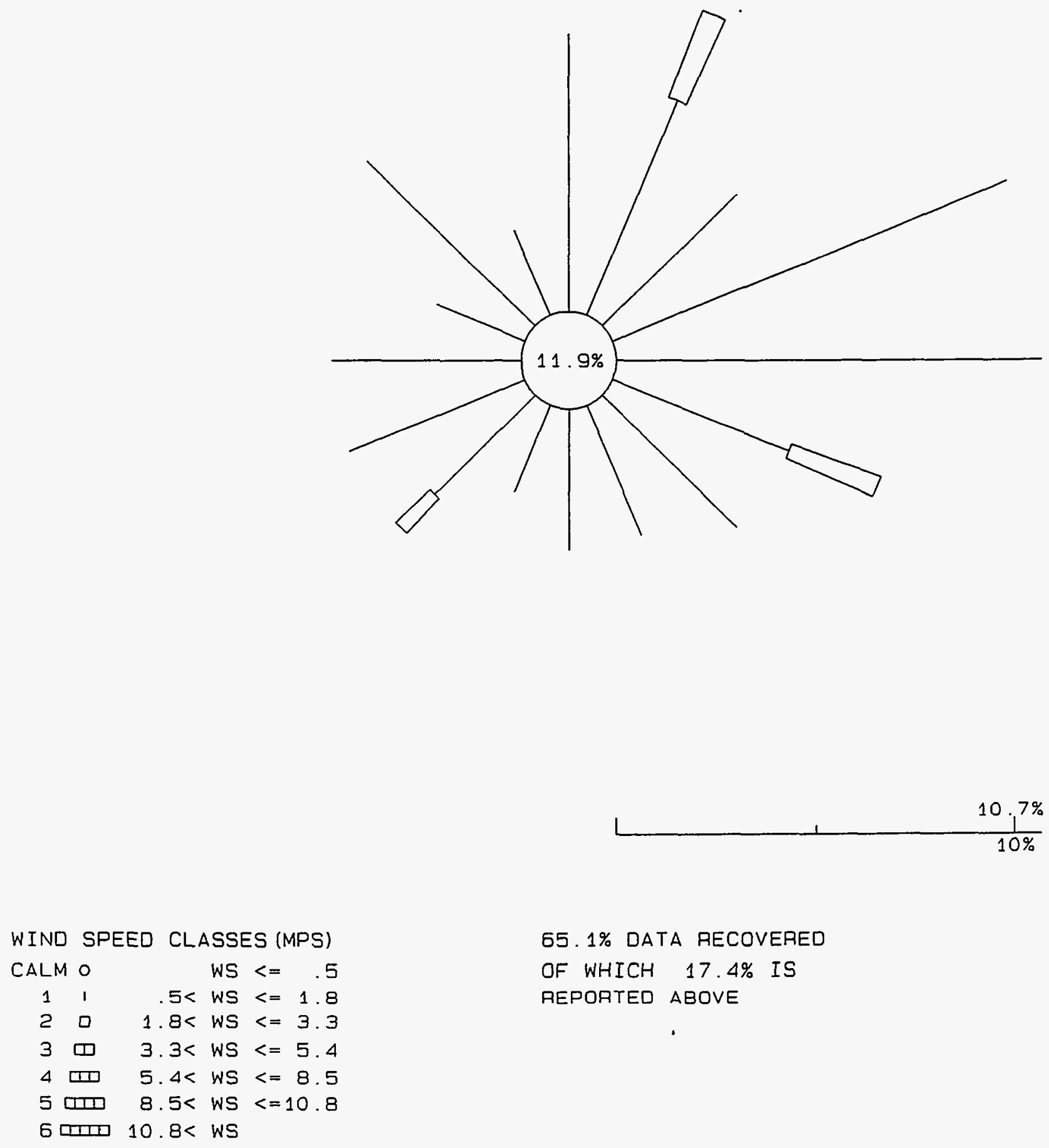


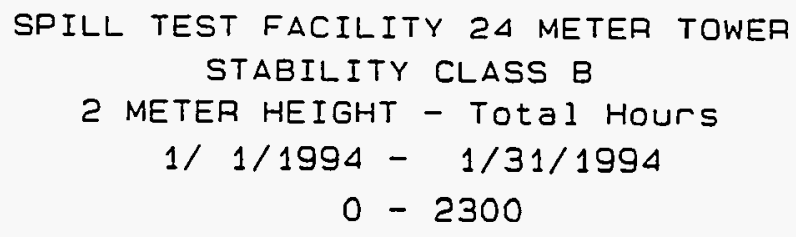

$N$

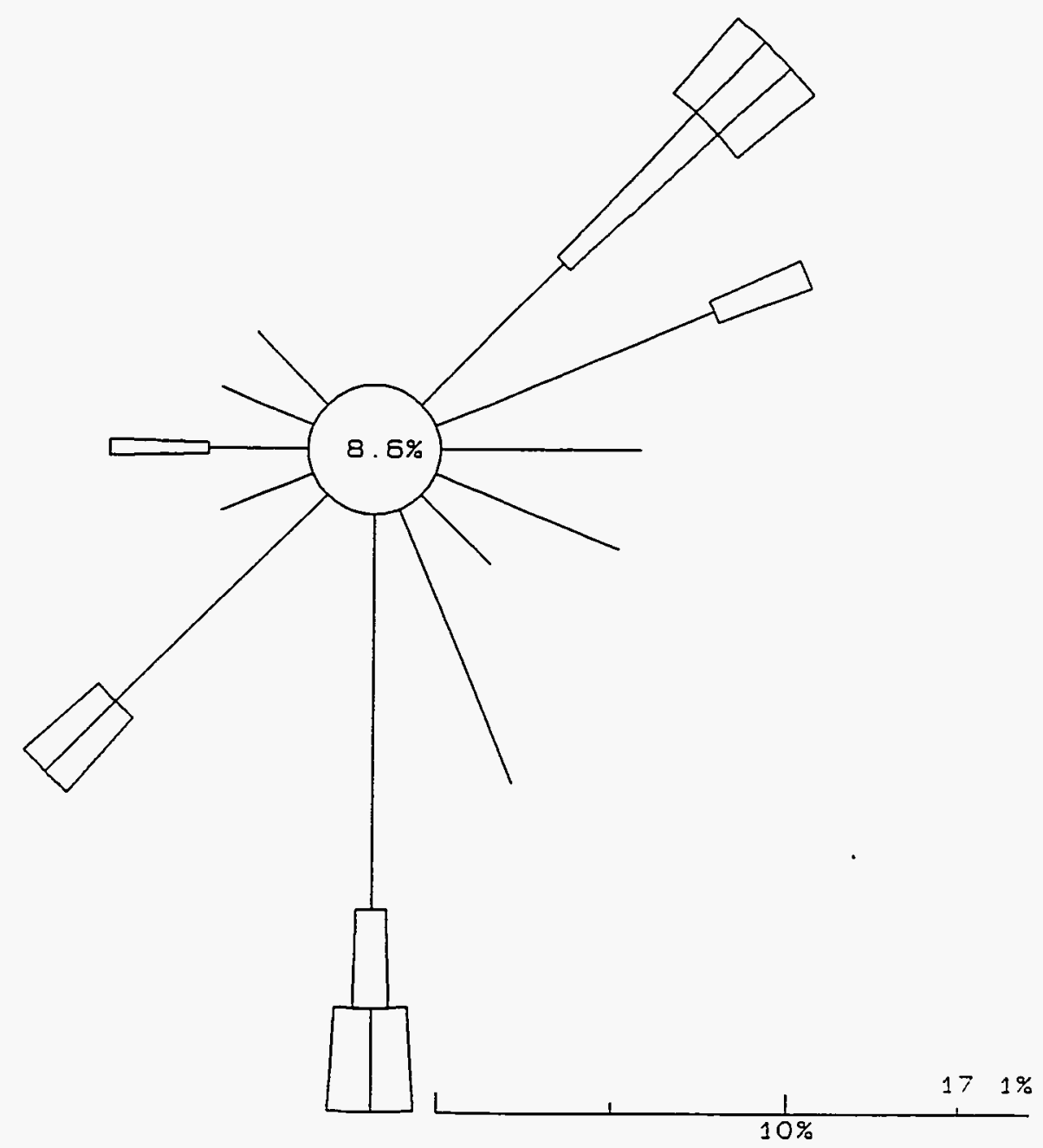

\begin{tabular}{|c|c|c|c|c|c|}
\hline WIND & $S P$ & EED & $C L$ & $\Delta S S$ & S (MPS) \\
\hline CALM & 10 & & & WS & $<=$ \\
\hline 1 & 1 & & $5<$ & WS & $<=1.8$ \\
\hline 2 & ם & 1 & $.8<$ & WS & $<=3$. \\
\hline 3 & प & 3 & $.3<$ & WS & $<=5.4$ \\
\hline 4 & प्म & 5 & $.4<$ & WS & $<=8$ \\
\hline 5 & סדיד & 8 & $.5<$ & WS & $c=10$ \\
\hline $6 c$ & שחप & 10 & $.8<$ & WS & \\
\hline
\end{tabular}

78. O\% DATA RECOVERED

OF WHICH 6.0\% IS REPORTED ABOVE 


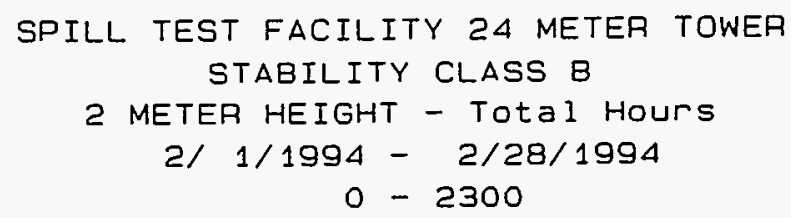

$N$

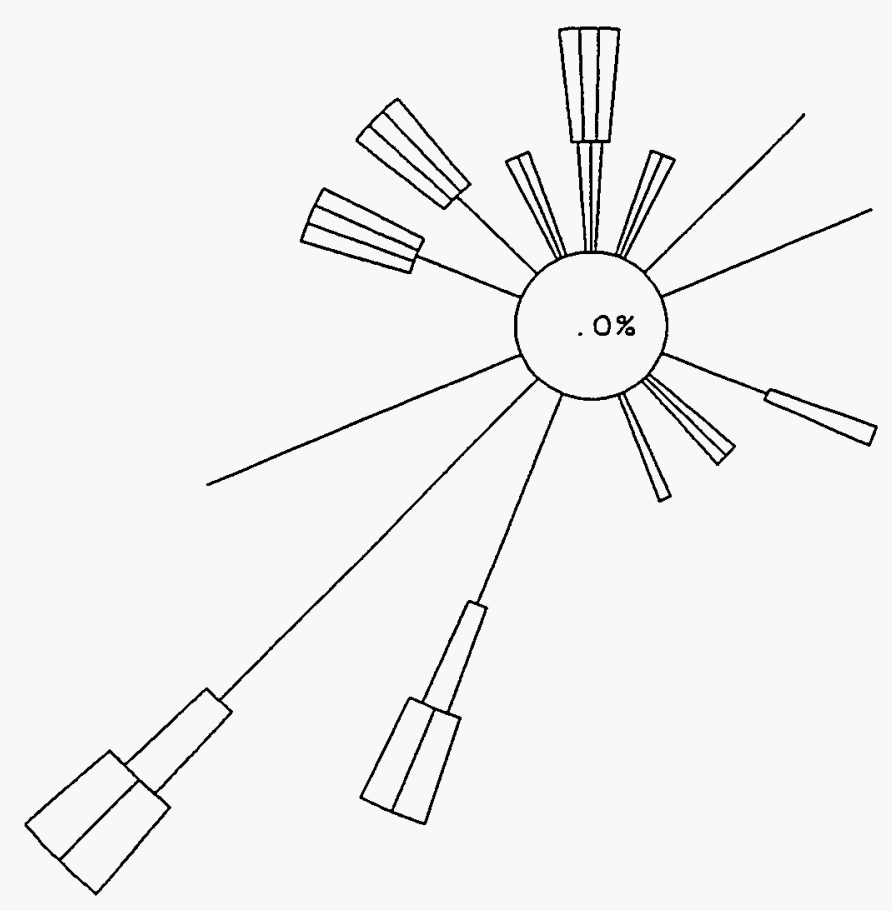

\begin{tabular}{|c|c|c|c|c|}
\hline W I NO & SPE & $=0 \mathrm{CL}$ & sst & 5 IMPS \\
\hline CALM & 0 & & WS & $<=$ \\
\hline 1 & 1 & $5<$ & WS & $<=1$. \\
\hline 2 & 口 & $1.8<$ & WS & $<=3$. \\
\hline 3 & ㅁ & $3.3<$ & WS & $<=5$. \\
\hline 4 & סש & $5.4<$ & WS & $<=8$. \\
\hline 5 & سחש & $8.5<$ & WS & $<=10$. \\
\hline 6 & סIII & $10.8<$ & WS & \\
\hline
\end{tabular}

85. 4\% DATA RECOVERED

OF WHICH $5.1 \%$ IS REPORTED ABOVE 
SPILL TEST FACILITY 24 METER TOWER STABILITY CLASS $B$

2 METER HEIGHT - Total Hours

$3 / 1 / 1994-3 / 31 / 1994$

$0-2300$

$N$

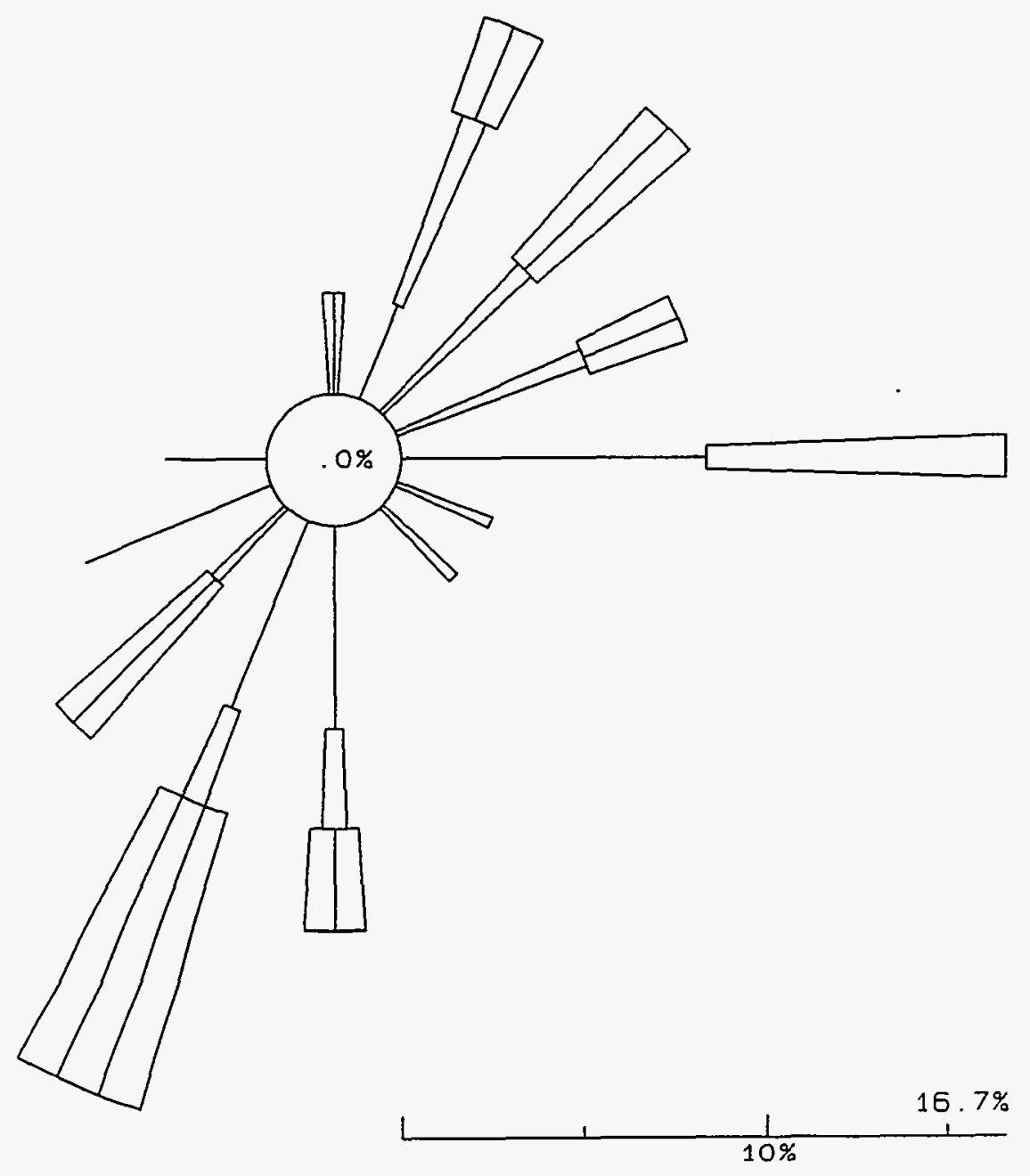

$$
\begin{aligned}
& \text { WIND SPEED CLASSES (MPS) } \\
& \text { CALM } O \quad \text { WS }<=\text {. } 5 \\
& 11.5<\text { WS }<=1.8 \\
& 2 \square \quad 1.8<\text { WS }<=3.3 \\
& 3 \text { 미 } 3.3<W S<=5.4 \\
& 4 \text { पा } 5.4<W S<=8.5 \\
& 5 \text { पाया } 8.5<\text { WS }<=10.8 \\
& 6 \text { पाण } 10.8<\text {.WS }
\end{aligned}
$$




\section{SPILL TEST FACILITY 24 METER TOWEA STABILITY CLASS B \\ 2 METER HEIGHT - Total Hours \\ 5/ $1 / 1994-5 / 31 / 1994$ \\ $0-2300$}

N
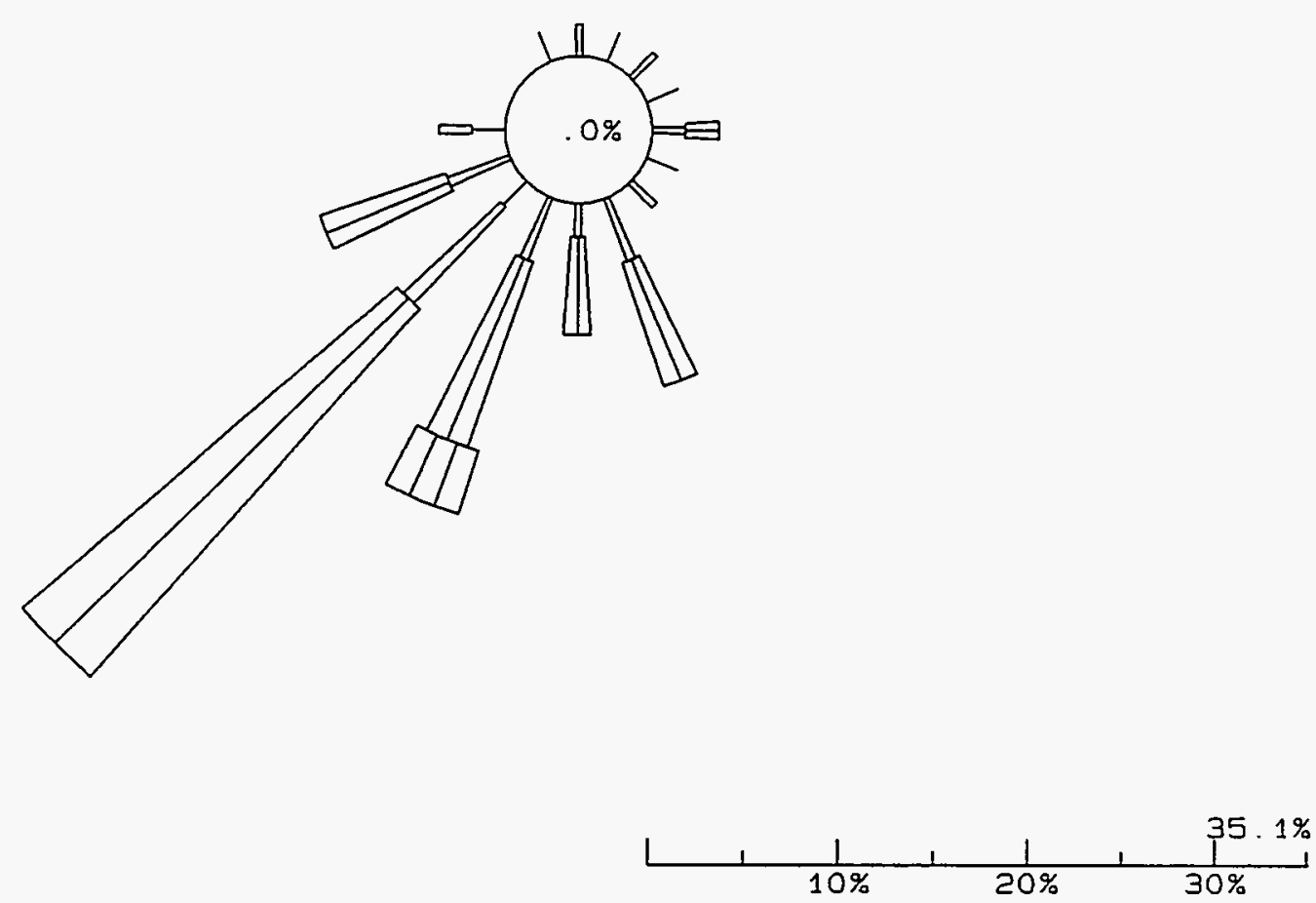

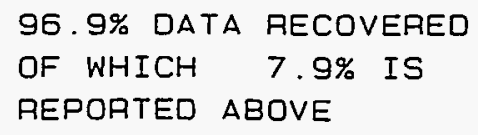




\section{SPILL TEST FACILITY 24 METER TOWER \\ STABILITY CLASS $B$ \\ 2 METER HEIGHT - Total Hours \\ 6/ $1 / 1994-6 / 30 / 1994$ \\ $0-2300$}

$N$
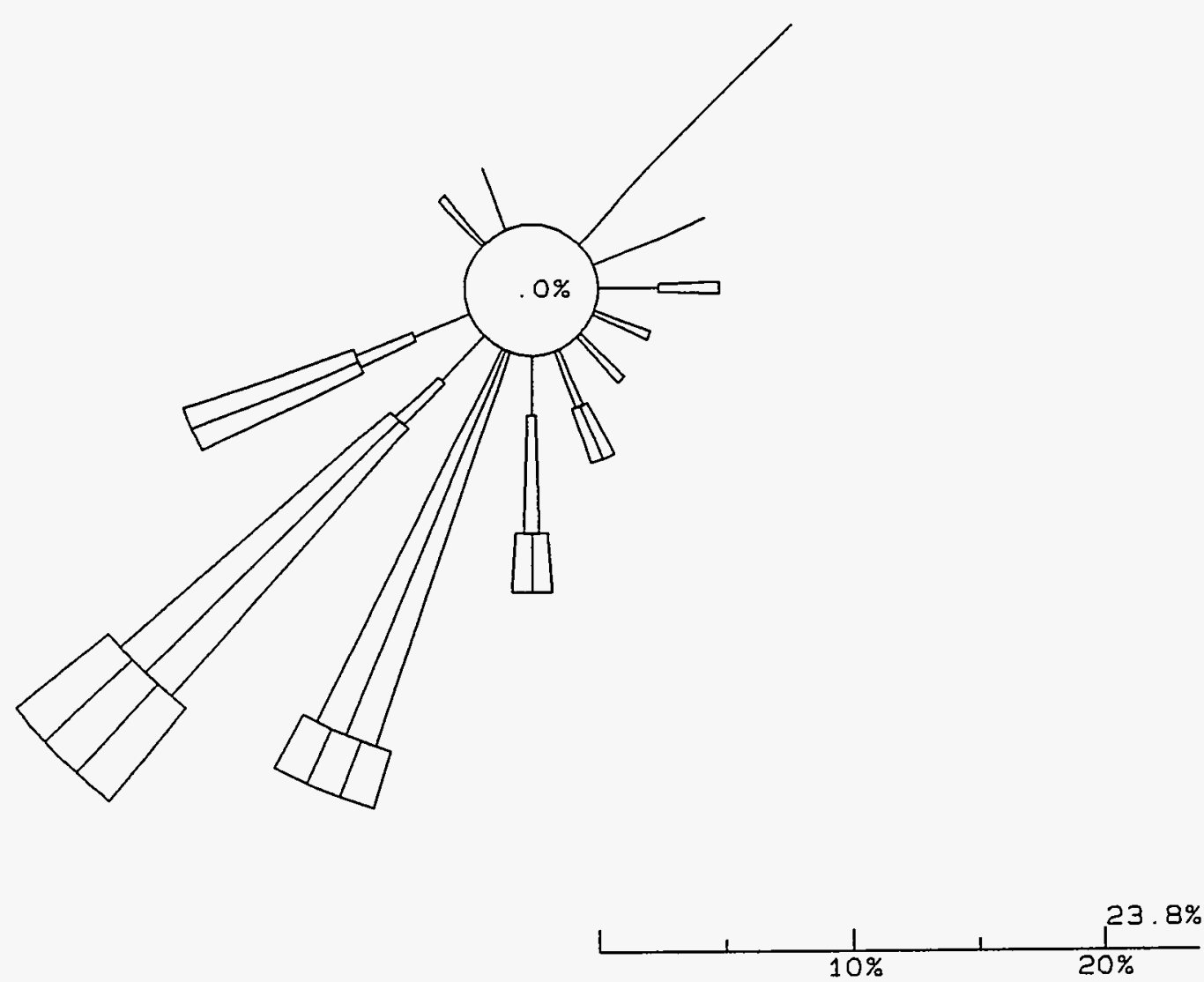

100.0\% DATA RECOVERED

OF WHICH $5.8 \%$ IS

REPORTED ABOVE 


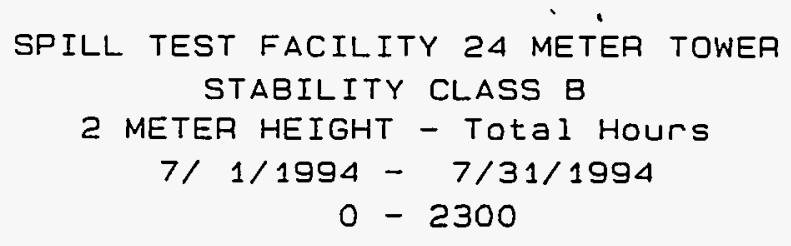

$N$

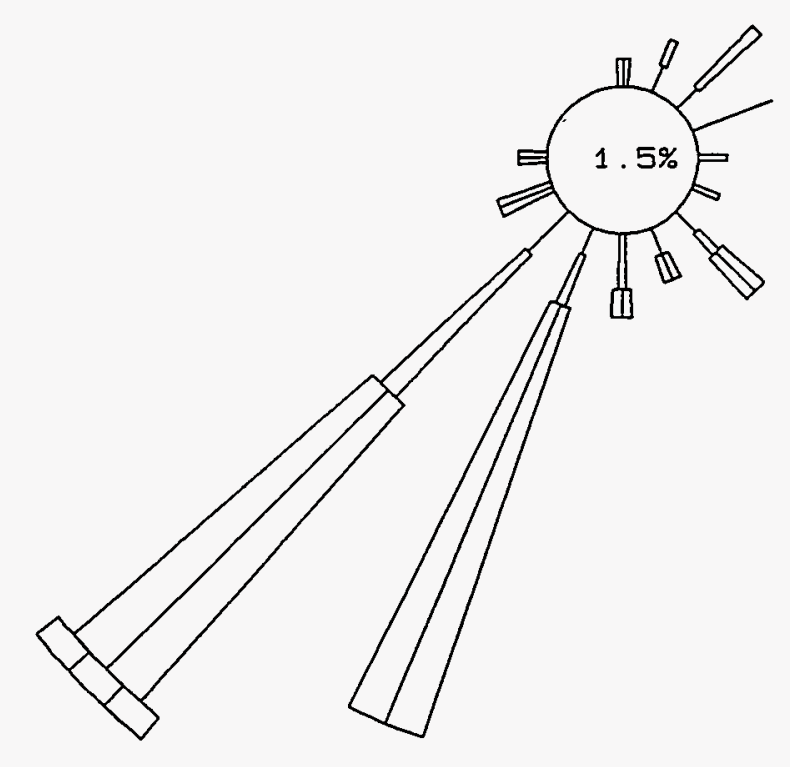

WIND SPEED CLASSES (MPS)

CALM $0 \quad W S<=.5$

$11.5<W S<=1.8$

$20 \quad 1.8<$ WS $<=3.3$

$3 \square \quad 3.3<$ WS $<=5.4$

4 पाग $5.4<W S<=8.5$

5 पा $8.5<$ WS $<=10.8$

6 पाला $10.8<$ WS

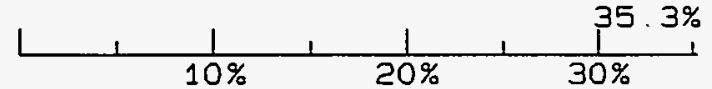

$100.0 \%$ DATA RECOVERED

OF WHICH $9.1 \%$ IS

REPORTED ABOVE 


\section{SPILL TEST FACILITY 24 METER TOWER STABILITY CLASS $B$ \\ 2 METER HEIGHT - Total Hours \\ 8/1/1994 - 8/31/1994 \\ $0-2300$}

N
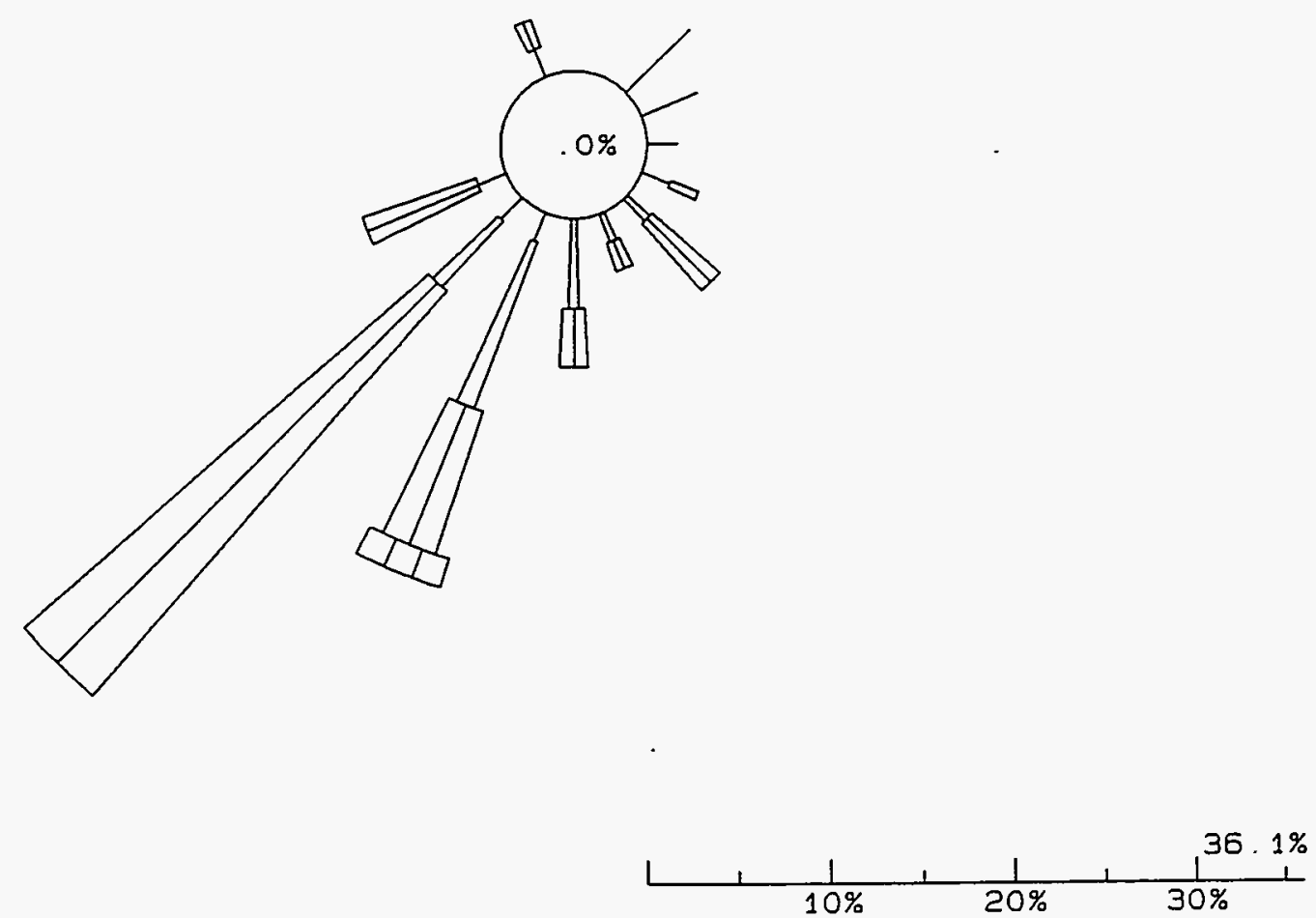

\begin{tabular}{|c|c|c|c|c|c|}
\hline WIND & $S P E$ & ED & CL & $A S E$ & S (MPS) \\
\hline CALM & 10 & & & WS & $<=$ \\
\hline 1 & I & & $5<$ & WS & $<=1.8$ \\
\hline 2 & $\square$ & 1 & $.8<$ & WS & $<=3.3$ \\
\hline 3 & $\infty$ & 3 & $.3<$ & WS & $c=5.4$ \\
\hline 4 & 메 & 5 & $.4<$ & WS & $<=8.5$ \\
\hline 5 & पापा & 8 & $.5<$ & WS & $<=10.8$ \\
\hline 60 & ע11ד & 10 & $.8<$ & WS & \\
\hline
\end{tabular}

100.0\% DATA RECOVERED

OF WHICH $8.2 \%$ IS

REPORTED ABOVE 


\section{SPILL TEST FACILITY 24 METER TOWER \\ STABILITY CLASS $B$ \\ 2 METER HEIGHT - Total Hours \\ 9/ $1 / 1994-9 / 30 / 1994$ \\ $0-2300$}

$N$
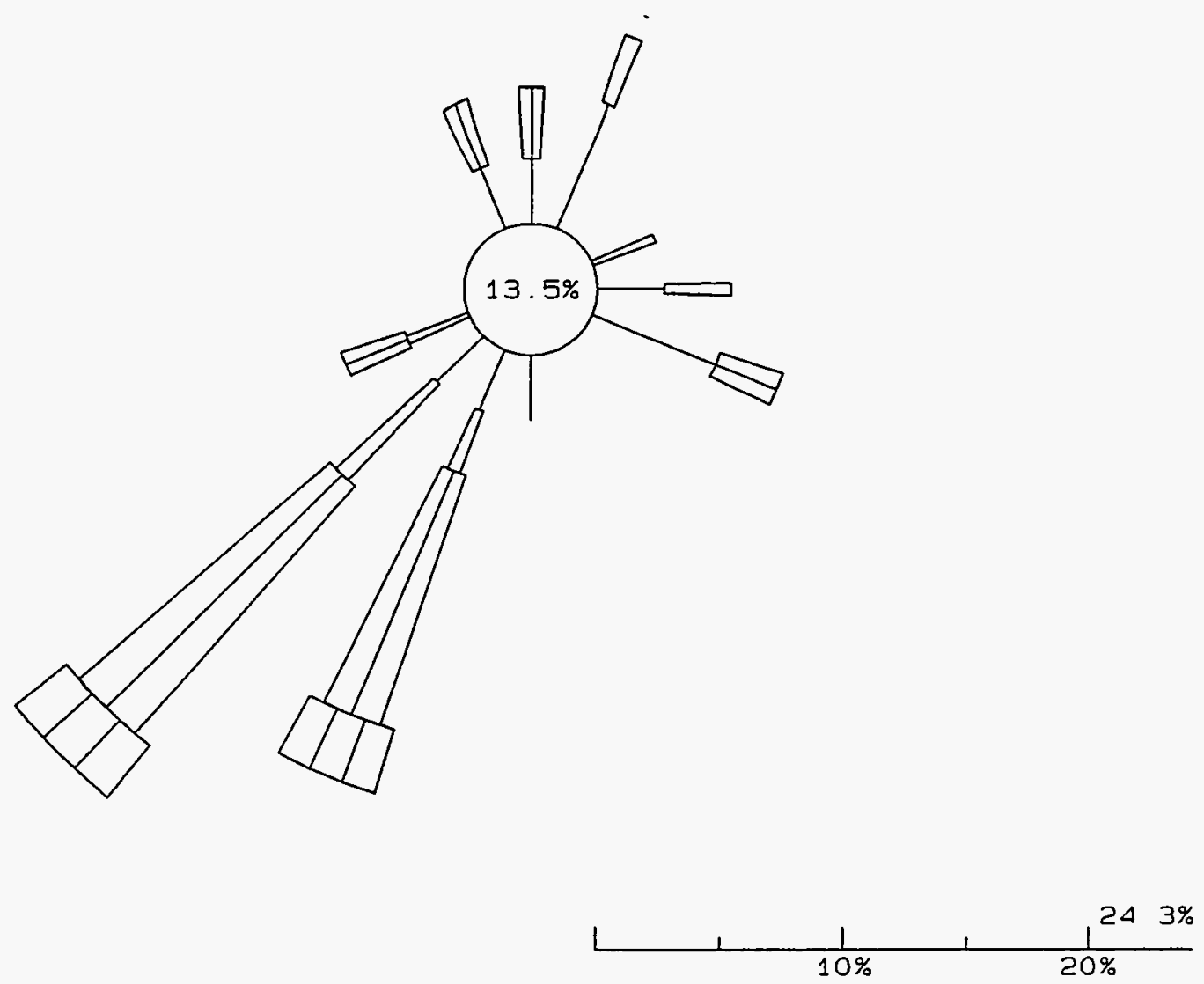

99.7\% DATA RECOVERED

OF WHICH $5.2 \%$ IS

REPORTED ABOVE 


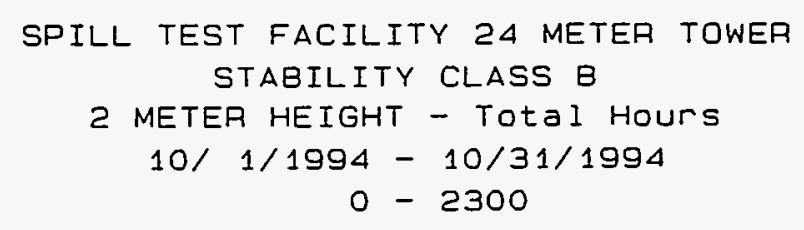

$N$
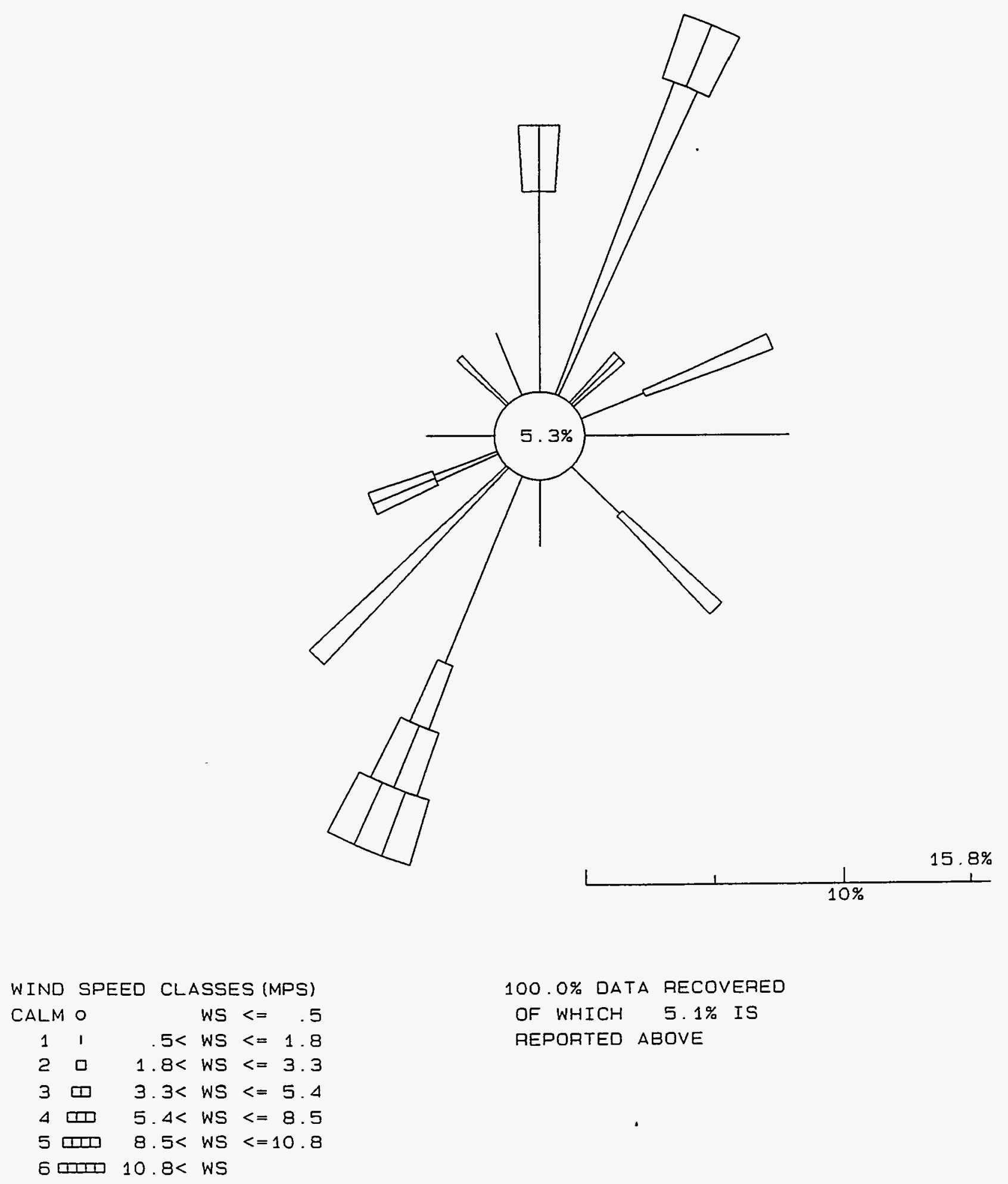


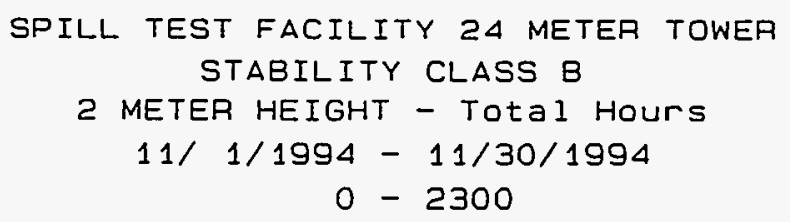

$N$

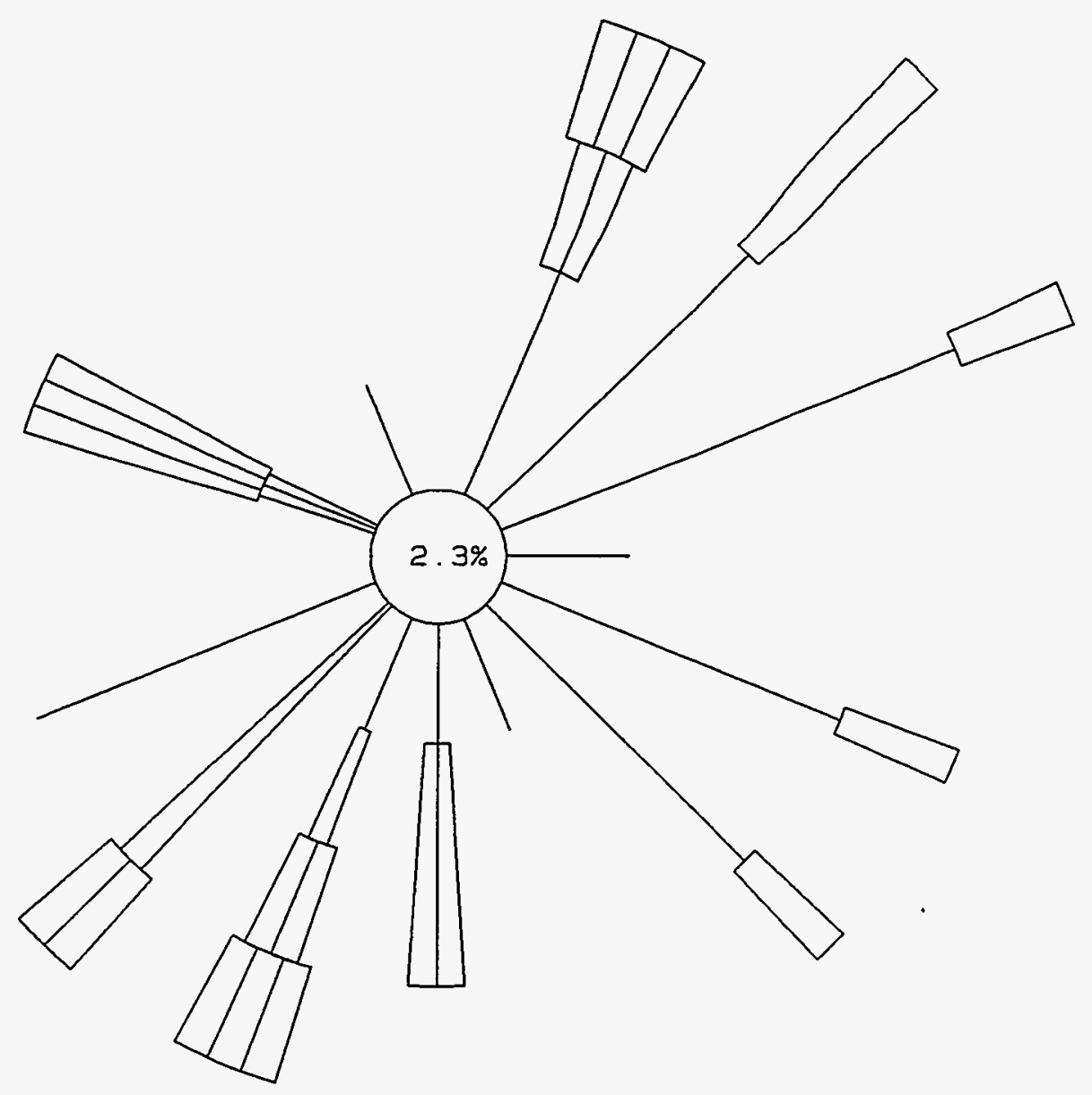

\begin{tabular}{|c|c|c|c|c|c|}
\hline IND & SPE & $=0$ & CL & $S S E$ & ES (MPS \\
\hline CALM & 10 & & & WS & $<=$ \\
\hline 1 & 1 & & $.5<$ & WS & $<=1$ \\
\hline 7 & ㅁ & 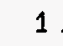 & $8<$ & WS & $<=3$. \\
\hline 3 & पᄄ & 3. & $3<$ & WS & $<=5$ \\
\hline 4 & סי & 5 & $4<$ & WS & $<=8$. \\
\hline 50 & דIII & & $.5<$ & WS & $<=10$. \\
\hline 60 & דाप & 10 & $.8<$ & WS & \\
\hline
\end{tabular}

$100.0 \%$ DATA RECOVERED

OF WHICH 6.0\% IS

REPORTEO ABOVE 


\section{SPILL TEST FACILITY 24 METER TOWER STABILITY CLASS B 2 METER HEIGHT - Total Hours 12/ $1 / 1994$ - 12/31/1994 \\ $0-2300$}

$N$

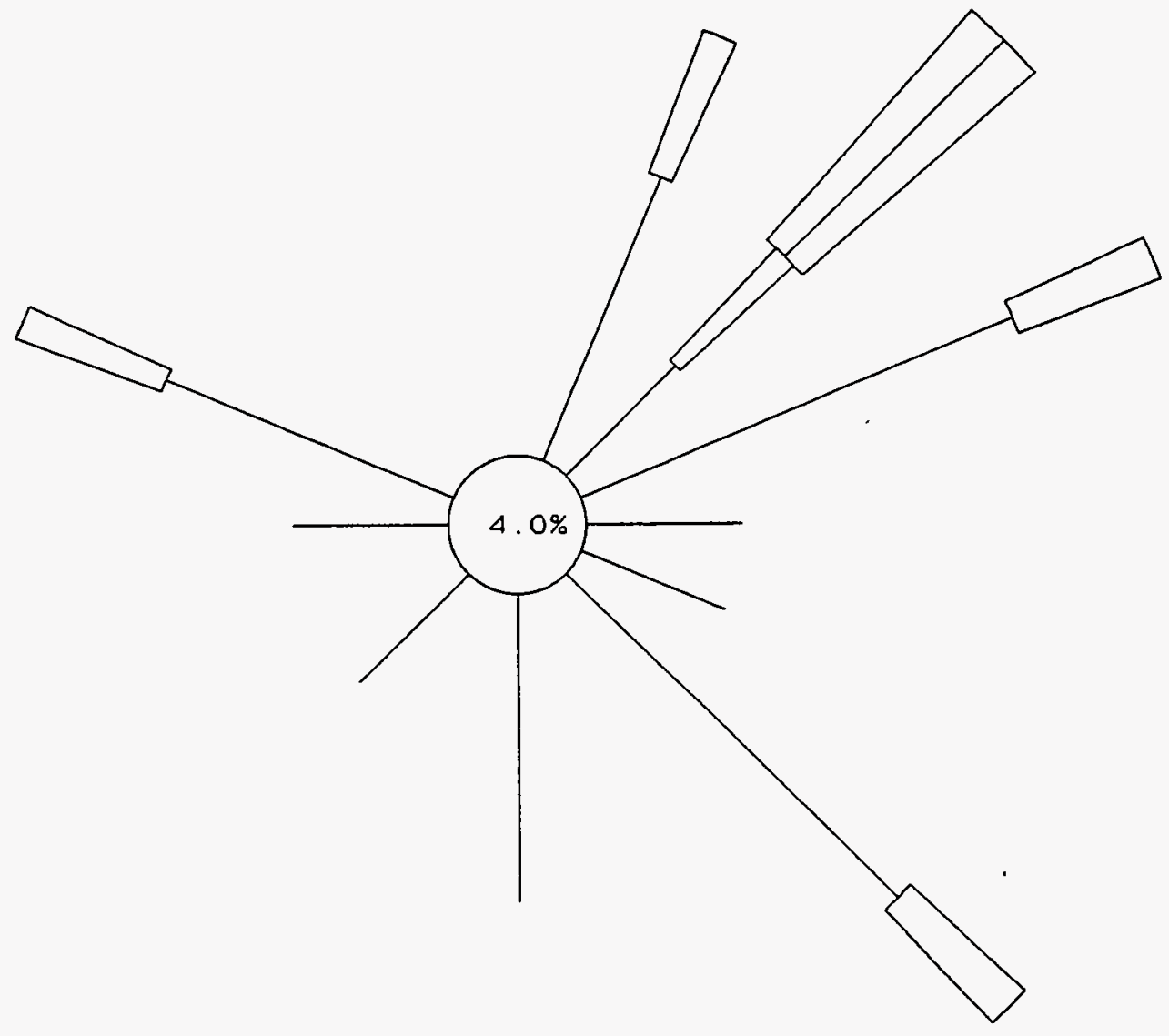

$16.0 \%$

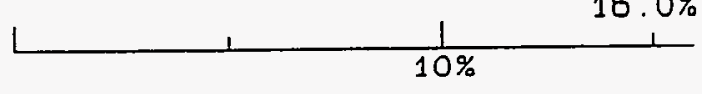

\begin{tabular}{|c|c|c|c|c|c|}
\hline WINL & $S P E$ & ED & CL & SSE & S (MPS) \\
\hline CALN & 10 & & & WS & $<=$ \\
\hline 1 & 1 & & $5<$ & WS & $<=1.8$ \\
\hline 2 & $\square$ & 1 & $8<$ & WS & $<=3.3$ \\
\hline 3 & שם & 3 & $3<$ & WS & $<=5.4$ \\
\hline 4 & שים & 5 & $4<$ & WS & $c=8.5$ \\
\hline 5 & पाप & 8 & $5<$ & WS & $<=10.8$ \\
\hline 6 & מעד & 10 & $.8<$ & WS & \\
\hline
\end{tabular}

65. 1\% DATA RECOVERED

OF WHICH $5.2 \%$ IS REPORTED ABOVE 
SPILL TEST FACILITY 24 METER TOWER

STABILITY CLASS C

2 METER HEIGHT - Total Hours

$1 / 1 / 1994-1 / 31 / 1994$

$0-2300$

$N$

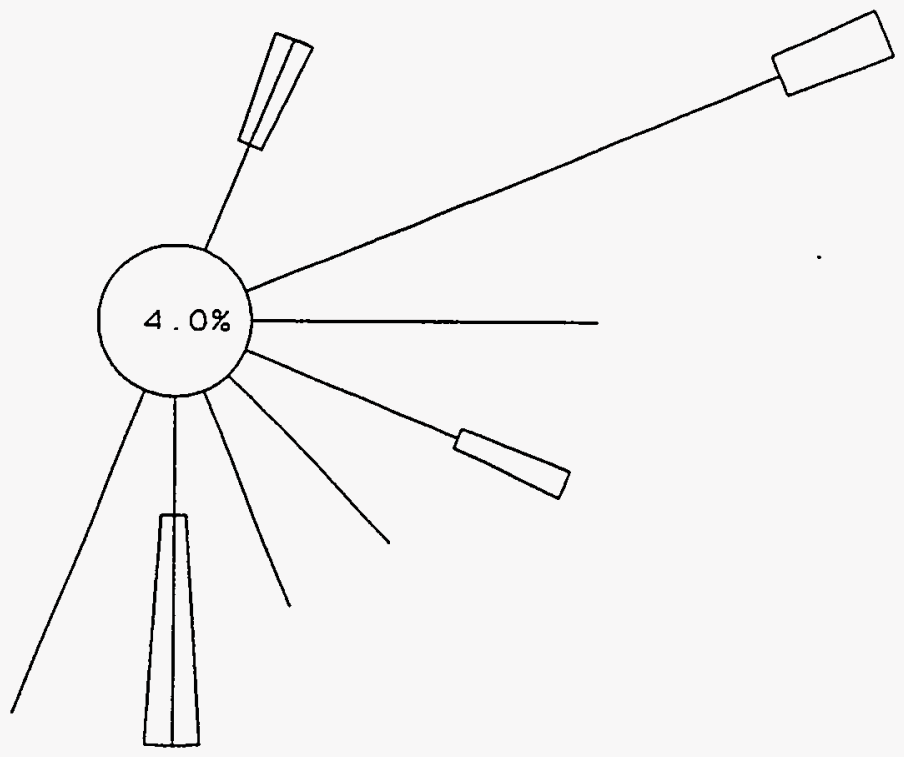

WIND SPEED CLASSES (MPS)

CALM $O \quad W S<=: 5$

$11 . .5<$ WS $<=1.8$

$2 \square \quad 1.8<$ WS $<=3.3$

$3 \square \quad 3.3<W S<=5.4$

4 एण $5.4<W S<=8.5$

5 III $8.5<$ WS $<=10.8$

$610.8<W S$

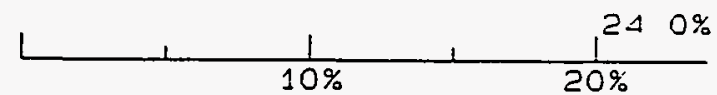

$78.0 \%$ DATA RECOVERED

OF WHICH $4.3 \%$ IS

REPORTED ABOVE 


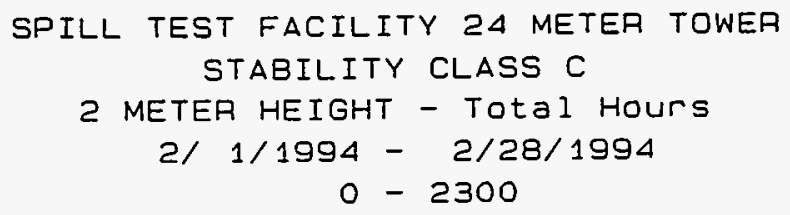

$N$
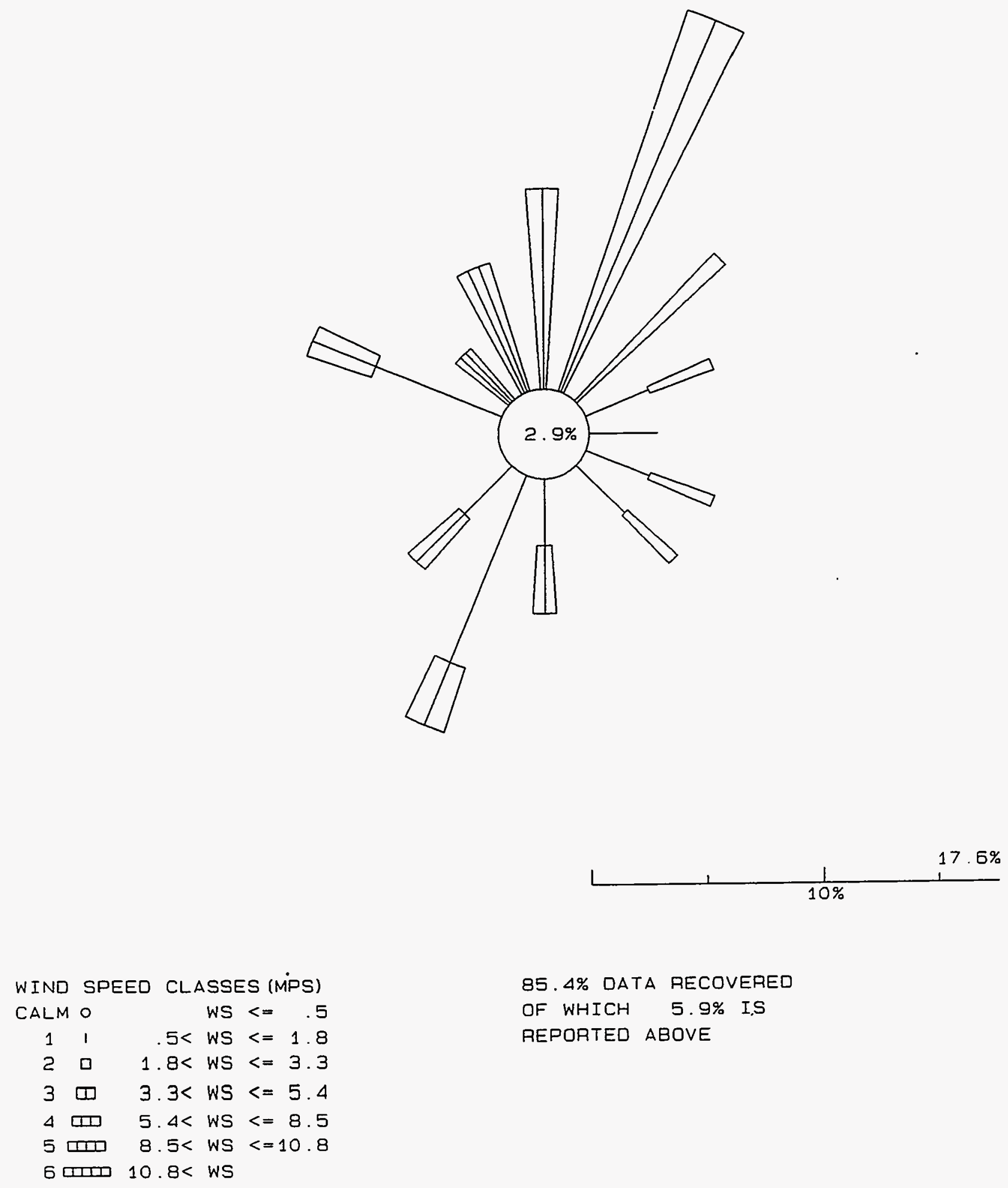

85. 4\% DATA RECOVERED

OF WHICH $5.9 \%$ I.S REPORTED ABOVE 


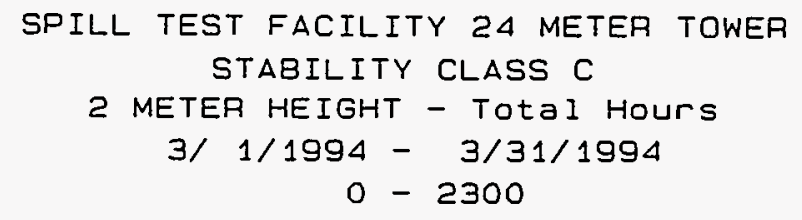

$N$

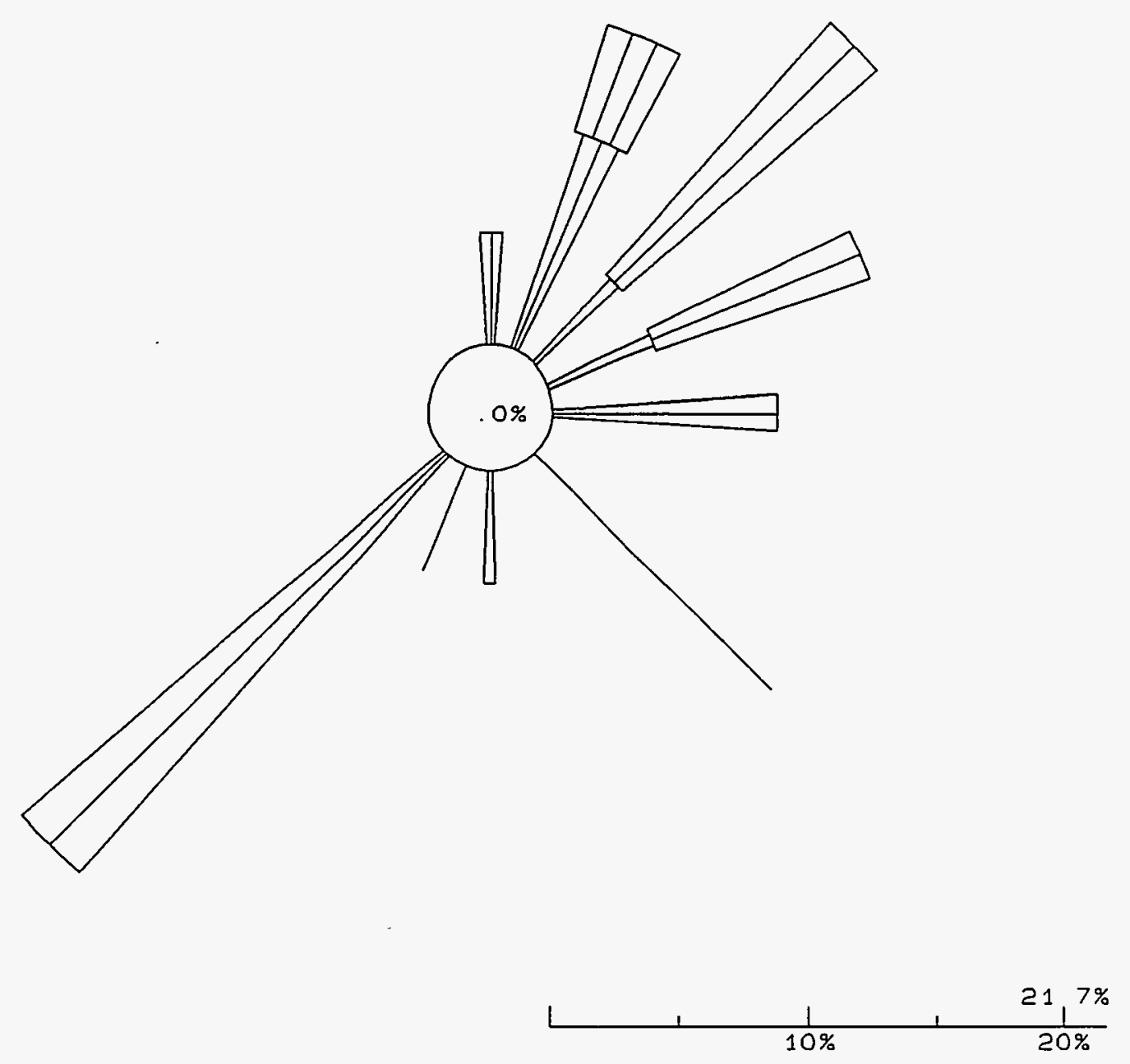

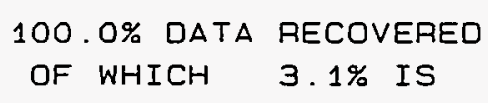




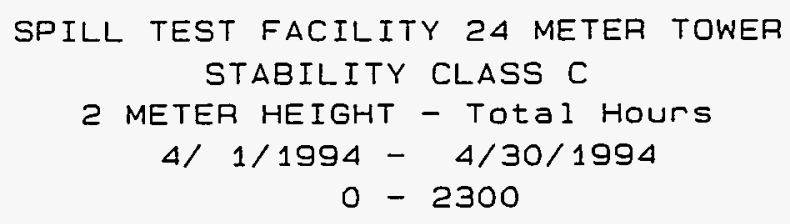

$N$
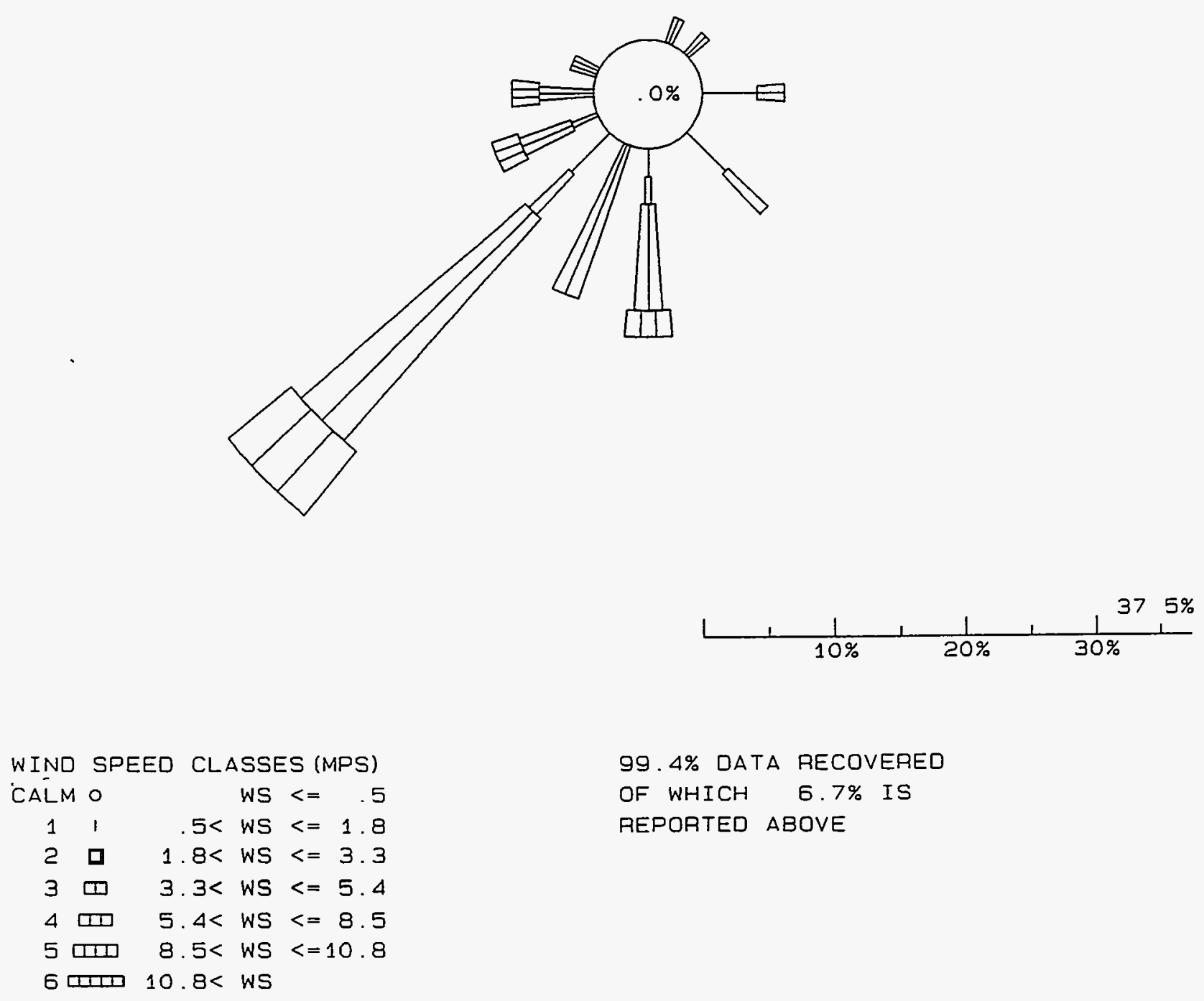

99. 4\% DATA RECOVERED

OF WHICH $6.7 \%$ IS

REPORTED ABOVE 


\section{SPILL TEST FACILITY 24 METER TOWER \\ STABILITY CLASS C \\ 2 METER HEIGHT - Total Hours \\ $5 / 1 / 1994-5 / 31 / 1994$ \\ $0-2300$}

$N$
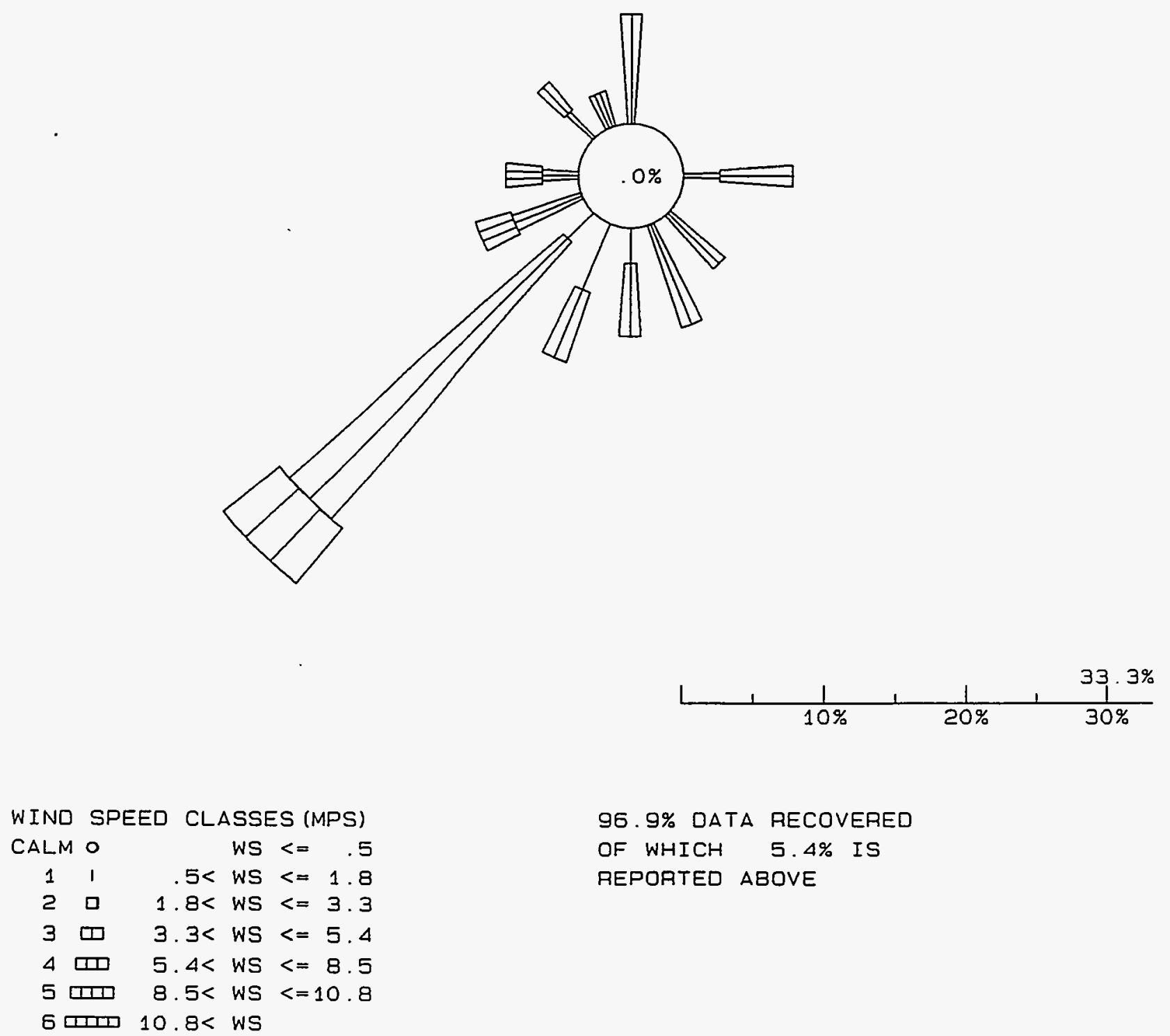

96.9\% DATA RECOVERED

OF WHICH $5.4 \%$ IS

REPORTED ABOVE 


\section{SPILL TEST FACILITY 24 METER TOWER \\ STABILITY CLASS C \\ 2 METER HEIGHT - Total Hours \\ E/ $1 / 1994-6 / 30 / 1994$ \\ $0-2300$}

$N$
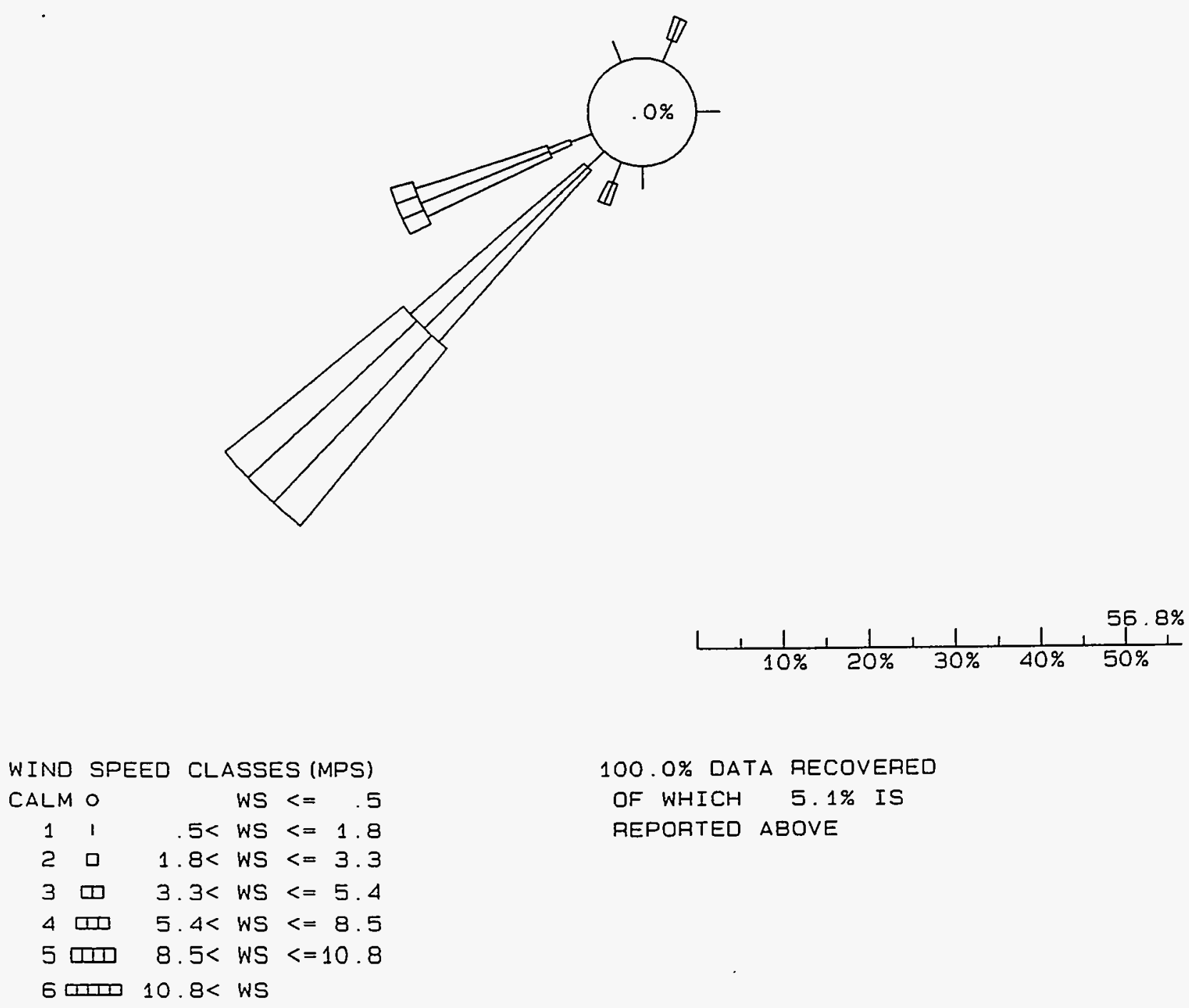


\section{SPILL TEST FACILITY 24 METER TOWER \\ STABILITY CLASS C \\ 2 METER HEIGHT - Total Hours \\ 7/1/1994 - 7/31/1994 \\ $0-2300$}

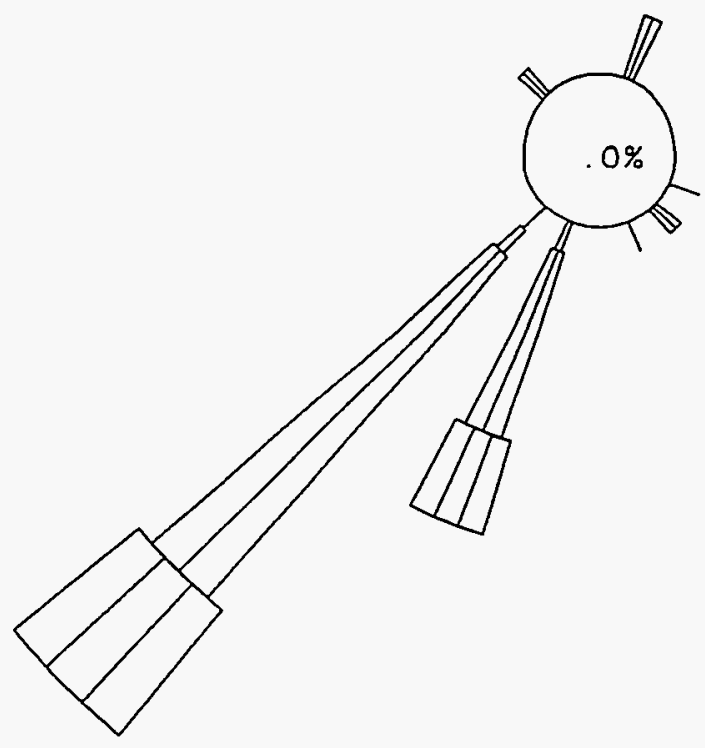

\begin{tabular}{|c|c|c|c|c|c|}
\hline WIND & SPE & ED & CL & $\mathrm{SSE}$ & ES (MPS \\
\hline CALM & 10 & & & WS & $<=$ \\
\hline 1 & 1 & & $5<$ & WS & $<=1.8$ \\
\hline 2 & 口 & 1 & $.8<$ & WS & $c=3.3$ \\
\hline 3 & דם & 3 & $3<$ & WS & $<=5.4$ \\
\hline 4 & प्म & 5 & $.4<$ & WS & $<=8.5$ \\
\hline 5 & पाप & 8 & $.5<$ & WS & $<=10.8$ \\
\hline 5 & סשण & 10 & $.8<$ & WS & \\
\hline
\end{tabular}

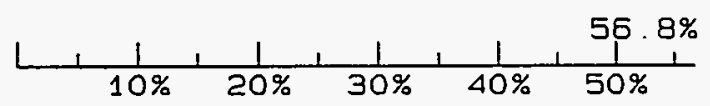

$100.0 \%$ DATA RECOVERED

OF WHICH $5.0 \%$ IS

REPORTED ABOVE 


\section{SPILL TEST FACILITY 24 METER TOWER STABILITY CLASS C \\ 2 METER HEIGHT - Total Hours \\ $8 / 1 / 1994-8 / 31 / 1994$ \\ $0-2300$}

N
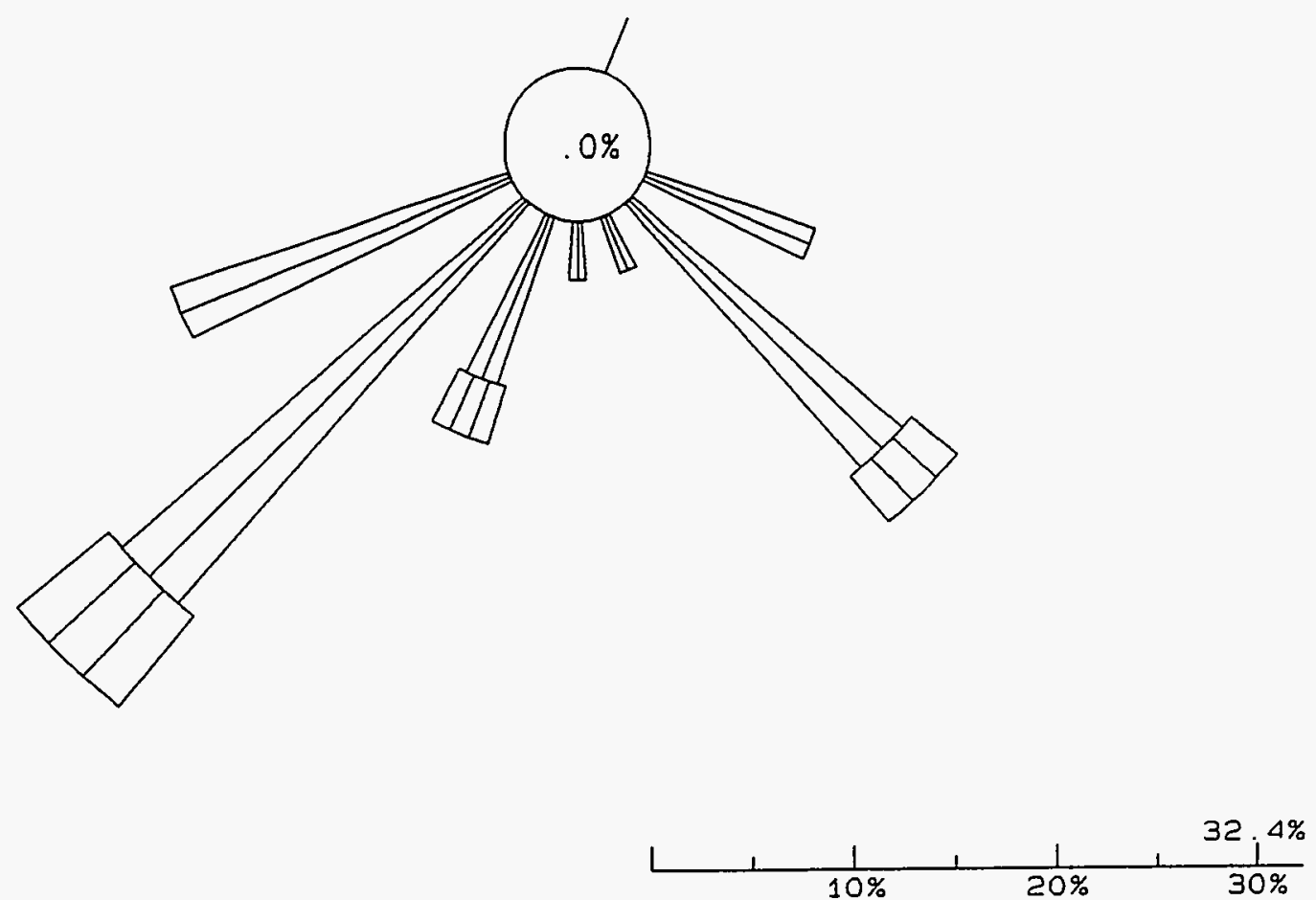

\begin{tabular}{|c|c|c|c|c|}
\hline NIND & SPE & ED CLA & $A S S E$ & S IMPS \\
\hline CALM & 10 & & WS & $<=$ \\
\hline 1 & I & $5<$ & WS & $<=1.8$ \\
\hline 2 & $\square$ & $1.8<$ & WS & $<=3$. \\
\hline 3 & Ш & $3.3<$ & WS & $<=5$. \\
\hline 4 & هس & $5.4<$ & WS & $<=8$. \\
\hline 50 & ستس & $8.5<$ & WS & $<=10$. \\
\hline $6 \square$ & סחסI & $10.8<$ & WS & \\
\hline
\end{tabular}

100. O\% DATA RECOVERED

OF WHICH $4.6 \%$ IS

REPORTED ABOVE 


\section{SPILL TEST FACILITY 24 METER TOWER \\ STABILITY CLASS C \\ 2 METER HEIGHT - Total Hours \\ 9/ $1 / 1994-9 / 30 / 1994$ \\ $0-2300$}

N
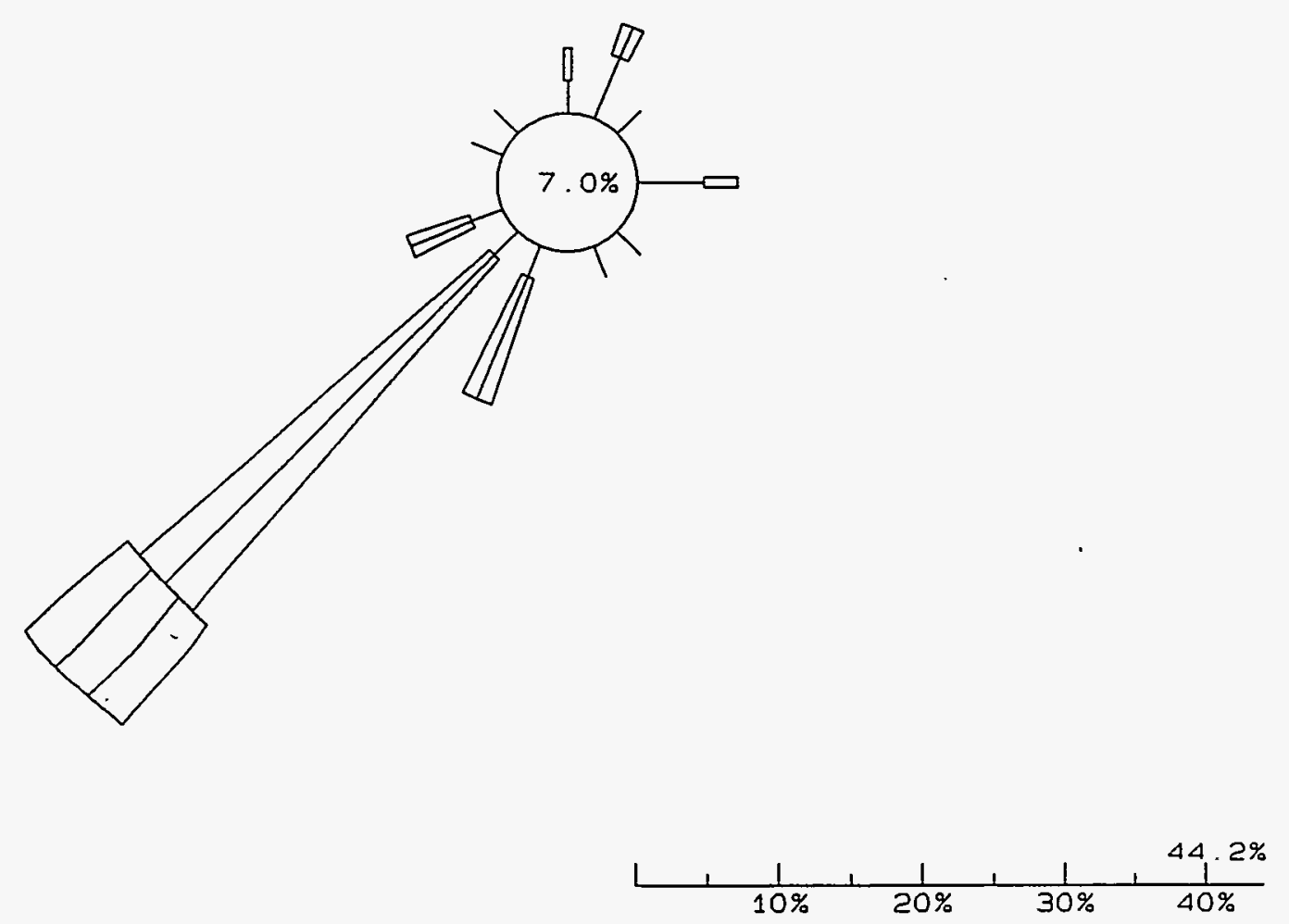

99. 7\% DATA RECOVERED

OF WHICH 6.O\% IS

REPORTED ABOVE 


\section{SPILL TEST FACILITY 24 METER TOWER STABILITY CLASS C \\ 2 METER HEIGHT - Total Hours $10 / 1 / 1994$ - $10 / 31 / 1994$ \\ $0-2300$}

$N$
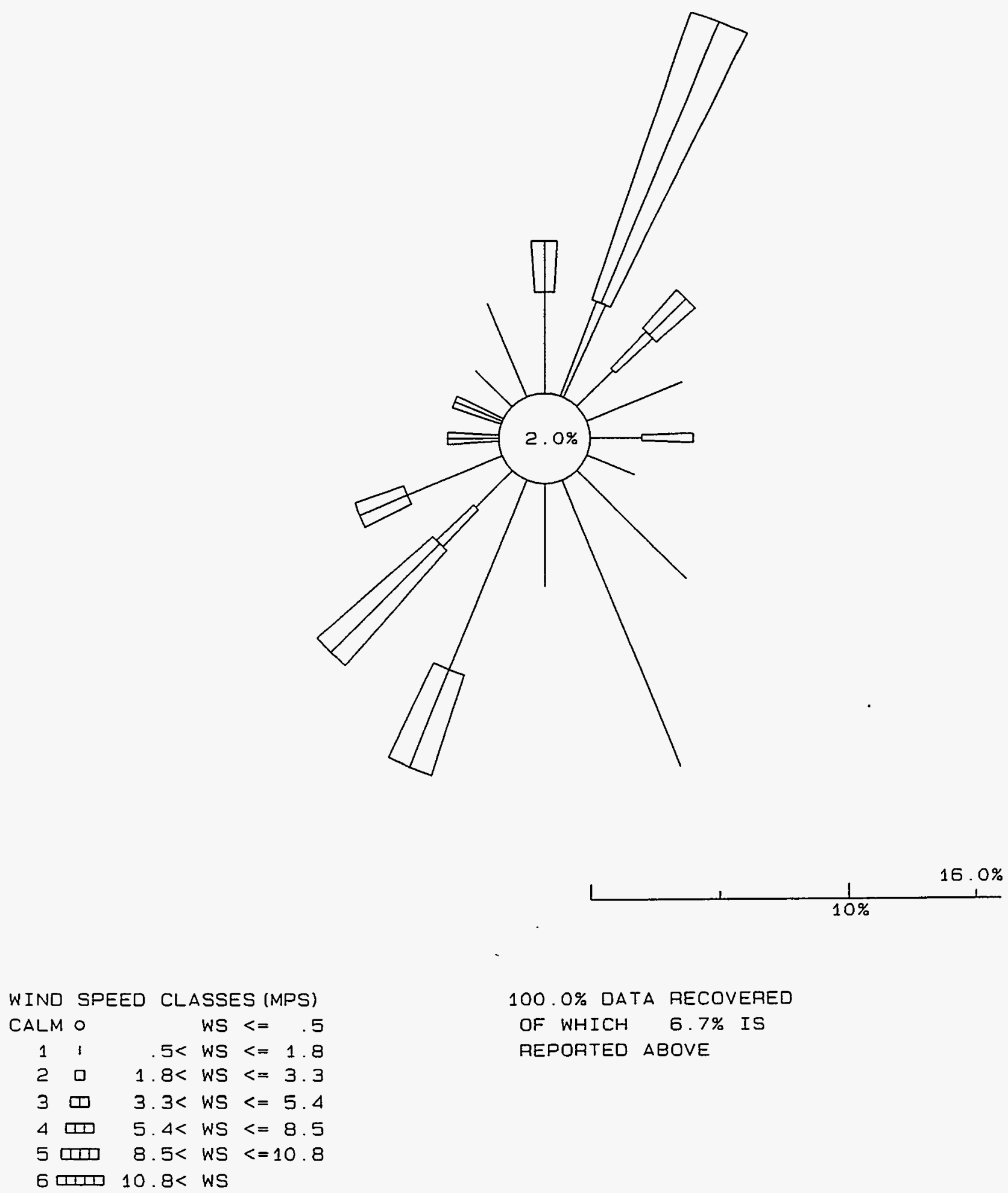


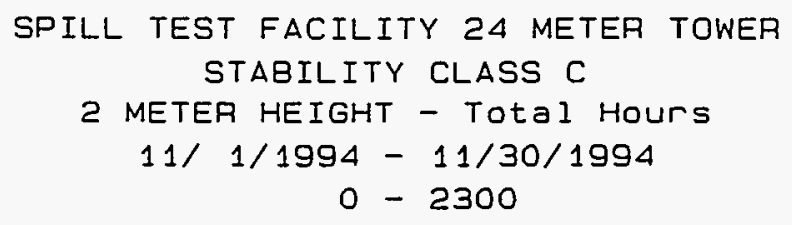

$N$
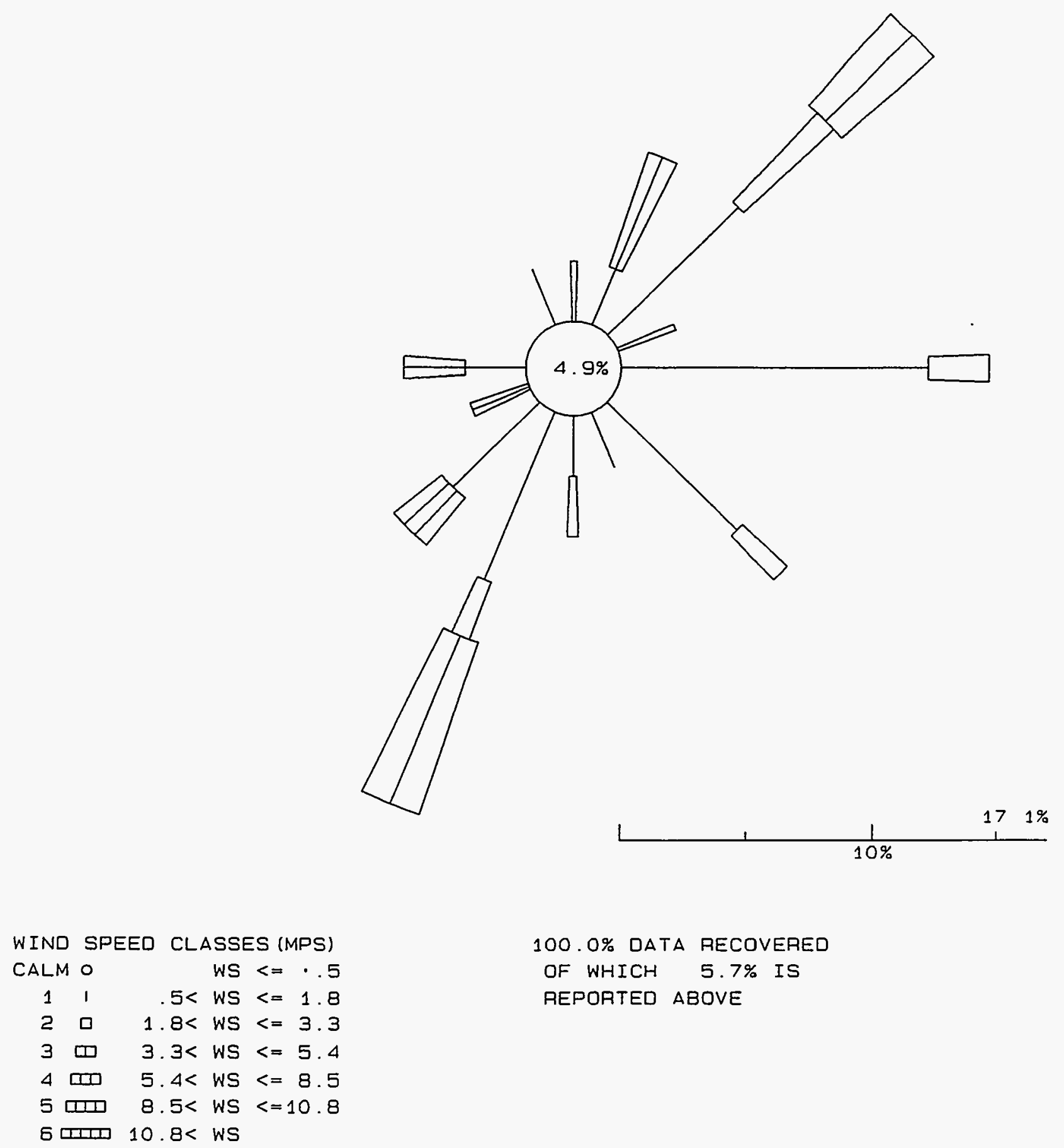

100.0\% DATA RECOVERED

OF WHICH 5.7\% IS

AEPORTED ABOVE 


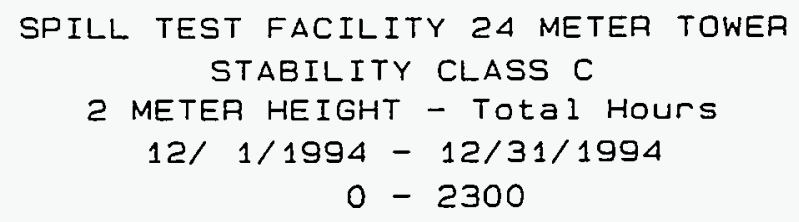

$N$
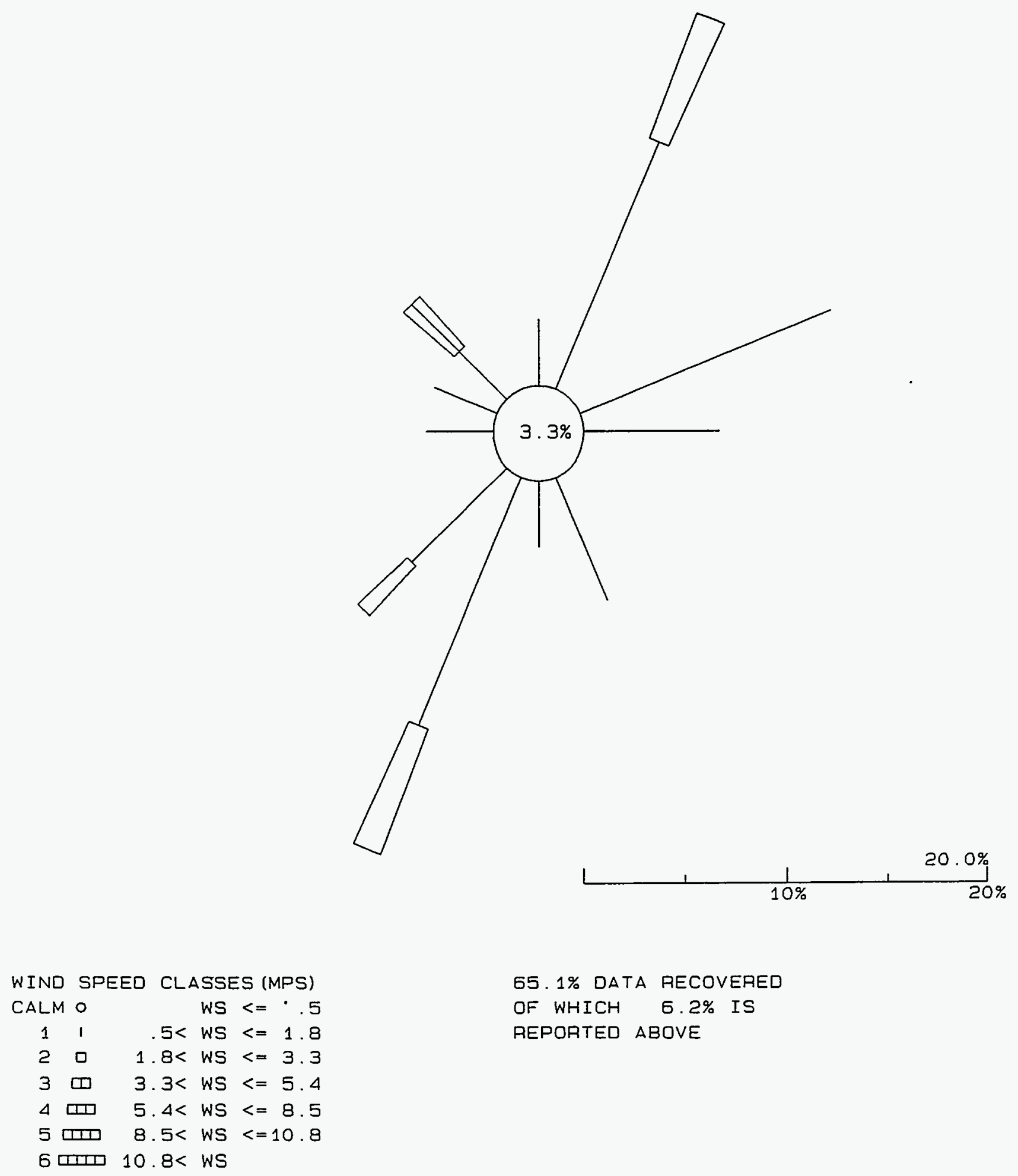

65. 1\% DATA RECOVERED

OF WHICH $6.2 \%$ IS

REPORTED ABOVE 


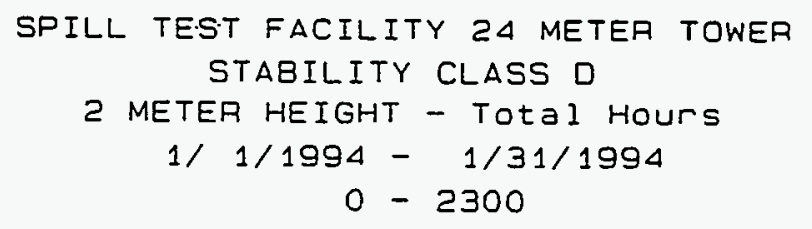

N
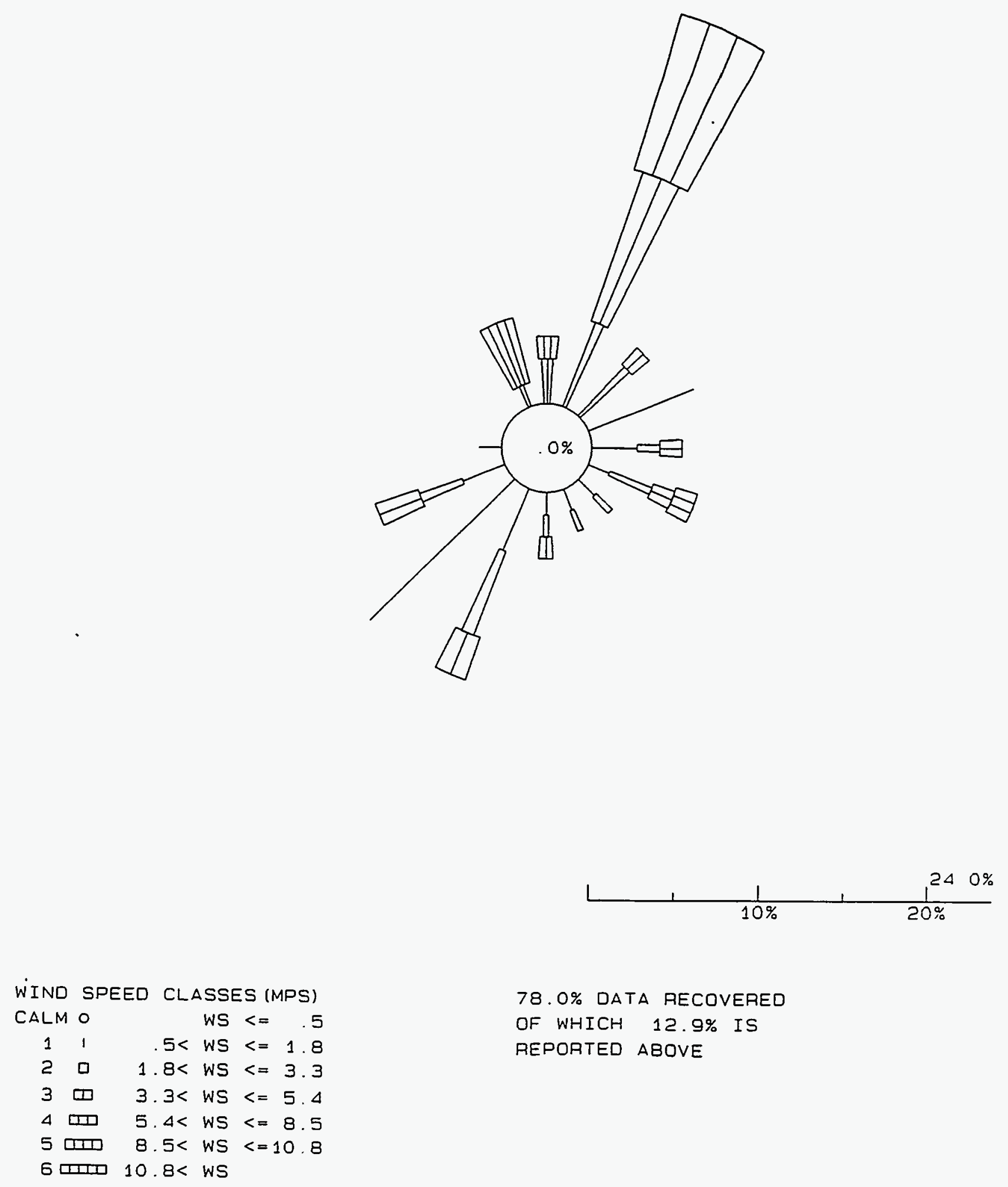

$78.0 \%$ DATA RECOVERED

OF WHICH $12.9 \%$ IS REPORTED ABOVE 


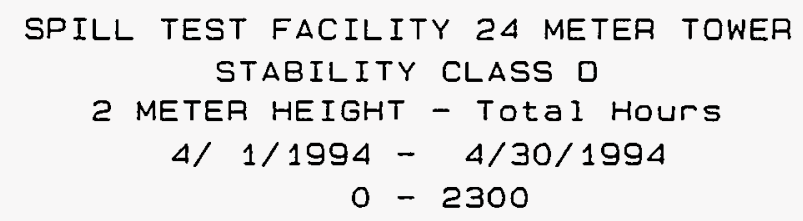

$N$

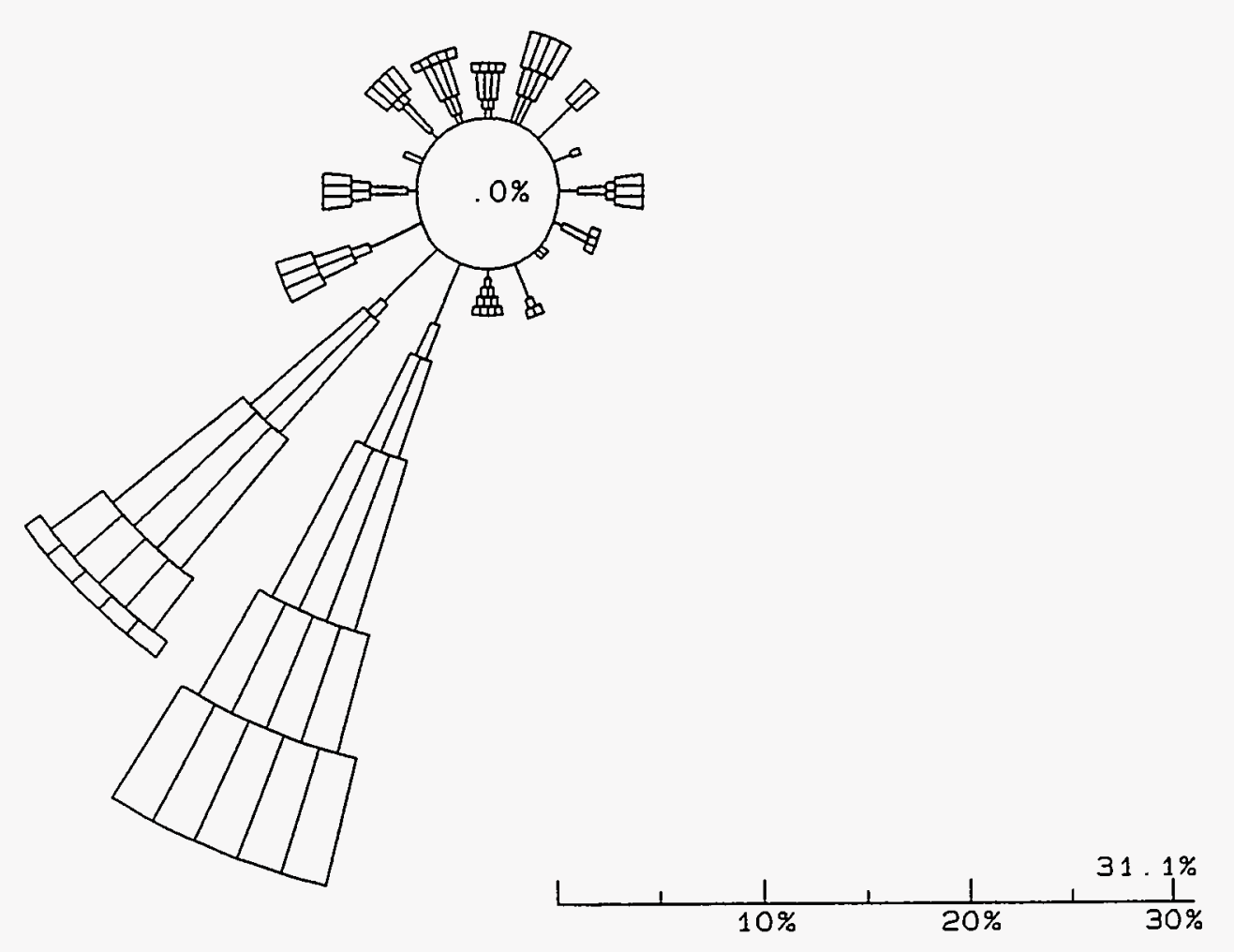

99. 4\% DATA RECOVERED

OF WHICH $30.6 \%$ IS

REPORTED ABOVE 


\section{SPILL TEST FACILITY 24 METER TOWER \\ STABILITY CLASS D \\ 2 METER HEIGHT - Total Hours \\ $5 / 1 / 1994-5 / 31 / 1994$ \\ $0-2300$}

$N$
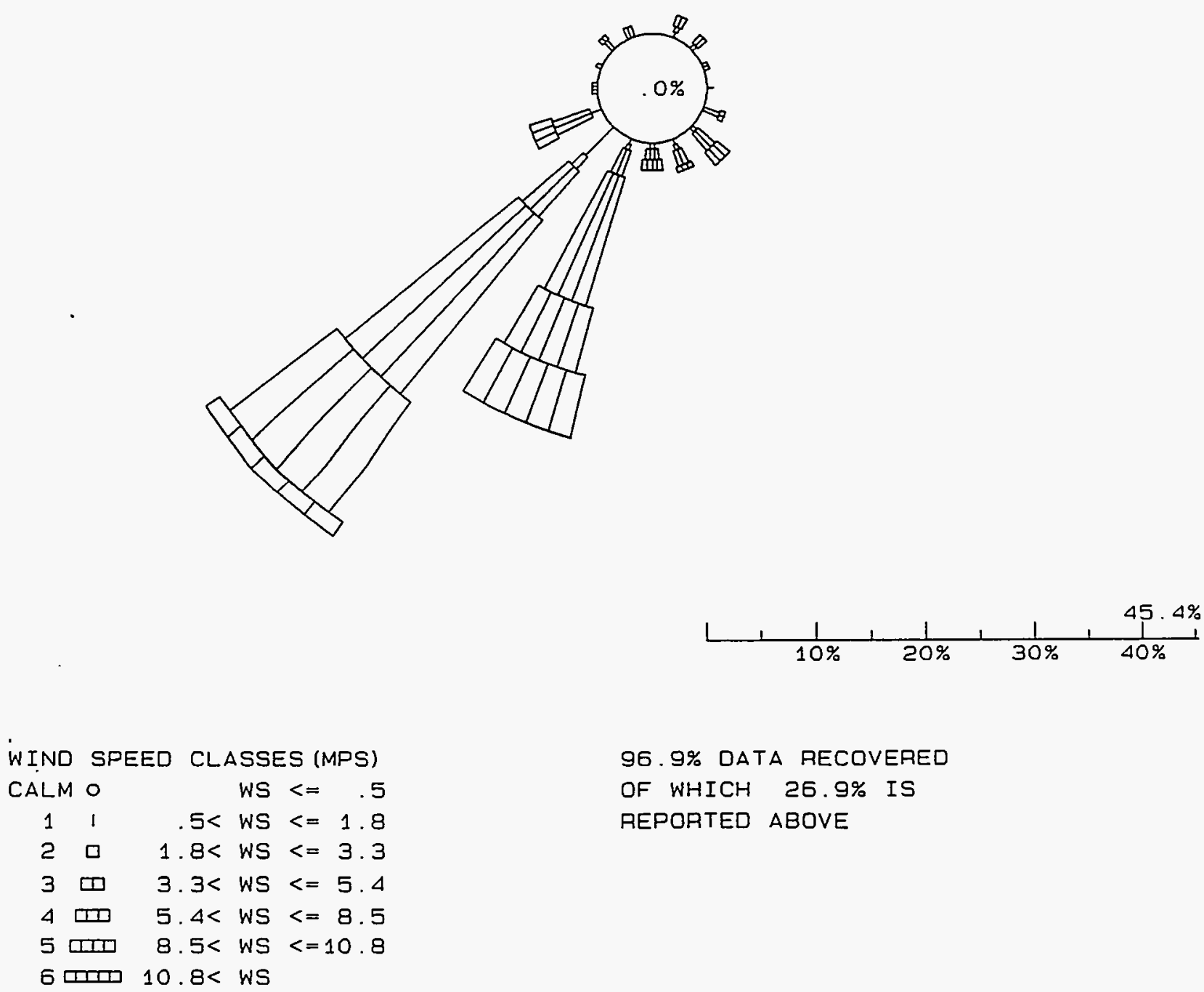


\section{SPILL TEST FACILITY 24 METER TOWEA STABILITY CLASS D \\ 2 METER HEIGHT - Total Hours \\ 6/ $1 / 1994-6 / 30 / 1994$ \\ $0-2300$}
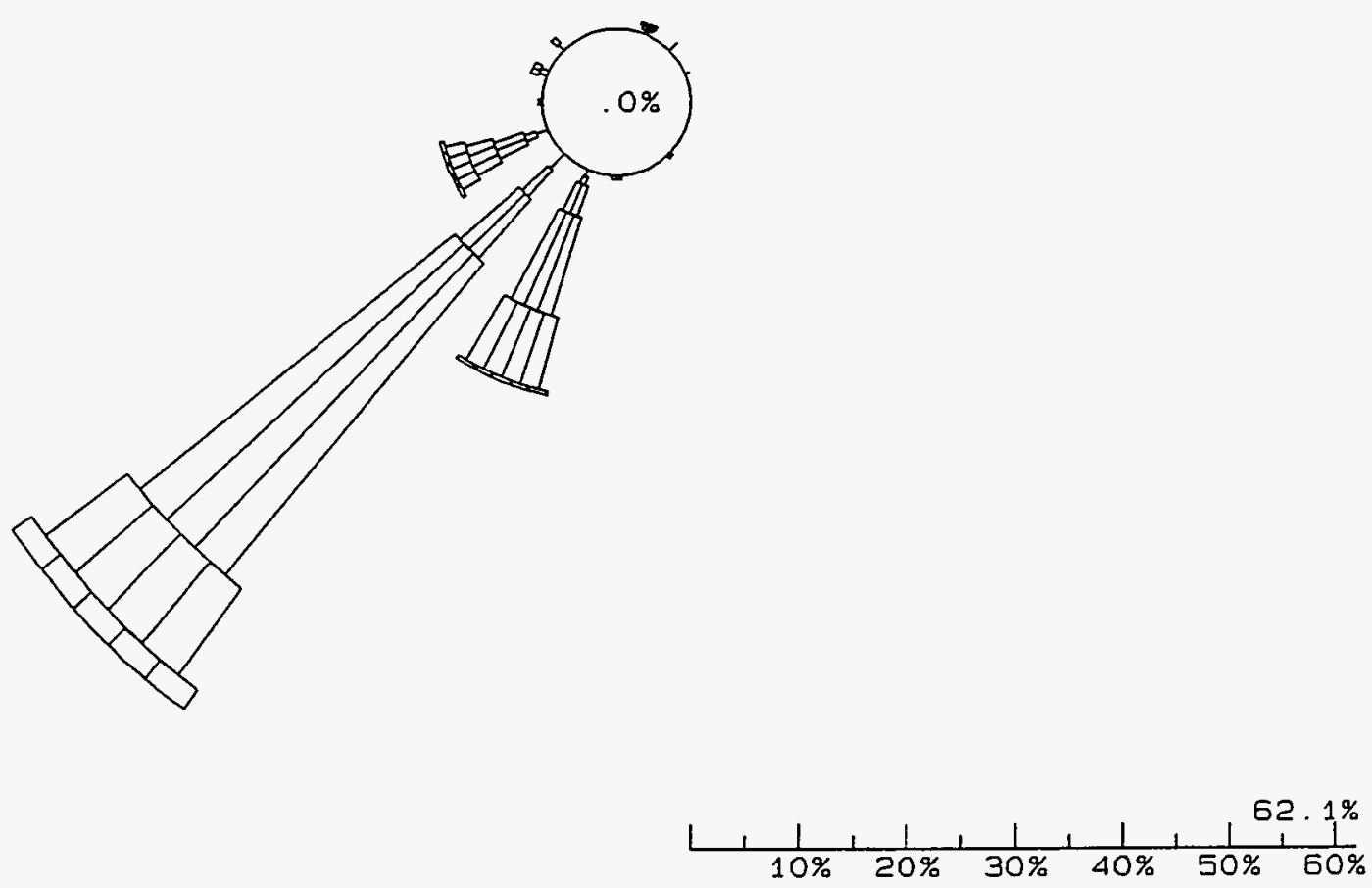

$100.0 \%$ DATA RECOVERED

OF WHICH $37.8 \%$ IS

REPORTED ABOVE 


\section{SPILL TEST FACILITY 24 METER TOWER STABILITY CLASS D \\ 2 METER HEIGHT - Tota 1 Hours \\ $7 / 1 / 1994-7 / 31 / 1994$ \\ $0-2300$}

$N$

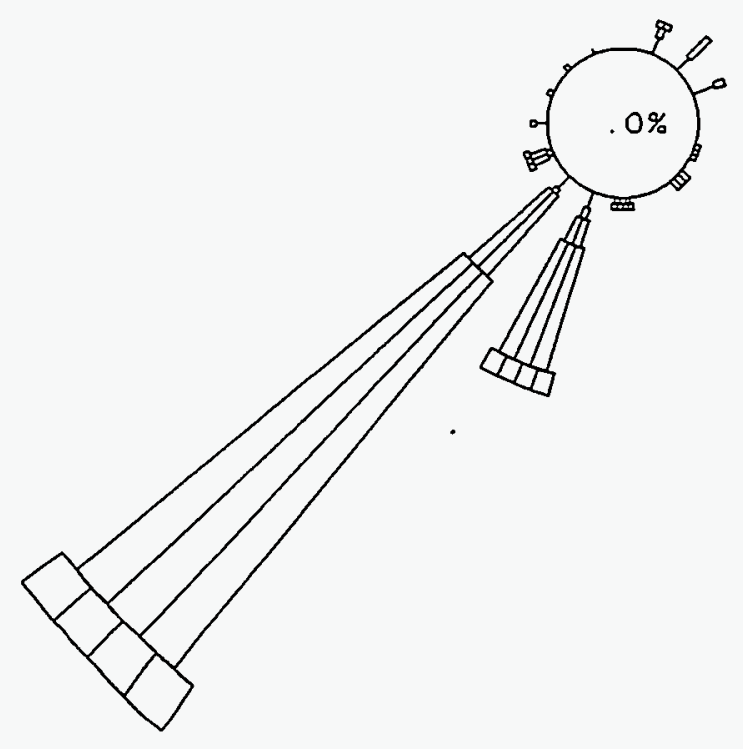

\begin{tabular}{|c|c|c|c|c|c|}
\hline \multirow{2}{*}{\multicolumn{3}{|c|}{$\begin{array}{l}\text { WIND SPEED } \\
\text { CALM O }\end{array}$}} & \multicolumn{3}{|c|}{ CLASSES (MPS) } \\
\hline & & & & WS & $<=$ \\
\hline 1 & I & & $5<$ & WS & $<=1.8$ \\
\hline 2 & ם & 1 & $.8<$ & WS & $<=3.3$ \\
\hline 3 & पᄆ & 3 & $.3<$ & WS & $<=5.4$ \\
\hline 4 & שם & 5 & $.4<$ & WS & $<=8.5$ \\
\hline 5 & पाप & 8 & $.5<$ & WS & $<=10.8$ \\
\hline 6 & ]IIII & 10 & $.8<$ & WS & \\
\hline
\end{tabular}

$L_{10 \%}+\frac{1}{20 \%}+\frac{1}{30 \%}+\frac{1}{40 \%}+\frac{1}{50 \%} \frac{1}{60 \%}$

100.0\% DATA RECOVERED

OF WHICH 26.1\% IS

REPORTED ABOVE 


\section{SPILL TEST FACILITY 24 METER TOWER \\ STABILITY CLASS D \\ 2 METER HEIGHT - Total Hours \\ 8/ $1 / 1994-8 / 31 / 1994$ \\ $0-2300$}

$N$
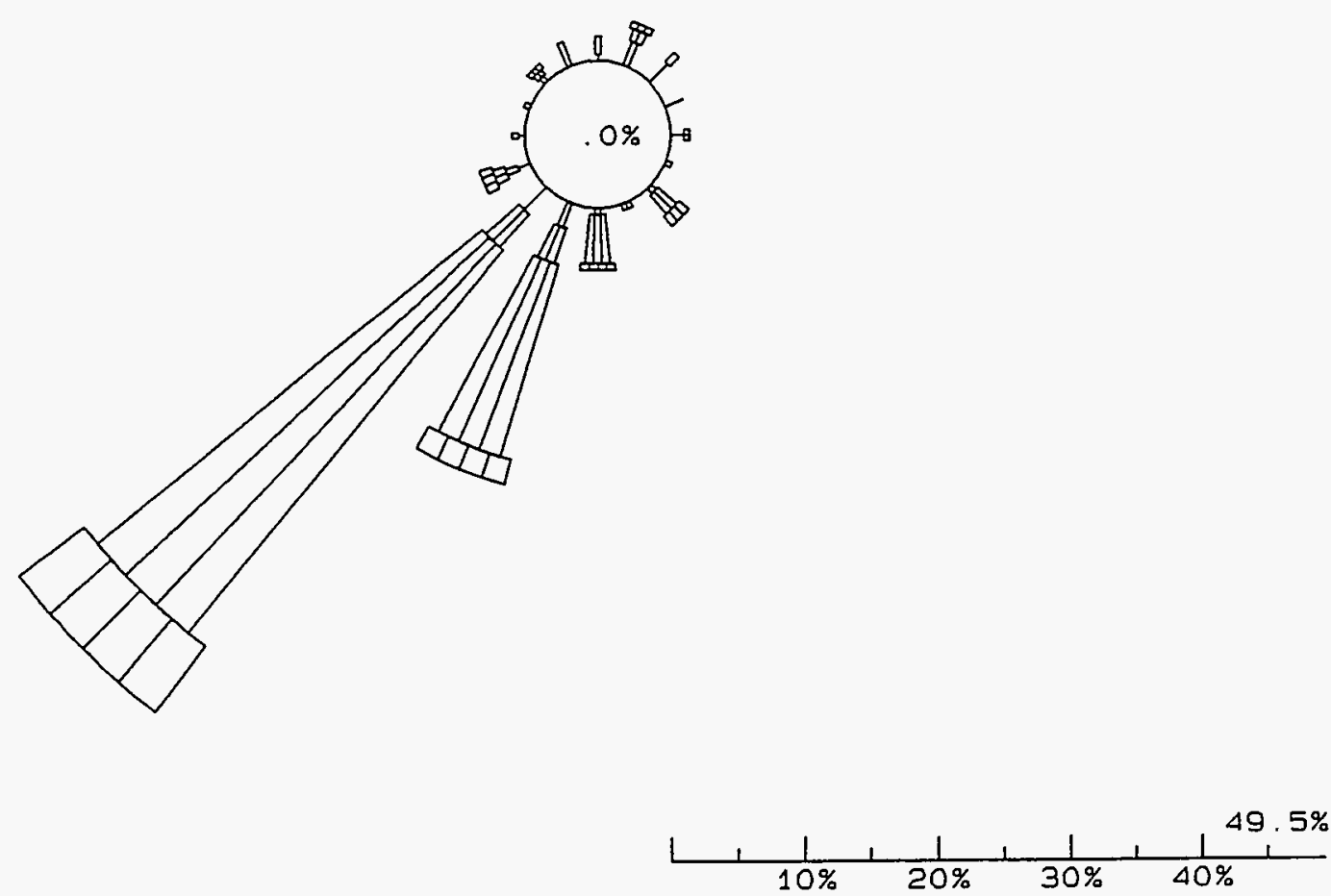

$100.0 \%$ DATA RECOVERED

OF WHICH $28.2 \%$ IS

REPORTED ABOVE 


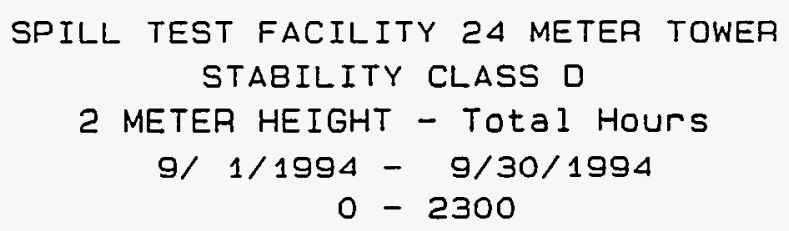

$N$
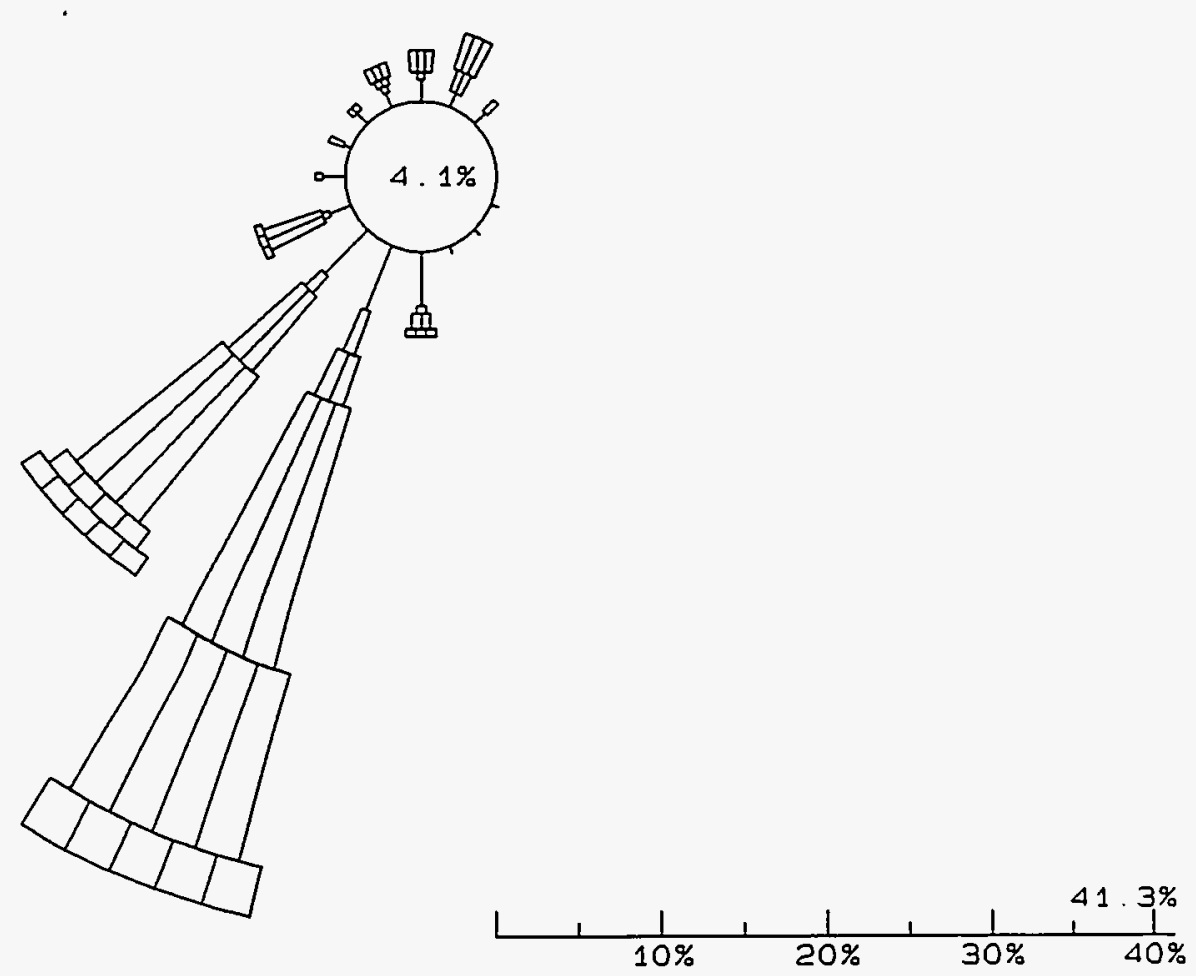

99. 7\% DATA RECOVERED

OF WHICH $30.4 \%$ IS

REPORTED ABOVE

\begin{tabular}{|c|c|c|c|c|}
\hline$A L M$ & 10 & & WS & $<=$ \\
\hline 1 & I & $5<$ & WS & $<=1$ \\
\hline 2 & 口 & $1.8<$ & wS & $<=3.3$ \\
\hline 3 & Ш & $3.3<$ & WS & $<=5$. \\
\hline 4 & סד & $5.4<$ & WS & $<=8.5$ \\
\hline 5 & סسי & $8.5<$ & WS & $<=10.8$ \\
\hline 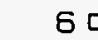 & & $10.8<$ & & \\
\hline
\end{tabular}




\section{SPILL TEST FACILITY 24 METER TOWER STABILITY CLASS D \\ 2 METER HEIGHT - Total Hours \\ 10/1/1994 - 10/31/1994 \\ $0-2300$}

$N$
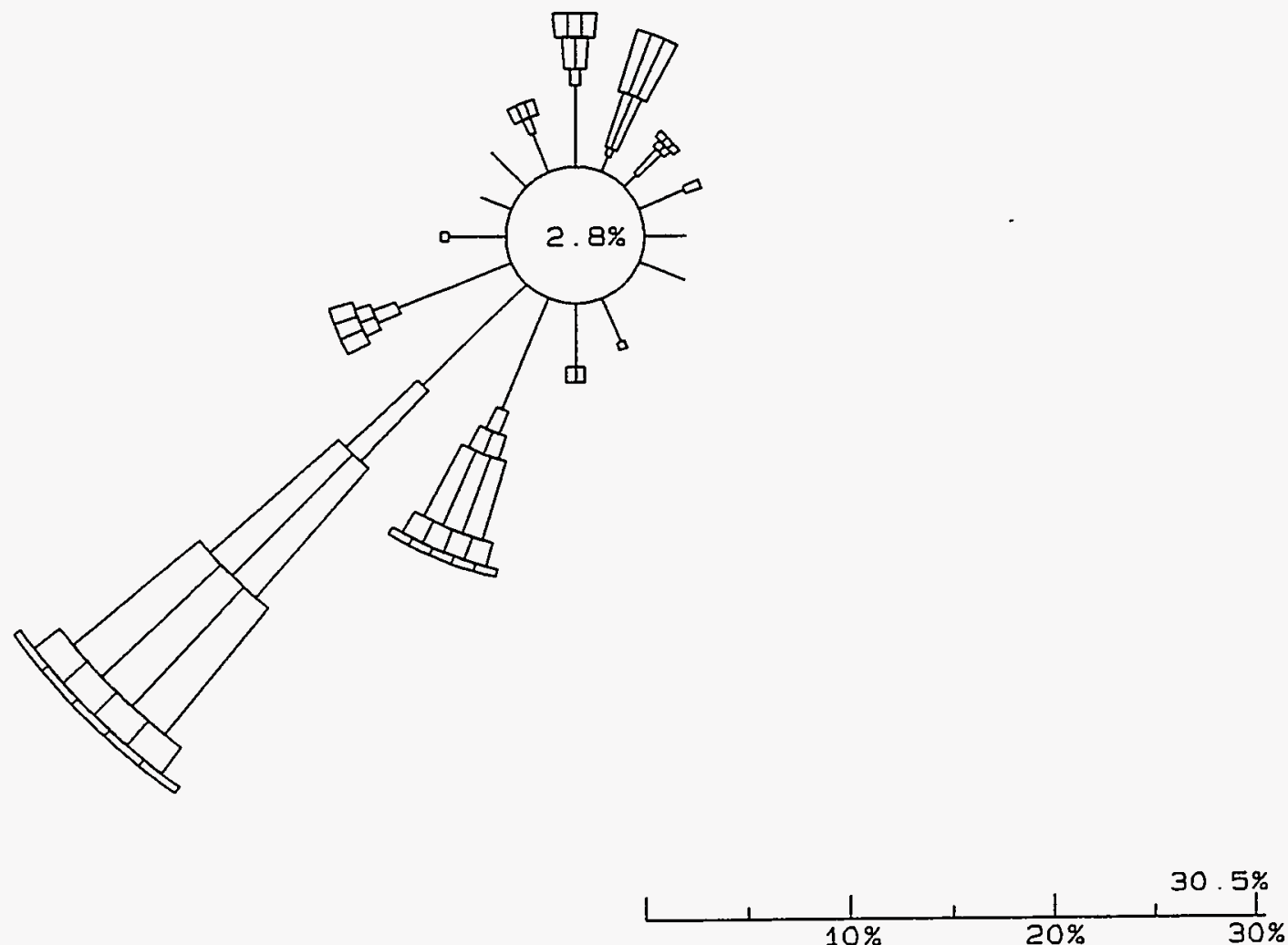

100.0\% DATA RECOVERED

OF WHICH $33.5 \%$ IS

REPORTED ABOVE 


\section{SPILL TEST FACILITY 24 METEA TOWEA STABILITY CLASS D \\ 2 METER HEIGHT - Total Hours $11 / 1 / 1994-11 / 30 / 1994$ \\ $0-2300$}

$N$
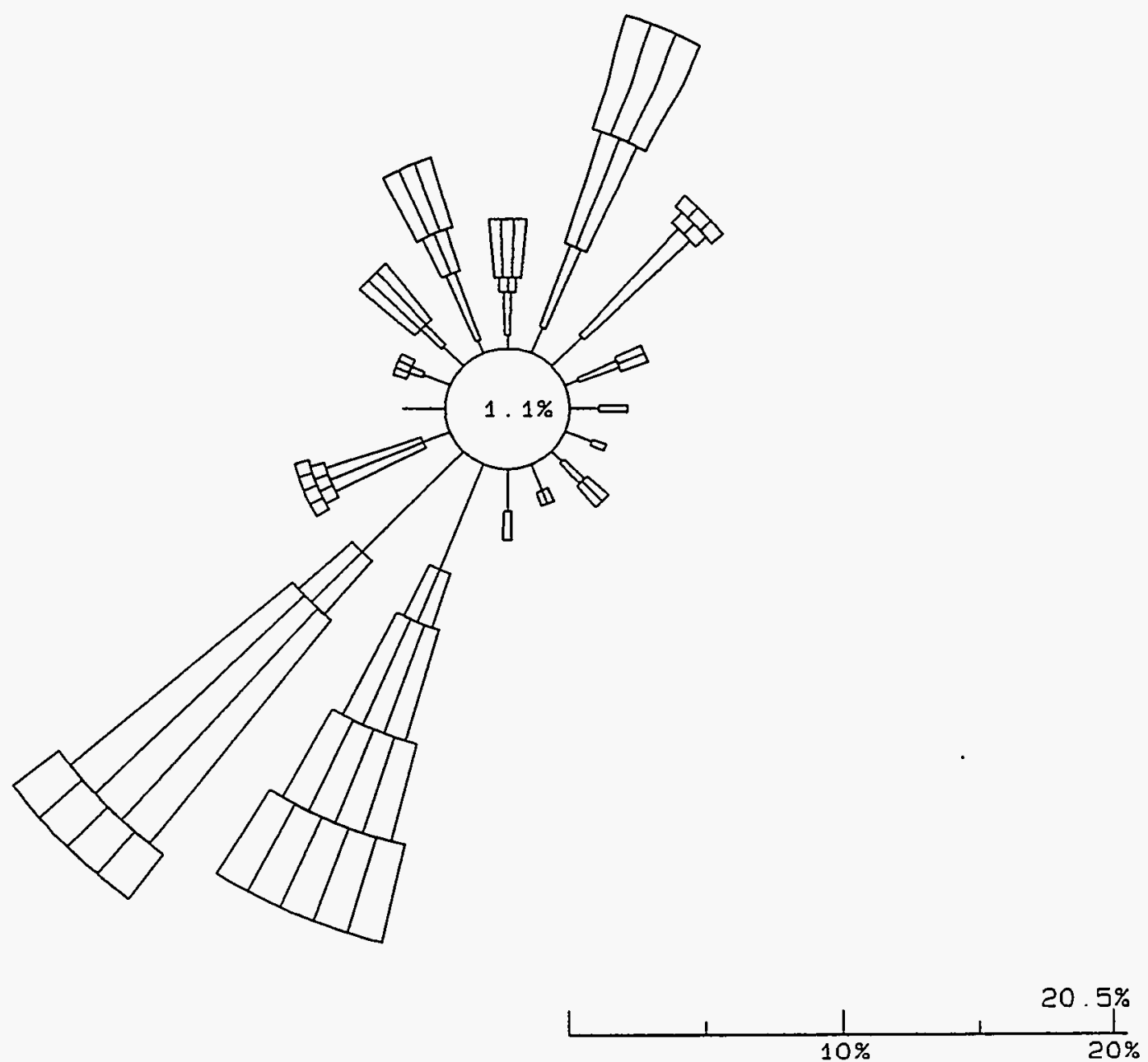

$100.0 \%$ DATA RECOVERED

OF WHICH 26.4\% IS REPORTED ABOVE 


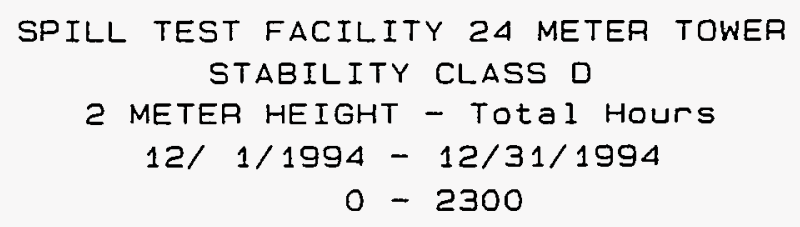

N
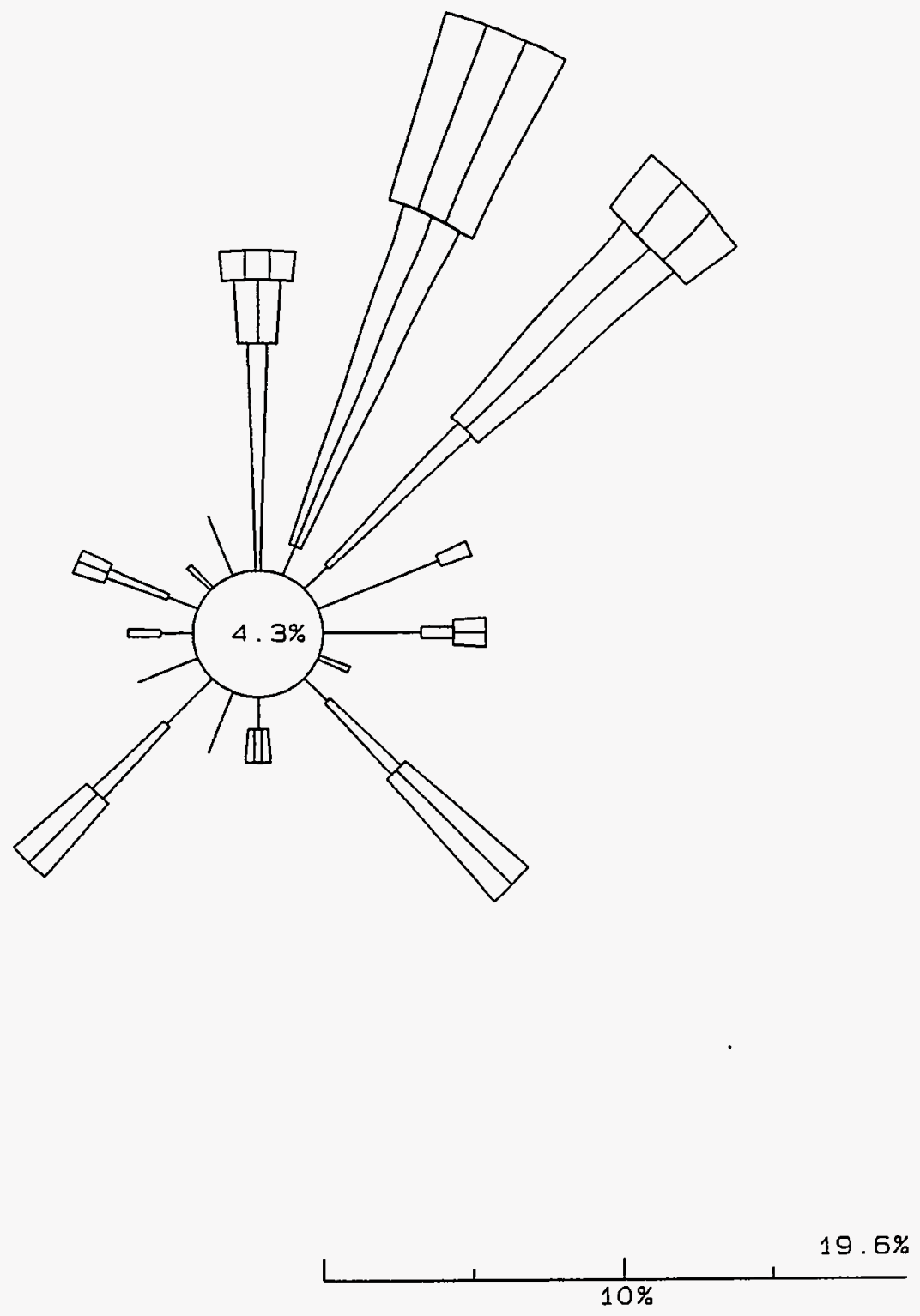

\begin{tabular}{|c|c|c|c|c|}
\hline WIND & SPR & EED CL & ASSE & $S$ (MPS) \\
\hline CALM & 10 & & WS & $<=$ \\
\hline 1 & 1 & $.5<$ & WS & $<=1.8$ \\
\hline 2 & 口 & $1.8<$ & WS & $<=3.3$ \\
\hline 3 & $\square$ & $3.3<$ & WS & $<=5.4$ \\
\hline 4 & סש & $5.4<$ & WS & $<=8.5$ \\
\hline 5 & ס्मा & $8.5<$ & WS & $<=10.8$ \\
\hline 60 & דחים & $10.8<$ & WS & \\
\hline
\end{tabular}

65. 1\% DATA RECOVERED

OF WHICH 19.0\% IS

REPORTED ABOVE 


\section{SPILL TEST FACILITY 24 METER TOWER STABILITY CLASS E \\ 2 METER HEIGHT - Total Hours \\ $1 / 1 / 1994-1 / 31 / 1994$ \\ $0-2300$}

$N$

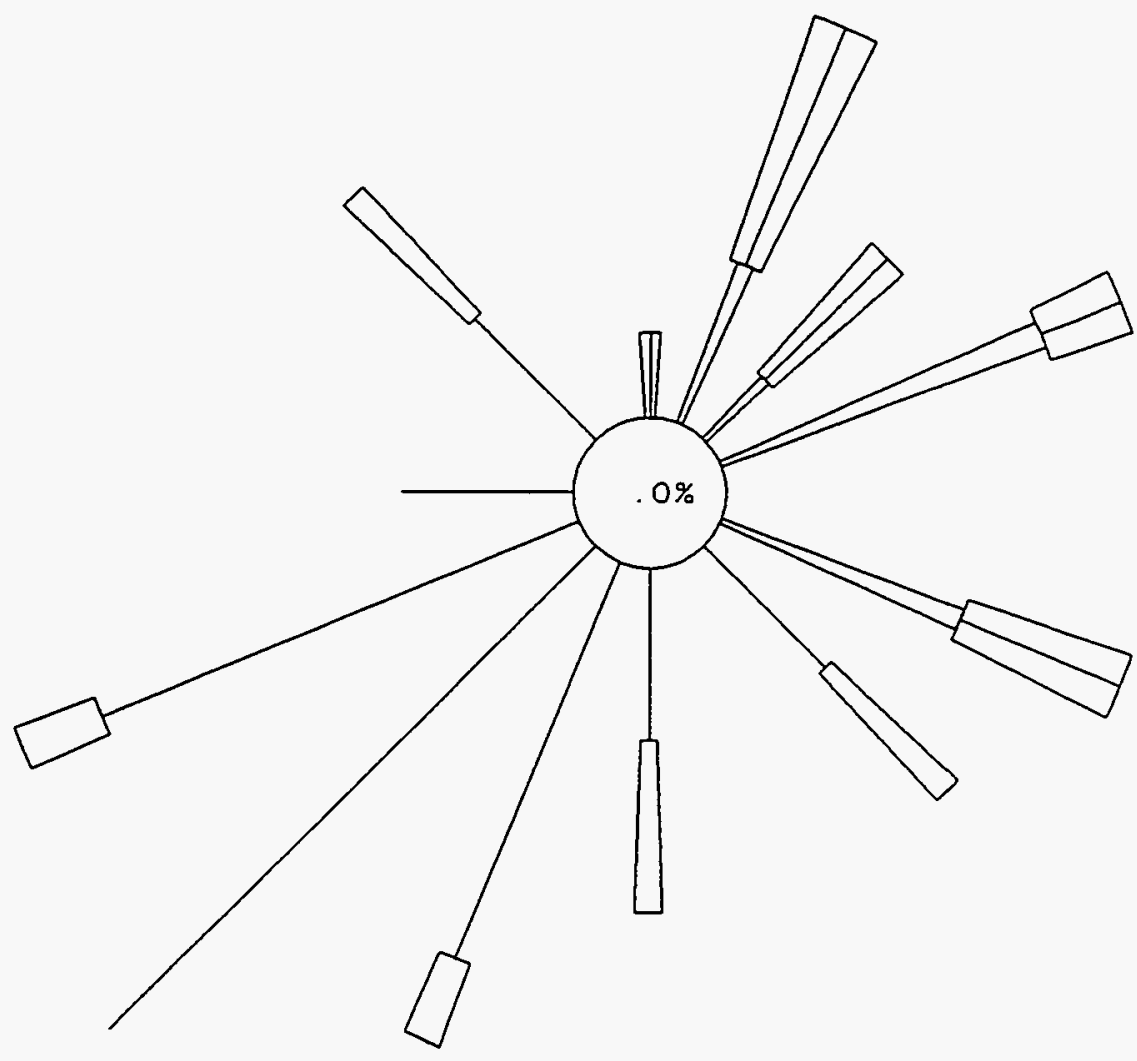

\begin{tabular}{|c|c|c|c|c|c|}
\hline WIND & \multicolumn{2}{|c|}{ SPEED } & \multicolumn{3}{|c|}{ CLASSES (MPS) } \\
\hline CALM & 0 & & & WS & $<=$ \\
\hline 1 & I & & $.5<$ & WS & $<=1: 8$ \\
\hline 2 & $\square$ & 1 & $.8<$ & WS & $<=3.3$ \\
\hline 3 & ד & 3 & $.3<$ & WS & $c=5.4$ \\
\hline 4 & प्ण & 5 & $.4<$ & WS & $<=8.5$ \\
\hline 50 & שIדם & 8 & $.5<$ & WS & $c=10.8$ \\
\hline 60 & סדבד & 10 & $.8<$ & WS & \\
\hline
\end{tabular}

78. O\% DATA RECOVERED

OF WHICH $9.3 \%$ IS

REPORTED ABOVE 


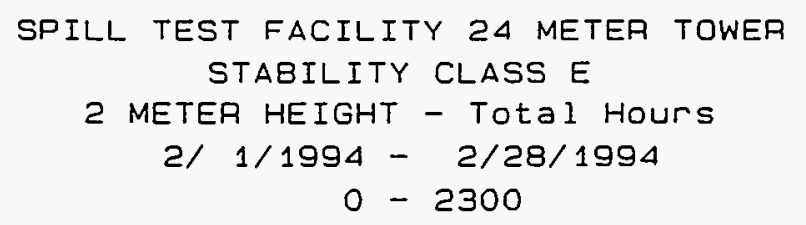

$N$

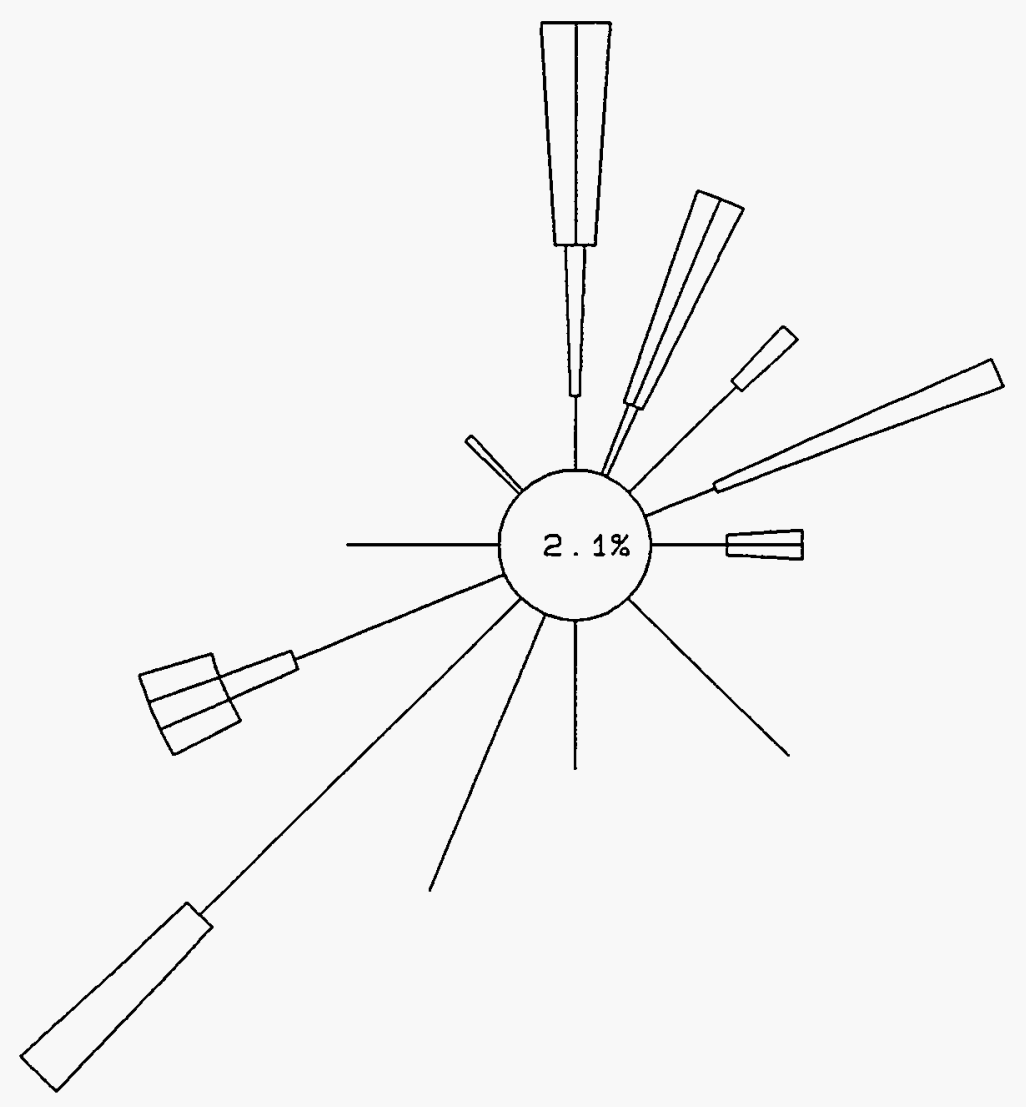

WIND SPEED CLASSES (MPS)

$\begin{array}{cr}\text { CALM } 0 & \text { WS }<=.5 \\ 11 & .5<\text { WS }<=1.8 \\ 2 \square & 1.8<\text { WS }<=3.3 \\ 3 \text { प } & 3.3<\text { WS }<=5.4 \\ 4 \text { पा } & 5.4<\text { WS }<=8.5 \\ 5 \text { पाI } 8.5<\text { WS }<=10.8 \\ 6 \text { पाD } 10.8<\text { WS }\end{array}$

85. 4\% DATA RECOVERED

OF WHICH 8.2\% IS

REPORTED ABOVE 


\section{SPILL TEST FACILITY 24 METER TOWER \\ STABILITY CLASS E \\ 2 METER HEIGHT - Total Hours \\ $3 / 1 / 1994-3 / 31 / 1994$ \\ $0-2300$}

$N$
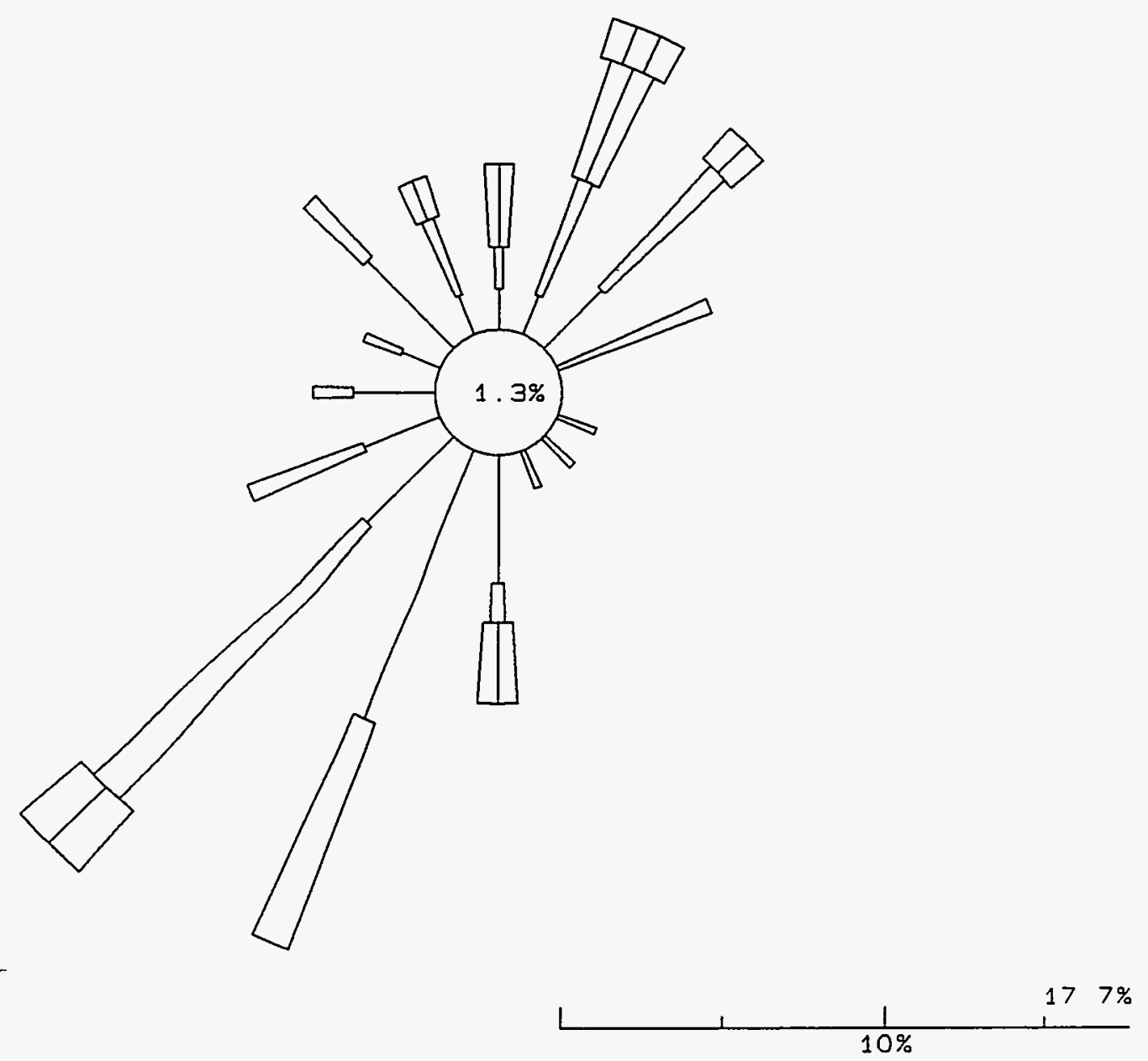

100.0\% DATA RECOVERED

OF WHICH $10.6 \%$ IS

REPORTED ABOVE 


\section{SPILL TEST FACILITY 24 METER TOWER STABILITY CLASS E \\ 2 METER HEIGHT - Total Hours \\ $4 / 1 / 1994-4 / 30 / 1994$ \\ $0-2300$}

N
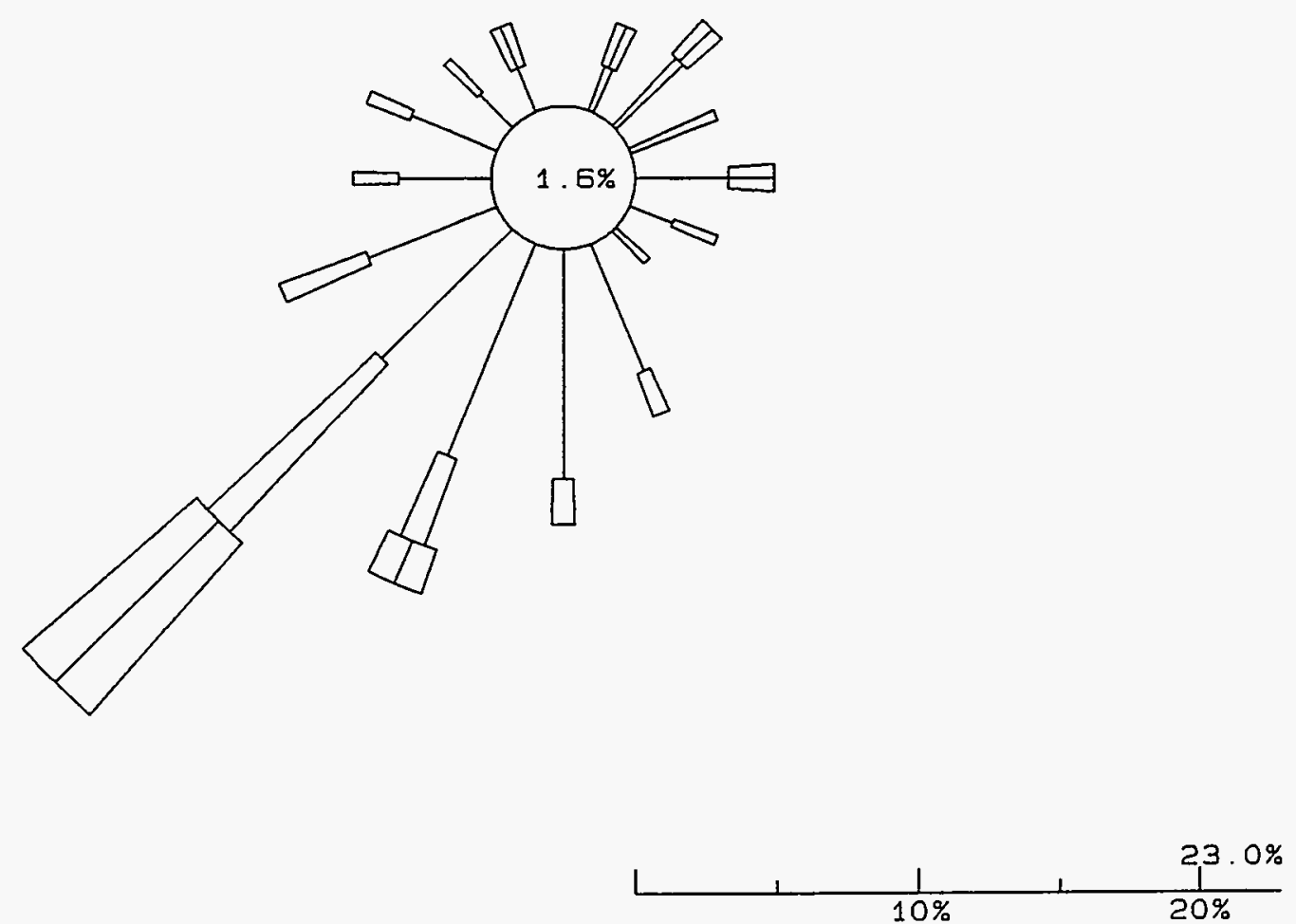

99.4\% DATA RECOVERED

OF WHICH $8.5 \%$ IS

REPORTED ABOVE 


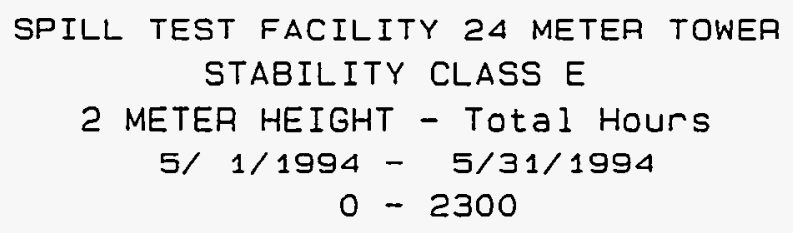

$N$

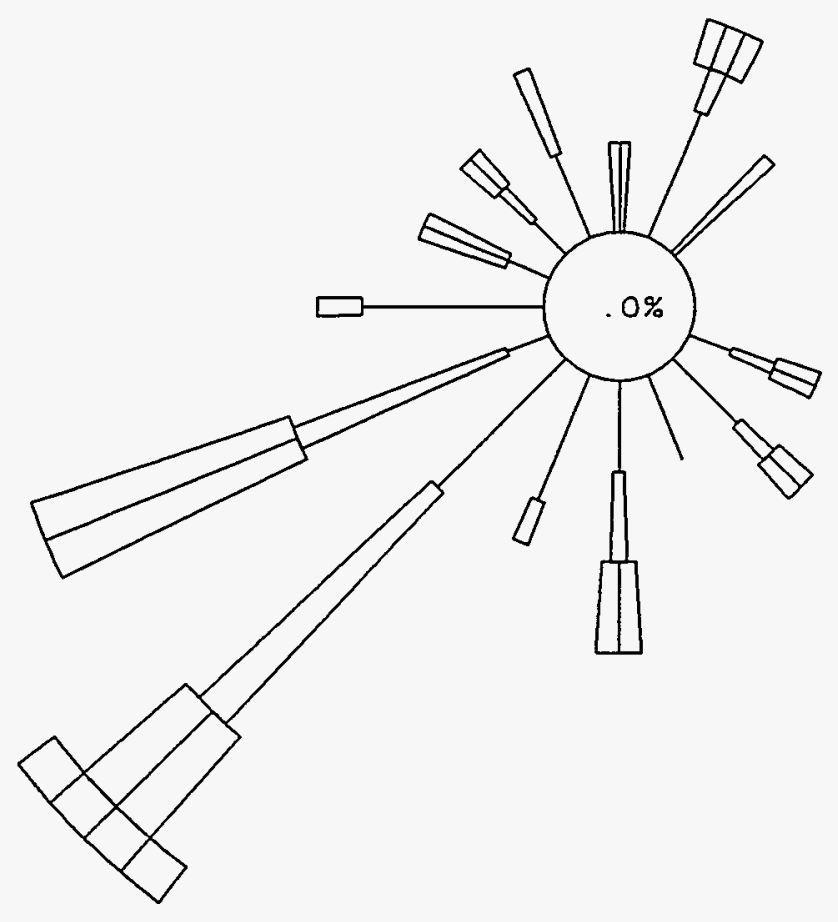

96.9\% DATA RECOVERED OF WHICH . $9.8 \%$ IS REPORTED ABOVE 


\section{SPILL TEST FACILITY 24 METER TOWER \\ STABILITY CLASS E \\ 2 METER HEIGHT - Total Hours \\ 6/ $1 / 1994$ - 6/30/1994 \\ $0-2300$}

$N$
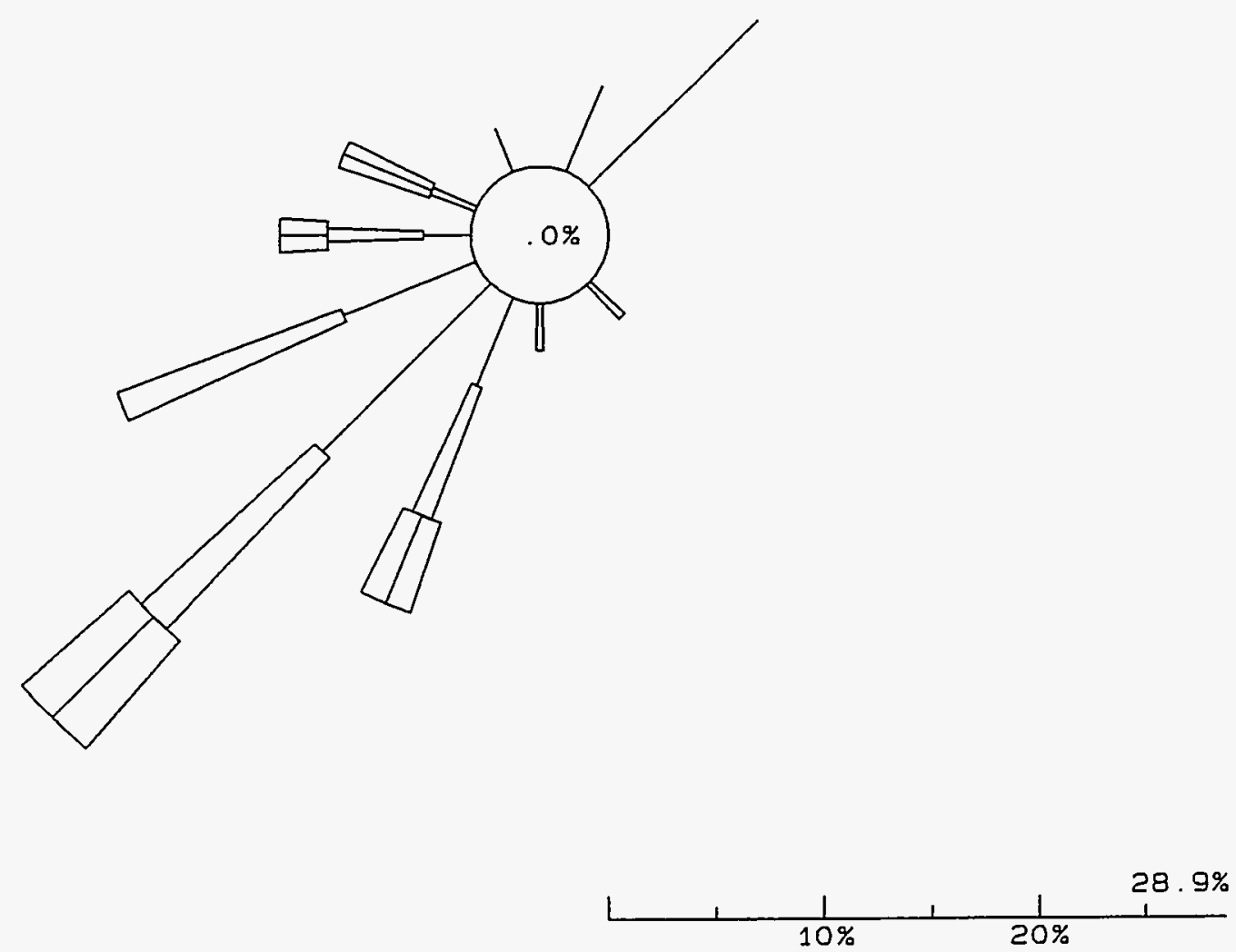

\begin{tabular}{|c|c|c|c|c|c|}
\hline \multirow{2}{*}{\multicolumn{3}{|c|}{$\begin{array}{l}\text { WIND SPEED } \\
\text { CALM O }\end{array}$}} & \multicolumn{3}{|c|}{ CLASSES (MPS) } \\
\hline & & & & WS & $<=$ \\
\hline 1 & 1 & & $5<$ & WS & $<=1.8$ \\
\hline 2 & 口 & 1 & $.8<$ & WS & $<=3.3$ \\
\hline 3 & ㅁ & 3 & $3<$ & WS & $c=5.4$ \\
\hline 4 & पा & 5 & $4<$ & WS & $<=8.5$ \\
\hline 5 & पामा & 8 & $5<$ & WS & $<=10.8$ \\
\hline 60 & דाIIप & 10 & $.8<$ & WS & \\
\hline
\end{tabular}

100.0\% DATA RECOVERED

OF WHICH 6.3\% IS

REPORTED ABOVE 


\section{SPILL TEST FACILITY 24 METER TOWER \\ STABILITY CLASS E \\ 2 METER HEIGHT - Total Hours \\ $7 / 1 / 1994-7 / 31 / 1994$ \\ $0-2300$}

N
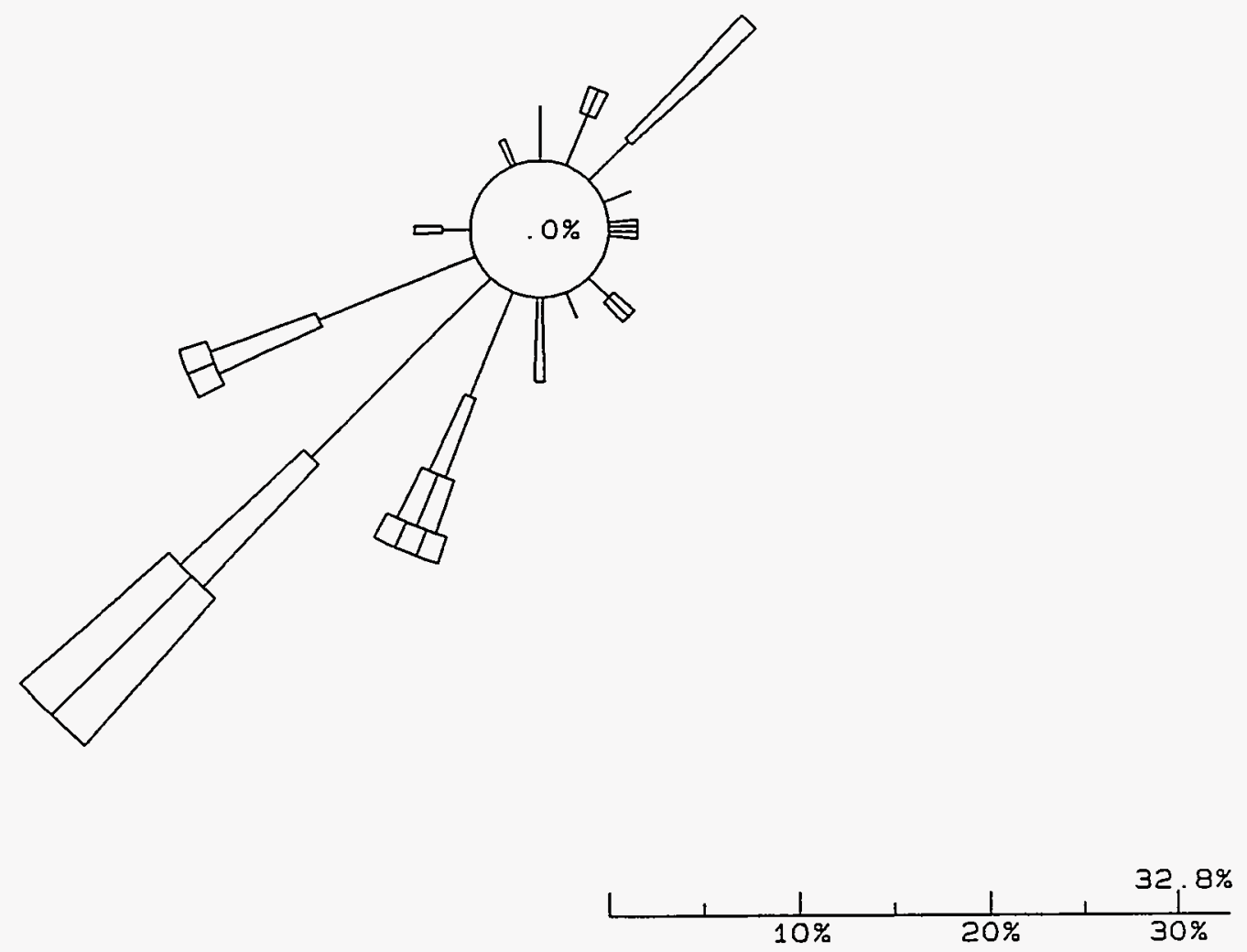

100.0\% DATA RECOVERED

OF WHICH $9.0 \%$ IS

REPORTED ABOVE 


\section{SPILL TEST FACILITY 24 METER TOWER \\ STABILITY CLASS E \\ 2 METER HEIGHT - Total Hours \\ $8 / 1 / 1994-8 / 31 / 1994$ \\ $0-2300$}

N
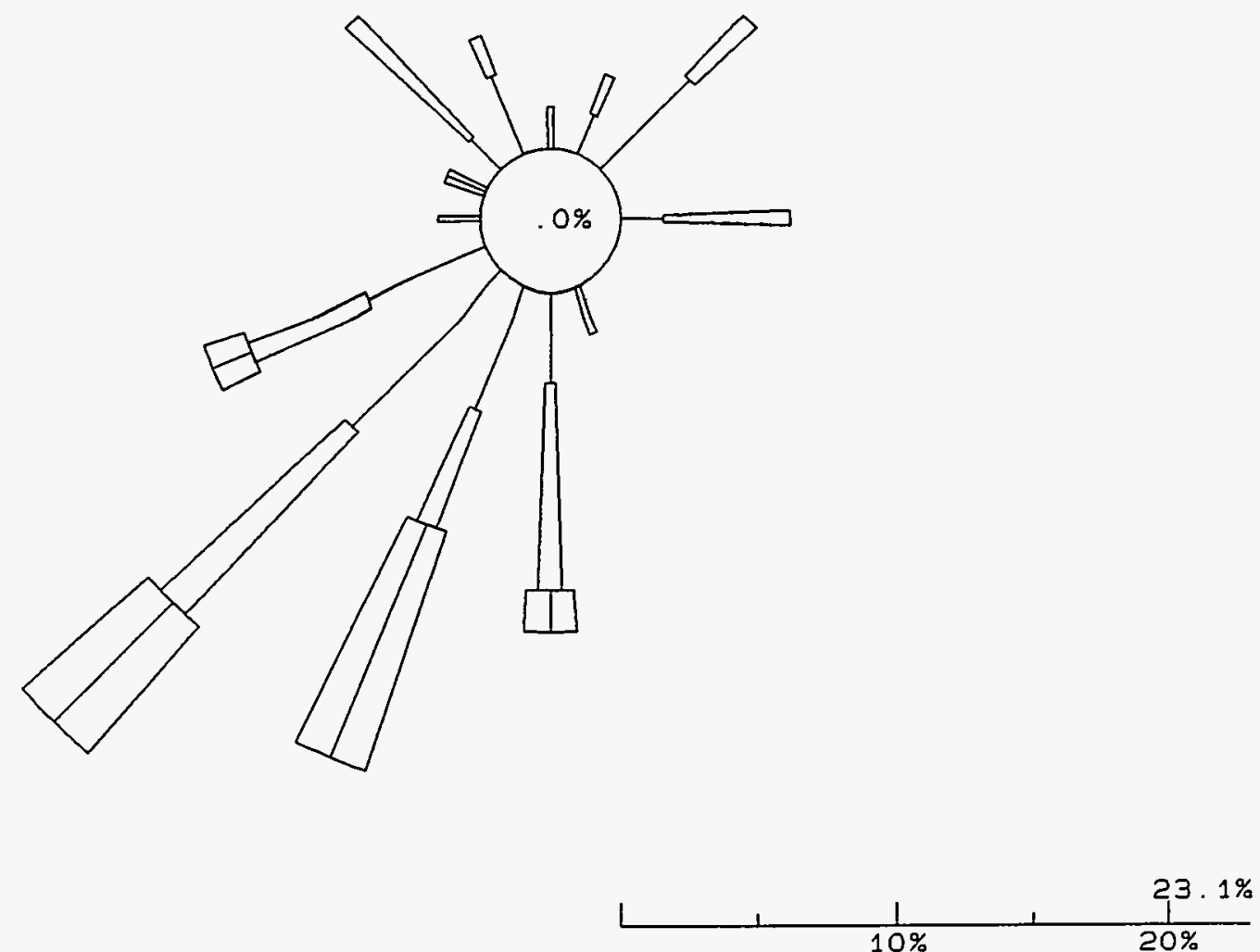

100.0\% DATA RECOVERED

OF WHICH $8.7 \%$ IS

REPORTED ABOVE 


\section{SPILL TEST FACILITY 24 METER TOWER STABILITY CLASS E \\ 2 METER HEIGHT - Total Hours \\ 9/ $1 / 1994$ - 9/30/1994 \\ $0-2300$}

N
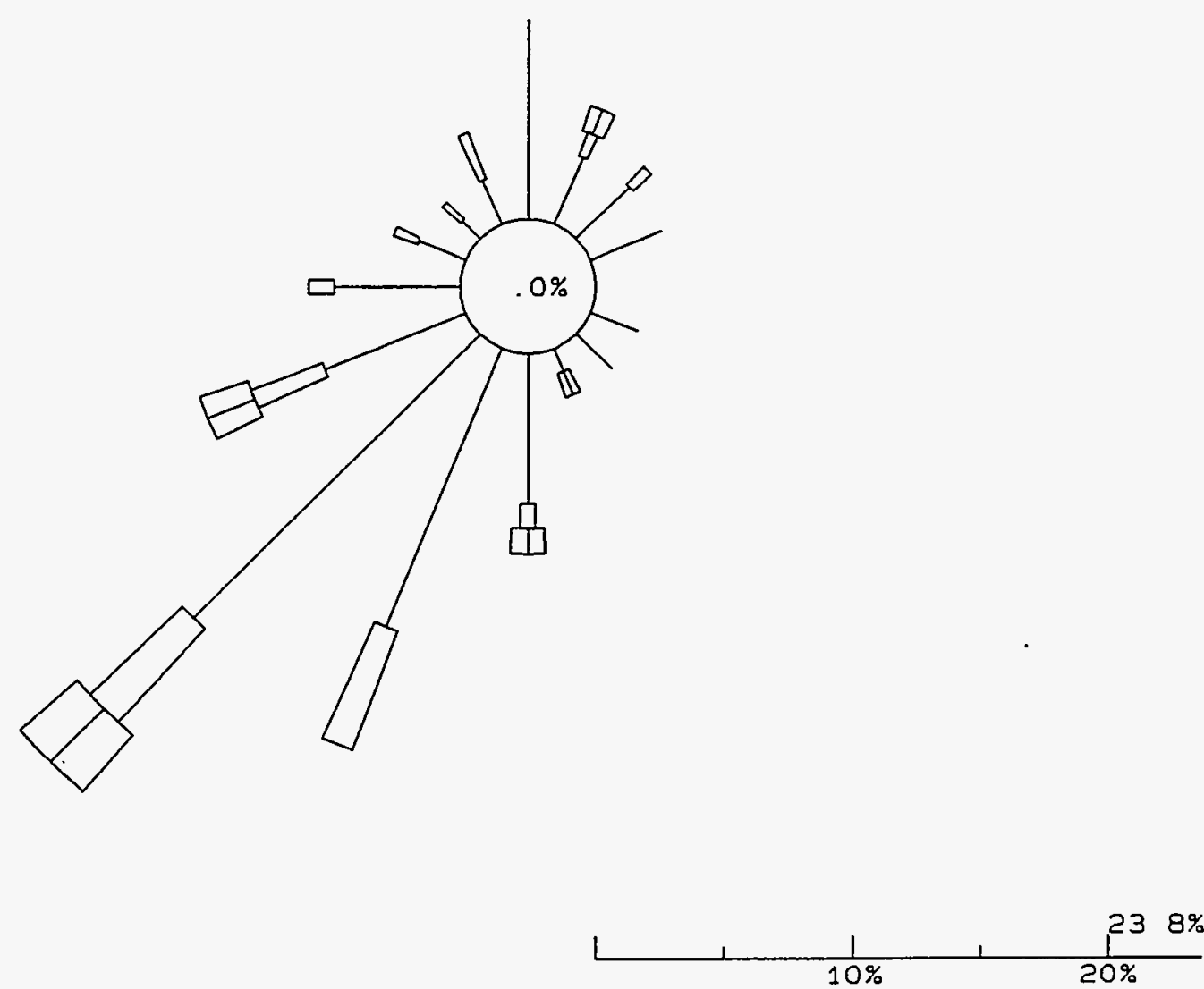

99.7\% DATA RECOVERED

OF WHICH 14.1\% IS REPORTED ABOVE 


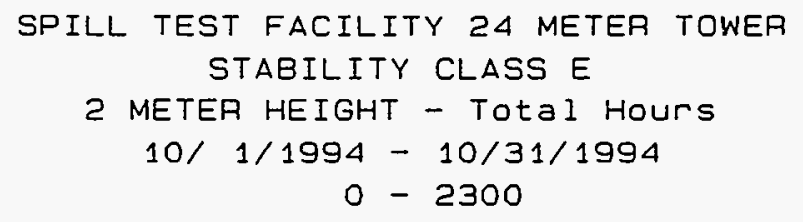

$N$
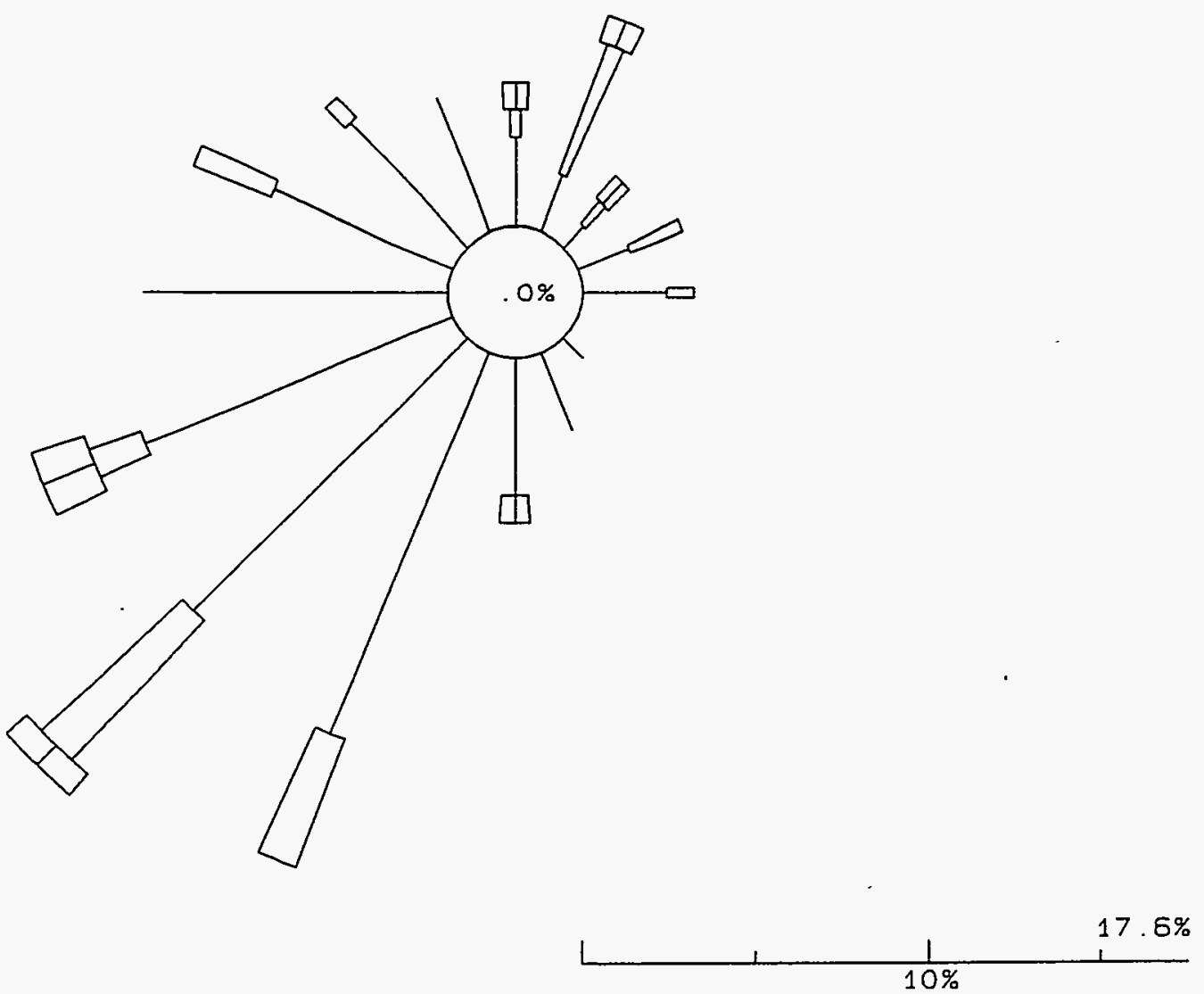

$100.0 \%$ DATA RECOVERED

OF WHICH $16.8 \%$ IS

REPOATED ABOVE 


\section{SPILL TEST FACILITY 24 METER TOWER STABILITY CLASS E \\ 2 METER HEIGHT - Total Hours $11 / 1 / 1994-11 / 30 / 1994$ \\ $0-2300$}

$N$

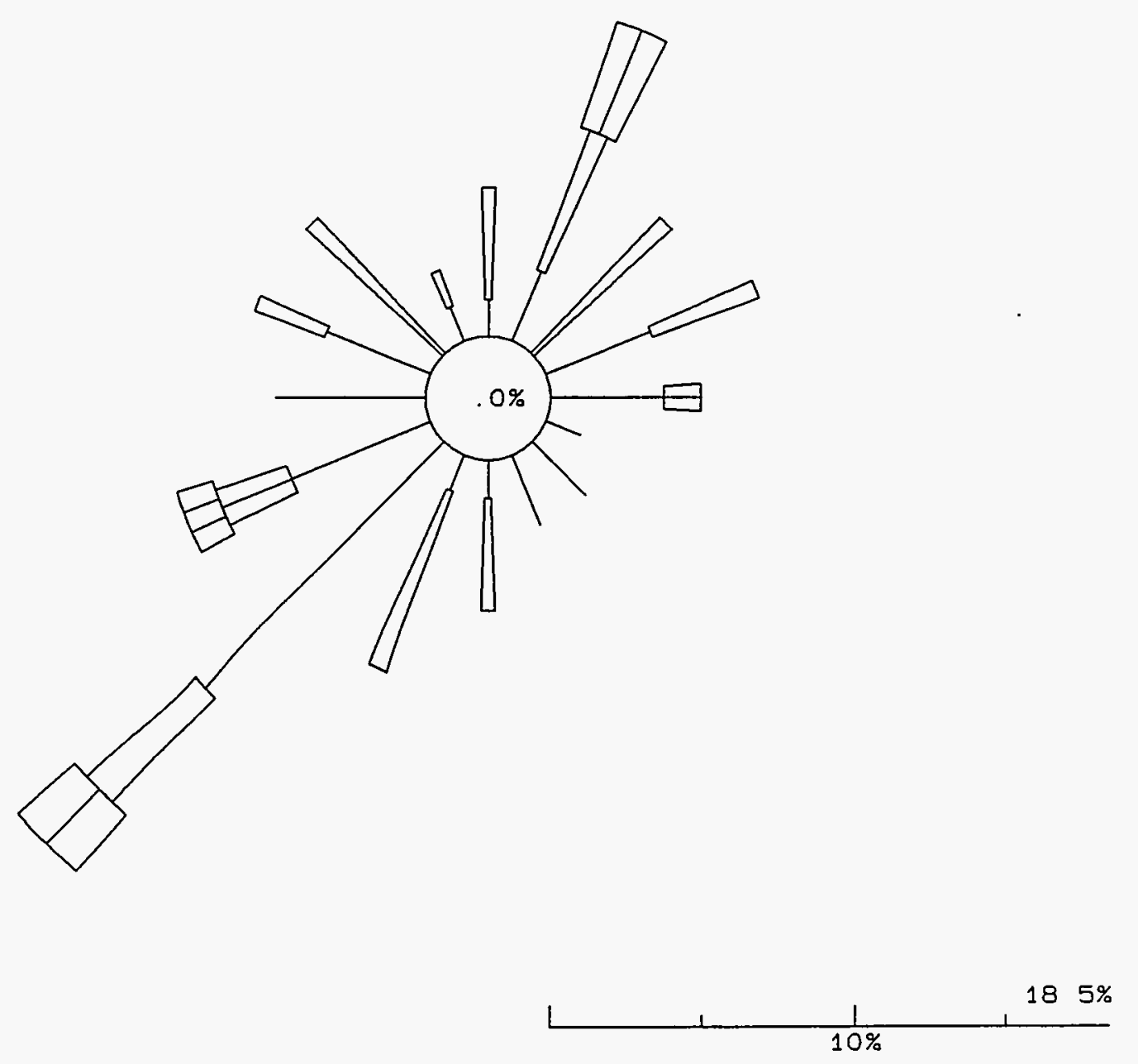

100.0\% DATA RECOVERED OF WHICH 11.3\% IS REPORTED ABOVE 


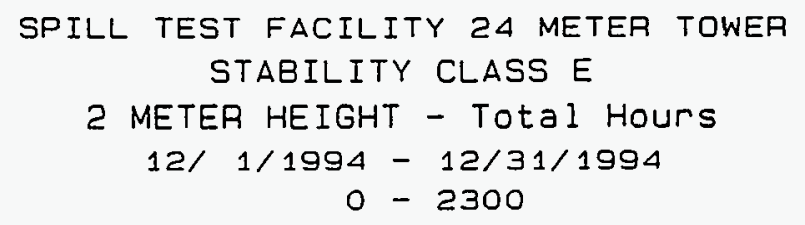

$N$
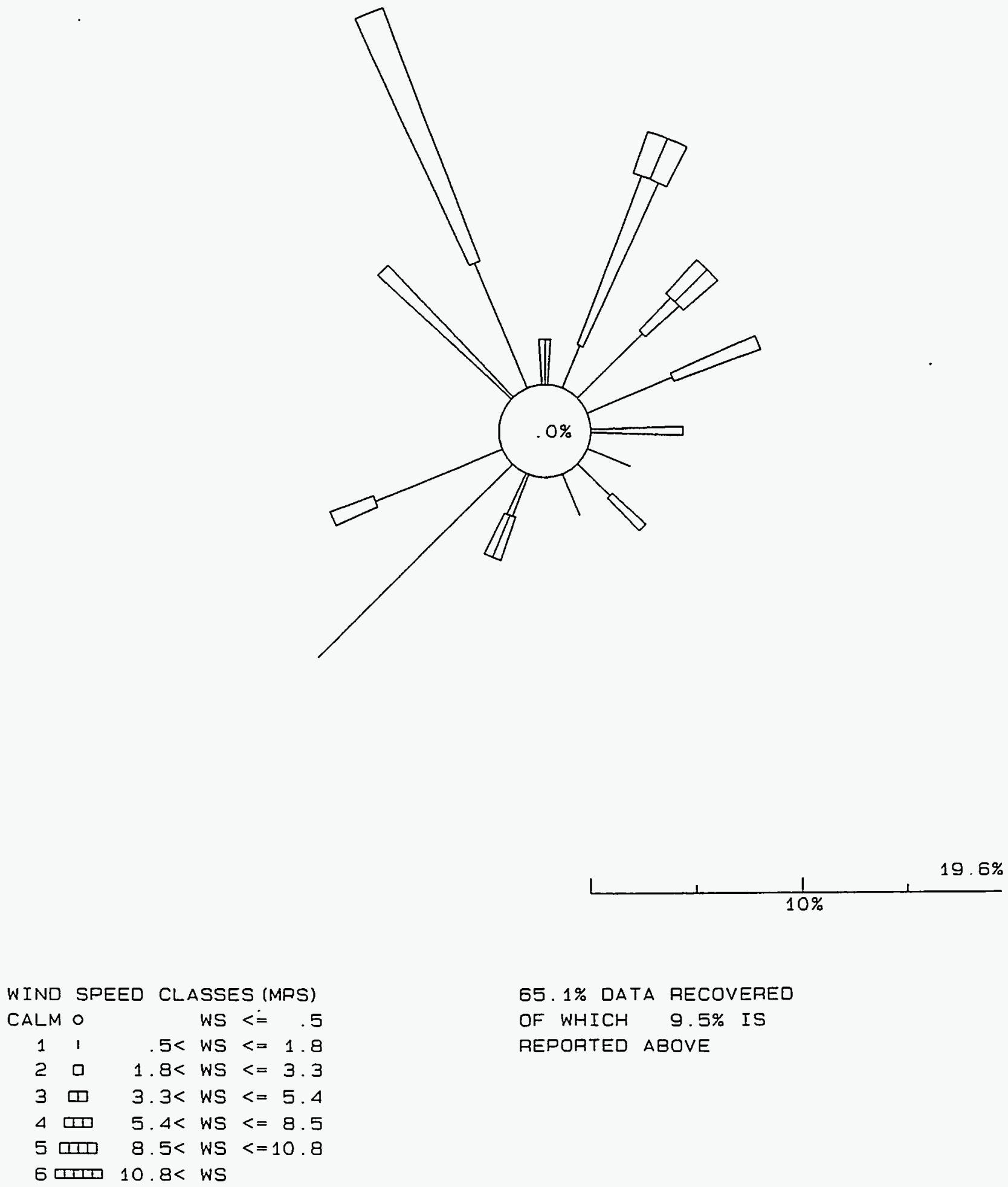


\section{SPILL TEST FACILITY 24 METER TOWER STABILITY CLASS F \\ 2 METER HEIGHT - Total Hours \\ $1 / 1 / 1994-1 / 31 / 1994$ \\ $0-2300$}

$N$
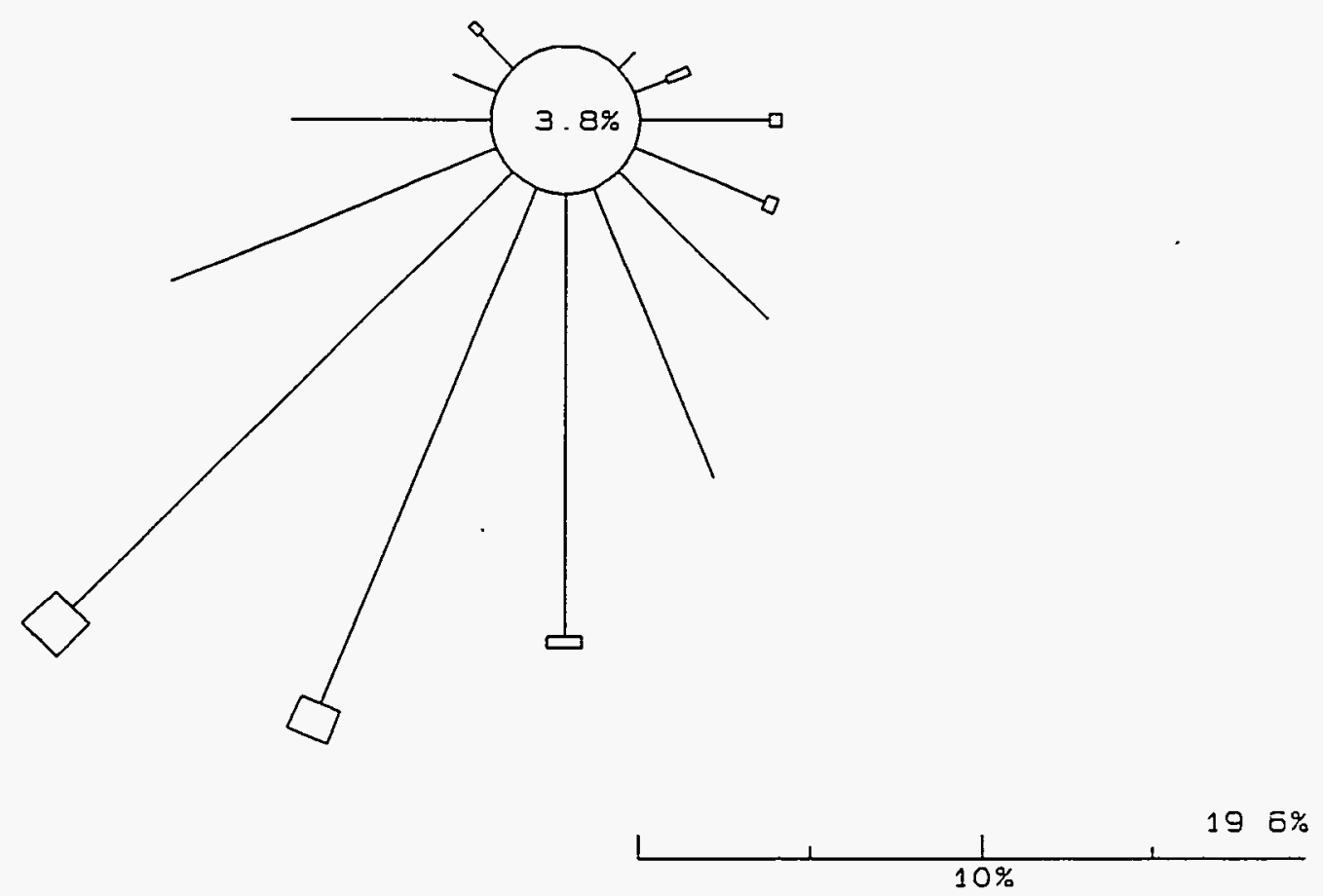

78.0\% DATA RECOVERED

OF WHICH $50.2 \%$ IS

REPORTED ABOVE 


\section{SPILL TEST FACILITY 24 METER TOWER \\ STABILITY CLASS $F$ \\ 2 METER HEIGHT - Total Hours \\ 2/ $1 / 1994-2 / 28 / 1994$ \\ $0-2300$}

$N$
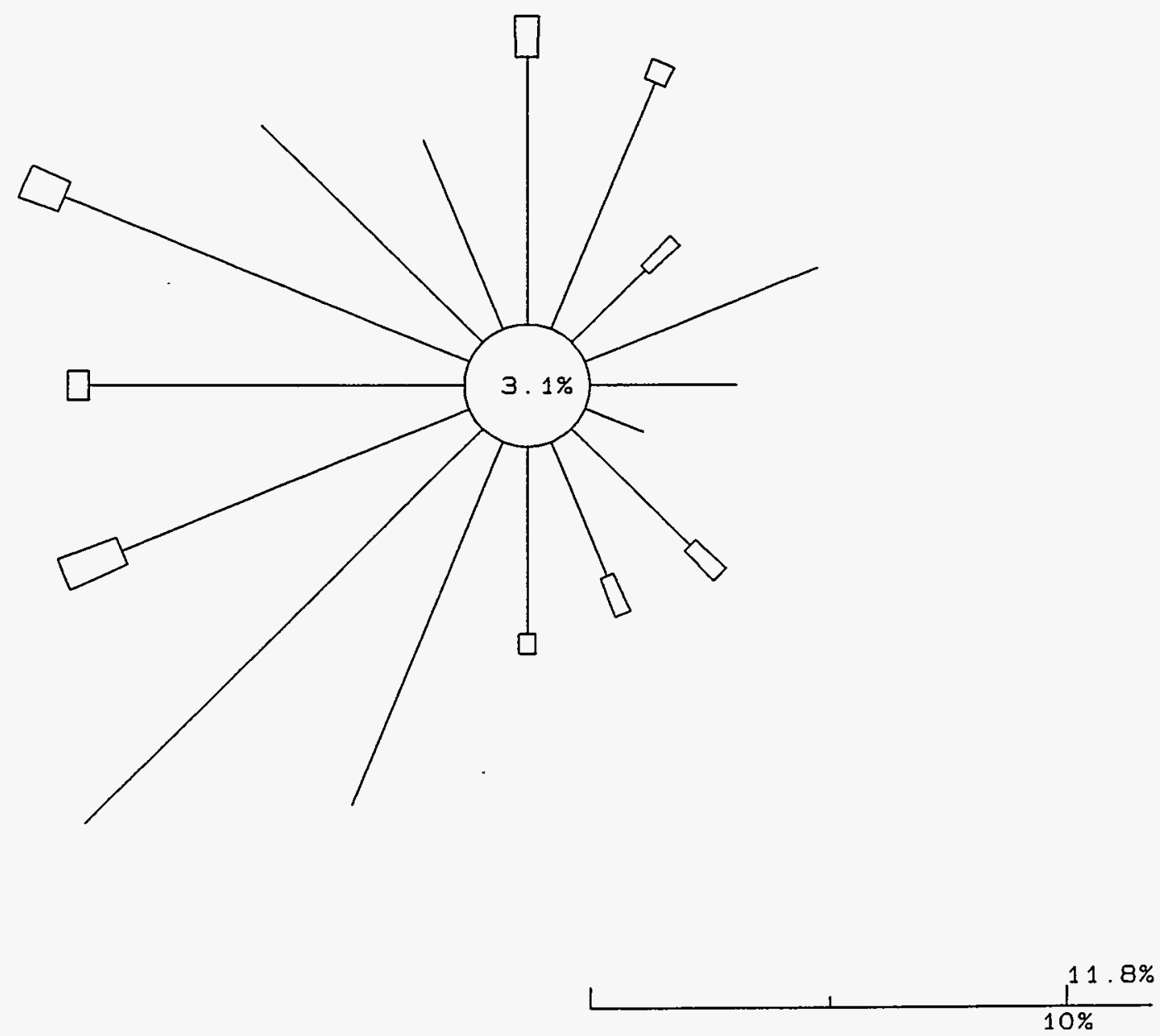

85. 4\% DATA RECOVERED

OF WHICH $39.7 \%$ IS

REPORTED ABOVE 


\section{SPILL TEST FACILITY 24 METER TOWER \\ STABILITY CLASS F \\ 2 METER HEIGHT - Total Hours \\ $3 / 1 / 1994-3 / 31 / 1994$ \\ $0-2300$}

$N$

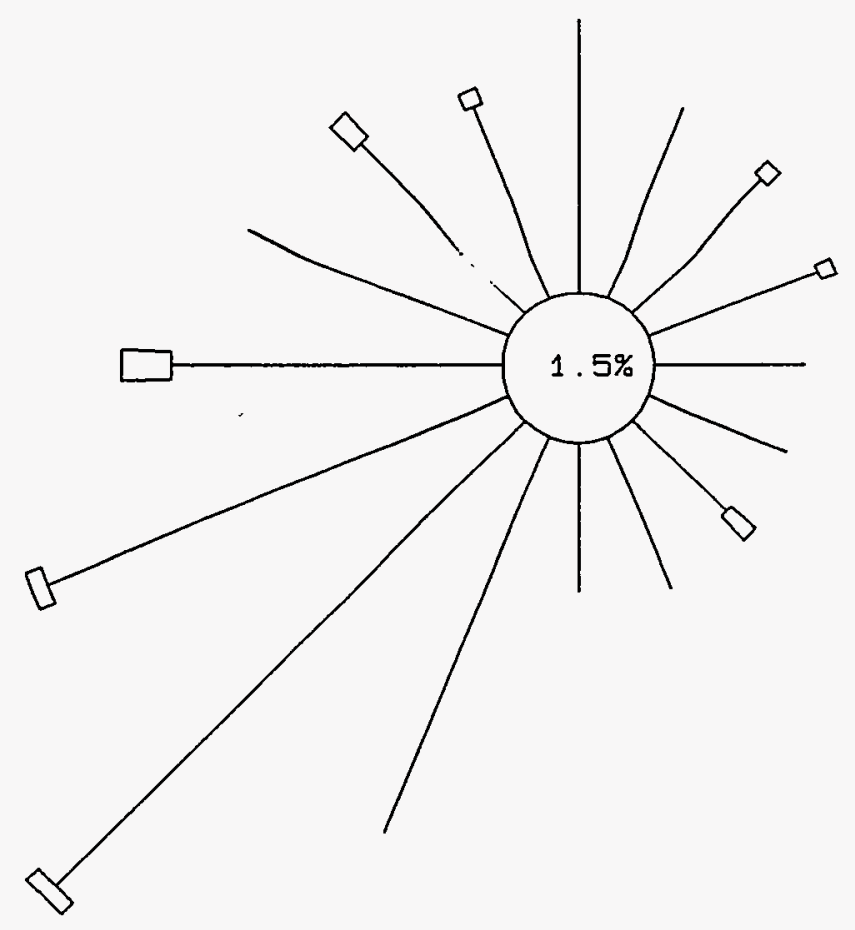

\begin{tabular}{|c|c|c|c|c|c|}
\hline WIND & J $S P$ & ED & CL & ASS & ES (MPS) \\
\hline CALM & 40 & & & WS & $<=$ \\
\hline 1 & 1 & & $5<$ & WS & $<=1.8$ \\
\hline 2 & $\square$ & 1 & $.8<$ & WS & $c=3.3$ \\
\hline 3 & טי & 3 & $3<$ & WS & $c=5.4$ \\
\hline 4 & דा & 5 & $4<$ & WS & $c=8.5$ \\
\hline 5 & पIII) & 8 & $5<$ & WS & $<=10.8$ \\
\hline$c$ & שחप & 10 & $.8<$ & WS & \\
\hline
\end{tabular}

100.0\% DATA RECOVERED

OF WHICH 36.3\% IS

REPORTED ABOVE 


\section{SPILL TEST FACILITY 24 METER TOWER \\ STABILITY CLASS $F$ \\ 2 METER HEIGHT - Total Hours \\ $4 / 1 / 1994-4 / 30 / 1994$ \\ $0-2300$}

$N$

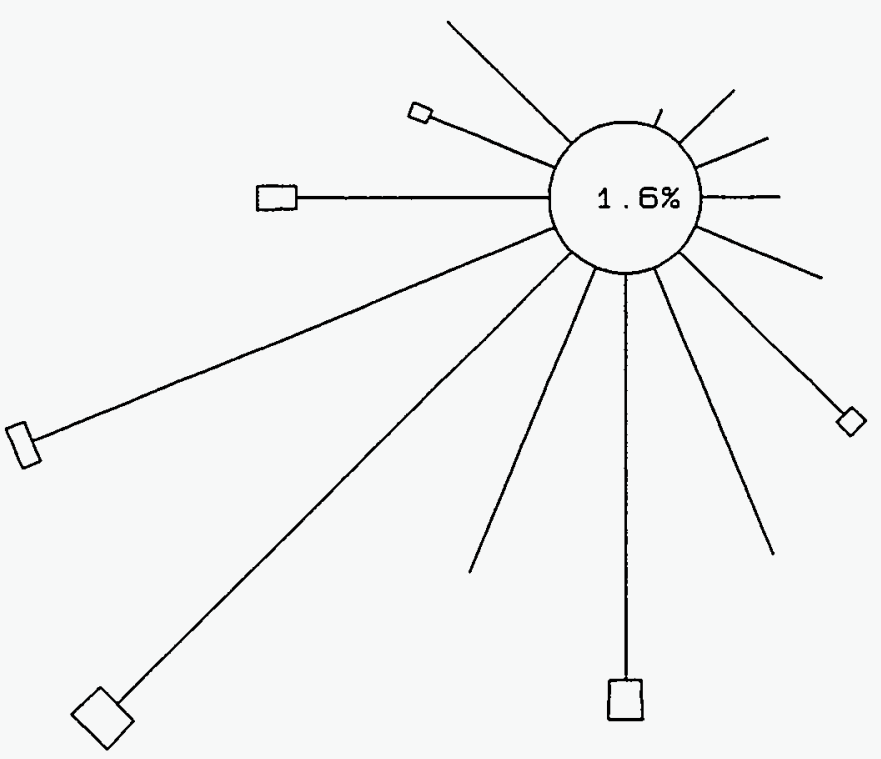

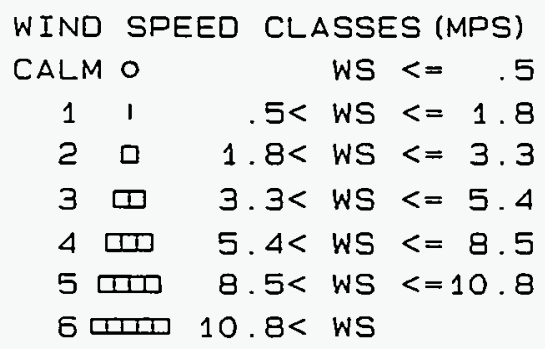

99. 4\% DATA RECOVERED

OF WHICH 26.4\% IS

REPORTED ABOVE 


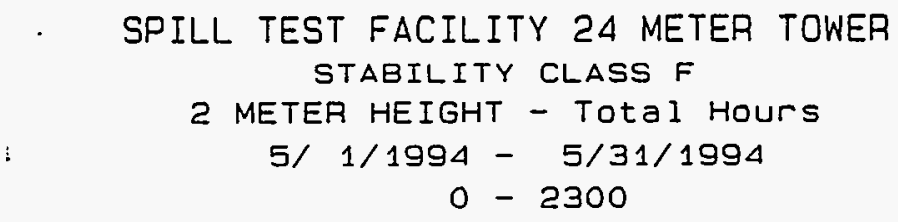

$N$

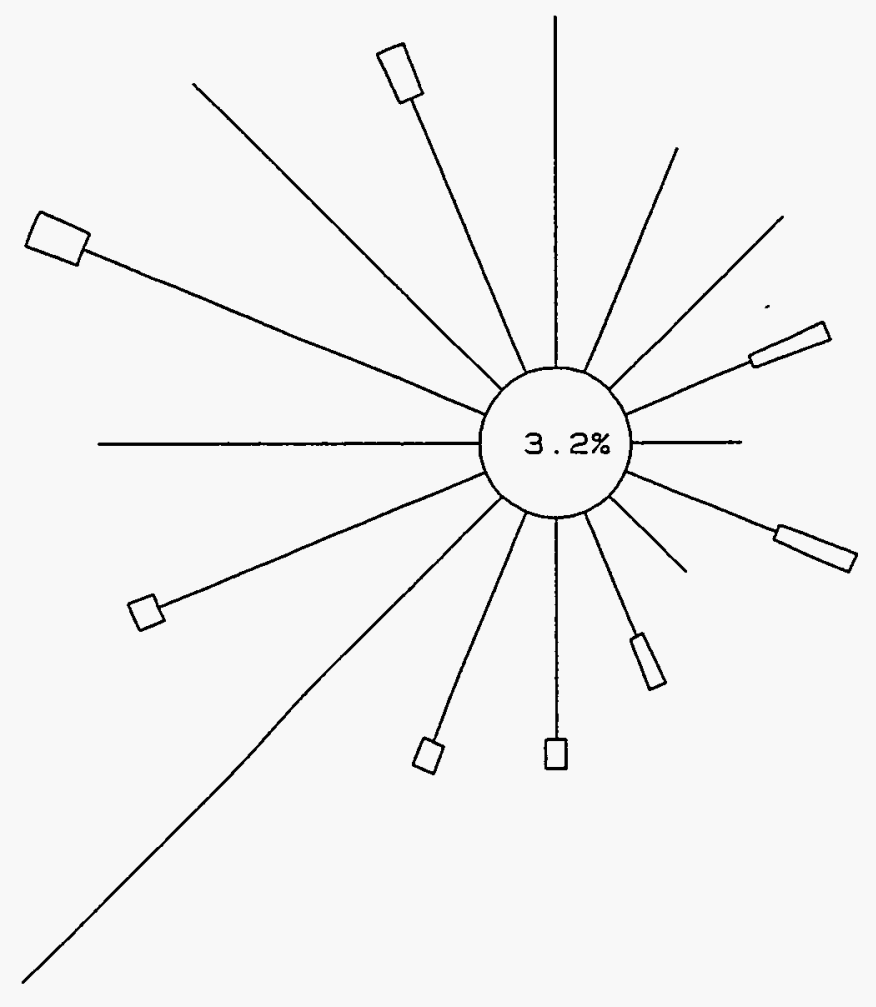

\begin{tabular}{|c|c|c|c|c|c|}
\hline \multirow{2}{*}{$\begin{array}{l}\text { WIND } \\
\text { CALM }\end{array}$} & \multicolumn{2}{|c|}{ SPEED } & \multicolumn{3}{|c|}{ CLASSES (MPS) } \\
\hline & 10 & & & WS & $<=$ \\
\hline 1 & I & & $5<$ & WS & $<=1.8$ \\
\hline 2 & 口 & 1 & $.8<$ & WS & $<=3.3$ \\
\hline 3 & $\square$ & 3 & $3<$ & WS & $<=5.4$ \\
\hline 4 & דם & 5 & $4<$ & WS & $<=8.5$ \\
\hline 5 & סाप्त & 8 & $.5<$ & WS & $<=10.8$ \\
\hline 6 & חI & 10 & $.8<$ & WS & \\
\hline
\end{tabular}

96.9\% DATA RECOVERED

OF WHICH 26.1\% IS

REPORTED ABOVE 


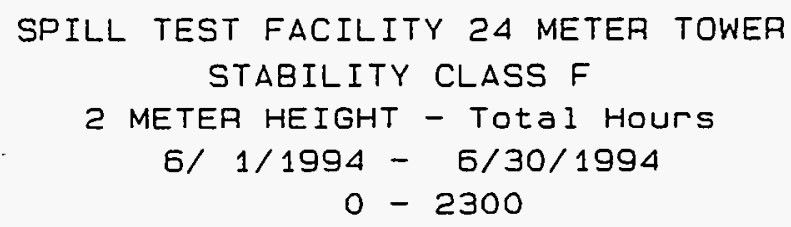

$N$
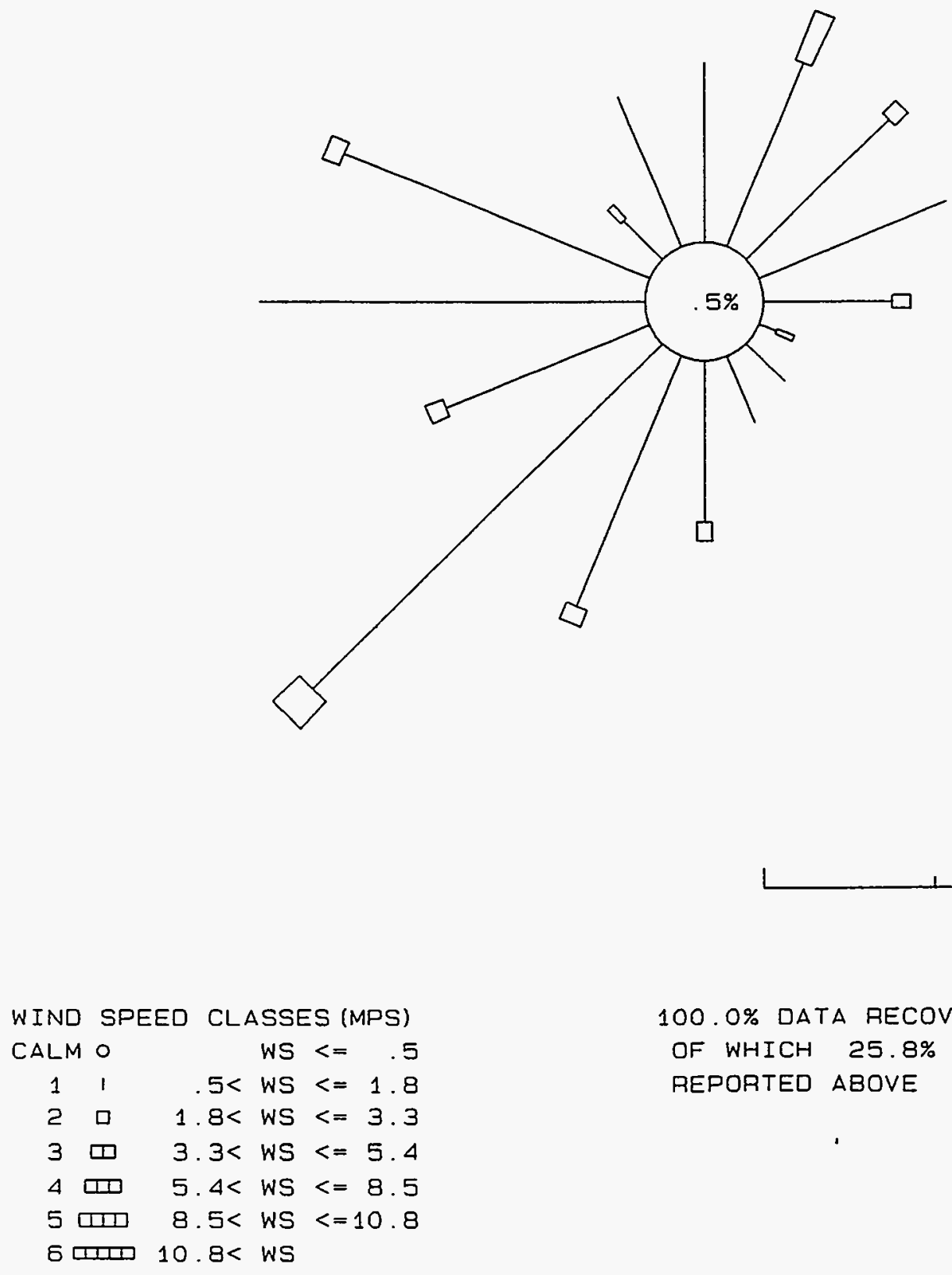


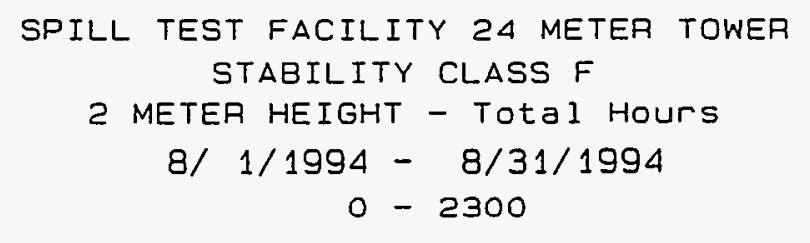

$N$

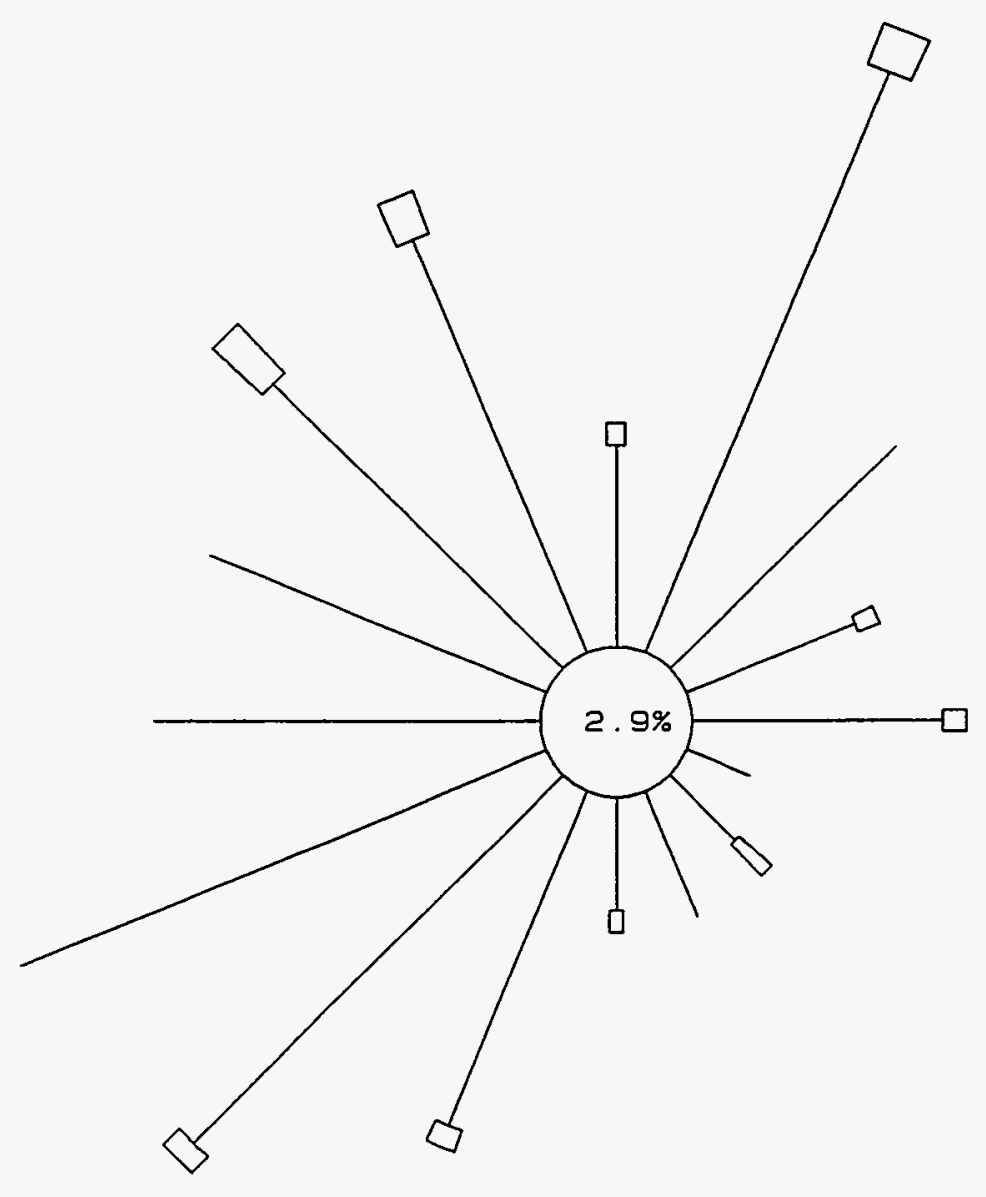

\begin{tabular}{|c|c|c|c|c|c|}
\hline WIND & $S P$ & ED & CL & SSE & S (MPS) \\
\hline CALM & 10 & & & WS & $<=$ \\
\hline 1 & I & & $5<$ & WS & $<=1.8$ \\
\hline 2 & $\square$ & 1 & $.8<$ & WS & $<=3.3$ \\
\hline 3 & एᄆ & 3 & $3<$ & WS & $<=5.4$ \\
\hline 4 & סש & 5 & $.4<$ & WS & $<=8.5$ \\
\hline 5 & שII & 8 & $.5<$ & WS & $<=10.8$ \\
\hline 60 & סIII & 10 & $.8<$ & WS & \\
\hline
\end{tabular}

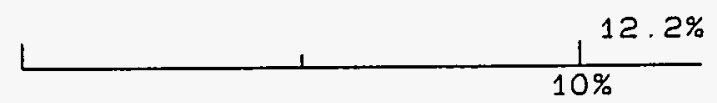

$100.0 \%$ DATA RECOVERED

OF WHICH $32.9 \%$ IS

REPORTED ABOVE 


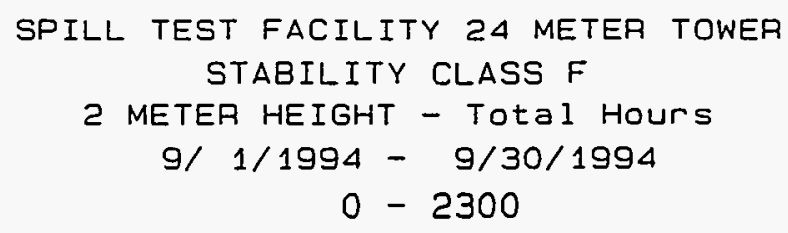

$N$
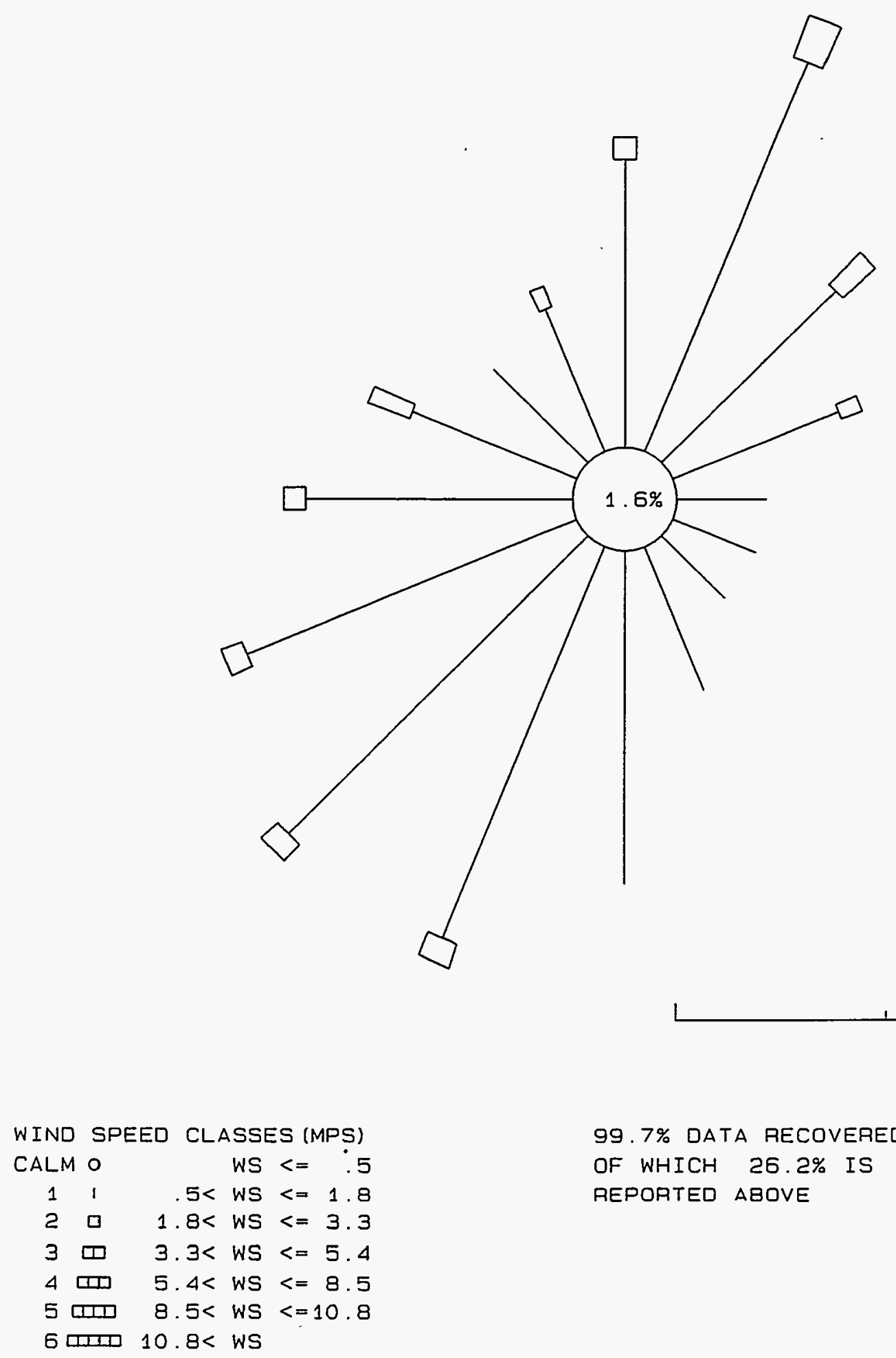

99.7\% DATA RECOVERED

OF WHICH $26.2 \%$ IS

REPOATED ABOVE 


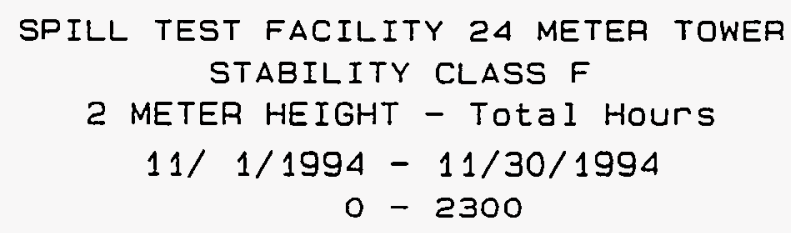

$N$
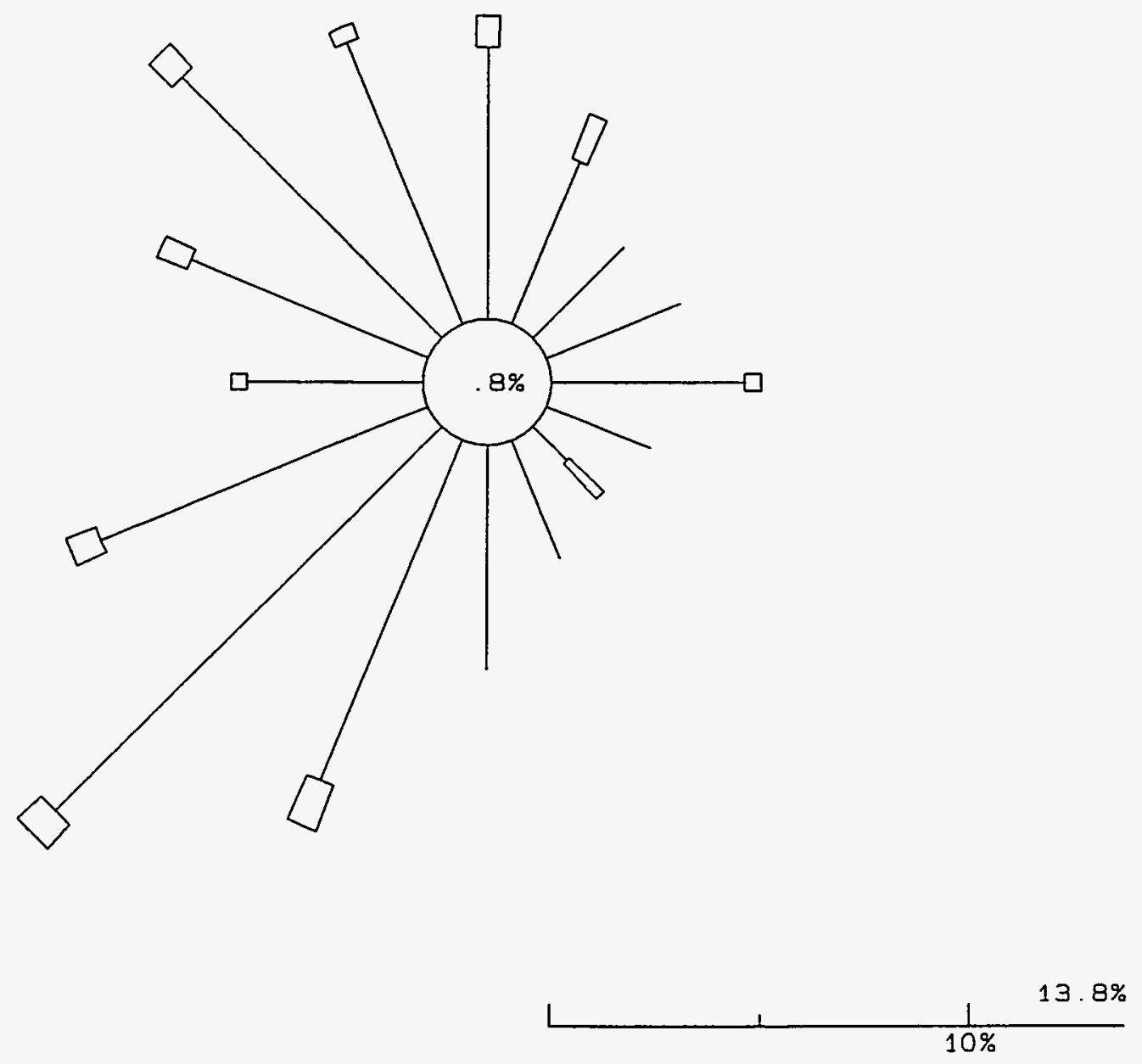

100.0\% DATA RECOVERED

OF WHICH $36.3 \%$ IS

REPOATED ABOVE 


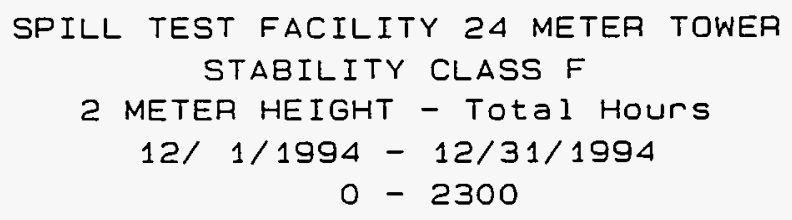

$N$
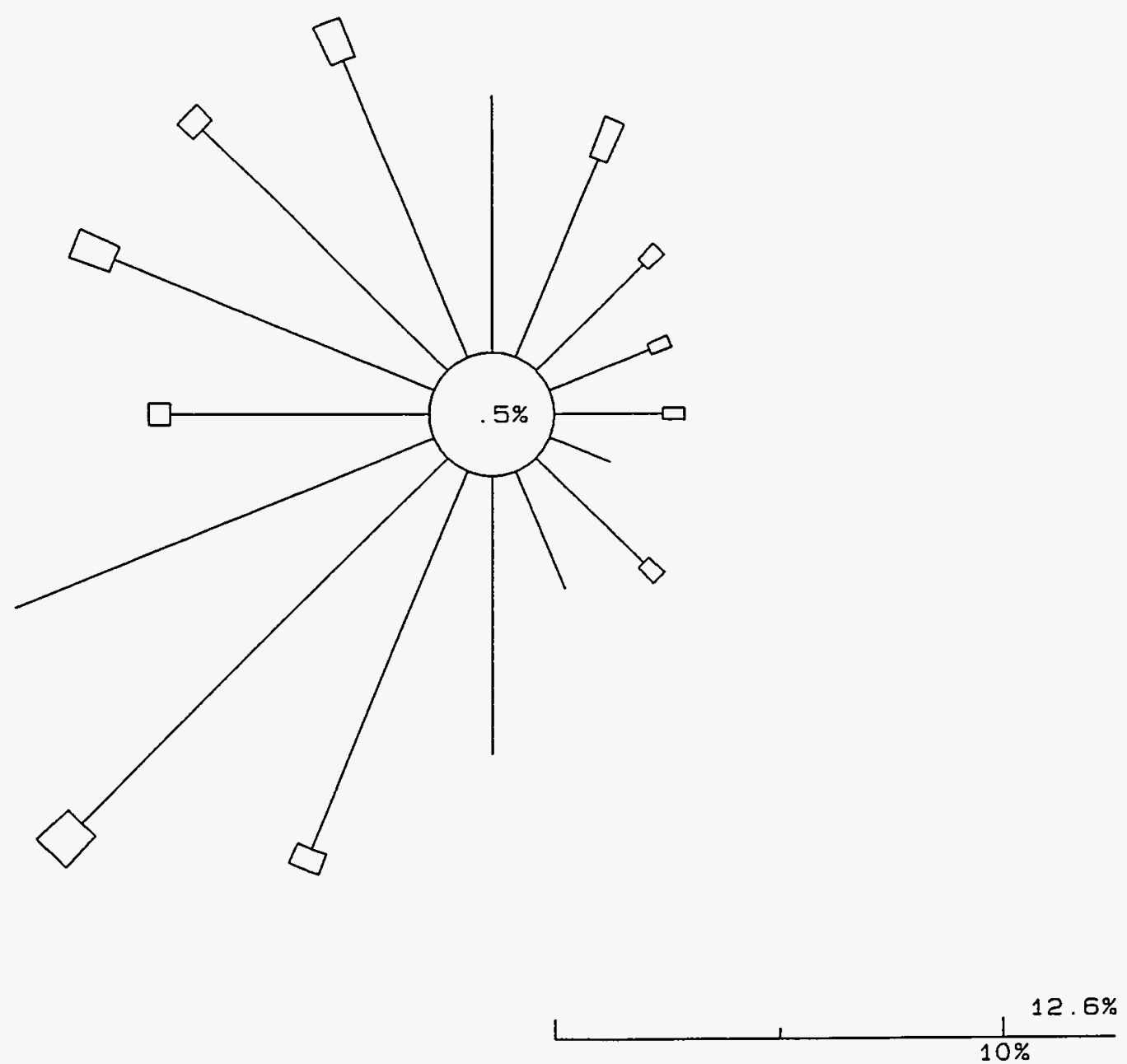

65. 1\% DATA RECOVERED

OF WHICH $42.8 \%$ IS

REPORTED ABOVE 


\section{SPILL TEST FACILITY 24 METER TOWER \\ 8 METER HEIGHT - Total Hours \\ $1 / 1 / 1994-1 / 31 / 1994$ \\ $0-2300$}

$N$

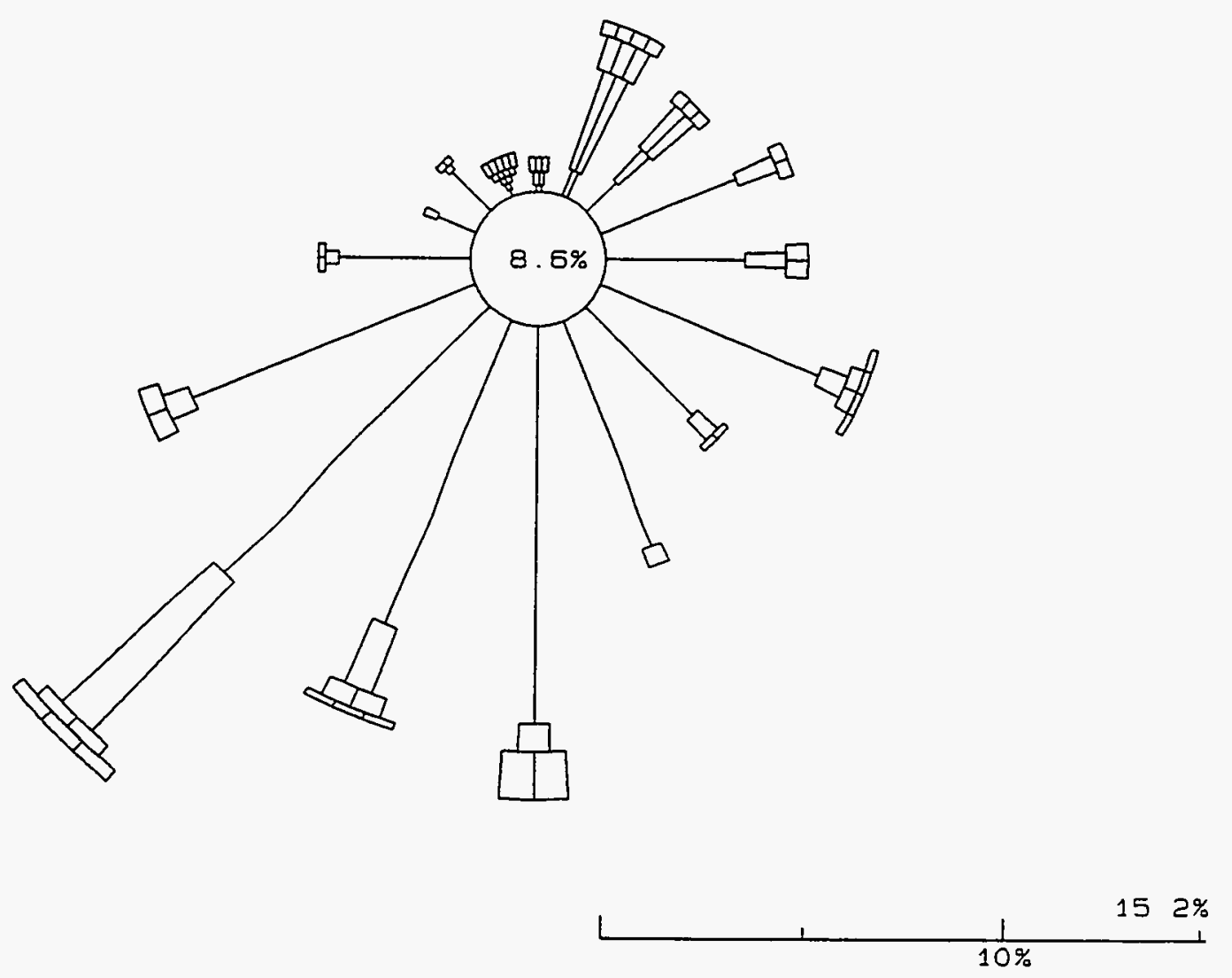

78.0\% DATA RECOVERED

OF WHICH $100.0 \%$ IS REPORTED ABOVE 


\section{SPILL TEST FACILITY 24 METER TOWER
8 METER HEIGHT - Total Hours
2/ $1 / 1994-2 / 28 / 1994$ \\ $0-2300$}

N

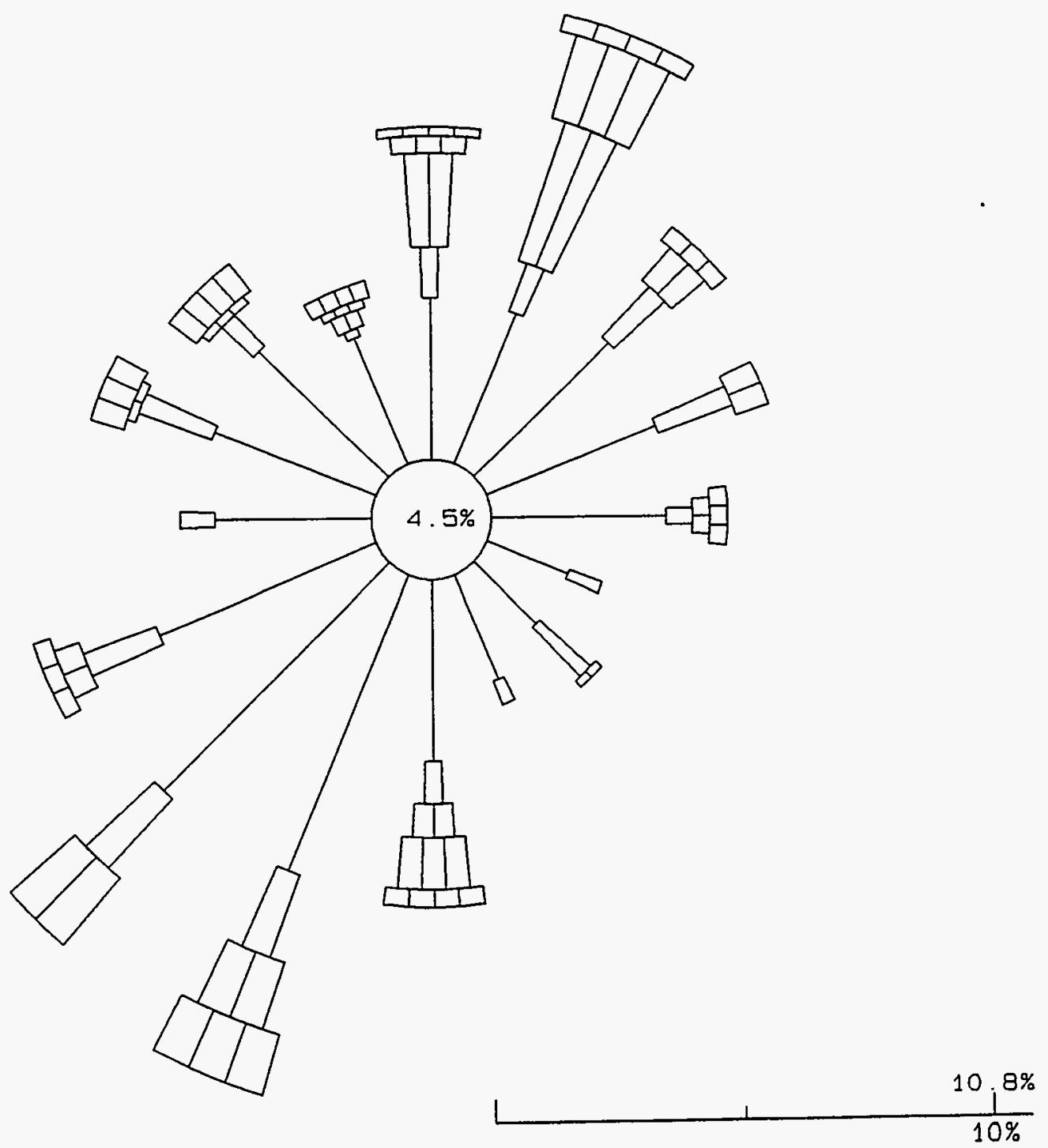

85. 4\% DATA RECOVERED

OF WHICH $100.0 \%$ IS

REPORTED ABOVE 


\section{SPILL TEST FACILITY 24 METER TOWER \\ 8 METER HEIGHT - Total Hours \\ 3/ $1 / 1994-3 / 31 / 1994$ \\ $0-2300$}

$N$

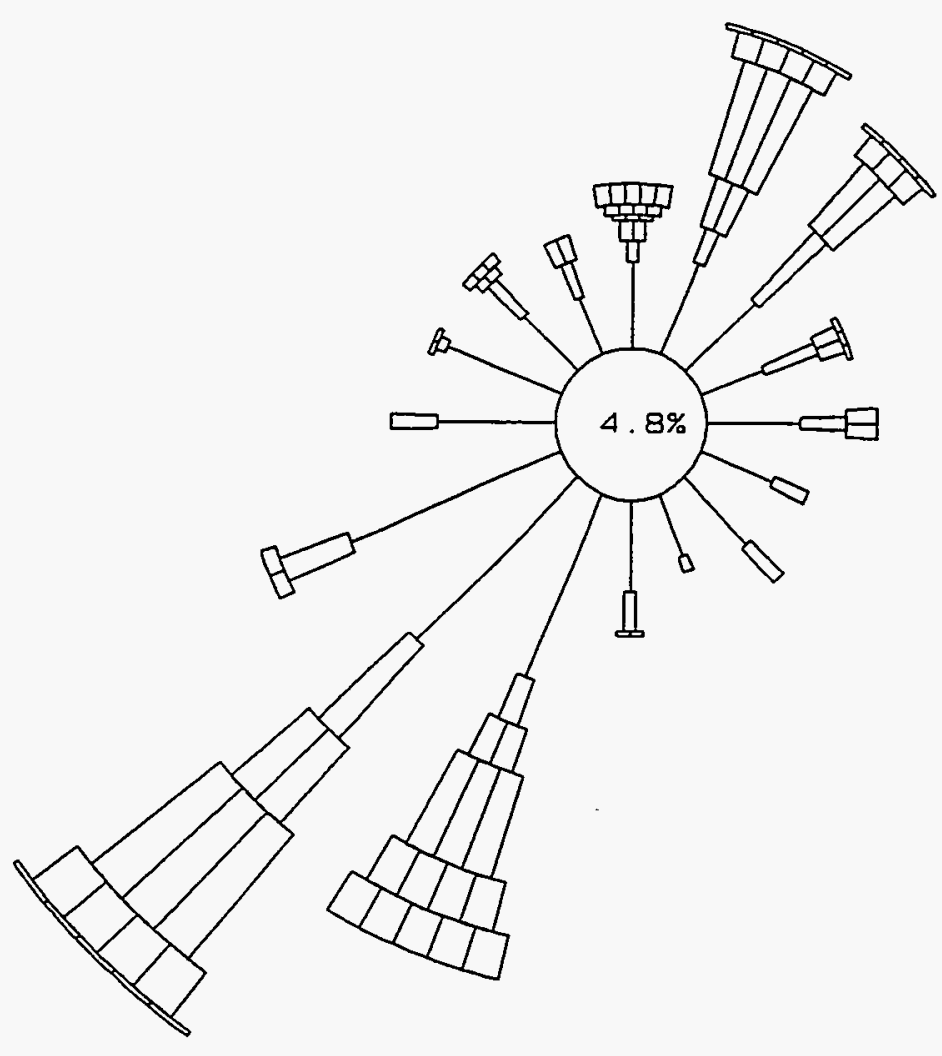

$177 \%$

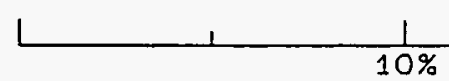

\begin{tabular}{|c|c|c|c|c|c|}
\hline WIND & $S P$ & EDD & CL & $A S S E$ & ES (MPS) \\
\hline CALM & 10 & & & WS & $<=$ \\
\hline 1 & 1 & & $5<$ & WS & $<=1.8$ \\
\hline 2 & $\square$ & 1 & $.8<$ & WS & $c=3.3$ \\
\hline 3 & שם & 3 & $.3<$ & WS & $<=5.4$ \\
\hline 4 & שח & 5 & $.4<$ & WS & $<=8.5$ \\
\hline 50 & דחש & 8 & $.5<$ & WS & $<=10.8$ \\
\hline $6 \mathrm{C}$ & סחד & & $.8<$ & WS & \\
\hline
\end{tabular}

100.0\% DATA RECOVERED

OF WHICH 100.0\% IS

REPORTED ABOVE 


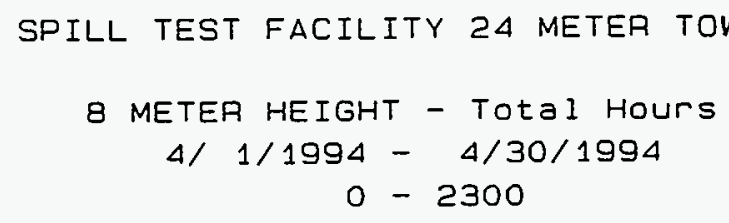

$N$

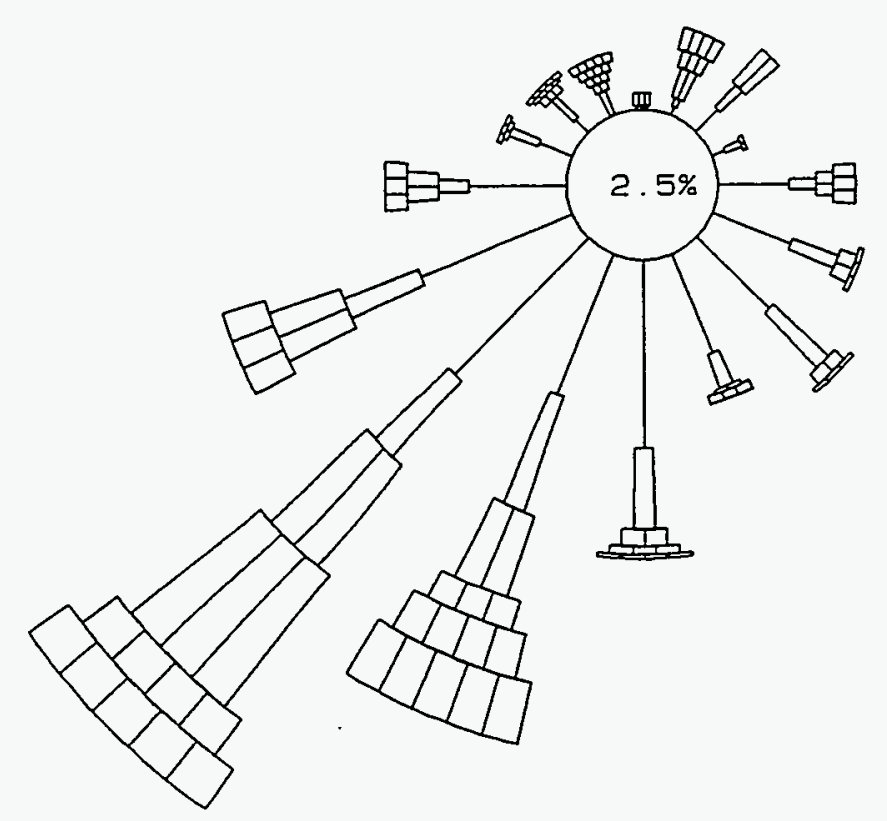

\begin{tabular}{|c|c|c|c|c|c|}
\hline WIND & \multirow{2}{*}{\multicolumn{2}{|c|}{$\begin{array}{l}\text { SPEED } \\
0\end{array}$}} & \multicolumn{3}{|c|}{ CLASSES (MPS) } \\
\hline CALM & & & & WS & $<=$ \\
\hline 1 & 1 & & $.5<$ & WS & $<=1.8$ \\
\hline 2 & $\square$ & 1 & $.8<$ & WS & $<=3.3$ \\
\hline 3 & $\square$ & 3 & $3<$ & WS & $<=5.4$ \\
\hline 4 & סח & 5 & $.4<$ & WS & $<=8.5$ \\
\hline 5 & प11 & 8 & $.5<$ & WS & $<=10.8$ \\
\hline & III & & 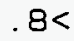 & WS & \\
\hline
\end{tabular}

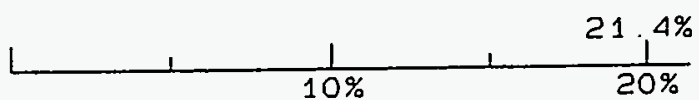

99.9\% DATA RECOVERED

OF WHICH $100.0 \%$ IS

REPORTED ABOVE 


\section{SPILL TEST FACILITY 24 METER TOWER \\ 8 METER HEIGHT - Total Hours \\ $5 / 1 / 1994-5 / 31 / 1994$ \\ $0-2300$}
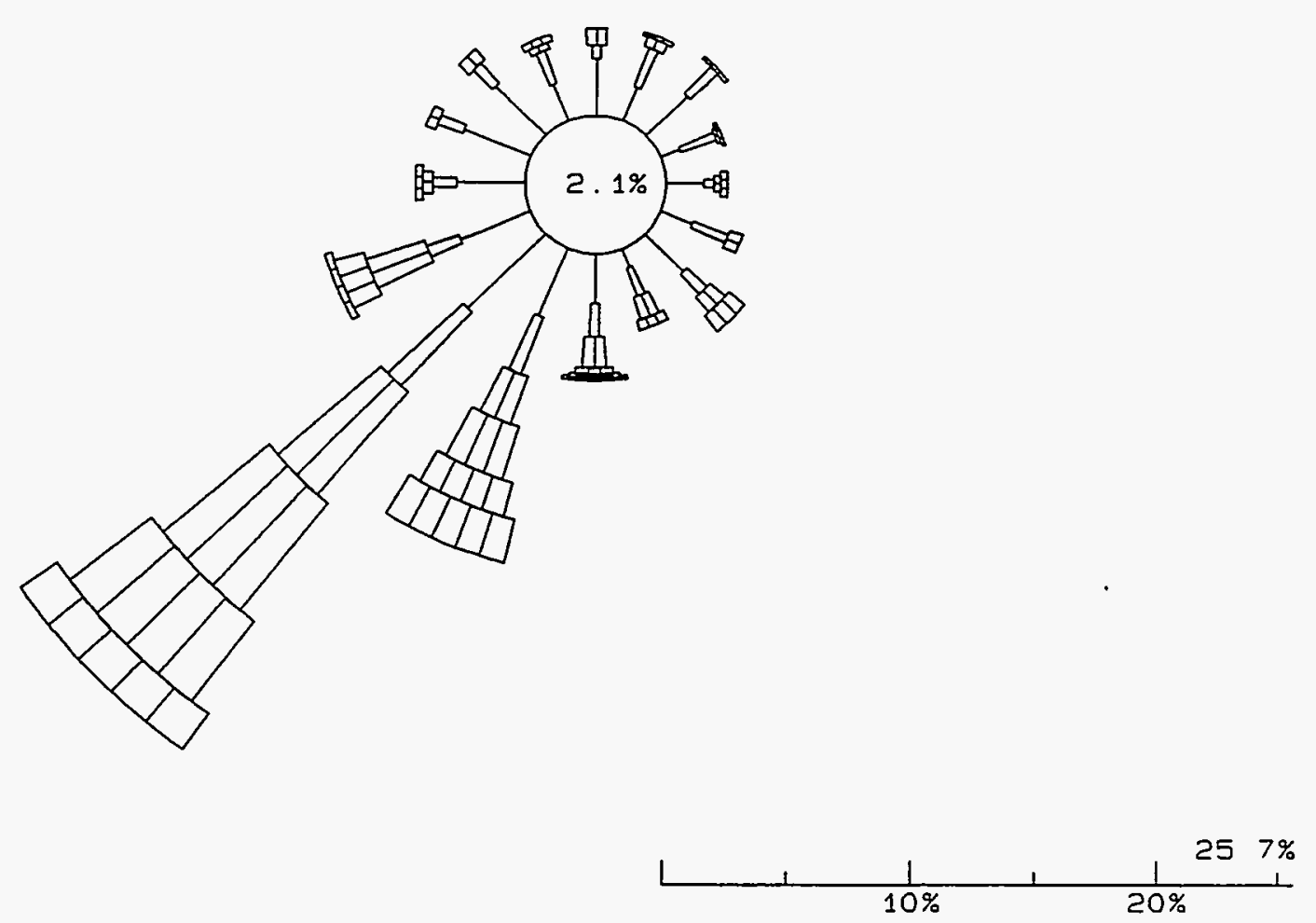

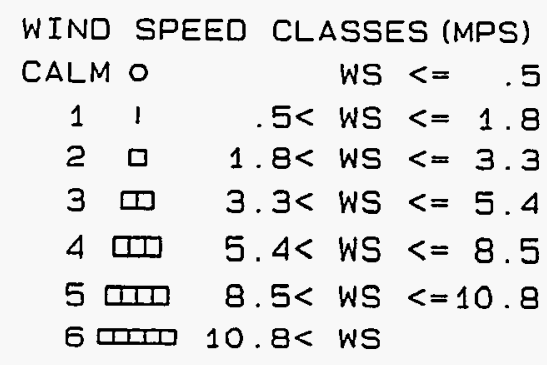

96. 9\% DATA RECOVERED

OF WHICH $100.0 \%$ IS .

REPORTED ABOVE 


\section{SPILL TEST FACILITY 24 METER TOWER \\ 8 METER HEIGHT - Total Hours \\ 6/ $1 / 1994-6 / 30 / 1994$ \\ $0-2300$}

$N$
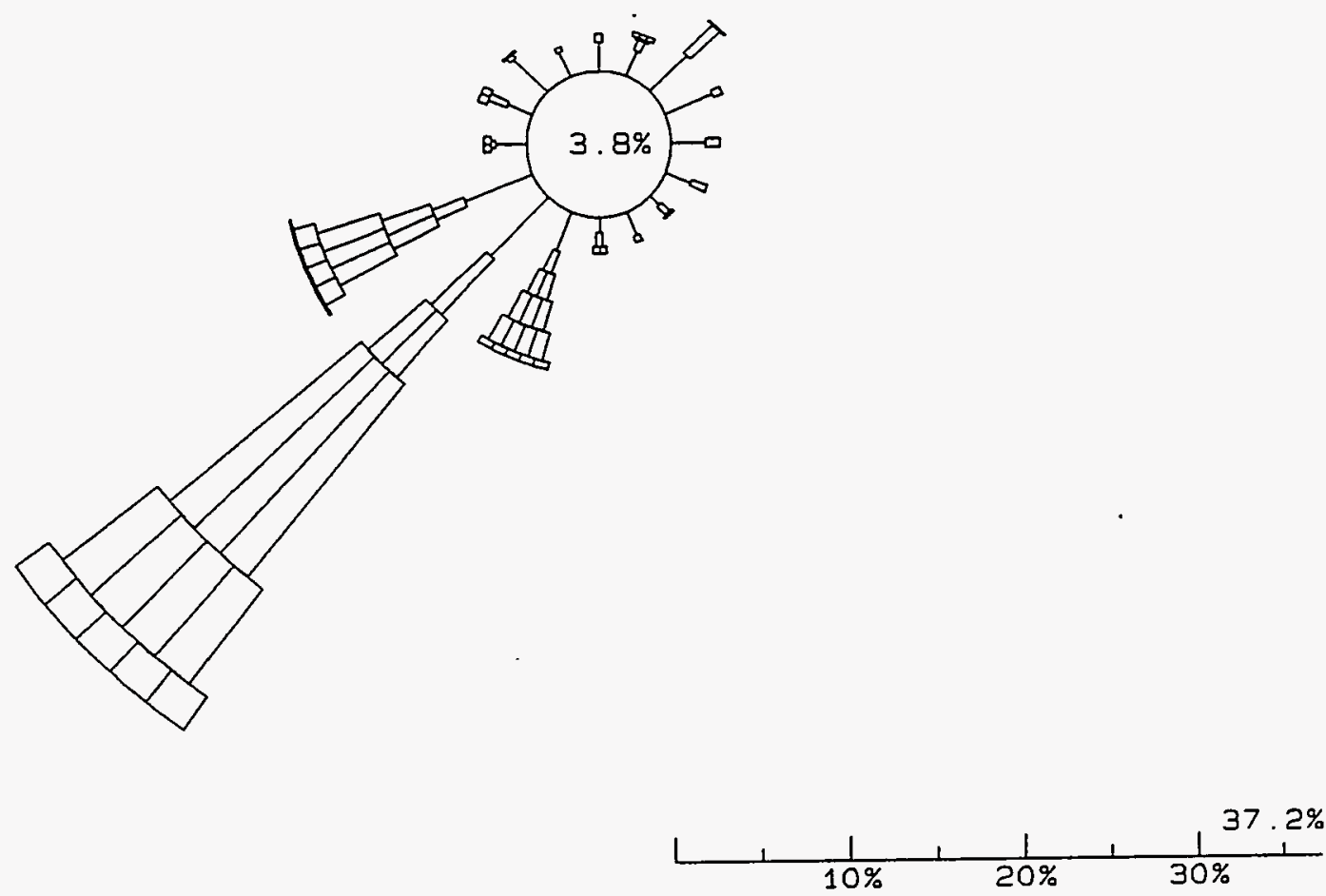

\begin{tabular}{|c|c|c|c|c|}
\hline W IND & \multirow{2}{*}{ SPEE } & \multicolumn{3}{|c|}{ D CLASSES (MPS) } \\
\hline & & & WS & $<=$ \\
\hline 1 & 1 & $5<$ & WS & $<=1.8$ \\
\hline 2 & $\square$ & $1.8<$ & WS & $<=3.3$ \\
\hline 3 & س & $3.3<$ & WS & $c=5.4$ \\
\hline 4 & סש & $5.4<$ & ws & $<=8.5$ \\
\hline 5 & سلس & $8.5<$ & WS & $<=10.8$ \\
\hline 60 & סחד & $10.8<$ & WS & \\
\hline
\end{tabular}

100.0\% DATA RECOVERED

OF WHICH $100.0 \%$ IS

AEPORTED ABOVE 


\section{SPILL TEST FACILITY 24 METER TOWER \\ 8 METER HEIGHT - Total Hours \\ $7 / 1 / 1994-7 / 31 / 1994$ \\ $0-2300$}

$N$
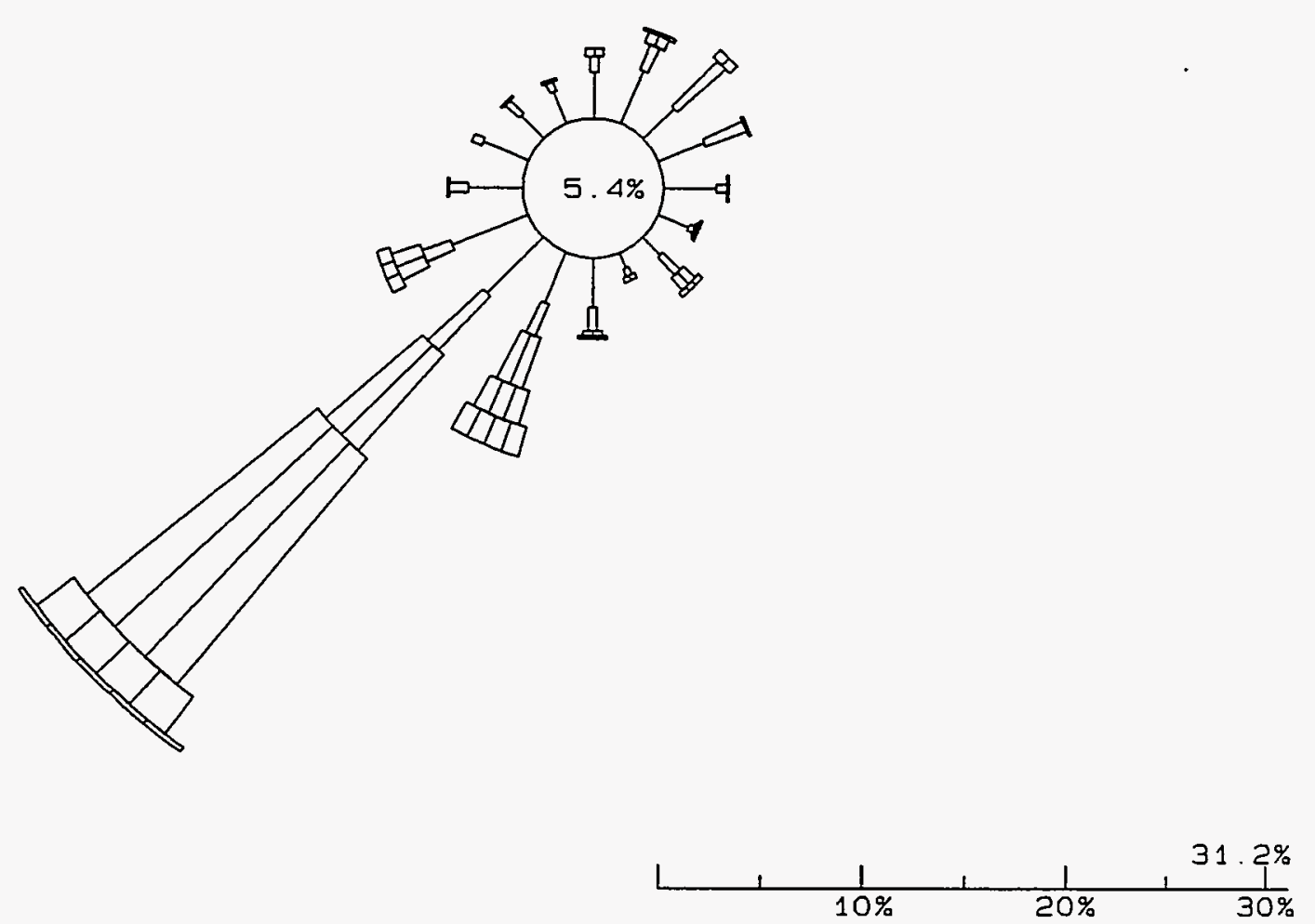

\begin{tabular}{|c|c|c|c|c|c|}
\hline IND & $S P E$ & $E D$ & $C L$ & SSE & ES $1 \mathrm{MPS}$ \\
\hline CALM & 10 & & & WS & $<=$ \\
\hline 1 & 1 & & $.5<$ & WS & $c=1.8$ \\
\hline 2 & 口 & 1. & $.8<$ & WS & $<=3.3$ \\
\hline 3 & Ш & 3. & $3<$ & wS & $<=5$. \\
\hline$\Delta$ & سש & 5. & $4<$ & WS & $c=8$. \\
\hline 5 & סיس & 8. & $.5<$ & WS & $<=10$. \\
\hline c & पागत & 10 & R & $s$ & \\
\hline
\end{tabular}

100.0\% DATA RECOVERED

OF WHICH $100.0 \%$ IS

REPORTED ABOVE 


\section{SPILL TEST FACILITY 24 METER TOWER \\ 8 METER HEIGHT - Total Hours \\ $8 / 1 / 1994-8 / 31 / 1994$ \\ $0-2300$}

$N$
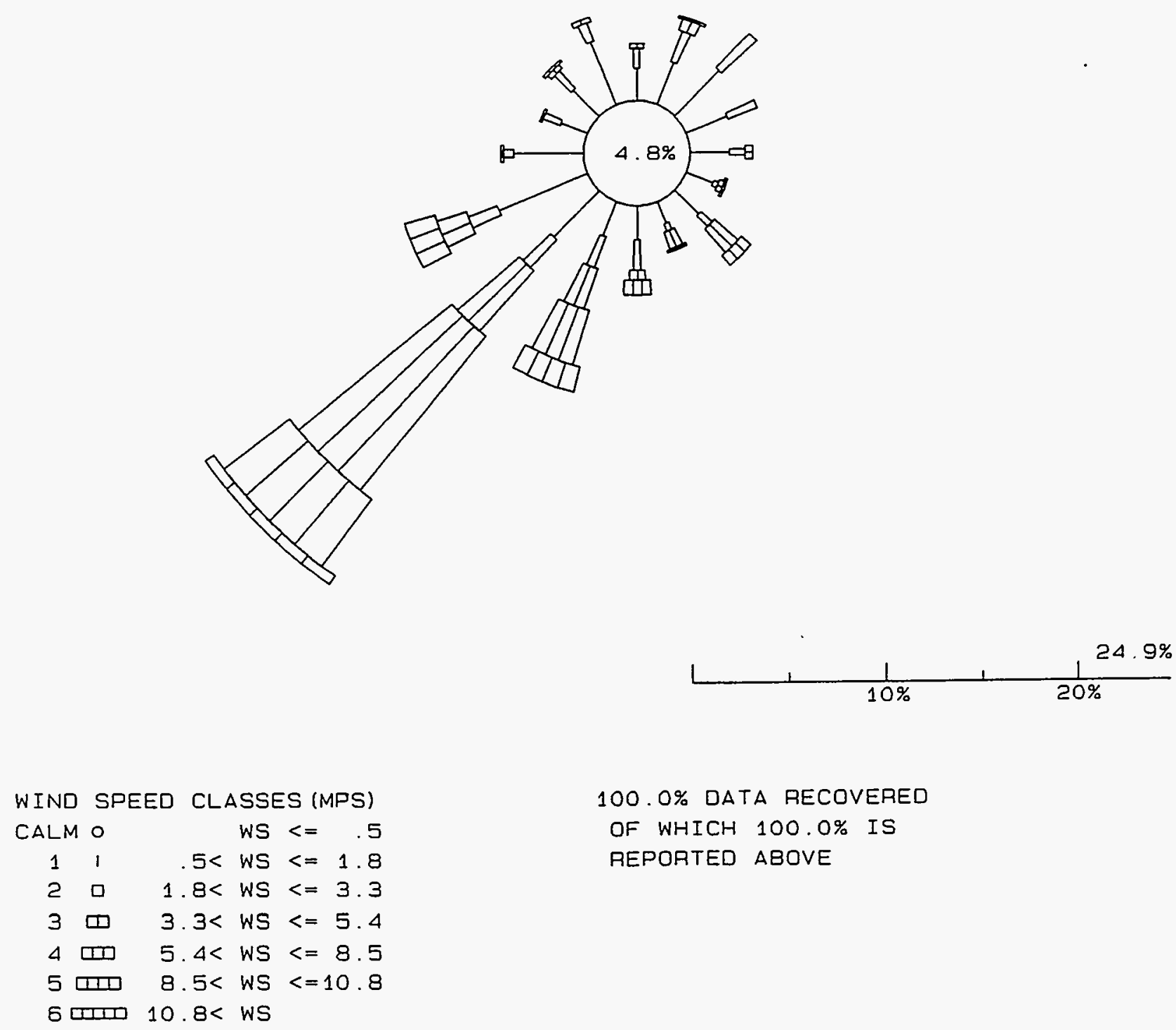

100.0\% DATA RECOVERED

OF WHICH $100.0 \%$ IS

REPOATED ABOVE 


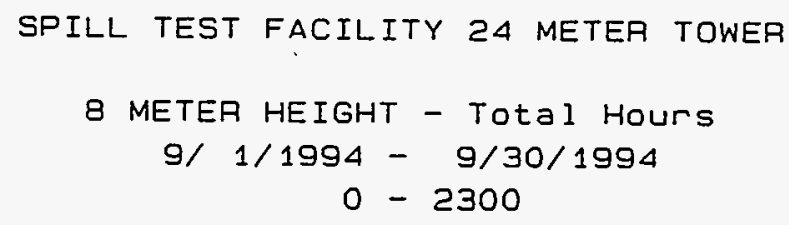

$N$
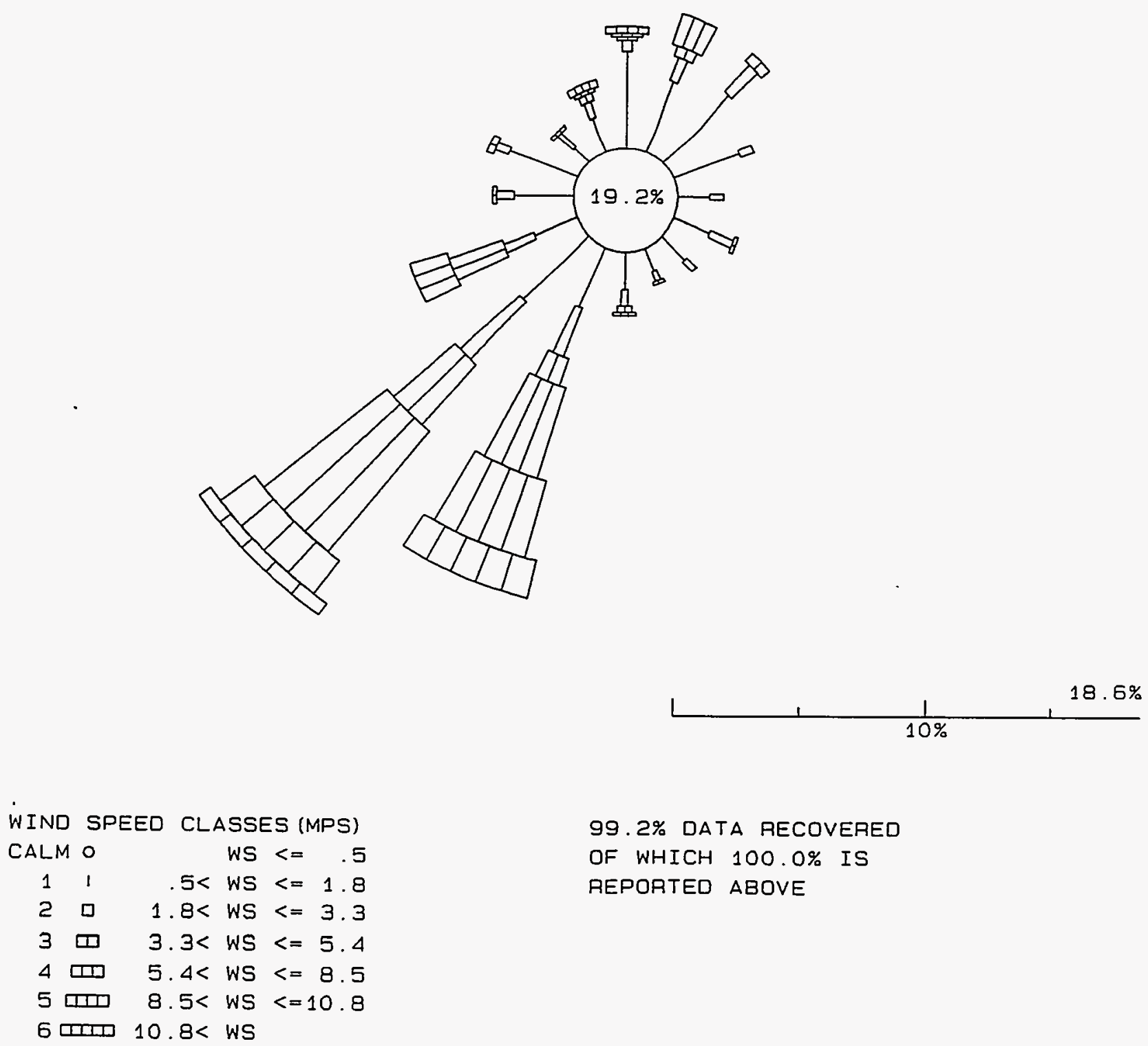


\section{SPILL TEST FACILITY 24 METER TOWER \\ 8 METER HEIGHT - Total Hours $10 / 1 / 1994-10 / 31 / 1994$ \\ $0-2300$}

N
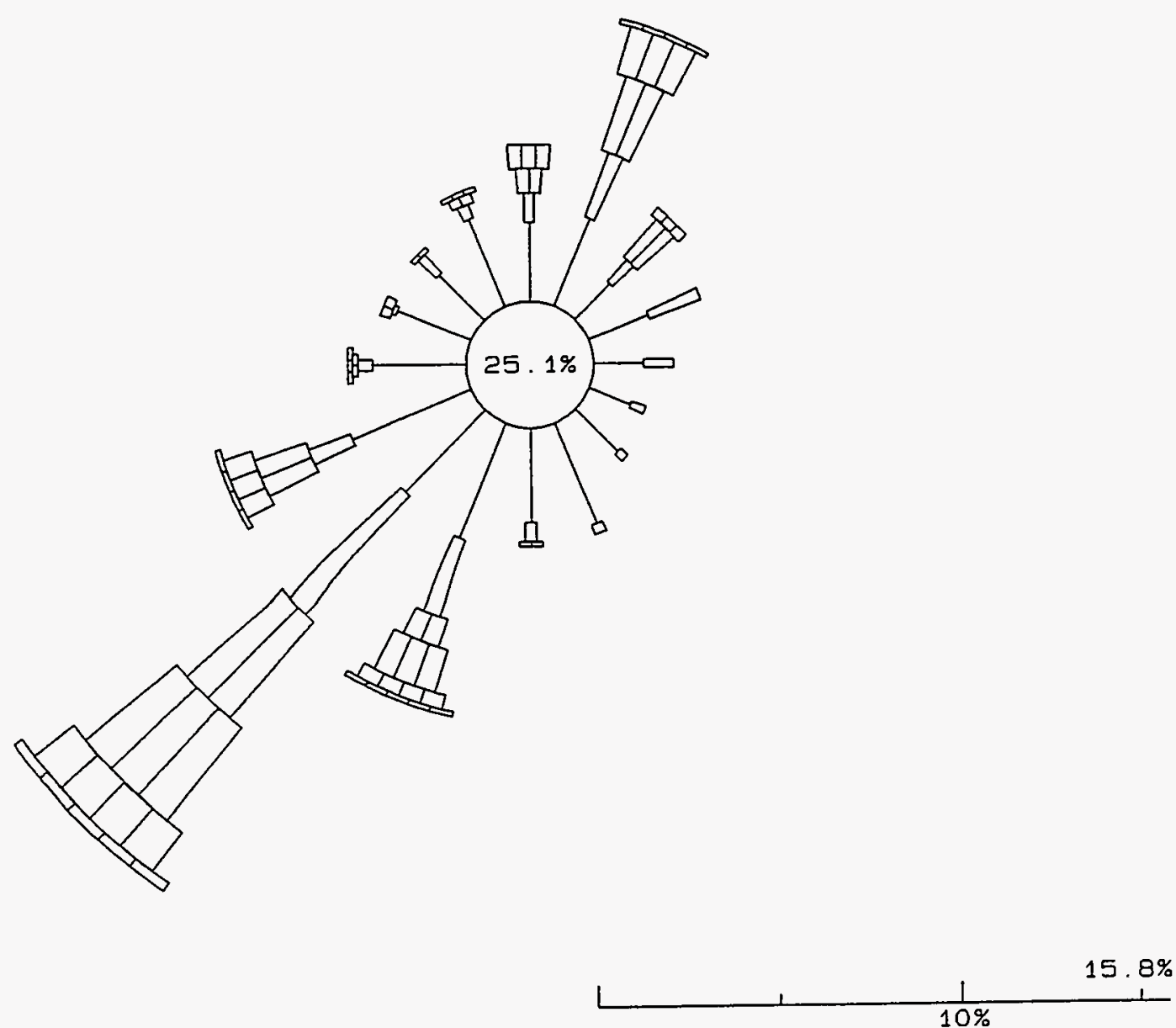

98.5\% DATA RECOVERED OF WHICH $100.0 \%$ IS REPORTED ABOVE 


\section{SPILL TEST FACILITY 24 METER TOWER \\ 8 METER HEIGHT - Total Hours \\ $11 / 1 / 1994$ - 11/30/1994 \\ $0-2300$}

N

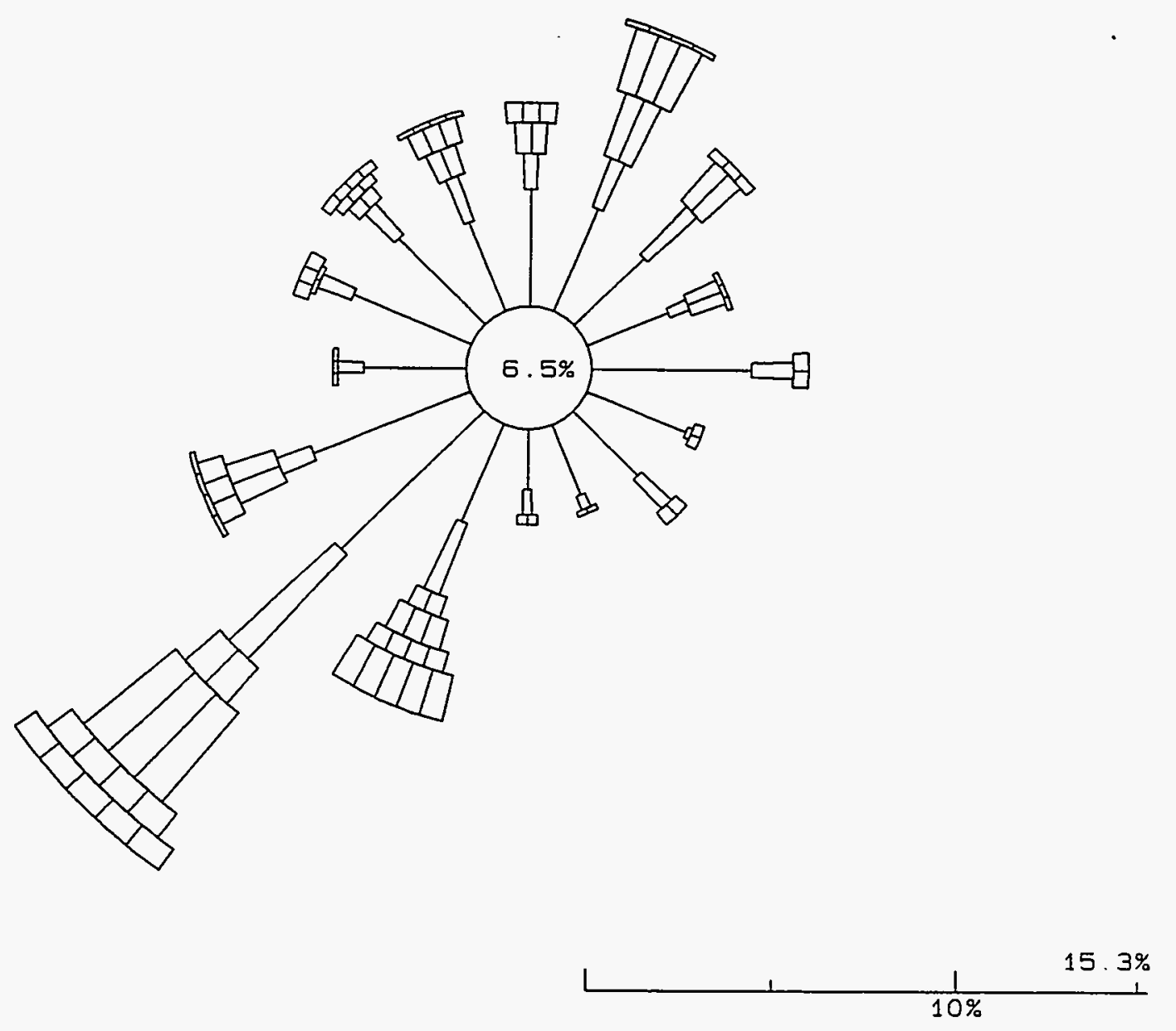

99.7\% DATA RECOVERED

OF WHICH 100.0\% IS

REPOATED ABOVE 


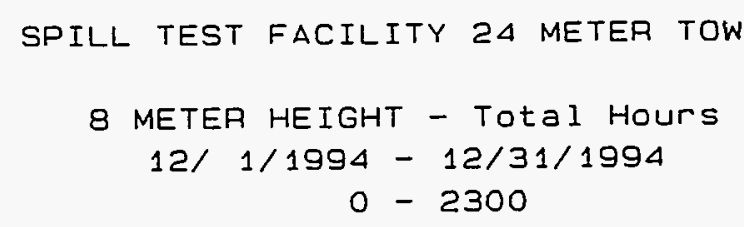

$N$

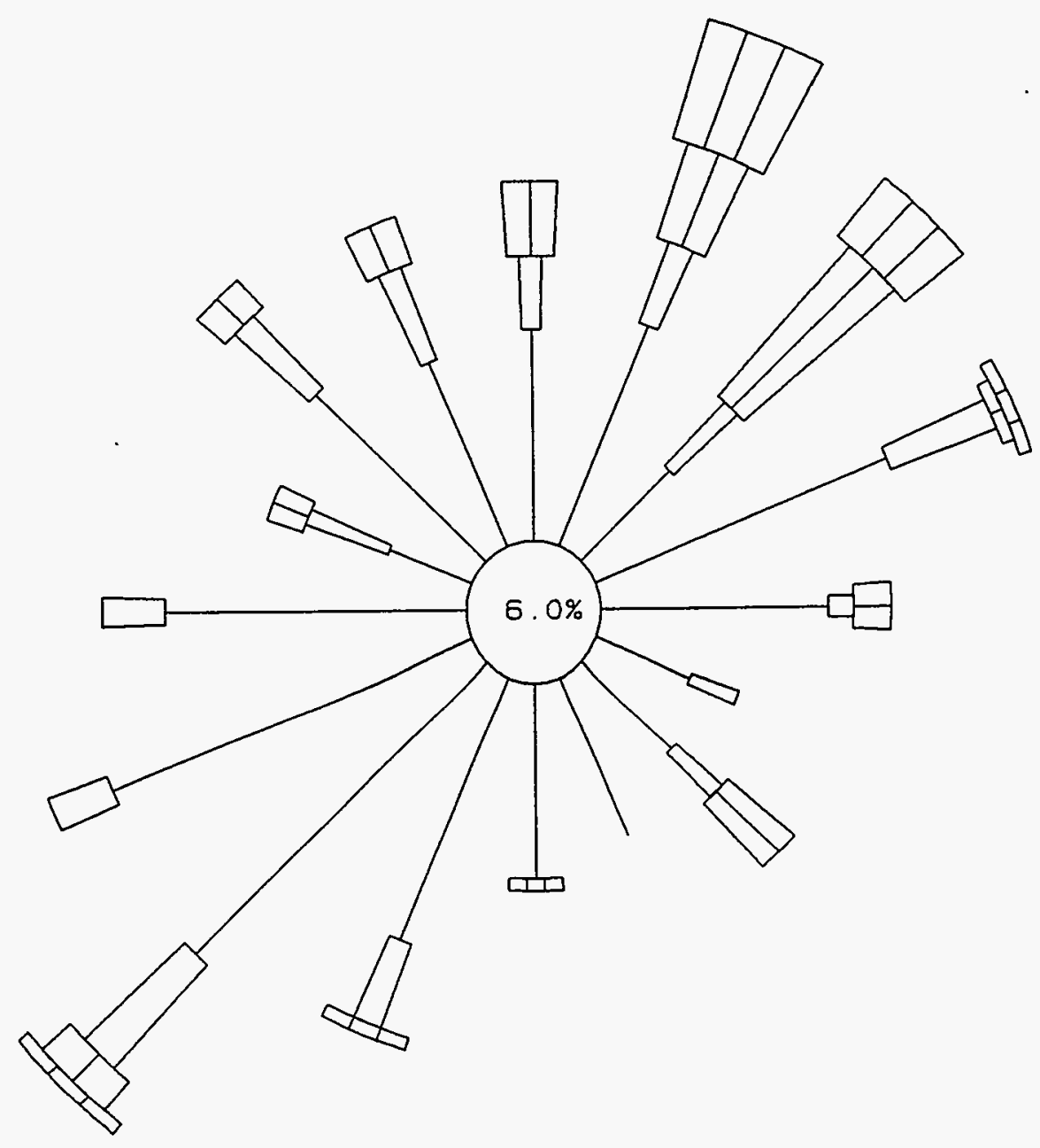

\begin{tabular}{|c|c|c|c|c|c|}
\hline \multirow{2}{*}{$\begin{array}{l}\text { WIND } \\
\text { CALM }\end{array}$} & \multicolumn{2}{|c|}{ SPEED } & \multicolumn{3}{|c|}{ CLASSES (MPS) } \\
\hline & 10 & & & WS & $<=$ \\
\hline 1 & 1 & & $.5<$ & WS & $<=1.8$ \\
\hline 2 & $\square$ & 1 & $.8<$ & WS & $<=3.3$ \\
\hline 3 & $\square$ & 3 & $.3<$ & WS & $<=5.4$ \\
\hline 4 & שाप & 5 & $.4<$ & WS & $c=8.5$ \\
\hline 5 & प्पात & 8 & $.5<$ & WS & $<=10.8$ \\
\hline 60 & IIIप & 10 & $.8<$ & WS & \\
\hline
\end{tabular}

65. 1\% DATA RECOVERED OF WHICH $100.0 \%$ IS REPORTED ABOVE 


\section{SPILL TEST FACILITY 24 METER TOWER}

8 METER HEIGHT - Morning Transition

1/ $1 / 1994-1 / 31 / 1994$

$600-1000$

$N$
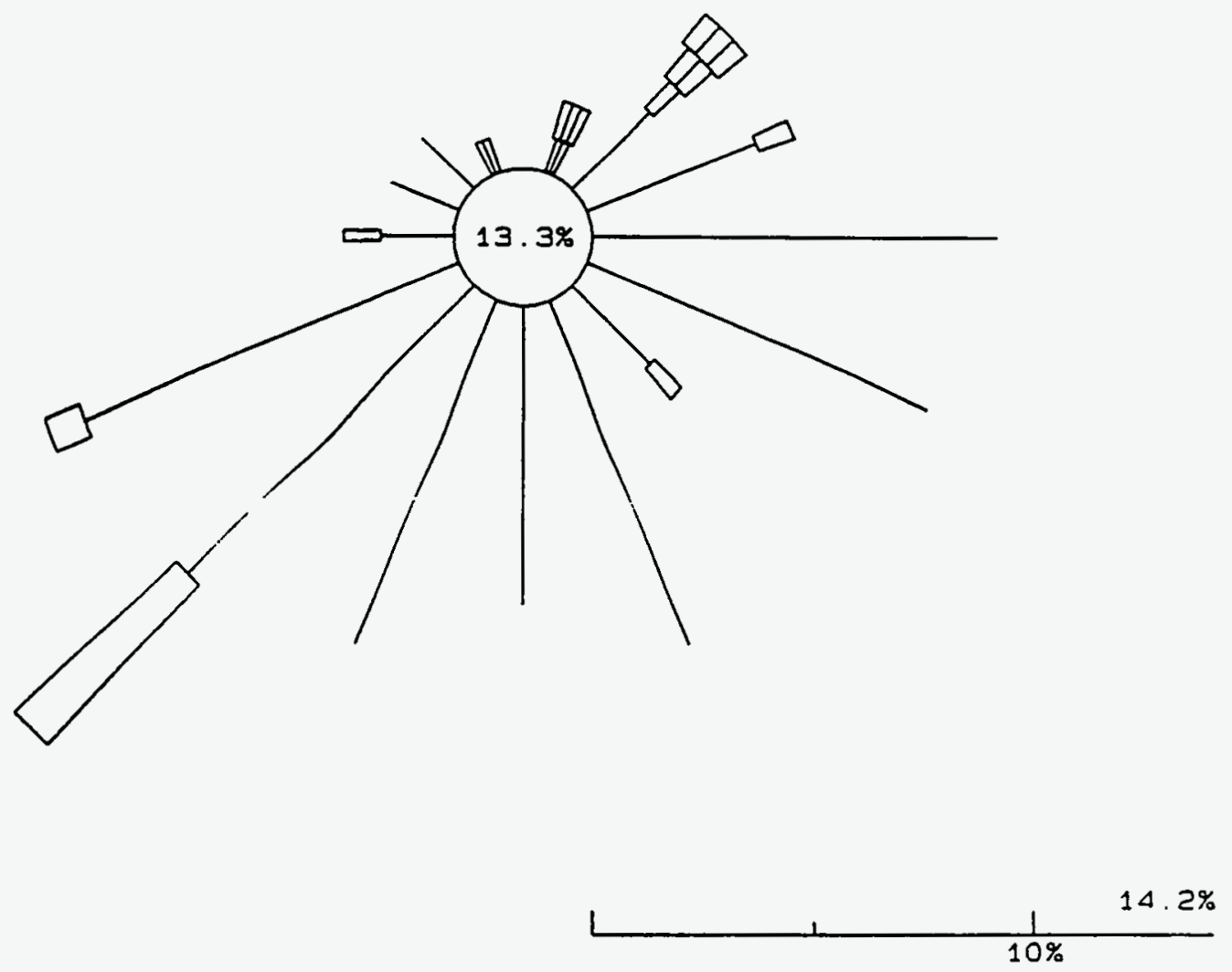

78. O\% DATA RECOVERED

OF WHICH 20.7\% IS

REPORTED ABOVE 


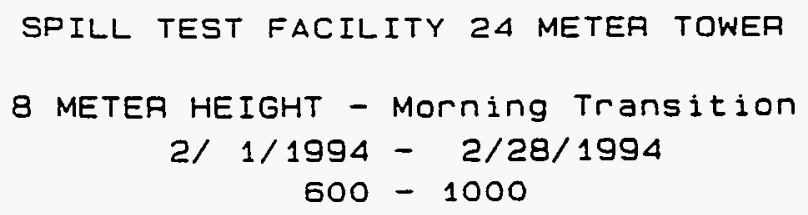

$N$

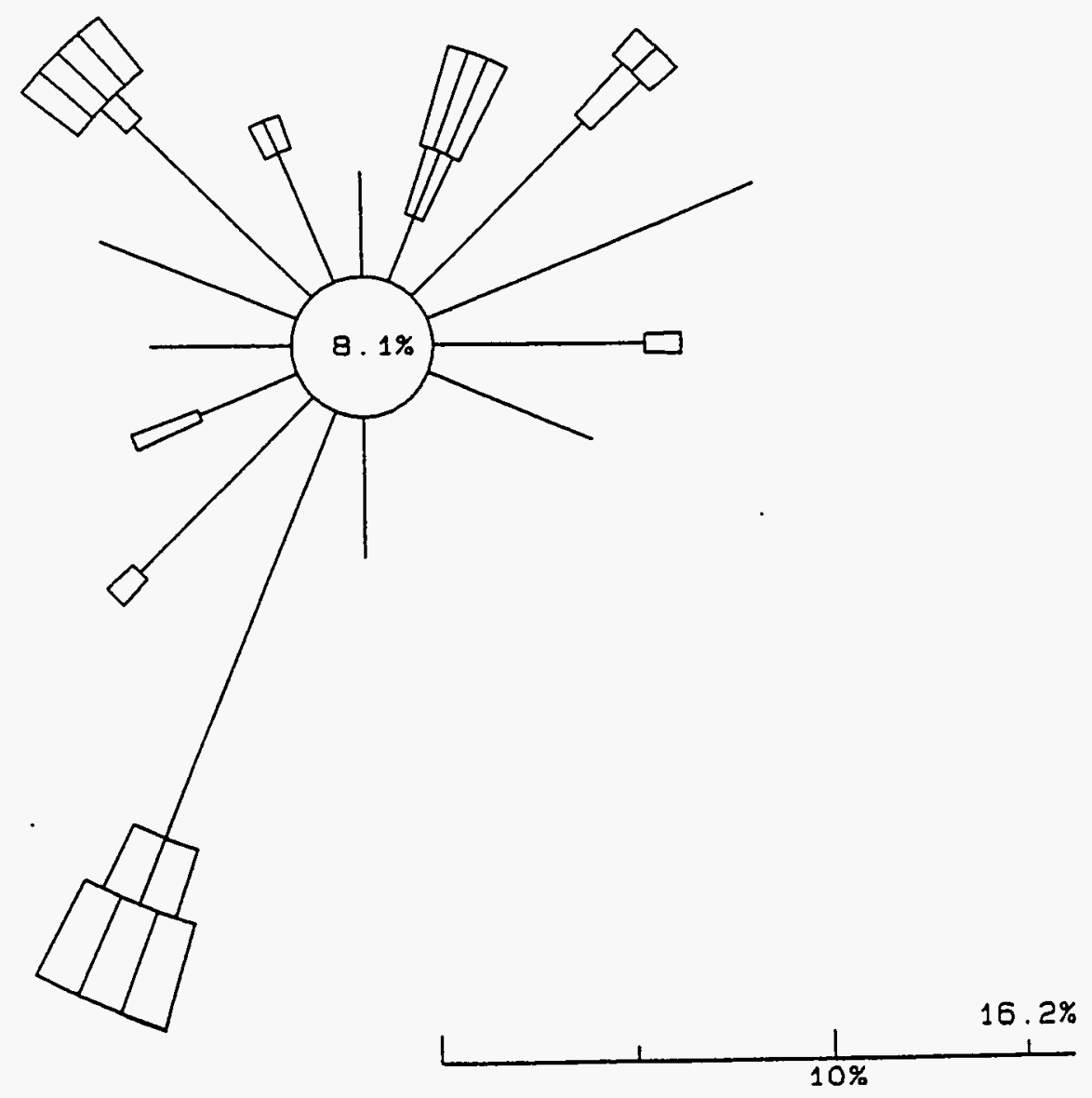

\begin{tabular}{|c|c|c|c|c|c|}
\hline WIND & \multicolumn{2}{|c|}{ SPEED } & \multicolumn{3}{|c|}{ CLASSES (MPS) } \\
\hline CALM & 10 & & & WS & $<=$ \\
\hline 1 & 1 & & $.5<$ & WS & $<=1.8$ \\
\hline 2 & $\square$ & 1 & $.8<$ & WS & $<=3.3$ \\
\hline 3 & סם & 3 & $.3<$ & WS & $<=5.4$ \\
\hline 4 & שים & 5 & $.4<$ & WS & $<=8.5$ \\
\hline 5 & ס्ण & 8 & $.5<$ & WS & $<=10.8$ \\
\hline C & 7 & 10 & 8 & WS & \\
\hline
\end{tabular}

85. $4 \%$ DATA RECOVEAED

OF WHICH 19.3\% IS

REPORTED ABOVE 
SPILL TEST FACILITY 24 METER TOWER

8 METER HEIGHT - Morning Transition

$3 / 1 / 1994$ - 3/31/1994

$600-1000$

$N$
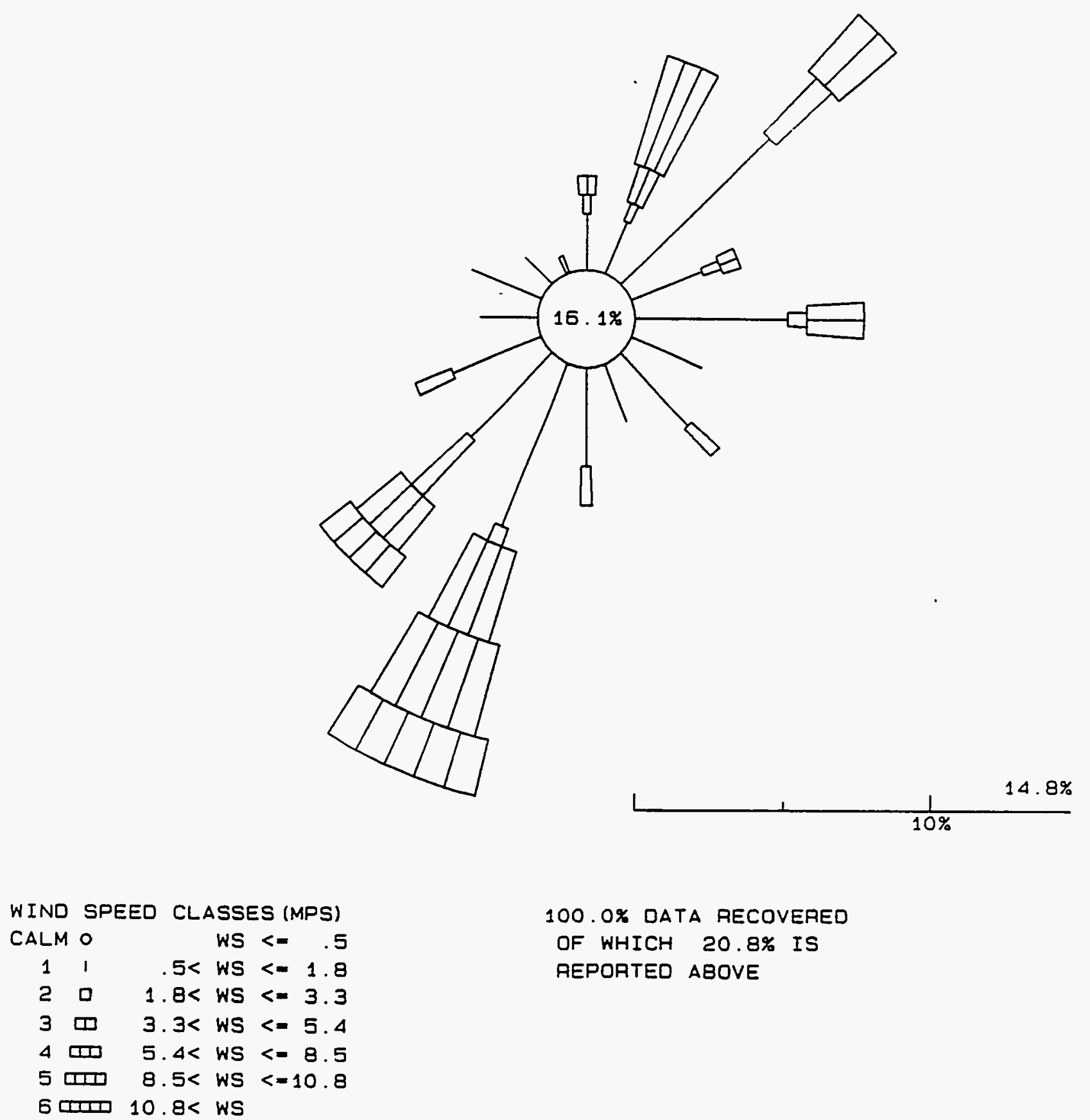

100. O\% DATA RECOVERED

OF WHICH 20.8\% IS

REPORTEO ABOVE 


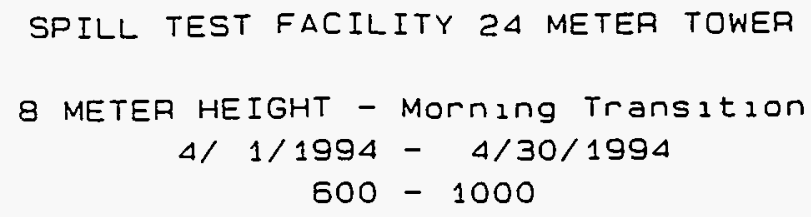

$N$
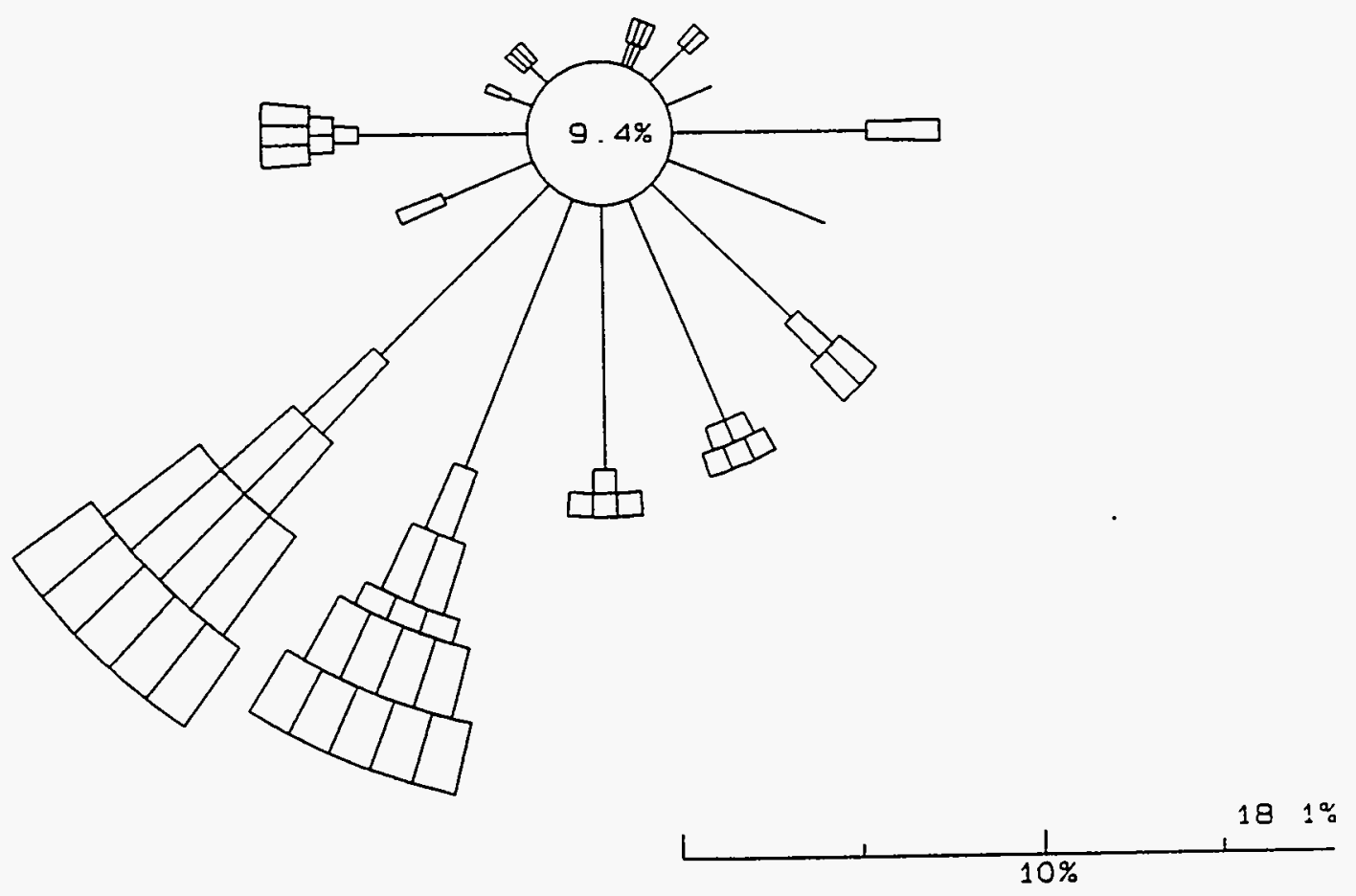

99.9\% DATA RECOVERED

OF WHICH $20.7 \%$ IS REPORTED ABOVE 


\section{SPILL TEST FACILITY $2 \triangle$ METER TOWER \\ 8 METER HEIGHT - Morning Transition \\ 5/ $1 / 1994-5 / 31 / 1994$ \\ $600-1000$}

$N$
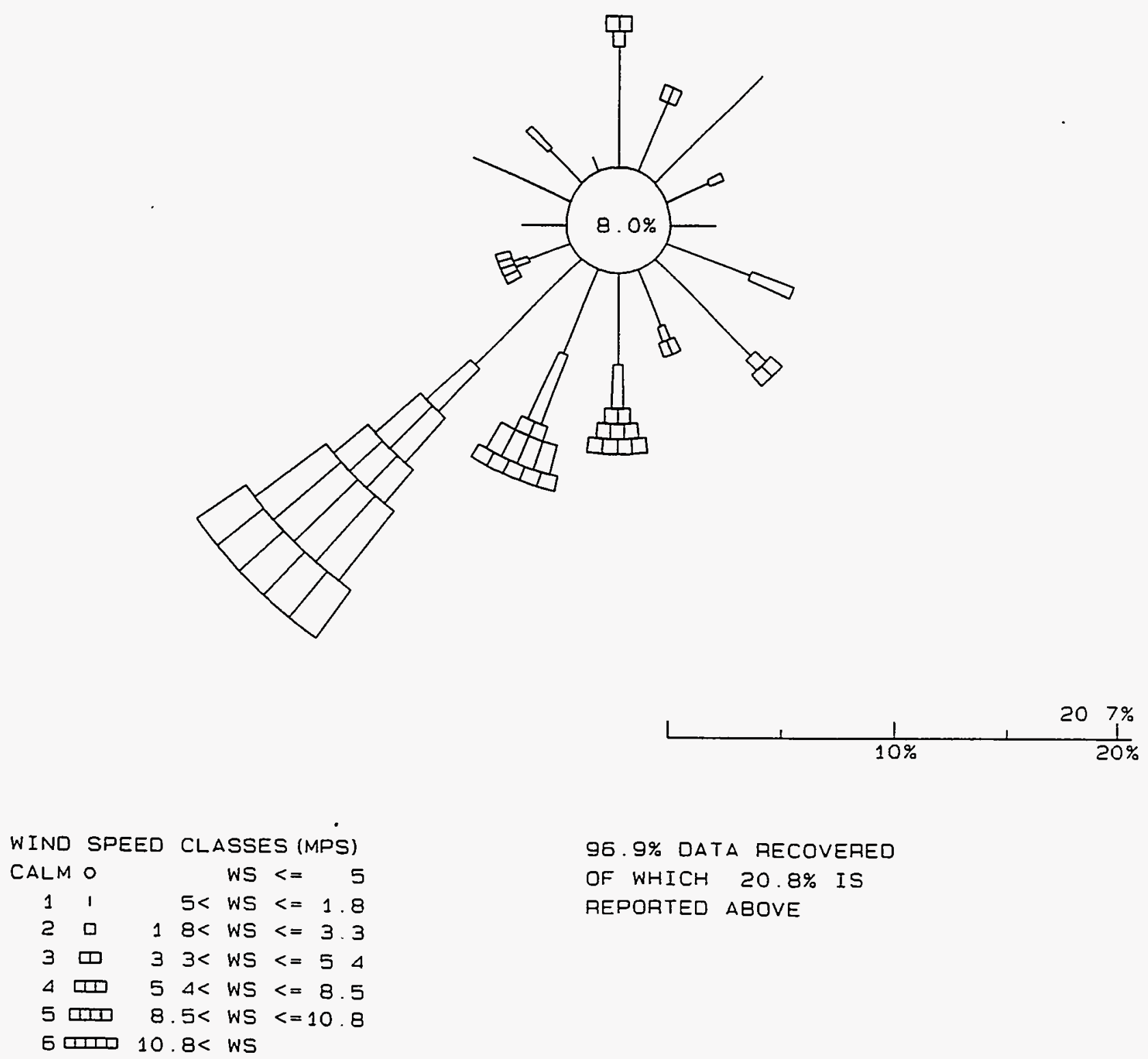
SPILL TEST FACILITY 24 METER TOWER

8 METER HEIGHT - Morning Transition

6/ $1 / 1994-6 / 30 / 1994$

$600-1000$

$N$
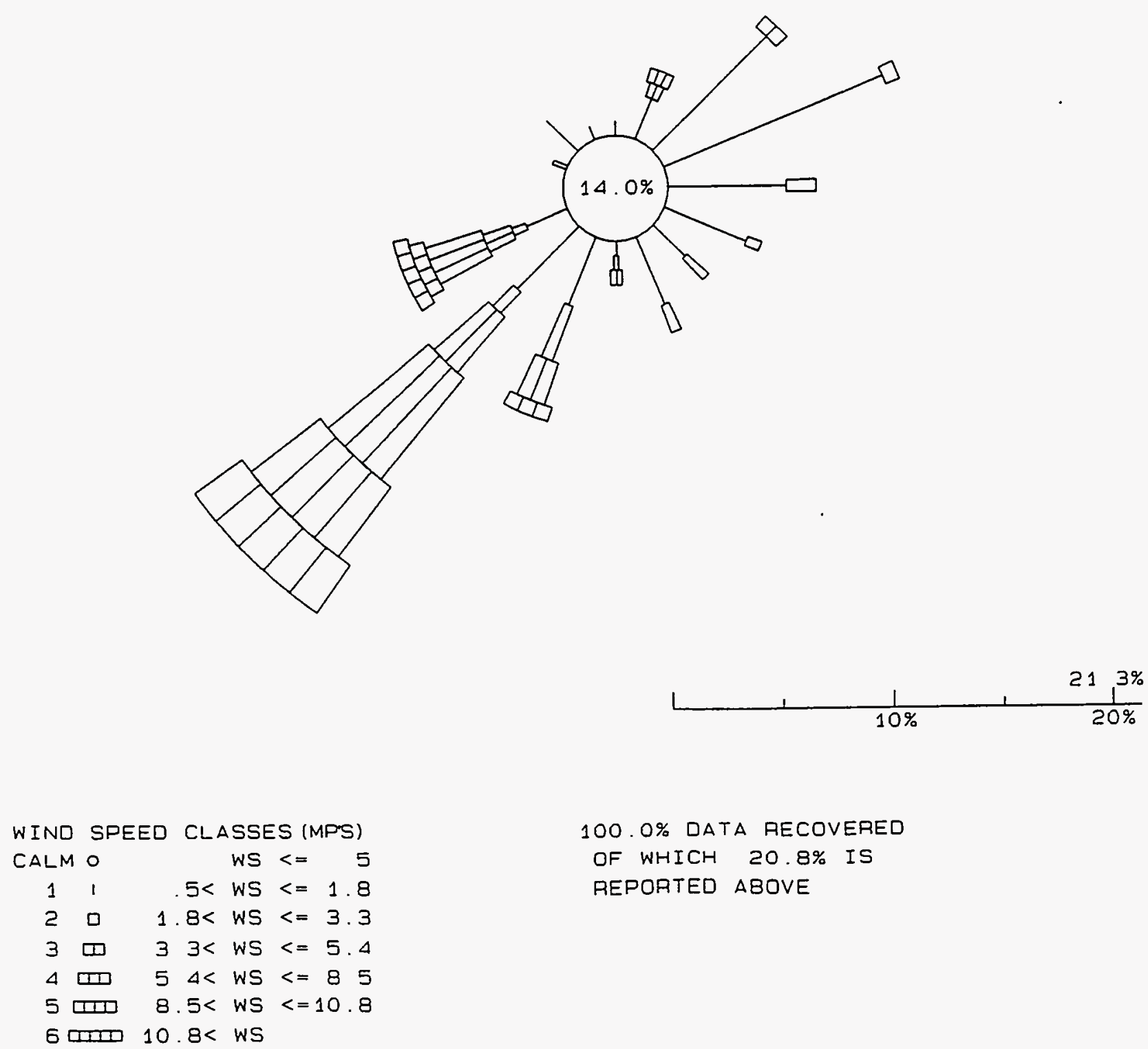

$100.0 \%$ DATA RECOVERED

OF WHICH $20.8 \%$ IS

REPOATED ABOVE 


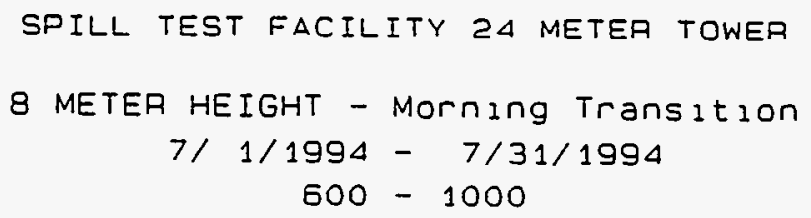

N

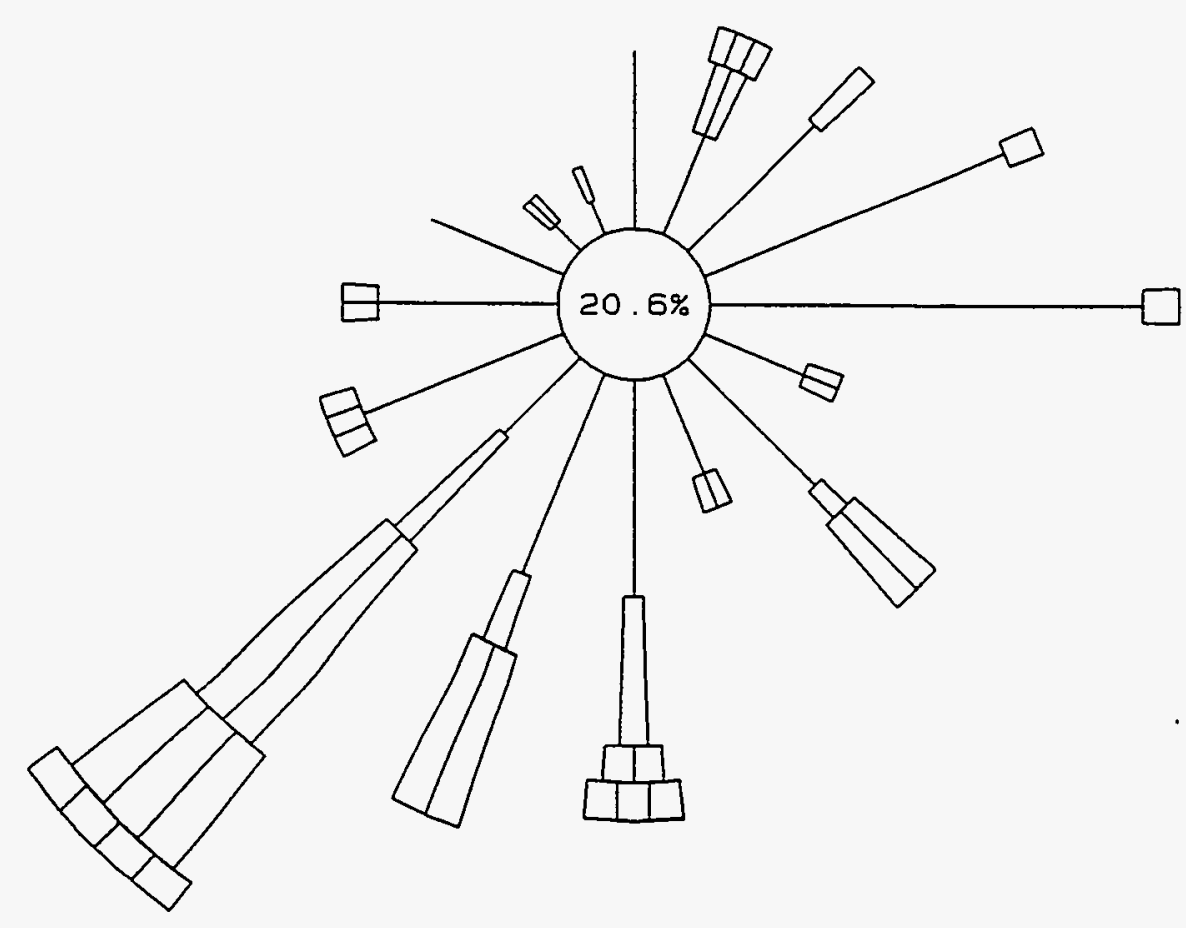

\begin{tabular}{|c|c|c|c|c|c|c|c|}
\hline WIND & \multicolumn{2}{|c|}{ SPEED } & \multicolumn{5}{|c|}{ CLASSES (MPS) } \\
\hline CALM & 10 & & & WS & $<=$ & & 5 \\
\hline 1 & 1 & & $5<$ & WS & $<=$ & 1. & 8 \\
\hline 2 & ם & 1 & $8<$ & WS & $<=3$ & 3 & 3 \\
\hline 3 & שם & 3 & $3<$ & WS & $<=5$ & 5. & $\Delta$ \\
\hline$\Delta$ & דם & 5 & $\Delta<$ & WS & $<=\varepsilon$ & 8 . & 5 \\
\hline 5 & هחب & 8 & $.5<$ & WS & $<=10$ & & 8 \\
\hline 60 & هIIIC & 10 & $8<$ & WS & & & \\
\hline
\end{tabular}

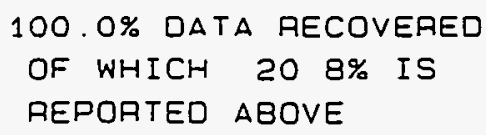




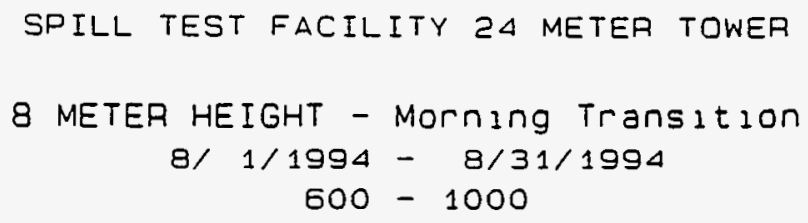

$N$

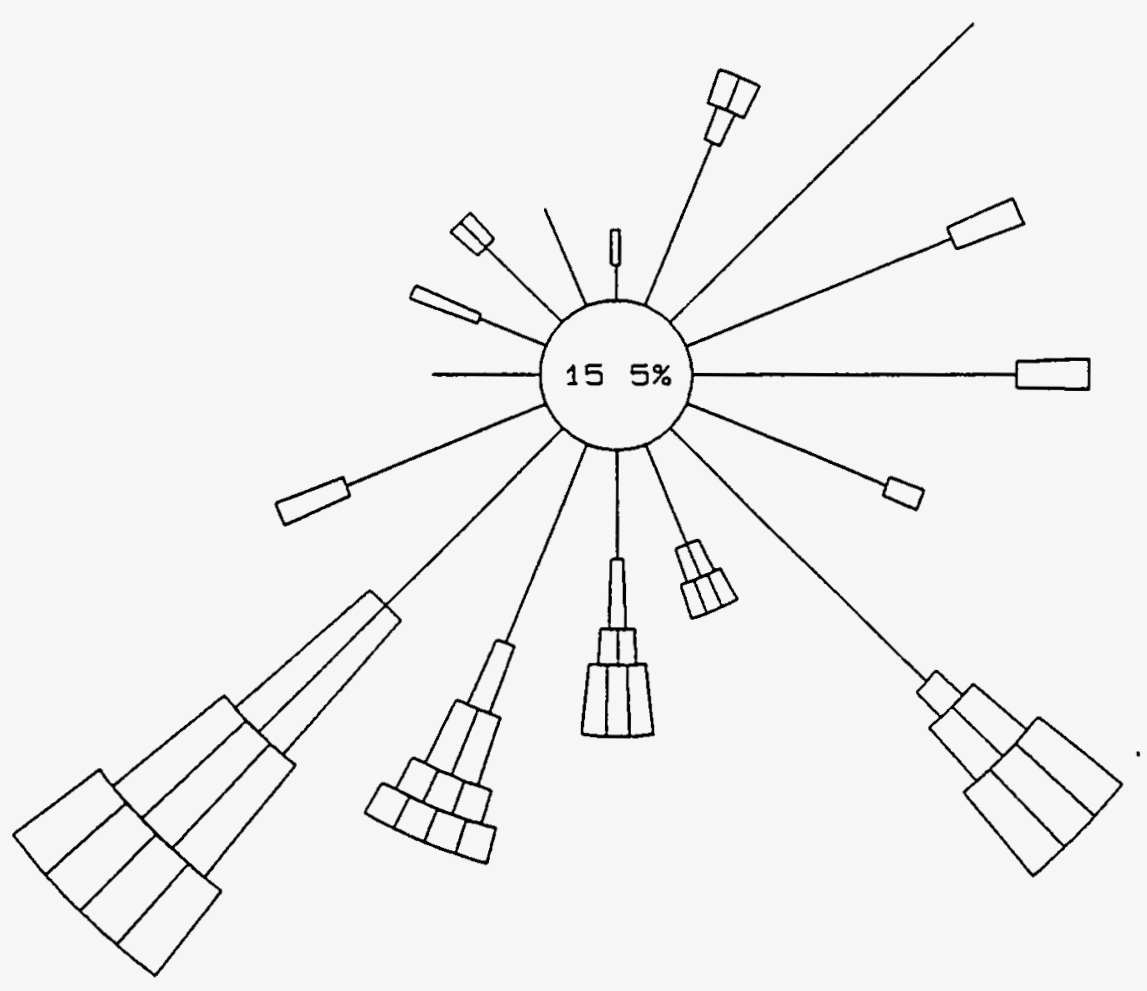

\begin{tabular}{|c|c|c|c|c|c|c|c|}
\hline WIND & \multicolumn{2}{|c|}{ SPEEO } & \multicolumn{5}{|c|}{ CLASSES (MPS) } \\
\hline CALM & 10 & & & WS & $<=$ & & 5 \\
\hline 1 & 1 & & $5<$ & WS & $<=1$ & & 8 \\
\hline 2 & $\square$ & 1 & $8<$ & WS & $<=3$ & & 3 \\
\hline 3 & هם & 3 & $3<$ & WS & $<=5$ & 5 & 4 \\
\hline$\Delta$ & पा & 5 & $\Delta<$ & WS & $<=\varepsilon$ & 85 & 5 \\
\hline 5 & DIII & 8 & $5<$ & WS & $<=10$ & & 8 \\
\hline 60 & סDست] & 10 & $8<$ & WS & & & \\
\hline
\end{tabular}

100. O\% DATA RECQVERED

OF WHICH $20.8 \%$ IS

REPORTED ABOVE 


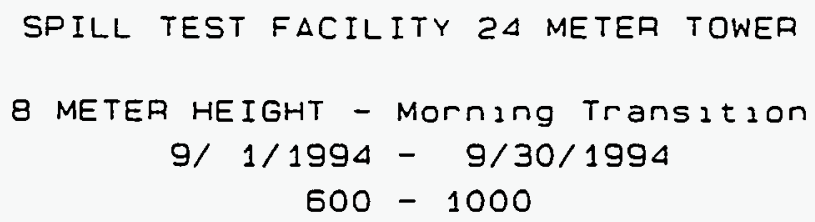

$N$

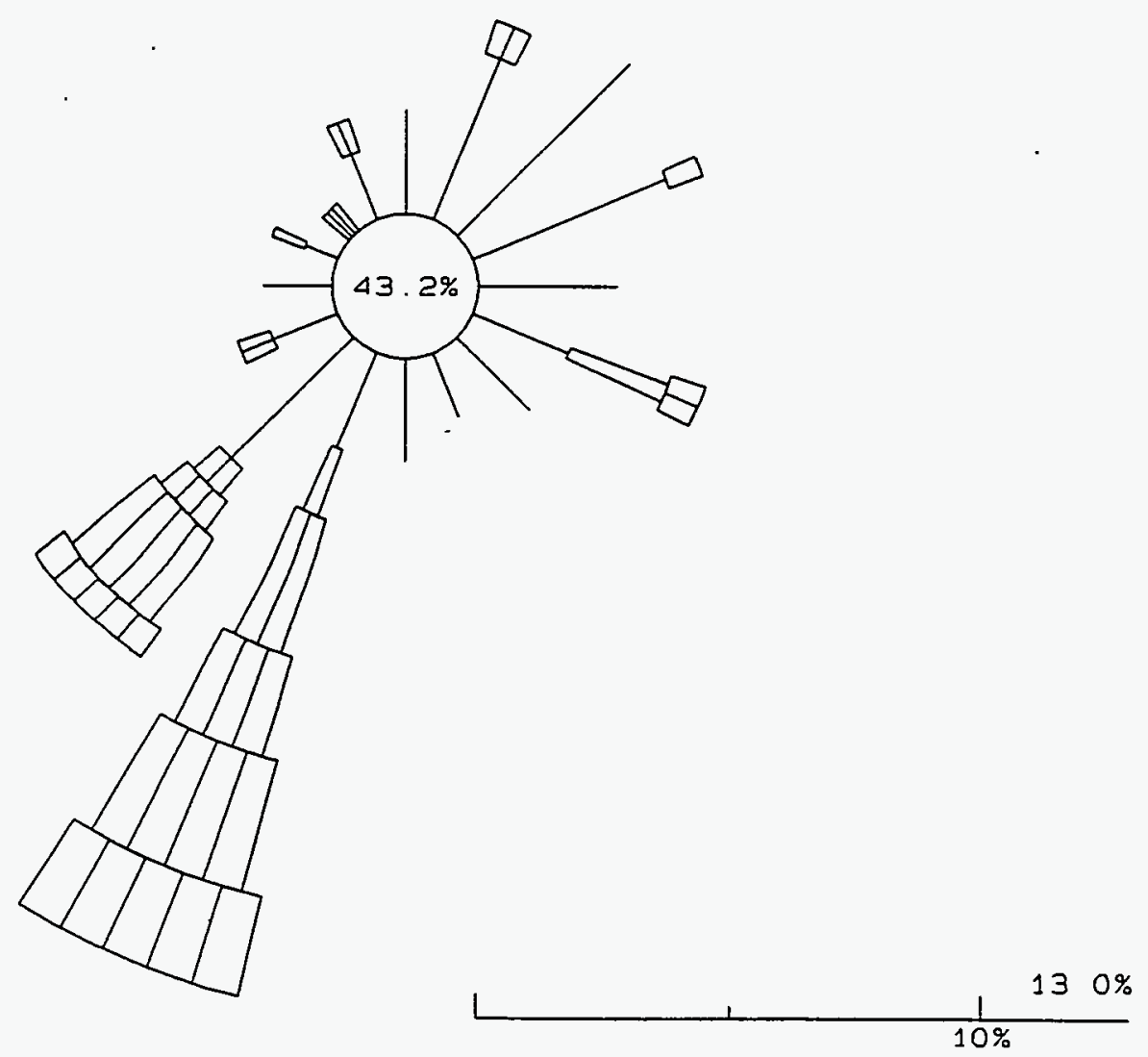

99.2\% DATA RECOVERED

OF WHICH $20.4 \%$ IS REPORTED ABOVE 
SPILL TEST FACILITY 24 METER TOWER

8 METER HEIGHT - Morning Transition

$10 / 1 / 1994-10 / 31 / 1994$

$600-1000$

$N$

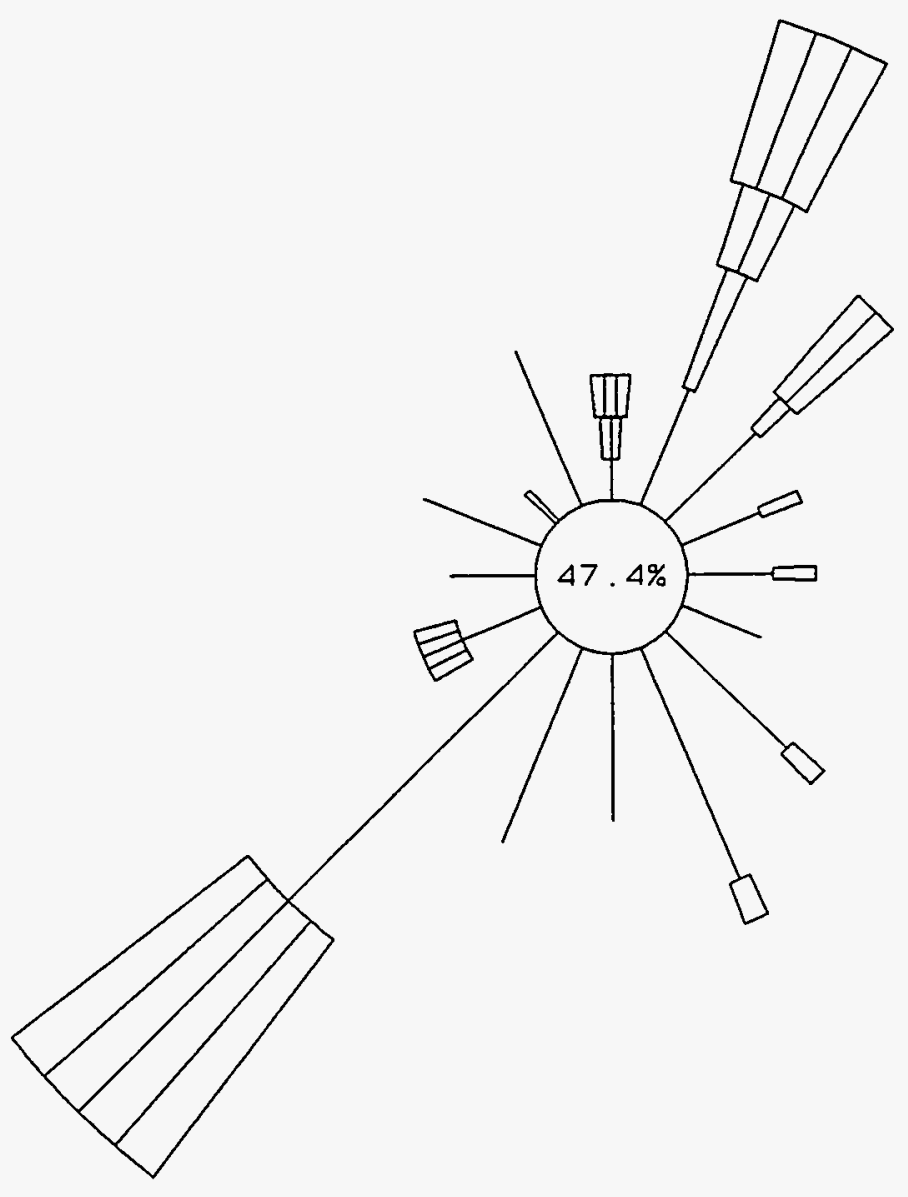

WIND SPEED CLASSES (MPSS)

\begin{tabular}{|c|c|c|c|c|}
\hline$A L M$ & 10 & & WS & $<=$ \\
\hline 1 & 1 & $5<$ & WS & $<=1$ \\
\hline 2 & D & $1.8<$ & WS & $<=3$. \\
\hline 3 & ه & $3.3<$ & WS & $<=5$. \\
\hline 4 & סس & $5.4<$ & WS & $<=8$ \\
\hline 5 & סس" & $8.5<$ & WS & $<=10$. \\
\hline 60 & טדा & $10.8<$ & WS & \\
\hline
\end{tabular}

$98.5 \%$ DATA RECOVERED

OF WHICH $20.7 \%$ IS

REPORTED $\triangle B O V E$ 


\section{SPILL TEST FACILITY 24 METER TOWER \\ 8 METER HEIGHT - Morning Transition \\ $11 / 1 / 1994-11 / 30 / 1994$ \\ $600-1000$}

N
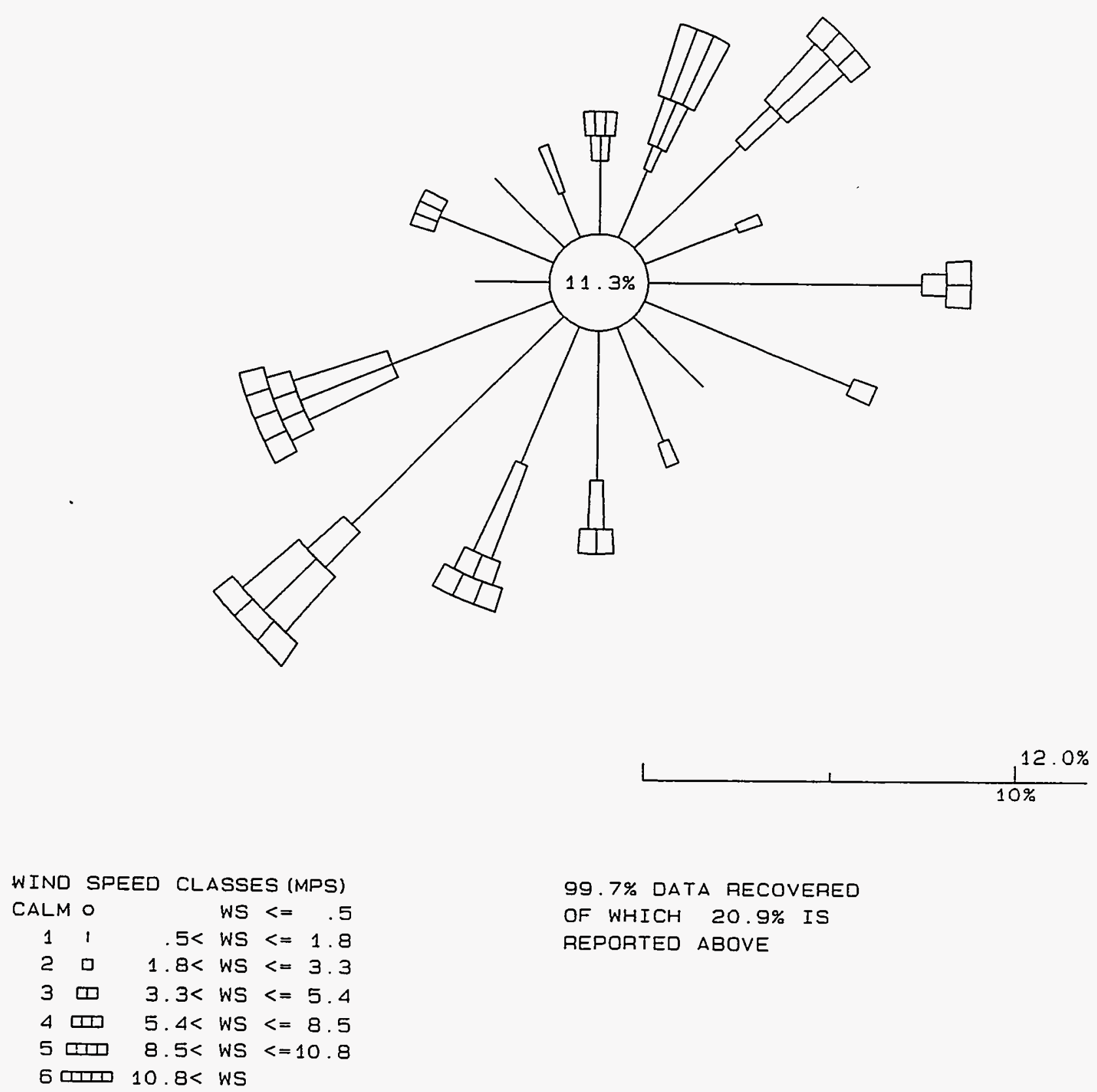

99.7\% DATA RECOVERED

OF WHICH $20.9 \%$ IS

REPORTED ABOVE 


\section{SPILL TEST FACILITY 24 METER TOWEA}

8 METER HEIGHT - Morning Transition $12 / 1 / 1994-12 / 31 / 1994$

$600-1000$

N
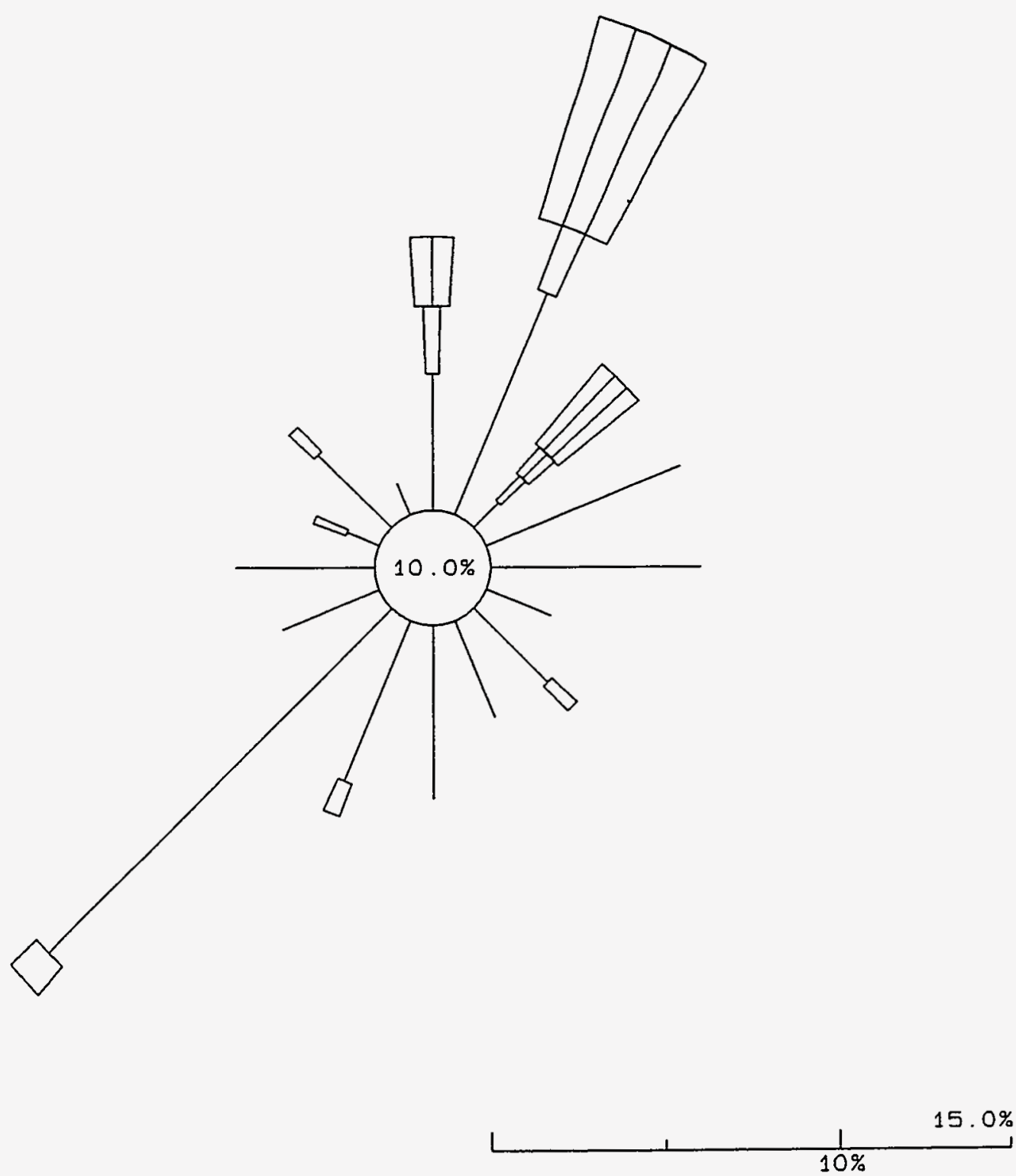

65. $1 \%$ DATA RECOVERED

OF WHICH $20.7 \%$ IS

REPORTED ABOVE 


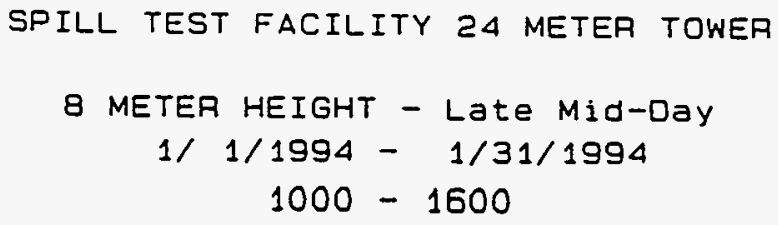

$N$
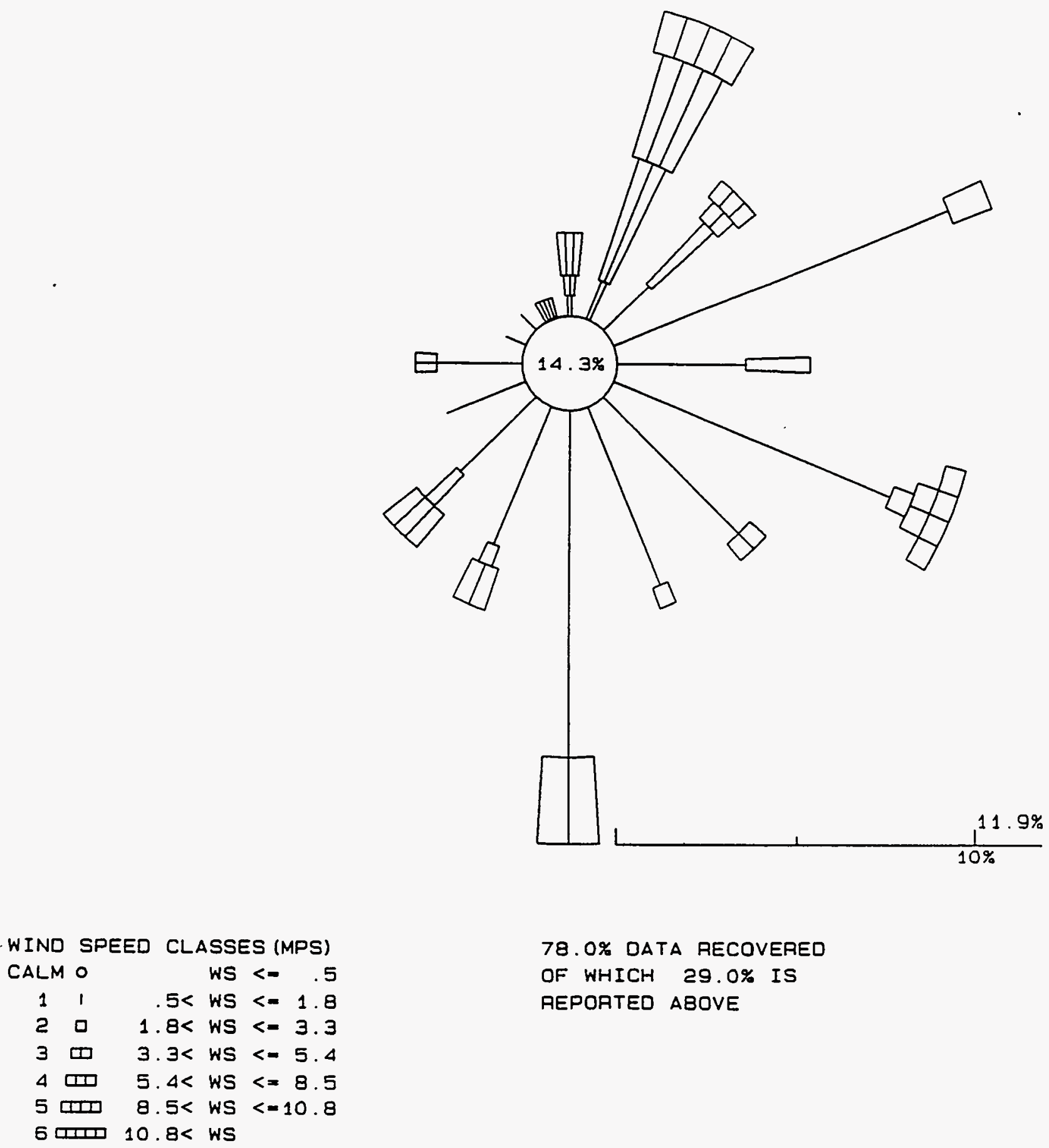


\section{SPILL TEST FACILITY 24 METER TOWEA \\ 8 METER HEIGHT - Late Mid-Day \\ 2/ $1 / 1994$ - 2/28/1994 \\ $1000-1600$}

$N$

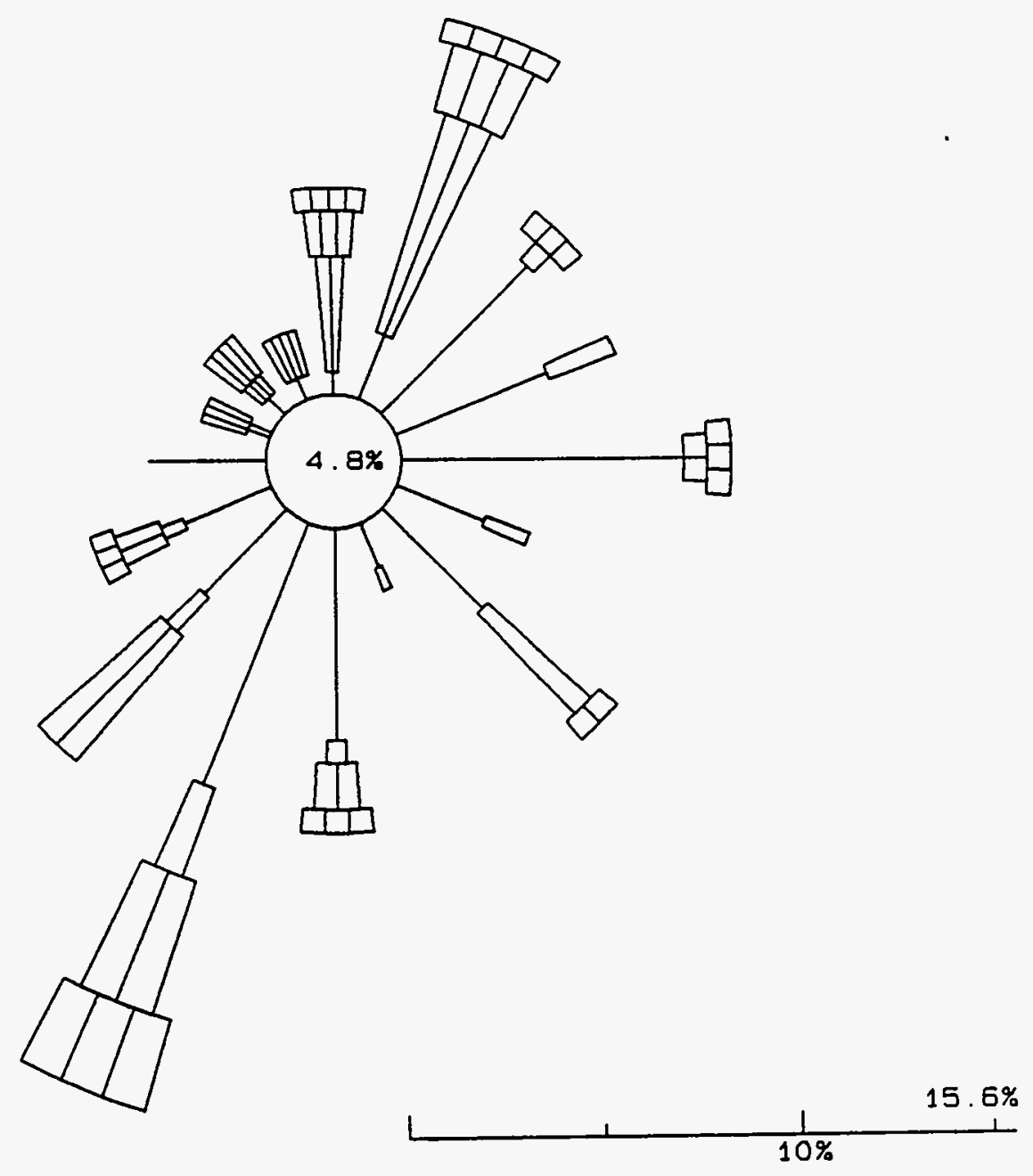

WIND SPEED CLASSES (MPS)

CALM 0 WS $<=.5$

$11.5<W S<=1.8$

$2 \square \quad 1.8<W S<=3.3$

$3 \square \quad 3.3<W S<=5.4$

4 III $5.4<W S<=8.5$

5 पात्या 8.5 WS $<=10.8$

8 पामा $10.8<$ WS
85. $\triangle \%$ DATA RECOVERED

OF WHICH 29.1\% IS

REPORTED ABOVE 


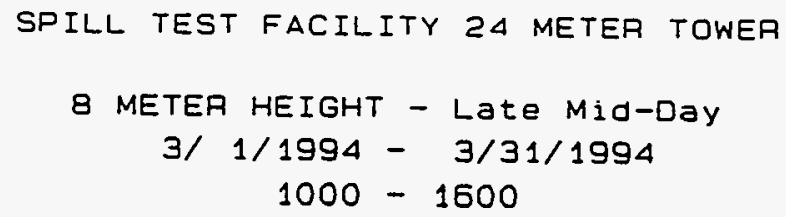

$N$
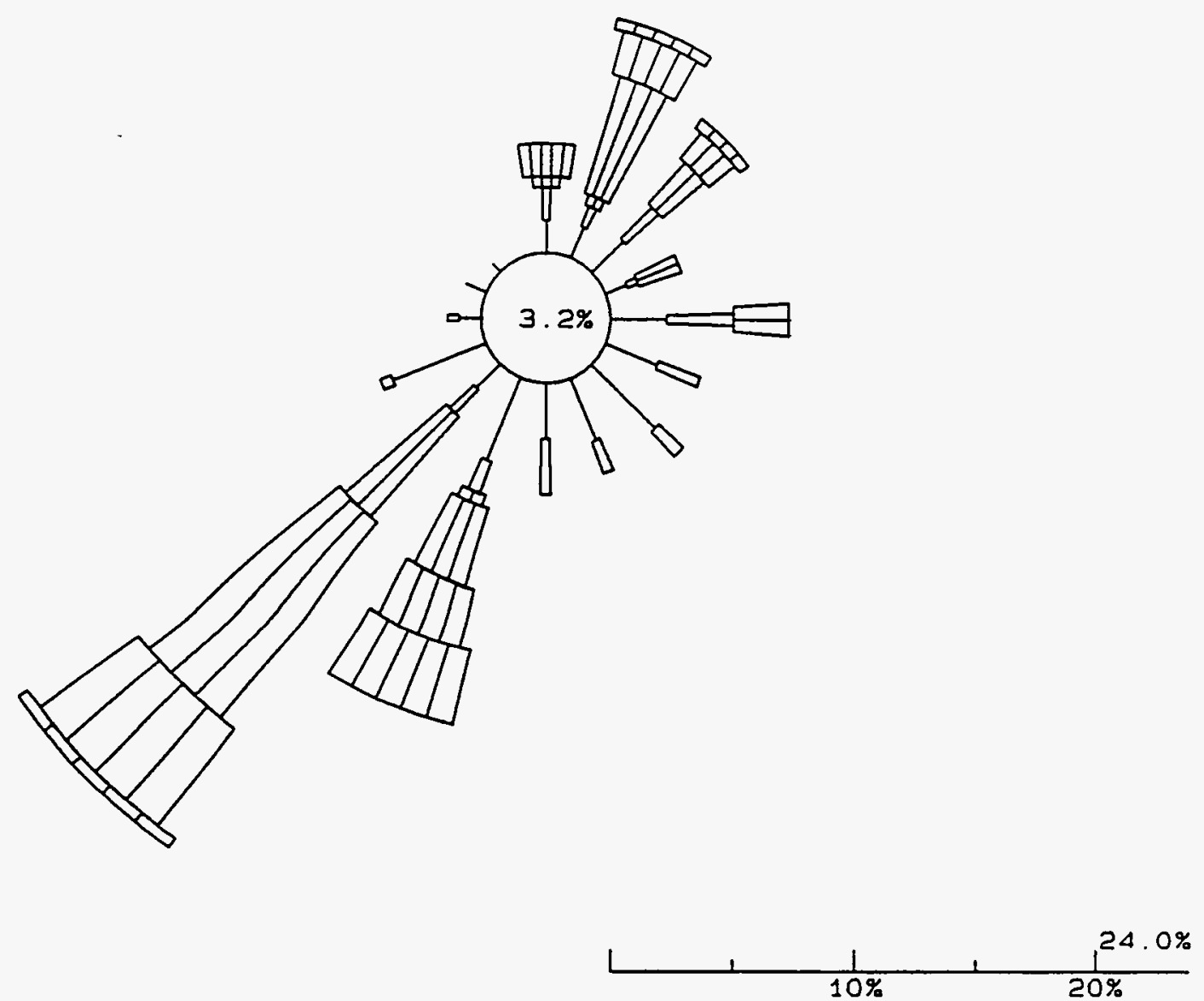

\begin{tabular}{|c|c|c|c|c|c|}
\hline WIND & \multirow{2}{*}{\multicolumn{2}{|c|}{$\begin{array}{l}\text { SPEED } \\
\text { M }\end{array}$}} & \multicolumn{3}{|c|}{ CLASSES (MPS) } \\
\hline CALM & & & & WS & $<=$ \\
\hline 1 & 1 & & $5<$ & WS & $<=1.8$ \\
\hline 2 & $\square$ & 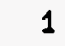 & $.8<$ & WS & $<=3.3$ \\
\hline 3 & ד & & $3<$ & WS & $<=5.4$ \\
\hline 4 & שח & & ;. $4<$ & WS & $<=8.5$ \\
\hline 5 & סाप्त & 8 & $3.5<$ & WS & $<=10.8$ \\
\hline 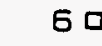 & 7 & & $.8<$ & WS & \\
\hline
\end{tabular}




\section{SPILL TEST FACILITY 24 METER TOWER \\ 8 METER HEIGHT - Late MId-Day \\ $4 / 1 / 1994-4 / 30 / 1994$ \\ $1000-1600$}

$N$

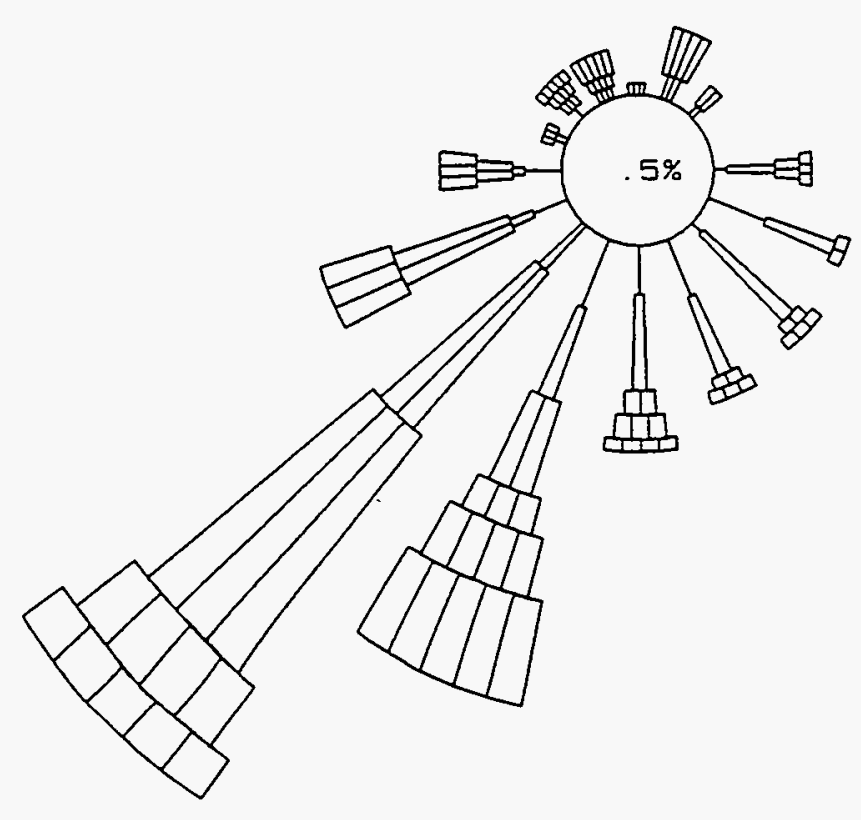

WIND SPEED CLASSES (MPS)

CALM O

11

20

30

$\triangle$ पII

5 페

6 एक
WS $<=.5$

$5<W S<=1.8$

$1.8<$ WS $<=3.3$

3. $3<$ WS $<=54$

5. $\Delta<W S<=85$

$8.5<W S<=10.8$

0 B $<S$

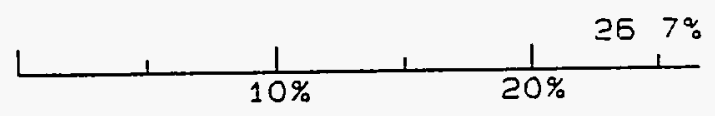

99.9\% DATA RECOVERED

OF WHICH $29.2 \%$ IS

REPORTED ABOVE 


\section{SPILL TEST FACILITY 24 METER TOWER \\ 8 METER HEIGHT - Late MId-Day \\ $5 / 1 / 1994-5 / 31 / 1994$ \\ $1000-1600$}

N

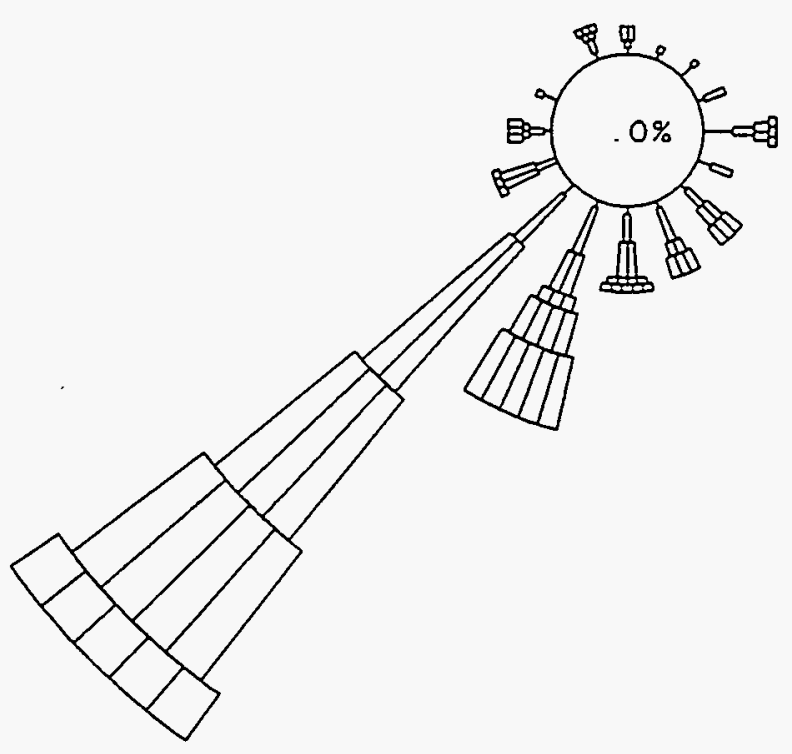

\begin{tabular}{|c|c|c|c|c|c|c|}
\hline WIND & $S P$ & EED & CL & $A S S E$ & :S (MF & PS) \\
\hline CALM & 10 & & & WS & $<=$ & 5 \\
\hline 1 & 1 & & $.5<$ & WS & $<=$ & 1.8 \\
\hline 2 & $\square$ & 1 & $8<$ & WS & $<=3$ & 3.3 \\
\hline 3 & ه & 3 & $.3<$ & WS & $<=5$ & 5.4 \\
\hline 4 & דा & 5 & $4<$ & WS & $<=\varepsilon$ & 8.5 \\
\hline 5 & סسים & 8 & $.5<$ & WS & $<=1$ & 0.8 \\
\hline 60 & סח11 & 10 & $3<$ & WS & & \\
\hline
\end{tabular}

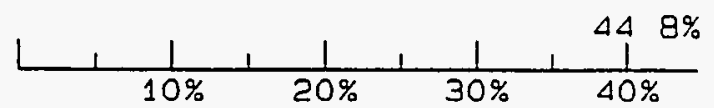

96. 9\% DATA RECOVERED

OF WHICH 29.1\% IS

REPORTED ABOVE 


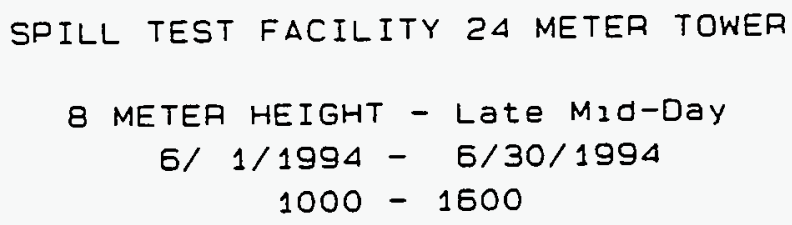

$N$
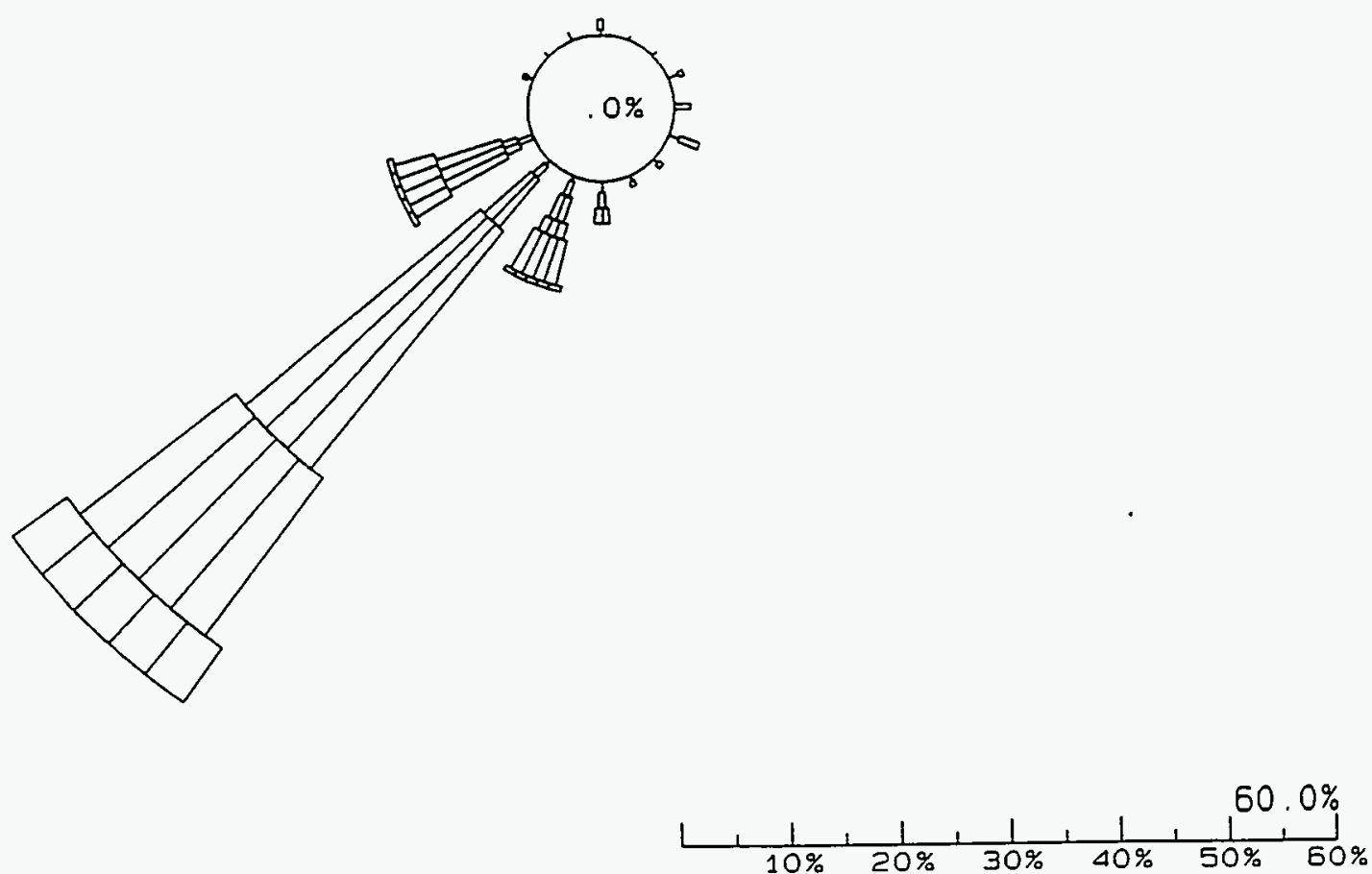

\begin{tabular}{|c|c|c|c|c|c|}
\hline WIND & \multicolumn{2}{|c|}{ SPEED } & \multicolumn{3}{|c|}{ CLASSES (MPS) } \\
\hline CALM & 10 & & & WS & $<=$ \\
\hline 1 & 1 & & $5<$ & WS & $<=1.8$ \\
\hline 2 & ם & 1 & $8<$ & WS & $<=3.3$ \\
\hline 3 & (1) & 3 & $3<$ & WS & $<=5.4$ \\
\hline$\Delta$ & ס्मा & 5 & $\Delta<$ & WS & $<=8.5$ \\
\hline ל & Dיד & 8 & $5<$ & WS & $<=108$ \\
\hline 6 & סחיב & 10 & $8<$ & WS & \\
\hline
\end{tabular}

100.0\% DATA RECOVERED

OF WHICH $29.2 \%$ IS

REPORTED ABOVE 


\section{SPILL TEST FACILITY 24 METER TOWEA

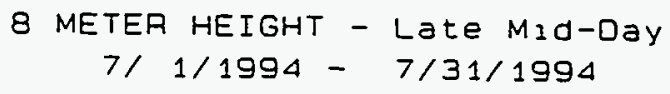

$N$

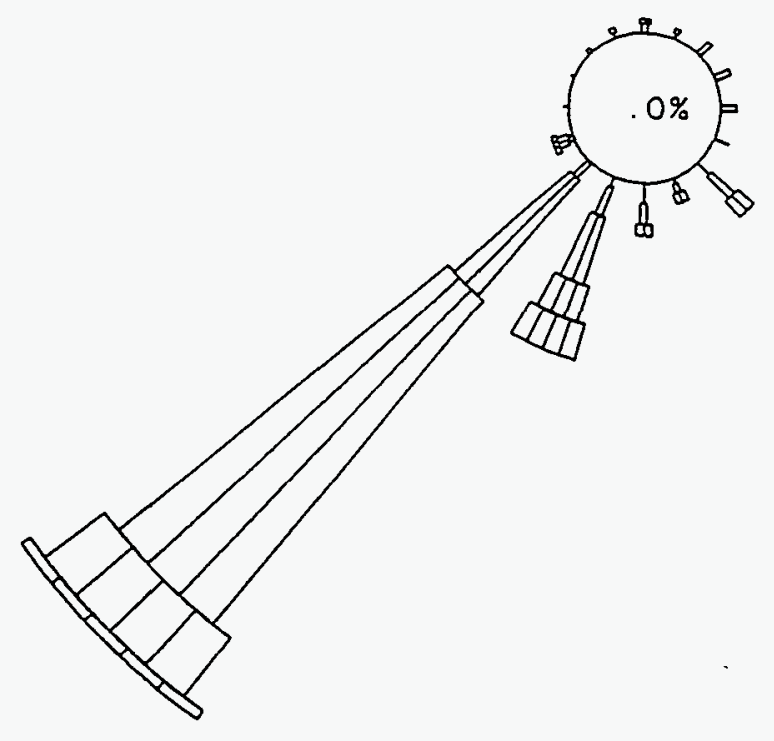




\section{SPILL TEST FACILITY 24 METER TOWER \\ 8 METER HEIGHT - Late MId-Day \\ $8 / 1 / 1994-8 / 31 / 1994$ $1000-1600$}

$N$

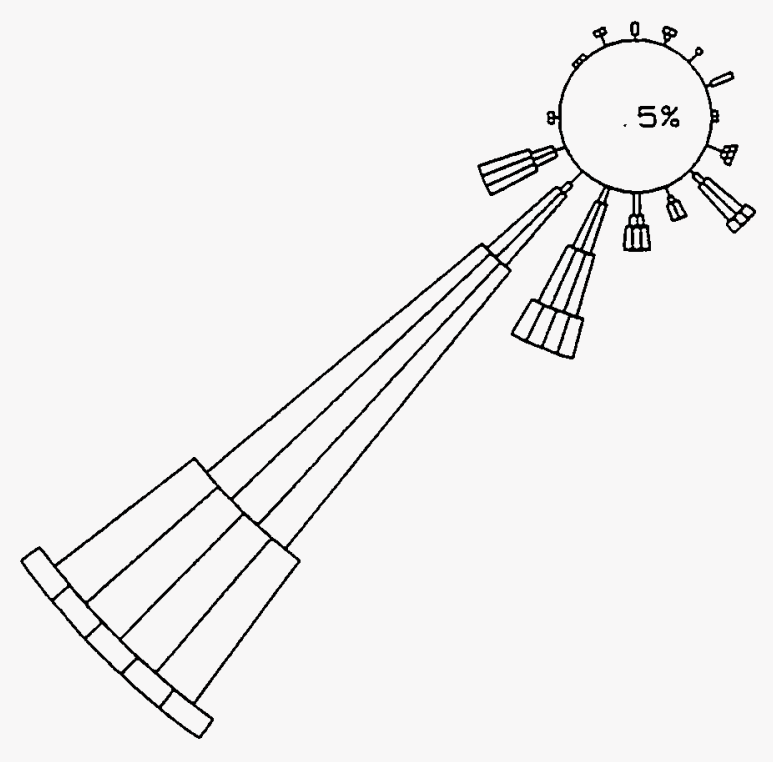

\begin{tabular}{|c|c|c|c|c|c|c|}
\hline W IND & $S P E$ & $E D$ & CL & 5 St & $S$ IMPS & 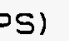 \\
\hline$A L M$ & 10 & & & WS & $<=$ & 5 \\
\hline 1 & 1 & & $5<$ & WS & $<=1$ & 1.8 \\
\hline 2 & 口 & 1 & $8<$ & WS & $<=3$ & 3.3 \\
\hline 3 & $\square$ & 3 & $3<$ & WS & $c=5$ & 54 \\
\hline 4 & דा & 5 & $4<$ & WS & $c=8$ & 3.5 \\
\hline 5 & هسם & 8 & $5<$ & WS & $<=10$ & 8 \\
\hline 60 & ד्या & 10 & $8<$ & WS & & \\
\hline
\end{tabular}

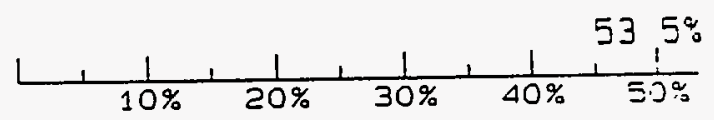

$100.0 \%$ DATA RECOVERED

OF WHICH 29.2\% IS

REPORTED ABOVE 


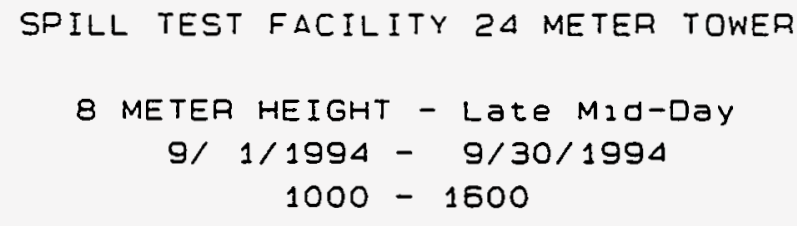

$N$
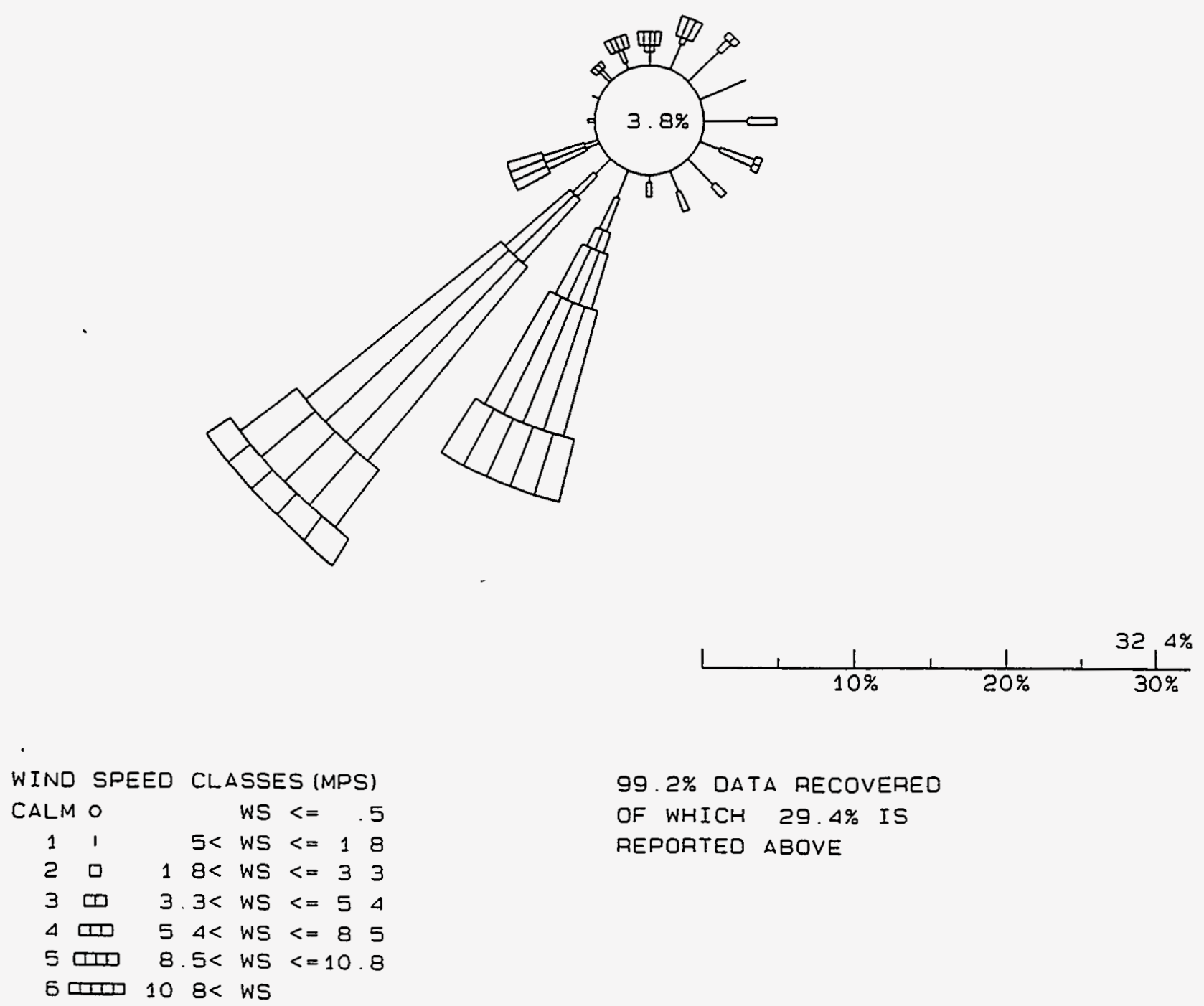

$99.2 \%$ DATA RECOVERED

OF WHICH 29.4\% IS

REPORTED ABOVE 
SPILL TEST FACILITY 24 METER TOWER

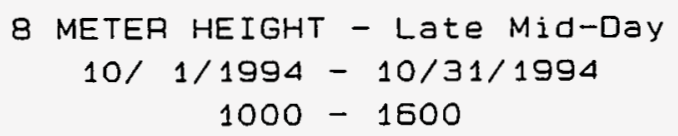

N
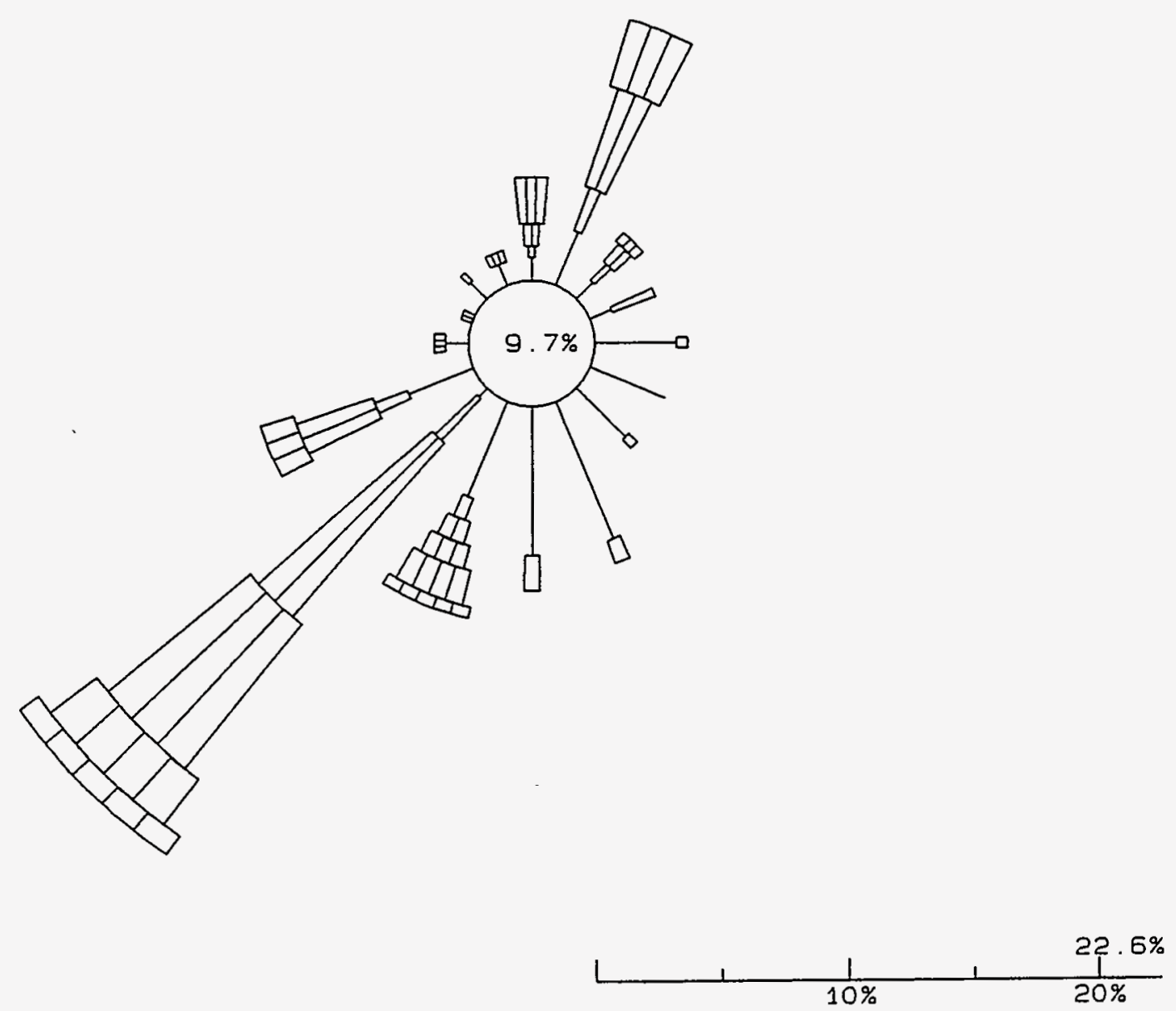

$98.5 \%$ DATA RECOVERED

OF WHICH $29.6 \%$ IS

REPORTED ABOVE 


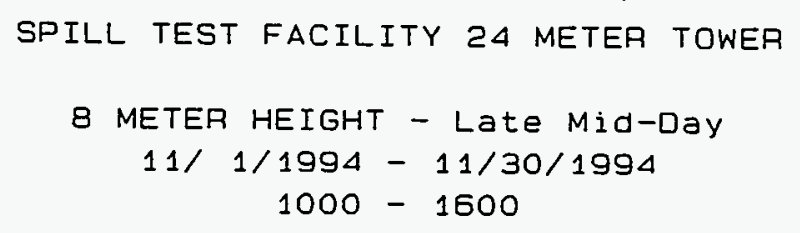

$N$
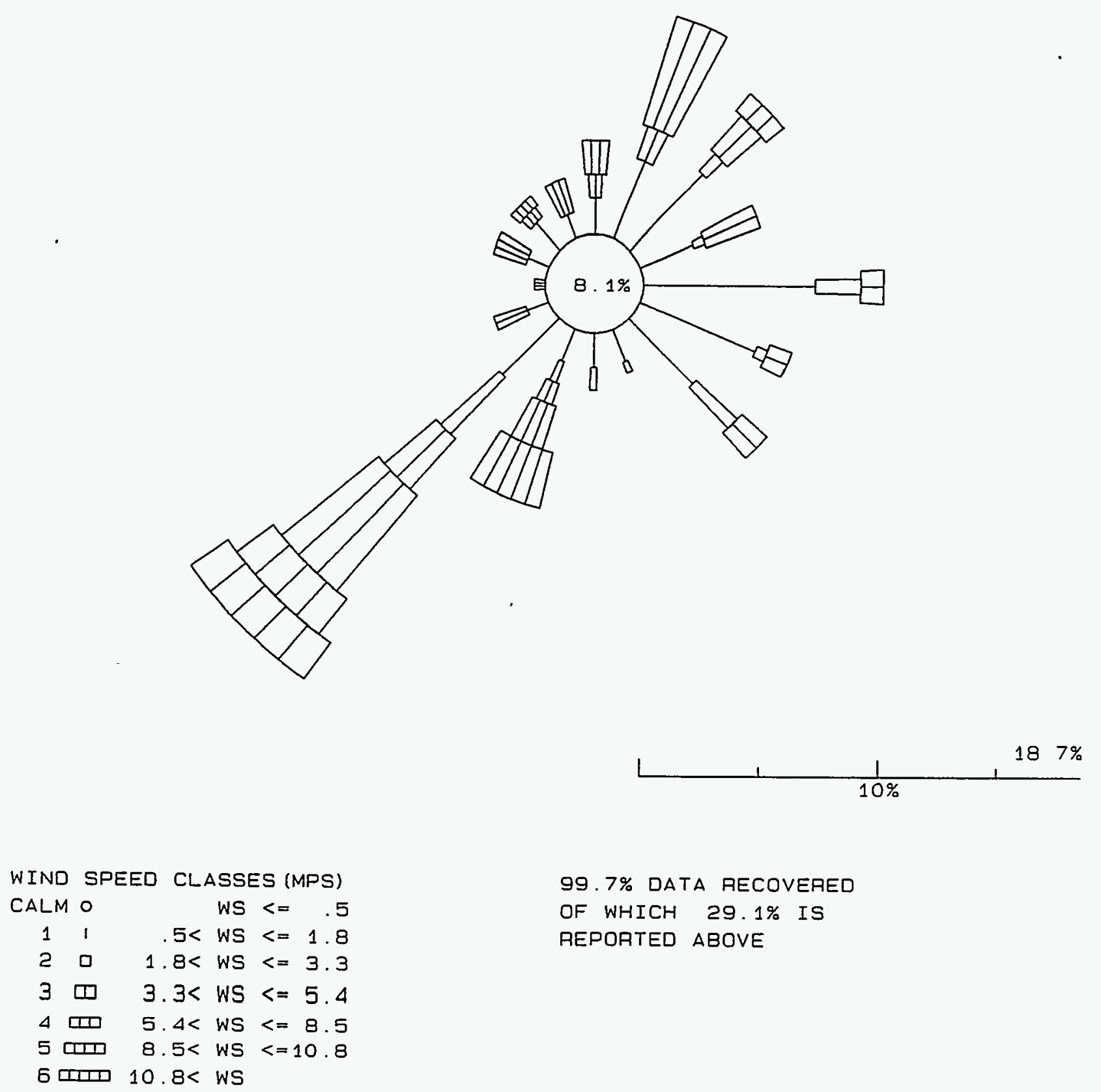

$99.7 \%$ DATA RECOVERED

OF WHICH 29.1\% IS

REPORTED ABOVE 


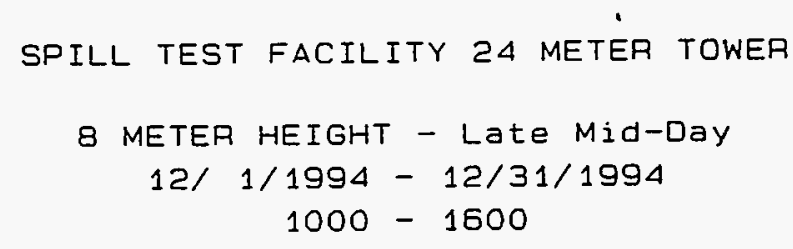

$N$
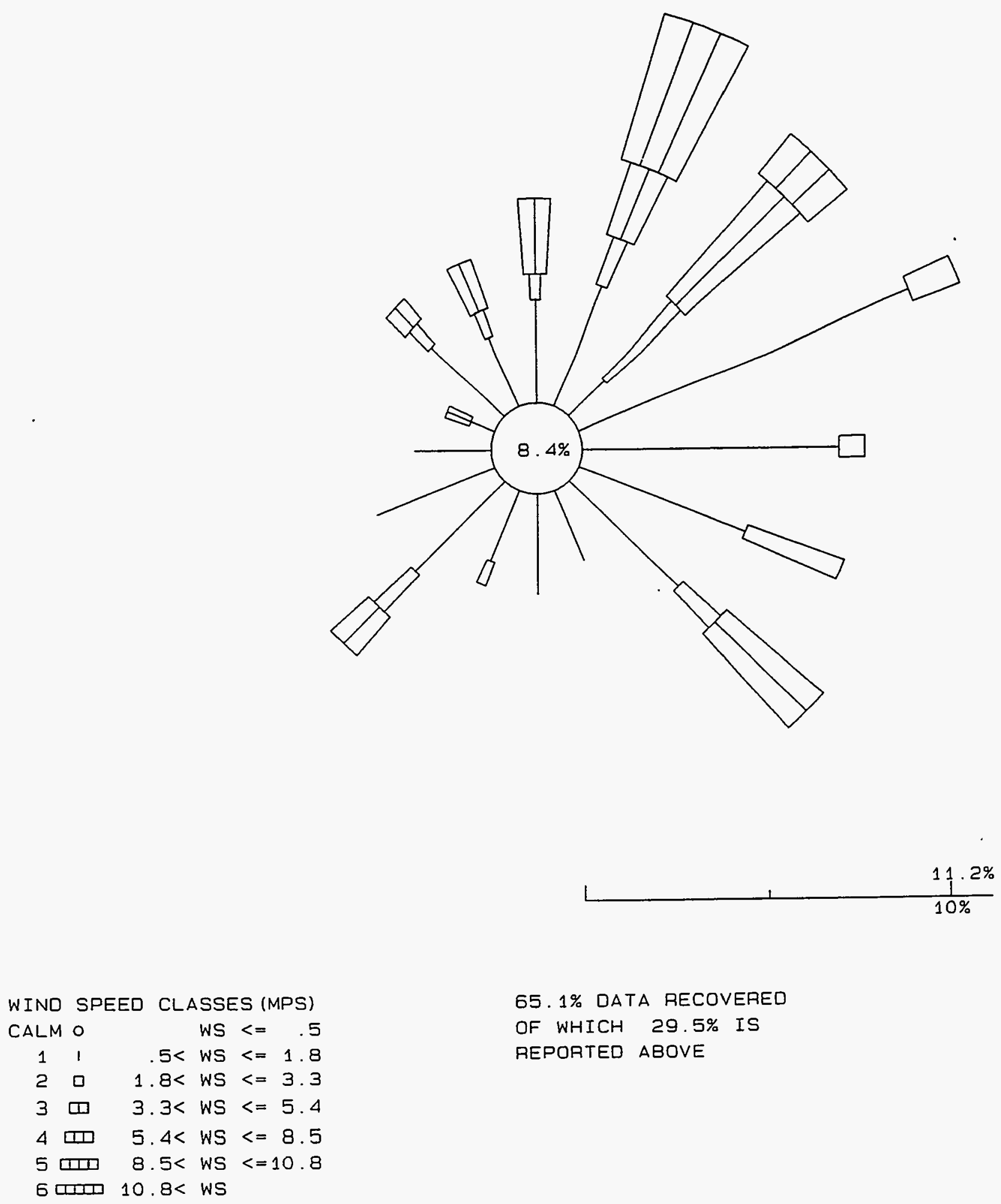

65. 1\% DATA RECOVERED

OF WHICH $29.5 \%$ IS

REPORTED ABOVE 
SPILL TEST FACILITY 24 METER TOWER

8 METER HEIGHT - Evening Transition

$$
\begin{gathered}
1 / 1 / 1994-1 / 31 / 1994 \\
1600-2000
\end{gathered}
$$

N
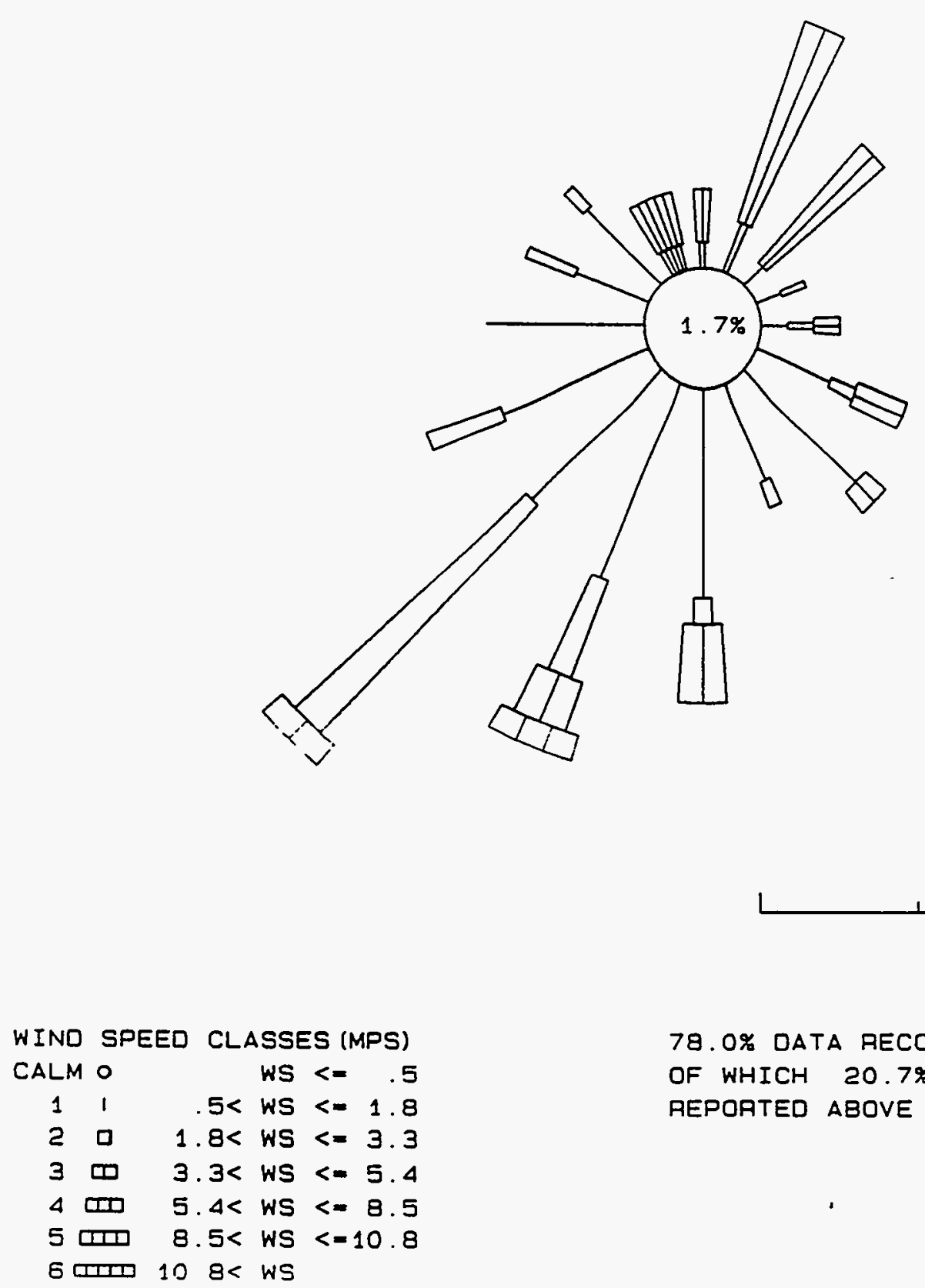

78.0\% DATA RECOVERED OF WHICH 20.7\% IS REPORTED ABOVE 
SPILL TEST FACILITY $2 \triangle$ METEA TOWEA

8 METER HEIGHT - Evening Transition

2/ $1 / 1994-2 / 28 / 1994$

$1600-2000$

$N$
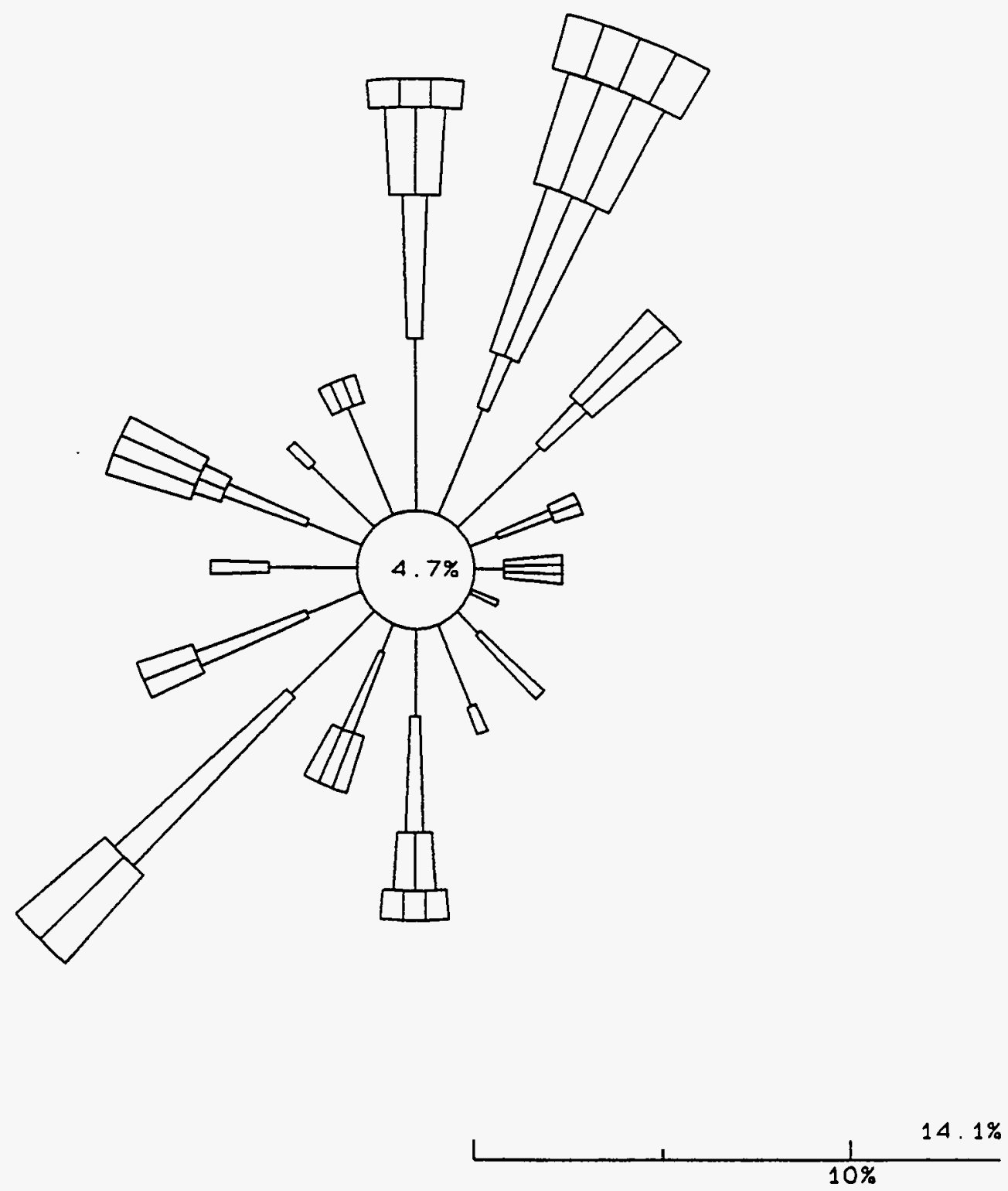

85. 4\% DATA RECOVERED

OF WHICH 22.3\% IS

REPOATED ABOVE 


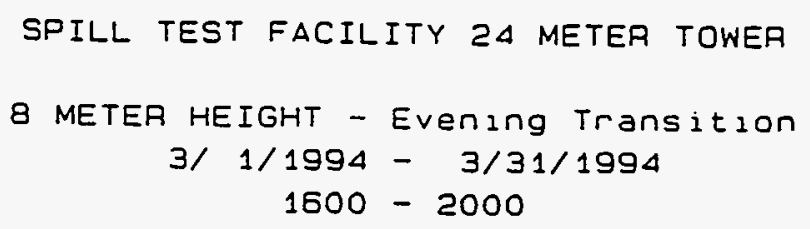

$N$
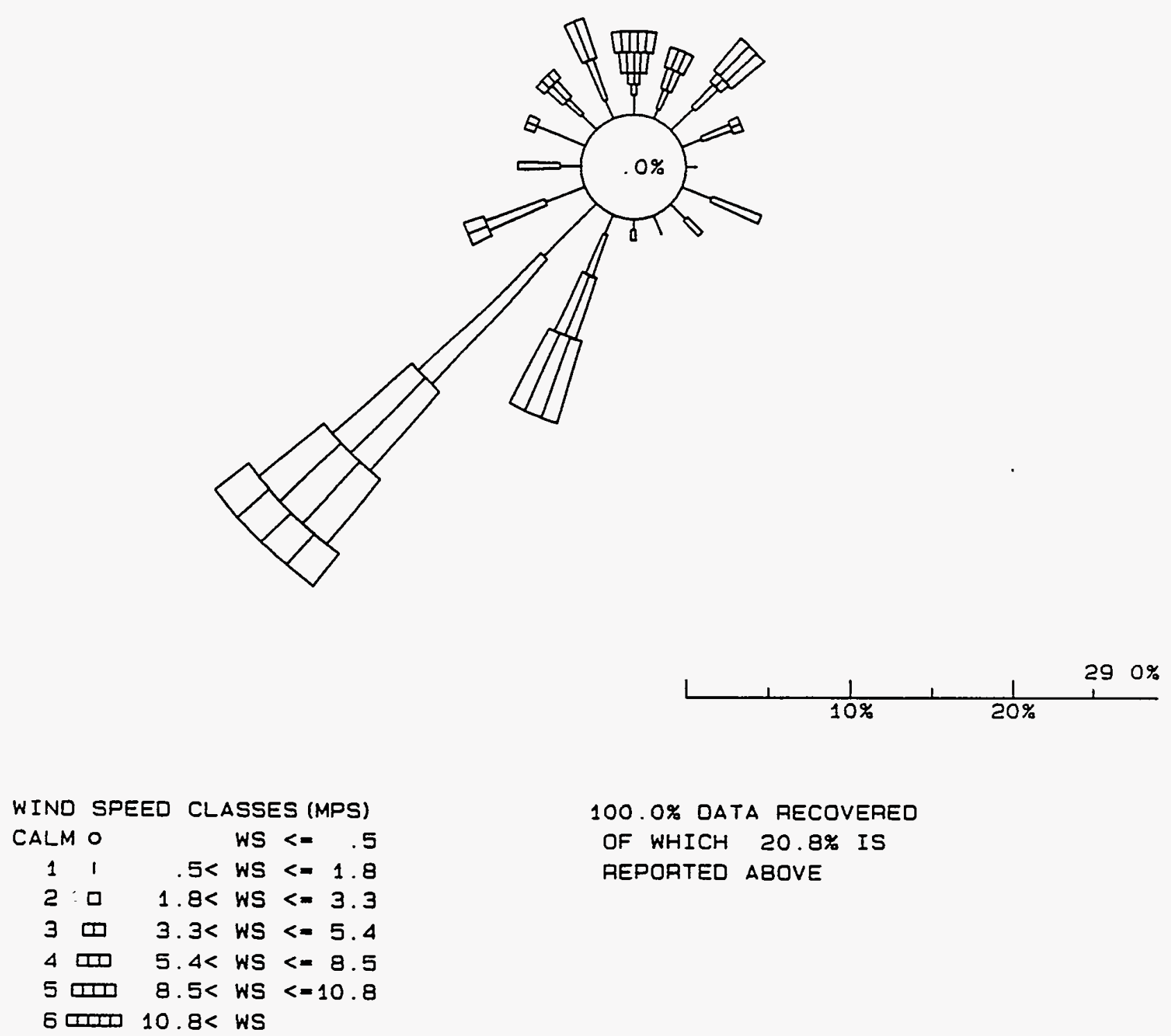

100. O\% DATA RECOVERED

OF WHICH $20.8 \%$ IS

REPOATED ABOVE 


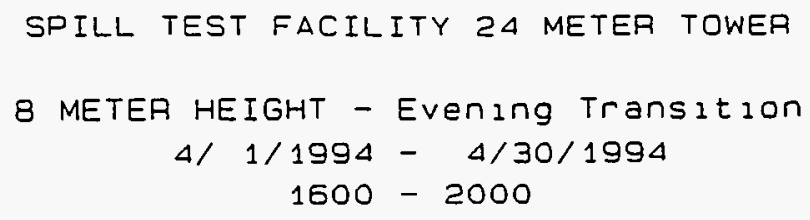

N
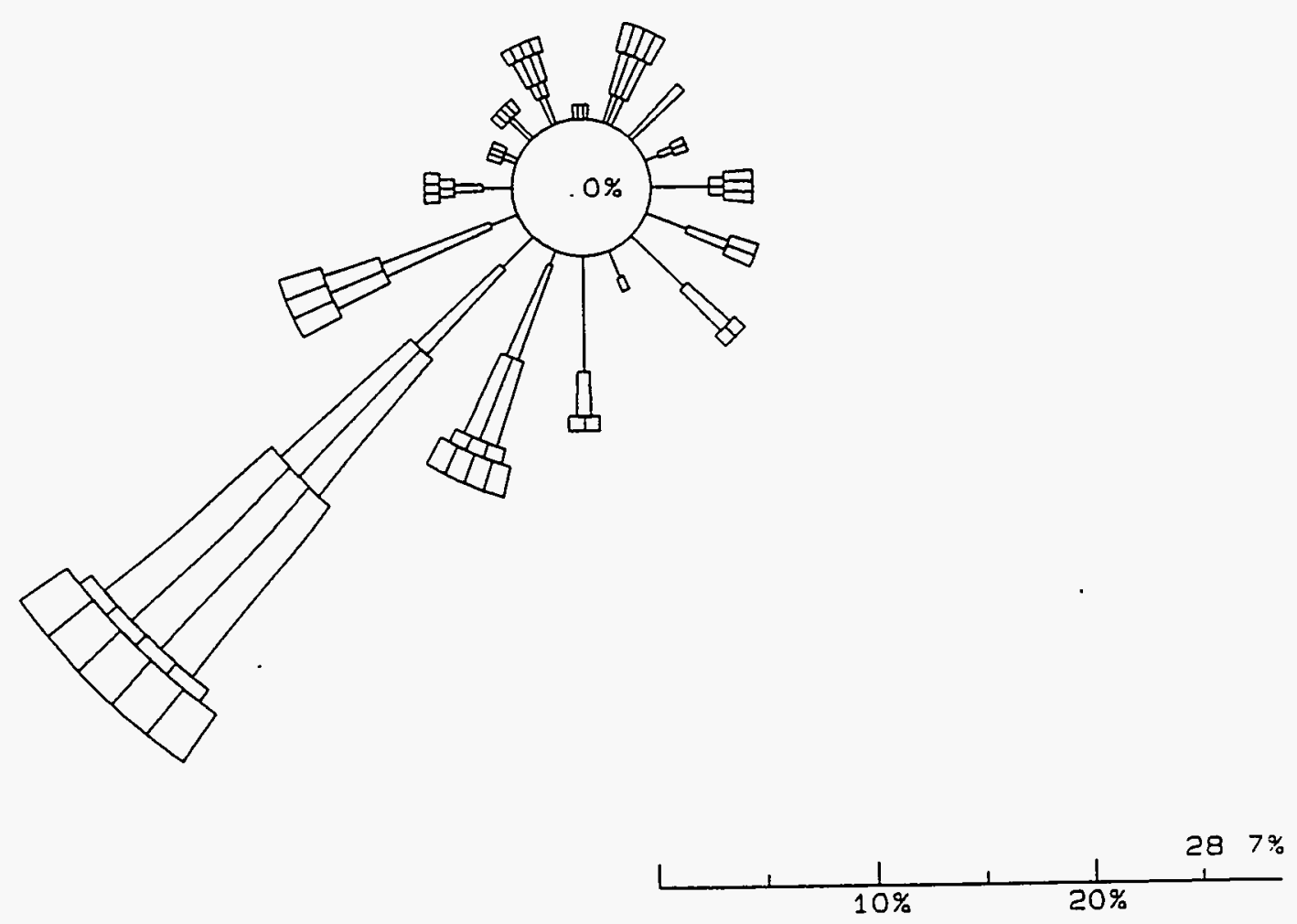

99.9\% DATA RECOVERED

OF WHICH 20.9\% IS REPORTED ABOVE 


\section{SPILL TEST FACILITY 24 METER TOWEA \\ 8 METER HEIGHT - Evening Transition \\ 5/ $1 / 1994-5 / 31 / 1994$ \\ $1600-2000$}

$N$
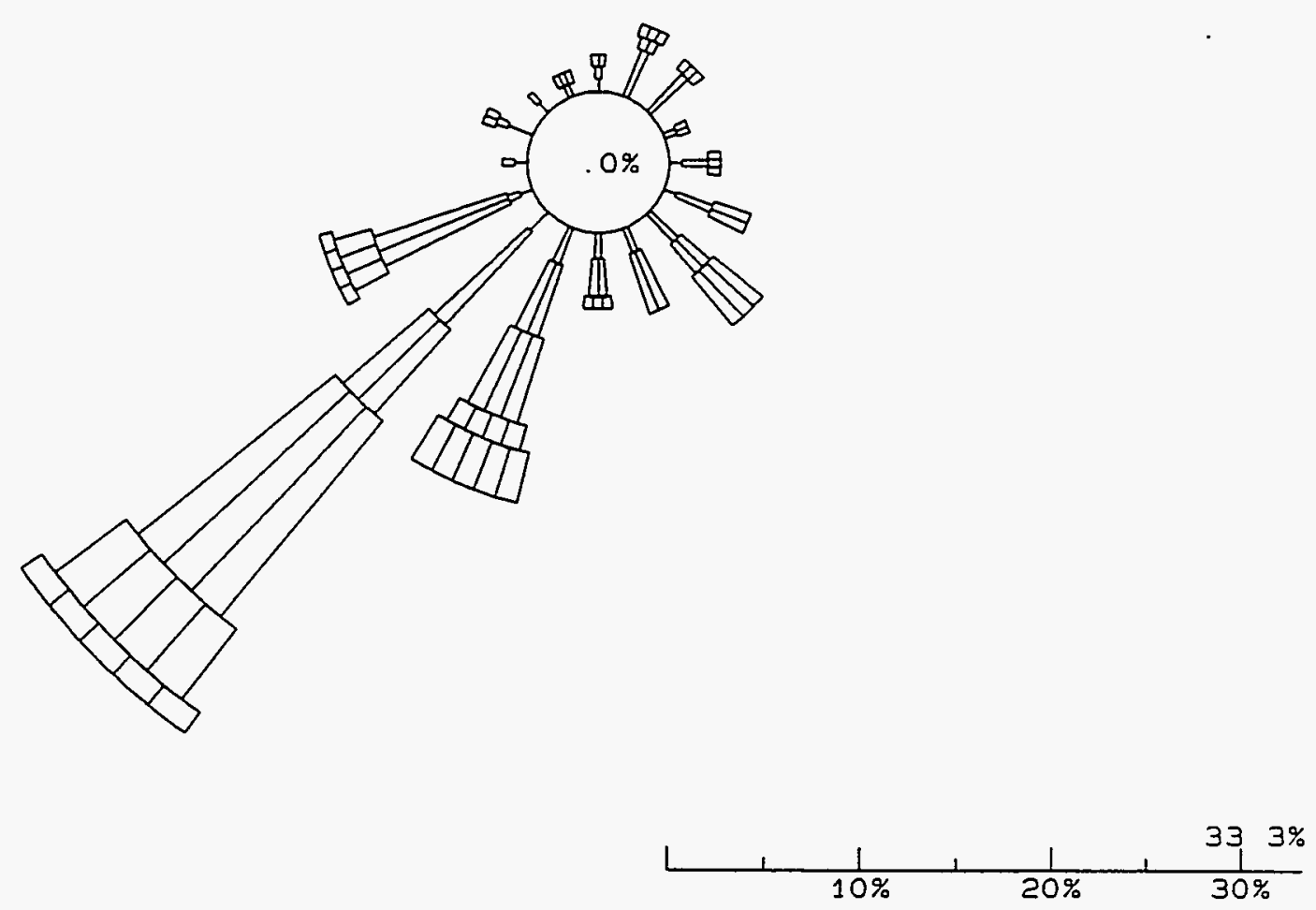

\begin{tabular}{|c|c|c|c|c|c|c|}
\hline WIND & $\mathrm{SP}$ & $E D$ & $C L$ & $\triangle S C$ & $S I M$ & \\
\hline CALM & 10 & & & WS & $<=$ & 5 \\
\hline 1 & 1 & & $.5<$ & WS & $<=1$ & 1.8 \\
\hline 2 & $\square$ & 1 & $8<$ & WS & $c=3$ & 3. 3 \\
\hline 3 & סי & 3 & $3<$ & WS & $<=5$ & 5.4 \\
\hline 4 & पाप & 5 & $\Delta<$ & WS & $<=8$ & 35 \\
\hline 50 & ס्म" & 8 & $5<$ & WS & $<=10$ & .8 \\
\hline $6 \square$ & סוII & 10 & $.8<$ & WS & & \\
\hline
\end{tabular}

96.9\% DATA RECOVERED

OF WHICH 20.8\% IS

AEPOATED ABOVE 


\section{SPILL TEST FACILITY 24 METER TOWER}

8 METER HEIGHT - Evening Transition

$7 / 1 / 1994-7 / 31 / 1994$

$1600-2000$

$N$.
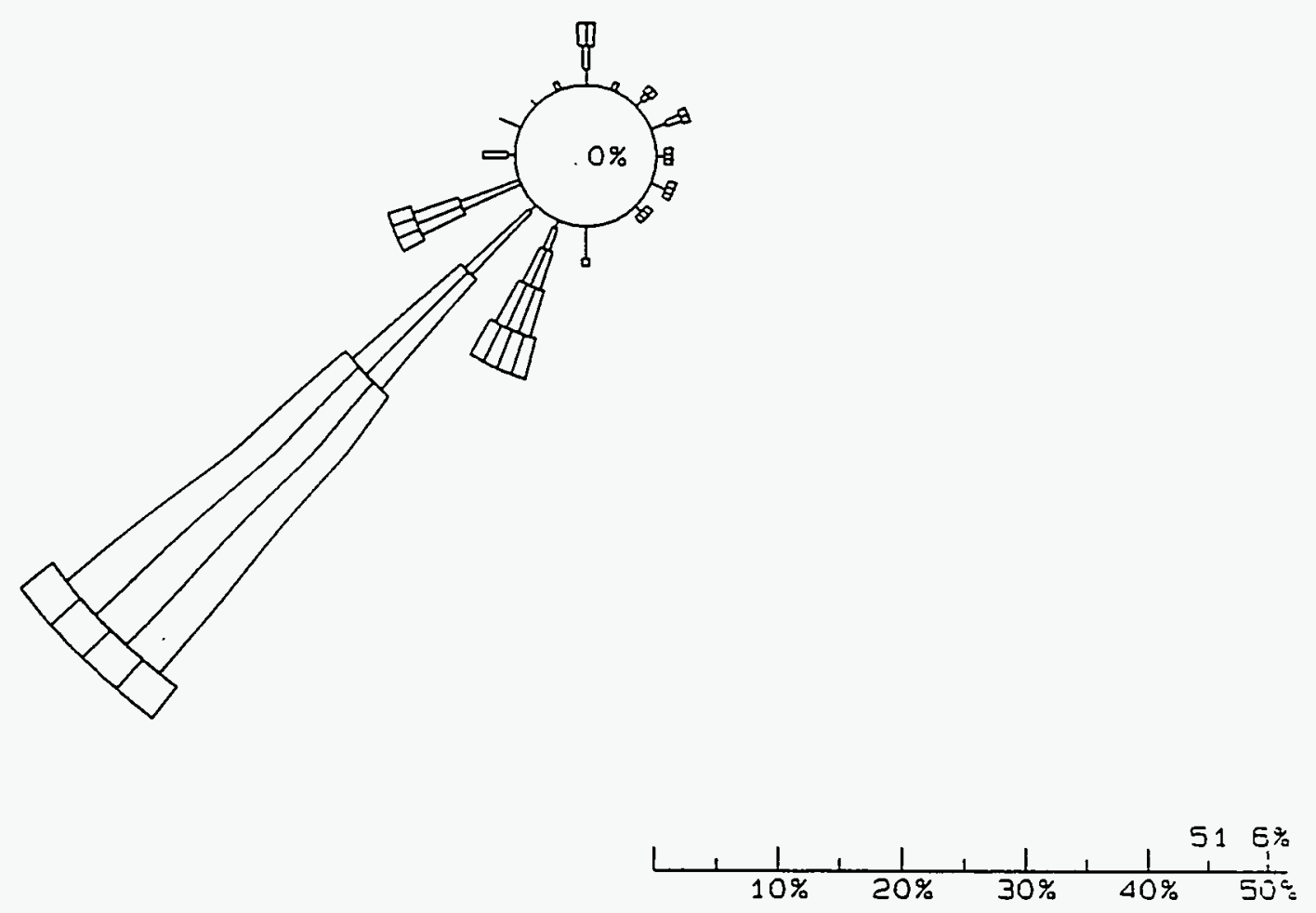

\begin{tabular}{|c|c|c|c|c|c|}
\hline WIND & $S P$ & EEO & CLS & ASS & ES IMPS \\
\hline CALM & 10 & & & WS & $<=$ \\
\hline 1 & 1 & & $5<$ & WS & $<=1.8$ \\
\hline 2 & $\square$ & 1. & $8<$ & WS & $<=3.3$ \\
\hline 3 & س & 3 & $3<$ & WS & $<=5.4$ \\
\hline 4 & एण & 5 & $4<$ & WS & $\Leftrightarrow=8.5$ \\
\hline 5 & سய & 8. & $.5<$ & WS & $<=10.8$ \\
\hline 60 & مستب & 10 & $8<$ & WS & \\
\hline
\end{tabular}

100.0\% DATA RECOVERED

OF WHICH $208 \%$ IS

REPORTED ABOVE 


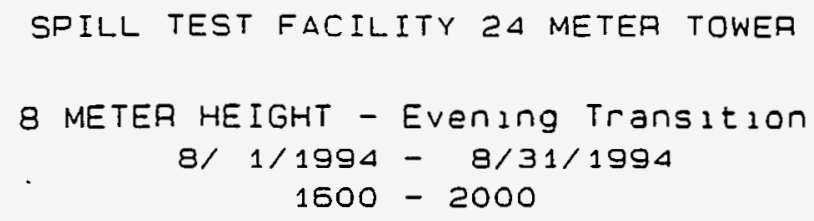

N
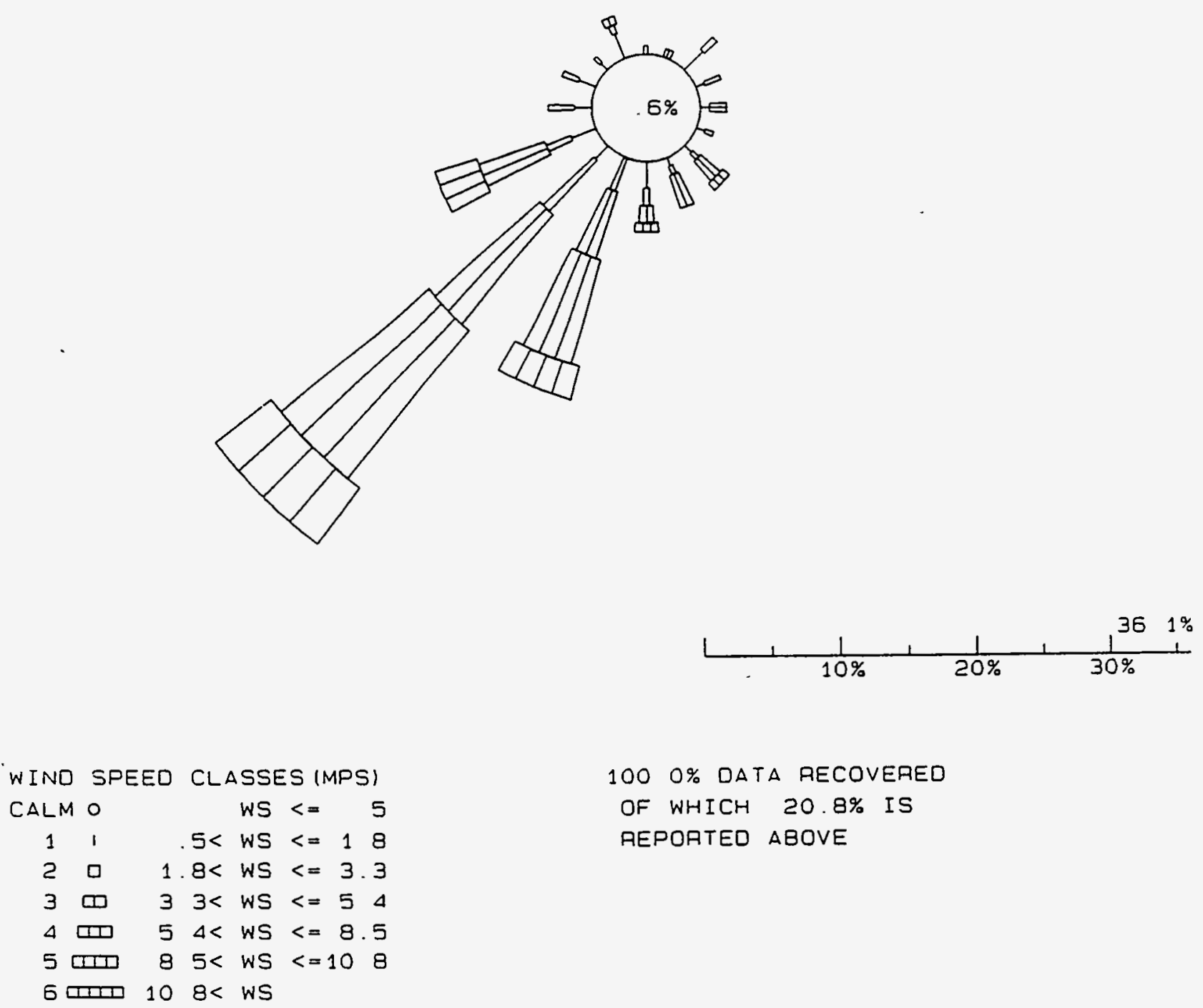
SPILL TEST FACILITY 24 METER TOWER

8 METER HEIGHT - Evening Transition 10/ $1 / 1994-10 / 31 / 1994$

$1600-2000$

$N$
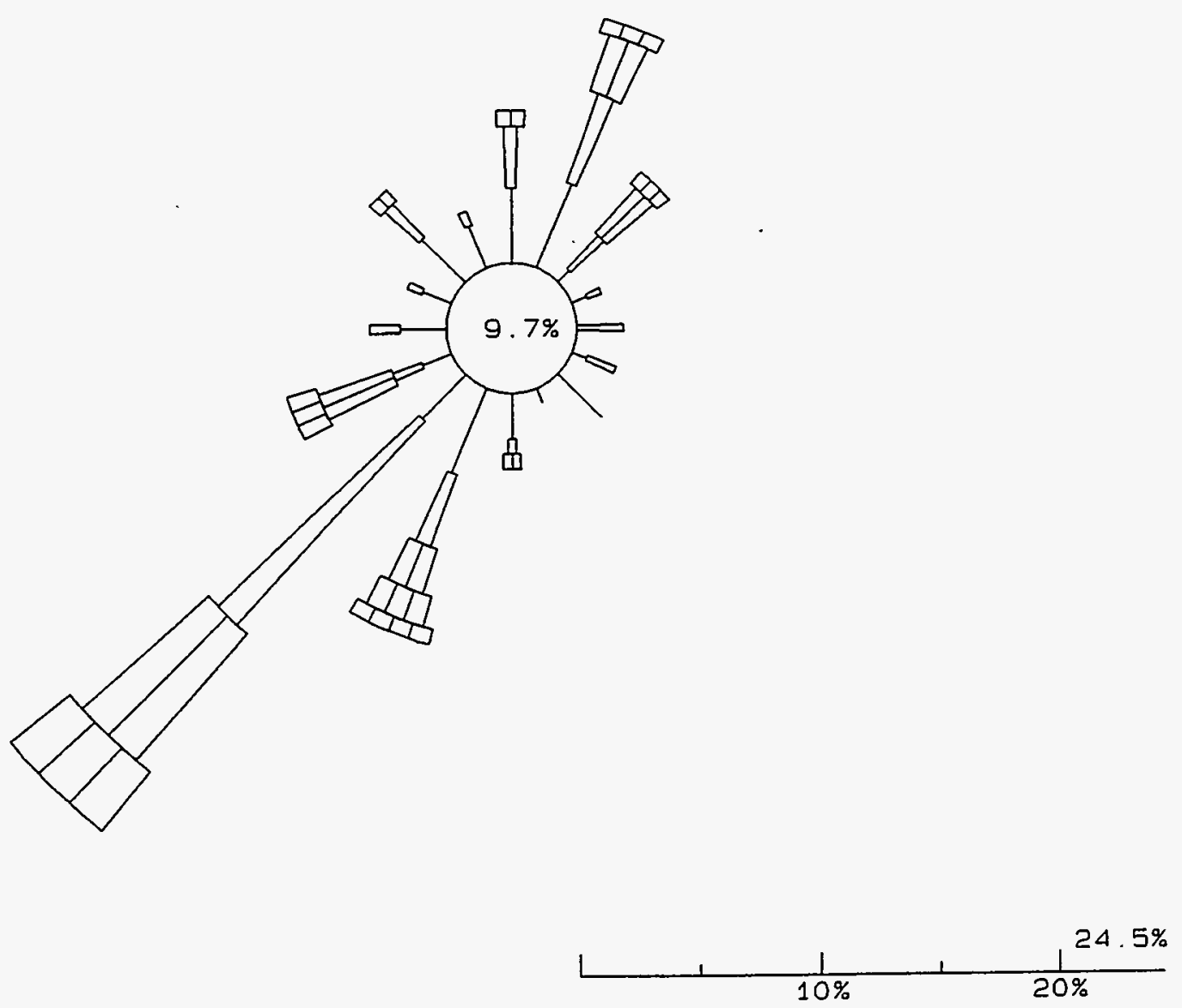

\begin{tabular}{|c|c|c|c|c|c|}
\hline WIND & SPE & ED & CLA & ASS & ES (MPS) \\
\hline CALM & 10 & & & WS & $<=$ \\
\hline 1 & I & & $5<$ & WS & $<=1.8$ \\
\hline 2 & $\square$ & 1 & $.8<$ & WS & $c=3.3$ \\
\hline 3 & $\square$ & 3 & $3<$ & WS & $<=5.4$ \\
\hline 4 & דा & 5 & $.4<$ & WS & $c=8.5$ \\
\hline 5 & סשד & 8 & $.5<$ & WS & $<=10.8$ \\
\hline 6 & שחדם & 10 & $.8<$ & WS & \\
\hline
\end{tabular}

98.5\% DATA RECOVERED

OF WHICH $21.1 \%$ IS

REPORTED ABOVE 
SPILL TEST FACILITY 24 METER TOWER

8 METER HEIGHT - Evening Transition

11/1/1994 - 11/30/1994

$1600-2000$

N
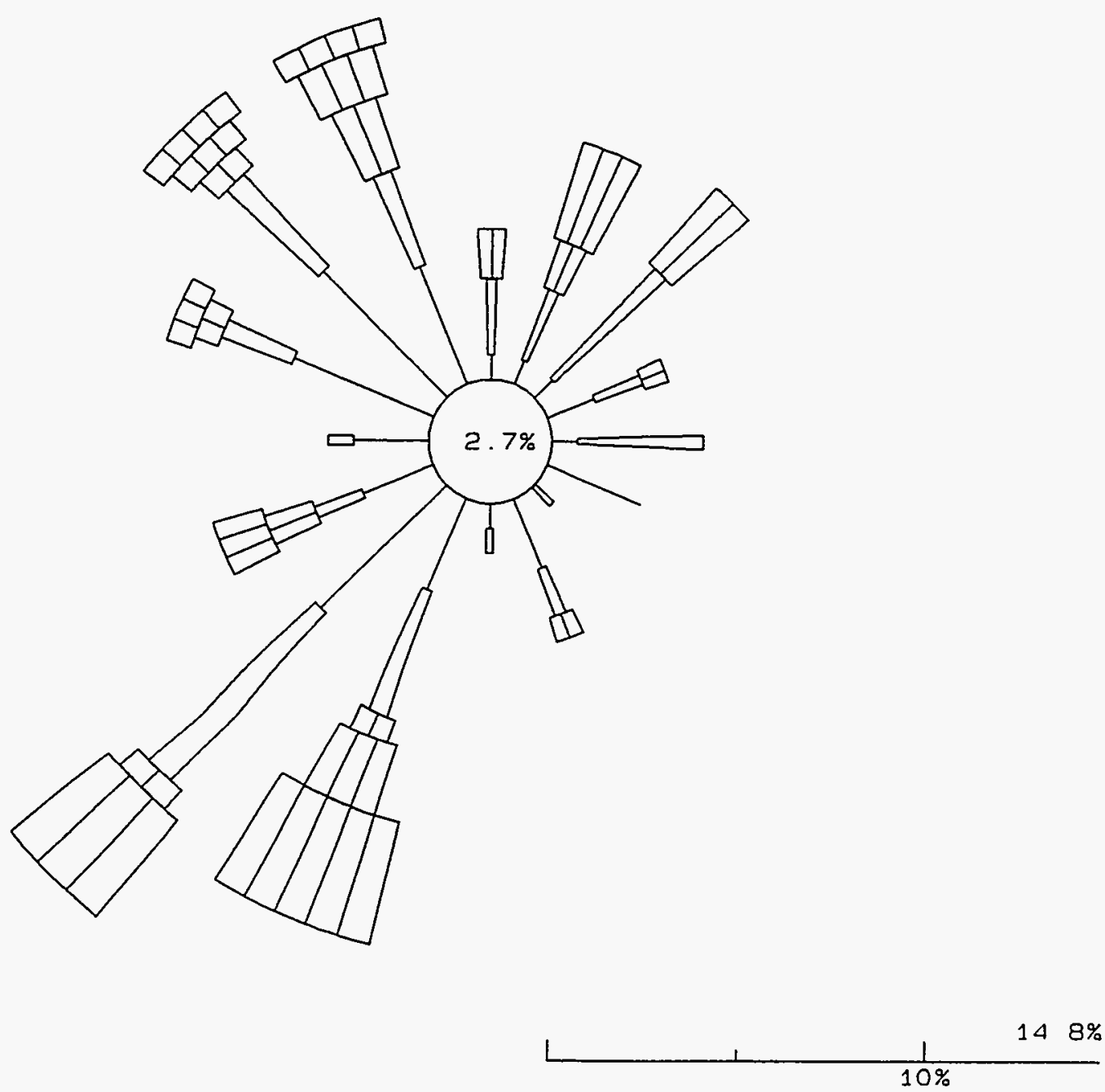

99.7\% DATA RECOVERED

OF WHICH $20.8 \%$ IS

REPORTED ABOVE 
SPILL TEST FACILITY 24 METER TOWER

8 METER HEIGHT - Evening Transition

$$
\begin{aligned}
12 / 1 / 1994 & -12 / 31 / 1994 \\
1600 & -2000
\end{aligned}
$$

N
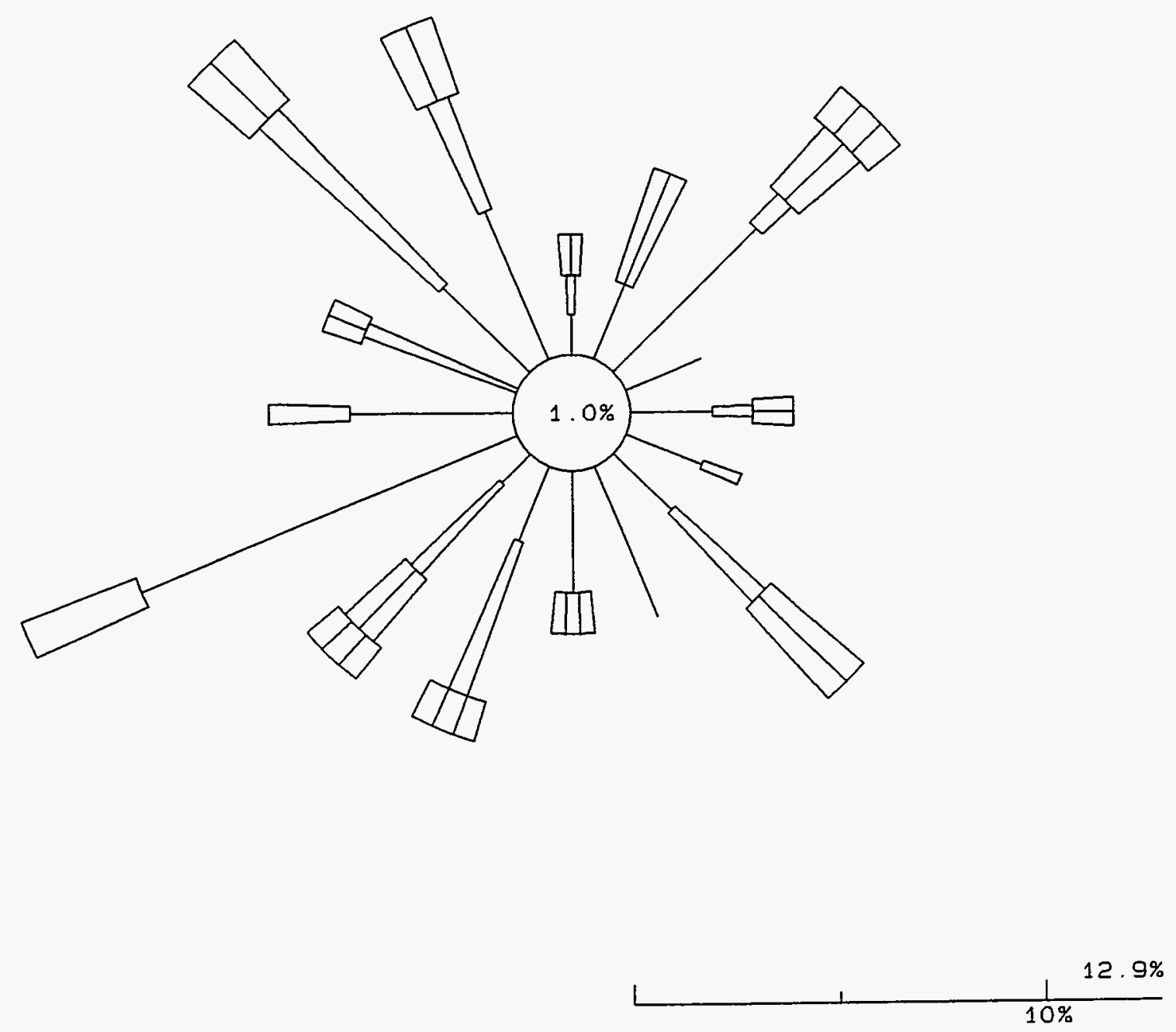

65. 1\% DATA RECOVERED

OF WHICH $20.9 \%$ IS

REPORTED ABOVE 


\section{SPILL TEST FACILITY 24 METER TOWER \\ 8 METEA HEIGHT - NIgRE TIME \\ 1.'1:1994 - 1/31/1994 \\ $2000-500$}

$N$

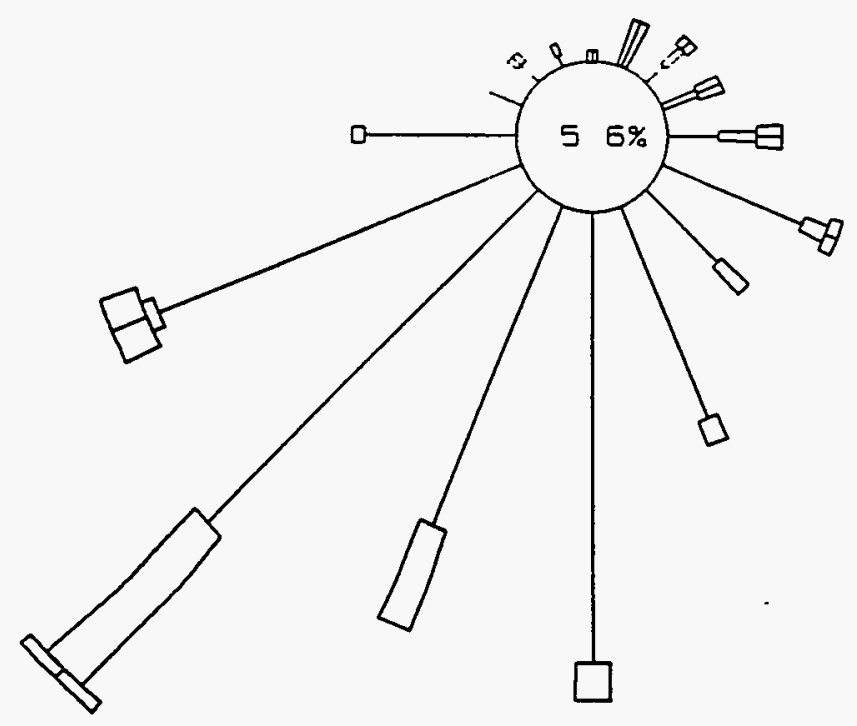

\begin{tabular}{|c|c|c|c|c|c|}
\hline \multicolumn{6}{|l|}{0} \\
\hline CALM & 40 & & & WS & $<=$ \\
\hline 1 & 1 & & $5<$ & WS & $<=1$ \\
\hline 2 & $\square$ & 1 & $.8<$ & WS & $<=3$. \\
\hline 3 & هم & 3 & $.3<$ & WS & $<=5$. \\
\hline 4 & דा & 5 & $.4<$ & WS & $<=8$. \\
\hline 5 & סדי & 8 & $.5<$ & WS & $<=10$. \\
\hline 65 & שחד & 10 & $.8<$ & WS & \\
\hline
\end{tabular}

78. O\% DATA RECOVERED

OF WHICH $\triangle 6.2 \%$ IS REPORTED ABOVE 
SPILL TEST FACILITY 24 METER TOWER

8 METER HEIGHT - Night Time

2/ 1/1994 - 2/28/1994

$2000-600$

N

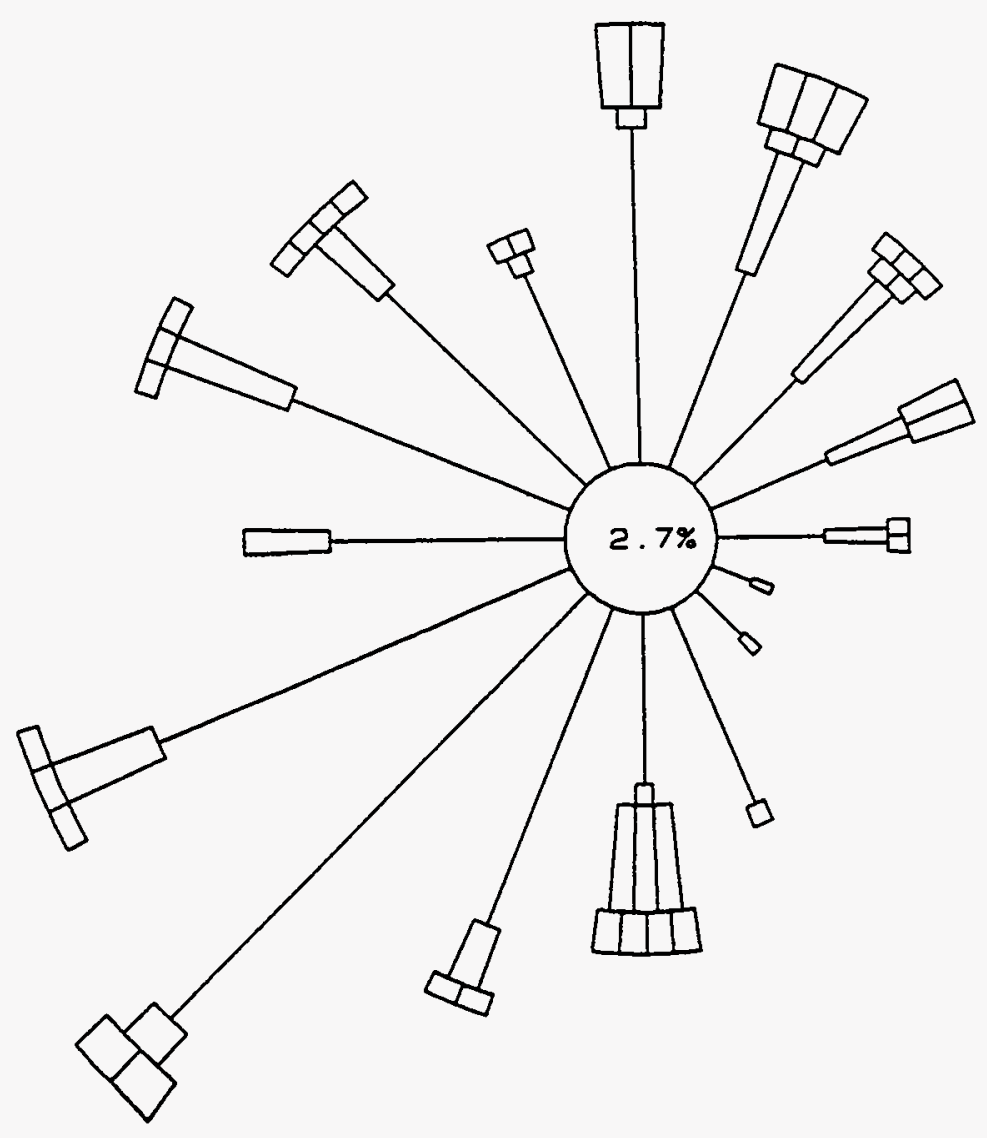

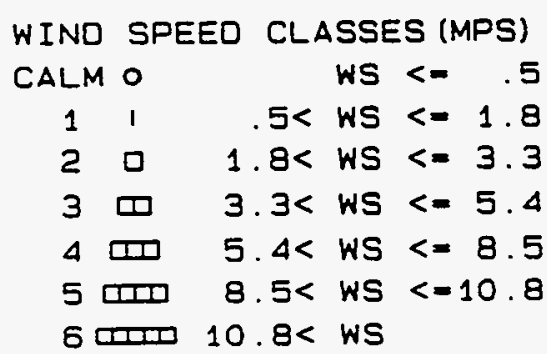

85. 4\% DATA RECOVERED

OF WHICH $46.0 \%$ IS

REPORTED ABOVE 
SPILL TEST FACILITY 24 METER TOWER

8 METER HEIGHT - Night Time

3/ $1 / 1994-3 / 31 / 1994$

$2000-600$

$N$

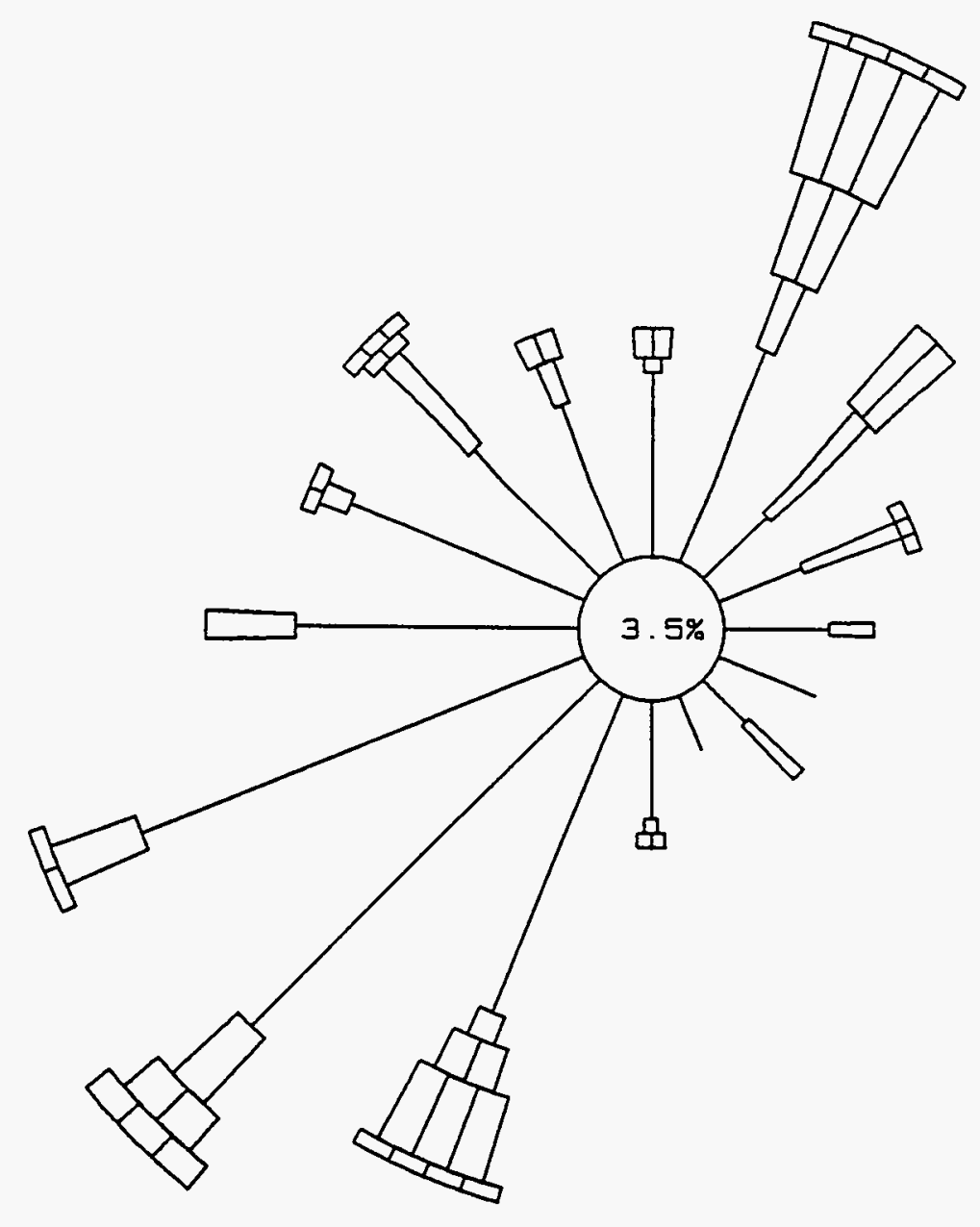

\begin{tabular}{|c|c|c|c|c|}
\hline \multirow{2}{*}{ WIND } & SPEED & \multicolumn{3}{|c|}{ CLASSES (MPSS) } \\
\hline & 10 & & WS & $<=$ \\
\hline 1 & 1 & $5<$ & WS & $<=1.8$ \\
\hline 2 & 口 & $1.8<$ & WS & $<=3.3$ \\
\hline 3 & שם & $3.3<$ & WS & $<=5.4$ \\
\hline 4 & סחם & $5.4<$ & WS & $<=8.5$ \\
\hline 5 & סד & $8.5<$ & WS & $<=10.8$ \\
\hline 60 & סाI & $10.8<$ & WS & \\
\hline
\end{tabular}

100.0\% DATA RECOVERED

OF WHICH 45.8\% IS

REPORTED ABOVE 


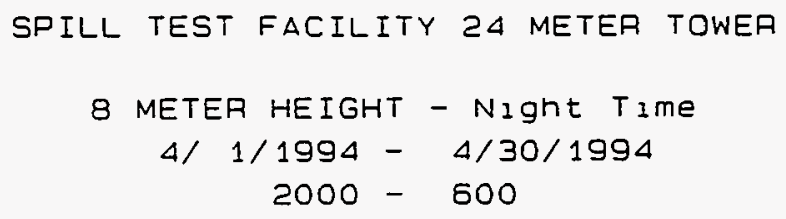

$N$

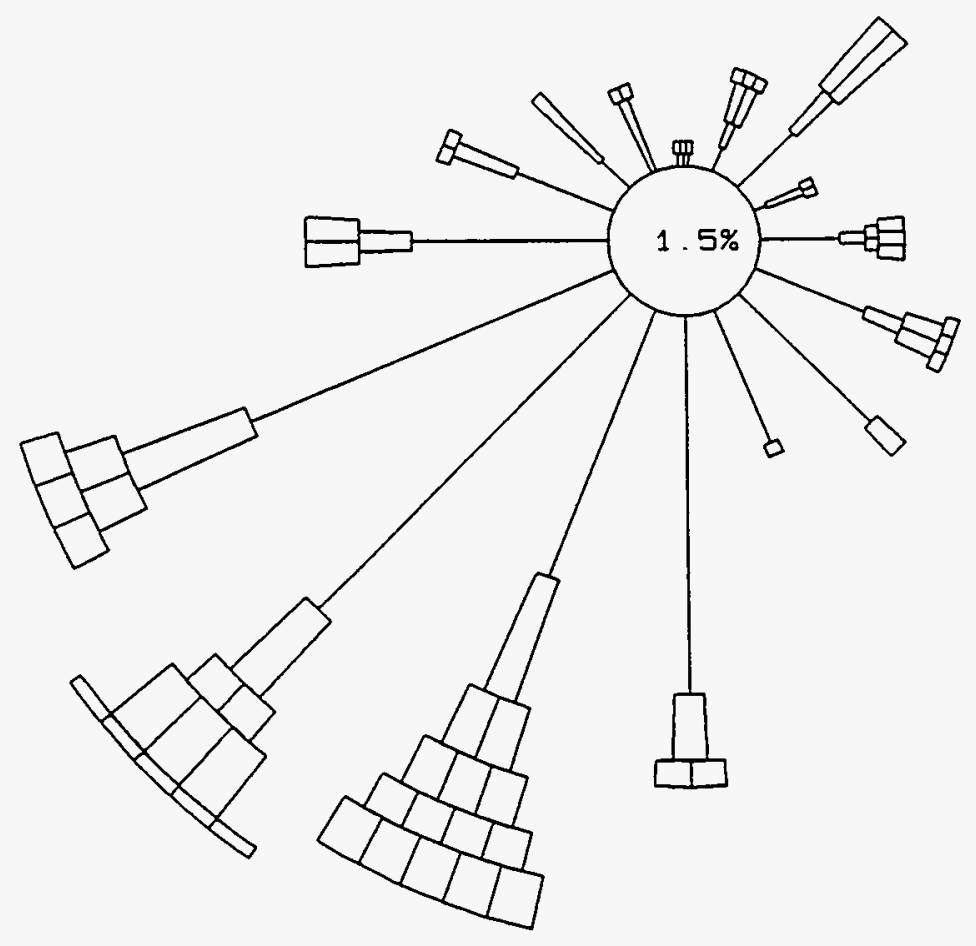

\begin{tabular}{|c|c|c|c|c|c|}
\hline W IND & $S P E$ & $E D$ & CL & $\triangle S S E$ & $S$ (MPS) \\
\hline CALN & 10 & & & WS & $<=$ \\
\hline 1 & I & & $5<$ & WS & $<=1.8$ \\
\hline 2 & $\square$ & 1 & $.8<$ & WS & $c=3.3$ \\
\hline 3 & प & 3 & $.3<$ & WS & $<=5.4$ \\
\hline 4 & هד & 5 & $\Delta<$ & WS & $<=8.5$ \\
\hline 5 & प1D & 8 & $5<$ & WS & $<=10.8$ \\
\hline 6 & דلس & 10 & $8<$ & WS & \\
\hline
\end{tabular}

99. 9\% DATA RECOVERED OF WHICH $45.9 \%$ IS REPOATED ABOVE 


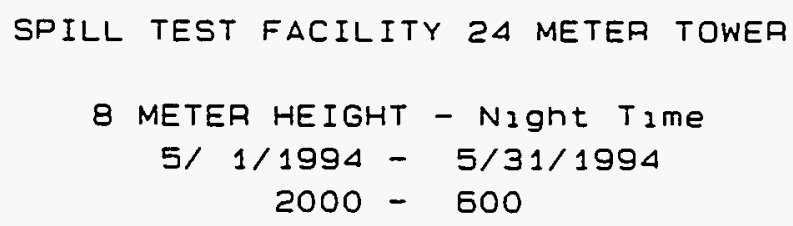

$N$
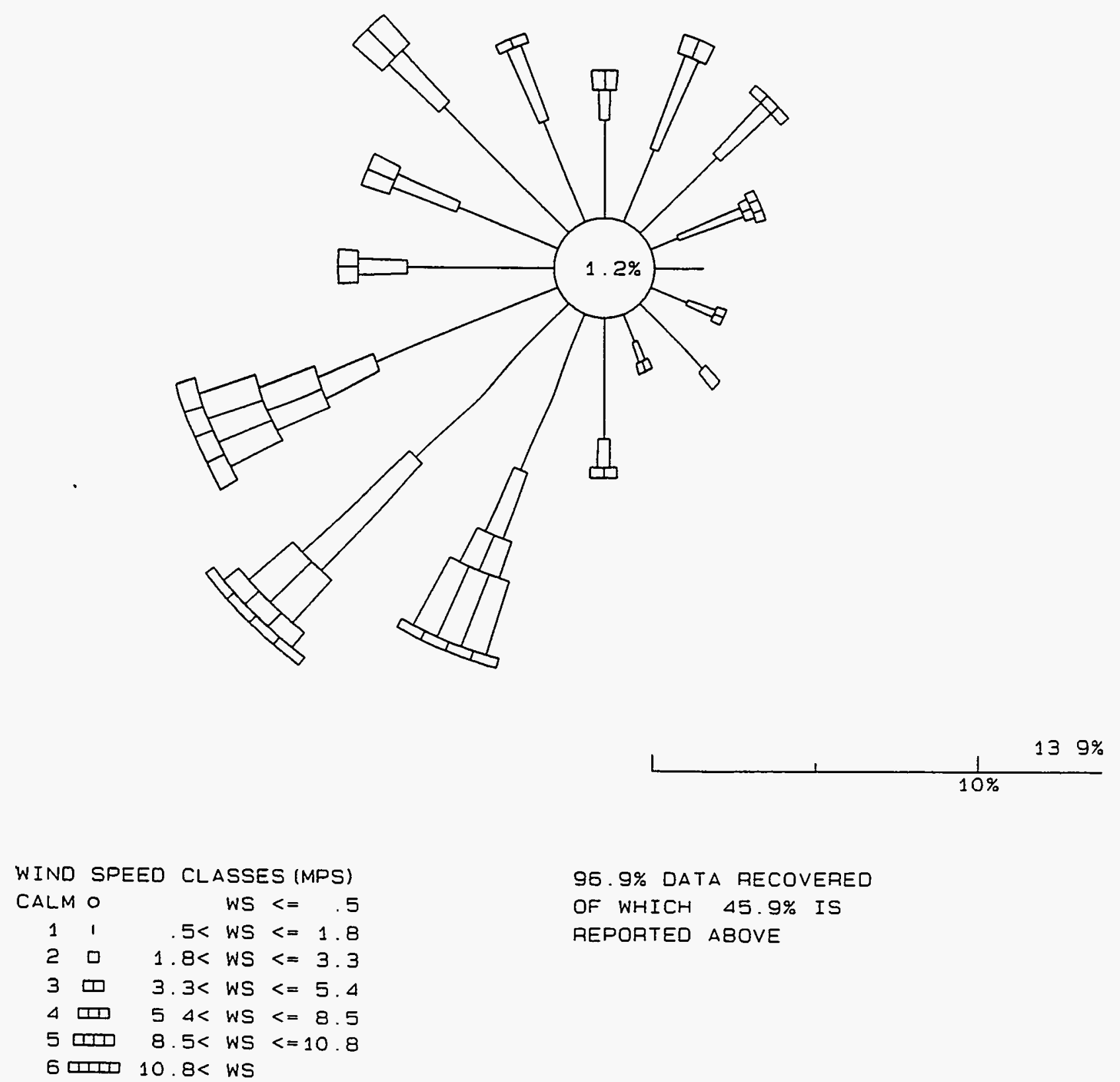

95.9\% DATA RECOVERED

OF WHICH $45.9 \%$ IS

REPORTED ABOVE 


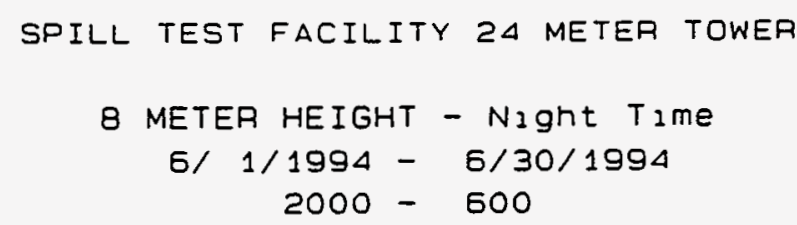

N
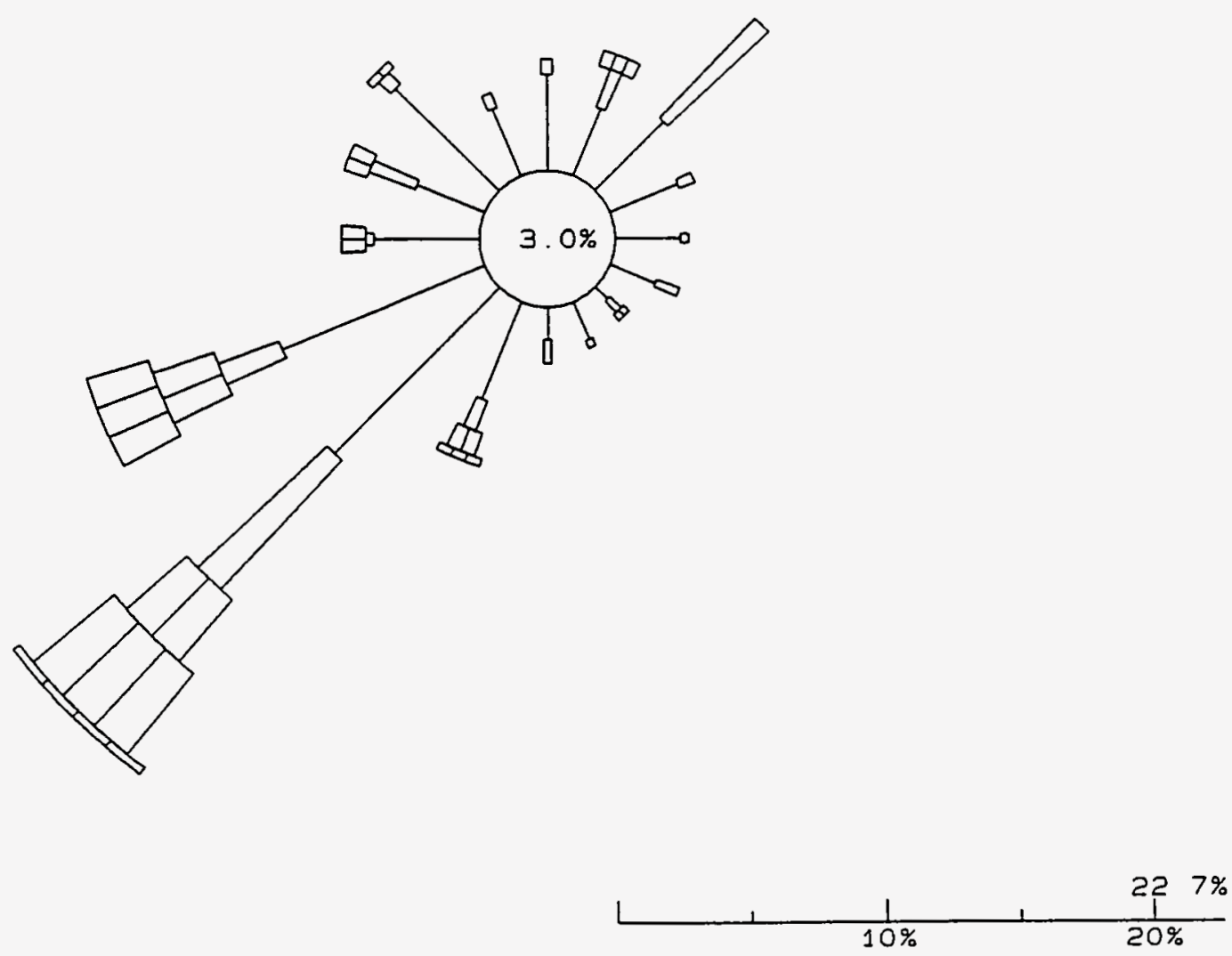

100.0\% DATA RECOVERED

OF WHICH $\triangle 5.8 \%$ IS

REPORTED ABOVE 

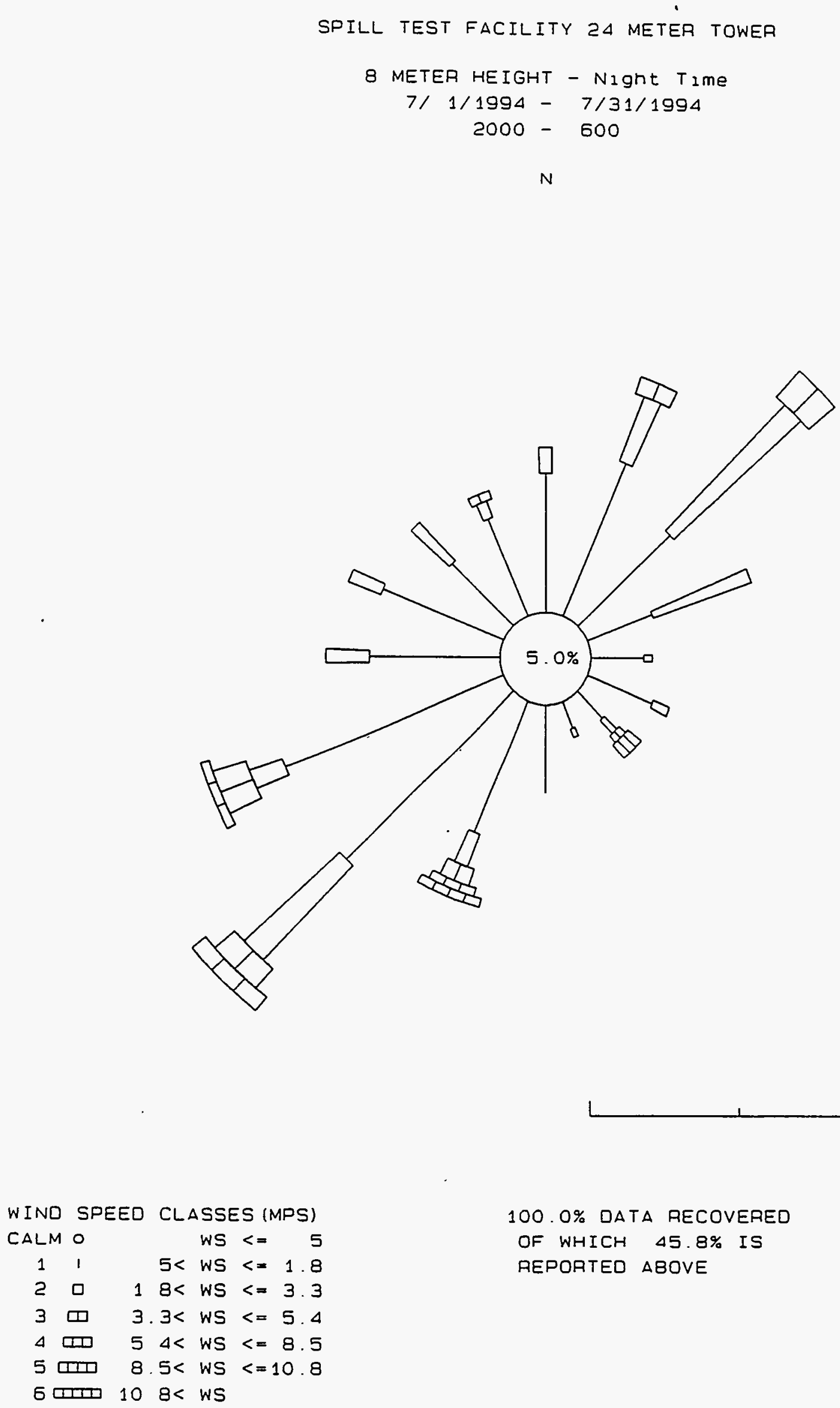

100.0\% DATA RECOVERED

OF WHICH $45.8 \%$ IS

REPORTED $\triangle B O V E$ 


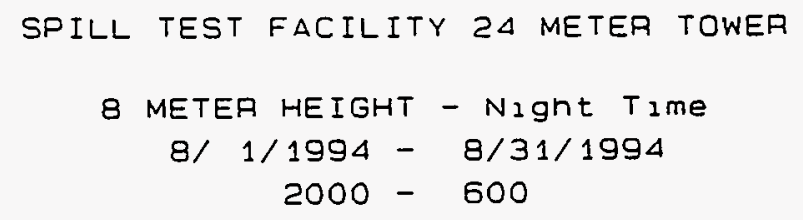

N
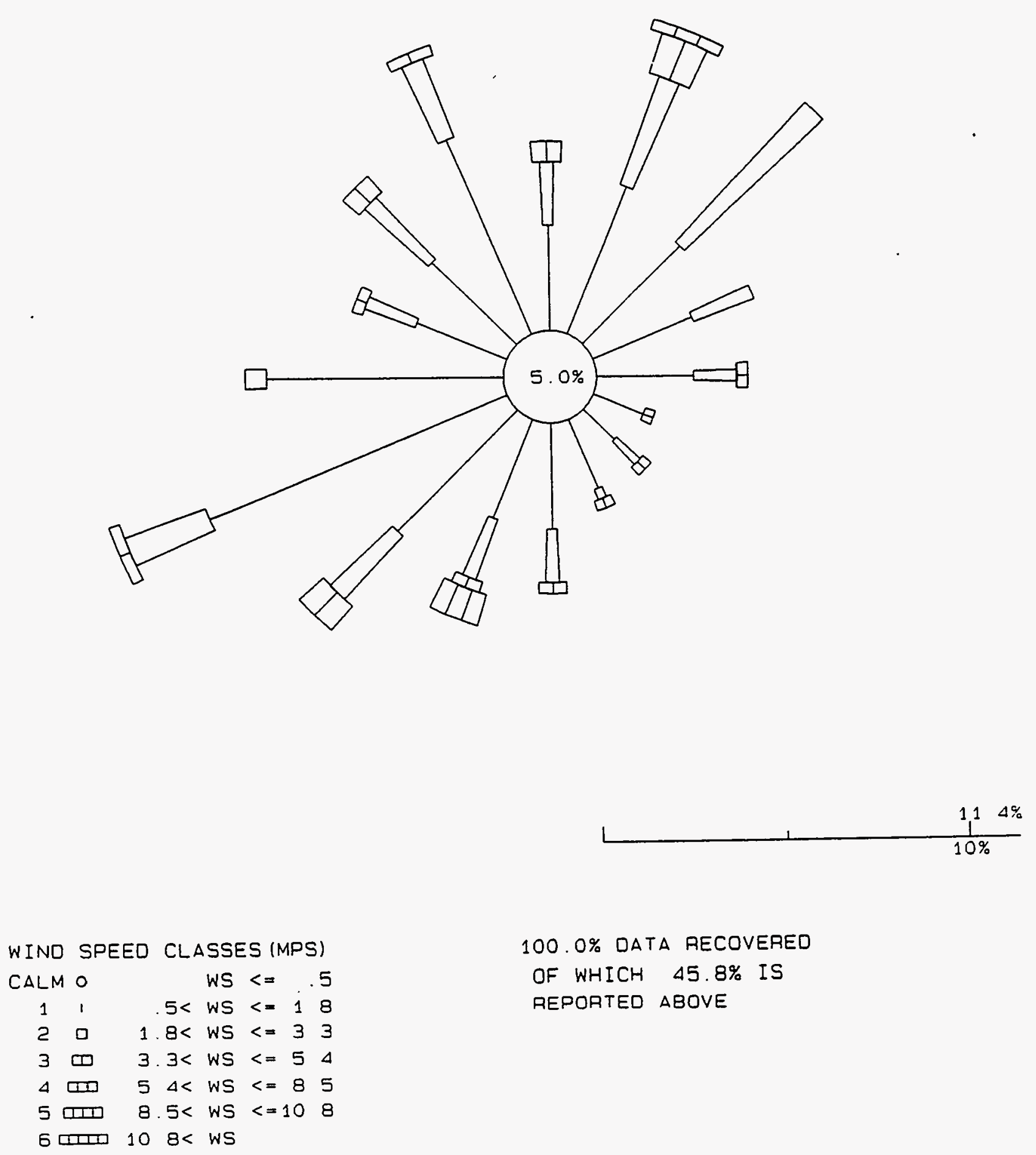

100.0\% DATA RECOVERED

OF WHICH $45.8 \%$ IS

REPORTED ABOVE 


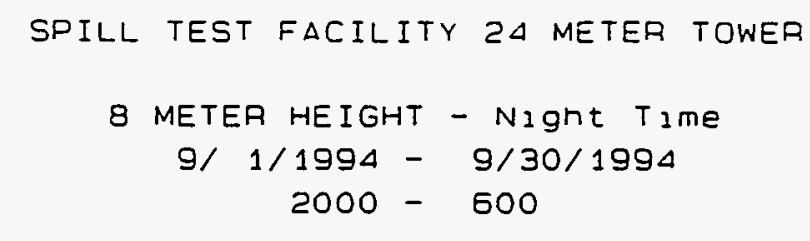

$N$

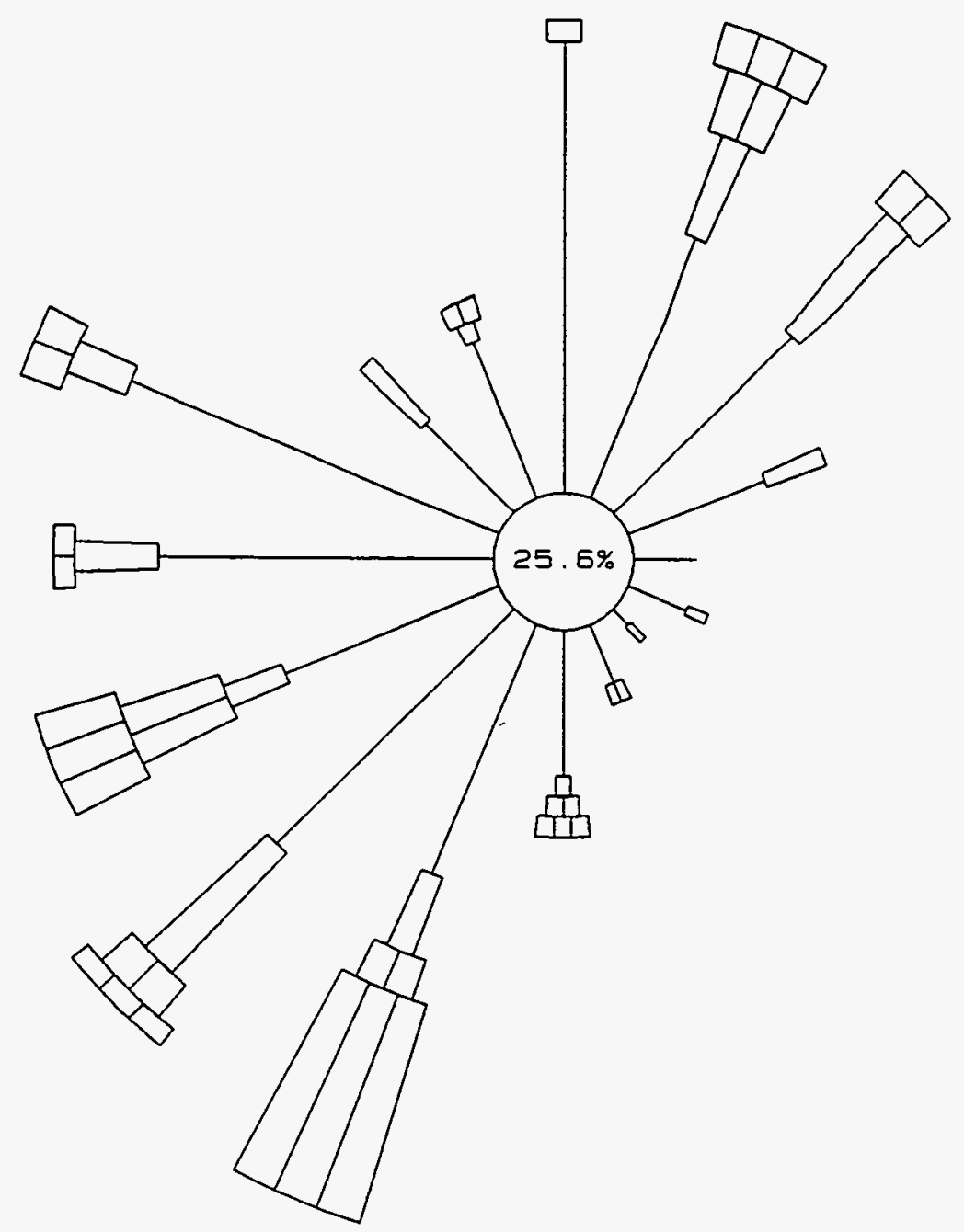

$99.2 \%$ DATA RECOVERED

OF WHICH $45.9 \%$ IS

REPORTED ABOVE 


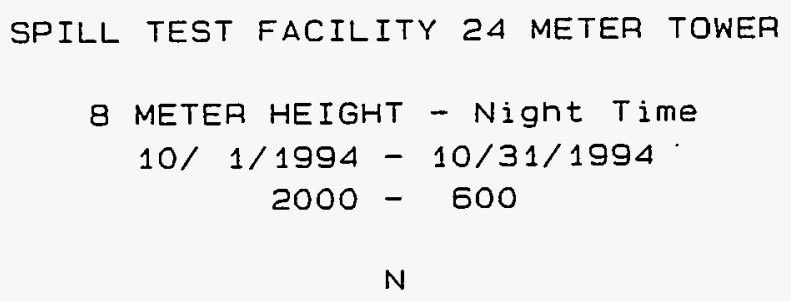

$N$
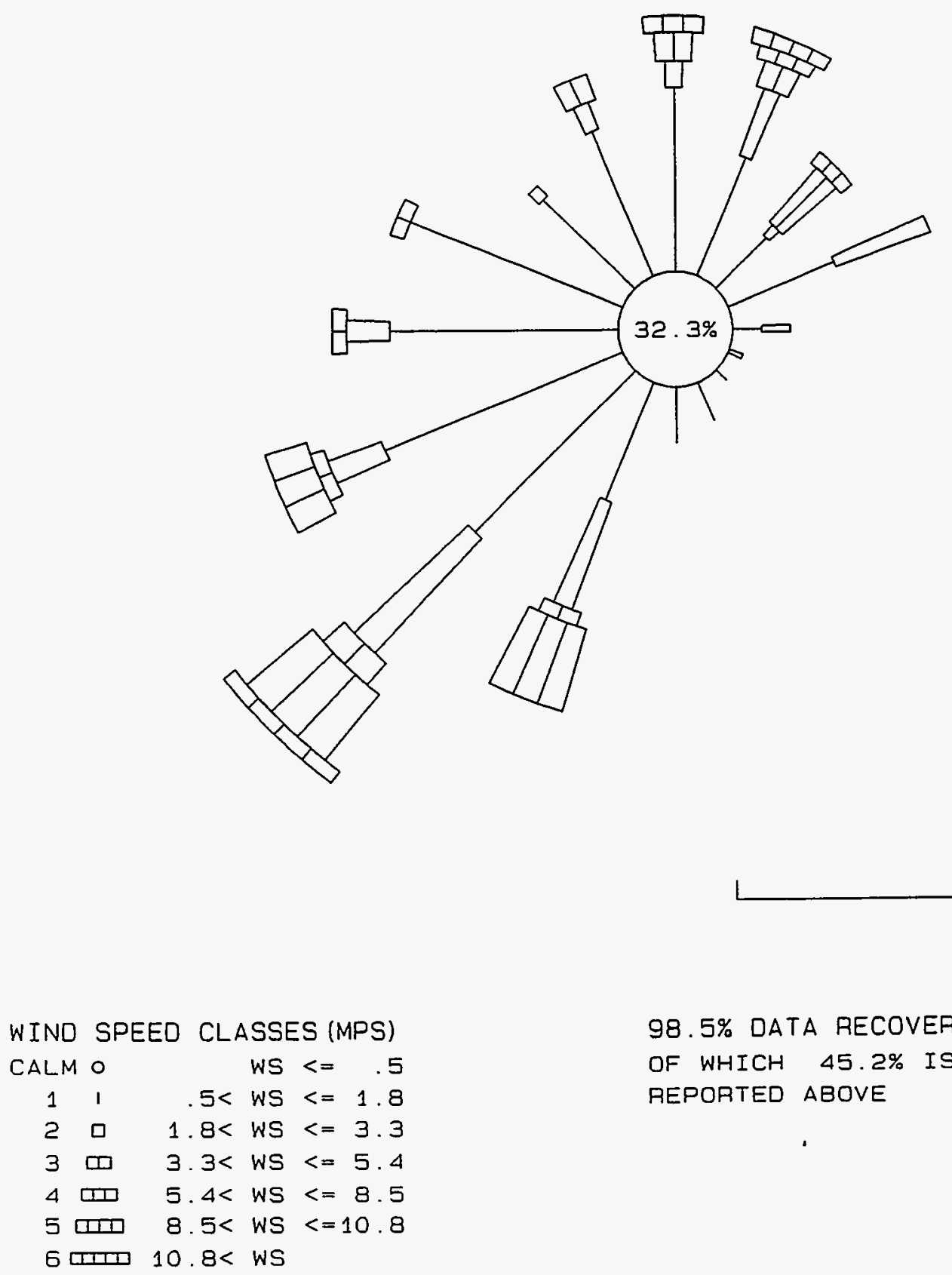
SPILL TEST FACILITY 24 METER TOWER

8 METER HEIGHT - Night Time

11/1/1994 - 11/30/1994

$2000-600$

N
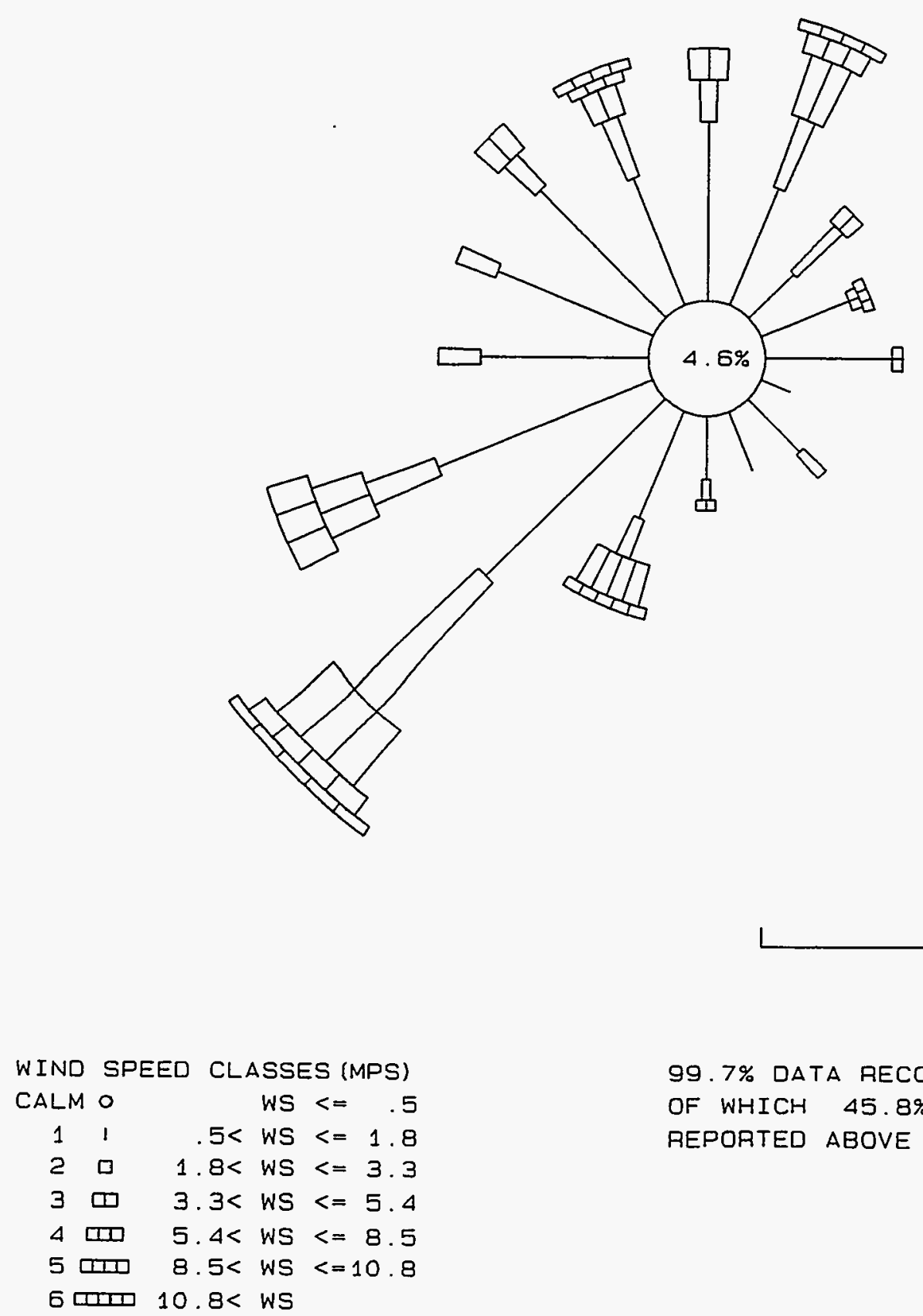

99.7\% DATA RECOVERED

OF WHICH $45.8 \%$ IS

REPORTED ABOVE 


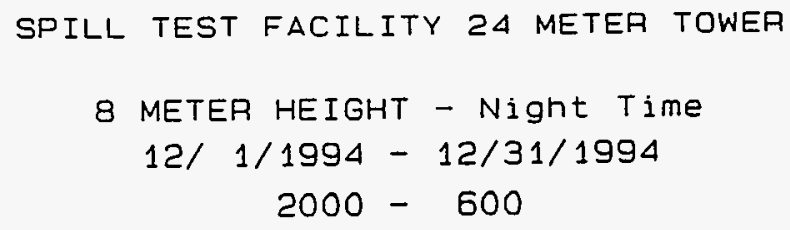

$N$

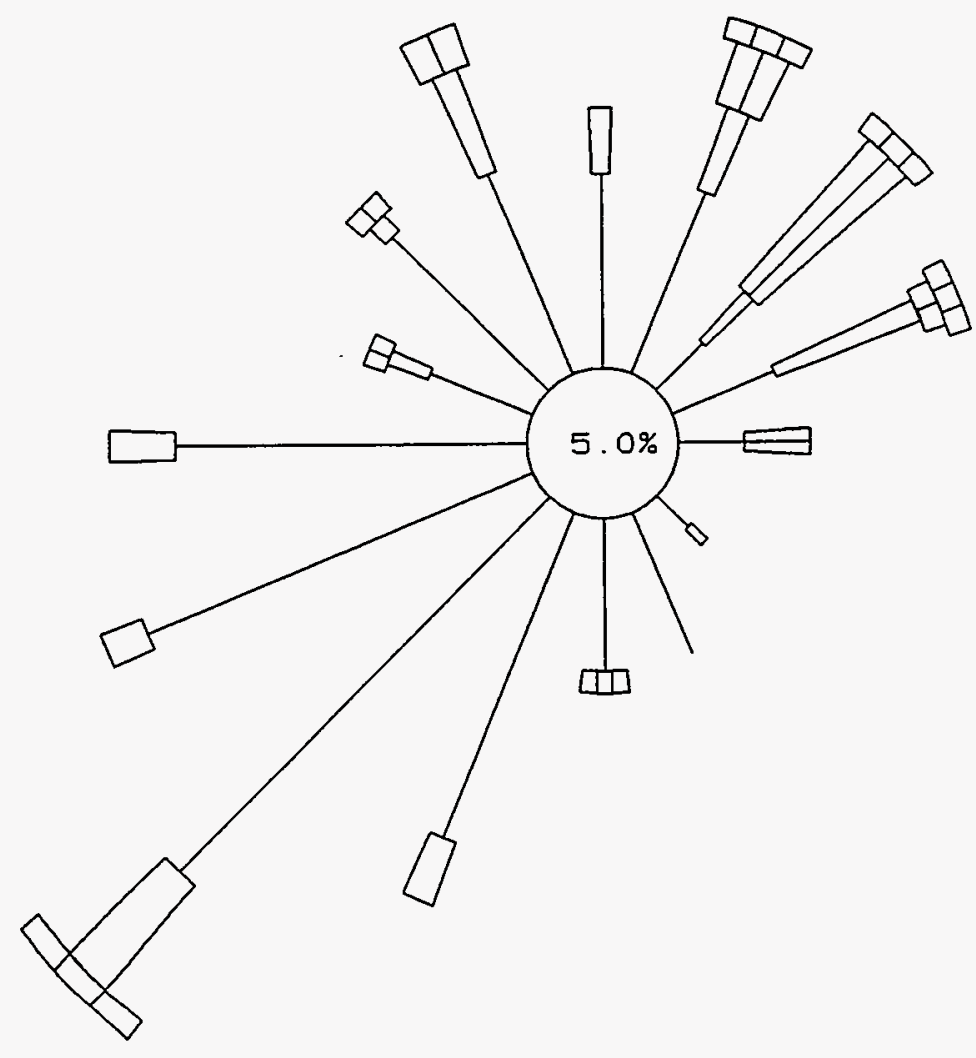

WIND SPEED CLASSES (MPS)

CALM $0 \quad$ WS $<=.5$

$11 \quad .5<$ WS $<=1.8$

$2 \square \quad 1.8<$ WS $<=3.3$

3 का $3.3<$ WS $<=5.4$

4 पा $5.4<W S<=8.5$

5 पात $8.5<$ WS $<=10.8$

6 पामा $10.8<$ WS
65. 1\% DATA RECOVERED

OF WHICH $45.7 \%$ IS REPORTED ABOVE 
SPILL TEST FACILITY 24 METER TOWER

STABILITY CLASS A

8 METER HEIGHT - Total Hours

$1 / 1 / 1994-1 / 31 / 1994$

$0-2300$

$N$
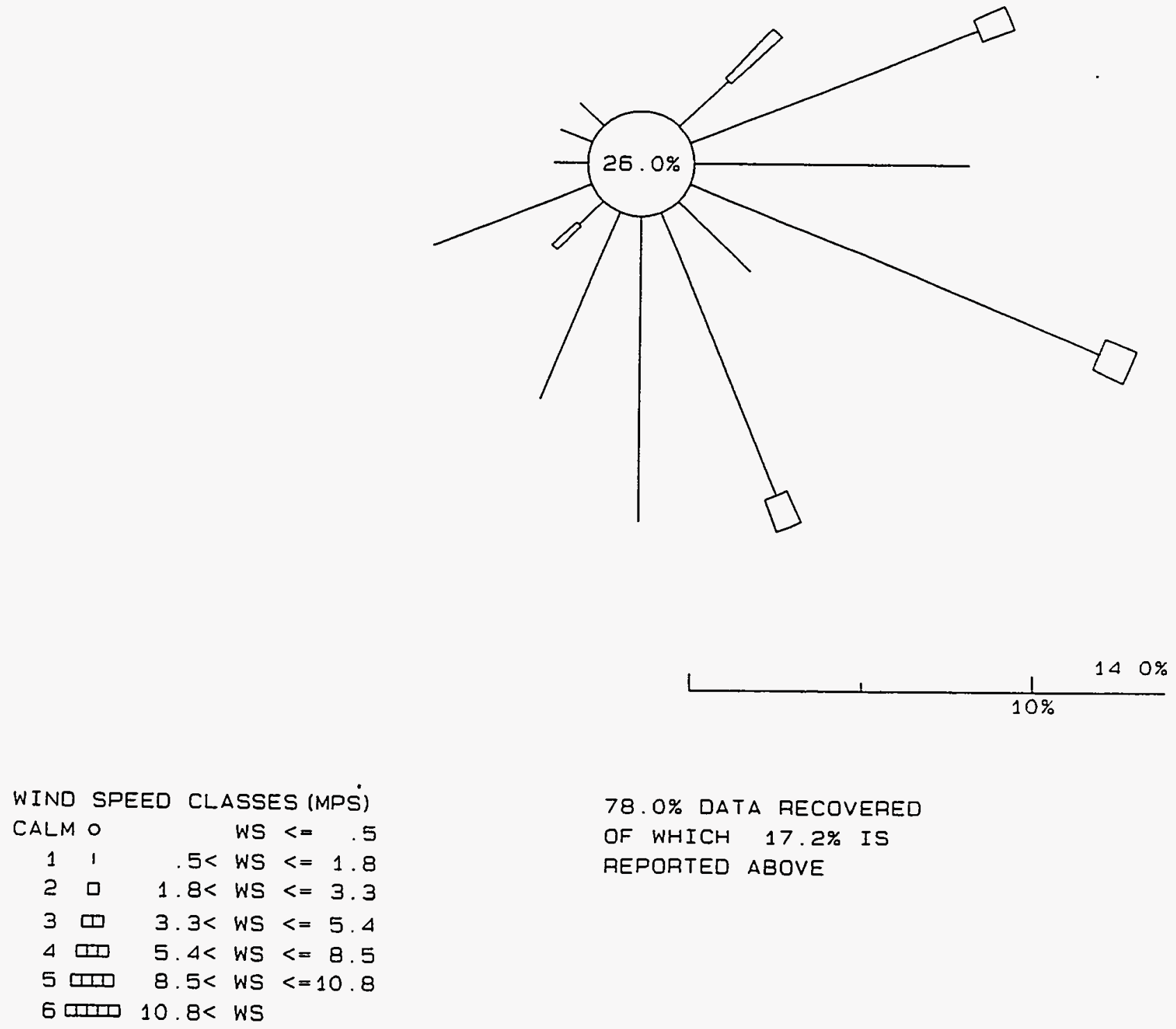

$78.0 \%$ DATA RECOVERED

OF WHICH $17.2 \%$ IS

REPORTED ABOVE 


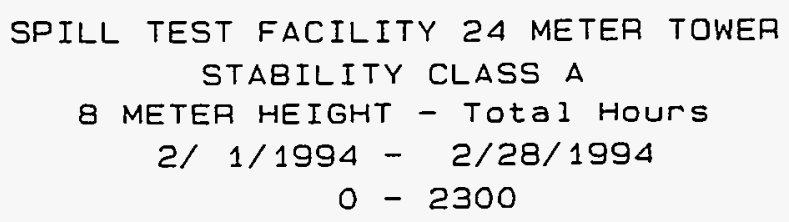

N
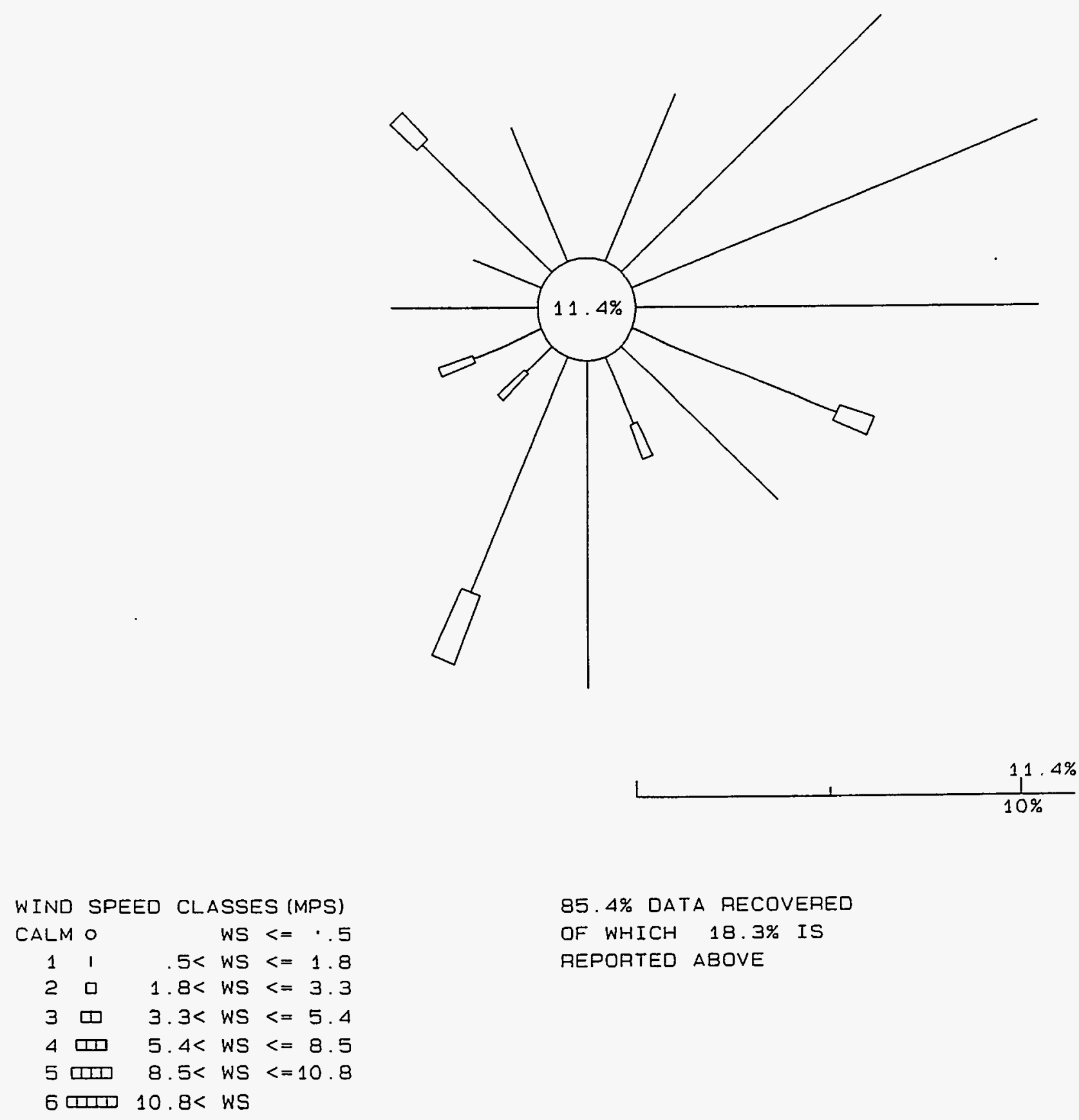

85. $4 \%$ DATA RECOVERED

OF WHICH $18.3 \%$ IS

REPORTED ABOVE 


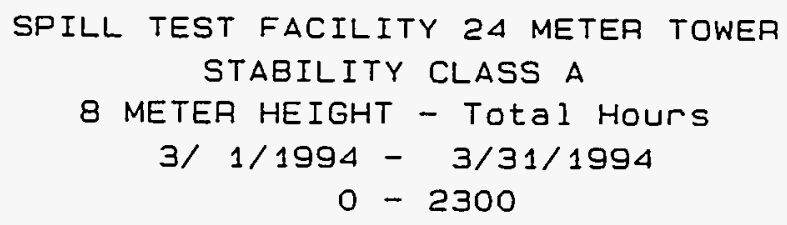

$N$
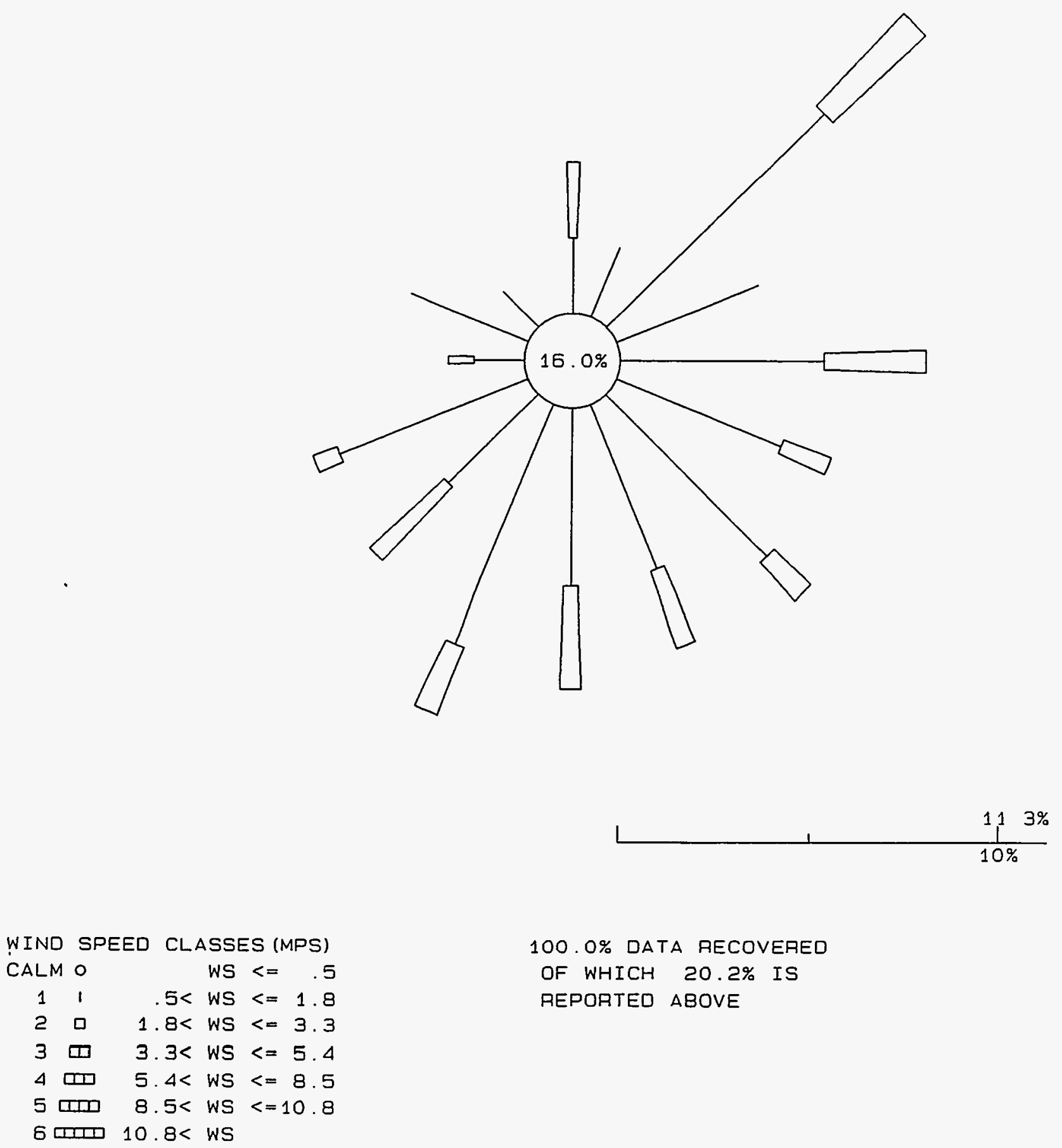


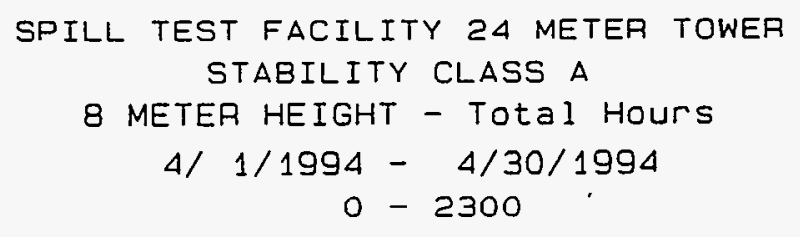

$N$
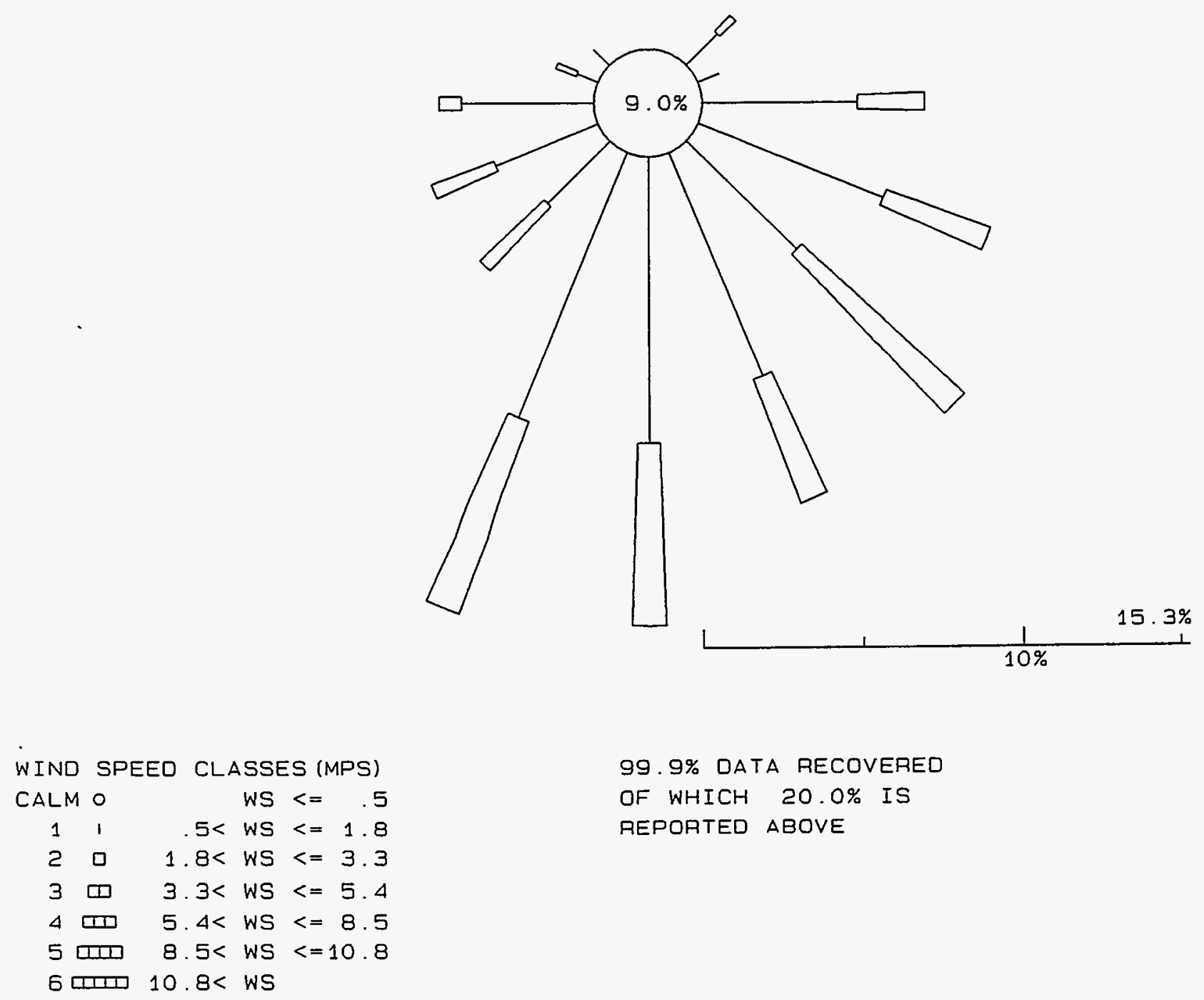

99.9\% DATA RECOVERED

OF WHICH $20.0 \%$ IS

REPOATED ABOVE 


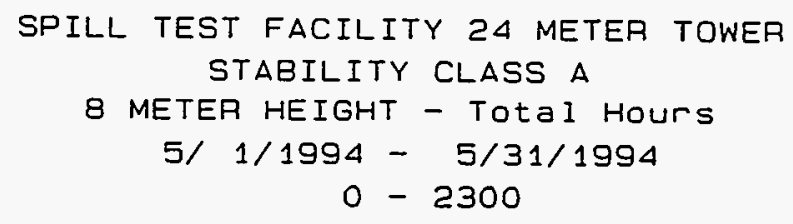

$N$

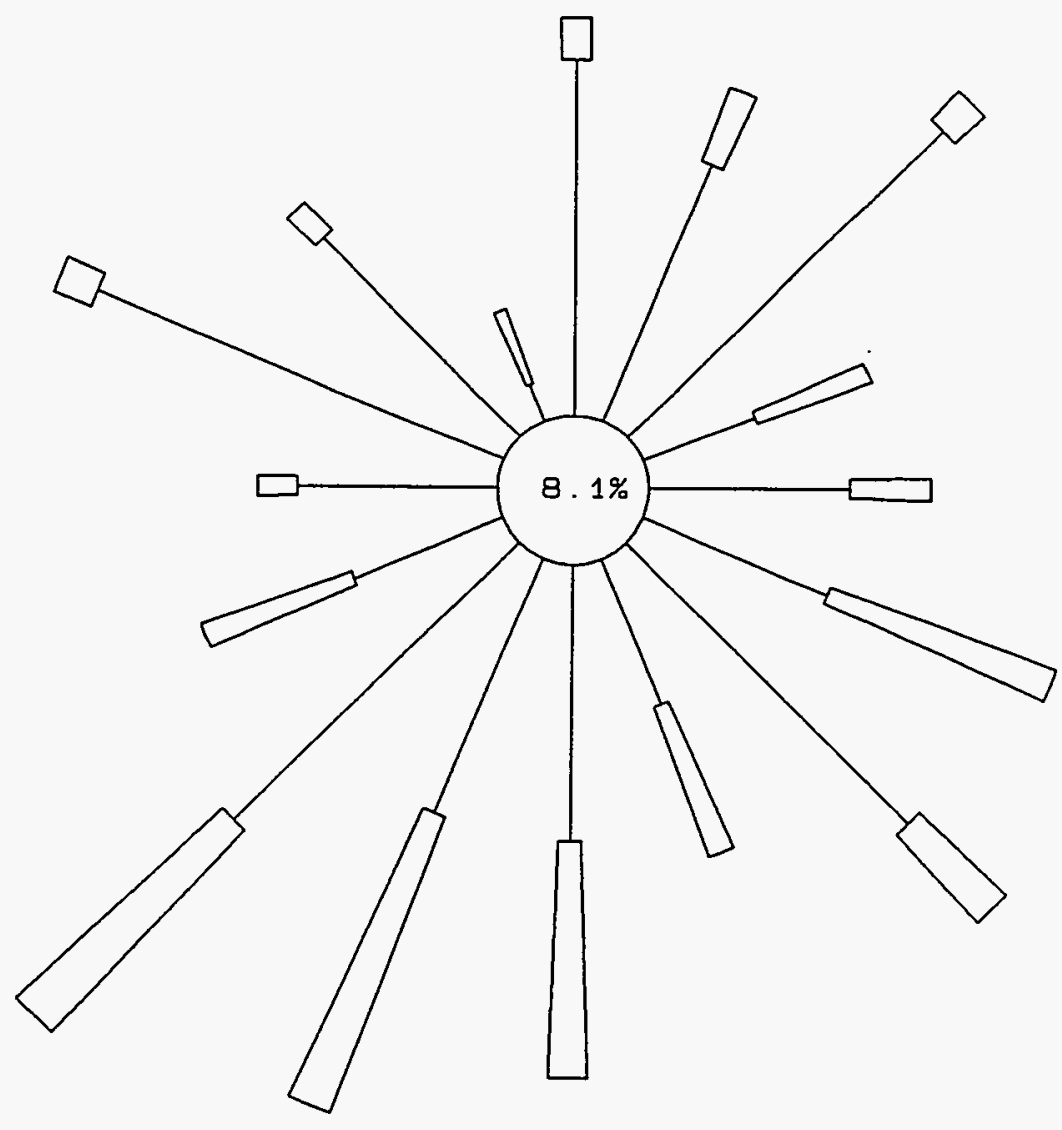

$9.9 \%$

\begin{tabular}{|c|c|c|c|c|c|}
\hline WINC & SPE & ED & $\mathrm{CL}$ & ASSE & ES (MPS) \\
\hline CALN & 40 & & & WS & $<=$ \\
\hline 1 & 1 & & $5<$ & WS & $<=1.8$ \\
\hline 2 & $\square$ & 1 & $.8<$ & WS & $<=3.3$ \\
\hline 3 & שם & 3 & $3<$ & WS & $<=5.4$ \\
\hline 4 & ס्प & 5 & $.4<$ & WS & $<=8.5$ \\
\hline 5 & טחד & 8 & $.5<$ & WS & $<=10.8$ \\
\hline 60 & ס11प & 10 & $.8<$ & ws & \\
\hline
\end{tabular}

96.9\% DATA RECOVERED

OF WHICH 23.9\% IS REPORTED ABOVE 


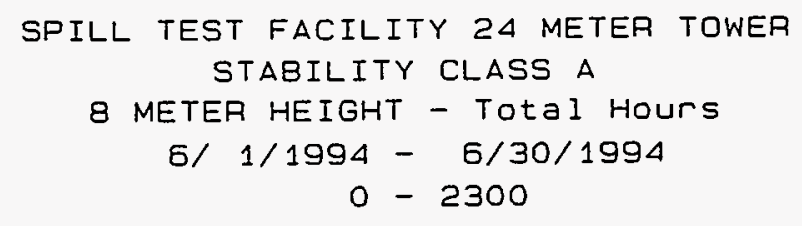

$N$
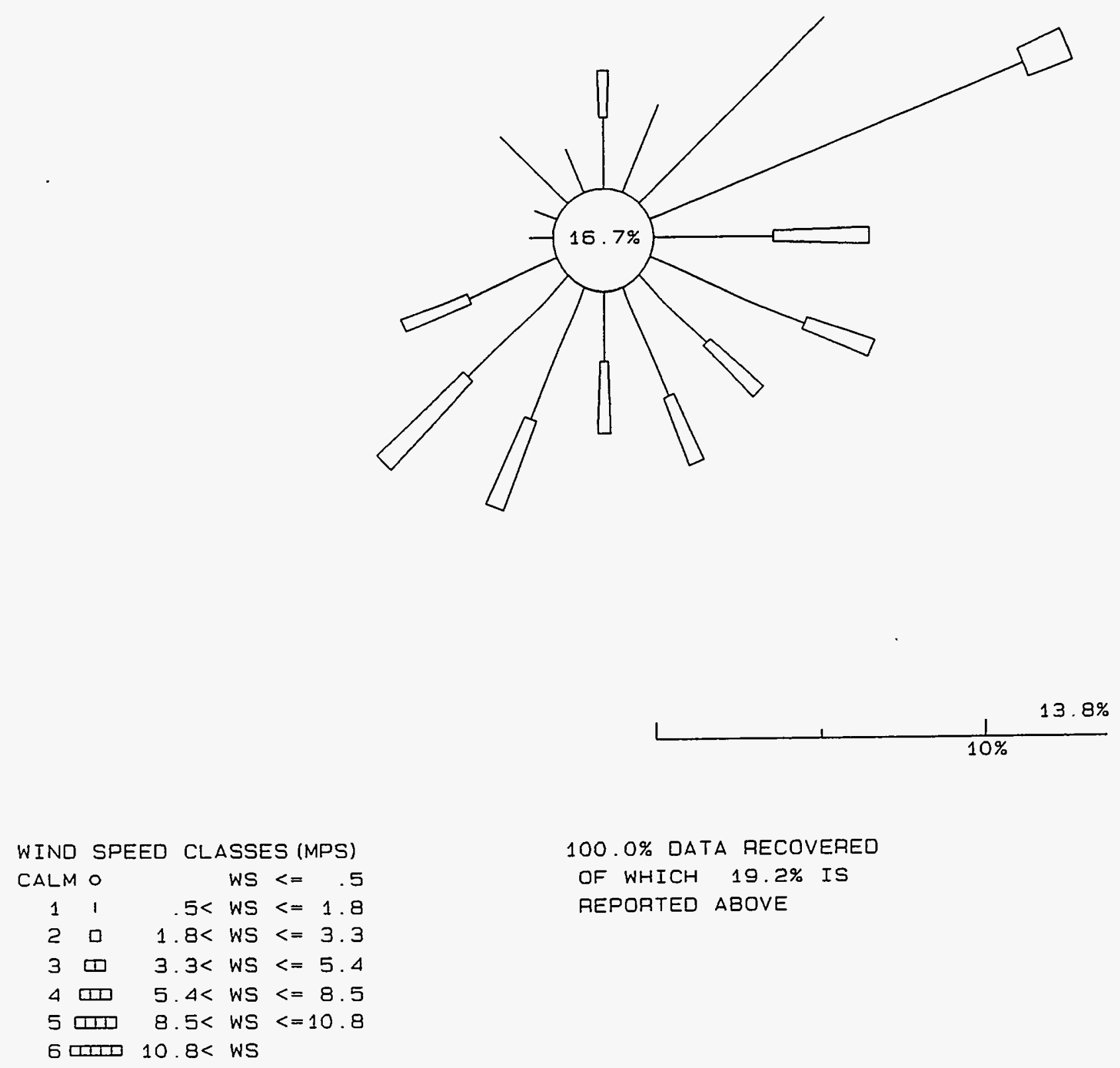

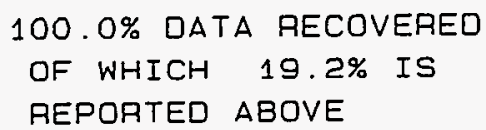

REPORTED ABOVE 
SPILL TEST FACILITY 24 METER TOWER

STABILITY CLASS A

8 METER HEIGHT - Total Hours

7/ $1 / 1994$ - 7/31/1994

$0-2300$

$N$

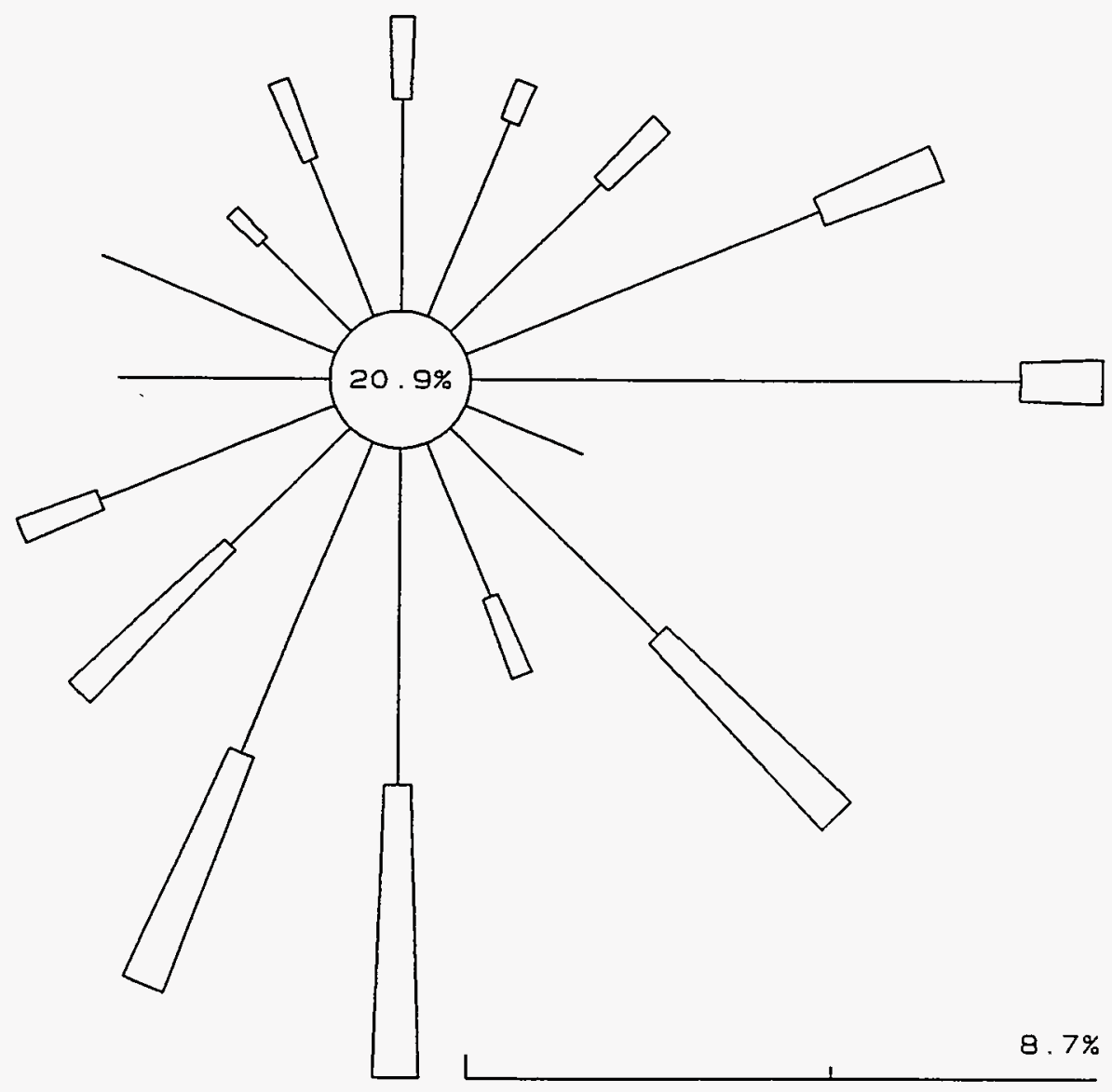

WIND SPEED CLASSES (MPS)

CALM $0 \quad$ WS $<=$

$11 \quad .5<W S<=1.8$

2 口 $1.8<$ WS $<=3.3$

3 ㅁ $3.3<W S<5.4$

$\triangle$ पा $5.4<W S<=8.5$

5 पाI $8.5<$ WS $<=10.8$

6 10.8 6 WS
100.0\% DATA RECOVERED

OF WHICH 23.1\% IS

REPORTED ABOVE 


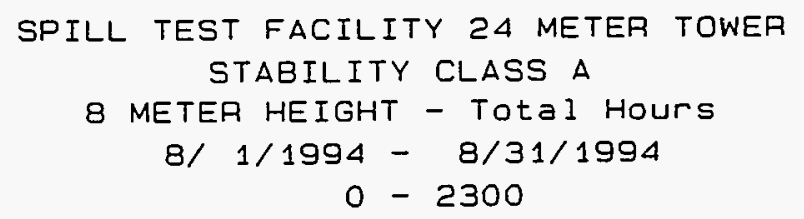

$N$

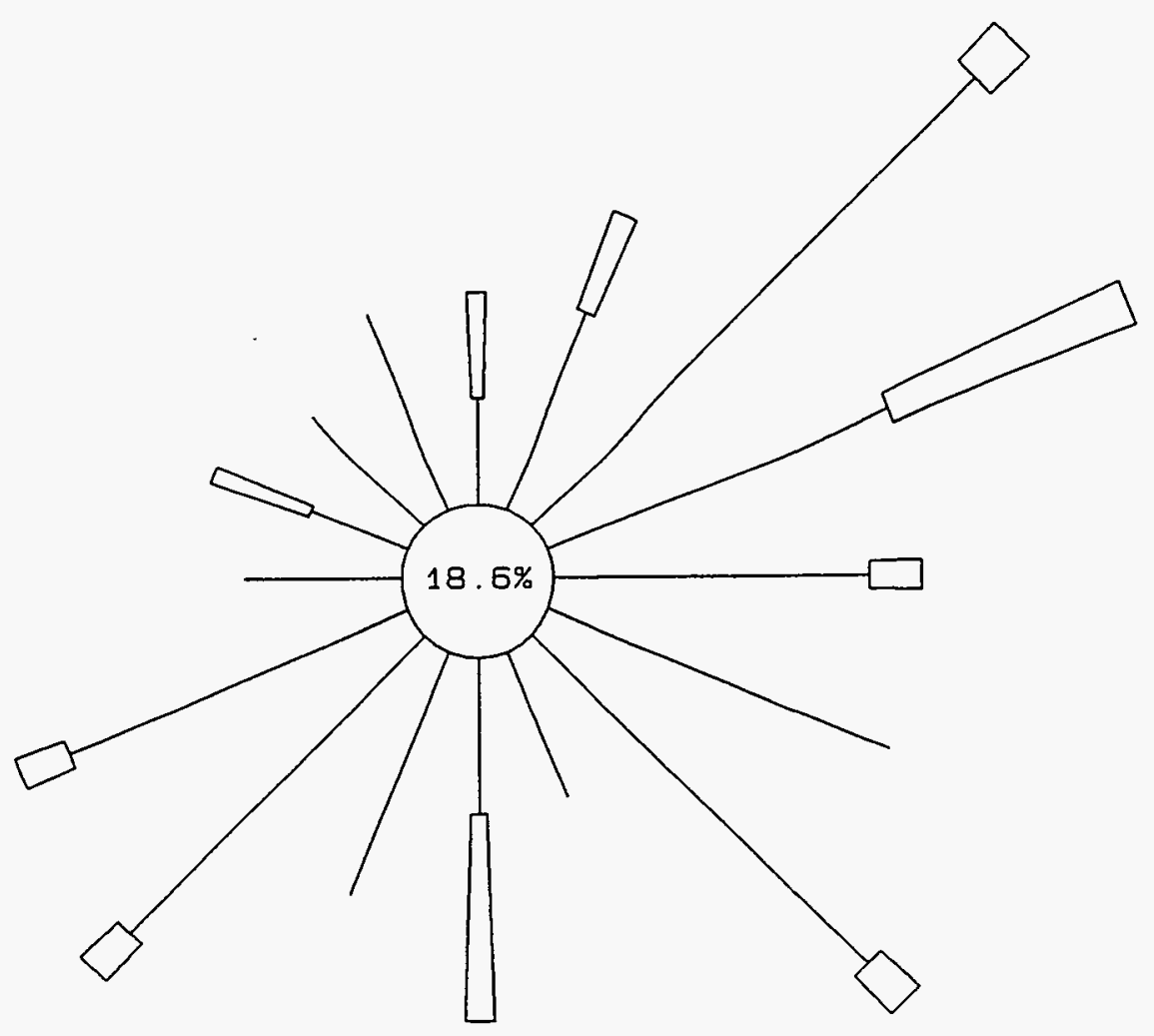

\begin{tabular}{|c|c|c|c|c|}
\hline NIND & SPE & $E D \quad C L$ & SSE & $S$ IMPS \\
\hline CALM & 10 & & WS & $<=$ \\
\hline 1 & 1 & $5<$ & WS & $<=1$. \\
\hline 2 & D & $1.8<$ & WS & $<=3$. \\
\hline 3 & $\square$ & $3.3<$ & WS & $<=5$. \\
\hline 4 & س山 & $5.4<$ & WS & $<=8$. \\
\hline 5 & שI" & $8.5<$ & WS & $<=10$. \\
\hline & $\square$ & 108 & ws & \\
\hline
\end{tabular}

100.0\% DATA RECOVERED

OF WHICH $17.3 \%$ IS

REPORTED ABOVE 


\section{SPILL TEST FACILITY 24 METER TOWER \\ STABILITY CLASS A \\ 8 METER HEIGHT - Total Hours \\ 9/ $1 / 1994-9 / 30 / 1994$ \\ $0-2300$}

$N$

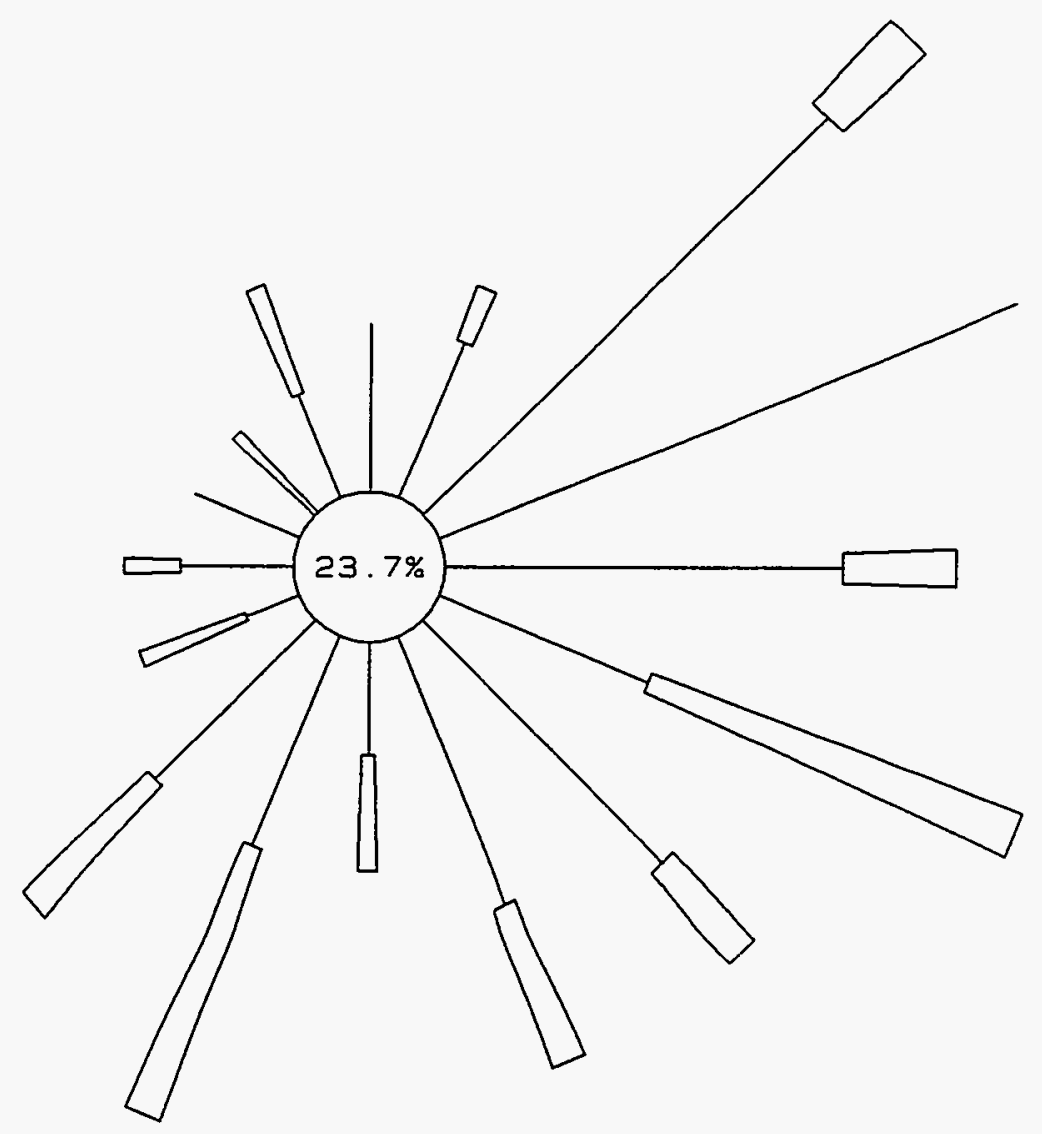

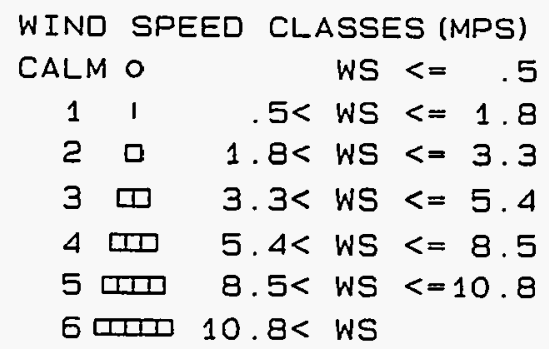

99.2\% DATA RECOVERED

OF WHICH 18.3\% IS

REPORTED ABOVE

$9.2 \%$ 


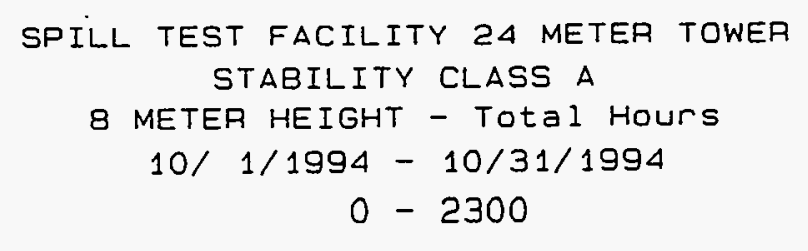

$N$

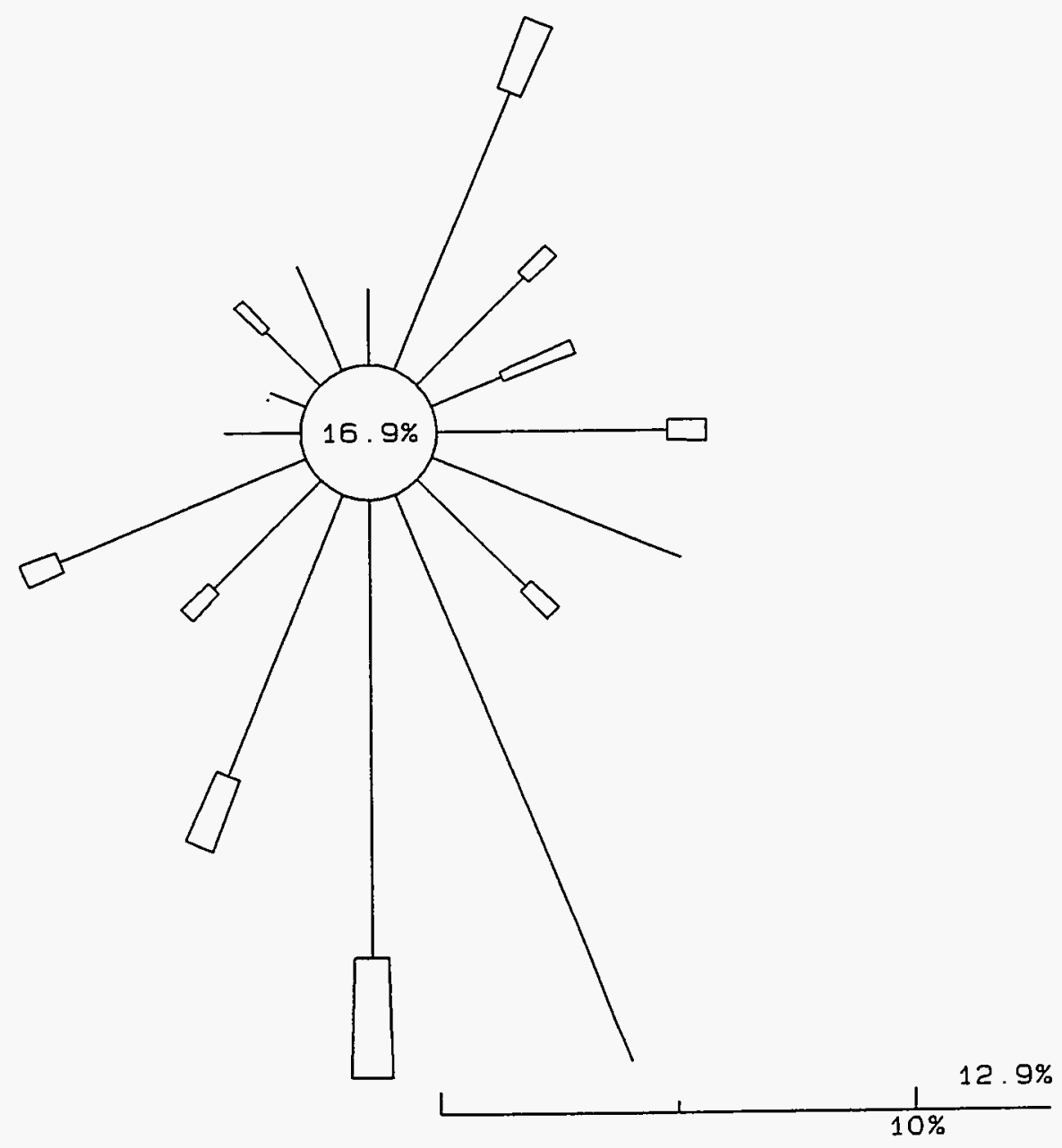

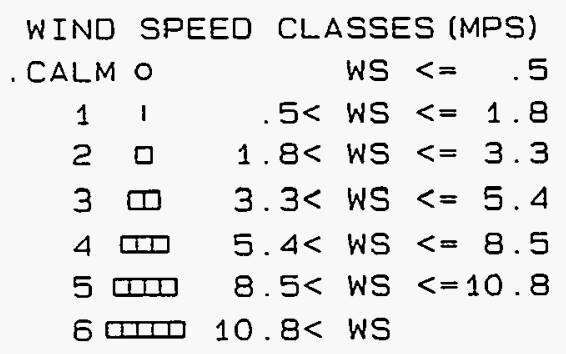

$98.5 \%$ DATA RECOVERED

OF WHICH 16.9\% IS

REPOATED ABOVE 


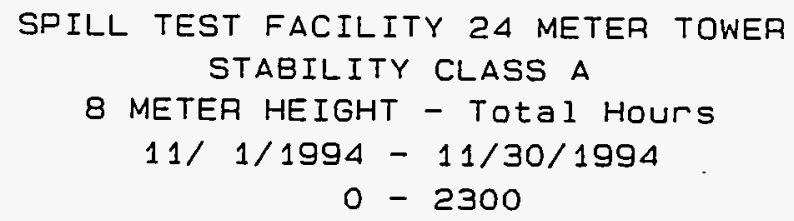

N
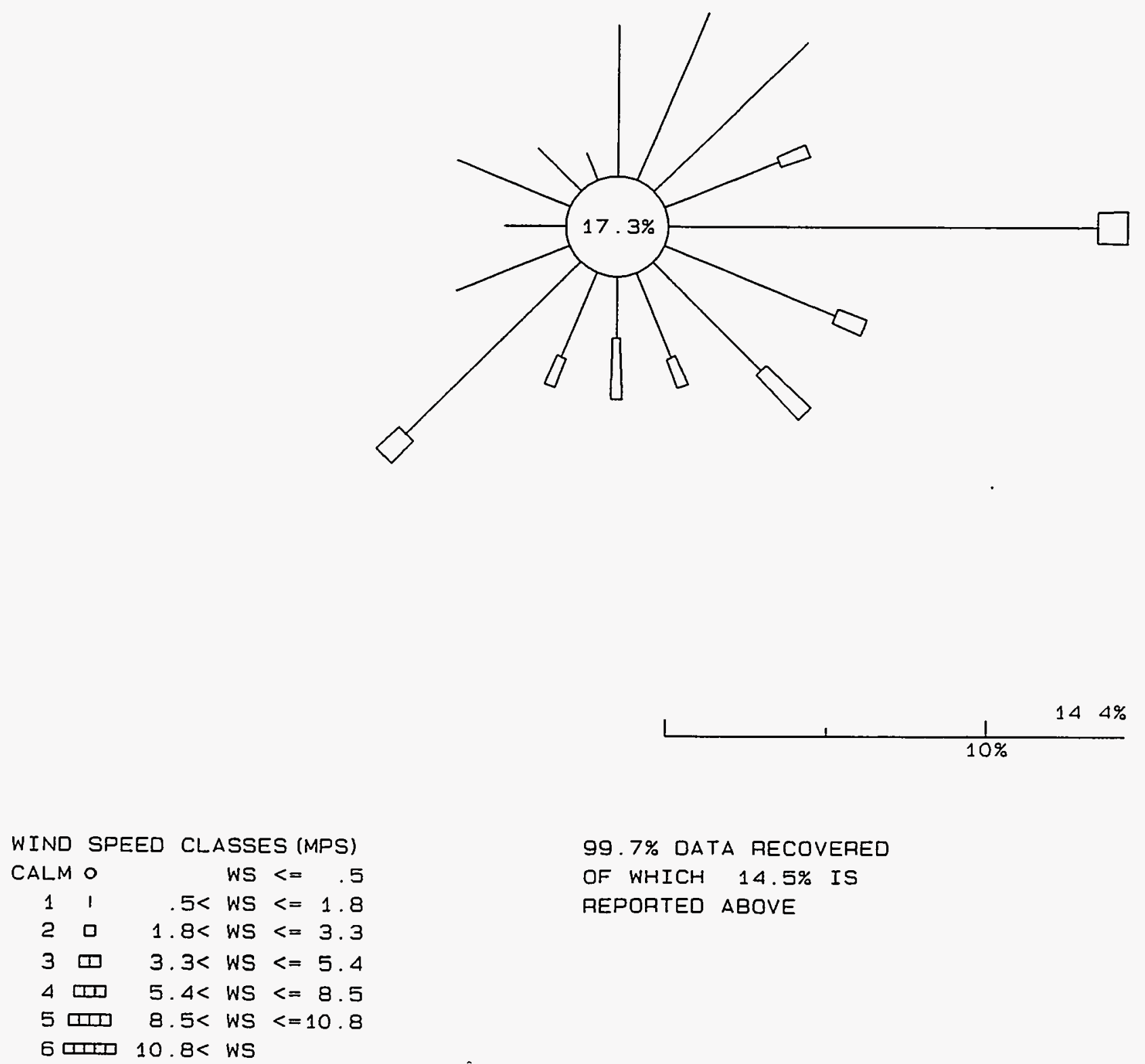
SPILL TEST FACILITY 24 METER TOWER

STABILITY CLASS A

8 METER HEIGHT - Total Hours

$12 / 1 / 1994-12 / 31 / 1994$

$0-2300$

$N$
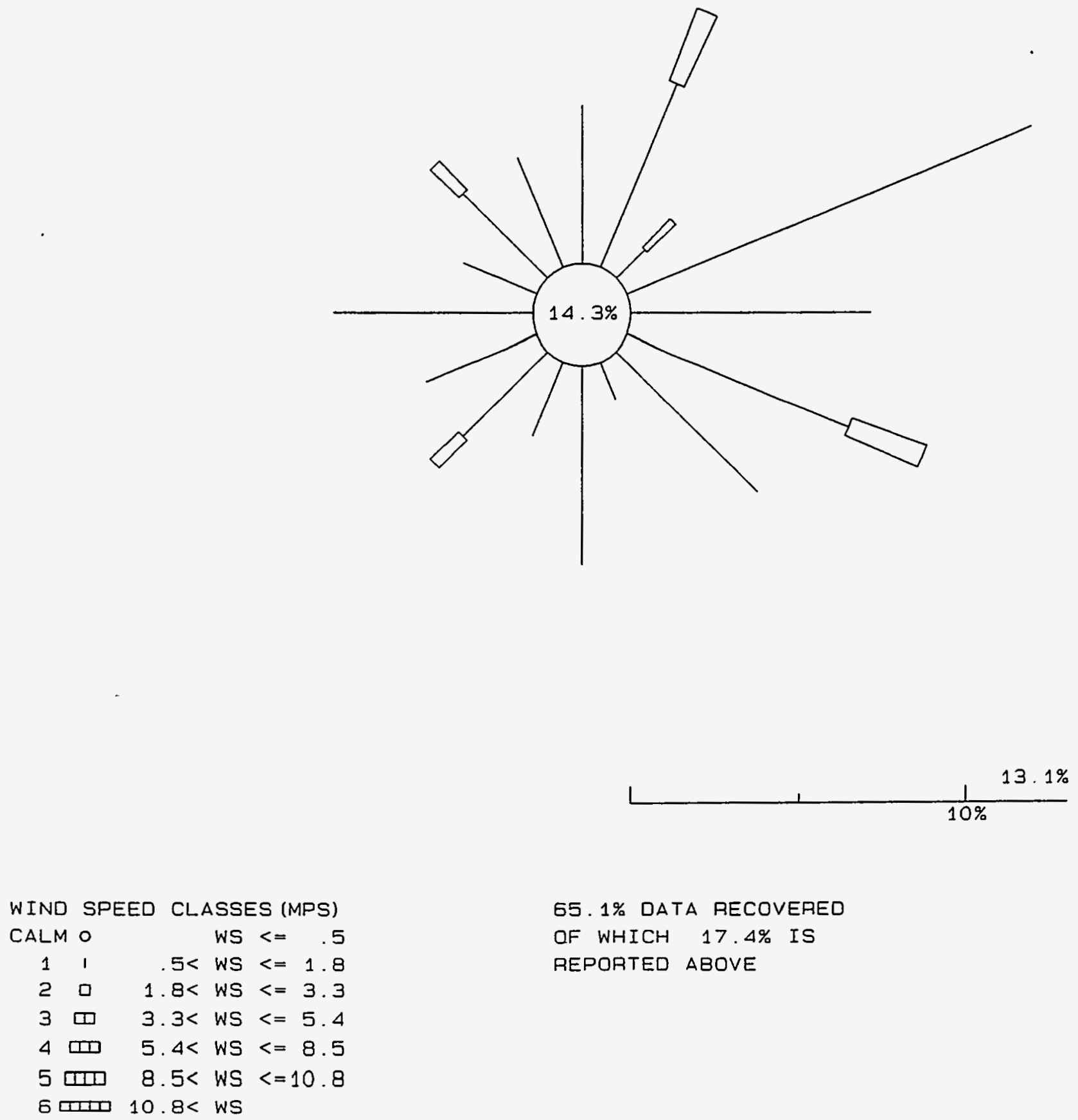

65. 1\% DATA RECOVERED

OF WHICH $17.4 \%$ IS

REPORTED ABOVE 


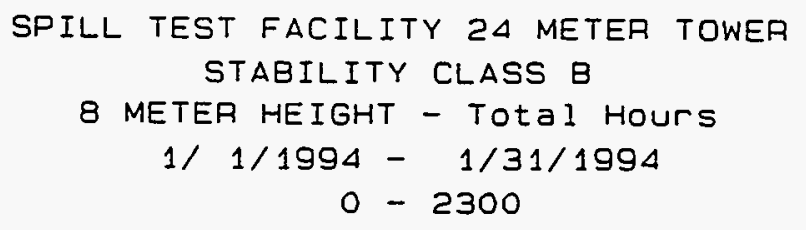

$N$

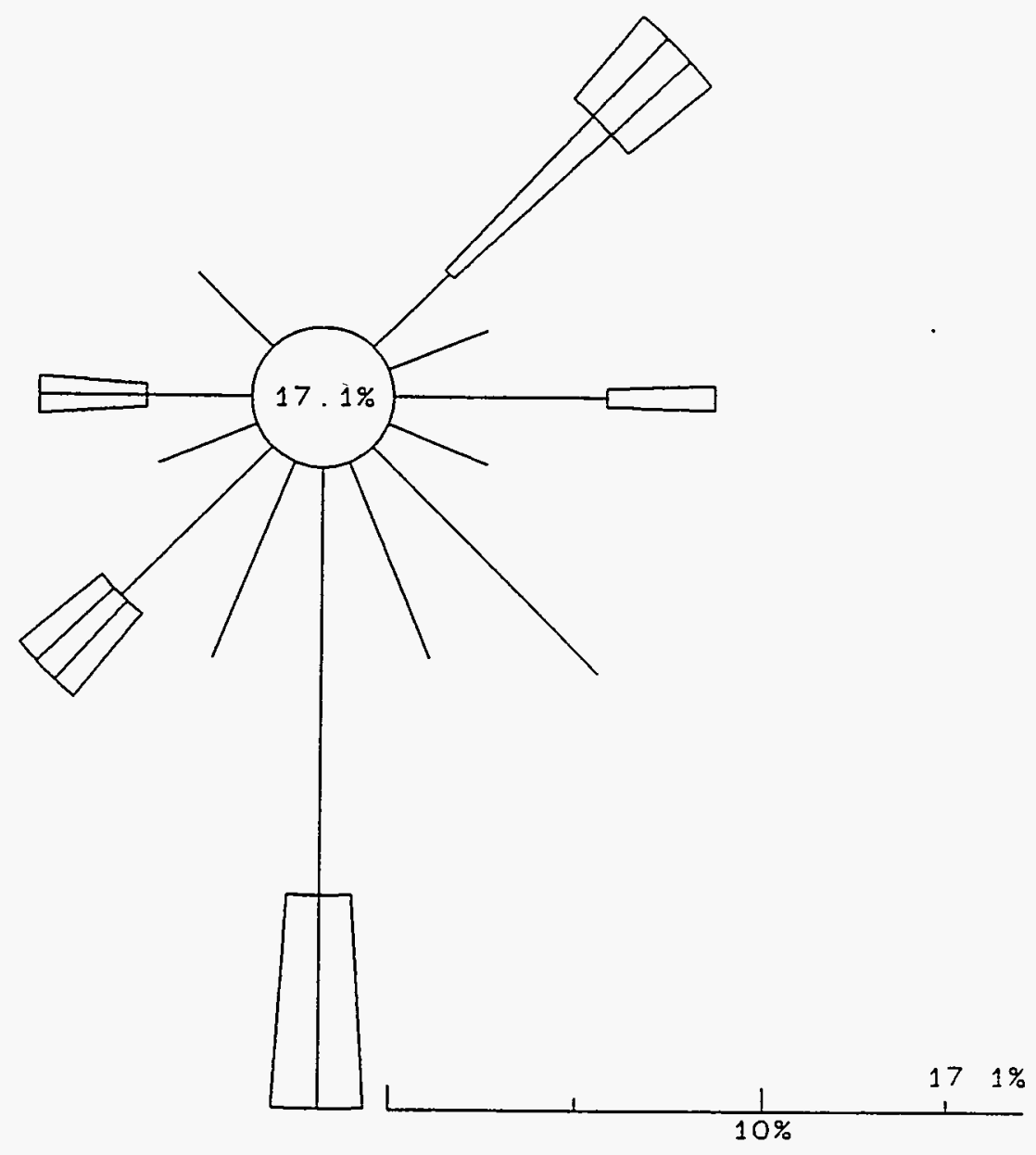

WIND SPEED CLASSES (MPS) CALM $\quad$ WS $<=.5$ $11.5<W S<=1.8$ $2 \square \quad 1.8<$ WS $<=3.3$ 3 का $3.3<$ WS $<=5.4$ 4 पा $5.4<W S<=8.5$ 5 पामा $8.5<$ WS $<=10.8$ 6 10.8< WS

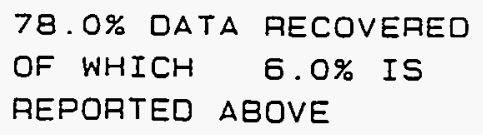




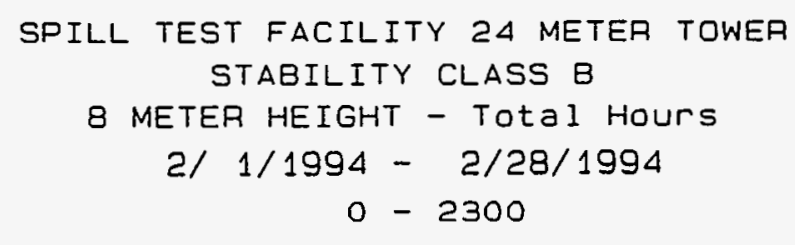

$N$
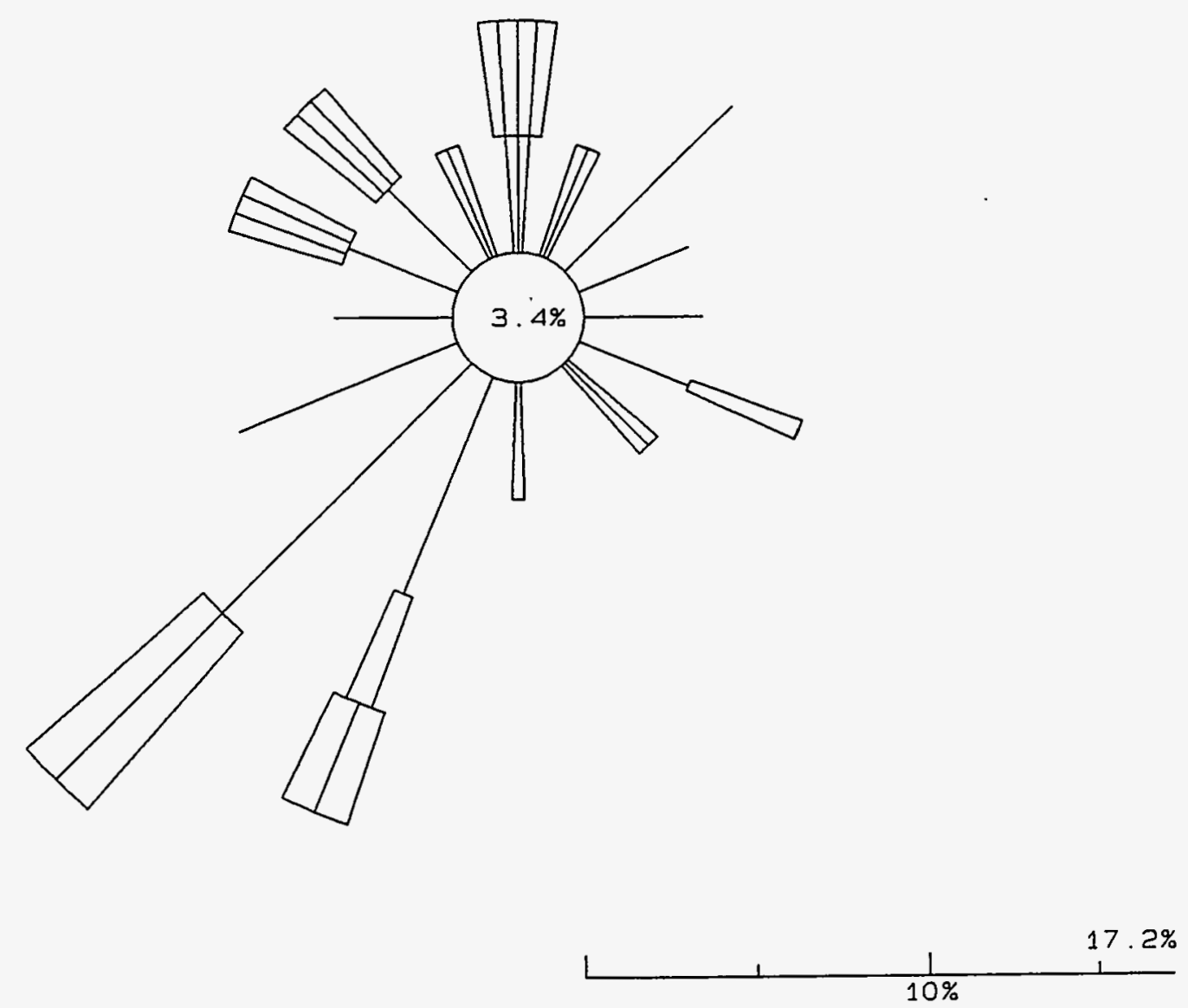

85. 4\% DATA RECOVERED

OF WHICH 5.1\% IS

REPORTED ABOVE 


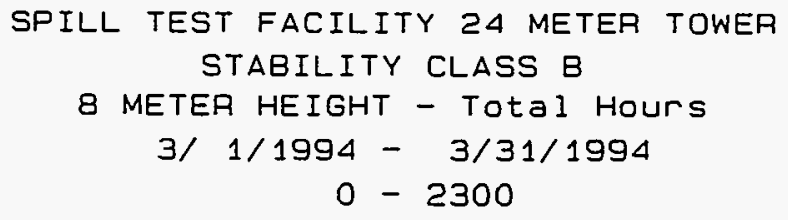

$N$

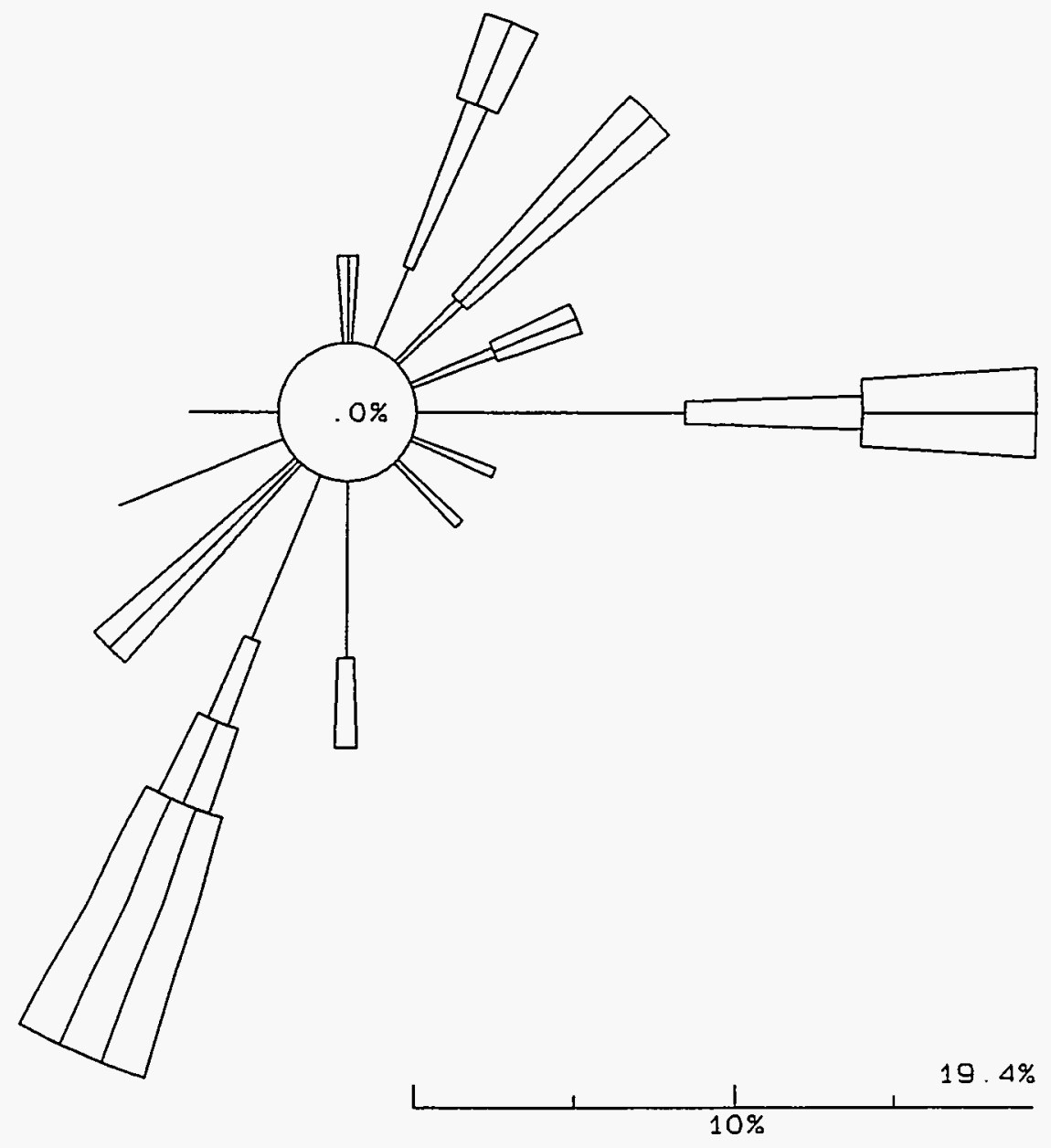

W'IND SPEED CLASSES (MPS)

CALM O WS $<=$

$11.5<$ WS $<=1.8$

2 口 $1.8<$ WS $<=3.3$

3 का $3.3<$ WS $<=5.4$

4 पा $5.4<$ WS $<=8.5$

5 पाता $8.5<W S<=10.8$

6 पामा $10.8<$ WS

100.0\% DATA RECOVERED

OF WHICH 4.8\% IS

REPOATED ABOVE 


\section{SPILL TEST FACILITY 24 METER TOWEA \\ STABILITY CLASS $B$ \\ 8 METER HEIGHT - Total Hours \\ 4/ $1 / 1994$ - 4/30/1994 \\ $0-2300$}
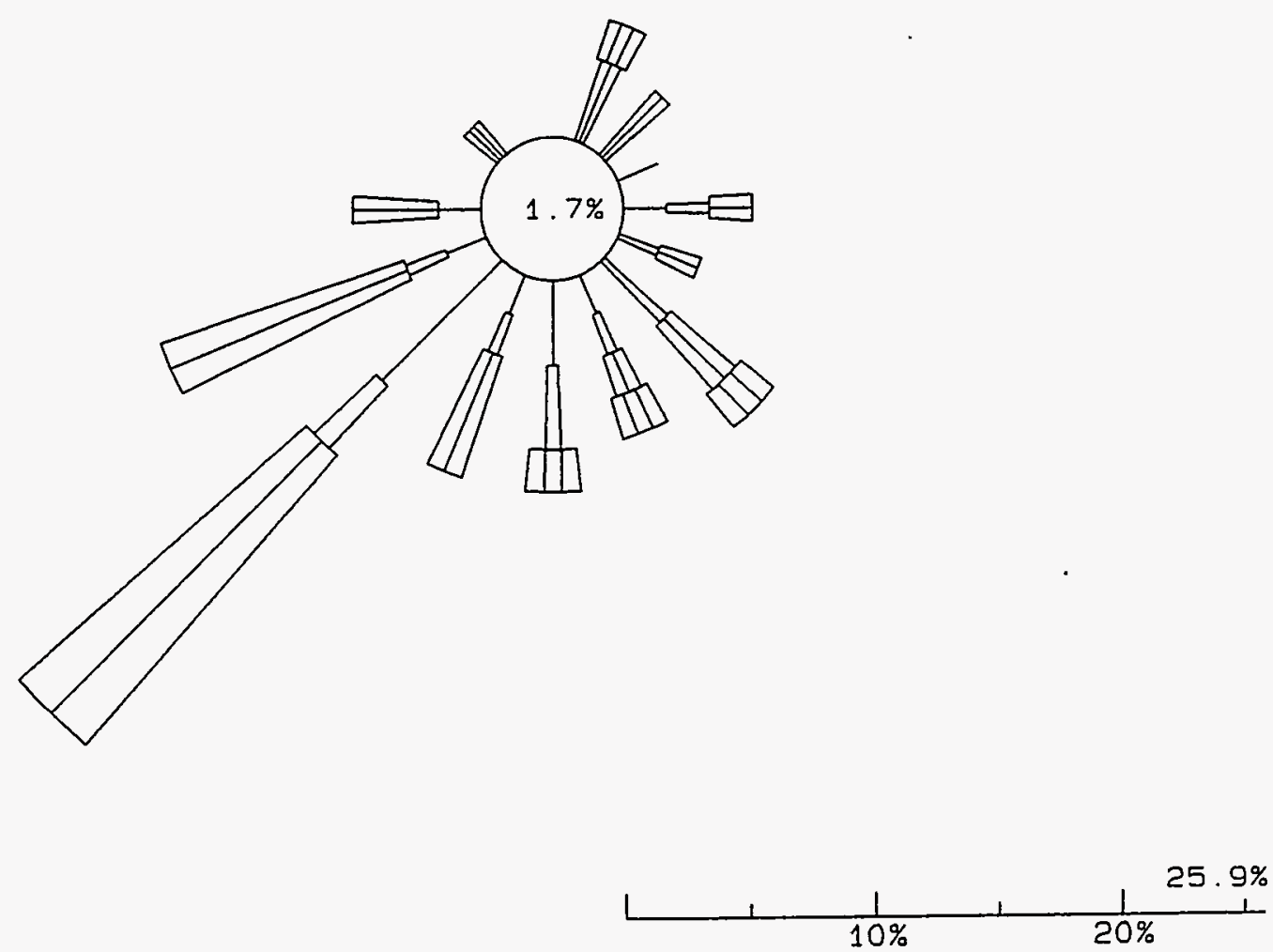

\footnotetext{
WIND SPEED CLASSES (MPS)

CALM 0
11
}

99.9\% DATA RECOVERED

OF WHICH 8.1\% IS

REPORTED ABOVE 

SPILL TEST FACILITY 24 METER TOWER
STABILITY CLASS $B$
8 METER HEIGHT - TotaI Hours
$5 / 1 / 1994-5 / 31 / 1994$
$0-2300$

$N$
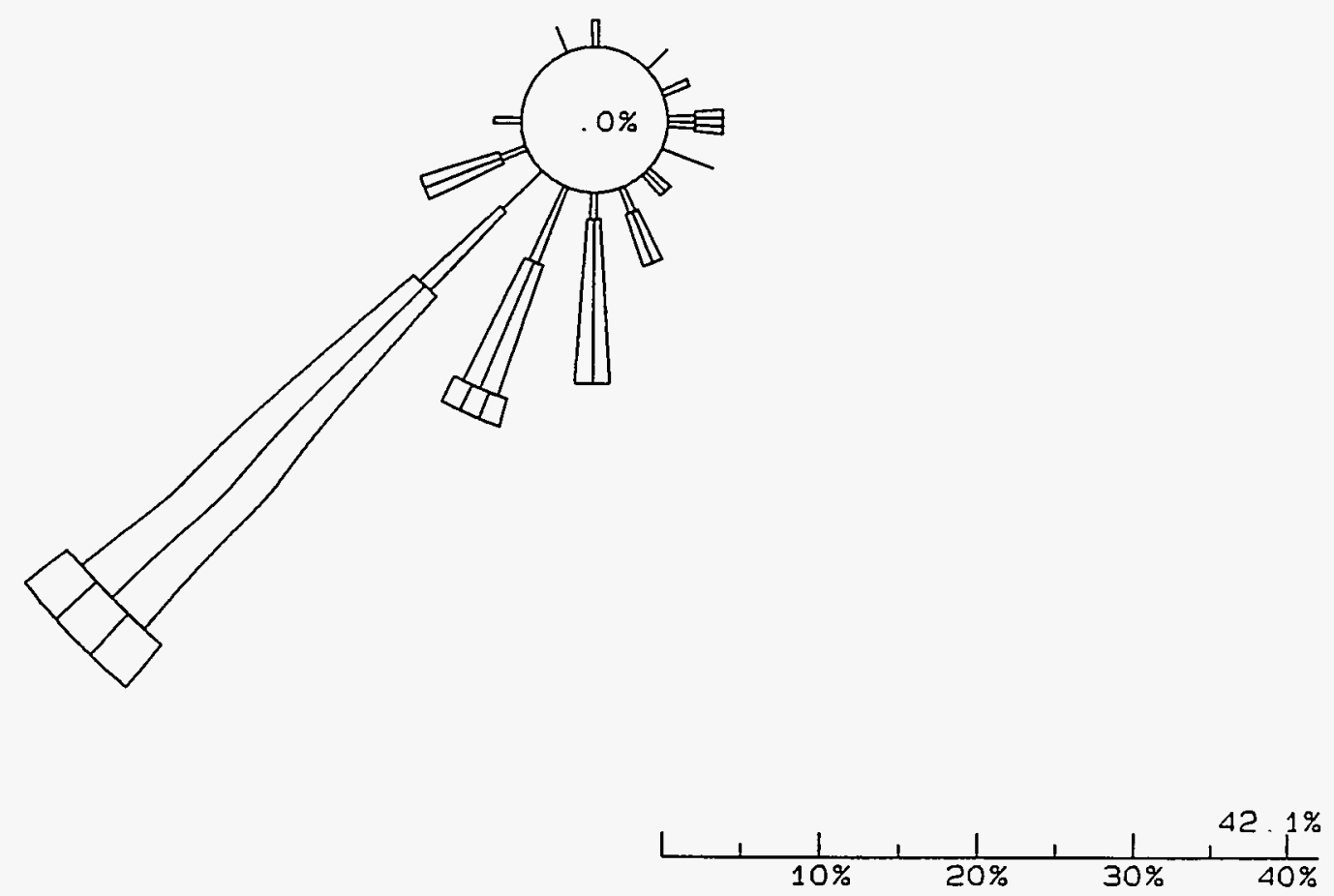

96.9\% DATA RECOVERED

OF WHICH $7.9 \%$ IS

REPORTED ABOVE 


\section{SPILL TEST FACILITY 24 METER TOWER STABILITY CLASS B \\ 8 METER HEIGHT - Total Hours \\ 6/ $1 / 1994$ - 6/30/1994 \\ $0-2300$}

N

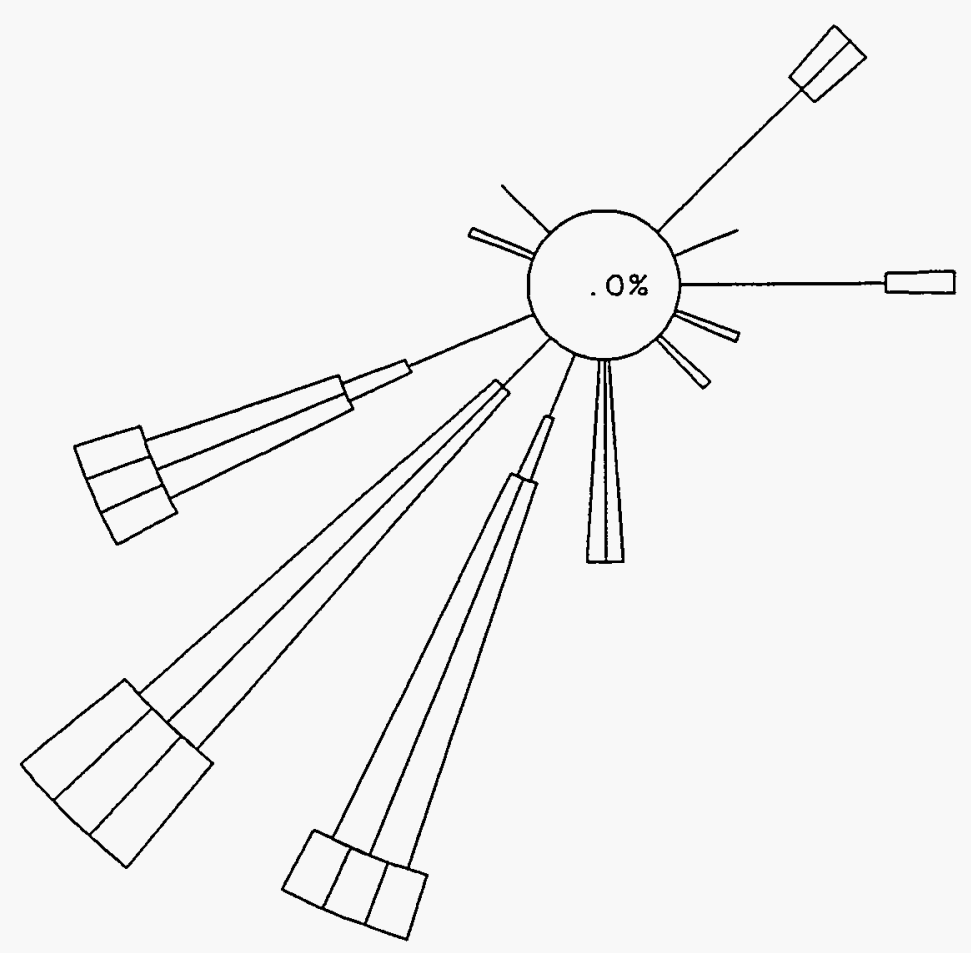

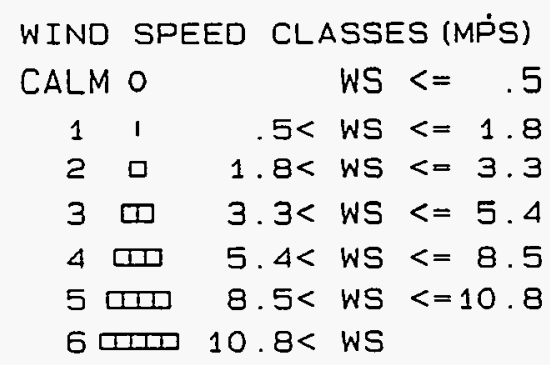

100.0\% DATA RECOVERED -

OF WHICH $5.8 \%$ IS

REPORTED ABOVE 


\section{SPILL TEST FACILITY 24 METER TOWER \\ STABILITY CLASS B \\ 8 METER HEIGHT - Total Hours \\ 7/ $1 / 1994$ - 7/31/1994 \\ $0-2300$}

N
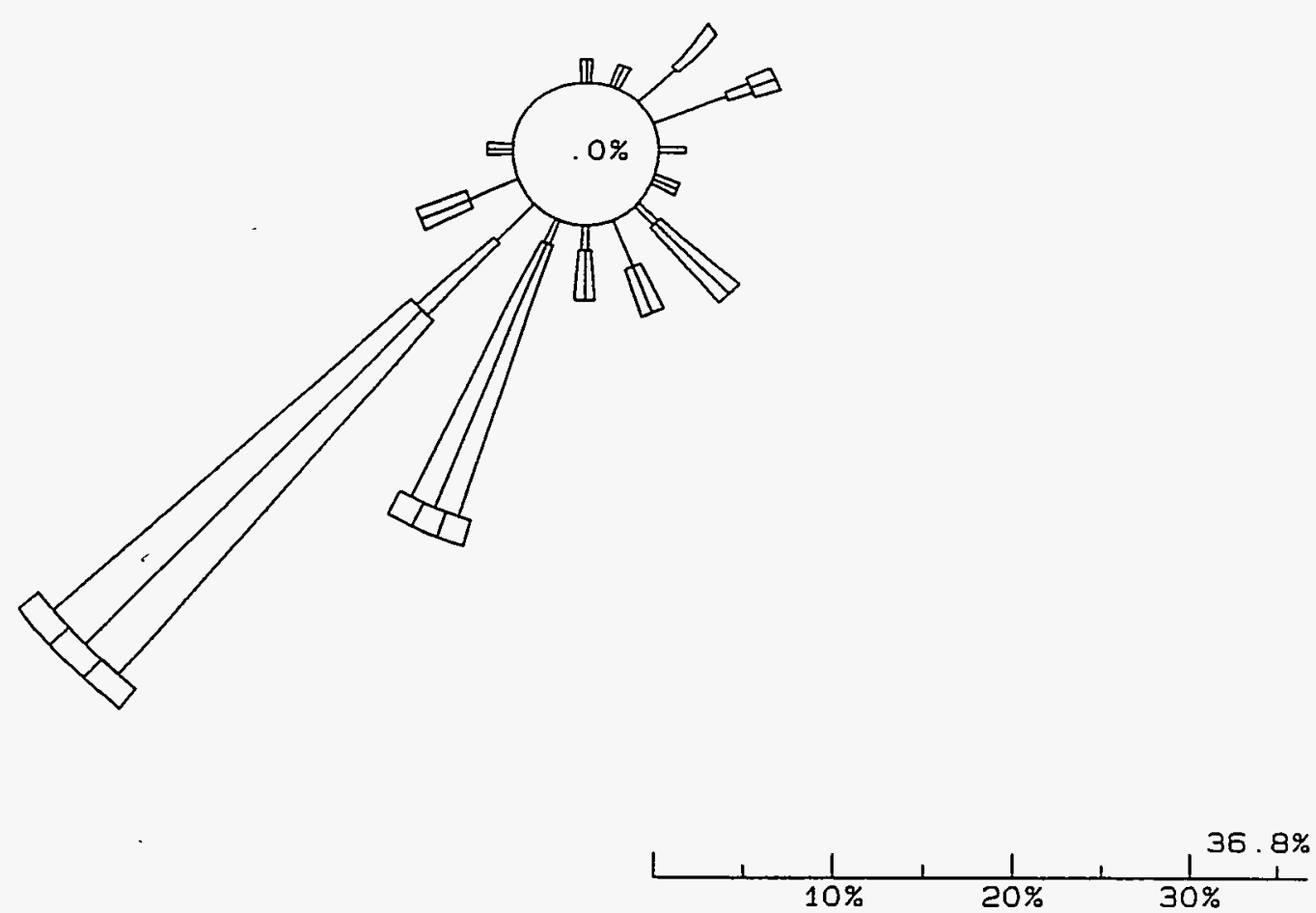

\begin{tabular}{|c|c|c|c|c|}
\hline \multirow{2}{*}{\multicolumn{3}{|c|}{$\begin{array}{l}\text { WIND SPEED } \\
\text { CALM } 0\end{array}$}} & \multicolumn{2}{|c|}{ CLASSES (MPS) } \\
\hline & & & WS & $<=$ \\
\hline 1 & 1 & $5<$ & WS & $<=1.8$ \\
\hline 2 & $\square$ & $1.8<$ & WS & $<=3.3$ \\
\hline 3 & דם & $3.3<$ & WS & $<=5.4$ \\
\hline 4 & שח & $5.4<$ & WS & $<=8.5$ \\
\hline 50 & פדים & $8.5<$ & WS & $<=10.8$ \\
\hline 65 & סחדב & $10.8<$ & WS & \\
\hline
\end{tabular}

$100.0 \%$ DATA RECOVERED

OF WHICH $9.1 \%$ IS

REPORTED ABOVE 


\section{SPILL TEST FACILITY 24 METER TOWER \\ STABILITY CLASS B \\ 8 METER HEIGHT - Total Hours \\ $8 / 1 / 1994-8 / 31 / 1994$ \\ $0-2300$}

$N$

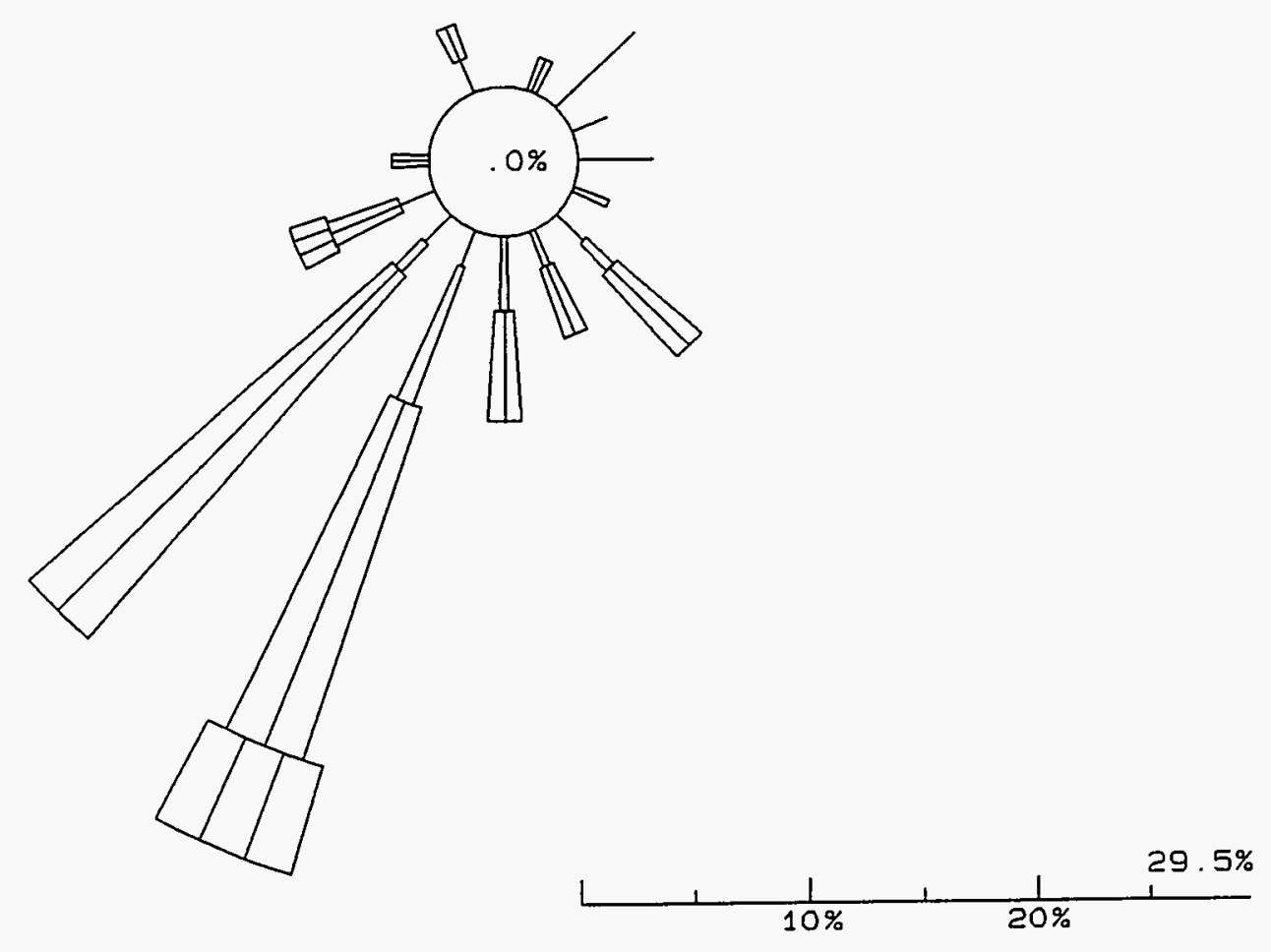

WIND SPEED CLASSES (MPS)

CALM O

11

20

3 ㅁ $3.3<$ WS $<=5.4$

4 एण $5.4<W S<=8.5$

5 때 $8.5<$ WS $<=10.8$

6 पामा $10.8<$ WS
100.0\% DATA RECOVERED

OF WHICH $8.2 \%$ IS

REPORTED ABOVE 


\section{SPILL TEST FACILITY 24 METER TOWER STABILITY CLASS $B$ \\ 8 METER HEIGHT - Total Hours \\ 9/ $1 / 1994$ - 9/30/1994 \\ $0-2300$}

$N$
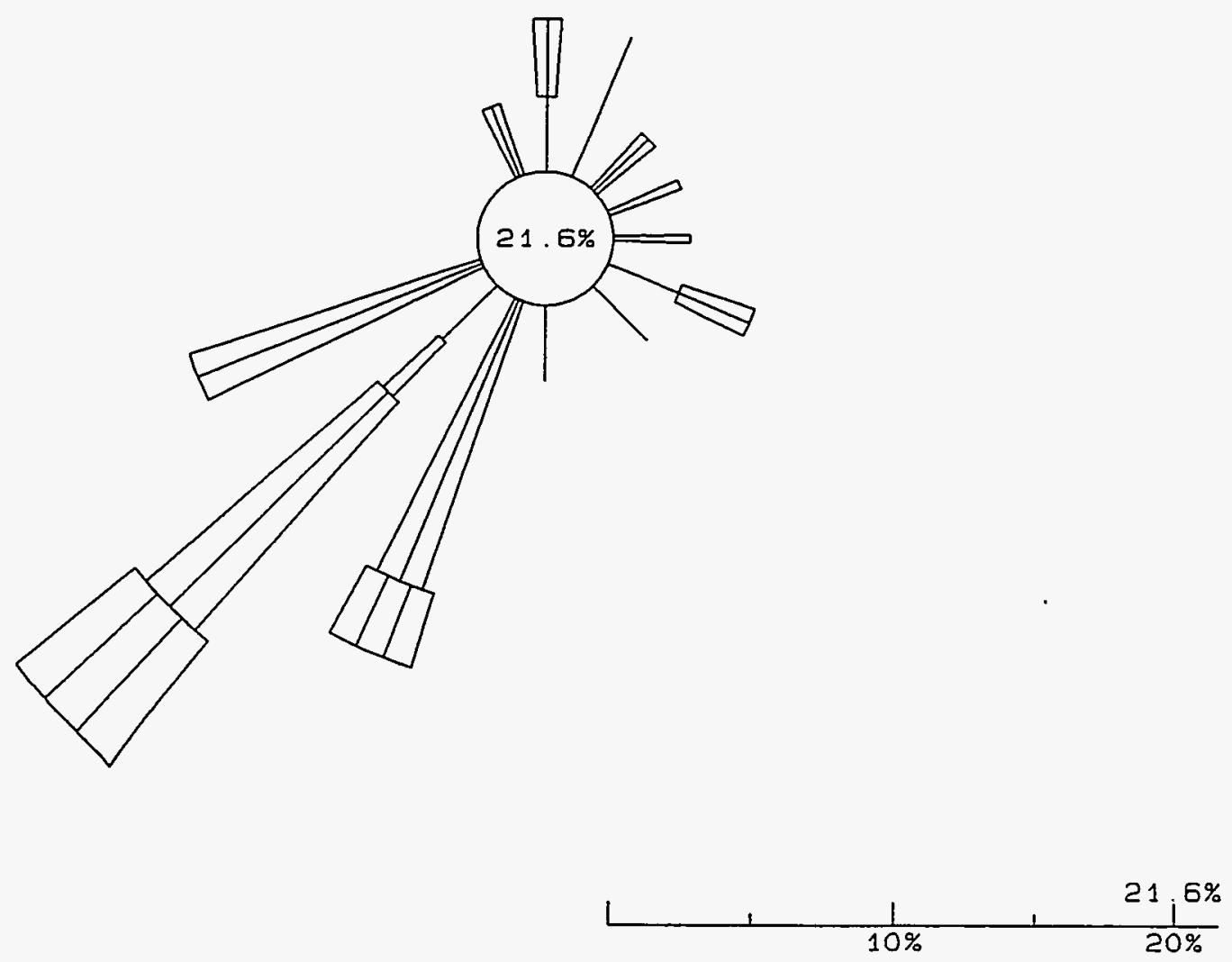

99.2\% DATA RECOVERED

OF WHICH $5.2 \%$ IS

REPORTED ABOVE 


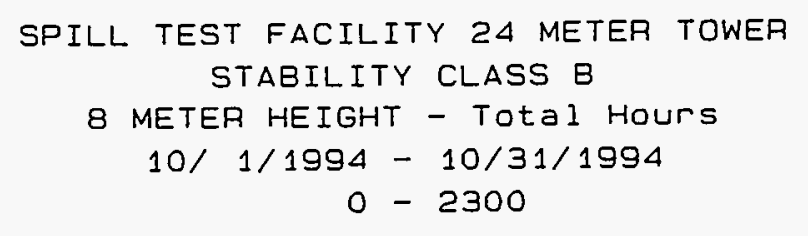

$N$
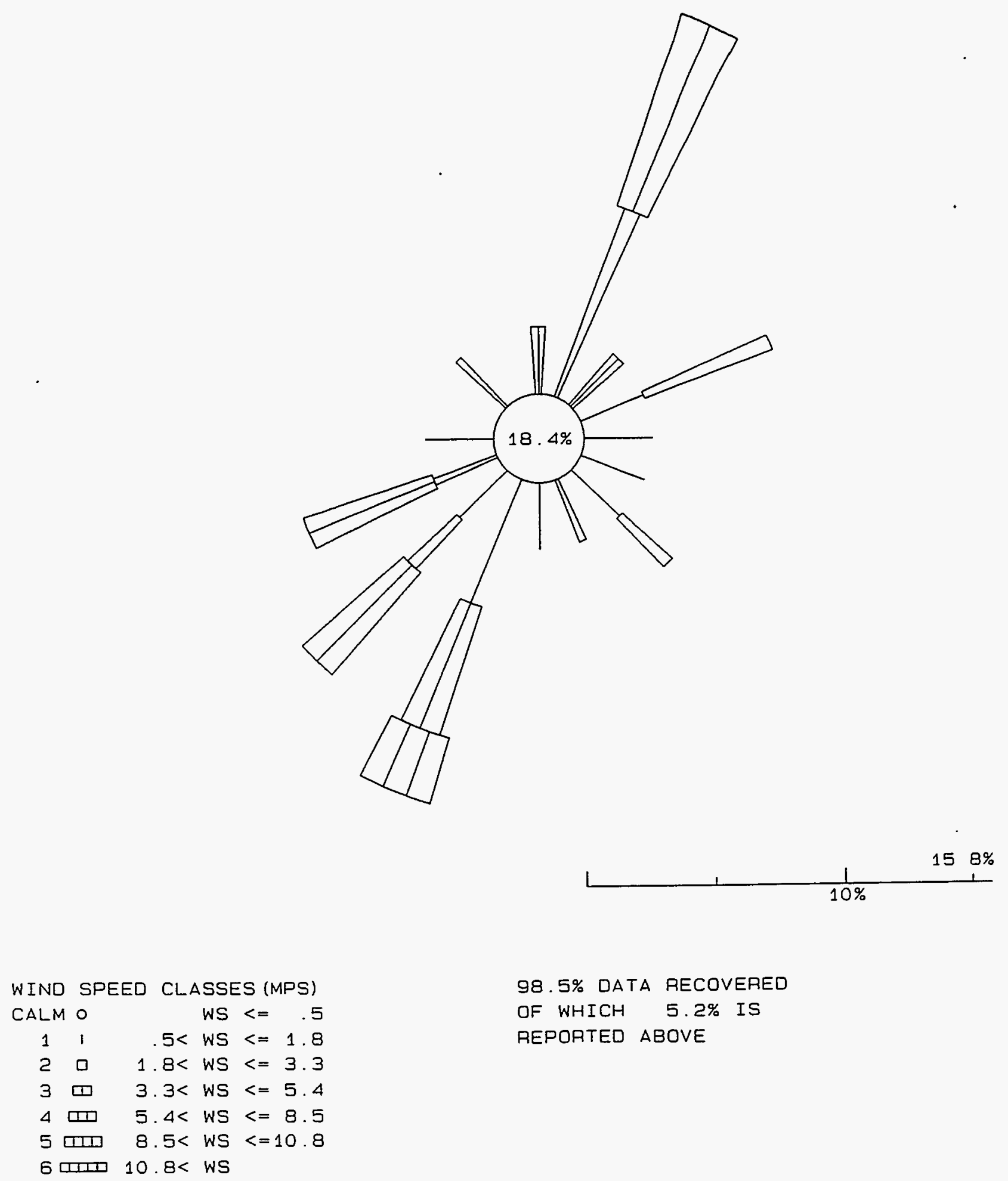

98.5\% DATA RECOVERED

OF WHICH $5.2 \%$ IS

REPORTED ABOVE 


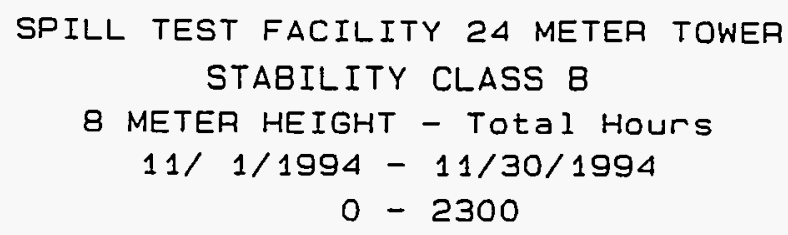

N

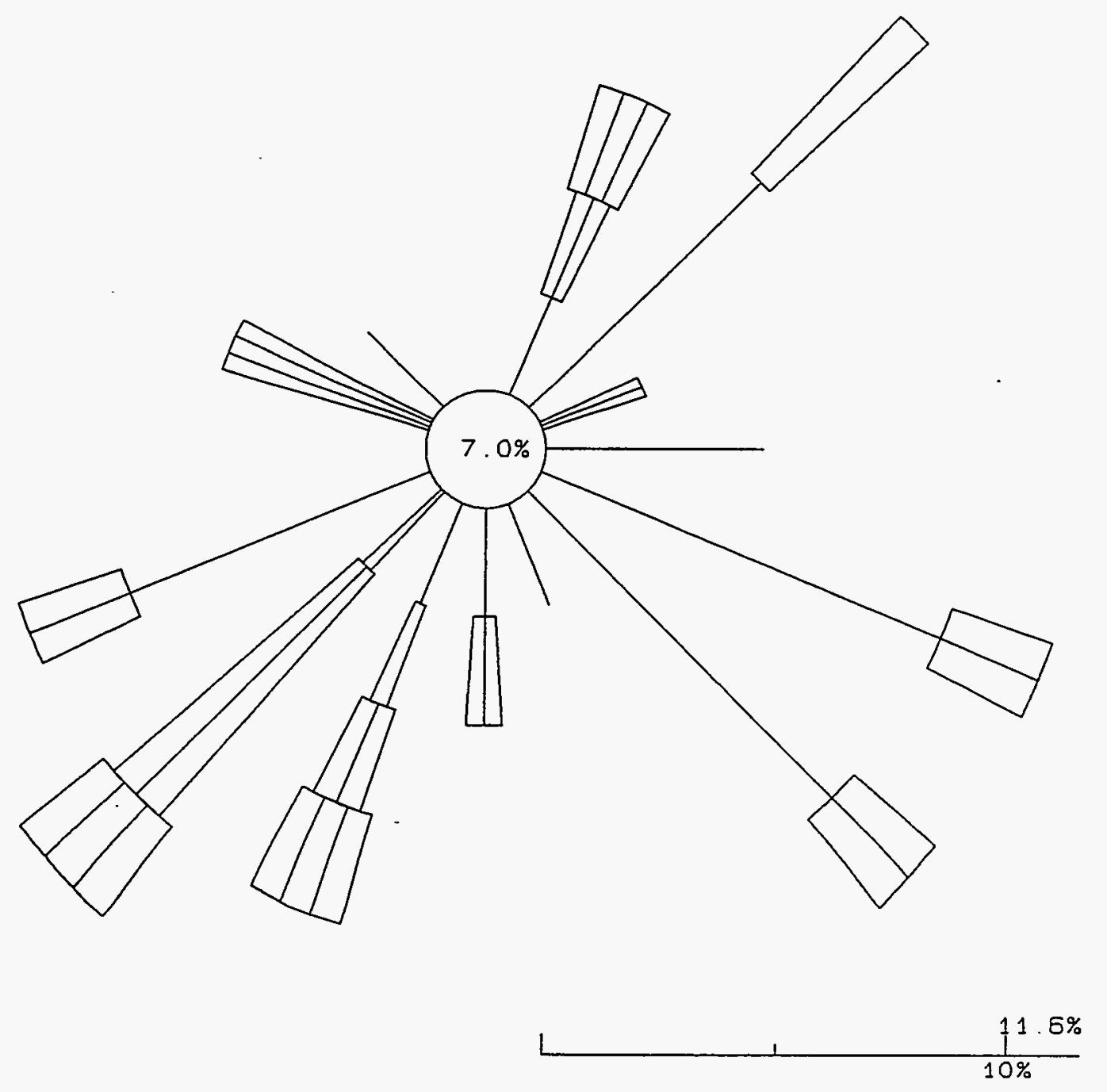

99.7\% DATA RECOVERED

OF WHICH $6.0 \%$ IS

REPORTED ABOVE 


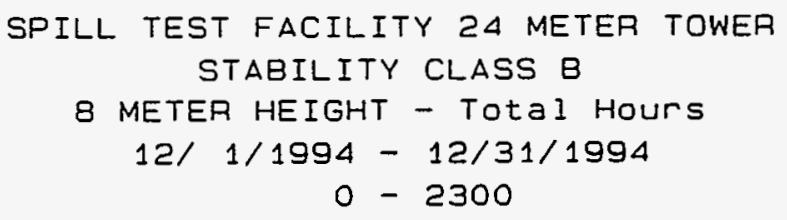

N
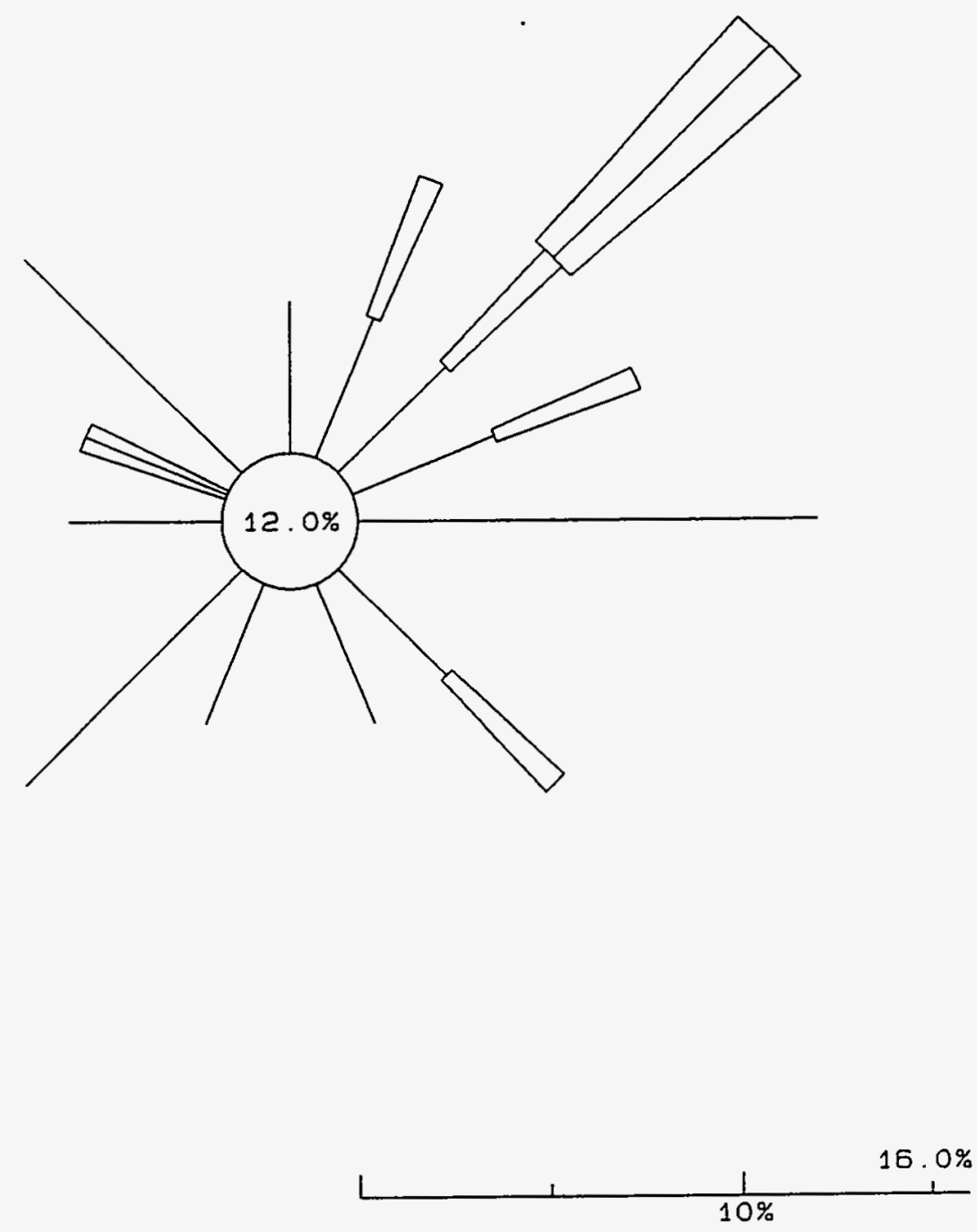

\begin{tabular}{|c|c|c|c|c|c|}
\hline WIND & $S P E$ & $E D$ & CLA & isSE & S (MPS) \\
\hline CALM & 10 & & & WS & $<=$ \\
\hline 1 & 1 & & $5<$ & WS & $<=1.8$ \\
\hline 2 & $\square$ & 1 & $8<$ & WS & $c=3.3$ \\
\hline 3 & דם & 3 & $3<$ & WS & $<=5.4$ \\
\hline 4 & דा & 5 & $.4<$ & WS & $<=8.5$ \\
\hline 5 & पाता & 8 & $.5<$ & WS & $c=10.8$ \\
\hline$E$ & שחتप & 0 & $.8<$ & WS & \\
\hline
\end{tabular}

65. 1\% DATA RECOVEAED

OF WHICH $5.2 \%$ IS

REPORTED ABOVE 


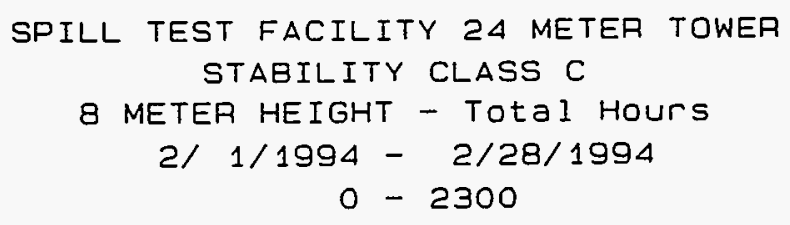

N

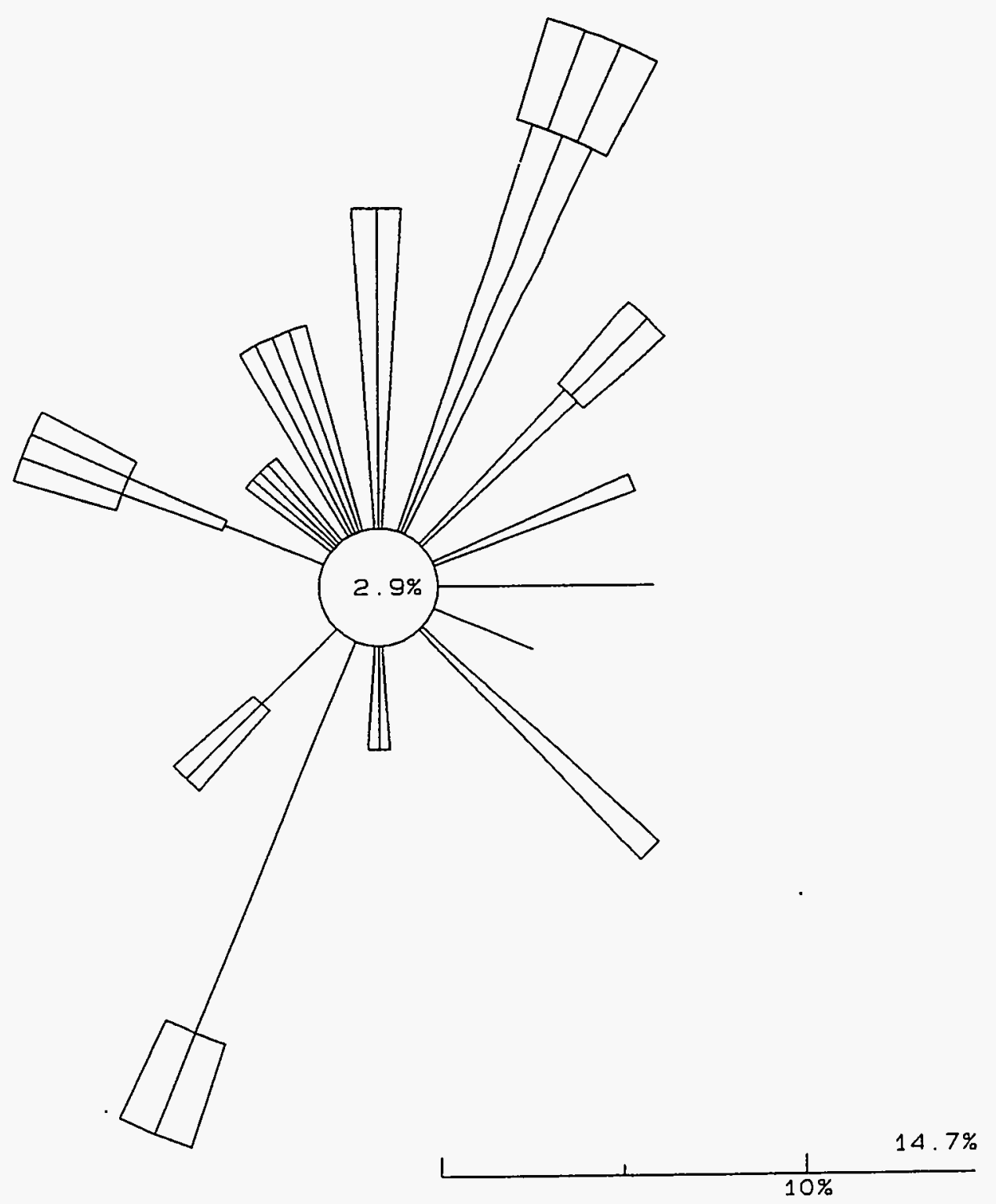

85. 4\% DATA RECOVERED

OF WHICH $5.9 \%$ IS

REPORTED ABOVE 

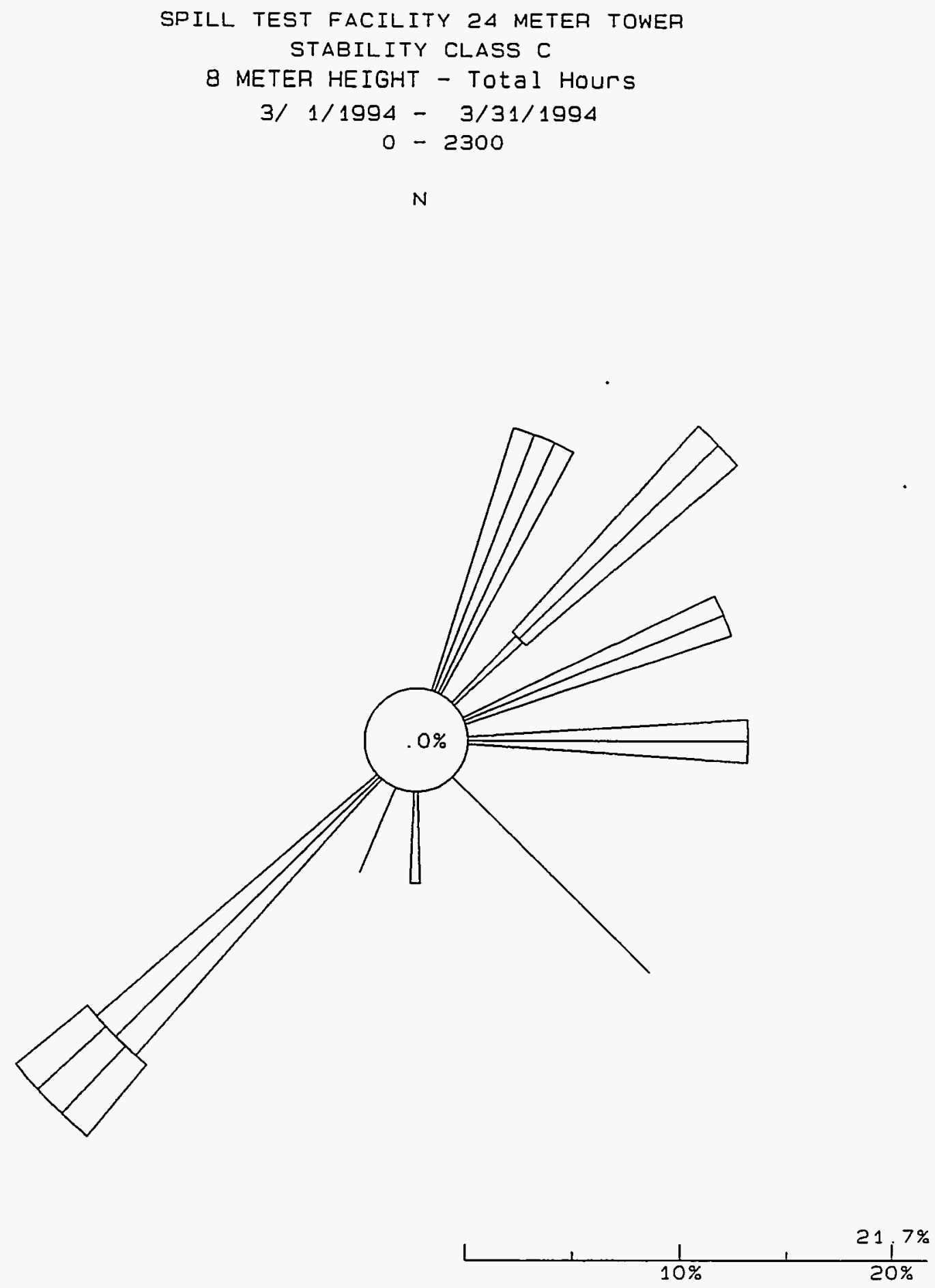


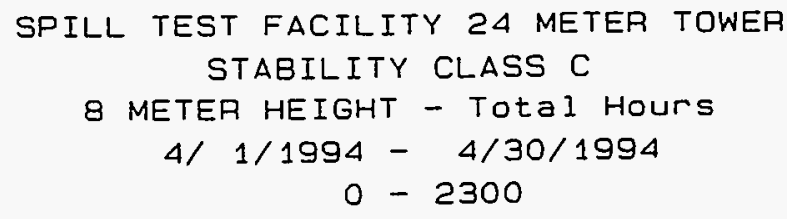

$N$

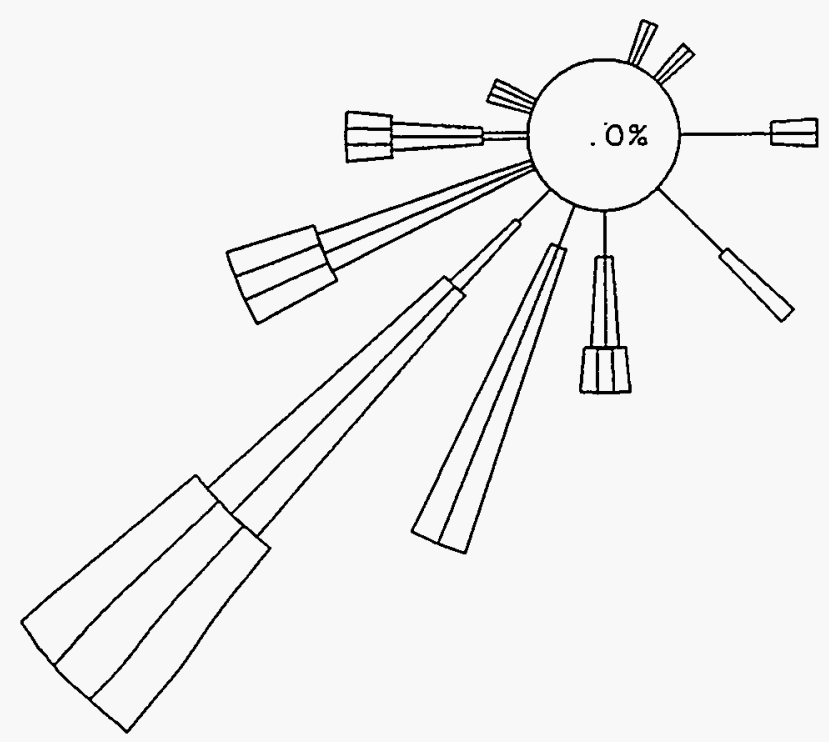

\begin{tabular}{|c|c|c|c|c|c|c|}
\hline IND & $D S F$ & & CLA & $A S S E$ & & \\
\hline$A L M$ & 10 & & & WS & $<=$ & .5 \\
\hline 1 & 1 & & $.5<$ & WS & $<=$ & 1.8 \\
\hline ? & D & 1 & $.8<$ & WS & $<=$ & 3. \\
\hline 3 & ه & 3 & $.3<$ & WS & $6=$ & 5. \\
\hline 4 & סש & 5 & $.4<$ & WS & $<=$ & 8. \\
\hline 5 & שप & 8 & $.5<$ & WS & $<=$ & 10. \\
\hline & III & 10 & $.8<$ & WS & & \\
\hline
\end{tabular}

99.9\% DATA RECOVERED

OF WHICH $6.7 \%$ IS

REPOATED ABOVE 


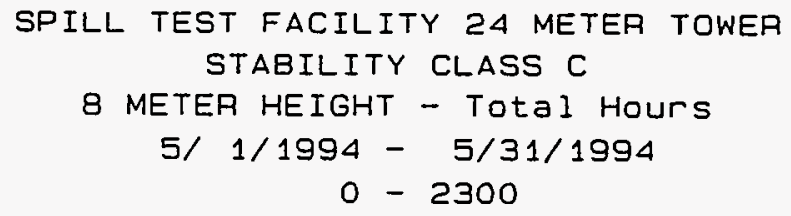

N
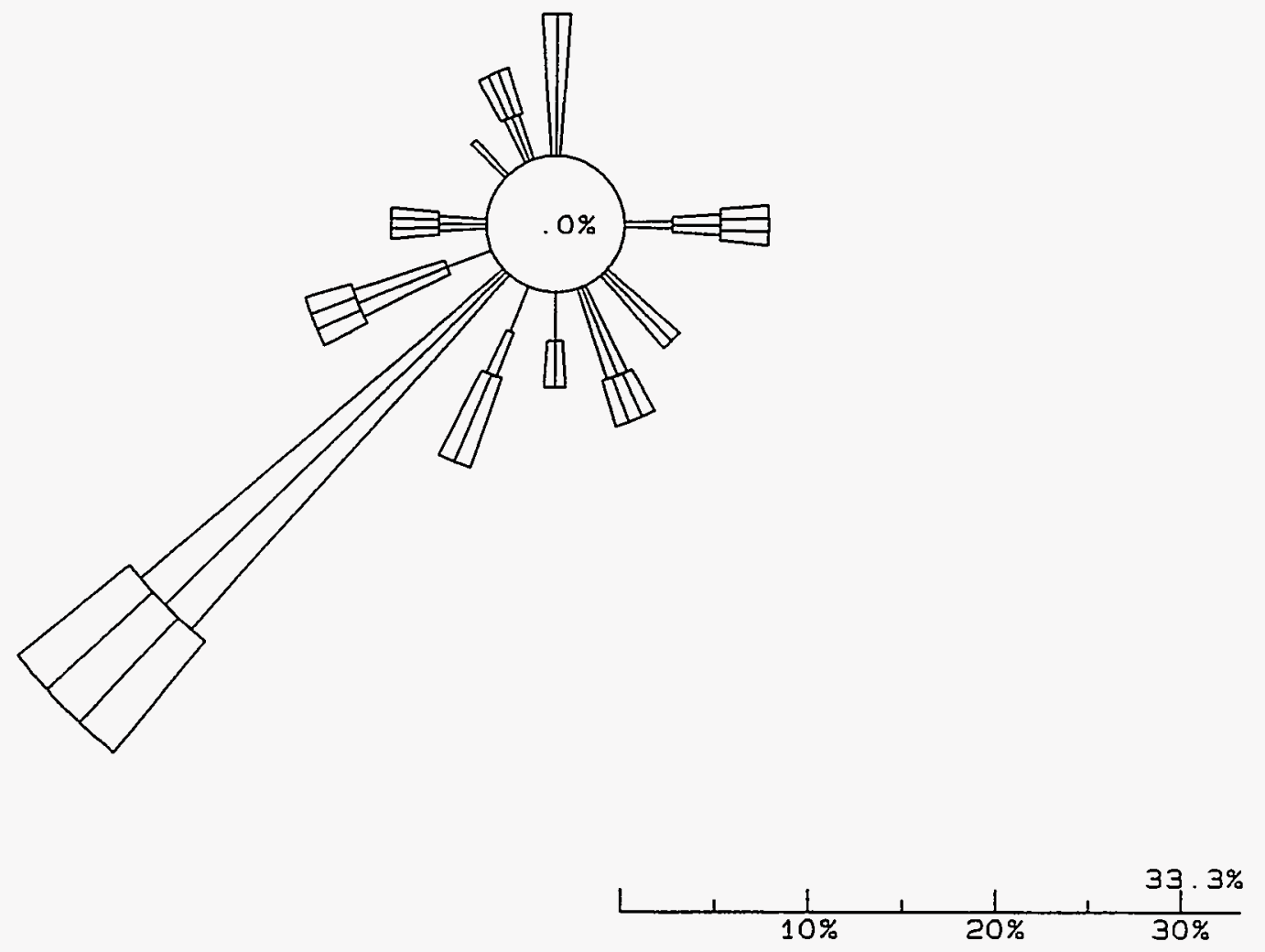

96.9\% DATA RECOVERED

OF WHICH 5.4\% IS

REPORTED ABOVE 
SPILL TEST FACILITY 24 METER TOWER

STABILITY CLASS C

8 METER HEIGHT - Total Hours

6/ $1 / 1994-6 / 30 / 1994$

$0-2300$
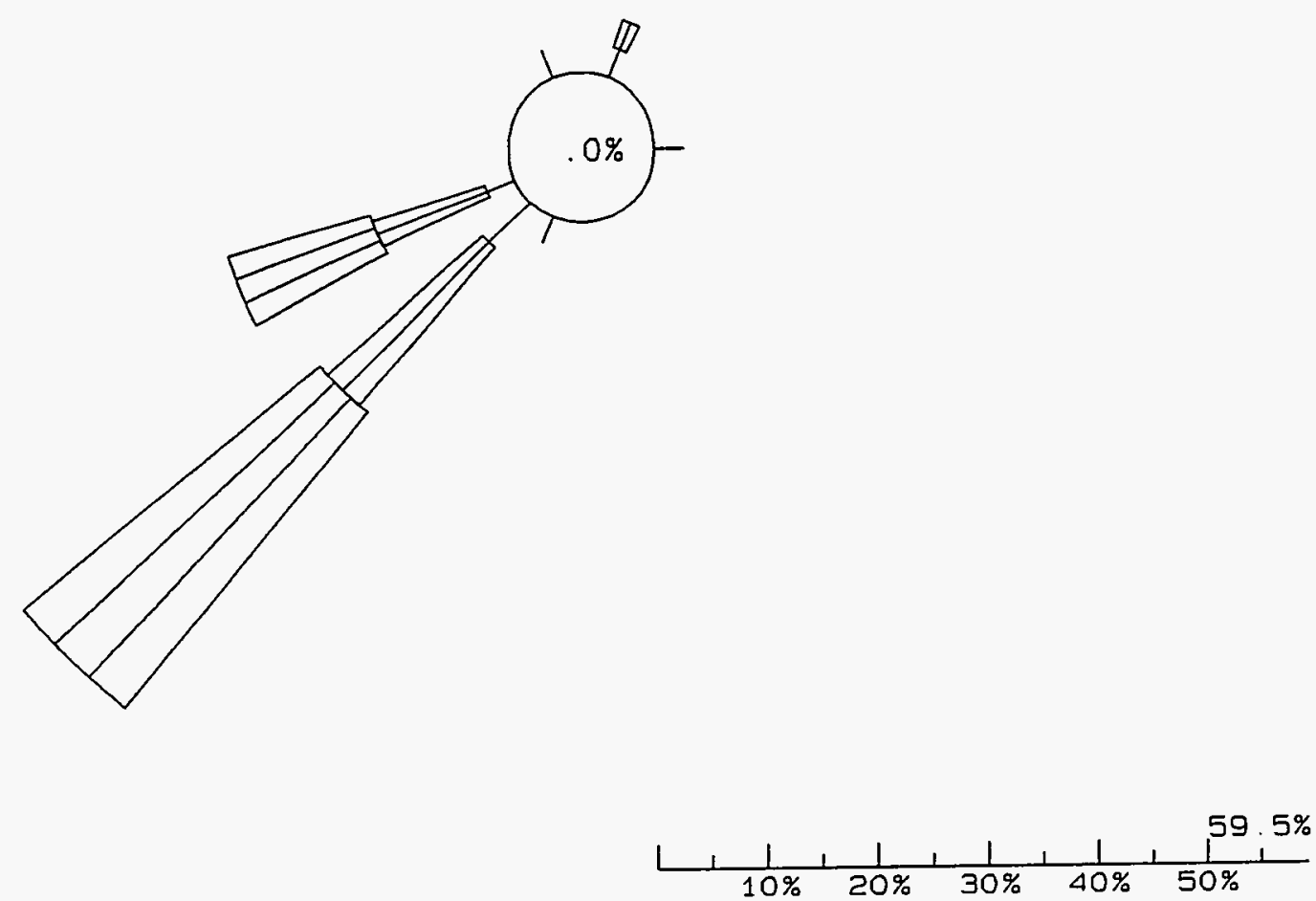

\begin{tabular}{|c|c|c|c|c|c|}
\hline \multirow{2}{*}{$\begin{array}{l}\text { WIND } \\
\text { CALM }\end{array}$} & \multicolumn{2}{|c|}{ SPEED } & \multicolumn{3}{|c|}{ CLASSES (MPS) } \\
\hline & 40 & & & WS & $<=$ \\
\hline 1 & $\mathbf{I}$ & & $5<$ & WS & $<=1.8$ \\
\hline 2 & $\square$ & 1 & $8<$ & WS & $<=3.3$ \\
\hline 3 & שם & 3 & $3<$ & WS & $<=5.4$ \\
\hline 4 & ता & 5 & $4<$ & WS & $<=8.5$ \\
\hline 5 & पण & 8 & $5<$ & WS & $<=10.8$ \\
\hline & טדप & 1 & $8<$ & WS & \\
\hline
\end{tabular}

$100.0 \%$ DATA RECOVERED

OF WHICH 5.1\% IS

REPORTED ABOVE 


\section{SPILL TEST FACILITY 24 METER TOWER STABILITY CLASS C \\ 8 METER HEIGHT - Total Hours \\ 7/ 1/1994 - 7/31/1994 \\ $0-2300$}

N
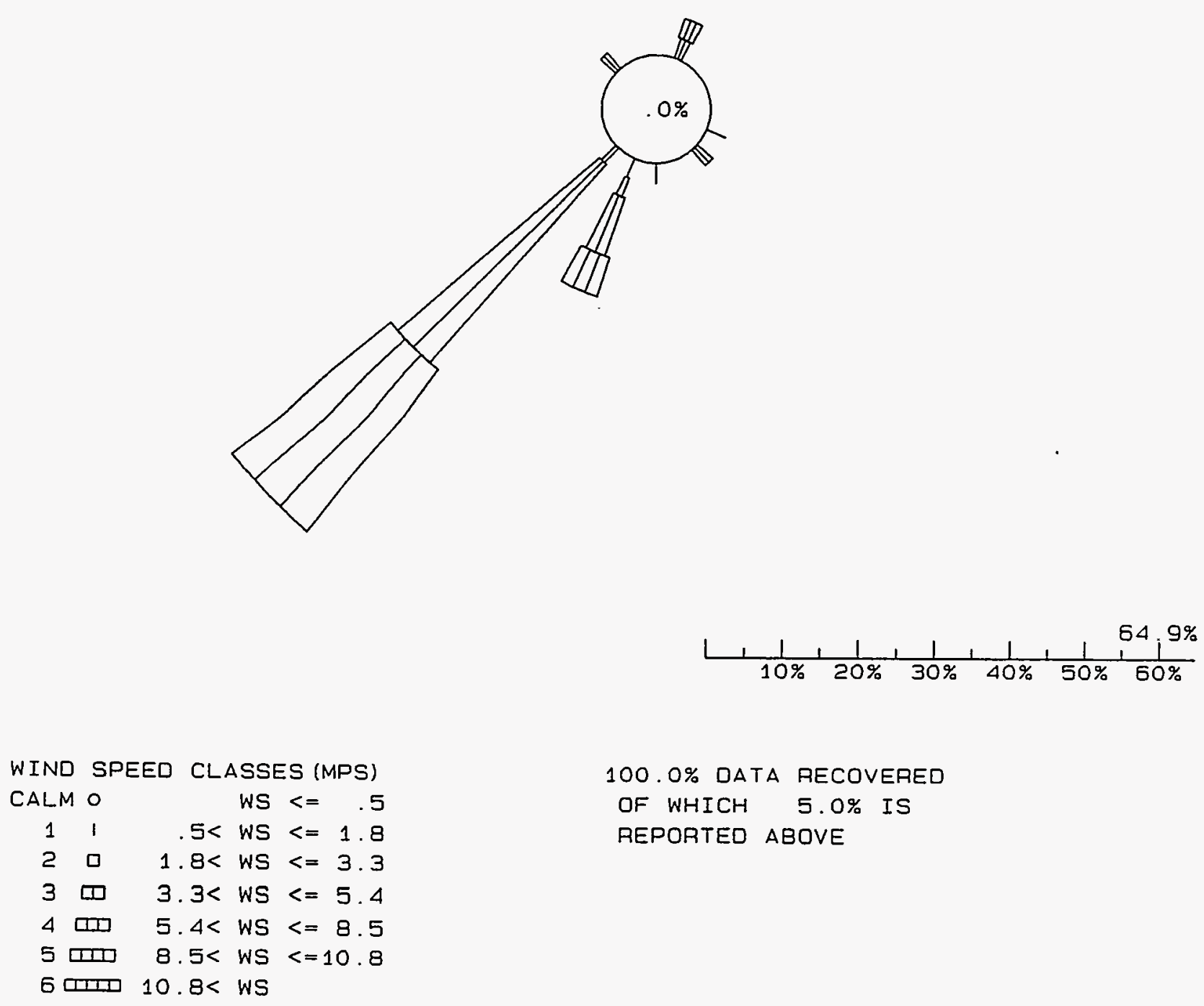

100.0\% DATA RECOVERED

OF WHICH $5.0 \%$ IS

REPORTED ABOVE 


\section{SPILL TEST FACILITY 24 METER TOWER STABILITY CLASS C \\ 8 METER HEIGHT - Total Hours \\ 8/ $1 / 1994$ - 8/31/1994 \\ $0-2300$}

$N$
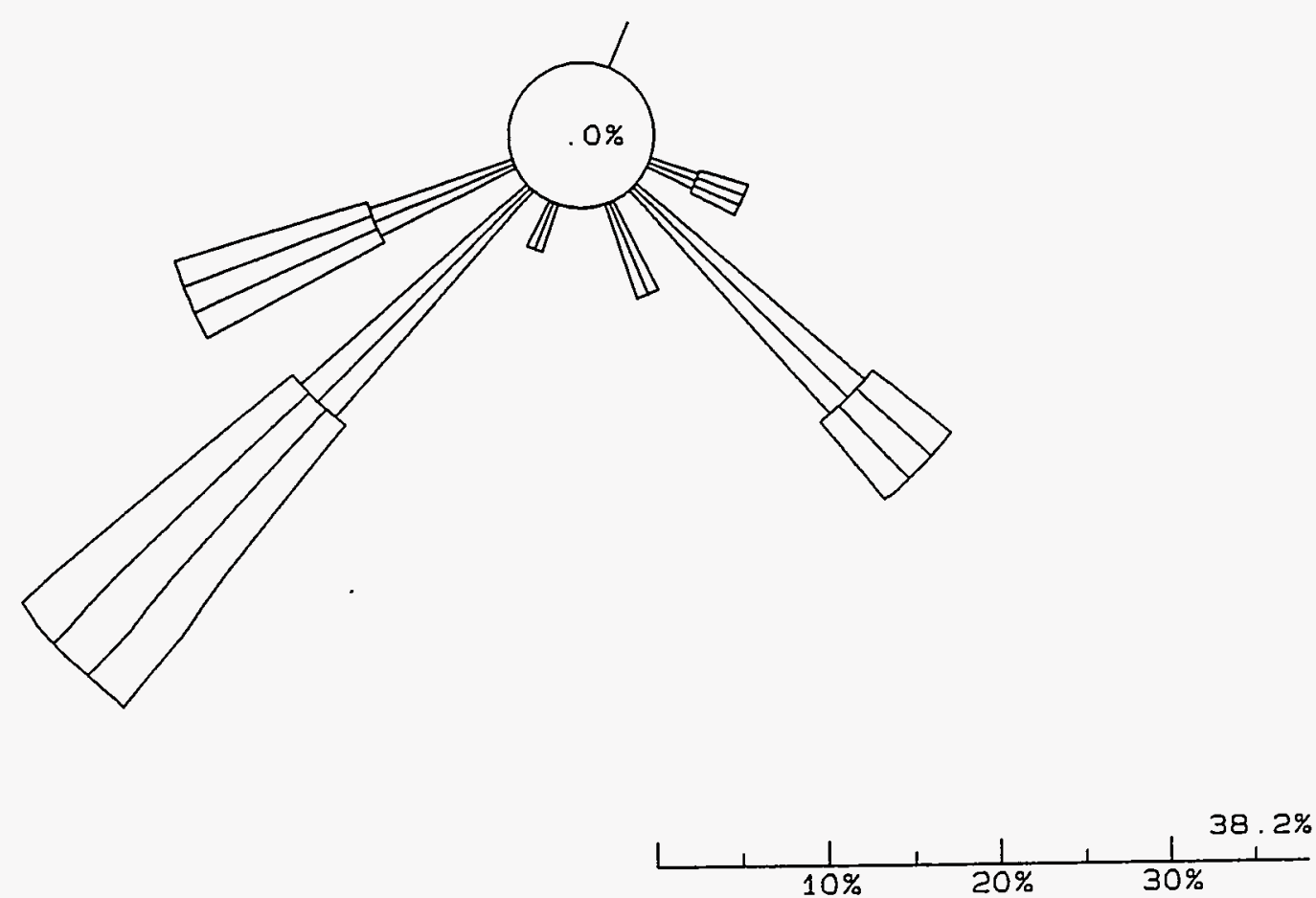

\begin{tabular}{|c|c|c|c|c|c|}
\hline WIND & \multirow{2}{*}{\multicolumn{2}{|c|}{$\begin{array}{l}\text { SPEED } \\
10\end{array}$}} & \multicolumn{3}{|c|}{ CLASSES (MPS) } \\
\hline CALM & & & & WS & $<=$ \\
\hline 1 & 1 & & $5<$ & WS & $<=1.8$ \\
\hline 2 & $\square$ & 1 & $.8<$ & WS & $<=3.3$ \\
\hline 3 & $\square$ & 3 & $.3<$ & WS & $<=5.4$ \\
\hline 4 & סח & 5 & $.4<$ & WS & $<=8.5$ \\
\hline 50 & पाI & 8 & $.5<$ & WS & $<=10.8$ \\
\hline 0 & 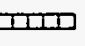 & & $.8<$ & WS & \\
\hline
\end{tabular}

$100.0 \%$ DATA RECOVERED

OF WHICH $4.6 \%$ IS

REPORTED ABOVE 


\section{SPILL TEST FACILITY 24 METER TOWER STABILITY CLASS C \\ 8 METER HEIGHT - Total Hours \\ 9/ $1 / 1994$ - 9/30/1994 \\ $0-2300$}
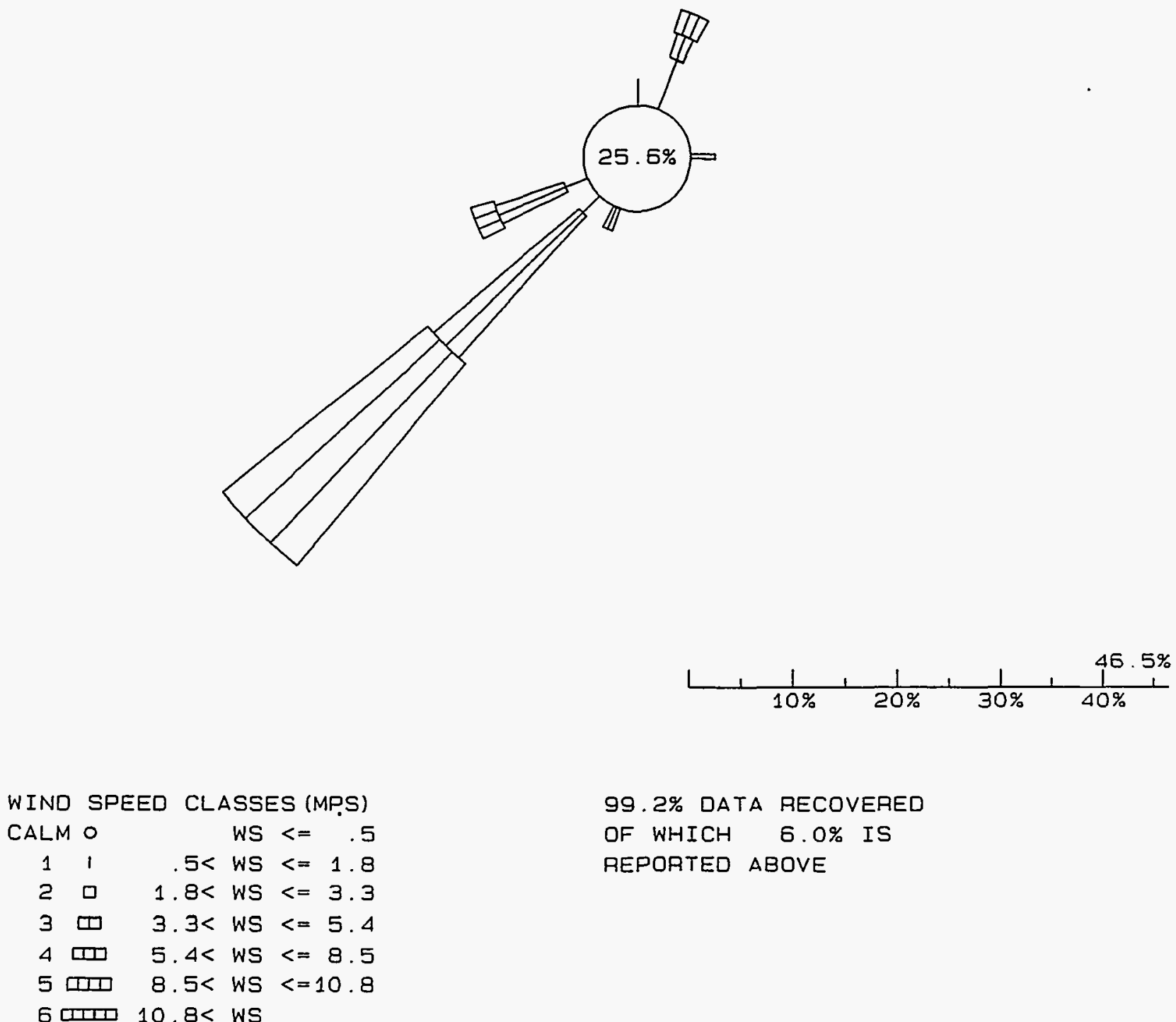

99.2\% DATA RECOVERED

OF WHICH 6.O\% IS

REPORTED ABOVE 


\section{SPILL TEST FACILITY 24 METER TOWER \\ STABILITY CLASS C \\ 8 METER HEIGHT - Total Hours \\ $10 / 1 / 1994-10 / 31 / 1994$ \\ $0-2300$}

N
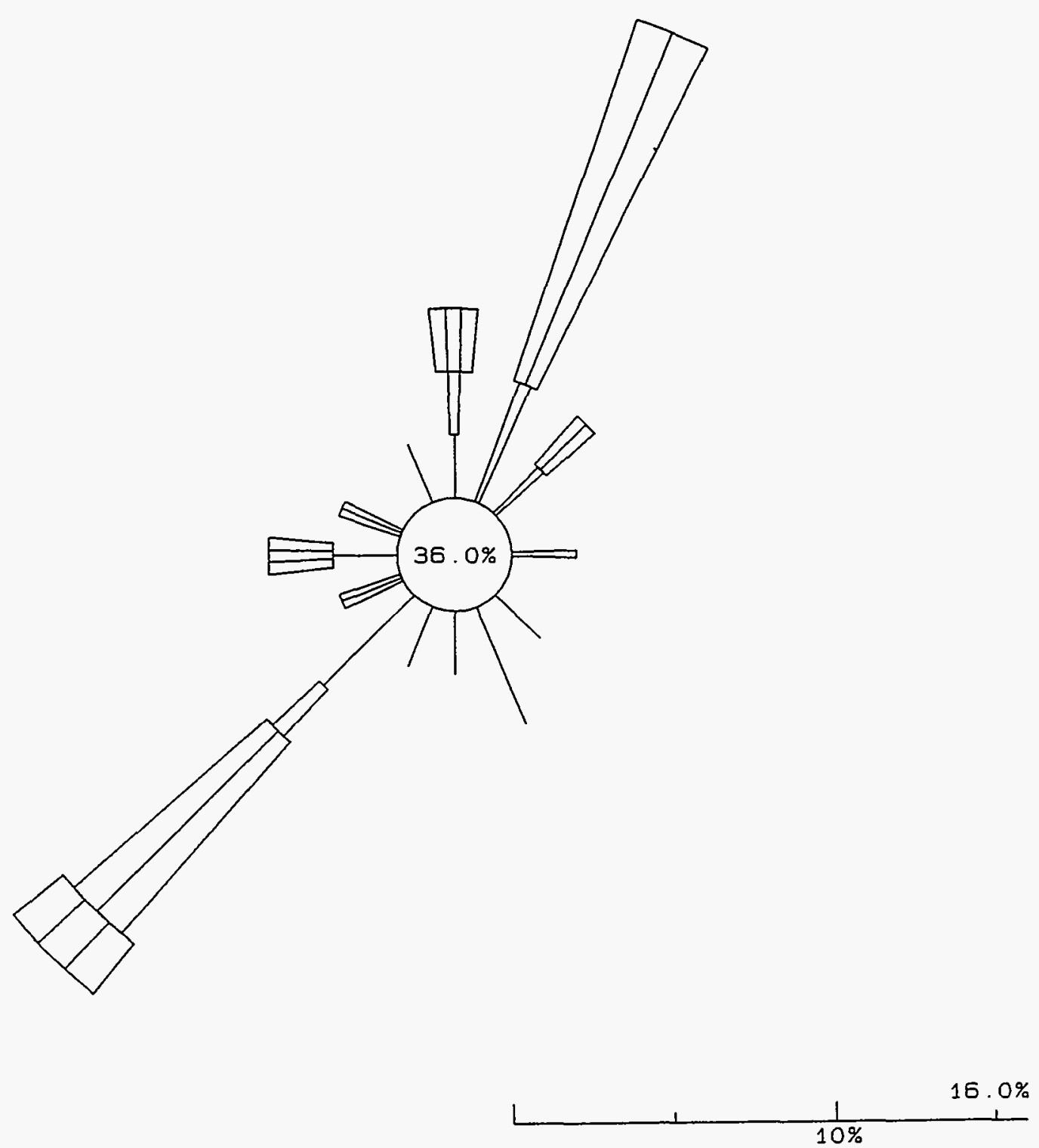

98.5\% DATA RECOVERED

OF WHICH $6.8 \%$ IS

REPORTED ABOVE 


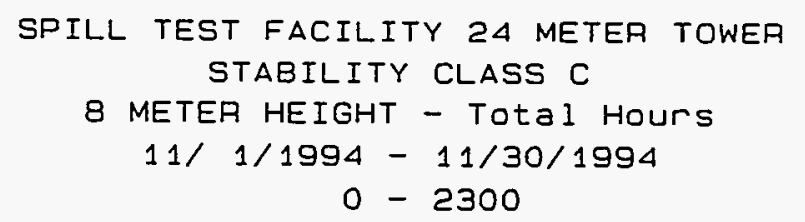

$N$

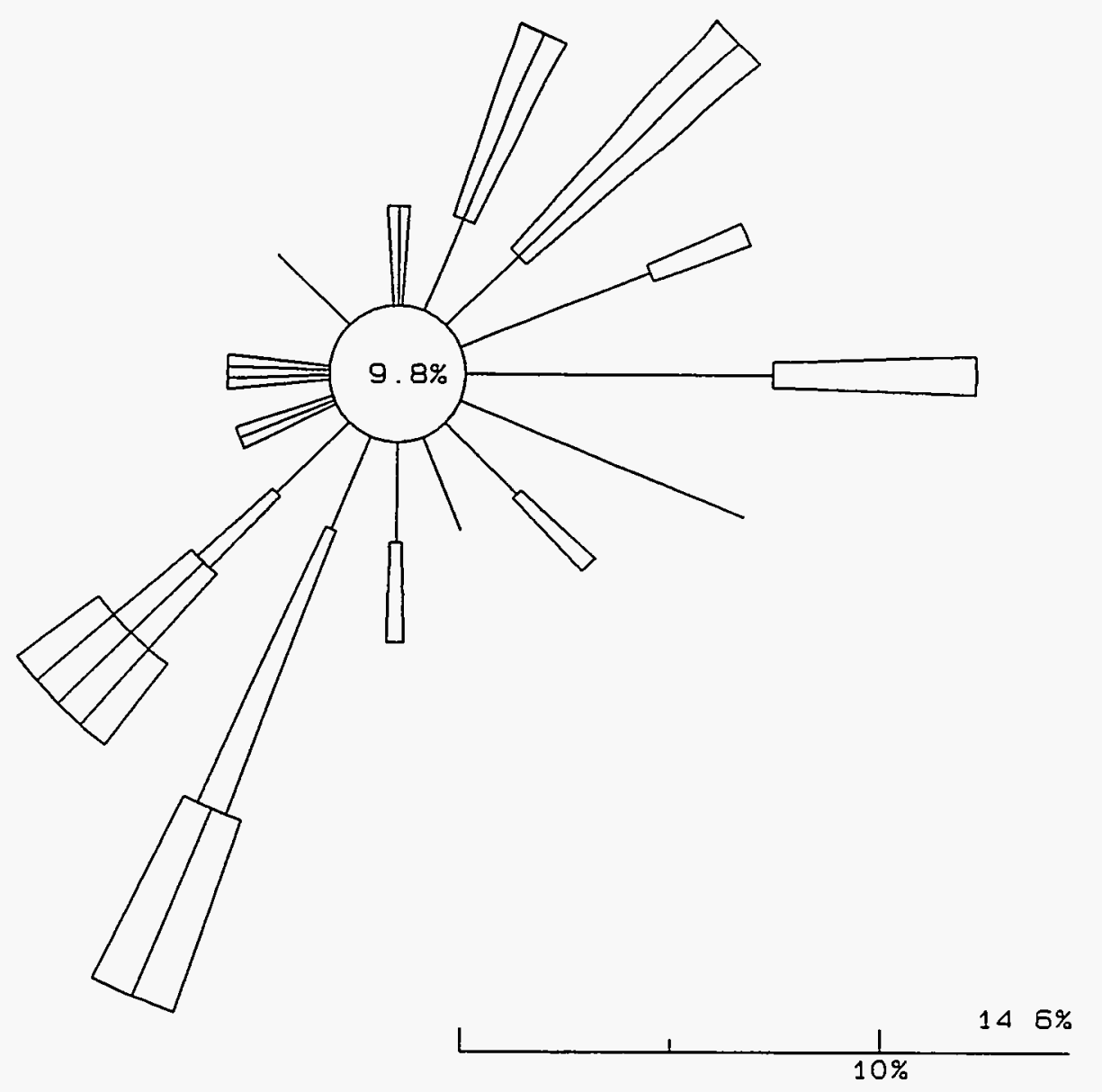

99.7\% DATA RECOVERED

OF WHICH $5.7 \%$ IS

AEPORTED ABOVE 

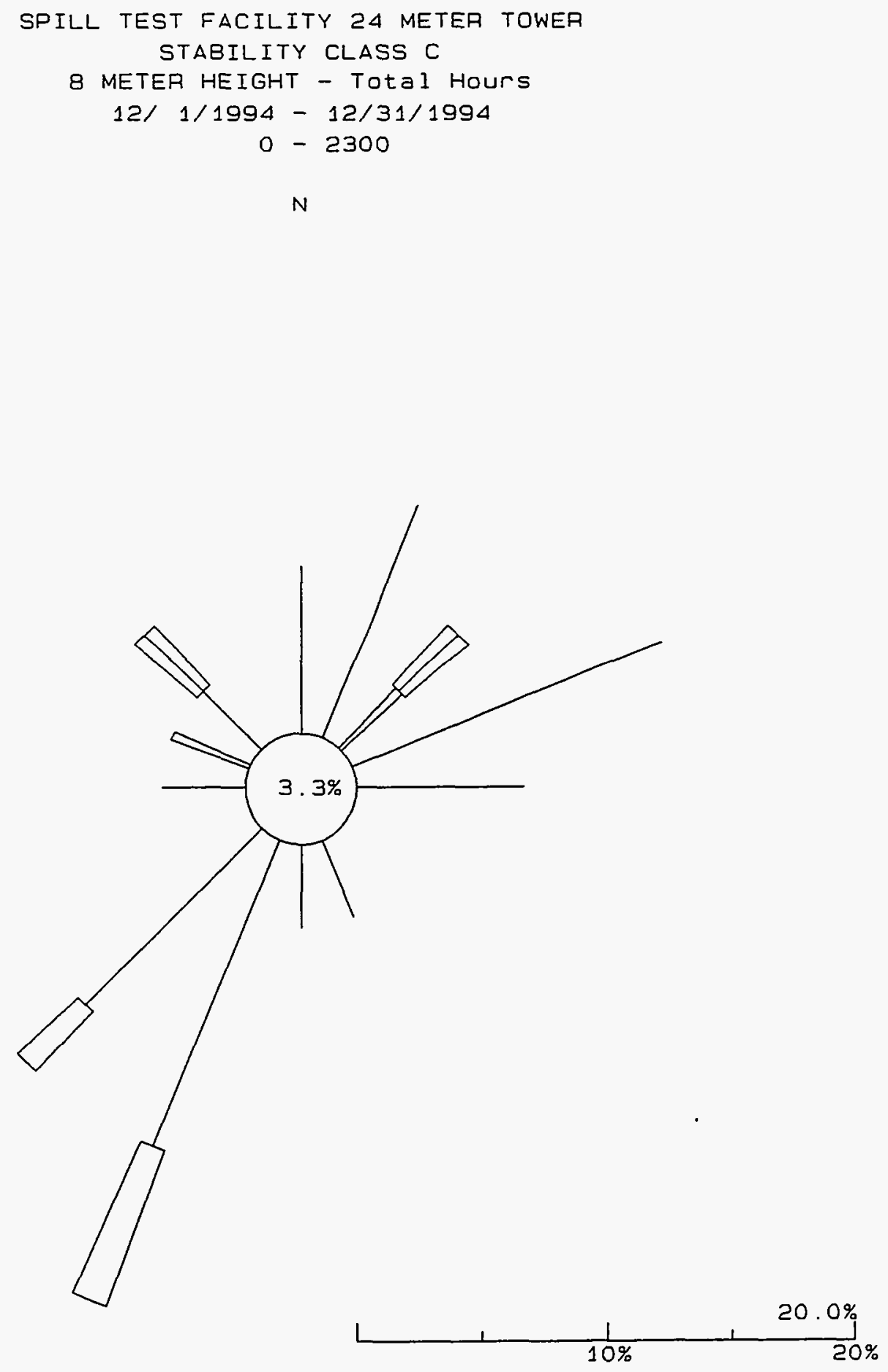

WIND SPEED CLASSES (MPS) CALM $\quad$ WS $<=.5$ $11.5<$ WS $<=1.8$ $2 \square \quad 1.8<$ WS $<=3.3$ $3 \square 3.3<$ WS $<=5.4$ 4 ए $5.4<W S<=8.5$ 5 페 $8.5<W S<=10.8$ 6 पाग $10.8<$ WS
65. 1\% DATA RECOVERED

OF WHICH $6.2 \%$ IS REPORTED ABOVE 


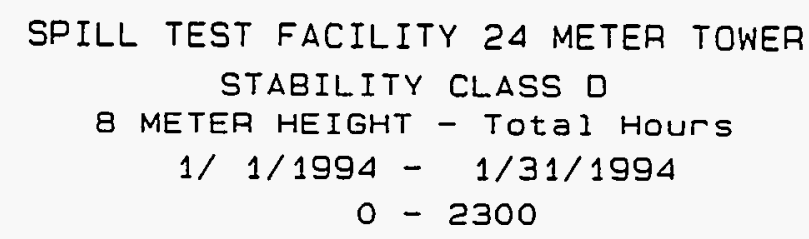

$N$
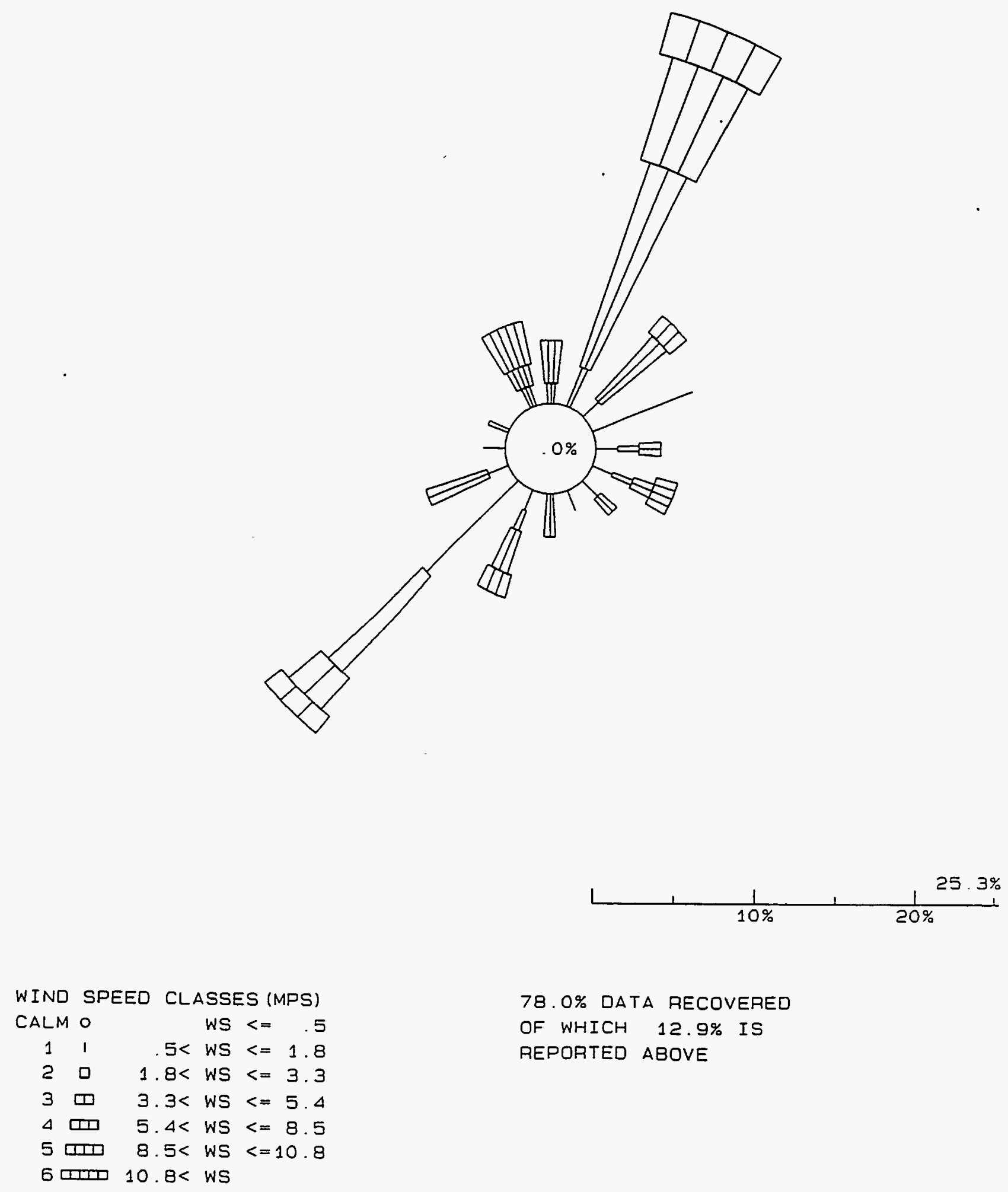

78.0\% DATA RECOVERED

OF WHICH 12.9\% IS

REPORTED ABOVE 


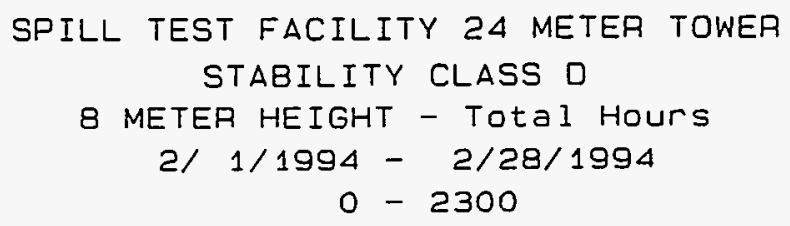

N
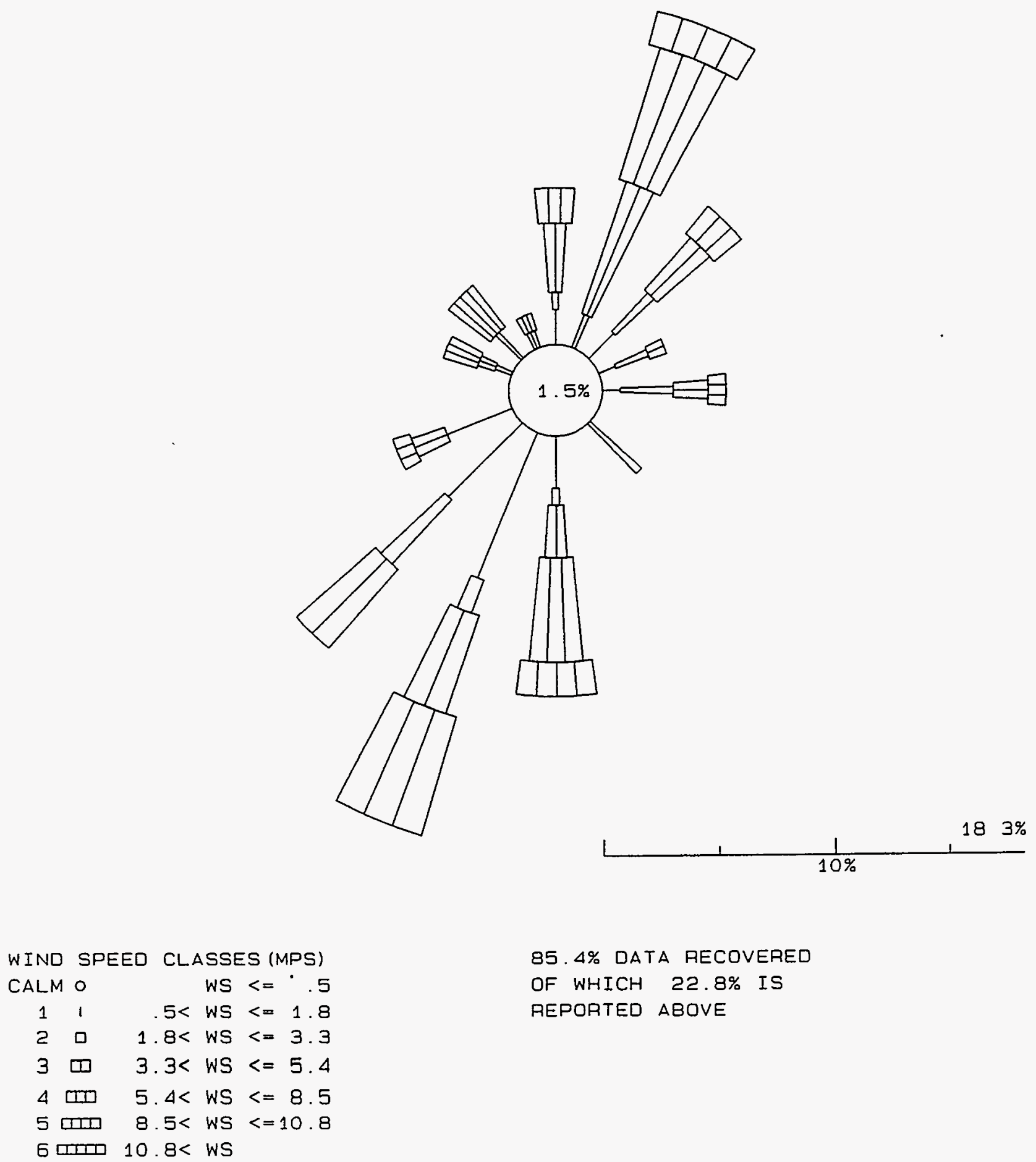

SPILL TEST FACILITY 24 METER TOWER
STABILITY CLASS $\square$
8 METER HEIGHT - Total Hours
$3 / 1 / 1994-3 / 31 / 1994$
$0-2300$

$N$
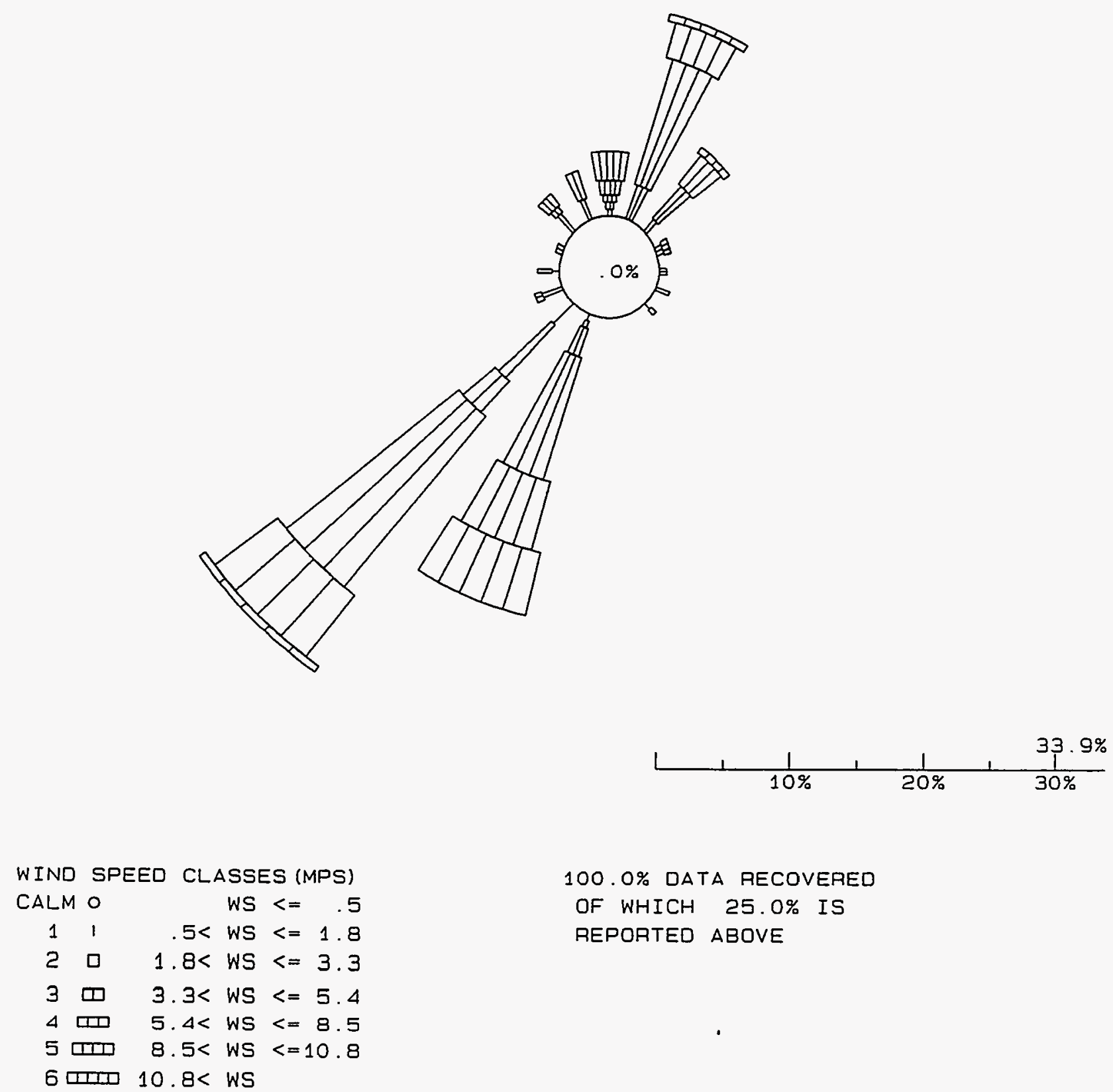

$100.0 \%$ DATA RECOVERED

OF WHICH 25.O\% IS

REPORTED ABOVE 


\section{SPILL TEST FACILITY 24 METER TOWER \\ STABILITY CLASS D \\ 8 METER HEIGHT - Total Hours \\ 4/ $1 / 1994-4 / 30 / 1994$ \\ $0-2300$}

$N$
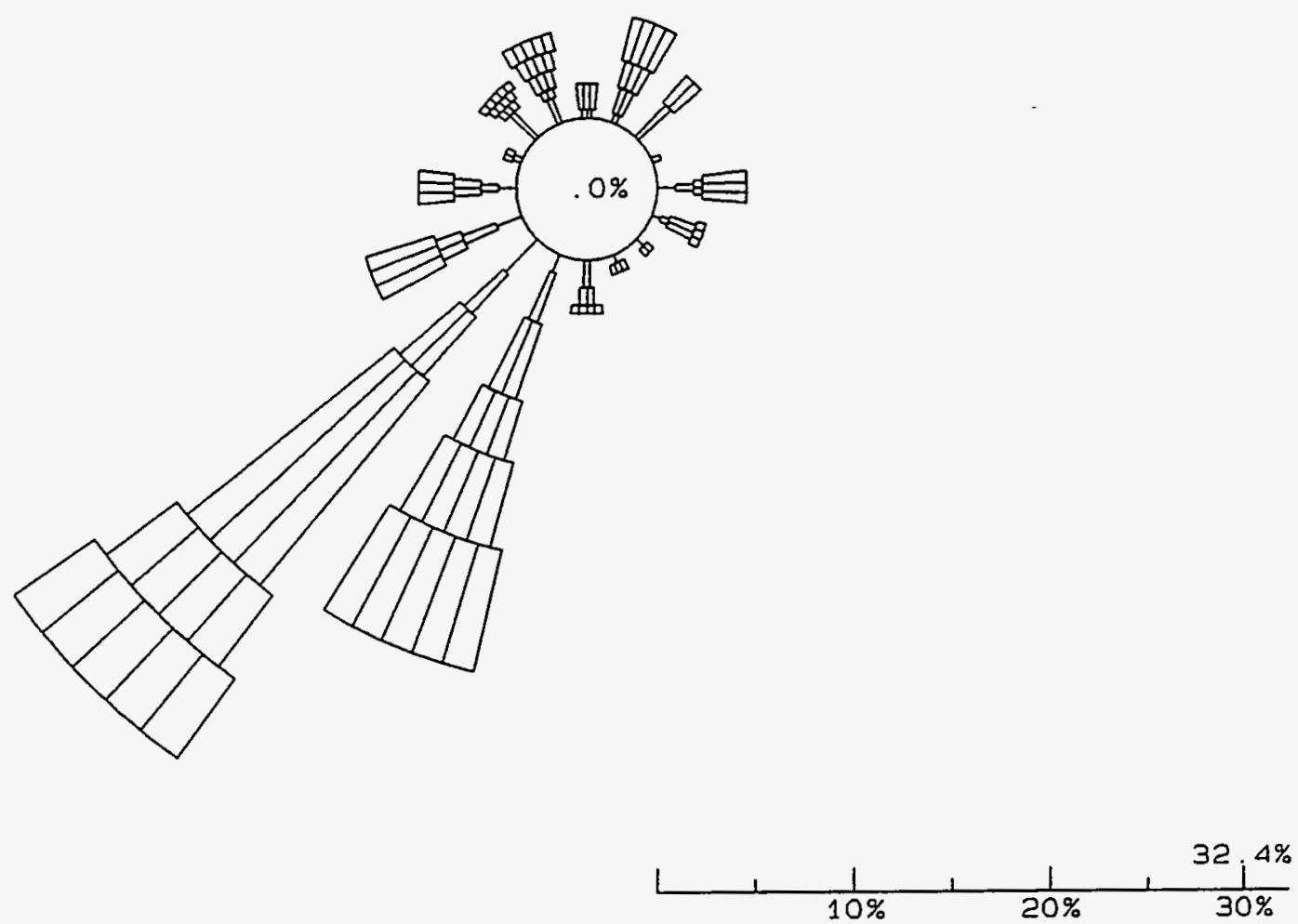

\begin{tabular}{|c|c|c|c|c|c|}
\hline WIND & $S P$ & 0 & CL & & ES (MPS \\
\hline CALM & 10 & & & WS & $<=$ \\
\hline 1 & 1 & & $5<$ & WS & $<=1$. \\
\hline 2 & $\square$ & 1. & $.8<$ & WS & $<=3$ \\
\hline 3 & ס & 3. & $.3<$ & WS & $<=5$. \\
\hline 4 & סדם & 5 & $.4<$ & WS & $<=8$ \\
\hline 5 & 매므 & 8 & $.5<$ & WS & $<=10$ \\
\hline & प1110 & 10 & $.8<$ & is & \\
\hline
\end{tabular}

99.9\% DATA RECOVERED

OF WHICH $30.5 \%$ IS

REPORTED ABOVE 


\section{SPILL TEST FACILITY 24 METER TOWER STABILITY CLASS D \\ 8 METER HEIGHT - Total Hours \\ $5 / 1 / 1994-5 / 31 / 1994$ \\ $0-2300$}
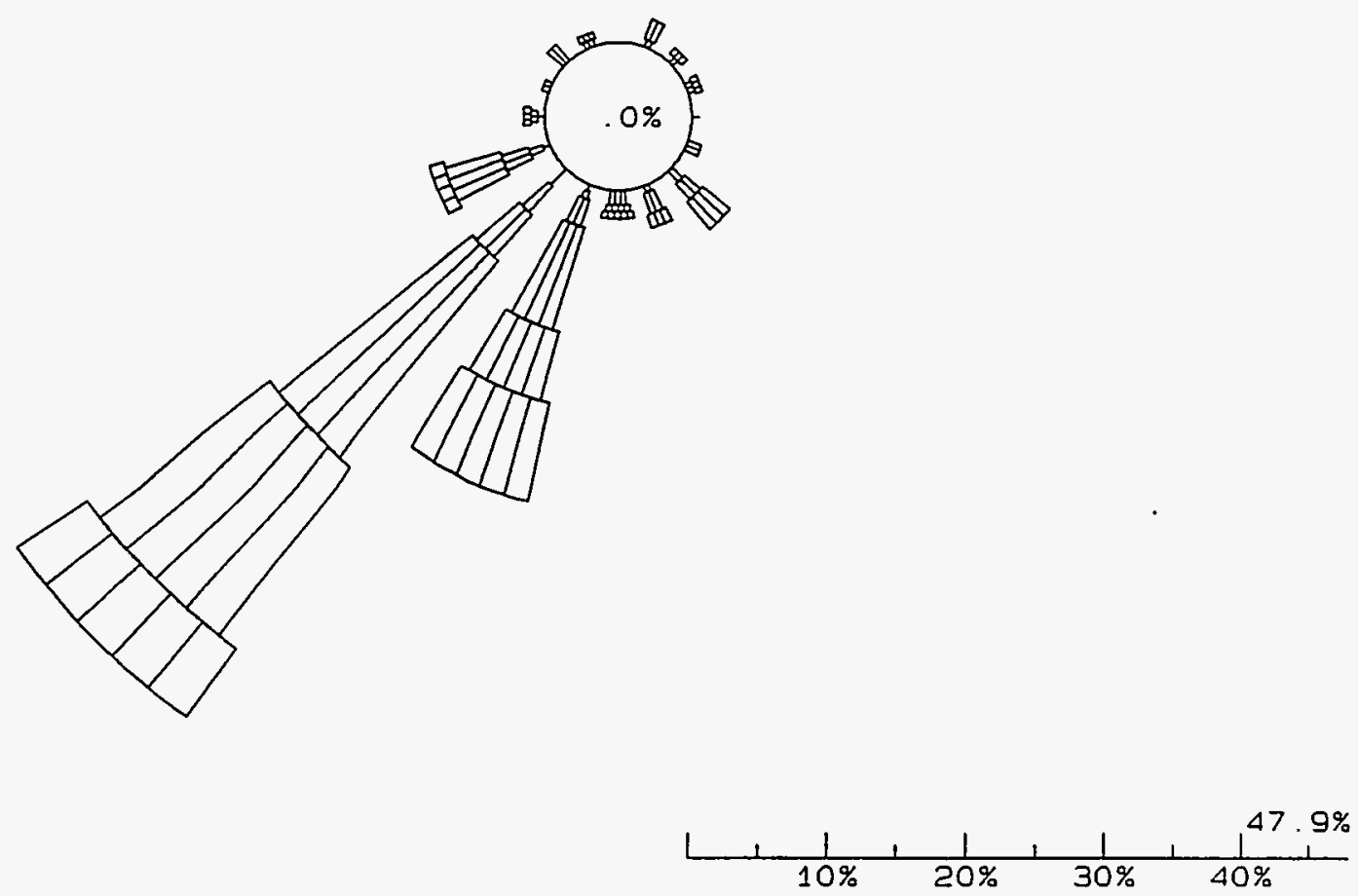

\begin{tabular}{|c|c|c|c|c|c|}
\hline WIND & $\checkmark S P$ & :ED & CLA & $A S S E$ & ES (MPS) \\
\hline CALM & 10 & & & WS & $<=$ \\
\hline 1 & 1 & & $5<$ & WS & $<=1.8$ \\
\hline 2 & 口 & 1 & $.8<$ & WS & $<=3.3$ \\
\hline 3 & ש & 3 & $.3<$ & WS & $<=5.4$ \\
\hline 4 & דा & 5 & $.4<$ & WS & $<=8.5$ \\
\hline 5 & כדण & 8 & $.5<$ & WS & $<=10.8$ \\
\hline$\sigma$ & II & & $8<$ & WS & \\
\hline
\end{tabular}

96.9\% DATA RECOVERED

OF WHICH $26.9 \%$ IS

REPORTED ABOVE 


\section{SPILL TEST FACILITY 24 METER TOWER STABILITY CLASS D \\ 8 METER HEIGHT - Total Hours \\ 6/ $1 / 1994-6 / 30 / 1994$ \\ $0-2300$}

$N$

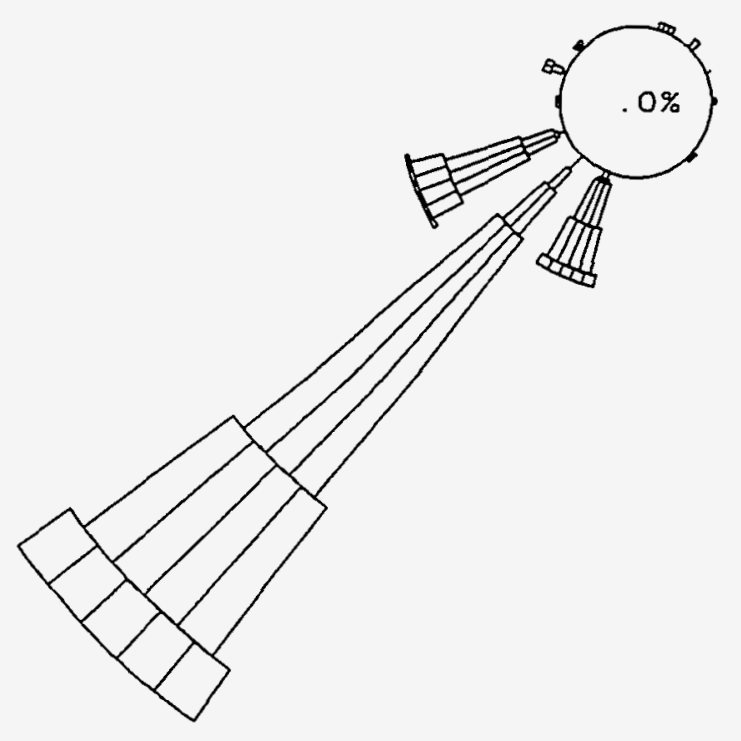

$\frac{1}{10 \%} \frac{1}{20 \%} \frac{1}{30 \%}+\frac{1}{40 \%}+\frac{1}{50 \%} \frac{1}{50 \%}$

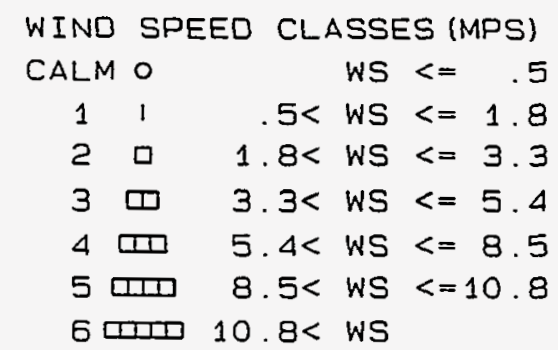

100.0\% DATA RECOVERED

OF WHICH $37.8 \%$ IS

REPORTED ABOVE 


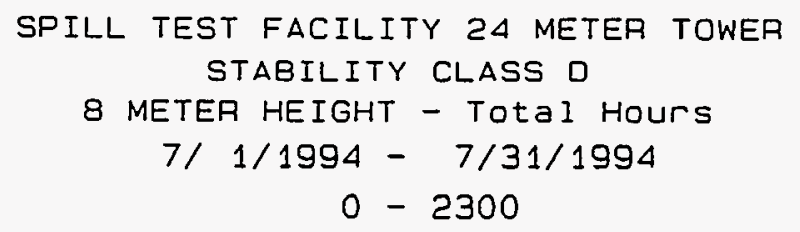

$N$
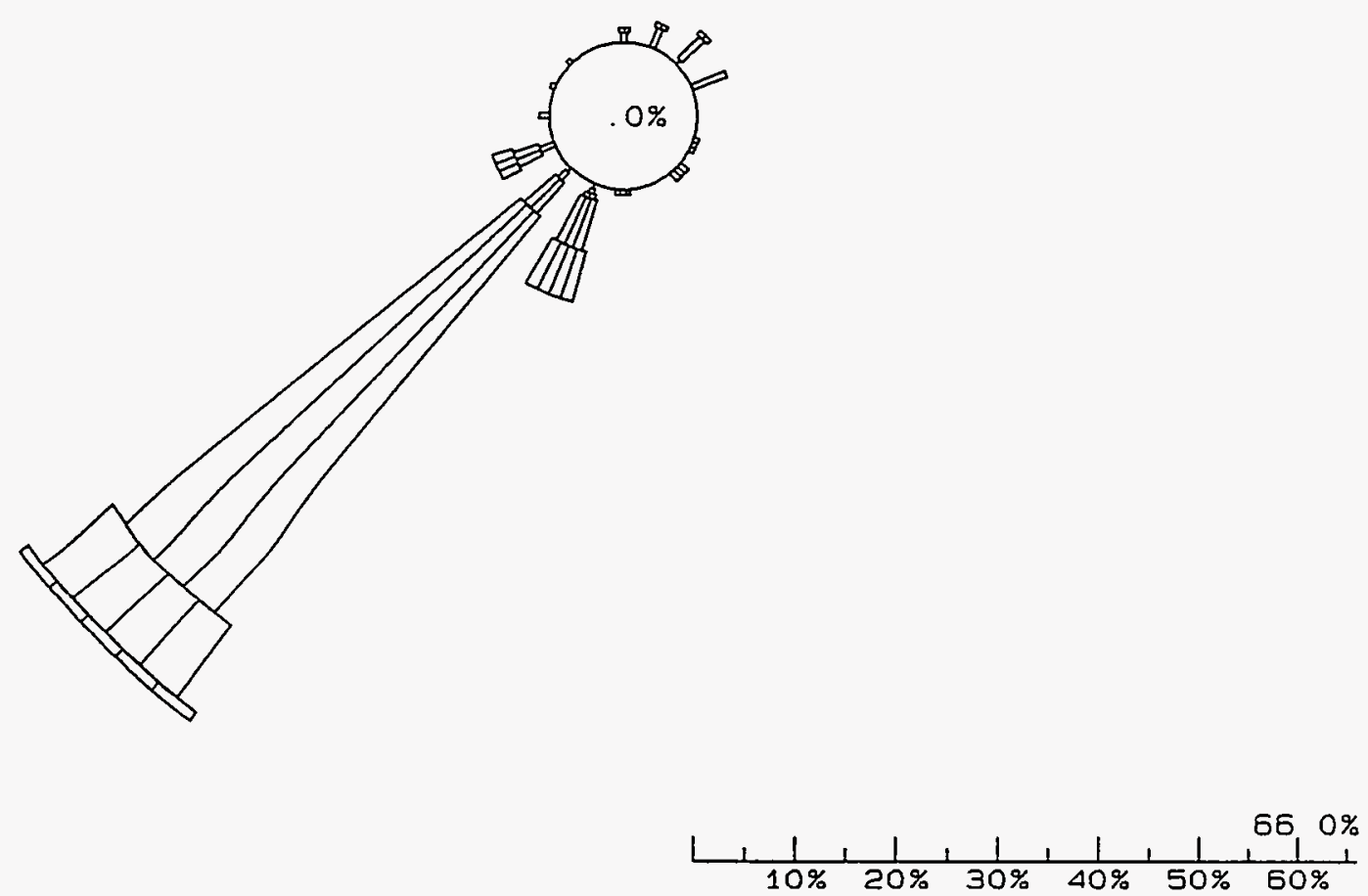

\begin{tabular}{|c|c|c|c|c|c|}
\hline WIND & SP & ED & CLA & $S S$ & S (MP'S) \\
\hline CALM & 10 & & & WS & $<=$ \\
\hline 1 & 1 & & $5<$ & WS & $<=1.8$ \\
\hline 2 & 0 & 1 & $.8<$ & WS & $<=3.3$ \\
\hline 3 & ש & 3 & $.3<$ & WS & $<=5.4$ \\
\hline 4 & דाप & 5 & $.4<$ & WS & $c=8.5$ \\
\hline 5 & पापा & 8 & $.5<$ & WS & $<=10.8$ \\
\hline 65 & דוIד & 10 & $.8<$ & WS & \\
\hline
\end{tabular}

100.0\% DATA RECOVERED

OF WHICH 26.1\% IS

REPORTED ABOVE 


\section{SPILL TEST FACILITY 24 METER TOWER STABILITY CLASS D \\ 8 METER HEIGHT - Total Hours \\ $8 / 1 / 1994-8 / 31 / 1994$ \\ $0-2300$}

$N$
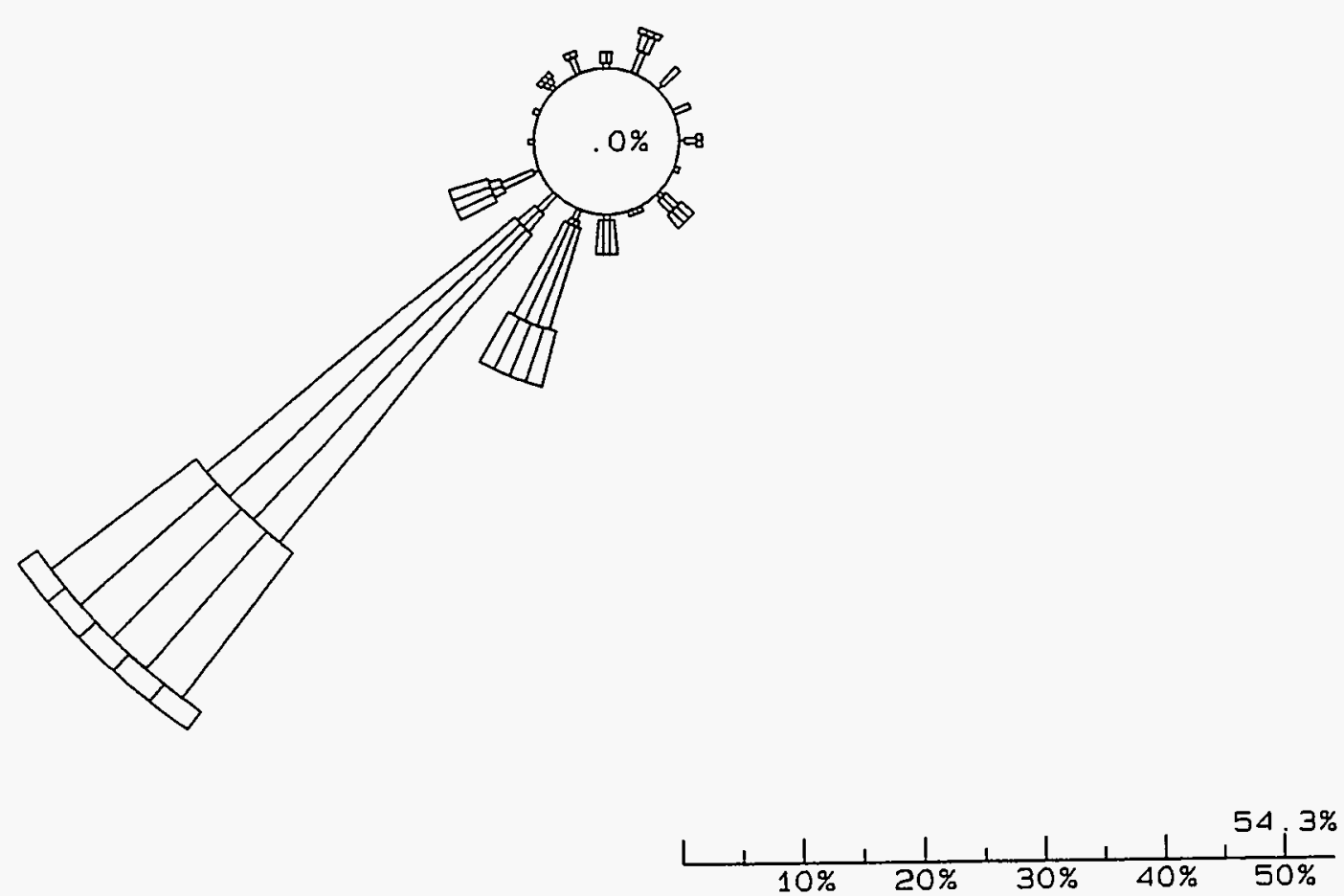

\begin{tabular}{|c|c|c|c|c|c|}
\hline WIND & \multirow{2}{*}{\multicolumn{2}{|c|}{$\begin{array}{l}\text { SPEED } \\
10\end{array}$}} & \multicolumn{3}{|c|}{ CLASSES (MPS) } \\
\hline CALM & & & & WS & $<=$ \\
\hline 1 & 1 & & $.5<$ & WS & $<=1.8$ \\
\hline 2 & $\square$ & 1 & $1.8<$ & WS & $<=3.3$ \\
\hline 3 & $\square$ & 3 & $3.3<$ & WS & $<=5.4$ \\
\hline$\Delta$ & סד & 5 & $5.4<$ & WS & $<=8.5$ \\
\hline 5 & סחים & $\varepsilon$ & $3.5<$ & WS & $<=10.8$ \\
\hline 65 & पा1 & & $.8<$ & WS & \\
\hline
\end{tabular}

100.0\% DATA RECOVERED

OF WHICH $28.2 \%$ IS

REPORTED ABOVE 


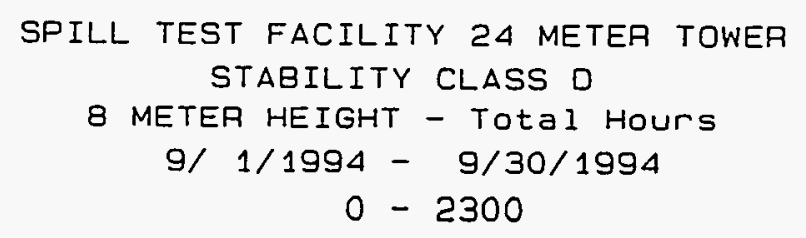

$N$

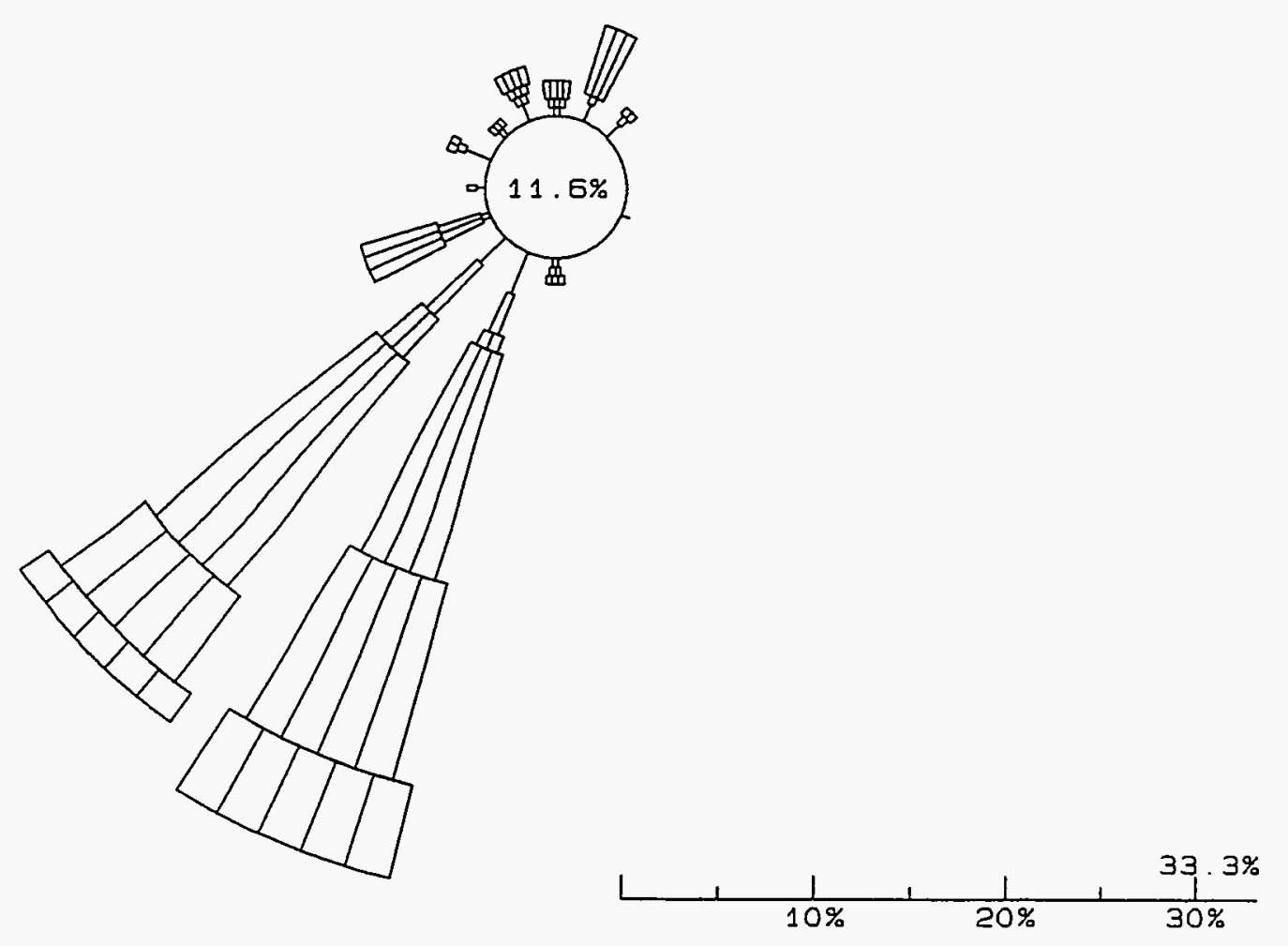

99.2\% DATA RECOVERED

OF WHICH $30.3 \%$ IS

REPORTED ABOVE 


\section{SPILL TEST FACILITY 24 METER TOWER STABILITY CLASS D \\ 8 METER HEIGHT - Total Hours \\ 10/ $1 / 1994$ - 10/31/1994 \\ $0-2300$}

$N$
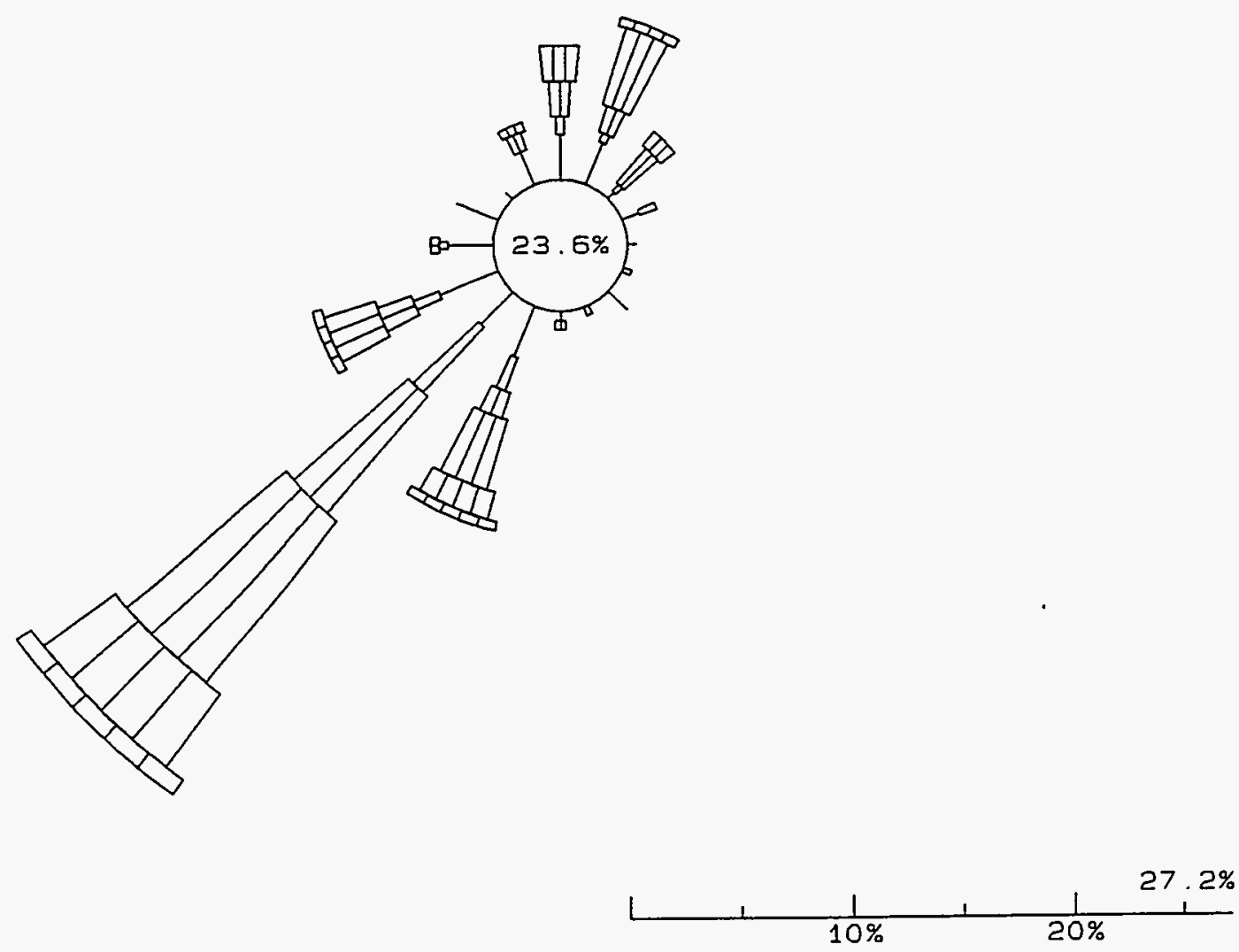

\begin{tabular}{|c|c|c|c|c|c|}
\hline WIND & $S P$ & ED & $C L$ & $\Delta S S$ & $S$ (MPS) \\
\hline CALM & 10 & & & WS & $<=$ \\
\hline 1 & 1 & & $5<$ & WS & $<=1.8$ \\
\hline 2 & 口 & 1 & $8<$ & WS & $<=3.3$ \\
\hline 3 & $\square$ & 3 & $3<$ & WS & $<=5.4$ \\
\hline 4 & סד & 5 & $4<$ & WS & $<=8.5$ \\
\hline 5 & पण & 8 & $5<$ & WS & $<=10.8$ \\
\hline 60 & ㅁ11 & 10 & $8<$ & WS & \\
\hline
\end{tabular}

98.5\% DATA RECOVERED

OF WHICH $33.6 \%$ IS

REPORTED ABOVE 


\section{SPILL TEST FACILITY 24 METER TOWER STABILITY CLASS D \\ 8 METER HEIGHT - Total Hours $11 / 1 / 1994-11 / 30 / 1994$ \\ $0-2300$}
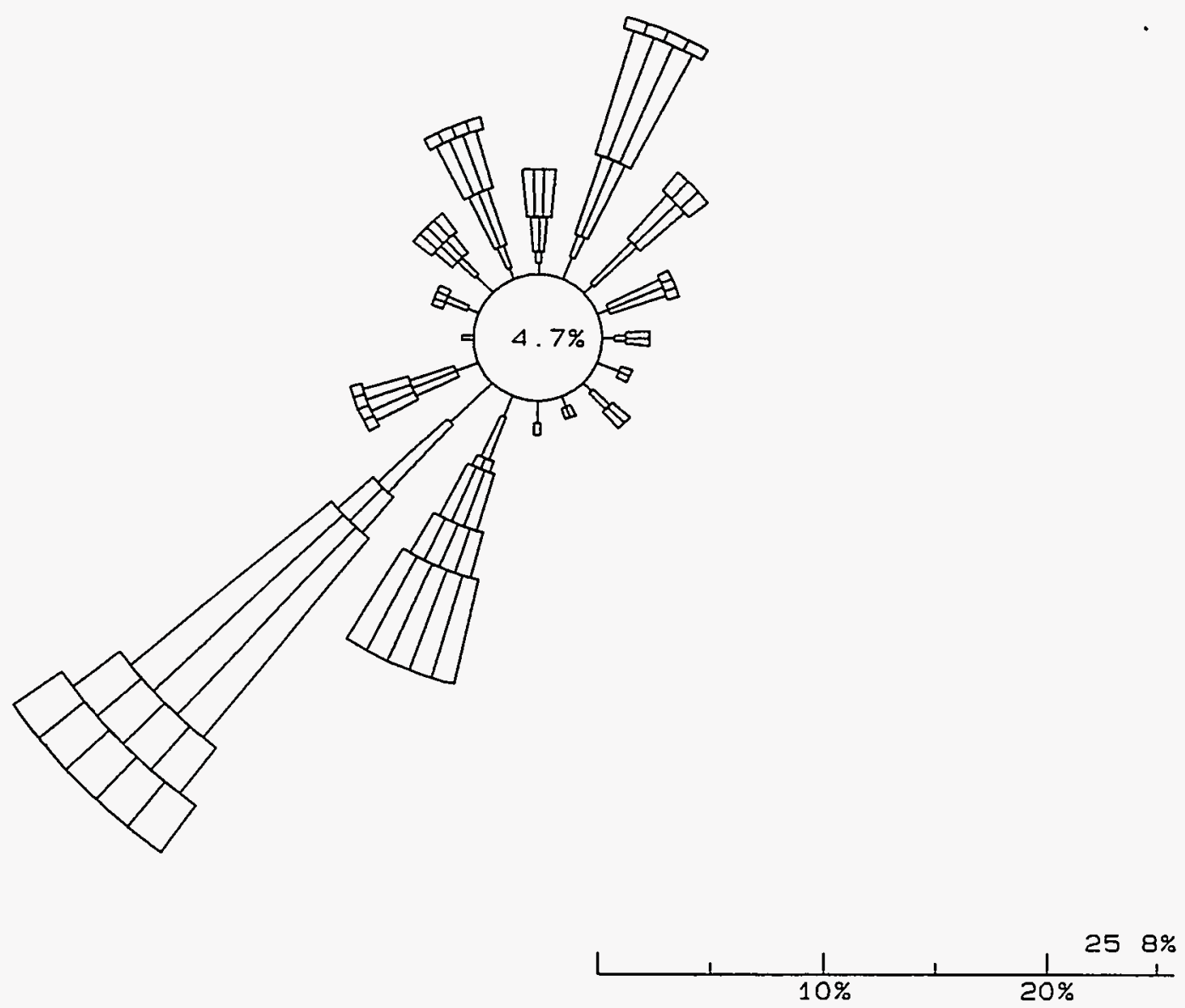

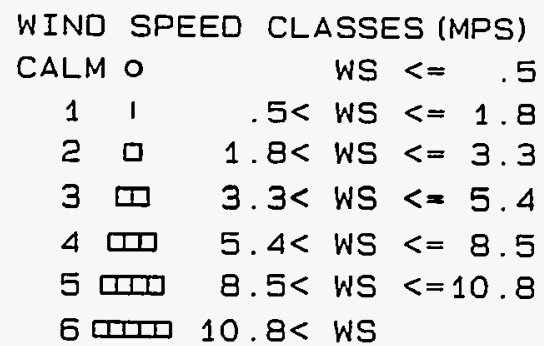

99.7\% DATA RECOVERED

OF WHICH 26.5\% IS

REPORTED ABOVE 


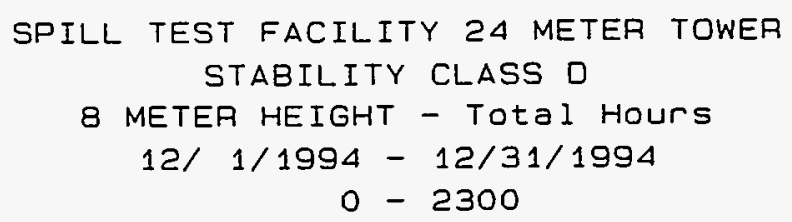

$N$
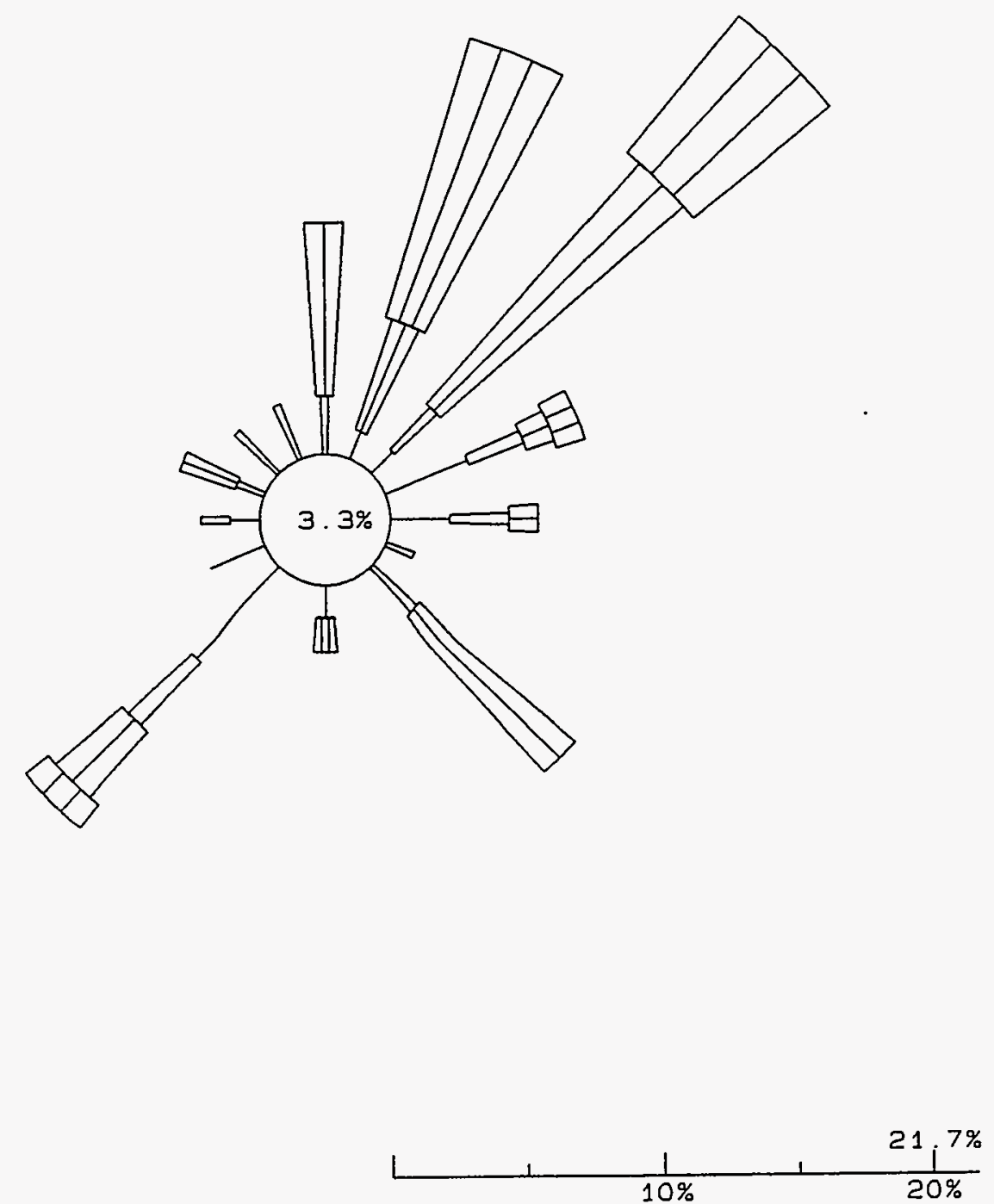

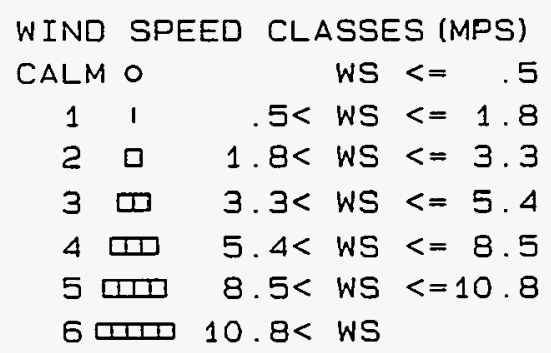

65. 1\% DATA RECOVERED

OF WHICH 19.0\% IS

REPORTED ABOVE 


\section{SPILL TEST FACILITY 24 METER TOWER STABILITY CLASS E \\ 8 METER HEIGHT - Total Hours \\ $1 / 1 / 1994-1 / 31 / 1994$ \\ $0-2300$}

N
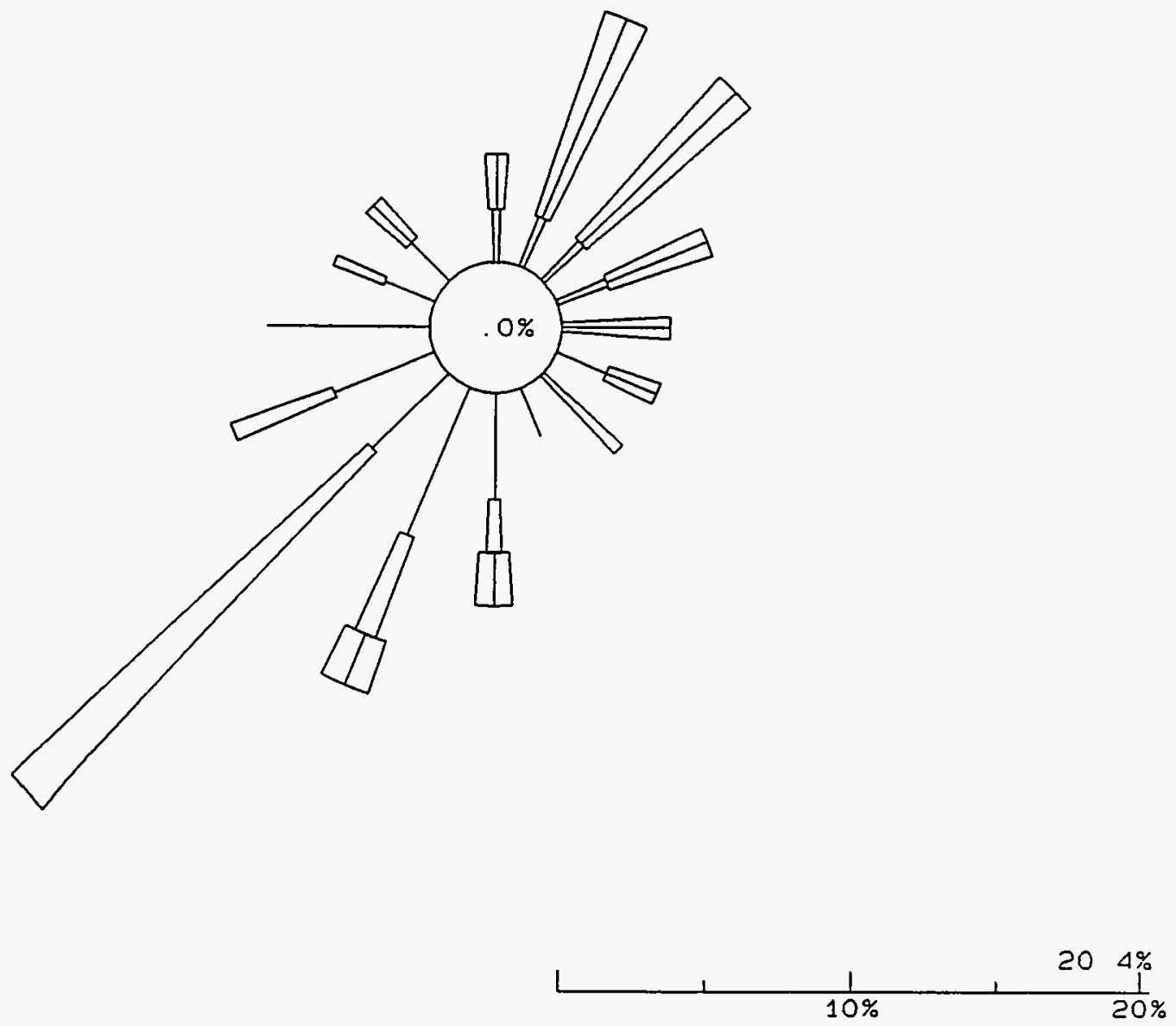

78. O\% DATA RECOVERED

OF WHICH $9.3 \%$ IS

REPORTED ABOVE 


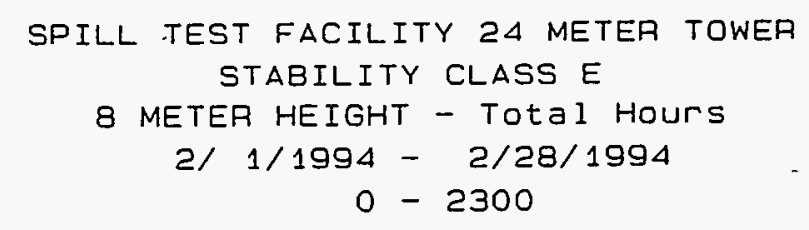

$N$
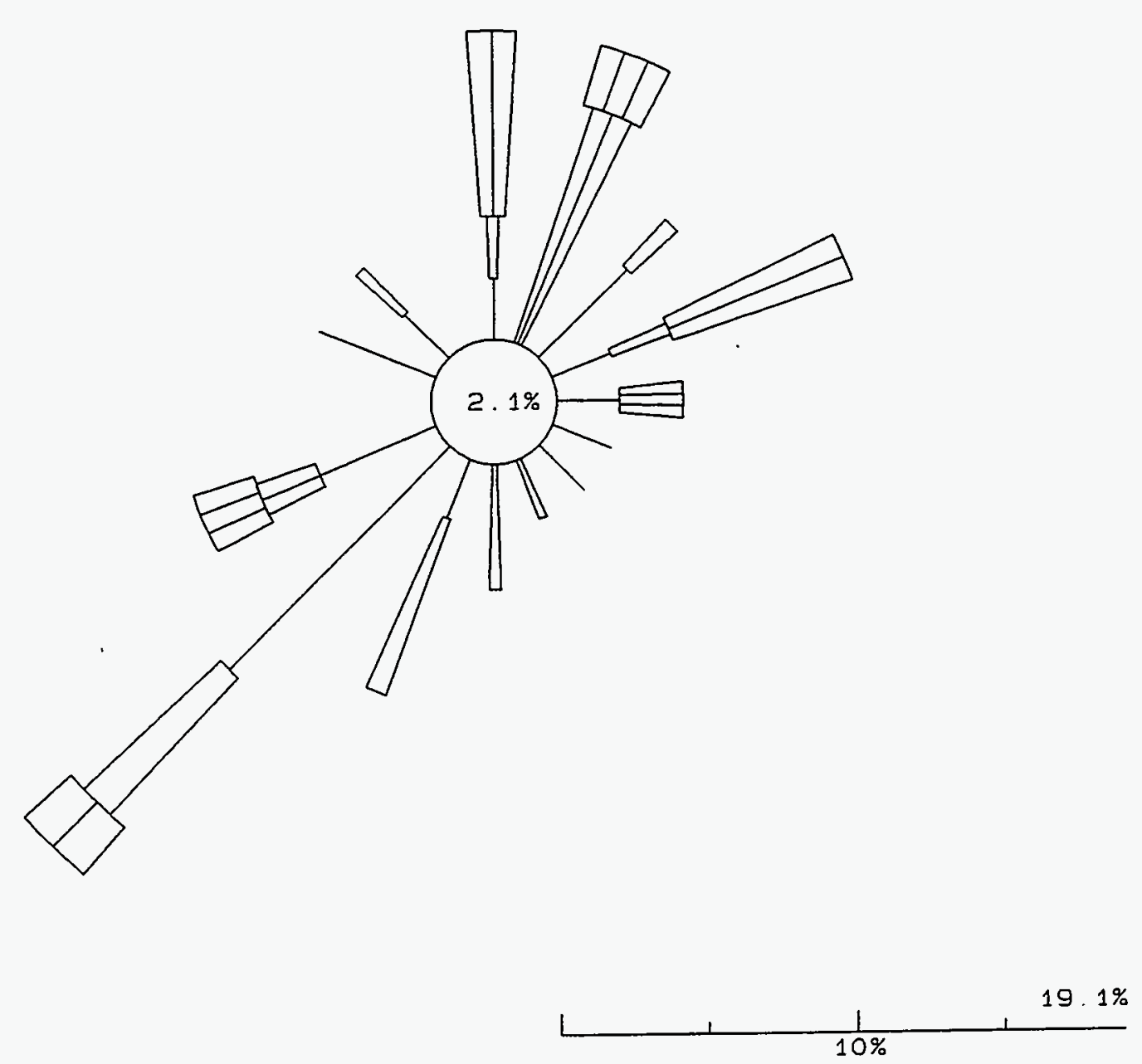

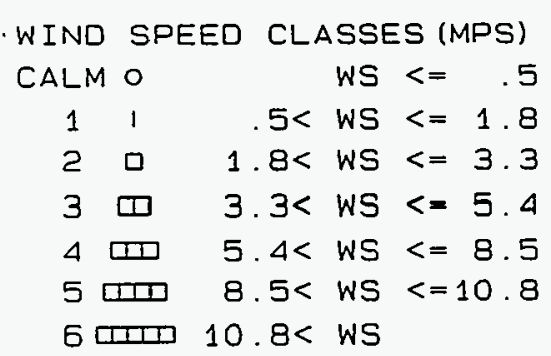

85. 4\% DATA RECOVERED

OF WHICH $8.2 \%$ IS REPORTED ABOVE 


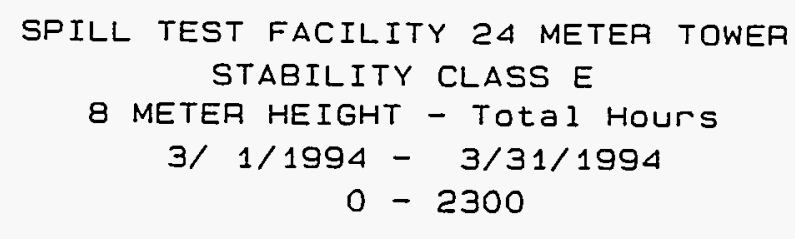

$N$

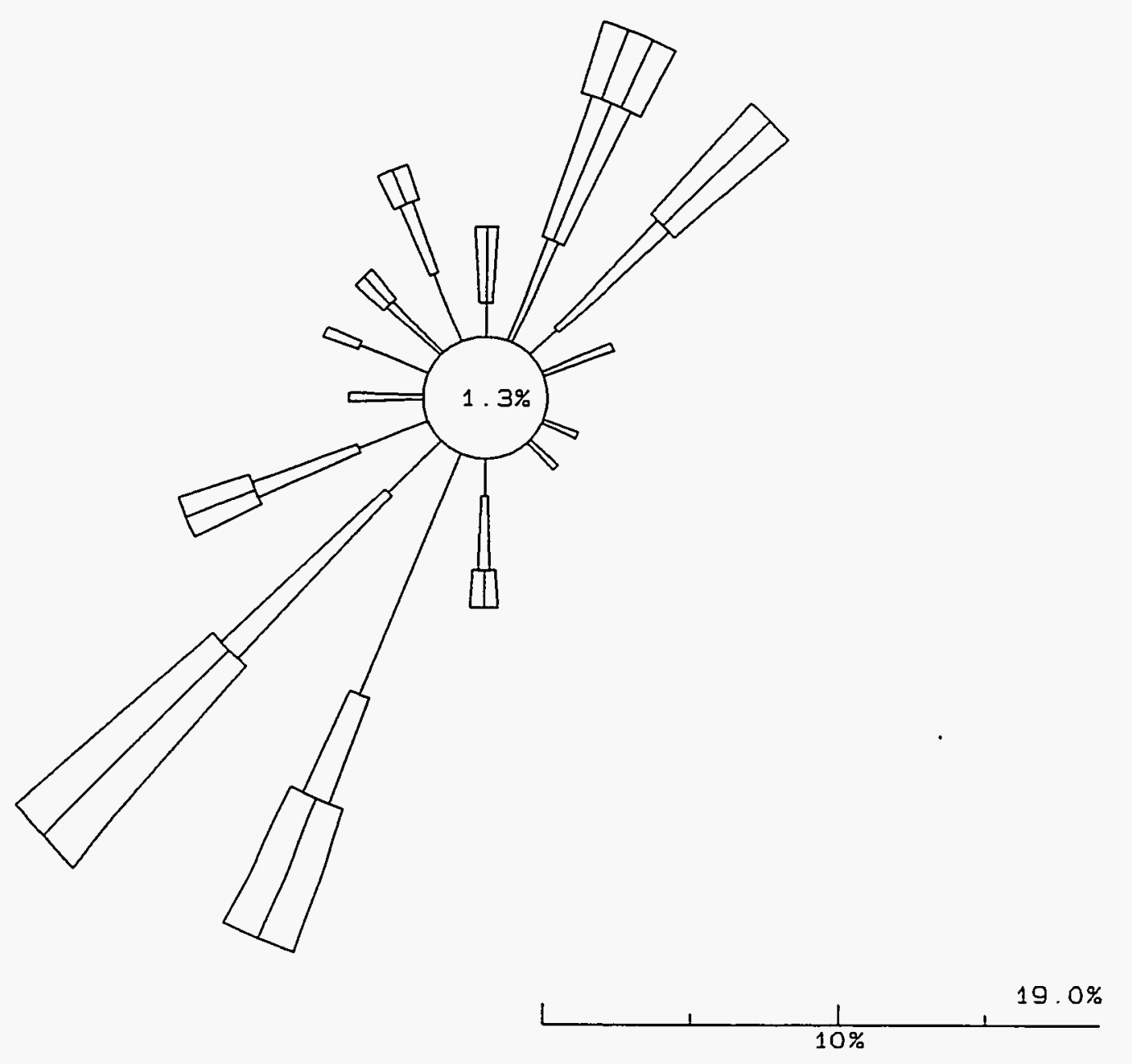

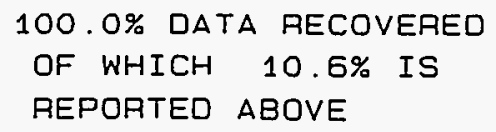

$11.5<$ WS $<=1.8$

$2 \square \quad 1.8<$ WS $<=3.3$

3 ए $3.3<$ WS $<=5.4$

4 III $5.4<$ WS $<=8.5$

5 페 $8.5<$ WS $<=10.8$

6 पामा $10.8<$ WS 


\section{SPILL TEST FACILITY 24 METEA TOWEA \\ STABILITY CLASS E \\ 8 METER HEIGHT - Total Hours \\ $4 / 1 / 1994-4 / 30 / 1994$ \\ $0-2300$}

N
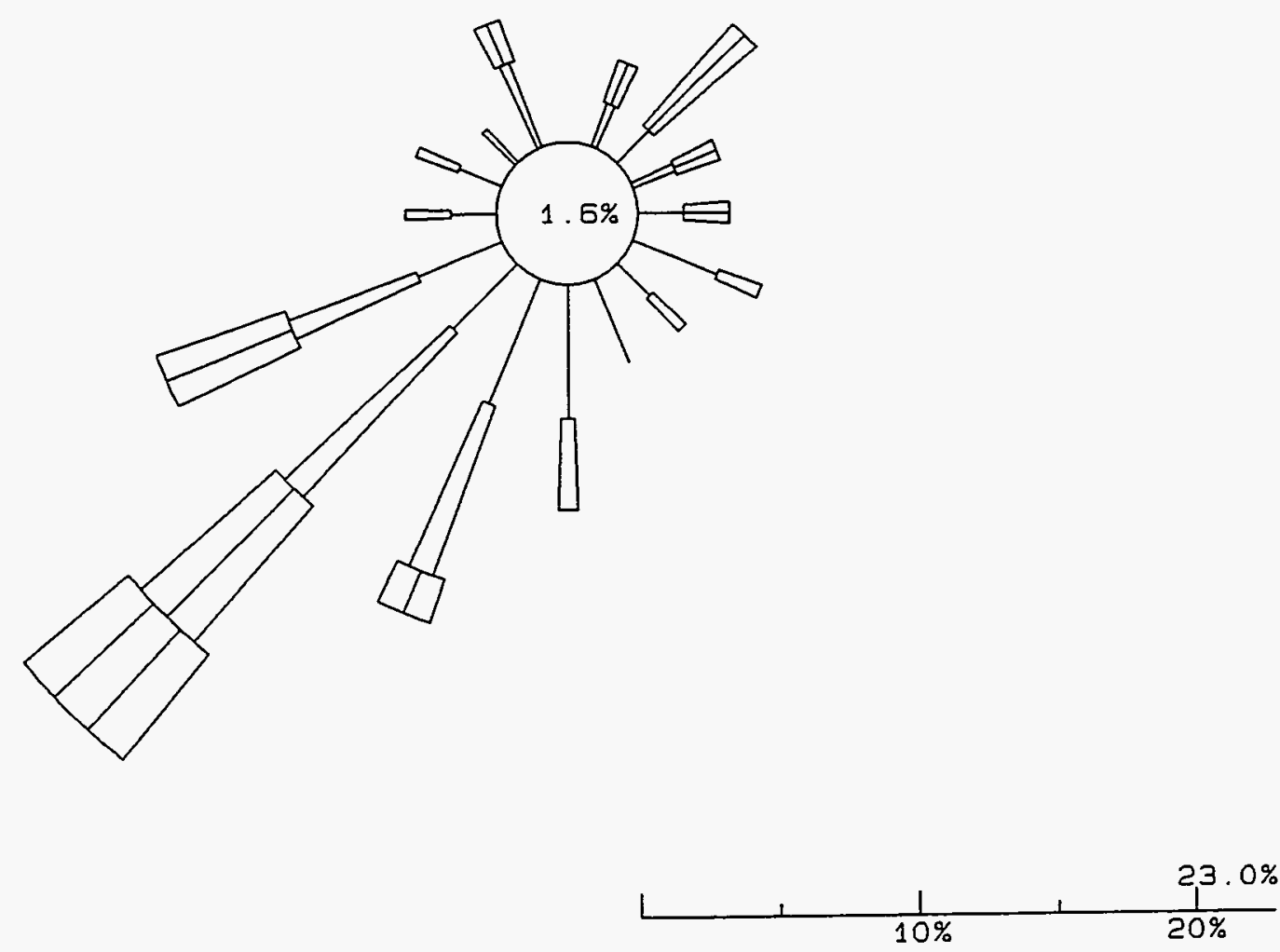

\begin{tabular}{|c|c|c|c|c|}
\hline WIND & SPE & ED CLA & ASSE & ES IMPS \\
\hline CALM & 10 & & wS & $<=$ \\
\hline 1 & 1 & $5<$ & wS & $<=1.8$ \\
\hline 2 & ( & $1.8<$ & WS & $<=3.3$ \\
\hline 3 & ه & $3.3<$ & WS & $<=5 . \angle$ \\
\hline 4 & שس & $5.4<$ & WS & $<=8.5$ \\
\hline 5 & שח & $8.5<$ & WS & $<=10$. \\
\hline 6 & एत्या & $10.8<$ & WS & \\
\hline
\end{tabular}

99.9\% DATA RECOVERED

OF WHICH $8.5 \%$ IS

REPORTED ABOVE 


\section{SPILL TEST FACILITY 24 METER TOWER \\ STABILITY CLASS E \\ 8 METER HEIGHT - Total Hours \\ $5 / 1 / 1994-5 / 31 / 1994$ \\ $0-2300$}

N

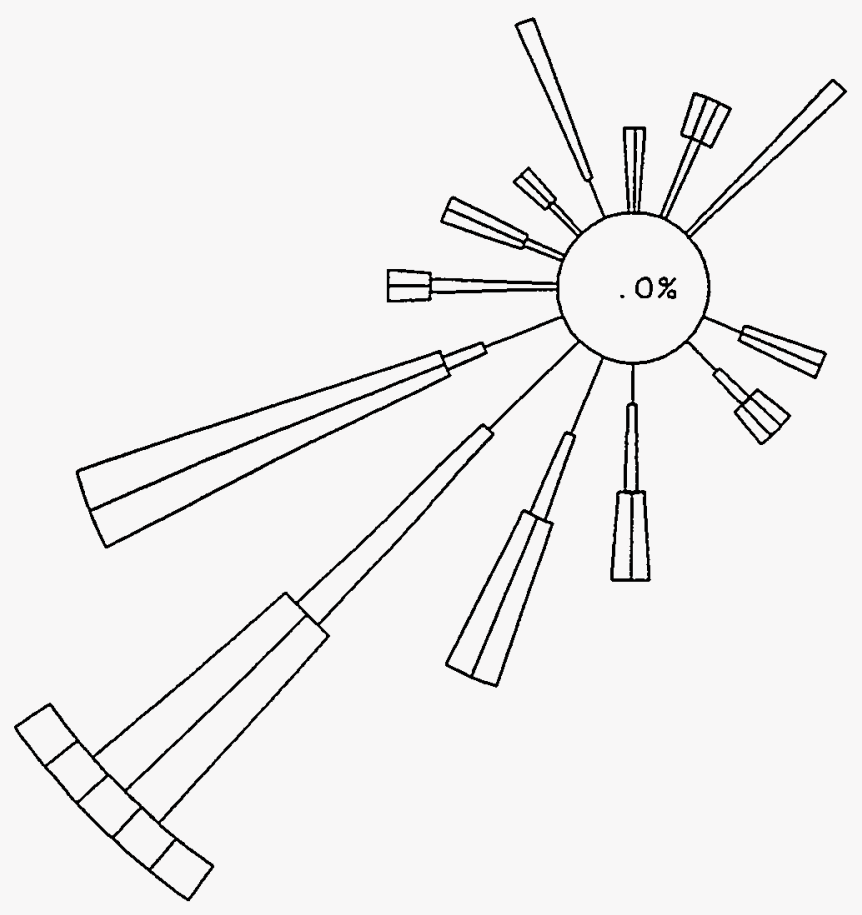

\begin{tabular}{|c|c|c|c|c|c|}
\hline NIND & $S P E$ & $E D$ & $C L$ & של & ES $1 \mathrm{MPS}$ \\
\hline CALM & 10 & & & WS & $<=$ \\
\hline 1 & 1 & & $.5<$ & WS & $<=1.8$ \\
\hline ? & 口 & 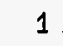 & $.8<$ & WS & $<=3.3$ \\
\hline 3 & ष & 3 & $3<$ & WS & $<=5$. \\
\hline 4 & דשי & 5 & $.4<$ & WS & $<=8$. \\
\hline 5 & पाम & 8 & $.5<$ & WS & $<=10$. \\
\hline & סा1 & 10 & $8<$ & WS & \\
\hline
\end{tabular}

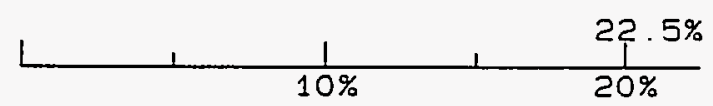

96. 9\% DATA RECOVERED

OF WHICH $9.8 \%$ IS REPORTED ABOVE 


\section{SPILL TEST FACILITY 24 METER TOWEA \\ STABILITY CLASS E \\ 8 METER HEIGHT - Total Hours \\ $6 / 1 / 1994-5 / 30 / 1994$ \\ $0-2300$}

$N$

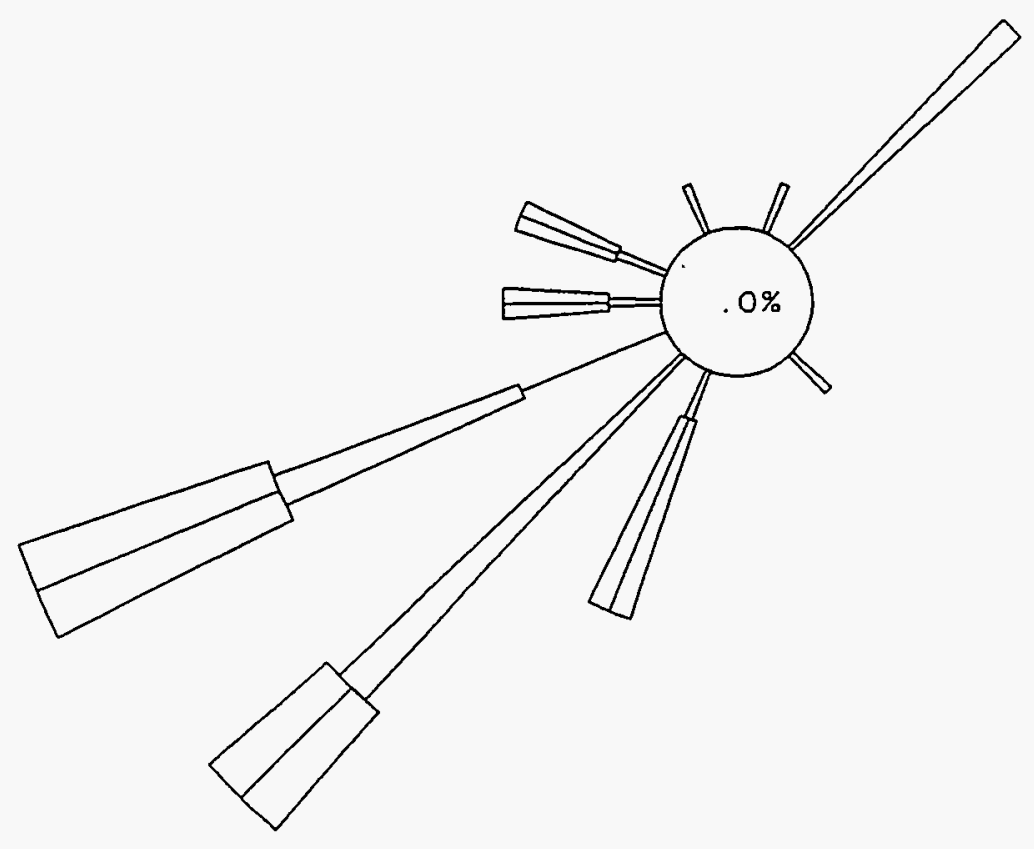

WIND SPEED CLASSES (MPS)

CALM O

11

20

3 미

4 पा

5 패마

6 प्या1
WS $<=.5$

$.5<W S<=1.8$

$1.8<$ WS $<=3.3$

$3.3<$ WS $<=5.4$

$5.4<W S<=8.5$

$8.5<$ WS $<=10.8$

$10.8<$ WS
100. O\% DATA RECOVERED

OF WHICH $6.3 \%$ IS

REPORTED ABOVE 


\section{SPILL TEST FACILITY $2 \triangle$ METER TOWER STABILITY CLASS E \\ 8 METER HEIGHT - Total Hours \\ $7 / 1 / 1994$ - 7/31/1994 \\ $0-2300$}

$N$
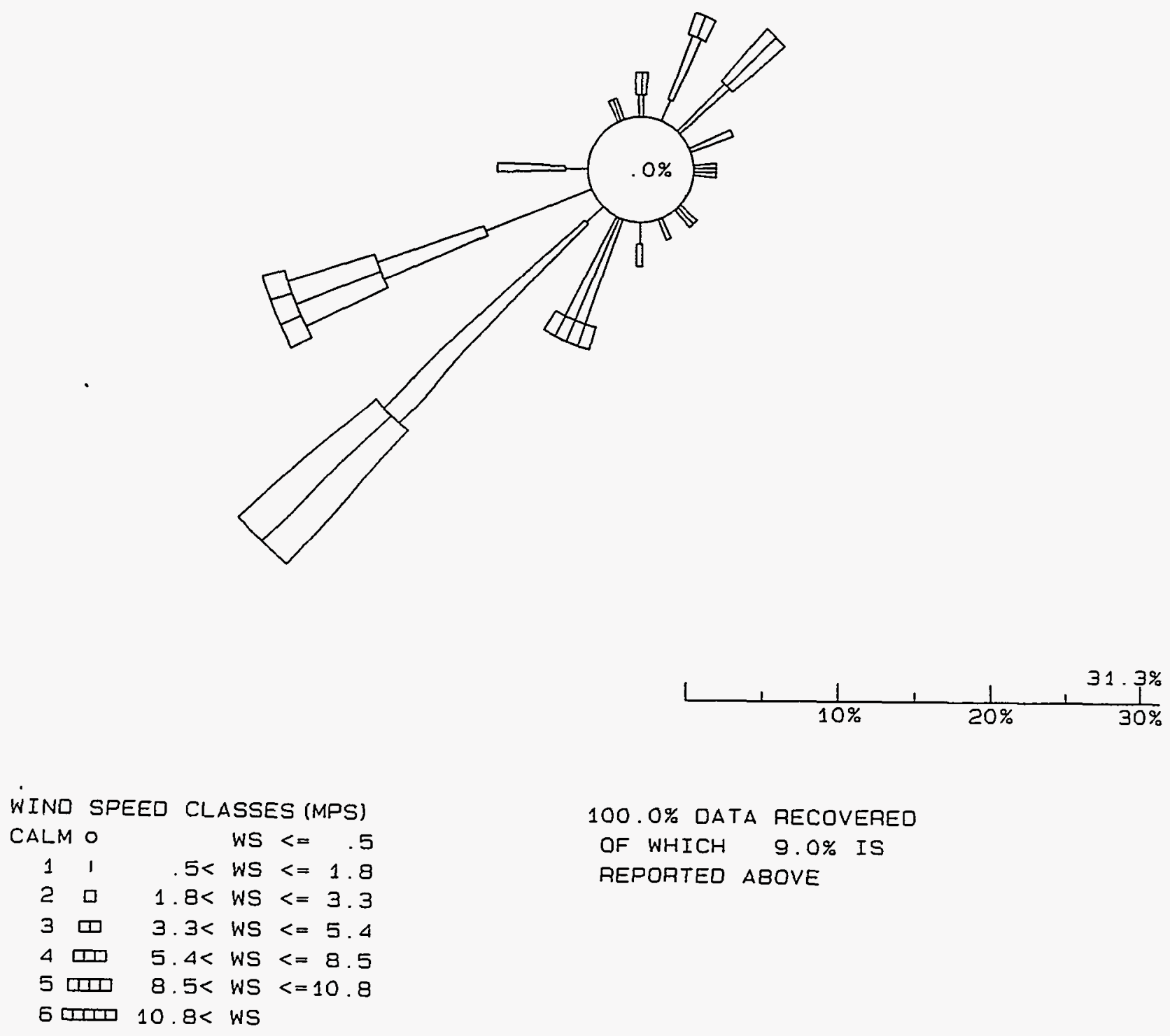


\section{SPILL TEST FACILITY 24 METER TOWER \\ STABILITY CLASS E \\ 8 METER HEIGHT - Total Hours \\ $8 / 1 / 1994-8 / 31 / 1994$ \\ $0-2300$}

$N$
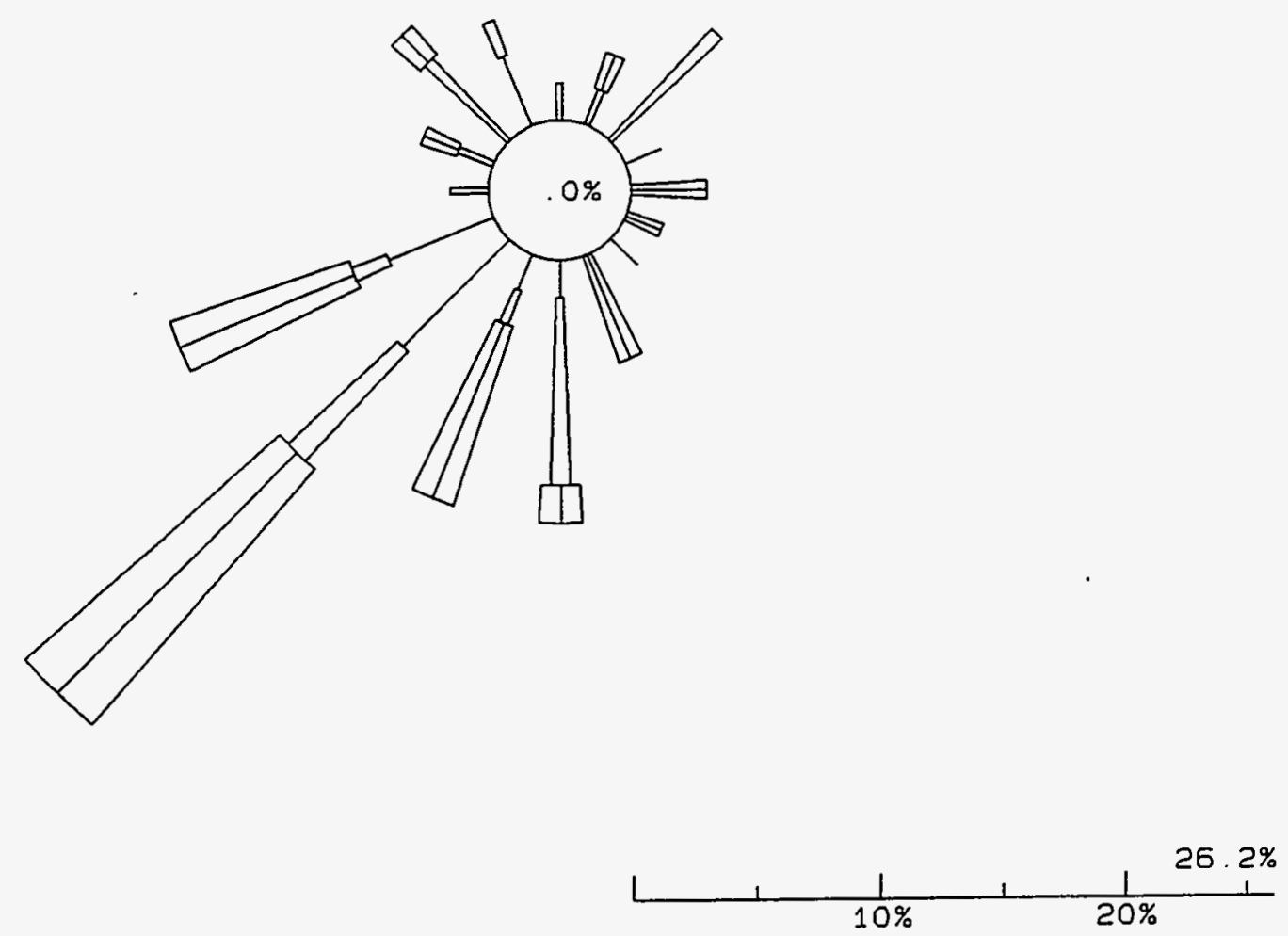

100.0\% DATA RECOVERED

OF WHICH $8.7 \%$ IS

REPORTED ABOVE 


\section{SPILL TEST FACILITY 24 METER TOWER STABILITY CLASS E \\ 8 METER HEIGHT - Total Hours \\ 9/ $1 / 1994-9 / 30 / 1994$

$$
0-2300
$$

N
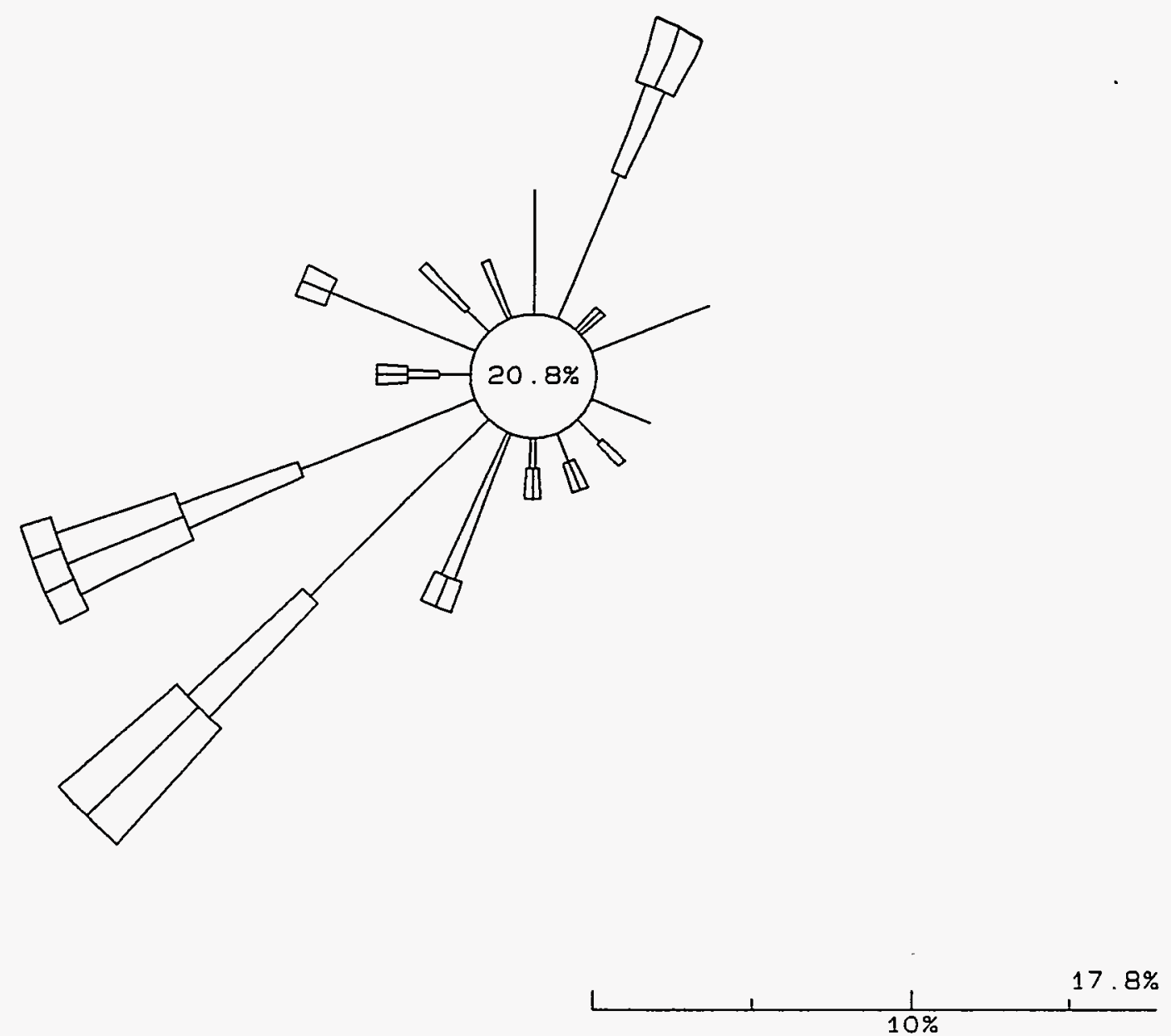

\begin{tabular}{|c|c|c|c|c|c|}
\hline WIND & $S P$ & ED & CL & ASSE & S (MPS) \\
\hline CALM & 10 & & & WS & $<=$ \\
\hline 1 & 1 & & $.5<$ & WS & $<=1.8$ \\
\hline 2 & $\square$ & 1 & $.8<$ & WS & $<=3.3$ \\
\hline 3 & $\mathbb{T}$ & 3 & $.3<$ & WS & $<=5.4$ \\
\hline 4 & דा & 5 & $.4<$ & WS & $<=8.5$ \\
\hline 5 & هחי & 8 & $.5<$ & WS & $<=10.8$ \\
\hline $6 c$ & DIIII & 10 & $.8<$ & WS & \\
\hline
\end{tabular}

99. 2\% DATA RECOVERED

OF WHICH 14.1\% IS

REPORTED ABOVE 


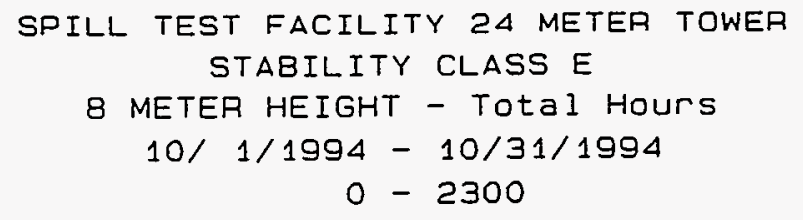

$N$
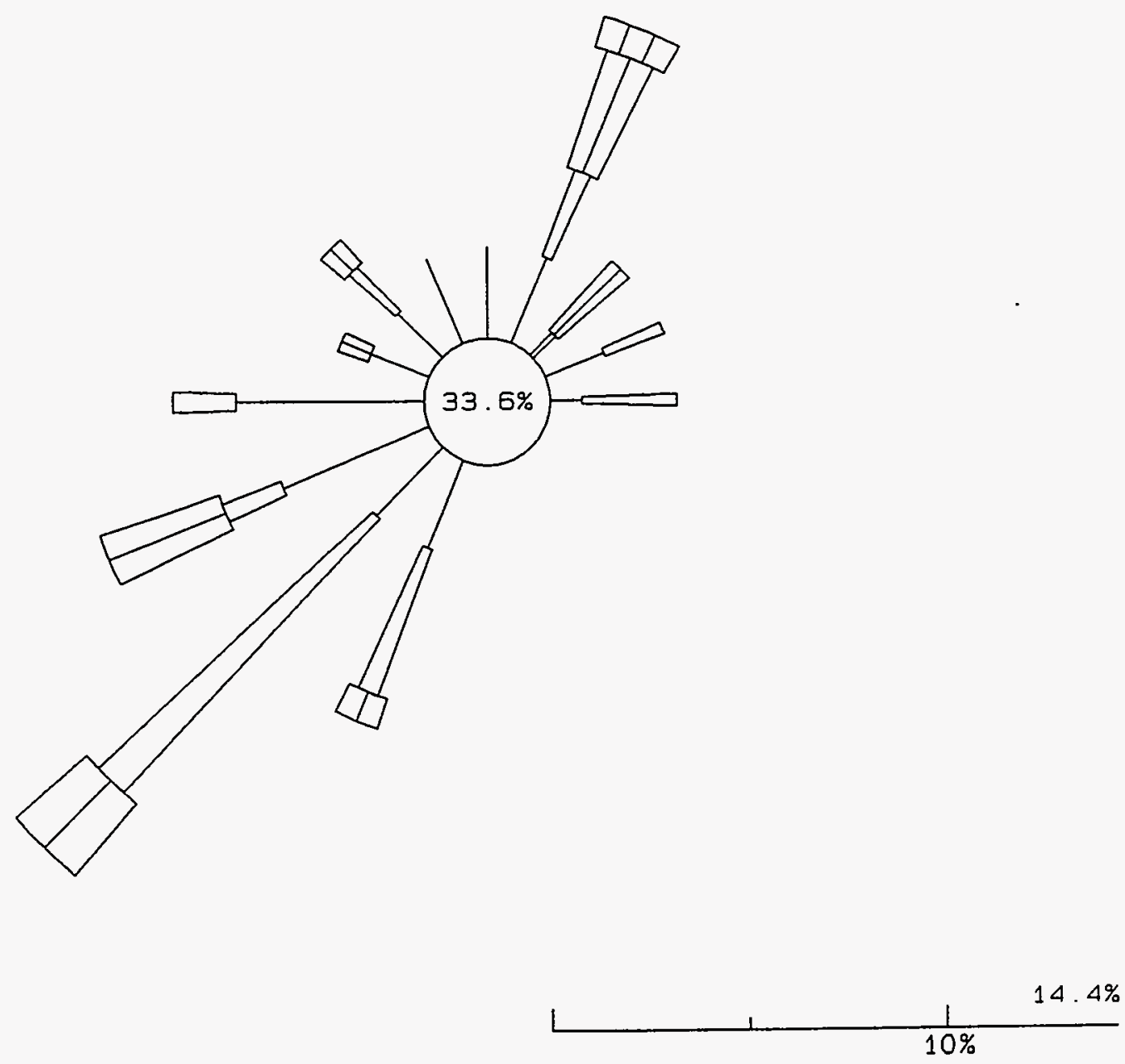

98.5\% DATA RECOVERED

OF WHICH $17.1 \%$ IS

REPORTED ABOVE 


\section{SPILL TEST FACILITY 24 METER TOWER \\ STABILITY CLASS E \\ 8 METER HEIGHT - Total Hours \\ $11 / 1 / 1994-11 / 30 / 1994$ \\ $0-2300$}

$N$

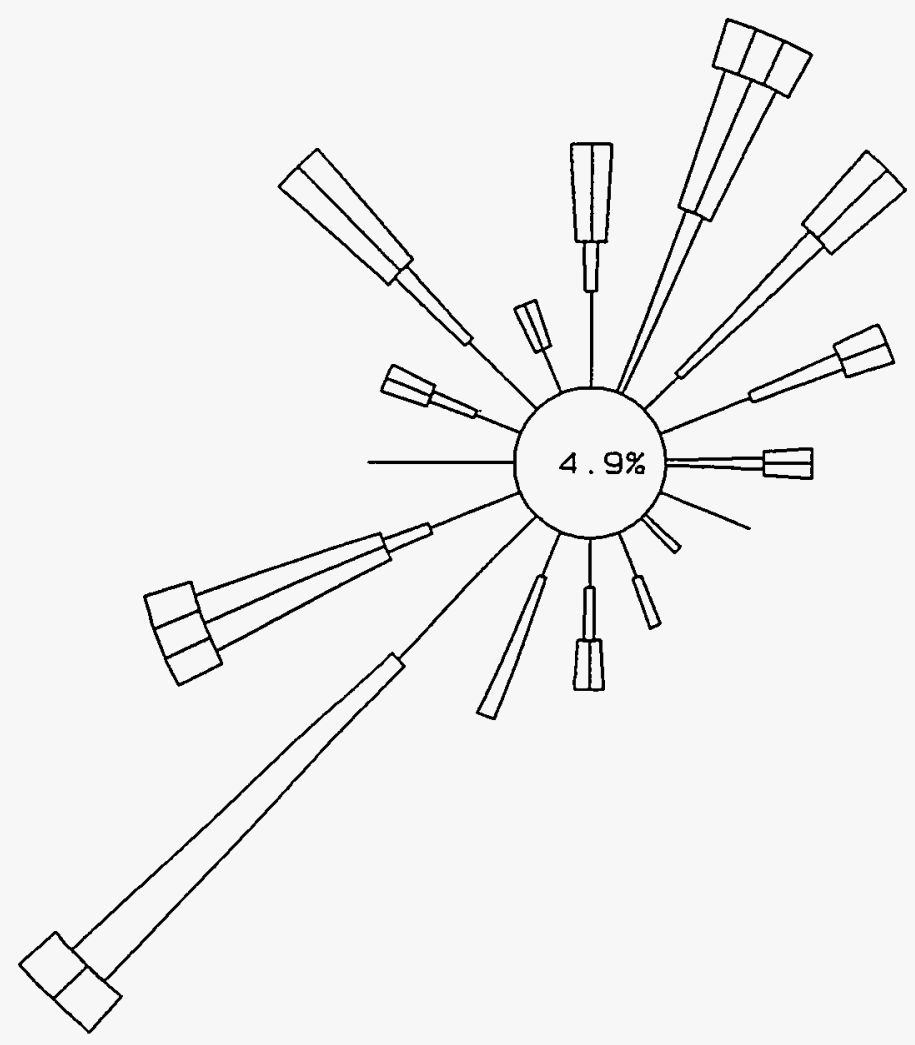

\begin{tabular}{|c|c|c|c|c|c|}
\hline NIND & SPE & $E D$ & CL & SS & ES (MPS) \\
\hline CALM & 10 & & & WS & $<=$ \\
\hline 1 & I & & $.5<$ & WS & $<=1.8$ \\
\hline 2 & 口 & 1. & $.8<$ & WS & $c=3.3$ \\
\hline 3 & ד & 3. & $3<$ & WS & $c=5.4$ \\
\hline 4 & שים & 5. & $4<$ & WS & $c=8.5$ \\
\hline 5 & דיד & 8 & $5<$ & WS & $<=10.8$ \\
\hline 60 & סדسד & 10. & $.8<$ & WS & \\
\hline
\end{tabular}

99.7\% DATA RECOVERED

OF WHICH 11.3\% IS

REPORTED ABOVE 


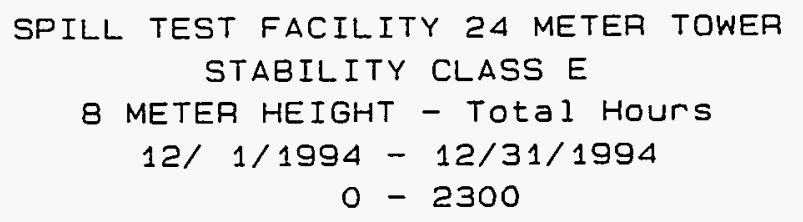

N
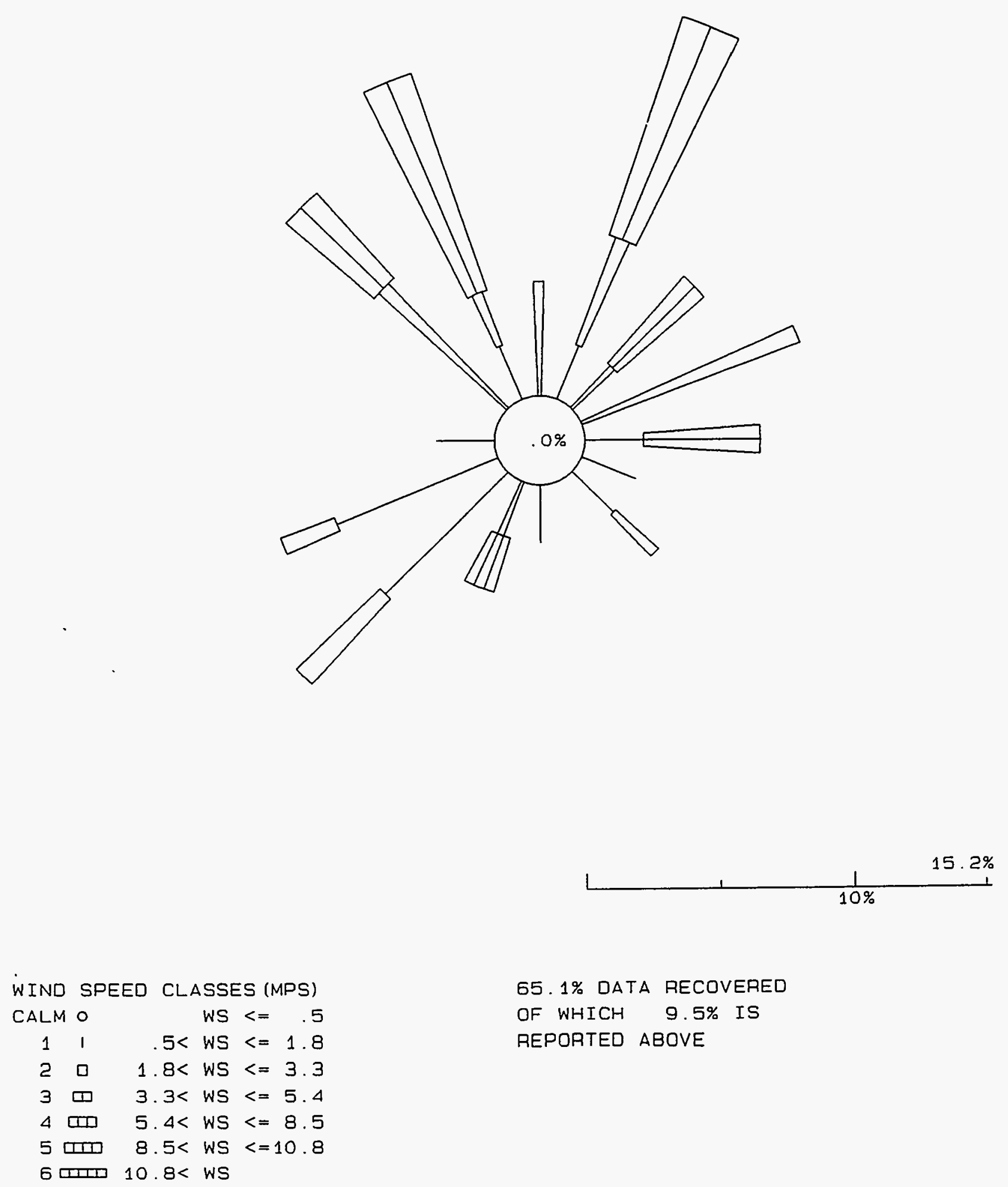

65. 1\% DATA RECOVERED

OF WHICH $9.5 \%$ IS

REPORTED ABOVE 


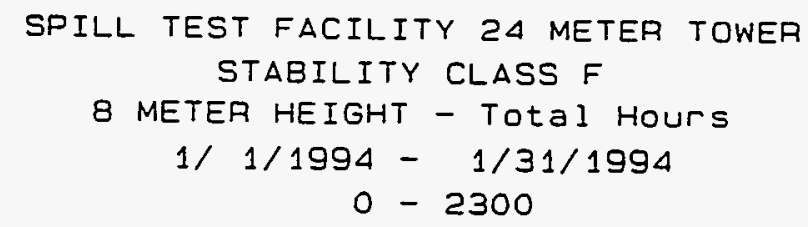

$N$

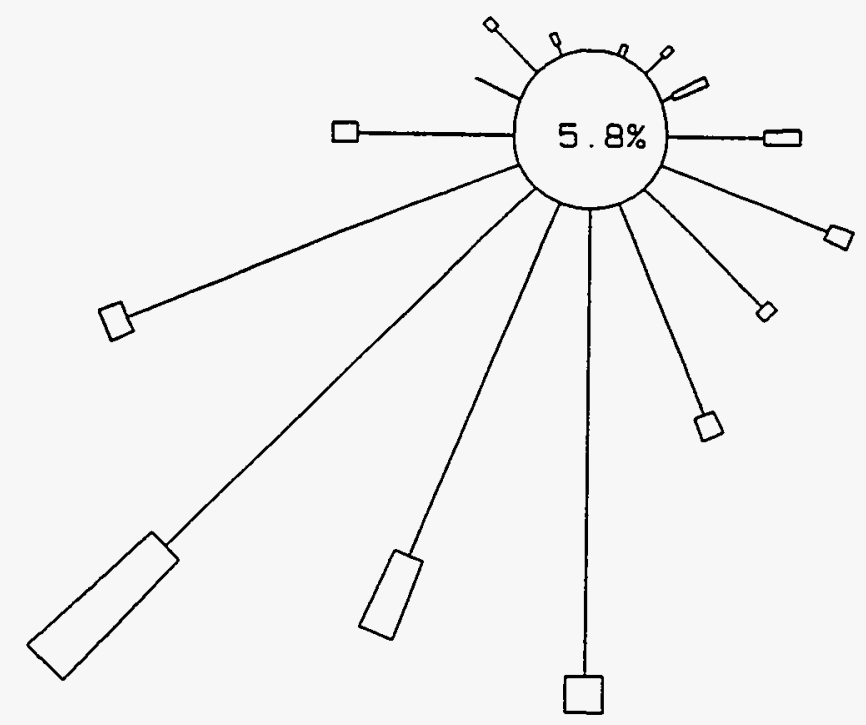

\begin{tabular}{|c|c|c|c|c|c|}
\hline WIND & $S P$ & ED & $C L$ & $A S S E$ & $=S$ (MPS) \\
\hline CALM & 10 & & & WS & $<=$ \\
\hline 1 & 1 & & $.5<$ & WS & $<=1.8$ \\
\hline 2 & $\square$ & 1 & $.8<$ & WS & $c=3.3$ \\
\hline 3 & דם & 3 & $.3<$ & WS & $<=5.4$ \\
\hline 4 & ס्ण & 5 & $.4<$ & WS & $<=8.5$ \\
\hline 50 & पाप & 8 & $5<$ & WS & $<=10.8$ \\
\hline 6 & पाII & 10 & $.8<$ & WS & \\
\hline
\end{tabular}

78. O\% DATA RECOVEAED

OF WHICH $50.2 \%$ IS

REPOATED ABOVE 


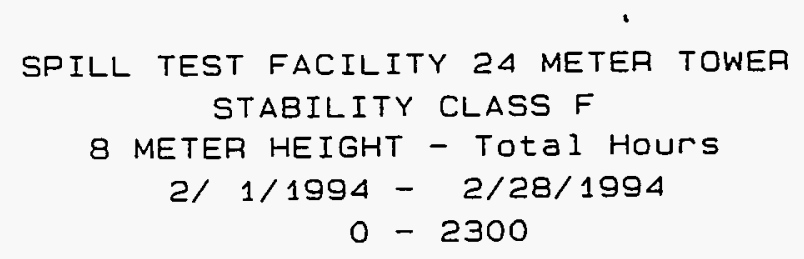

$N$
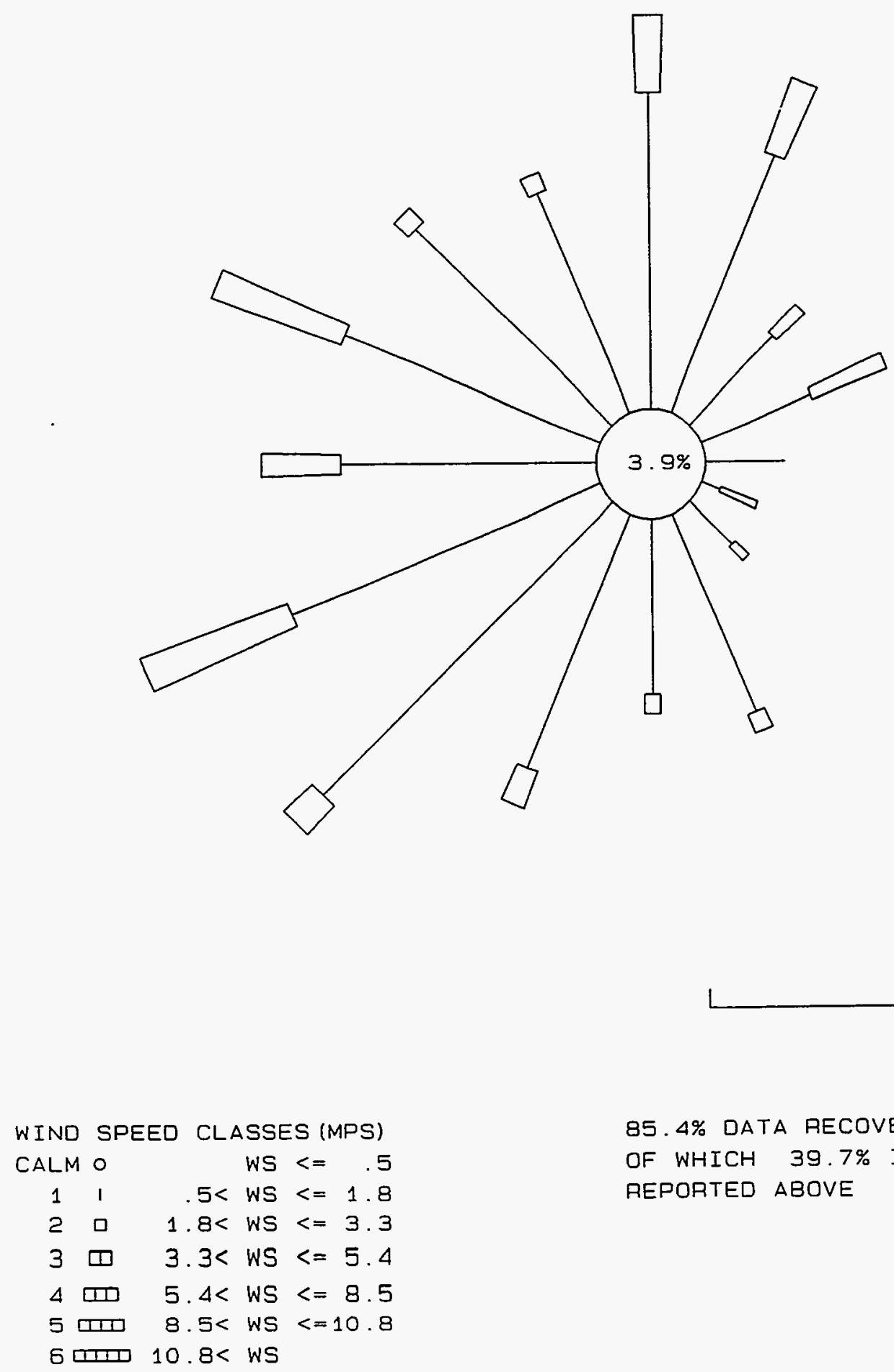

85. 4\% DATA RECOVERED

OF WHICH $39.7 \%$ IS

REPORTED ABOVE 


\section{SPILL TEST FACILITY 24 METER TOWER STABILITY CLASS F \\ 8 METER HEIGHT - Tota 1 Hours \\ 3/ $1 / 1994-3 / 31 / 1994$ \\ $0-2300$}

$N$

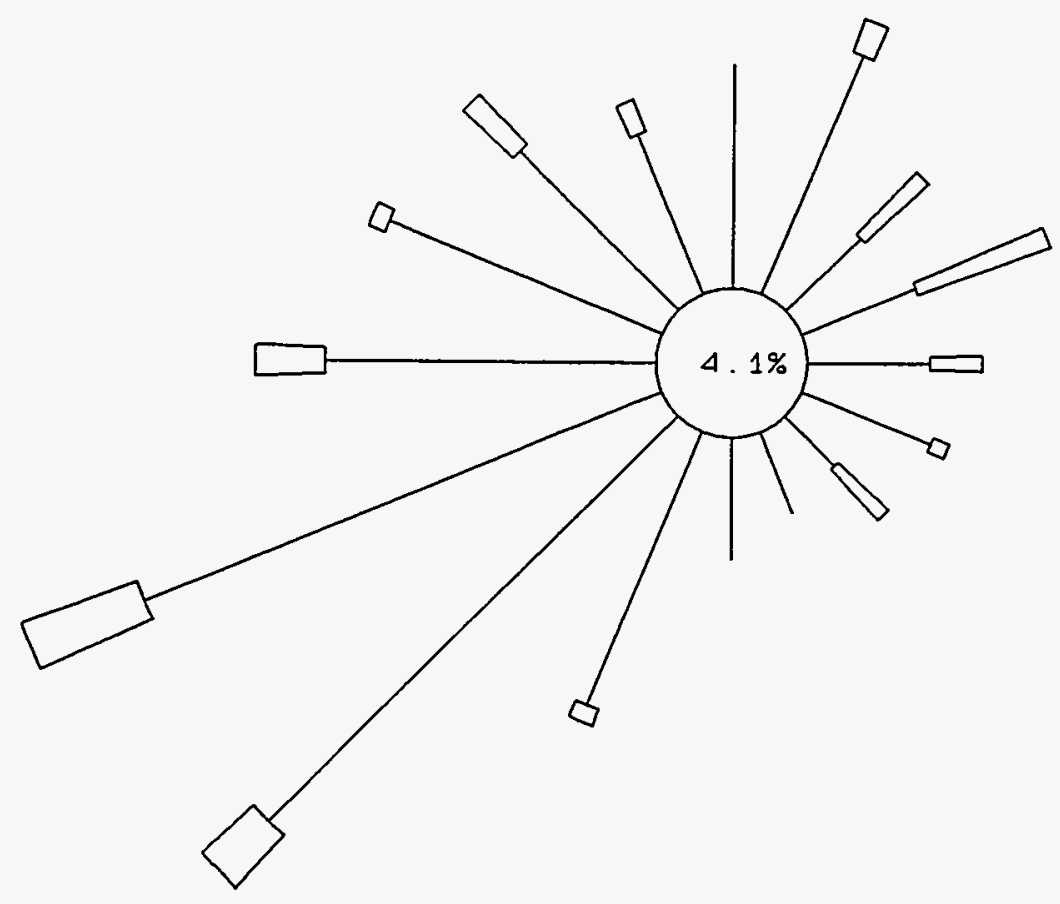

\begin{tabular}{|c|c|c|c|c|}
\hline NIND & SPE & EED CL & ASSE & $S$ (MPS \\
\hline CALM & 10 & & WS & $<=$ \\
\hline 1 & 1 & $5<$ & WS & $<=1.8$ \\
\hline 2 & $\square$ & $1.8<$ & WS & $<=3.3$ \\
\hline 3 & ш & $3.3<$ & WS & $<=5$ \\
\hline 4 & סח & $5.4<$ & WS & $c=8.5$ \\
\hline 5 & סחם & $8.5<$ & WS & $<=10.8$ \\
\hline 60 & סسח & $10.8<$ & WS & \\
\hline
\end{tabular}

100.0\% DATA RECOVERED

OF WHICH 36.3\% IS

REPORTED ABOVE 


\section{SPILL TEST FACILITY 24 METER TOWER \\ STABILITY CLASS F \\ 8 METER HEIGHT - Total Hours \\ $4 / 1 / 1994-4 / 30 / 1994$ \\ $0-2300$}

$N$
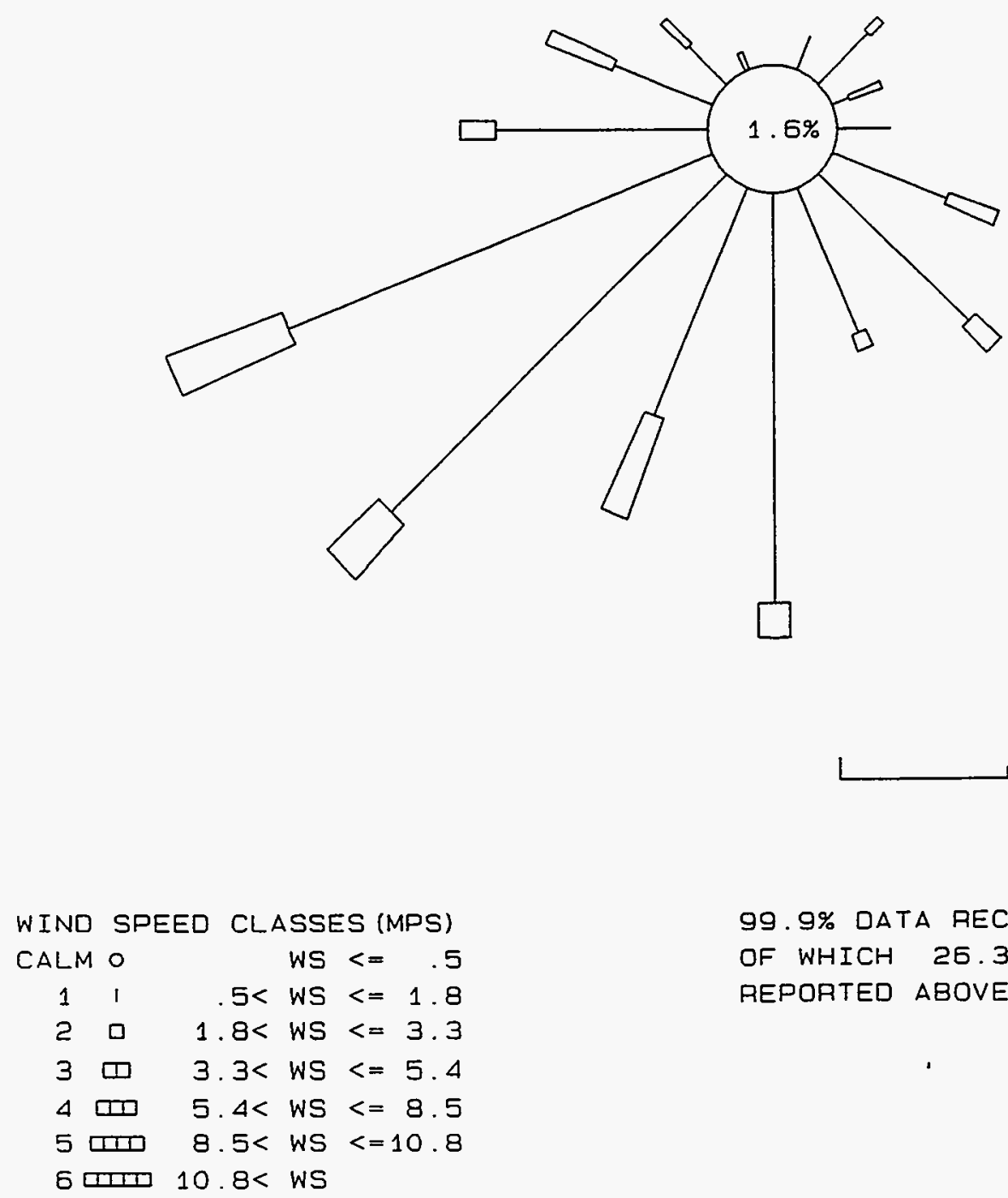

99.9\% DATA RECOVERED

OF WHICH $25.3 \%$ IS

REPORTED ABOVE 


\section{SPILL TEST FACILITY 24 METER TOWER \\ STABILITY CLASS $F$ \\ 8 METER HEIGHT - Total Hours \\ $5 / 1 / 1994-5 / 31 / 1994$ \\ $0-2300$}

N
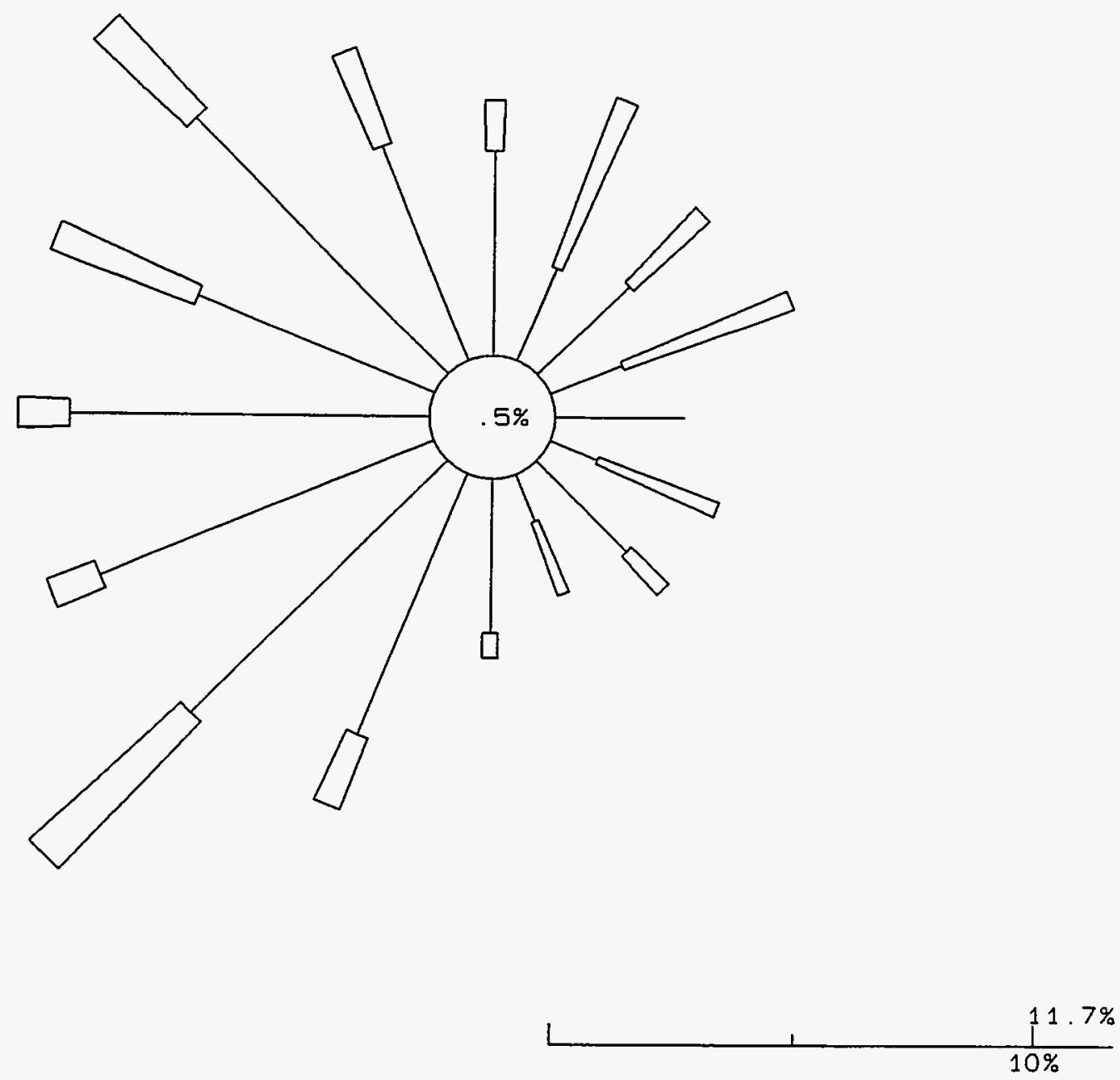

96. 9\% DATA RECOVERED

OF WHICH $26.1 \%$ IS

REPORTED ABOVE 


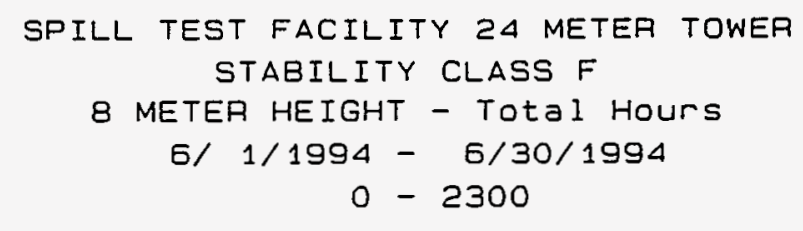

$N$
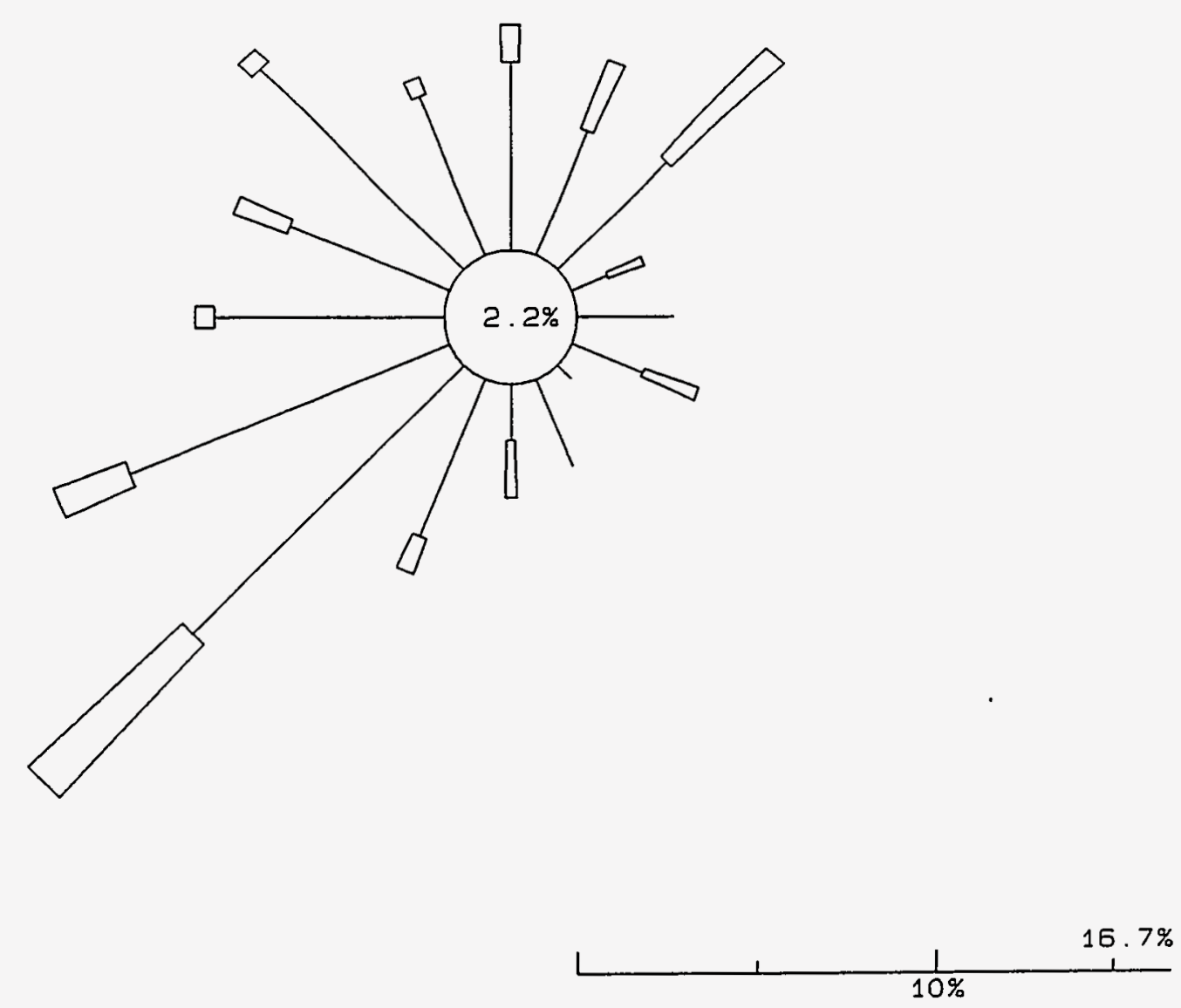

$100.0 \%$ DATA RECOVERED

OF WHICH 25.8\% IS

REPORTED ABOVE 


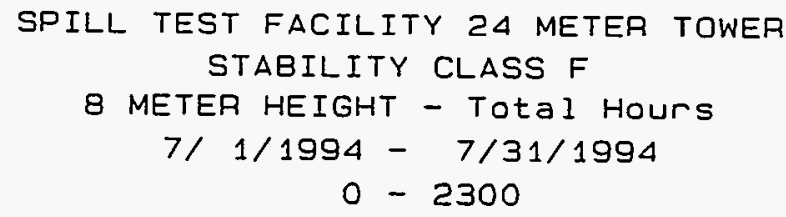

$N$
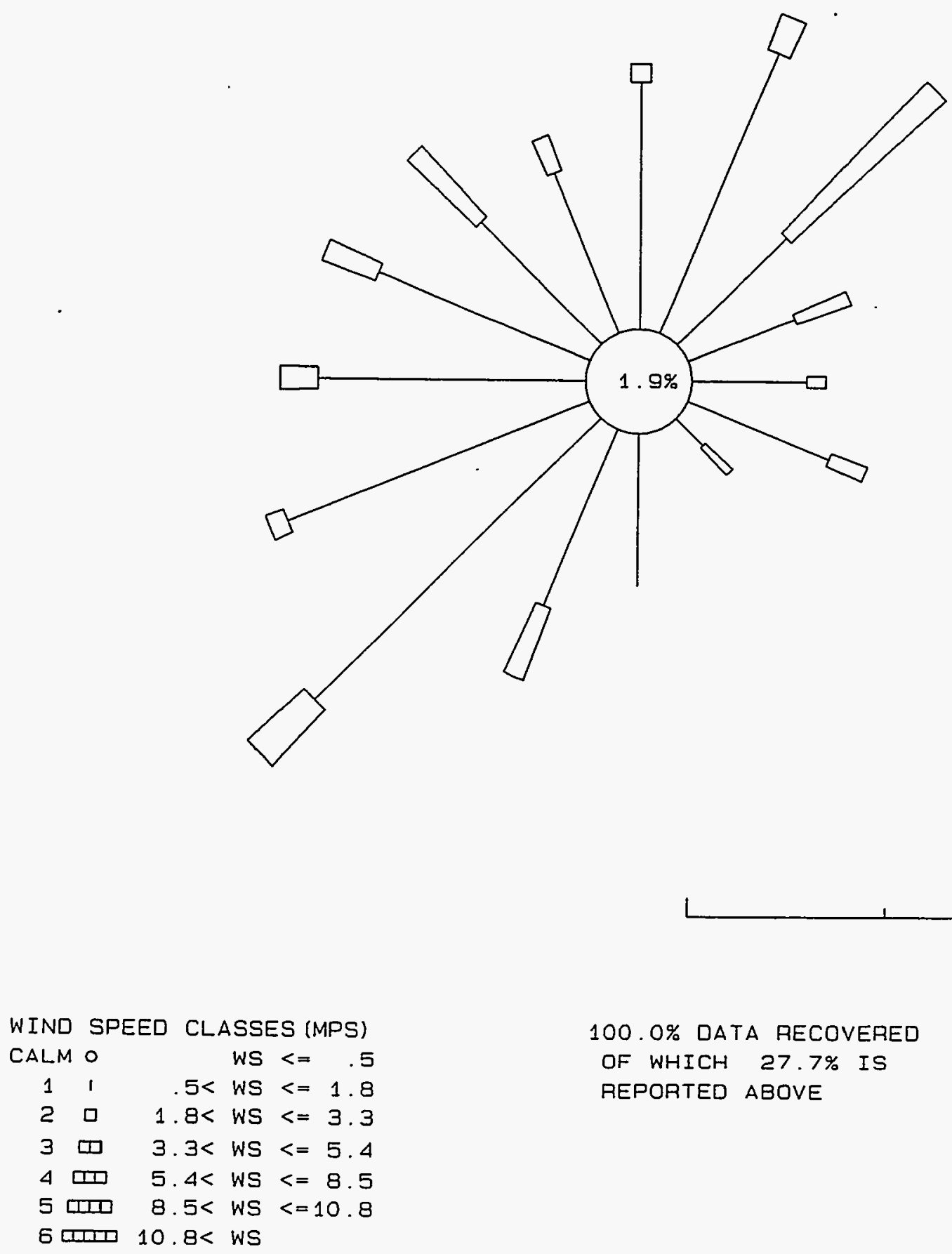

100.0\% DATA RECOVERED

OF WHICH $27.7 \%$ IS

REPORTED ABOVE 


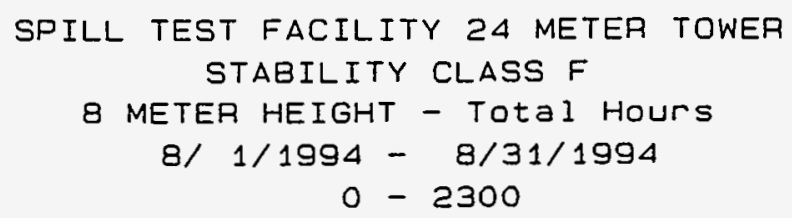

$N$
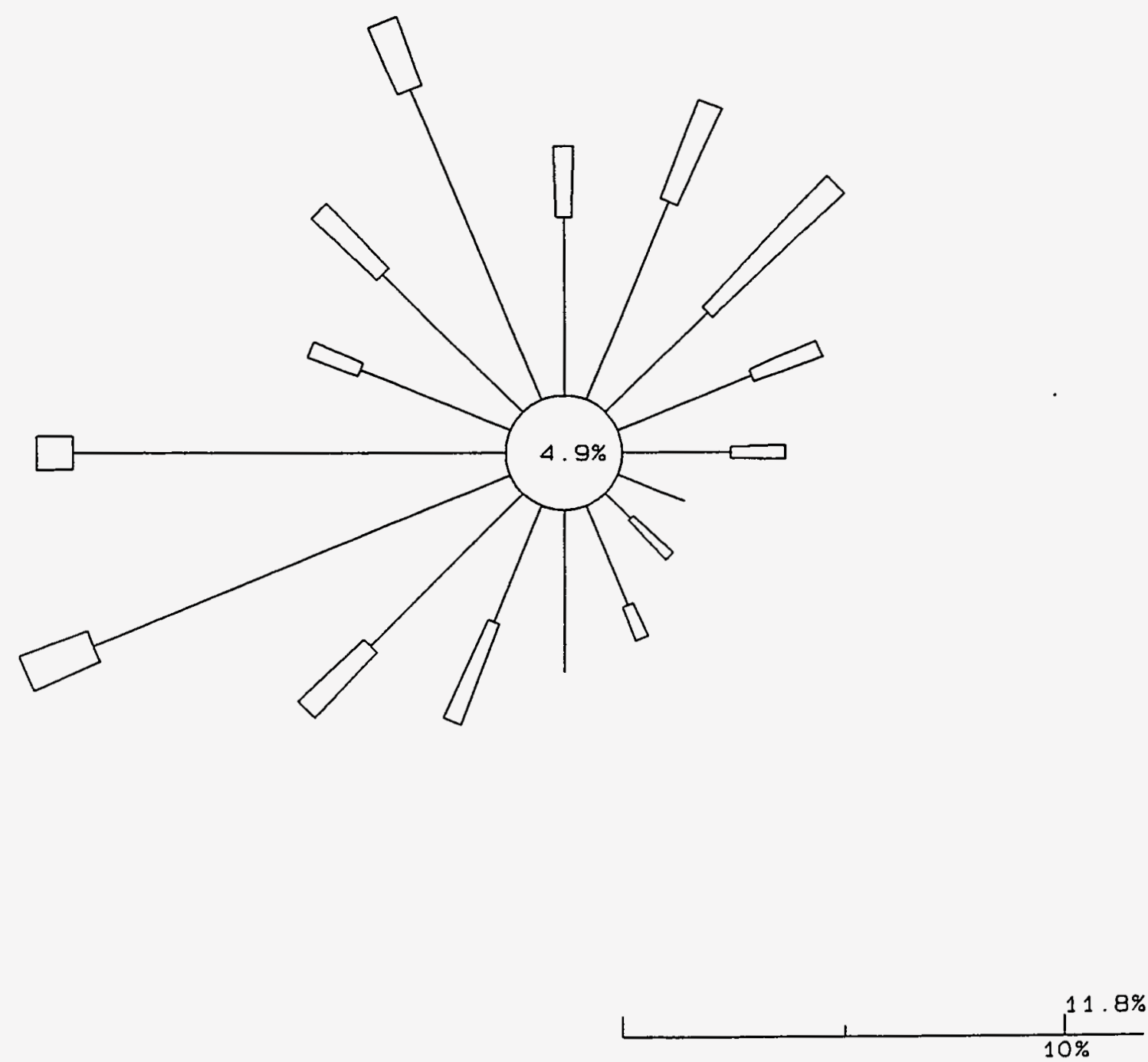

100.0\% DATA RECOVERED

OF WHICH 32.9\% IS

REPORTED ABOVE 


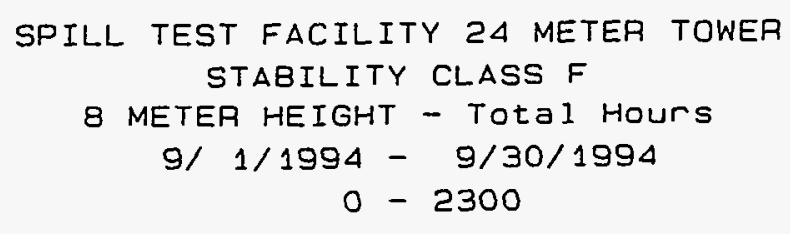

$N$
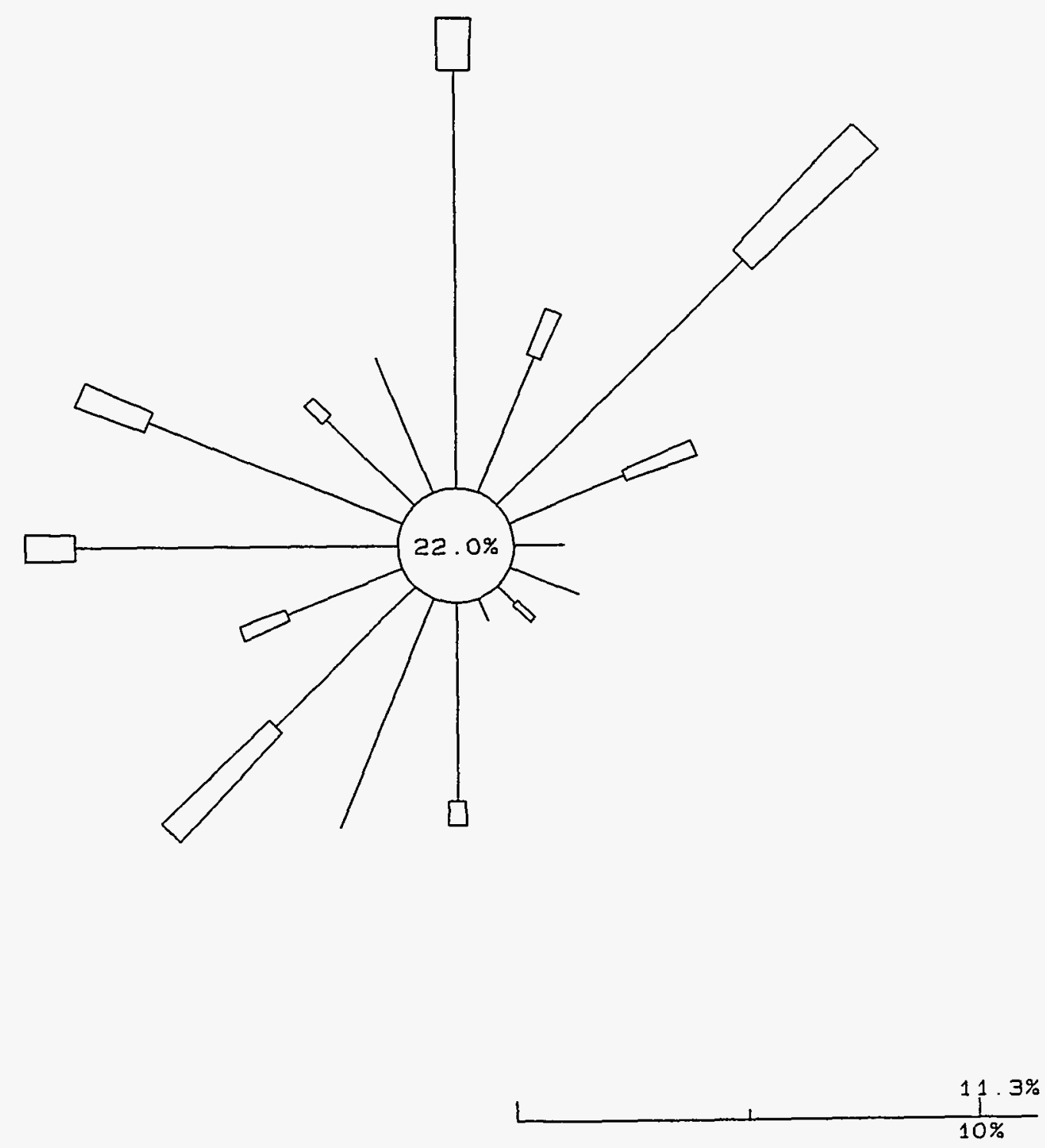

$99.2 \%$ DATA RECOVERED

OF WHICH 26.1\% IS

REPORTED ABOVE 


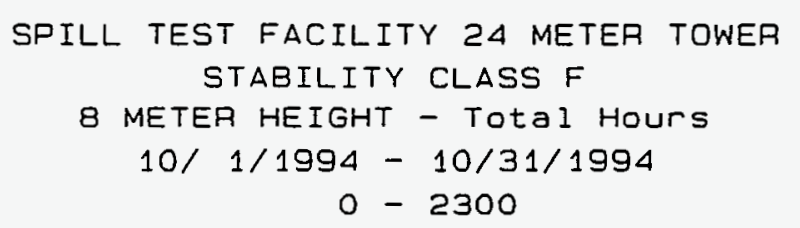

$N$
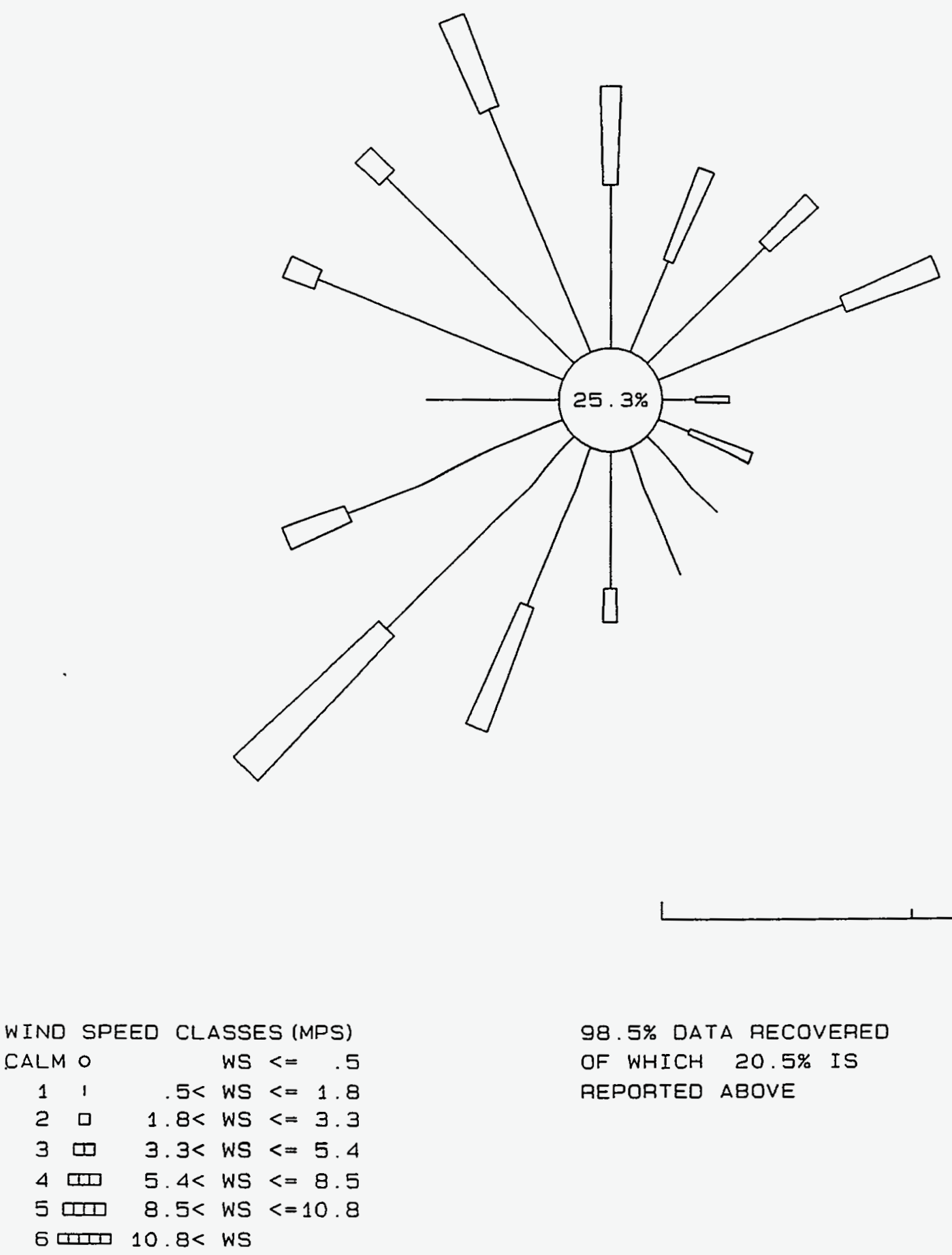


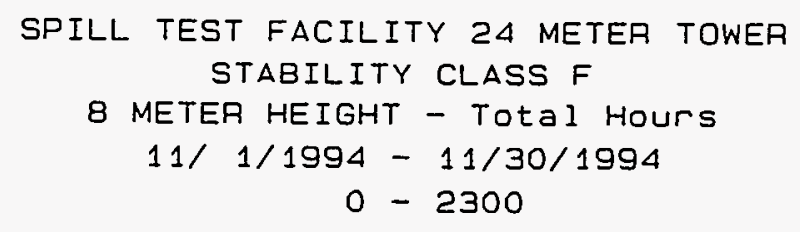

$N$
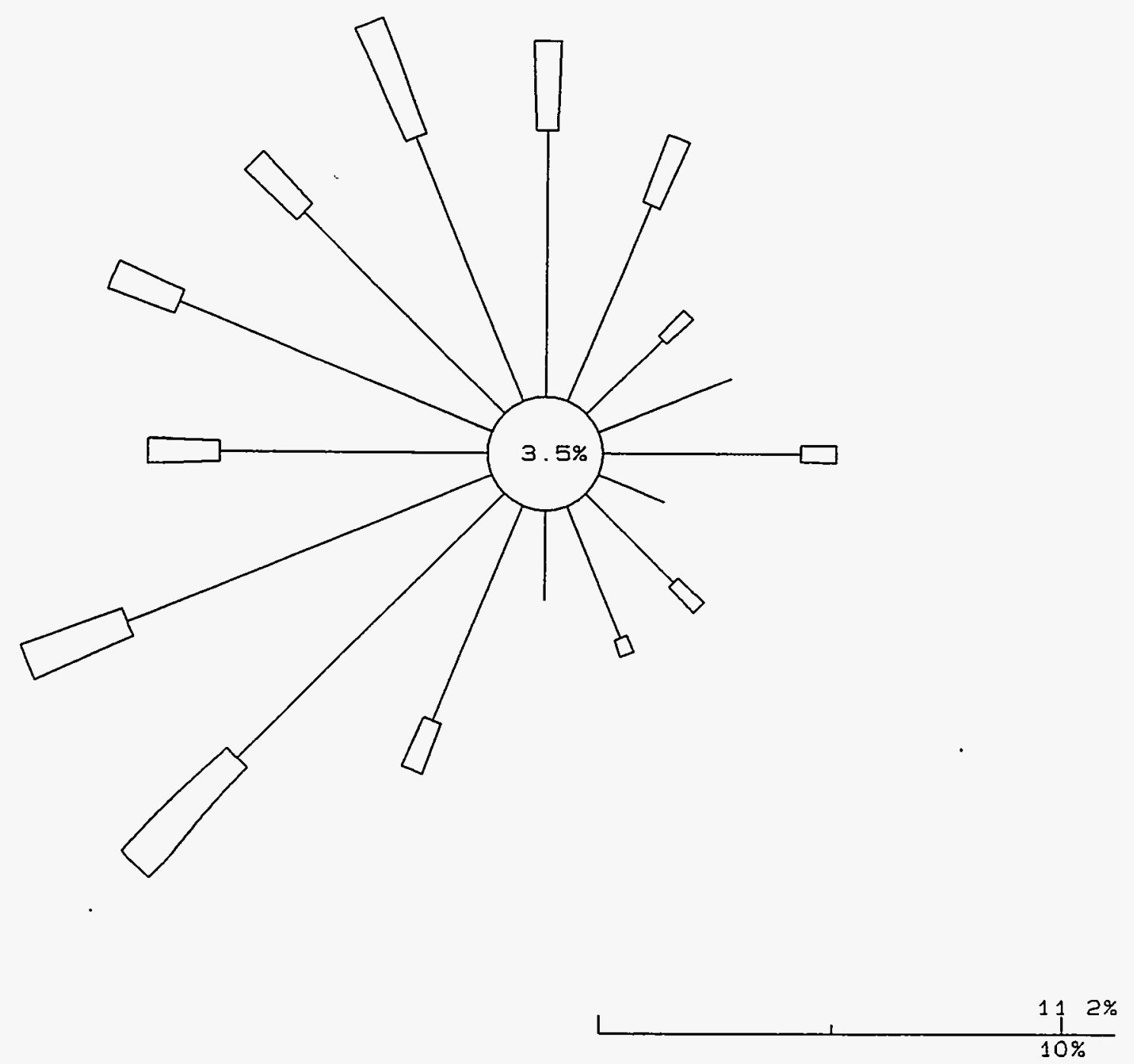

99.7\% DATA RECOVERED

OF WHICH 36.1\% IS

REPORTED ABOVE 


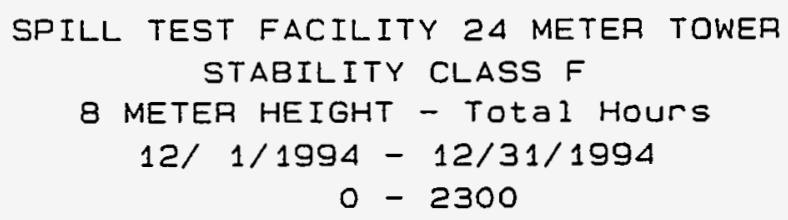

$N$
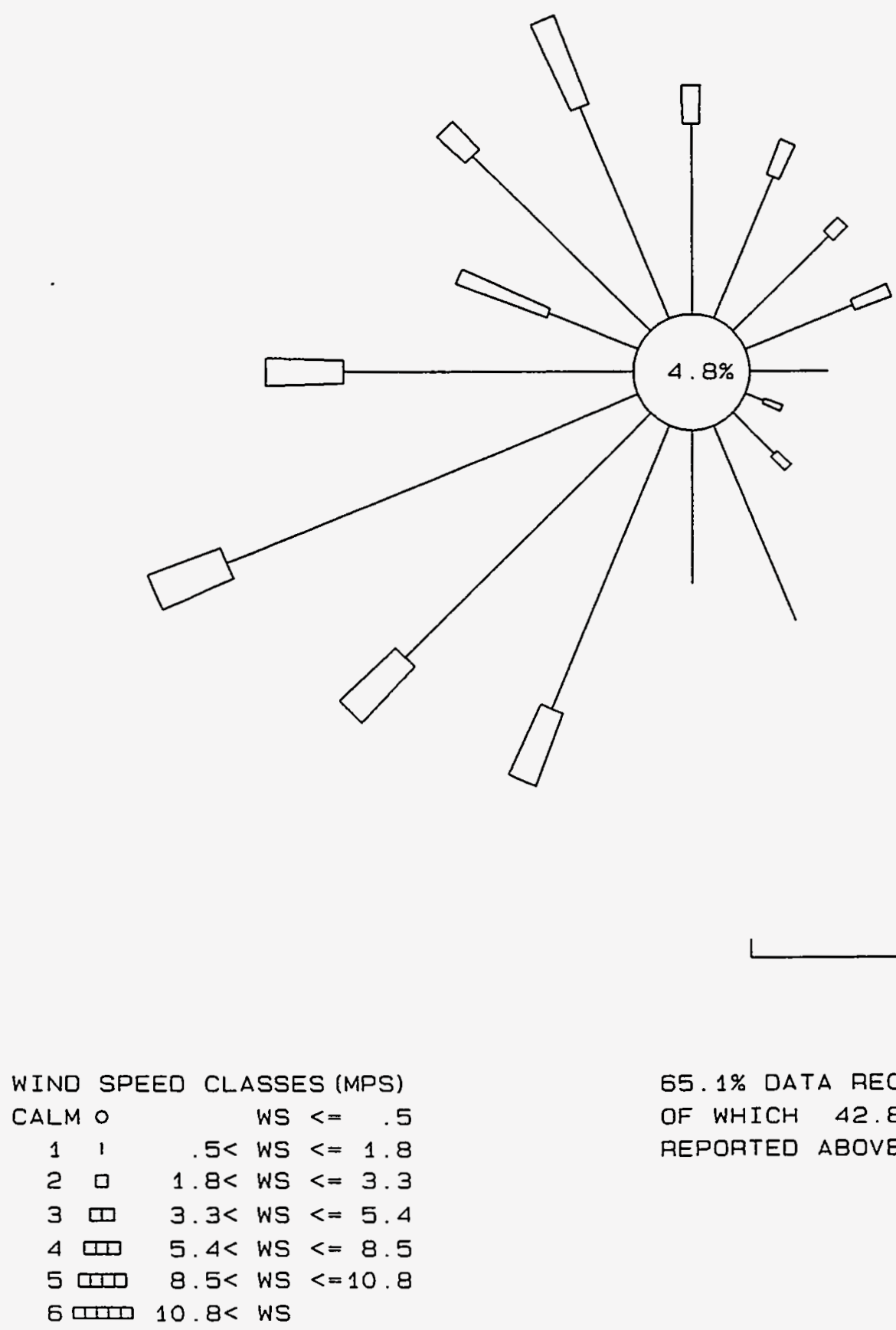


\section{APPENDIX C: MONTHLY WIND FREQUENCY DISTRIBUTIONS, TWO AND EIGHT METERS}

\section{Two Meters}

1-12 Total Hours (0000-2400), January-December, 1994

13-24 Morning Transition (0600-1000), January-December 1994

25-36 Late Mid-day (1000-1600), January-December, 1994

37-48 Evening Transition (1600-2000), January-December 1994

49-60 Night Time (2000-0600), January-December, 1994

61-72 All Stability Class A (Yamartino Sigma Theta), January-December, 1994

73-84 All Stability Class B (Yamartino Sigma Theta), January-December, 1994

85-96 All Stability Class C (Yamartino Sigma Theta), January-December, 1994

97-108 All Stability Class D (Yamartino Sigma Theta), January-December, 1994

109-120 All Stability Class E (Yamartino Sigma Theta), January-December, 1994

121-132 All Stability Class F (Yamartino Sigma Theta), January-December, 1994

\section{Eight Meters}

133-144 Total Hours (0000-2400), January-December, 1994

145-156 Morning Transition (0600-1000), January-December 1994

157-168 Late Mid-day (1000-1600), January-December, 1994

169-180 Evening Transition (1600-2000), January-December 1994

181-192 Night Time (2000-0600), January-December, 1994

193-204 All Stability Class A (Yamartino Sigma Theta), January-December, 1994

205-216 All Stability Class B (Yamartino Sigma Theta), January-December, 1994 


\section{APPENDIX C: MONTHLY WIND FREQUENCY DISTRIBUTIONS, TWO AND EIGHT METERS (con't)}

217-228 All Stability Class C (Yamartino Sigma Theta), January-December, 1994

229-240 All Stability Class D (Yamartino Sigma Theta), January-December, 1994

241-252 All Stability Class E (Yamartino Sigma Theta), January-December, 1994

253-264 All Stability Class F (Yamartino Sigma Theta), January-December, 1994 
METEOROLOGICAL JOIHT FREQUENCY DISTRIBUTION (PERCENT OF VALIO HOUR OBSERVATIONS) SPILL TEST FACILITY 24 METER TOUER

2 METER HEIGHT - Total Hours $\begin{gathered}1 / 1994 \cdot 1 / 31 / 1994 \\ 0-2300 \text { (MST) }\end{gathered}$

HIND SPEED CLASS

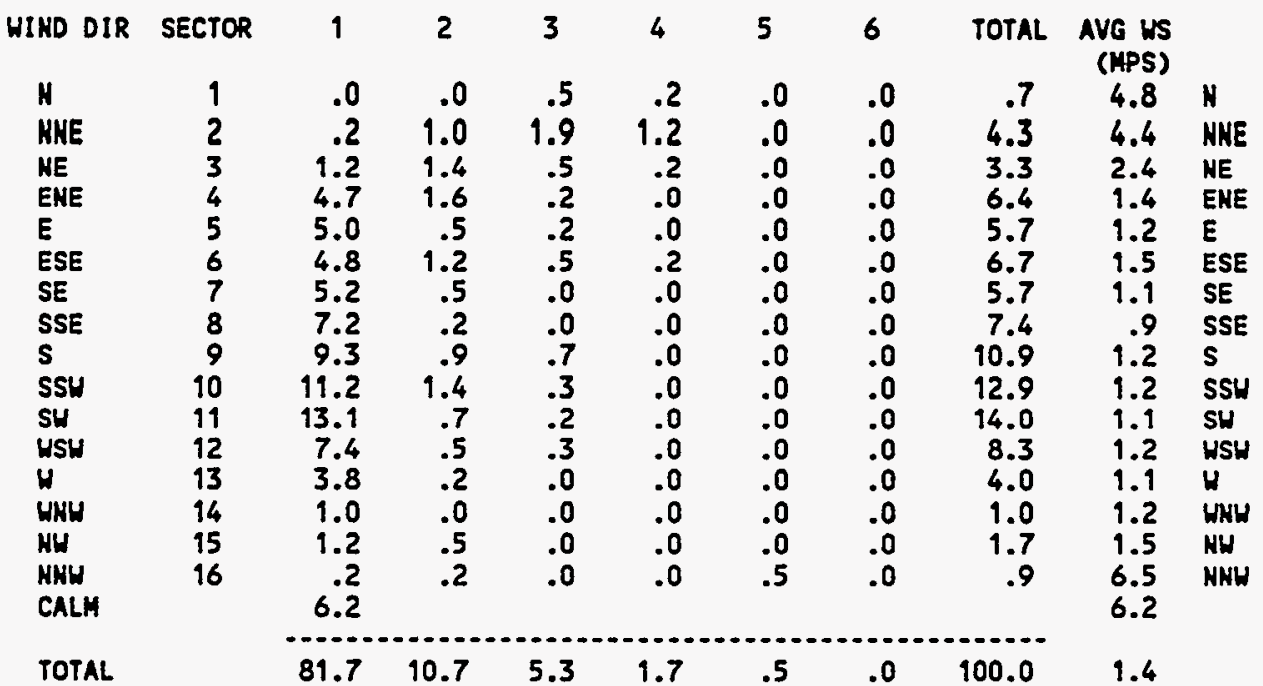

78. OX DATA RECOVERED 100.0\% OF RECOVERED DATA REPORTED ABOVE

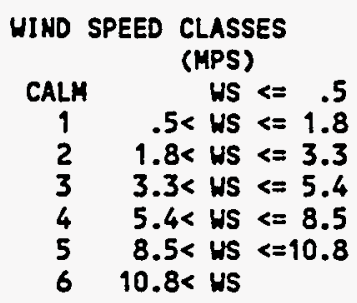


METEOROLOGICAL JOINT FREQUENCY DISTRIBUTION (PERCENT OF VALID HOUR OBSERVATIOHS) SPILL TEST FACILITY 24 METER TONER

2 METER HEIGHT - Total Hours $2 / 1 / 1994-2 / 28 / 1994$

HIND SPEED CLASS

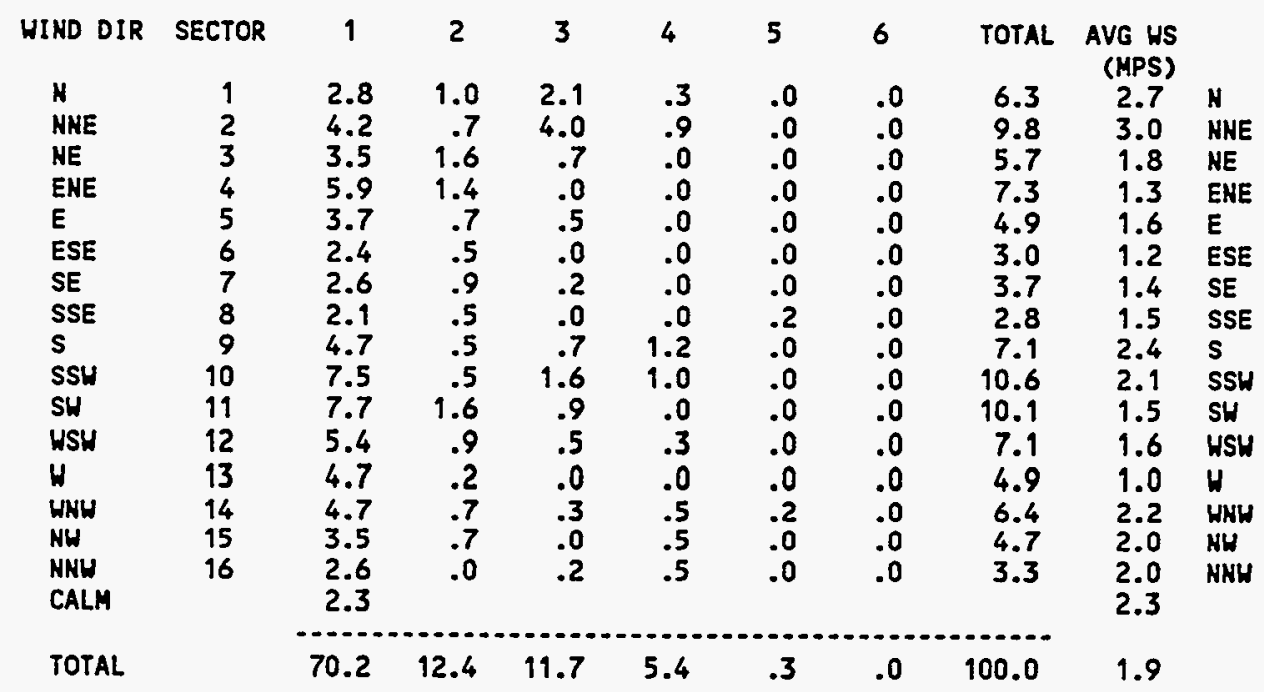

85.4\% DATA RECOVERED

100.0\% OF RECOVERED DATA REPORTED ABOVE

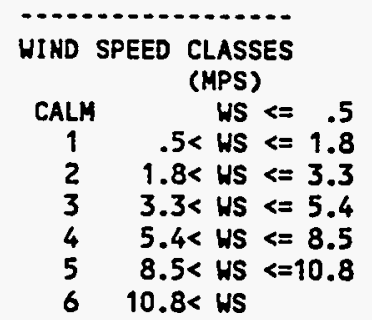


METEOROLOGICAL JOINT FREQUENCY DISTRIBUTION (PERCENT OF VALID HOUR OBSERVATIONS)

SPILL TEST FACILITY 24 METER TOWER

2 METER HEIGHT - Total Hours

3/ $1 / 1994-3 / 31 / 1994$

$0-2300$ (MST)

HIN D SPEED CLASS

\begin{tabular}{|c|c|c|c|c|c|c|c|c|c|c|}
\hline HIND DIR & SECTOR & 1 & 2 & 3 & 4 & 5 & 6 & TOTAL & AVG US & \\
\hline $\boldsymbol{N}$ & 1 & 3.0 & .4 & .8 & .4 & .5 & .1 & 5.2 & 3.3 & H \\
\hline NAE & 2 & 2.4 & 1.1 & 1.7 & 2.6 & .0 & .1 & 7.9 & 4.1 & NHE \\
\hline NE & 3 & 3.2 & 2.0 & 1.7 & .7 & .0 & .0 & 7.7 & 2.6 & NE \\
\hline ENE & 4 & 3.0 & 1.2 & .4 & .0 & .0 & .0 & 4.6 & 1.8 & ENE \\
\hline E & 5 & 3.0 & 1.1 & .4 & .0 & .0 & .0 & 4.4 & 1.7 & $\varepsilon$ \\
\hline ESE & 6 & 2.0 & .8 & .0 & .0 & .0 & .0 & 2.8 & 1.4 & ESE \\
\hline SE & 7 & 2.6 & .9 & .0 & .0 & .0 & .0 & 3.5 & 1.5 & SE \\
\hline $\begin{array}{l}\text { SSE } \\
\text { S }\end{array}$ & $\begin{array}{l}8 \\
9\end{array}$ & $\begin{array}{l}2.4 \\
2.8\end{array}$ & .3 & $\begin{array}{l}.0 \\
.4\end{array}$ & .0 & $\begin{array}{l}.0 \\
.1\end{array}$ & $\begin{array}{l}.0 \\
.0\end{array}$ & $\begin{array}{l}2.7 \\
5.0\end{array}$ & $\begin{array}{l}1.2 \\
2.6\end{array}$ & $\begin{array}{l}\text { SSE } \\
\mathbf{S}\end{array}$ \\
\hline SSH & 10 & 6.5 & 2.2 & .9 & 3.6 & .8 & .9 & 14.9 & 4.2 & SSH \\
\hline SH & 11 & 7.5 & 2.3 & 2.3 & 3.1 & .7 & .0 & 15.9 & 3.3 & SW \\
\hline WSH & 12 & 6.0 & .8 & .0 & .0 & .0 & .0 & $\begin{array}{l}6.9 \\
4.4\end{array}$ & 1.3 & WSH \\
\hline H & $\begin{array}{l}13 \\
14\end{array}$ & $\begin{array}{l}3.6 \\
3.0\end{array}$ & .8 & .0 & $\begin{array}{l}.0 \\
.0\end{array}$ & $\begin{array}{l}.0 \\
.0\end{array}$ & $\begin{array}{l}.0 \\
.0\end{array}$ & $\begin{array}{l}4.4 \\
3.4\end{array}$ & $\begin{array}{l}1.3 \\
1.3\end{array}$ & WWH \\
\hline NH & 15 & 2.6 & .8 & .1 & .1 & .0 & .0 & 3.6 & 1.7 & NH \\
\hline NHW & 16 & 2.2 & .8 & .5 & .0 & .0 & .0 & 3.5 & 1.8 & NHH \\
\hline CALM & & & & & & & & & & \\
\hline TOTAL & & 59.3 & 16.7 & 9.5 & 11.2 & 2.2 & 1.2 & 100.0 & 2.6 & \\
\hline
\end{tabular}

100.0\% DATA RECOVERED

100.0\% OF RECOVERED DATA REPORTED ABOVE

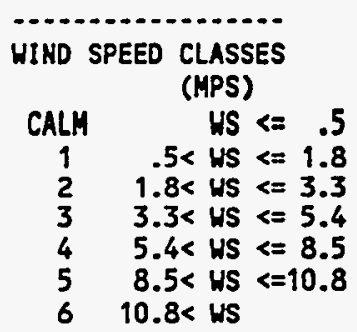




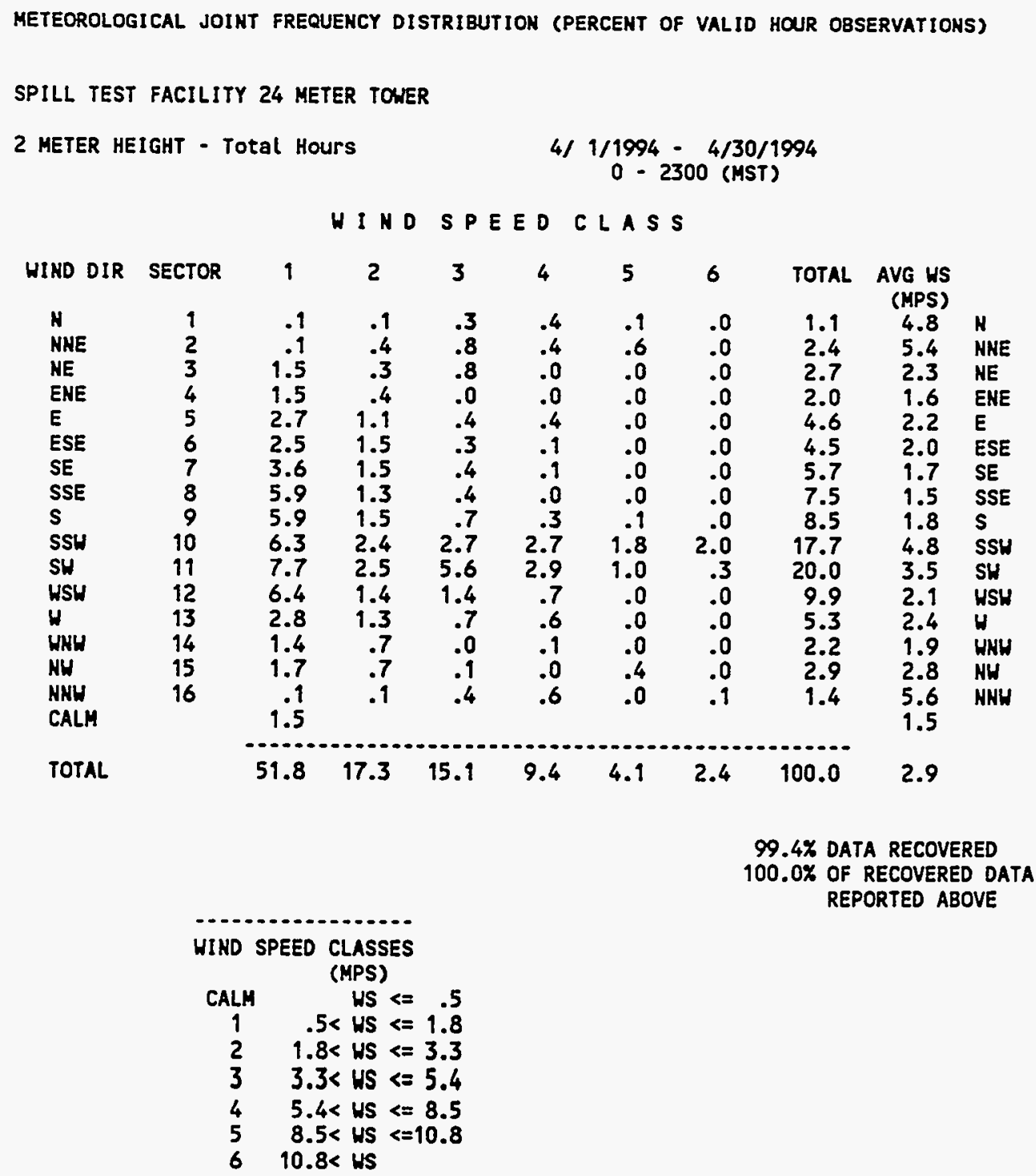


METEOROLOGICAL JOINT FREQUENCY DISTRIBUTION (PERCENT OF VALID HOUR OBSERVATIONS) SPILL TEST FACILITY 24 METER TOWER

2 METER HEIGHT - Total Hours $\begin{gathered}\text { 5/ } 1 / 1994-5 / 31 / 1994 \\ 0-2300 \text { (MST) }\end{gathered}$

HIND SPEED CLASS

\begin{tabular}{|c|c|c|c|c|c|c|c|c|c|c|}
\hline WIND DIR & SECTOR & 1 & 2 & 3 & 4 & 5 & 6 & TOTAL & $\begin{array}{l}\text { AVG WS } \\
\text { (MPS) }\end{array}$ & \\
\hline H & 1 & 3.5 & .3 & .7 & .0 & .0 & .0 & 4.4 & 1.6 & N \\
\hline NNE & $\begin{array}{l}2 \\
3\end{array}$ & $\begin{array}{l}3.7 \\
2.4\end{array}$ & .4 & .3 & $\begin{array}{l}.1 \\
.0\end{array}$ & $\begin{array}{l}.0 \\
.0\end{array}$ & $\begin{array}{l}.0 \\
.0\end{array}$ & $\begin{array}{l}4.6 \\
3.6\end{array}$ & $\begin{array}{l}1.5 \\
1.7\end{array}$ & $\begin{array}{l}\text { NNE } \\
\text { NE }\end{array}$ \\
\hline ENE & 4 & $\begin{array}{l}2.4 \\
1.5\end{array}$ & .8 & .3 & .0 & .0 & .0 & $\begin{array}{l}3.0 \\
2.5\end{array}$ & 1.6 & $\begin{array}{l}\text { NE } \\
\text { ENE }\end{array}$ \\
\hline$E$ & 5 & 1.5 & .6 & .4 & .0 & .0 & .0 & 2.5 & 1.9 & $E$ \\
\hline $\begin{array}{l}\text { ESE } \\
\text { SE }\end{array}$ & $\begin{array}{l}6 \\
7\end{array}$ & $\begin{array}{l}2.5 \\
1.7\end{array}$ & $\begin{array}{r}1.9 \\
.4\end{array}$ & $\begin{array}{r}.3 \\
1.0\end{array}$ & $\begin{array}{l}.0 \\
.4\end{array}$ & $\begin{array}{l}.0 \\
.0\end{array}$ & $\begin{array}{l}.0 \\
.0\end{array}$ & $\begin{array}{l}4.7 \\
3.5\end{array}$ & $\begin{array}{l}1.7 \\
2.8\end{array}$ & $\begin{array}{l}\text { ESE } \\
\text { SE }\end{array}$ \\
\hline SSE & 8 & 2.1 & 1.1 & 9.4 & .1 & .0 & .0 & 4.7 & 2.4 & SSE \\
\hline S & 9 & 2.8 & 9.4 & 1.0 & .3 & .3 & .0 & 5.7 & 2.6 & 5 \\
\hline $\begin{array}{l}\text { SSH } \\
\text { SH }\end{array}$ & $\begin{array}{l}10 \\
11\end{array}$ & $\begin{array}{l}2.8 \\
6.8\end{array}$ & $\begin{array}{l}1.2 \\
2.8\end{array}$ & $\begin{array}{l}1.8 \\
5.4\end{array}$ & $\begin{array}{l}3.6 \\
5.8\end{array}$ & $\begin{array}{l}1.7 \\
3.5\end{array}$ & $\begin{array}{r}1.5 \\
.4\end{array}$ & $\begin{array}{l}12.6 \\
24.7\end{array}$ & $\begin{array}{l}5.8 \\
4.6\end{array}$ & $\begin{array}{l}\text { SSH } \\
\text { SH }\end{array}$ \\
\hline USH & 12 & 3.5 & 1.2 & 2.6 & .7 & .0 & .0 & 8.0 & 2.8 & WSW \\
\hline $\mathbf{H}$ & 13 & 2.9 & .4 & .1 & .3 & .0 & .0 & 3.7 & 1.7 & $\boldsymbol{H}$ \\
\hline WNH & 14 & 3.3 & .6 & .3 & .0 & .0 & .0 & 4.2 & 1.4 & WHH \\
\hline NH & 15 & 3.3 & .8 & .4 & .0 & .0 & .0 & 4.6 & 1.7 & NH \\
\hline $\begin{array}{l}\text { NHW } \\
\text { CALM }\end{array}$ & 16 & $\begin{array}{l}2.6 \\
2.1\end{array}$ & .8 & .3 & .1 & .0 & .0 & 3.9 & $\begin{array}{l}1.8 \\
2.1\end{array}$ & NKH \\
\hline & & & & & & & & & & \\
\hline TOTAL & & 49.0 & 15.8 & 16.4 & 11.5 & 5.4 & 1.9 & 100.0 & 3.1 & \\
\hline
\end{tabular}

96.9\% DATA RECOVERED 100.0X OF RECOVERED DATA REPORTED ABOVE

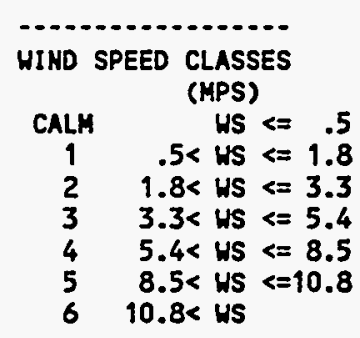


METEOROLOGICAL JOINT FREQUENCY DISTRIBUTION (PERCEHT OF VALID HOUR OBSERVATIONS) SPILL TEST FACILITY 24 METER TONER

2 METER HEIGHT - Total Hours

$$
\begin{gathered}
6 / 1 / 1994-6 / 30 / 1994 \\
0-2300 \text { (MST) }
\end{gathered}
$$

HINDSPEED CLASS

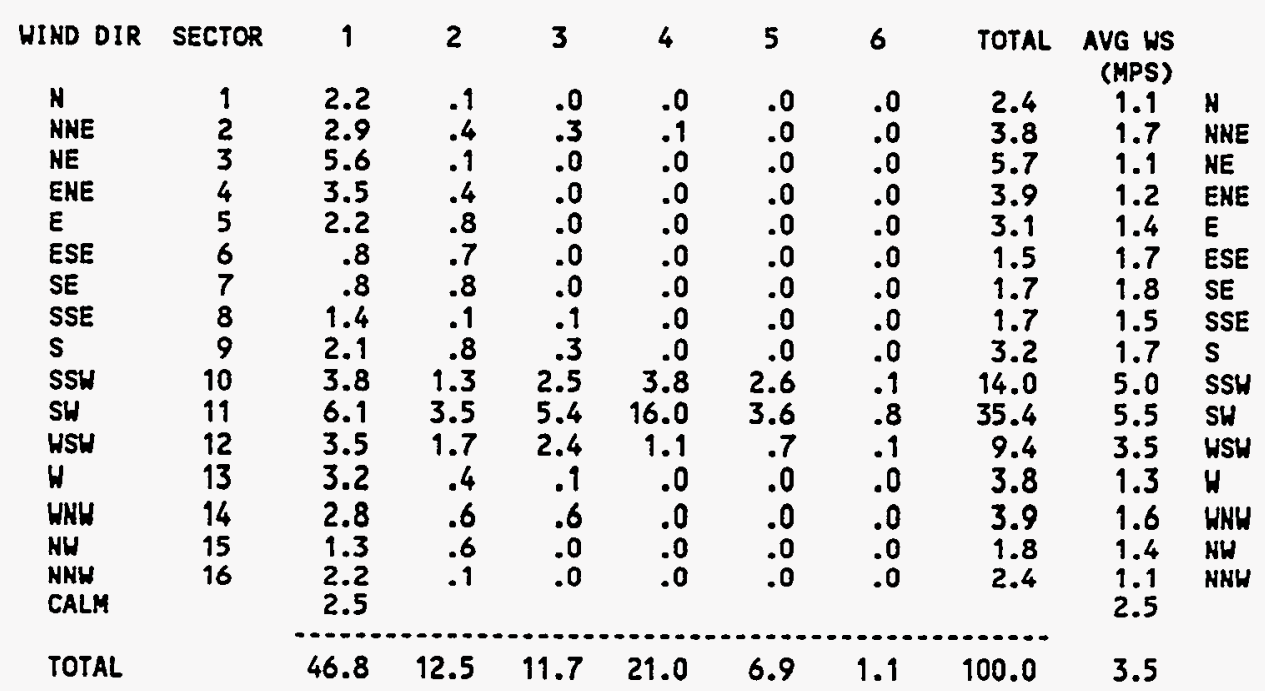

100.0\% DATA RECOVERED 100.0\% OF RECOVERED DATA REPORTED ABOVE

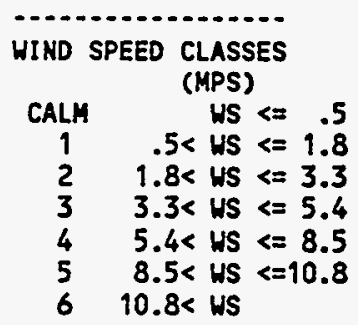


METEOROLOGICAL JOINT FREQUENCY DISTRIBUTION (PERCENT OF VALID HOUR OBSERVATIONS) SPILL TEST FACILITY 24 METER TOWER

2 METER HEIGHT - Total Hours

$$
\begin{aligned}
& \text { 7/ } 1 / 1994-7 / 31 / 1994 \\
& 0-2300 \text { (MST) }
\end{aligned}
$$

HIHD SPEED CLASS

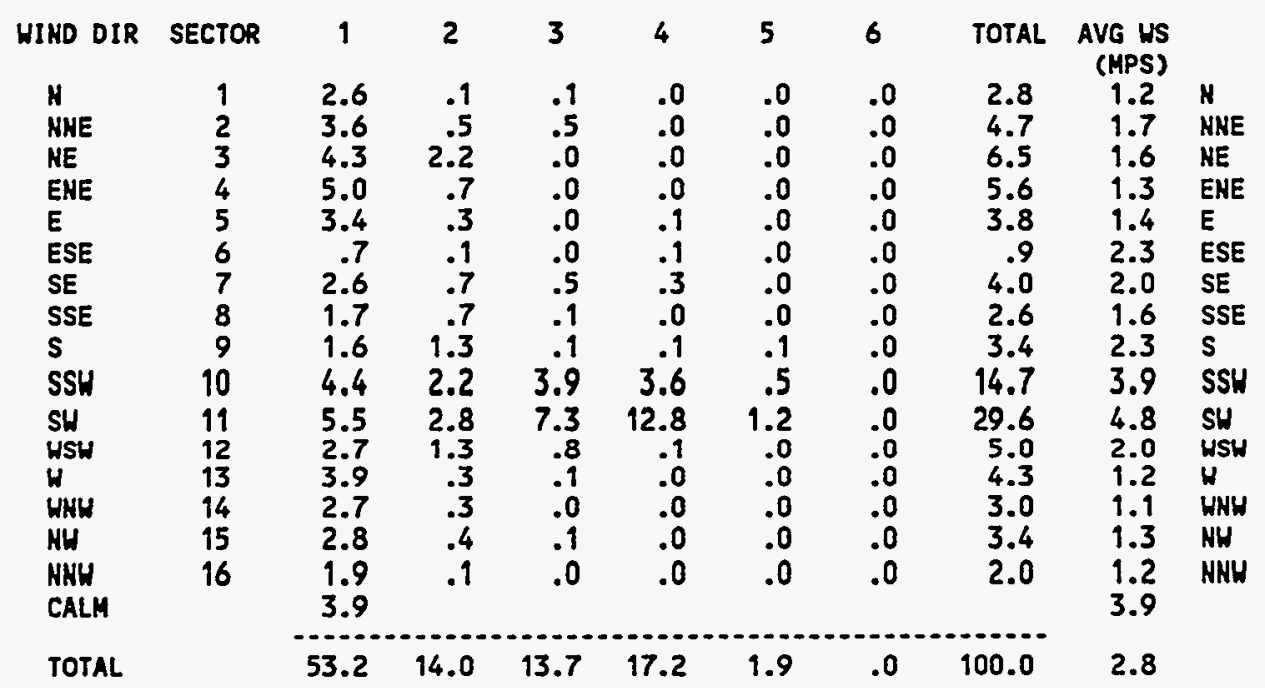

100.0\% DATA RECOVERED

100.0\% OF RECOVERED DATA REPORTED ABOVE

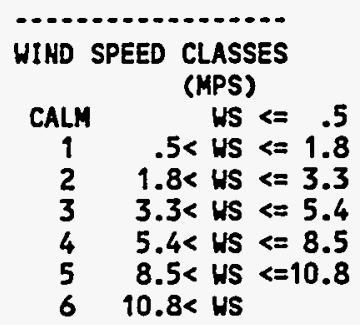


METEOROLOGICAL JOINT FREQUENCY DISTRIBUTION (PERCENT OF VALID HOUR OBSERVATIONS) SPILL TEST FACILITY 24 METER TONER

2 METER HEIGHT - Total Hours

$8 / 1 / 1994-8 / 31 / 1994$

0 - 2300 (MST)

HI D SPEED CLASS

\begin{tabular}{|c|c|c|c|c|c|c|c|c|c|c|}
\hline HIND DIR & SECTOR & 1 & 2 & 3 & 4 & 5 & 6 & TOTAL & $\begin{array}{r}\text { AVG WS } \\
\text { (MPS) }\end{array}$ & \\
\hline N & 1 & 2.2 & .8 & .0 & .0 & .0 & .0 & 3.0 & 1.6 & $\mathrm{H}$ \\
\hline NHE & 2 & 4.7 & 1.1 & .3 & .1 & .0 & .0 & 6.2 & 1.6 & $\begin{array}{l}\text { NNE } \\
\text { NE }\end{array}$ \\
\hline NE & 3 & 5.2 & .5 & .0 & .0 & .0 & .0 & 5.8 & 1.2 & $\mathrm{ME}$ \\
\hline ENE & 4 & 2.8 & .8 & .0 & .0 & .0 & .0 & 3.6 & 1.5 & ENE \\
\hline E & 5 & 3.1 & .7 & .1 & .0 & .0 & .0 & 3.9 & 1.5 & \\
\hline $\begin{array}{l}\text { ESE } \\
\text { SE }\end{array}$ & $\begin{array}{l}6 \\
7\end{array}$ & $\begin{array}{l}1.2 \\
1.6\end{array}$ & $\begin{array}{l}.3 \\
.7\end{array}$ & $\begin{array}{r}.4 \\
1.7\end{array}$ & $\begin{array}{l}.0 \\
.4\end{array}$ & $\begin{array}{l}.0 \\
.0\end{array}$ & $\begin{array}{l}.0 \\
.0\end{array}$ & $\begin{array}{l}1.9 \\
4.4\end{array}$ & $\begin{array}{l}2.1 \\
2.9\end{array}$ & $\begin{array}{l}\text { ESE } \\
\text { SE }\end{array}$ \\
\hline SSE & 8 & 1.2 & .4 & .4 & .0 & .0 & .0 & 2.0 & 2.2 & SSE \\
\hline $\mathbf{s}$ & 9 & 1.6 & 1.6 & .5 & 1.1 & .1 & .0 & 5.0 & 3.2 & \\
\hline $\begin{array}{l}\text { SSH } \\
\text { SH }\end{array}$ & $\begin{array}{l}10 \\
11\end{array}$ & $\begin{array}{l}3.5 \\
5.0\end{array}$ & $\begin{array}{l}1.9 \\
1.5\end{array}$ & $\begin{array}{l}2.7 \\
5.1\end{array}$ & $\begin{array}{r}4.6 \\
10.9\end{array}$ & $\begin{array}{r}.5 \\
1.7\end{array}$ & $\begin{array}{l}.0 \\
.0\end{array}$ & $\begin{array}{l}13.2 \\
24.2\end{array}$ & $\begin{array}{l}4.4 \\
5.1\end{array}$ & SSH \\
\hline WSW & 12 & 5.0 & .8 & 1.7 & .3 & .0 & .0 & $\begin{array}{r}24.2 \\
7.8\end{array}$ & $\begin{array}{l}5.7 \\
2.2\end{array}$ & WSH \\
\hline$H$ & 13 & 3.1 & .3 & .0 & .0 & .0 & .0 & 3.4 & 1.1 & \\
\hline WNH & 14 & 2.7 & .3 & .1 & .0 & .0 & .0 & 3.1 & 1.3 & HWH \\
\hline NH & 15 & 2.8 & 1.1 & .1 & .1 & .0 & .0 & 4.2 & 1.6 & NH \\
\hline NNG & 16 & 3.9 & .9 & .1 & .0 & .0 & .0 & 5.0 & & NNH \\
\hline CALM & & & & & & & & & & \\
\hline TOTAL & & 53.1 & 13.6 & 13.4 & 17.5 & 2.4 & .0 & 100.0 & 2.9 & \\
\hline
\end{tabular}

$100.0 \%$ DATA RECOVERED

100.0\% OF RECOVERED DATA REPORTED ABOVE

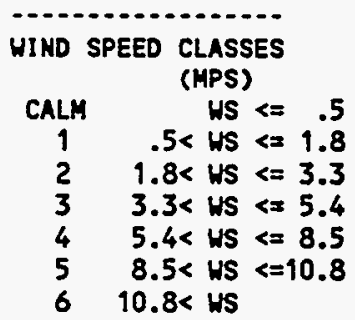


METEOROLOGICAL JOIHT FREQUENCY DISTRIBUTION (PERCENT OF VALID HOUR OBSERVATIONS)

SPILL TEST FACILITY 24 METER TONER

2 METER HEIGHT - Total Hours

9/ $1 / 1994-9 / 30 / 1994$

0 - 2300 (MST)

HINDSPEED CLASS

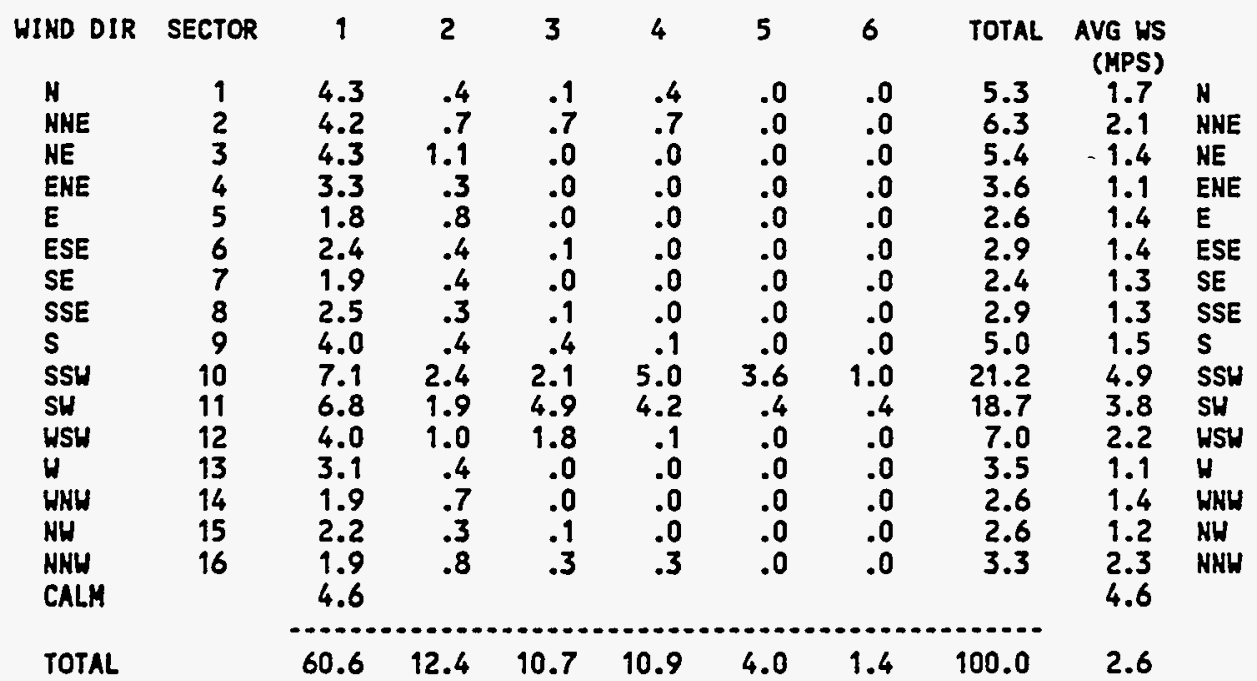

$99.7 \%$ DATA RECOVERED

100.0\% OF RECOVERED DATA

REPORTED ABOVE

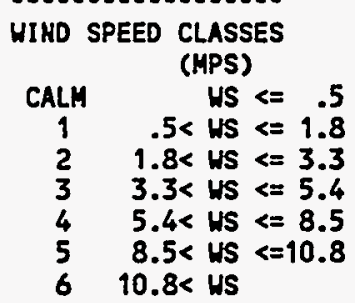


METEOROLOGICAL JOINT FREQUENCY DISTRIBUTION (PERCENT OF VALIO HOUR OBSERVATIONS) SPILL TEST FACILITY 24 METER TONER

2 METER HEIGHT - TOtal Hours $10 / 1 / 1994-10 / 31 / 1994$ $0-2300$ (MST)

HI N D SEED CLASS

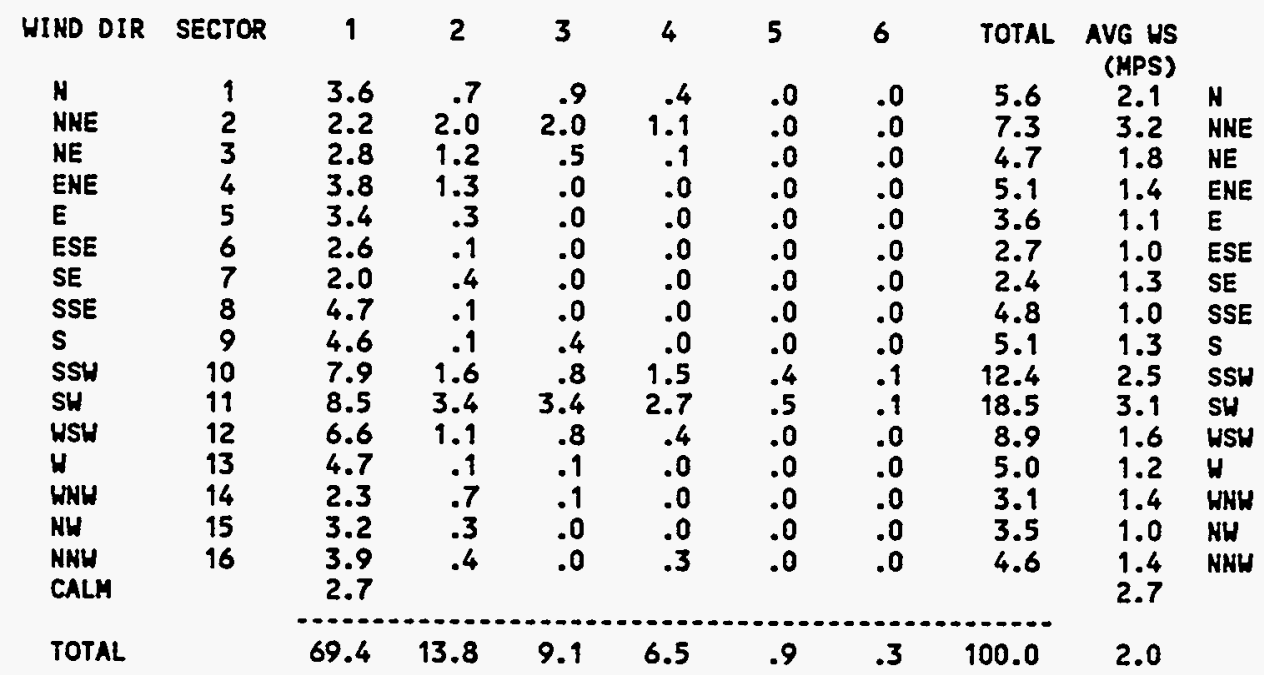

100.0\% DATA RECOVERED

100.0\% OF RECOVERED DATA REPORTED ABOVE

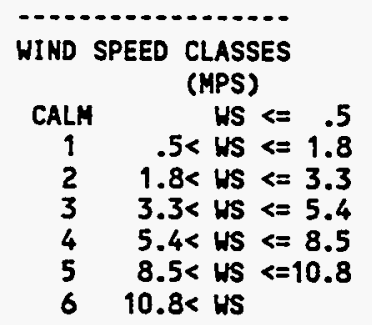


METEOROLOGICAL JOINT FREQUENCY DISTRIBUTION (PERCENT OF VALID MOUR OBSERVATIONS) SPILL TEST FACILITY 24 METER TOWER

2 METER HEIGHT - Total Hours

$11 / 1 / 1994 \cdot 11 / 30 / 1994$

$0-2300$ (MST)

HI H SPEED CLASS

\begin{tabular}{|c|c|c|c|c|c|c|c|c|c|c|}
\hline WIND DIR & SECTOR & 1 & 2 & 3 & 4 & 5 & 6 & TOTAL & $\begin{array}{r}\text { AVG WS } \\
\text { (MPS) }\end{array}$ & \\
\hline N & 1 & 3.5 & 1.3 & .1 & .6 & .0 & .0 & 5.4 & 2.1 & H \\
\hline MHE & 2 & 3.9 & 1.8 & 1.9 & 1.3 & .0 & .0 & 8.9 & 2.8 & NHE \\
\hline $\mathrm{HE}$ & 3 & 3.3 & 2.6 & .4 & .1 & .0 & .0 & 6.5 & 2.0 & NE \\
\hline ENE & 4 & 3.1 & 1.3 & .3 & .0 & .0 & .0 & 4.6 & 1.5 & ENE \\
\hline$E$ & 5 & 5.1 & .8 & .1 & .0 & .0 & .0 & 6.1 & 1.3 & E \\
\hline $\begin{array}{l}\text { ESE } \\
\text { SE }\end{array}$ & $\begin{array}{l}6 \\
7\end{array}$ & $\begin{array}{l}2.8 \\
2.2\end{array}$ & $\begin{array}{r}.3 \\
1.3\end{array}$ & $\begin{array}{l}.0 \\
.3\end{array}$ & $\begin{array}{l}.0 \\
.0\end{array}$ & $\begin{array}{l}.0 \\
.0\end{array}$ & $\begin{array}{l}.0 \\
.0\end{array}$ & $\begin{array}{l}3.1 \\
3.8\end{array}$ & $\begin{array}{l}1.1 \\
1.7\end{array}$ & $\begin{array}{l}\text { ESE } \\
\text { SE }\end{array}$ \\
\hline $\begin{array}{l}\text { SSE } \\
\text { S }\end{array}$ & $\begin{array}{l}8 \\
9\end{array}$ & $\begin{array}{l}2.5 \\
3.3\end{array}$ & $\begin{array}{l}.0 \\
1.1\end{array}$ & $\begin{array}{l}.1 \\
.3\end{array}$ & $\begin{array}{l}.0 \\
.0\end{array}$ & $\begin{array}{l}.0 \\
.0\end{array}$ & $\begin{array}{l}.0 \\
.0\end{array}$ & $\begin{array}{l}2.6 \\
4.7\end{array}$ & $\begin{array}{l}1.0 \\
1.5\end{array}$ & $\begin{array}{l}\text { SSE } \\
\text { S }\end{array}$ \\
\hline $\begin{array}{l}\text { SSW } \\
\text { SW }\end{array}$ & $\begin{array}{l}10 \\
11\end{array}$ & $\begin{array}{l}5.8 \\
8.5\end{array}$ & $\begin{array}{l}1.4 \\
1.4\end{array}$ & $\begin{array}{l}1.1 \\
1.1\end{array}$ & $\begin{array}{l}1.3 \\
2.9\end{array}$ & $\begin{array}{r}1.0 \\
.6\end{array}$ & $\begin{array}{r}1.0 \\
.0\end{array}$ & $\begin{array}{l}11.5 \\
14.4\end{array}$ & & $\begin{array}{l}\text { SSH } \\
\text { SW }\end{array}$ \\
\hline WSH & 12 & 4.6 & .3 & 1.4 & .3 & .1 & .0 & 6.7 & 2.1 & WSH \\
\hline H & 13 & 2.9 & .1 & .1 & .0 & .0 & .0 & 3.2 & 1.4 & W \\
\hline WNH & 14 & 3.3 & .7 & .1 & .4 & .0 & .0 & 4.6 & 1.8 & WNH \\
\hline $\begin{array}{l}\text { NH } \\
\text { NHW }\end{array}$ & $\begin{array}{l}75 \\
16\end{array}$ & $\begin{array}{l}4.6 \\
3.8\end{array}$ & $\begin{array}{l}1.3 \\
1.0\end{array}$ & $\begin{array}{l}.0 \\
.4\end{array}$ & .7 & .0 & .00 & $\begin{array}{l}6.0 \\
5.8\end{array}$ & $\begin{array}{l}2.7 \\
2.2\end{array}$ & NNW \\
\hline CALM & & 2. & & & & & & & 2.1 & \\
\hline TOTAL & & 64.7 & 16.5 & 7.9 & 8.2 & 1.7 & 1.0 & 100.0 & 2.2 & \\
\hline
\end{tabular}

100.0\% DATA RECOVERED 100.0\% OF RECOVERED DATA REPORTED ABOVE

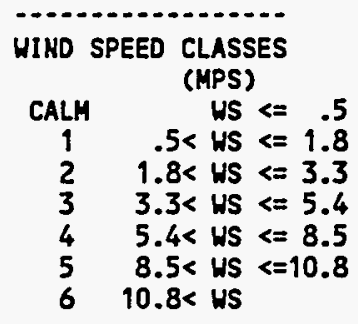


METEOROLOGICAL JOINT FREQUENCY DISTRIBUTION (PERCENT OF VALID HOUR OBSERVATIOHS)

SPILL TEST FACILITY 24 METER TOWER

2 METER HEIGHT - Total Hours

$12 / 1 / 1994 \cdot 12 / 31 / 1994$

$0 \cdot 2300$ (MST)

WINDSPEED CLASS

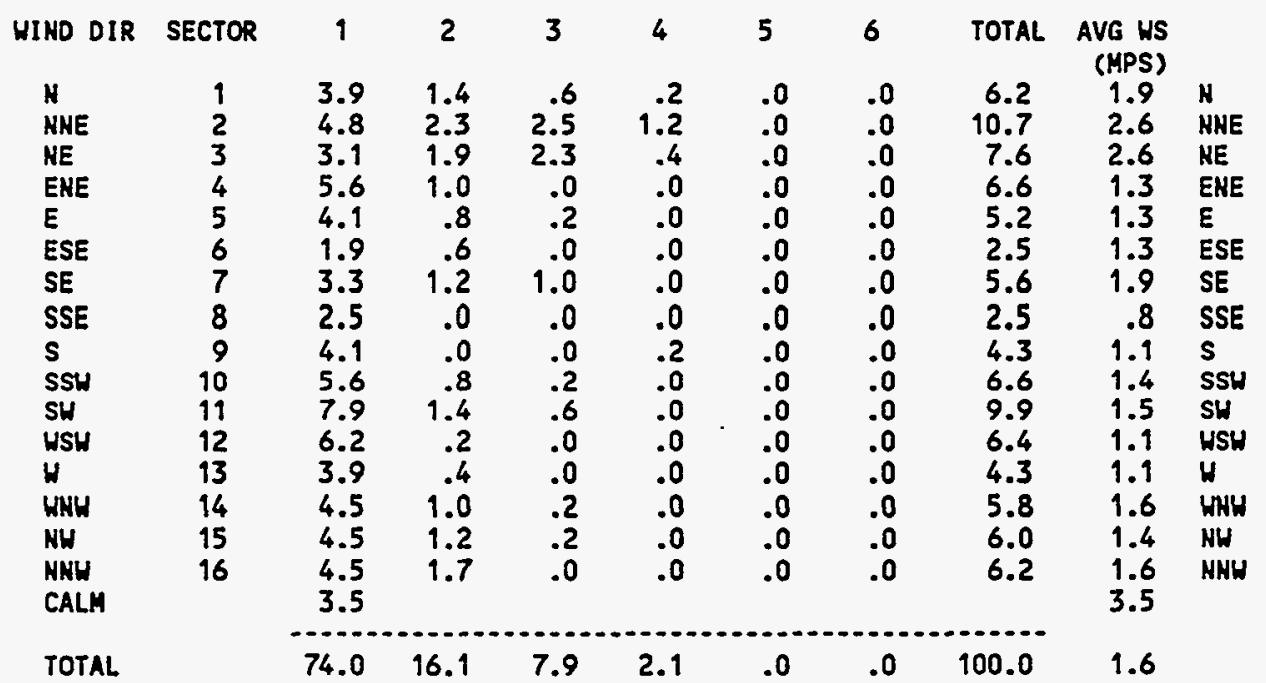

65.1\% DATA RECOVERED

100.0X OF RECOVERED DATA REPORTED ABOVE

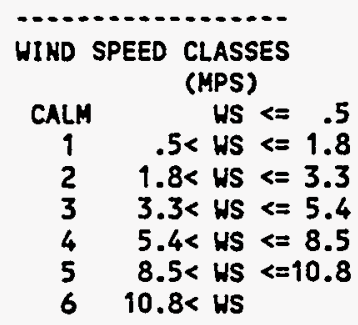


METEOROLOGICAL JOINT FREQUENCY DISTRIEUTION (PERCENT OF VALID HOUR OBSERVATIONS) SPILL TEST FACILITY 26 METER TONER

2 METER HEIGHT - Mornin Transition

$1 / 1 / 1994 \cdot 1 / 31 / 1994$

$600 \cdot 1000$ (MST)

HIDSPEEDCLASS

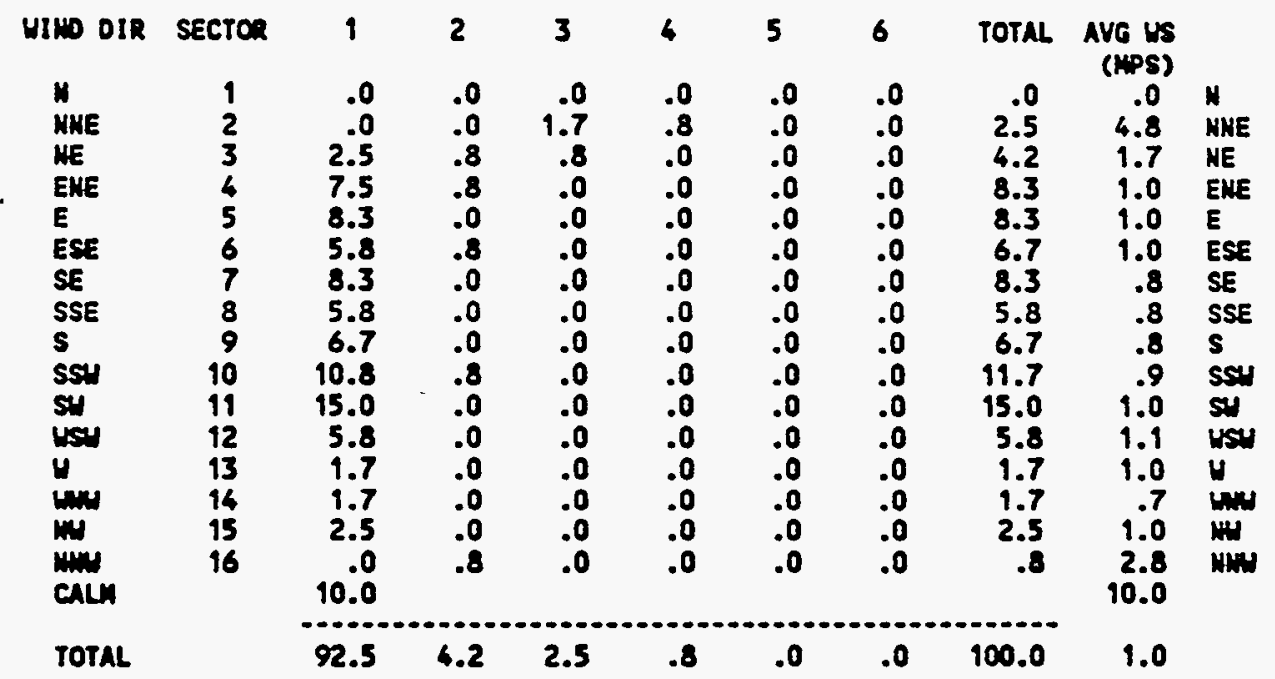

78.0X DATA RECOVERED

20.7\% OF RECOVERED DATA REPORTED APOVE

HIMD SPEE CLASSES

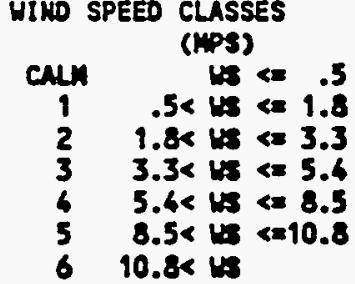


METEOROLOGICAL JOINT FREQUENCY OISTRIBUTION (PERCENT OF VALID HOUR OBSERVATIONS)

SPILL TEST FACILITY 24 METER TONER

2 METER HEIGHT - Morning Transition

2/ $1 / 19 \% 4 \cdot 2 / 28 / 19 \%$

$600 \cdot 1000$ (MST)

HINO SPEED CLASS

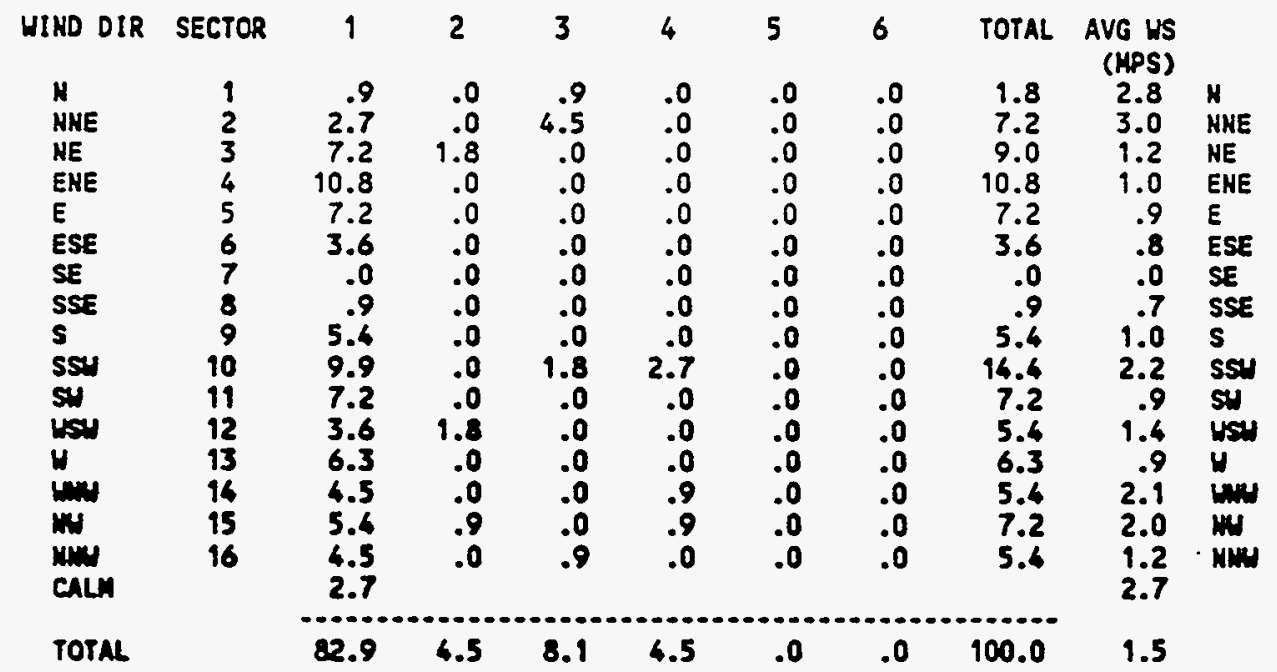

85.4\% DATA RECOVERED

19.3\% OF RECOVERED DATA REPORTED ABOVE

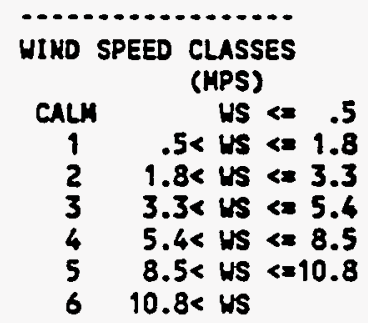


METECROLOGICAL JOINT FRECUEMCY DISTRIBUTION (PERCENT OF VALID HOUR OSSERVATIONS)

SPILL TEST FACILITY 24 METER TONER

2 METER HEIGHT - Morning Transition

$3 / 1 / 1994-3 / 31 / 1994$

$600 \cdot 1000$ (MST)

HIHD SPEEDCLASS

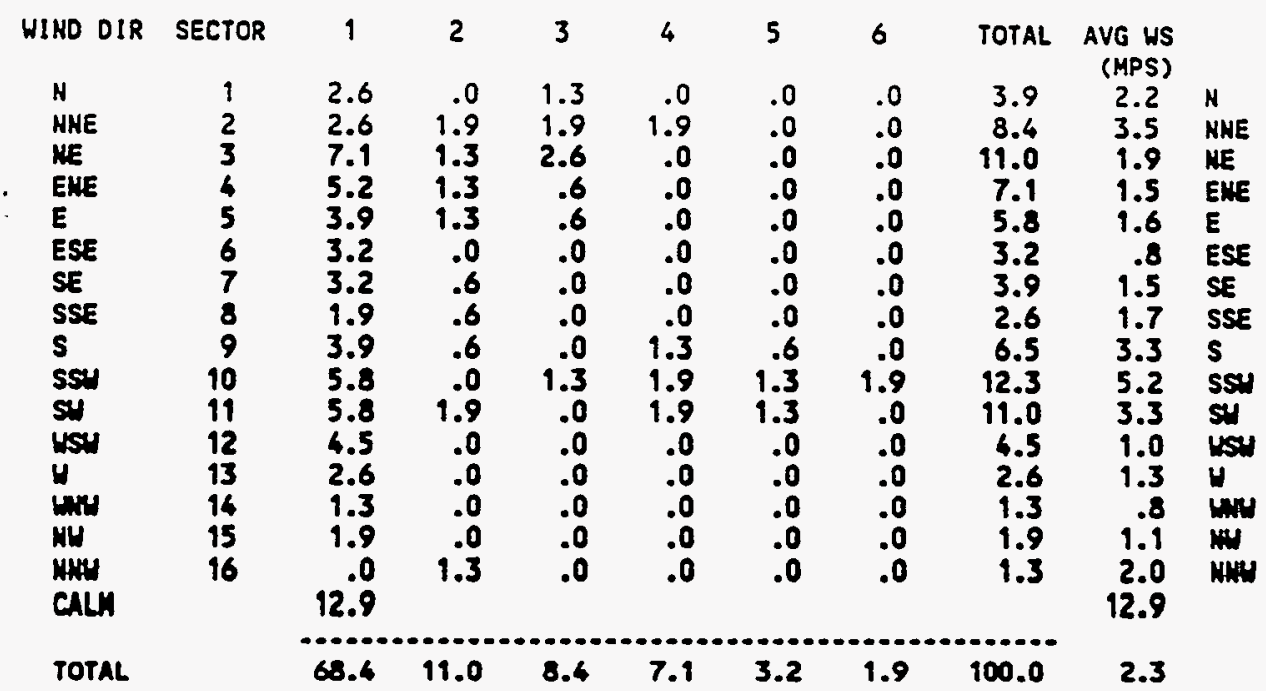

100.0\% DATA RECOVERED

20.8\% OF RECOVERED DATA REPORTED ABOVE

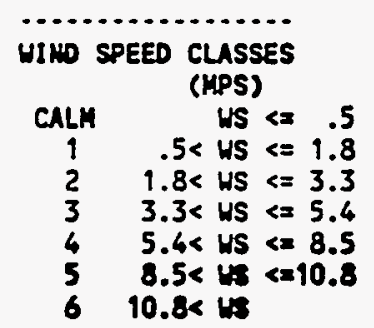


METEOROLOGICAL JOIHT FREQUENCY DISTRIBUTION (PERCENT OF VALIO HOUR OBSERVATIONS) SPILL TEST FACILITY 24 METER TOWER

2 METER HEIGHT - Morning Transition

$4 / 1 / 1994 \cdot 4 / 30 / 1994$

$600-1000$ (MST)

\section{HINDSPEED CLASS}

\begin{tabular}{|c|c|c|c|c|c|c|c|c|c|c|}
\hline WIND OIR & SECTOR & 1 & 2 & 3 & 4 & 5 & 6 & TOTAL & $\begin{array}{r}\text { AVG WS } \\
\text { (MPS) }\end{array}$ & \\
\hline H & 1 & .0 & .0 & .0 & .7 & .0 & .0 & .7 & 5.9 & N \\
\hline HNE & 2 & .0 & .7 & .7 & .0 & .0 & .0 & 1.3 & 3.6 & AHE \\
\hline NE & 3 & .7 & .0 & .0 & .0 & .0 & .0 & .7 & .9 & $\mathrm{NE}$ \\
\hline ENE & 4 & 3.3 & .0 & .0 & .0 & .0 & .0 & 3.3 & 1.2 & ENE \\
\hline E & 5 & 6.7 & 1.3 & .0 & .0 & .0 & .0 & 8.0 & $1 . \overline{3}$ & $E$ \\
\hline ESE & 6 & 3.3 & .0 & .7 & .0 & .0 & .0 & 4.0 & 1.7 & ESE \\
\hline SE & 7 & 8.0 & 1.3 & 1.3 & .0 & .0 & .0 & 10.7 & 1.5 & SE \\
\hline $\begin{array}{l}\text { SSE } \\
\text { S }\end{array}$ & $\begin{array}{l}8 \\
9\end{array}$ & $\begin{array}{l}8.7 \\
8.0\end{array}$ & $\begin{array}{r}.0 \\
1.3\end{array}$ & $\begin{array}{l}.7 \\
.0\end{array}$ & $\begin{array}{l}.0 \\
.7\end{array}$ & $\begin{array}{l}.0 \\
.0\end{array}$ & $\begin{array}{l}.0 \\
.0\end{array}$ & $\begin{array}{r}9.3 \\
10.0\end{array}$ & $\begin{array}{l}1.3 \\
1.4\end{array}$ & $\begin{array}{l}\text { SSE } \\
\text { S }\end{array}$ \\
\hline SSW & 10 & 8.7 & 3.3 & 2.0 & 2.0 & 2.0 & 2.0 & 20.0 & 4.2 & SSW \\
\hline SW & 11 & 7.3 & 1.3 & 2.7 & 1.3 & 2.7 & .0 & 15.3 & 3.8 & SW \\
\hline WSW & 12 & 4.0 & 1.3 & .0 & .0 & .0 & .0 & 5.3 & 1.3 & WSH \\
\hline$y$ & 13 & 2.7 & .0 & .7 & .0 & .0 & .0 & 3.3 & 1.6 & H \\
\hline WNH & 14 & .7 & .7 & .0 & .0 & .0 & .0 & 1.3 & 2.0 & WHW \\
\hline NW & 15 & .7 & .0 & .7 & .0 & .0 & .0 & 1.3 & 3.1 & NH \\
\hline $\begin{array}{l}\text { NHW } \\
\text { CALM }\end{array}$ & 16 & $\begin{array}{r}.0 \\
4.7\end{array}$ & .0 & .0 & .7 & .0 & .0 & .7 & $\begin{array}{l}6.2 \\
4.7\end{array}$ & NHW \\
\hline TOTAL & & 67.3 & 19.3 & 9.3 & 5.3 & 4.7 & 2.0 & 100.0 & 2.4 & \\
\hline
\end{tabular}

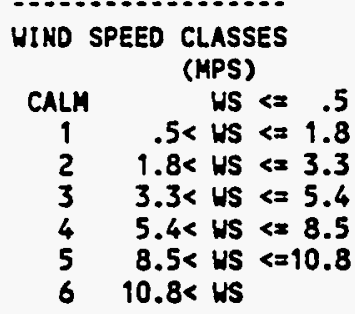


METEOROLOGICAL JOIHT FREQUENCY DISTRIBUTION (PERCENT OF VALID HOUR OBSERVATIONS)

SPILL TEST FACILITY 24 METER TONER

2 METER HEIGHT - Morning Transition

$5 / 1 / 1994-5 / 31 / 1994$

$600 \cdot 1000$ (MST)

HIND SPEEDCLASS

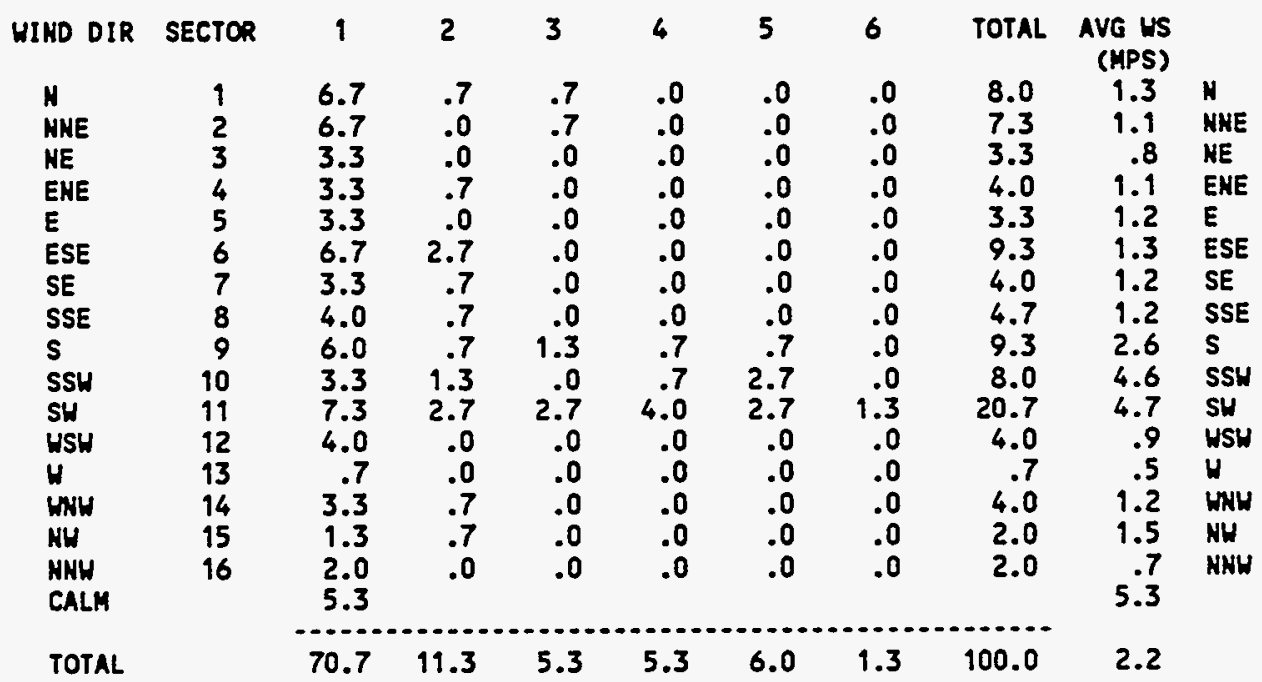

96.9\% DATA RECOVERED

20.8\% OF RECOVERED DATA

REPORTED ABOVE

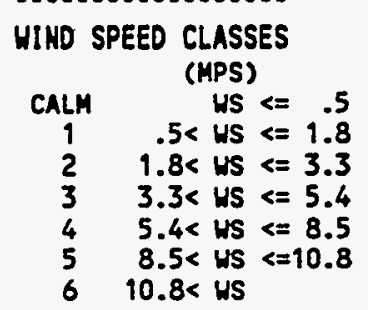


METEOROLOGICAL JOINT FREOUENCY OISTRIBUTION (PERCENT OF VALID HOUR OBSERVATIONS)

SPILL TEST FACILITY 24 METER TONER

2 METER HEIGHT - Morning Transition

$6 / 1 / 1994 \cdot 6 / 30 / 1994$

$600 \cdot 1000$ (MST)

HINDSPEED CLASS

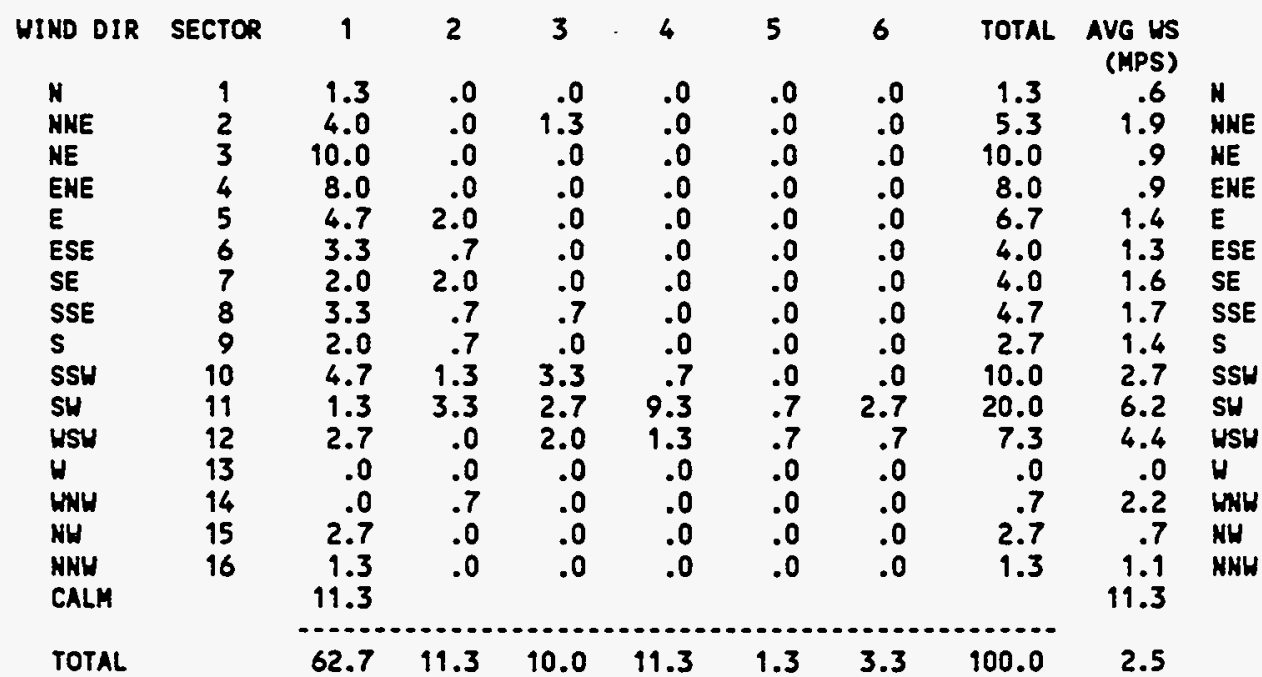

100.0\% DATA RECOVERED

20.8\% OF RECOVERED DATA REPORTED ABOVE

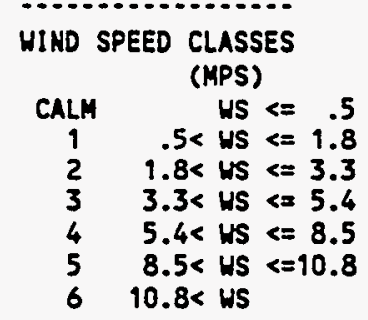


METEOROLOGICAL JOIHT FREQUENCY DISTRIBUTION (PERCENT OF VALID HOUR OBSERVATIONS) SPILL TEST FACILITY 24 METER TOWER 2 METER HEIGHT - Morning Transition

$7 / 1 / 1994 \cdot 7 / 31 / 1994$

$600 \cdot 1000($ MST)

WIND SPEED CLASS

\begin{tabular}{|c|c|c|c|c|c|c|c|c|c|c|}
\hline HIND DIR & SECTOR & 1 & 2 & 3 & 4 & 5 & 6 & TOTAL & $\begin{array}{r}\text { AVG US } \\
\text { (MPS) }\end{array}$ & \\
\hline H & 1 & 2.6 & .0 & .0 & .0 & .0 & .0 & 2.6 & .8 & N \\
\hline MNE & 2 & 3.9 & .6 & 1.3 & .0 & .0 & .0 & 5.8 & 2.0 & NHE \\
\hline ME & 3 & 5.2 & 1.3 & .0 & .0 & .0 & .0 & 6.5 & 1.2 & NE \\
\hline ENE & 4 & 9.7 & .0 & .0 & .0 & .0 & .0 & 9.7 & 1.0 & ENE \\
\hline$E$ & 5 & 6.5 & .6 & .0 & .0 & .0 & .0 & 7.1 & 1.3 & E \\
\hline ESE & 6 & 1.3 & .6 & .0 & .0 & .0 & .0 & 1.9 & 1.5 & ESE \\
\hline SE & 7 & 4.5 & .0 & 1.3 & .0 & .0 & .0 & 5.8 & 1.7 & SE \\
\hline SSE & 8 & 2.6 & .0 & .6 & .0 & .0 & .0 & 3.2 & 1.5 & SSE \\
\hline 5 & 9 & 2.6 & 1.3 & .0 & .6 & .0 & .0 & 4.5 & 2.1 & $\mathbf{s}$ \\
\hline SSH & 10 & 4.5 & 1.9 & 5.2 & .6 & .6 & .0 & 12.9 & 3.1 & SSH \\
\hline SW & 11 & 3.2 & 3.9 & 3.2 & 1.9 & .0 & .0 & 12.3 & 3.1 & SH \\
\hline WSH & 12 & 1.9 & .6 & .0 & .6 & .0 & .0 & 3.2 & 2.0 & USH \\
\hline$y$ & 13 & 3.2 & .0 & .6 & .0 & .0 & .0 & 3.9 & 1.4 & $W$ \\
\hline HNH & 14 & .6 & .0 & .0 & .0 & .0 & .0 & .6 & 1.5 & WHW \\
\hline HW & 15 & 3.2 & .0 & .6 & .0 & .0 & .0 & 3.9 & 1.5 & NH \\
\hline $\begin{array}{l}\text { HNH } \\
\text { CALM }\end{array}$ & 16 & $\begin{array}{r}1.9 \\
14.2\end{array}$ & .0 & .0 & .0 & .0 & .0 & 1.9 & $\begin{array}{r}.9 \\
14.2\end{array}$ & HNW \\
\hline TOTAL & & 71.6 & 11.0 & 12.9 & 3.9 & .6 & .0 & 100.0 & 1.7 & \\
\hline
\end{tabular}

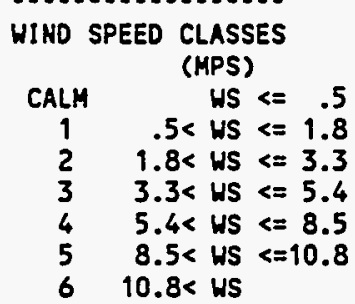


METEOROLOGICAL JOINT FREQUENCY OISTRIBUTION (PERCENT OF VALID HOUR OBSERVATIONS)

SPILL TEST FACILITY 24 METER TOWER

2 METER HEIGHT - Morning Transition

$8 / 1 / 1994-8 / 31 / 1994$

$600-1000$ (MST)

HI H D SPEED CLASS

\begin{tabular}{|c|c|c|c|c|c|c|c|c|c|c|}
\hline HIND DIR & SECTOR & 1 & 2 & 3 & 4 & 5 & 6 & TOTAL & $\begin{array}{r}\text { AVG WS } \\
\text { (MPS) }\end{array}$ & \\
\hline N & 1 & 3.2 & .0 & .0 & .0 & .0 & .0 & 3.2 & 1.2 & H \\
\hline NNE & 2 & 3.9 & .6 & .6 & .0 & .0 & .0 & 5.2 & 1.3 & NHE \\
\hline NE & 3 & 9.7 & .0 & .0 & .0 & .0 & .0 & 9.7 & .9 & NE \\
\hline ENE & 4 & 7.1 & .6 & .0 & .0 & .0 & .0 & 7.7 & 1.3 & ENE \\
\hline$E$ & 5 & 6.5 & .6 & .0 & .0 & .0 & .0 & 7.1 & 1.1 & E \\
\hline ESE & 6 & 3.2 & .6 & .6 & .0 & .0 & .0 & 4.5 & 1.6 & ESE \\
\hline $\begin{array}{l}\text { SE } \\
\text { SSE }\end{array}$ & $\begin{array}{l}7 \\
8\end{array}$ & 5.2 & .6 & .6 & 1.9 & .0 & .0 & 8.4 & 2.5 & SE \\
\hline $\begin{array}{l}\text { SSE } \\
\text { S }\end{array}$ & $\begin{array}{l}8 \\
9\end{array}$ & $\begin{array}{l}1.3 \\
2.6\end{array}$ & $\begin{array}{l}.6 \\
.6\end{array}$ & $\begin{array}{r}1.3 \\
.6\end{array}$ & $\begin{array}{r}.0 \\
1.3\end{array}$ & $\begin{array}{l}.0 \\
.0\end{array}$ & $\begin{array}{l}.0 \\
.0\end{array}$ & $\begin{array}{l}3.2 \\
5.2\end{array}$ & $\begin{array}{l}2.8 \\
2.9\end{array}$ & $\begin{array}{l}\text { SSE } \\
\text { S }\end{array}$ \\
\hline SSH & 10 & 4.5 & 1.3 & 1.3 & .6 & .6 & .0 & 8.4 & 2.9 & ssu \\
\hline SH & 11 & 2.6 & .6 & 2.6 & 2.6 & 1.9 & .0 & 10.3 & 4.8 & SH \\
\hline WSH & 12 & 3.2 & 1.3 & .0 & .0 & .0 & .0 & 4.5 & 1.2 & WSU \\
\hline$H$ & 13 & 2.6 & .0 & .0 & .0 & .0 & .0 & 2. & .9 & W \\
\hline WHW & $\begin{array}{l}14 \\
15\end{array}$ & 1.9 & .6 & .0 & .0 & .0 & .0 & 2. & 1.3 & WHU \\
\hline NH & 15 & 1.3 & .0 & .6 & .0 & .0 & .0 & 1.9 & 1.7 & NH \\
\hline $\begin{array}{l}\text { NHW } \\
\text { CALM }\end{array}$ & 16 & $\begin{array}{r}3.2 \\
12.3\end{array}$ & .0 & .0 & .0 & .0 & .0 & 3.2 & 12.8 & NKW \\
\hline TOTAL & & 74.2 & 8.4 & 8.4 & 6.5 & 2.6 & .0 & 100.0 & 1.8 & \\
\hline
\end{tabular}

100.0\% DATA RECOVERED

20.8\% OF RECOVERED DATA REPORTED ABOVE

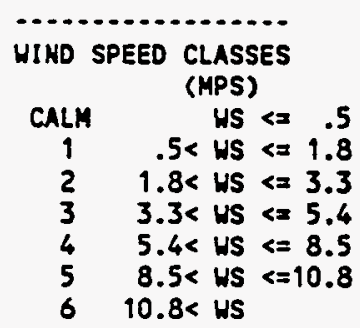


METEOROLOGICAL JOINT FREQUENCY DISTRIBUTIOH (PERCENT OF VALIO HOUR OBSERVATIONS)

SPILL TEST FACILITY 24 METER TOUER

2 METER heIGHT - Morning Transition

$9 / 1 / 1994-9 / 30 / 1994$ $600 \cdot 1000$ (MST)

WINDSPEEDCLASS

\begin{tabular}{|c|c|c|c|c|c|c|c|c|c|c|}
\hline HIND DIR & SECTOR & 1 & 2 & 3 & 4 & 5 & 6 & TOTAL & $\begin{array}{l}\text { AVG WS } \\
\text { (MPS) }\end{array}$ & \\
\hline N & 1 & 3.4 & .0 & .0 & .0 & .0 & .0 & 3.4 & .9 & N \\
\hline NHE & 2 & 2.7 & .0 & .7 & .0 & .0 & .0 & 3.4 & 1.4 & NNE \\
\hline NE & 3 & 7.4 & .0 & .0 & .0 & .0 & .0 & 7.4 & 1.1 & NE \\
\hline ENE & 4 & 6.8 & .7 & .0 & .0 & .0 & .0 & 7.4 & .9 & EHE \\
\hline$E$ & 5 & 4.1 & 1.4 & .0 & .0 & 0 & .0 & 5.4 & 1.2 & $E$ \\
\hline $\begin{array}{l}\text { ESE } \\
\text { SE }\end{array}$ & $\begin{array}{l}6 \\
7\end{array}$ & $\begin{array}{l}3.4 \\
2.7\end{array}$ & .7 & .7 & .0 & .0 & $\begin{array}{l}.0 \\
.0\end{array}$ & $\begin{array}{l}4.7 \\
2.7\end{array}$ & $\begin{array}{r}1.5 \\
.7\end{array}$ & $\begin{array}{l}\text { ESE } \\
\text { SE }\end{array}$ \\
\hline SSE & 8 & 4.1 & .0 & .0 & .0 & .0 & .0 & 4.1 & .8 & SSE \\
\hline s & 9 & 3.4 & .0 & .0 & .0 & .0 & .0 & 3.4 & 1.0 & $s$ \\
\hline SSH & 10 & 5.4 & 1.4 & 2.7 & 4.1 & 2.7 & 1.4 & 17.6 & 5.3 & SSW \\
\hline SH & 19 & 6.1 & .0 & .0 & .7 & .7 & .7 & 8.1 & 3.0 & SH \\
\hline WSH & 12 & 2.7 & .7 & .0 & .0 & .0 & .0 & 3.4 & 1.3 & USW \\
\hline H & 13 & 1.4 & .0 & .0 & .0 & .0 & .0 & 1.4 & .8 & $H$ \\
\hline WNH & 14 & 2.0 & .7 & .0 & .0 & .0 & .0 & 2.7 & 1.1 & WNW \\
\hline HW & 15 & 3.4 & .0 & .7 & .0 & .0 & .0 & 4.1 & 1.5 & NH \\
\hline $\begin{array}{l}\text { NKH } \\
\text { CALY }\end{array}$ & 16 & $\begin{array}{r}1.4 \\
18.9\end{array}$ & .0 & .7 & .0 & .0 & .0 & 2.0 & $\begin{array}{r}1.8 \\
189\end{array}$ & HNW \\
\hline & & & & & & & & & & \\
\hline TOTAL & & 79.1 & 5.4 & 5.4 & 4.7 & 3.4 & 2.0 & 100.0 & 1.8 & \\
\hline
\end{tabular}

99.T\% DATA RECOVERED

20.6\% OF RECOVERED DATA REPORTED ABOVE

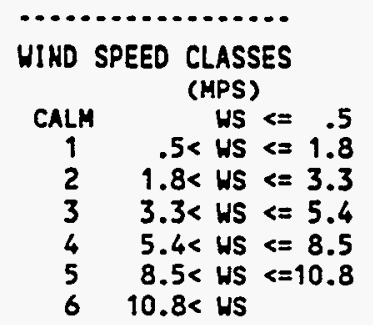


METEOROLOGICAL JOIMT FREQUENCY DISTRIBUTION (PERCENT OF VALID HOUR OBSERVATIONS)

SPILL TEST FACILITY 24 METER TOUER

2 METER HEIGHT - Morning Transition

$10 / 1 / 1994-10 / 31 / 1994$

$600 \cdot 1000$ (MST)

WIND SPEED CLASS

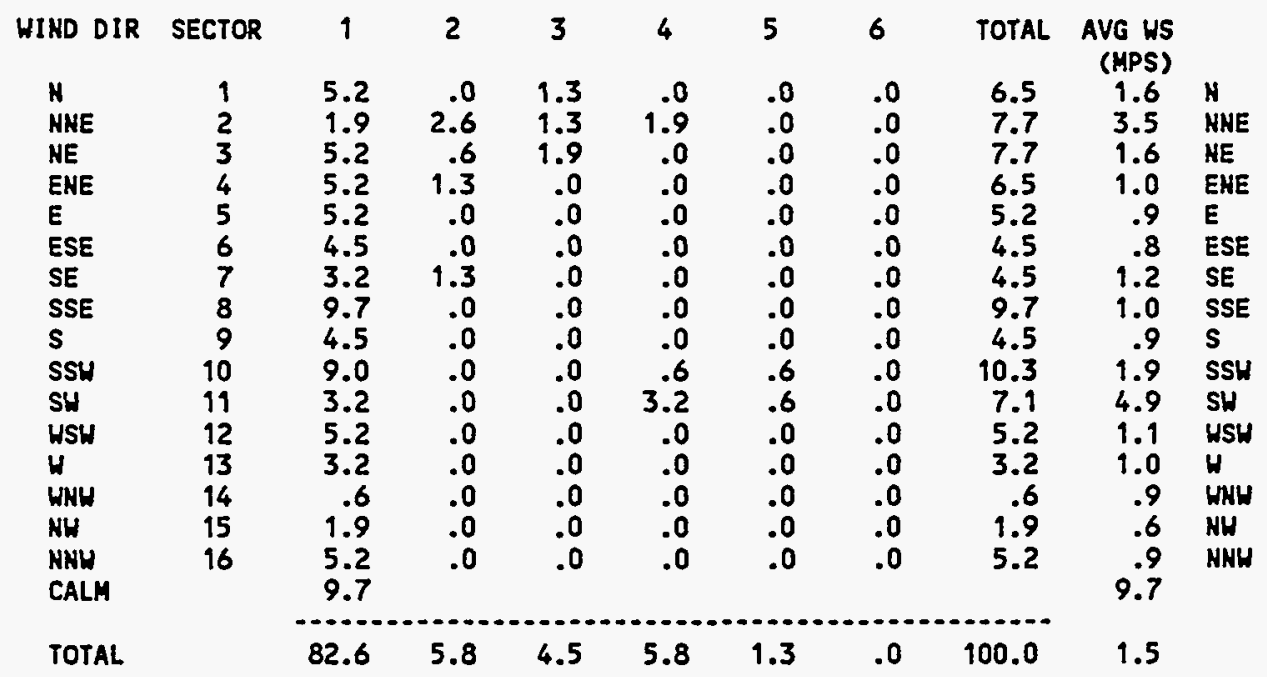

100.0\% DATA RECOVERED

20.8\% OF RECOVERED DATA REPORTED ABOVE

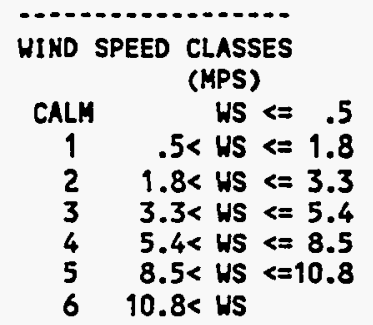


METEOROLOGICAL JOINT FREQUENCY DISTRIBUTION (PERCENT OF VALID HOUR OBSERVATIONS)

SPILL TEST FACILITY 24 METER TOWER

2 METER HEIGHT - Morning Transition

$11 / 1 / 1994-11 / 30 / 1994$

$600-1000$ (MST)

HINDSPEEDCLASS

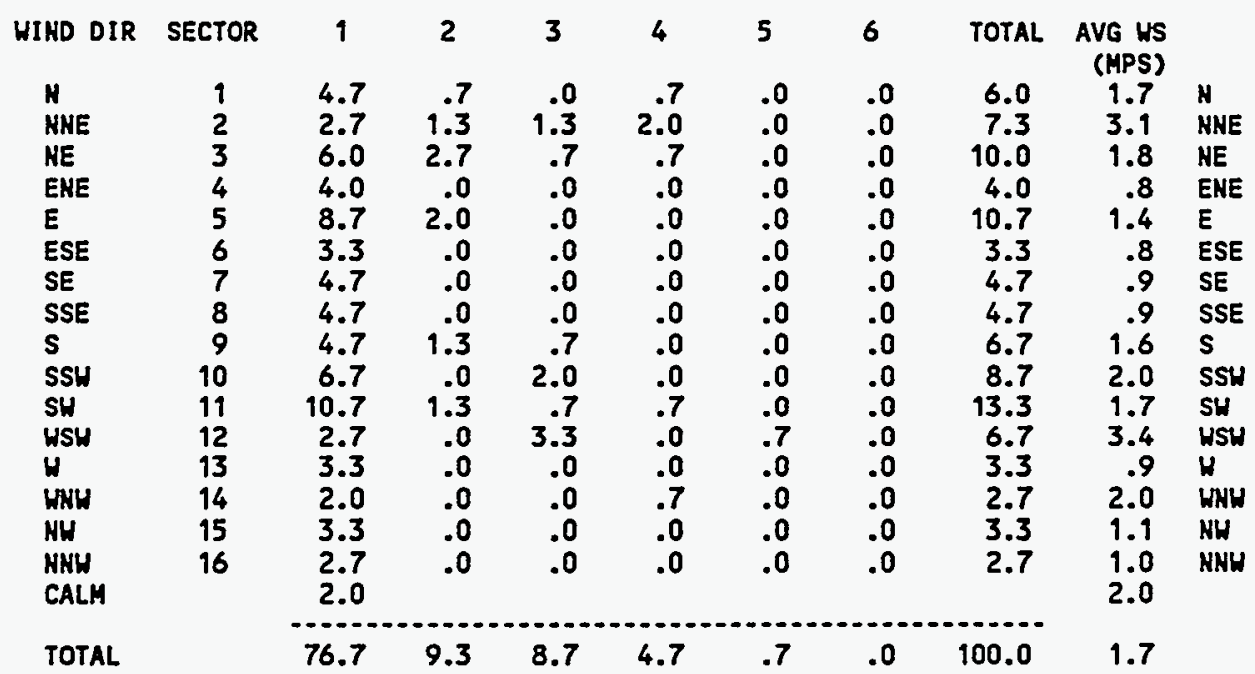

100.0\% DATA RECOVERED

20.8\% OF RECOVERED DATA

REPORTED ABOVE

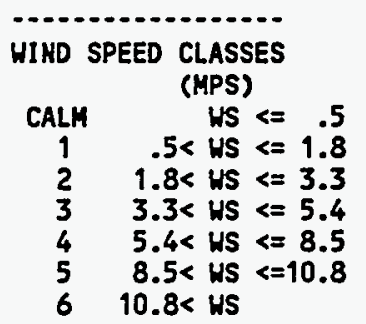


METEOROLOGICAL JOINT FREQUENCY DISTRIBUTION (PERCENT OF VALID HOUR OBSERVATIONS) SPILL TEST FACILITY 24 METER TONER

2 METER HEIGHT - Morning Transition

12/ $1 / 1994-12 / 31 / 1994$

$600-1000$ (MST)

WINDSPEEDCLASS

\begin{tabular}{|c|c|c|c|c|c|c|c|c|c|c|}
\hline HIND DIR & SECTOR & 1 & 2 & 3 & 4 & 5 & 6 & TOTAL & AVG US & \\
\hline H & 1 & 5.0 & 2.0 & 1.0 & 1.0 & .0 & .0 & 9.0 & 2.2 & N \\
\hline NNE & 2 & 5.0 & 2.0 & 3.0 & 4.0 & .0 & .0 & 14.0 & 3.4 & NHE \\
\hline NE & 3 & 2.0 & 1.0 & 2.0 & .0 & .0 & .0 & 5.0 & 2.8 & NE \\
\hline ENE & 4 & 6.0 & .0 & .0 & .0 & .0 & .0 & 6.0 & 1.0 & ENE \\
\hline E & 5 & 6.0 & .0 & .0 & .0 & .0 & .0 & 6.0 & .9 & E \\
\hline ESE & 6 & 3.0 & .0 & .0 & .0 & .0 & .0 & 3.0 & .9 & ESE \\
\hline SE & 7 & 4.0 & 1.0 & .0 & .0 & .0 & .0 & 5.0 & 1.2 & SE \\
\hline SSE & 8 & 3.0 & .0 & .0 & .0 & .0 & .0 & 3.0 & .8 & SSE \\
\hline s & 9 & 7.0 & .0 & .0 & .0 & .0 & .0 & 7.0 & .8 & s \\
\hline SSW & 10 & 4.0 & 1.0 & .0 & .0 & .0 & .0 & 5.0 & 1.3 & SSH \\
\hline su & 11 & 13.0 & .0 & .0 & .0 & .0 & .0 & 13.0 & 1.1 & SW \\
\hline USW & 12 & 4.0 & .0 & .0 & .0 & .0 & .0 & 4.0 & 1.0 & WSH \\
\hline$W$ & 13 & 4.0 & .0 & .0 & .0 & .0 & .0 & 4.0 & .8 & $H$ \\
\hline HNH & 14 & 2.0 & .0 & .0 & .0 & .0 & .0 & 2.0 & 1.2 & WHM \\
\hline NH & 15 & 4.0 & .0 & .0 & .0 & .0 & .0 & 4.0 & 1.2 & $\mathrm{NH}$ \\
\hline $\begin{array}{l}\text { NWH } \\
\text { CALM }\end{array}$ & 16 & $\begin{array}{l}2.0 \\
7.0\end{array}$ & 1.0 & .0 & .0 & .0 & .0 & 3.0 & $\begin{array}{l}1.3 \\
7.0\end{array}$ & NNH \\
\hline TOTAL & & 81.0 & 8.0 & 6.0 & 5.0 & .0 & .0 & 100.0 & 1.5 & \\
\hline
\end{tabular}

65.1\% DATA RECOVERED

20.7\% OF RECOVERED DATA REPORTED ABOVE

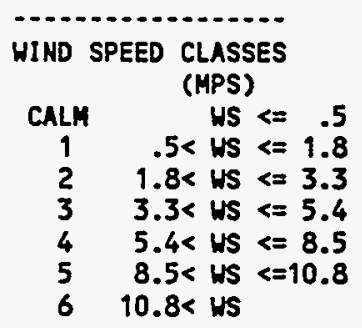


METECROLOGICAL JOINT FREQUENCY DISTRIQUTION (PERCENT OF VALIO HOUR OBSERVATIONS)

SPILL TEST FACILITY 26 METER TONER

2 METER HEIGHT - Late Mid-DaY $1 / 1 / 1994-1 / 31 / 1996$

HI HO SPEED CLASS

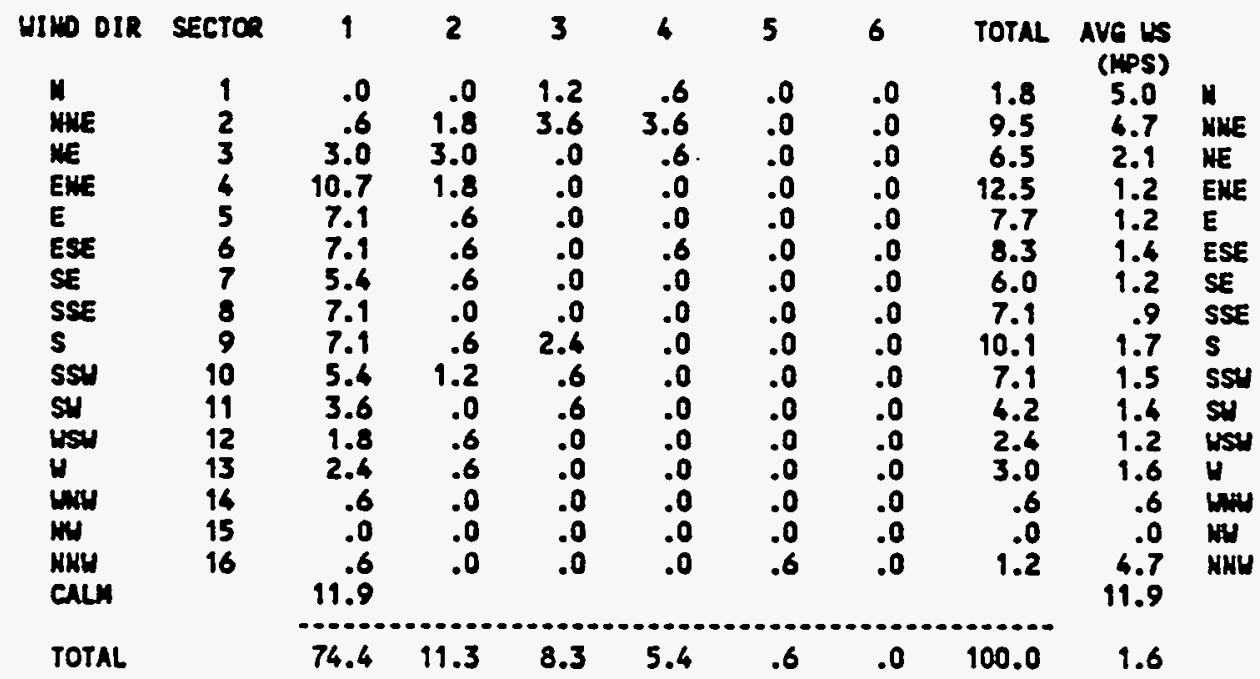

78.0\% DATA RECOVERED

29.0X OF RECOVERED DATA REPORTED ASOVE

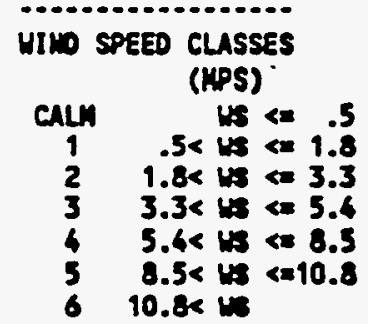


METECROLOGICAL JOINT FREQUENCY DISTRIDUTION (PERCEMT OF VALID HOUR OBSERVATIONS)

SPILL TEST FACILITY 24 METER TONER

2 METER HEIGHT - LATE Mid-DOY

21 $1 / 1994-2 / 28 / 1994$

1000 - 1600 (MST)

WINDSPEEDCLASS

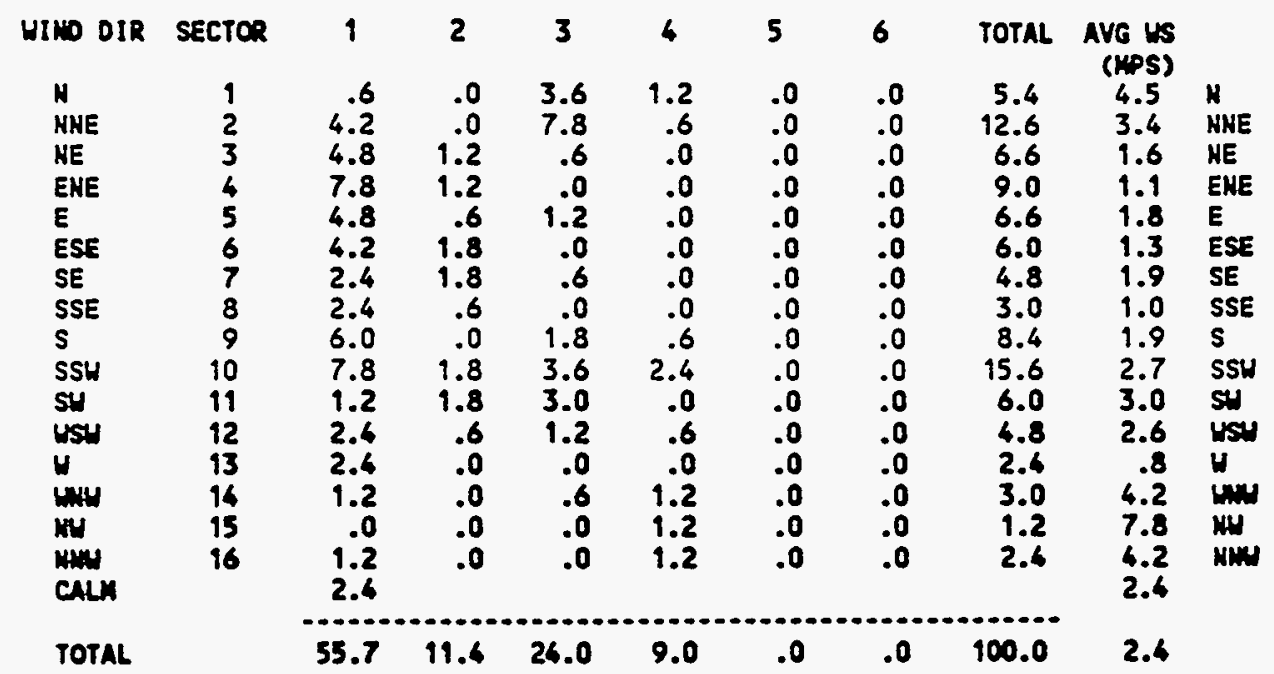

85.4\% DATA RECOVERED

29.1\% OF RECONERED DATA REPORTED ABOVE

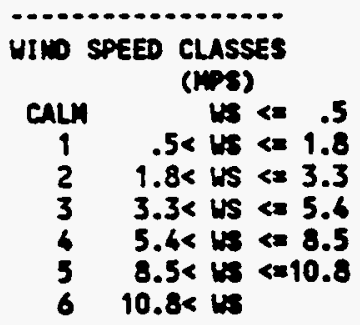


METEOROLOGICAL JOINT FREQUENCY OISTRIBUTION (PERCEHT OF VALIO HOUR OBSERVATIONS) SPILL TEST FACILITY 26 METER TOUER

HINO SPEED CLASS

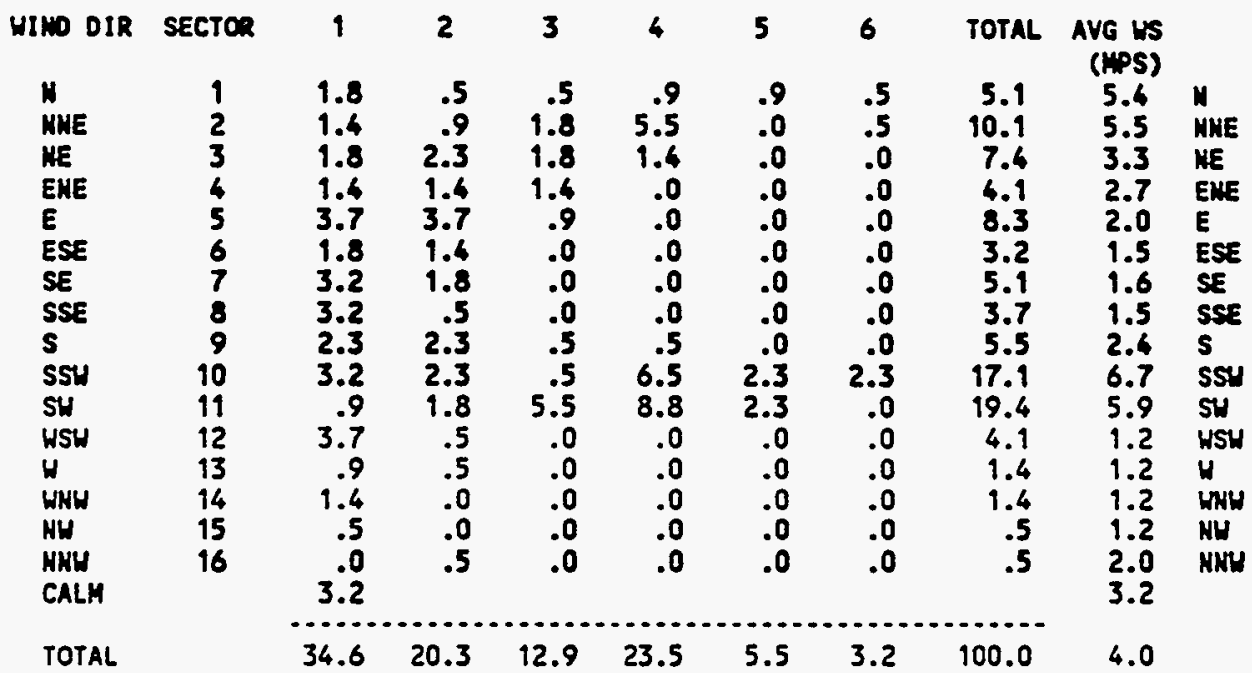

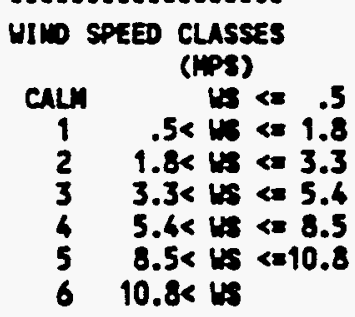


METEOROLOGICAL JOINT FREQUENCY DISTRIBUTION (PERCENT OF VALIO HOUR OBSERVATIONS) SPILL TEST FACILITY 24 METER TOWER

2 METER HEIGHT - Late Mid-Day 4/ 1/1994 - 4/30/1994

$1000 \cdot 1600$ (MST)

WI NDSPEED CLASS

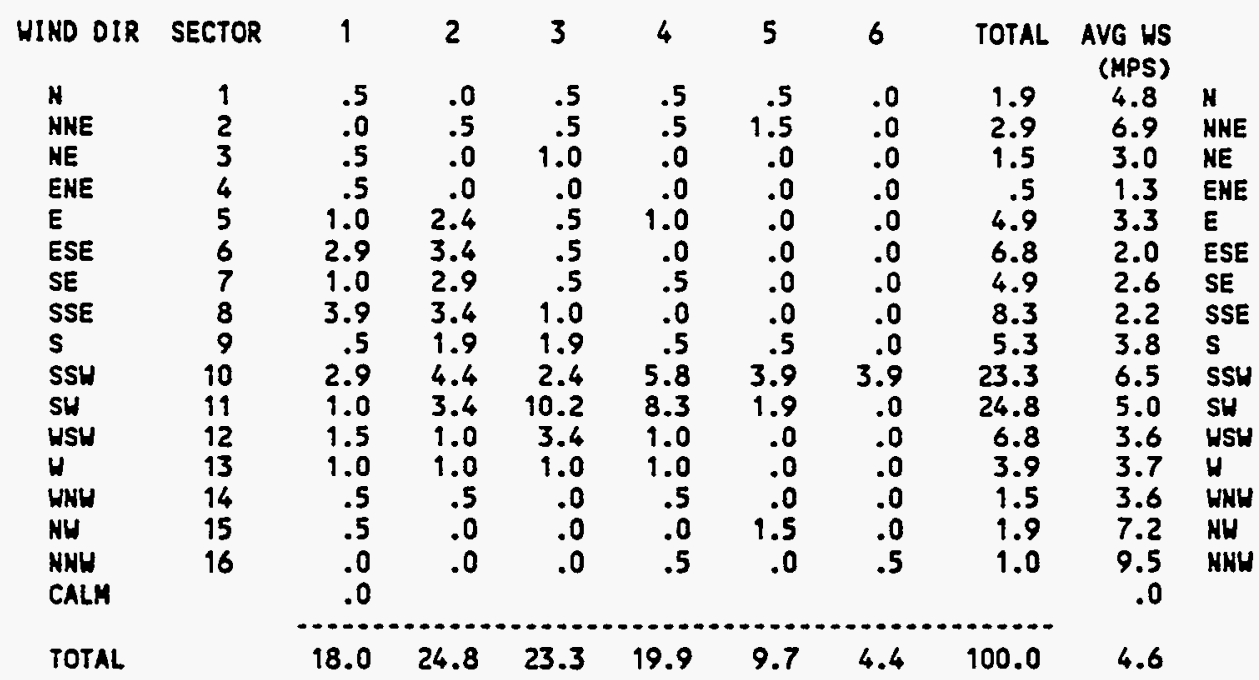

$\$ 9.4 \%$ DATA RECOVERED

28.8\% OF RECOVERED DATA REPORTED ABOVE

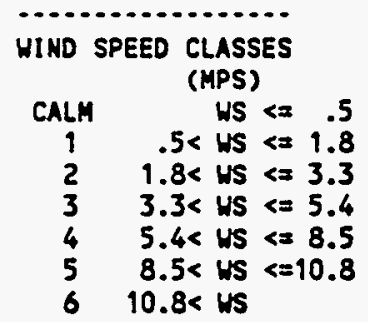


METEOROLOGICAL JOINT FREQUENCY DISTRIBUTION (PERCENT OF VALIO HOUR OBSERVATIONS) SPILL TEST FACILITY 24 METER TONER

2 METER HEIGHT - Late Mid-DaY

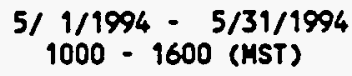

WI ND SPEED CLASS

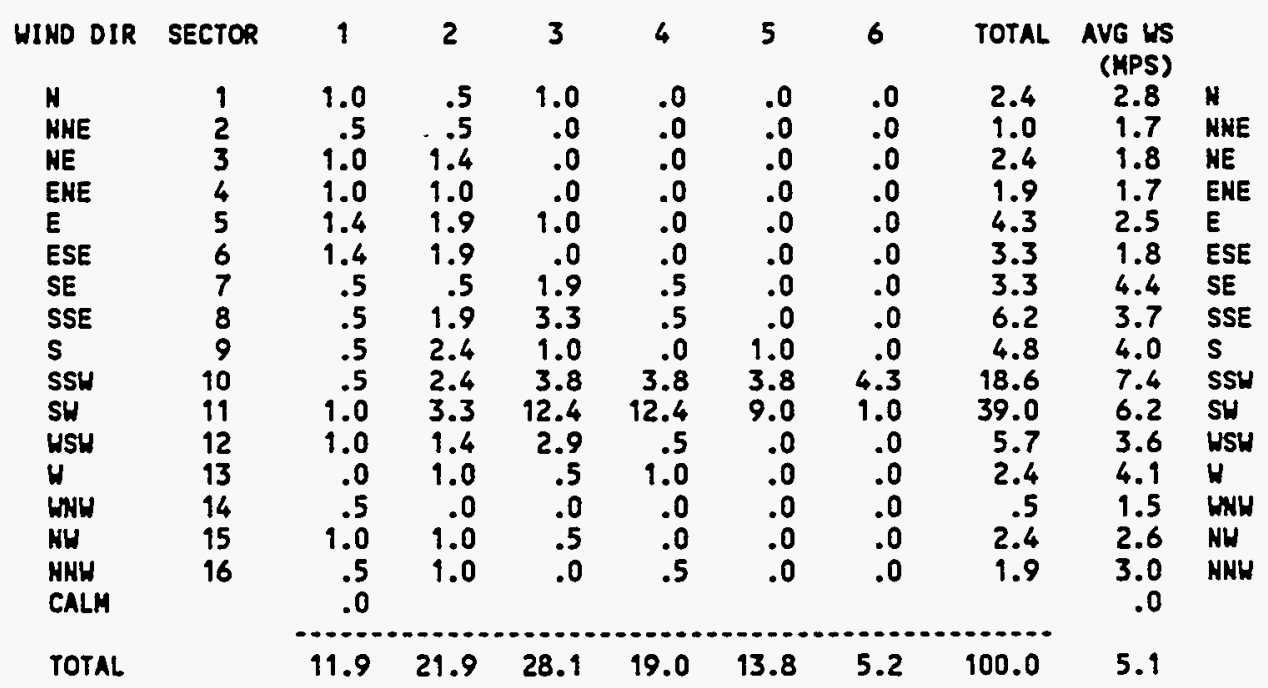

96.9\% DATA RECOVERED

29.1\% OF RECOVERED DATA

REPORTED ABOVE

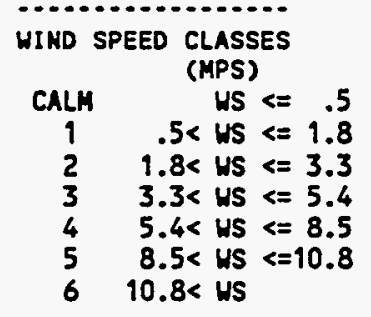


METEOROLOGICAL JOINT FREQUENCY DISTRIBUTION (PERCENT OF VALID HOUR OBSERVATIONS) SPILL TEST FACILITY 24 METER TOWER

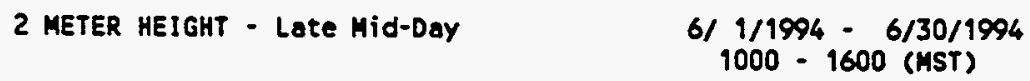

HINDSPEED CLASS

\begin{tabular}{|c|c|c|c|c|c|c|c|c|c|c|}
\hline UIND DIR & SECTOR & 1 & 2 & 3 & 4 & 5 & 6 & TOTAL & $\begin{array}{l}\text { AVG WS } \\
\text { (MPS) }\end{array}$ & \\
\hline N & 1 & 1.0 & .5 & .0 & .0 & .0 & .0 & 1.4 & 1.6 & N \\
\hline NNE & 2 & .0 & .0 & .0 & .0 & .0 & .0 & .0 & .0 & NHE \\
\hline NE & 3 & 1.0 & .0 & .0 & .0 & .0 & .0 & 1.0 & .9 & NE \\
\hline ENE & 4 & .0 & 1.4 & .0 & .0 & .0 & .0 & 1.4 & 2.1 & ENE \\
\hline$E$ & 5 & .5 & 1.0 & .0 & .0 & .0 & .0 & 1.4 & 1.8 & $E$ \\
\hline $\begin{array}{l}\text { ESE } \\
\text { SE }\end{array}$ & $\begin{array}{l}6 \\
7\end{array}$ & $\begin{array}{r}1.0 \\
.0\end{array}$ & $\begin{array}{r}1.4 \\
.0\end{array}$ & $\begin{array}{l}.0 \\
.0\end{array}$ & $\begin{array}{l}0 \\
0\end{array}$ & $\begin{array}{l}.0 \\
.0\end{array}$ & .0 & $\begin{array}{r}2.4 \\
.0\end{array}$ & $\begin{array}{r}1.9 \\
.0\end{array}$ & $\begin{array}{l}\text { ESE } \\
\text { SE }\end{array}$ \\
\hline & 8 & $\begin{array}{l}1.0 \\
1.4\end{array}$ & .5 & .05 & 0 & .0 & .0 & $\begin{array}{l}1.9 \\
3.3\end{array}$ & 2.3 & $\begin{array}{l}\text { SSE } \\
S\end{array}$ \\
\hline SSW & 10 & .5 & 1.4 & 3.3 & 4.3 & 6.2 & .5 & 16.2 & 7.0 & SSW \\
\hline SW & 11 & .5 & 3.3 & 6.7 & 39.0 & 10.5 & 1.9 & 61.9 & 7.1 & su \\
\hline USW & 12 & .0 & .5 & 1.9 & 1.4 & 1.9 & .5 & 6.2 & 6.4 & USW \\
\hline $\mathbf{H}$ & 13 & .0 & .0 & .0 & .0 & .0 & .0 & .0 & .0 & $W$ \\
\hline WNH & 14 & .5 & .0 & .0 & .0 & .0 & .0 & .5 & 1.4 & WNH \\
\hline NH & 15 & .5 & .5 & .0 & .0 & .0 & .0 & 1.0 & 2.1 & NH \\
\hline $\begin{array}{l}\text { NHW } \\
\text { CALH }\end{array}$ & 16 & 1.0 & .5 & .0 & .0 & .0 & .0 & 1.4 & 1.5 & NHW \\
\hline & & & & & & & & & & \\
\hline TOTAL & & 8.6 & 12.4 & 12.9 & 44.8 & 18.6 & 2.9 & 100.0 & 6.2 & \\
\hline
\end{tabular}

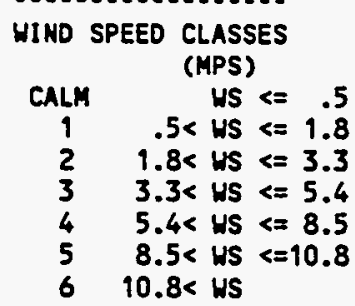


METEOROLOGICAL JOINT FREQUEHCY DISTRIBUTION (PERCENT OF VALID HOUR OBSERVATIONS)

SPILL TEST FACILITY 24 METER TOWER

2 METER MEIGHT - Late Mid-Day

$7 / 1 / 1994 \cdot 7 / 31 / 1994$

$1000-1600$ (MST)

WIND SPEED CLASS

\begin{tabular}{|c|c|c|c|c|c|c|c|c|c|c|}
\hline WIND OIR & SECTOR & 1 & 2 & 3 & 4 & 5 & 6 & TOTAL & $\begin{array}{l}\text { AVG WS } \\
\text { (MPS) }\end{array}$ & \\
\hline H & 1 & .0 & .5 & .5 & .0 & .0 & .0 & .9 & 3.3 & N \\
\hline NME & 2 & .5 & .5 & .0 & .0 & .0 & .0 & 9 & 1.6 & $\begin{array}{l}\text { NHE } \\
\text { NE }\end{array}$ \\
\hline $\begin{array}{l}\text { NE } \\
\text { EHE }\end{array}$ & $\begin{array}{l}3 \\
4\end{array}$ & $\begin{array}{l}.0 \\
.0\end{array}$ & $\begin{array}{r}1.4 \\
.9\end{array}$ & $\begin{array}{l}.0 \\
.0\end{array}$ & $\begin{array}{l}.0 \\
.0\end{array}$ & $\begin{array}{l}.0 \\
.0\end{array}$ & $\begin{array}{l}.0 \\
.0\end{array}$ & $\begin{array}{r}1.4 \\
.9\end{array}$ & $\begin{array}{l}2.6 \\
2.4\end{array}$ & $\begin{array}{l}\text { ME } \\
\text { ENE }\end{array}$ \\
\hline$\varepsilon$ & 5 & 1.4 & .9 & .0 & .0 & .0 & .0 & 2.3 & 1.9 & $E$ \\
\hline ESE & 6 & .0 & .0 & .0 & .0 & .0 & .0 & .0 & .0 & ESE \\
\hline SE & 7 & 1.4 & 2.3 & 1.4 & .0 & .0 & .0 & 5.1 & 2.5 & SE \\
\hline $\begin{array}{l}\text { SSE } \\
\text { S }\end{array}$ & $\begin{array}{l}8 \\
9\end{array}$ & $\begin{array}{r}1.4 \\
.9\end{array}$ & $\begin{array}{l}2.3 \\
1.8\end{array}$ & $\begin{array}{l}.5 \\
.5\end{array}$ & $\begin{array}{l}.0 \\
.0\end{array}$ & $\begin{array}{l}.0 \\
.5\end{array}$ & $\begin{array}{l}.0 \\
.0\end{array}$ & $\begin{array}{l}4.1 \\
3.7\end{array}$ & $\begin{array}{l}2.2 \\
3.3\end{array}$ & $\begin{array}{l}\text { SSE } \\
\text { S }\end{array}$ \\
\hline SSW & 10 & 1.4 & 3.2 & 8.3 & 7.4 & 1.8 & .0 & 22.1 & 5.1 & SSW \\
\hline SH & 11 & .5 & 3.2 & 12.4 & 34.6 & 4.1 & .0 & 54.8 & 6.2 & SW \\
\hline WSW & 12 & .0 & .9 & .9 & .0 & .0 & .0 & 1.8 & 3.3 & WSW \\
\hline$W$ & 13 & .0 & .0 & .0 & .0 & .0 & .0 & .0 & .0 & $H$ \\
\hline WNH & 14 & .5 & .0 & .0 & .0 & .0 & .0 & .5 & 1.5 & WNW \\
\hline NH & 15 & .0 & .5 & .0 & .0 & .0 & .0 & .5 & 2.1 & NH \\
\hline $\begin{array}{l}\text { NNH } \\
\text { CALM }\end{array}$ & 16 & .9 & .0 & .0 & .0 & .0 & .0 & .9 & $\begin{array}{r}1.8 \\
.0\end{array}$ & NAW \\
\hline TOTAL. & & 8.8 & 18.4 & 24.4 & 41.9 & 6.5 & .0 & 100.0 & 5.1 & \\
\hline
\end{tabular}

100.0\% DATA RECOVERED

29.2\% OF RECOVERED DATA REPORTED ABOVE

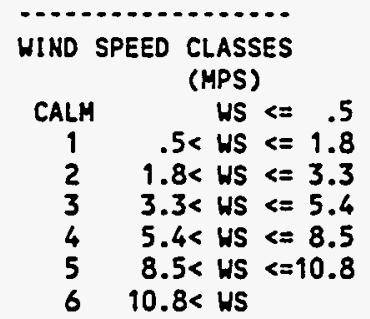


METEOROLOGICAL JOINT FREQUENCY DISTRIBUTION (PERCENT OF VALID HOUR OBSERVATIOHS)

SPILL TEST FACILITY 24 METER TOWER

2 METER HEIGHT - Late Mid-Day

$8 / 1 / 1994 \cdot 8 / 31 / 1994$

$1000 \cdot 1600$ (MST)

WIND SPEEDCLASS

\begin{tabular}{|c|c|c|c|c|c|c|c|c|c|c|}
\hline WIND OIR & SECTOR & 1 & 2 & 3 & 4 & 5 & 6 & TOTAL & $\begin{array}{l}\text { AVG US } \\
\text { (MPS) }\end{array}$ & \\
\hline N & 1 & .9 & .5 & .0 & .0 & .0 & .0 & 1.4 & 1.9 & $N$ \\
\hline NME & 2 & .5 & .0 & .0 & .0 & .0 & .0 & .5 & 9.0 & NNE \\
\hline NE & 3 & .9 & .0 & .0 & .0 & .0 & .0 & .9 & 1.4 & NE \\
\hline ENE & 4 & .9 & 1.8 & .0 & .0 & .0 & .0 & 2.8 & 1.9 & ENE \\
\hline E & 5 & .9 & .0 & .5 & .0 & .0 & .0 & 1.4 & 2.0 & $E$ \\
\hline ESE & 6 & .9 & $\begin{array}{r}0 \\
0\end{array}$ & .9 & .0 & .0 & .0 & 1.8 & 2.8 & ESE \\
\hline $\begin{array}{l}\text { SE } \\
\text { SSE }\end{array}$ & 8 & .5 & $\begin{array}{l}.9 \\
.5\end{array}$ & $\begin{array}{r}4.7 \\
.5\end{array}$ & $\begin{array}{l}.5 \\
.0\end{array}$ & $\begin{array}{l}.0 \\
.0\end{array}$ & & $\begin{array}{l}6.0 \\
1.8\end{array}$ & $\begin{array}{l}3.7 \\
2.9\end{array}$ & $\begin{array}{l}\text { SE } \\
\text { SSE }\end{array}$ \\
\hline S & 9 & .9 & 1.8 & .9 & 2.8 & .0 & .0 & 6.5 & 4.2 & 5 \\
\hline SSH & 10 & .0 & 1.8 & 3.7 & 12.0 & 1.8 & .0 & 19.4 & 6.5 & SSH \\
\hline SH & 19 & .0 & 1.8 & 9.2 & 30.9 & 5.5 & .0 & 47.5 & 6.7 & SH \\
\hline WSH & 12 & 1.4 & .0 & 4.6 & .9 & .0 & .0 & 6.9 & 4.2 & WSH \\
\hline$W$ & 13 & .9 & .0 & .0 & .0 & .0 & .0 & .9 & 1.1 & $\omega$ \\
\hline WNW & 14 & .5 & .0 & .0 & .0 & .0 & .0 & .5 & 1.1 & WNH \\
\hline NH & 15 & .0 & .0 & .0 & .5 & .0 & .0 & .5 & 6.6 & WH \\
\hline $\begin{array}{l}\text { HNH } \\
\text { CALM }\end{array}$ & 16 & $\begin{array}{l}.9 \\
.0\end{array}$ & .0 & .5 & .0 & .0 & .0 & 1.4 & $\begin{array}{r}2.2 \\
.0\end{array}$ & NHH \\
\hline TOTAL & & 11.1 & 9.2 & 24.9 & 47.5 & 7.4 & .0 & 100.0 & 5.5 & \\
\hline
\end{tabular}

100.0X DATA RECOVERED

29.2X OF RECOVERED DATA REPORTED ABOVE

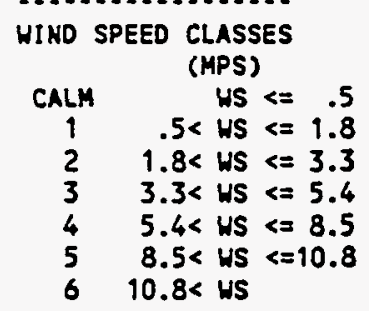


METEOROLOGICAL JOINT FREQUENCY DISTRIBUTION (PERCENT OF VALID HOUR OBSERVATIONS)

SPILL TEST FACILITY 24 METER TOWER

2 METER HEIGHT - Late Mid-DaY

$9 / 1 / 1994-9 / 30 / 1994$

$1000 \cdot 1600$ (MST)

HINDSPEEDCLASS

\begin{tabular}{|c|c|c|c|c|c|c|c|c|c|c|}
\hline HIND DIR & SECTOR & 1 & 2 & 3 & 4 & 5 & 6 & TOTAL & $\begin{array}{r}\text { AVG WS } \\
\text { (MPS) }\end{array}$ & \\
\hline H & 1 & 1.9 & .5 & .5 & 1.0 & .0 & .0 & 3.8 & 3.4 & N \\
\hline NNE & 2 & 1.4 & 1.0 & .0 & 1.0 & .0 & .0 & 3.3 & 3.3 & NHE \\
\hline NE & 3 & 2.9 & 1.4 & .0 & .0 & .0 & .0 & 4.3 & 1.5 & $\mathrm{NE}$ \\
\hline ENE & 4 & 3.8 & .0 & .0 & .0 & .0 & .0 & 3.8 & 1.1 & ENE \\
\hline$E$ & $\begin{array}{l}5 \\
6\end{array}$ & 2.4 & 2.4 & $\begin{array}{r}.0 \\
5\end{array}$ & .0 & .0 & .0 & $\begin{array}{l}4.8 \\
4.3\end{array}$ & 1.7 & $\begin{array}{l}E \\
\text { ESE }\end{array}$ \\
\hline $\begin{array}{l}\text { ESE } \\
\text { SE }\end{array}$ & $\begin{array}{l}6 \\
7\end{array}$ & $\begin{array}{l}2.9 \\
2.9\end{array}$ & $\begin{array}{l}1.0 \\
1.4\end{array}$ & $\begin{array}{l}.5 \\
.0\end{array}$ & $\begin{array}{l}.0 \\
.0\end{array}$ & $\begin{array}{l}.0 \\
.0\end{array}$ & $\begin{array}{l}.0 \\
.0\end{array}$ & $\begin{array}{l}4.3 \\
4.3\end{array}$ & $\begin{array}{l}1.9 \\
1.5\end{array}$ & $\begin{array}{l}\text { ESE } \\
\text { SE }\end{array}$ \\
\hline $\begin{array}{l}\text { SSE } \\
\text { S }\end{array}$ & $\begin{array}{l}8 \\
9\end{array}$ & $\begin{array}{r}1.9 \\
.0\end{array}$ & $\begin{array}{r}1.0 \\
.5\end{array}$ & $\begin{array}{l}.0 \\
.0\end{array}$ & & $\begin{array}{l}.0 \\
.0\end{array}$ & $\begin{array}{l}.0 \\
.0\end{array}$ & $\begin{array}{r}2.9 \\
.5\end{array}$ & $\begin{array}{l}1.6 \\
2.7\end{array}$ & $\begin{array}{l}\text { SSE } \\
\text { S }\end{array}$ \\
\hline SSW & 10 & 3.8 & 1.9 & 3.3 & 7.6 & 11.0 & 2.9 & 30.5 & 7.1 & SSH \\
\hline SH & 11 & 1.9 & 2.4 & 10.5 & 11.9 & 1.0 & 1.4 & 29.0 & 5.5 & SW \\
\hline WSW & 12 & .0 & .5 & 1.9 & .5 & .0 & .0 & 2.9 & 4.4 & WSW \\
\hline$H$ & 13 & .5 & .0 & .0 & .0 & .0 & .0 & .5 & 1.6 & 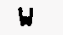 \\
\hline WHW & 14 & .0 & .0 & .0 & .0 & .0 & .0 & .0 & .0 & WNH \\
\hline $\mathrm{HW}$ & 15 & 1.0 & .5 & .5 & .0 & .0 & .0 & 1.9 & 2.3 & NH \\
\hline $\begin{array}{l}\text { NNW } \\
\text { CALM }\end{array}$ & 16 & $\begin{array}{r}1.0 \\
.5\end{array}$ & 1.0 & .0 & 1.0 & .0 & .0 & 2.9 & $\begin{array}{r}3.7 \\
.5\end{array}$ & NNH \\
\hline TOTAL & & 28.6 & 15.2 & 17.1 & 22.9 & 11.9 & 4.3 & 100.0 & 4.7 & \\
\hline
\end{tabular}

99.7\% OATA RECOVERED

29.2\% OF RECOVERED DATA REPORTED ABOVE

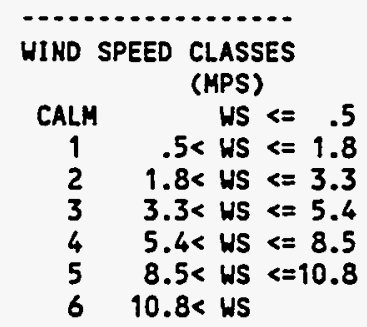


METEOROLOGICAL JOINT FREQUENCY DISTRIBUTION (PERCENT OF VALID HOUR OBSERVATIONS)

SPILL TEST FACILITY 24 METER TONER

2 METER HEIGHT - Late Mid-Day

10/ $1 / 1994 \cdot 10 / 31 / 1994$

1000 - 1600 (MST)

\section{HINDSPEED CLASS}

\begin{tabular}{|c|c|c|c|c|c|c|c|c|c|c|}
\hline HIND DIR & SECTOR & 9 & 2 & 3 & 4 & 5 & 6 & TOTAL & $\begin{array}{c}\text { AVG WS } \\
\text { (MPS) }\end{array}$ & \\
\hline M & 1 & 1.4 & .0 & 1.4 & .9 & .0 & .0 & 3.7 & 3.8 & N \\
\hline MHE & 2 & 2.8 & 2.3 & 4.6 & 2.3 & .0 & .0 & 12.0 & 3.8 & NHE \\
\hline NE & 3 & 1.4 & 1.4 & .5 & .0 & .0 & .0 & 3.2 & 2.0 & ME \\
\hline ENE & $\begin{array}{l}4 \\
5\end{array}$ & 3.2 & $\begin{array}{r}1.4 \\
5\end{array}$ & .0 & .0 & .0 & .0 & 4.6 & 1.4 & ENE \\
\hline $\begin{array}{l}E \\
\text { ESE }\end{array}$ & $\begin{array}{l}5 \\
6\end{array}$ & $\begin{array}{l}4.1 \\
3.2\end{array}$ & $\begin{array}{l}.5 \\
.0\end{array}$ & .0 & $\begin{array}{l}0 \\
.0\end{array}$ & $\begin{array}{l}.0 \\
0\end{array}$ & $\begin{array}{l}0 \\
0\end{array}$ & $\begin{array}{l}4.6 \\
3.2\end{array}$ & 1.2 & $\begin{array}{l}\text { E } \\
\text { ESE }\end{array}$ \\
\hline SE & 7 & 3.2 & .9 & .0 & .0 & .0 & .0 & 4.1 & 1.5 & SE \\
\hline $\begin{array}{l}\text { SSE } \\
\mathbf{S}\end{array}$ & $\begin{array}{l}8 \\
9\end{array}$ & $\begin{array}{l}8.3 \\
5.1\end{array}$ & .5 & .0 & .0 & .0 & .0 & 8.8 & 1.2 & SSE \\
\hline $\begin{array}{l}\text { s } \\
\text { SSW }\end{array}$ & 10 & 3.2 & .9 & 1.4 & 1.4 & .0 & .0 & $\begin{array}{l}5.5 \\
8.3\end{array}$ & $\begin{array}{l}1.4 \\
4.2\end{array}$ & SSH \\
\hline SH & 11 & 2.3 & 6.0 & 8.3 & 6.0 & 1.4 & .5 & 24.4 & 4.8 & SH \\
\hline USH & 12 & 2.3 & 1.4 & 1.8 & .9 & .0 & .0 & 6.5 & 2.9 & HSW \\
\hline $\begin{array}{l}\text { WWH } \\
\text { WNW }\end{array}$ & $\begin{array}{l}13 \\
14\end{array}$ & $\begin{array}{r}2.8 \\
.0\end{array}$ & .0 & $\begin{array}{l}.5 \\
.5\end{array}$ & $\begin{array}{l}.0 \\
.0\end{array}$ & $\begin{array}{l}.0 \\
.0\end{array}$ & $\begin{array}{l}.0 \\
.0\end{array}$ & $\begin{array}{r}3.2 \\
.5\end{array}$ & $\begin{array}{l}1.6 \\
4.2\end{array}$ & $\begin{array}{l}\mathbf{W} \\
\text { WNW }\end{array}$ \\
\hline NH & 15 & 1.8 & .5 & .0 & .0 & .0 & .0 & 2.3 & 1.2 & NH \\
\hline HNW & 16 & $\begin{array}{r}.9 \\
3.2\end{array}$ & .0 & .0 & .9 & .0 & .0 & 1.8 & 3.6 & NNH \\
\hline CALM & & 3. & & & & & & & & \\
\hline TOTAL & & 49.3 & 16.1 & 18. & 12.4 & 2.3 & .9 & 100.0 & 2.9 & \\
\hline
\end{tabular}

100.0\% DATA RECOVERED

29.2\% OF RECOVERED DATA REPORTED ABOVE

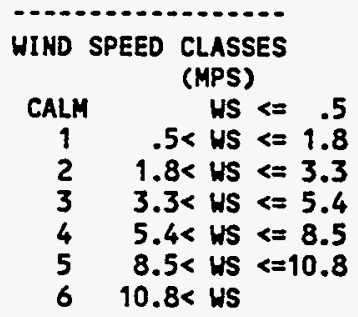


METEOROLOGICAL JOIMT FREQUENCY DISTRIBUTIOH (PERCENT OF VALID HOUR OBSERVATIONS)

SPILL TEST FACILITY 24 METER TONER

2 METER HEIGHT - Late Mid-Day

$11 / 1 / 1994 \cdot 11 / 30 / 1994$

$1000-1600$ (MST)

HINDSPEEDCLASS

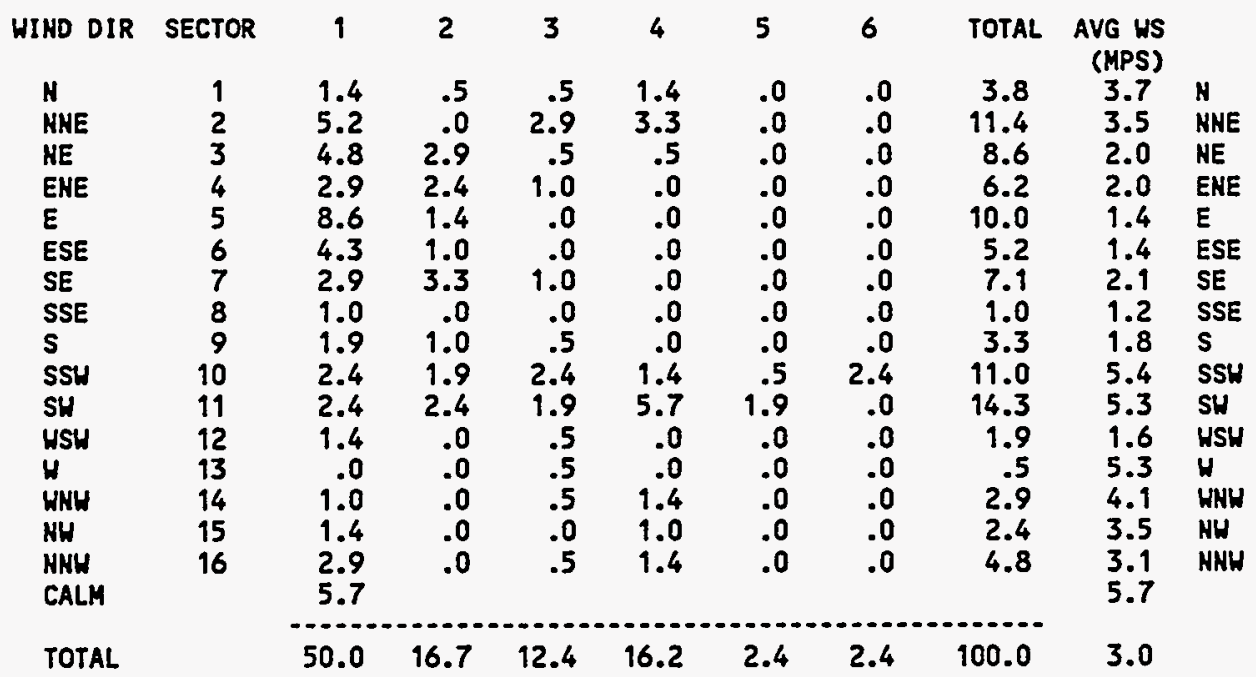

100.0\% DATA RECOVERED

29.2\% OF RECOVERED DATA REPORTED ABOVE

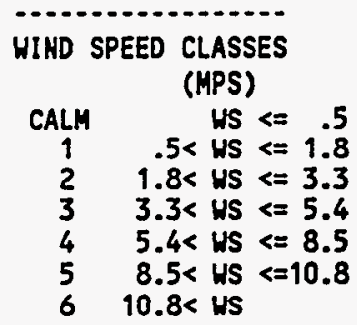


METEOROLOGICAL JOINT FREQUENCY DISTRIBUTION (PERCENT OF VALID HOUR OBSERVATIOHS) SPILL TEST FACILITY 24 METER TONER

HI NDSPEED CLASS

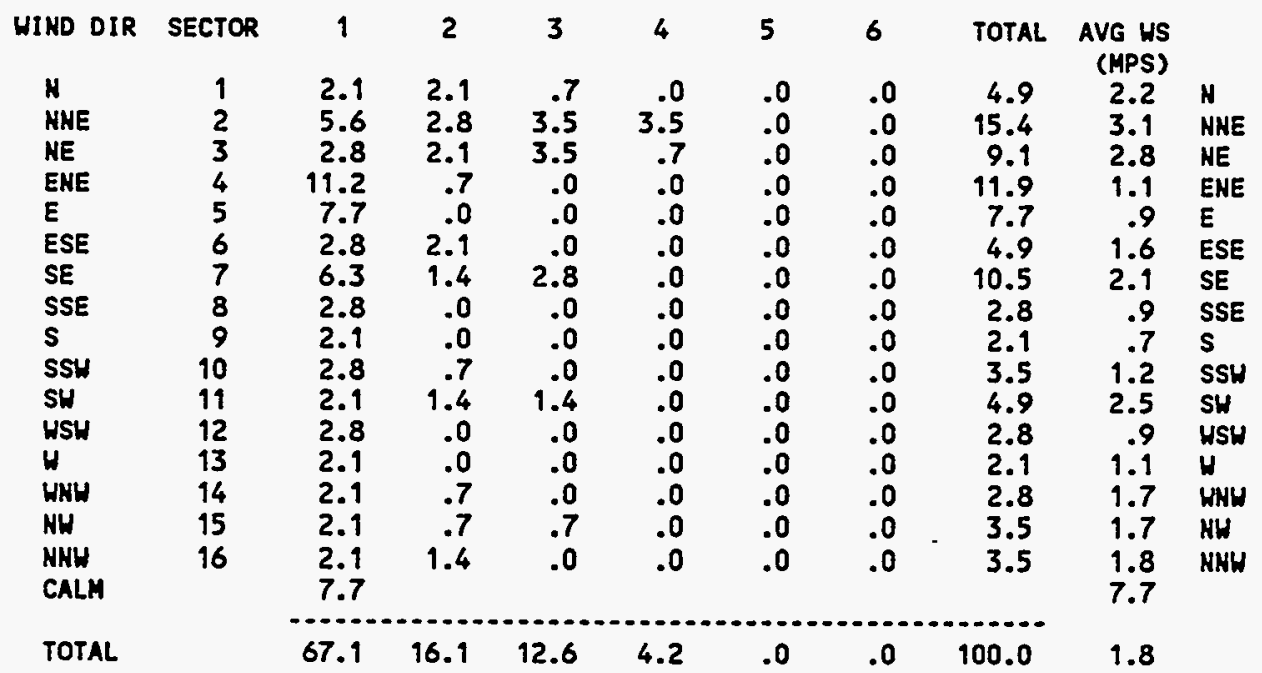

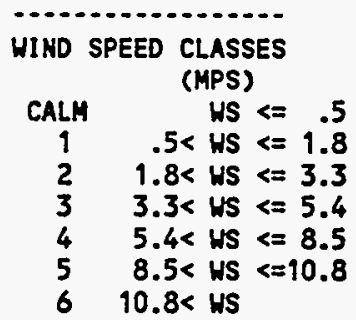


METECROLOGICAL JOINT FREOUEHCY DISTRIEUTION (PERCENT OF VALID HOUR OBSERVATIONS)

SPILL TEST FACILITY 26 METER TOER

2 METER HeIGHT - Evening Trensition

$1 / 1 / 1996-1 / 31 / 1996$

UI TO SPEEDCLASS

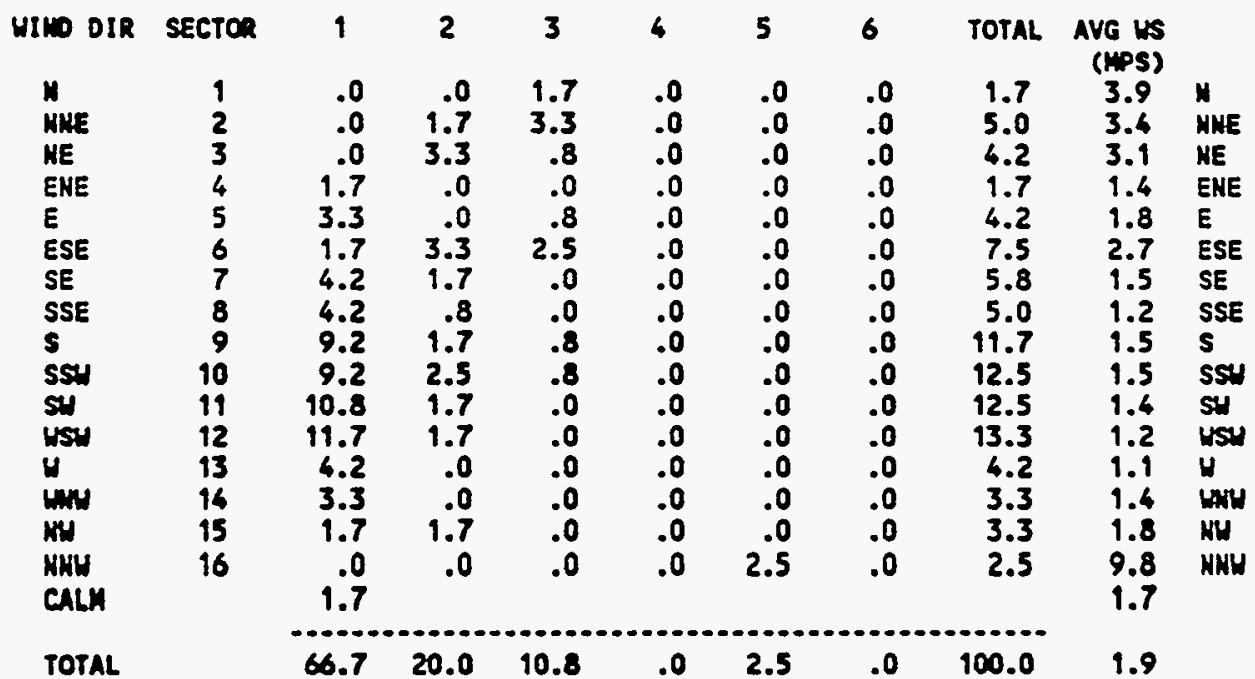

78. OX DATA RECOVERED

20.7\% OF RECOVERED DATA REPORTED AMOVE

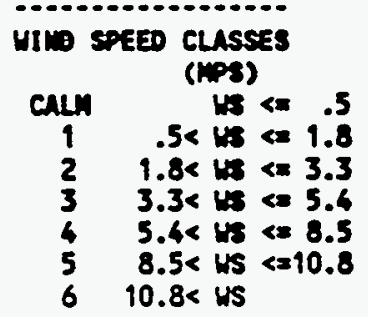


METEOROLOGICAL JOINT FREQUENCY OISTRIBUTION (PERCENT OF VALID HOUR OBSERVATIONS) SPILL TEST FACILITY 24 METER TOWER

2 METER HEIGHT - Evening Transition

$2 / 1 / 1996 \cdot 2 / 28 / 1996$ $1600 \cdot 2000$ (MST)

UID SPEEDCLASS

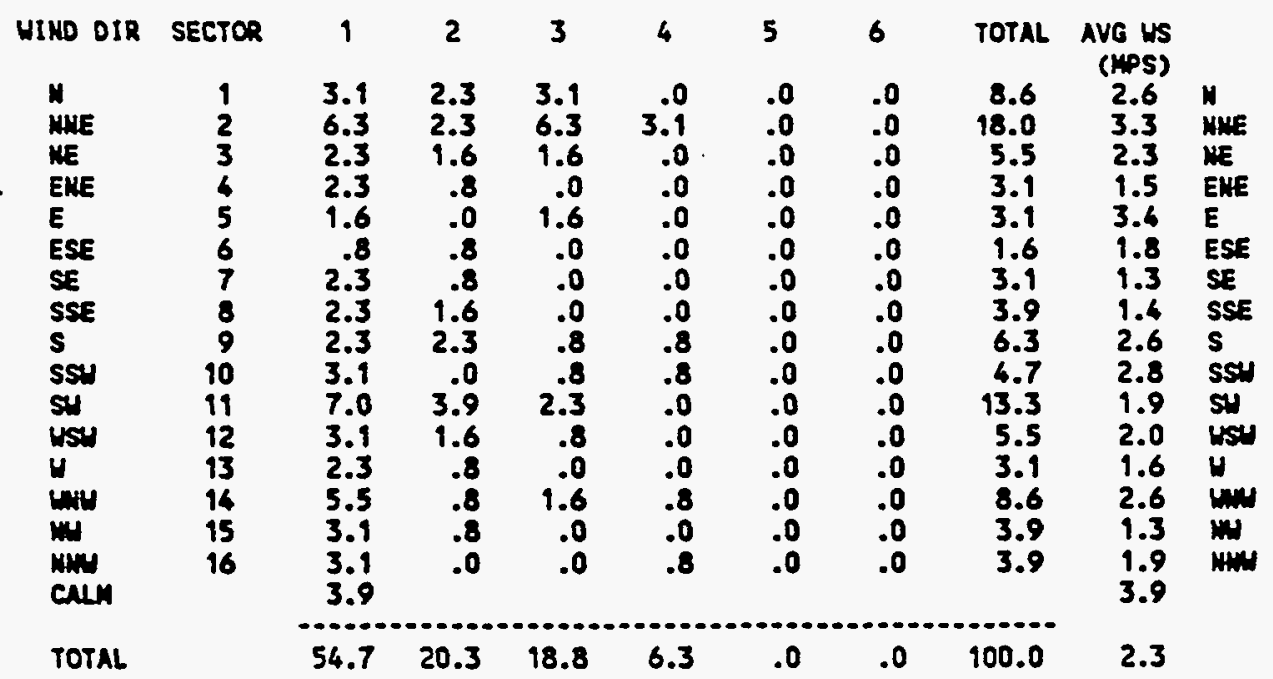

85.4X DATA RECOVERED 22.3X OF RECOVERED DATA REPORTED ABOVE

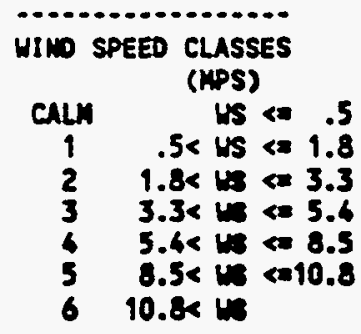


METEOROLOGICAL JOINT FREOUENCY DISTRIQUTION (PERCENT OF VALID HOUR COSERVATIONS)

SPILL TEST FACILITY 24 METER TOER

2 METER HEIGHT - EVening Transition

3/ $1 / 1994 \cdot 3 / 31 / 1994$

$1600-2000$ (MST)

HINDSPEEDCLASS

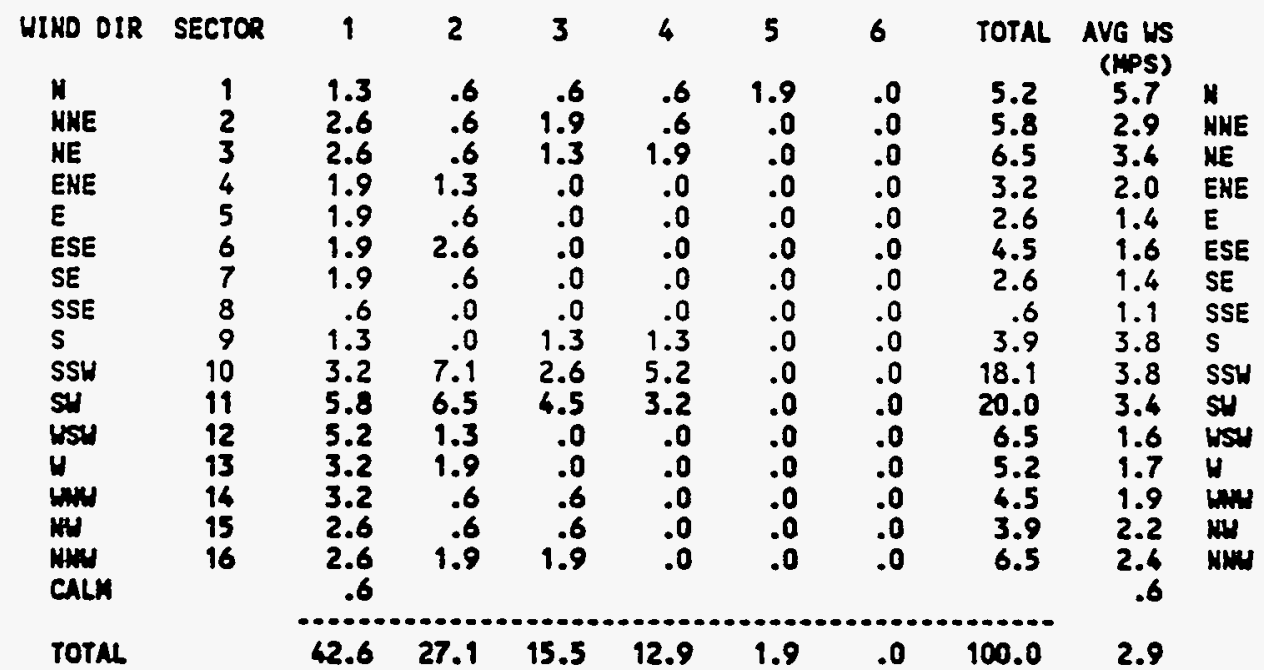

100.0\% DATA RECOVERED

20. $2 \%$ OF RECOVERED DATA REPORTED APOVE

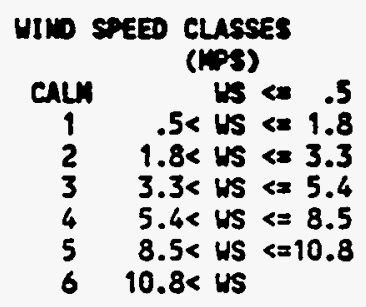




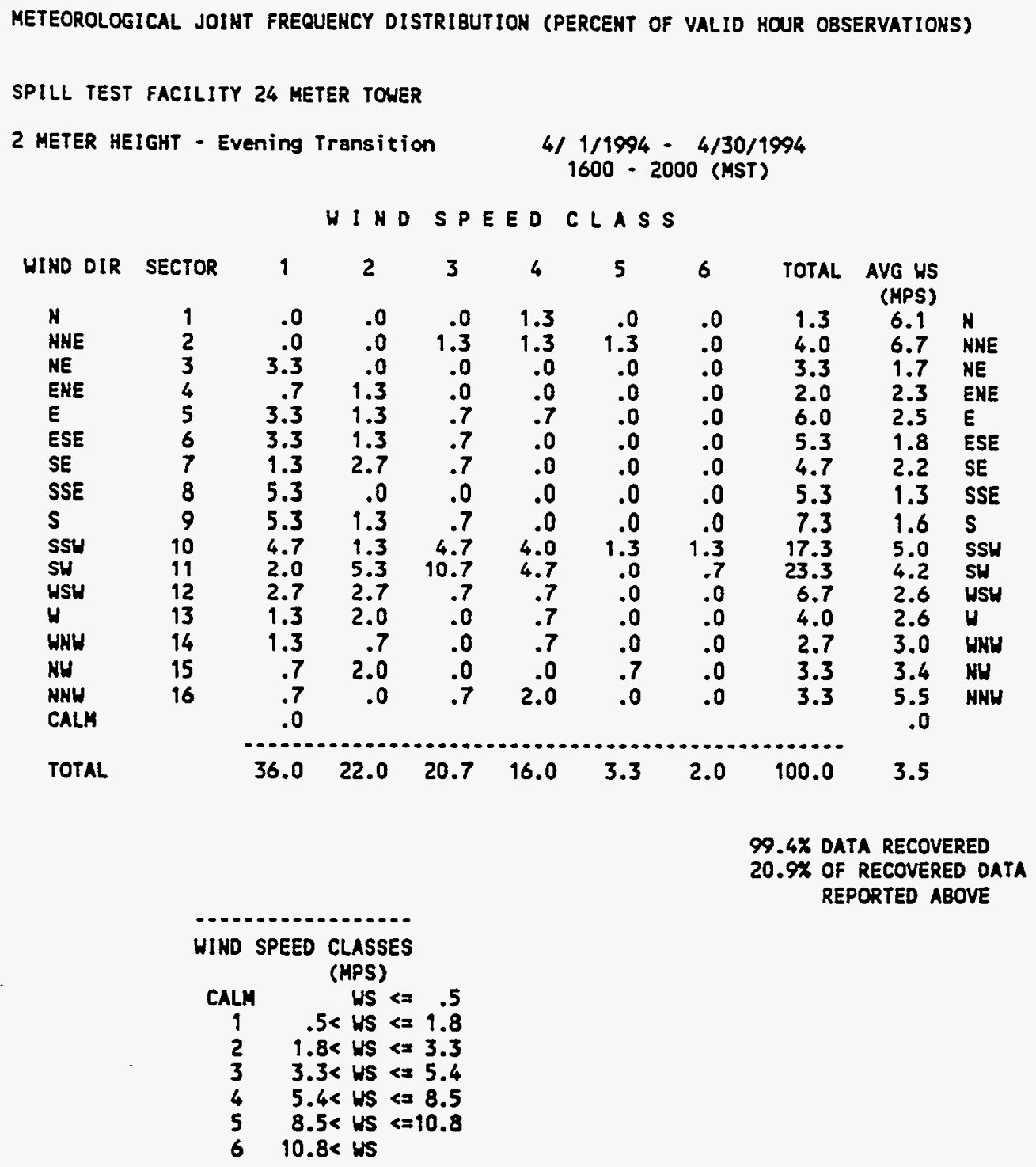


METECROLOGICAL JOIHT FREQUENCY OISTRIBUTION (PERCENT OF VALIO HOUR OBSERVATIONS)

SPILL TEST FACILITY 24 METER TONER

2 METER HEIGHT - Evening Transition

5/ $1 / 1994 \cdot 5 / 31 / 1994$

1600 - 2000 (MST)

WI H D SPEED CLASS

\begin{tabular}{|c|c|c|c|c|c|c|c|c|c|c|}
\hline HIND DIR & SECTOR & 1 & 2 & 3 & 4 & 5 & 6 & TOTAL & $\begin{array}{l}\text { AVG US } \\
\text { (MPS) }\end{array}$ & \\
\hline H & 1 & 1.3 & .0 & .7 & .0 & .0 & .0 & 2.0 & 2.1 & N \\
\hline HKE & 2 & 2.7 & .7 & .7 & .7 & .0 & .0 & 4.7 & 2.6. & NNE \\
\hline $\mathrm{NE}$ & 3 & 1.3 & 2.0 & .7 & .0 & .0 & .0 & 4.0 & 2.4 & NE \\
\hline EHE & 4 & .0 & .7 & .7 & .0 & .0 & .0 & 1.3 & 2.9 & ENE \\
\hline & 5 & .7 & .7 & .7 & .0 & .0 & .0 & 2.0 & & $\begin{array}{l}E \\
\text { ESE }\end{array}$ \\
\hline $\begin{array}{l}\text { ESE } \\
\text { SE }\end{array}$ & $\begin{array}{l}6 \\
7\end{array}$ & $\begin{array}{l}1.3 \\
2.7\end{array}$ & $\begin{array}{l}2.7 \\
1.3\end{array}$ & $\begin{array}{l}1.3 \\
2.7\end{array}$ & $\begin{array}{r}.0 \\
2.0\end{array}$ & $\begin{array}{l}.0 \\
.0\end{array}$ & $\begin{array}{l}.0 \\
.0\end{array}$ & $\begin{array}{l}5.3 \\
8.7\end{array}$ & $\begin{array}{l}2.3 \\
3.6\end{array}$ & $\begin{array}{l}\text { ESE } \\
\text { SE }\end{array}$ \\
\hline $\begin{array}{l}\text { SSE } \\
\text { S }\end{array}$ & $\begin{array}{l}8 \\
9\end{array}$ & .7 & $\begin{array}{r}.0 \\
2.0\end{array}$ & $\begin{array}{l}3.3 \\
2.0\end{array}$ & $\begin{array}{l}.0 \\
.7\end{array}$ & $\begin{array}{l}.0 \\
.0\end{array}$ & $\begin{array}{l}.0 \\
.0\end{array}$ & $\begin{array}{l}4.0 \\
5.3\end{array}$ & $\begin{array}{l}3.5 \\
3.3\end{array}$ & $\begin{array}{l}\text { SSE } \\
\text { S }\end{array}$ \\
\hline SSH & 10 & .7 & 1.3 & 2.7 & 6.0 & 2.0 & 2.7 & 15.3 & 7.0 & ssu \\
\hline SH & 11 & 4.0 & 4.7 & $7.3^{\circ}$ & 12.0 & 3.3 & .0 & 31.3 & 5.0 & SH \\
\hline WSH & 12 & .0 & 1.3 & 6.0 & 2.0 & .0 & .0 & 9.3 & 4.1 & WSH \\
\hline W & 13 & .7 & .7 & .0 & .0 & .0 & .0 & 1.3 & 1.9 & $W$ \\
\hline WHH & 14 & .7 & .7 & .0 & .0 & .0 & .0 & 1.3 & 2.0 & WWH \\
\hline HW & 15 & 2.7 & .0 & .0 & .0 & .0 & .0 & 2.7 & 1.5 & HW \\
\hline NNH & 16 & .7 & .0 & .7 & .0 & .0 & .0 & 1.3 & 3.4 & NNH \\
\hline ILA & & & & & & & & & & \\
\hline TOTAL & & 20.7 & 18.7 & 29.3 & 23.3 & 5.3 & 2.7 & 100.0 & 4.3 & \\
\hline
\end{tabular}

96.9\% DATA RECOVERED

20.8\% OF RECOVERED DATA REPORTED ABOVE

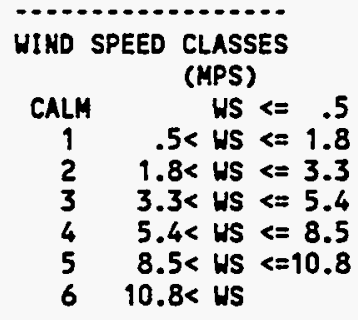


METEOROLOGICAL JOINT FREQUENCY DISTRIBUTION (PERCENT OF VALID HOUR OBSERVATIONS)

SPILL TEST FACILITY 24 METER TONER

2 METER HEIGHT - Evening Transition

6/ 1/1994 - 6/30/1994

$1600-2000$ (MST)

HIND SPEED CLASS

\begin{tabular}{|c|c|c|c|c|c|c|c|c|c|c|}
\hline HIND DIR & SECTOR & 1 & 2 & 3 & 4 & 5 & 6 & TOTAL & AVG WS & \\
\hline N & 1 & .7 & .0 & .0 & .0 & .0 & .0 & .7 & 1.2 & $\mathbf{N}$ \\
\hline NME & 2 & .7 & .0 & .0 & .0 & .0 & .0 & .7 & 1.2 & HNE \\
\hline NE & 3 & .7 & .0 & .0 & .0 & .0 & .0 & .7 & .8 & NE \\
\hline ENE & 4 & 2.0 & .0 & .0 & .0 & .0 & .0 & 2.0 & 1.0 & ENE \\
\hline E & 5 & 1.3 & .0 & .0 & .0 & .0 & .0 & 1.3 & 1.0 & E \\
\hline ESE & 6 & .0 & .0 & .0 & .0 & .0 & .0 & .0 & .0 & ESE \\
\hline SE & 7 & .7 & .0 & .0 & .0 & .0 & .0 & .7 & .9 & SE \\
\hline $\begin{array}{l}\text { SSE } \\
\text { S }\end{array}$ & $\begin{array}{l}8 \\
9\end{array}$ & .00 & .0 & .0 & .0 & .0 & .0 & .0 & .0 & $\begin{array}{l}\text { SSE } \\
5\end{array}$ \\
\hline SSH & 10 & 1.3 & .7 & 3.3 & 14.0 & 5.3 & .0 & $\begin{array}{r}2.0 \\
24.7\end{array}$ & $\begin{array}{l}2.3 \\
6.7\end{array}$ & $\begin{array}{l}\text { S } \\
\text { SSH }\end{array}$ \\
\hline SH & 11 & 4.7 & 8.0 & 10.0 & 24.0 & 2.0 & .7 & 49.3 & 5.3 & SH \\
\hline USH & 12 & 3.3 & 4.7 & 5.3 & .7 & .0 & .0 & 14.0 & 3.2 & USW \\
\hline$H$ & 13 & .7 & .7 & .0 & .0 & .0 & .0 & 1.3 & 2.5 & $\boldsymbol{H}$ \\
\hline WNW & 14 & .0 & .0 & .7 & .0 & .0 & .0 & .7 & 4.0 & WNH \\
\hline NH & 15 & 1.3 & .0 & .0 & .0 & .0 & .0 & 1.3 & 1.3 & NH \\
\hline $\begin{array}{l}\text { NHW } \\
\text { CALM }\end{array}$ & 16 & .7 & .0 & .0 & .0 & .0 & .0 & .7 & 1.8 & NHW \\
\hline TOTAL & & 19.3 & 4.0 & 20.0 & 38.7 & 7.3 & .7 & 100.0 & 4.9 & \\
\hline
\end{tabular}

100.0\% DATA RECOVERED

20.8\% OF RECOVERED DATA REPORTED ABOVE

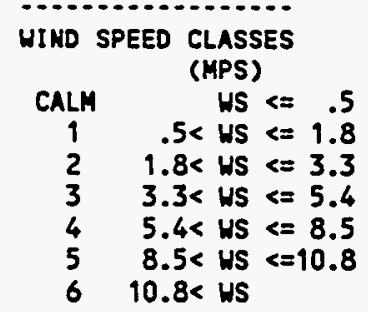


METEOROLOGICAL JOINT FREOUENCY DISTRIBUTION (PERCENT OF VALID HOUR OBSERVATIONS) SPILL TEST FACILITY 24 METER TOUER

2 METER HEIGHT - Evening Transition

$$
\begin{gathered}
7 / 1 / 1994-7 / 31 / 1994 \\
1600 \cdot 2000 \text { (MST) }
\end{gathered}
$$

\begin{tabular}{|c|c|c|c|c|c|c|c|c|c|c|}
\hline WIKD DIR. & SECTOR & 1 & 2 & 3 & 4 & 5 & 6 & TOTAL & $\begin{array}{r}\text { AVG WS } \\
\text { (MPS) }\end{array}$ & \\
\hline N & 1 & 1.3 & .6 & .6 & .0 & .0 & .0 & 2.6 & 2.1 & $N$ \\
\hline NAE & 2 & .0 & .6 & .0 & .0 & .0 & .0 & .6 & 2.1 & HHE \\
\hline NE & 3 & .6 & 1.3 & .0 & .0 & .0 & .0 & 1.9 & 2.4 & NE \\
\hline ENE & 4 & 2.6 & .0 & .0 & .0 & .0 & .0 & 2.6 & 1.5 & ENE \\
\hline$E$ & 5 & 1.9 & .0 & .0 & .6 & .0 & .0 & 2.6 & 2.4 & $\boldsymbol{E}$ \\
\hline ESE & 6 & .0 & .0 & .0 & .6 & .0 & .0 & .6 & 7.1 & ESE \\
\hline SE & 7 & 2.6 & .0 & .0 & .6 & .0 & .0 & 3.2 & 2.2 & SE \\
\hline $\begin{array}{l}\text { SSE } \\
\text { S }\end{array}$ & $\begin{array}{l}8 \\
9\end{array}$ & 9.6 & $\begin{array}{l}.0 \\
.6\end{array}$ & .0 & .0 & .0 & .0 & .6 & $\begin{array}{l}1.6 \\
1.6\end{array}$ & $\begin{array}{l}\text { SSE } \\
\text { S }\end{array}$ \\
\hline SSW & 10 & 4.5 & 3.2 & 5.2 & & .0 & .0 & 29.3 & 4.5 & ssu \\
\hline SH & 11 & 3.2 & 4.5 & 17.4 & 23.9 & .0 & .0 & 49.0 & 5.2 & SW \\
\hline WSW & 12 & 1.9 & 3.2 & 9.8 & .0 & .0 & .0 & 7.1 & 2.6 & WSH \\
\hline$W$ & 13 & 1.9 & .6 & .0 & .0 & .0 & .0 & 2.6 & 1.6 & $H$ \\
\hline WNW & 14 & .0 & .0 & .0 & .0 & .0 & .0 & .0 & .0 & WNW \\
\hline NH & 15 & 2.6 & .0 & .0 & .0 & .0 & .0 & 2.6 & .9 & $N$ \\
\hline HNH & 16 & .6 & .0 & .0 & .0 & .0 & .0 & .6 & 1.2 & NNW \\
\hline CAL & & & & & & & & & & \\
\hline TOTAL. & & 25.8 & 14.8 & 25.2 & 34.2 & .0 & .0 & 100.0 & 4.1 & \\
\hline
\end{tabular}

WI N D SPEED CLASS

100.0\% DATA RECOVERED

20.8X OF RECOVERED DATA REPORTED ABOVE

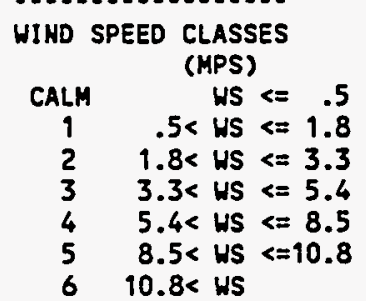


METEOROLOGICAL JOINT FREQUENCY OISTRIBUTIOH (PERCENT OF VALID HOUR OBSERVATIONS)

SPILL TEST FACILITY 24 METER TOWER

2 METER HEIGHT - Evening Transition

$8 / 1 / 1994-8 / 31 / 1994$

$1600-2000$ (MST)

HIND SPEEDCLASS

\begin{tabular}{|c|c|c|c|c|c|c|c|c|c|c|}
\hline WIND DIR & SECTOR & 1 & 2 & 3 & 4 & 5 & 6 & TOTAL & $\begin{array}{l}\text { AVG US } \\
\text { (MPS) }\end{array}$ & \\
\hline N & 1 & 1.3 & .0 & .0 & .0 & .0 & .0 & 1.3 & 1.2 & $\mathbf{N}$ \\
\hline HHE & 2 & 1.3 & .6 & .6 & .0 & .0 & .0 & 2.6 & 2.3 & NHE \\
\hline NE & 3 & 3.9 & .0 & .0 & .0 & .0 & .0 & 3.9 & 1.4 & NE \\
\hline ENE & 4 & 1.3 & .6 & .0 & .0 & .0 & .0 & 1.9 & 1.3 & ENE \\
\hline E & 5 & $1 . \overline{3}$ & .6 & .6 & .0 & .0 & .0 & 2.6 & 2.3 & $E$ \\
\hline $\begin{array}{l}\text { ESE } \\
\text { SE }\end{array}$ & $\begin{array}{l}6 \\
7\end{array}$ & $\begin{array}{l}.6 \\
.6\end{array}$ & $\begin{array}{l}.6 \\
.6\end{array}$ & $\begin{array}{r}.0 \\
2.6\end{array}$ & $\begin{array}{l}.0 \\
.0\end{array}$ & $\begin{array}{l}.0 \\
.0\end{array}$ & $\begin{array}{l}.0 \\
.0\end{array}$ & $\begin{array}{l}1.3 \\
3.9\end{array}$ & $\begin{array}{l}2.0 \\
3.7\end{array}$ & $\begin{array}{l}\text { ESE } \\
\text { SE }\end{array}$ \\
\hline SSE & 8 & .6 & .6 & .6 & .0 & .0 & .0 & 1.9 & 3.1 & SSE \\
\hline $\mathbf{s}$ & 9 & .6 & 2.6 & .6 & .6 & .6 & .0 & 5.2 & 3.8 & $\mathbf{S}$ \\
\hline SSH & 10 & 1.9 & 3.9 & 7.1 & 7.7 & .0 & .0 & 20.6 & 4.8 & SSW \\
\hline $\begin{array}{l}\text { SH } \\
\text { WSH }\end{array}$ & $\begin{array}{l}11 \\
12\end{array}$ & $\begin{array}{l}3.2 \\
1.3\end{array}$ & $\begin{array}{l}3.2 \\
1.9\end{array}$ & $\begin{array}{r}12.9 \\
2.6\end{array}$ & $\begin{array}{r}16.1 \\
.0\end{array}$ & $\begin{array}{r}1.3 \\
.0\end{array}$ & $\begin{array}{l}.0 \\
.0\end{array}$ & $\begin{array}{r}36.8 \\
5.8\end{array}$ & $\begin{array}{l}5.2 \\
3.2\end{array}$ & $\begin{array}{l}\text { SW } \\
\text { WSW }\end{array}$ \\
\hline$H$ & 13 & 2.6 & 1.3 & $\begin{array}{r}2.0 \\
.0\end{array}$ & .0 & .0 & .0 & $\begin{array}{l}3.0 \\
3.9\end{array}$ & 9.5 & $H$ \\
\hline WHW & 14 & 1.9 & .0 & .0 & .0 & .0 & .0 & 1.9 & 1.2 & WHW \\
\hline NH & 15 & 1.9 & 1.3 & .0 & .0 & .0 & .0 & 3.2 & 1.5 & $\mathbf{H W}$ \\
\hline $\begin{array}{l}\text { NNW } \\
\text { CALM }\end{array}$ & 16 & $\begin{array}{r}1.3 \\
.6\end{array}$ & .6 & .6 & .0 & .0 & .0 & & $\begin{array}{r}2.2 \\
.6\end{array}$ & KNH \\
\hline TOTAL & & 26.5 & 18.7 & 28.4 & 24.5 & 1.9 & .0 & 100.0 & 3.9 & \\
\hline
\end{tabular}

100. O\% OATA RECOVERED

20.8\% OF RECOVERED DATA REPORTED ABOVE

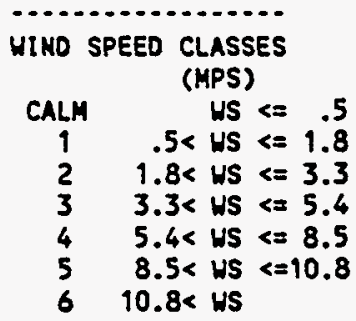


METEOROLOGICAL JOINT FREQUENCY DISTRIBUTION (PERCENT OF VALID HOUR OBSERVATIONS) SPILL TEST FACILITY 24 METER TOWER

2 METER HEIGHT - Evening Transition

$9 / 1 / 1994-9 / 30 / 1994$

$1600-2000$ (HST)

HINDSPEEDCLASS

\begin{tabular}{|c|c|c|c|c|c|c|c|c|c|c|}
\hline INO DIR & SECTOR & 1 & 2 & 3 & 4 & 5 & 6 & TOTAL & AVG US & \\
\hline $\mathrm{H}$ & 1 & 1.3 & 1.3 & .0 & .7 & .0 & .0 & 3.3 & 2.8 & N \\
\hline NHE & 2 & 4.0 & 1.3 & 2.0 & 3.3 & .0 & .0 & 10.7 & 3.5 & HNE \\
\hline $\mathrm{HE}$ & 3 & 3.3 & .7 & .0 & .0 & .0 & .0 & 4.0 & 1.6 & NE \\
\hline ENE & 4 & 6.0 & .0 & .0 & .0 & .0 & .0 & 6.0 & 1.1 & EN \\
\hline$\vec{E}$ & 5 & .0 & .7 & .0 & .0 & .0 & .0 & .7 & 2.4 & \\
\hline ESE & 6 & 1.3 & .0 & .0 & .0 & .0 & .0 & 1.3 & 1.0 & ESE \\
\hline SE & 7 & 2.7 & .0 & .0 & .0 & .0 & .0 & 2.7 & 1.3 & SE \\
\hline SSE & 8 & 1.3 & .0 & .0 & .0 & .0 & .0 & 1.3 & 1.2 & SSE \\
\hline$s$ & 9 & 4.0 & .0 & .7 & .0 & .0 & .0 & 4.7 & 1.4 & s \\
\hline SSW & 10 & 5.3 & 5.3 & 1.3 & 8.7 & 2.0 & .7 & 23.3 & 4.8 & SSH \\
\hline SH & 11 & 4.7 & 4.0 & 10.7 & 4.7 & .0 & .0 & 24.0 & 3.9 & Sh \\
\hline HSH & 12 & .0 & 2.7 & 4.0 & .0 & .0 & .0 & 6.7 & 3.7 & \\
\hline $\boldsymbol{H}$ & 13 & 2.0 & .7 & .0 & .0 & .0 & .0 & 2.7 & 1.7 & H \\
\hline HNH & 14 & .7 & .0 & .0 & .0 & .0 & .0 & .7 & .8 & WNH \\
\hline NH & 15 & 1.3 & .0 & .0 & .0 & .0 & .0 & 1.3 & 1.0 & NH \\
\hline NHW & 16 & 4.0 & 1.3 & .7 & .7 & .0 & .0 & 6.7 & 2.5 & NWH \\
\hline CALM & & .0 & & & & & & & 0 & \\
\hline TOTAL & & 42.0 & 18.0 & 19.3 & 18.0 & 2.0 & .7 & 100.0 & 3.3 & \\
\hline
\end{tabular}

99.7\% DATA RECOVERED

20.9\% OF RECOVERED DATA REPORTED ABOVE

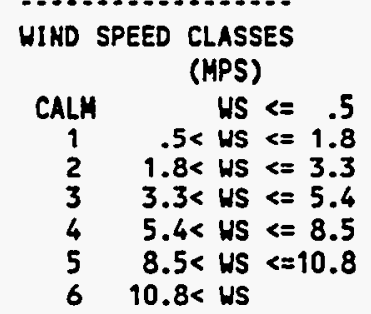


METEOROLOGICAL JOINT FREQUENCY OISTRIBUTIOH (PERCEMT OF VALID HOUR OBSERVATIOHS) SPILL TEST FACILITY 24 METER TONER

2 METER HEIGHT - Evening Transition $10 / 1 / 1994-10 / 31 / 1994$
$1600 \cdot 2000$ (MST)

HIND SPEED CLASS

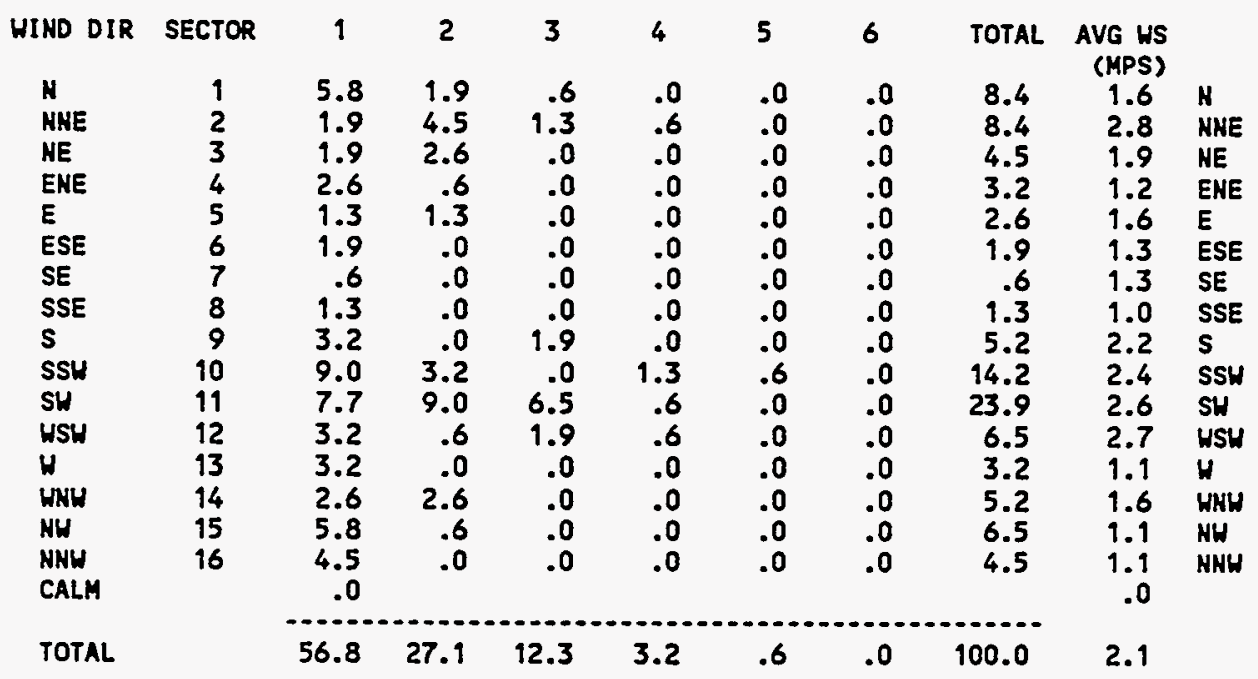

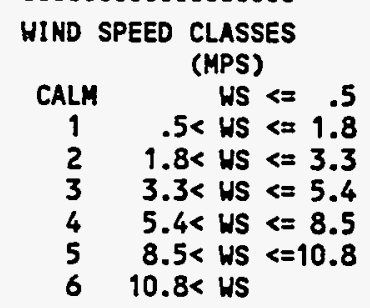


METEOROLOGICAL JOIHT FREQUENCY DISTRIBUTION (PERCENT OF VALID HOUR OBSERVATIONS)

SPILL TEST FACILITY 24 METER TOWER

2 METER HEIGHT - Evening Transition

$11 / 1 / 1994 \cdot 11 / 30 / 1994$

$1600-2000$ (MST)

HIND SPEED CLASS

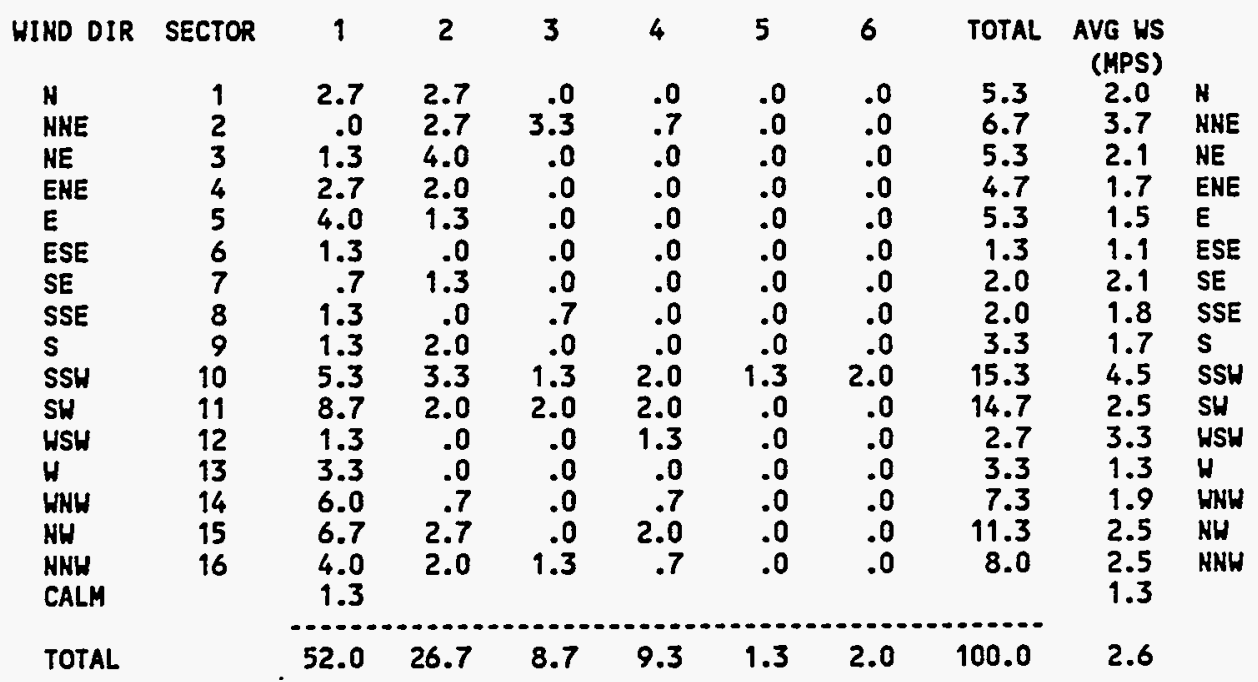

100.0\% DATA RECOVERED

20.8\% OF RECOVERED DATA REPORTED ABOVE

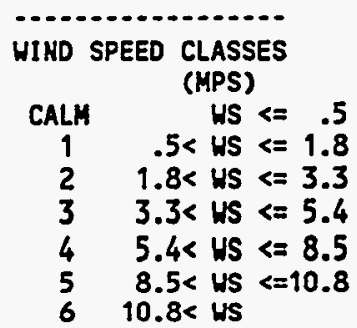


METEOROLOGICAL JOIHT FREQUENCY DISTRIBUTION (PERCENT OF VALID HOUR OBSERVATIOHS)

SPILL TEST FACILITY 24 METER TONER

2 METER HEIGHT - Evening Transition

$1211 / 1994-12 / 31 / 1994$
$1600 \cdot 2000$ (MST)

WI N D SPEED CLASS

\begin{tabular}{|c|c|c|c|c|c|c|c|c|c|c|}
\hline WIND DIR & SECTOR & 1 & 2 & 3 & 4 & 5 & 6 & TOTAL & AVG US & \\
\hline H & 1 & 3.0 & 1.0 & .0 & .0 & .0 & .0 & 4.0 & 1.5 & H \\
\hline MNE & 2 & 4.0 & 1.0 & 4.0 & .0 & .0 & .0 & 8.9 & 2.5 & NHE \\
\hline $\begin{array}{l}\text { NE } \\
\text { ENE }\end{array}$ & $\begin{array}{l}3 \\
4\end{array}$ & $\begin{array}{l}3.0 \\
5.0\end{array}$ & $\begin{array}{r}1.0 \\
.0\end{array}$ & $\begin{array}{l}.0 \\
.0\end{array}$ & $\begin{array}{r}1.0 \\
.0\end{array}$ & $\begin{array}{l}.0 \\
.0\end{array}$ & $\begin{array}{l}.0 \\
.0\end{array}$ & $\begin{array}{l}5.0 \\
5.0\end{array}$ & $\begin{array}{l}2.1 \\
1.0\end{array}$ & $\begin{array}{l}\text { NE } \\
\text { ENE }\end{array}$ \\
\hline $\boldsymbol{E}$ & 5 & 1.0 & 2.0 & .0 & .0 & .0 & .0 & 3.0 & 1.8 & $\bar{E}$ \\
\hline ESE & 6 & 1.0 & .0 & .0 & .0 & .0 & .0 & 1.0 & .6 & ESE \\
\hline SE & 7 & 4.0 & 3.0 & 2.0 & .0 & .0 & .0 & 8.9 & 2.1 & SE \\
\hline SSE & 8 & 1.0 & .0 & .0 & .0 & .0 & .0 & 1.0 & .6 & SSE \\
\hline $\mathbf{s}$ & 9 & 5.9 & .0 & .0 & 1.0 & .0 & .0 & 6.9 & 1.7 & $s$ \\
\hline SSW & 10 & 4.0 & 2.0 & 1.0 & .0 & .0 & .0 & 6.9 & 2.1 & SSH \\
\hline SW & 11 & 4.0 & 4.0 & 2.0 & .0 & .0 & .0 & 9.9 & 2.3 & SH \\
\hline HSH & 12 & 8.9 & 1.0 & .0 & .0 & .0 & .0 & 9.9 & 1.2 & WSH \\
\hline $\mathbf{u}$ & 13 & 3.0 & 2.0 & .0 & .0 & .0 & .0 & 5.0 & 1.6 & $H$ \\
\hline WNH & 14 & 5.0 & 3.0 & .0 & .0 & .0 & .0 & 7.9 & 1.8 & HWW \\
\hline NW & 15 & 4.0 & 5.0 & .0 & .0 & .0 & .0 & 8.9 & 1.9 & NW \\
\hline $\begin{array}{l}\text { NNH } \\
\text { CALM }\end{array}$ & 16 & $\begin{array}{r}5.0 \\
.0\end{array}$ & 3.0 & .0 & .0 & .0 & .0 & 7.9 & $\begin{array}{r}1.8 \\
.0\end{array}$ & NWH \\
\hline AL & & 61.4 & 27.7 & 8.9 & 2.0 & .0 & .0 & 100.0 & 1.8 & \\
\hline
\end{tabular}

65.1\% DATA RECOVERED

20.9\% OF RECOVERED DATA REPORTED ABOVE

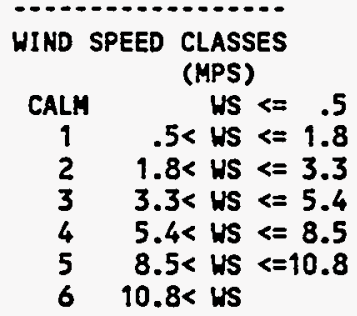


METECROLOGICAL JOIMT FREOLENCY DISTRIDUTION (PERCENT OF VALID HOUR OSSERVATIONS) SPILL TEST FACILITY 24 METER TOAER
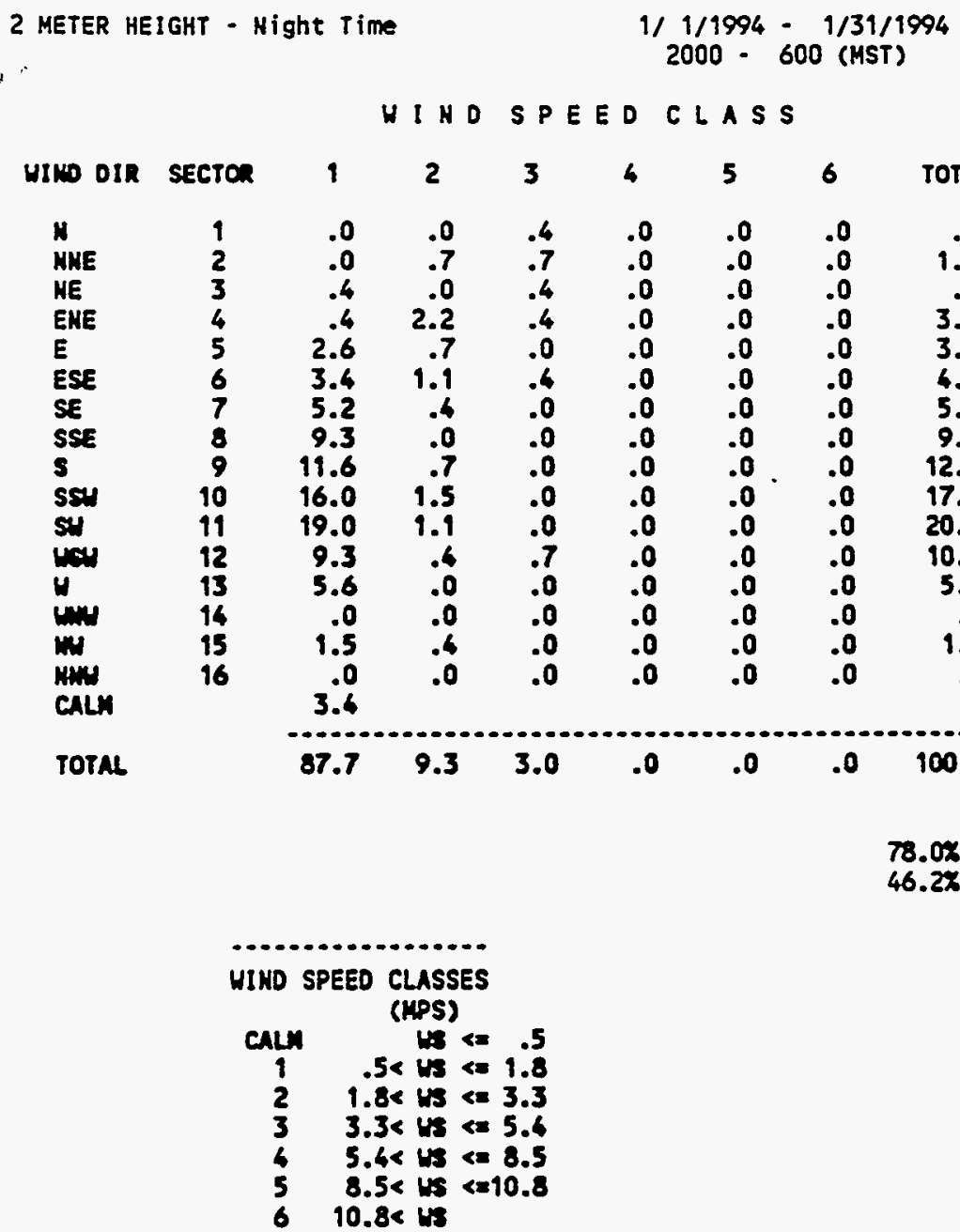
METEOROLOGICAL JOINT FREQUENCY DISTRIBUTION (PERCENT OF VALID HOUR OBSERVATIONS) SPILL TEST FACILITY 24 METER TOUER

2 METER HEIGHT - Mighe Tim

$2 / 1 / 1996-2 / 28 / 1996$

$2000 \cdot 600$ (NST)

HINDSPEEDCLASS

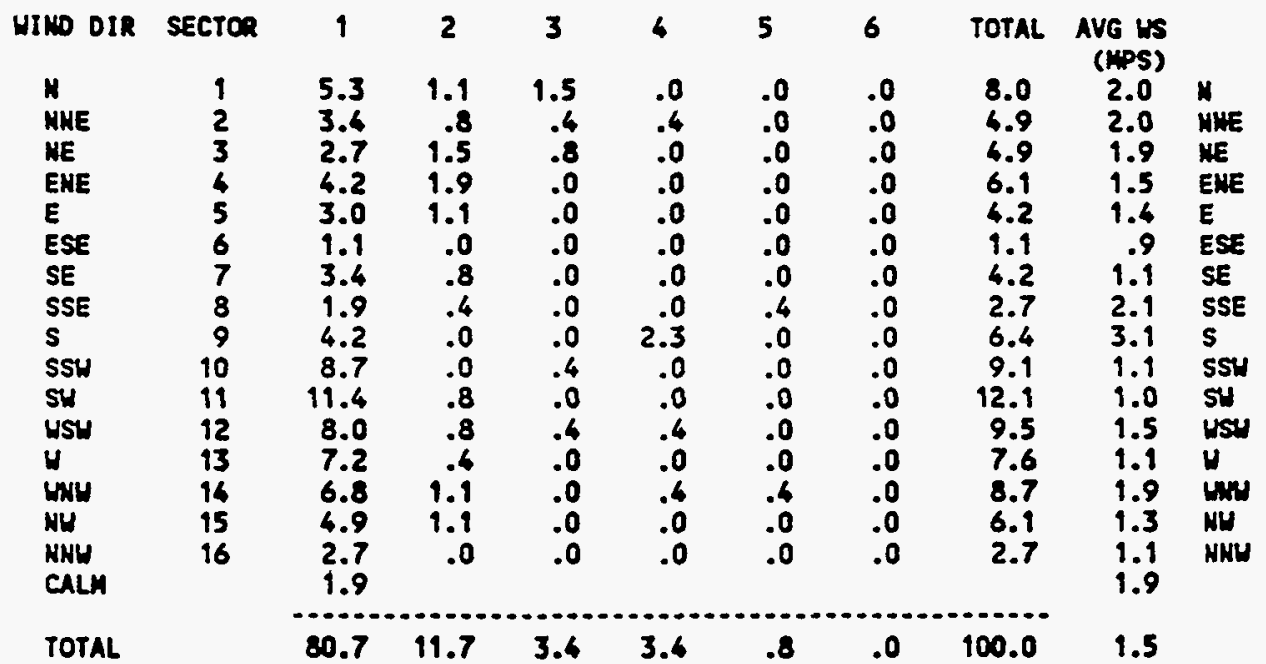

85.4\% DATA RECOVERED

46.0\% OF RECOVERED DATA

REPCRTED APOVE

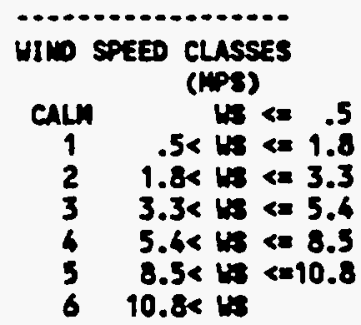


METEOROLOGICAL JOINT FREQUENCY DISTRIBUTION (PERCENT OF VALIO HOUR OBSERVATIOHS)

SPILL TEST FACILITY 24 METER TOWER

2 METER HEIGHT - Night Time

3/ 1/1994 - 3/31/1994

2000 - 600 (MST)

WI HO SPEED CLASS

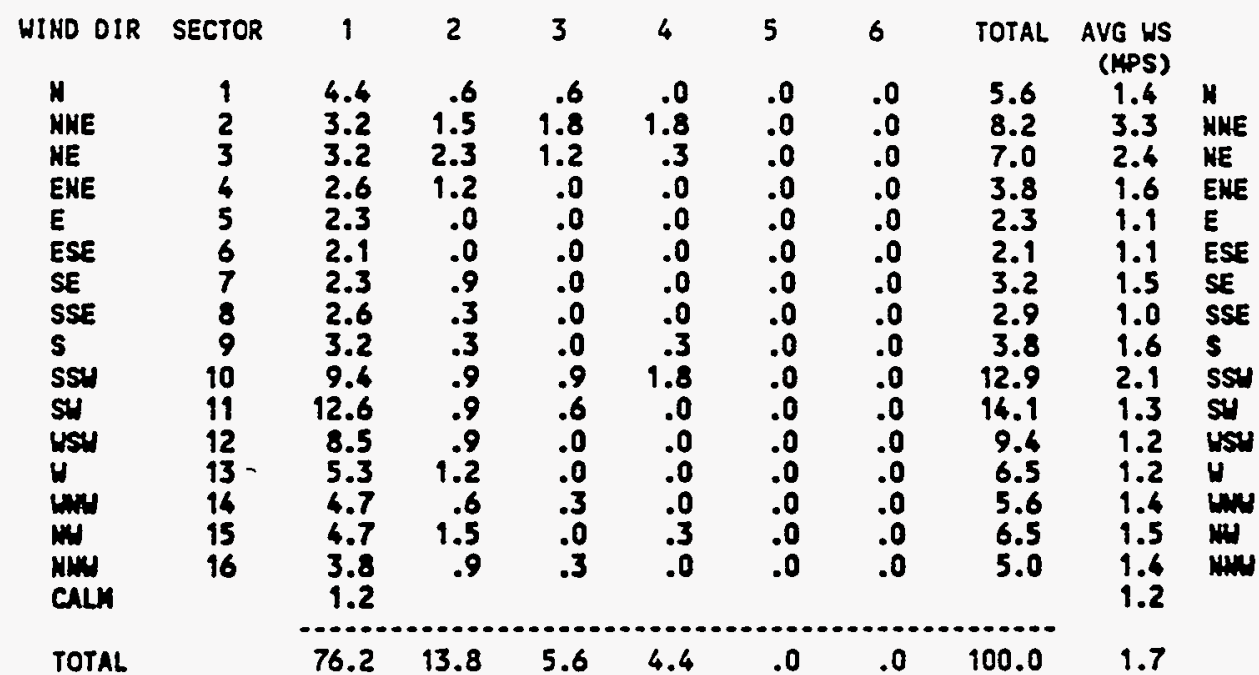

100.0\% DATA RECOVERED

45.8\% OF RECOVERED DATA

REPORTED ABOVE

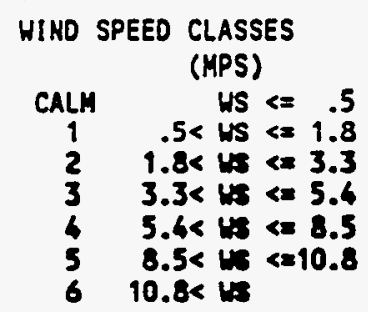


METEOROLOGICAL JOINT FREOUENCY DISTRIBUTION (PERCENT OF VALID HOUR OBSERVATIONS)

SPILL TEST FACILITY 24 METER TONER

2 METER HEIGHT - Night Time

$4 / 1 / 1994-4 / 30 / 1994$

$2000-600$ (MST)

HIND SPEEDCLASS

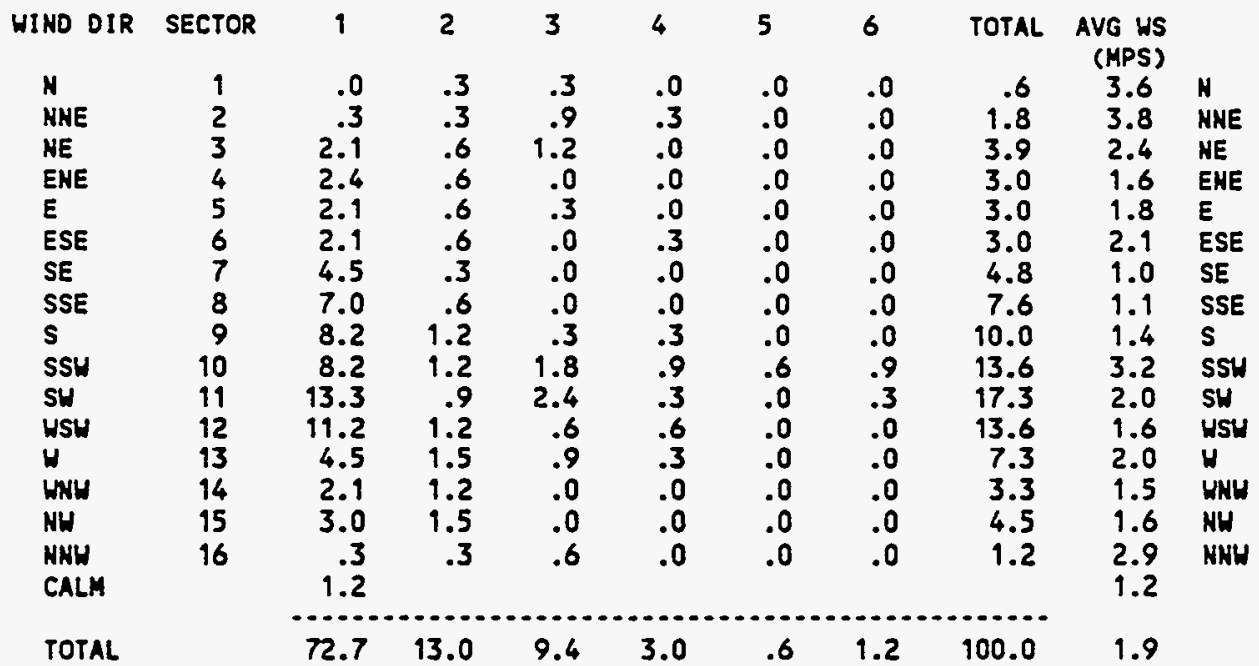

99.4X DATA RECOVERED

46.1\% OF RECOVERED DATA REPORTED ABOVE

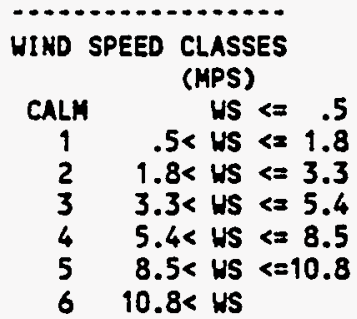


METEOROLOGICAL JOIHT FREQUENCY OISTRIBUTION (PERCENT OF VALID HOUR OBSERVATIONS) SPILL TEST FACILITY 24 METER TONER 


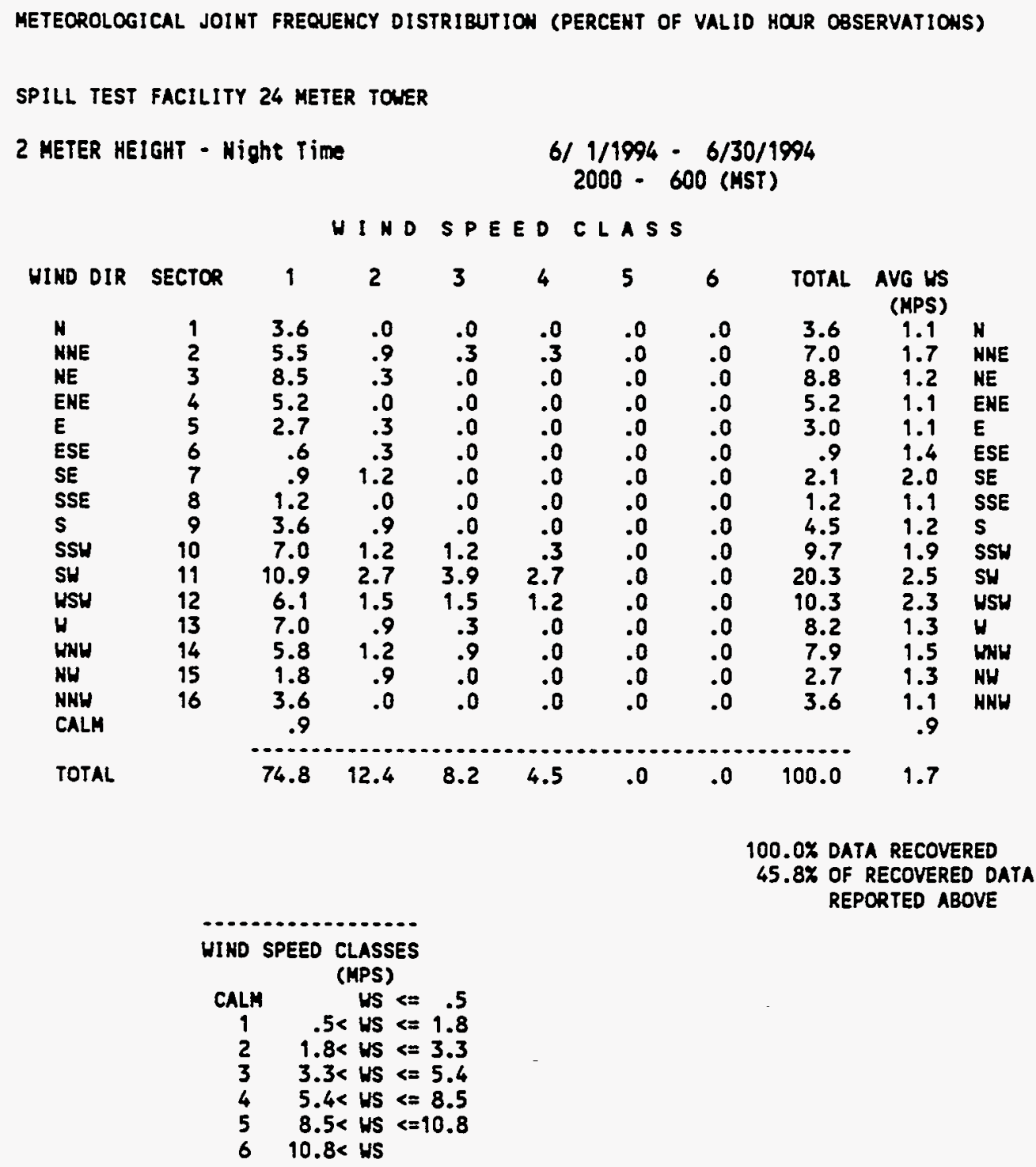


METEOROLOGICAL JOINT FREQUENCY OISTRIBUTION (PERCENT OF VALID HOUR OBSERVATIONS) SPILL TEST FACILITY 24 METER TOWER

2 METER HEIGHT - Night Time

$7 / 1 / 1994-7 / 31 / 1994$

$2000 \cdot 600$ (MST)

WI N D SPEED CLASS

\begin{tabular}{|c|c|c|c|c|c|c|c|c|c|c|}
\hline HIND DIR & SECTOR & 1 & 2 & 3 & 4 & 5 & 6 & TOTAL & $\begin{array}{l}\text { AVG WS } \\
\text { (MPS) }\end{array}$ & \\
\hline $\mathbf{N}$ & 1 & 5.0 & .0 & .0 & .0 & .0 & .0 & 5.0 & 1.0 & N \\
\hline NNE & 2 & 7.0 & .3 & .6 & .0 & .0 & .0 & 7.9 & 1.4 & NME \\
\hline $\mathrm{NE}$ & 3 & 7.9 & 3.2 & .0 & .0 & .0 & .0 & 11.1 & 1.5 & NE \\
\hline ENE & 4 & 6.5 & .9 & .0 & .0 & .0 & .0 & 7.3 & 1.4 & ENE \\
\hline E & 5 & 3.8 & .0 & .0 & .0 & .0 & .0 & 3.8 & 1.1 & $E$ \\
\hline ESE & 6 & 1.2 & .0 & .0 & .0 & .0 & .0 & 1.2 & 1.3 & ESE \\
\hline SE & 7 & 3.5 & .0 & .3 & .6 & .0 & .0 & 4.4 & 1.9 & $\mathrm{SE}$ \\
\hline $\begin{array}{l}\text { SSE } \\
\text { S }\end{array}$ & $\begin{array}{l}8 \\
9\end{array}$ & $\begin{array}{l}2.9 \\
1.8\end{array}$ & $\begin{array}{l}.0 \\
.9\end{array}$ & $\begin{array}{l}.0 \\
.0\end{array}$ & $\begin{array}{l}.0 \\
.0\end{array}$ & $\begin{array}{l}.0 \\
.0\end{array}$ & $\begin{array}{l}.0 \\
.0\end{array}$ & $\begin{array}{l}2.9 \\
2.6\end{array}$ & $\begin{array}{l}1.0 \\
1.7\end{array}$ & $\begin{array}{l}\text { SSE } \\
\text { S }\end{array}$ \\
\hline SSH & 10 & 6.5 & .9 & .3 & .3 & .0 & .0 & 7.9 & 1.7 & SSW \\
\hline SH & 11 & 10.3 & 1.8 & 1.5 & .0 & .0 & .0 & 13.5 & 1.6 & SW \\
\hline WSW & 12 & 5.3 & 1.2 & .3 & .0 & .0 & .0 & 6.7 & 1.4 & HSW \\
\hline W & 13 & 6.7 & .3 & .0 & .0 & .0 & .0 & 7.0 & 1.1 & $H$ \\
\hline HHW & 14 & 5.6 & .6 & .0 & .0 & .0 & .0 & 6.2 & 1.1 & WNH \\
\hline HH & 15 & 5.0 & .6 & .0 & .0 & .0 & .0 & 5.6 & 1.2 & NH \\
\hline NNH & 16 & 2.9 & .3 & .0 & .0 & .0 & .0 & 3.2 & $\begin{array}{l}1.2 \\
3.5\end{array}$ & NNH \\
\hline & & & & & & & & & & \\
\hline TOTAL & & 85.3 & 10.9 & 2.9 & .9 & .0 & .0 & 100.0 & 1.3 & \\
\hline
\end{tabular}

100.0\% DATA RECOVERED

45.8\% OF RECOVERED DATA REPORTED ABOVE

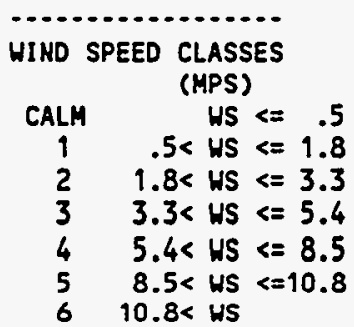


METEOROLOGICAL JOINT FREQUENCY DISTRIBUTION (PERCENT OF VALID HOUR OBSERVATIOHS)

SPILL TEST FACILITY 24 METER TOWER

2 METER HEIGHT - Night Time

$8 / 1 / 1994-8 / 31 / 1994$

$2000 \cdot 600$ (MST)

WINDSPEED CLASS

\begin{tabular}{|c|c|c|c|c|c|c|c|c|c|c|}
\hline HIND DIR & SECTOR & 1 & 2 & 3 & 4 & 5 & 6 & TOTAL & $\begin{array}{l}\text { AVG US } \\
\text { (MPS) }\end{array}$ & \\
\hline N & 1 & 3.2 & 1.5 & .0 & .0 & .0 & .0 & 4.7 & 1.7 & N \\
\hline NHE & 2 & 9.7 & 2.1 & .6 & .3 & .0 & .0 & 12.6 & 1.6 & NAE \\
\hline NE & 3 & 7.6 & 1.2 & .0 & .0 & .0 & .0 & 8.8 & 1.3 & HE \\
\hline ENE & 4 & 2.9 & .0 & .0 & .0 & .0 & .0 & 2.9 & 1.3 & ENE \\
\hline$E$ & 5 & 4.1 & .9 & .0 & .0 & .0 & .0 & 5.0 & 9.4 & $E$ \\
\hline ESE & 6 & 1.8 & .0 & .0 & .0 & .0 & .0 & 1.8 & 1.1 & ESE \\
\hline SE & 7 & 1.2 & .6 & .3 & .0 & .0 & .0 & 2.1 & 1.9 & SE \\
\hline SSE & 8 & 1.8 & .3 & .0 & .0 & .0 & .0 & 2.1 & 1.3 & SSE \\
\hline $\mathbf{s}$ & 9 & 2.3 & 1.2 & .0 & .0 & .0 & .0 & 3.5 & 1.6 & s \\
\hline SSH & 10 & 5.3 & 1.8 & .3 & .6 & .0 & .0 & 7.9 & 2.0 & SSH \\
\hline SH & 11 & 9.1 & .6 & .6 & .0 & .0 & .0 & 10.3 & 1.2 & SW \\
\hline HSW & 12 & 8.8 & .6 & .3 & .0 & .0 & .0 & 9.7 & 1.2 & USH \\
\hline H & 13 & 4.7 & .0 & .0 & .0 & .0 & .0 & 4.7 & 1.0 & $H$ \\
\hline WNH & 14 & 5.0 & .3 & .3 & .0 & .0 & .0 & 5.6 & 1.3 & WNH \\
\hline NH & 15 & 5.0 & 1.8 & .3 & .0 & .0 & .0 & 7.0 & 1.5 & WH \\
\hline $\begin{array}{l}\text { NNW } \\
\text { CALM }\end{array}$ & 16 & $\begin{array}{l}6.5 \\
2.9\end{array}$ & 2.1 & .0 & .0 & .0 & .0 & 8.5 & $\begin{array}{l}1.5 \\
2.9\end{array}$ & NNW \\
\hline TAL & & 81.8 & 14.7 & 2.6 & .9 & .0 & .0 & 100.0 & 1.4 & \\
\hline
\end{tabular}

100.0X DATA RECOVERED

45.8\% OF RECOVERED DATA REPORTED ABOVE

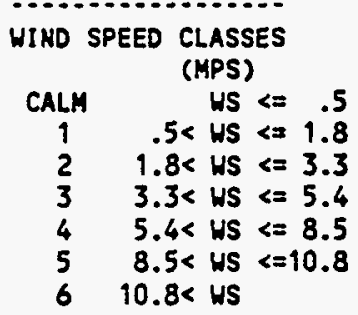


METEOROLOGICAL JOINT FREQUENCY DISTRIBUTION (PERCENT OF VALID HOUR OBSERVATIONS)

SPILL TEST FACILITY 24 METER TOWER

2 METER HEIGHT - Night Time

$9 / 1 / 1994 \cdot 9 / 30 / 1994$

$2000 \cdot 600$ (MST)

WI HD SPEED CLASS

\begin{tabular}{|c|c|c|c|c|c|c|c|c|c|c|}
\hline WIND DIR & SECTOR & 1 & 2 & 3 & 4 & 5 & 6 & TOTAL & $\begin{array}{l}\text { AVG WS } \\
\text { (MPS) }\end{array}$ & \\
\hline N & 1 & 7.3 & .3 & .0 & .0 & .0 & .0 & 7.6 & 1.0 & N \\
\hline NKE & 2 & 6.7 & .6 & .9 & .3 & .0 & .0 & 8.5 & 1.5 & NHE \\
\hline $\mathrm{NE}$ & 3 & 4.5 & 1.5 & .0 & .0 & .0 & .0 & 6.1 & 1.4 & NE \\
\hline $\begin{array}{l}\text { ENE } \\
E\end{array}$ & $\begin{array}{l}4 \\
5\end{array}$ & $\begin{array}{l}2.1 \\
1.5\end{array}$ & .3 & $\begin{array}{l}.0 \\
.0\end{array}$ & $\begin{array}{l}.0 \\
.0\end{array}$ & $\begin{array}{l}.0 \\
.0\end{array}$ & $\begin{array}{l}.0 \\
.0\end{array}$ & 2.4 & 1.1 & $\begin{array}{l}\text { ENE } \\
\text { E }\end{array}$ \\
\hline ESE & 6 & 1.8 & .0 & .0 & $\begin{array}{l}.0 \\
.0\end{array}$ & .0 & .0 & 1.8 & 1.0 & ESE \\
\hline SE & 7 & .9 & .0 & .0 & .0 & .0 & .0 & .9 & 1.2 & SE \\
\hline SSE & 8 & 2.7 & .0 & .3 & .0 & .0 & .0 & 3.0 & 1.2 & SSE \\
\hline s & 9 & 6.4 & .6 & .6 & .3 & .0 & .0 & 7.9 & 1.5 & 5 \\
\hline SSH & 10 & 10.9 & 1.2 & 1.5 & 2.4 & .0 & .0 & 16.1 & 2.2 & SSH \\
\hline SH & 11 & 10.9 & 1.2 & 1.2 & .3 & .0 & .0 & 13.6 & 1.6 & SH \\
\hline WSH & 12 & $\begin{array}{l}8.2 \\
5.8\end{array}$ & .3 & 1.2 & .0 & .0 & .0 & 9.7 & 1.5 & WSW \\
\hline HyH & $\begin{array}{l}13 \\
14\end{array}$ & $\begin{array}{l}5.8 \\
3.6\end{array}$ & 1.9 & $\begin{array}{l}.0 \\
.0\end{array}$ & $\begin{array}{l}.0 \\
.0\end{array}$ & $\begin{array}{l}.0 \\
.0\end{array}$ & $\begin{array}{l}.0 \\
.0\end{array}$ & $\begin{array}{l}6.7 \\
4.8\end{array}$ & $\begin{array}{l}1.1 \\
1.4\end{array}$ & WNH \\
\hline HH & 15 & 2.7 & .3 & .0 & .0 & .0 & .0 & 3.0 & 1.1 & NW \\
\hline $\begin{array}{l}\text { NHW } \\
\text { CALM }\end{array}$ & 16 & $\begin{array}{l}2.7 \\
2.4\end{array}$ & .9 & .0 & .0 & .0 & .0 & 3.6 & $\begin{array}{l}1.4 \\
2.4\end{array}$ & NHW \\
\hline TOTAL & & 81.2 & 9.7 & 5.8 & 3.3 & .0 & .0 & 100.0 & 1.5 & \\
\hline
\end{tabular}

99.7X DATA RECOVERED

46.0\% OF RECOVERED DATA REPORTED ABOVE

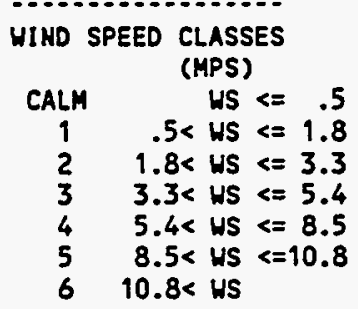


METEOROLOGICAL JOINT FREQUENCY DISTRIBUTION (PERCENT OF VALID HOUR OBSERVATIONS)

SPILL TEST FACILITY 24 METER TOWER

2 METER HEIGHT - Night TIME

$10 / 1 / 1994 \cdot 10 / 31 / 1994$

$2000-600$ (MST)

HI ND SPEED CLASS

\begin{tabular}{|c|c|c|c|c|c|c|c|c|c|c|}
\hline HIND DIR & SECTOR & 1 & 2 & 3 & 4 & 5 & 6 & TOTAL & $\begin{array}{l}\text { AVG WS } \\
\text { (MPS) }\end{array}$ & \\
\hline N & 1 & 3.2 & .6 & .9 & .3 & .0 & .0 & 5.0 & 2.1 & N \\
\hline NHE & 2 & 1.8 & .9 & .9 & .3 & .0 & .0 & 3.8 & 2.4 & NHE \\
\hline ME & 3 & 2.9 & 1.2 & .6 & .3 & .0 & .0 & 5.0 & 1.9 & NE \\
\hline ENE & 4 & 3.5 & 1.5 & .0 & .0 & .0 & .0 & 5.0 & 1.5 & ENE \\
\hline E & 5 & 2.6 & .0 & .0 & .0 & .0 & .0 & 2.6 & .9 & $\mathbf{E}$ \\
\hline ESE & 6 & 1.8 & .3 & .0 & .0 & .0 & .0 & 2.1 & 1.0 & ESE \\
\hline SE & 7 & .9 & .0 & .0 & .0 & .0 & .0 & .9 & .9 & SE \\
\hline SSE & 8 & 2.6 & .0 & 0 & .0 & .0 & .0 & 2.6 & .7 & SSE \\
\hline $\begin{array}{l}\text { s } \\
\text { SSH }\end{array}$ & $\begin{array}{r}9 \\
10\end{array}$ & $\begin{array}{l}4.7 \\
8.5\end{array}$ & $\begin{array}{r}.0 \\
1.5\end{array}$ & $\begin{array}{l}.0 \\
.9\end{array}$ & $\begin{array}{r}.0 \\
1.8\end{array}$ & $\begin{array}{l}.0 \\
.3\end{array}$ & $\begin{array}{l}.0 \\
.0\end{array}$ & $\begin{array}{r}4.7 \\
12.9\end{array}$ & $\begin{array}{l}1.0 \\
2.3\end{array}$ & $\begin{array}{l}\text { S } \\
\text { SSH }\end{array}$ \\
\hline SH & 11 & 14.1 & 1.5 & 1.2 & .9 & .0 & .0 & 17.6 & 9.6 & SH \\
\hline WSH & $\begin{array}{l}12 \\
13\end{array}$ & $\begin{array}{r}11.7 \\
8.2\end{array}$ & 1.2 & $\begin{array}{r}0 \\
0\end{array}$ & .3 & .0 & .0 & $\begin{array}{r}13.2 \\
8.5\end{array}$ & 1.2 & $\begin{array}{l}\text { WSH } \\
W\end{array}$ \\
\hline WNH & $\begin{array}{l}12 \\
14\end{array}$ & $\begin{array}{l}0.5 \\
4.7\end{array}$ & .3 & .0 & .0 & .0 & .0 & 5.0 & 1.1 & WNW \\
\hline NH & 15 & 3.8 & .0 & .0 & .0 & .0 & .0 & 3.8 & .9 & NH \\
\hline $\begin{array}{l}\text { NHH } \\
\text { CALM }\end{array}$ & 16 & $\begin{array}{l}4.7 \\
1.8\end{array}$ & .9 & .0 & .0 & .0 & .0 & 5.6 & $\begin{array}{l}1.3 \\
1.8\end{array}$ & HNH \\
\hline TOTAL & & 81.5 & 10.0 & 4.4 & 3.8 & .3 & .0 & 100.0 & 1.5 & \\
\hline
\end{tabular}

100.0\% DATA RECOVERED

45.8\% OF RECOVERED DATA REPORTED ABOVE

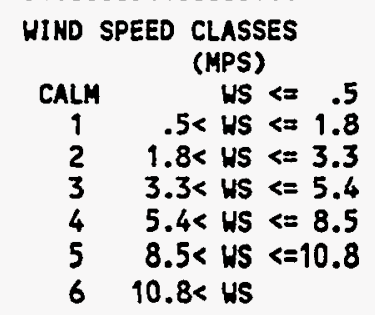


METEOROLOGICAL, JOINT FREQUENCY DISTRIBUTIOH (PERCENT OF VALID HOUR OBSERVATIONS)

SPILL TEST FACILITY 24 METER TONER

2 METER HEIGHT - Night Time

$11 / 1 / 1994-11 / 30 / 1994$ $2000 \cdot 600$ (HST)

HI H D SPEEDCLASS

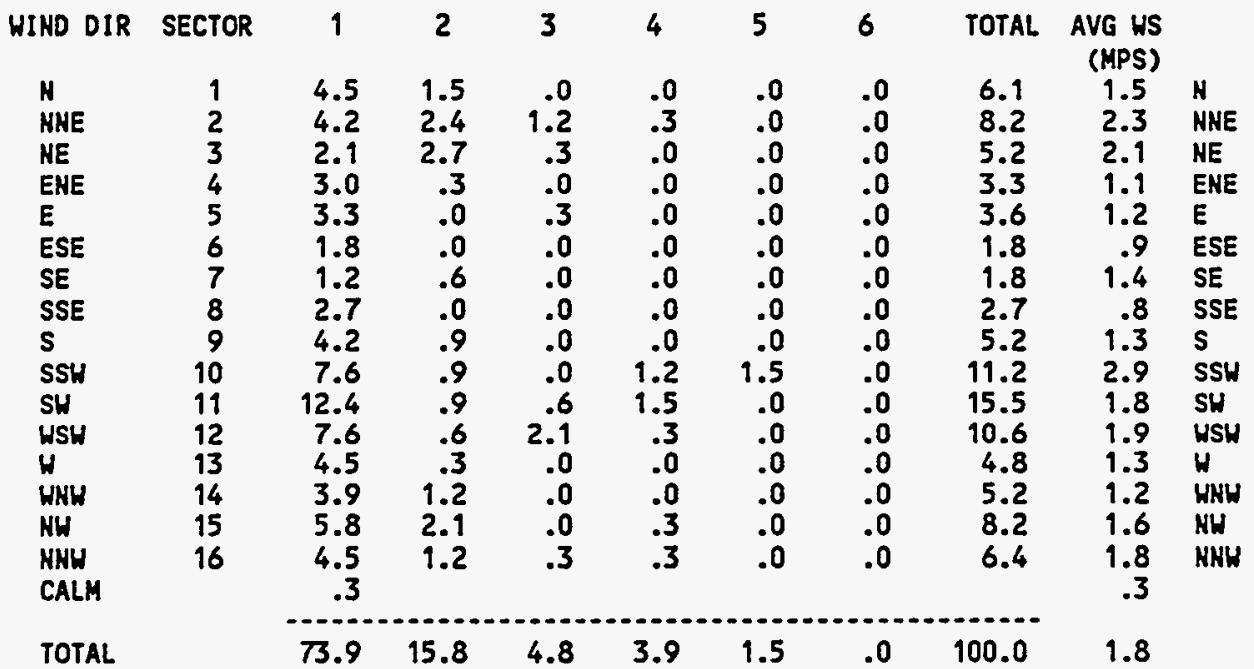

100.0\% DATA RECOVERED

45.8\% OF RECOVERED DATA REPORTED ABOVE

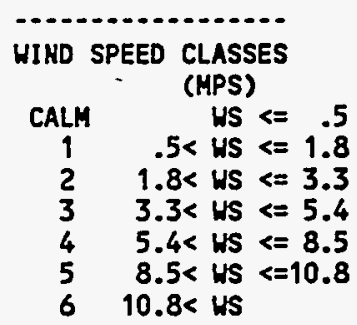


METEOROLOGICAL JOINT FREQUENCY OISTRIBUTIOH (PERCENT OF VALID HOUR OBSERVATIONS)

SPILL TEST FACILITY 24 METER TOWER

2 METER HEIGHT - Night Time

$12 / 1 / 1994-12 / 31 / 1994$

2000 - 600 (MST)

WI HO SPEEDCLASS

\begin{tabular}{|c|c|c|c|c|c|c|c|c|c|c|}
\hline WIND DIR & SECTOR & 1 & 2 & 3 & 4 & 5 & 6 & TOTAL & $\begin{array}{r}\text { AVG WS } \\
\text { (MPS) }\end{array}$ & \\
\hline H & 1 & 4.1 & .5 & .5 & .0 & .0 & .0 & 5.0 & 1.5 & H \\
\hline MNE & 2 & 4.1 & 2.3 & 1.4 & .0 & .0 & .0 & 7.7 & 2.0 & NHE \\
\hline NE & 3 & 3.2 & 2.7 & 2.3 & .0 & .0 & .0 & 8.1 & 2.4 & NE \\
\hline ENE & 4 & 1.8 & 1.8 & .0 & .0 & .0 & .0 & 3.6 & 1.8 & ENE \\
\hline E & 5 & 1.8 & 1.4 & .5 & .0 & .0 & .0 & 3.6 & 1.8 & $\varepsilon$ \\
\hline ESE & 6 & 1.4 & .0 & .0 & .0 & .0 & .0 & 1.4 & 1.0 & ESE \\
\hline SE & 7 & 2.3 & .5 & .0 & .0 & .0 & .0 & 2.7 & 1.1 & SE \\
\hline SSE & 8 & 2.7 & .0 & .0 & .0 & .0 & .0 & 2.7 & .8 & SSE \\
\hline S & 9 & 4.1 & .0 & .0 & .5 & .0 & .0 & 4.5 & 1.3 & $\mathbf{S}$ \\
\hline SSH & 10 & 9.0 & .5 & .0 & .0 & .0 & .0 & 9.5 & 1.2 & SSW \\
\hline SH & 11 & 13.1 & .5 & .5 & .0 & .0 & .0 & 14.0 & $1 . \overline{3}$ & SH \\
\hline WSW & 12 & 9.0 & .0 & .0 & .0 & .0 & .0 & 9.0 & 1.0 & WSW \\
\hline WNW & $\begin{array}{l}13 \\
14\end{array}$ & $\begin{array}{l}4.5 \\
6.3\end{array}$ & $\begin{array}{l}.0 \\
.9\end{array}$ & .0 & $\begin{array}{l}.0 \\
.0\end{array}$ & $\begin{array}{l}.0 \\
.0\end{array}$ & .0 & $\begin{array}{l}4.5 \\
7.7\end{array}$ & $\begin{array}{l}1.0 \\
1.5\end{array}$ & HWH \\
\hline NH & 15 & 5.4 & .9 & .0 & .0 & .0 & .0 & 6.3 & 1.2 & NH \\
\hline $\begin{array}{l}\text { HNH } \\
\text { CALM }\end{array}$ & 16 & $\begin{array}{r}6.3 \\
.9\end{array}$ & 2.3 & .0 & .0 & .0 & .0 & 8.6 & $\begin{array}{r}1.5 \\
.9\end{array}$ & HNH \\
\hline TOTAL & & 80.1 & 14.0 & 5.4 & .5 & .0 & .0 & 100.0 & 1.4 & \\
\hline
\end{tabular}

65.1\% DATA RECOVERED

45.7\% OF RECOVERED DATA REPORTED ABOVE

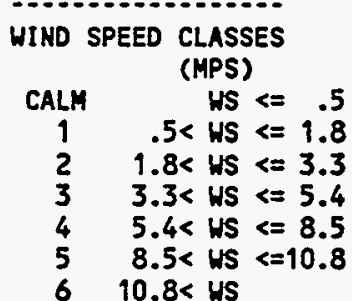


METEOROLOGICAL JOIHT FREQUENCY DISTRIBUTION (PERCENT OF VALID HOUR OBSERVATIONS)

SPILL TEST FACILITY 24 METER TONER

2 METER HEIGHT - Total Hours

$1 / 1 / 1994-1 / 31 / 1994$

STABILITY CLASS A

$0 \cdot 2300$ (MST)

$0.5-1.5$

HIND SPEED CLASS

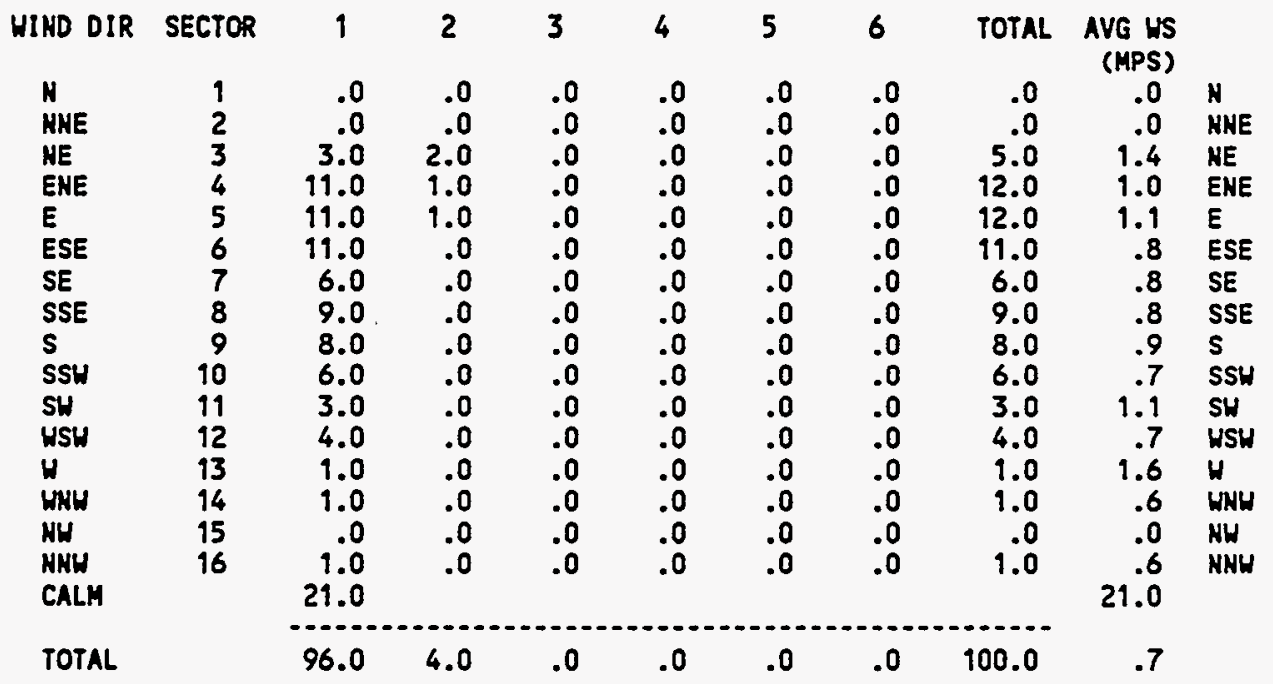

78.0\% DATA RECOVERED

17.2\% OF RECOVERED DATA

REPORTED ABOVE

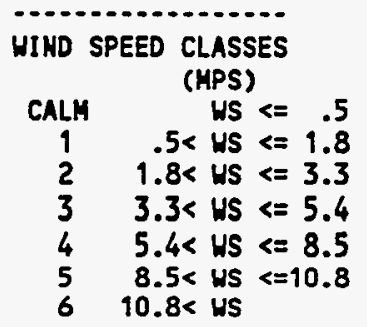


METEOROLOGICAL JOINT FREQUENCY OISTRIBUTIOH (PERCENT OF VALID HOUR OBSERVATIOHS) SPILL TEST FACILITY 24 METER TONER

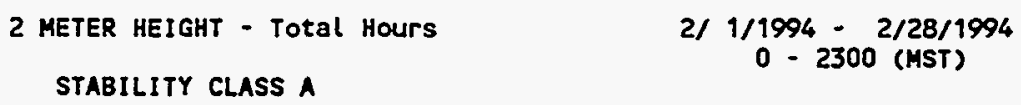

\begin{tabular}{|c|c|c|c|c|c|c|c|c|c|c|}
\hline HIND DIR & SECTOR & 1 & 2 & 3 & 4 & 5 & 6 & TOTAL & $\begin{array}{l}\text { AVG WS } \\
\text { (MPS) }\end{array}$ & \\
\hline H & 1 & 1.0 & .0 & .0 & .0 & .0 & .0 & 1.0 & .7 & H \\
\hline HHE & 2 & 7.6 & .0 & .0 & .0 & .0 & .0 & 7.6 & .8 & NHE \\
\hline NE & 3 & 9.5 & .0 & .0 & .0 & .0 & .0 & 9.5 & .9 & NE \\
\hline ENE & 4 & 15.2 & .0 & .0 & .0 & .0 & .0 & 15.2 & 1.0 & ENE \\
\hline$E$ & 5 & 10.5 & 1.0 & .0 & .0 & .0 & .0 & 11.4 & .9 & $E$ \\
\hline ESE & 6 & 7.6 & .0 & .0 & .0 & .0 & .0 & 7.6 & 1.0 & ESE \\
\hline SE & 7 & 2.9 & .0 & .0 & .0 & .0 & .0 & 2.9 & 1.0 & SE \\
\hline SSE & 8 & 3.8 & .0 & .0 & .0 & .0 & .0 & 3.8 & .7 & SSE \\
\hline $\mathbf{s}$ & 9 & 8.6 & .0 & .0 & .0 & .0 & .0 & 8.6 & .8 & s \\
\hline SSW & 10 & 4.8 & 1.9 & .0 & .0 & .0 & .0 & 6.7 & 1.2 & SSH \\
\hline SH & 11 & .0 & 1.0 & .0 & .0 & .0 & .0 & 1.0 & 2.5 & SH \\
\hline WSH & 12 & 2.9 & 1.0 & .0 & .0 & .0 & .0 & 3.8 & 1.3 & USH \\
\hline W & 13 & 5.7 & .0 & .0 & .0 & .0 & .0 & 5.7 & .8 & $W$ \\
\hline WHW & 14 & 1.9 & .0 & .0 & .0 & .0 & .0 & 1.9 & .9 & WHH \\
\hline NH & 15 & 3.8 & 1.0 & .0 & .0 & .0 & .0 & 4.8 & 1.1 & HH \\
\hline $\begin{array}{l}\text { HNU } \\
\text { CALM }\end{array}$ & 16 & $\begin{array}{l}4.8 \\
3.8\end{array}$ & .0 & .0 & .0 & .0 & .0 & 4.8 & $\begin{array}{r}.7 \\
3.8\end{array}$ & HKH \\
\hline & & & & & & & & & & \\
\hline OTAL & & 94.3 & 5.7 & .0 & .0 & .0 & .0 & 100.0 & .9 & \\
\hline
\end{tabular}

85.4\% DATA RECOVERED

18.3\% OF RECOVERED DATA REPORTED ABOVE

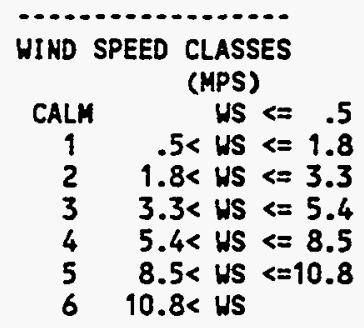


METEOROLOGICAL JOINT FREQUENCY DISTRIBUTION (PERCENT OF VALID HOUR OBSERVATIONS)

SPILL TEST FACILITY 24 METER TONER

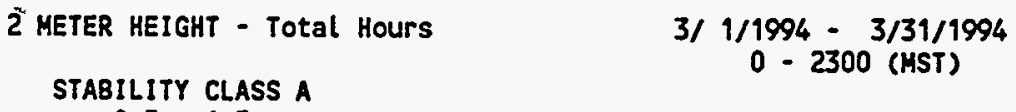

UIND SPEEDCLASS

\begin{tabular}{|c|c|c|c|c|c|c|c|c|c|c|}
\hline WIND DIR & SECTOR & 1 & 2 & 3 & 4 & 5 & 6 & TOTAL & $\begin{array}{l}\text { AVG WS } \\
\text { (MPS) }\end{array}$ & \\
\hline & 1 & 3.3 & .7 & .0 & .0 & .0 & .0 & 4.0 & 1.5 & $N$ \\
\hline HNE & 2 & 2.7 & .7 & .0 & .0 & .0 & .0 & 3.3 & 1.0 & NHE \\
\hline NE & 3 & 7.3 & 2.7 & .0 & .0 & .0 & .0 & 10.0 & 1.3 & $\mathrm{NE}$ \\
\hline ENE & 4 & 7.3 & $\begin{array}{r}.0 \\
27\end{array}$ & .0 & .0 & .0 & .0 & 7.3 & 9.0 & ENE \\
\hline $\begin{array}{l}\text { E } \\
\text { ESE }\end{array}$ & $\begin{array}{l}5 \\
6\end{array}$ & $\begin{array}{l}6.7 \\
4.0\end{array}$ & $\begin{array}{l}2.7 \\
1.3\end{array}$ & $\begin{array}{l}.0 \\
.0\end{array}$ & $\begin{array}{l}.0 \\
.0\end{array}$ & $\begin{array}{l}.0 \\
0\end{array}$ & $\begin{array}{l}.0 \\
0\end{array}$ & $\begin{array}{l}9.3 \\
5.3\end{array}$ & 1.4 & $\begin{array}{l}E \\
\text { ESE }\end{array}$ \\
\hline SE & 7 & 4.7 & 2.0 & .0 & .0 & .0 & .0 & $\begin{array}{l}2.3 \\
6.7\end{array}$ & 1.5 & SE \\
\hline SSE & $\begin{array}{l}8 \\
0\end{array}$ & 5.3 & .7 & .0 & .0 & .0 & .0 & 6.0 & 1.5 & SSE \\
\hline $\begin{array}{l}\text { s } \\
\text { sSH }\end{array}$ & $\begin{array}{r}9 \\
10\end{array}$ & $\begin{array}{l}4.7 \\
6.0\end{array}$ & $\begin{array}{l}2.7 \\
2.0\end{array}$ & $\begin{array}{l}.0 \\
.0\end{array}$ & $\begin{array}{l}.0 \\
.0\end{array}$ & $\begin{array}{l}.0 \\
.0\end{array}$ & $\begin{array}{l}.0 \\
.0\end{array}$ & $\begin{array}{l}7.3 \\
8.0\end{array}$ & 1.5 & $\begin{array}{l}\text { s } \\
\text { SSH }\end{array}$ \\
\hline SH & 11 & 4.0 & 1.3 & .0 & .0 & .0 & .0 & 5.3 & 1.6 & SU \\
\hline HSH & 12 & 4.7 & .7 & .0 & .0 & .0 & 0 & 5.3 & 1.3 & USY \\
\hline$H$ & 13 & 2.0 & .7 & .0 & .0 & .0 & .0 & 2.7 & 1.1 & $H$ \\
\hline WHW & 14 & 2.7 & .0 & .0 & .0 & .0 & .0 & 2.7 & 1. & WNH \\
\hline HW & 15 & 1.3 & .0 & .0 & .0 & .0 & .0 & 1.3 & $\because$ & NW \\
\hline $\begin{array}{l}\text { MNH } \\
\text { CALM }\end{array}$ & 16 & $\begin{array}{r}.0 \\
14.7\end{array}$ & .7 & .0 & .0 & .0 & .0 & .7 & 2.0 & HNH \\
\hline & & & & & & & & & & \\
\hline TOTAL & & 81.3 & 18.7 & .0 & .0 & .0 & .0 & 100.0 & 1.1 & \\
\hline
\end{tabular}

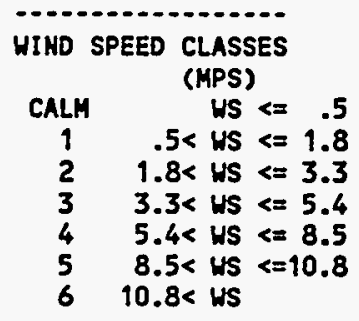


METEOROLOGICAL JOIHT FREQUENCY DISTRIBUTION (PERCENT OF VALID HOUR OBSERVATIOHS) SPILL TEST FACILITY 24 METER TOWER
2 METER HEIGHT - TOtal HOURS
4/ $1 / 1994-4 / 30 / 1994$
$0-2300$ (MST)

STABILITY CLASS A

$0.5 \cdot 1.5$

HIND SPEEDCLASS

\begin{tabular}{|c|c|c|c|c|c|c|c|c|c|c|}
\hline WIND DIR & SECTOR & 1 & 2 & 3 & 4 & 5 & 6 & TOTAL & $\begin{array}{c}\text { AVG WS } \\
\text { (MPS) }\end{array}$ & \\
\hline$N$ & 1 & .7 & .0 & .0 & .0 & .0 & .0 & .7 & 1.2 & N \\
\hline NHE & 2 & .0 & .0 & .0 & .0 & .0 & .0 & .0 & .0 & ANE \\
\hline NE & 3 & 1.4 & .0 & .0 & .0 & .0 & .0 & 1.4 & 1.3 & NE \\
\hline ENE & 4 & 2.8 & .0 & .0 & .0 & .0 & .0 & 2.8 & 1.1 & ENE \\
\hline E & 5 & 5.0 & 2.8 & .0 & .0 & .0 & .0 & 7.8 & 1.5 & $E$ \\
\hline ESE & 6 & 6.4 & 3.5 & .0 & .0 & .0 & .0 & 9.9 & 1.5 & ESE \\
\hline SE & 7 & 7.8 & 3.5 & .0 & .0 & .0 & .0 & 11.3 & 1.4 & SE \\
\hline $\begin{array}{l}\text { SSE } \\
S\end{array}$ & $\begin{array}{l}8 \\
9\end{array}$ & $\begin{array}{r}12.8 \\
8.5\end{array}$ & $\begin{array}{l}4.3 \\
2.8\end{array}$ & .0 & $\begin{array}{l}.0 \\
.0\end{array}$ & $\begin{array}{l}.0 \\
.0\end{array}$ & $\begin{array}{l}.0 \\
.0\end{array}$ & $\begin{array}{l}17.0 \\
11.3\end{array}$ & $\begin{array}{l}1.4 \\
1.3\end{array}$ & $\begin{array}{l}\text { SSE } \\
\text { S }\end{array}$ \\
\hline SSH & 10 & 10.6 & 5.0 & .0 & .0 & .0 & .0 & 15.6 & 1.4 & SSH \\
\hline SH & 19 & 3.5 & 2.8 & .0 & .0 & .0 & .0 & 6.4 & 1.6 & SH \\
\hline USW & 12 & 4.3 & 1.4 & .0 & .0 & .0 & .0 & 5.7 & 1.4 & WSW \\
\hline $\mathbf{u}$ & 13 & 2.1 & .7 & .0 & .0 & .0 & .0 & 2.8 & 1.3 & $\mathbf{H}$ \\
\hline WNW & 14 & .7 & .7 & .0 & .0 & .0 & .0 & 1.4 & 2.0 & WNH \\
\hline NH & 15 & .7 & .0 & .0 & .0 & .0 & .0 & .7 & .8 & HH \\
\hline HNH & 16 & .0 & .0 & .0 & .0 & .0 & .0 & .0 & $\therefore 0$ & HNH \\
\hline CALM & & & & & & & & & & \\
\hline TOTAL & & 72.3 & 27.7 & .0 & .0 & .0 & .0 & 100.0 & 1.3 & \\
\hline
\end{tabular}

99.4\% DATA RECOVERED

19.7\% OF RECOVERED DATA REPORTED ABOVE

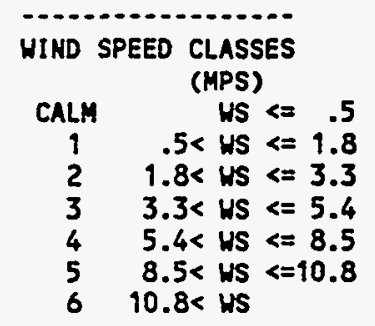


METEOROLOGICAL JOINT FREQUENCY DISTRIBUTION (PERCENT OF VALID HOUR OBSERVATIONS)

SPILL TEST FACILITY 24 METER TONER

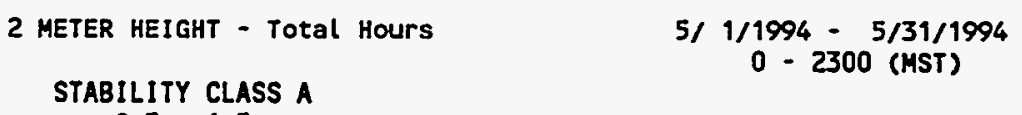

HI HO SPEED CLASS

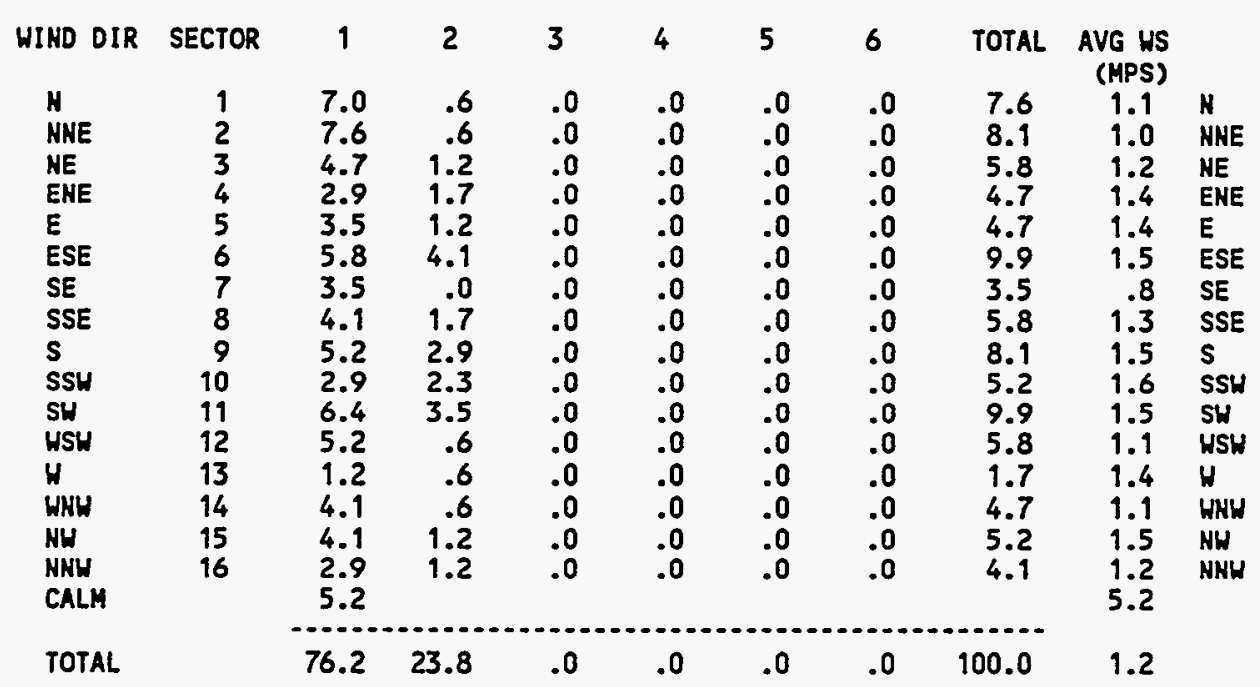

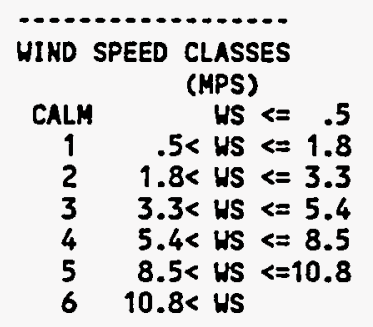




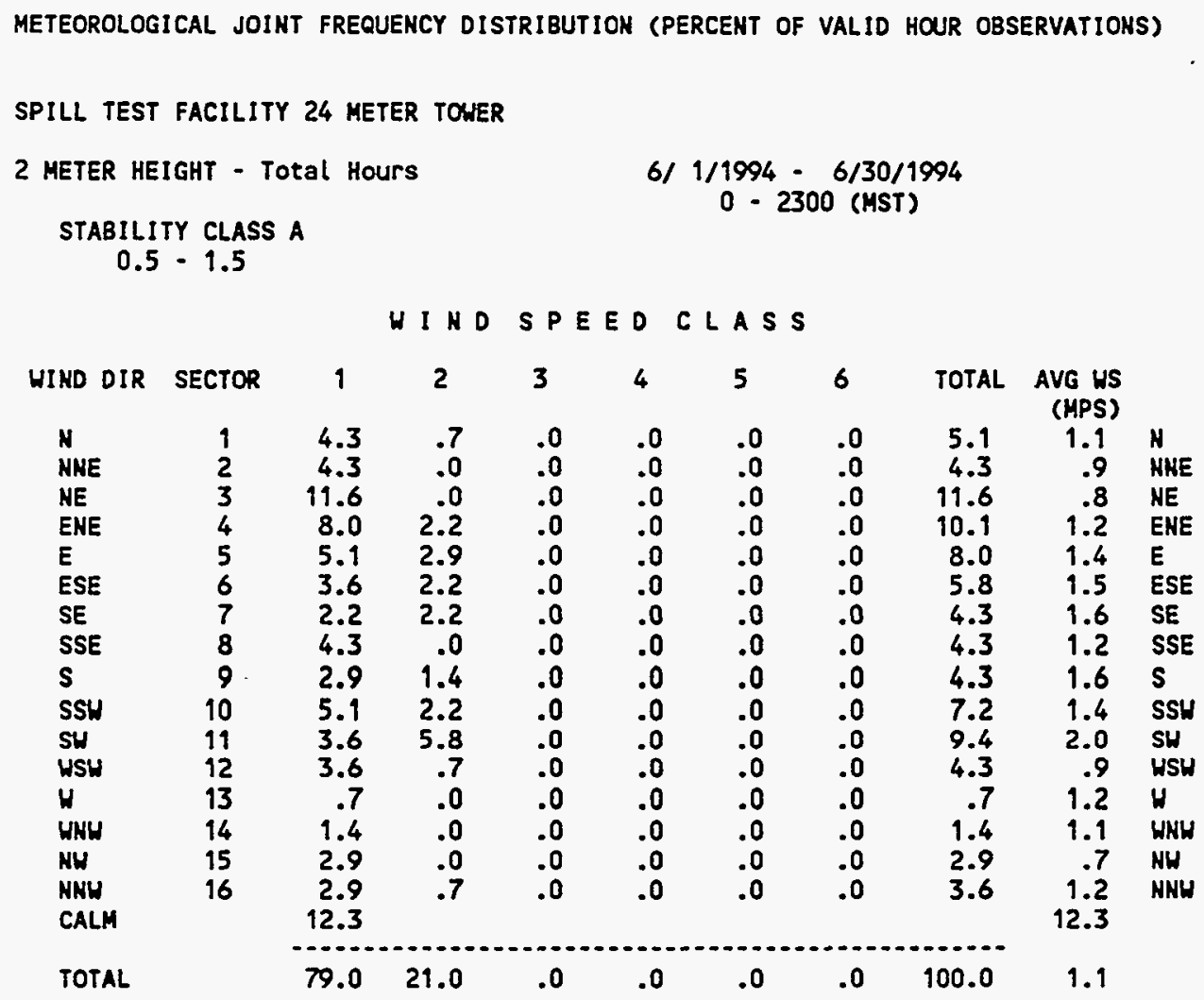

100.0\% DATA RECOVERED

19.2\% OF RECOVERED DATA

REPORTED ABOVE

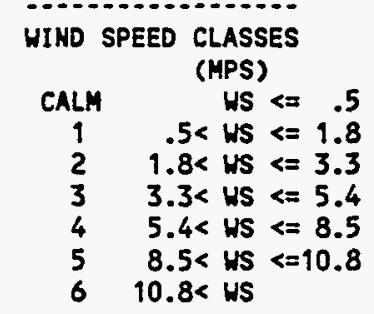


METEOROLOGICAL JOIHT FREQUENCY DISTRIBUTION (PERCENT OF VALID HOUR OBSERVATIONS)

SPILL TEST FACILITY 24 METER TOWER

2 METER HEIGHT - TOtal Hours

$7 / 1 / 1994-7 / 31 / 1994$

STABILITY CLASS A

$0-2300$ (HST)

$0.5 \cdot 1.5$

WINDSPEEDCLASS

\begin{tabular}{|c|c|c|c|c|c|c|c|c|c|c|}
\hline HIND DIR & SECTOR & 1 & 2 & 3 & 4 & 5 & 6 & TOTAL & $\begin{array}{l}\text { AVG WS } \\
\text { (MPS) }\end{array}$ & \\
\hline N & 1 & 3.5 & .6 & .0 & .0 & .0 & .0 & 4.1 & .9 & N \\
\hline NME & 2 & 3.5 & .6 & .0 & .0 & .0 & .0 & 4.1 & 1.1 & NHE \\
\hline NE & 3 & 4.7 & 1.2 & .0 & .0 & .0 & .0 & 5.8 & 1.2 & NE \\
\hline ENE & 4 & 8.1 & 1.2 & .0 & .0 & .0 & .0 & 9.3 & 1.2 & ENE \\
\hline $\begin{array}{l}\text { E } \\
\text { ESE }\end{array}$ & $\begin{array}{l}5 \\
6\end{array}$ & $\begin{array}{r}7.0 \\
.6\end{array}$ & .6 & .0 & .0 & $\begin{array}{l}.0 \\
.0\end{array}$ & $\begin{array}{l}.0 \\
.0\end{array}$ & $\begin{array}{r}7.6 \\
.6\end{array}$ & $\begin{array}{r}1.2 \\
.6\end{array}$ & $\begin{array}{l}\text { E } \\
\text { ESE }\end{array}$ \\
\hline SE & 7 & 6.4 & 2.3 & .0 & .0 & .0 & .0 & 8.7 & 1.2 & SE \\
\hline SSE & 8 & 3.5 & 2.9 & .0 & .0 & .0 & .0 & 6.4 & 1.6 & SSE \\
\hline s & 9 & 4.1 & 2.3 & .0 & .0 & .0 & .0 & 6.4 & 1.6 & $s$ \\
\hline SSH & 10 & 4.7 & 3.5 & .0 & .0 & .0 & .0 & 8.1 & 1.6 & SSW \\
\hline SH & 11 & 3.5 & 2.9 & .0 & .0 & .0 & .0 & 6.4 & 1.7 & SH \\
\hline USW & 12 & 2.9 & 2.3 & .0 & .0 & .0 & .0 & 5.2 & 1.5 & WSH \\
\hline $\mathbf{H}$ & 13 & 4.1 & .0 & .0 & .0 & .0 & .0 & 4.1 & .8 & H \\
\hline HHH & 14 & 2.3 & .0 & .0 & .0 & .0 & .0 & 2.3 & .9 & $\begin{array}{l}\text { WNH } \\
\text { NW }\end{array}$ \\
\hline HW & 15 & 3.5 & .6 & .0 & .0 & .0 & .0 & $\begin{array}{l}4.9 \\
20\end{array}$ & 1.1 & NW \\
\hline $\begin{array}{l}\text { NWH } \\
\text { CALM }\end{array}$ & 16 & $\begin{array}{r}2.9 \\
14.0\end{array}$ & .0 & .0 & .0 & .0 & .0 & 2.9 & $\begin{array}{r}1.2 \\
14.0\end{array}$ & NKW \\
\hline TOTAL & & 79.1 & 20.9 & .0 & .0 & .0 & .0 & 100.0 & 1.1 & \\
\hline
\end{tabular}

100.0\% DATA RECOVERED

23.1\% OF RECOVERED DATA REPORTED ABOVE

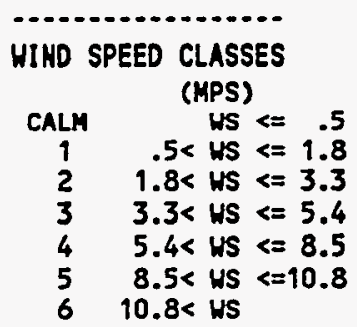


METEOROLOGICAL JOINT FREQUENCY DISTRIBUTION (PERCENT OF VALIO HOUR OBSERVATIONS) SPILL TEST FACILITY 24 METER TONER

2 METER HEIGHT - TOtal HOURS

8) $1 / 1994-8 / 31 / 1994$

STABILITY CLASS A

$0 \cdot 2300$ (MST)

$0.5 \cdot 1.5$

WINDSPEEDCLASS

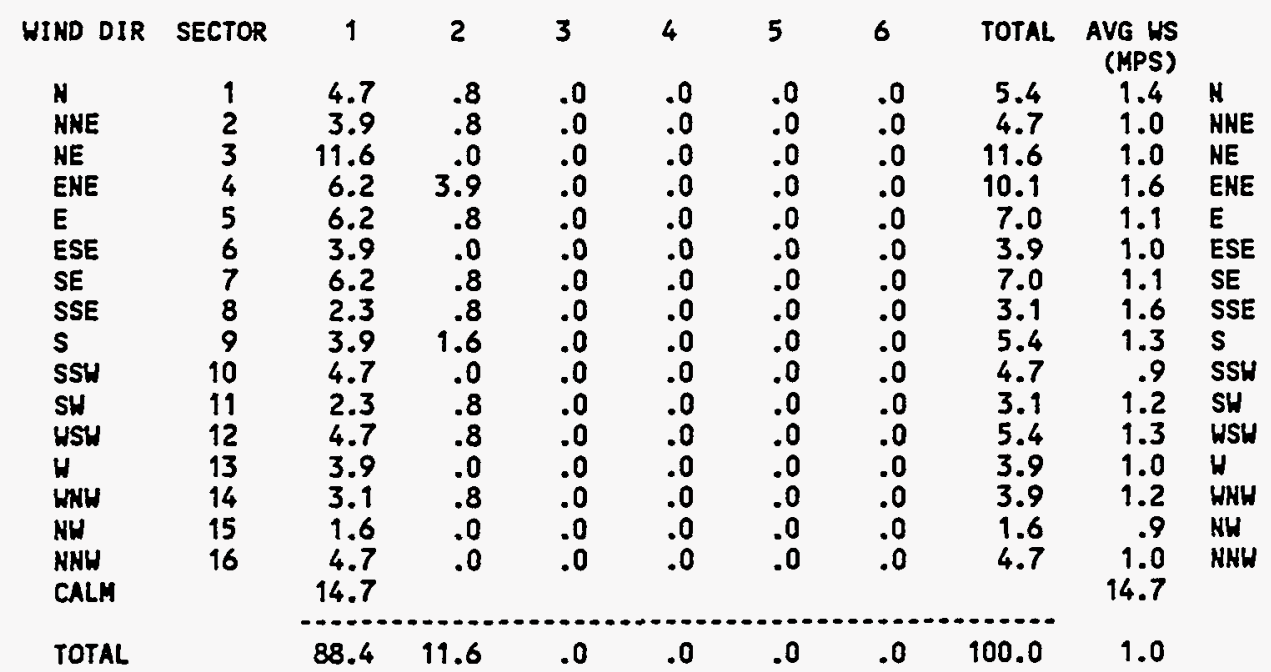

100.0\% DATA RECOVERED

17.3\% OF RECOVERED DATA

REPORTED ABOVE

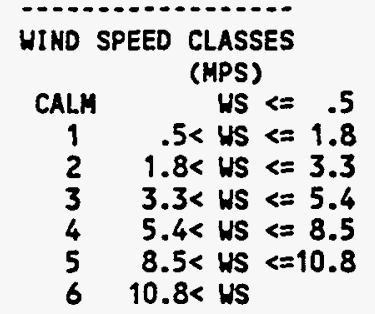


METEOROLOGICAL JOINT FREQUENCY DISTRIBUTION (PERCENT OF VALID HOUR OBSERVATIONS) SPILL TEST FACILITY 24 METER TOWER

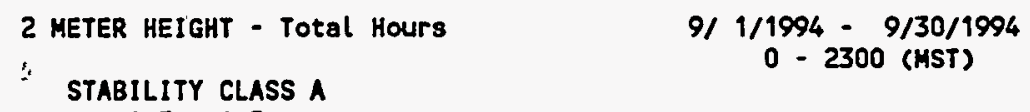

HIND SPEED CLASS

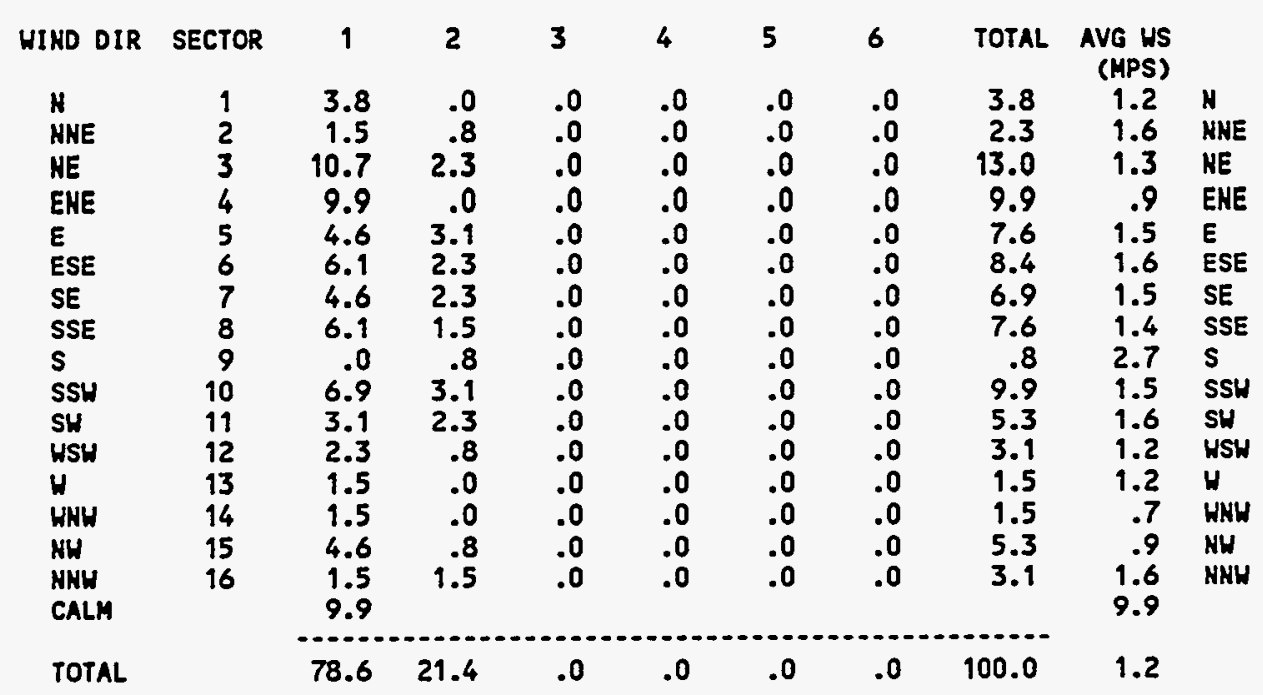

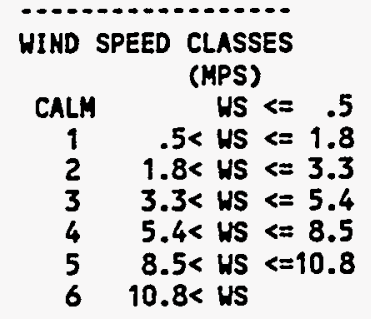


METEOROLOGICAL JOINT FREQUENCY DISTRIBUTION (PERCENT OF VALID HOUR OBSERVATIONS) SPILL TEST FACILITY 24 METER TOWER

2 METER HEIGHT - Total Hours

$10 / 1 / 1994 \cdot 10 / 31 / 1994$

STABILITY CLASS A

$0-2300$ (MST)

$0.5-1.5$

HIND SPEEDCLASS

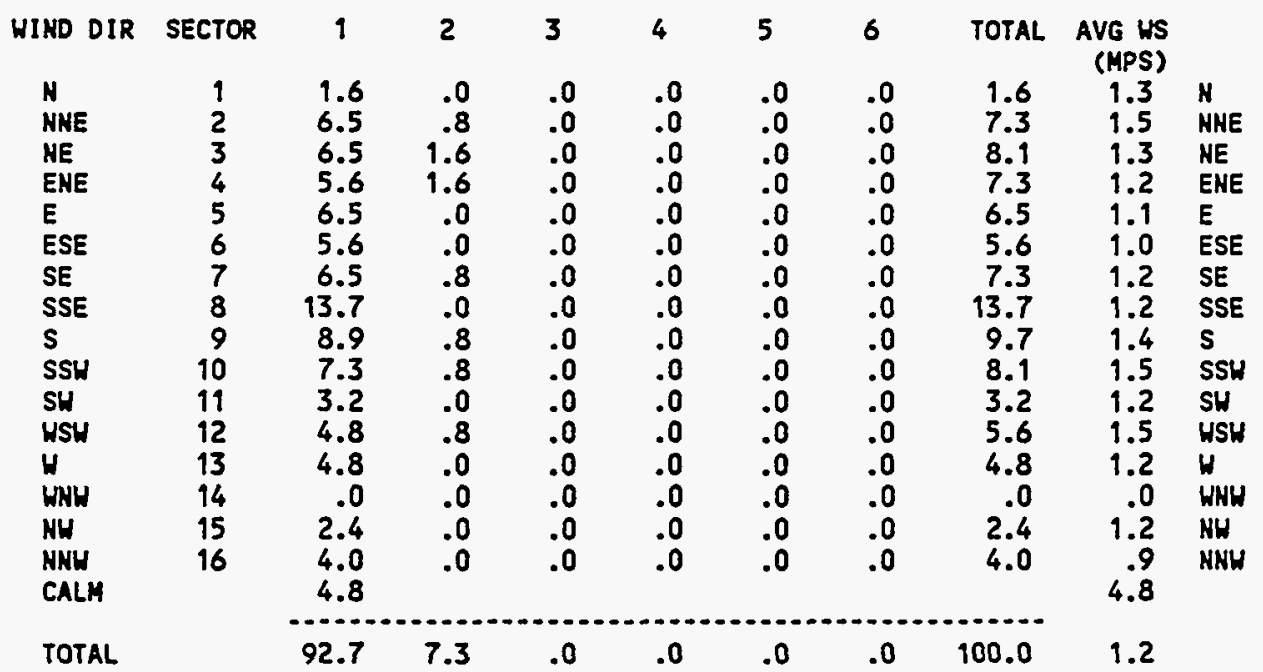

100.0\% DATA RECOVERED

16.7\% OF RECOVERED DATA REPORTED ABOVE

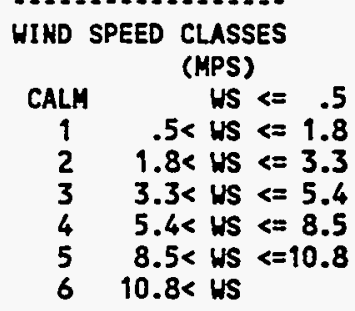


METEOROLOGICAL JOIHT FREQUENCY DISTRIBUTION (PERCENT OF VALID HOUR OBSERVATIONS)

SPILL TEST FACILITY 24 METER TOWER

2 METER HEIGHT - Total Hours

$11 / 1 / 1994-11 / 30 / 1994$

$0-2300$ (MST)

\section{STABILITY CLASS A}

$0.5-1.5$

HIND SPEEDCLASS

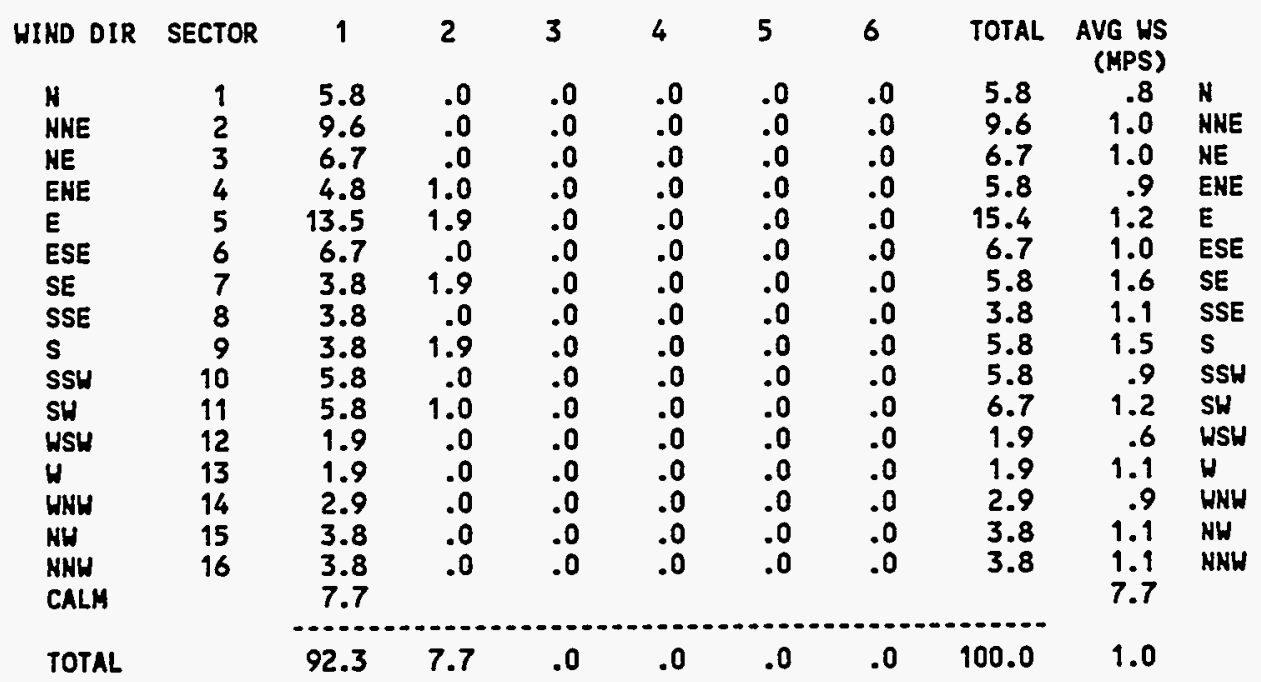

100.0\% DATA RECOVERED

14.4\% OF RECOVERED DATA REPORTED ABOVE

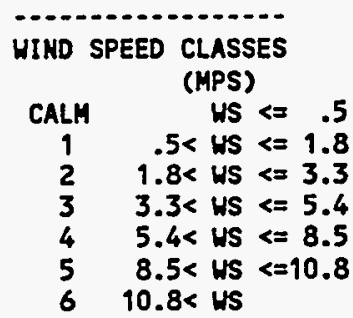




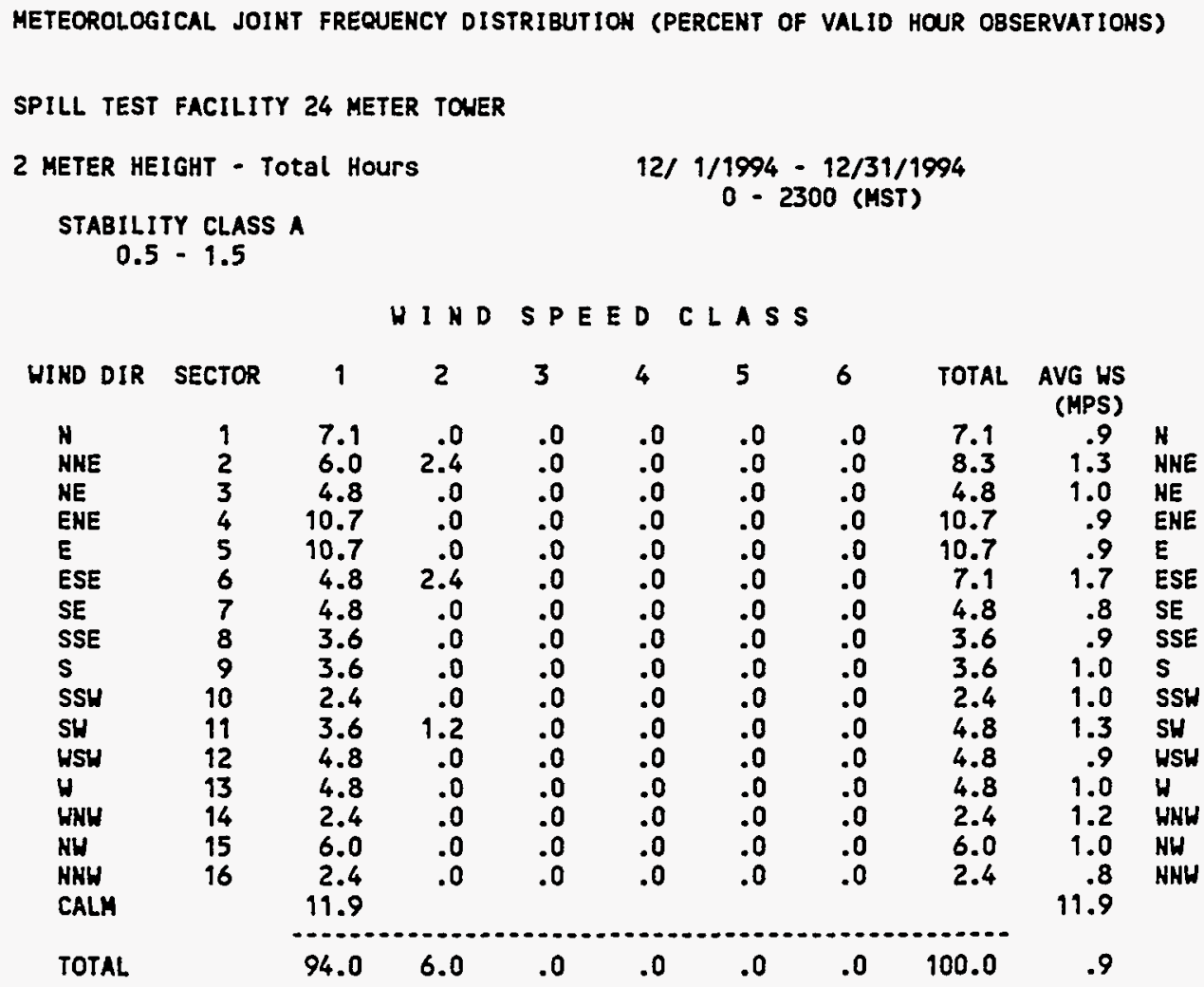
REPORTED ABOVE

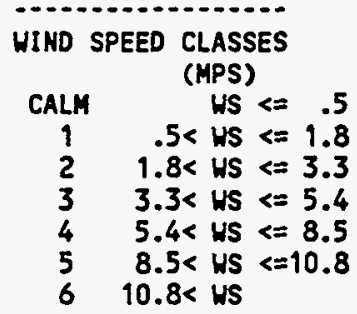


METEOROLOGICAL JOINT FREQUENCY DISTRIBUTION (PERCENT OF VALID HOUR OBSERVATIONS) SPILL TEST FACILITY 24 METER TONER

2 METER HEIGHT - Total Hours

$1 / 1 / 1994-1 / 31 / 1994$

STABILITY CLASS B

0. 2300 (MST)

$1.5 \cdot 2.5$

WIND SPEEDCLASS

\begin{tabular}{|c|c|c|c|c|c|c|c|c|c|c|}
\hline HIND DIR & SECTOR & 1 & 2 & 3 & 4 & 5 & 6 & TOTAL & $\begin{array}{l}\text { AVG US } \\
\text { (MPS) }\end{array}$ & \\
\hline H & 1 & .0 & .0 & .0 & .0 & .0 & .0 & .0 & .0 & N \\
\hline NHE & 2 & .0 & .0 & .0 & .0 & .0 & .0 & .0 & .0 & HKE \\
\hline NE & 3 & 5.7 & 5.7 & .0 & 2.9 & .0 & .0 & 14.3 & 2.5 & NE \\
\hline ENE & 4 & 8.6 & 2.9 & .0 & .0 & .0 & .0 & 11.4 & 1.1 & ENE \\
\hline$E$ & 5 & 5.7 & .0 & .0 & .0 & .0 & .0 & 5.7 & .9 & E \\
\hline ESE & 6 & 5.7 & .0 & .0 & .0 & .0 & .0 & 5.7 & .9 & ESE \\
\hline SE & 7 & 2.9 & .0 & .0 & .0 & .0 & .0 & 2.9 & 1.4 & SE \\
\hline SSE & 8 & 8.6 & .0 & .0 & .0 & .0 & .0 & 8.6 & .9 & SSE \\
\hline $\mathbf{S}$ & 9 & 11.4 & 2.9 & 2.9 & .0 & .0 & .0 & 17.1 & 1.6 & $\mathbf{s}$ \\
\hline SSH & 10 & .0 & .0 & .0 & .0 & .0 & .0 & .0 & .0 & SSH \\
\hline SH & 11 & 8.6 & .0 & 2.9 & .0 & .0 & .0 & 11.4 & 1.7 & SW \\
\hline USH & 12 & 2.9 & .0 & .0 & .0 & .0 & .0 & 2.9 & 1.1 & WSH \\
\hline$H$ & 13 & 2.9 & 2.9 & .0 & .0 & .0 & .0 & 5.7 & 2.1 & $\mathbf{H}$ \\
\hline WHH & 14 & 2.9 & .0 & .0 & .0 & .0 & .0 & 2.9 & .8 & WNH \\
\hline NW & 15 & 2.9 & .0 & .0 & .0 & .0 & .0 & 2.9 & 1.0 & NH \\
\hline NKW & 16 & .0 & .0 & .0 & .0 & .0 & .0 & .0 & .0 & NHW \\
\hline ONL & & $\ldots$ & & & & & & & & \\
\hline TOTAL & & 77.1 & 14.3 & 5.7 & 2.9 & .0 & .0 & 100.0 & 1.4 & \\
\hline
\end{tabular}

78.0\% DATA RECOVERED

6.0\% OF RECOVERED DATA

REPORTED ABOVE

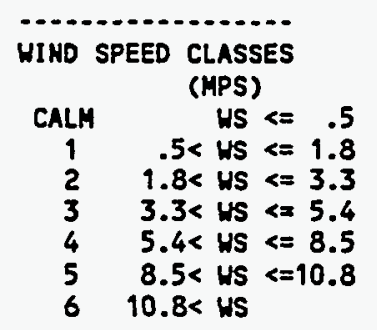


METEOROLOGICAL JOINT FREQUENCY DISTRIBUTION (PERCENT OF VALID HOUR OBSERVATIONS)

SPILL TEST FACILITY 24 METER TOWER

2 METER HEIGHT - Total Hours

$2 / 1 / 1994 \cdot 2 / 28 / 1994$

STABILITY CLASS B

$0-2300$ (MST)

$1.5 \cdot 2.5$

WINDSPEEDCLASS

\begin{tabular}{|c|c|c|c|c|c|c|c|c|c|c|}
\hline WIND OIR & SECTOR & 1 & 2 & 3 & 4 & 5 & 6 & TOTAL & AVG WS & \\
\hline H & 1 & .0 & .0 & 3.4 & 3.4 & .0 & .0 & 6.9 & 6.3 & $N$ \\
\hline NME & 2 & .0 & .0 & 3.4 & .0 & .0 & .0 & 3.4 & 3.4 & HAE \\
\hline ME & 3 & 6.9 & .0 & .0 & .0 & .0 & .0 & 6.9 & 1.0 & NE \\
\hline ENE & 4 & 6.9 & .0 & .0 & .0 & .0 & .0 & 6.9 & .9 & ENE \\
\hline E & 5 & .0 & .0 & .0 & .0 & .0 & .0 & .0 & .0 & E \\
\hline ESE & 6 & 3.4 & 3.4 & .0 & .0 & .0 & .0 & 6.9 & 1.4 & ESE \\
\hline SE & 7 & .0 & .0 & 3.4 & .0 & .0 & .0 & 3.4 & 3.4 & SE \\
\hline SSE & 8 & .0 & 3.4 & .0 & .0 & .0 & .0 & 3.4 & 1.8 & SSE \\
\hline$s$ & 9 & .0 & .0 & .0 & .0 & .0 & .0 & .0 & .0 & $\mathbf{s}$ \\
\hline SSH & 10 & 6.9 & 3.4 & 3.4 & .0 & .0 & .0 & 13.8 & 2.0 & SSW \\
\hline SH & 11 & 13.8 & 3.4 & 3.4 & .0 & .0 & .0 & 20.7 & 1.8 & SH \\
\hline WSH & 12 & 10.3 & .0 & .0 & .0 & .0 & .0 & 10.3 & 1.0 & WSH \\
\hline H & 13 & .0 & .0 & .0 & .0 & .0 & .0 & .0 & .0 & W \\
\hline WNW & 14 & 3.4 & .0 & .0 & 3.4 & .0 & .0 & 6.9 & 3.3 & WHU \\
\hline NH & 15 & 3.4 & .0 & .0 & 3.4 & .0 & .0 & 6.9 & 4.4 & NH \\
\hline NNW & 16 & .0 & .0 & 3.4 & .0 & .0 & .0 & 3.4 & 3.6 & NNW \\
\hline CALM & & .0 & & & & & & & .0 & \\
\hline TOTAL & & 55.2 & 13.8 & 20.7 & 10.3 & .0 & .0 & 100.0 & 2.4 & \\
\hline
\end{tabular}

85.4\% DATA RECOVERED

5.1\% OF RECOVERED DATA REPORTED ABOVE

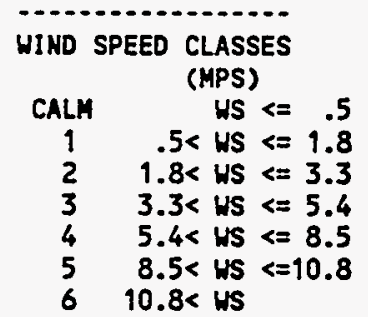


METEOROLOGICAL JOINT FREQUENCY DISTRIBUTION (PERCENT OF VALID HOUR OBSERVATIONS) SPILL TEST FACILITY 24 METER TONER

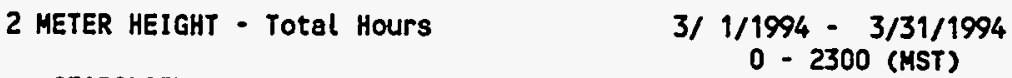

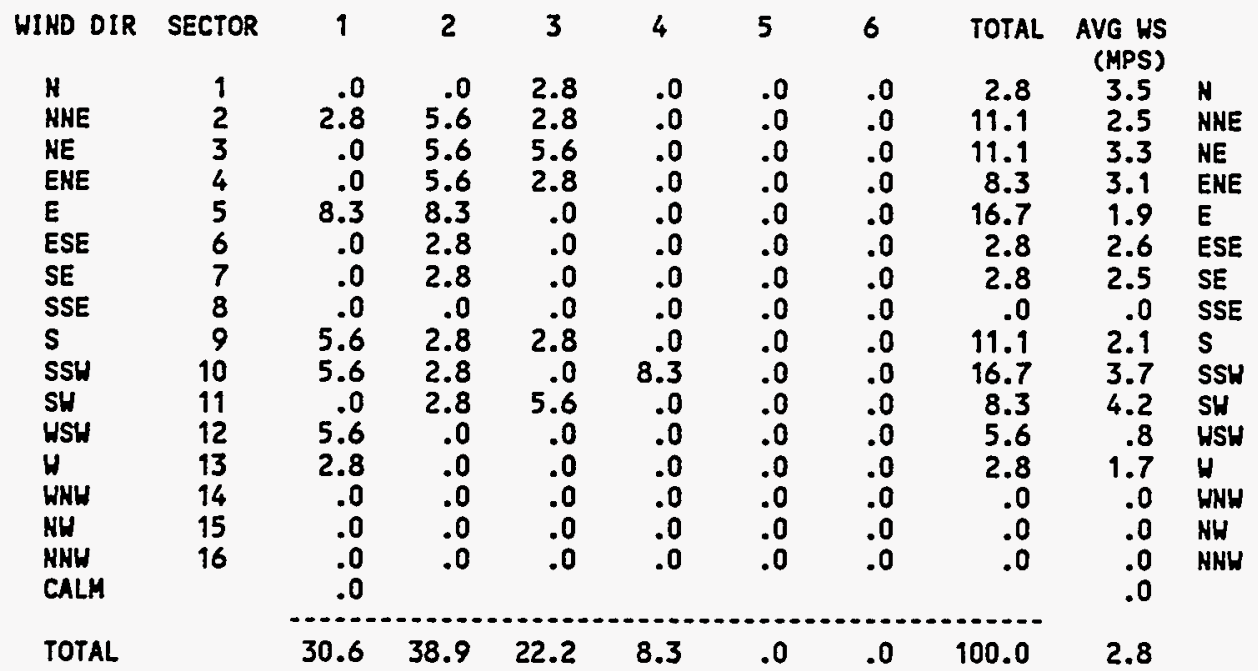
REPORTED ABOVE

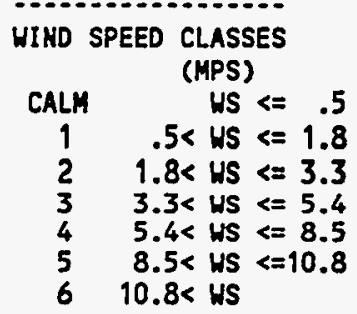


METEOROLOGICAL JOINT FREQUENCY DISTRIBUTION (PERCENT OF VALID HOUR OBSERVATIONS)

SPILL TEST FACILITY 24 METER TONER

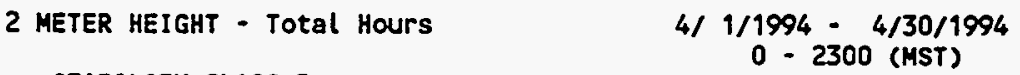

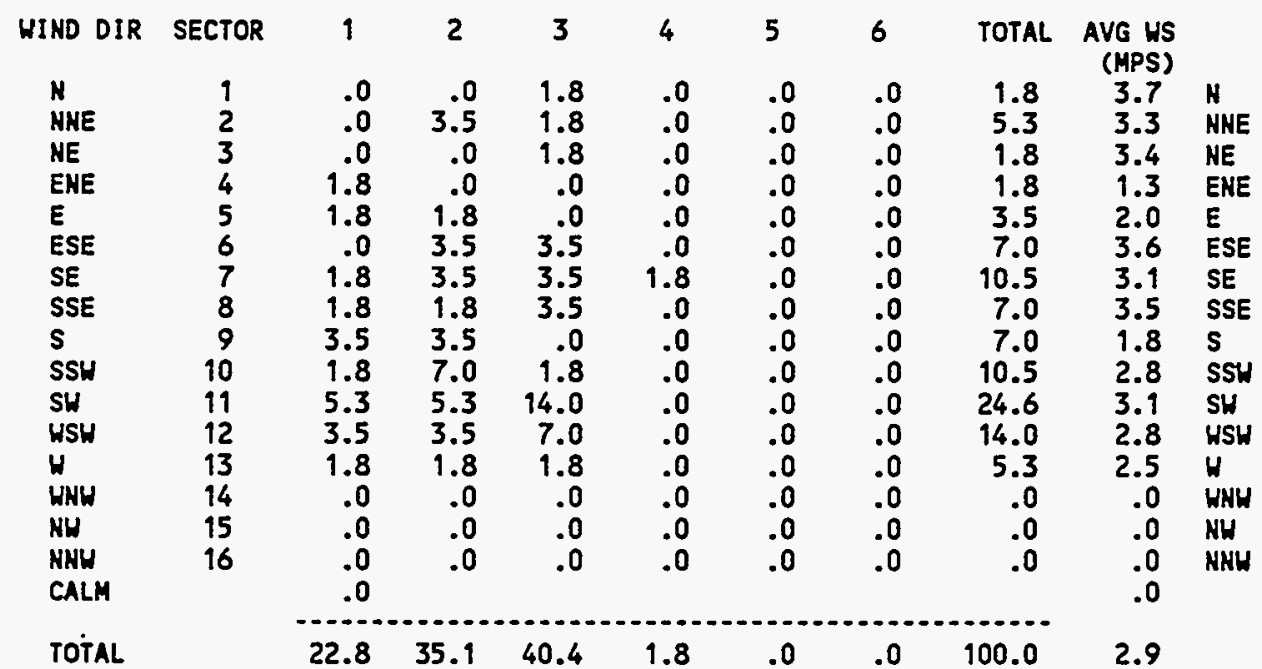

99.4\% DATA RECOVERED

8.0\% OF RECOVERED DATA REPORTED ABOVE

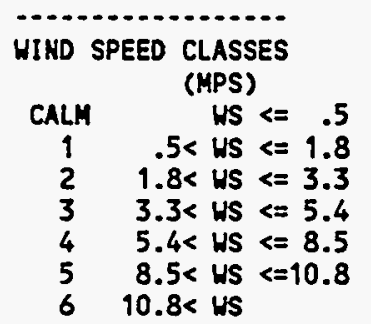


METEOROLOGICAL JOIHT FREQUENCY DISTRIBUTIOH (PERCENT OF VALID HOUR OBSERVATIONS) SPILL TEST FACILITY 24 METER TOWER
2 METER HEIGHT - Total HourS
5/ $1 / 1994-5 / 31 / 1994$
STABILITY CLASS B
0 - 2300 (MST)

$$
1.5 \cdot 2.5
$$

H I H D SPEED C L A S S

\begin{tabular}{|c|c|c|c|c|c|c|c|c|c|c|}
\hline WIND DIR & SECTOR & 1 & 2 & 3 & 4 & 5 & 6 & TOTAL & $\begin{array}{l}\text { AVG WS } \\
\text { (MPS) }\end{array}$ & \\
\hline H & 1 & .0 & 1.8 & .0 & .0 & .0 & .0 & 1.8 & 2.8 & \\
\hline HAE & 2 & 1.8 & .0 & .0 & .0 & .0 & .0 & 1.8 & 1.6 & NNE \\
\hline NE & 3 & .0 & 1.8 & .0 & .0 & .0 & .0 & 1.8 & 2.2 & NE \\
\hline ENE & 4 & 1.8 & .0 & .0 & .0 & .0 & .0 & 1.8 & .8 & ENE \\
\hline E & 5 & .0 & 1.8 & 1.8 & .0 & .0 & .0 & 3.5 & 4.0 & $\mathbf{E}$ \\
\hline ESE & 6 & 1.8 & .0 & .0 & .0 & .0 & .0 & 1.8 & 1.3 & ESE \\
\hline SE & 7 & .0 & 1.8 & .0 & .0 & .0 & .0 & 1.8 & 3.2 & SE \\
\hline SSE & 8 & .0 & 3.5 & 7.0 & .0 & .0 & .0 & 10.5 & 3.7 & SSE \\
\hline $\mathbf{s}$ & 9 & .0 & 1.8 & 5.3 & .0 & .0 & .0 & 7.0 & 3.7 & $\mathbf{s}$ \\
\hline SSH & 10 & .0 & 3.5 & 10.5 & 3.5 & .0 & .0 & 17.5 & 4.0 & SSH \\
\hline SH & 11 & 1.8 & 7.0 & 26.3 & .0 & .0 & .0 & 35.1 & 3.5 & SH \\
\hline USH & 12 & .0 & 3.5 & 7.0 & .0 & .0 & .0 & 10 & & WSW \\
\hline H & 13 & 1.8 & 1.8 & .0 & .0 & .0 & .0 & 3.5 & 1.7 & $\boldsymbol{W}$ \\
\hline WNW & 14 & .0 & .0 & .0 & .0 & .0 & .0 & .0 & .0 & HNH \\
\hline HW & 15 & .0 & .0 & .0 & .0 & .0 & .0 & .0 & .0 & NH \\
\hline NHW & 16 & 1.8 & .0 & .0 & .0 & .0 & .0 & 1.8 & 1.0 & NWH \\
\hline CALM & & & & & & & & & .0 & \\
\hline TAL & & 10.5 & 28.1 & 57.9 & 3.5 & .0 & .0 & 100.0 & 3.4 & \\
\hline
\end{tabular}

\section{9\% DATA RECOVERED \\ 7.9\% OF RECOVERED DATA REPORTED ABOVE}

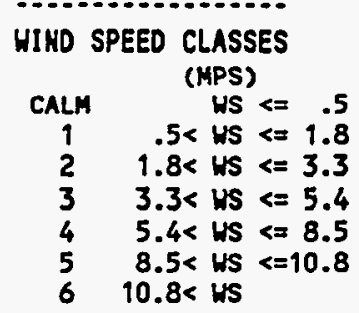


METEOROLOGICAL JOINT FREQUENCY DISTRIBUTION (PERCENT OF VALID HOUR OBSERVATIONS) SPILL TEST FACILITY 24 METER TOWER

2 METER HEIGHT - TOtal Hours

6/ $1 / 1994 \cdot 6 / 30 / 1994$

STABILITY CLASS B

$0 \cdot 2300$ (MST)

$1.5 \cdot 2.5$

HIND SPEEDCLASS

\begin{tabular}{|c|c|c|c|c|c|c|c|c|c|c|}
\hline HIND DIR & SECTOR & 1 & 2 & 3 & 4 & 5 & 6 & TOTAL & AVG US & \\
\hline$N$ & 1 & .0 & .0 & .0 & .0 & .0 & .0 & .0 & .0 & N \\
\hline NNE & 2 & .0 & .0 & .0 & .0 & .0 & .0 & .0 & .0 & NNE \\
\hline NE & 3 & 11.9 & .0 & .0 & .0 & .0 & .0 & 11.9 & .9 & NE \\
\hline ENE & 4 & 4.8 & .0 & .0 & .0 & .0 & .0 & 4.8 & .9 & ENE \\
\hline$E$ & 5 & 2.4 & 2.4 & .0 & .0 & .0 & .0 & 4.8 & 2.2 & $E$ \\
\hline ESE & 6 & .0 & 2.4 & .0 & .0 & .0 & .0 & 2.4 & 2.9 & ESE \\
\hline SE & 7 & .0 & 2.4 & .0 & .0 & .0 & .0 & 2.4 & 2.4 & SE \\
\hline SSE & 8 & .0 & 2.4 & 2.4 & .0 & .0 & .0 & 4.8 & 3.2 & SSE \\
\hline$s$ & 9 & 2.4 & 4.8 & 2.4 & .0 & .0 & .0 & 9.5 & 2.6 & 5 \\
\hline SSH & 10 & .0 & .0 & 16.7 & 2.4 & .0 & .0 & 19.0 & 4.3 & SSH \\
\hline SU & 11 & 2.4 & 2.4 & 14.3 & 4.8 & .0 & .0 & 23.8 & 3.9 & SH \\
\hline USW & 12 & 2.4 & 2.4 & 7.1 & .0 & .0 & .0 & 11.9 & 3.2 & WSW \\
\hline U & 13 & .0 & .0 & .0 & .0 & .0 & .0 & .0 & .0 & $H$ \\
\hline WNW & 14 & .0 & .0 & .0 & .0 & .0 & .0 & .0 & $\therefore 0$ & WNH \\
\hline NW & 15 & .0 & 2.4 & .0 & .0 & .0 & .0 & 2.4 & 2.9 & NW \\
\hline $\begin{array}{l}\text { NNW } \\
\text { CALM }\end{array}$ & 16 & $\begin{array}{r}2.4 \\
.0\end{array}$ & .0 & .0 & .0 & .0 & .0 & 2.4 & $\begin{array}{r}1.0 \\
0\end{array}$ & NNW \\
\hline TOTAL & & 28.6 & 21.4 & 42.9 & 7.1 & .0 & .0 & 100.0 & 3.0 & \\
\hline
\end{tabular}

100.0\% DATA RECOVERED

5.8\% OF RECOVERED DATA REPORTED ABOVE

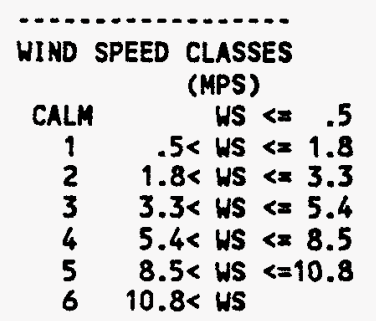


METEOROLOGICAL JOINT FREQUENCY OISTRIBUTIOH (PERCENT OF VALID HOUR OBSERVATIONS)

SPILL TEST FACILITY 24 METER TONER

2 METER HEIGHT - Total Hours

$7 / 1 / 1994 \cdot 7 / 31 / 1994$

STABILITY CLASS B

$0 \cdot 2300$ (MST)

$1.5 \cdot 2.5$

\section{HIND SPEEDCLASS}

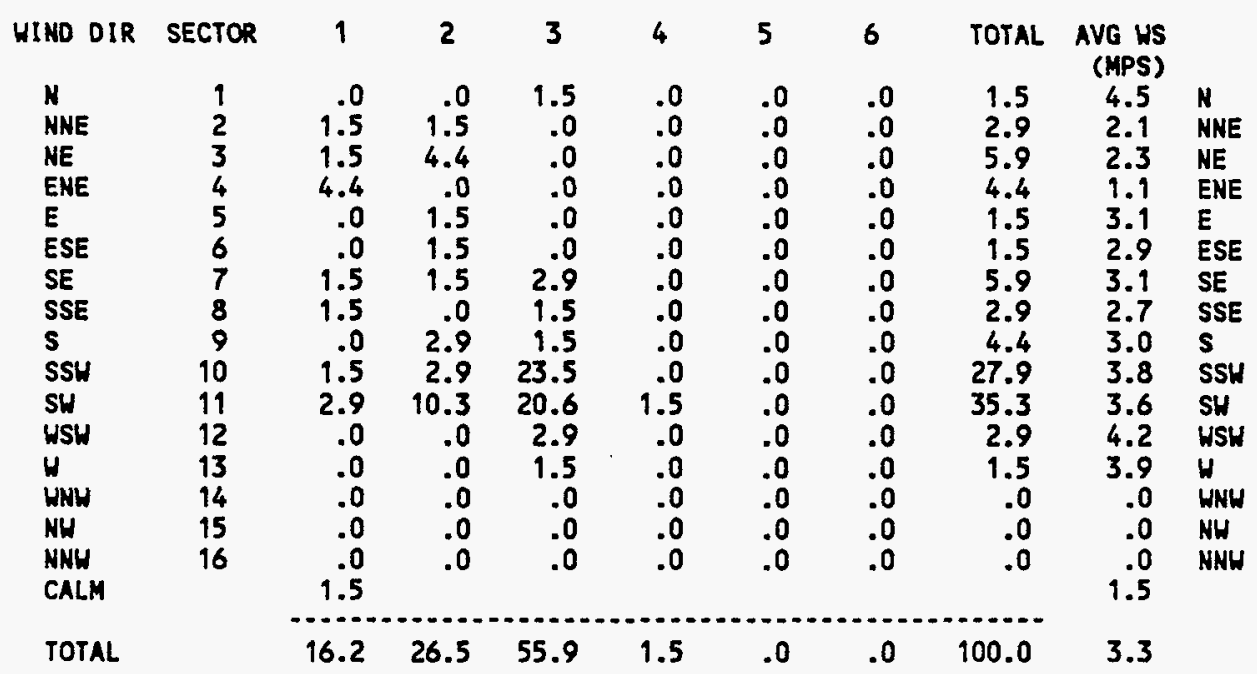

100.0\% DATA RECOVERED

9.1\% OF RECOVERED DATA REPORTED ABOVE

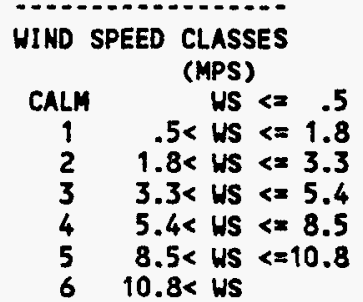


METEOROLOGICAL JOINT FREQUEMCY DISTRIBUTION (PERCENT OF VALID HOUR OBSERVATIONS)

SPILL TEST FACILITY 24 METER TONER
2 METER HEIGHT - Total Hours
$8 / 1 / 1994-8 / 31 / 1994$
$0=2300$ (MST)

STABILITY CLASS B

$1.5-2.5$

UIND SPEEDCLASS

\begin{tabular}{|c|c|c|c|c|c|c|c|c|c|c|}
\hline WIND DIR & SECTOR & 1 & 2 & 3 & 4 & 5 & 6 & TOTAL & $\begin{array}{l}\text { AVG US } \\
\text { (MPS) }\end{array}$ & \\
\hline $\mathrm{N}$ & 1 & .0 & .0 & .0 & .0 & .0 & .0 & .0 & .0 & $\mathbf{N}$ \\
\hline NME & 2 & .0 & .0 & .0 & .0 & .0 & .0 & .0 & .0 & NME \\
\hline NE & 3 & 4.9 & .0 & .0 & .0 & .0 & .0 & 4.9 & 1.2 & NE \\
\hline ENE & 4 & 3.3 & .0 & .0 & .0 & .0 & .0 & 3.3 & .9 & ENE \\
\hline E & 5 & 1.6 & .0 & .0 & .0 & .0 & .0 & 1.6 & .7 & E \\
\hline ESE & 6 & 1.6 & 1.6 & .0 & .0 & .0 & .0 & 3.3 & 1.9 & ESE \\
\hline SE & 7 & .0 & 1.6 & 4.9 & .0 & .0 & .0 & 6.6 & 3.3 & SE \\
\hline SSE & 8 & .0 & 1.6 & 1.6 & .0 & .0 & .0 & 3.3 & 3.9 & SSE \\
\hline $\mathbf{S}$ & 9 & .0 & 4.9 & 3.3 & .0 & .0 & .0 & 8.2 & 3.2 & $\mathbf{s}$ \\
\hline SSW & 10 & 1.6 & 9.8 & 8.2 & 1.6 & .0 & .0 & 21.3 & 3.6 & SSH \\
\hline SH & 11 & 1.6 & 4.9 & 29.5 & .0 & .0 & .0 & 36.1 & 3.9 & SH \\
\hline WSH & 12 & 1.6 & .0 & 6.6 & .0 & .0 & .0 & 8.2 & 3.6 & HSH \\
\hline $\mathbf{H}$ & 13 & .0 & .0 & .0 & .0 & .0 & .0 & .0 & .0 & $\mathbf{W}$ \\
\hline WNH & 14 & .0 & .0 & .0 & .0 & .0 & .0 & .0 & .0 & WNH \\
\hline NH & 15 & .0 & .0 & .0 & .0 & .0 & .0 & .0 & .0 & NW \\
\hline NNW & 16 & 1.6 & .0 & 1.6 & .0 & .0 & .0 & 3.3 & 2.3 & NNH \\
\hline CALLA & & & & & & & & & & \\
\hline TOTAL & & 18.0 & 24.6 & 55.7 & 1.6 & .0 & .0 & 100.0 & 3.3 & \\
\hline
\end{tabular}

100. OX DATA RECOVERED

8.2\% OF RECOVERED DATA REPORTED ABOVE

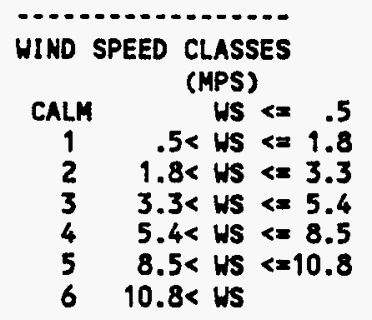


METEOROLOGICAL JOIHT FREQUENCY DISTRIBUTION (PERCENT OF VALID HOUR OBSERVATIONS)

SPILL TEST FACILITY 24 METER TOWER

2 METER HEIGHT - Total Hours

$9 / 1 / 1994-9 / 30 / 1994$

STABILITY CLASS B

0 - 2300 (MST)

$1.5 \cdot 2.5$

HINDSPEED CLASS

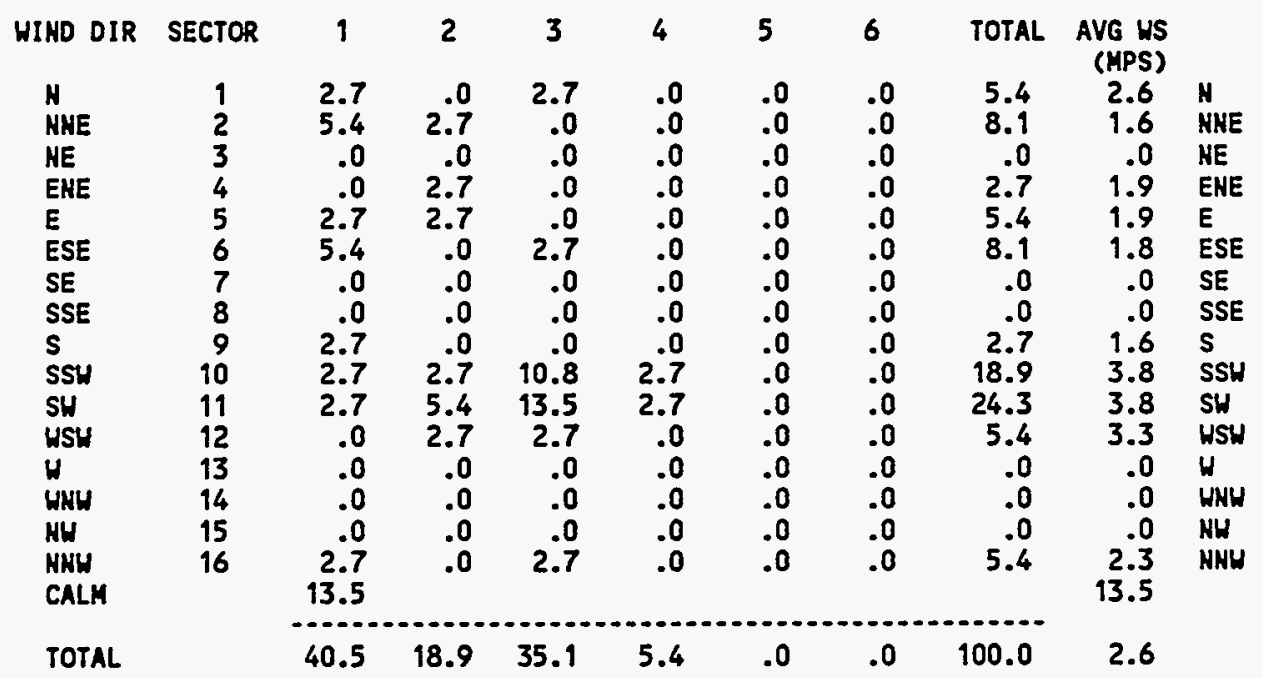

99.7X DATA RECOVERED

5.2X OF RECOVERED DATA

REPORTED ABOVE

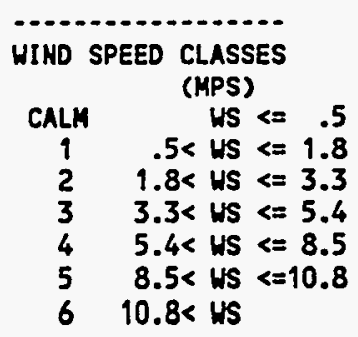


METEOROLOGICAL JOINT FREQUENCY DISTRIBUTION (PERCENT OF VALID HOUR OBSERVATIONS)

SPILL TEST FACILITY 24 METER TONER

2 METER HEIGHT - Total Hours

$10 / 1 / 9994-10 / 31 / 1994$

STABILITY CLASS B

0 - 2300 (MST)

$1.5-2.5$

HINDSPEEDCLASS

\begin{tabular}{|c|c|c|c|c|c|c|c|c|c|c|}
\hline HIND DIR & SECTOR & 1 & 2 & 3 & 4 & 5 & 6 & TOTAL & $\begin{array}{l}\text { AVG WS } \\
\text { (MPS) }\end{array}$ & \\
\hline N & 1 & 7.9 & .0 & 2.6 & .0 & .0 & .0 & 10.5 & 1.4 & N \\
\hline NNE & 2 & .0 & 13.2 & 2.6 & .0 & .0 & .0 & 15.8 & 3.1 & NHE \\
\hline NE & 3 & .0 & .0 & 2.6 & .0 & .0 & .0 & 2.6 & 3.4 & NE \\
\hline ENE & 4 & 2.6 & 5.3 & .0 & .0 & .0 & .0 & 7.9 & 2.1 & ENE \\
\hline$E$ & 5 & 7.9 & .0 & .0 & .0 & .0 & .0 & 7.9 & .8 & E \\
\hline ESE & 6 & .0 & .0 & .0 & .0 & .0 & .0 & .0 & .0 & ESE \\
\hline SE & 7 & 2.6 & 5.3 & .0 & .0 & .0 & .0 & 7.9 & 2.1 & SE \\
\hline SSE & 8 & .0 & .0 & .0 & .0 & .0 & .0 & .0 & .0 & SSE \\
\hline s & 9 & 2.6 & .0 & .0 & .0 & .0 & .0 & 2.6 & 1.0 & $\mathbf{s}$ \\
\hline SSW & 10 & 7.9 & 2.6 & 2.6 & 2.6 & .0 & .0 & 15.8 & 2.8 & SSH \\
\hline SW & 11 & .0 & 10.5 & .0 & .0 & .0 & .0 & 10.5 & 2.8 & SH \\
\hline WSW & 12 & .0 & 2.6 & 2.6 & .0 & .0 & .0 & 5.3 & 2.6 & HSW \\
\hline$H$ & 13 & 2.6 & .0 & .0 & .0 & .0 & .0 & 2.6 & 1.1 & $H$ \\
\hline WNH & 14 & .0 & .0 & .0 & .0 & .0 & .0 & .0 & .0 & WHW \\
\hline NH & 15 & .0 & 2.6 & .0 & .0 & .0 & .0 & 2.6 & 1.9 & NH \\
\hline $\begin{array}{l}\text { NWH } \\
\text { CALH }\end{array}$ & 16 & $\begin{array}{l}2.6 \\
5.3\end{array}$ & .0 & .0 & .0 & .0 & .0 & 2.6 & $\begin{array}{r}.6 \\
5.3\end{array}$ & NNH \\
\hline & & & & & & & & & & \\
\hline TOTAL & & 42.1 & 42.1 & 13.2 & 2.6 & .0 & .0 & 100.0 & 2.1 & \\
\hline
\end{tabular}

100.0\% DATA RECOVERED

5.1\% OF RECOVERED DATA REPORTED ABOVE

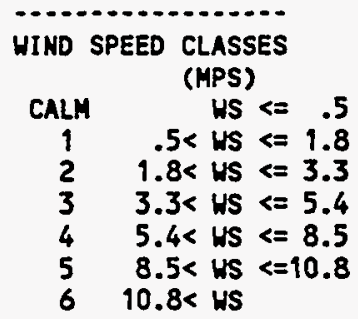


METEOROLOGICAL JOIHT FREQUENCY DISTRIBUTION (PERCENT OF VALID HOUR OSSERVATIONS) SPILL TEST FACILITY 24 METER TOWER

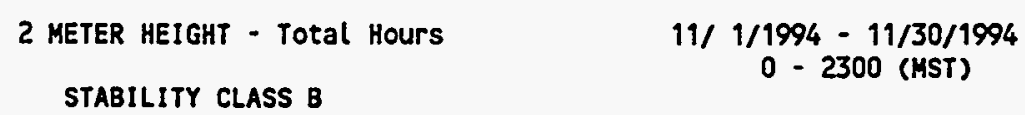

HINDSPEEDCLASS

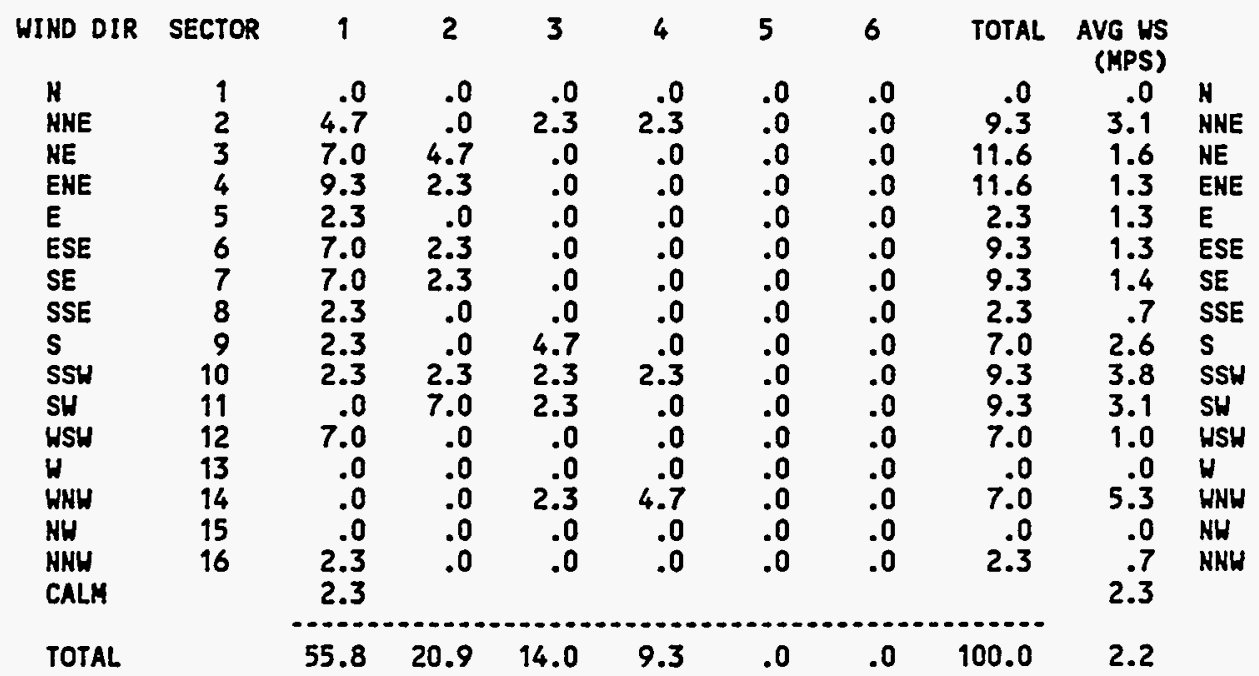

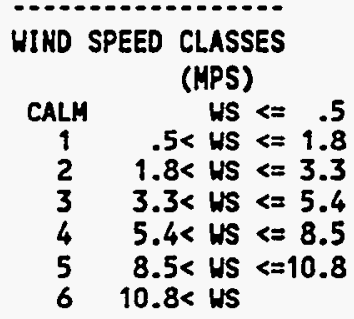


METEOROLOGICAL JOINT FREQUENCY DISTRIBUTION (PERCENT OF VALID HOUR OBSERVATIOHS)

SPILL TEST FACILITY 24 METER TOWER

2 METER HEIGHT - Total Hours

$12 / 1 / 1994-12 / 31 / 1994$

STABILITY CLASS B

0 - 2300 (MST)

$1.5-2.5$

HINDSPEEDCLASS

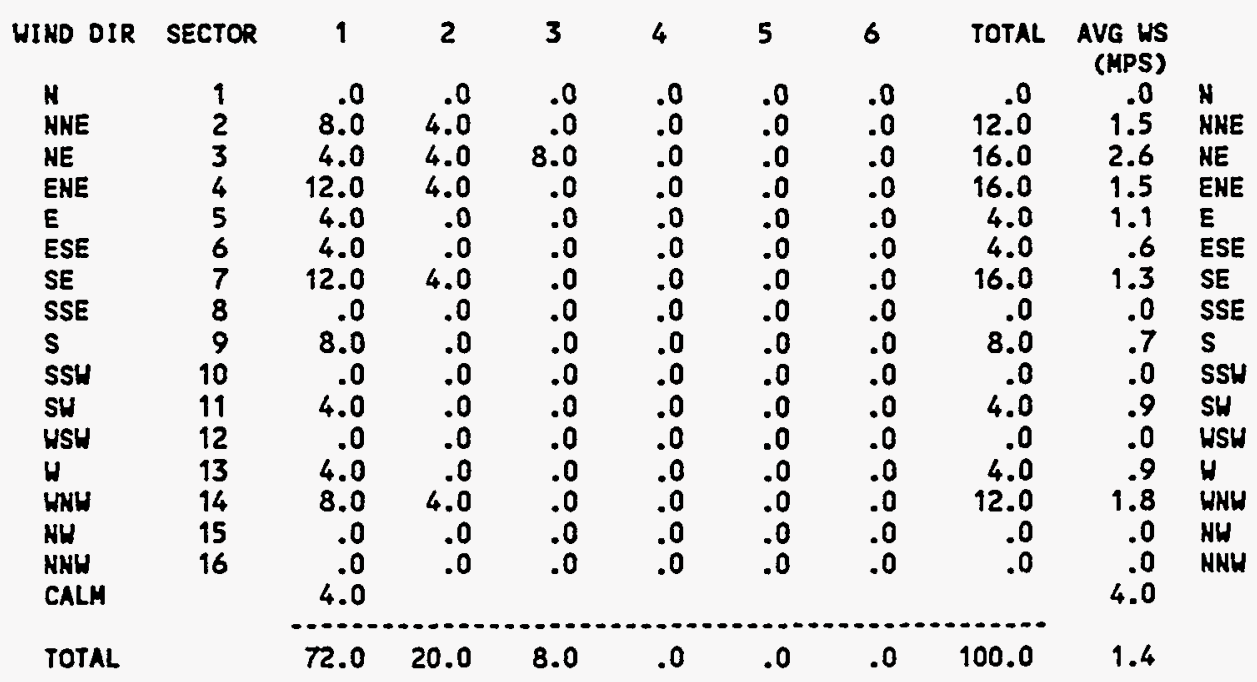

65.1\% DATA RECOVERED

5.2\% OF RECOVERED DATA REPORTED ABOVE

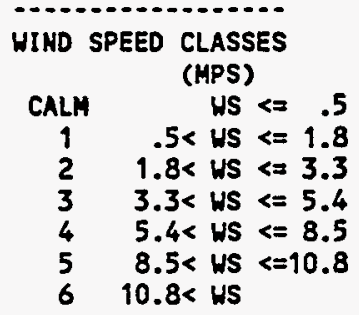


METEOROLOGICAL JOINT FREQUEMCY DISTRIBUTION (PERCENT OF VALID HOUR OBSERVATIONS)

SPILL TEST FACILITY 24 METER TOWER

2 METER HEIGHT - TOtal HourS

$1 / 1 / 1994 \cdot 1 / 31 / 1994$

STABILITY CLASS C

0 - 2300 (MST)

$2.5 \cdot 3.5$

HI HD SPEEDCLASS

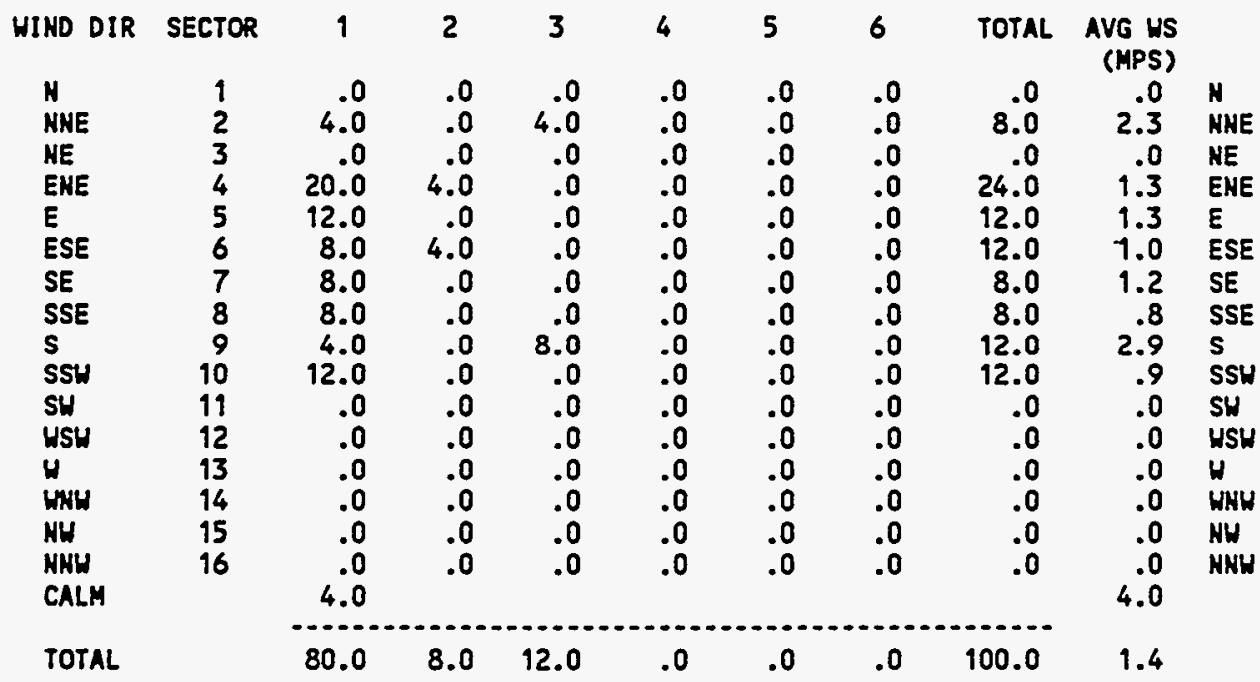

78.0\% DATA RECOVERED

4.3\% OF RECOVERED DATA REPORTED ABOVE

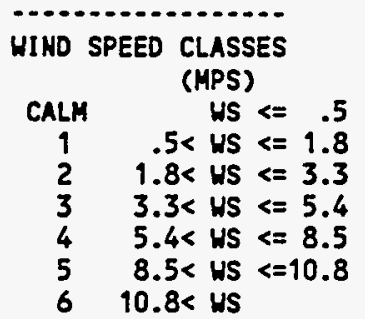


METEOROLOGICAL JOINT FREQUENCY DISTRIBUTION (PERCENT OF VALIO HOUR OBSERVATIONS)

SPILL TEST FACILITY 24 METER TOWER

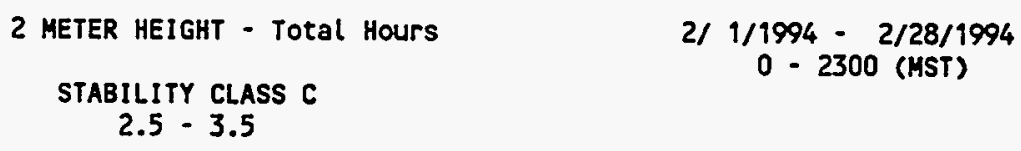

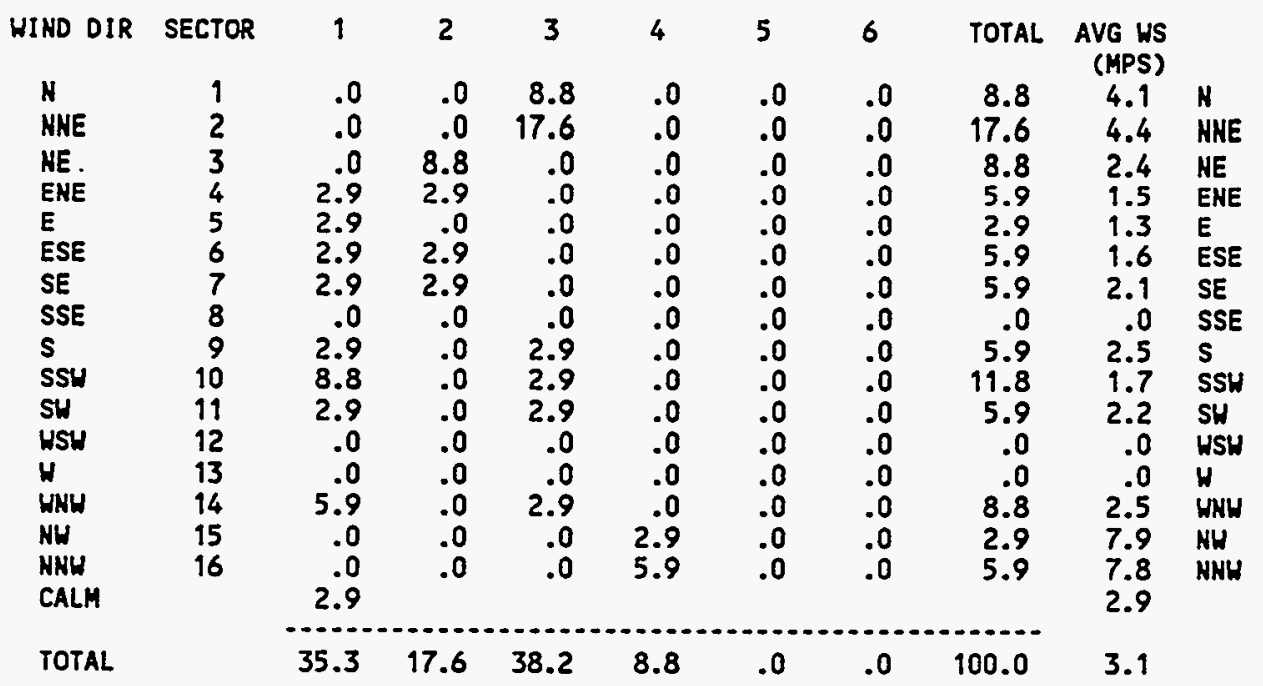

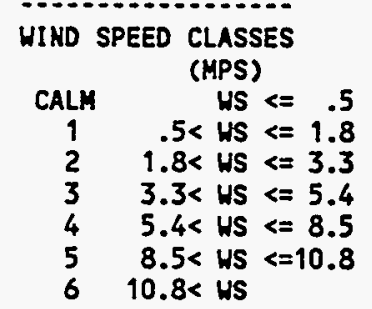


METEOROLOGICAL JOINT FREQUENCY DISTRIBUTIOH (PERCENT OF VALID HOUR OBSERVATIONS) SPILL TEST FACILITY 24 METER TOWER

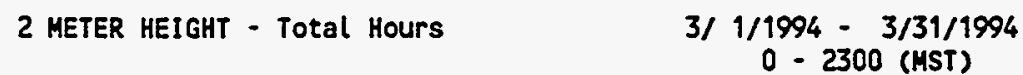

\begin{tabular}{|c|c|c|c|c|c|c|c|c|c|c|}
\hline HIND DIR & SECTOR & 1 & 2 & 3 & 4 & 5 & 6 & TOTAL & AVG WS & \\
\hline H & 1 & .0 & .0 & 4.3 & .0 & .0 & .0 & 4.3 & 5.3 & H \\
\hline NNE & 2 & .0 & .0 & 8.7 & 4.3 & .0 & .0 & 13.0 & 5.4 & NNE \\
\hline NE & 3 & .0 & 4.3 & 13.0 & .0 & .0 & .0 & 17.4 & 3.4 & NE \\
\hline ENE & 4 & .0 & 4.3 & 8.7 & .0 & .0 & .0 & 13.0 & 3.6 & ENE \\
\hline E & 5 & .0 & .0 & 8.7 & .0 & .0 & .0 & 8.7 & 3.7 & $\mathbf{E}$ \\
\hline ESE & 6 & .0 & .0 & .0 & .0 & .0 & .0 & .0 & .0 & ESE \\
\hline SE & 7 & 13.0 & .0 & .0 & .0 & .0 & .0 & 13.0 & 1.4 & SE \\
\hline SSE & 8 & .0 & .0 & .0 & .0 & .0 & .0 & .0 & .0 & SSE \\
\hline $\mathbf{s}$ & 9 & .0 & 4.3 & .0 & .0 & .0 & .0 & 4.3 & 2.4 & $\mathbf{s}$ \\
\hline SSH & 10 & 4.3 & .0 & .0 & .0 & .0 & .0 & 4.3 & .8 & SSW \\
\hline SH & 11 & .0 & .0 & 21.7 & .0 & .0 & .0 & 21.7 & 4.4 & SH \\
\hline USW & 12 & .0 & .0 & .0 & .0 & .0 & .0 & .0 & .0 & WSW \\
\hline 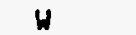 & 13 & .0 & .0 & .0 & .0 & .0 & .0 & .0 & .0 & $H$ \\
\hline WNH & 14 & .0 & .0 & .0 & .0 & .0 & .0 & .0 & .0 & HNH \\
\hline NH & 15 & .0 & .0 & .0 & .0 & .0 & .0 & .0 & .0 & NH \\
\hline NWW & 16 & .0 & .0 & .0 & .0 & .0 & .0 & .0 & .0 & NNW \\
\hline CALM & & 0 & & & & & & & .0 & \\
\hline
\end{tabular}

TOTAL

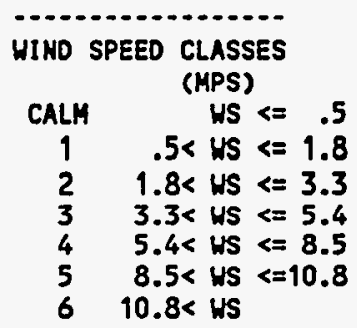


METEOROLOGICAL JOINT FREQUENCY DISTRIBUTION (PERCENT OF VALID HOUR OBSERVATIONS) SPILL TEST FACILITY 24 METER TOWER

2 METER HEIGHT - Total Hours $4 / 1 / 1994-4 / 30 / 1994$

STABILITY CLASS C

0 - 2300 (MST)

$2.5-3.5$

HIND SPEED CLASS

\begin{tabular}{|c|c|c|c|c|c|c|c|c|c|c|}
\hline HIND DIR & SECTOR & 1 & 2 & 3 & 4 & 5 & 6 & TOTAL & $\begin{array}{r}\text { AVG US } \\
\text { (MPS) }\end{array}$ & \\
\hline N & 1 & .0 & .0 & .0 & .0 & .0 & .0 & .0 & .0 & N \\
\hline NNE & 2 & .0 & .0 & 2.1 & .0 & .0 & .0 & 2.1 & 4.2 & NNE \\
\hline NE & 3 & .0 & .0 & 2.1 & .0 & .0 & .0 & 2.1 & 4.0 & NE \\
\hline ENE & 4 & .0 & .0 & .0 & .0 & .0 & .0 & .0 & .0 & ENE \\
\hline$E$ & 5 & 4.2 & .0 & 2.1 & .0 & .0 & .0 & 6.3 & 2.1 & $E$ \\
\hline ESE & 6 & .0 & .0 & .0 & .0 & .0 & .0 & .0 & .0 & ESE \\
\hline SE & 7 & 4.2 & 4.2 & .0 & .0 & .0 & .0 & 8.3 & 1.8 & SE \\
\hline SSE & 8 & .0 & .0 & .0 & .0 & .0 & .0 & .0 & .0 & SSE \\
\hline s & 9 & 2.1 & 2.1 & 8.3 & 2.1 & .0 & .0 & 14.6 & 3.5 & $\mathbf{s}$ \\
\hline SSW & 10 & .0 & .0 & 12.5 & .0 & .0 & .0 & 12.5 & 3.9 & SSH \\
\hline SW & 11 & 4.2 & 4.2 & 22.9 & 6.3 & .0 & .0 & 37.5 & 3.9 & SH \\
\hline USW & 12 & .0 & 2.1 & 4.2 & 2.1 & .0 & .0 & 8.3 & 4.4 & HSH \\
\hline H & 13 & .0 & .0 & 4.2 & 2.1 & .0 & .0 & 6.3 & 4.7 & $H$ \\
\hline WNH & 14 & .0 & .0 & .0 & 2.1 & .0 & .0 & 2.1 & 6.7 & WNH \\
\hline NW & 15 & .0 & .0 & .0 & .0 & .0 & .0 & .0 & .0 & NH \\
\hline $\begin{array}{l}\text { NHH } \\
\text { CALM }\end{array}$ & 16 & .0 & .0 & .0 & .0 & .0 & .0 & .0 & $\begin{array}{l}.0 \\
.0\end{array}$ & NHH \\
\hline TOTAL & & 14.6 & 12.5 & 58.3 & 14.6 & .0 & .0 & 100.0 & 3.7 & \\
\hline
\end{tabular}

99.4\% DATA RECOVERED

$6.7 \%$ OF RECOVERED DATA REPORTED ABOVE

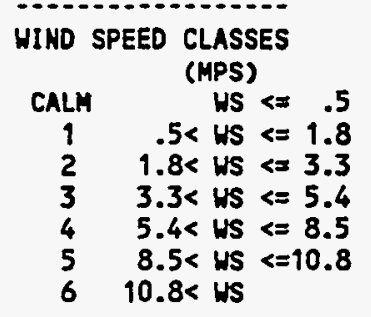


METEOROLOGICAL JOINT FREQUENCY OISTRIBUTION (PERCEHT OF VALID HOUR OBSERVATIONS) SPILL TEST FACILITY 24 METER TONER

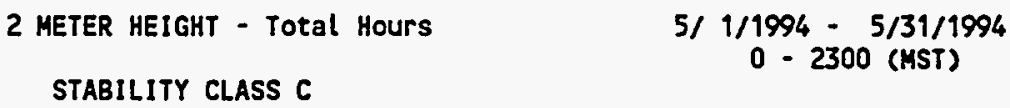

\begin{tabular}{|c|c|c|c|c|c|c|c|c|c|c|}
\hline WIHD DIR & SECTOR & 1 & 2 & 3 & 4 & 5 & 6 & TOTAL & $\begin{array}{r}\text { AVG WS } \\
\text { (MPS) }\end{array}$ & \\
\hline $\mathbf{N}$ & 1 & .0 & .0 & 7.7 & .0 & .0 & .0 & 7.7 & 4.1 & $N$ \\
\hline NHE & 2 & .0 & .0 & .0 & .0 & .0 & .0 & .0 & .0 & NNE \\
\hline NE & 3 & .0 & .0 & .0 & .0 & .0 & .0 & .0 & .0 & $\mathrm{HE}$ \\
\hline ENE & 4 & .0 & .0 & .0 & .0 & .0 & .0 & .0 & .0 & ENE \\
\hline$E$ & 5 & .0 & 2.6 & 5.1 & .0 & .0 & .0 & 7.7 & 3.5 & \\
\hline $\begin{array}{l}\text { ESE } \\
\text { SE }\end{array}$ & $\begin{array}{l}6 \\
7\end{array}$ & $\begin{array}{l}.0 \\
.0\end{array}$ & $\begin{array}{l}.0 \\
.0\end{array}$ & $\begin{array}{r}.0 \\
5.1\end{array}$ & $\begin{array}{l}.0 \\
.0\end{array}$ & $\begin{array}{l}.0 \\
.0\end{array}$ & $\begin{array}{l}.0 \\
.0\end{array}$ & $\begin{array}{r}.0 \\
5.1\end{array}$ & $\begin{array}{r}.0 \\
4.4\end{array}$ & $\begin{array}{l}\text { ESE } \\
\text { SE }\end{array}$ \\
\hline SSE & 8 & .0 & .0 & 7.7 & .0 & .0 & .0 & 7.7 & 4.2 & SSE \\
\hline s & 9 & 2.6 & .0 & 5.1 & .0 & .0 & .0 & $\begin{array}{r}7.7 \\
103\end{array}$ & 3.3 & \\
\hline SSH & 10 & $\begin{array}{l}5.1 \\
2.6\end{array}$ & .0 & 5.1 & $\div 0$ & .0 & $\begin{array}{l}0 \\
0\end{array}$ & 10.3 & 2.8 & $\begin{array}{l}\text { SSH } \\
\text { SH }\end{array}$ \\
\hline $\begin{array}{l}\text { SH } \\
\text { WSH }\end{array}$ & $\begin{array}{l}11 \\
12\end{array}$ & $\begin{array}{r}2.6 \\
.0\end{array}$ & $\begin{array}{l}.0 \\
.0\end{array}$ & $\begin{array}{r}25.6 \\
5.1\end{array}$ & $\begin{array}{l}5.1 \\
2.6\end{array}$ & .0 & $\begin{array}{l}.0 \\
.0\end{array}$ & $\begin{array}{r}33.3 \\
7.7\end{array}$ & $\begin{array}{l}4.4 \\
4.7\end{array}$ & $\begin{array}{l}\text { SW } \\
\text { WSH }\end{array}$ \\
\hline W & 13 & .0 & .0 & 2.6 & 2.6 & .0 & .0 & 5.1 & 5.0 & W \\
\hline WNH & 14 & .0 & .0 & .0 & .0 & .0 & .0 & .0 & 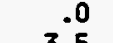 & HWH \\
\hline NH & $\begin{array}{l}15 \\
16\end{array}$ & $\begin{array}{l}.0 \\
.0\end{array}$ & $\begin{array}{r}2.6 \\
.0\end{array}$ & $\begin{array}{r}2.6 \\
.0\end{array}$ & 2.0 & .0 & $\begin{array}{l}.0 \\
.0\end{array}$ & $\begin{array}{l}5.1 \\
2.6\end{array}$ & $\begin{array}{l}3.5 \\
6.3\end{array}$ & $\begin{array}{l}\text { NH } \\
\text { NNH }\end{array}$ \\
\hline CALM & & .0 & .0 & & 2.0 & & .0 & & $\begin{array}{r}0.0 \\
.0\end{array}$ & NHT \\
\hline TOTAL & & 10.3 & 5.1 & 71.8 & 12.8 & .0 & .0 & 100.0 & 4.1 & \\
\hline
\end{tabular}
REPORTED ABOVE

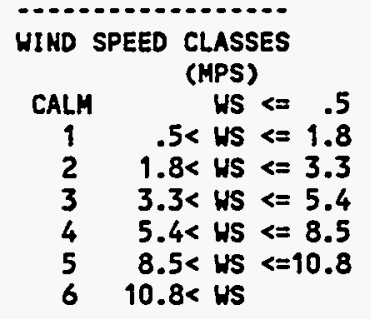


METEOROLOGICAL JOINT FREQUENCY DISTRIBUTION (PERCENT OF VALIO HOUR OBSERVATIONS) SPILL TEST FACILITY 24 METER TONER
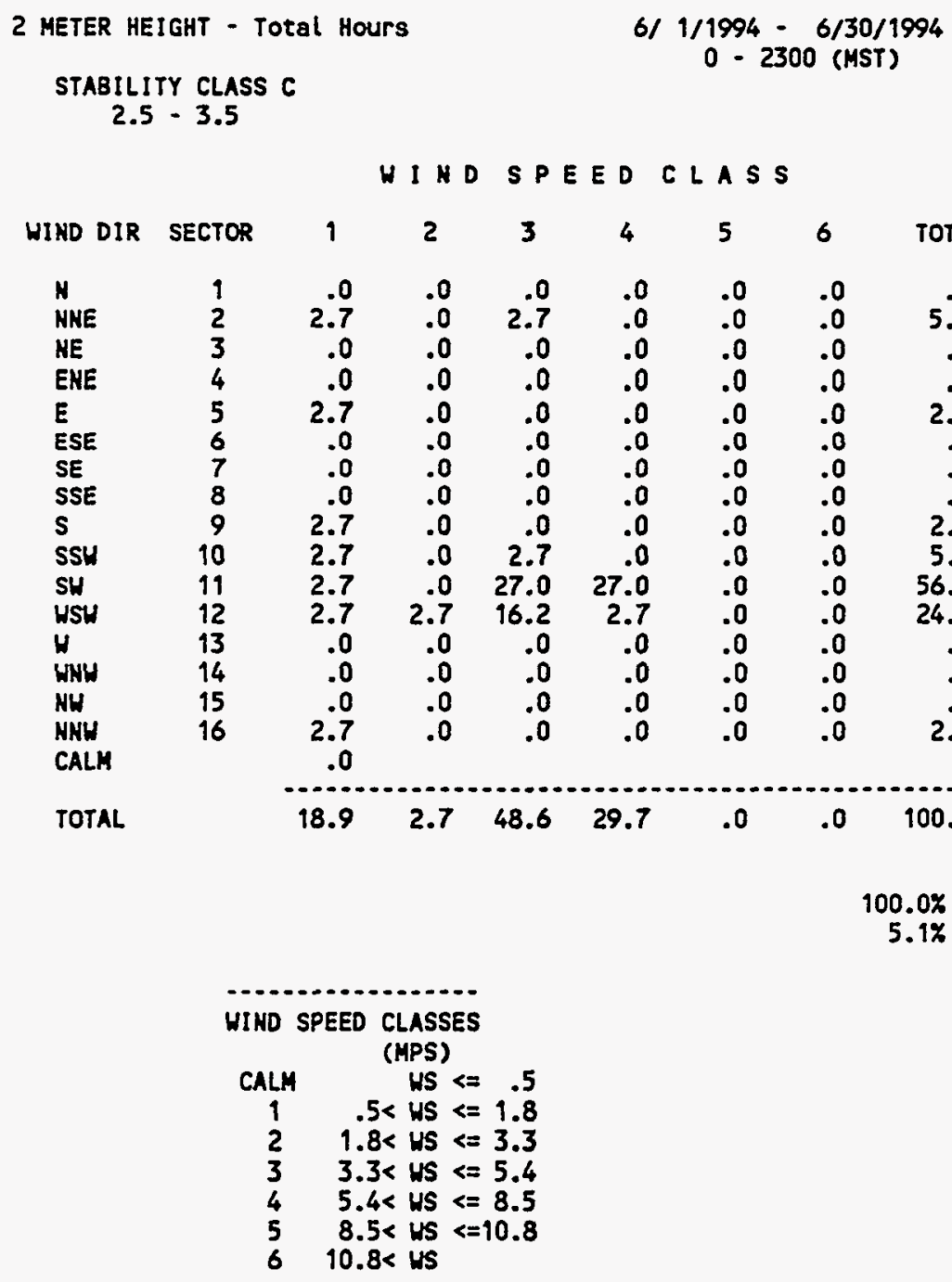
METEOROLOGICAL JOINT FREQUENCY DISTRIBUTIOH (PERCENT OF VALID HOUR OBSERVATIONS)

SPILL TEST FACILITY 24 METER TOWER

2 METER HEIGHT - TOtal hours

$7 / 1 / 1994-7 / 31 / 1994$

STABILITY CLASS C

0 - 2300 (MST)

$2.5-3.5$

HIND SPEEDCLASS

\begin{tabular}{|c|c|c|c|c|c|c|c|c|c|c|}
\hline HIKD DIR & SECTOR & 1 & 2 & 3 & 4 & 5 & 6 & TOTAL & $\begin{array}{c}\text { AVG US } \\
\text { (MPS) }\end{array}$ & \\
\hline H & 1 & .0 & .0 & .0 & .0 & .0 & .0 & .0 & .0 & H \\
\hline AHE & 2 & .0 & .0 & 5.4 & .0 & .0 & .0 & 5.4 & 4.7 & NNE \\
\hline ME & 3 & .0 & .0 & .0 & .0 & .0 & .0 & .0 & .0 & NE \\
\hline ENE & 4 & .0 & .0 & .0 & . & .0 & .0 & .0 & .0 & ENE \\
\hline$E$ & 5 & .0 & .0 & .0 & .0 & .0 & .0 & .0 & .0 & $E$ \\
\hline ESE & 6 & 2.7 & .0 & .0 & .0 & .0 & .0 & 2.7 & 1.0 & ESE \\
\hline $\mathrm{SE}$ & 7 & .0 & .0 & 2.7 & .0 & .0 & .0 & 2.7 & 3.9 & SE \\
\hline SSE & 8 & 2.7 & .0 & .0 & .0 & .0 & .0 & 2.7 & .9 & SSE \\
\hline S & 9 & .0 & .0 & .0 & .0 & .0 & .0 & .0 & .0 & s \\
\hline SSH & 10 & .0 & 2.7 & 16.2 & 8.1 & .0 & .0 & 27.0 & 4.9 & SSH \\
\hline SH & 11 & 2.7 & 2.7 & 37.8 & 13.5 & .0 & .0 & 56.8 & 4.8 & SH \\
\hline WSW & 12 & .0 & .0 & .0 & .0 & .0 & .0 & .0 & .0 & HSW \\
\hline H & 13 & .0 & .0 & .0 & .0 & .0 & .0 & .0 & .0 & $\boldsymbol{H}$ \\
\hline WNW & 14 & .0 & .0 & .0 & .0 & .0 & .0 & .0 & .0 & HNH \\
\hline $\mathrm{HH}$ & 15 & .0 & .0 & 2.7 & .0 & .0 & .0 & 2.7 & 4.0 & NH \\
\hline NHW & 16 & .0 & .0 & .0 & .0 & .0 & .0 & .0 & .0 & NWW \\
\hline ALM & & 0 & & & & & & & & \\
\hline AL & & 8.1 & 5.4 & 64.9 & 21.6 & .0 & .0 & 100.0 & 4.5 & \\
\hline
\end{tabular}

100.0X DATA RECOVERED

5.0\% OF RECOVERED DATA REPORTED ABOVE

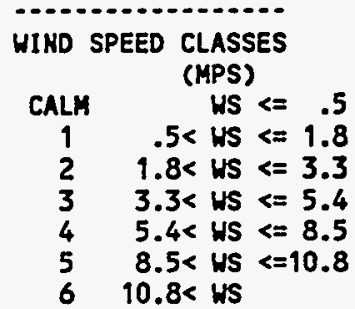


METEOROLOGICAL JOIHT FREQUENCY DISTRIBUTION (PERCENT OF VALID HOUR OBSERVATIOHS)

SPILL TEST FACILITY 24 METER TONER

$$
\begin{array}{cc}
2 \text { METER HEIGHT - Total Hours } & 8 / 1 / 1994-8 / 31 / 1994 \\
\text { STABILITY CLASS C } & 0-2300 \text { (MST) }
\end{array}
$$

$$
2.5-3.5
$$

WINDSPEED CLASS

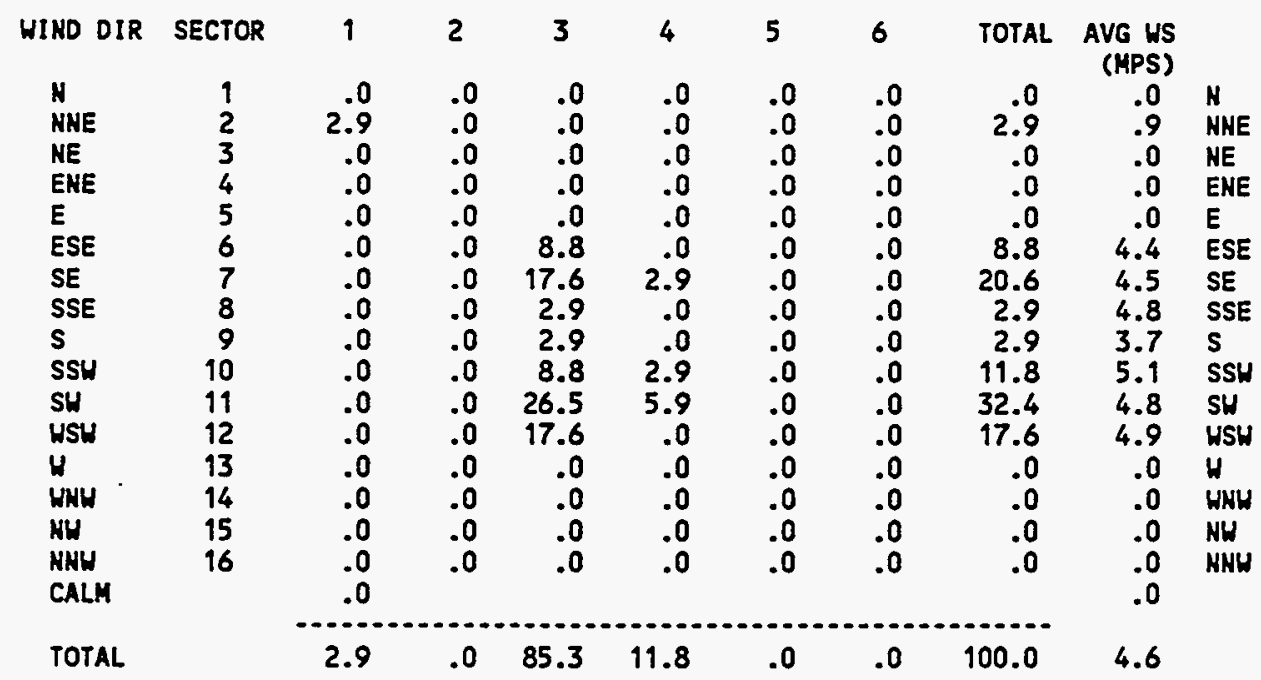

100.0\% DATA RECOVERED

4.6\% OF RECOVERED DATA REPORTED ABOVE

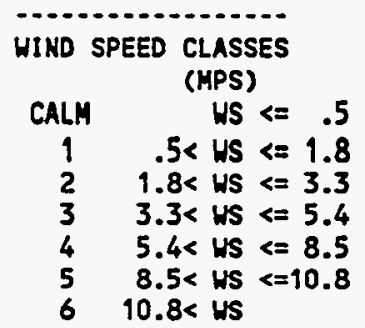


METEOROLOGICAL JOINT FREQUEKCY DISTRIBUTION (PERCENT OF VALID HOUR OBSERVATIONS) SPILL TEST FACILITY 24 METER TONER

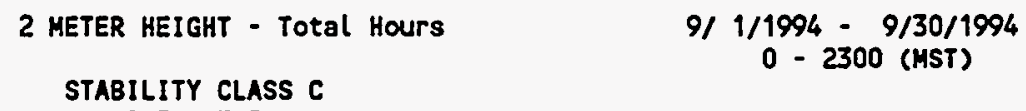

HIN D SPEED CLASS

\begin{tabular}{|c|c|c|c|c|c|c|c|c|c|c|}
\hline WIND DIR & SECTOR & 1 & 2 & 3 & 4 & 5 & 6 & TOTAL & AVG US & \\
\hline H & 1 & 2.3 & 2.3 & .0 & .0 & .0 & .0 & 4.7 & 1.4 & H \\
\hline MHE & 2 & 4.7 & .0 & 2.3 & .0 & .0 & .0 & 7.0 & 1.7 & NHE \\
\hline NE & 3 & 2.3 & .0 & .0 & .0 & .0 & .0 & 2.3 & 1.4 & NE \\
\hline ENE & 4 & .0 & .0 & .0 & .0 & .0 & .0 & .0 & .0 & ENE \\
\hline$E$ & 5 & 4.7 & 2.3 & .0 & .0 & .0 & .0 & 7.0 & 1.4 & $\mathbf{E}$ \\
\hline ESE & 6 & .0 & .0 & .0 & .0 & .0 & .0 & .0 & .0 & ESE \\
\hline SE & 7 & 2.3 & .0 & .0 & .0 & .0 & .0 & 2.3 & .7 & SE \\
\hline SSE & 8 & 2.3 & .0 & .0 & .0 & .0 & .0 & 2.3 & .6 & SSE \\
\hline $\mathbf{s}$ & 9 & .0 & .0 & .0 & .0 & .0 & .0 & .0 & .0 & $\mathbf{s}$ \\
\hline SSH & 10 & 2.3 & .0 & 9.3 & .0 & .0 & .0 & 11.6 & 3.9 & SSH \\
\hline su & 11 & 2.3 & .0 & 32.6 & 9.3 & .0 & .0 & 44.2 & 4.8 & SH \\
\hline WSH & 12 & 2.3 & .0 & 4.7 & .0 & .0 & .0 & 7.0 & 3.1 & USH \\
\hline$H$ & 13 & .0 & .0 & .0 & .0 & .0 & .0 & .0 & .0 & $H$ \\
\hline WNH & 14 & 2.3 & .0 & .0 & .0 & .0 & .0 & 2.3 & .6 & WNH \\
\hline MH & 15 & 2.3 & .0 & .0 & .0 & .0 & .0 & 2.3 & 1.1 & NH \\
\hline NHW & 16 & .0 & .0 & .0 & .0 & .0 & .0 & .0 & .0 & NNH \\
\hline & & & & & & & & & & \\
\hline TOTAL & & 37.2 & 4.7 & 48.8 & 9.3 & .0 & .0 & 100.0 & 3.2 & \\
\hline
\end{tabular}

99.7X DATA RECOVERED

6.0\% OF RECOVERED DATA REPORTED ABOVE

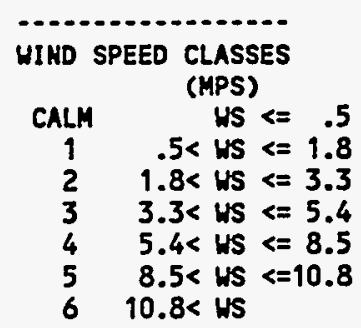




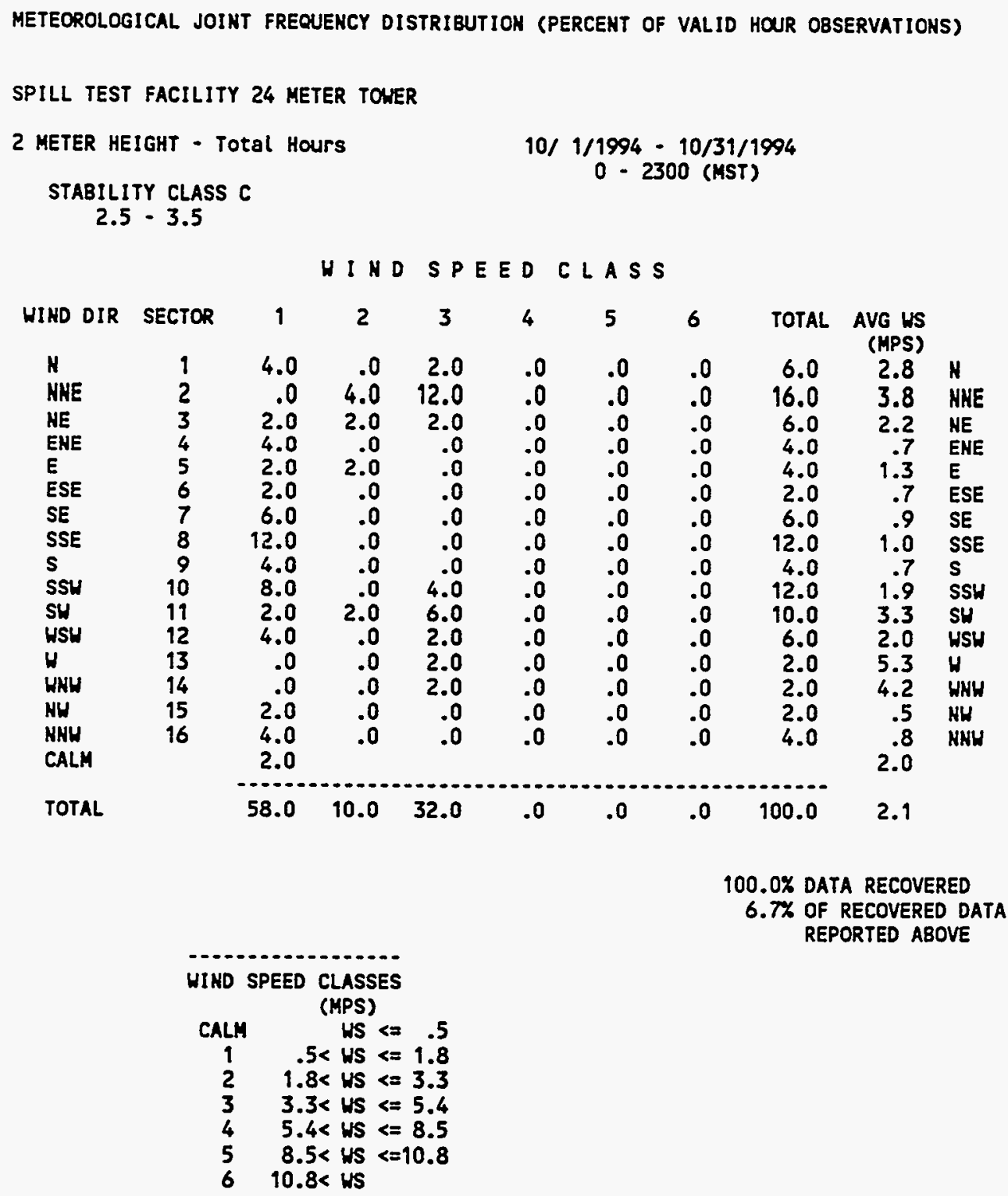


METEOROLOGICAL JOINT FREQUENCY DISTRIBUTION (PERCENT OF VALID HOUR OBSERVATIONS)

SPILL TEST FACILITY 24 METER TONER

2 METER HEIGHT - Total Hours

$11 / 1 / 1994-11 / 30 / 1994$

STABILITY CLASS C

0 - 2300 (HST)

$2.5-3.5$

HINDSPEED CLASS

\begin{tabular}{|c|c|c|c|c|c|c|c|c|c|c|}
\hline WIND DIR & SECTOR & 1 & 2 & 3 & 4 & 5 & 6 & TOTAL & $\begin{array}{l}\text { AVG US } \\
\text { (MPS) }\end{array}$ & \\
\hline N & 1 & .0 & 2.4 & .0 & .0 & .0 & .0 & 2.4 & 3.1 & H \\
\hline NME & 2 & 2.4 & .0 & 4.9 & .0 & .0 & .0 & 7.3 & 2.9 & HNE \\
\hline HE & 3 & 7.3 & 4.9 & 4.9 & .0 & .0 & .0 & 17.1 & 2.2 & NE \\
\hline ENE & 4 & .0 & 2.4 & .0 & .0 & .0 & .0 & 2.4 & 2.3 & ENE \\
\hline$E$ & 5 & 12.2 & 2.4 & .0 & .0 & .0 & .0 & 14.6 & 1.4 & \\
\hline ESE & 6 & .0 & .0 & .0 & .0 & .0 & .0 & .0 & .0 & ESE \\
\hline SE & 7 & 7.3 & 2.4 & .0 & .0 & .0 & .0 & 9.8 & 1.4 & SE \\
\hline SSE & 8 & 2.4 & .0 & .0 & .0 & .0 & .0 & 2.4 & 1.2 & SSE \\
\hline 5 & 9 & 2.4 & 2.4 & 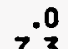 & .0 & .0 & .0 & 4.9 & 2.0 & \\
\hline $\begin{array}{l}\text { SSW } \\
\text { SH }\end{array}$ & $\begin{array}{l}10 \\
11\end{array}$ & $\begin{array}{l}7.3 \\
4.9\end{array}$ & $\begin{array}{r}2.4 \\
.0\end{array}$ & $\begin{array}{r}7.3 \\
.0\end{array}$ & $\begin{array}{r}.0 \\
2.4\end{array}$ & .0 & $\begin{array}{l}.0 \\
.0\end{array}$ & $\begin{array}{r}17.1 \\
7.3\end{array}$ & $\begin{array}{l}2.7 \\
3.1\end{array}$ & $\begin{array}{l}\text { SSH } \\
\text { SW }\end{array}$ \\
\hline USW & 12 & .0 & .0 & 2.4 & .0 & .0 & .0 & 2.4 & 4.0 & WS \\
\hline $\boldsymbol{H}$ & 13 & 2.4 & .0 & 2.4 & .0 & .0 & .0 & 4.9 & 3.0 & \\
\hline WNH & 14 & .0 & .0 & .0 & .0 & .0 & .0 & .0 & .0 & WK \\
\hline NW & 15 & .0 & .0 & .0 & .0 & .0 & .0 & .0 & .0 & NH \\
\hline NHY & 16 & $\begin{array}{l}2.4 \\
4.9\end{array}$ & .0 & .0 & .0 & .0 & .0 & 2.4 & .6 & \\
\hline & & & & & & & & & & \\
\hline TOTAL & & 56.1 & 19.5 & 22.0 & 2.4 & .0 & .0 & 100.0 & 2.1 & \\
\hline
\end{tabular}

100.0X DATA RECOVERED

5.7X OF RECOVERED DATA

REPORTED ABOVE

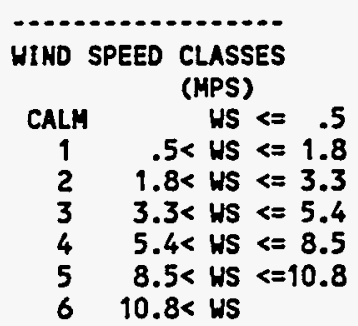


METEOROLOGICAL JOINT FREQUENCY DISTRIBUTION (PERCENT OF VALID HOUR OBSERVATIONS) SPILL TEST FACILITY 24 METER TOWER

2 METER HEIGHT - TOtal HourS

12/ $1 / 1994-12 / 31 / 1994$

STABILITY CLASS C

$0-2300$ (MST)

$2.5 \cdot 3.5$

HINDSPEED CLASS

\begin{tabular}{|c|c|c|c|c|c|c|c|c|c|c|}
\hline WIHD DIR & SECTOR & 1 & 2 & 3 & 4 & 5 & 6 & TOTAL & $\begin{array}{l}\text { AVG US } \\
\text { (MPS) }\end{array}$ & \\
\hline H & 1 & 3.3 & .0 & .0 & .0 & .0 & .0 & 3.3 & .7 & K \\
\hline NME & 2 & 13.3 & 6.7 & .0 & .0 & .0 & .0 & 20.0 & 1.7 & NHE \\
\hline NE & 3 & .0 & .0 & .0 & .0 & .0 & .0 & .0 & .0 & $\mathrm{HE}$ \\
\hline ENE & 4 & 13.3 & .0 & .0 & .0 & .0 & .0 & 13.3 & 1.0 & ENE \\
\hline $\bar{E}$ & 5 & 6.7 & .0 & .0 & .0 & .0 & .0 & 6.7 & .9 & E \\
\hline ESE & 6 & .0 & .0 & .0 & .0 & .0 & .0 & .0 & .0 & ESE \\
\hline SE & 7 & .0 & .0 & .0 & .0 & .0 & .0 & .0 & .0 & SE \\
\hline $\begin{array}{l}\text { SSE } \\
S\end{array}$ & $\begin{array}{l}8 \\
9\end{array}$ & $\begin{array}{l}6.7 \\
3.3\end{array}$ & $\begin{array}{l}.0 \\
0\end{array}$ & .0 & $\begin{array}{l}.0 \\
0\end{array}$ & .0 & $\begin{array}{l}.0 \\
.0\end{array}$ & $\begin{array}{l}6.7 \\
3.3\end{array}$ & .8 & $\begin{array}{l}\text { SSE } \\
\text { S }\end{array}$ \\
\hline SSH & 10 & 13.3 & 6.7 & .0 & .0 & .0 & .0 & 20.0 & 1.0 & SSH \\
\hline SH & 11 & 6.7 & 3.3 & .0 & .0 & .0 & .0 & 10.0 & 1.6 & SH \\
\hline WSU & 12 & .0 & .0 & .0 & .0 & .0 & .0 & .0 & .0 & HSW \\
\hline $\mathbf{H}$ & 13 & 3.3 & .0 & .0 & .0 & .0 & .0 & 3.3 & .6 & H \\
\hline WWH & 14 & 3.3 & .0 & .0 & .0 & .0 & .0 & 3.3 & 1.5 & WHW \\
\hline NH & 15 & 3.3 & .0 & 3.3 & .0 & .0 & .0 & 6.7 & 2.4 & HN \\
\hline NKH & 16 & .0 & .0 & .0 & .0 & .0 & .0 & .0 & .0 & NHH \\
\hline & & & & & & & & & & \\
\hline TOTAL & & 80.0 & 16.7 & 3.3 & .0 & .0 & .0 & 100.0 & 1.3 & \\
\hline
\end{tabular}

65.1\% DATA RECOVERED

6.2\% OF RECOVERED DATA

REPORTED ABOVE

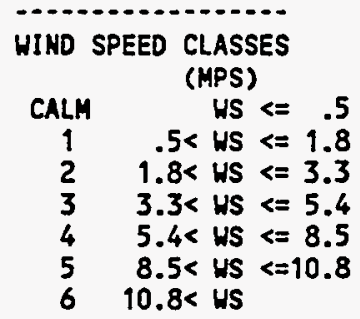




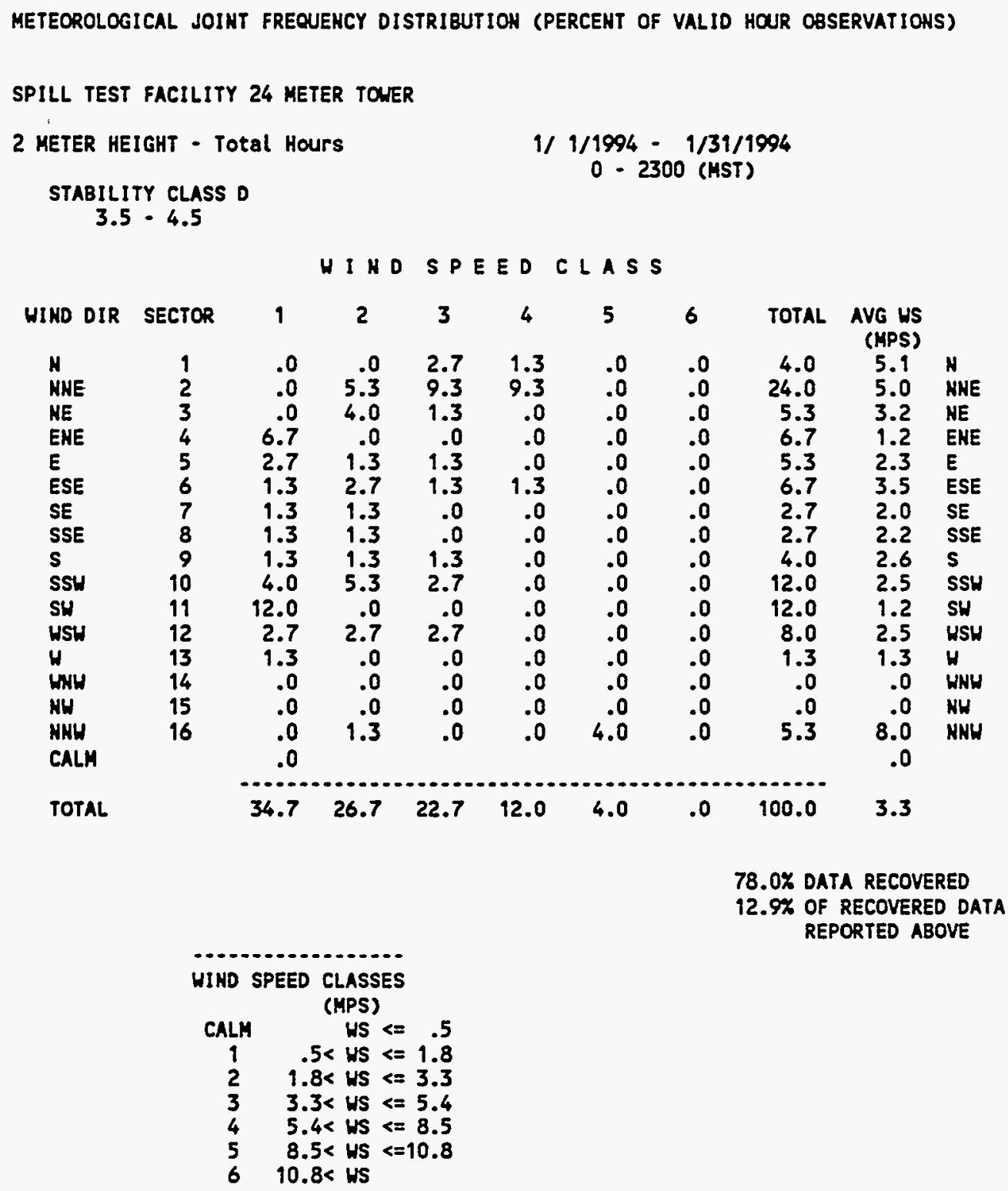


METEOROLOGICAL JOINT FREQUENCY DISTRIBUTION (PERCENT OF VALID HOUR OBSERVATIONS) SPILL TEST FACILITY 24 METER TONER

2 METER HEIGHT - Total Hours

2/ $1 / 1994 \cdot 2 / 28 / 1994$

STABILITY CLASS D

$0-2300$ (MST)

$$
3.5-4.5
$$

WI D SPEED CLASS

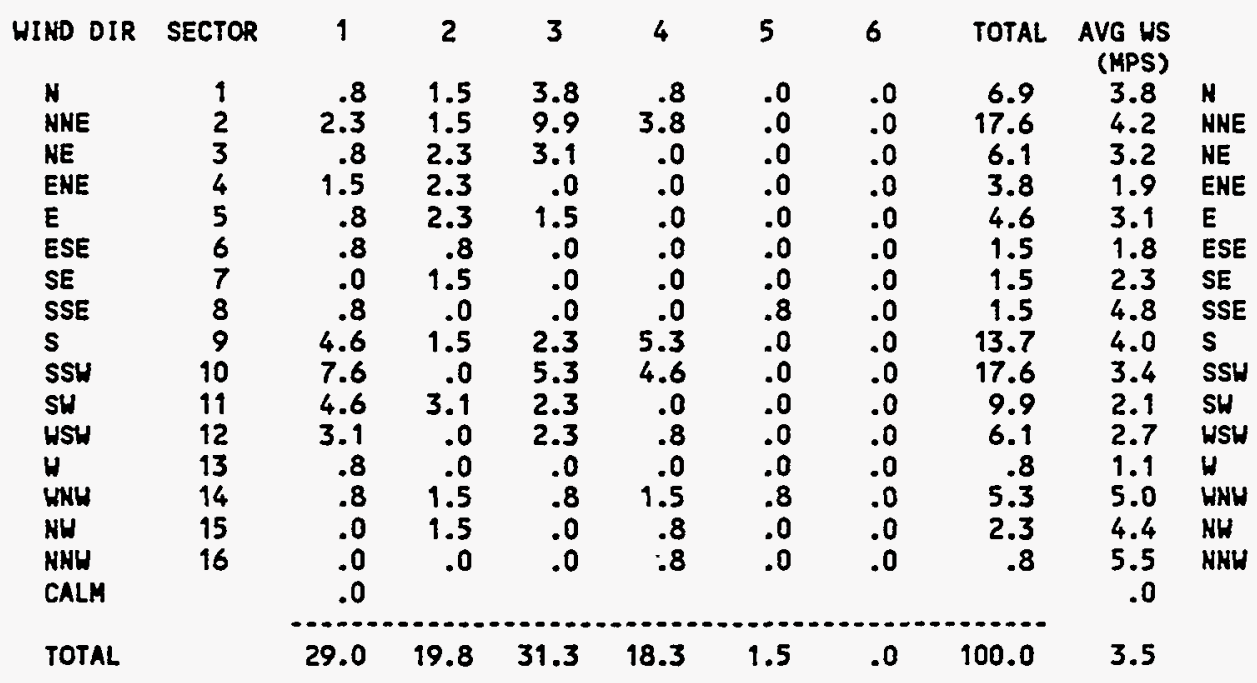

85.4\% DATA RECOVERED 22.8\% OF RECOVERED DATA REPORTED ABOVE

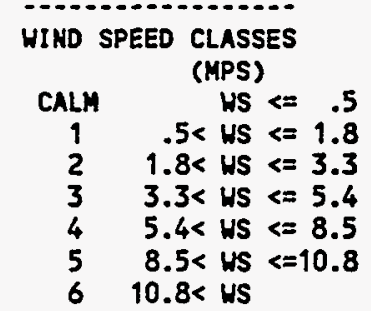


METEOROLOGICAL JOINT FREQUENCY DISTRIBUTION (PERCENT OF VALIO HOUR OBSERVATIONS)

SPILL TEST FACILITY 24 METER TONER

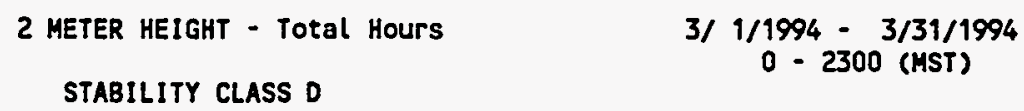

HINDSPEED CLASS

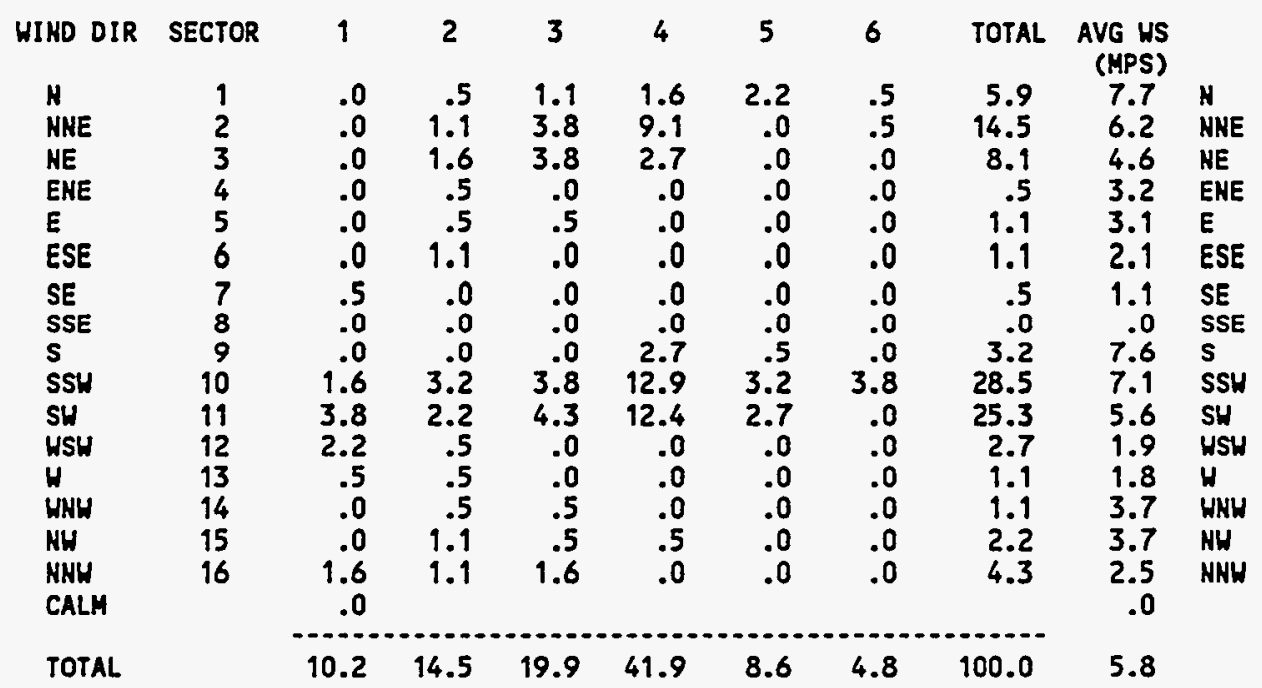

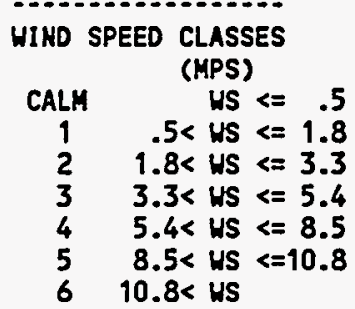


METEOROLOGICAL JOINT FREQUEKCY DISTRIBUTION (PERCENT OF VALID HOUR OBSERVATIONS) SPILL TEST FACILITY 24 METER TONER
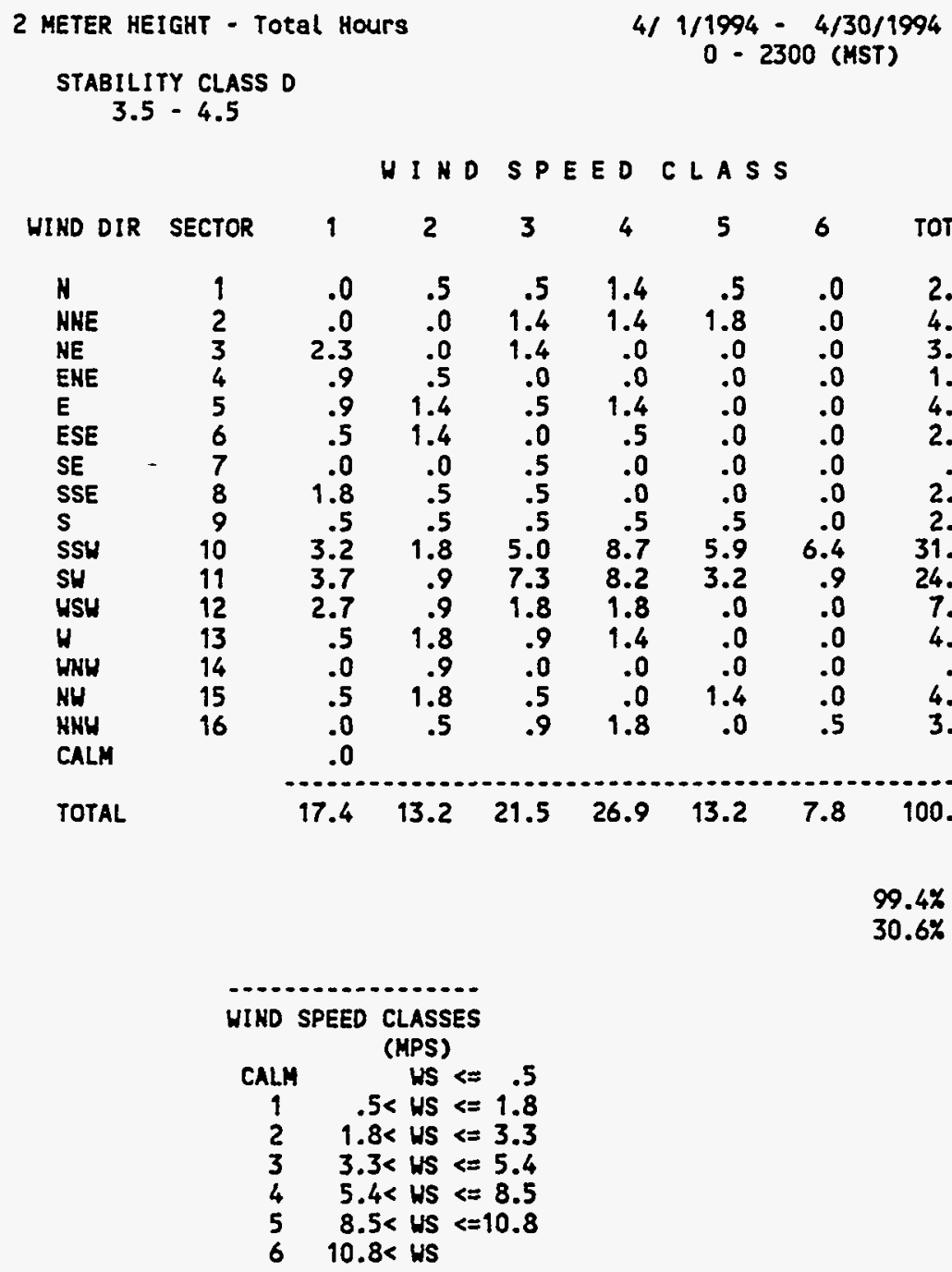
METEOROLOGICAL JOIMT FREQUENCY DISTRIBUTION (PERCENT OF VALID HOUR OBSERVATIONS)

SPILL TEST FACILITY 24 METER TOUER

2 METER HEIGHT - Total Hours

5/ $1 / 1994-5 / 31 / 1994$

STABILITY CLASS D

$3.5-4.5$

$0 \cdot 2300$ (MST)

WI D S PEEDCLASS

\begin{tabular}{|c|c|c|c|c|c|c|c|c|c|c|}
\hline WIND DIR & SECTOR & 1 & 2 & 3 & 4 & 5 & 6 & TOTAL & $\begin{array}{l}\text { AVG US } \\
\text { (MPS) }\end{array}$ & \\
\hline N & 1 & .0 & .0 & .0 & .0 & .0 & .0 & .0 & .0 & H \\
\hline HNE & 2 & .5 & .5 & 1.0 & .0 & .0 & .0 & 2.1 & 2.8 & NHE \\
\hline NE & 3 & .0 & .5 & 1.0 & .0 & .0 & .0 & 1.5 & 4.0 & HE \\
\hline ENE & 4 & .0 & .0 & .5 & .0 & .0 & .0 & .5 & 3.8 & ENE \\
\hline E & 5 & .5 & .0 & .0 & .0 & .0 & .0 & .5 & 1.3 & \\
\hline ESE & 6 & .0 & 1.5 & .5 & .0 & .0 & .0 & 2.1 & 2.8 & ESE \\
\hline SE & 7 & .0 & .5 & 2.1 & 1.5 & .0 & .0 & 4.1 & $\begin{array}{l}4.9 \\
30\end{array}$ & $\begin{array}{l}\text { SE } \\
\text { SSE }\end{array}$ \\
\hline $\begin{array}{l}\text { SSE } \\
\text { S }\end{array}$ & $\begin{array}{l}8 \\
9\end{array}$ & .5 & $\begin{array}{l}.5 \\
.5\end{array}$ & $\begin{array}{r}1.5 \\
.0\end{array}$ & $\begin{array}{r}.5 \\
1.0\end{array}$ & $\begin{array}{r}.0 \\
1.0\end{array}$ & $\begin{array}{l}.0 \\
.0\end{array}$ & $\begin{array}{l}3.1 \\
2.6\end{array}$ & $\begin{array}{l}3.9 \\
7.0\end{array}$ & $\begin{array}{l}\text { SSE } \\
\text { S }\end{array}$ \\
\hline ssu & 10 & .5 & .3 & 2.6 & 12.4 & 6.2 & 5.7 & 27.8 & 8.2 & SSH \\
\hline SW & 11 & 3.6 & 1.5 & 5.7 & 20.6 & 12.4 & 1.5 & 45.4 & 6.8 & $\begin{array}{l}\text { SH } \\
\text { HSH }\end{array}$ \\
\hline $\begin{array}{l}\text { USW } \\
\text { U }\end{array}$ & $\begin{array}{l}12 \\
13\end{array}$ & $\begin{array}{r}1.0 \\
.0\end{array}$ & $\begin{array}{l}.0 \\
.0\end{array}$ & $\begin{array}{r}3.6 \\
.0\end{array}$ & $\begin{array}{r}2.7 \\
.5\end{array}$ & $\begin{array}{l}.0 \\
.0\end{array}$ & $\begin{array}{l}.0 \\
.0\end{array}$ & $\begin{array}{r}6.7 \\
.5\end{array}$ & $\begin{array}{l}4.4 \\
5.8\end{array}$ & N \\
\hline HNH & 14 & .0 & .5 & .0 & .0 & .0 & .0 & .5 & 3.0 & WNH \\
\hline NH & 15 & .0 & 1.0 & .5 & .0 & .0 & .0 & 1.5 & 3.0 & NH \\
\hline $\begin{array}{l}\text { NNH } \\
\text { CALM }\end{array}$ & 16 & $\begin{array}{l}.0 \\
.0\end{array}$ & .0 & 1.0 & .0 & .0 & .0 & 1.0 & $\begin{array}{r}4.7 \\
.0\end{array}$ & NKH \\
\hline & & 6.7 & 7. & 20. & 38.7 & 19. & 7.2 & 20.0 & 6.5 & \\
\hline
\end{tabular}

96.9\% DATA RECOVERED

26.9\% OF RECOVERED DATA REPORTED ABOVE

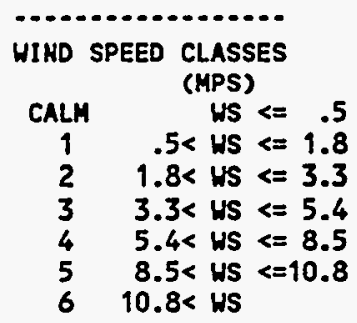


METEOROLOGICAL JOINT FREQUENCY OISTRIBUTION (PERCENT OF VALID HOUR OBSERVATIONS) SPILL TEST FACILITY 24 METER TONER

2 METER HEIGHT - Total Hours

STABILITY CLASS D
6/ $1 / 1994-6 / 30 / 1994$

$0-2300$ (MST)

$3.5 \cdot 4.5$

HIND SPEED CLASS

\begin{tabular}{|c|c|c|c|c|c|c|c|c|c|c|}
\hline WIKD DIR & SECTOR & 1 & 2 & 3 & 4 & 5 & 6 & TOTAL & $\begin{array}{l}\text { AVG US } \\
\text { (MPS) }\end{array}$ & \\
\hline $\boldsymbol{H}$ & 1 & .0 & .0 & .0 & .0 & .0 & .0 & .0 & .0 & N \\
\hline NHE & 2 & .4 & .0 & .4 & .4 & .0 & .0 & 1.1 & 4.3 & NNE \\
\hline NE & 3 & 1.1 & .0 & .0 & .0 & .0 & .0 & 1.1 & 1.5 & NE \\
\hline ENE & 4 & .4 & .0 & .0 & .0 & .0 & .0 & & 1.5 & ENE \\
\hline & 5 & .0 & .0 & .0 & .0 & .0 & .0 & .0 & .0 & $\mathbf{E}$ \\
\hline ESE & 6 & .0 & .0 & .0 & .0 & .0 & .0 & .0 & .0 & ESE \\
\hline SE & 7 & .0 & .4 & .0 & .0 & .0 & .0 & .4 & 3.2 & SE \\
\hline SSE & 8 & .0 & .0 & .0 & .0 & .0 & .0 & & .0 & SSE \\
\hline s & 9 & .0 & 0 & .4 & 0 & .0 & .0 & & 4.9 & $S$ \\
\hline SSU & 10 & .7 & .7 & 2.9 & 9.6 & 7.0 & .4 & 21.3 & 7.2 & SSH \\
\hline SH & 11 & 1.8 & 3.3 & 7.4 & 37.9 & 9.6 & 2.2 & 62.1 & 6.9 & SH \\
\hline $\begin{array}{l}\text { HSW } \\
\text { U }\end{array}$ & $\begin{array}{l}12 \\
13\end{array}$ & $\begin{array}{r}1.1 \\
.0\end{array}$ & $\begin{array}{r}1.1 \\
.4\end{array}$ & $\begin{array}{r}2.9 \\
.0\end{array}$ & $\begin{array}{r}2.6 \\
.0\end{array}$ & $\begin{array}{r}1.8 \\
.0\end{array}$ & $\begin{array}{l}.4 \\
.0\end{array}$ & $\begin{array}{r}9.9 \\
.4\end{array}$ & $\begin{array}{l}5.4 \\
2.4\end{array}$ & $\begin{array}{l}\text { HSH } \\
\boldsymbol{W}\end{array}$ \\
\hline WNH & 14 & .0 & .7 & .7 & .0 & .0 & .0 & 1.5 & 3.0 & HNW \\
\hline $\mathrm{NH}$ & 15 & .7 & .7 & .0 & .0 & .0 & .0 & 1.5 & 1.9 & NH \\
\hline $\begin{array}{l}\text { NHH } \\
\text { CALM }\end{array}$ & 16 & $\begin{array}{l}.0 \\
.0\end{array}$ & .0 & .0 & .0 & .0 & .0 & .0 & $\begin{array}{l}.0 \\
.0\end{array}$ & HHW \\
\hline TOTAL & & 6.3 & 7.4 & 14.7 & 50.4 & 18.4 & 2.9 & 100.0 & 6.5 & \\
\hline
\end{tabular}

100.0\% DATA RECOVERED

37.8\% OF RECOVERED DATA REPORTEO ABOVE 
METEOROLOGICAL JOINT FREQUENCY DISTRIBUTIOH (PERCENT OF VALID HOUR OBSERVATIONS)

SPILL TEST FACILITY 24 METER TOWER

2 METER HEIGHT - Total Hours

$7 / 1 / 1994 \cdot 7 / 31 / 1994$

STABILITY CLASS D

0 - 2300 (MST)

$$
3.5 \cdot 4.5
$$

HINDSPEEDCLASS

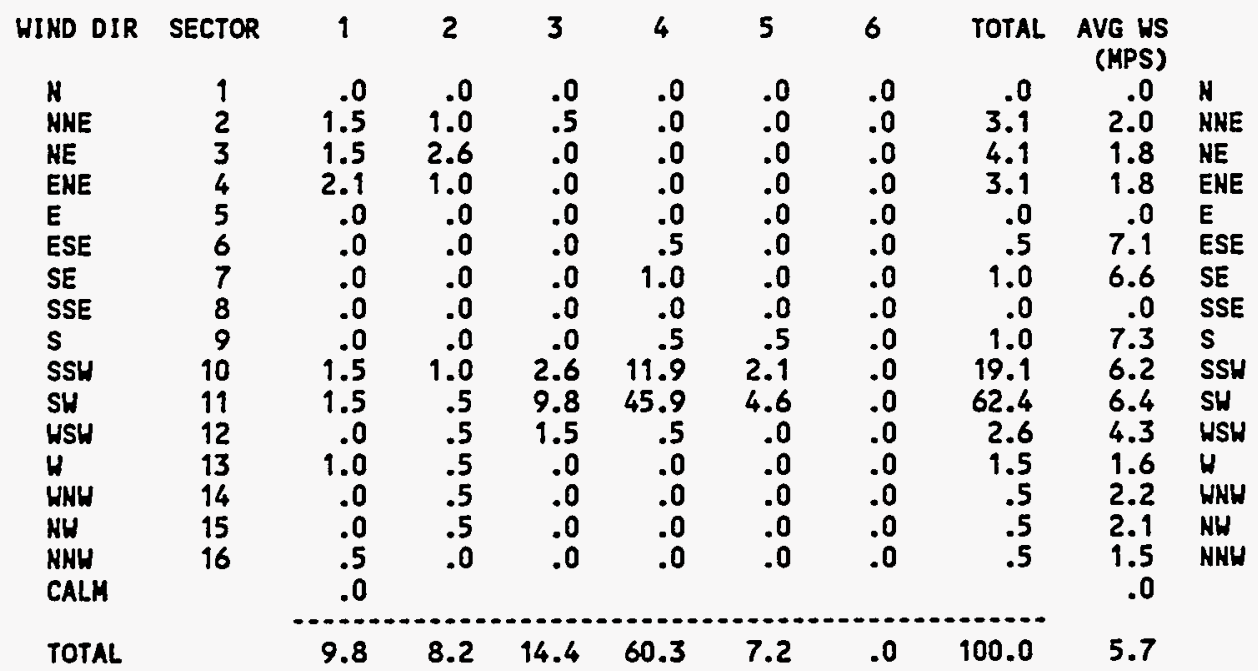

100.0\% DATA RECOVERED

26. $1 \%$ OF RECOVERED DATA

REPORTED ABOVE

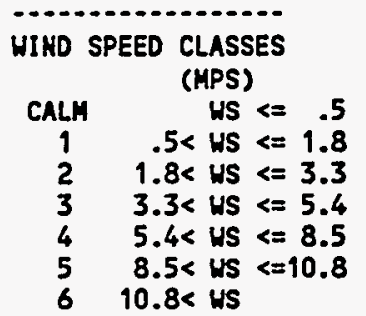


METEOROLOGICAL JOIMT FREQUEHCY DISTRIBUTION (PERCENT OF VALID HOUR OBSERVATIONS)

SPILL TEST FACILITY 24 METER TONER

2 METER HEIGHT - Total Hours

$8 / 1 / 1994 \cdot 8 / 31 / 1994$

STABILITY CLASS D

0 - 2300 (MST)

$3.5 \cdot 4.5$

HINDSPEEDCLASS

\begin{tabular}{|c|c|c|c|c|c|c|c|c|c|c|}
\hline WIND DIR & SECTOR & 1 & 2 & 3 & 4 & 5 & 6 & TOTAL & $\begin{array}{c}\text { AVG US } \\
\text { (MPS) }\end{array}$ & \\
\hline H & 1 & & 1.4 & & .0 & .0 & .0 & 1.9 & 2.5 & \\
\hline HNE & 2 & .0 & 1.9 & 1.0 & .5 & .0 & .0 & 3.3 & 3.5 & NHE \\
\hline $\begin{array}{l}\text { NE } \\
\text { EME }\end{array}$ & $\begin{array}{l}3 \\
4\end{array}$ & $\begin{array}{l}1.9 \\
1.4\end{array}$ & $\begin{array}{l}1.0 \\
.0\end{array}$ & .0 & .0 & .0 & .0 & 2.9 & 1.7 & $\begin{array}{l}\text { NE } \\
\text { ENE }\end{array}$ \\
\hline $\begin{array}{l}\text { ENE } \\
\text { E }\end{array}$ & $\begin{array}{l}4 \\
5\end{array}$ & $\begin{array}{l}1.4 \\
1.0\end{array}$ & $\begin{array}{l}.0 \\
.0\end{array}$ & $\begin{array}{l}.0 \\
.5\end{array}$ & $\begin{array}{l}.0 \\
.0\end{array}$ & $\begin{array}{l}.0 \\
.0\end{array}$ & $\begin{array}{l}.0 \\
.0\end{array}$ & $\begin{array}{l}1.4 \\
1.4\end{array}$ & $\begin{array}{l}1.8 \\
2.4\end{array}$ & $\begin{array}{l}\text { ENE } \\
\text { E }\end{array}$ \\
\hline ESE & 6 & .0 & .5 & .0 & .0 & .0 & .0 & .5 & 3.0 & ESE \\
\hline SE & 7 & .0 & .5 & 1.9 & 1.0 & .0 & .0 & 3.3 & 4.7 & SE \\
\hline SSE & 8 & .0 & .0 & .5 & .0 & .0 & .0 & .5 & 5.1 & SSE \\
\hline $\mathbf{s}$ & 9 & .0 & .5 & .0 & 3.8 & .5 & .0 & 4.8 & 6.4 & $\mathbf{s}$ \\
\hline SSW & 10 & .0 & 1.9 & 2.9 & 15.2 & 1.9 & .0 & 21.9 & 6.7 & SSH \\
\hline SW & 11 & 2.4 & .0 & 3.3 & 37.6 & 6.2 & .0 & 49.5 & 6.9 & SH \\
\hline WSW & 12 & 1.0 & 1.0 & 1.0 & 1.0 & .0 & .0 & 3.8 & 3.4 & WSH \\
\hline 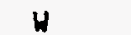 & 13 & .5 & .5 & .0 & .0 & .0 & .0 & 1.0 & 1.6 & $H$ \\
\hline WNG & 14 & .0 & .5 & .0 & .0 & .0 & .0 & .5 & 2.3 & WNH \\
\hline NW & 15 & .0 & .5 & .5 & .5 & .0 & .0 & 1.4 & 4.1 & NH \\
\hline $\begin{array}{l}\text { NNW } \\
\text { CALM }\end{array}$ & 16 & $\begin{array}{l}.0 \\
.0\end{array}$ & 1.9 & .0 & .0 & .0 & .0 & 1.9 & $\begin{array}{r}2.5 \\
.0\end{array}$ & NHH \\
\hline TOTAL & & 8.6 & 11.9 & 19.4 & 59.5 & 8.6 & .0 & 100.0 & 5.9 & \\
\hline
\end{tabular}

100.0\% DATA RECOVERED

28.2\% OF RECOVERED DATA REPORTED ABOVE

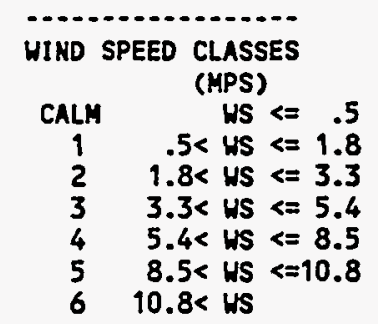


METEOROLOGICAL JOINT FREQUENCY DISTRIBUTION (PERCENT OF VALID HOUR OBSERVATIONS)

SPILL TEST FACILITY 24 METER TOWER

2 METER HEIGHT - Total HourS

$9 / 1 / 1994 \cdot 9 / 30 / 1994$

STABILITY CLASS D

$3.5 \cdot 4.5$

$$
0 \cdot 2300 \text { (MST) }
$$

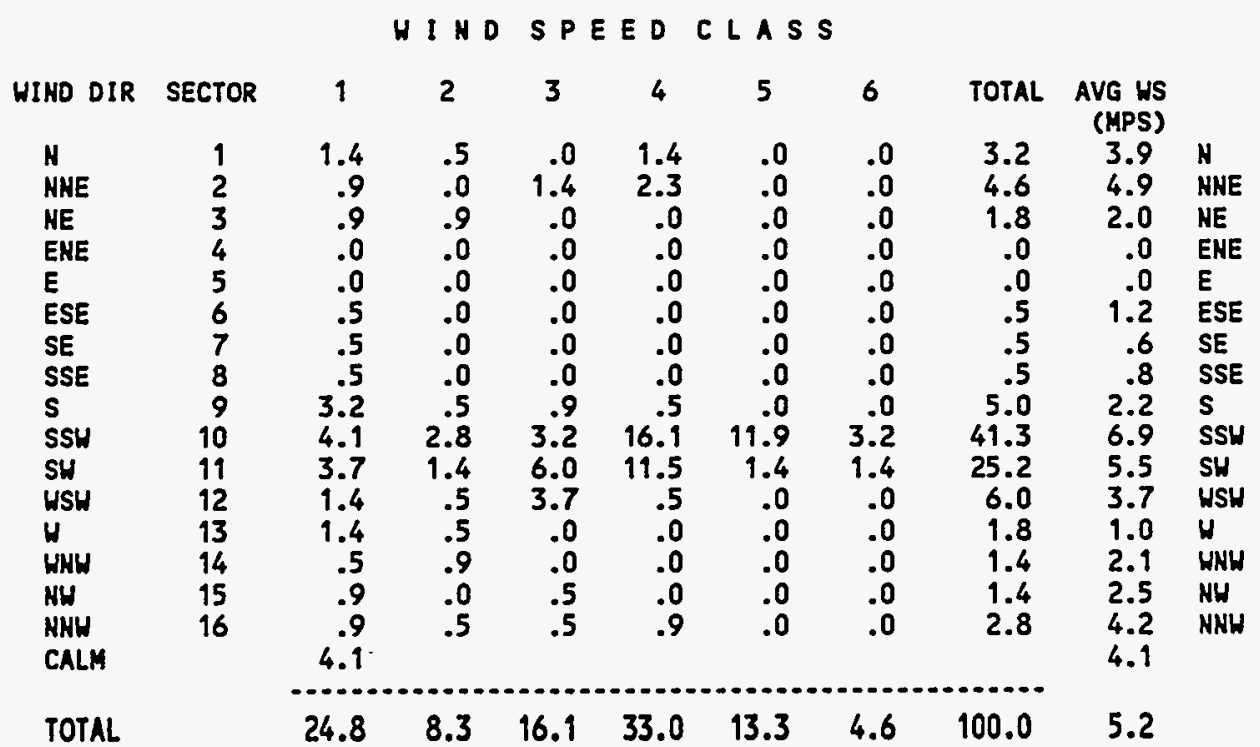

$99.7 \%$ DATA RECOVERED

30.4X OF RECOVERED DATA REPORTED ABOVE

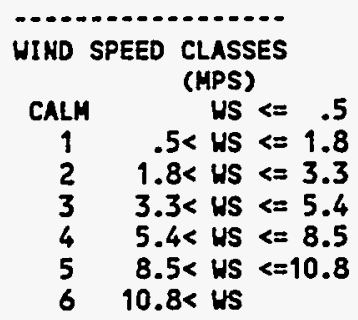


METEOROLOGICAL JOINT FREQUENCY DISTRIBUTION (PERCENT OF VALID HOUR OBSERVATIONS) SPILL TEST FACILITY 24 METER TONER

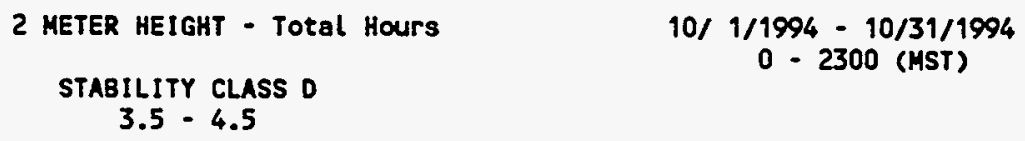

HINDSPEEDCLASS

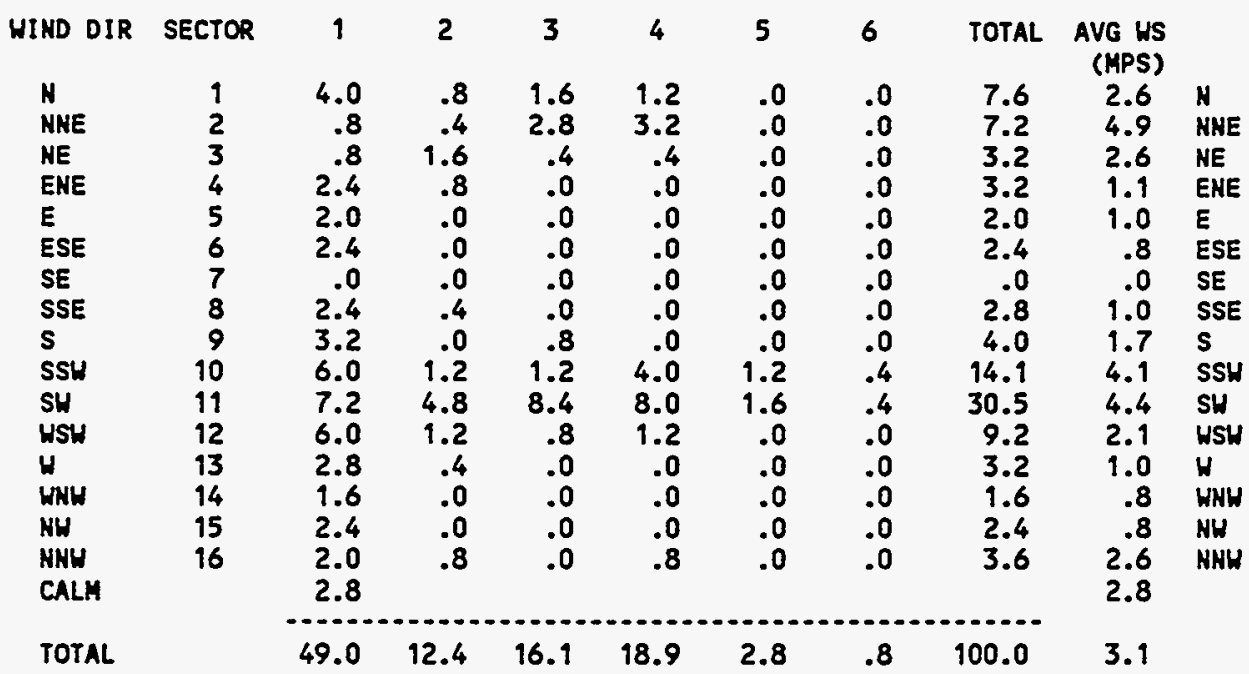

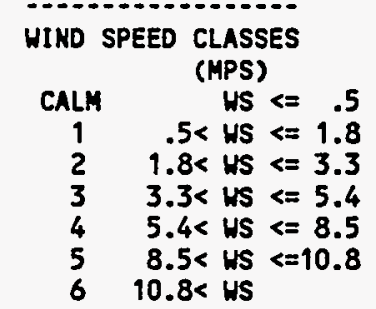


METEOROLOGICAL JOINT FREQUENCY DISTRIBUTION (PERCENT OF VALIO HOUR OBSERVATIONS)

SPILL TEST FACILITY 24 METER TOWER

2 METER HEIGHT - TOtal HourS

$11 / 1 / 1994-11 / 30 / 1994$

STABILITY CLASS D

$0-2300$ (MST)

$$
3.5 \cdot 4.5
$$

HINDSPEEDCLASS

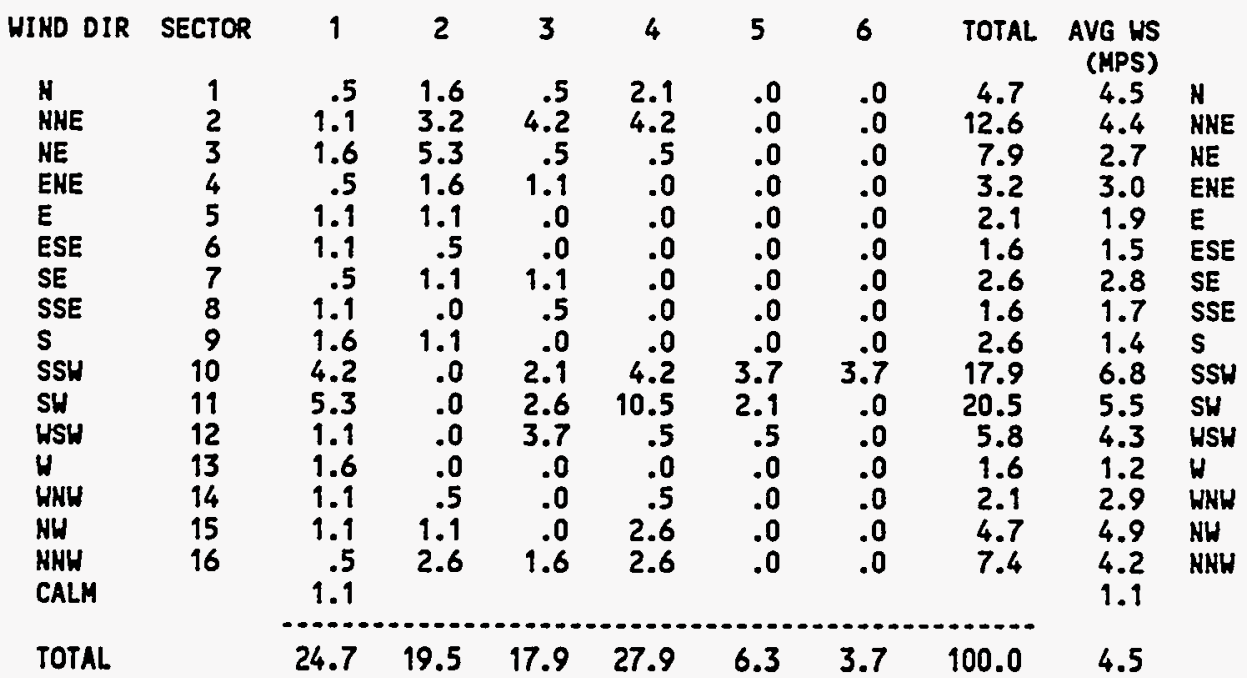

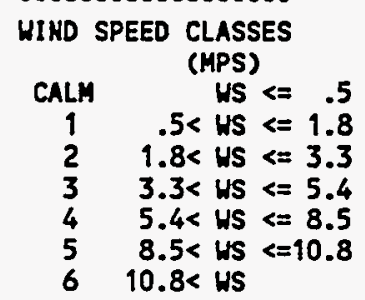




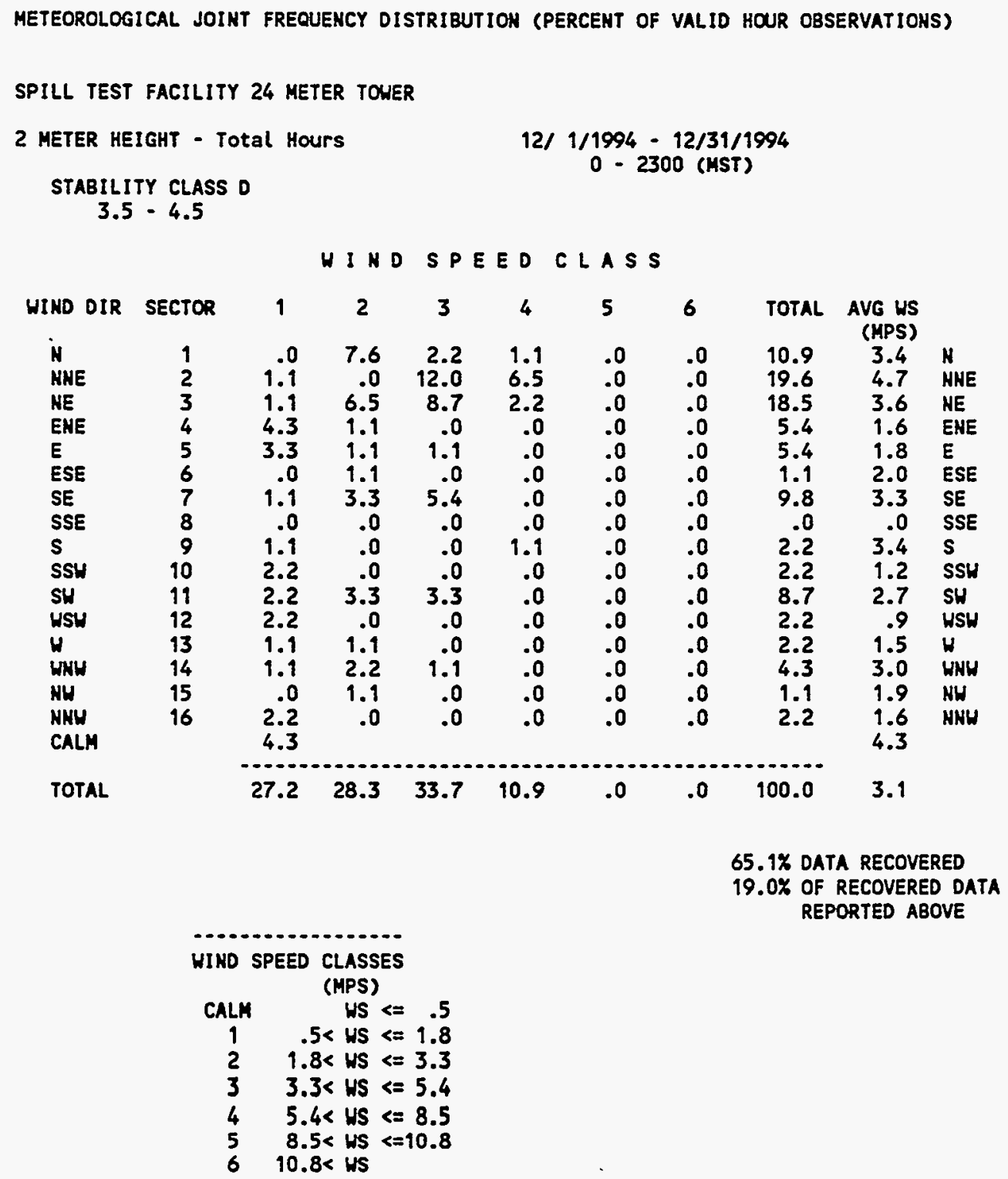




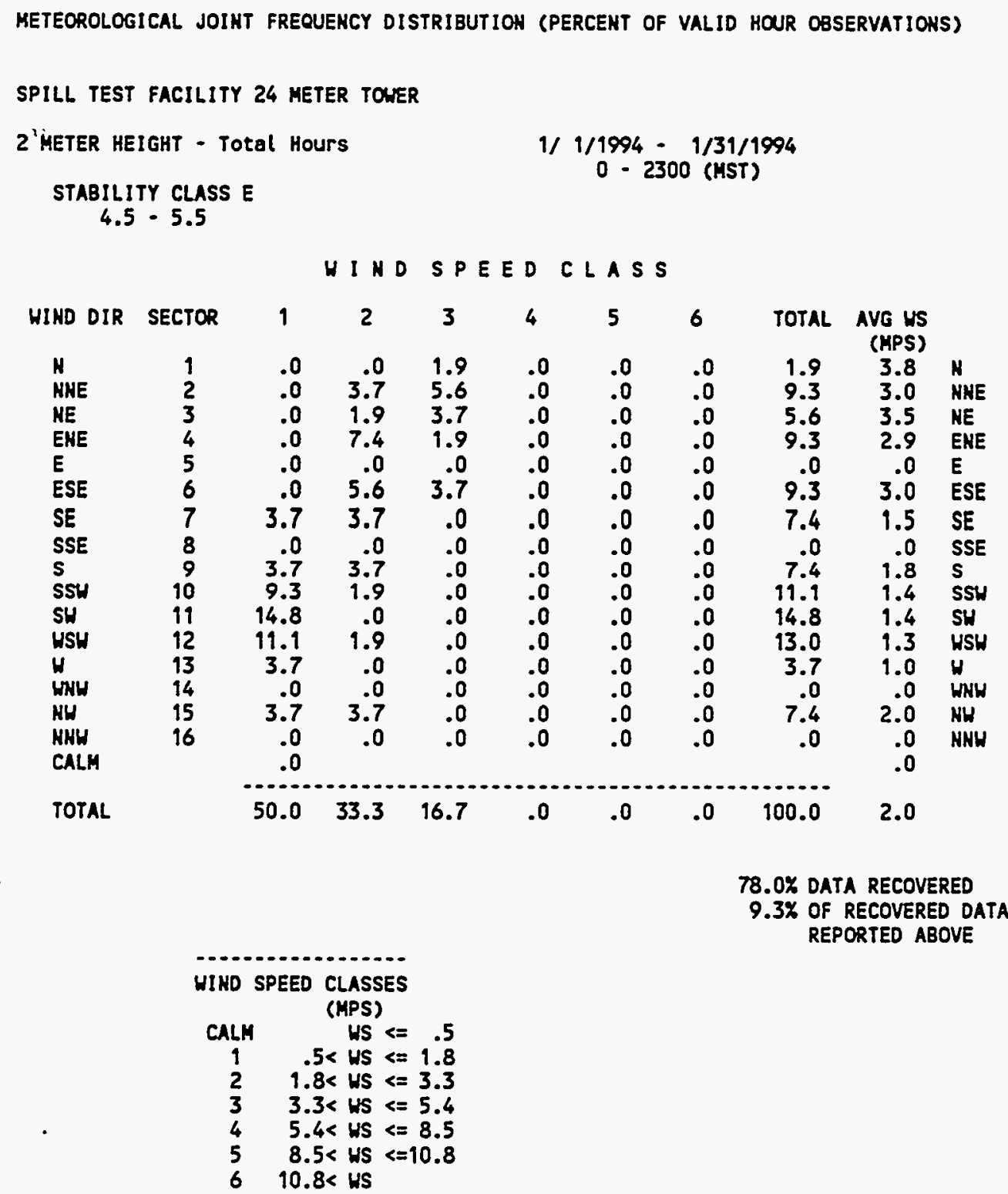


METEOROLOGICAL JOINT FREQUENCY DISTRIBUTION (PERCENT OF VALID HOUR OBSERVATIONS)

SPILL TEST FACILITY 24 METER TONER

2 METER HEIGHT - Total Hours

$2 / 1 / 1994 \cdot 2 / 28 / 1994$

STABILITY CLASS E

$4.5-5.5$

0 - 2300 (MST)

WI HD SPEED CLASS

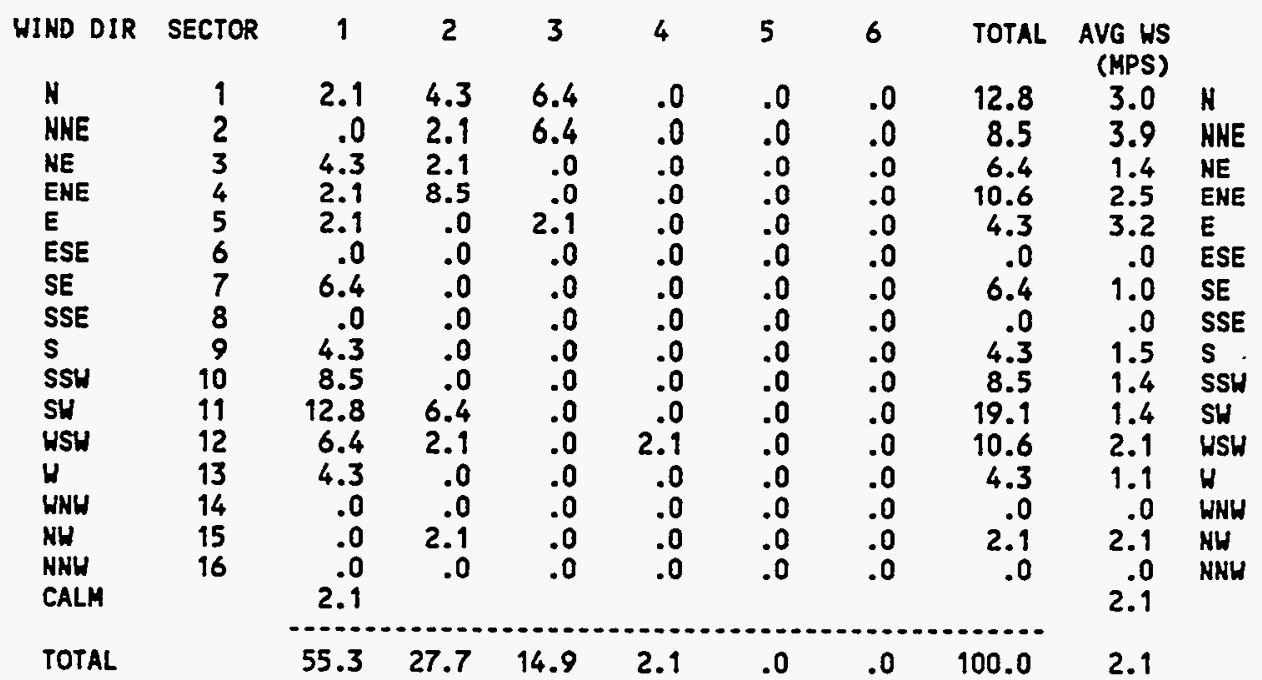

85.4\% DATA RECOVERED

8.2\% OF RECOVERED DATA

REPORTED ABOVE

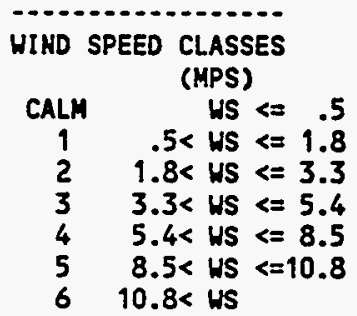


METEOROLOGICAL JOINT FREQUENCY DISTRIBUTION (PERCENT OF VALID HOUR OBSERVATIONS) SPILL TEST FACILITY 24 METER TOWER

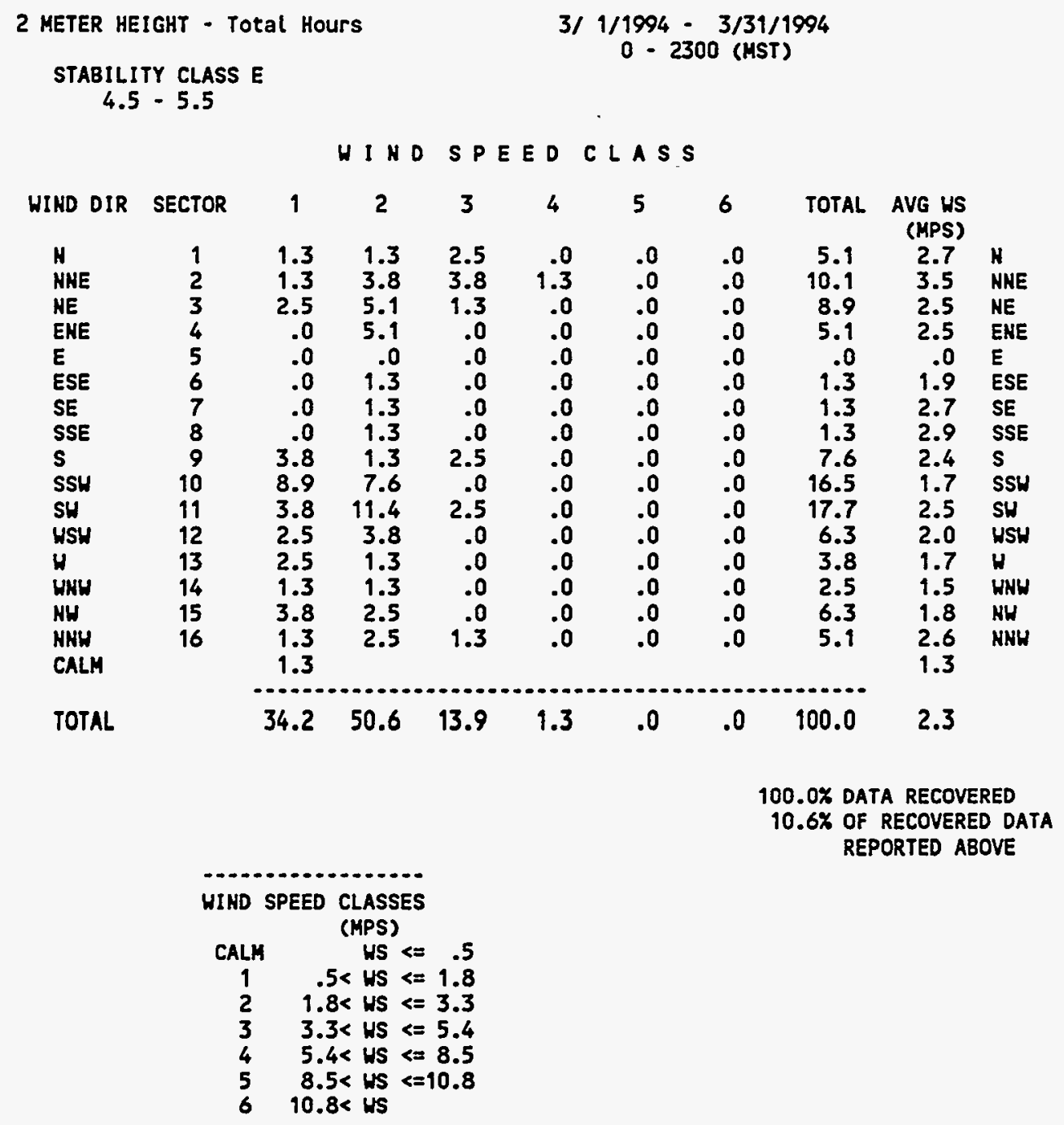


METEOROLOGICAL JOINT FREQUENCY DISTRIBUTION (PERCENT OF VALID HOUR OBSERVATIONS)

SPILL TEST FACILITY 24 METER TONER

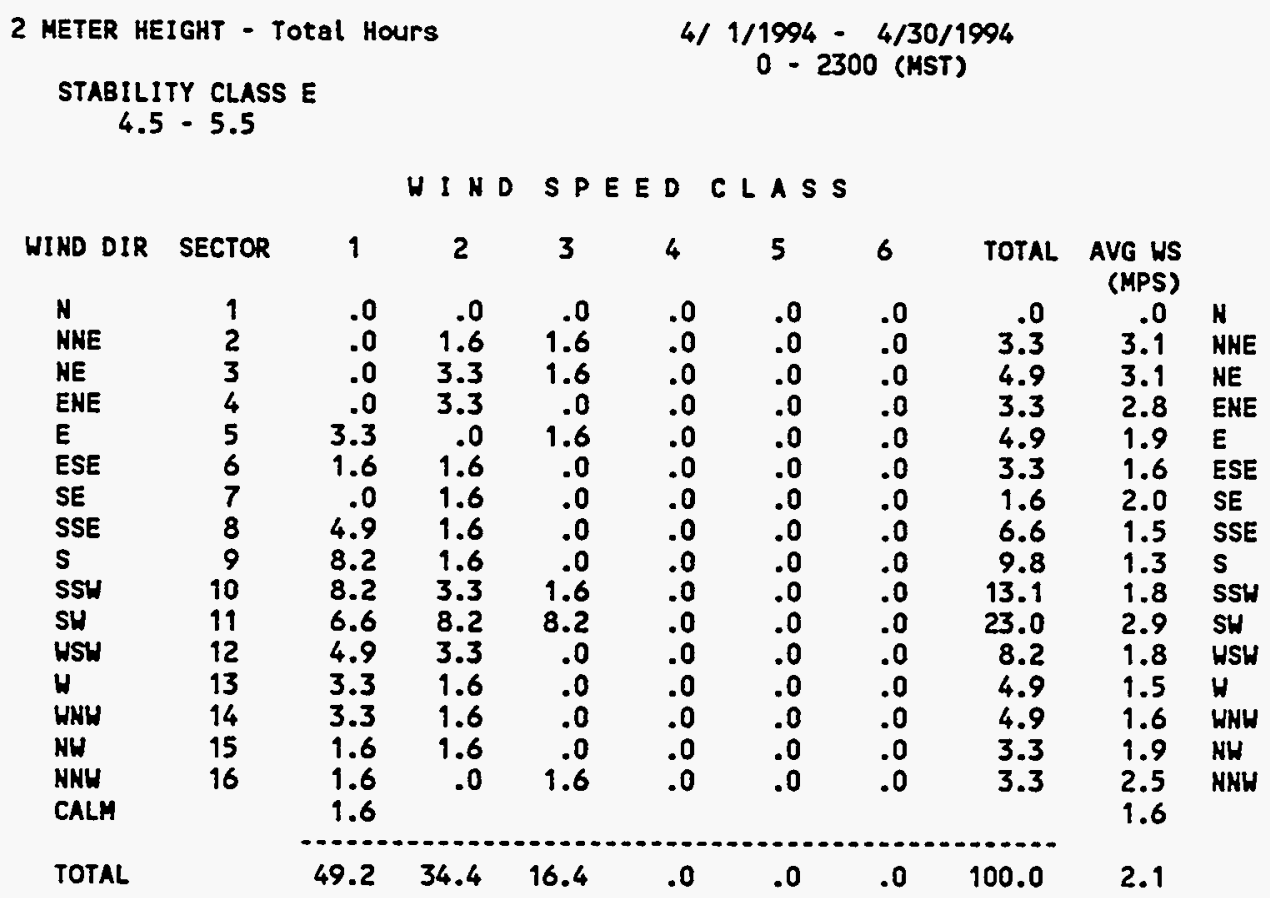

99.4\% DATA RECOVERED

8.5\% OF RECOVERED DATA

REPORTED ABOVE

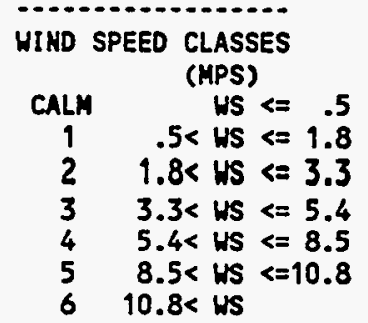




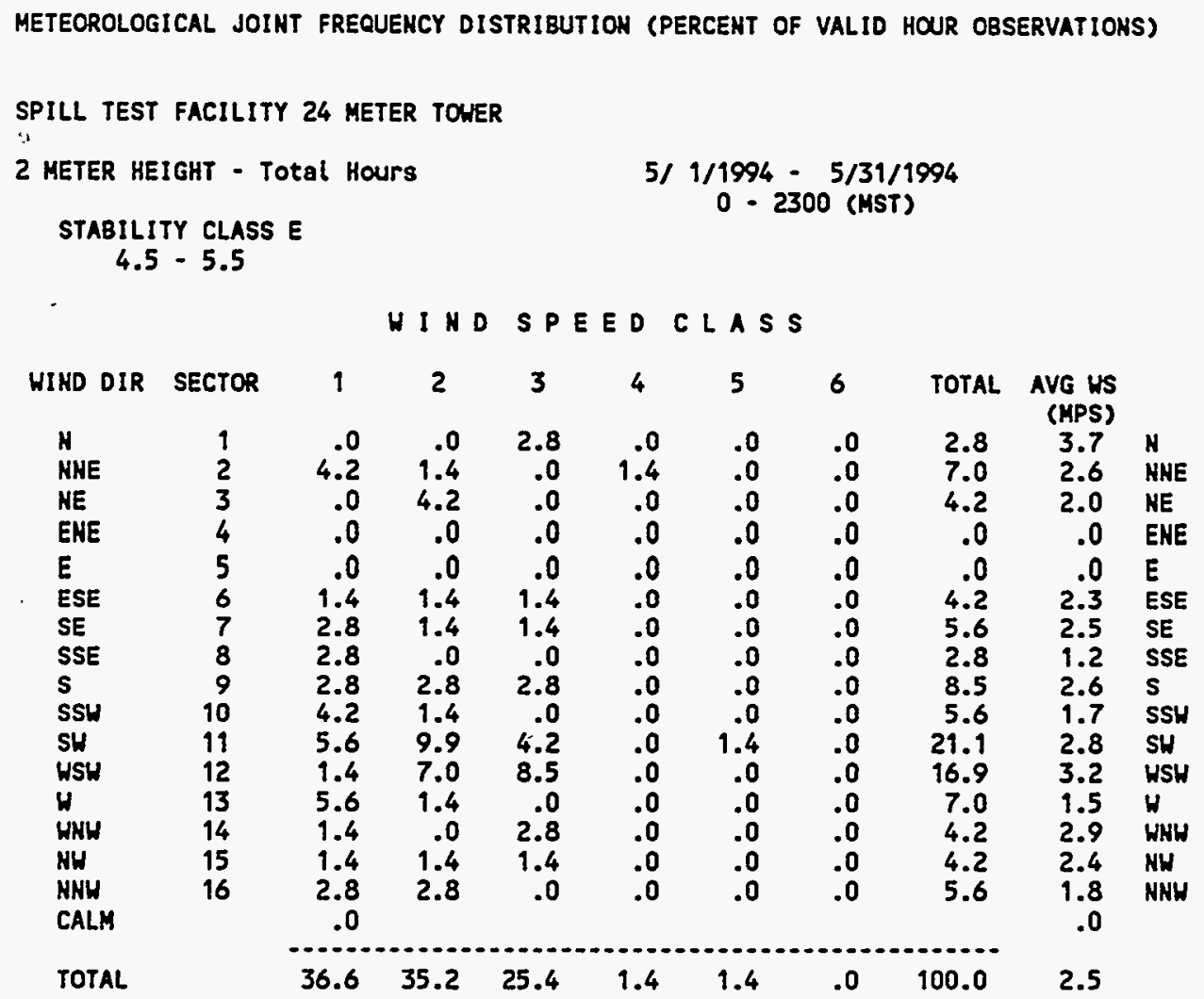

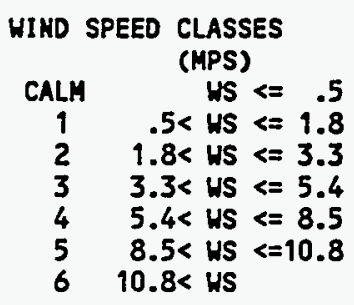


METEOROLOGICAL JOINT FREQUENCY DISTRIBUTION (PERCENT OF VALID HOUR OBSERVATIONS)

SPILL TEST FACILITY 24 METER TONER

2 METER HEIGHT - Total Hours

6/ $1 / 1994-6 / 30 / 1994$

STABILITY CLASS E

$0-2300$ (HST)

$4.5-5.5$

HIND SPEED CLASS

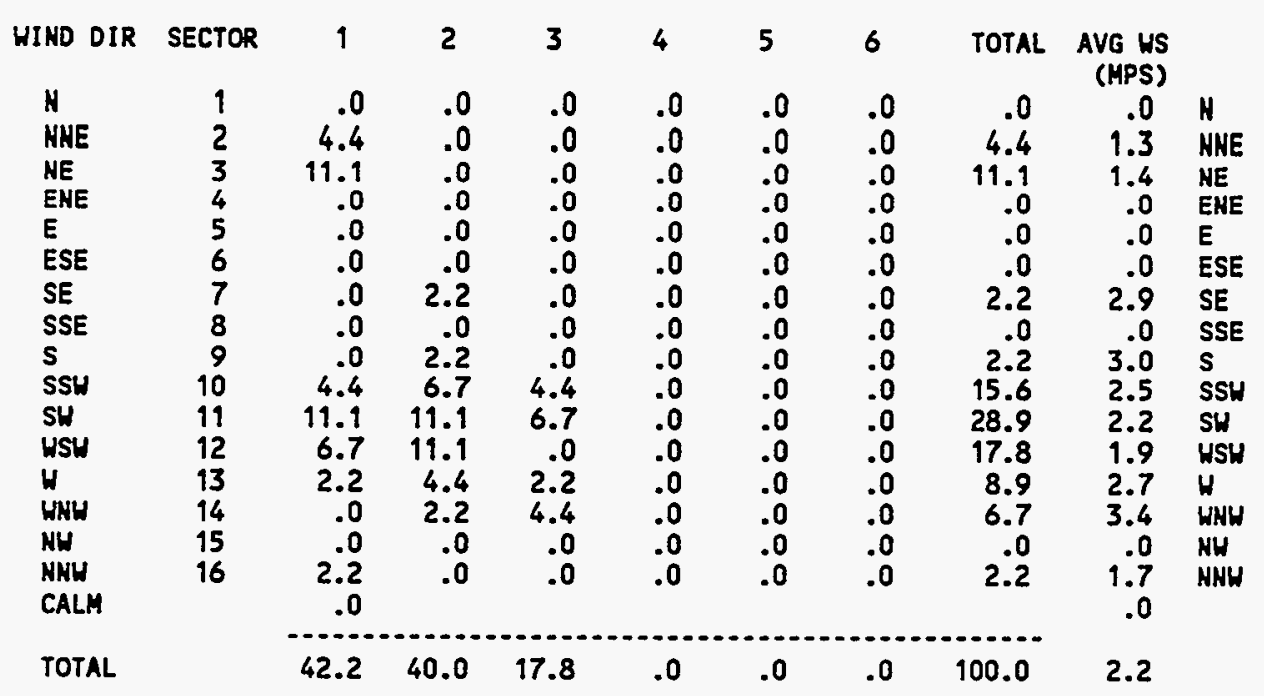

100.0\% DATA RECOVERED

6.3\% OF RECOVERED DATA REPORTED ABOVE

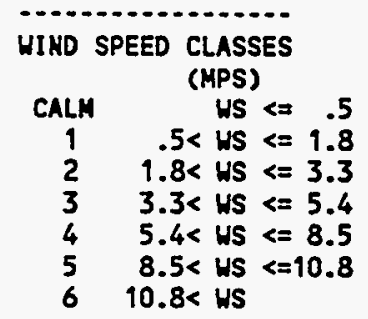


METEOROLOGICAL JOINT FREQUENCY DISTRIBUTION (PERCENT OF VALID HOUR OBSERVATIONS)

SPILL TEST FACILITY 24 METER TONER

2 METER HEIGHT - Total Hours

$7 / 1 / 1994-7 / 31 / 1994$

STABILITY CLASS E

$0-2300$ (MST)

$4.5-5.5$

WINDSPEED CLASS

\begin{tabular}{|c|c|c|c|c|c|c|c|c|c|c|}
\hline WIHD DIR & SECTOR & 1 & 2 & 3 & 4 & 5 & 6 & TOTAL & $\begin{array}{r}\text { AVG WS } \\
\text { (MPS) }\end{array}$ & \\
\hline N & 1 & 3.0 & .0 & .0 & .0 & .0 & .0 & 3.0 & 1.4 & N \\
\hline NHE & 2 & 3.0 & .0 & 1.5 & .0 & .0 & .0 & 4.5 & 2.3 & NHE \\
\hline HE & 3 & 3.0 & 9.0 & .0 & .0 & .0 & .0 & 11.9 & 2.0 & HE \\
\hline ENE & 4 & 1.5 & .0 & .0 & .0 & .0 & .0 & 1.5 & 1.7 & ENE \\
\hline$E$ & 5 & .0 & .0 & .0 & 1.5 & .0 & .0 & 1.5 & 6.7 & $E$ \\
\hline ESE & 6 & .0 & .0 & .0 & .0 & .0 & .0 & .0 & .0 & ESE \\
\hline SE & 7 & 1.5 & .0 & 1.5 & .0 & .0 & .0 & 3.0 & 2.4 & SE \\
\hline SSE & 8 & 1.5 & .0 & .0 & .0 & .0 & .0 & 1.5 & 1.7 & SSE \\
\hline s & 9 & .0 & 4.5 & .0 & .0 & .0 & .0 & 4.5 & 2.8 & $\mathbf{s}$ \\
\hline SSH & 10 & 6.0 & 4.5 & 3.0 & 1.5 & .0 & .0 & 14.9 & 2.9 & SSW \\
\hline SH. & 11 & 13.4 & 9.0 & 10.4 & .0 & .0 & .0 & 32.8 & 2.5 & SH \\
\hline WSH & 12 & 9.0 & 6.0 & 1.5 & .0 & .0 & .0 & 16.4 & 1.9 & WSW \\
\hline H & 13 & 1.5 & 1.5 & .0 & .0 & .0 & .0 & 3.0 & 2.0 & $W$ \\
\hline WHW & 14 & .0 & .0 & .0 & .0 & .0 & .0 & .0 & .0 & WNW \\
\hline HW & 15 & .0 & .0 & .0 & .0 & .0 & .0 & .0 & .0 & NW \\
\hline NHW & 16 & .0 & 1.5 & .0 & .0 & .0 & .0 & 1.5 & 3.1 & NNH \\
\hline CALM & & 0 & & & & & & & .0 & \\
\hline TOTAL & & 43. & 35.8 & 17.9 & 3.0 & 0 & 0 & 100.0 & 2.4 & \\
\hline
\end{tabular}

100.0\% DATA RECOVERED

9.0\% OF RECOVERED DATA

REPORTED ABOVE

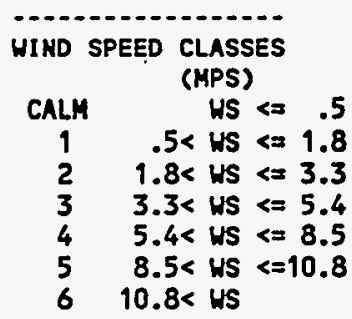




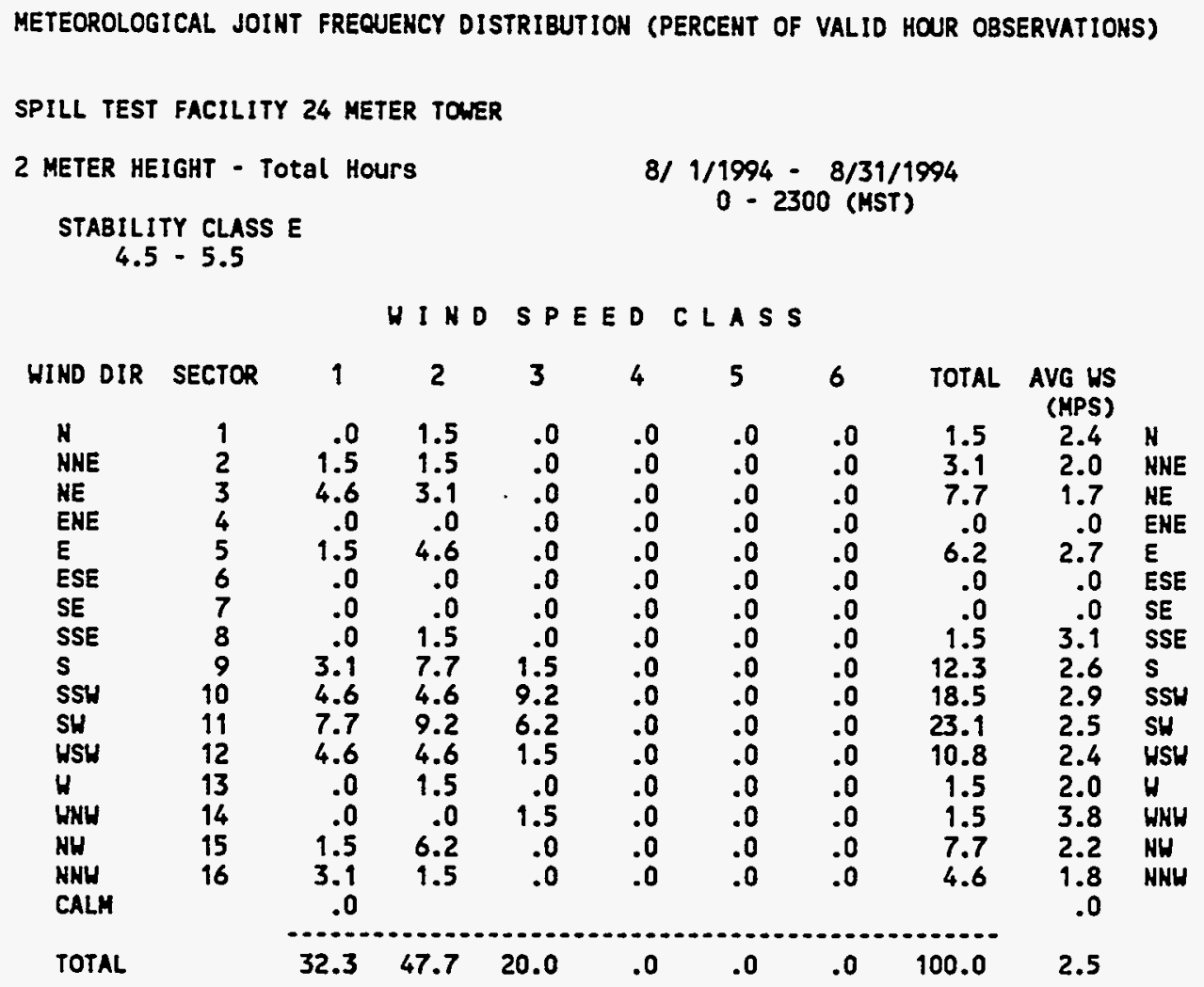

100.0\% DATA RECOVERED

8.7\% OF RECOVERED DATA REPORTED ABOVE

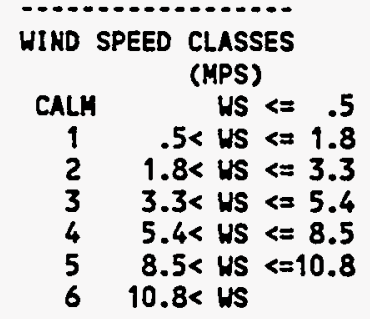


METEOROLOGICAL JOINT FREQUENCY DISTRIBUTION (PERCENT OF VALID HOUR OBSERVATIONS)

SPILL TEST FACILITY 24 METER TONER

2 METER HEIGHT - Total Hours

$9 / 1 / 1994-9 / 30 / 1994$

STABILITY CLASS E

D - 2300 (MST)

$$
4.5-5.5
$$

HIND SPEEDCLASS

\begin{tabular}{|c|c|c|c|c|c|c|c|c|c|c|}
\hline HIND DIR & SECTOR & 1 & 2 & 3 & 4 & 5 & 6 & TOTAL & AVG US & \\
\hline$N$ & 1 & 7.9 & .0 & .0 & .0 & .0 & .0 & 7.9 & 1.0 & N \\
\hline HNE & 2 & 3.0 & 1.0 & 1.0 & .0 & .0 & .0 & 5.0 & 1.7 & NME \\
\hline NE & 3 & 3.0 & 1.0 & .0 & .0 & .0 & .0 & 4.0 & 1.4 & NE \\
\hline ENE & 4 & 3.0 & .0 & .0 & .0 & .0 & .0 & 3.0 & 1.0 & ENE \\
\hline$E$ & 5 & .0 & .0 & .0 & .0 & .0 & .0 & .0 & .0 & $E$ \\
\hline ESE & 6 & 2.0 & .0 & .0 & .0 & .0 & .0 & 2.0 & .7 & ESE \\
\hline SE & 7 & 2.0 & .0 & .0 & .0 & .0 & .0 & 2.0 & 1.3 & SE \\
\hline SSE & 8 & 1.0 & .0 & 1.0 & .0 & .0 & .0 & 2.0 & 2.7 & SSE \\
\hline $\mathbf{s}$ & 9 & 5.9 & 1.0 & 1.0 & .0 & .0 & .0 & 7.9 & 1.4 & $\mathbf{s}$ \\
\hline SSW & 10 & 11.9 & 5.0 & .0 & .0 & .0 & .0 & 16.8 & 1.5 & SSH \\
\hline SH & 11 & 15.8 & 5.0 & 3.0 & .0 & .0 & .0 & 23.8 & 1.8 & SH \\
\hline HSH & 12 & 5.9 & 3.0 & 2.0 & .0 & .0 & .0 & 10.9 & 2.1 & WSH \\
\hline H & 13 & $\begin{array}{l}5.0 \\
2.0\end{array}$ & 9.0 & .0 & $\begin{array}{l}0 \\
0\end{array}$ & .0 & .0 & $\begin{array}{l}5.9 \\
3.0\end{array}$ & 1.2 & W \\
\hline WH & $\begin{array}{l}14 \\
15\end{array}$ & 1.0 & 1.0 & .0 & .0 & .0 & .0 & 2.0 & 1.5 & NH \\
\hline $\begin{array}{l}\text { NNH } \\
\text { CALM }\end{array}$ & 16 & $\begin{array}{r}2.0 \\
.0\end{array}$ & 2.0 & .0 & .0 & .0 & .0 & & $\begin{array}{r}1.9 \\
.0\end{array}$ & HNH \\
\hline TOTAL & & 71.3 & 20.8 & 7.9 & .0 & .0 & 0 & 100.0 & 1.6 & \\
\hline
\end{tabular}

99.7\% DATA RECOVERED

14.1\% OF RECOVERED DATA REPORTED ABOVE 
METEOROLOGICAL JOIHT FREQUENCY DISTRIBUTION (PERCEHT OF VALID HOUR OBSERVATIOHS) SPILL TEST FACILITY 24 METER TOWER

2 METER HEIGHT - TOtal HOURS

$10 / 1 / 1994 \cdot 10 / 31 / 1994$

STABILITY CLASS E

0 - 2300 (MST)

HIND SPEED CLASS

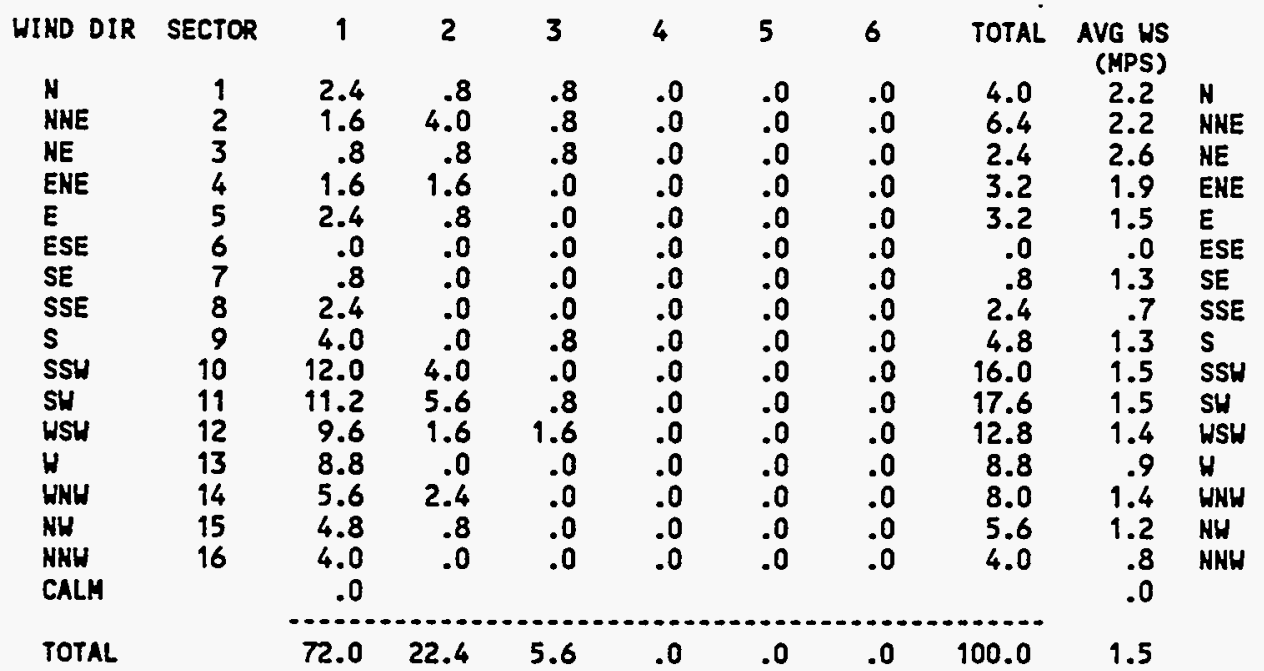

100.0\% DATA RECOVERED

16.8\% OF RECOVERED DATA

REPORTED ABOVE

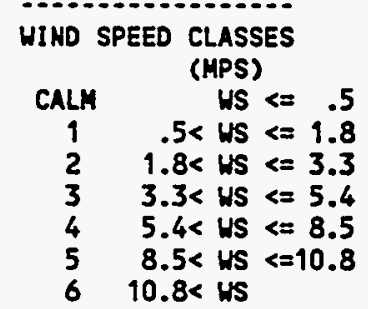


METEOROLOGICAL JOIHT FREQUENCY DISTRIBUTION (PERCENT OF VALID HOUR OBSERVATIONS)

SPILL TEST FACILITY 24 METER TOWER

2 METER HEIGHT - Total Hours

$11 / 1 / 1994-11 / 30 / 1994$

STABILITY CLASS E

$0 \cdot 2300$ (MST)

$4.5-5.5$

HINDSPEED CLASS

\begin{tabular}{|c|c|c|c|c|c|c|c|c|c|c|}
\hline WIHD DIR & SECTOR & 1 & 2 & 3 & 4 & 5 & 6 & TOTAL & $\begin{array}{r}\text { AVG US } \\
\text { (MPS) }\end{array}$ & \\
\hline N & 1 & 1.2 & 3.7 & .0 & .0 & .0 & .0 & 4.9 & 2.6 & N \\
\hline HNE & 2 & 2.5 & 4.9 & 3.7 & .0 & .0 & .0 & 11.1 & 2.7 & NHE \\
\hline $\begin{array}{l}\text { ME } \\
\text { EME }\end{array}$ & 3 & .0 & 6.2 & .0 & .0 & .0 & .0 & 6.2 & 2.5 & $\begin{array}{l}\text { NE } \\
\text { ENE }\end{array}$ \\
\hline $\begin{array}{l}\text { ENE } \\
E\end{array}$ & $\begin{array}{l}4 \\
5\end{array}$ & $\begin{array}{l}3.7 \\
3.7\end{array}$ & $\begin{array}{r}3.7 \\
.0\end{array}$ & $\begin{array}{r}.0 \\
1.2\end{array}$ & $\begin{array}{l}.0 \\
.0\end{array}$ & $\begin{array}{l}.0 \\
.0\end{array}$ & $\begin{array}{l}.0 \\
.0\end{array}$ & $\begin{array}{l}7.4 \\
4.9\end{array}$ & $\begin{array}{l}1.6 \\
2.0\end{array}$ & $\begin{array}{l}\text { ENE } \\
\text { E }\end{array}$ \\
\hline ESE & 6 & 1.2 & .0 & .0 & .0 & .0 & .0 & 1.2 & .9 & ESE \\
\hline SE & 7 & 2.5 & .0 & .0 & .0 & .0 & .0 & 2.5 & 1.6 & SE \\
\hline & & & $\begin{array}{r}.0 \\
3.7\end{array}$ & $\begin{array}{l}.0 \\
.0\end{array}$ & $\begin{array}{l}.0 \\
.0\end{array}$ & $\begin{array}{l}.0 \\
.0\end{array}$ & $\begin{array}{l}.0 \\
.0\end{array}$ & $\begin{array}{l}2.5 \\
4.9\end{array}$ & $\begin{array}{l}1.1 \\
2.0\end{array}$ & $\begin{array}{l}\text { SSE } \\
\text { S }\end{array}$ \\
\hline SSH & 10 & 1.2 & 6.2 & .0 & .0 & .0 & .0 & 7.4 & 1.9 & SSW \\
\hline SW & $\begin{array}{l}11 \\
12\end{array}$ & $\begin{array}{r}11.1 \\
4.9\end{array}$ & 4.9 & $\begin{array}{l}2.5 \\
2.5\end{array}$ & $\therefore$ & .0 & .0 & 18.5 & 1.8 & SW \\
\hline WSW & $\begin{array}{l}12 \\
13\end{array}$ & $\begin{array}{l}4.9 \\
4.9\end{array}$ & .0 & $\begin{array}{r}2.5 \\
.0\end{array}$ & $\begin{array}{r}1.2 \\
.0\end{array}$ & $\begin{array}{l}.0 \\
.0\end{array}$ & $\begin{array}{l}.0 \\
.0\end{array}$ & $\begin{array}{l}8.0 \\
4.9\end{array}$ & $\begin{array}{l}2.4 \\
1.1\end{array}$ & $\mathrm{H}$ \\
\hline WNH & 14 & 3.7 & 2.5 & .0 & .0 & .0 & .0 & 6.2 & 1.4 & WNH \\
\hline NH & 15 & .0 & 6.2 & .0 & .0 & .0 & .0 & 6.2 & 2.6 & NW \\
\hline HसH & 16 & 1.2 & 1.2 & .0 & .0 & .0 & .0 & 2.5 & 2.0 & HNG \\
\hline CALM & & 0 & & & & & & & .0 & \\
\hline TOTAL & & 45.7 & 43.2 & 9.9 & 1.2 & .0 & .0 & 100.0 & 2.0 & \\
\hline
\end{tabular}

100.0\% DATA RECOVERED

11.3\% OF RECOVERED DATA REPORTED ABOVE

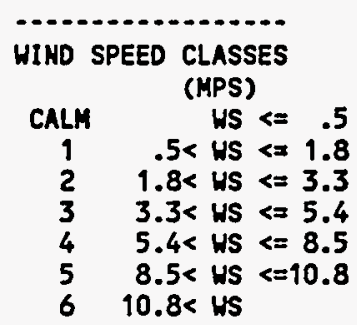


METEOROLOGICAL JOINT FREQUENCY DISTRIBUTION (PERCENT OF VALID HOUR OBSERVATIONS)

SPILL TEST FACILITY 24 METER TOWER

2 METER HEIGHT - TOtal HourS

12/ $1 / 1994-12 / 31 / 1994$

STABILITY CLASS E

$0-2300$ (MST)

$4.5-5.5$

UINO SPEED CLASS

$\begin{array}{lrrrrrrrrrr}\text { HIND DIR } & \text { SECTOR } & 1 & 2 & 3 & 4 & 5 & 6 & \text { TOTAL } & \begin{array}{c}\text { AVG US } \\ \text { (MPS) }\end{array} \\ \text { H } & 1 & .0 & .0 & 2.2 & .0 & .0 & .0 & 2.2 & 3.9 & \text { N } \\ \text { NHE } & 2 & 2.2 & 8.7 & 2.2 & .0 & .0 & .0 & 13.0 & 2.6 & \text { NWE } \\ \text { NE } & 3 & 4.3 & 2.2 & 2.2 & .0 & .0 & .0 & 8.7 & 2.5 & \text { NE } \\ \text { ENE } & 4 & 4.3 & 4.3 & .0 & .0 & .0 & .0 & 8.7 & 1.7 & \text { ENE } \\ \text { E } & 5 & .0 & 4.3 & .0 & .0 & .0 & .0 & 4.3 & 2.4 & \text { E } \\ \text { ESE } & 6 & 2.2 & .0 & .0 & .0 & .0 & .0 & 2.2 & .6 & \text { ESE } \\ \text { SE } & 7 & 2.2 & 2.2 & .0 & .0 & .0 & .0 & 4.3 & 1.5 & \text { SE } \\ \text { SSE } & 8 & 2.2 & .0 & .0 & .0 & .0 & .0 & 2.2 & .6 & \text { SSE } \\ \text { S } & 9 & .0 & .0 & .0 & .0 & .0 & .0 & .0 & .0 & \text { S } \\ \text { SSH } & 10 & .0 & 2.2 & 2.2 & .0 & .0 & .0 & 4.3 & 3.6 & \text { SSH } \\ \text { SH } & 11 & 13.0 & .0 & .0 & .0 & .0 & .0 & 13.0 & 1.2 & \text { SH } \\ \text { HSH } & 12 & 6.5 & 2.2 & .0 & .0 & .0 & .0 & 8.7 & 1.3 & \text { WSH } \\ \text { H } & 13 & .0 & .0 & .0 & .0 & .0 & .0 & .0 & .0 & \text { H } \\ \text { WHW } & 14 & .0 & .0 & .0 & .0 & .0 & .0 & .0 & .0 & \text { WNH } \\ \text { NH } & 15 & .0 & 8.7 & .0 & .0 & .0 & .0 & 8.7 & 2.7 & \text { NH } \\ \text { NNH } & 16 & 6.5 & 13.0 & .0 & .0 & .0 & .0 & 19.6 & 2.3 & \text { NHW } \\ \text { CALM } & & .0 & & & & & & & .0 & \end{array}$

TOTAL

$\begin{array}{lll}43.5 & 47.8 & 8.7\end{array}$

.0

00.0

2.1

65.1\% DATA RECOVERED

9.5\% OF RECOVERED DATA REPORTED ABOVE

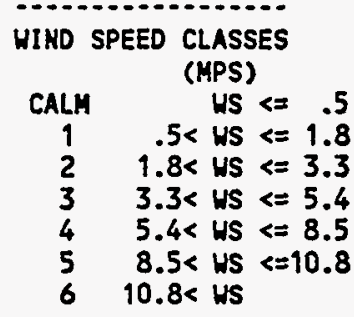


METEOROLOGICAL JOINT FREQUENCY OISTRIBUTION (PERCENT OF VALID HOUR OBSERVATIONS)

SPILL TEST FACILITY 24 METER TONER
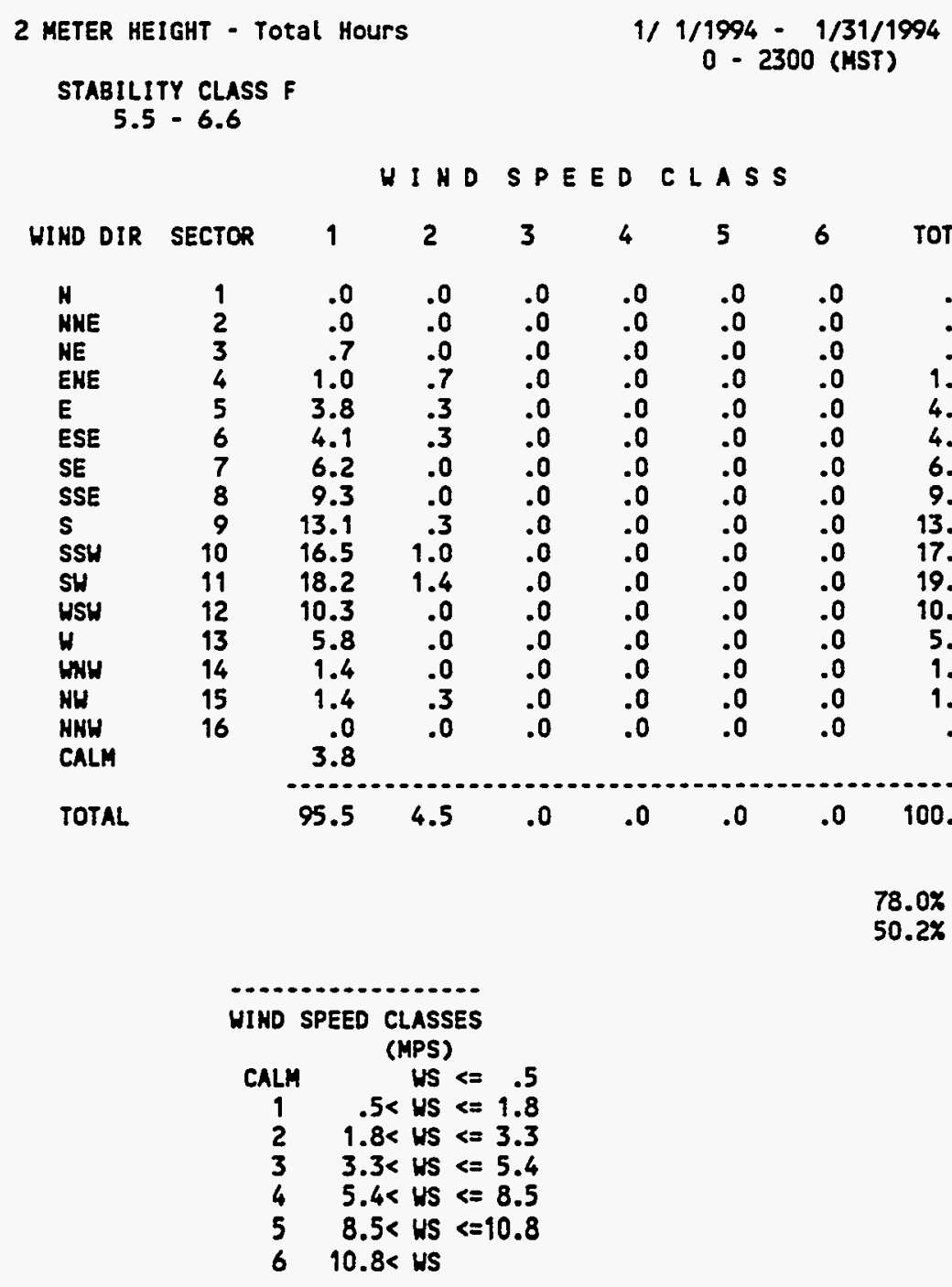
METEOROLOGICAL JOINT FREQUENCY DISTRIBUTION (PERCENT OF VALID HOUR OBSERVATIONS)

SPILL TEST FACILITY 24 METER TOWER

2 METER HEIGHT - Total Hours

2/ $1 / 1994-2 / 28 / 1994$

STABILITY CLASS F

0 - 2300 (HST)

HIND SPEED CLASS

\begin{tabular}{|c|c|c|c|c|c|c|c|c|c|c|}
\hline WIND OIR & SECTOR & 1 & 2 & 3 & 4 & 5 & 6 & TOTAL & $\begin{array}{l}\text { AVG US } \\
\text { (MPS) }\end{array}$ & \\
\hline N & 1 & 5.7 & .9 & .0 & .0 & .0 & .0 & 6.6 & 1.4 & $\mathbf{N}$ \\
\hline NNE & 2 & 5.7 & .4 & .0 & .0 & .0 & .0 & 6.1 & 1.2 & NHE \\
\hline NE & 3 & 2.2 & .9 & .0 & .0 & .0 & .0 & 3.1 & 1.4 & NE \\
\hline ENE & 4 & 5.3 & .0 & .0 & .0 & .0 & .0 & 5.3 & 1.0 & ENE \\
\hline $\mathbf{E}$ & 5 & 3.1 & .0 & .0 & .0 & .0 & .0 & 3.1 & 1.1 & $\bar{E}$ \\
\hline ESE & 6 & 1.3 & .0 & .0 & .0 & .0 & .0 & 1.3 & .9 & ESE \\
\hline SE & 7 & 3.5 & .9 & .0 & .0 & .0 & .0 & 4.4 & 1.1 & SE \\
\hline SSE & 8 & 3.1 & .9 & .0 & .0 & .0 & .0 & 3.9 & 9.2 & SSE \\
\hline s & 9 & 3.9 & .4 & .0 & .0 & .0 & .0 & 4.4 & 1.0 & $s$ \\
\hline SSH & 10 & 8.3 & .0 & .0 & .0 & .0 & .0 & 8.3 & 1.0 & SSH \\
\hline SH & 11 & 11.8 & .0 & .0 & .0 & .0 & .0 & 11.8 & 1.0 & SH \\
\hline WSH & 12 & 7.9 & 1.3 & .0 & .0 & .0 & .0 & 9.2 & 1.3 & WSH \\
\hline H & 13 & 7.9 & .4 & .0 & .0 & .0 & .0 & 8.3 & 1.1 & H \\
\hline WNH & 14 & 9.2 & .9 & .0 & .0 & .0 & .0 & 10.1 & 1.3 & HNH \\
\hline $\begin{array}{l}\text { NW } \\
\text { NWW }\end{array}$ & $\begin{array}{l}15 \\
16\end{array}$ & $\begin{array}{l}6.6 \\
4.4\end{array}$ & $\begin{array}{l}.0 \\
.0\end{array}$ & $\begin{array}{l}.0 \\
.0\end{array}$ & $\begin{array}{l}.0 \\
.0\end{array}$ & $\begin{array}{l}.0 \\
.0\end{array}$ & $\begin{array}{l}.0 \\
.0\end{array}$ & $\begin{array}{l}6.6 \\
4.4\end{array}$ & $\begin{array}{l}1.0 \\
1.1\end{array}$ & $\begin{array}{l}\text { NH } \\
\text { NNH }\end{array}$ \\
\hline CALM & & 3.1 & & & & & & & 3.1 & \\
\hline TOTAL & & 93.0 & 7.0 & .0 & .0 & .0 & .0 & 100.0 & 1.1 & \\
\hline
\end{tabular}

85.4\% DATA RECOVERED

39.7\% OF RECOVERED DATA REPORTED ABOVE

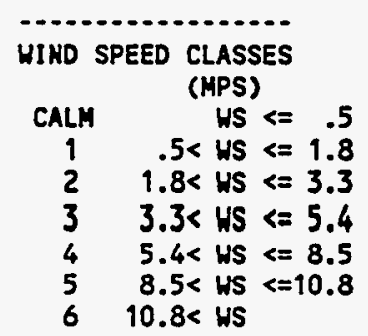


METEOROLOGICAL JOINT FREQUENCY OISTRIBUTION (PERCENT OF VALID HOUR OBSERVATIONS)

SPILL TEST FACILITY 24 METER TOWER

2 METER HEIGHT - Total Hours

$3 / 1 / 1994 \cdot 3 / 31 / 1994$

STABILITY CLASS F

$0-2300$ (MST)

$5.5 \cdot 6.6$

HIND SPEED CLASS

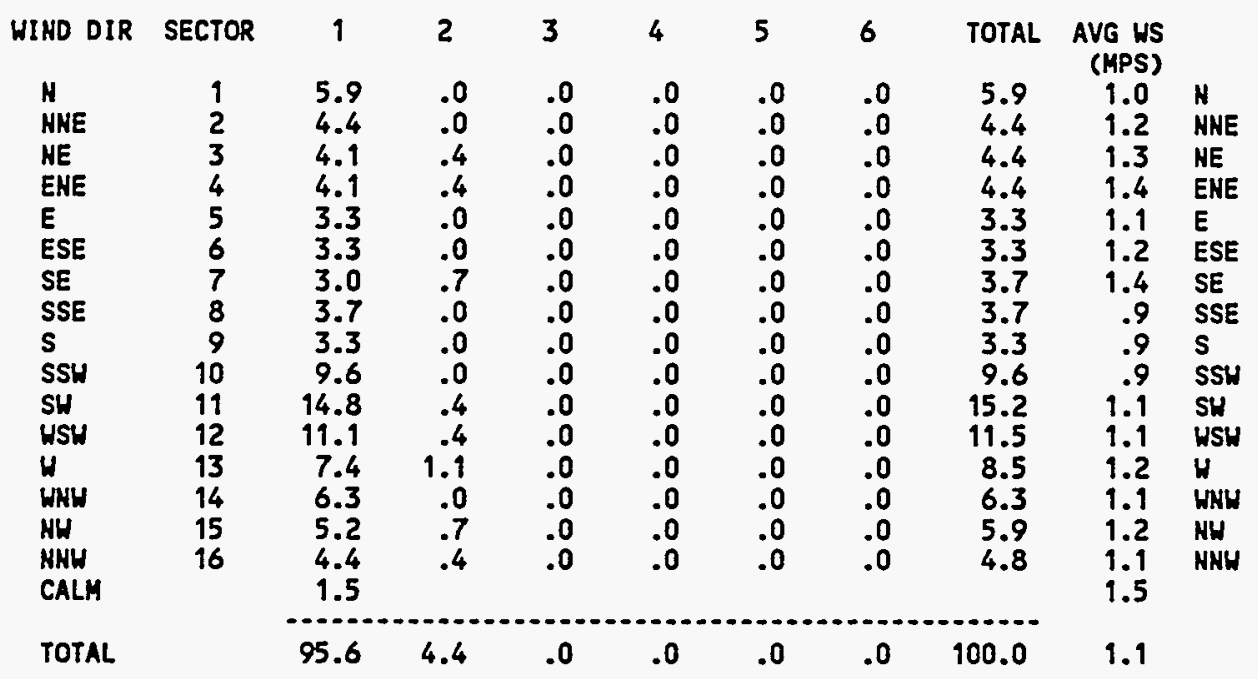

100.0\% DATA RECOVERED

36.3\% OF RECOVERED DATA REPORTED ABOVE

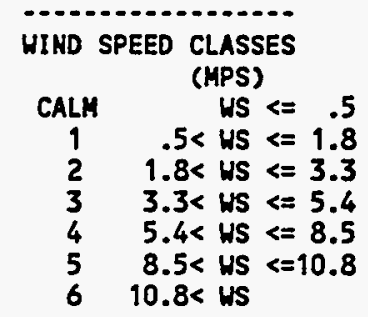


METEOROLOGICAL JOINT FREQUENCY DISTRIBUTION (PERCENT OF VALID HOUR OBSERVATIONS) SPILL TEST FACILITY 24 METER TONER

2 METER HEIGHT - Total HOURS

$4 / 1 / 1994 \cdot 4 / 30 / 1994$

STABILITY CLASS F

$0-2300$ (MST)

$5.5-6.6$

WIND SPEED CLASS

\begin{tabular}{|c|c|c|c|c|c|c|c|c|c|c|}
\hline HIND OIR & SECTOR & 1 & 2 & 3 & 4 & 5 & 6 & TOTAL & $\begin{array}{r}\text { AVG US } \\
\text { (MPS) }\end{array}$ & \\
\hline H & 1 & .0 & .0 & .0 & .0 & .0 & .0 & .0 & .0 & N \\
\hline NNE & 2 & .5 & .0 & .0 & .0 & .0 & .0 & .5 & 1.5 & NHE \\
\hline HE & 3 & 2.9 & .0 & .0 & .0 & .0 & .0 & 2.1 & 1.2 & ME \\
\hline ENE & 4 & 2.1 & .0 & .0 & .0 & .0 & .0 & 2.1 & 1.2 & ENE \\
\hline $\begin{array}{l}E \\
\text { ESE }\end{array}$ & $\begin{array}{l}5 \\
6\end{array}$ & 2.1 & $\begin{array}{r}.0 \\
0\end{array}$ & $\begin{array}{l}.0 \\
.0\end{array}$ & $\begin{array}{l}.0 \\
.0\end{array}$ & .0 & $\begin{array}{r}.0 \\
.0\end{array}$ & $\begin{array}{l}2.1 \\
3.7\end{array}$ & 1.3 & $\begin{array}{l}\text { E } \\
\text { ESE }\end{array}$ \\
\hline SE & 7 & 6.3 & .0 & .0 & .0 & .0 & $\begin{array}{l}.0 \\
.0\end{array}$ & $\begin{array}{l}3.1 \\
6.9\end{array}$ & 1.6 & SE \\
\hline SSE & 8 & 8.5 & .0 & .0 & .0 & .0 & .0 & 8.5 & .9 & SSE \\
\hline s & 9 & 11.1 & 1.1 & .0 & .0 & .0 & .0 & 12.2 & 1.1 & $s$ \\
\hline SSH & 10 & 9.0 & .0 & .0 & .0 & .0 & .0 & 9.0 & 1.0 & SSH \\
\hline SH & 11 & 17.5 & 1.1 & .0 & .0 & .0 & .0 & 18.5 & 1.2 & SH \\
\hline WSH & 12 & 15.3 & .5 & .0 & .0 & .0 & .0 & 15.9 & 1.1 & WSW \\
\hline Wu & 13 & $\begin{array}{l}6.9 \\
3.7\end{array}$ & $\begin{array}{r}1.1 \\
5\end{array}$ & .0 & .0 & .0 & .0 & 7.9 & 1.3 & $\begin{array}{l}W \\
\text { WWW }\end{array}$ \\
\hline NH & 15 & 4.8 & .0 & .0 & .0 & .0 & .0 & 4.8 & 1.2 & NW \\
\hline $\begin{array}{l}\text { NHW } \\
\text { CALM }\end{array}$ & 16 & $\begin{array}{r}.0 \\
1.6\end{array}$ & .0 & .0 & .0 & .0 & .0 & & $\begin{array}{r}.0 \\
1.6\end{array}$ & NNW \\
\hline TOTAL & & 9 & 4.8 & .0 & .0 & .0 & 0 & 100.0 & 1.1 & \\
\hline $101 \mathrm{~A}$ & & & 4.0 & .0 & .0 & .0 & .0 & 100.0 & 1.1 & \\
\hline
\end{tabular}

99.4\% DATA RECOVERED

26.4\% OF RECOVERED DATA REPORTED ABOVE

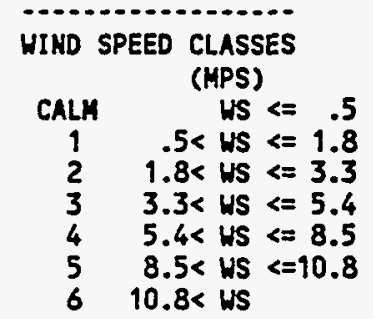


METEOROLOGICAL JOINT FREQUENCY DISTRIBUTION (PERCENT OF VALID HOUR OBSERVATIONS)

SPILL TEST FACILITY 24 METER TOWER
2 METER HEIGHT - Total Hours
$5 / 1 / 1994-5 / 31 / 1994$
STABILITY CLASS F
0 - 2300 (MST)

$5.5-6.6$

HI D SPEED CLASS

\begin{tabular}{|c|c|c|c|c|c|c|c|c|c|c|}
\hline HIKD DIR & SECTOR & 1 & 2 & 3 & 4 & 5 & 6 & TOTAL & $\begin{array}{l}\text { AVG US } \\
\text { (MPS) }\end{array}$ & \\
\hline N & 1 & 6.9 & .0 & .0 & .0 & .0 & .0 & 6.9 & 1.1 & $\mathbf{N}$ \\
\hline HNE & 2 & 4.8 & .0 & .0 & .0 & .0 & .0 & 4.8 & 1.2 & NNE \\
\hline NE & 3 & 4.8 & .0 & .0 & .0 & .0 & .0 & 4.8 & 1.4 & NE \\
\hline ENE & 4 & 2.7 & 1.6 & .0 & .0 & .0 & .0 & 4.3 & 1.6 & ENE \\
\hline$E$ & 5 & 2.1 & .0 & .0 & .0 & .0 & .0 & 2.1 & .7 & $\mathbf{E}$ \\
\hline ESE & 6 & 3.2 & 1.6 & .0 & .0 & .0 & .0 & 4.8 & 1.5 & ESE \\
\hline SE & 7 & 2.1 & .0 & .0 & .0 & .0 & .0 & 2.1 & 1.1 & SE \\
\hline SSE & 8 & 2.7 & 1.1 & .0 & .0 & .0 & .0 & 3.7 & 1.1 & SSE \\
\hline s & $\begin{array}{r}9 \\
10\end{array}$ & $\begin{array}{l}4.3 \\
4.8\end{array}$ & .5 & .0 & .0 & .0 & .0 & 4.8 & 1.0 & $S$ \\
\hline $\begin{array}{l}\text { SSH } \\
\text { SW }\end{array}$ & $\begin{array}{l}10 \\
11\end{array}$ & $\begin{array}{r}4.8 \\
13.3\end{array}$ & .5 & $\begin{array}{l}.0 \\
.0\end{array}$ & $\begin{array}{r}.0 \\
0\end{array}$ & $\begin{array}{l}.0 \\
.0\end{array}$ & .0 & $\begin{array}{r}5.3 \\
13.3\end{array}$ & 1.2 & SSW \\
\hline USH & 12 & 6.9 & .5 & .0 & .0 & .0 & .0 & 7.4 & 1.2 & WSW \\
\hline Hus & 13 & 7.4 & .0 & .0 & .0 & .0 & .0 & 7.4 & 1.1 & W \\
\hline WNW & $\begin{array}{l}14 \\
15\end{array}$ & $\begin{array}{l}8.5 \\
8.5\end{array}$ & 1.1 & .0 & .0 & .0 & .0 & 9.6 & 1.1 & WHW \\
\hline $\begin{array}{l}\text { NIN } \\
\text { NWH }\end{array}$ & $\begin{array}{l}15 \\
16\end{array}$ & 5. & 1.1 & .0 & $\begin{array}{l}.0 \\
.0\end{array}$ & $\begin{array}{l}.0 \\
.0\end{array}$ & $\begin{array}{l}.0 \\
.0\end{array}$ & $\begin{array}{l}8.5 \\
6.9\end{array}$ & $\begin{array}{l}1.2 \\
1.3\end{array}$ & $\begin{array}{l}\text { NH } \\
\text { NNH }\end{array}$ \\
\hline CALH & & & & & & & & & 3.2 & \\
\hline TOTAL & & 92. & 8.0 & .0 & .0 & .0 & .0 & 100.0 & 1.1 & \\
\hline
\end{tabular}

96.9\% DATA RECOVERED

26.1\% OF RECOVERED DATA REPORTED ABOVE

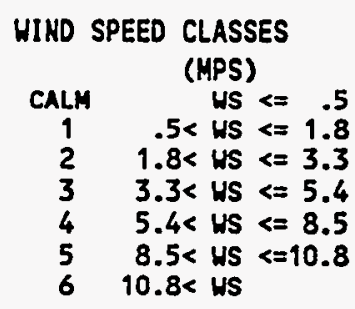


METEOROLOGICAL JOINT FREQUENCY DISTRIBUTION (PERCENT OF VALID HOUR OBSERVATIONS) SPILL TEST FACILITY 24 METER TONER

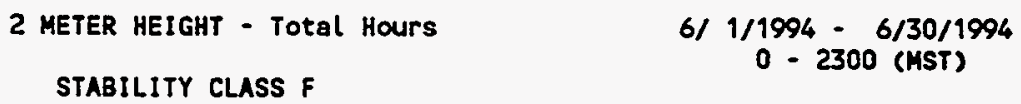

HIND SPEED CLASS

\begin{tabular}{|c|c|c|c|c|c|c|c|c|c|c|}
\hline WIND DIR & SECTOR & 1 & 2 & 3 & 4 & 5 & 6 & TOTAL & $\begin{array}{l}\text { AVG US } \\
\text { (MPS) }\end{array}$ & \\
\hline $\mathrm{N}$ & 1 & 5.4 & .0 & .0 & .0 & .0 & .0 & 5.4 & 1.1 & H \\
\hline NNE & 2 & 5.9 & 1.6 & .0 & .0 & .0 & .0 & 7.5 & 1.4 & MHE \\
\hline NE & 3 & 5.9 & .5 & .0 & .0 & .0 & .0 & 6.5 & 1.3 & $\mathrm{NE}$ \\
\hline ENE & 4 & 5.9 & .0 & .0 & .0 & .0 & .0 & 5.9 & 1.2 & ENE \\
\hline$E$ & 5 & 3.8 & .5 & .0 & .0 & .0 & .0 & 4.3 & 1.2 & $E$ \\
\hline ESE & 6 & .5 & .5 & .0 & .0 & .0 & .0 & 1.1 & 1.8 & ESE \\
\hline $\begin{array}{l}\text { SE } \\
\text { SSE }\end{array}$ & $\begin{array}{l}7 \\
8\end{array}$ & $\begin{array}{l}1.6 \\
2.2\end{array}$ & $\begin{array}{l}.0 \\
.0\end{array}$ & $\begin{array}{l}.0 \\
.0\end{array}$ & $\begin{array}{l}.0 \\
.0\end{array}$ & $\begin{array}{l}.0 \\
.0\end{array}$ & $\begin{array}{l}.0 \\
.0\end{array}$ & $\begin{array}{l}1.6 \\
2.2\end{array}$ & $\begin{array}{l}1.2 \\
1.1\end{array}$ & $\begin{array}{l}\text { SE } \\
\text { SSE }\end{array}$ \\
\hline $\mathrm{s}$ & 9 & 4.8 & .5 & .0 & .0 & .0 & .0 & 5.4 & 1.1 & $\mathbf{s}$ \\
\hline SSW & 10 & 8.1 & .5 & .0 & .0 & .0 & .0 & 8.6 & 1.2 & SSH \\
\hline SH & 11 & 14.5 & 1.1 & .0 & .0 & .0 & .0 & 15.6 & 1.1 & SH \\
\hline USW & 12 & 6.5 & .5 & .0 & .0 & .0 & .0 & 7.0 & 1.3 & WSH \\
\hline H & 13 & 11.3 & .0 & .0 & .0 & .0 & .0 & 11.3 & 1.0 & $H$ \\
\hline WHW & 14 & 9.7 & .5 & .0 & .0 & .0 & .0 & 10.2 & 1.0 & WNH \\
\hline NH & 15 & 1.6 & .5 & .0 & .0 & .0 & .0 & 2.2 & 9.3 & HH \\
\hline $\begin{array}{l}\text { NHW } \\
\text { CALM }\end{array}$ & 16 & $\begin{array}{r}4.8 \\
.5\end{array}$ & .0 & .0 & .0 & .0 & .0 & 4.8 & $\begin{array}{r}1.1 \\
.5\end{array}$ & NHE \\
\hline & & & & & & & & & & \\
\hline TOTAL & & 93.0 & 7.0 & .0 & .0 & .0 & .0 & 100.0 & 1.1 & \\
\hline
\end{tabular}

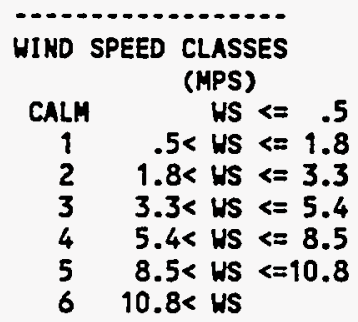


METEOROLOGICAL JOINT FREQUENCY OISTRIBUTION (PERCENT OF VALID HOUR OBSERVATIONS) SPILL TEST FACILITY 24 METER TONER

2 METER HEIGHT - Total HOURS

$$
\text { 7/ } 1 / 1994-7 / 31 / 1994
$$

STABILITY CLASS F

$0-2300$ (MST)

$$
5.5-6.6
$$

\begin{tabular}{|c|c|c|c|c|c|c|c|c|c|c|}
\hline HIMD DIR & SECTOR & 1 & 2 & 3 & 4 & 5 & 6 & TOTAL & $\begin{array}{l}\text { AVG US } \\
\text { (MPS) }\end{array}$ & \\
\hline N & 1 & 5.3 & .0 & .0 & .0 & .0 & .0 & 5.3 & 1.0 & N \\
\hline NNE & 2 & 7.3 & .0 & .0 & .0 & .0 & .0 & 7.3 & 1.2 & NHE \\
\hline HE & 3 & 8.7 & .0 & .0 & .0 & .0 & .0 & 8.7 & 1.3 & NE \\
\hline EHE & 4 & 7.3 & .5 & .0 & .0 & .0 & .0 & 7.8 & 1.3 & ENE \\
\hline$E$ & 5 & 6.3 & .0 & .0 & .0 & .0 & .0 & 6.3 & 1.1 & $E$ \\
\hline ESE & 6 & 1.5 & .0 & .0 & .0 & .0 & .0 & 1.5 & 1.5 & ESE \\
\hline $\begin{array}{l}\text { SE } \\
\text { SSE }\end{array}$ & & $\begin{array}{l}2.9 \\
1.9\end{array}$ & $\begin{array}{l}.0 \\
.0\end{array}$ & $\begin{array}{l}.0 \\
.0\end{array}$ & $\begin{array}{l}.0 \\
.0\end{array}$ & $\begin{array}{l}.0 \\
.0\end{array}$ & $\begin{array}{l}.0 \\
.0\end{array}$ & $\begin{array}{l}2.9 \\
1.9\end{array}$ & $\begin{array}{l}1.0 \\
1.3\end{array}$ & $\begin{array}{l}\text { SE } \\
\text { SSE }\end{array}$ \\
\hline s & 9 & 2.4 & .5 & .0 & .0 & .0 & .0 & 2.9 & 1.3 & 5 \\
\hline SSH & 10 & 8.3 & 1.0 & .0 & .0 & .0 & .0 & 9.2 & 1.2 & SSH \\
\hline SH & $\begin{array}{l}11 \\
12\end{array}$ & $\begin{array}{l}9.7 \\
4.4\end{array}$ & .5 & .0 & .0 & $\begin{array}{r}.0 \\
0\end{array}$ & .0 & $\begin{array}{r}10.2 \\
4.9\end{array}$ & 1.0 & $\begin{array}{l}\text { SH } \\
\text { WSH }\end{array}$ \\
\hline USW & $\begin{array}{l}14 \\
13\end{array}$ & $\begin{array}{l}4.4 \\
9.2\end{array}$ & .0 & .0 & .0 & .0 & .0 & $\begin{array}{l}4.8 \\
9.2\end{array}$ & 1.1 & W \\
\hline WHW & 14 & 7.8 & .5 & .0 & .0 & .0 & .0 & 8.3 & 1.1 & WHW \\
\hline NH & 15 & 7.3 & .5 & .0 & .0 & .0 & .0 & 7.8 & 1.1 & NW \\
\hline NHM & 16 & 3.9 & .0 & .0 & .0 & .0 & .0 & 3.9 & .9 & NNH \\
\hline CALM & & 1. & & & & & & & 1.9 & \\
\hline TOTAL & & 96.1 & 3.9 & .0 & .0 & .0 & .0 & 100.0 & 1.1 & \\
\hline
\end{tabular}

HIHD SPEED CLASS

100.0X DATA RECOVERED

27.7\% OF RECOVERED DATA

REPORTED ABOVE

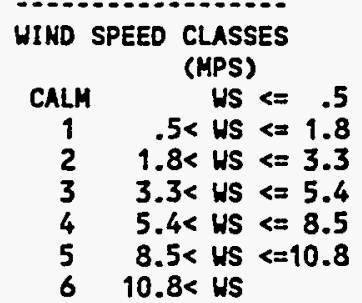


METEOROLOGICAL JOINT FREQUENCY DISTRIBUTION (PERCENT OF VALID HOUR OBSERVATIONS)

SPILL TEST FACILITY 24 METER TONER

2 METER HEIGHT - Total Hours

$8 / 1 / 1994-8 / 31 / 1994$

STABILITY CLASS F

$0 \cdot 2300$ (MST)

$5.5-6.6$

WI H SPEEDCLASS

\begin{tabular}{|c|c|c|c|c|c|c|c|c|c|c|}
\hline HIND DIR & SECTOR & 1 & 2 & 3 & 4 & 5 & 6 & TOTAL & $\begin{array}{l}\text { AVG US } \\
\text { (MPS) }\end{array}$ & \\
\hline N & q & 3.7 & .4 & .0 & .0 & .0 & .0 & 4.1 & 1.3 & H \\
\hline HAE & 2 & 11.4 & .8 & .0 & .0 & .0 & .0 & 12.2 & 1.2 & NME \\
\hline NE & 3 & 5.7 & .0 & .0 & .0 & .0 & .0 & 5.7 & 1.2 & NE \\
\hline ENE & 4 & 3.3 & .4 & .0 & .0 & .0 & .0 & 3.7 & 1.3 & ENE \\
\hline $\mathrm{E}$ & 5 & 4.5 & .4 & .0 & .0 & .0 & .0 & 4.9 & 1.2 & E \\
\hline ESE & 6 & 1.2 & .0 & .0 & .0 & .0 & .0 & 1.2 & 1.4 & ESE \\
\hline SE & 7 & 1.6 & .8 & .0 & .0 & .0 & .0 & 2.4 & 1.6 & SE \\
\hline $\begin{array}{l}\text { SSE } \\
\text { S }\end{array}$ & $\begin{array}{l}8 \\
9\end{array}$ & $\begin{array}{l}2.4 \\
2.0\end{array}$ & $\begin{array}{l}.0 \\
.4\end{array}$ & $\begin{array}{l}.0 \\
.0\end{array}$ & $\begin{array}{l}.0 \\
.0\end{array}$ & $\begin{array}{l}.0 \\
.0\end{array}$ & $\begin{array}{l}.0 \\
.0\end{array}$ & $\begin{array}{l}2.4 \\
2.4\end{array}$ & $\begin{array}{l}1.0 \\
1.1\end{array}$ & $\begin{array}{l}\text { SSE } \\
\text { S }\end{array}$ \\
\hline SSH & 10 & 6.5 & .4 & .0 & .0 & .0 & .0 & 6.9 & 1.1 & SSH \\
\hline SH & 11 & 9.4 & .4 & .0 & .0 & .0 & .0 & 9.8 & 1.0 & SH \\
\hline USW & 12 & 10.2 & .0 & .0 & .0 & .0 & .0 & 10.2 & 1.1 & HSW \\
\hline H & 13 & 6.9 & .0 & .0 & .0 & .0 & .0 & 6.9 & 1.1 & $w$ \\
\hline WN & 14 & 6.5 & .0 & .0 & .0 & .0 & .0 & 6.5 & 1.1 & HNH \\
\hline NH & 15 & 7.3 & 1.2 & .0 & .0 & .0 & .0 & 8.6 & 1.2 & NH \\
\hline $\begin{array}{l}\text { NHW } \\
\text { CALM }\end{array}$ & 16 & $\begin{array}{l}8.2 \\
2.9\end{array}$ & .8 & .0 & .0 & .0 & .0 & 9.0 & $\begin{array}{l}1.3 \\
2.9\end{array}$ & HNH \\
\hline TOTAL & & 93.9 & 6.1 & .0 & .0 & .0 & .0 & 100.0 & 1.1 & \\
\hline
\end{tabular}

100.0\% DATA RECOVERED

32.9\% OF RECOVERED DATA REPORTED ABOVE

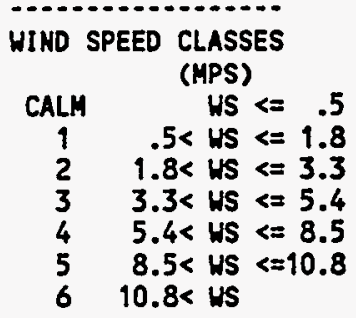


METEOROLOGICAL JOIHT FREQUENCY DISTRIBUTION (PERCENT OF VALID HOUR OBSERVATIONS) SPILL TEST FACILITY 24 METER TONER

2 METER HEIGHT - Total HOUrS

$9 / 1 / 1994-9 / 30 / 1994$

STABILITY CLASS F

0 - 2300 (MST)

$5.5-6.6$

HINDSPEED CLASS

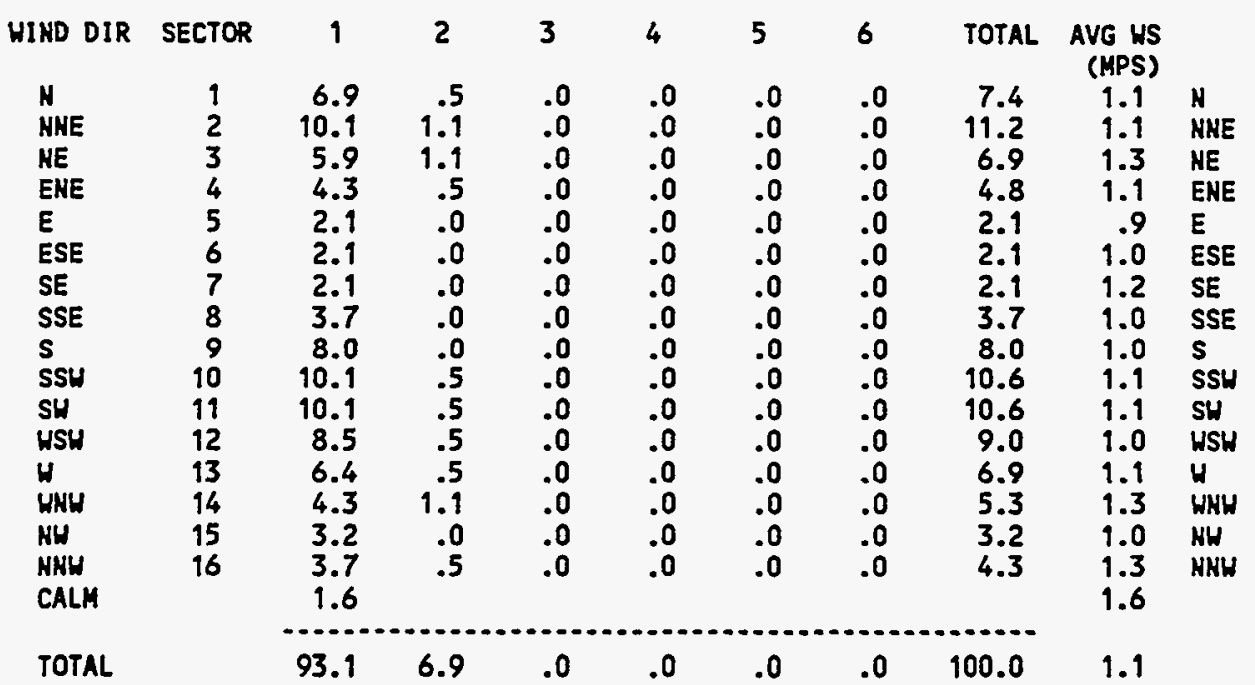

\$.7\% DATA RECOVERED

$26.2 \%$ OF RECOVERED DATA REPORTED ABOVE

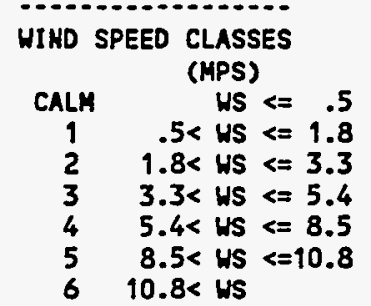


METEOROLOGICAL JOINT FREQUENCY DISTRIBUTIOH (PERCENT OF VALID HOUR OBSERVATIONS)

SPILL TEST FACILITY 24 METER TONER

2 METER HEIGHT - Total Hours

$10 / 1 / 1994 \cdot 10 / 31 / 1994$

STABILITY CLASS F

$5.5-6.6$

$0=2300$ (MST)

HIND SPEEDCLASS

\begin{tabular}{|c|c|c|c|c|c|c|c|c|c|c|}
\hline WIND DIR & SECTOR & 1 & 2 & 3 & 4 & 5 & 6 & TOTAL & AVG US & \\
\hline N & 1 & 4.4 & 1.3 & .0 & .0 & .0 & .0 & 5.7 & 1.3 & H \\
\hline NHE & 2 & 2.5 & .6 & .0 & .0 & .0 & .0 & 3.2 & 1.2 & NME \\
\hline HE & 3 & 5.7 & .6 & .0 & .0 & .0 & .0 & 6.3 & 1.2 & NE \\
\hline ENE & 4 & 6.3 & 1.3 & .0 & .0 & .0 & .0 & 7.6 & 1.4 & ENE \\
\hline E & 5 & 3.2 & .0 & .0 & .0 & .0 & .0 & 3.2 & .8 & E \\
\hline ESE & 6 & 3.2 & .6 & .0 & .0 & .0 & .0 & 3.8 & 1.2 & ESE \\
\hline SE & 7 & 1.3 & .0 & .0 & .0 & .0 & .0 & 1.3 & .9 & SE \\
\hline SSE & 8 & 1.9 & .0 & .0 & .0 & .0 & .0 & 1.9 & .8 & SSE \\
\hline s & 9 & 4.4 & .0 & .0 & .0 & .0 & .0 & 4.4 & 1.0 & s \\
\hline SSH & 10 & 8.2 & 1.3 & .0 & .0 & .0 & .0 & 9.5 & 1.3 & SSW \\
\hline SH & 11 & 16.5 & .6 & .0 & .0 & .0 & .0 & 17.1 & 1.1 & SW \\
\hline WSW & 12 & 8.9 & .6 & .0 & .0 & .0 & .0 & 9.5 & 1.0 & WSH \\
\hline 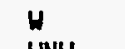 & 13 & 6.3 & .0 & .0 & .0 & .0 & .0 & 6.3 & 1.2 & H \\
\hline WNH & $\begin{array}{l}14 \\
15\end{array}$ & 3.8 & 1.3 & .0 & .0 & .0 & .0 & $\begin{array}{l}5.1 \\
5.1\end{array}$ & $\begin{array}{r}1.3 \\
.9\end{array}$ & $\begin{array}{l}\text { WWH } \\
\text { NH }\end{array}$ \\
\hline $\begin{array}{l}\text { NH } \\
\text { NNH }\end{array}$ & $\begin{array}{l}12 \\
16\end{array}$ & 7.0 & .6 & .0 & .0 & .0 & .0 & $\begin{array}{l}3.7 \\
7.6\end{array}$ & 1.2 & HNH \\
\hline CALH & & & & & & & & & 2.5 & \\
\hline TOTAL & & 91.1 & 8.9 & .0 & .0 & .0 & .0 & 100.0 & 1.1 & \\
\hline
\end{tabular}

100.0\% DATA RECOVERED

21.2\% OF RECOVERED DATA

REPORTED ABOVE

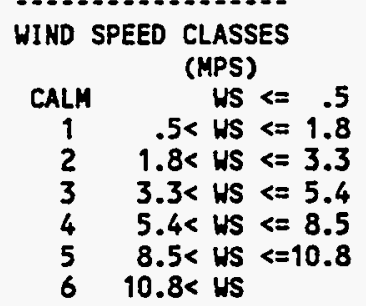


METEOROLOGICAL JOINT FREQUENCY DISTRIBUTION (PERCENT OF VALID HOUR OBSERVATIOHS)

SPILL TEST FACILITY 24 METER TONER

2 METER HEIGHT - Total Hours

$11 / 1 / 1994-11 / 30 / 1994$

STABILITY CLASS F

0 - 2300 (MST)

$$
5.5 \cdot 6.6
$$

HINDSPEEDCLASS

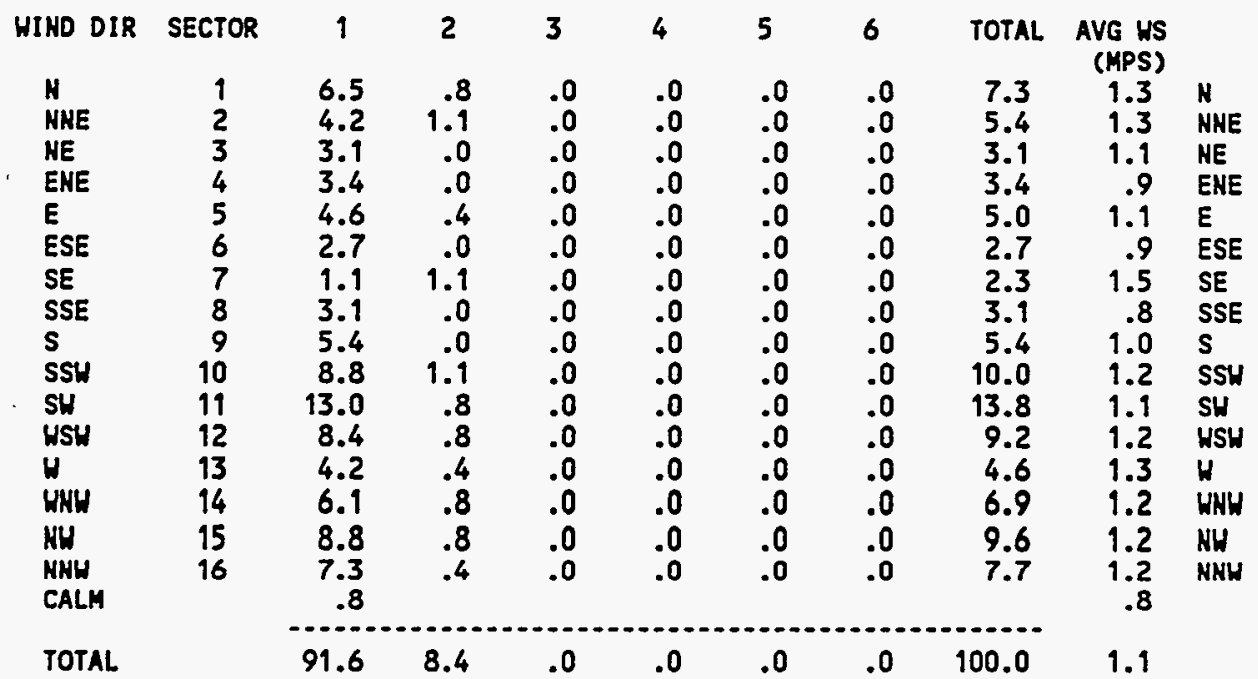

100.0\% DATA RECOVERED

36.3\% OF RECOVERED DATA REPORTED ABOVE

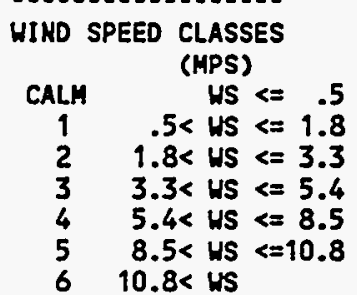


METEOROLOGICAL JOINT FREQUENCY DISTRIBUTION (PERCENT OF VALID HOUR OBSERVATIONS)

SPILL TEST FACILITY 24 METER TONER

2 METER HEIGHT - TOtal Hours

12/ $1 / 1994 \cdot 12 / 31 / 1994$

STABILITY CLASS F

$5.5 \cdot 6.6$

$0 \cdot 2300$ (HST)

HIHD SPEED CLASS

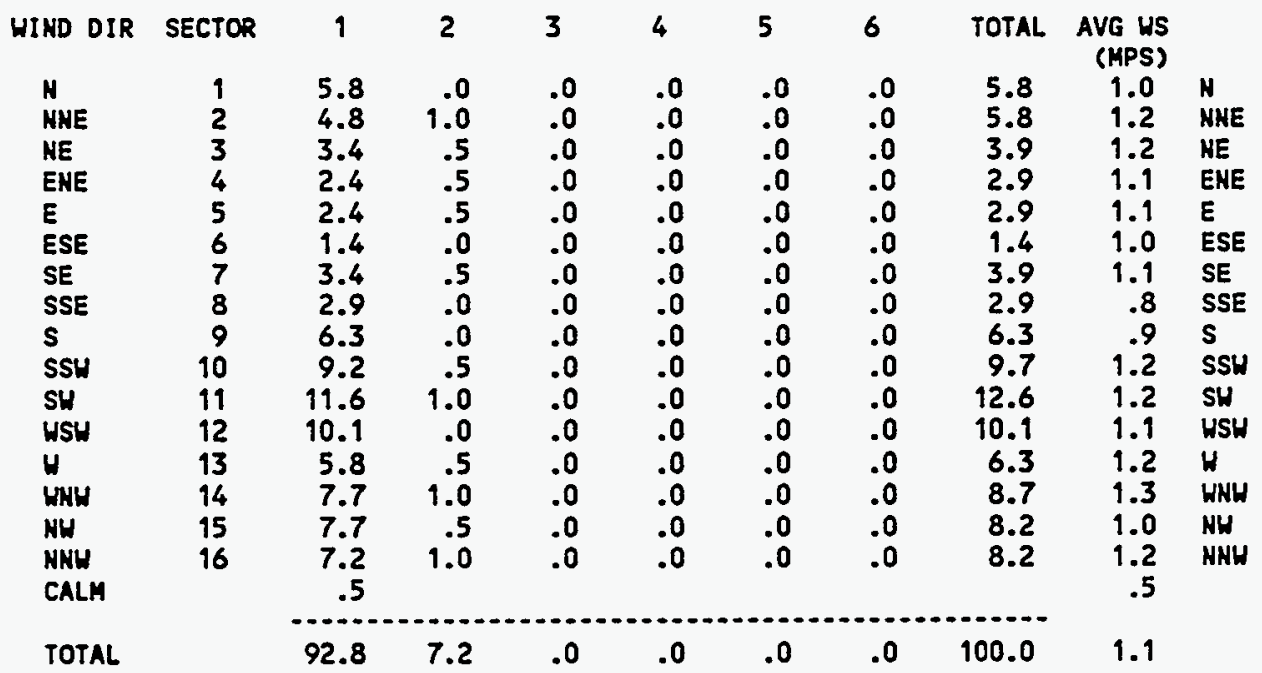

65.1\% DATA RECOVERED

42.8\% OF RECOVERED DATA

REPORTED ABOVE

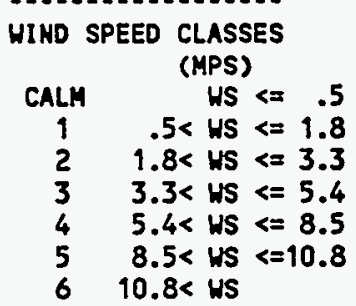


METEOROLOGICAL JOINT FREQUENCY DISTRIBUTION (PERCENT OF VALID HOUR OBSERVATIONS)

SPILL TEST FACILITY 24 METER TOUER

8 METER HEIGHT - TOtal Hours

$1 / 1 / 1994-1 / 31 / 1994$
$0-2300$ (MST)

WINDSPEEDCLASS

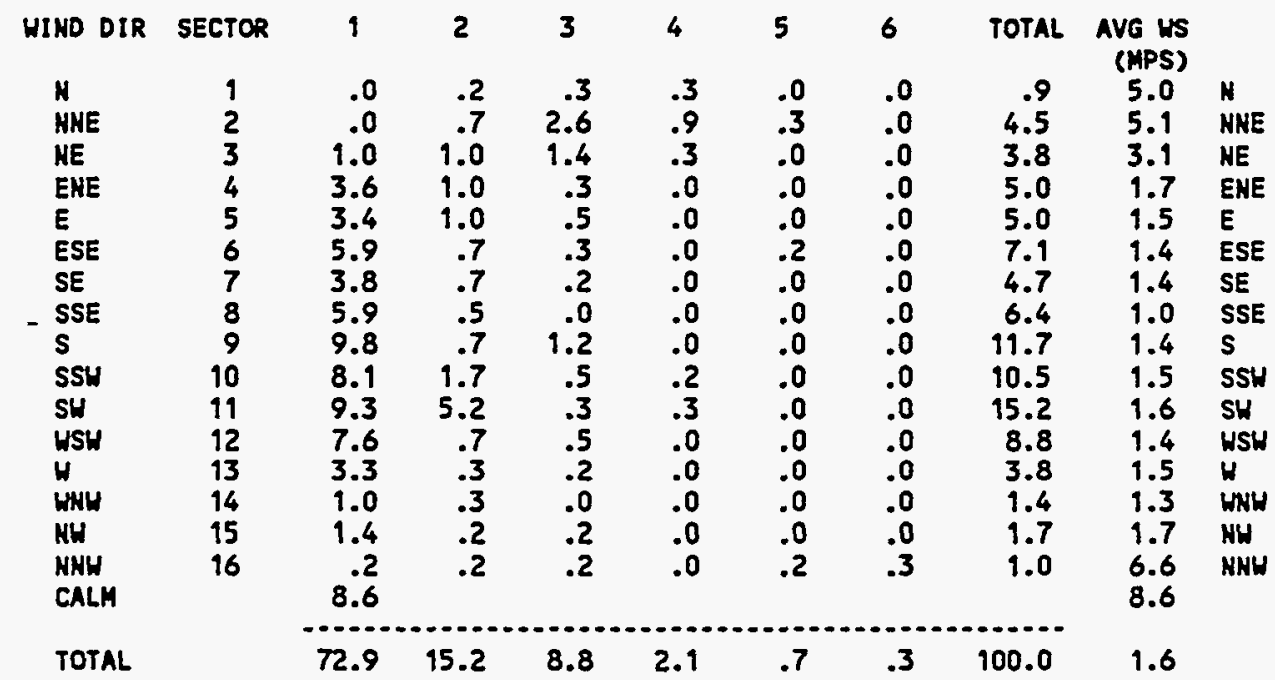

78.0\% DATA RECOVERED

100.0\% OF RECOVERED DATA REPORTED ABOVE

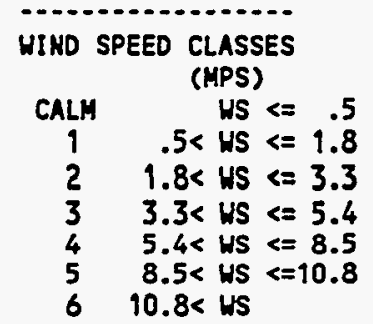


METEOROLOGICAL JOINT FREQUENCY DISTRIBUTION (PERCENT OF VALID HOUR OBSERVATIONS)

SPILL TEST FACILITY 24 METER TONER

8 METER HEIGHT - TOtal HOURS

2) $1 / 1994 \cdot 2 / 28 / 1994$

$0-2300$ (MST)

WIND SPEEDCLASS

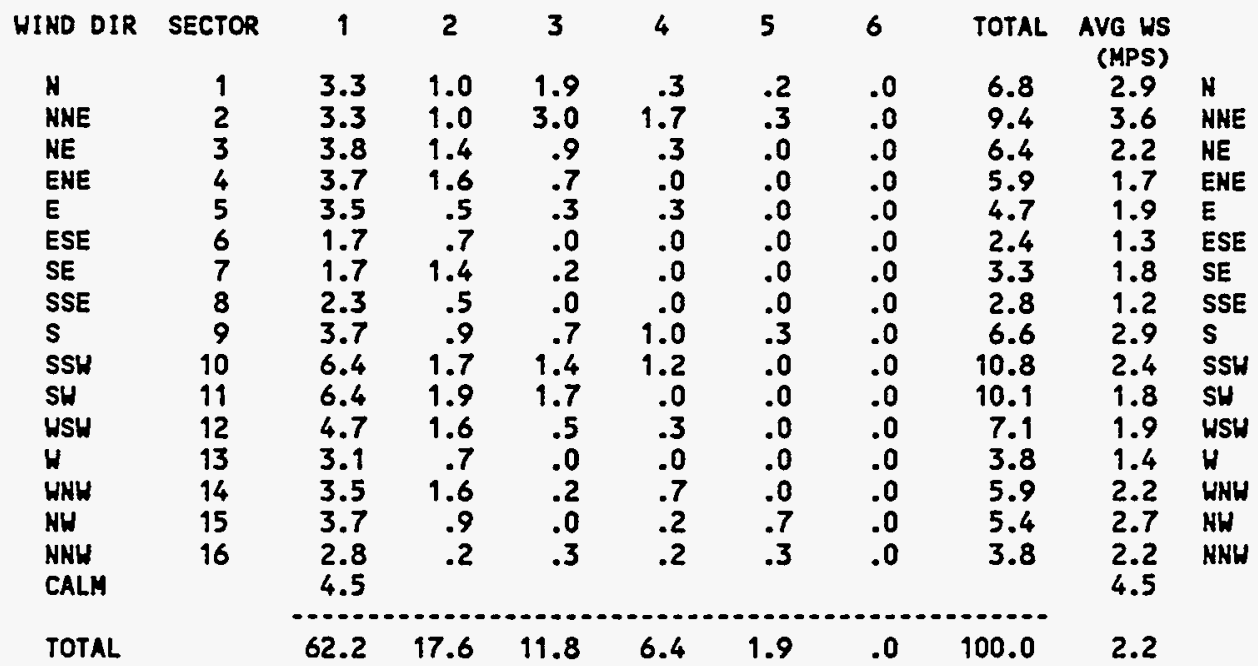

85.4X DATA RECOVERED

$100.0 \%$ OF RECOVERED DATA REPORTED ABOVE

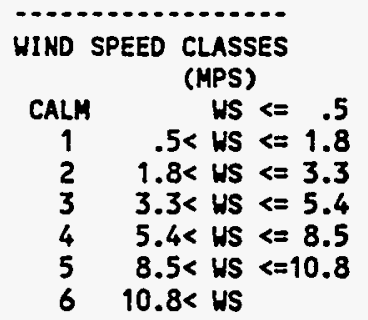


METEOROLOGICAL JOIHT FREQUENCY DISTRIBUTION (PERCENT OF VALID HOUR OBSERVATIONS) SPILL TEST FACILITY 24 METER TONER

8 METER HEIGHT - Total Hours

3/ $1 / 1994 \cdot 3 / 31 / 1994$

$0 \cdot 2300$ (MST)

WI HD SPEED CLASS

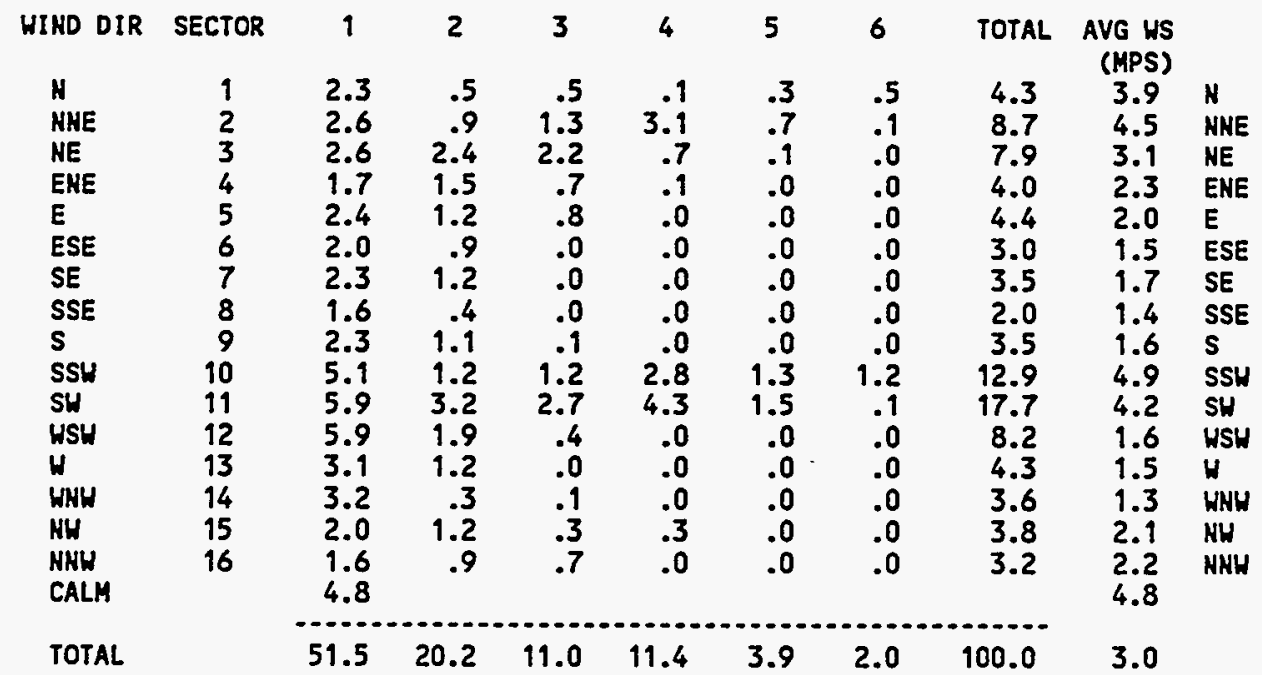

100.0\% DATA RECOVERED

100.0\% OF RECOVERED DATA REPORTED ABOVE

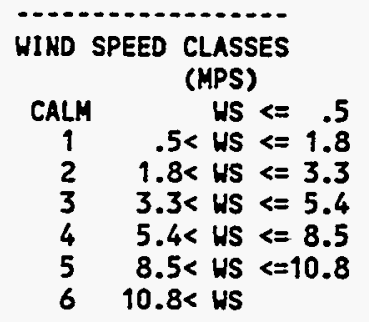


METEOROLOGICAL JOINT FREQUENCY DISTRIBUTION (PERCENT OF VALID HOUR OBSERVATIONS) SPILL TEST FACILITY 24 METER TONER

8 METER HEIGHT - Total Hours

4/ $1 / 1994 \cdot 4 / 30 / 1994$

0 - 2300 (MST)

WI ND SPEED CLASS

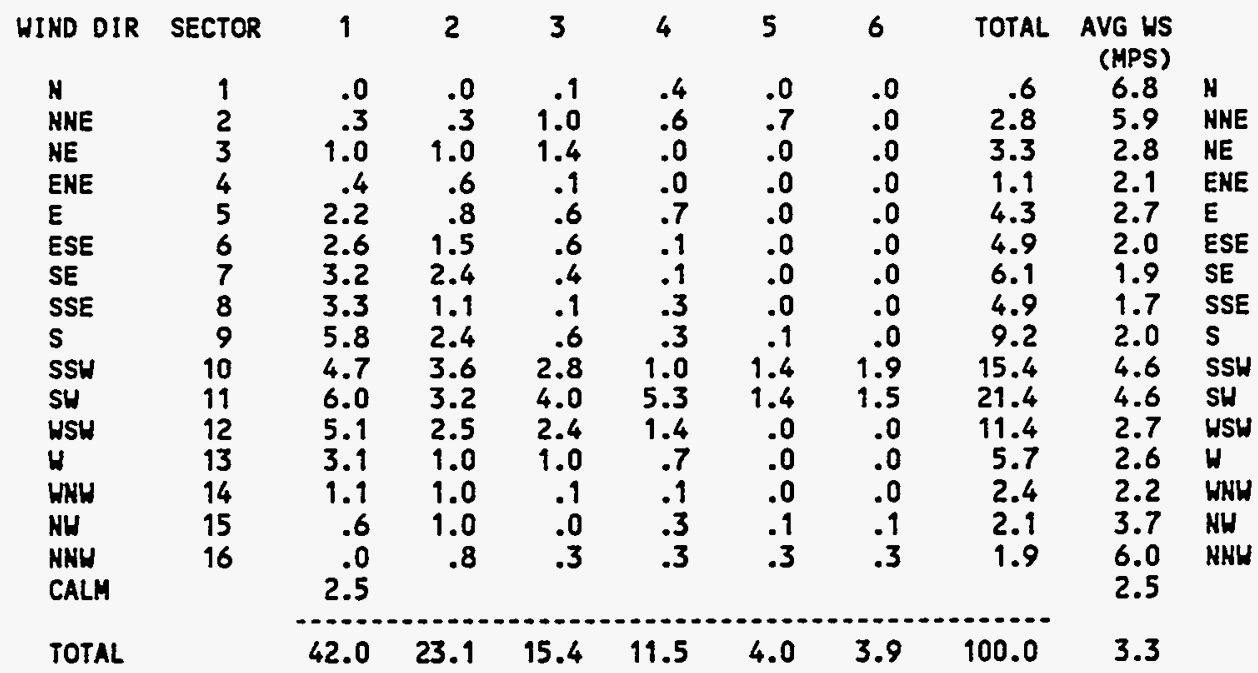

99.9\% DATA RECOVERED

100.0\% OF RECOVERED DATA

REPORTED ABOVE

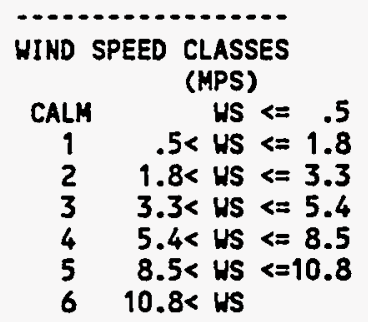


METEOROLOGICAL JOIHT FREQUENCY DISTRIBUTION (PERCEHT OF VALID HOUR OBSERVATIONS)

SPILL TEST FACILITY 24 METER TOUER

8 METER HEIGHT - TOtal HourS

$$
\text { 5/ } 1 / 1994-5 / 31 / 1994
$$

HIND SPEED CLASS

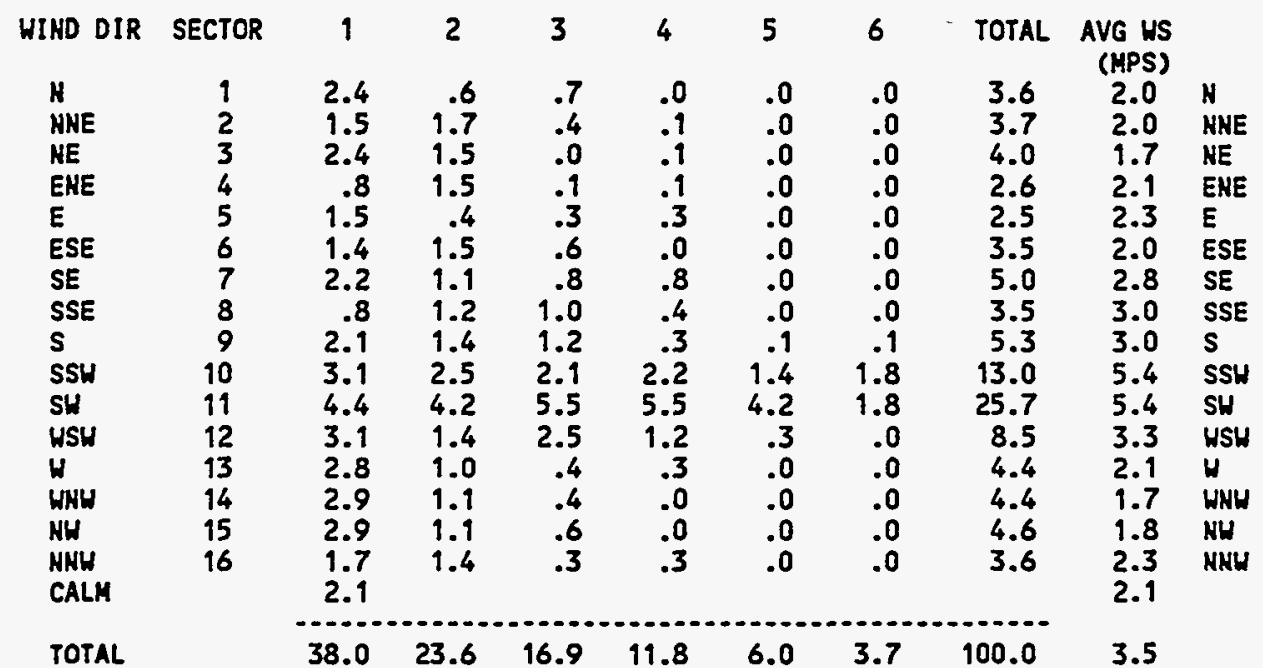

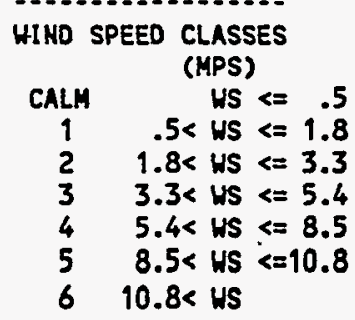


METEOROLOGICAL JOINT FREQUENCY DISTRIBUTION (PERCENT OF VALID HOUR OBSERVATIONS) SPILL. TEST FACILITY 24 METER TONER

8 METER HEIGHT - Total Hours

$$
\begin{gathered}
\text { 6/ } 1 / 1994-6 / 30 / 1994 \\
0-2300 \text { (MST) }
\end{gathered}
$$

\begin{tabular}{|c|c|c|c|c|c|c|c|c|c|c|}
\hline WIND DIR & SECTOR & 1 & 2 & 3 & 4 & 5 & 6 & TOTAL & $\begin{array}{l}\text { AVG WS } \\
\text { (MPS) }\end{array}$ & \\
\hline N & 1 & 1.8 & .6 & .0 & .0 & .0 & .0 & 2.4 & 1.5 & N \\
\hline $\begin{array}{l}\text { NHE } \\
\text { NE }\end{array}$ & $\begin{array}{l}2 \\
3\end{array}$ & $\begin{array}{l}1.7 \\
3.1\end{array}$ & $\begin{array}{r}.7 \\
2.4\end{array}$ & .1 & .3 & $\begin{array}{l}.0 \\
.0\end{array}$ & $\begin{array}{l}.0 \\
.0\end{array}$ & $\begin{array}{l}2.8 \\
5.6\end{array}$ & $\begin{array}{l}2.2 \\
1.5\end{array}$ & $\begin{array}{l}\text { HNE } \\
\text { HE }\end{array}$ \\
\hline ENE & 4 & 2.9 & .6 & .0 & .0 & .0 & .0 & 3.5 & 1.3 & ENE \\
\hline $\mathbf{E}$ & 5 & 1.9 & .8 & .0 & .0 & .0 & .0 & 2.8 & 1.4 & $E$ \\
\hline $\begin{array}{l}\text { ESE } \\
\text { SE }\end{array}$ & $\begin{array}{l}6 \\
7\end{array}$ & 1.5 & 1.0 & .0 & $\begin{array}{r}.0 \\
0\end{array}$ & .0 & .0 & 2.5 & 1.6 & $\begin{array}{l}\text { ESE } \\
\text { SE }\end{array}$ \\
\hline $\begin{array}{l}\text { SE } \\
\text { SSE }\end{array}$ & $\begin{array}{l}7 \\
8\end{array}$ & 1.4 & .4 & .0 & .0 & .0 & $\begin{array}{l}.0 \\
.0\end{array}$ & 1.8 & 1.3 & SSE \\
\hline $\mathbf{s}$ & 9 & .8 & .8 & .4 & .0 & .0 & .0 & 2.1 & 2.2 & $\mathbf{s}$ \\
\hline SSH & 10 & 2.4 & 1.4 & 1.5 & 1.8 & 1.7 & .4 & 9.2 & 5.1 & SSH \\
\hline SH & 11 & 4.7 & 4.4 & 4.4 & 14.3 & 6.9 & 2.4 & 37.2 & 6.2 & SH \\
\hline WSH & 12 & 4.2 & 1.9 & 2.9 & 3.8 & 1.3 & .1 & 14.2 & 4.2 & WSW \\
\hline$H$ & 13 & 1.8 & .3 & .4 & .0 & .0 & .0 & 2.5 & 1.7 & $\mathbf{H}$ \\
\hline WNH & 14 & 1.5 & 1.1 & .6 & .0 & .0 & .0 & 3.2 & 2.2 & WWH \\
\hline NH & 15 & 2.8 & .3 & .1 & .0 & .0 & .0 & 3.2 & 1.4 & NH \\
\hline $\begin{array}{l}\text { NHW } \\
\text { CALM }\end{array}$ & 16 & $\begin{array}{l}1.7 \\
3.8\end{array}$ & .3 & .0 & .0 & .0 & .0 & 1.9 & $\begin{array}{l}1.3 \\
3.8\end{array}$ & HNH \\
\hline TOTAL & & 38.6 & 17.6 & 10.8 & 20.1 & 9.9 & 2.9 & 100.0 & 3.9 & \\
\hline
\end{tabular}

HINDSPEED CLASS

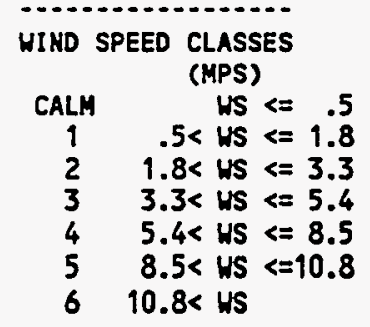


METEOROLOGICAL JOIHT FREQUENCY DISTRIBUTION (PERCENT OF VALID HOUR OBSERVATIONS)

SPILL TEST FACILITY 24 METER TOWER

8 METER HEIGHT - Total Hours

$7 / 1 / 1994-7 / 31 / 1994$

$0-2300$ (MST)

HIND SPEED CLASS

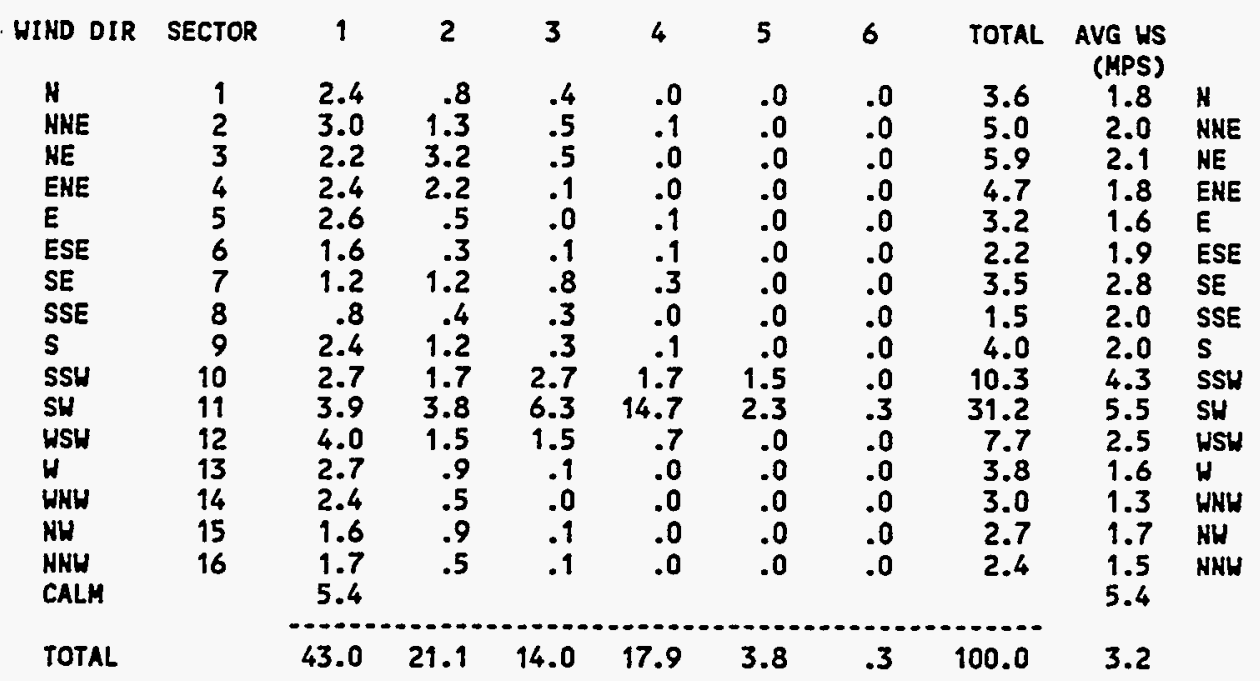

100.0\% DATA RECOVERED

100.0\% OF RECOVERED DATA

REPORTED ABOVE

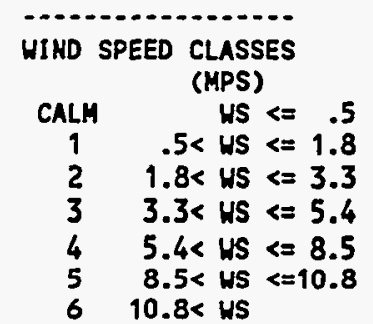


METEOROLOGICAL JOINT FREQUENCY DISTRIBUTION (PERCENT OF VALIO HOUR OBSERVATIONS)

SPILL TEST FACILITY 24 METER TONER

8 METER HEIGHT - TOtal Hours

$8 / 1 / 1994-8 / 31 / 1994$

$0-2300$ (MST)

WINDSPEED CLASS

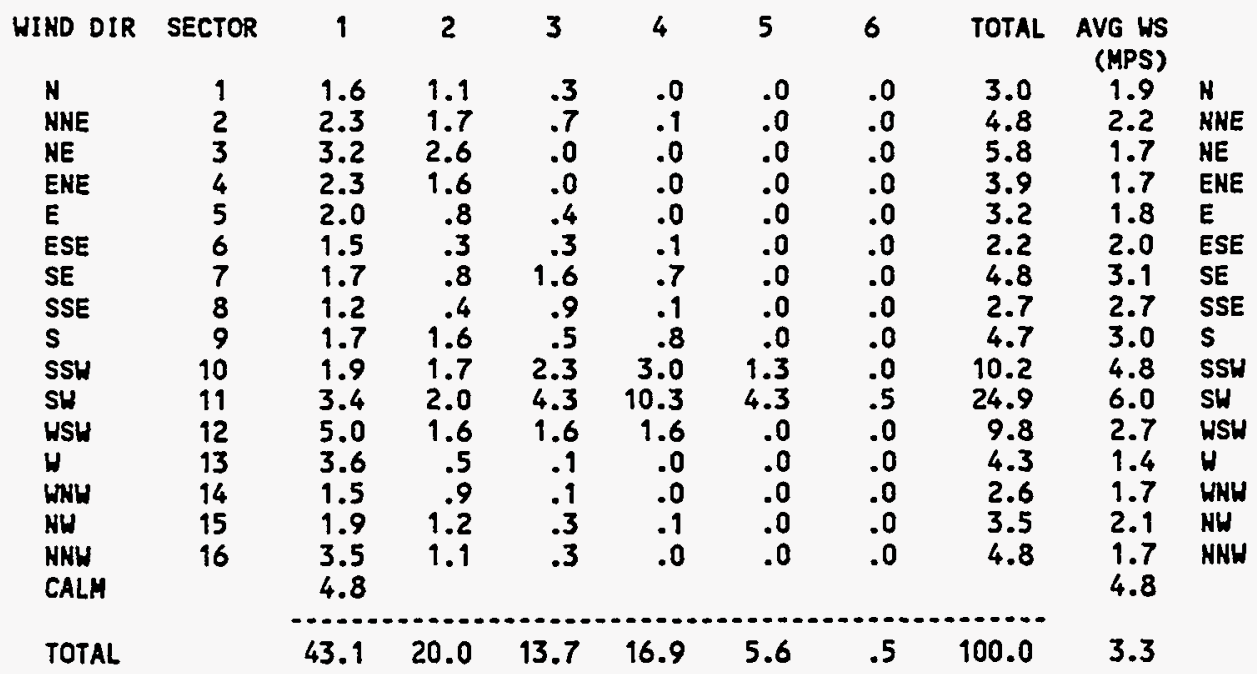

100.0\% DATA RECOVERED

100.0\% OF RECOVERED DATA

REPORTED ABOVE

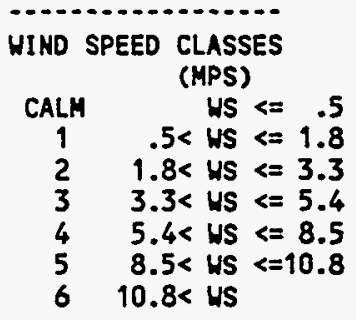


METEOROLOGICAL JOIHT FREQUENCY DISTRIBUTION (PERCENT OF VALID HOUR OBSERVATIONS) SPILL TEST FACILITY 24 METER TOWER

8 METER HEIGHT - Total Hours

$9 / 1 / 1994-9 / 30 / 1994$

0 - 2300 (HST)

HINDSPEEDCLASS

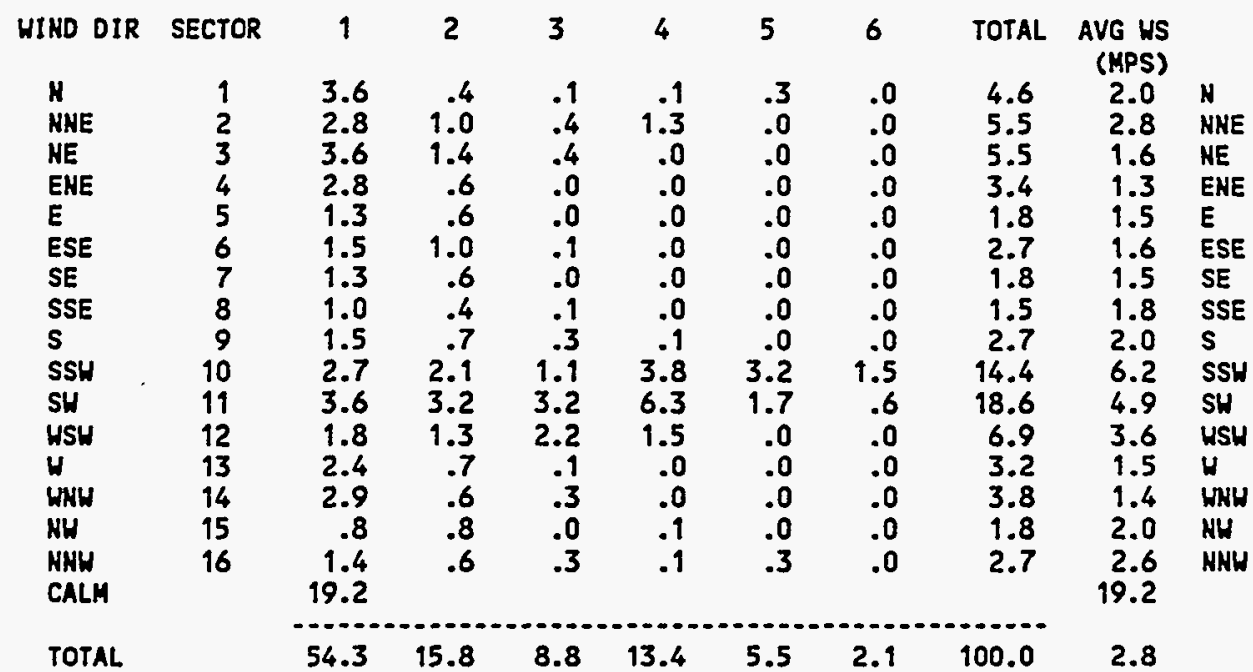

99.2X DATA RECOVERED 100.0\% OF RECOVERED DATA REPORTED ABOVE

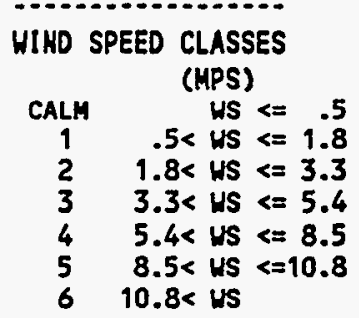


METEOROLOGICAL JOIHT FREQUENCY OISTRIBUTION (PERCENT OF VALID HOUR OBSERVATIONS) SPILL TEST FACILITY 24 METER. TOWER 8 METER HEIGHT - Total Hours $\quad \begin{gathered}10 / 11994-10 / 31 / 1994 \\ 0-2300 \text { (MST) }\end{gathered}$

WINDSPEED CLASS

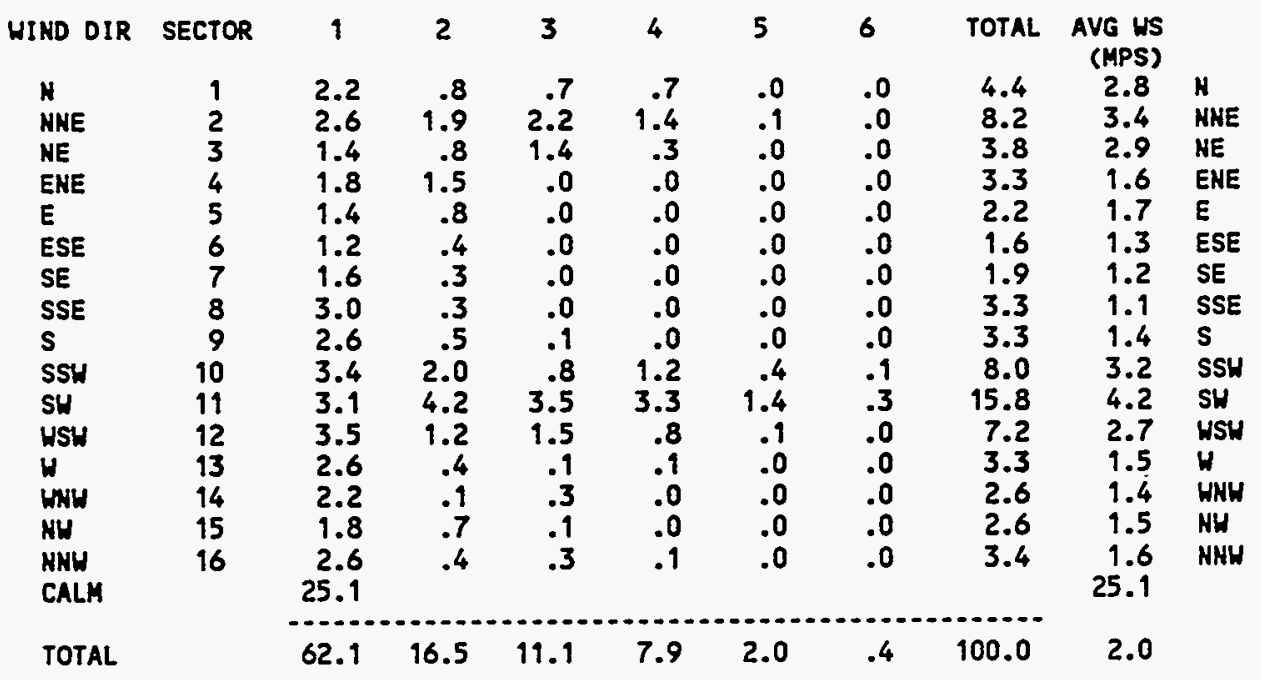

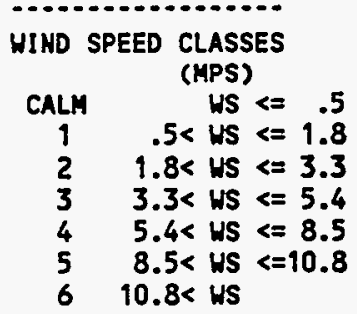


METEOROLOGICAL JOIHT FREQUENCY DISTRIBUTION (PERCENT OF VALID HOUR OBSERVATIOHS) SPILL TEST FACILITY 24 METER TOUER

8 METER HEIGHT - Total Hours

$11 / 1 / 1994-11 / 30 / 1994$

$0 \cdot 2300$ (HST)

HIND SPEED CLASS

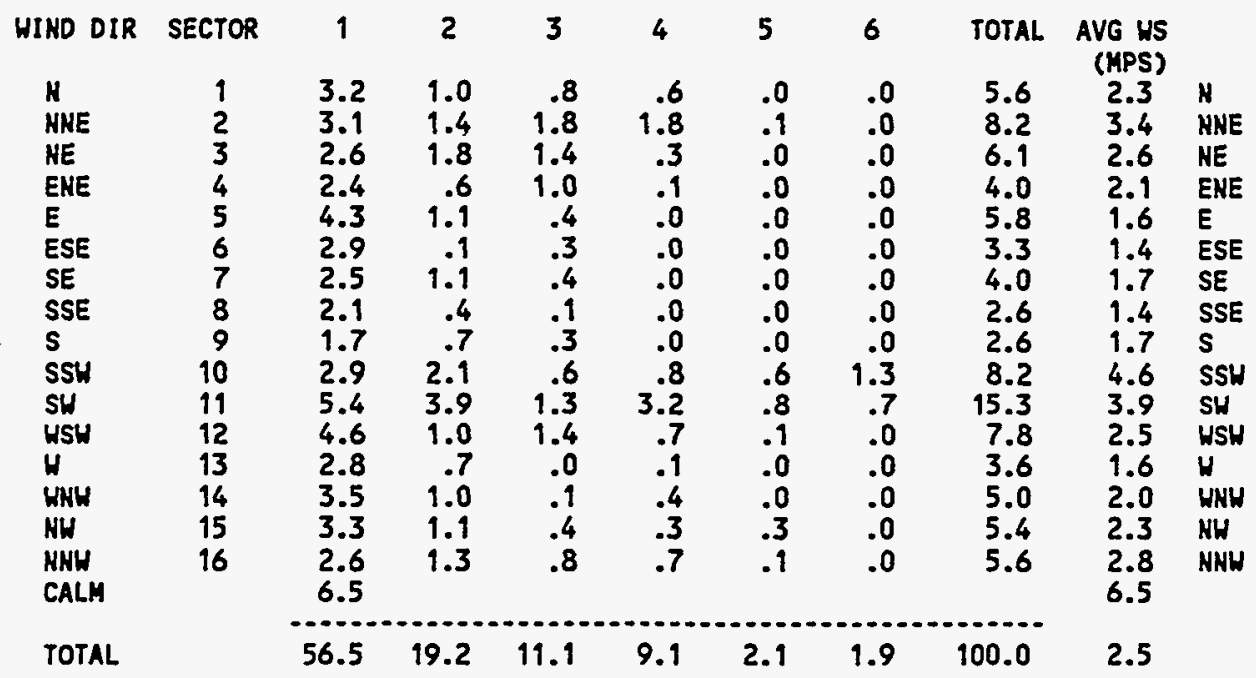

99.77 DATA RECOVERED

100.0\% OF RECOVERED DATA REPORTED ABOVE

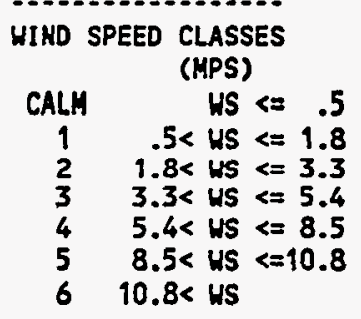


METEOROLOGICAL JOINT FREQUENCY DISTRIBUTION (PERCEHT OF VALID HOUR OBSERVATIOHS)

SPILL TEST FACILITY 24 METER TONER

8 METER HEIGHT - Total Hours

12) $1 / 1994-12 / 31 / 1994$

$0 \cdot 2300$ (HST)

\section{UI ND SPEED CLASS}

\begin{tabular}{|c|c|c|c|c|c|c|c|c|c|c|}
\hline WIND DIR & SECTOR & 1 & 2 & 3 & 4 & 5 & 6 & TOTAL. & $\begin{array}{l}\text { AVG US } \\
\text { (MPS) }\end{array}$ & \\
\hline N & 1 & 3.5 & 1.2 & 1.2 & .0 & .0 & .0 & 6.0 & 1.9 & H \\
\hline NME & 2 & 3.9 & 1.4 & 1.7 & 2.1 & .0 & .0 & 9.1 & 3.2 & $\begin{array}{l}\text { NHE } \\
\text { ME }\end{array}$ \\
\hline & $\begin{array}{l}3 \\
4\end{array}$ & $\begin{array}{l}2.1 \\
5.2\end{array}$ & $\begin{array}{l}1.4 \\
1.9\end{array}$ & $\begin{array}{r}3.3 \\
.2\end{array}$ & $\begin{array}{r}9.2 \\
.2\end{array}$ & $\begin{array}{l}.0 \\
.0\end{array}$ & $\begin{array}{l}.0 \\
.0\end{array}$ & $\begin{array}{l}8.1 \\
7.4\end{array}$ & $\begin{array}{l}3.5 \\
1.6\end{array}$ & $\begin{array}{l}\text { NE } \\
\text { ENE }\end{array}$ \\
\hline$E$ & 5 & 3.7 & .4 & .6 & .0 & .0 & .0 & 4.8 & 1.6 & $E$ \\
\hline $\begin{array}{l}\text { ESE } \\
\text { SE }\end{array}$ & $\begin{array}{l}6 \\
7\end{array}$ & $\begin{array}{l}1.7 \\
2.1\end{array}$ & $\begin{array}{r}.8 \\
1.0\end{array}$ & $\begin{array}{r}.0 \\
1.4\end{array}$ & $\begin{array}{l}.0 \\
.0\end{array}$ & $\begin{array}{l}.0 \\
.0\end{array}$ & $\begin{array}{l}.0 \\
.0\end{array}$ & $\begin{array}{l}2.5 \\
4.5\end{array}$ & $\begin{array}{l}1.6 \\
2.4\end{array}$ & $\begin{array}{l}\text { ESE } \\
\text { SE }\end{array}$ \\
\hline SSE & 8 & 2.9 & .0 & .0 & .0 & .0 & .0 & 2.9 & 1.0 & SSE \\
\hline $\mathbf{s}$ & 9 & 3.3 & .0 & .0 & .2 & .0 & .0 & 3.5 & 1.4 & $\mathbf{s}$ \\
\hline SSW & 10 & 4.8 & 1.4 & .0 & .2 & .0 & .0 & 6.4 & 1.6 & SSH \\
\hline SW & 19 & 6.8 & 2.3 & .6 & .2 & .0 & .0 & 9.9 & 1.8 & SW \\
\hline USH & 12 & 6.4 & 1.0 & .0 & .0 & .0 & .0 & 7.4 & 1.3 & WSH \\
\hline WH & $\begin{array}{l}13 \\
14\end{array}$ & $\begin{array}{l}5.0 \\
1.4\end{array}$ & $\begin{array}{l}1.0 \\
1.4\end{array}$ & .0 & $\begin{array}{l}0 \\
0\end{array}$ & .0 & .0 & $\begin{array}{l}6.0 \\
3.5\end{array}$ & $\begin{array}{l}1.4 \\
2.0\end{array}$ & $\begin{array}{l}\text { HW } \\
\text { HWU }\end{array}$ \\
\hline NH & 15 & 3.9 & 1.7 & .6 & .0 & .0 & .0 & 6.2 & 1.8 & NH \\
\hline HKH & 16 & 3.3 & 1.7 & .8 & .0 & .0 & .0 & 5.8 & 1.8 & NNH \\
\hline ILA & & & & & & & & & & \\
\hline TOTAL & & 2.7 & 18.8 & 1.2 & 4.1 & .0 & .0 & 100.0 & 1.9 & \\
\hline
\end{tabular}

65.1\% DATA RECOVERED 100.0\% OF RECOVERED DATA REPORTED ABOVE

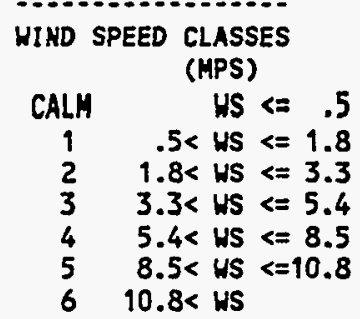




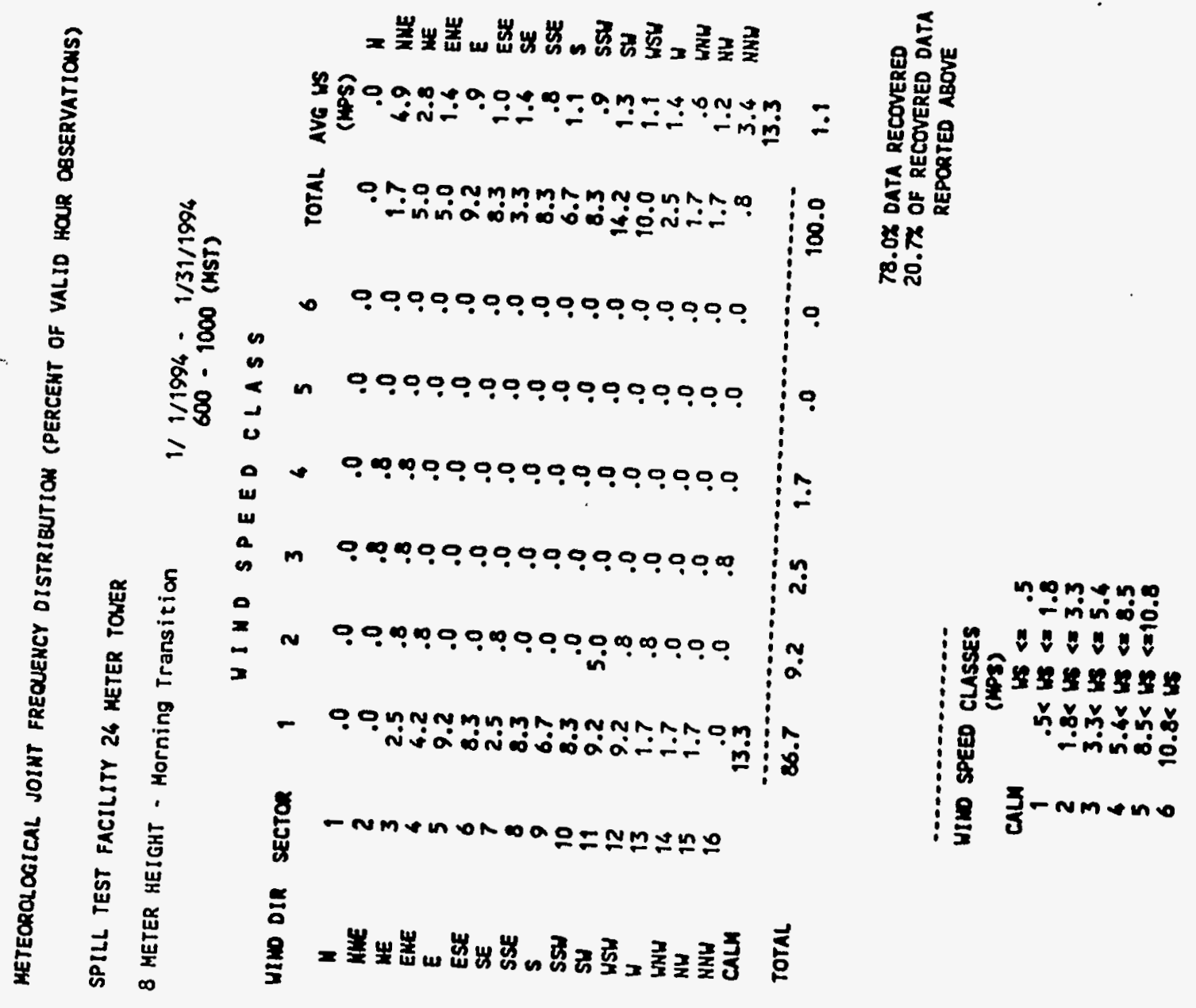


METEOROLOGICAL JOINT FREQUEHCY DISTRIBUTION (PERCENT OF VALID HOUR OBSERVATIONS)

SPILL TEST FACILITY 24 METER TOWER

8 METER HEIGHT - Morning Transition

2) $1 / 1994 \cdot 2 / 28 / 1994$

$600 \cdot 1000$ (HST)

HINDSPEEDCLASS

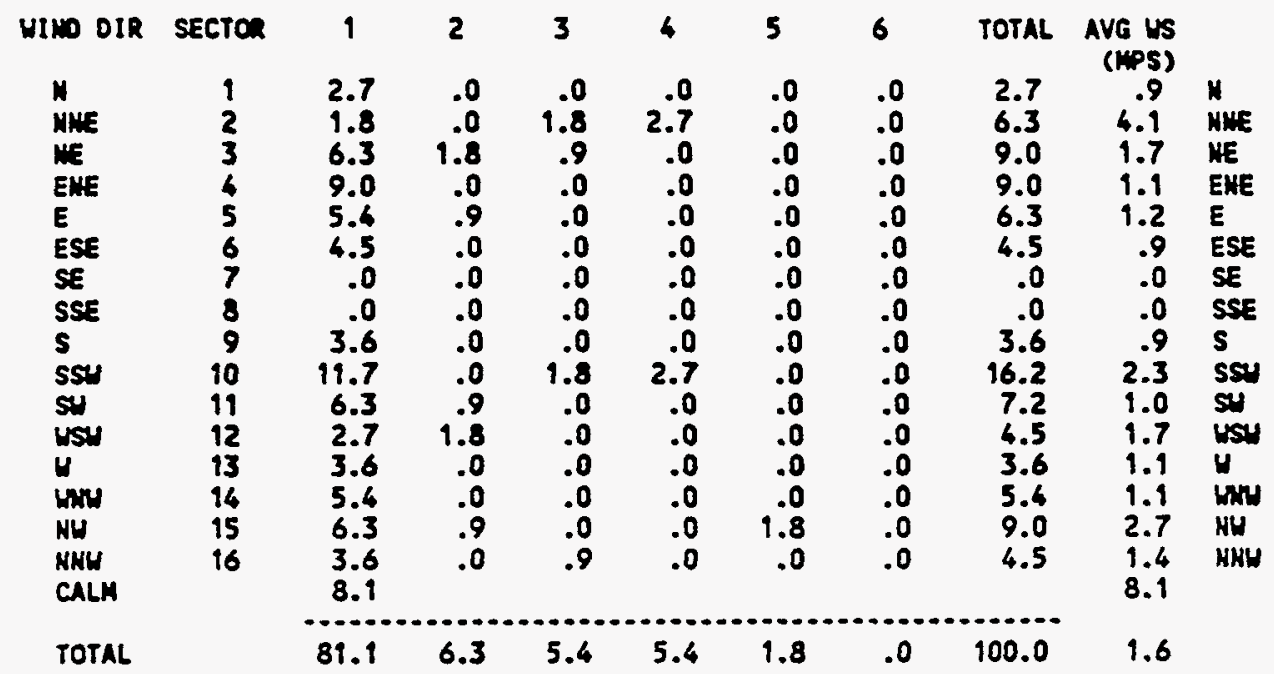

85.4\% DATA RECOVERED

19.3\% OF RECOVERED DATA REPORTED ABOVE

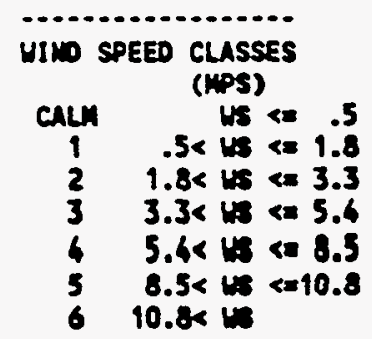


METEOROLOGICAL JOINT FREQUENCY OISTRIBUTION (PERCENT OF VALID HOUR OBSERVATIONS)

SPILL TEST FACILITY 24 METER TOAER

8 METER HEIGHT - Horning Transition

$3 / 1 / 1996 \cdot 3 / 31 / 1996$

$600-1000$ (MST)

HINDSPEEDCLASS

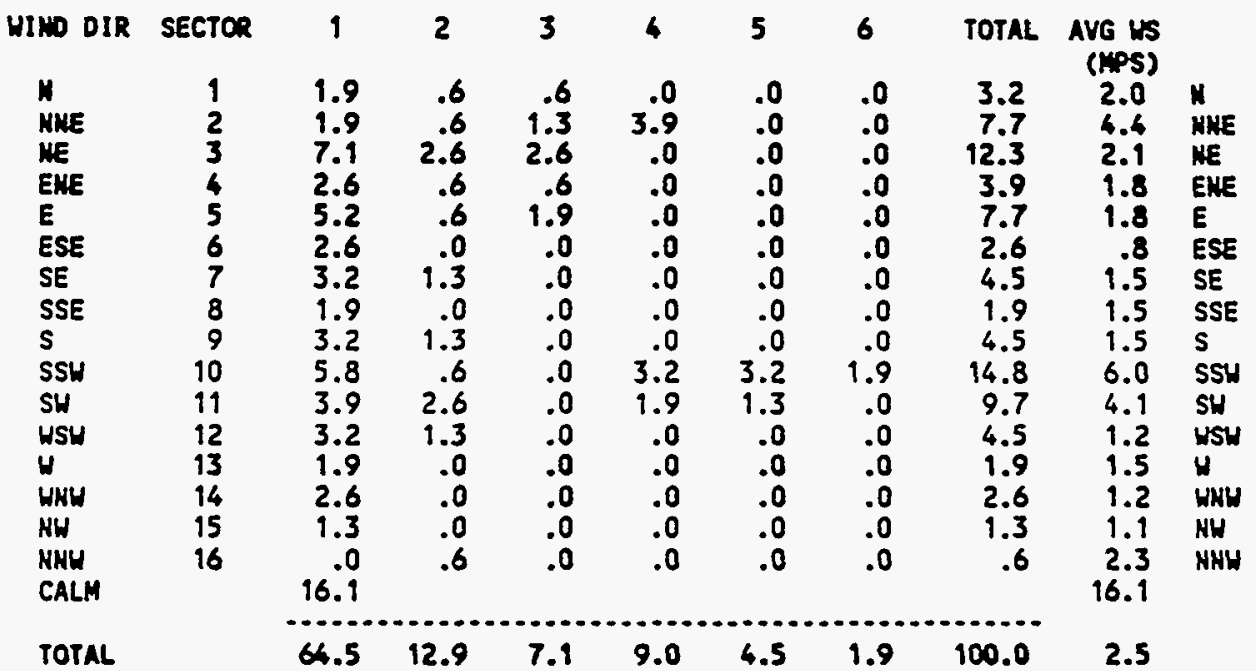

$100.0 \%$ DATA PECONERED

20.8\% OF RECOVERED DATA

REPORTED APOVE

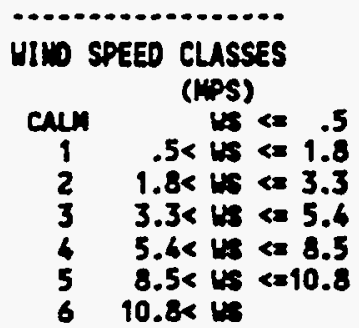


METEOROLOGICAL JOINT FREQUENCY DISTRIBUTION (PERCENT OF VALIO HOUR OBSERVATIONS) SPILL TEST FACILITY 24 METER TOWER

8 METER HEIGHT - Morning Transition

4/ $1 / 1994-4 / 30 / 1994$
$600-1000$ (MST)

WINO SPEEDCLASS

\begin{tabular}{|c|c|c|c|c|c|c|c|c|c|c|}
\hline WIND OIR & SECTOR & 1 & 2 & 3 & 4 & 5 & 6 & TOTAL & $\begin{array}{l}\text { AVG WS } \\
\text { (MPS) }\end{array}$ & \\
\hline N & 1 & .0 & .0 & .0 & .0 & .0 & .0 & .0 & .0 & N \\
\hline NHE & 2 & .0 & .0 & .7 & .7 & .0 & .0 & 1.3 & 5.2 & NHE \\
\hline NE & 3 & 1.3 & .0 & .7 & .0 & .0 & .0 & 2.0 & 1.9 & NE \\
\hline ENE & 4 & 1.3 & .0 & .0 & .0 & .0 & .0 & 1.3 & 1.2 & ENE \\
\hline $\begin{array}{l}\text { E } \\
\text { ESE }\end{array}$ & $\begin{array}{l}5 \\
6\end{array}$ & $\begin{array}{l}5.4 \\
4.7\end{array}$ & $\begin{array}{r}2.0 \\
.0\end{array}$ & $\begin{array}{l}.0 \\
.0\end{array}$ & $\begin{array}{l}.0 \\
.0\end{array}$ & $\begin{array}{l}.0 \\
.0\end{array}$ & $\begin{array}{l}.0 \\
.0\end{array}$ & $\begin{array}{l}7.4 \\
4.7\end{array}$ & $\begin{array}{r}1.5 \\
.9\end{array}$ & $\begin{array}{l}\text { E } \\
\text { ESE }\end{array}$ \\
\hline SE & 7 & 5.4 & 1.3 & 1.3 & .0 & .0 & .0 & 8.1 & 1.7 & SE \\
\hline $\begin{array}{l}\text { SSE } \\
\text { S }\end{array}$ & $\begin{array}{l}8 \\
9\end{array}$ & $\begin{array}{l}6.7 \\
7.4\end{array}$ & $\begin{array}{l}.0 \\
.7\end{array}$ & $\begin{array}{l}.7 \\
.0\end{array}$ & $\begin{array}{l}.7 \\
.7\end{array}$ & $\begin{array}{l}.0 \\
.0\end{array}$ & $\begin{array}{l}.0 \\
.0\end{array}$ & $\begin{array}{l}8.1 \\
8.7\end{array}$ & $\begin{array}{l}1.6 \\
1.4\end{array}$ & $\begin{array}{l}\text { SSE } \\
\text { S }\end{array}$ \\
\hline $\begin{array}{l}\text { S } \\
\text { SSH }\end{array}$ & 10 & $\begin{array}{l}1.4 \\
8.1\end{array}$ & 2.0 & 2.0 & .7 & 2.0 & 2.0 & 16.8 & 4.0 & SSW \\
\hline SH & 11 & 6.7 & 2.7 & 2.7 & .0 & 3.4 & 2.7 & 18.1 & 4.9 & SH \\
\hline USW & 12 & 2.7 & 1.3 & .0 & .0 & .0 & .0 & 4.0 & 1.6 & HSH \\
\hline W & 13 & 4.7 & .7 & .7 & 1.3 & .0 & .0 & 7.4 & 2.4 & $\mathbf{H}$ \\
\hline WNH & 14 & .7 & .7 & .0 & .0 & .0 & .0 & 1.3 & 1.9 & WNH \\
\hline NW & 15 & .7 & .0 & .0 & .7 & .0 & .0 & 1.3 & 3.3 & NH \\
\hline $\begin{array}{l}\text { NHE } \\
\text { CALH }\end{array}$ & 16 & $\begin{array}{r}.0 \\
9.4\end{array}$ & .0 & .0 & .0 & .0 & .0 & .0 & $\begin{array}{r}.0 \\
9.4\end{array}$ & HNH \\
\hline TOTAL & & 65.1 & 11.4 & 8.7 & 4.7 & 5.4 & 4.7 & 100.0 & 2.5 & \\
\hline
\end{tabular}

$99.9 \%$ DATA RECOVERED

20.7\% OF RECOVERED DATA

REPORTED ABOVE

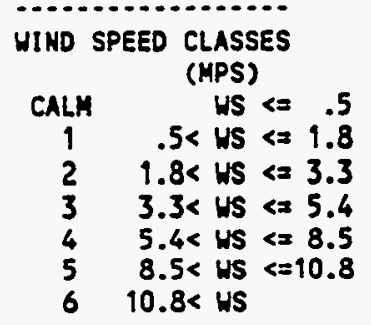


METEOROLOGICAL JOINT FREQUENCY DISTRIBUTION (PERCENT OF VALID HOUR OBSERVATIONS)

SPILL TEST FACILITY 24 METER TOWER

8 METER HEIGHT - Morning Transition

$5 / 1 / 1994-5 / 31 / 1994$

$600 \cdot 1000$ (MST)

WINDSPEED CLASS

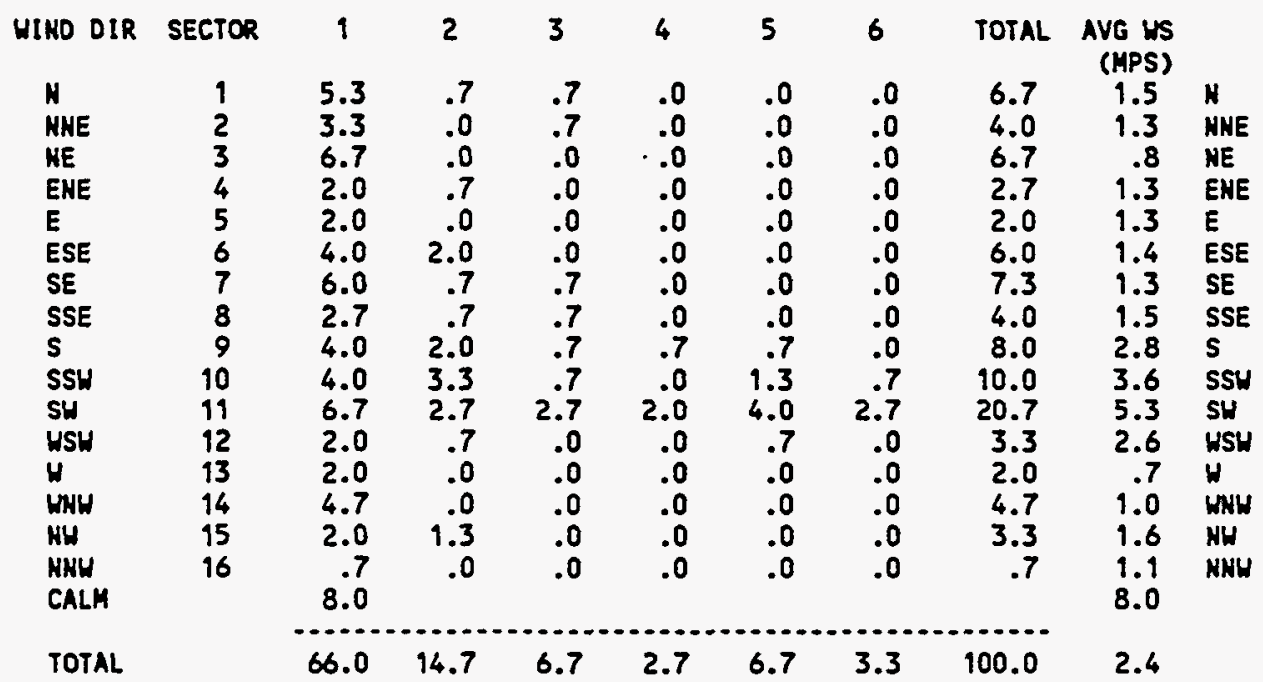

96.9\% DATA RECOVERED

20.8\% OF RECOVERED DATA REPORTED ABOVE

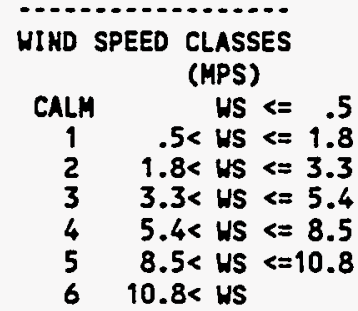


METEOROLOGICAL JOINT FREQUENCY DISTRIBUTION (PERCENT OF VALIO HOUR OBSERVATIONS)

SPILL TEST FACILITY 24 METER TONER

8 METER HEIGHT - Morning Transition

6/ $1 / 1994 \cdot 6 / 30 / 1994$

$600 \cdot 1000$ (MST)

HINDSPEEDCLASS

\begin{tabular}{|c|c|c|c|c|c|c|c|c|c|c|}
\hline HIND DIR & SECTOR & 1 & 2 & 3 & 4 & 5 & 6 & TOTAL & $\begin{array}{r}\text { AVG WS } \\
\text { (MPS) }\end{array}$ & \\
\hline $\mathbf{N}$ & 1 & .7 & .0 & .0 & .0 & .0 & .0 & .7 & .5 & N \\
\hline NNE & 2 & 2.0 & .0 & .7 & .7 & .0 & .0 & 3.3 & 2.9 & NNE \\
\hline NE & 3 & 7.3 & .0 & .7 & .0 & .0 & .0 & 8.0 & 1.1 & NE \\
\hline ENE & 4 & 10.7 & .7 & .0 & .0 & .0 & .0 & 19.3 & 1.1 & ENE \\
\hline$E$ & 5 & 5.3 & 1.3 & .0 & .0 & .0 & .0 & 6.7 & 1.3 & $E$ \\
\hline ESE & 6 & 4.0 & .7 & .0 & .0 & .0 & .0 & 4.7 & 1.2 & ESE \\
\hline SE & 7 & 2.0 & 1.3 & .0 & .0 & .0 & .0 & 3.3 & 1.7 & SE \\
\hline $\begin{array}{l}\text { SSE } \\
S\end{array}$ & & 3.3 & $\begin{array}{r}1.3 \\
.7\end{array}$ & .0 & & .0 & .0 & 4.7 & 1.2 & SSE \\
\hline $\begin{array}{l}\text { S } \\
\text { SSH }\end{array}$ & $\begin{array}{r}9 \\
10\end{array}$ & 3.3 & 2.7 & 2.0 & $\begin{array}{l}.0 \\
.7\end{array}$ & $\begin{array}{l}.0 \\
.0\end{array}$ & $\begin{array}{l}.0 \\
.0\end{array}$ & $\begin{array}{l}2.0 \\
8.7\end{array}$ & $\begin{array}{l}2.5 \\
2.8\end{array}$ & $\begin{array}{l}\text { S } \\
\text { SSU }\end{array}$ \\
\hline SH & 19 & 4.0 & 1.3 & 3.3 & 6.0 & 4.0 & 2.7 & 21.3 & 6.3 & SH \\
\hline WSH & 12 & 2.0 & .7 & 1.3 & 2.7 & .7 & .7 & 8.0 & 5.2 & WSW \\
\hline$H$ & 13 & .0 & .0 & .0 & .0 & .0 & .0 & .0 & .0 & $H$ \\
\hline WWH & 14 & .0 & .7 & .0 & .0 & .0 & .0 & .7 & 2.8 & WWH \\
\hline NH & 15 & 2.0 & .0 & .0 & .0 & .0 & .0 & 2.0 & 1.0 & NW \\
\hline NHW & 16 & .7 & .0 & .0 & .0 & .0 & .0 & .7 & 1.1 & NNW \\
\hline CALLA & & 14. & & & & & & & & \\
\hline TOTAL & & 62.0 & 11.3 & 8.7 & 10.0 & 4.7 & 3.3 & 100.0 & 2.7 & \\
\hline
\end{tabular}

100.0\% DATA RECOVERED

20.8\% OF RECOVERED DATA REPORTED ABOVE

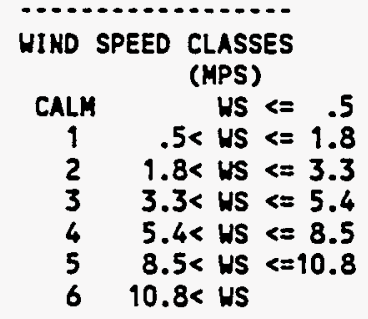


METEOROLOGICAL JOINT FREQUENCY DISTRIBUTION (PERCENT OF VALIO HOUR OBSERVATIONS)

SPILL TEST FACILITY 24 METER TOWER

8 METER HEIGHT - Morning Transition

$7 / 1 / 1994 \cdot 7 / 31 / 1994$

$600 \cdot 1000$ (MST)

\section{HIND SPEED CLASS}

\begin{tabular}{|c|c|c|c|c|c|c|c|c|c|c|}
\hline WIND OIR & SECTOR & 1 & 2 & 3 & 4 & 5 & 6 & TOTAL & $\begin{array}{l}\text { AVG WS } \\
\text { (MPS) }\end{array}$ & \\
\hline$N$ & 1 & 3.2 & .0 & .0 & .0 & .0 & .0 & 3.2 & 1.0 & $N$ \\
\hline NHE & 2 & 1.9 & .0 & 1.3 & .6 & .0 & .0 & 3.9 & 2.8 & NNE \\
\hline $\mathrm{NE}$ & 3 & 3.2 & 1.3 & .0 & .0 & .0 & .0 & 4.5 & 1.5 & NE \\
\hline ENE & 4 & 5.8 & .6 & .0 & .0 & .0 & .0 & 6.5 & 1.1 & ENE \\
\hline E & 5 & 7.7 & .6 & .0 & .0 & .0 & .0 & 8.4 & 1.2 & $E$ \\
\hline & $\begin{array}{l}6 \\
7\end{array}$ & $\begin{array}{l}1.9 \\
3.2\end{array}$ & $\begin{array}{l}.0 \\
.6\end{array}$ & $\begin{array}{r}.6 \\
1.9\end{array}$ & $\begin{array}{l}.0 \\
.0\end{array}$ & $\begin{array}{l}.0 \\
.0\end{array}$ & $\begin{array}{l}.0 \\
.0\end{array}$ & $\begin{array}{l}2.6 \\
5.8\end{array}$ & $\begin{array}{l}1.8 \\
2.5\end{array}$ & $\begin{array}{l}\text { ESE } \\
\text { SE }\end{array}$ \\
\hline SSE & 8 & 1.9 & .0 & .6 & .0 & .0 & .0 & 2.6 & 1.9 & SSE \\
\hline $\mathbf{S}$ & 9 & 3.9 & 2.6 & .6 & .6 & .0 & .0 & 7.7 & 2.3 & $\mathbf{s}$ \\
\hline SSH & 10 & 3.9 & 1.3 & 3.2 & .0 & .0 & .0 & 8.4 & 2.5 & SSH \\
\hline SH & 11 & 1.9 & 2.6 & 4.5 & 2.6 & .6 & .0 & 12.3 & 4.2 & SW \\
\hline WSH & 12 & 3.9 & .0 & .0 & .6 & .0 & .0 & 4.5 & 1.6 & WSH \\
\hline$H$ & 13 & 3.2 & .0 & .6 & .0 & .0 & .0 & 3.9 & 1.5 & $\mathbf{W}$ \\
\hline HNW & 14 & 2.6 & .0 & .0 & .0 & .0 & .0 & 2.6 & .9 & WNH \\
\hline NH & 15 & .6 & .0 & .6 & .0 & .0 & .0 & 1.3 & 2.6 & NH \\
\hline $\begin{array}{l}\text { NNH } \\
\text { CALM }\end{array}$ & 16 & $\begin{array}{r}.6 \\
20.6\end{array}$ & .6 & .0 & .0 & .0 & .0 & 1.3 & $\begin{array}{r}1.3 \\
20.6\end{array}$ & NMH \\
\hline TOTAL & & 70.3 & 10.3 & 14. & 4. & .6 & .0 & 00.0 & 7 & \\
\hline
\end{tabular}

100.0\% DATA RECOVERED

20.8\% OF RECOVERED DATA

REPORTED ABOVE

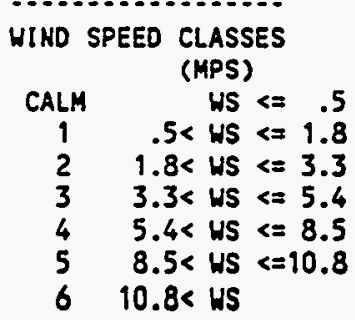


METEOROLOGICAL JOINT FREQUENCY DISTRIBUTION (PERCENT OF VALID HOUR OBSERVATIOHS)

SPILL TEST FACILITY 24 METER TOWER

8 METER HEIGHT - Morning Transition

$8 / 1 / 1994 \cdot 8 / 31 / 1994$

$600 \cdot 1000$ (MST)

WI HO SPEED CLASS

\begin{tabular}{|c|c|c|c|c|c|c|c|c|c|c|}
\hline WIHD DIR & SECTOR & 1 & 2 & 3 & 4 & 5 & 6 & TOTAL & $\begin{array}{l}\text { AVG WS } \\
\text { (MPS) }\end{array}$ & \\
\hline N & 1 & .6 & .6 & .0 & .0 & .0 & .0 & 1.3 & 1.4 & N \\
\hline NNE & 2 & 3.2 & .6 & .6 & .0 & .0 & .0 & 4.5 & 1.6 & HME \\
\hline $\mathrm{NE}$ & 3 & 7.7 & .0 & .0 & .0 & .0 & .0 & 7.7 & 1.1 & NE \\
\hline ENE & 4 & 5.2 & 1.3 & .0 & .0 & .0 & .0 & 6.5 & 1.3 & ENE \\
\hline$E$ & 5 & 5.8 & 1.3 & .0 & .0 & .0 & .0 & 7.1 & 1.3 & $E$ \\
\hline ESE & 6 & 3.9 & .6 & .0 & .0 & .0 & .0 & 4.5 & 1.2 & ESE \\
\hline SE & 7 & 6.5 & .6 & 1.3 & 1.9 & .0 & .0 & 10.3 & 2.6 & $S E$ \\
\hline SSE & 8 & 1.9 & .0 & .6 & .6 & .0 & .0 & 3.2 & 2.9 & SSE \\
\hline s & 9 & 1.9 & 1.3 & .6 & 1.3 & .0 & .0 & 5.2 & 3.4 & $\mathbf{s}$ \\
\hline SSH & 10 & 3.9 & 1.3 & 1.3 & .6 & .6 & .0 & 7.7 & 3.1 & SSH \\
\hline SH & 11 & 4.5 & .0 & 3.2 & 2.6 & 1.9 & .0 & 12.3 & 4.7 & SW \\
\hline USH & 12 & 3.9 & 1.3 & .0 & .0 & .0 & .0 & 5.2 & 1.2 & WSH \\
\hline$H$ & 13 & 1.8 & .0 & .0 & .0 & .0 & .0 & 1. & .7 & 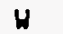 \\
\hline WNW & 14 & 1.3 & 1.3 & .0 & .0 & .0 & .0 & 2.6 & 1.4 & WHW \\
\hline NH & 15 & 1.9 & .0 & .6 & .0 & .0 & .0 & 2.6 & 1.7 & NW \\
\hline $\begin{array}{l}\text { HHW } \\
\text { CALM }\end{array}$ & 16 & $\begin{array}{r}1.9 \\
15.5\end{array}$ & .0 & .0 & .0 & .0 & .0 & 1.9 & $\begin{array}{r}.9 \\
15.5\end{array}$ & HNH \\
\hline TOTAL & & 71.6 & 10.3 & 8.4 & 7.1 & 2.6 & .0 & 100.0 & 1.9 & \\
\hline
\end{tabular}

100.0\% DATA RECOVERED

20.8\% OF RECOVERED DATA

REPORTED ABOVE

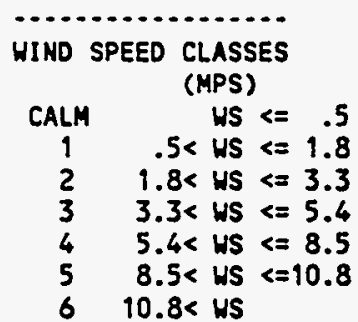


METEOROLOGICAL JOINT FREQUENCY DISTRIBUTION (PERCENT OF VALIO HOUR OBSERVATIONS)

SPILL TEST FACILITY 24 METER TOWER

8 METER HEIGHT - Morning Transition

9/ 1/1994 - 9/30/1994

$600 \cdot 1000$ (MST)

HI ND SPEED CLASS

\begin{tabular}{|c|c|c|c|c|c|c|c|c|c|c|}
\hline HIND DIR & SECTOR & 1 & 2 & 3 & 4 & 5 & 6 & TOTAL & $\begin{array}{r}\text { AVG WS } \\
\text { (HPS) }\end{array}$ & \\
\hline$H$ & 1 & 2.1 & .0 & .0 & .0 & .0 & .0 & 2.1 & .7 & $\mathbf{N}$ \\
\hline HHE & 2 & 3.4 & .0 & .7 & .0 & .0 & .0 & 4.1 & 1.3 & NNE \\
\hline NE & 3 & 4.8 & .0 & .0 & .0 & .0 & .0 & 4.8 & 1.9 & $\mathrm{NE}$ \\
\hline ENE & 4 & 4.1 & .7 & .0 & .0 & .0 & .0 & 4.8 & 1.1 & ENE \\
\hline E & 5 & 2.7 & .0 & .0 & .0 & .0 & .0 & 2.7 & .8 & $E$ \\
\hline $\begin{array}{l}\text { ESE } \\
\text { SE }\end{array}$ & $\begin{array}{l}6 \\
7\end{array}$ & $\begin{array}{l}2.1 \\
2.1\end{array}$ & $\begin{array}{r}2.1 \\
.0\end{array}$ & $\begin{array}{l}.7 \\
.0\end{array}$ & $\begin{array}{l}.0 \\
.0\end{array}$ & $\begin{array}{l}.0 \\
.0\end{array}$ & $\begin{array}{l}.0 \\
.0\end{array}$ & $\begin{array}{l}4.8 \\
2.1\end{array}$ & $\begin{array}{r}1.8 \\
.7\end{array}$ & $\begin{array}{l}\text { ESE } \\
\text { SE }\end{array}$ \\
\hline SSE & 8 & 1.4 & .0 & .0 & .0 & .0 & .0 & 1.4 & 1.1 & SSE \\
\hline s & 9 & 2.1 & .0 & .0 & .0 & .0 & .0 & 2.1 & 1.1 & $\mathbf{s}$ \\
\hline SSW & 10 & 2.1 & 1.4 & 2.7 & 2.1 & 2.7 & 2.1 & 13.0 & 6.5 & SSH \\
\hline SH & 11 & 3.4 & .0 & .7 & .7 & 2.1 & .7 & 7.5 & 5.5 & SH \\
\hline HSW & 12 & 1.4 & .0 & .7 & .0 & .0 & .0 & 2.1 & 1.6 & USW \\
\hline 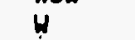 & 13 & 1.4 & .0 & .0 & .0 & .0 & .0 & 1.4 & .7 & $\mathbf{u}$ \\
\hline WNH & 14 & .7 & .7 & .0 & .0 & .0 & .0 & 1.4 & 1.5 & WNH \\
\hline NH & 15 & .0 & .0 & .0 & .7 & .0 & .0 & .7 & 6.3 & HW \\
\hline $\begin{array}{l}\text { NNH } \\
\text { CALM }\end{array}$ & 16 & $\begin{array}{r}1.4 \\
43.2\end{array}$ & .0 & .7 & .0 & .0 & .0 & 2.1 & $\begin{array}{r}1.9 \\
43.2\end{array}$ & NNW \\
\hline TOTAL & & 78.1 & 4.8 & 6.2 & 3.4 & 4.8 & 2.7 & 100.0 & 9.7 & \\
\hline
\end{tabular}

99.2\% DATA RECOVERED

20.4\% OF RECOVERED DATA REPORTED ABOVE

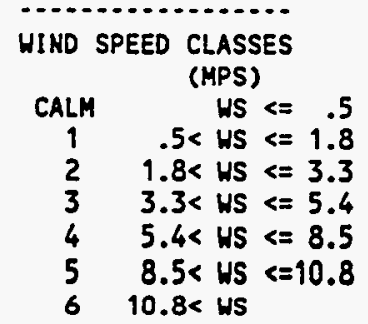


METEOROLOGICAL JOINT FREQUENCY DISTRIBUTION (PERCENT OF VALID HOUR OBSERVATIONS)

SPILL TEST FACILITY 24 METER TONER

8 METER HEIGHT - Morning Transition

$10 / 1 / 1994-10 / 31 / 1994$

$600-1000$ (MST)

HI N D PEED CLASS

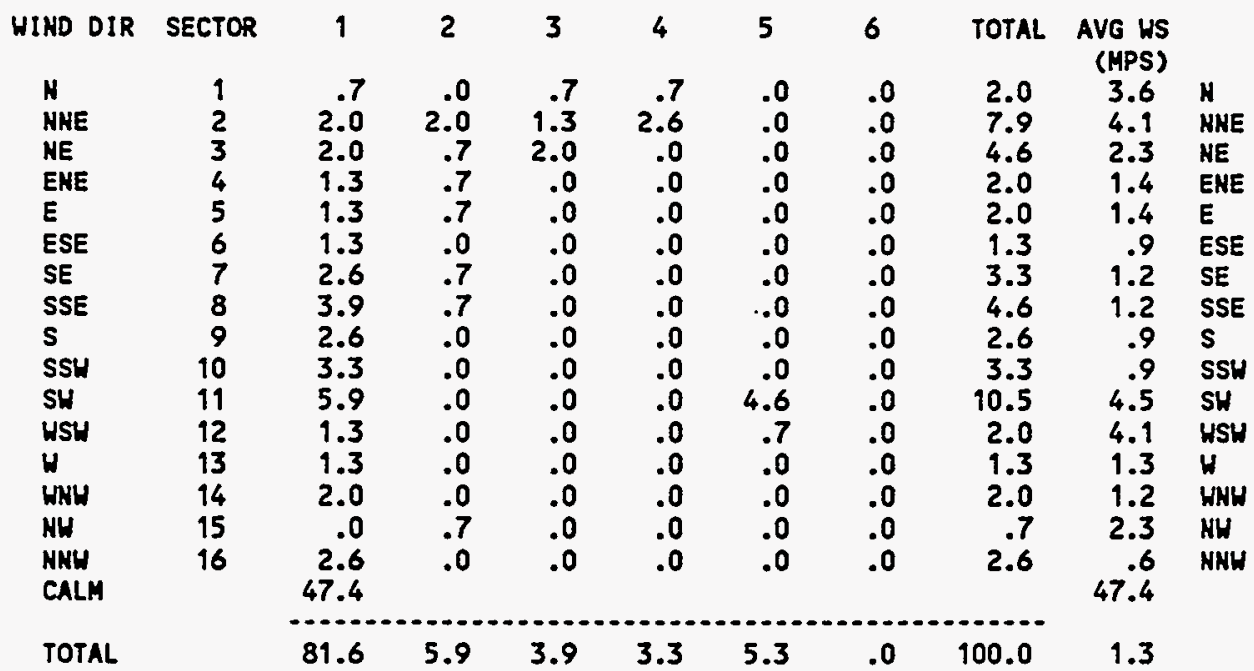

98.5\% DATA RECOVERED

20.7X OF RECOVERED DATA

REPORTED ABOVE

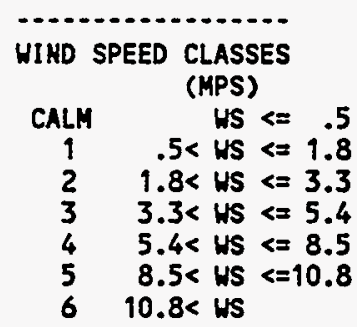


METEOROLOGICAL JOINT FREQUENCY OISTRIBUTIOH (PERCENT OF VALID HOUR OBSERVATIONS) SPILL TEST FACILITY 24 METER TONER

8 METER HEIGHT - Morning Transition

$11 / 1 / 1994-11 / 30 / 1994$

$600-1000$ (HST)

HINDSPEEDCLASS

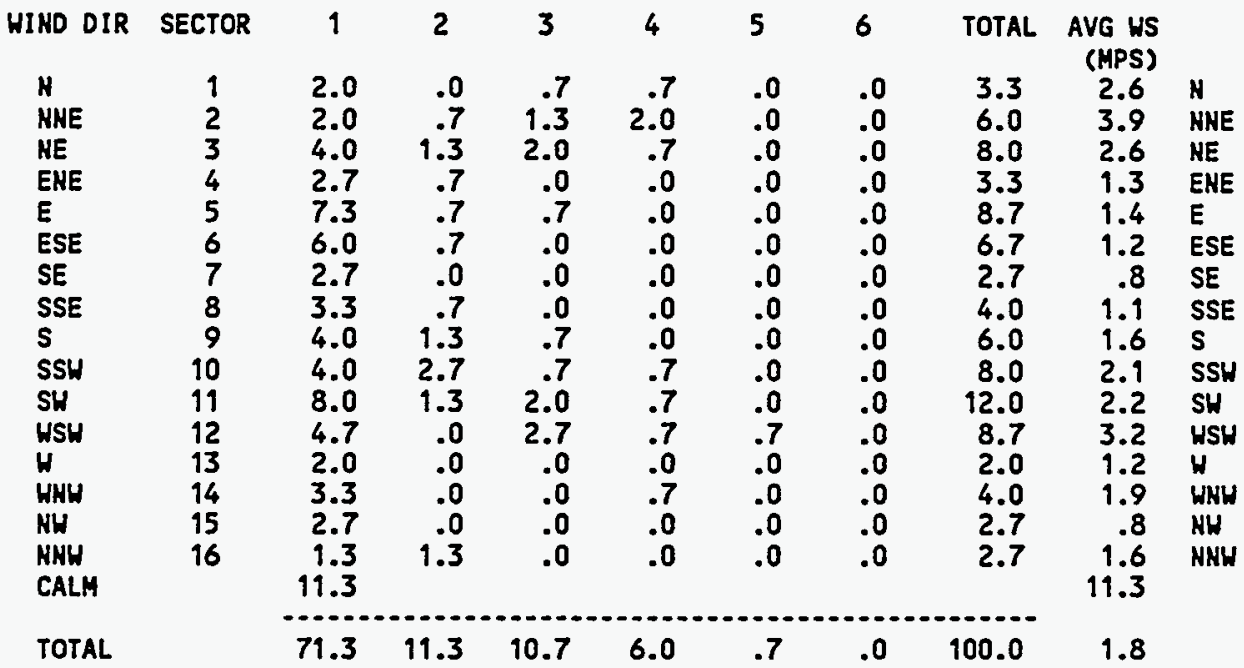

99.7\% DATA RECOVERED

20.9\% OF RECOVERED DATA REPORTED ABOVE

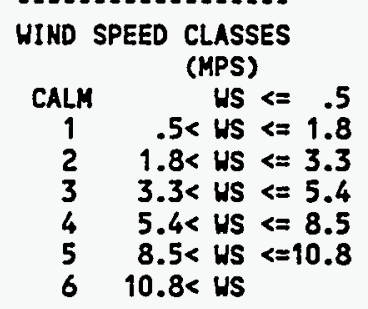


METEOROLOGICAL JOIHT FREQUENCY DISTRIBUTION (PERCENT OF VALIO HOUR OBSERVATIONS)

SPILL TEST FACILITY 24 METER TONER

8 METER HEIGHT - Morning Transition

$12 / 1 / 1994 \cdot 12 / 31 / 1994$

$600-1000$ (MST)

HINDSPEEDCLASS

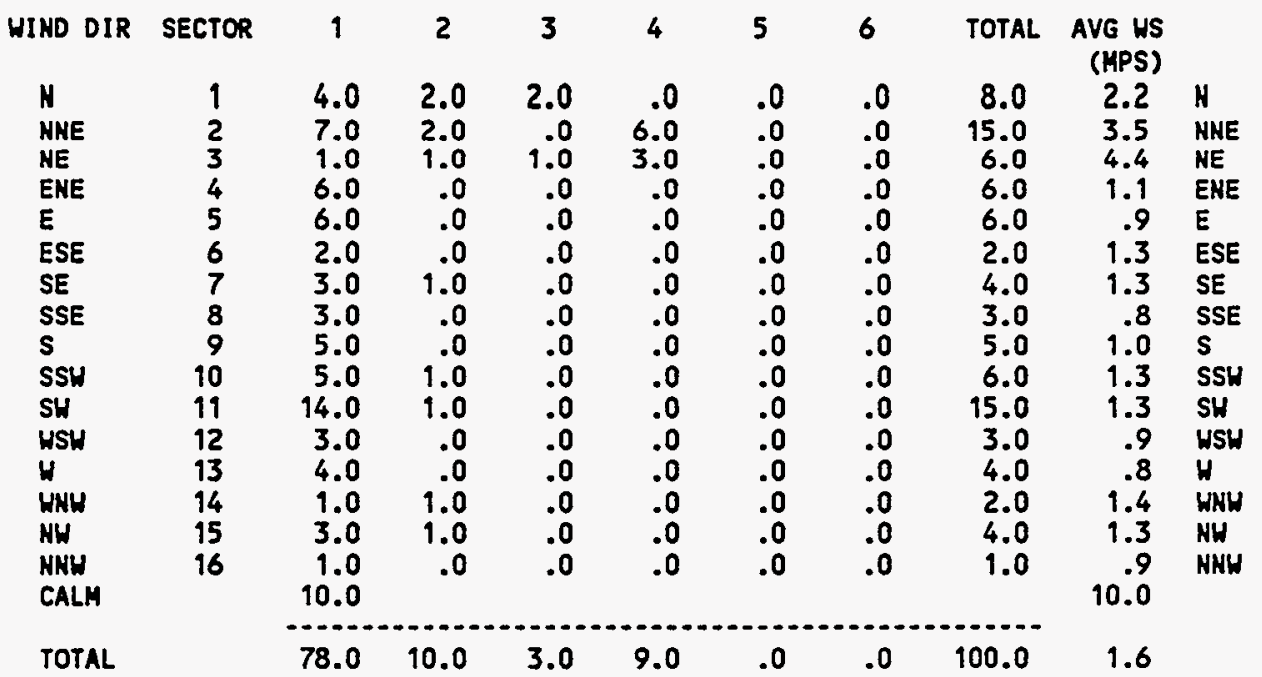

65.1\% DATA RECOVERED

20.7\% OF RECOVERED DATA

REPORTED ABOVE

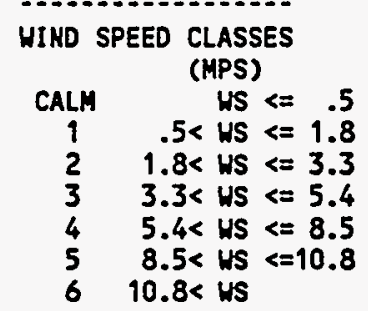


METECAOLOGICAL JOINT FREQUEHCY OISTRIOUTION (PERCENT OF VALIO HOU COSERVATIOHS)

SPILL TEST FACILITY 26 METER TOWER

8 METER HEIGHT - Late Mid-Day

1/ 1/1996 - 1/31/1996

$1000-1600$ (KST)

HI D SPEEDCLASS

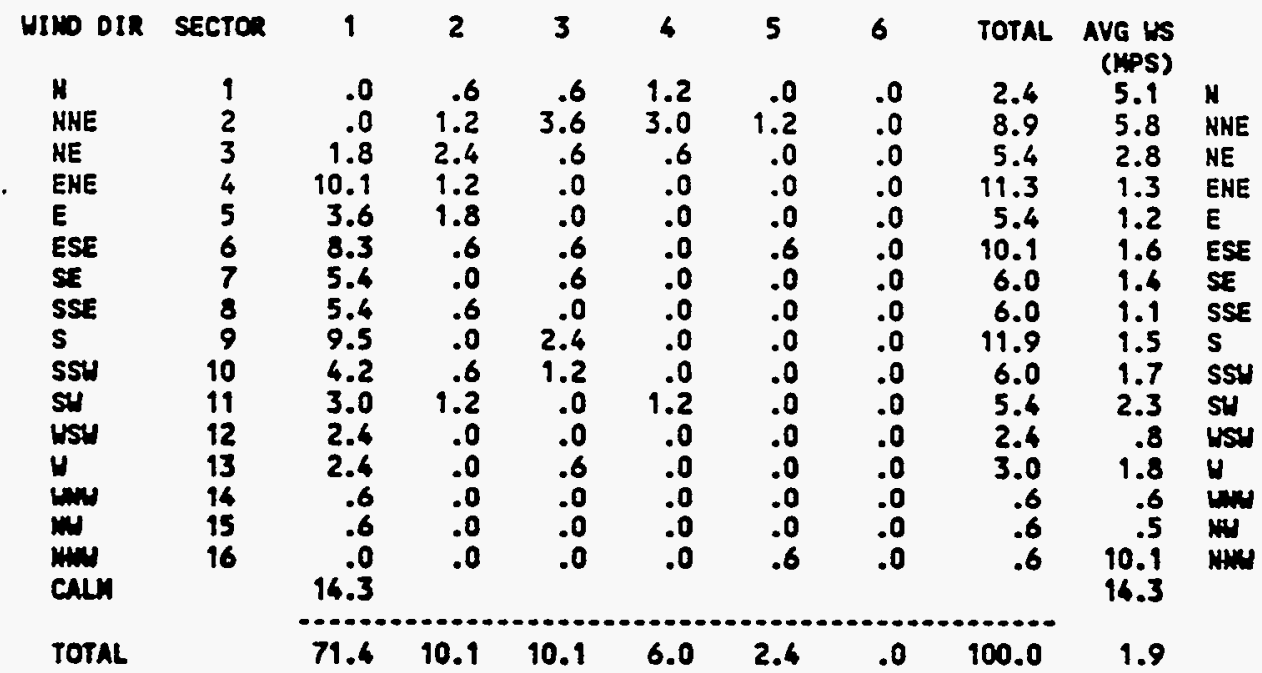

78.0X DATA RECOVERED

29.0\% OF RECOVERED DATA

REPORTED AROVE

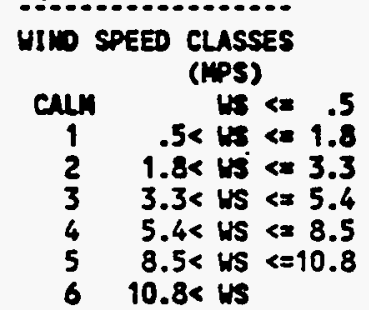


METEOROLOGICAL JOINT FREQUENCY DISTRIBUTION (PERCENT OF VALID HOUR OBSERVATIONS) SPILL TEST FACILITY 26 METER TOMER

8 meter hEIGHT - Late Mid-DaY 2/ 1/1994 $2 / 28 / 1994$

HINDSPEEDCLASS

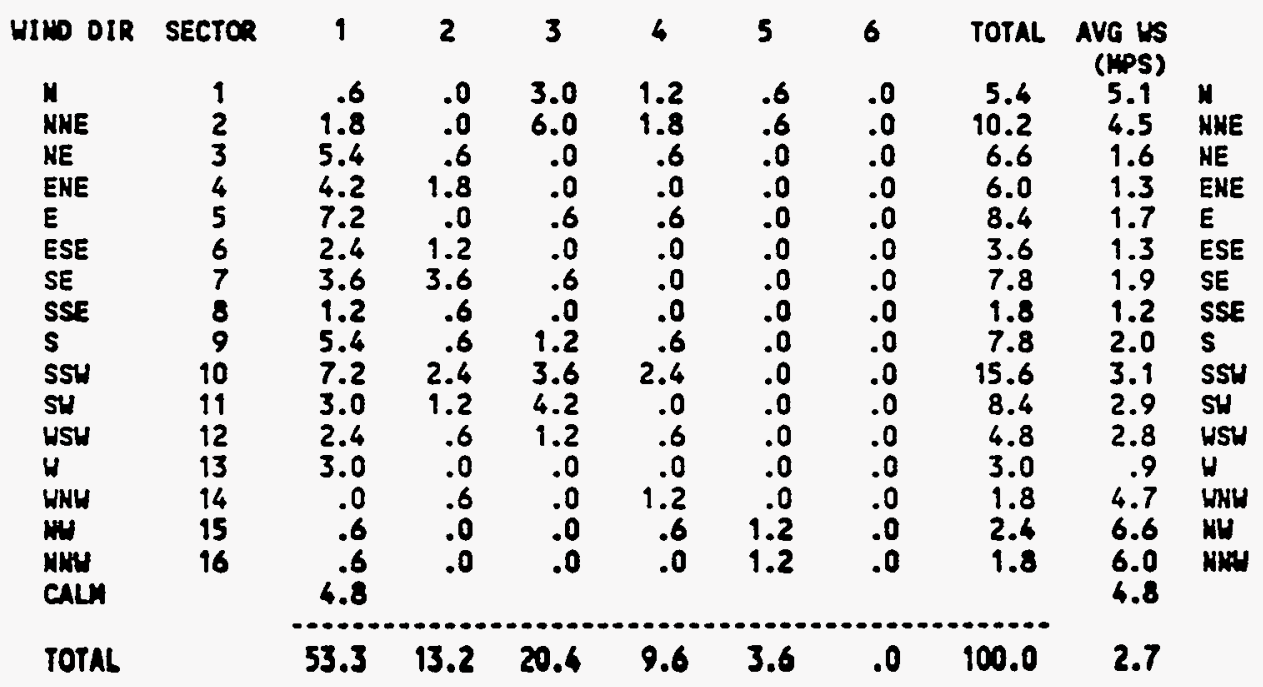

85.6\% DATA RECOVERED

29.1X OF RECOVERED DATA

REPORTED ASOVE

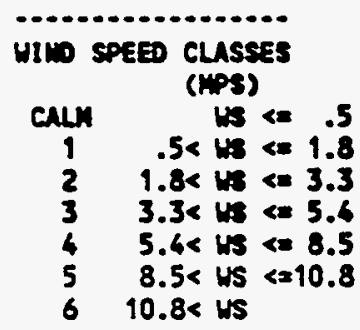


METEOROLOGICAL JOINT FRECUENCY DISTRIBUTION (PERCENT OF VALID HOUR OSSERVATIONS)

SPILL TEST FACILITY 24 METER TOAER

8 METER MEIGHT - Late Mid-DaY

$3 / 1 / 1994-3 / 31 / 1994$

$1000 \cdot 1600$ (HST)

WINDSPEED CLASS

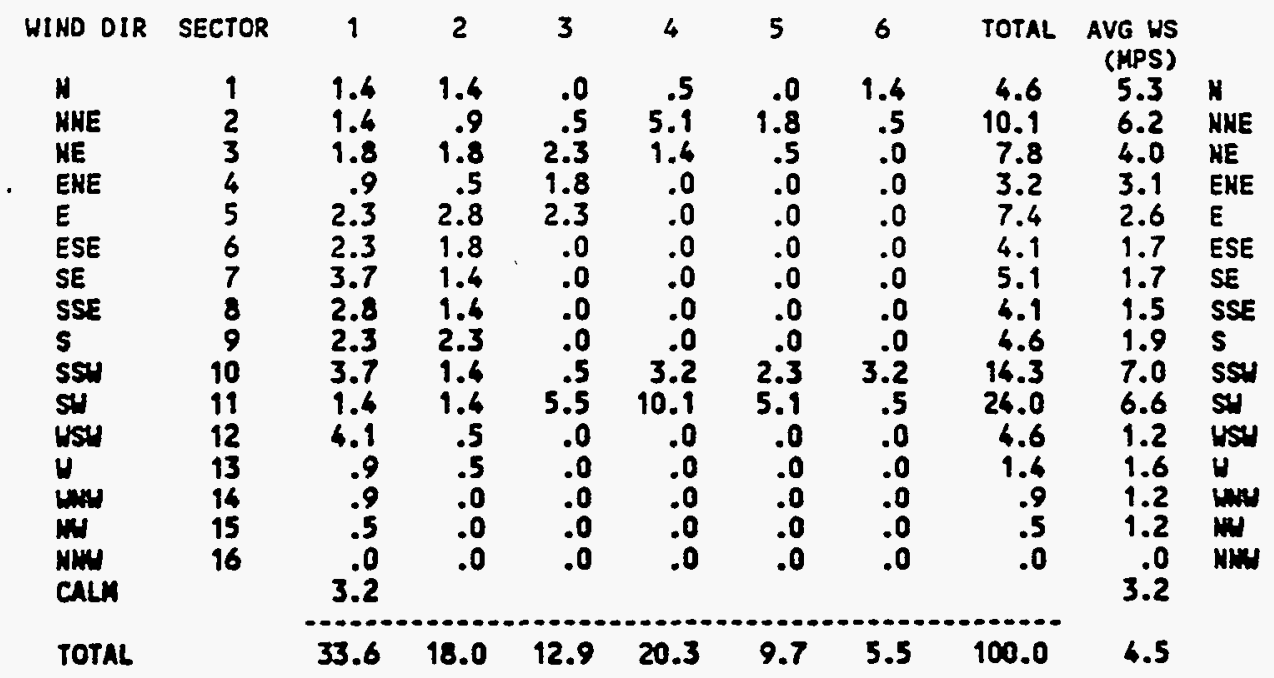

100. OS DATA RECONERED

29.2W OF RECONERED DATA

REPORTED ADOVE

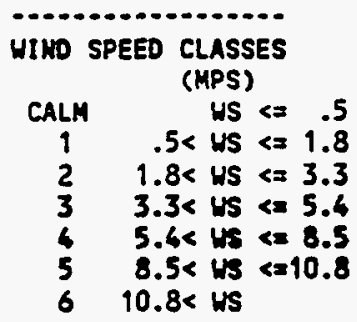


METEOROLOGICAL JOIHT FREQUENCY DISTRIBUTIOH (PERCENT OF VALID HOUR OBSERVATIONS) SPILL TEST FACILITY 24 METER TOWER

\begin{tabular}{|c|c|c|c|c|c|c|c|c|c|c|}
\hline METER HE & GHT - L & e Mid & bay & & & $\begin{array}{l}19994 \\
00-\end{array}$ & $\begin{array}{l}4 / 3 C \\
0 \text { CMS }\end{array}$ & & & \\
\hline & & & $1 \mathrm{H}$ & $S P$ & $E D$ & LA & & & & \\
\hline HIND DIR & SECTOR & 1 & 2 & 3 & 4 & 5 & 6 & TOTAL & $\begin{array}{r}\text { AVG WS } \\
\text { (MPS) }\end{array}$ & \\
\hline N & 1 & .0 & .0 & .0 & .5 & .0 & .0 & .5 & 7.7 & N \\
\hline NME & 2 & .0 & .0 & 1.0 & .0 & 1.9 & .0 & 2.9 & 7.7 & NME \\
\hline NE & 3 & .0 & .5 & 1.0 & .0 & .0 & .0 & 1.4 & 3.3 & NE \\
\hline ENE & 4 & .0 & .0 & .0 & .0 & .0 & .0 & .0 & .0 & ENE \\
\hline$E$ & 5 & .5 & 1.9 & 1.0 & .5 & .0 & .0 & 3.8 & 3.5 & $E$ \\
\hline ESE & 6 & 2.4 & 2.9 & .5 & .0 & .0 & .0 & 5.7 & 2.1 & ESE \\
\hline SE & 7 & .5 & 4.8 & .5 & .5 & .0 & .0 & 6.2 & 2.7 & SE \\
\hline $\begin{array}{l}\text { SSE } \\
\text { S }\end{array}$ & $\begin{array}{l}8 \\
9\end{array}$ & $\begin{array}{l}2.4 \\
1.9\end{array}$ & $\begin{array}{l}3.3 \\
3.8\end{array}$ & $\begin{array}{r}.5 \\
1.0\end{array}$ & $\begin{array}{r}.5 \\
1.0\end{array}$ & $\begin{array}{r}.0 \\
5\end{array}$ & $\begin{array}{l}.0 \\
.0\end{array}$ & $\begin{array}{l}6.7 \\
8.1\end{array}$ & $\begin{array}{l}2.2 \\
3.3\end{array}$ & $\begin{array}{l}\text { SSE } \\
\text { S }\end{array}$ \\
\hline SSH & 10 & 2.9 & 3.8 & 3.8 & 1.4 & 2.4 & 3.8 & 18.1 & 6.2 & SSH \\
\hline SH & 19 & 0 & 2.4 & 8.1 & 11.6 & 2.9 & 1.9 & 26.7 & 6.4 & SH \\
\hline & $\begin{array}{l}12 \\
13\end{array}$ & $\begin{array}{l}1.4 \\
1.4\end{array}$ & $\begin{array}{r}1.0 \\
.5\end{array}$ & $\begin{array}{l}4.8 \\
1.4\end{array}$ & $\begin{array}{l}2.9 \\
1.4\end{array}$ & $\begin{array}{l}.0 \\
.0\end{array}$ & $\begin{array}{l}.0 \\
.0\end{array}$ & $\begin{array}{r}10.0 \\
4.8\end{array}$ & $\begin{array}{l}4.3 \\
3.9\end{array}$ & WSW \\
\hline $\begin{array}{l}\text { WNH } \\
\text { NH }\end{array}$ & $\begin{array}{l}14 \\
15\end{array}$ & .0 & $\begin{array}{l}.5 \\
.0\end{array}$ & $\begin{array}{l}.0 \\
.0\end{array}$ & $\begin{array}{l}.5 \\
.5\end{array}$ & $\begin{array}{l}.0 \\
.5\end{array}$ & $\begin{array}{l}.0 \\
.5\end{array}$ & $\begin{array}{l}1.0 \\
1.9\end{array}$ & $\begin{array}{l}5.2 \\
6.8\end{array}$ & $\begin{array}{l}\text { HWH } \\
\text { WH }\end{array}$ \\
\hline MHU & 16 & $\begin{array}{l}.0 \\
.5\end{array}$ & .0 & .0 & .5 & .5 & 1.0 & 1.9 & $\begin{array}{r}10.6 \\
.5\end{array}$ & NAW \\
\hline TOTAL & & 14.3 & 25.2 & 23.3 & 21.4 & 8.6 & 7.1 & 100.0 & 5.0 & \\
\hline
\end{tabular}

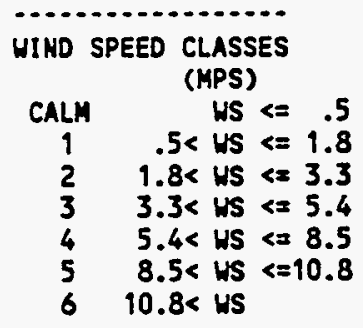


METEOROLOGICAL JOIKT FREQUEMCY DISTRIBUTION (PERCENT OF VALID HOUR OBSERVATIONS)

SPILL TEST FACILITY 24 METER TONER

8 METER HEIGHT - Late Mid-Day

$5 / 1 / 1994 \cdot 5 / 31 / 1994$

$1000-1600$ (MST)

HI ND SPEEDCLASS

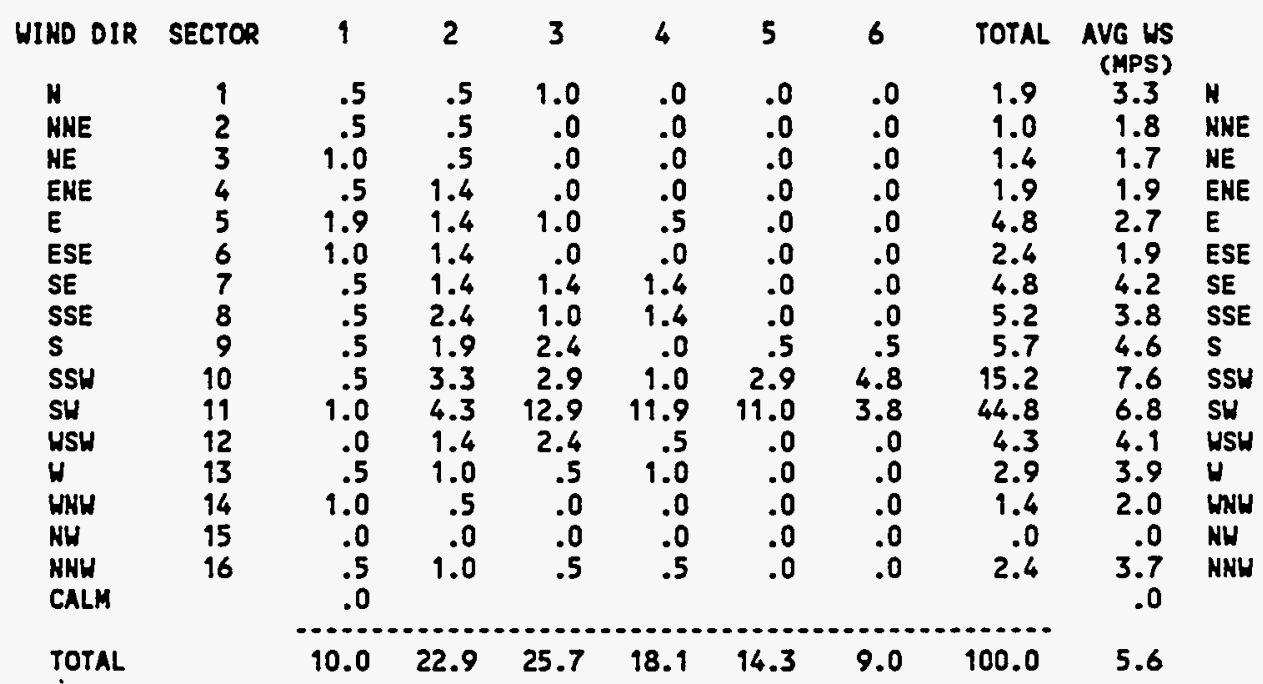

96.9\% DATA RECOVERED

29.1\% OF RECOVERED DATA REPORTED ABOVE

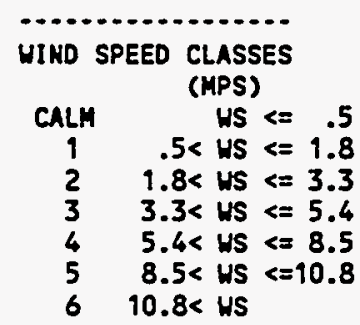


METEOROLOGICAL JOIHT FREOUENCY DISTRIBUTION (PERCENT OF VALID HOUR OBSERVATIONS)

SPILL TEST FACILITY 24 METER TQNER

8 METER HEIGHT - Late Mid-DaY

6/ $1 / 1994 \cdot 6 / 30 / 1994$

$1000 \cdot 1600$ (HST)

HI NDSPEEDCLASS

\begin{tabular}{|c|c|c|c|c|c|c|c|c|c|c|}
\hline HIND OIR & SECTOR & 1 & 2 & 3 & 4 & 5 & 6 & TOTAL & $\begin{array}{l}\text { AVG US } \\
\text { (MPS) }\end{array}$ & \\
\hline N & 1 & .5 & 1.0 & .0 & .0 & .0 & .0 & 1.4 & 1.8 & N \\
\hline NHE & 2 & .5 & .0 & .0 & .0 & .0 & .0 & .5 & 1.4 & NME \\
\hline NE & 3 & .5 & .0 & .0 & .0 & .0 & .0 & .5 & 1.3 & NE \\
\hline ENE & 4 & 1.0 & .5 & .0 & .0 & .0 & .0 & 1.4 & 1.3 & ENE \\
\hline$E$ & 5 & .0 & 1.4 & .0 & .0 & .0 & .0 & $\begin{array}{l}1.4 \\
2.9\end{array}$ & $\begin{array}{l}2.2 \\
2.1\end{array}$ & $\begin{array}{l}E \\
\text { ESE }\end{array}$ \\
\hline $\begin{array}{l}\text { ESE } \\
\text { SE }\end{array}$ & $\frac{6}{7}$ & $\begin{array}{r}1.0 \\
.5\end{array}$ & $\begin{array}{r}1.9 \\
.5\end{array}$ & $\begin{array}{l}.0 \\
.0\end{array}$ & .0 & .0 & .0 & $\begin{array}{l}2.9 \\
1.0\end{array}$ & $\begin{array}{l}2.7 \\
2.1\end{array}$ & $\begin{array}{l}\text { ESE } \\
\text { SE }\end{array}$ \\
\hline SSE & 8 & .5 & .5 & .0 & .0 & .0 & .0 & 1.0 & 1.4 & SSE \\
\hline s & 9 & 1.0 & 9.4 & 1.4 & .0 & .0 & .0 & 3.8 & 2.7 & $\begin{array}{l}\text { S } \\
\text { SSW }\end{array}$ \\
\hline $\begin{array}{l}\text { SSW } \\
\text { SH }\end{array}$ & $\begin{array}{l}10 \\
11\end{array}$ & $\begin{array}{l}.5 \\
.5\end{array}$ & $\begin{array}{l}1.4 \\
1.4\end{array}$ & $\begin{array}{l}2.4 \\
5.7\end{array}$ & $\begin{array}{r}1.4 \\
28.1\end{array}$ & $\begin{array}{r}4.3 \\
18.9\end{array}$ & $\begin{array}{r}.5 \\
6.2\end{array}$ & $\begin{array}{l}10.5 \\
60.0\end{array}$ & $\begin{array}{l}7.0 \\
7.9\end{array}$ & $\begin{array}{l}\text { SSW } \\
\text { SW }\end{array}$ \\
\hline USH & 12 & .0 & 1.4 & 1.4 & 6.2 & 3.8 & .5 & 13.3 & 7.0 & WSW \\
\hline $\mathbf{u}$ & 13 & .0 & .0 & .0 & .0 & .0 & .0 & .0 & .0 & $W$ \\
\hline WH & 14 & .5 & .5 & .0 & .0 & .0 & .0 & 1.0 & 2.2 & WWH \\
\hline NW & 15 & .5 & .0 & .0 & .0 & .0 & .0 & .5 & 1.2 & NH \\
\hline $\begin{array}{l}\text { NHH } \\
\text { CALH }\end{array}$ & 16 & $\begin{array}{r}1.0 \\
.0\end{array}$ & .0 & .0 & .0 & .0 & .0 & 1.0 & $\begin{array}{r}1.3 \\
.0\end{array}$ & NHW \\
\hline TOTAL & & 8.1 & 11.9 & 11.0 & 35.7 & 26.2 & 7.1 & 100.0 & 6.7 & \\
\hline
\end{tabular}

100.0\% DATA RECOVERED

29.2\% OF RECOVERED DATA REPORTED ABOVE

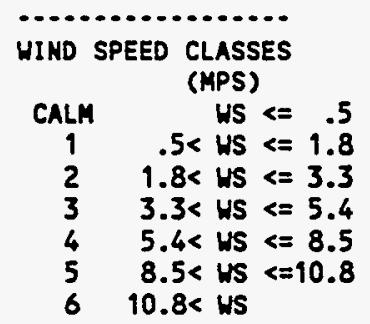


METEOROLOGICAL JOINT FREQUENCY DISTRIBUTION (PERCENT OF VALID HOUR OBSERVATIONS) SPILL TEST FACILITY 24 METER TOWER

8 METER HEIGHT - Late Mid-DaY

7) $1 / 1994-7 / 31 / 1994$

$1000 \cdot 1600$ (MST)

\section{HI HO SPEED CLASS}

\begin{tabular}{|c|c|c|c|c|c|c|c|c|c|c|}
\hline WIND DIR & SECTOR & 1 & 2 & 3 & 4 & 5 & 6 & TOTAL & $\begin{array}{l}\text { AVG US } \\
\text { (MPS) }\end{array}$ & \\
\hline H & 1 & .0 & .9 & .5 & .0 & .0 & .0 & 1.4 & 3.4 & $\mathbf{N}$ \\
\hline ANE & 2 & .5 & .5 & .0 & .0 & .0 & .0 & .9 & 1.6 & HNE \\
\hline HE & 3 & .0 & 1.4 & .0 & .0 & .0 & .0 & 1.4 & 2.8 & HE \\
\hline EKE & 4 & .0 & 1.4 & .0 & .0 & .0 & .0 & 1.4 & 2.8 & ENE \\
\hline E & 5 & .0 & 1.4 & .0 & .0 & .0 & .0 & 1.4 & 2.8 & $E$ \\
\hline $\begin{array}{l}\text { ESE } \\
\text { SE }\end{array}$ & $\begin{array}{l}6 \\
7\end{array}$ & $\begin{array}{l}1.4 \\
1.4\end{array}$ & $\begin{array}{r}.0 \\
2.8\end{array}$ & $\begin{array}{r}.0 \\
1.8\end{array}$ & $\begin{array}{l}.0 \\
.0\end{array}$ & $\begin{array}{l}.0 \\
.0\end{array}$ & $\begin{array}{l}.0 \\
.0\end{array}$ & $\begin{array}{l}1.4 \\
6.0\end{array}$ & $\begin{array}{l}1.2 \\
2.6\end{array}$ & $\begin{array}{l}\text { ESE } \\
\text { SE }\end{array}$ \\
\hline SSE & 8 & .5 & .9 & .9 & .0 & .0 & .0 & 2.3 & 2.9 & SSE \\
\hline S & 9 & 1.8 & 1.8 & .9 & .0 & .0 & .0 & 4.6 & 2.4 & $\mathbf{s}$ \\
\hline SSH & 10 & .9 & 2.8 & 6.0 & 3.2 & 3.2 & .0 & 16.1 & 5.4 & SSH \\
\hline SH & 11 & .0 & 9.8 & 13.4 & 36.4 & 6.5 & .9 & 59.0 & 6.8 & SW \\
\hline WSH & 12 & .0 & .5 & .9 & .5 & .0 & .0 & 1.8 & 4.6 & WSH \\
\hline $\boldsymbol{W}$ & 13 & .5 & .0 & .0 & .0 & .0 & .0 & .5 & 1.4 & $H$ \\
\hline WNW & 14 & .5 & .0 & .0 & .0 & .0 & .0 & .5 & 1.6 & WHH \\
\hline NW & 15 & .0 & .5 & .0 & .0 & .0 & .0 & .5 & 2.1 & NH \\
\hline $\begin{array}{l}\text { NNH } \\
\text { CALM }\end{array}$ & 16 & .5 & .5 & .0 & .0 & .0 & .0 & .9 & $\begin{array}{r}1.8 \\
.0\end{array}$ & NNW \\
\hline TOTAL & & 7.8 & 17.1 & 24.4 & 40.1 & 9.7 & .9 & 100.0 & 5.5 & \\
\hline
\end{tabular}

100.0\% DATA RECOVERED

29.2\% OF RECOVERED DATA

REPORTED ABOVE

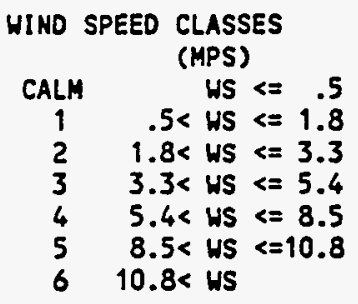


METEOROLOGICAL JOINT FREQUENCY DISTRIBUTION (PERCENT OF VALID HOUR OBSERVATIONS)

SPILL TEST FACILITY 24 METER TOWER

8 METER HEIGHT - Late Mid-DaY

$8 / 1 / 1994-8 / 31 / 1994$

$1000-1600$ (MST)

HIND SPEEDCLASS

\begin{tabular}{|c|c|c|c|c|c|c|c|c|c|c|}
\hline WIND DIR & SECTOR & 1 & 2 & 3 & 4 & 5 & 6 & TOTAL & $\begin{array}{l}\text { AVG US } \\
\text { (MPS) }\end{array}$ & \\
\hline N & 1 & .5 & .9 & .0 & .0 & .0 & .0 & 1.4 & 2.0 & N \\
\hline NHE & 2 & .5 & .5 & .5 & .0 & .0 & .0 & 1.4 & 2.4 & NNE \\
\hline NE & 3 & .9 & .5 & .0 & .0 & .0 & .0 & 1.4 & 1.8 & NE \\
\hline ENE & 4 & .5 & 1.8 & .0 & .0 & .0 & .0 & 2.3 & 1.9 & ENE \\
\hline E & 5 & .0 & .0 & .5 & .0 & .0 & .0 & .5 & 5.0 & $E$ \\
\hline ESE & 6 & 1.4 & .0 & .5 & .5 & .0 & .0 & 2.3 & 2.7 & ESE \\
\hline $\begin{array}{l}\text { SE } \\
\text { SSE }\end{array}$ & 8 & .5 & .9 & 3.7 & .9 & .0 & .0 & 6.0 & 4.0 & $\begin{array}{l}\text { SE } \\
S S E\end{array}$ \\
\hline s & 9 & .0 & 1.8 & .9 & 1.8 & .0 & .0 & $\begin{array}{l}2.0 \\
4.6\end{array}$ & 4.6 & 2 \\
\hline SSH & 10 & .0 & 1.4 & 4.1 & 5.1 & 3.2 & .0 & 13.8 & 6.4 & SSH \\
\hline SH & 11 & 1.4 & .9 & 7.4 & 28.1 & 13.8 & 1.8 & 53.5 & 7.3 & SH \\
\hline WSW & 12 & .9 & .0 & 9.8 & 4.1 & .0 & .0 & 6.9 & 5.2 & WSH \\
\hline$w$ & 13 & .5 & .0 & .5 & .0 & .0 & .0 & .9 & 2.3 & $\omega$ \\
\hline WNH & 14 & .0 & .0 & .0 & .0 & .0 & .0 & .0 & .0 & WHW \\
\hline NH & 15 & .0 & .0 & .0 & .5 & .0 & .0 & .5 & 7.2 & NH \\
\hline $\begin{array}{l}\text { NNH } \\
\text { CALM }\end{array}$ & 16 & $\begin{array}{r}.9 \\
.5\end{array}$ & .0 & .5 & .0 & .0 & .0 & 1.4 & $\begin{array}{r}2.3 \\
.5\end{array}$ & NNW \\
\hline TOTAL & & 9.2 & 9.2 & 21.7 & 41.0 & 17.1 & 1.8 & 100.0 & 6.0 & \\
\hline
\end{tabular}

100.0\% DATA RECOVERED

29.2\% OF RECOVERED DATA REPORTED ABOVE

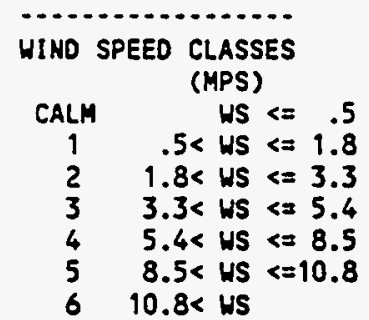


METEOROLOGICAL JOIHT FREOUENCY DISTRIBUTION (PERCENT OF VALIO HOUR OBSERVATIONS)

SPILL TEST FACILITY 24 METER TOWER

8 METER HEIGHT - Late Mid-DaY

9/ $1 / 1994-9 / 30 / 1994$

$1000 \cdot 1600$ (HST)

\section{WIND SPEED CLASS}

\begin{tabular}{|c|c|c|c|c|c|c|c|c|c|c|}
\hline HIND DIR & SECTOR & 1 & 2 & 3 & 4 & 5 & 6 & TOTAL & $\begin{array}{r}\text { AVG WS } \\
\text { (HPS) }\end{array}$ & \\
\hline$H$ & 1 & 1.0 & .0 & .5 & .0 & 1.0 & .0 & 2.4 & 5.0 & N \\
\hline NME & 2 & 1.9 & .5 & .0 & 1.4 & .0 & .0 & 3.8 & 3.8 & NHE \\
\hline NE & 3 & 2.9 & 1.0 & .5 & .0 & .0 & .0 & 4.3 & 1.9 & NE \\
\hline ENE & 4 & 3.3 & .0 & .0 & .0 & .0 & .0 & 3.3 & 1.1 & ENE \\
\hline E & 5 & 2.9 & 1.9 & .0 & .0 & .0 & .0 & 4.8 & 1.7 & $\mathrm{E}$ \\
\hline ESE & 6 & 1.4 & 2.4 & .5 & .0 & .0 & .0 & 4.3 & 2.1 & ESE \\
\hline SE & 7 & 2.4 & 1.0 & .0 & .0 & .0 & .0 & 3.3 & 1.6 & SE \\
\hline SSE & 8 & 1.4 & 1.4 & .0 & .0 & .0 & .0 & 2.9 & 1.8 & SSE \\
\hline s & 9 & .5 & 1.0 & .0 & .0 & .0 & .0 & 1.4 & 1.9 & $\mathbf{s}$ \\
\hline SSH & 10 & 1.9 & 2.4 & 1.4 & 3.8 & 8.6 & 4.3 & 22.4 & 8.0 & SSH \\
\hline SW & 11 & 1.4 & 1.9 & 5.7 & 16.7 & 4.8 & 1.9 & 32.4 & 6.6 & SH \\
\hline WSW & 12 & .0 & 1.0 & 2.9 & 2.4 & .0 & .0 & 6.2 & 4.8 & WSH \\
\hline H & 13 & .0 & .5 & .0 & .0 & .0 & .0 & .5 & 1.8 & $H$ \\
\hline WNH & 14 & .5 & .0 & .0 & .0 & .0 & .0 & .5 & 1.3 & WNH \\
\hline NH & 15 & .0 & 1.0 & .0 & .5 & .0 & .0 & 1.4 & 3.4 & NH \\
\hline $\begin{array}{l}\text { NHH } \\
\text { CALM }\end{array}$ & 16 & $\begin{array}{r}.5 \\
3.8\end{array}$ & 1.0 & .0 & .0 & 1.0 & .0 & 2.4 & $\begin{array}{l}4.4 \\
3.8\end{array}$ & NNH \\
\hline TOTAL & & 25.7 & 16.7 & 11.4 & 24.8 & 15.2 & 6.2 & 100.0 & 5.1 & \\
\hline
\end{tabular}

99.2X DATA RECOVERED

29.4\% OF RECOVERED DATA REPORTED ABOVE

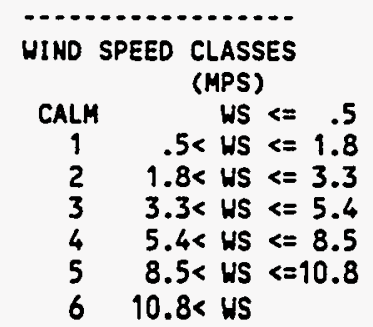


METEOROLOGICAL JOINT FREQUENCY DISTRIBUTION (PERCENT OF VALID HOUR OBSERVATIOHS)

SPILL TEST FACILITY 24 METER TONER

8 METER HEIGHT - Late Mid-Day

$10 / 1 / 1994-10 / 31 / 1994$

$1000-1600$ (MST)

HI H D S PED CLASS

\begin{tabular}{|c|c|c|c|c|c|c|c|c|c|c|}
\hline WIND DIR & SECTOR & 1 & 2 & 3 & 4 & 5 & 6 & TOTAL & AVG WS & \\
\hline $\begin{array}{l}\text { NHE } \\
\text { NHE }\end{array}$ & $\begin{array}{l}1 \\
2\end{array}$ & 2.9 & $\begin{array}{r}.5 \\
1.8\end{array}$ & $\begin{array}{r}.9 \\
4.1\end{array}$ & $\begin{array}{l}1.8 \\
2.8\end{array}$ & $\begin{array}{l}.0 \\
.0\end{array}$ & $\begin{array}{l}.0 \\
.0\end{array}$ & $\begin{array}{r}4.1 \\
11.1\end{array}$ & $\begin{array}{l}4.6 \\
4.0\end{array}$ & $\begin{array}{l}\text { N } \\
\text { HHE }\end{array}$ \\
\hline $\mathrm{HE}$ & 3 & .9 & .9 & .9 & .5 & .0 & .0 & 3.2 & 3.3 & NE \\
\hline ENE & 4 & 39 & 1.8 & .0 & .0 & .0 & .0 & 2.8 & 1.9 & ENE \\
\hline $\begin{array}{l}\text { E } \\
\text { ESE }\end{array}$ & $\begin{array}{l}5 \\
6\end{array}$ & $\begin{array}{l}3.2 \\
3.2\end{array}$ & $\begin{array}{l}.5 \\
.0\end{array}$ & $\begin{array}{l}.0 \\
.0\end{array}$ & $\begin{array}{l}.0 \\
.0\end{array}$ & $\begin{array}{l}.0 \\
.0\end{array}$ & $\begin{array}{l}.0 \\
.0\end{array}$ & $\begin{array}{l}3.7 \\
3.2\end{array}$ & $\begin{array}{l}1.3 \\
1.1\end{array}$ & $\begin{array}{l}\text { E } \\
\text { ESE }\end{array}$ \\
\hline SE & 7 & $\begin{array}{l}3.2 \\
2.8\end{array}$ & .0 & .0 & .0 & .0 & .00 & $\begin{array}{l}3.2 \\
3.2\end{array}$ & 1.4 & SE \\
\hline SSE & 8 & 6.0 & .9 & .0 & .0 & .0 & .0 & 6.9 & 1.3 & SSE \\
\hline s & 9 & 6.0 & 1.4 & .0 & .0 & .0 & .0 & 7.4 & 1.3 & $\mathbf{s}$ \\
\hline SSH & 10 & 4.1 & .9 & .9 & .9 & 1.4 & .5 & 8.8 & 4.0 & SSH \\
\hline SH & 11 & .5 & 2.3 & 9.2 & 7.4 & 2.3 & .9 & 22.6 & 5.6 & SH \\
\hline WSH & 12 & 2.8 & 1.4 & 3.2 & 1.4 & .0 & .0 & 8.8 & 3.3 & WSH \\
\hline$H$ & 13 & .9 & .0 & .0 & .5 & .0 & .0 & 1.4 & 2.6 & $H$ \\
\hline WNH & 14 & .0 & .0 & .5 & .0 & .0 & .0 & .5 & 4.6 & WNH \\
\hline NH & 15 & .9 & .5 & .0 & .0 & .0 & .0 & 1.4 & 1.4 & NW \\
\hline NNH & 16 & .97 & .0 & .0 & .5 & .0 & .0 & 1.4 & $\begin{array}{l}3.0 \\
9.7\end{array}$ & NNH \\
\hline
\end{tabular}

TOTAL

46.1

13.4

19.8

15.7

3.7

1.4

100.0

3.1

98.5\% DATA RECOVERED

29.6\% OF RECOVERED DATA REPORTED ABOVE

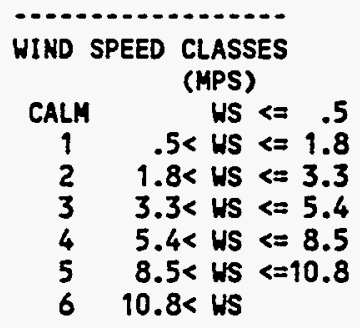


METEOROLOGICAL JOINT FREQUENCY DISTRIBUTION (PERCENT OF VALID HOUR OBSERVATIONS) SPILL TEST FACILITY 24 METER TOWER

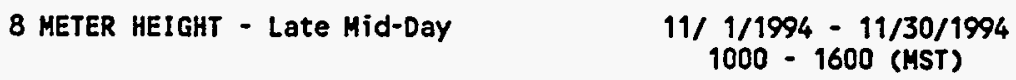

WINO SPEED CLASS

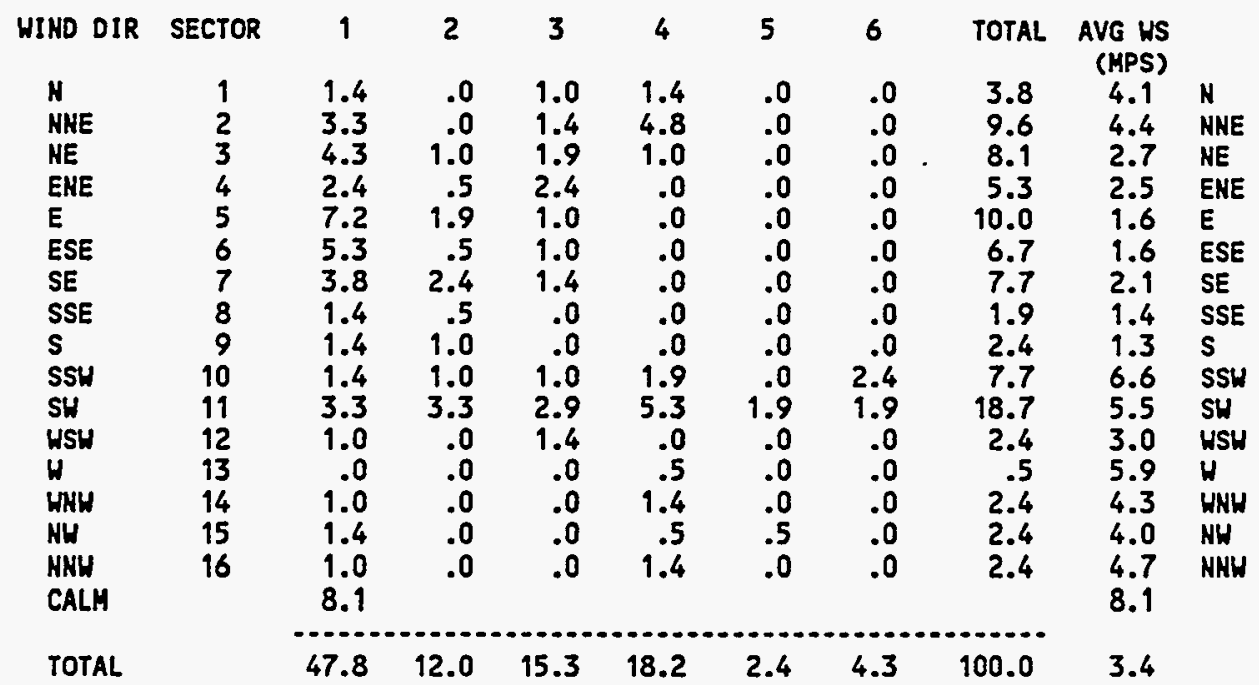

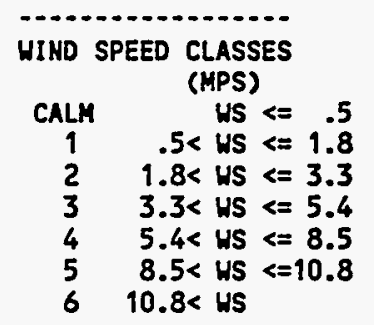


METEOROLOGICAL JOINT FREQUENCY OISTRIBUTION (PERCENT OF VALID HOUR OBSERVATIOHS) SPILL TEST FACILITY 24 METER TOWER

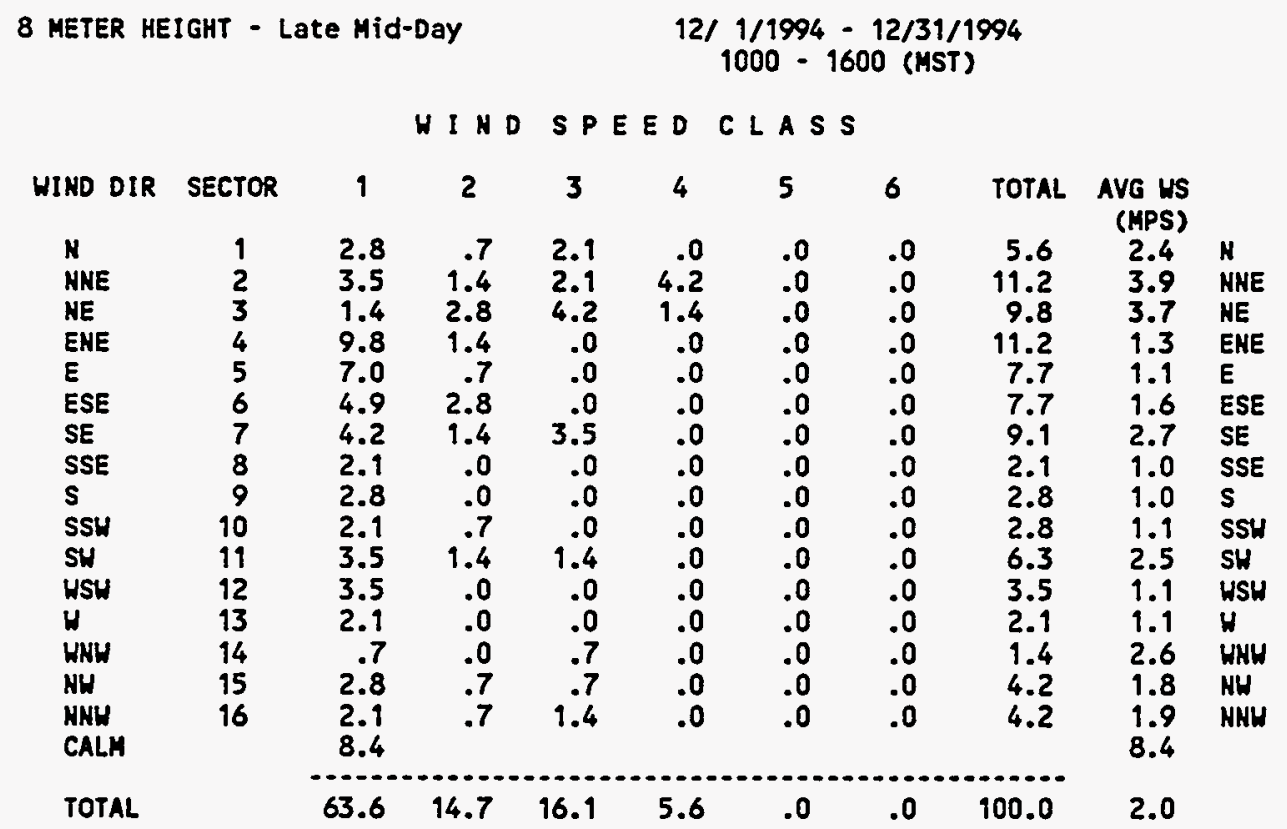

65.1\% DATA RECOVERED

29.5\% OF RECOVERED DATA

$\begin{array}{ccc}\text { WIND SPEED CLASSES } \\ \text { (MPS) } \\ \text { CALM } & \text { WS }<= & .5 \\ 1 & .5<\text { US }<=1.8 \\ 2 & 1.8<\text { WS }<=3.3 \\ 3 & 3.3<\text { WS }<=5.4 \\ 4 & 5.4<\text { US }<=8.5 \\ 5 & 8.5<\text { WS }<=10.8 \\ 6 & 10.8<\text { WS }\end{array}$


METECROLOGICAL JOINT FREQUENCY DISTRIDUTION (PERCENT OF VALIO HOUR OASERVATIONS)

SPILL TEST FACILITY 24 METER TOWER

8 METER HEIGHT - Evening Transition

$1 / 1 / 1994 \cdot 1 / 31 / 1994$

$1600-2000$ (HST)

HI DOSPEEDCLASS

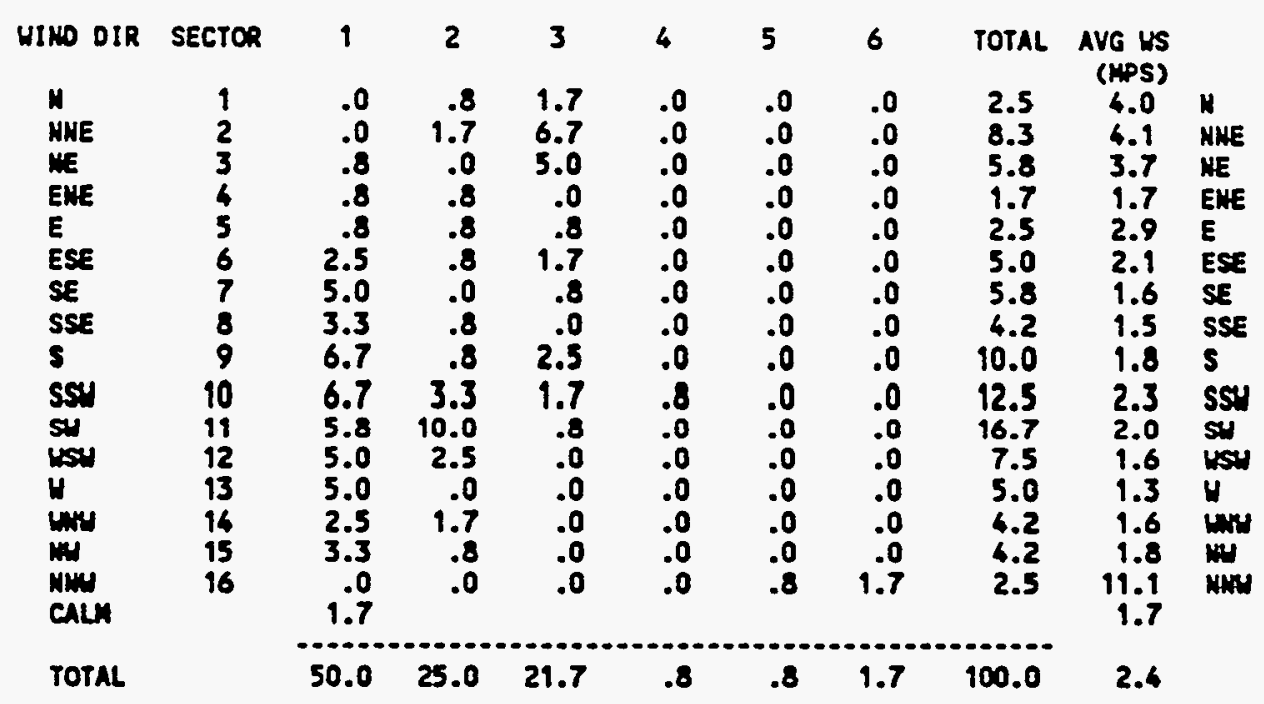

78.0\% DATA RECOVERED

20.7\% OF RECOVERED DATA REPORTED ABOVE

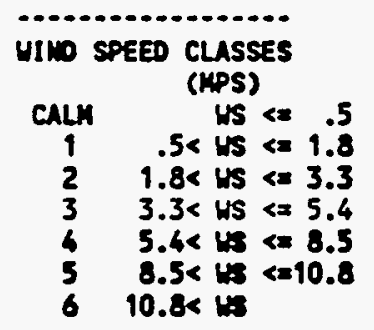


METEOROLOGICAL JOIMT FREQUENCY DISTRIBUTION (PERCENT OF VALID HOUR OBSERVATIONS) SPILL TEST FACILITY 24 METER TOWER

8 METER HEIGHT - Evening Transition

2/ $1 / 1994 \cdot 2 / 28 / 1994$

$1600 \cdot 2000$ (MST)

HINDSPEEDCLASS

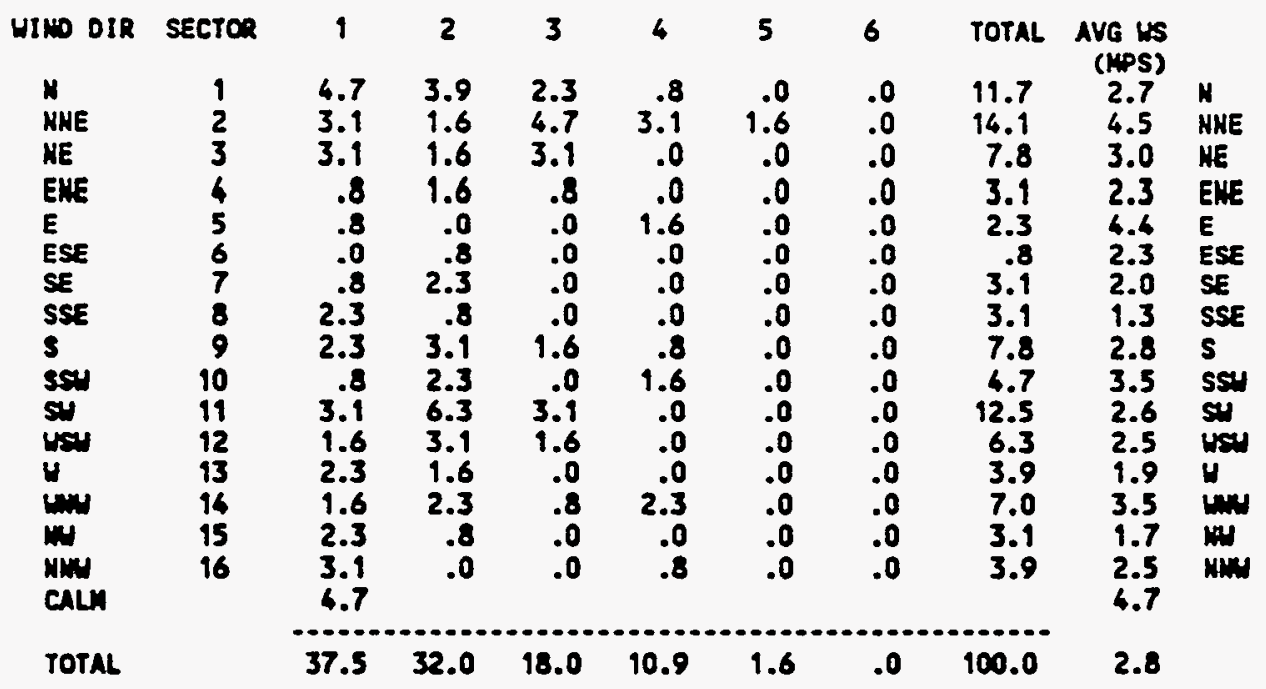

85.4\% DATA RECONERED

22.3\% OF RECOVERED DATA REPORTED ABOVE

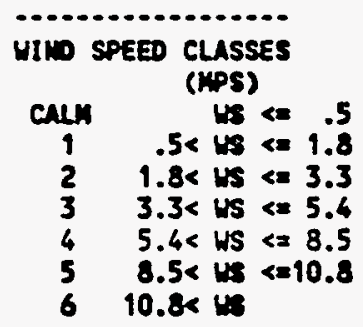


METEOROLOGICAL JOINT FREQUENCY DISTRIBUTIOH (PERCENT OF VALID HOUR OBSERVATIONS) SPILL TEST FACILITY 24 METER TOWER

8 METER HEIGHT - Evening Transition

$$
\begin{aligned}
& \text { 3) } 1 / 1994-3 / 31 / 1994 \\
& 1600-2000 \text { (MST) }
\end{aligned}
$$

UINDSPEEDCLASS

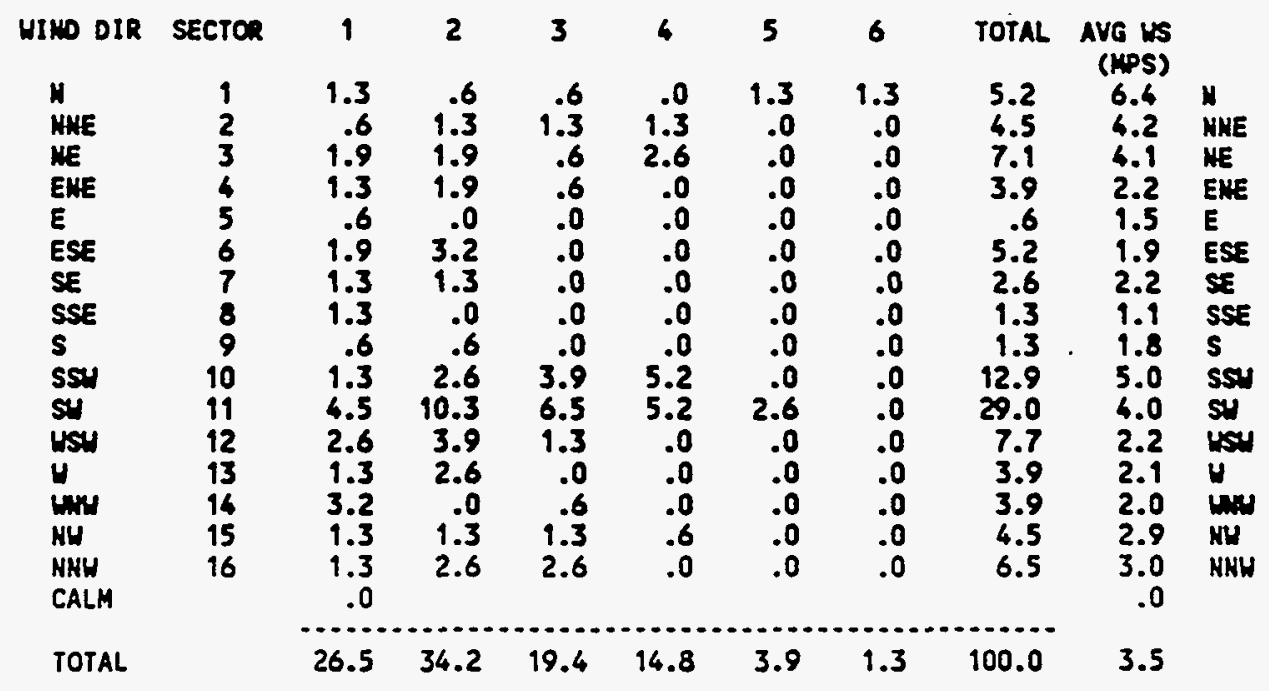

100.0\% DATA RECOVERED

20.8\% OF RECOVERED DATA REPORTED ABOVE

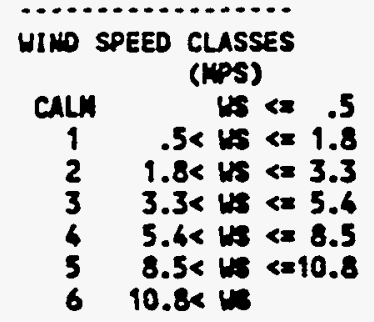


METEOROLOGICAL JOIHT FREQUENCY DISTRIBUTION (PERCENT OF VALID MOUR OBSERVATIONS) SPILL TEST FACILITY 24 METER TONER

8 METER HEIGHT - Evening Transition

$4 / 1 / 1994-4 / 30 / 1994$

$1600-2000$ (MST)

HIND SPEED CLASS

\begin{tabular}{|c|c|c|c|c|c|c|c|c|c|c|}
\hline WIND DIR & SECTOR & 1 & 2 & 3 & 4 & 5 & 6 & TOTAL & $\begin{array}{l}\text { AVG US } \\
\text { (MPS) }\end{array}$ & \\
\hline $\mathrm{N}$ & 1 & .0 & .0 & .0 & .7 & .0 & .0 & .7 & 7.5 & $\mathrm{H}$ \\
\hline NHE & 2 & .0 & .0 & 1.3 & 2.0 & 1.3 & .0 & 4.7 & 7.5 & NHE \\
\hline NE & 3 & .0 & 3.3 & .0 & .0 & .0 & .0 & 3.3 & 2.4 & NE \\
\hline ENE & 4 & .7 & .7 & .7 & .0 & .0 & .0 & 2.0 & 2.8 & ENE \\
\hline $\begin{array}{l}\text { E } \\
\text { ESE }\end{array}$ & $\begin{array}{l}5 \\
6\end{array}$ & $\begin{array}{l}2.7 \\
2.0\end{array}$ & $\begin{array}{r}.0 \\
2.0\end{array}$ & $\begin{array}{r}.7 \\
1.3\end{array}$ & $\begin{array}{r}1.3 \\
.0\end{array}$ & $\begin{array}{l}.0 \\
.0\end{array}$ & $\begin{array}{l}.0 \\
.0\end{array}$ & $\begin{array}{l}4.7 \\
5.3\end{array}$ & $\begin{array}{l}3.0 \\
2.6\end{array}$ & $\begin{array}{l}\varepsilon \\
\text { ESE }\end{array}$ \\
\hline SE & 7 & 3.3 & 2.7 & .7 & .0 & .0 & .0 & 6.7 & 2.2 & SE \\
\hline & $\begin{array}{l}8 \\
9\end{array}$ & $\begin{array}{l}1.3 \\
5.3\end{array}$ & $\begin{array}{r}.7 \\
2.0\end{array}$ & $\begin{array}{l}.0 \\
.7\end{array}$ & $\begin{array}{l}.0 \\
.0\end{array}$ & $\begin{array}{l}.0 \\
.0\end{array}$ & $\begin{array}{l}.0 \\
.0\end{array}$ & $\begin{array}{l}2.0 \\
8.0\end{array}$ & $\begin{array}{l}1.5 \\
2.0\end{array}$ & $\begin{array}{l}\text { SSE } \\
\text { S }\end{array}$ \\
\hline SSW & 10 & .7 & 4.7 & 4.0 & .7 & 9.3 & .0 & 11.3 & 4.1 & SSW \\
\hline SH & 11 & 2.0 & 5.3 & 8.0 & 10.0 & .7 & 2.7 & 28.7 & 5.5 & SH \\
\hline HSW & 12 & 1.3 & 5.3 & 2.7 & 2.0 & .0 & .0 & 11.3 & 3.3 & WSH \\
\hline 4 & 13 & 1.3 & 1.3 & .7 & .7 & .0 & .0 & $\begin{array}{l}4.0 \\
1.3\end{array}$ & $\begin{array}{l}3.0 \\
4.8\end{array}$ & $\begin{array}{l}W \\
\text { HWH }\end{array}$ \\
\hline $\begin{array}{l}\text { WNH } \\
\text { NH }\end{array}$ & $\begin{array}{l}14 \\
15\end{array}$ & $\begin{array}{l}.0 \\
.0\end{array}$ & 1.7 & $\begin{array}{l}.0 \\
.0\end{array}$ & $\begin{array}{l}.7 \\
.0\end{array}$ & .0 & $\begin{array}{l}.0 \\
.0\end{array}$ & $\begin{array}{l}1.3 \\
2.0\end{array}$ & $\begin{array}{l}4.8 \\
5.1\end{array}$ & $\begin{array}{l}\text { WHW } \\
\text { NH }\end{array}$ \\
\hline $\begin{array}{l}\text { NHY } \\
\text { CALY }\end{array}$ & 16 & $\begin{array}{l}.0 \\
.0\end{array}$ & 1.3 & .7 & 1.3 & .7 & .0 & 4.0 & $\begin{array}{r}5.9 \\
.0\end{array}$ & NHW \\
\hline & & & & & 103 & 67 & & 100 & 1 & \\
\hline TOTAL & & 7 & 1.3 & 21.3 & 19.3 & 4.7 & 2.7 & 100.0 & 4.1 & \\
\hline
\end{tabular}

99.9\% DATA RECOVERED

20.9\% OF RECOVERED DATA REPORTED ABOVE

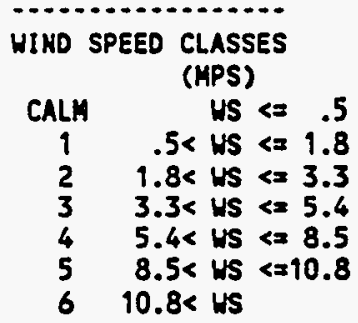


METEOROLOGICAL JOINT FREQUENCY OISTRIBUTION (PERCENT OF VALID HOUR OBSERVATIONS)

SPILL TEST FACILITY 24 METER TONER

8 METER HEIGHT - Evening Transition

$5 / 1 / 1994-5 / 31 / 1994$

$1600 \cdot 2000$ (MST)

WINDSPEEDCLASS

\begin{tabular}{|c|c|c|c|c|c|c|c|c|c|c|}
\hline HIND DIR & SECTOR & 1 & 2 & 3 & 4 & 5 & 6 & TOTAL & $\begin{array}{l}\text { AVG US } \\
\text { (MPS) }\end{array}$ & \\
\hline N & 1 & .7 & .7 & .7 & .0 & .0 & .0 & 2.0 & 2.5 & $N$ \\
\hline ANE & 2 & .0 & 2.7 & .7 & .7 & .0 & .0 & 4.0 & 3.5 & NWE \\
\hline NE & $\overline{3}$ & .0 & 2.7 & .0 & .7 & .0 & .0 & 3.3 & 3.2 & ME \\
\hline ENE & 4 & .0 & .7 & .7 & .0 & .0 & .0 & 1.3 & 3.7 & ENE \\
\hline$E$ & 5 & .7 & 1.3 & .0 & .7 & .0 & .0 & 2.7 & 3.0 & E \\
\hline ESE & 6 & .7 & 2.0 & 2.0 & .0 & .0 & .0 & 4.7 & 2.7 & ESE \\
\hline $\begin{array}{l}\text { SE } \\
\text { SSE }\end{array}$ & $\begin{array}{l}7 \\
8\end{array}$ & $\begin{array}{l}.0 \\
.0\end{array}$ & $\begin{array}{l}2.0 \\
1.3\end{array}$ & $\begin{array}{l}2.0 \\
3.3\end{array}$ & $\begin{array}{r}3.3 \\
.0\end{array}$ & $\begin{array}{l}0 \\
.0\end{array}$ & $\begin{array}{l}0 \\
.0\end{array}$ & 7.3 & $\begin{array}{l}4.9 \\
3.8\end{array}$ & $\begin{array}{l}\text { SE } \\
\text { SSE }\end{array}$ \\
\hline s & 9 & .0 & 1.3 & 2.0 & .7 & .0 & .0 & 4.0 & 4.2 & S \\
\hline SSH & 10 & .0 & 2.0 & 4.0 & 4.7 & 1.3 & 2.7 & 14.7 & 7.0 & SSH \\
\hline SW & 11 & 1.3 & 6.7 & 6.0 & 13.3 & 4.7 & 1.3 & 33.3 & 6. & SW \\
\hline WSW & 12 & .7 & .7 & 7.3 & 2.0 & .7 & .0 & 11.3 & 4.7 & WSH \\
\hline$H$ & 13 & .7 & .7 & .0 & .0 & .0 & .0 & 1.3 & 2.4 & $\mathbf{W}$ \\
\hline HWW & 14 & 1.3 & .7 & .7 & .0 & .0 & .0 & 2.7 & 2.2 & WNH \\
\hline NH & 15 & .7 & .7 & .0 & .0 & .0 & .0 & 1.3 & 1.7 & HW \\
\hline $\begin{array}{l}\text { NHW } \\
\text { CALM }\end{array}$ & 16 & $\begin{array}{l}.0 \\
.0\end{array}$ & .7 & .0 & .7 & .0 & .0 & 1.3 & $\begin{array}{r}3.9 \\
.0\end{array}$ & NNH \\
\hline & & & & & & & & & & \\
\hline TOTAL & & 6.7 & 26.7 & 29.3 & 26.7 & 6.7 & 4.0 & 100.0 & 5.0 & \\
\hline
\end{tabular}

96.9\% DATA RECOVERED

20.8\% OF RECOVERED DATA REPORTED ABOVE

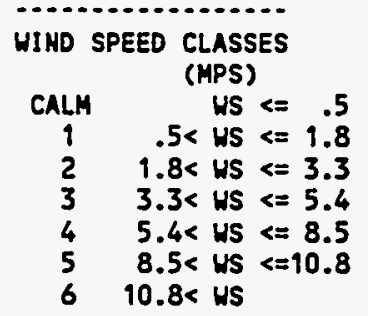


METEOROLOGICAL JOIHT FREQUENCY DISTRIBUTION (PERCENT OF VALID HOUR OBSERVATIONS)

SPILL TEST FACILITY 24 METER TONER

8 METER HEIGHT - Evening Transition

6/ $1 / 1994 \cdot 6 / 30 / 1994$

$1600 \cdot 2000$ (HST)

HINDSPEED CLASS

\begin{tabular}{|c|c|c|c|c|c|c|c|c|c|c|}
\hline WIND OIR & SECTOR & 1 & 2 & 3 & 4 & 5 & 6 & TOTAL & $\begin{array}{l}\text { AVG WS } \\
\text { (MPS) }\end{array}$ & \\
\hline $\boldsymbol{N}$ & 1 & .0 & .0 & .0 & .0 & .0 & .0 & .0 & .0 & $N$ \\
\hline NHE & 2 & .0 & .0 & .0 & .0 & .0 & .0 & .0 & .0 & NHE \\
\hline NE & 3 & .7 & .0 & .0 & .0 & .0 & .0 & .7 & .8 & NE \\
\hline ENE & 4 & .0 & .0 & .0 & .0 & .0 & .0 & .0 & .0 & ENE \\
\hline $\begin{array}{l}\text { E } \\
\text { ESE }\end{array}$ & $\begin{array}{l}5 \\
6\end{array}$ & $\begin{array}{r}1.3 \\
.7\end{array}$ & $\begin{array}{l}.0 \\
.0\end{array}$ & $\begin{array}{l}.0 \\
.0\end{array}$ & $\begin{array}{l}.0 \\
.0\end{array}$ & $\begin{array}{l}.0 \\
.0\end{array}$ & $\begin{array}{l}.0 \\
.0\end{array}$ & $\begin{array}{r}1.3 \\
.7\end{array}$ & $\begin{array}{l}1.1 \\
1.5\end{array}$ & $\begin{array}{l}\text { E } \\
\text { ESE }\end{array}$ \\
\hline SE & 7 & .0 & .0 & .0 & .0 & .0 & .0 & .0 & .0 & SE \\
\hline SSE & 8 & .0 & .0 & .0 & .0 & .0 & .0 & .0 & .0 & SSE \\
\hline $\mathbf{S}$ & 9 & .7 & .0 & .0 & .0 & .0 & .0 & .7 & 1.2 & $\mathbf{S}$ \\
\hline SSH & 10 & 1.3 & 1.3 & 1.3 & 6.7 & 4.7 & 2.0 & 17.3 & 7.3 & SSH \\
\hline SW & $\begin{array}{l}11 \\
12\end{array}$ & $\begin{array}{r}2.0 \\
1.3\end{array}$ & 7.3 & $\begin{array}{l}7.3 \\
7.3\end{array}$ & $\begin{array}{r}30.0 \\
5.3\end{array}$ & 5.3 & 2.0 & $\begin{array}{l}54.0 \\
10.3\end{array}$ & 6.2 & SH \\
\hline $\begin{array}{l}\text { WSW } \\
\text { H }\end{array}$ & $\begin{array}{l}12 \\
13\end{array}$ & $\begin{array}{r}1.3 \\
.0\end{array}$ & $\begin{array}{l}4.7 \\
1.3\end{array}$ & $\begin{array}{r}7.3 \\
.0\end{array}$ & $\begin{array}{r}5.3 \\
.0\end{array}$ & $\begin{array}{l}.7 \\
.0\end{array}$ & $\begin{array}{l}.0 \\
.0\end{array}$ & $\begin{array}{r}19.3 \\
1.3\end{array}$ & $\begin{array}{l}4.4 \\
2.1\end{array}$ & WSW \\
\hline WNH & 14 & .7 & 1.3 & .7 & .0 & .0 & .0 & 2.7 & 2.5 & WNH \\
\hline NH & 15 & .7 & .0 & .0 & .0 & .0 & .0 & .7 & 1.4 & NH \\
\hline $\begin{array}{l}\text { NHH } \\
\text { CALM }\end{array}$ & 16 & $\begin{array}{r}1.3 \\
.0\end{array}$ & .0 & .0 & .0 & .0 & .0 & 1.3 & $\begin{array}{r}1.4 \\
.0\end{array}$ & NHW \\
\hline TOTAL & & 10.7 & 16.0 & 16.7 & 42.0 & 10.7 & 4.0 & 100.0 & 5.7 & \\
\hline
\end{tabular}

100.0\% DATA RECOVERED

20.8\% OF RECOVERED DATA REPORTED ABOVE

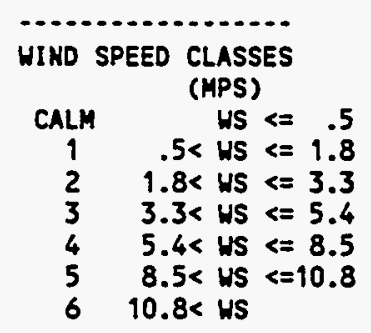


METEOROLOGICAL JOINT FREOUENCY DISTRIBUTION (PERCENT OF VALID HOUR OBSERVATIONS) SPILL TEST FACILITY 24 METER TOWER

8 METER HEIGHT - Evening Transition

$7 / 1 / 1994 \cdot 7 / 31 / 1994$

$1600 \cdot 2000$ (MST)

HIND SPEEDCLASS

\begin{tabular}{|c|c|c|c|c|c|c|c|c|c|c|}
\hline WIND DIR & SECTOR & 1 & 2 & 3 & 4 & 5 & 6 & TOTAL & $\begin{array}{r}\text { AVG WS } \\
\text { (MPS) }\end{array}$ & \\
\hline $\mathbf{N}$ & 1 & 1.3 & 1.9 & 1.9 & .0 & .0 & .0 & 5.2 & 2.8 & $N$ \\
\hline NNE & 2 & .0 & .6 & .0 & .0 & .0 & .0 & .6 & 3.3 & NNE \\
\hline NE & 3 & .6 & .6 & .6 & .0 & 0 & .0 & 1.9 & 2.6 & NE \\
\hline ENE & 4 & 1.3 & 1.3 & .6 & .0 & .0 & .0 & 3.2 & 2.3 & ENE \\
\hline$E$ & 5 & .6 & .0 & .0 & .6 & .0 & .0 & 1.3 & 4.7 & $E$ \\
\hline ESE & 6 & 1.3 & .0 & .0 & .6 & .0 & .0 & 1.9 & 3.5 & ESE \\
\hline SE & 7 & .6 & .0 & .0 & .6 & .0 & .0 & 1.3 & 4.3 & SE \\
\hline SSE & 8 & .0 & .0 & .0 & .0 & .0 & .0 & .0 & .0 & SSE \\
\hline$S$ & 9 & 2.6 & .6 & .0 & & .0 & .0 & 3.2 & 1.7 & $\mathbf{S}$ \\
\hline SSH & 10 & .6 & 1.9 & 3.2 & 3.9 & 3.2 & .0 & 12.9 & 5.8 & SSH \\
\hline SH & 11 & .6 & 7.1 & 11.6 & 29.0 & 3.2 & .0 & 51.6 & 5.9 & SH \\
\hline HSH & $\begin{array}{l}12 \\
13\end{array}$ & .0 & 5.2 & 3.9 & 1.9 & .0 & .0 & 11.0 & $\begin{array}{l}3.8 \\
2.8\end{array}$ & WSH \\
\hline $\begin{array}{l}\text { W } \\
\text { WHH }\end{array}$ & $\begin{array}{l}13 \\
14\end{array}$ & $\begin{array}{r}.6 \\
1.9\end{array}$ & $\begin{array}{r}1.9 \\
.0\end{array}$ & $\begin{array}{r}.0 \\
.0\end{array}$ & $\begin{array}{l}.0 \\
.0\end{array}$ & $\begin{array}{l}.0 \\
.0\end{array}$ & $\begin{array}{l}.0 \\
.0\end{array}$ & $\begin{array}{l}2.6 \\
1.9\end{array}$ & $\begin{array}{l}2.0 \\
1.3\end{array}$ & $\begin{array}{l}\text { W } \\
\text { WNH }\end{array}$ \\
\hline NW & 15 & .6 & .0 & .0 & .0 & .0 & .0 & .6 & .7 & NH \\
\hline $\begin{array}{l}\text { NNH } \\
\text { CALM }\end{array}$ & 16 & $\begin{array}{l}.0 \\
.0\end{array}$ & .6 & .0 & .0 & .0 & .0 & .6 & $\begin{array}{r}1.9 \\
.0\end{array}$ & NHH \\
\hline TOTAL & & 12.9 & 21.9 & 21.9 & 36.8 & 6.5 & .0 & 100.0 & 4.8 & \\
\hline
\end{tabular}

100.0\% DATA RECOVERED

20.8\% OF RECOVERED DATA REPORTED ABOVE

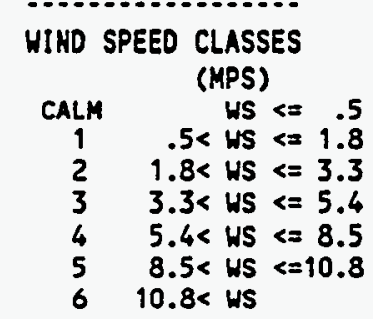




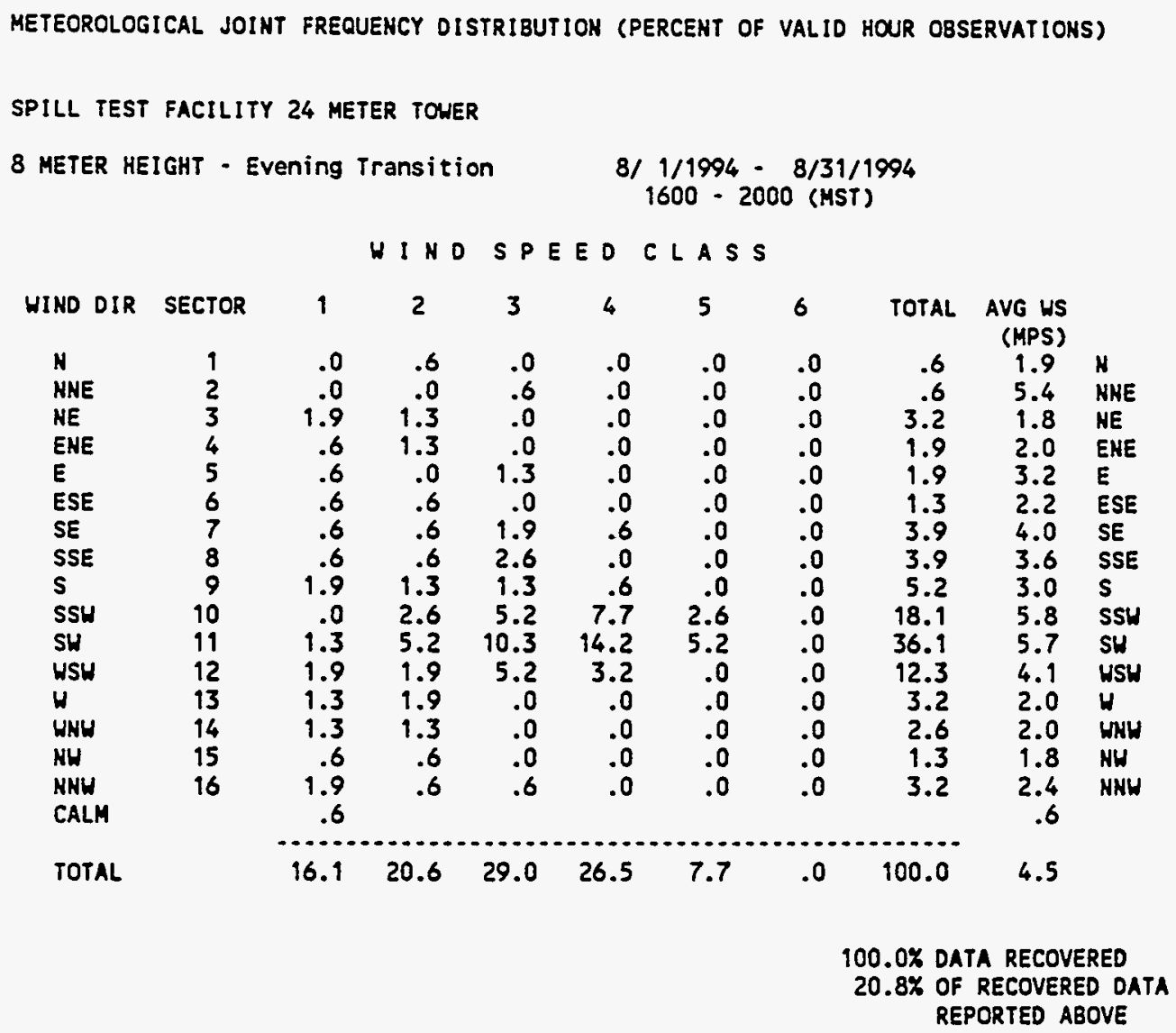


METEOROLOGICAL JOINT FREQUENCY DISTRIBUTION (PERCENT OF VALID HOUR OBSERVATIONS)

SPILL TEST FACILITY 24 METER TOWER

8 METER HEIGHT - Evening Transition

$$
\begin{gathered}
911 / 1994-9 / 30 / 1994 \\
1600 \cdot 2000 \text { (MST) }
\end{gathered}
$$

HINO SPEEDCLASS

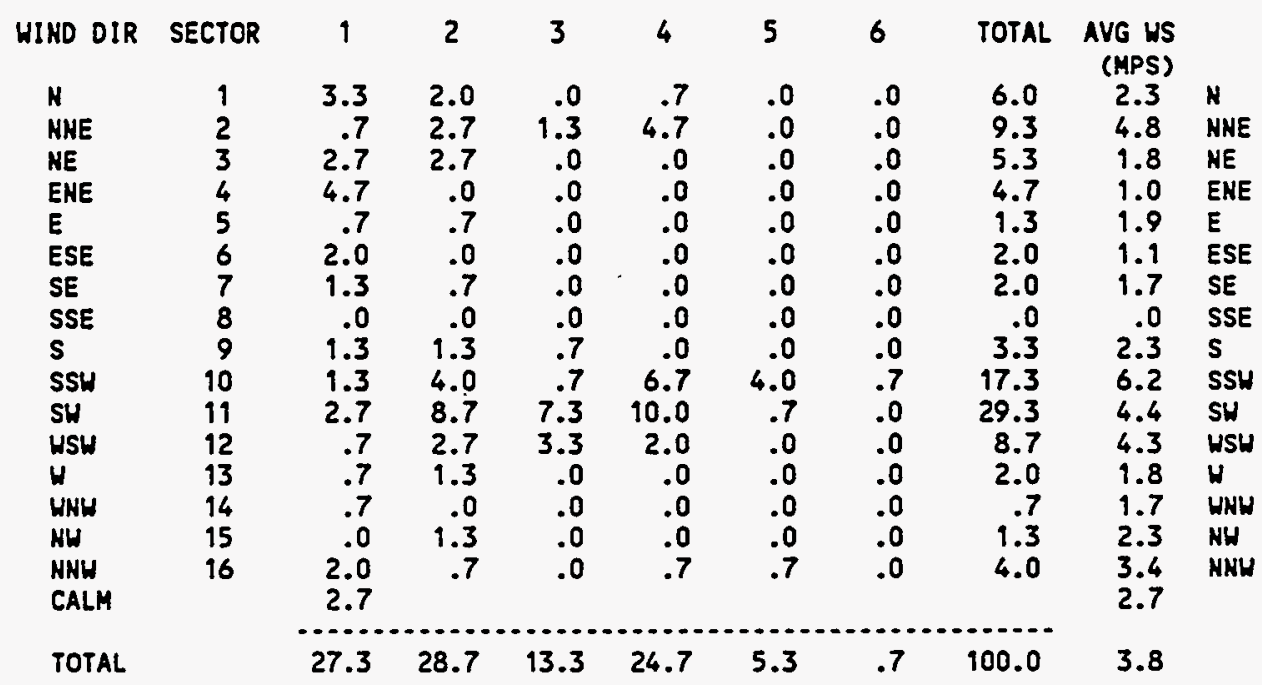

99.2\% DATA RECOVERED

21.0\% OF RECOVERED DATA REPORTED ABOVE

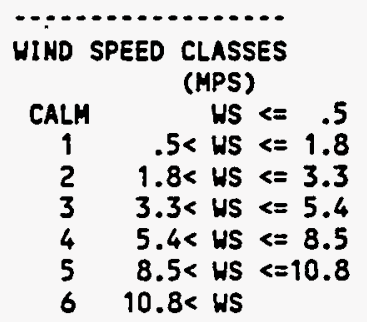


METEOROLOGICAL JOINT FREQUENCY DISTRIBUTION (PERCENT OF VALID HOUR OBSERVATIONS)

SPILL TEST FACILITY 24 METER TONER

8 METER HEIGHT - Evening Transition

$10 / 1 / 1994-10 / 31 / 1994$

$1600-2000$ (MST)

WINDSPEED CLASS

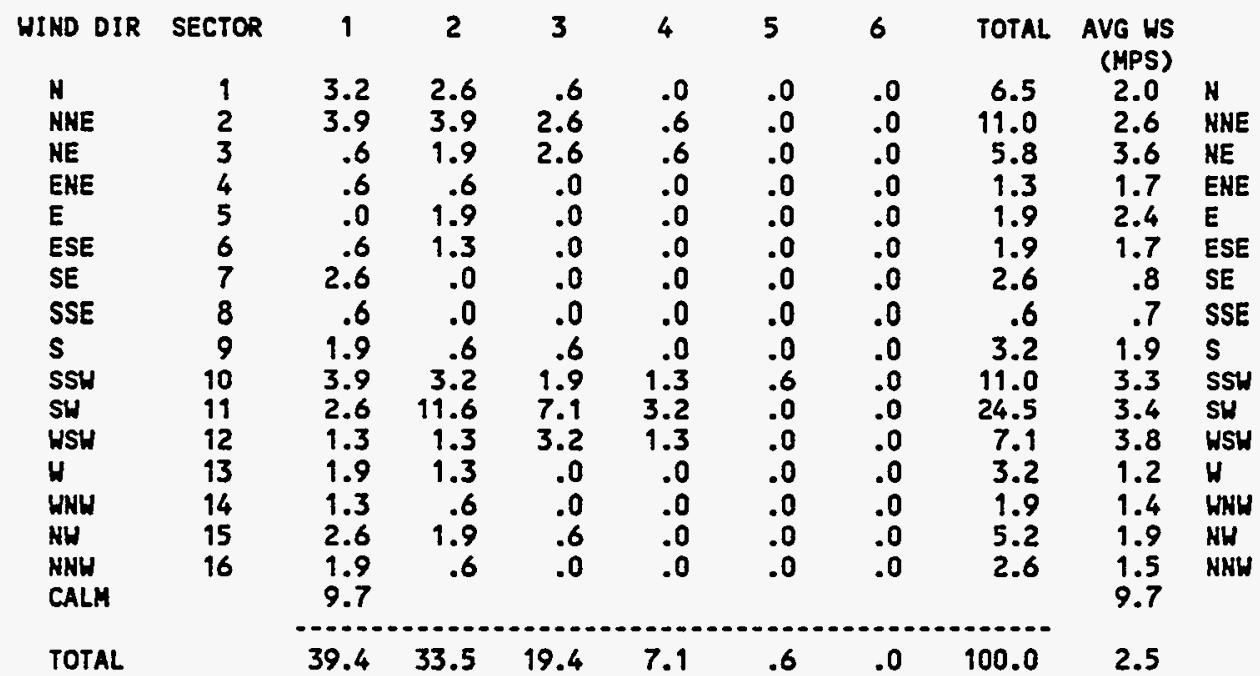

98.5\% DATA RECOVERED

21.1\% OF RECOVERED DATA REPORTED ABOVE

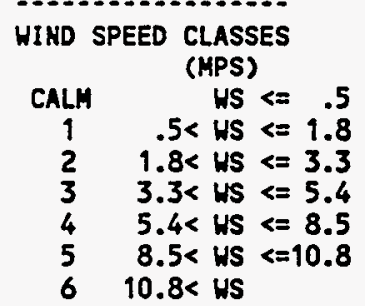


METEOROLOGICAL JOIHT FREQUENCY DISTRIBUTION (PERCENT OF VALID HOUR OBSERVATIONS)

SPILL TEST FACILITY 24 METER TOWER

8 METER HEIGHT - Evening Transition

$11 / 1 / 1994-11 / 30 / 1994$

$1600-2000$ (MST)

HIND SPEED CLASS

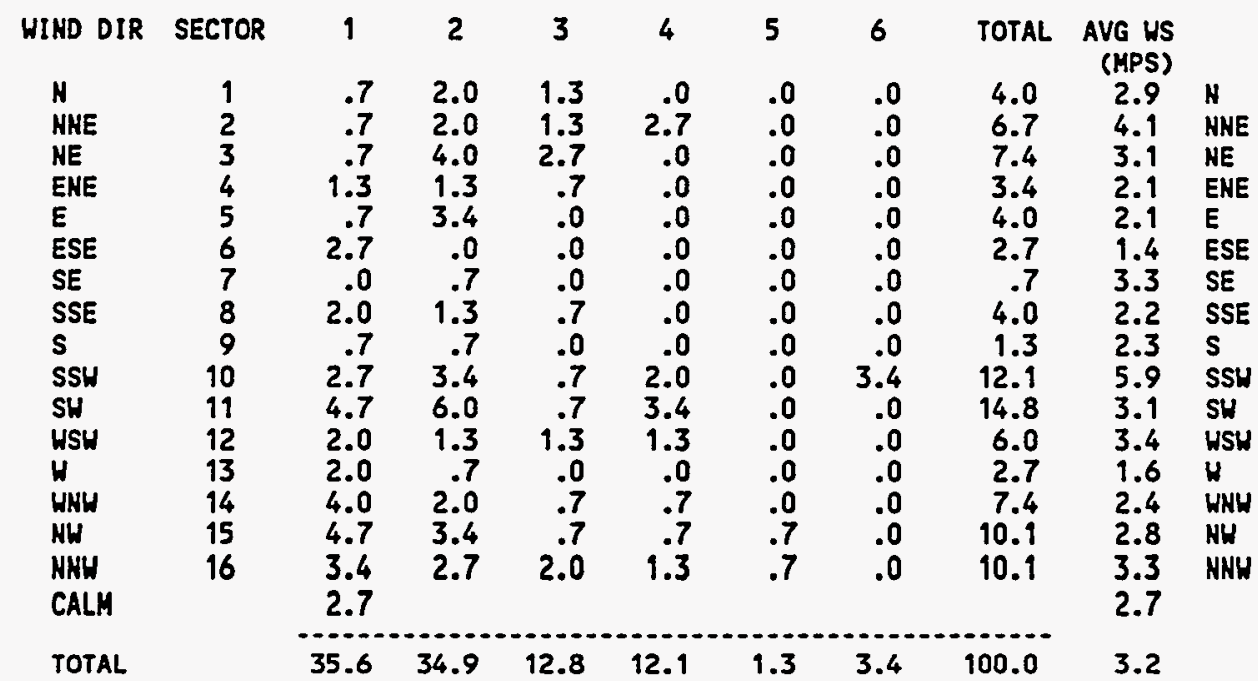

99.7\% DATA RECOVERED

20.8\% OF RECOVERED DATA REPORTED ABOVE

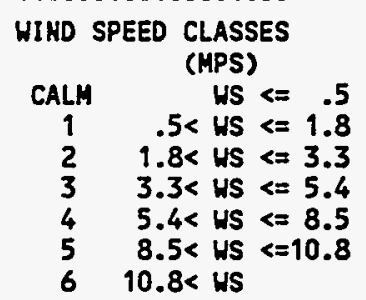


METEOROLOGICAL JOINT FREQUENCY DISTRIBUTION (PERCENT OF VALID HOUR OBSERVATIONS)

SPILL TEST FACILITY 24 METER TOWER

8 METER HEIGHT - Evening Transition

$12 / 1 / 1994-12 / 31 / 1994$

$1600 \cdot 2000$ (MST)

HINDSPEEDCLASS

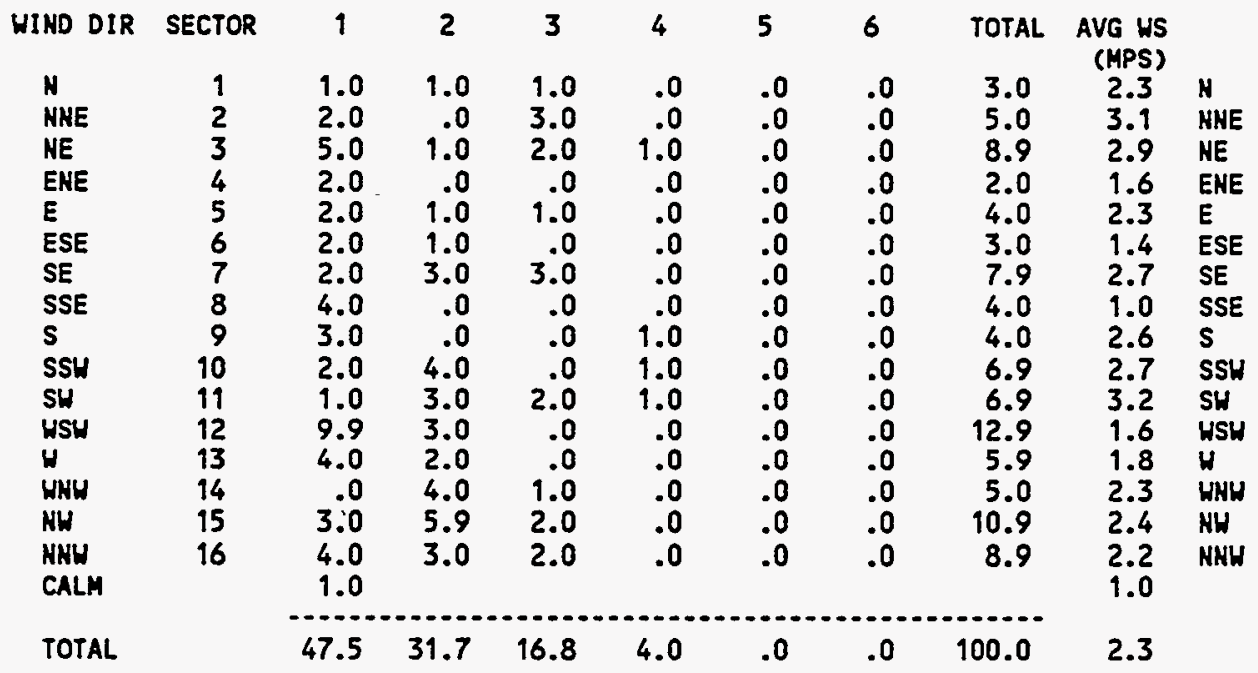

65.1\% DATA RECOVERED

20.9\% OF RECOVERED DATA REPORTED ABOVE

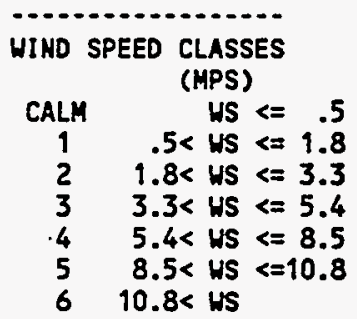


METECROLOGICAL JOINT FREQUENCY DISTRIBUTION (PERCENT OF VALID HOUR OBSERVATIOHS)

SPILL TEST FACILITY 24 METER TOER

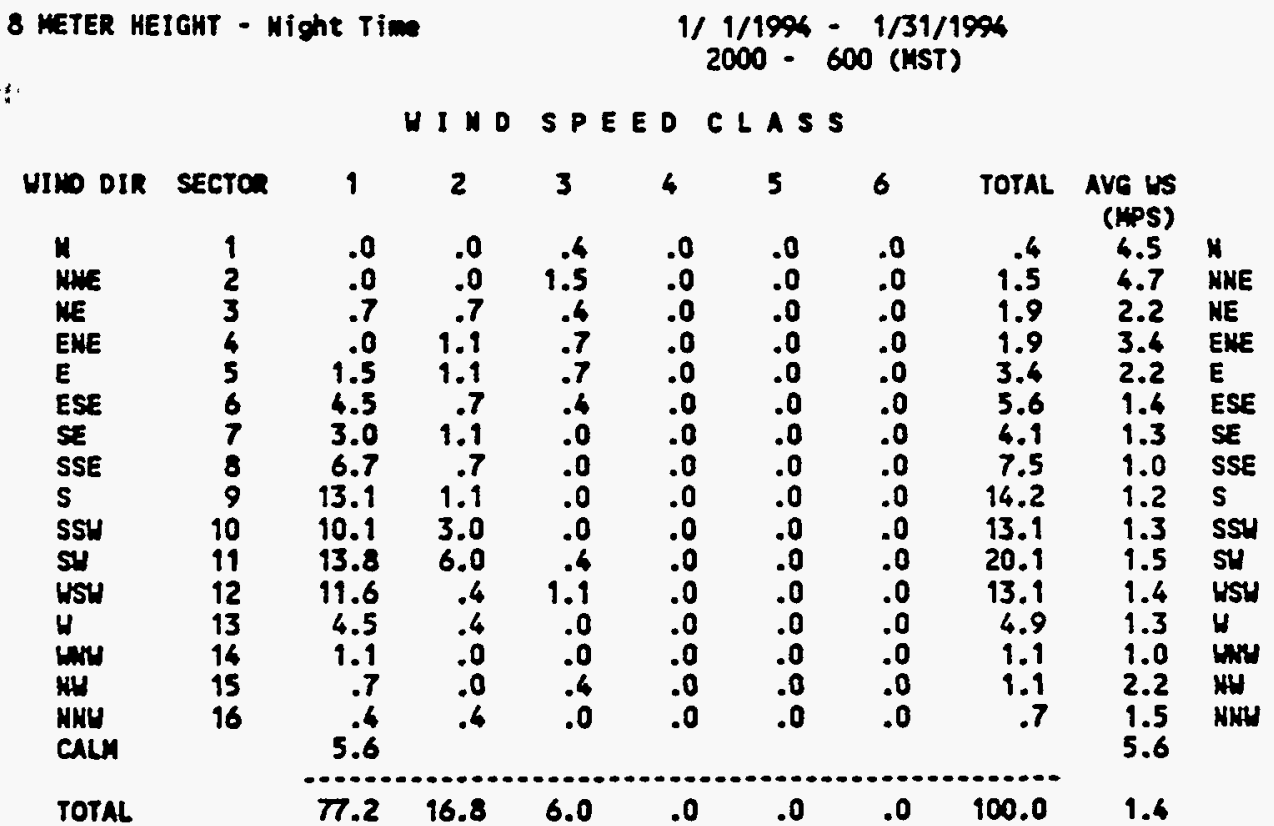

7O. OX DATA RECONERED 46. $2 \%$ OF RECONERED DATA REPORTED NOVE

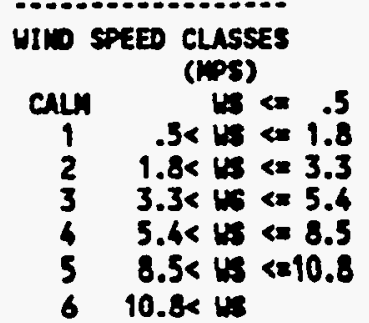


METEOROLOGICAL JOINT FREQUENCY DISTRIBUTION (PERCENT OF VALID HOUR OBSERVATIONS) SPILL TEST FACILITY 24 METER TONER

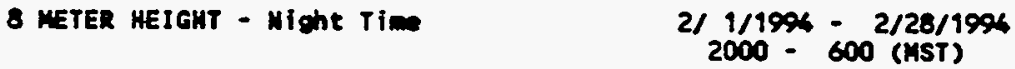

HINDSPEEDCLASS

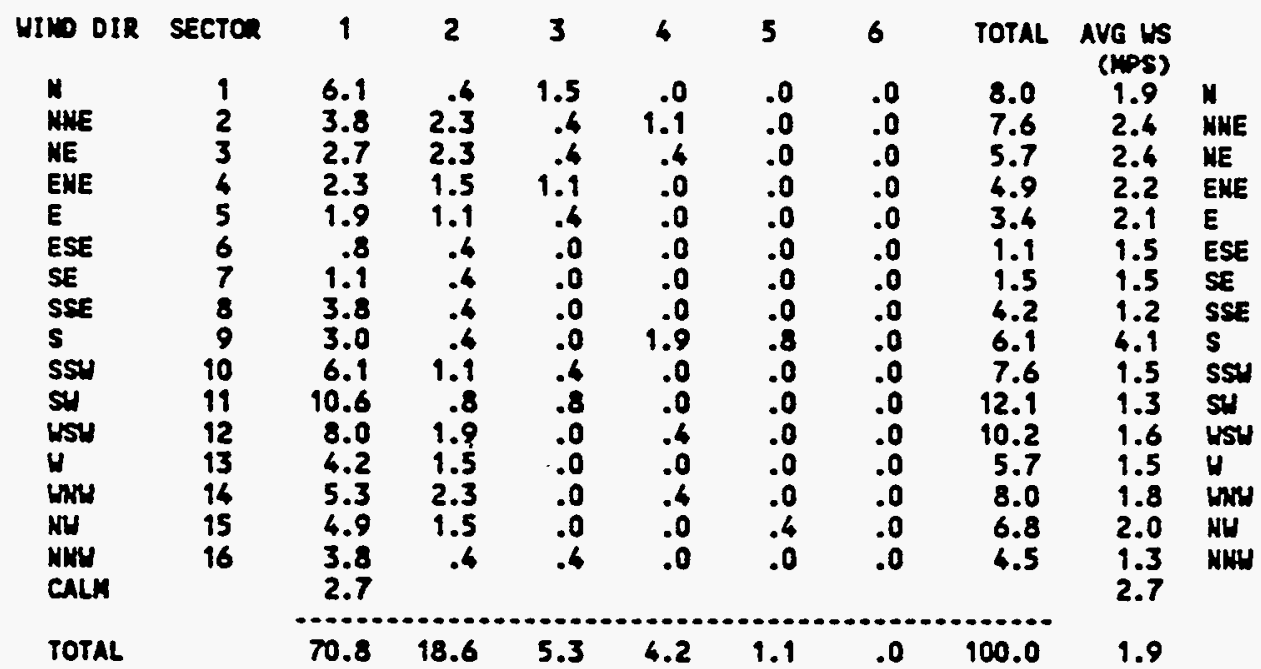

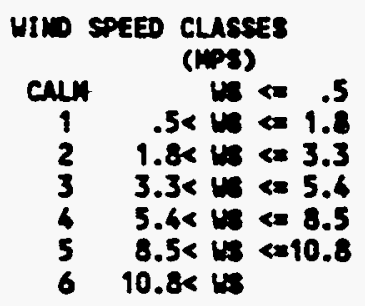


METEOROLOGICAL JOINT FREQUENCY DISTRIDUTION (PERCENT OF VALID HOUR COSERVATIONS)

SPILL TEST FACILITY 26 METER TOEER

8 METER HEIGHT - Might Tím

$3 / 1 / 1994-3 / 31 / 1994$

$2000-600$ (HST)

UINDSPEEDCLASS

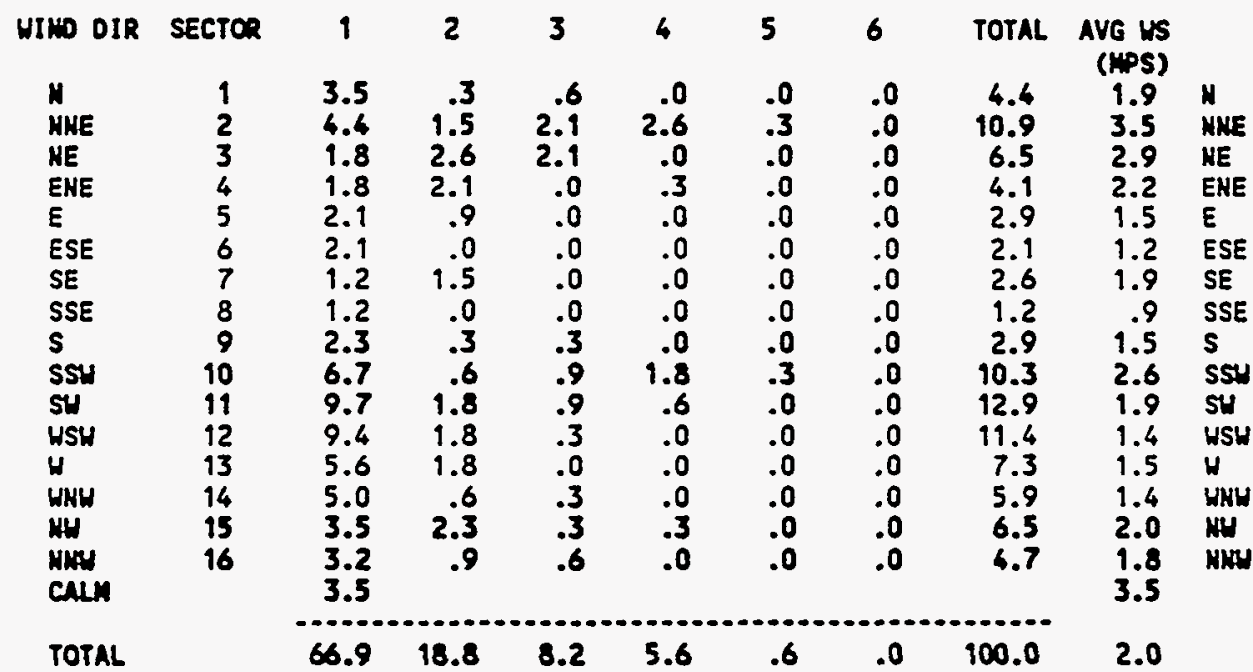

100.0\% DATA RECONERED

45.8\% OF RECONERED DATA REPOATED ADOVE

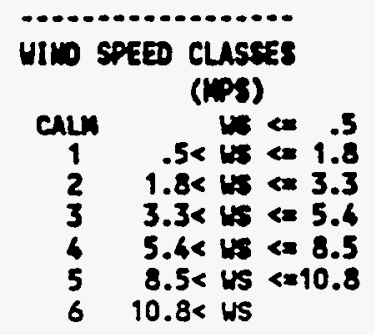


METEOROLOGICAL JOINT FREQUENCY DISTRIBUTION (PERCENT OF VALID HOUR OBSERVATIONS)

SPILL TEST FACILITY 24 METER TOWER

8 METER HEIGHT - Night TIME

$4 / 1 / 1994-4 / 30 / 1994$

$2000 \cdot 600$ (MST)

WINDSPEED CLASS

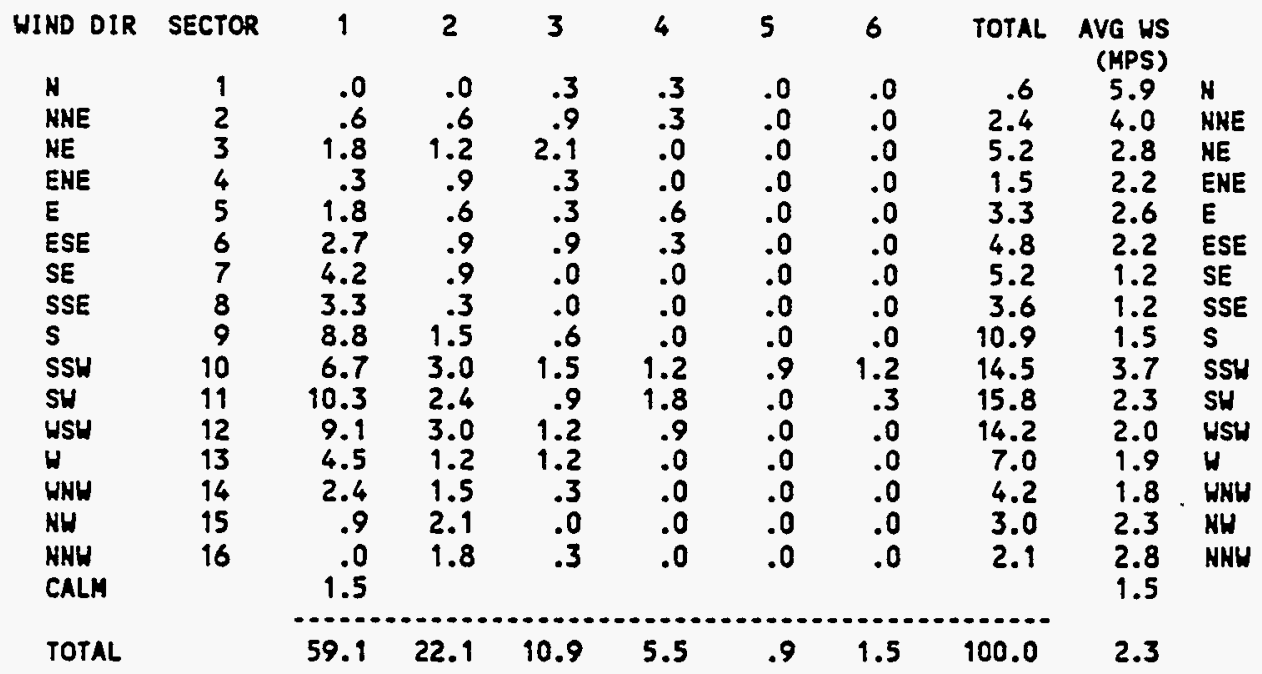

$99.9 \%$ DATA RECOVERED

45.9\% OF RECOVERED DATA REPORTED ABOVE

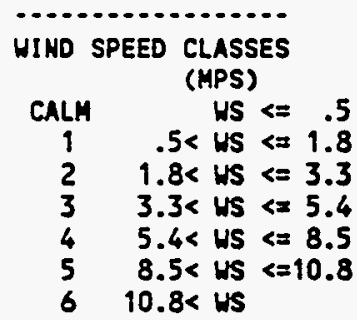


METEOROLOGICAL JOIHT FREQUENCY DISTRIBUTIOH (PERCENT OF VALID HOUR OBSERVATIONS)

SPILL TEST FACILITY 24 METER TOWER

8 METER HEIGHT - Night Time

$5 / 1 / 1994-5 / 31 / 1994$
$2000 \cdot 600$ (HST)

HIND SPEED CLASS

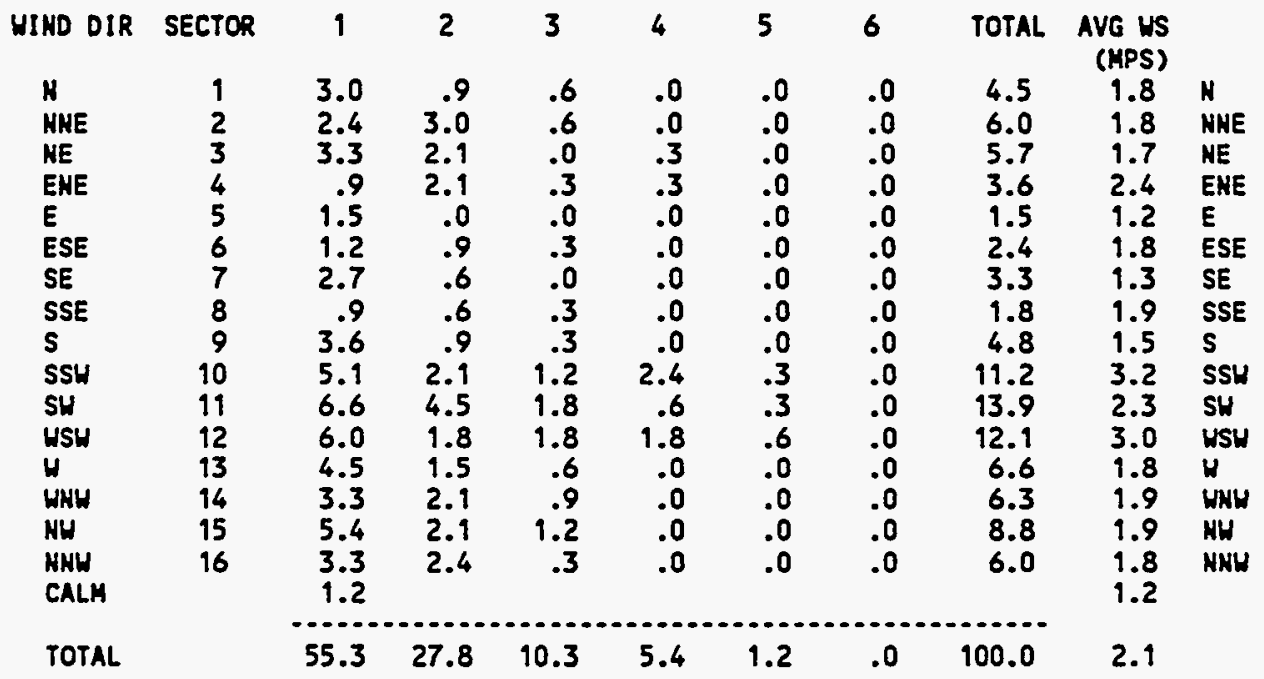

96.9\% DATA RECOVERED

45.9\% OF RECOVERED DATA REPORTED ABOVE

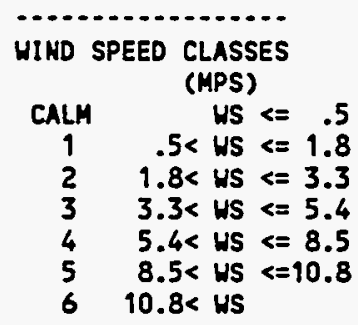


METEOROLOGICAL JOINT FREQUENCY DISTRIBUTION (PERCENT OF VALID HOUR OBSERVATIONS)

SPILL TEST FACILITY 24 METER TONER

8 METER HEIGHT - Wight Time

6/ $1 / 1994-6 / 30 / 1994$

$2000 \cdot 600$ (MST)

WINDSPEEDCLASS

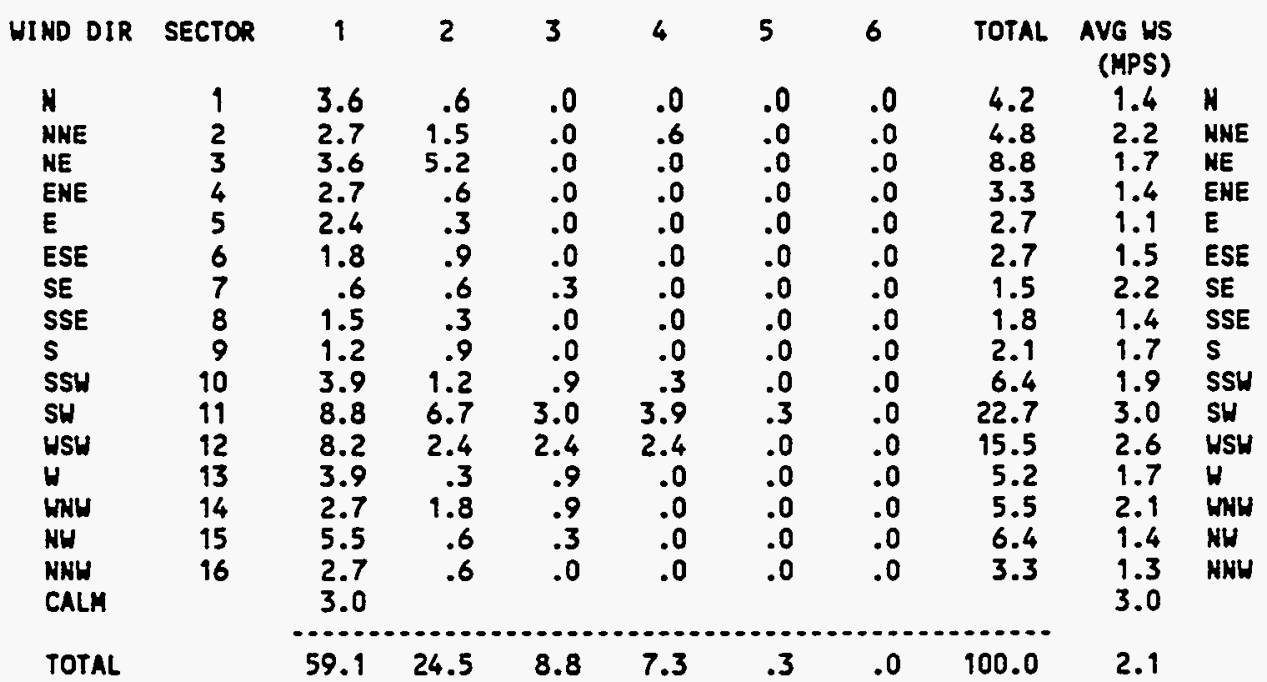

100.0X DATA RECOVERED

45.8\% OF RECOVERED DATA

REPORTED ABOVE

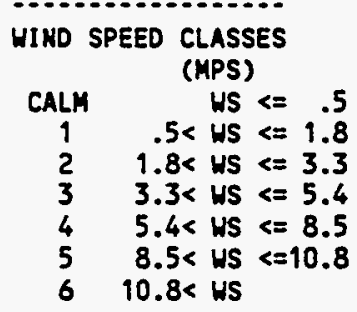




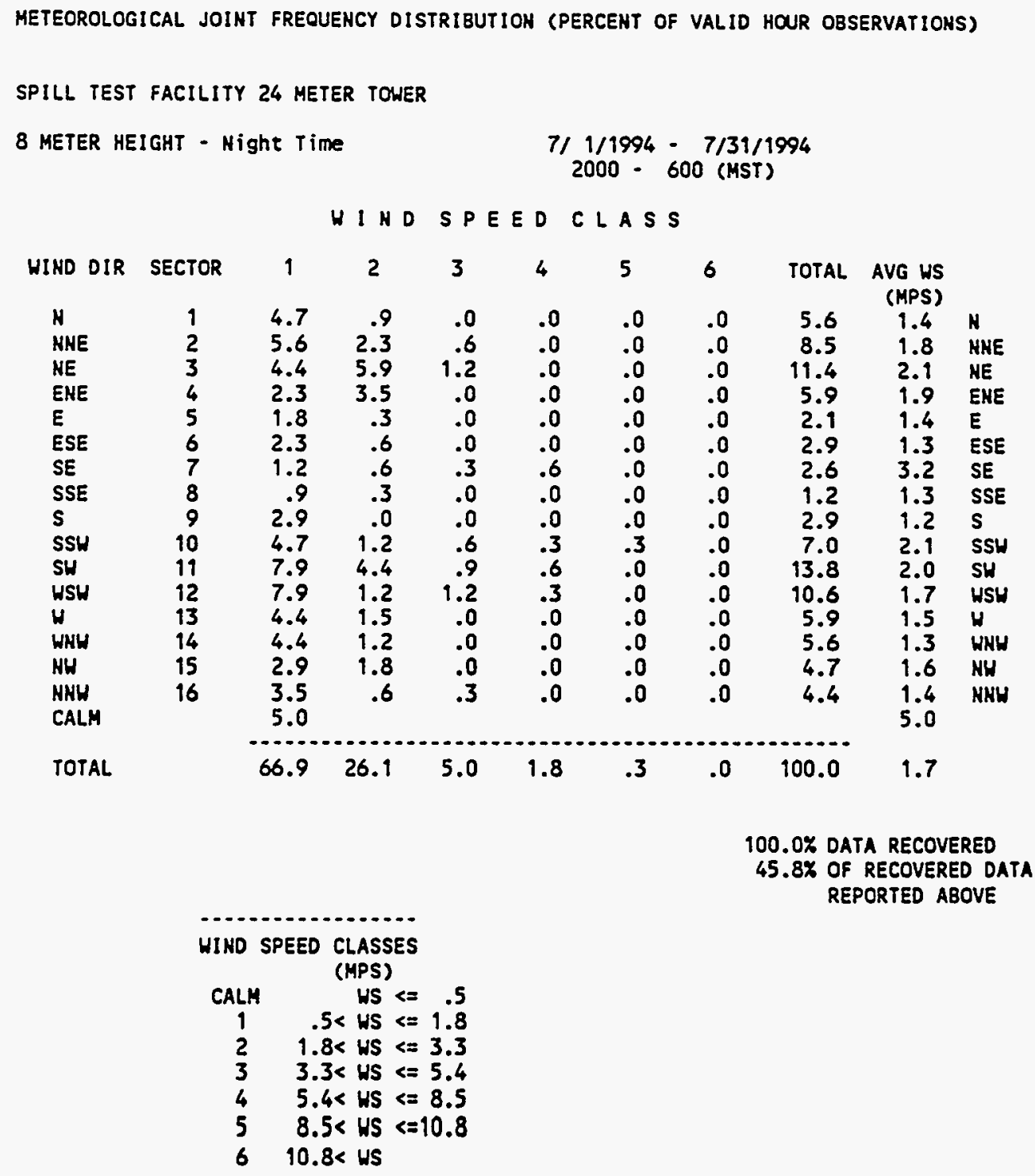


METEOROLOGICAL JOINT FREQUENCY DISTRIBUTION (PERCENT OF VALID HOUR OBSERVATIONS)

SPILL TEST FACILITY 24 METER TOWER

8 METER HEIGHT - Night TIME

$8 / 1 / 1994 \cdot 8 / 31 / 1994$

$2000-600$ (MST)

WIND SPEEDCLASS

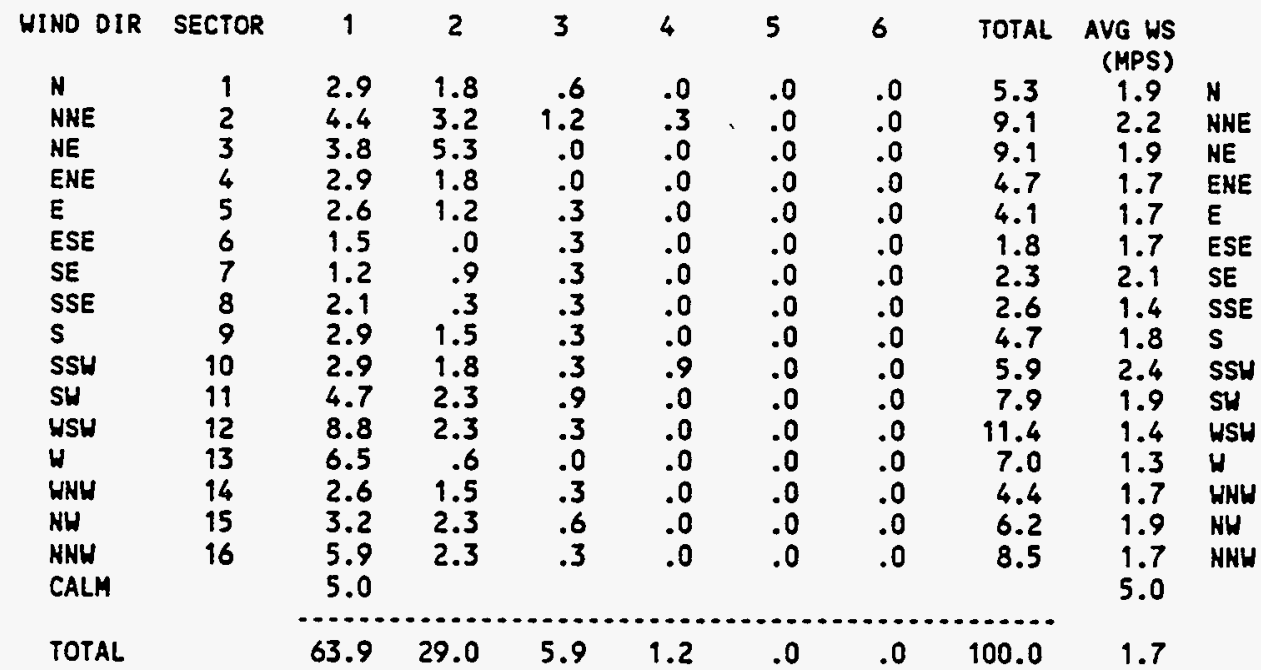

100.0\% DATA RECOVERED

45.8\% OF RECOVERED DATA

REPORTED ABOVE

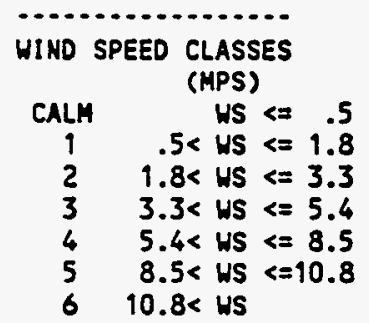


METEOROLOGICAL JOINT FREQUENCY DISTRIBUTION (PERCENT OF VALID HOUR OBSERVATIONS)

SPILL TEST FACILITY 24 METER TOWER

8 METER HEIGHT - Night Time

$9 / 1 / 1994-9 / 30 / 1994$
$2000 \cdot 600$ (MST)

WIND SPEED CLASS

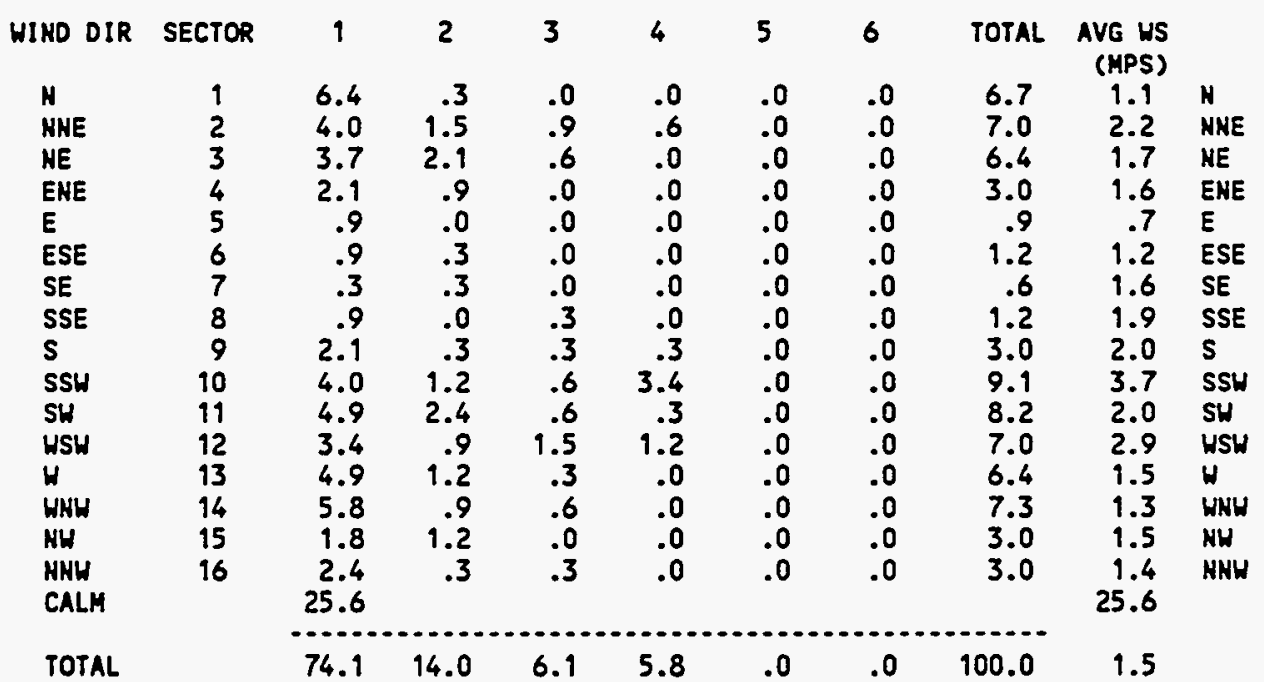

99.2X DATA RECOVERED

45.9\% OF RECOVERED DATA REPORTED ABOVE

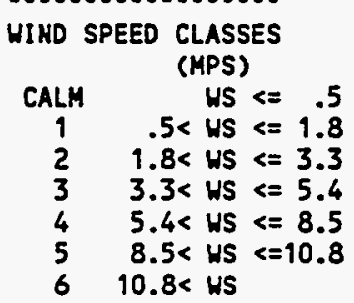


METEOROLOGICAL JOINT FREQUENCY DISTRIBUTION (PERCENT OF VALID HOUR OBSERVATIONS) SPILL TEST FACILITY 24 METER TONER

8 METER HEIGHT - Night Time

$10 / 1 / 1994-10 / 31 / 1994$ 2000 - 600 (MST)

HIND SPEED CLASS

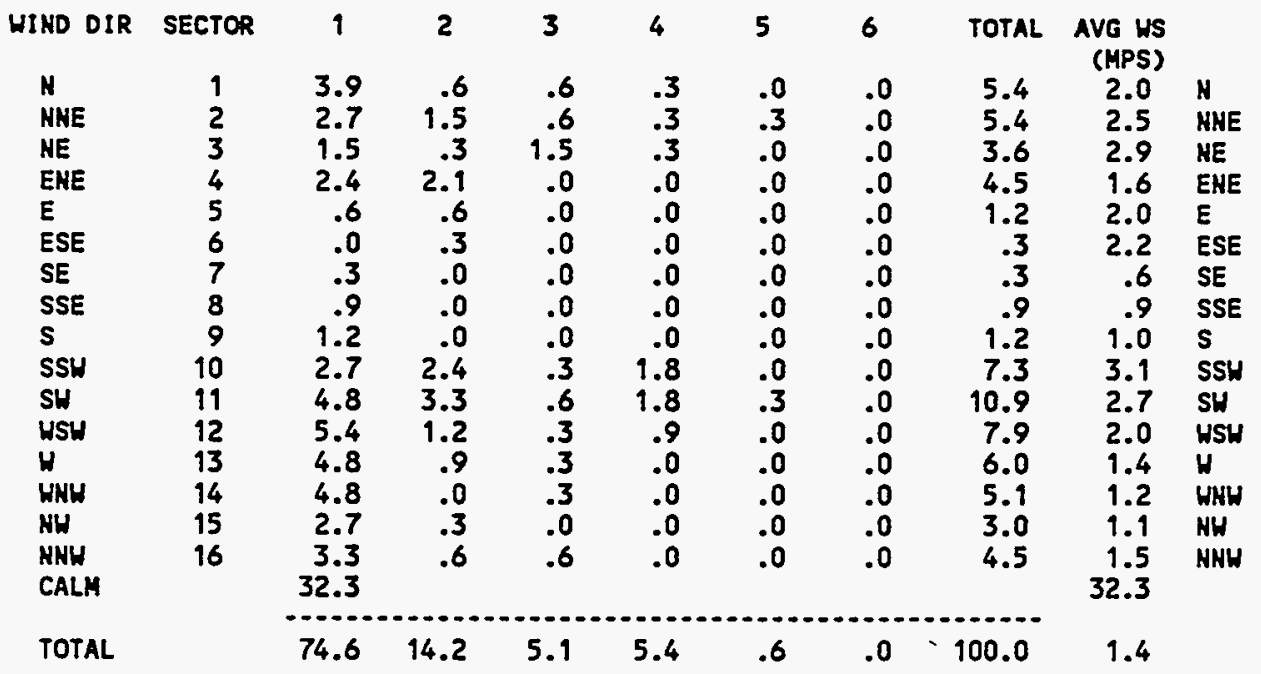

98.5\% DATA RECOVERED

45.2\% OF RECOVERED DATA REPORTED ABOVE

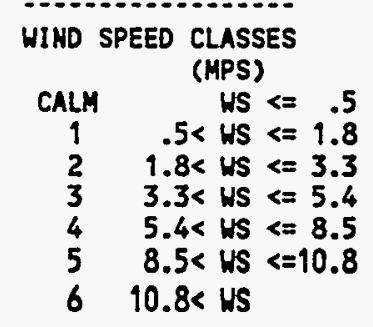


METEOROLOGICAL JOINT FREQUENCY DISTRIBUTION (PERCENT OF VALID HOUR OBSERVATIONS)

SPILL TEST FACILITY 24 METER TONER

8 METER HEIGHT - Hight TIME
$11 / 1 / 1994-11 / 30 / 1994$
$2000 \cdot 600$ (MST)

HI D D PEED CLASS

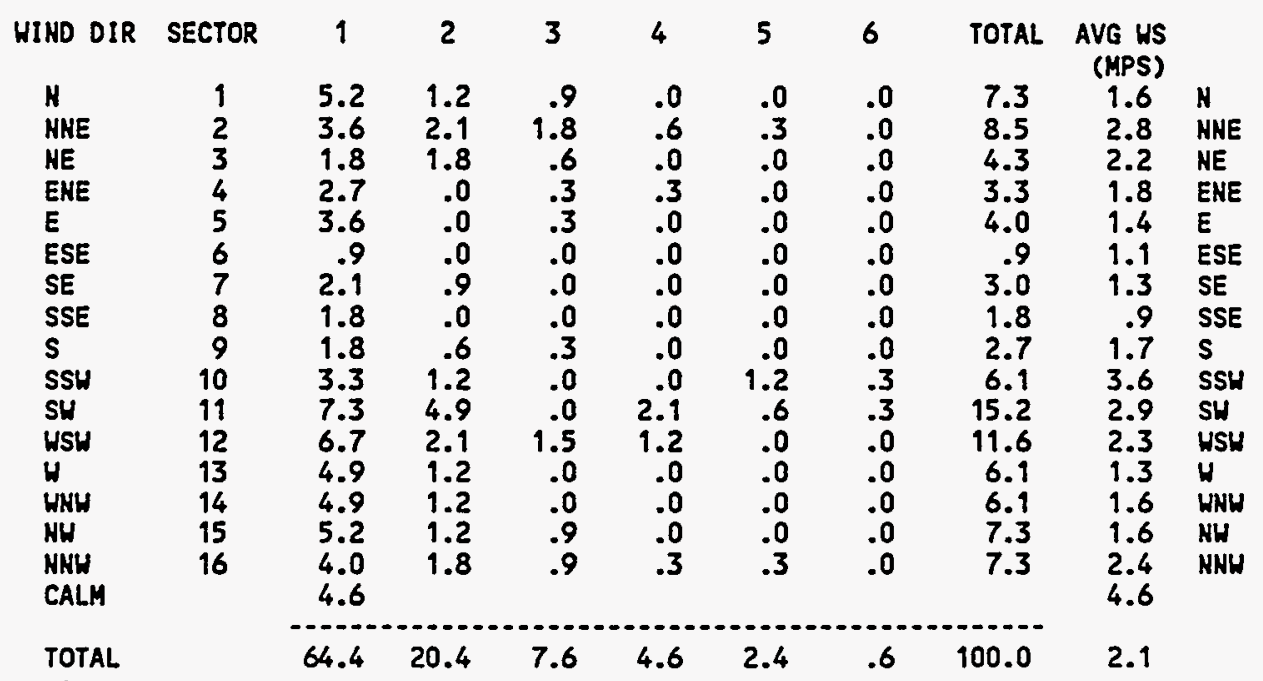

$99.7 \%$ DATA RECOVERED

45.8\% OF RECOVERED DATA

REPORTED ABOVE

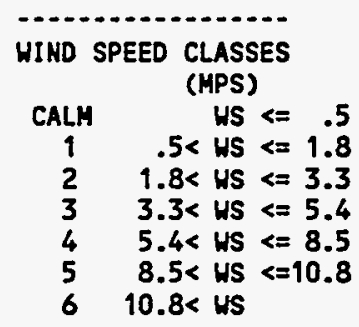


METEOROLOGICAL JOIHT FREQUENCY DISTRIBUTION (PERCENT OF VALID HQUR OBSERVATIONS)

SPILL TEST FACILITY 24 METER TONER

8 METER HEIGHT - Night Time

$12 / 1 / 1994-12 / 31 / 1994$ $2000 \cdot 600$ (MST)

WINDSPEED CLASS

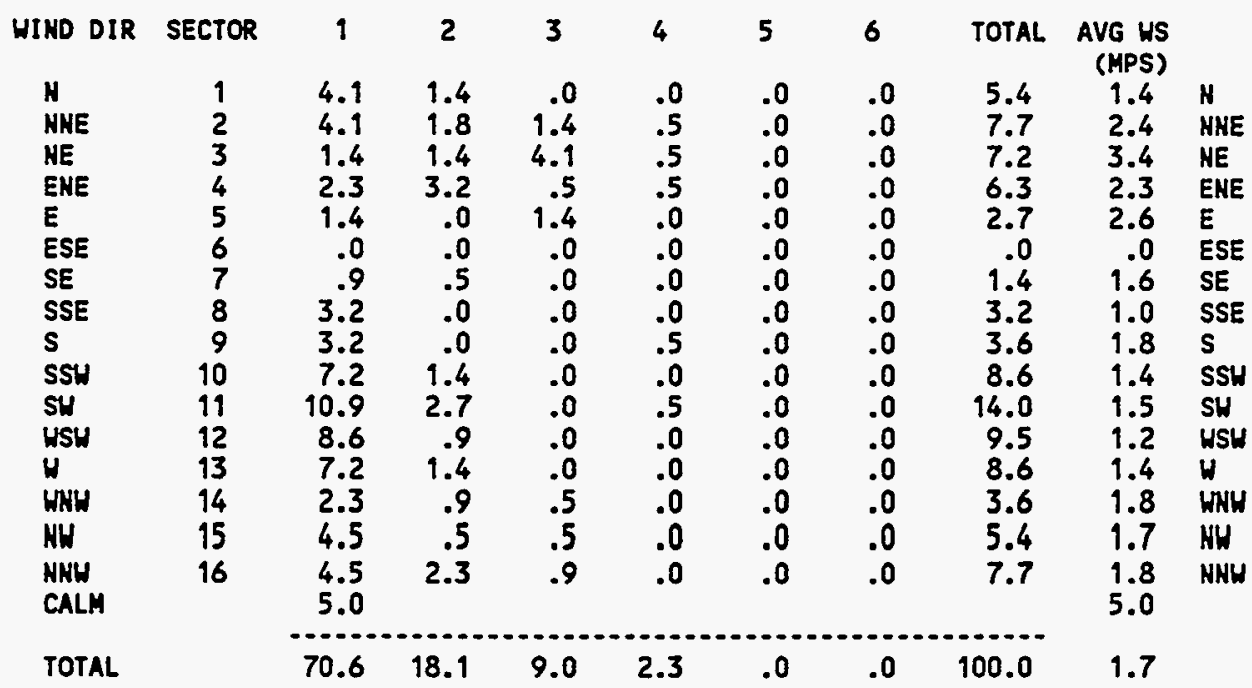

65.1\% DATA RECOVERED

45.7\% OF RECOVERED DATA REPORTED ABOVE

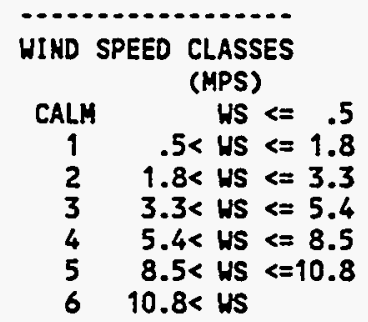


METEOROLOGICAL JOIMT FREQUENCY DISTRIBUTION (PERCENT OF VALID HOUR OBSERVATIONS)

SPILL TEST FACILITY 24 METER TONER
8 METER HEIGHT - Total Hours 1/ 1/1994 - 1/31/1994
$0=2300$ (MST)

STABILITY CLASS A

$0.5-1.5$

WINDSPEED CLASS

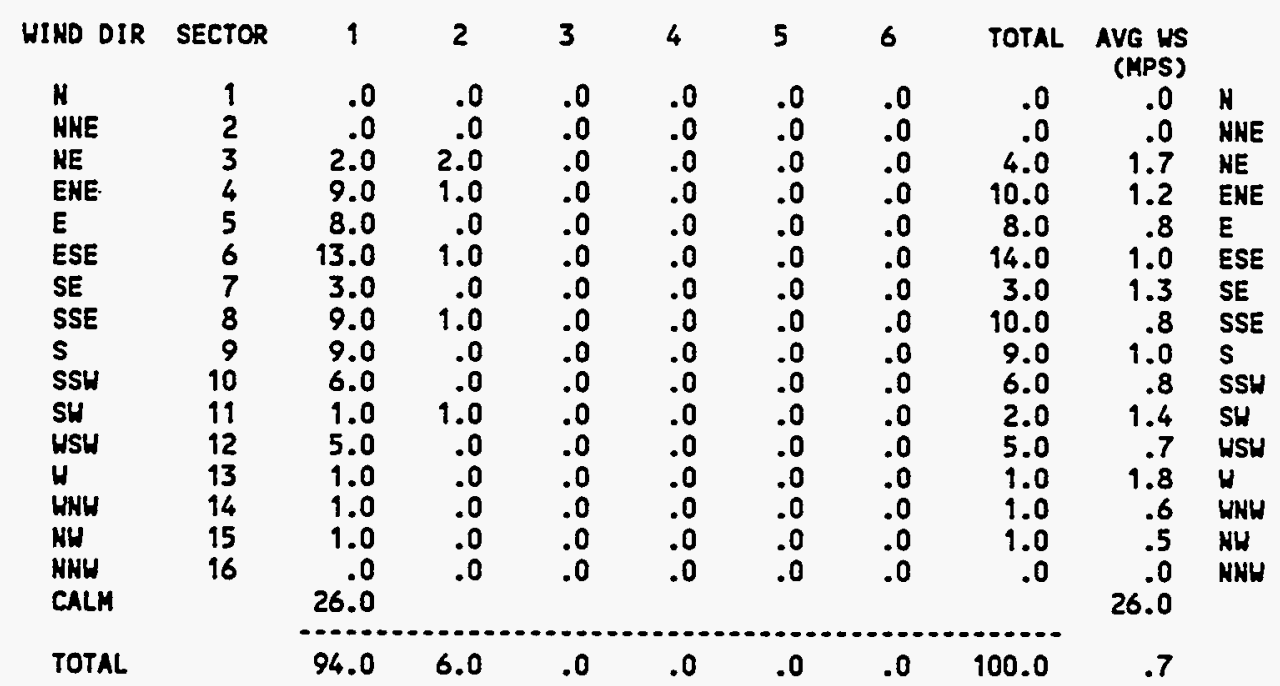

78.0\% DATA RECOVERED

17.2\% OF RECOVERED DATA REPORTED ABOVE

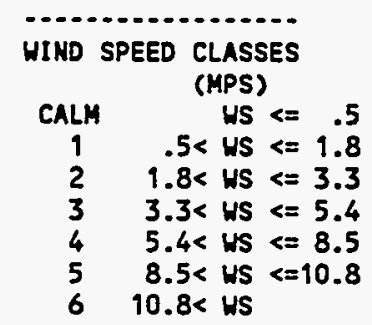


METEOROLOGICAL JOINT FREQUENCY DISTRIBUTION (PERCENT OF VALID HOUR OBSERVATIONS)

SPILL TEST FACILITY 24 METER TOWER

8 METER HEIGHT - Total HOurs

STABILITY CLASS A

$0.5 \cdot 1.5$
2/ $1 / 1994-2 / 28 / 1994$

0 - 2300 (MST)

WINDSPEED CLASS

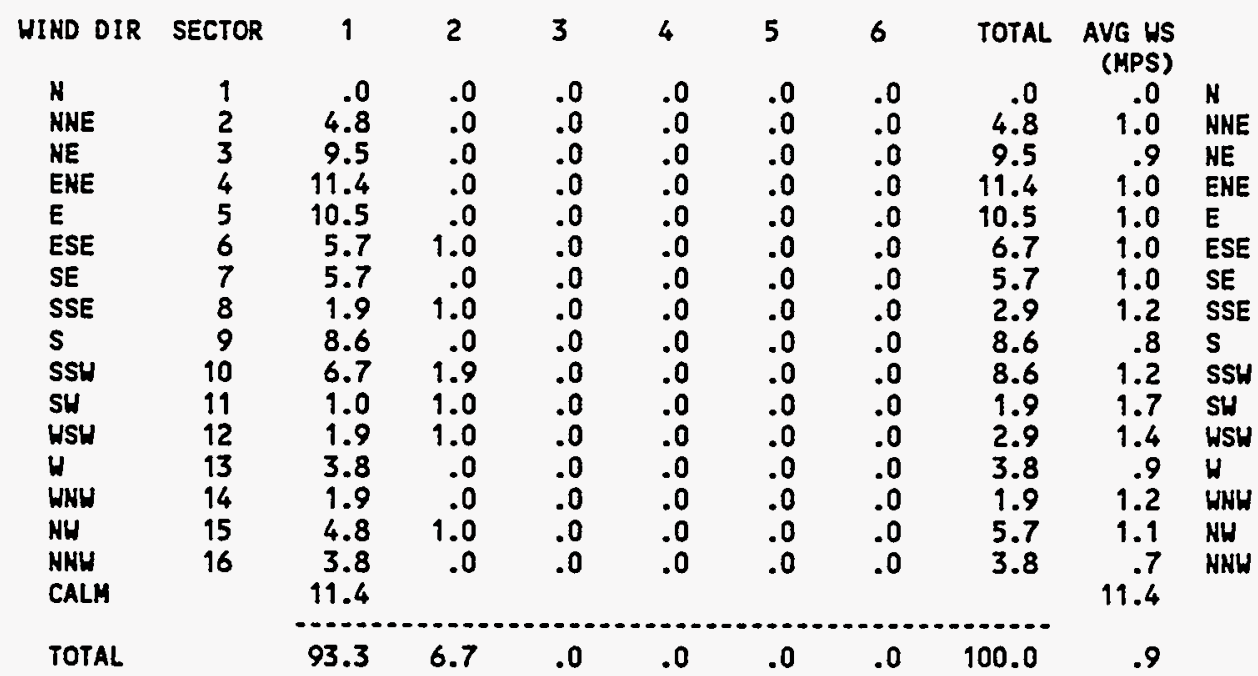

85.4\% DATA RECOVERED

18.3\% OF RECOVERED DATA

REPORTED ABOVE

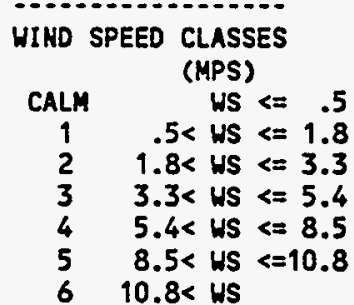


METEOROLOGICAL JOINT FREQUENCY DISTRIBUTION (PERCENT OF VALID HOUR OBSERVATIONS)

SPILL TEST FACILITY 24 METER TOUER

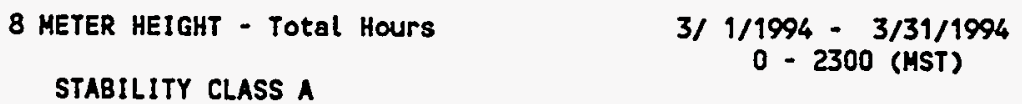

HI NDSPEED CLASS

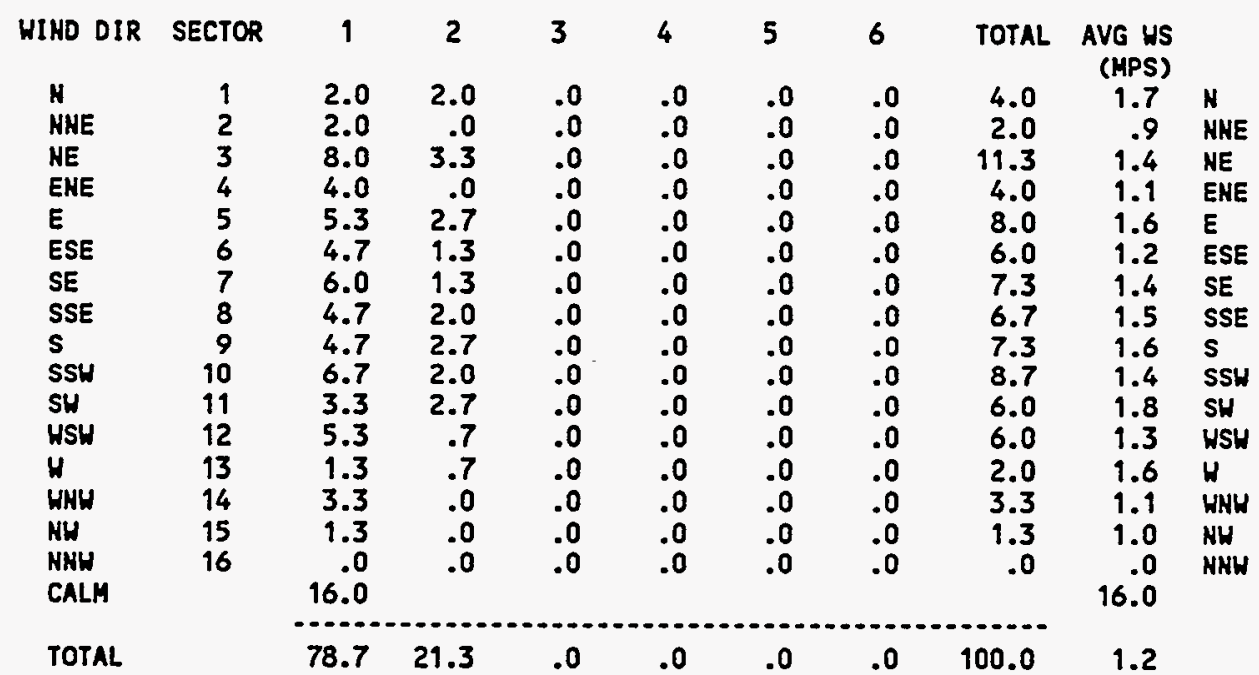

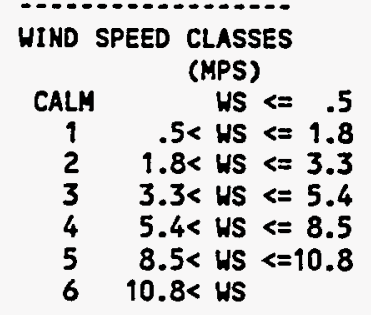


METEOROLOGICAL JOINT FREQUENCY DISTRIBUTION (PERCENT OF VALID HOUR OBSERVATIONS)

SPILL TEST FACILITY 24 METER TOWER

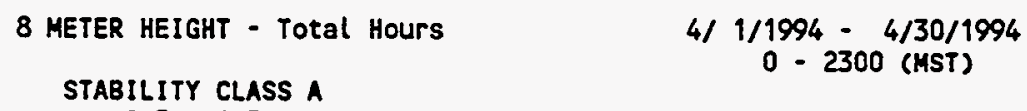

HIND SPEEDCLASS

\begin{tabular}{|c|c|c|c|c|c|c|c|c|c|c|}
\hline HIND DIR & SECTOR & 1 & 2 & 3 & 4 & 5 & 6 & TOTAL & $\begin{array}{r}\text { AVG US } \\
\text { (MPS) }\end{array}$ & \\
\hline H & 1 & .0 & .0 & .0 & .0 & .0 & .0 & .0 & .0 & N \\
\hline HHE & 2 & .0 & .0 & .0 & .0 & .0 & .0 & .0 & .0 & HAE \\
\hline NE & 3 & 1.4 & .7 & .0 & .0 & .0 & .0 & 2.1 & 1.4 & HE \\
\hline ENE & 4 & .7 & .0 & .0 & .0 & .0 & .0 & .7 & 1.1 & ENE \\
\hline E & 5 & 4.9 & 2.1 & .0 & .0 & .0 & .0 & 6.9 & 1.5 & E \\
\hline ESE & 6 & 6.3 & 3.5 & .0 & .0 & .0 & .0 & 9.7 & 1.5 & ESE \\
\hline SE & 7 & 4.9 & 6.9 & .0 & .0 & .0 & .0 & 11.8 & 1.7 & SE \\
\hline SSE & 8 & 7.6 & 4.2 & .0 & .0 & .0 & .0 & 11.8 & 1.4 & SSE \\
\hline $\mathbf{s}$ & 9 & 9.0 & 5.6 & .0 & .0 & .0 & .0 & 14.6 & 1.5 & $\mathbf{s}$ \\
\hline SSW & 10 & 9.0 & 6.3 & .0 & .0 & .0 & .0 & 15.3 & 1.6 & SSH \\
\hline SW & 11 & 2.8 & 2.8 & .0 & .0 & .0 & .0 & 5.6 & 1.8 & SH \\
\hline WSW & 12 & 3.5 & 2.1 & .0 & .0 & .0 & .0 & 5.6 & 1.7 & WSH \\
\hline$H$ & 13 & 4.2 & .7 & .0 & .0 & .0 & .0 & 4.9 & 1.1 & $W$ \\
\hline WWW & 14 & .7 & .7 & .0 & .0 & .0 & .0 & 1.4 & 1.9 & HHW \\
\hline NH & 15 & .7 & .0 & .0 & .0 & .0 & .0 & .7 & .7 & NW \\
\hline \multirow{2}{*}{$\begin{array}{l}\text { NNU } \\
\text { CALL }\end{array}$} & 16 & 90 & .0 & .0 & .0 & .0 & .0 & .0 & .0 & NHW \\
\hline & & & & & & & & & & \\
\hline TOTAL & & 64.6 & 35.4 & .0 & .0 & .0 & .0 & 100.0 & 1.4 & \\
\hline
\end{tabular}

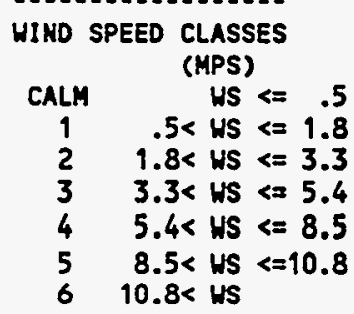


METEOROLOGICAL JOIHT FREQUENCY DISTRIBUTIOH (PERCENT OF VALID HOUR OBSERVATIONS)

SPILL TEST FACILITY 24 METER TONER
8 METER HEIGHT - Total HourS
$5 / 1 / 1994-5 / 31 / 1994$
$0 \cdot 2300$ (MST)

STABILITY CLASS A

$0.5 \cdot 1.5$

HIHD SPEED CLASS

\begin{tabular}{|c|c|c|c|c|c|c|c|c|c|c|}
\hline WIND DIR & SECTOR & 1 & 2 & 3 & 4 & 5 & 6 & TOTAL & AVG WS & \\
\hline N & 1 & 5.2 & .6 & .0 & .0 & .0 & .0 & 5.8 & 1.2 & N \\
\hline $\begin{array}{l}\text { NRE } \\
\text { ME }\end{array}$ & $\begin{array}{l}2 \\
3\end{array}$ & $\begin{array}{l}4.1 \\
6.4\end{array}$ & 1.2 & $\begin{array}{r}.0 \\
0\end{array}$ & .0 & .0 & .0 & 5.2 & 9.2 & HNE \\
\hline $\begin{array}{l}\text { NE } \\
\text { ENE }\end{array}$ & $\begin{array}{l}3 \\
4\end{array}$ & $\begin{array}{l}0.4 \\
1.7\end{array}$ & 1.6 & $\begin{array}{l}.0 \\
.0\end{array}$ & $\begin{array}{l}.0 \\
.0\end{array}$ & $\begin{array}{l}.0 \\
.0\end{array}$ & $\begin{array}{l}.0 \\
.0\end{array}$ & $\begin{array}{l}7.0 \\
3.5\end{array}$ & $\begin{array}{l}1.0 \\
1.5\end{array}$ & $\begin{array}{l}\text { ME } \\
\text { ENE }\end{array}$ \\
\hline$E$ & 5 & 2.9 & 1.2 & .0 & .0 & .0 & .0 & 4.1 & 1.6 & $E$ \\
\hline ESE & 6 & 2.9 & 3.5 & .0 & .0 & .0 & .0 & 6.4 & 1.7 & ESE \\
\hline SE & 7 & 5.8 & 1.7 & .0 & .0 & .0 & .0 & 7.6 & 1.3 & SE \\
\hline $\begin{array}{l}\text { SSE } \\
S\end{array}$ & 8 & 2.3 & 2.3 & .0 & & .0 & .0 & 4.7 & 1.6 & $\begin{array}{l}\text { SSE } \\
S\end{array}$ \\
\hline $\begin{array}{l}\text { S } \\
\text { SSH }\end{array}$ & $\begin{array}{r}9 \\
10\end{array}$ & $\begin{array}{l}4.7 \\
4.1\end{array}$ & $\begin{array}{l}3.5 \\
4.7\end{array}$ & .0 & $\begin{array}{l}.0 \\
.0\end{array}$ & $\begin{array}{l}.0 \\
.0\end{array}$ & $\begin{array}{l}.0 \\
.0\end{array}$ & $\begin{array}{l}7.6 \\
8.7\end{array}$ & 1.5 & $\begin{array}{l}\text { S } \\
\text { SSU }\end{array}$ \\
\hline SW & 91 & 5.8 & 4.1 & .0 & .0 & .0 & .0 & 9.9 & 1.6 & SW \\
\hline WSU & 12 & 2.3 & 2.3 & .0 & .0 & .0 & .0 & 4.7 & 1.5 & HSH \\
\hline$H$ & 13 & 2.9 & .6 & .0 & .0 & .0 & .0 & 3.5 & 1.0 & $H$ \\
\hline WHH & 14 & 6.4 & .6 & .0 & .0 & .0 & .0 & 7.0 & 1.2 & WNW \\
\hline NW & 15 & 4.1 & .6 & .0 & .0 & .0 & .0 & 4.7 & 1.1 & NH \\
\hline $\begin{array}{l}\text { NHH } \\
\text { CALM }\end{array}$ & 16 & $\begin{array}{r}.6 \\
8.1\end{array}$ & 1.2 & .0 & .0 & .0 & .0 & 1.7 & 2.2 & HNW \\
\hline & & & & & & & & & & \\
\hline TOTAL & & 69.8 & 30.2 & .0 & .0 & .0 & .0 & 100.0 & 1.3 & \\
\hline
\end{tabular}

96.9\% DATA RECOVERED

23.9\% OF RECOVERED DATA

REPORTED ABOVE

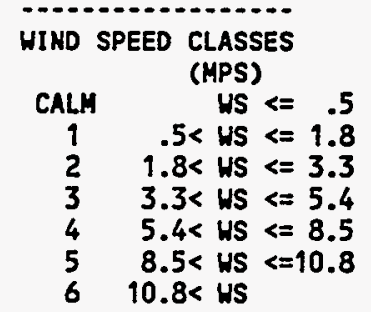


METEOROLOGICAL JOINT FREQUENCY DISTRIBUTION (PERCENT OF VALID HOUR OBSERVATIONS)

SPILL TEST FACILITY 24 METER TOWER

8 METER HEIGHT - Total Hours

STABILITY CLASS A

$0.5 \cdot 1.5$
6/ $1 / 1994-6 / 30 / 1994$

$0-2300$ (MST)

WIND SPEED CLASS

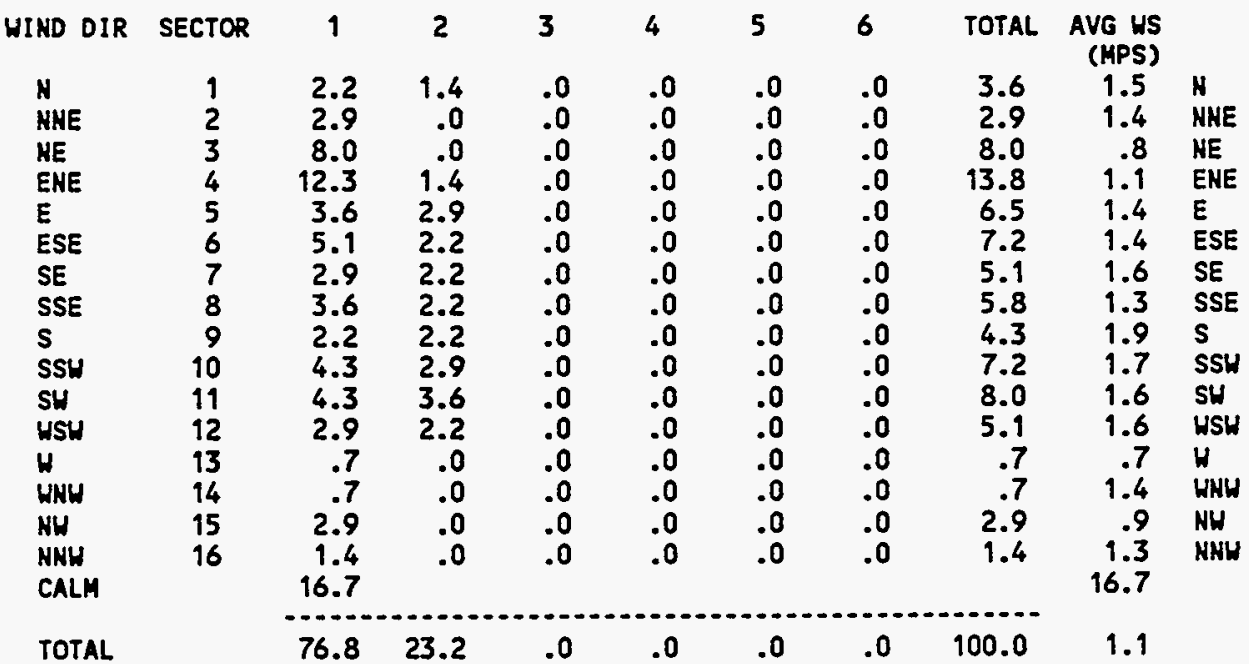

100.0\% DATA RECOVERED

19.2\% OF RECOVERED DATA REPORTED ABOVE

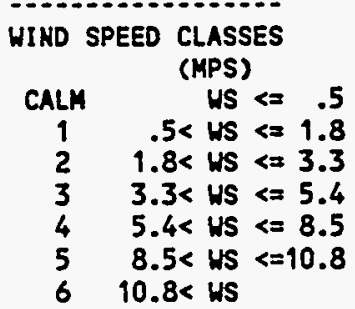


METEOROLOGICAL JOIHT FREQUENCY DISTRIBUTION (PERCENT OF VALID HOUR OBSERVATIONS) SPILL TEST FACILITY 24 METER TONER

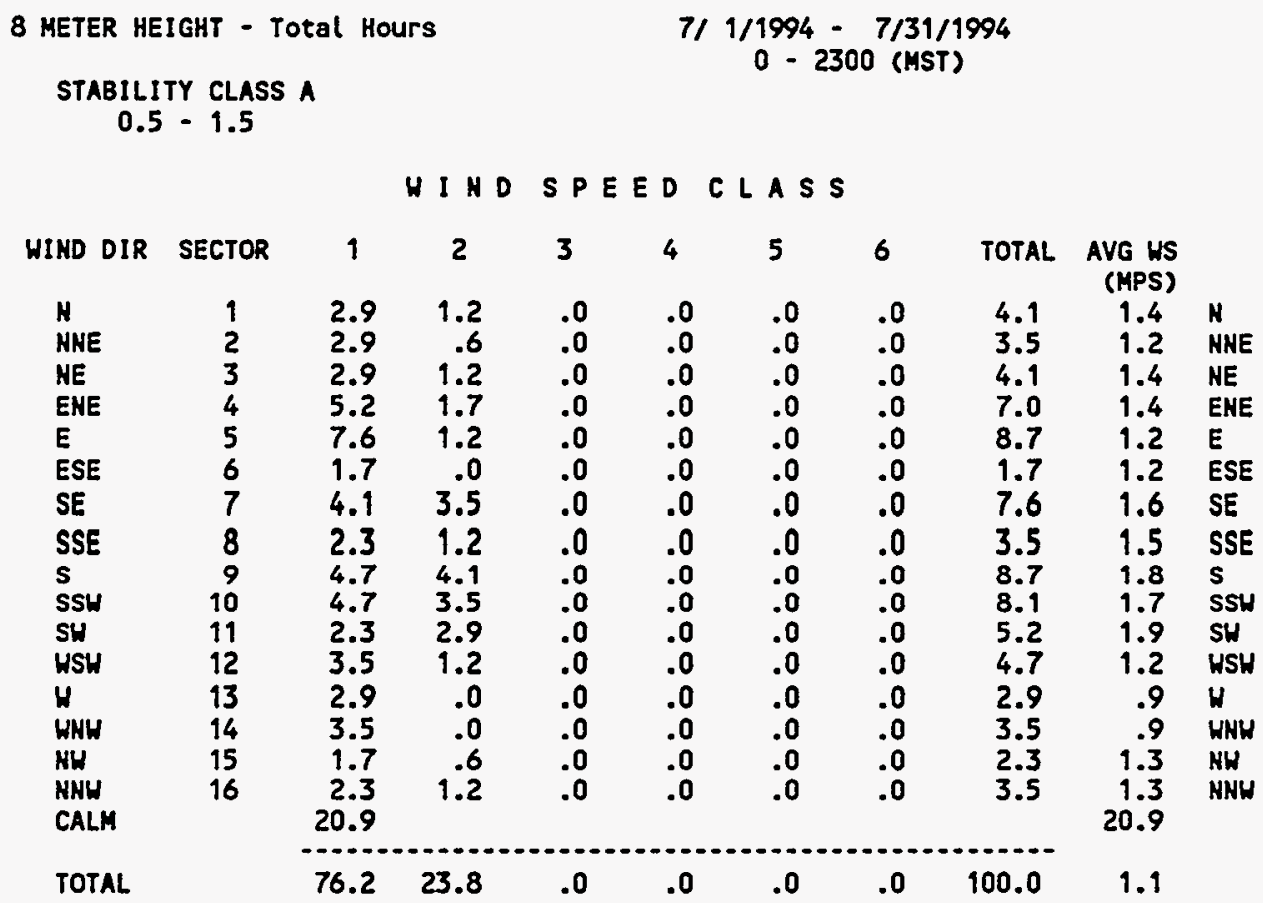

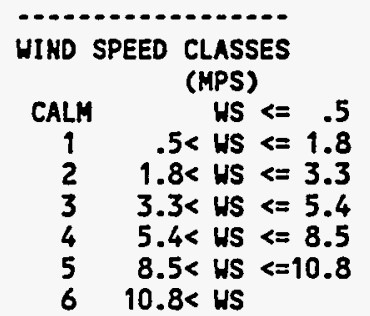


METEOROLOGICAL JOINT FREQUENCY DISTRIBUTION (PERCENT OF VALID HOUR OBSERVATIONS)

SPILL TEST FACILITY 24 METER TOWER

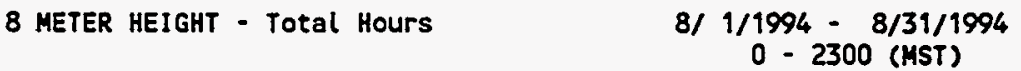

\begin{tabular}{|c|c|c|c|c|c|c|c|c|c|c|}
\hline WIND DIR & SECTOR & 1 & 2 & 3 & 4 & 5 & 6 & TOTAL & $\begin{array}{l}\text { AVG WS } \\
\text { (MPS) }\end{array}$ & \\
\hline $\mathbf{N}$ & 1 & 1.6 & 1.6 & .0 & .0 & .0 & .0 & 3.1 & 1.8 & H \\
\hline NNE & 2 & 3.1 & 1.6 & .0 & .0 & .0 & .0 & 4.7 & 1.3 & NNE \\
\hline NE & 3 & 9.3 & .8 & .0 & .0 & .0 & .0 & 10.1 & 1.2 & NE \\
\hline ENE & 4 & 5.4 & 3.9 & .0 & .0 & .0 & .0 & 9.3 & 1.6 & ENE \\
\hline $\mathbf{E}$ & 5 & 4.7 & .8 & .0 & .0 & .0 & .0 & 5.4 & 1.2 & \\
\hline ESE & 6 & 5.4 & .0 & .0 & .0 & .0 & .0 & 5.4 & 1.0 & ESE \\
\hline SE & 7 & 7.0 & .8 & .0 & .0 & .0 & .0 & 7.8 & 1.1 & SE \\
\hline SSE & 8 & 2.3 & .0 & .0 & .0 & .0 & .0 & 2.3 & 1.2 & SSE \\
\hline$s$ & 9 & 2.3 & 3.1 & .0 & .0 & .0 & .0 & 5.4 & 1.7 & $\mathbf{s}$ \\
\hline SSH & 10 & 3.9 & .0 & .0 & .0 & .0 & .0 & 3.9 & 1.0 & SSH \\
\hline SW & 11 & 6.2 & .8 & .0 & .0 & .0 & .0 & 7.0 & 1.1 & SH \\
\hline WSW & 12 & 5.4 & .8 & .0 & .0 & .0 & .0 & 6.2 & 1.1 & WSW \\
\hline $\boldsymbol{H}$ & 13 & 2.3 & .0 & .0 & .0 & .0 & .0 & 2.3 & .7 & $H$ \\
\hline WNH & 14 & 1.6 & 1.6 & .0 & .0 & .0 & .0 & 3.1 & 1.4 & WNH \\
\hline NH & 15 & 2.3 & .0 & .0 & .0 & .0 & .0 & 2.3 & .9 & NW \\
\hline $\begin{array}{l}\text { NKW } \\
\text { CALM }\end{array}$ & 16 & $\begin{array}{r}3.1 \\
18.6\end{array}$ & .0 & .0 & .0 & .0 & .0 & 3.1 & $\begin{array}{r}1.2 \\
18.6\end{array}$ & NKW \\
\hline AAL & & 84.5 & 15.5 & .0 &. & .0 & .0 & 100.0 & 1.0 & \\
\hline
\end{tabular}

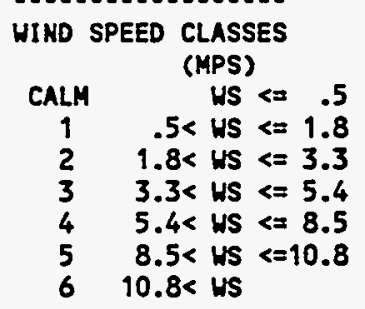


METEOROLOGICAL JOINT FREQUENCY DISTRIBUTION (PERCENT OF VALID HOUR OBSERVATIONS) SPILL TEST FACILITY 24 METER TOWER

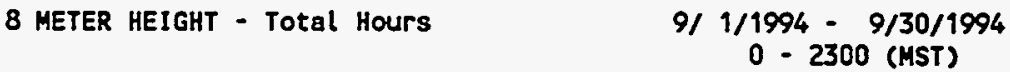

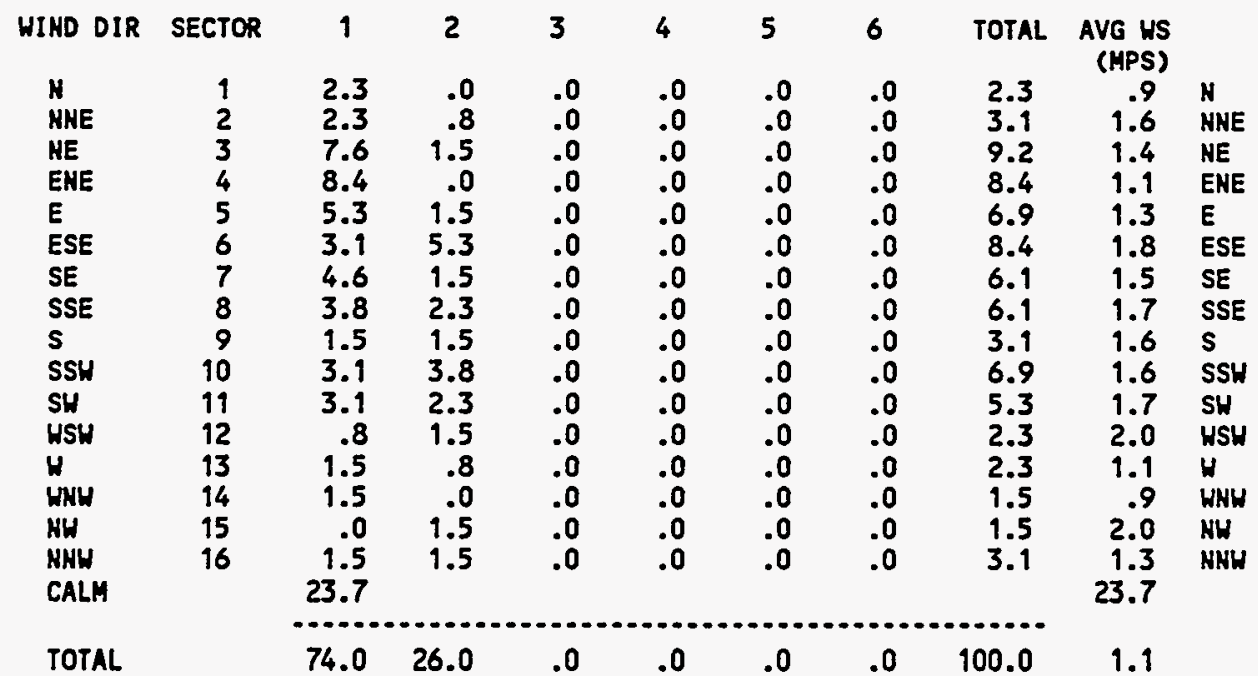

99.2\% DATA RECOVERED

18.3\% OF RECOVERED DATA REPORTED ABOVE

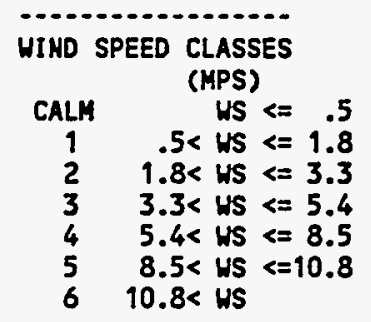


METEOROLOGICAL JOIHT FREQUENCY DISTRIBUTION (PERCENT OF VALID HOUR OBSERVATIONS)

SPILL TEST FACILITY 24 METER TONER

8 METER HEIGHT - Total Hours

STABILITY CLASS A

$0.5-1.5$
$10 / 1 / 1994 \cdot 10 / 31 / 1994$

$0 \cdot 2300$ (MST)

WIND SPEED CLASS

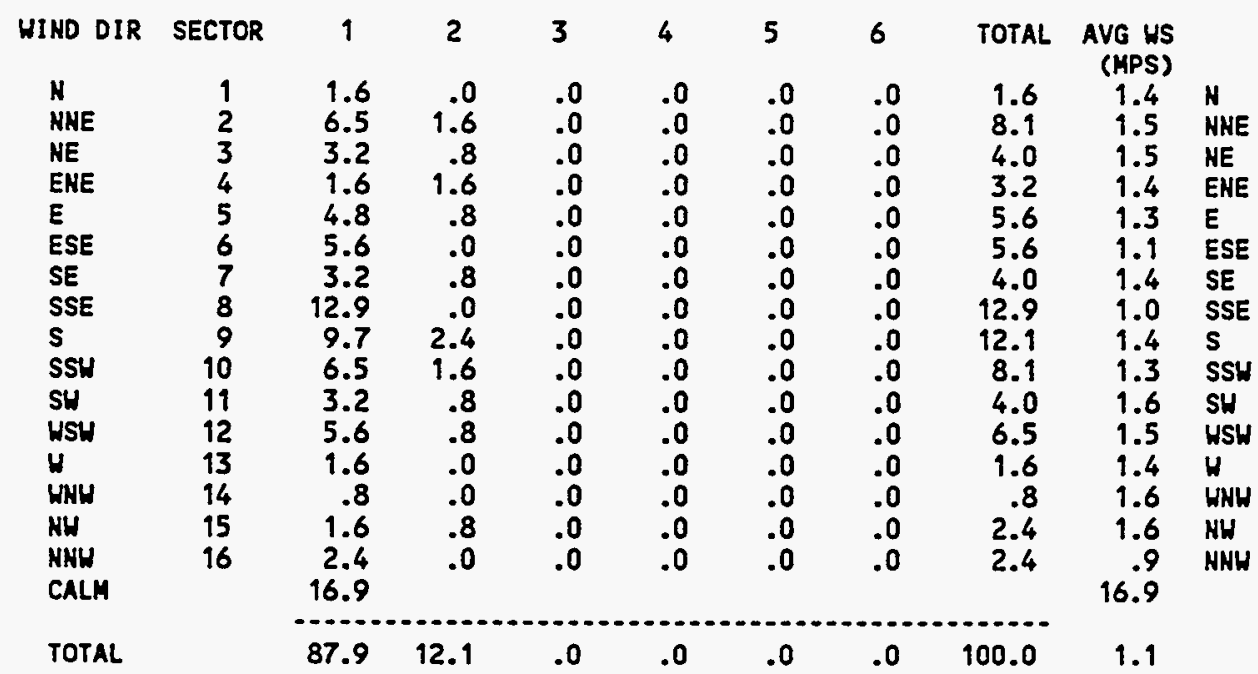

98.5\% DATA RECOVERED 16.9\% OF RECOVERED DATA REPORTED ABOVE

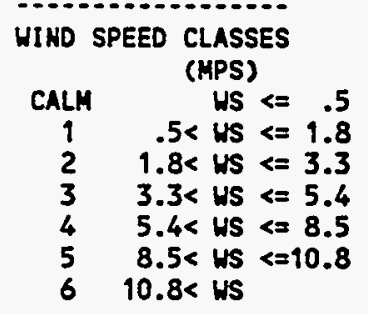


METEOROLOGICAL JOINT FREQUENCY OISTRIBUTION (PERCENT OF VALID HOUR OBSERVATIOHS)

SPILL TEST FACILITY 24 METER TOWER
8 METER HEIGHT - Total Hours
$11 / 1 / 1994-11 / 30 / 1994$
0 - 2300 (MST)

STABILITY CLASS A

$0.5-1.5$

HIND SPEEDCLASS

\begin{tabular}{|c|c|c|c|c|c|c|c|c|c|c|}
\hline HIKD DIR & SECTOR & 1 & 2 & 3 & 4 & 5 & 6 & TOTAL & $\begin{array}{l}\text { AVG WS } \\
\text { (MPS) }\end{array}$ & \\
\hline H & 1 & 4.8 & .0 & .0 & .0 & .0 & .0 & 4.8 & .8 & $\mathbf{N}$ \\
\hline NHE & 2 & 5.8 & .0 & .0 & .0 & .0 & .0 & 5.8 & 1.0 & NNE \\
\hline HE & 3 & 6.7 & .0 & .0 & .0 & .0 & .0 & 6.7 & 1.2 & NE \\
\hline ENE & 4 & 3.8 & 1.0 & .0 & .0 & .0 & .0 & 4.8 & 1.1 & ENE \\
\hline$E$ & 5 & 13.5 & 1.0 & .0 & .0 & .0 & .0 & 14.4 & 1.1 & $E$ \\
\hline ESE & 6 & 5.8 & 1.0 & .0 & .0 & .0 & .0 & 6.7 & 9.3 & ESE \\
\hline SE & 7 & 4.8 & 1.9 & .0 & .0 & .0 & .0 & 6.7 & 1.3 & SE \\
\hline SSE & 8 & 2.9 & 1.0 & .0 & .0 & .0 & .0 & 3.8 & 1.5 & SSE \\
\hline $\begin{array}{l}\text { S } \\
\text { SSH }\end{array}$ & $\begin{array}{r}9 \\
10\end{array}$ & $\begin{array}{l}1.9 \\
2.9\end{array}$ & $\begin{array}{l}1.9 \\
1.0\end{array}$ & $\begin{array}{l}.0 \\
.0\end{array}$ & $\begin{array}{l}.0 \\
.0\end{array}$ & $\begin{array}{l}.0 \\
.0\end{array}$ & $\begin{array}{l}.0 \\
.0\end{array}$ & $\begin{array}{l}3.8 \\
3.8\end{array}$ & $\begin{array}{l}1.5 \\
1.5\end{array}$ & $\begin{array}{l}\text { S } \\
\text { SSW }\end{array}$ \\
\hline SW & 11 & 7.7 & 1.0 & .0 & .0 & .0 & .0 & 8.7 & 1.1 & SH \\
\hline USW & 12 & 3.8 & .0 & .0 & .0 & .0 & .0 & 3.8 & .7 & USW \\
\hline $\boldsymbol{H}$ & 13 & 1.9 & .0 & .0 & .0 & .0 & .0 & 1.9 & 1.3 & $H$ \\
\hline WNH & 14 & 3.8 & .0 & .0 & .0 & .0 & .0 & 3.8 & .9 & WNW \\
\hline HH & 15 & 1.9 & .0 & .0 & .0 & .0 & .0 & 1.9 & 1.3 & NH \\
\hline NNH & 16 & 1.0 & .0 & .0 & .0 & .0 & .0 & 1.0 & 1.3 & NNH \\
\hline CALM & & 17.3 & & & & & & & 17.3 & \\
\hline TOTAL & & 90.4 & 9.6 & .0 & .0 & .0 & .0 & 100.0 & 1.0 & \\
\hline
\end{tabular}

$99.7 \%$ DATA RECOVERED

14.5\% OF RECOVERED DATA

REPORTED ABOVE

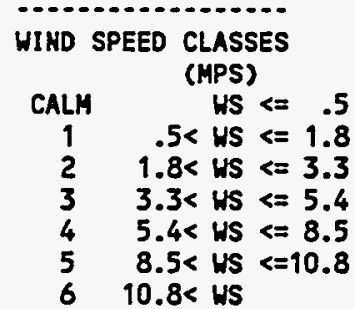


METEOROLOGICAL JOINT FREQUENCY DISTRIBUTION (PERCENT OF VALID HOUR OBSERVATIONS)

SPILL TEST FACILITY 24 METER TONER

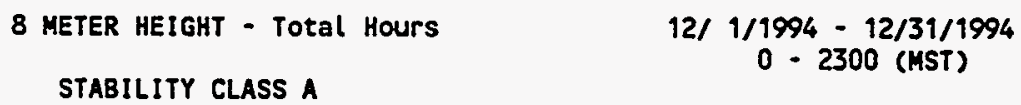

HIND SPEEDCLASS

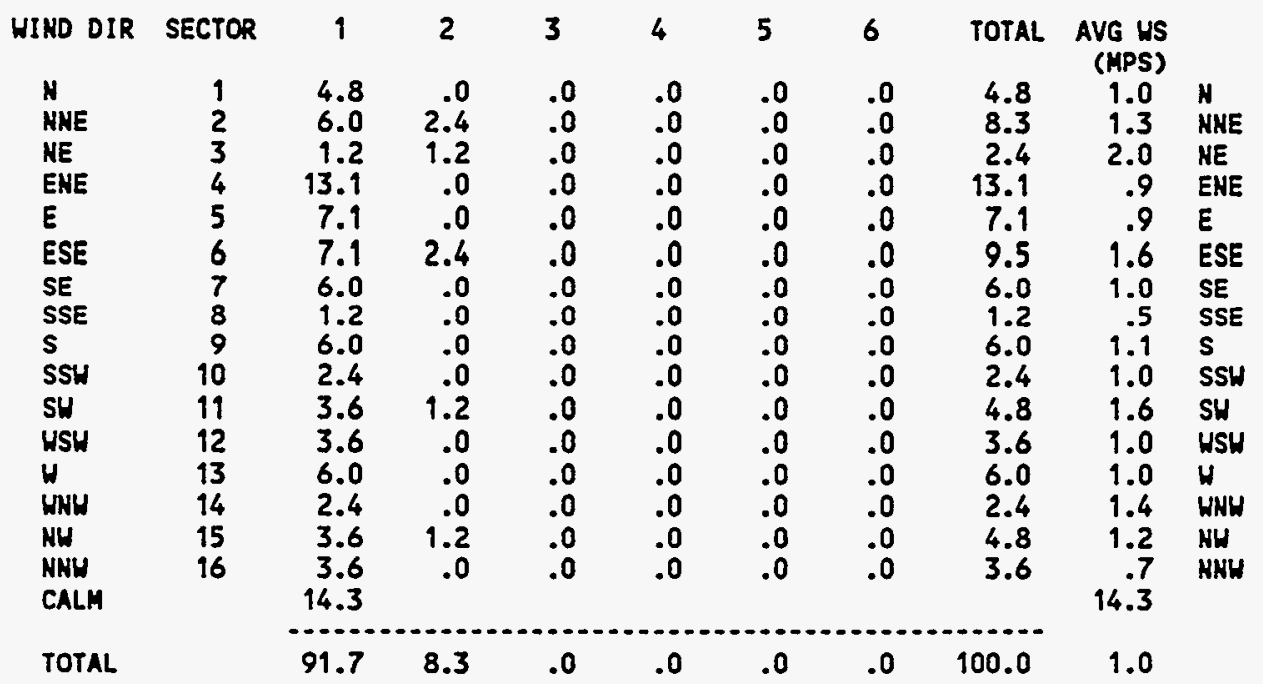
REPORTED ABOVE

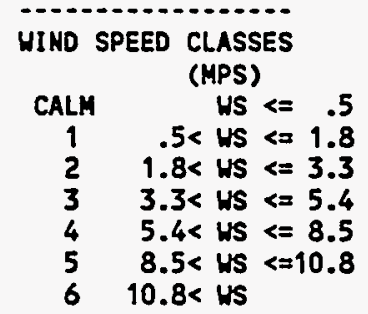


METEOROLOGICAL JOIHT FREQUENCY DISTRIBUTION (PERCENT OF VALID HOUR OBSERVATIONS) SPILL TEST FACILITY 24 METER TOWER

8 METER HEIGHT - Total Hours

STABILITY CLASS B

$1.5 \cdot 2.5$
$1 / 1 / 1994 \cdot 1 / 31 / 1994$

0 - 2300 (MST)

\section{HINDSPEEDCLASS}

\begin{tabular}{|c|c|c|c|c|c|c|c|c|c|c|}
\hline HIND DIR & SECTOR & 1 & 2 & 3 & 4 & 5 & 6 & TOTAL & $\begin{array}{l}\text { AVG WS } \\
\text { (MPS) }\end{array}$ & \\
\hline H & 1 & .0 & .0 & .0 & .0 & .0 & .0 & .0 & .0 & H \\
\hline NHE & 2 & .0 & .0 & .0 & .0 & .0 & .0 & .0 & .0 & NKE \\
\hline ME & 3 & 2.9 & 5.7 & .0 & 2.9 & .0 & .0 & 11.4 & 3.4 & NE \\
\hline ENE & 4 & 2.9 & .0 & .0 & .0 & .0 & .0 & 2.9 & .8 & ENE \\
\hline$E$ & 5 & 5.7 & 2.9 & .0 & .0 & .0 & .0 & 8.6 & 9.1 & $E$ \\
\hline $\begin{array}{l}\text { ESE } \\
\text { SE }\end{array}$ & $\begin{array}{l}6 \\
7\end{array}$ & $\begin{array}{l}2.9 \\
8.6\end{array}$ & .0 & .0 & $\begin{array}{l}.0 \\
.0\end{array}$ & $\begin{array}{l}.0 \\
.0\end{array}$ & .0 & $\begin{array}{l}2.9 \\
8.6\end{array}$ & $\begin{array}{l}1.0 \\
1.1\end{array}$ & $\begin{array}{l}\text { ESE } \\
\text { SE }\end{array}$ \\
\hline $\begin{array}{l}\text { SSE } \\
\text { S }\end{array}$ & 8 & $\begin{array}{r}5.7 \\
91.4\end{array}$ & $\begin{array}{l}.0 \\
.0\end{array}$ & $\begin{array}{r}.0 \\
5.7\end{array}$ & $\begin{array}{l}.0 \\
.0\end{array}$ & $\begin{array}{l}.0 \\
.0\end{array}$ & .00 & $\begin{array}{r}5.7 \\
17.1\end{array}$ & $\begin{array}{l}1.1 \\
1.8\end{array}$ & $\begin{array}{l}\text { SSE } \\
S\end{array}$ \\
\hline SSH & 10 & 5.7 & .0 & .0 & .0 & .0 & .0 & 5.7 & .8 & SSW \\
\hline SH & 11 & 5.7 & .0 & .0 & 2.9 & .0 & .0 & 8.6 & 2.4 & SH \\
\hline WSH & 12 & 2.9 & .0 & .0 & .0 & .0 & .0 & 2.9 & 1.3 & WSW \\
\hline H & 13 & 2.9 & .0 & 2.9 & .0 & .0 & .0 & 5.7 & 2.4 & H \\
\hline WHW & 14 & .0 & .0 & .0 & .0 & .0 & .0 & .0 & .0 & WNW \\
\hline HH & 15 & 2.9 & .0 & .0 & .0 & .0 & .0 & 2.9 & 1.0 & NH \\
\hline $\begin{array}{l}\text { NHW } \\
\text { CALM }\end{array}$ & 16 & .0 & .0 & .0 & .0 & .0 & .0 & .0 & .0 & NHH \\
\hline & & & & & & & & & & \\
\hline TOTAL & & 77.1 & 8.6 & 8.6 & 5.7 & .0 & .0 & 100.0 & 1.5 & \\
\hline
\end{tabular}

78.0\% DATA RECOVERED

6.0\% OF RECOVERED DATA REPORTED ABOVE

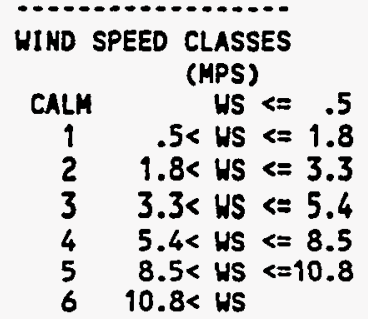


METEOROLOGICAL JOINT FREQUENCY DISTRIBUTION (PERCENT OF VALID HOUR OBSERVATIONS) SPILL TEST FACILITY 24 METER TONER

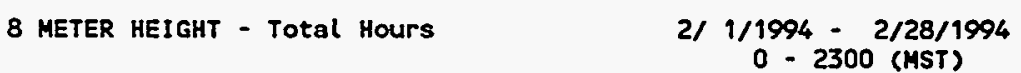

\begin{tabular}{|c|c|c|c|c|c|c|c|c|c|c|}
\hline HIND DIR & SECTOR & 1 & 2 & 3 & 4 & 5 & 6 & TOTAL & $\begin{array}{l}\text { AVG US } \\
\text { (MPS) }\end{array}$ & \\
\hline N & 1 & .0 & .0 & 3.4 & .0 & 3.4 & .0 & 6.9 & 6.9 & N \\
\hline NME & 2 & .0 & .0 & 3.4 & .0 & .0 & .0 & 3.4 & 3.7 & NHE \\
\hline NE & 3 & 6.9 & .0 & .0 & .0 & .0 & .0 & 6.9 & 1.0 & KE \\
\hline ENE & 4 & 3.4 & .0 & .0 & .0 & .0 & .0 & 3.4 & .8 & ENE \\
\hline $\mathbf{E}$ & 5 & 3.4 & .0 & .0 & .0 & .0 & .0 & 3.4 & 1.1 & E \\
\hline ESE & 6 & 3.4 & 3.4 & .0 & .0 & .0 & .0 & 6.9 & 1.5 & ESE \\
\hline SE & 7 & .0 & .0 & 3.4 & .0 & .0 & .0 & 3.4 & 3.8 & SE \\
\hline SSE & 8 & .0 & .0 & .0 & .0 & .0 & .0 & .0 & .0 & SSE \\
\hline s & 9 & .0 & 3.4 & .0 & .0 & .0 & .0 & 3.4 & 2.2 & $\mathbf{s}$ \\
\hline SSW & 10 & 6.9 & 3.4 & 3.4 & .0 & .0 & .0 & 13.8 & 2.2 & SSH \\
\hline SH & 11 & 10.3 & .0 & 6.9 & .0 & .0 & .0 & 17.2 & 2.3 & SH \\
\hline WSW & 12 & 6.9 & .0 & .0 & .0 & .0 & .0 & 6.9 & 1.0 & WSH \\
\hline $\mathrm{H}_{\mathrm{Hu}}$ & $\begin{array}{l}13 \\
14\end{array}$ & 3.4 & 0 & .0 & $\begin{array}{r}.0 \\
34\end{array}$ & .0 & $\begin{array}{r}.0 \\
0\end{array}$ & $\begin{array}{l}3.4 \\
6.9\end{array}$ & $\begin{array}{l}1.2 \\
3.7\end{array}$ & $H_{H}$ \\
\hline NG & $\begin{array}{l}14 \\
15\end{array}$ & $\begin{array}{l}3.4 \\
3.4\end{array}$ & .0 & .0 & $\begin{array}{l}3.4 \\
3.4\end{array}$ & .0 & $\begin{array}{l}.0 \\
.0\end{array}$ & $\begin{array}{l}6.9 \\
6.9\end{array}$ & 4.8 & NH \\
\hline NNW & 16 & .0 & .0 & 3.4 & .0 & .0 & .0 & 3.4 & 4.1 & NNH \\
\hline CALM & & & & & & & & & & \\
\hline TOTAL & & 55.2 & 10.3 & 24.1 & 6.9 & 3.4 & .0 & 100.0 & 2.6 & \\
\hline
\end{tabular}

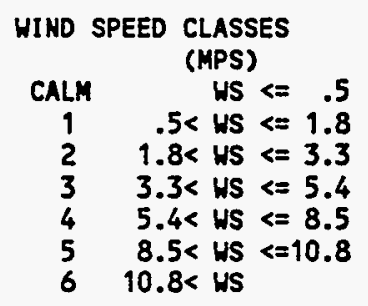


METEOROLOGICAL JOINT FREQUENCY DISTRIBUTION (PERCENT OF VALID HOUR OBSERVATIONS) SPILL TEST FACILITY 24 METER TONER

8 METER HEIGHT - Total Hours

3/ $1 / 1994-3 / 31 / 1994$

STABILITY CLASS 8

0 - 2300 (MST)

$$
1.5-2.5
$$

HI HD SPEED CLASS

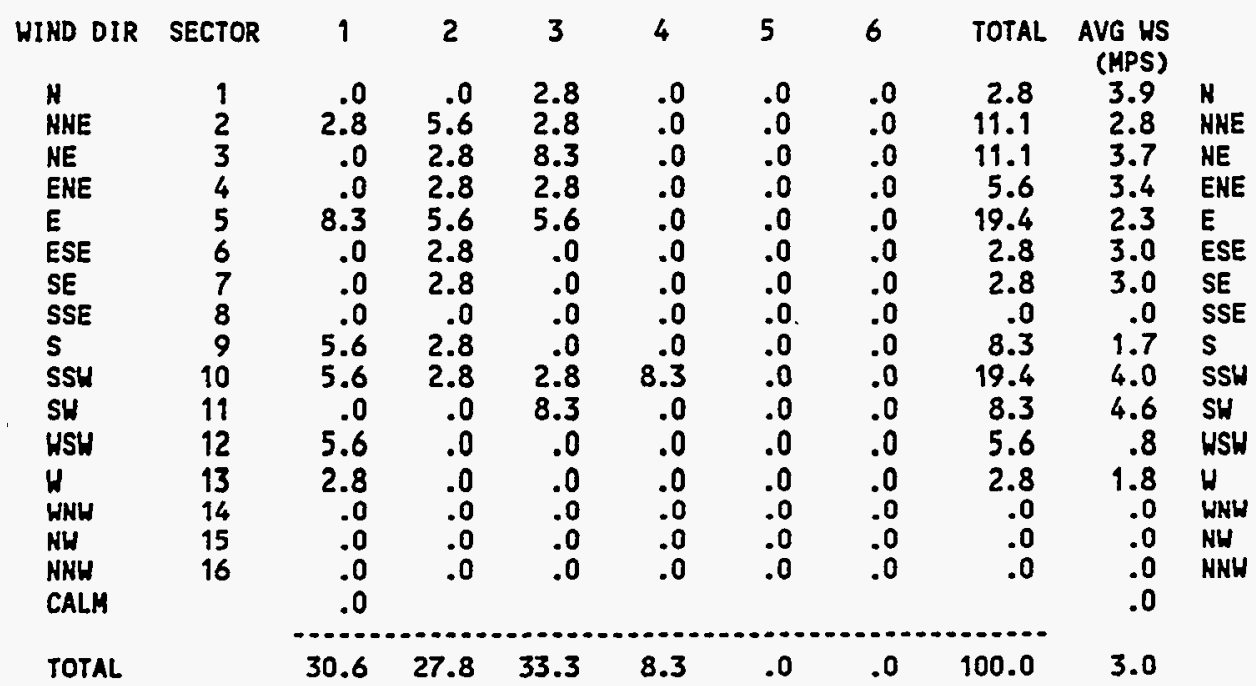

100.0\% DATA RECOVERED 4.8\% OF RECOVERED DATA REPORTED ABOVE

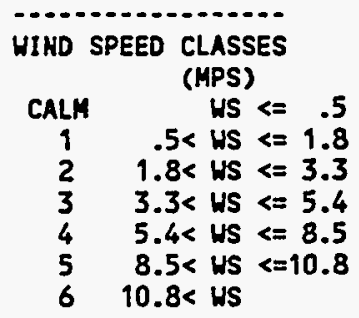


METEOROLOGICAL JOINT FREQUENCY DISTRIBUTION (PERCENT OF VALID HOUR OBSERVATIONS)

SPILL TEST FACILITY 24 METER TOWER

8 METER HEIGHT - Total Hours

$4 / 1 / 1994-4 / 30 / 1994$

STABILITY CLASS B

0 - 2300 (MST)

$1.5-2.5$

HINDSPEED CLASS

\begin{tabular}{|c|c|c|c|c|c|c|c|c|c|c|}
\hline HIND DIR & SECTOR & 1 & 2 & 3 & 4 & 5 & 6 & TOTAL & $\begin{array}{r}\text { AVG US } \\
\text { (MPS) }\end{array}$ & \\
\hline$N$ & 1 & .0 & .0 & .0 & .0 & .0 & .0 & .0 & & $\mathbf{N}$ \\
\hline NNE & 2 & & .0 & 3.4 & 1.7 & .0 & .0 & 5.2 & & HNE \\
\hline NE & 3 & .0 & .0 & 3.4 & .0 & .0 & .0 & 3.4 & 3.6 & NE \\
\hline ENE & 4 & 1.7 & .0 & & .0 & .0 & .0 & 1.7 & 1.4 & ENE \\
\hline E & 5 & 1.7 & 1.7 & 1.7 & & .0 & .0 & 5.2 & 2.8 & \\
\hline ESE & 6 & .0 & 1.7 & 1.7 & .0 & .0 & .0 & 3.4 & 3.4 & ESE \\
\hline SE & 7 & .0 & 3.4 & 3.4 & 1.7 & .0 & .0 & 8.6 & 4.0 & SE \\
\hline SSE & 8 & 1.7 & 1.7 & 1.7 & 1.7 & .0 & .0 & 6.9 & 3.3 & SSE \\
\hline S & 9 & 3.4 & 3.4 & .0 & 1.7 & .0 & .0 & 8.6 & 2.8 & S \\
\hline SSH & 10 & 1.7 & 1.7 & 5.2 & .0 & .0 & .0 & 8.6 & 3.1 & SSH \\
\hline su & 11 & 6.9 & 3.4 & 15.5 & .0 & .0 & .0 & 25.9 & 3.1 & SH \\
\hline HSH & 12 & 1.7 & 1.7 & 10.3 & .0 & .0 & .0 & 13.8 & 3.5 & WSH \\
\hline$H$ & 13 & 1.7 & .0 & 3.4 & .0 & .0 & .0 & 5.2 & 2.8 & $H$ \\
\hline WNH & 14 & .0 & .0 & .0 & .0 & .0 & .0 & .0 & & WNH \\
\hline NH & 15 & .0 & .0 & .0 & 1.7 & .0 & .0 & 1.7 & 6.0 & $\mathrm{NW}$ \\
\hline NNW & 16 & .0 & .0 & .0 & .0 & .0 & .0 & .0 & 7 & NNW \\
\hline & & & & & & & & & & \\
\hline TOTAL & & 22.4 & 19.0 & 50.0 & 8.6 & .0 & .0 & 100.0 & 3.2 & \\
\hline
\end{tabular}

99.9\% DATA RECOVERED

8.1\% OF RECOVERED DATA REPORTED ABOVE

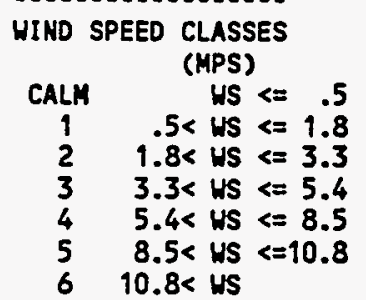


METEOROLOGICAL JOIHT FREQUENCY DISTRIBUTION (PERCENT OF VALID HOUR OBSERVATIONS) SPILL TEST FACILITY 24 METER TOWER

8 METER HEIGHT - Total Hours

$5 / 1 / 1994-5 / 31 / 1994$

STABILITY CLASS B

$0-2300$ (MST)

$1.5-2.5$

HINDSPEED CLASS

\begin{tabular}{|c|c|c|c|c|c|c|c|c|c|c|}
\hline WIKD DIR & SECTOR & 1 & 2 & 3 & 4 & 5 & 6 & TOTAL & $\begin{array}{c}\text { AVG US } \\
\text { (MPS) }\end{array}$ & \\
\hline H & 1 & .0 & 1.8 & .0 & .0 & .0 & .0 & 1.8 & 3.0 & H \\
\hline HNE & 2 & .0 & .0 & .0 & .0 & .0 & .0 & .0 & .0 & NKE \\
\hline NE & 3 & 1.8 & .0 & .0 & .0 & .0 & .0 & 1.8 & 1.7 & $\mathrm{NE}$ \\
\hline ENE & 4 & .0 & 1.8 & .0 & .0 & .0 & .0 & 1.8 & 2.4 & EHE \\
\hline$E$ & 5 & .0 & .0 & 1.8 & 1.8 & .0 & .0 & 3.5 & 4.8 & $\mathbf{E}$ \\
\hline ESE & 6 & 3.5 & .0 & .0 & .0 & .0 & .0 & 3.5 & 1.1 & ESE \\
\hline SE & 7 & .0 & .0 & 1.8 & .0 & .0 & .0 & 9. & 3.5 & SE \\
\hline SSE & 8 & .0 & 1.8 & 3.5 & .0 & .0 & .0 & 5.3 & 3.8 & SSE \\
\hline s & 9 & .0 & 1.8 & 10.5 & .0 & .0 & .0 & 12.3 & 4.2 & $s$ \\
\hline ssu & 10 & .0 & 5.3 & 8.8 & 1.8 & .0 & .0 & 15 & 3.9 & SSK \\
\hline SH & 11 & 3.5 & 7.0 & 28.1 & 3.5 & .0 & .0 & 42 & 3.9 & SH \\
\hline WSH & 12 & .0 & 1.8 & 5.3 & .0 & .0 & .0 & 7.0 & 4.2 & WSW \\
\hline$W$ & 13 & .0 & 1.8 & .0 & .0 & .0 & .0 & 1.8 & 3.0 & $\omega$ \\
\hline WHW & 14 & .0 & .0 & .0 & .0 & .0 & .0 & .0 & .0 & WHW \\
\hline HW & 15 & .0 & .0 & .0 & .0 & .0 & .0 & .0 & .0 & $\mathrm{NH}$ \\
\hline HKH & 16 & $\begin{array}{r}1.8 \\
0\end{array}$ & .0 & .0 & .0 & .0 & .0 & 1.8 & 1.1 & NNL \\
\hline & & 10.5 & 22.8 & 59.6 & 7.0 & .0 & .0 & 100.0 & 3.7 & \\
\hline
\end{tabular}

96.9\% DATA RECOVERED

7.9\% OF RECOVERED DATA REPORTED ABOVE

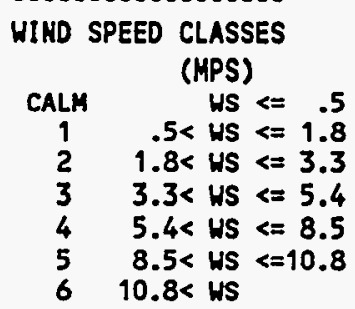


METEOROLOGICAL JOINT FREQUENCY OISTRIBUTION (PERCENT OF VALID HOUR OBSERVATIONS)

SPILL TEST FACILITY 24 METER TOWER

8 METER HEIGHT - Total Hours

6/ $1 / 1994 \cdot 6 / 30 / 1994$

STABILITY CLASS B

O - 2300 (MST)

$1.5-2.5$

HIND SPEED CLASS

\begin{tabular}{|c|c|c|c|c|c|c|c|c|c|c|}
\hline WIND DIR & SECTOR & 1 & 2 & 3 & 4 & 5 & 6 & TOTAL & $\begin{array}{l}\text { AVG WS } \\
\text { (MPS) }\end{array}$ & \\
\hline N- & 1 & .0 & .0 & .0 & .0 & .0 & .0 & .0 & .0 & N \\
\hline HNE & 2 & $\div 0$ & .0 & .0 & .0 & .0 & .0 & .0 & .0 & MNE \\
\hline $\begin{array}{l}\text { NE } \\
\text { ENE }\end{array}$ & 3 & $\begin{array}{l}7.1 \\
2.4\end{array}$ & .0 & $\begin{array}{r}2.4 \\
0\end{array}$ & $\begin{array}{l}0 \\
0\end{array}$ & .0 & .0 & 9.5 & 1.6 & $\begin{array}{l}\text { NE } \\
\text { EME }\end{array}$ \\
\hline ENE & $\begin{array}{l}4 \\
5\end{array}$ & 7.4 & 2.4 & $\begin{array}{l}.0 \\
.0\end{array}$ & $\begin{array}{l}.0 \\
.0\end{array}$ & $\begin{array}{l}.0 \\
.0\end{array}$ & $\begin{array}{l}.0 \\
.0\end{array}$ & $\begin{array}{l}2.4 \\
9.5\end{array}$ & $\begin{array}{r}.6 \\
1.6\end{array}$ & $\begin{array}{l}E \mathrm{ME} \\
\boldsymbol{E}\end{array}$ \\
\hline ESE & 6 & .0 & 2.4 & .0 & .0 & .0 & .0 & 2.4 & 3.0 & \\
\hline $\begin{array}{l}\text { SE } \\
\text { SSE }\end{array}$ & 7 & .0 & $\begin{array}{r}2.4 \\
.0\end{array}$ & .0 & .0 & $\begin{array}{r}0 \\
0\end{array}$ & $\begin{array}{l}.0 \\
0\end{array}$ & 2.4 & 2.8 & $\begin{array}{l}\text { SE } \\
\text { SSE }\end{array}$ \\
\hline $\begin{array}{l}\text { SSE } \\
\text { S }\end{array}$ & 9 & .0 & .0 & 7.1 & .0 & .0 & .0 & 7.0 & 3.8 & $s$ \\
\hline SSW & 10 & 2.4 & 2.4 & 14.3 & 2.4 & .0 & .0 & 21.4 & 4.1 & SSW \\
\hline Sw & 11 & 2.4 & .0 & 16.7 & 4.8 & .0 & .0 & 23.8 & 4.2 & SH \\
\hline HSW & 12 & 4.8 & 2.4 & 7.1 & 2.4 & .0 & .0 & 16.7 & 3.1 & \\
\hline 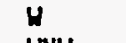 & 13 & .0 & .0 & .0 & .0 & .0 & .0 & .0 & .0 & \\
\hline WNW & 14 & .0 & 2.4 & .0 & .0 & .0 & .0 & 2.4 & 3.0 & WHW \\
\hline NH & 15 & 2.4 & .0 & .0 & .0 & .0 & .0 & 2.4 & 1.0 & NH \\
\hline $\begin{array}{l}\text { NNW } \\
\text { CALM }\end{array}$ & 16 & $\begin{array}{l}.0 \\
.0\end{array}$ & .0 & .0 & .0 & .0 & .0 & .0 & .0 & NNH \\
\hline & & & & & & & & & & \\
\hline TOTAL & & 28.6 & 14.3 & 47.6 & 9.5 & .0 & .0 & 100.0 & 3.2 & \\
\hline
\end{tabular}

100.0\% DATA RECOVERED

5.8\% OF RECOVERED DATA REPORTED ABOVE

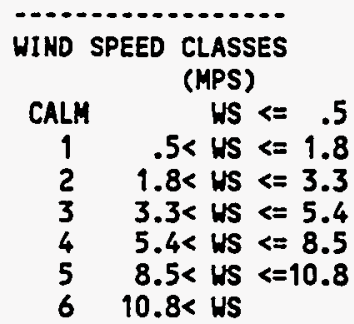


METEOROLOGICAL JOIHT FREQUENCY DISTRIBUTION (PERCENT OF VALID HOUR OBSERVATIONS)

SPILL TEST FACILITY 24 METER TONER

8 METER HEIGHT - TOtal HOURS

$7 / 1 / 1994 \cdot 7 / 31 / 1994$

STABILITY CLASS B

0 - 2300 (MST)

$1.5-2.5$

WI HD SPEEDCLASS

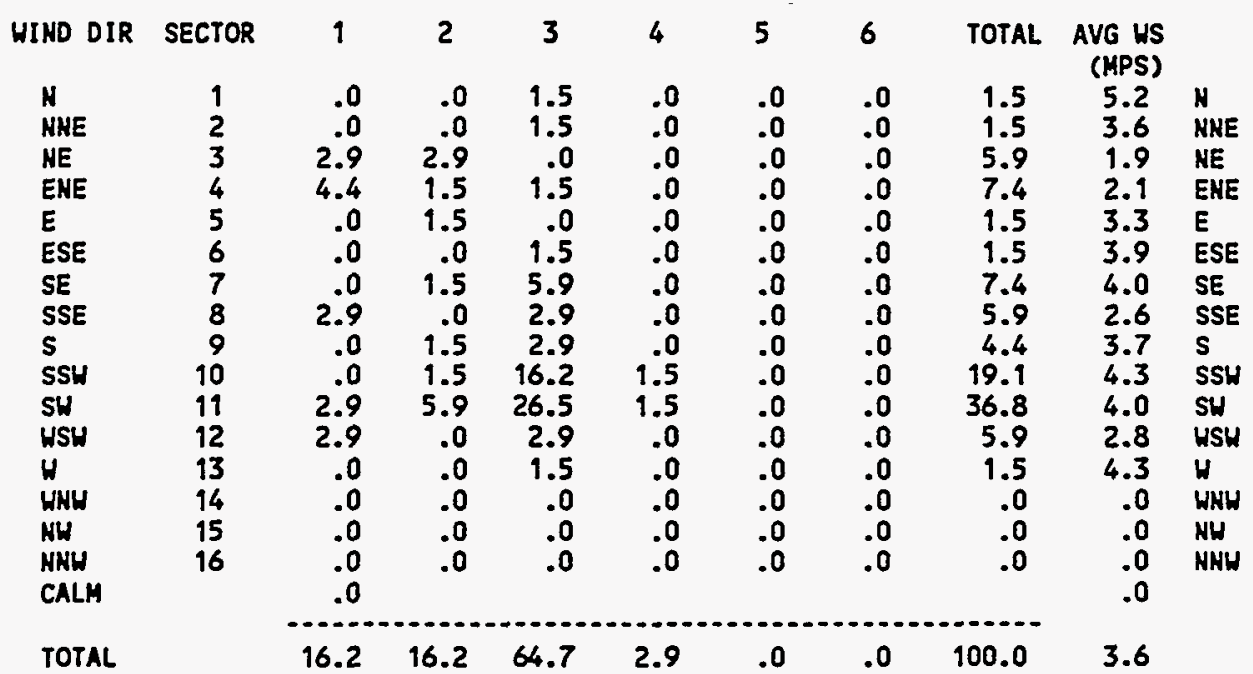

100.0\% DATA RECOVERED

9.1\% OF RECOVERED DATA REPORTED ABOVE

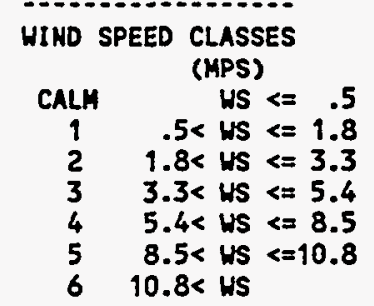


METEOROLOGICAL JOINT FREQUEMCY DISTRIBUTION (PERCENT OF VALID HOUR OBSERVATIONS)

SPILL TEST FACILITY 24 METER TONER

8 METER HEIGHT - TOtal HourS

$8 / 1 / 1994-8 / 31 / 1994$

STABILITY CLASS B

$0-2300$ (MST)

$1.5=2.5$

WINDSPEEDCLASS

\begin{tabular}{|c|c|c|c|c|c|c|c|c|c|c|}
\hline HIND DIR & SECTOR & 1 & 2 & 3 & 4 & 5 & 6 & TOTAL & $\begin{array}{c}\text { AVG WS } \\
\text { (MPS) }\end{array}$ & \\
\hline$N$ & 1 & .0 & .0 & .0 & .0 & .0 & .0 & .0 & .0 & H \\
\hline NRE & 2 & .0 & .0 & 1.6 & .0 & .0 & .0 & 1.6 & 4.4 & HNE \\
\hline NE & 3 & 4.9 & .0 & .0 & .0 & .0 & .0 & 4.9 & 9.2 & NE \\
\hline ENE & 4 & 1.6 & .0 & .0 & .0 & .0 & .0 & 1.6 & .7 & ENE \\
\hline$E$ & 5 & 3.3 & .0 & .0 & .0 & .0 & .0 & 3.3 & 1.1 & \\
\hline ESE & 6 & .0 & 1.6 & .0 & .0 & .0 & .0 & 1.6 & 3.0 & ESE \\
\hline SE & 7 & 1.6 & 1.6 & 4.9 & .0 & .0 & .0 & 8.2 & 2.9 & $E$ \\
\hline SSE & 8 & .0 & 1.6 & 3.3 & .0 & .0 & .0 & 4.9 & 4.0 & SE \\
\hline $\mathbf{s}$ & 9 & .0 & 3.3 & 4.9 & .0 & .0 & .0 & 8.2 & 3.6 & \\
\hline SSW & 10 & 1.6 & 6.6 & 16.4 & 4.9 & .0 & .0 & 29.5 & 4.1 & SSH \\
\hline SH & 11 & 1.6 & 1.6 & 21.3 & .0 & .0 & .0 & 24.6 & 4.2 & SH \\
\hline WSH & 12 & 1.6 & .0 & 3.3 & 1.6 & .0 & .0 & 6.6 & 4.1 & HSH \\
\hline$H$ & 13 & .0 & .0 & 1.6 & .0 & .0 & .0 & 1.6 & 3.6 & . \\
\hline WNM & 14 & .0 & .0 & .0 & .0 & .0 & .0 & .0 & .0 & WNH \\
\hline NH & 15 & .0 & .0 & .0 & .0 & .0 & .0 & .0 & .0 & NH \\
\hline $\begin{array}{l}\text { NNW } \\
\text { CALM }\end{array}$ & 16 & $\begin{array}{r}1.6 \\
.0\end{array}$ & .0 & 1.6 & .0 & .0 & .0 & 3.3 & $\begin{array}{r}2.4 \\
.0\end{array}$ & UW \\
\hline & & & & & & & & & & \\
\hline TOTAL & & 18.0 & 16.4 & 59.0 & 6.6 & .0 & .0 & 100.0 & 3.6 & \\
\hline
\end{tabular}

100.0\% DATA RECOVERED

8.2\% OF RECOVERED DATA REPORTED ABOVE

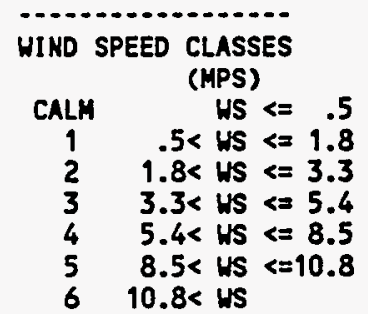


METEOROLOGICAL JOINT FREQUENCY DISTRIBUTION (PERCENT OF VALID HOUR OBSERVATIOHS)

SPILL TEST FACILITY 24 METER TOWER
8 METER HEIGHT - Total Hours 9/ 1/1994 - 9/30/1994
$0 \cdot 2300$ (MST)

STABILITY CLASS B

$1.5 \cdot 2.5$

WIHD SPEEDCLASS

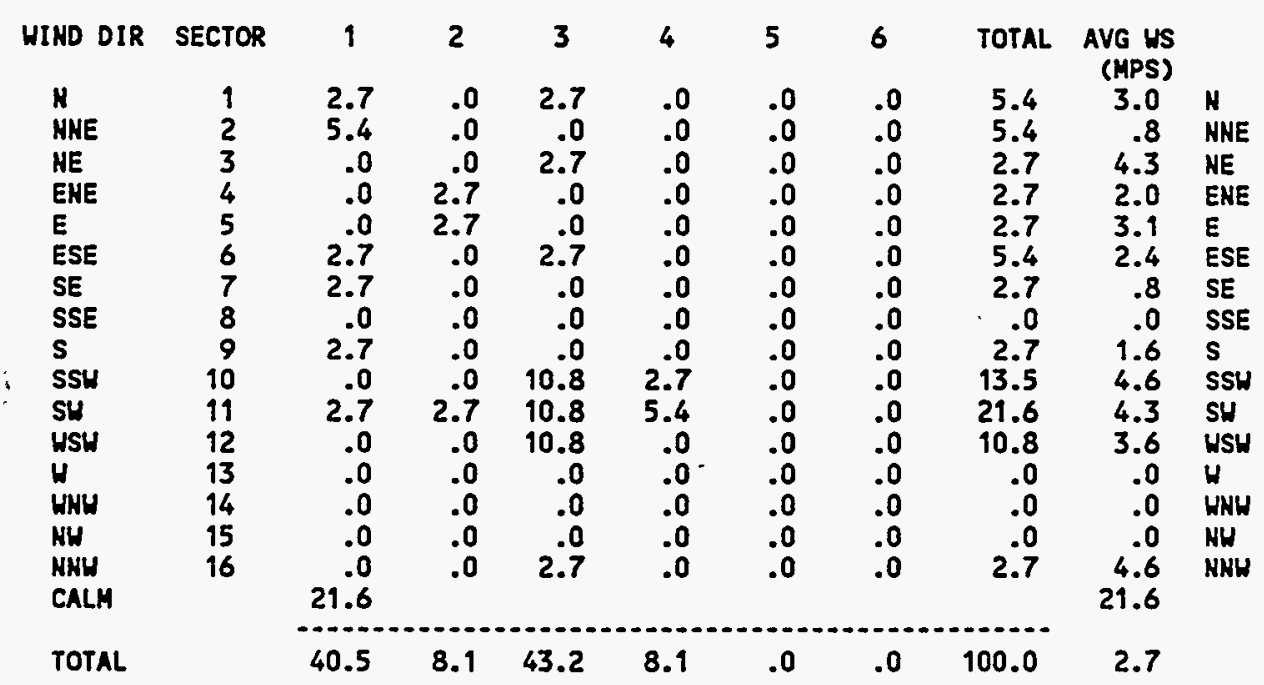

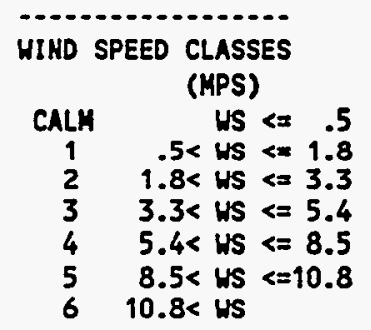




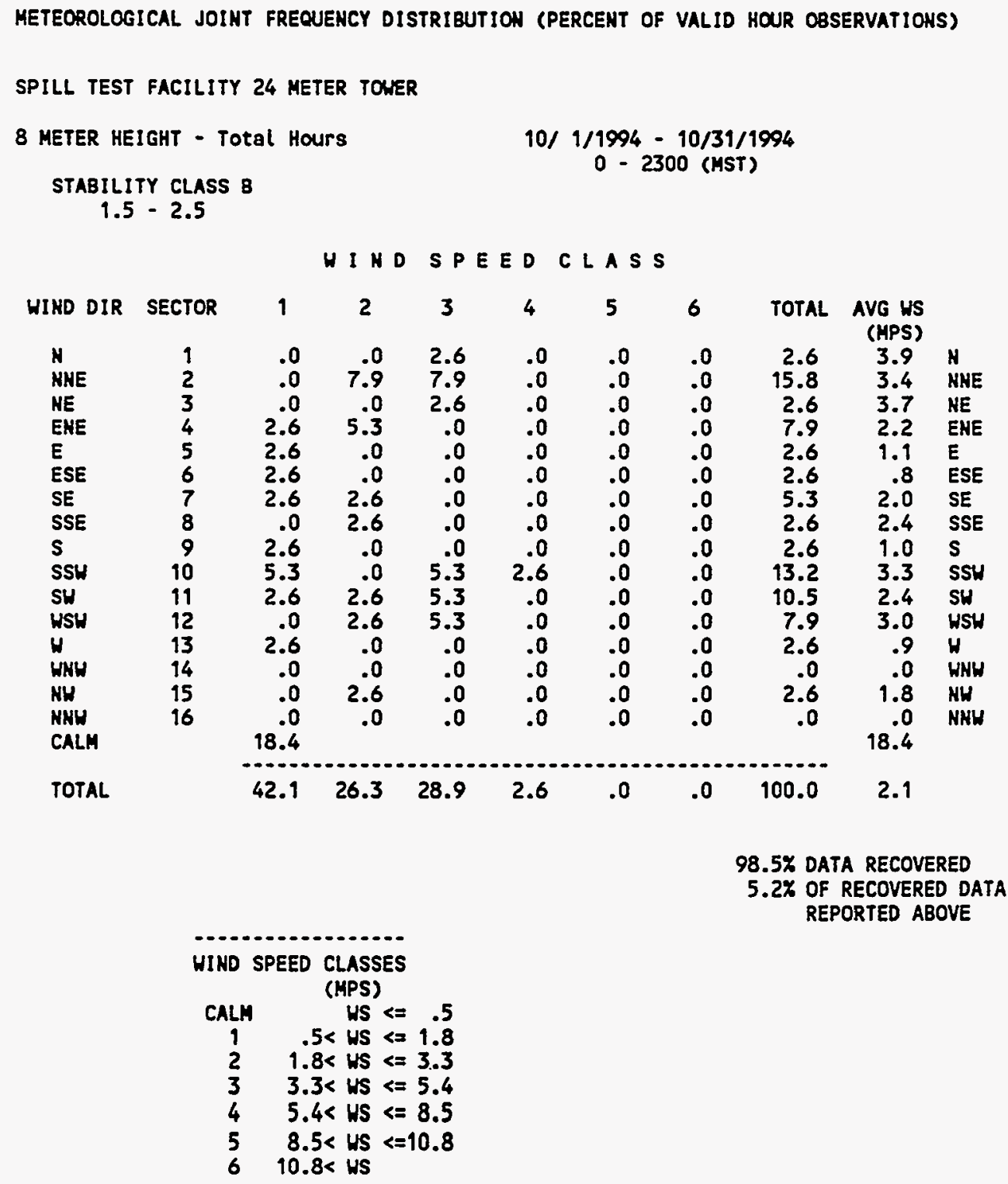


METEOROLOGICAL JOINT FREQUENCY DISTRIBUTION (PERCENT OF VALID HOUR OBSERVATIONS)

SPILL TEST FACILITY 24 METER TONER

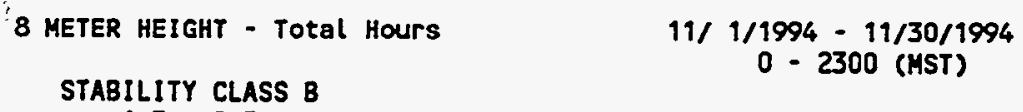

HIND SPEED CLASS

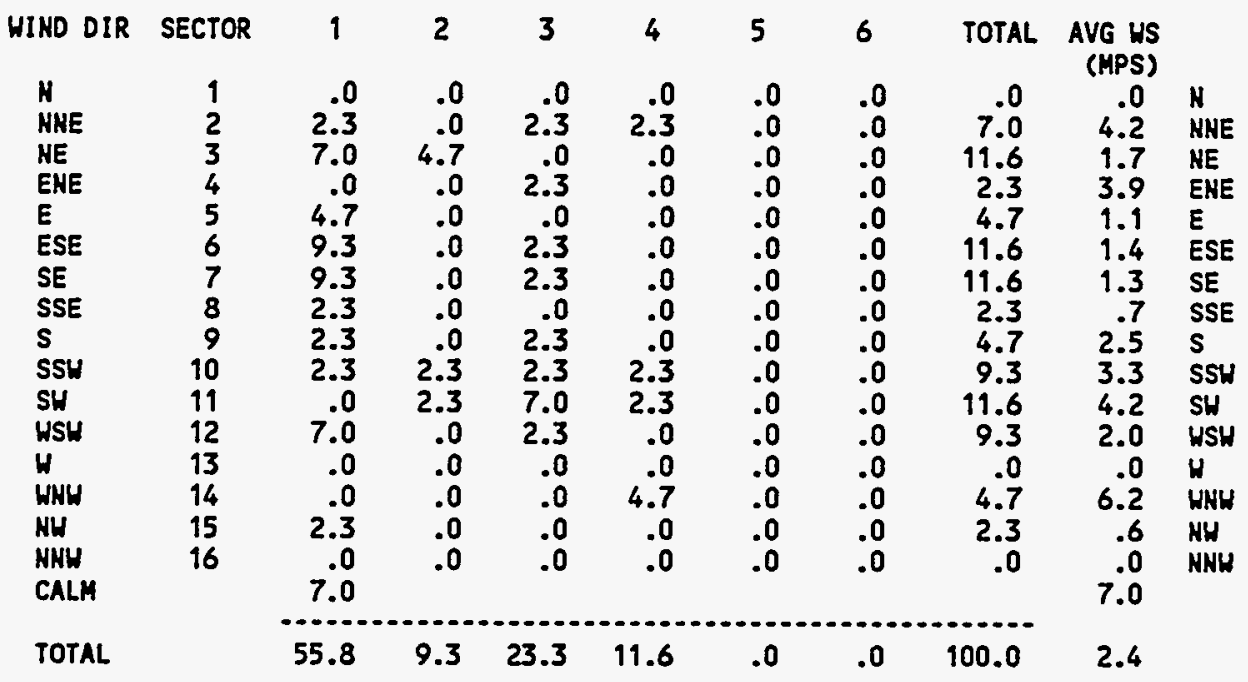

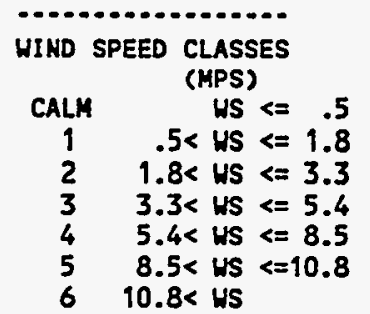


METEOROLOGICAL JOINT FREQUENCY DISTRIBUTION (PERCENT OF VALID HOUR OBSERVATIONS)

SPILL TEST FACILITY 24 METER TONER

8 METER HEIGHT - TOtal HOURS

$12 / 1 / 1994-12 / 31 / 1994$

STABILITY CLASS B

$0-2300$ (MST)

$1.5-2.5$

WINDSPEED CLASS

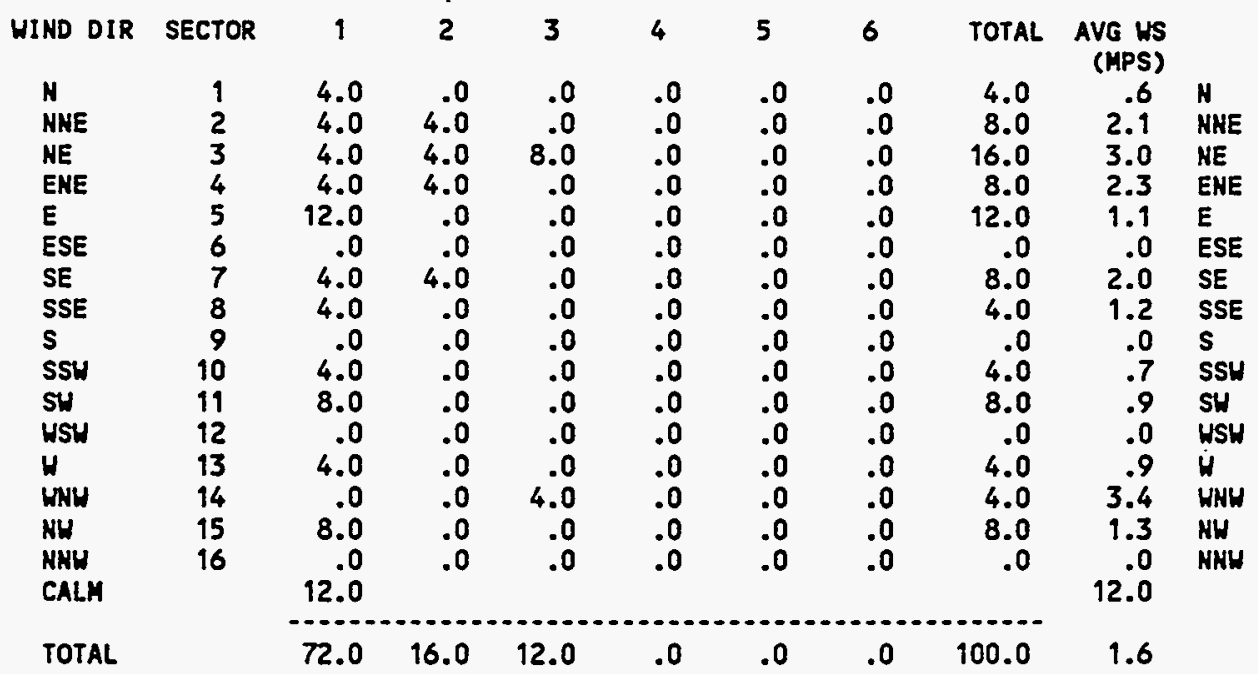

65.1\% DATA RECOVERED

5.2\% OF RECOVERED DATA REPORTED ABOVE

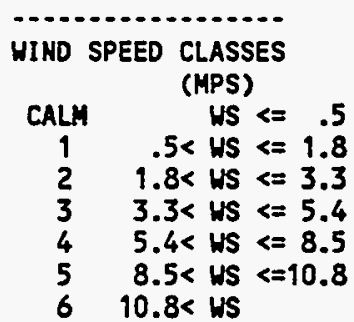


HETEOROLOGICAL JOINT FREQUENCY DISTRIBUTION (PERCENT OF VALID HOUR OBSERVATIONS) SPILL TEST FACILITY 24 METER TOWER

8 HETER HEIGHT - Total Hours

STABILITY CLASS C
$1 / 1 / 1994-1 / 31 / 1994$

$0-2300$ (MST) $2.5 \cdot 3.5$

HIND SPEED CLASS

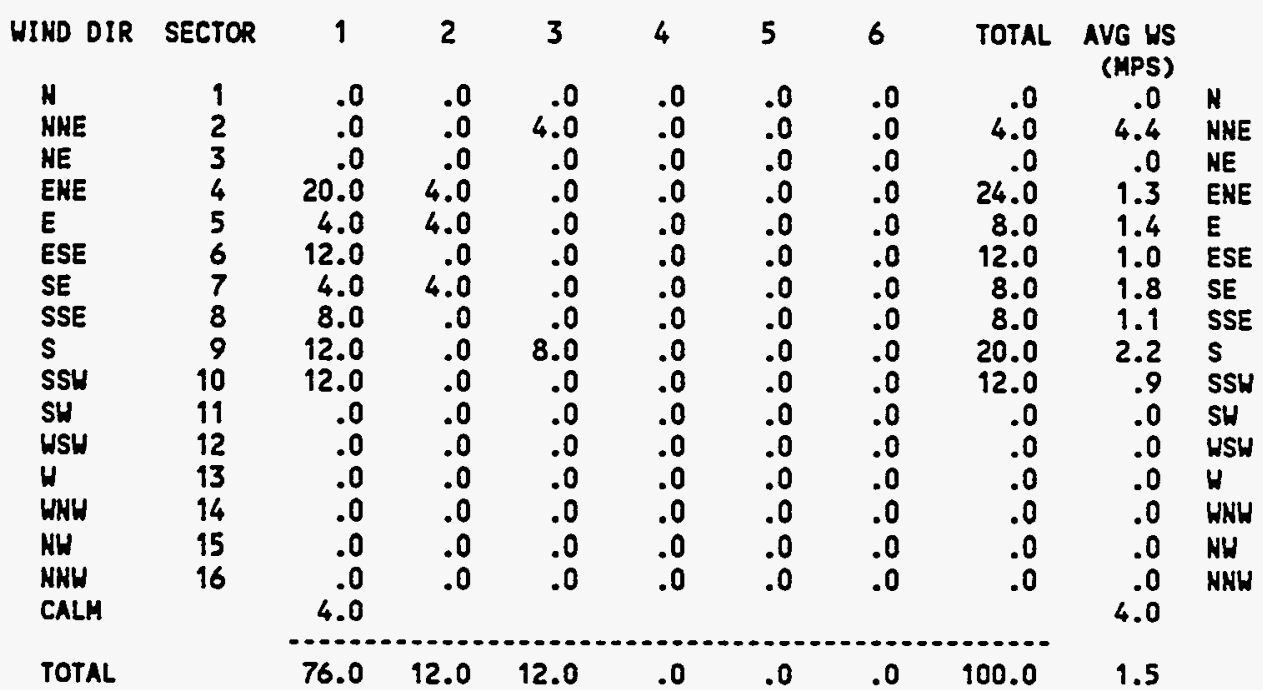

78. O\% DATA RECOVERED

4.3\% OF RECOVERED DATA REPORTED ABOVE

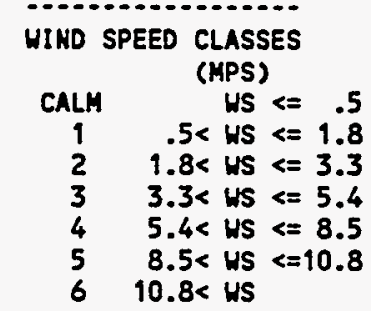


METEOROLOGICAL JOINT FREQUENCY DISTRIBUTION (PERCENT OF VALID HOUR OBSERVATIONS)

SPILL TEST FACILITY 24 METER TOWER

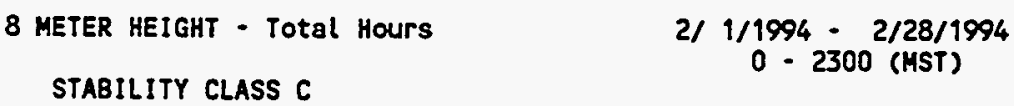

WI ND SPEED CLASS

\begin{tabular}{|c|c|c|c|c|c|c|c|c|c|c|}
\hline HIND DIR & SECTOR & 1 & 2 & 3 & 4 & 5 & 6 & TOTAL & $\begin{array}{l}\text { AVG US } \\
\text { (MPS) }\end{array}$ & \\
\hline N & $\begin{array}{l}1 \\
?\end{array}$ & .0 & .0 & $\begin{array}{r}8.8 \\
11.8\end{array}$ & $\begin{array}{r}0 \\
20\end{array}$ & .0 & .0 & $\begin{array}{r}8.8 \\
14\end{array}$ & $\begin{array}{l}4.6 \\
5.0\end{array}$ & H \\
\hline $\begin{array}{l}\text { NNE } \\
\text { NE }\end{array}$ & 3 & .0 & 5.9 & $\begin{array}{r}11.8 \\
2.9\end{array}$ & $\begin{array}{r}2.9 \\
.0\end{array}$ & .0 & $\begin{array}{l}.0 \\
.0\end{array}$ & $\begin{array}{r}14.7 \\
8.8\end{array}$ & $\begin{array}{l}5.0 \\
3.5\end{array}$ & $\begin{array}{l}\text { HNE } \\
\text { HE }\end{array}$ \\
\hline ENE & 4 & .0 & 5.9 & .0 & .0 & .0 & .0 & 5.9 & 2.2 & ENE \\
\hline E & 5 & 5.9 & .0 & .0 & .0 & .0 & .0 & 5.9 & 1.3 & $E$ \\
\hline $\begin{array}{l}\text { ESE } \\
\text { SE }\end{array}$ & $\begin{array}{l}6 \\
7\end{array}$ & $\begin{array}{r}2.9 \\
.0\end{array}$ & $\begin{array}{r}.0 \\
8.8\end{array}$ & $\begin{array}{l}.0 \\
.0\end{array}$ & $\begin{array}{l}.0 \\
.0\end{array}$ & $\begin{array}{l}.0 \\
.0\end{array}$ & $\begin{array}{l}.0 \\
.0\end{array}$ & $\begin{array}{l}2.9 \\
8.8\end{array}$ & $\begin{array}{l}1.2 \\
2.2\end{array}$ & $\begin{array}{l}\text { ESE } \\
\text { SE }\end{array}$ \\
\hline SSE & 8 & .0 & .0 & .0 & .0 & .0 & .0 & .0 & .0 & SSE \\
\hline s & $\begin{array}{r}9 \\
10\end{array}$ & $\begin{array}{r}.0 \\
11.8\end{array}$ & .0 & 2.9 & .0 & .0 & .0 & 2.9 & 4.4 & $\begin{array}{l}\text { s } \\
\text { ssu }\end{array}$ \\
\hline SH & 11 & 2.9 & .0 & 2.9 & .0 & .0 & .0 & $\begin{array}{l}14.1 \\
5.9\end{array}$ & 2.4 & SH \\
\hline USH & 12 & .0 & .0 & .0 & .0 & .0 & .0 & .0 & .0 & USW \\
\hline 4 & 13 & 0 & .0 & .0 & .0 & .0 & .0 & .0 & .0 & $\mathrm{H}$ \\
\hline WNW & 14 & 2.9 & 2.9 & .0 & 2.9 & .0 & .0 & 8.8 & 2.8 & WNH \\
\hline NH & 15 & .0 & .0 & .0 & .0 & 2.9 & .0 & 2.9 & 8.8 & NW \\
\hline $\begin{array}{l}\text { KNH } \\
\text { CALM }\end{array}$ & 16 & $\begin{array}{r}.0 \\
2.9\end{array}$ & .0 & .0 & .0 & 5.9 & .0 & 5.9 & $\begin{array}{l}8.6 \\
2.9\end{array}$ & NNH \\
\hline TOTAL & & 29.4 & 23.5 & 32.4 & 5.9 & 8.8 & .0 & 100.0 & 3.4 & \\
\hline
\end{tabular}

85.4\% DATA RECOVERED

5.9\% OF RECOVERED DATA REPORTED ABOVE

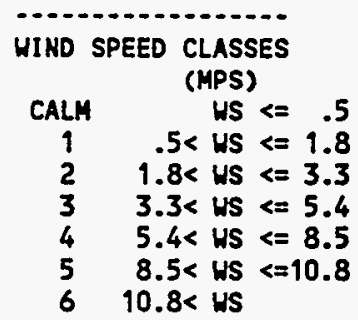


METEOROLOGICAL JOIHT FREQUENCY DISTRIBUTION (PERCENT OF VALID HOUR OBSERVATIONS)

SPILL TEST FACILITY 24 METER TOWER

8 METER HEIGHT - Total Hours

3/ $1 / 1994-3 / 31 / 1994$

STABILITY CLASS C

0 - 2300 (MST)

$2.5-3.5$

HIND SPEEDCLASS

\begin{tabular}{|c|c|c|c|c|c|c|c|c|c|c|}
\hline WIHD DIR & SECTOR & 1 & 2 & 3 & 4 & 5 & 6 & TOTAL & $\begin{array}{l}\text { AVG WS } \\
\text { (MPS) }\end{array}$ & \\
\hline H & 1 & .0 & .0 & .0 & .0 & .0 & .0 & .0 & .0 & N \\
\hline HHE & 2 & .0 & .0 & .0 & 13.0 & .0 & .0 & 13.0 & 6.2 & AHE \\
\hline ME & 3 & .0 & 4.3 & 13.0 & .0 & .0 & .0 & 17.4 & 4.1 & NE \\
\hline ENE & 4 & .0 & .0 & 13.0 & .0 & .0 & .0 & 13.0 & 4.1 & ENE \\
\hline E & 5 & .0 & .0 & 13.0 & .0 & .0 & .0 & 13.0 & 4.1 & $E$ \\
\hline ESE & 6 & .0 & .0 & .0 & .0 & .0 & .0 & .0 & .0 & ESE \\
\hline SE & 7 & 13.0 & .0 & .0 & .0 & .0 & .0 & 13.0 & 1.5 & SE \\
\hline SSE & 8 & .0 & .0 & .0 & .0 & .0 & .0 & .0 & .0 & SSE \\
\hline $\mathbf{s}$ & 9 & .0 & 4.3 & .0 & .0 & .0 & .0 & 4.3 & 2.6 & s \\
\hline SSH & 10 & 4.3 & .0 & .0 & .0 & .0 & .0 & 4.3 & .9 & SSU \\
\hline SH & 11 & .0 & .0 & 17.4 & 4.3 & .0 & .0 & 21.7 & 4.8 & SH \\
\hline WSH & 12 & .0 & .0 & .0 & .0 & .0 & .0 & .0 & .0 & WSH \\
\hline$H$ & 13 & .0 & .0 & .0 & .0 & .0 & .0 & .0 & .0 & $H$ \\
\hline WNW & 14 & .0 & .0 & .0 & .0 & .0 & .0 & .0 & .0 & HWH \\
\hline NH & 15 & .0 & .0 & .0 & .0 & .0 & .0 & .0 & .0 & NH \\
\hline $\begin{array}{l}\text { NNH } \\
\text { CALM }\end{array}$ & 16 & $\begin{array}{l}.0 \\
.0\end{array}$ & .0 & .0 & .0 & .0 & .0 & .0 & .0 & NNH \\
\hline & & & & & & & & & & \\
\hline TOTAL & & 17.4 & 8.7 & 56.5 & 17.4 & .0 & .0 & 100.0 & 4.0 & \\
\hline
\end{tabular}

100.0\% DATA RECOVERED

3.1\% OF RECOVERED DATA REPORTED ABOVE

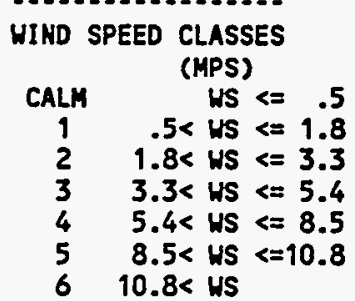


METEOROLOGICAL JOIMT FREQUENCY DISTRIBUTION (PERCENT OF VALID HOUR OBSERVATIONS) SPILL TEST FACILITY 24 METER TOWER

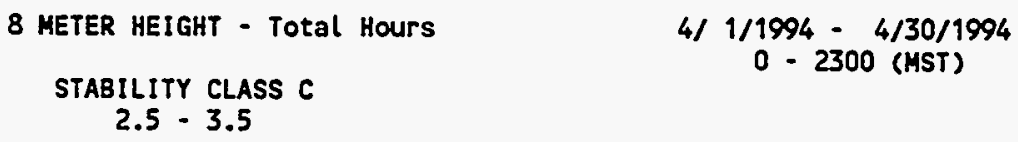

HIND SPEEDCLASS

\begin{tabular}{|c|c|c|c|c|c|c|c|c|c|c|}
\hline HIND DIR & SECTOR & 1 & 2 & 3 & 4 & 5 & 6 & TOTAL & $\begin{array}{l}\text { AVG WS } \\
\text { (MPS) }\end{array}$ & \\
\hline$N$ & 1 & .0 & .0 & .0 & .0 & .0 & .0 & .0 & .0 & $\mathbf{N}$ \\
\hline NHE & 2 & .0 & .0 & 2.1 & .0 & .0 & .0 & 2.1 & 4.6 & HNE \\
\hline NE & 3 & .0 & .0 & 2.1 & .0 & .0 & .0 & 2.1 & 4.3 & NE \\
\hline ENE & 4 & .0 & .0 & .0 & .0 & .0 & .0 & .0 & .0 & ENE \\
\hline E & 5 & 4.2 & .0 & 2.1 & .0 & .0 & .0 & 6.3 & 2.3 & $\mathbf{E}$ \\
\hline ESE & 6 & .0 & .0 & .0 & .0 & .0 & .0 & .0 & .0 & ESE \\
\hline SE & 7 & 4.2 & 4.2 & .0 & .0 & .0 & .0 & 8.3 & 2.1 & $\mathrm{SE}$ \\
\hline SSE & 8 & .0 & .0 & .0 & .0 & .0 & .0 & .0 & .0 & SSE \\
\hline s & 9 & 2.1 & .0 & 4.2 & 2.1 & .0 & .0 & 8.3 & 4.2 & $s$ \\
\hline SSH & 10 & 2.1 & .0 & 14.6 & .0 & .0 & .0 & 16.7 & 3.7 & SSW \\
\hline WSW & $\begin{array}{l}11 \\
12\end{array}$ & $\begin{array}{r}2.1 \\
.0\end{array}$ & $\begin{array}{r}4.2 \\
.0\end{array}$ & $\begin{array}{l}14.6 \\
10.4\end{array}$ & $\begin{array}{r}10.4 \\
4.2\end{array}$ & $\begin{array}{l}.0 \\
.0\end{array}$ & $\begin{array}{l}.0 \\
.0\end{array}$ & $\begin{array}{l}31.3 \\
14.6\end{array}$ & $\begin{array}{l}4.4 \\
4.8\end{array}$ & $\begin{array}{l}\text { SW } \\
\text { WSW }\end{array}$ \\
\hline$H$ & 13 & .0 & 2.1 & 4.2 & 2.1 & .0 & .0 & 8.3 & 4.4 & $H$ \\
\hline WNH & 14 & .0 & .0 & .0 & 2.1 & .0 & .0 & 2.1 & 7.5 & HNH \\
\hline NH & 15 & .0 & .0 & .0 & .0 & .0 & .0 & .0 & .0 & NH \\
\hline NKH & 16 & .0 & .0 & .0 & .0 & .0 & .0 & .0 & .0 & NNH \\
\hline CALM & & 0 & & & & & & & .0 & \\
\hline TOTAL & & 4.6 & 10.4 & 54.2 & 20.8 & .0 & .0 & 100.0 & 4.1 & \\
\hline
\end{tabular}

99.9\% DATA RECOVERED

6.7\% OF RECOVERED DATA REPORTED ABOVE

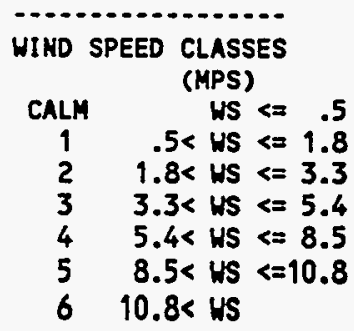


METEOROLOGICAL JOINT FREQUENCY DISTRIBUTIOH (PERCENT OF VALID HOUR OBSERVATIONS)

SPILL TEST FACILITY 24 METER TONER

8 METER HEIGHT - Total Hours

$5 / 1 / 1994-5 / 31 / 1994$

STABILITY CLASS C

0 - 2300 (HST)

$$
2.5 \cdot 3.5
$$

WIND SPEED CLASS

\begin{tabular}{|c|c|c|c|c|c|c|c|c|c|c|}
\hline HIHD DIR & SECTOR & 1 & 2 & 3 & 4 & 5 & 6 & TOTAL & $\begin{array}{l}\text { AVG WS } \\
\text { (MPS) }\end{array}$ & \\
\hline N & 1 & .0 & .0 & 7.7 & .0 & .0 & .0 & 7.7 & 4.5 & $N$ \\
\hline NHE & 2 & .0 & .0 & .0 & .0 & .0 & .0 & .0 & .0 & NHE \\
\hline $\mathrm{HE}$ & 3 & .0 & .0 & .0 & .0 & .0 & .0 & .0 & .0 & NE \\
\hline ENE & 4 & .0 & .0 & .0 & .0 & .0 & .0 & .0 & .0 & ENE \\
\hline E & 5 & .0 & 2.6 & 2.6 & 2.6 & .0 & .0 & 7.7 & 4.3 & $\mathbf{E}$ \\
\hline ESE & 6 & .0 & .0 & .0 & .0 & .0 & .0 & .0 & .0 & ESE \\
\hline SE & 7 & .0 & .0 & 5.1 & .0 & .0 & .0 & 5.1 & 4.9 & SE \\
\hline $\begin{array}{l}\text { SSE } \\
\text { S }\end{array}$ & $\begin{array}{l}8 \\
9\end{array}$ & $\begin{array}{r}.0 \\
2.6\end{array}$ & $\begin{array}{l}.0 \\
0\end{array}$ & $\begin{array}{l}5.1 \\
2.6\end{array}$ & $\begin{array}{r}2.6 \\
0\end{array}$ & .0 & $\begin{array}{r}0 \\
0\end{array}$ & $\begin{array}{l}7.7 \\
5.1\end{array}$ & 4.7 & $\begin{array}{l}\text { SSE } \\
\text { S }\end{array}$ \\
\hline SSH & 10 & 2.6 & 2.6 & 5.1 & .0 & .0 & .0 & 10.3 & 3.0 & SSH \\
\hline SH & 11 & .0 & .0 & 25.6 & 7.7 & .0 & .0 & 33.3 & 5.0 & SH \\
\hline WSH & 12 & 2.6 & .0 & 5.1 & 2.6 & .0 & .0 & 10.3 & 4.1 & USW \\
\hline Hus & 13 & .0 & $\begin{array}{l}.0 \\
0\end{array}$ & 2.6 & 2.6 & .0 & .0 & 5.1 & 5.4 & HWH \\
\hline WNA & $\begin{array}{l}14 \\
15\end{array}$ & .0 & .0 & .0 & .0 & .0 & .0 & $\therefore$ & $\stackrel{.0}{5}$ & NHW \\
\hline NHA & 16 & .0 & $\begin{array}{r}.0 \\
.0\end{array}$ & 2.6 & 2.6 & .0 & $\begin{array}{l}.0 \\
.0\end{array}$ & $\begin{array}{l}2.6 \\
5.1\end{array}$ & $\begin{array}{l}2.5 \\
6.0\end{array}$ & NHW \\
\hline CALM & & 0 & & & & & & & .0 & \\
\hline TOTAL & & 7.7 & 7.7 & 64.1 & 20.5 & .0 & .0 & 100.0 & 4.5 & \\
\hline
\end{tabular}

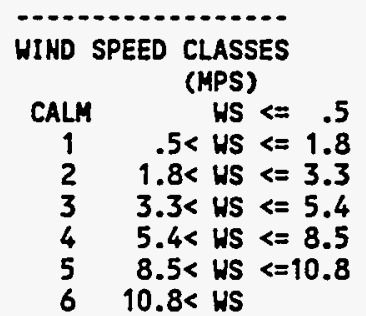


METEOROLOGICAL JOINT FREQUENCY DISTRIBUTION (PERCENT OF VALID HOUR OBSERVATIONS) SPILL TEST FACILITY 24 METER TONER

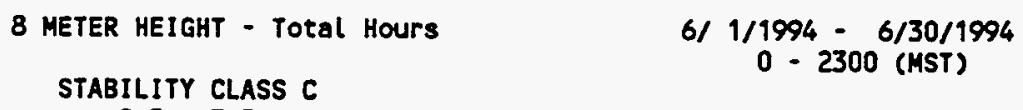

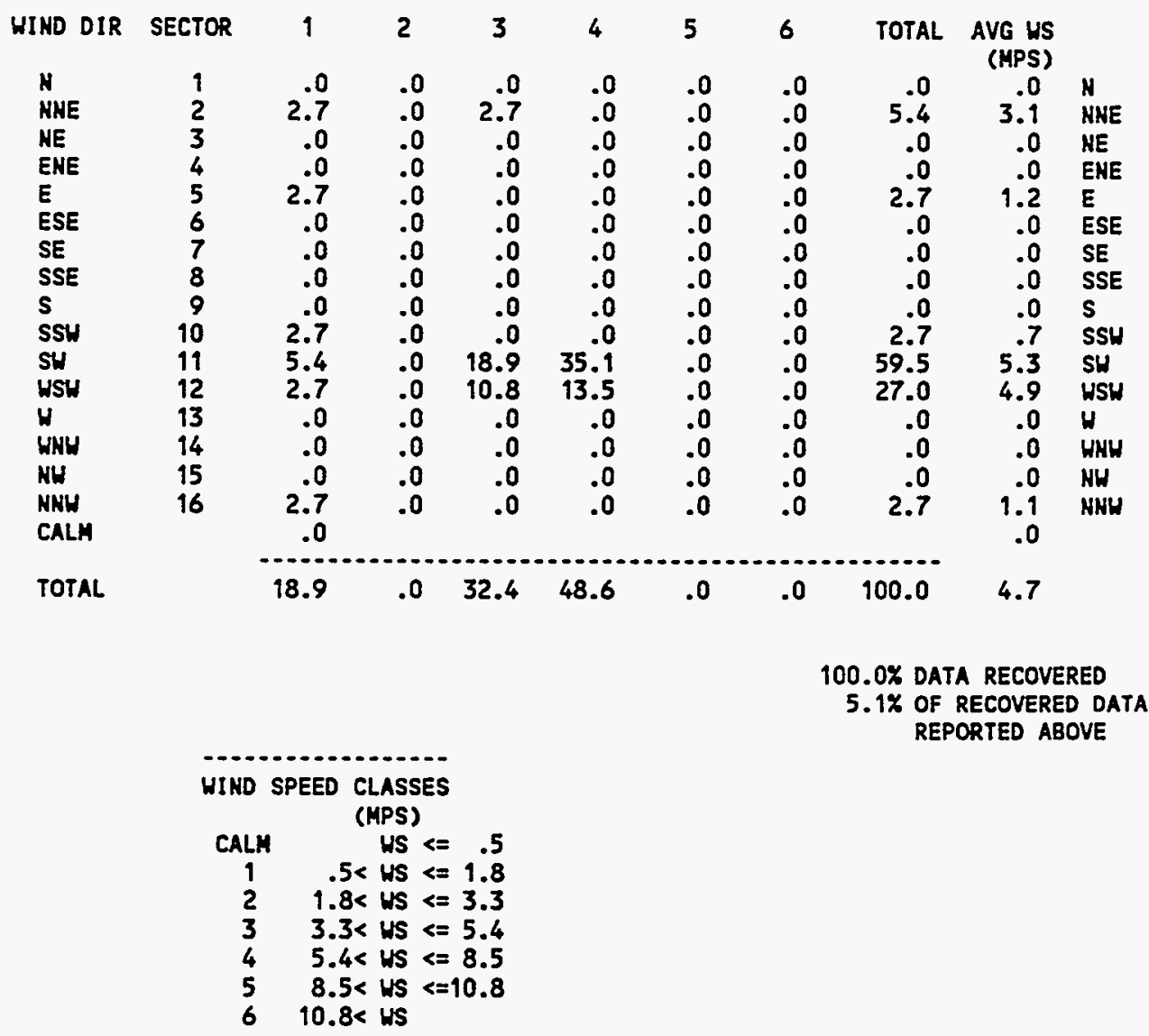


METEOROLOGICAL JOINT FREQUENCY DISTRIBUTION (PERCENT OF VALID HOUR OBSERVATIONS) SPILL TEST FACILITY 24 METER TONER

8 METER HEIGHT - Total HourS

$7 / 1 / 1994-7 / 31 / 1994$

STABILITY CLASS C

0 - 2300 (MST)

$2.5-3.5$

WINDSPEEDCLASS

\begin{tabular}{|c|c|c|c|c|c|c|c|c|c|c|}
\hline HIND DIR & SECTOR & 1 & 2 & 3 & 4 & 5 & 6 & TOTAL & $\begin{array}{l}\text { AVG US } \\
\text { (MPS) }\end{array}$ & \\
\hline $\mathbf{N}$ & 1 & .0 & .0 & .0 & .0 & .0 & .0 & .0 & .0 & N \\
\hline NHE & 2 & .0 & .0 & 2.7 & 2.7 & .0 & .0 & 5.4 & 5.3 & MNE \\
\hline NE & 3 & .0 & .0 & .0 & .0 & .0 & .0 & .0 & .0 & $\mathrm{NE}$ \\
\hline EME & 4 & .0 & .0 & .0 & .0 & .0 & .0 & .0 & .0 & ENE \\
\hline E & 5 & .0 & .0 & .0 & .0 & .0 & .0 & .0 & .0 & \\
\hline $\begin{array}{l}\text { ESE } \\
\text { SE }\end{array}$ & $\begin{array}{l}6 \\
7\end{array}$ & 2.7 & .0 & 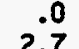 & .0 & .0 & $\begin{array}{l}.0 \\
0\end{array}$ & 2.7 & 1.1 & $\begin{array}{l}\text { ES } \\
\text { SE }\end{array}$ \\
\hline $\begin{array}{l}\text { SE } \\
\text { SSE }\end{array}$ & $\begin{array}{l}7 \\
8\end{array}$ & $\begin{array}{l}.0 \\
.0\end{array}$ & .0 & $\begin{array}{r}2.7 \\
.0\end{array}$ & .0 & .0 & .0 & $\begin{array}{r}2.7 \\
.0\end{array}$ & $\begin{array}{r}4.4 \\
.0\end{array}$ & $\begin{array}{l}\text { SE } \\
\text { SSE }\end{array}$ \\
\hline $\mathbf{s}$ & 9 & 2.7 & .0 & .0 & .0 & .0 & .0 & 2.7 & .9 & s \\
\hline SSH & 10 & 2.7 & 2.7 & 8.1 & 5.4 & .0 & .0 & 18.9 & 4.4 & SSH \\
\hline SW & 11 & .0 & 2.7 & 35.1 & 27.0 & .0 & .0 & 64.9 & 5.4 & ו \\
\hline HSH & 12 & .0 & .0 & .0 & .0 & .0 & .0 & .0 & .0 & WS \\
\hline H & 13 & .0 & .0 & .0 & .0 & .0 & .0 & .0 & .0 & $H$ \\
\hline WNH & 14 & .0 & .0 & .0 & .0 & .0 & .0 & .0 & .0 & WNH \\
\hline $\mathrm{HH}$ & 15 & .0 & .0 & 2.7 & .0 & .0 & .0 & 2.7 & 4.3 & $\mathrm{NH}$ \\
\hline NHW & 16 & .0 & .0 & .0 & .0 & .0 & .0 & .0 & .0 & NHW \\
\hline CALH & & .0 & & & & & & & .0 & \\
\hline TOTAL & & 8. & 5.4 & 51.4 & 35.1 & .0 & .0 & 100.0 & 4.9 & \\
\hline
\end{tabular}

100.0\% DATA RECOVERED

5.0\% OF RECOVERED DATA

REPORTED ABOVE

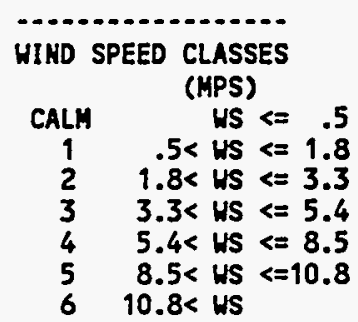


METEOROLOGICAL JOINT FREQUENCY DISTRIBUTION (PERCENT OF VALIO HOUR OBSERVATIONS)

SPILL TEST FACILITY 24 METER TONER

8 METER HEIGHT - Total Hours

$8 / 1 / 1994-8 / 31 / 1994$

STABILITY CLASS C

0 - 2300 (MST)

$2.5-3.5$

WIND SPEED CLASS

\begin{tabular}{|c|c|c|c|c|c|c|c|c|c|c|}
\hline WIKD DIR & SECTOR & 1 & 2 & 3 & 4 & 5 & 6 & TOTAL & $\begin{array}{l}\text { AVG WS } \\
\text { (MPS) }\end{array}$ & \\
\hline H & 1 & .0 & .0 & .0 & .0 & .0 & .0 & .0 & .0 & N \\
\hline AHE & 2 & 2.9 & .0 & .0 & .0 & .0 & .0 & 2.9 & 1.0 & NNE \\
\hline NE & 3 & .0 & .0 & .0 & .0 & .0 & .0 & .0 & .0 & NE \\
\hline ENE & 4 & .0 & .0 & .0 & .0 & .0 & .0 & .0 & .0 & ENE \\
\hline$E$ & 5 & .0 & .0 & .0 & .0 & .0 & .0 & .0 & .0 & $\mathbf{E}$ \\
\hline ESE & 6 & .0 & .0 & 2.9 & 2.9 & .0 & .0 & 5.9 & 4.9 & ESE \\
\hline SE & 7 & .0 & .0 & 17.6 & 5.9 & .0 & .0 & 23.5 & 4.9 & SE \\
\hline SSE & 8 & .0 & .0 & 5.9 & .0 & .0 & .0 & 5.9 & 4.7 & SSE \\
\hline s & 9 & .0 & .0 & .0 & .0 & .0 & .0 & $\because 0$ & .0 & s \\
\hline $\begin{array}{l}\text { SSH } \\
\text { SW }\end{array}$ & $\begin{array}{l}10 \\
11\end{array}$ & $\begin{array}{l}.0 \\
.0\end{array}$ & $\begin{array}{l}.0 \\
.0\end{array}$ & $\begin{array}{r}2.9 \\
17.6\end{array}$ & $\begin{array}{r}.0 \\
20.6\end{array}$ & $\begin{array}{l}.0 \\
.0\end{array}$ & $\begin{array}{l}.0 \\
.0\end{array}$ & $\begin{array}{r}2.9 \\
38.2\end{array}$ & $\begin{array}{l}4.4 \\
5.4\end{array}$ & $\begin{array}{l}\text { SSH } \\
\text { SH }\end{array}$ \\
\hline WSH & 12 & .0 & .0 & 8.8 & 11.8 & .0 & .0 & 20.6 & 5.3 & WSH \\
\hline 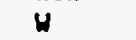 & 13 & .0 & .0 & .0 & .0 & .0 & .0 & .0 & .0 & $H$ \\
\hline WHW & 14 & .0 & .0 & .0 & .0 & .0 & .0 & .0 & .0 & WHW \\
\hline NH & 15 & .0 & .0 & .0 & .0 & .0 & .0 & .0 & .0 & NH \\
\hline NNH & 16 & .0 & .0 & .0 & .0 & .0 & .0 & .0 & .0 & NHW \\
\hline CALM & & 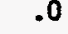 & & & & & & & .0 & \\
\hline TOTAL & & 2.9 & .0 & 55.9 & 41.2 & .0 & .0 & 100.0 & 5.0 & \\
\hline
\end{tabular}

100.0\% DATA RECOVERED

4.6\% OF RECOVERED DATA REPORTED ABOVE

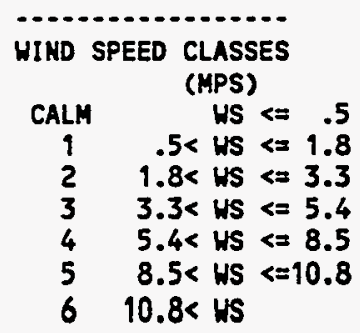


METEOROLOGICAL JOINT FREQUENCY DISTRIBUTION (PERCENT OF VALID HOUR OBSERVATIONS)

SPILL TEST FACILITY 24 METER TOWER
8 METER HEIGHT - TOtal Hours
9/ 1/1994 - 9/30/1994
$0-2300$ (MST)

STABILITY CLASS C

$$
2.5-3.5
$$

HIND SPEEDCLASS

\begin{tabular}{|c|c|c|c|c|c|c|c|c|c|c|}
\hline HIKD DIR & SECTOR & 1 & 2 & 3 & 4 & 5 & 6 & TOTAL & AVG US & \\
\hline $\begin{array}{l}\text { N } \\
\text { HHE }\end{array}$ & $\begin{array}{l}1 \\
2\end{array}$ & $\begin{array}{l}2.3 \\
4.7\end{array}$ & $\begin{array}{l}.0 \\
.0\end{array}$ & $\begin{array}{r}.0 \\
2.3\end{array}$ & $\begin{array}{r}.0 \\
2.3\end{array}$ & $\begin{array}{l}.0 \\
.0\end{array}$ & $\begin{array}{l}.0 \\
.0\end{array}$ & $\begin{array}{l}2.3 \\
9.3\end{array}$ & $\begin{array}{r}.7 \\
3.3\end{array}$ & $\begin{array}{l}\mathbf{N} \\
\text { NWE }\end{array}$ \\
\hline HE & 3 & .0 & .0 & .0 & .0 & .0 & .0 & .0 & .0 & NE \\
\hline ENE & 4 & .0 & .0 & .0 & .0 & .0 & .0 & .0 & .0 & ENE \\
\hline E & 5 & .0 & 2.3 & .0 & .0 & .0 & .0 & 2.3 & $\begin{array}{r}2.8 \\
0\end{array}$ & $\begin{array}{l}\text { E } \\
\text { ESE }\end{array}$ \\
\hline SE & 7 & .0 & .0 & .0 & .0 & .0 & .0 & .0 & .0 & SE \\
\hline SSE & 8 & .0 & .0 & .0 & .0 & .0 & .0 & .0 & .0 & SSE \\
\hline $\begin{array}{l}\text { S } \\
\text { sSU }\end{array}$ & 10 & .0 & .0 & 2.0 & .0 & .0 & .0 & .0 & .0 & $\begin{array}{l}\text { s } \\
\text { ssu }\end{array}$ \\
\hline SH & 11 & 2.3 & .0 & $\begin{array}{r}2.3 \\
18.6\end{array}$ & 25.6 & .0 & .0 & $\begin{array}{r}2.3 \\
46.5\end{array}$ & $\begin{array}{l}4.8 \\
5.2\end{array}$ & SH \\
\hline HSH & 12 & 2.3 & .0 & 7.0 & 2.3 & .0 & .0 & 11.6 & 4.1 & HSH \\
\hline$H$ & 13 & .0 & .0 & .0 & .0 & .0 & .0 & .0 & .0 & $\boldsymbol{H}$ \\
\hline WNW & 14 & .0 & .0 & .0 & .0 & .0 & .0 & .0 & .0 & WNW \\
\hline NH & 15 & .0 & .0 & .0 & .0 & .0 & .0 & .0 & .0 & NH \\
\hline $\begin{array}{l}\text { NNH } \\
\text { CALM }\end{array}$ & 16 & $\begin{array}{r}.0 \\
25.6\end{array}$ & .0 & .0 & .0 & .0 & .0 & .0 & $\begin{array}{r}.0 \\
25.6\end{array}$ & NHH \\
\hline TOTAL & & 37.2 & 2.3 & 30.2 & 30.2 & .0 & .0 & 100.0 & 3.4 & \\
\hline
\end{tabular}

99.2X DATA RECOVERED

6.0\% OF RECOVERED DATA REPORTED ABOVE

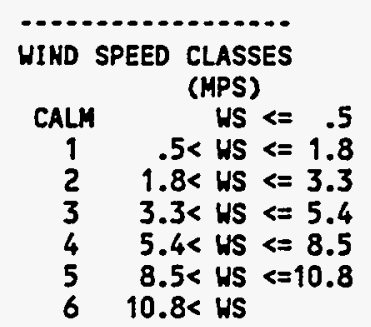


METEOROLOGICAL JOINT FREQUENCY DISTRIBUTION (PERCENT OF VALID HOUR OBSERVATIONS) SPILL TEST FACILITY 24 METER TOWER

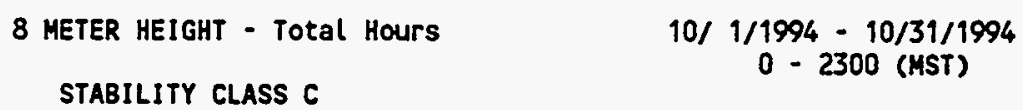

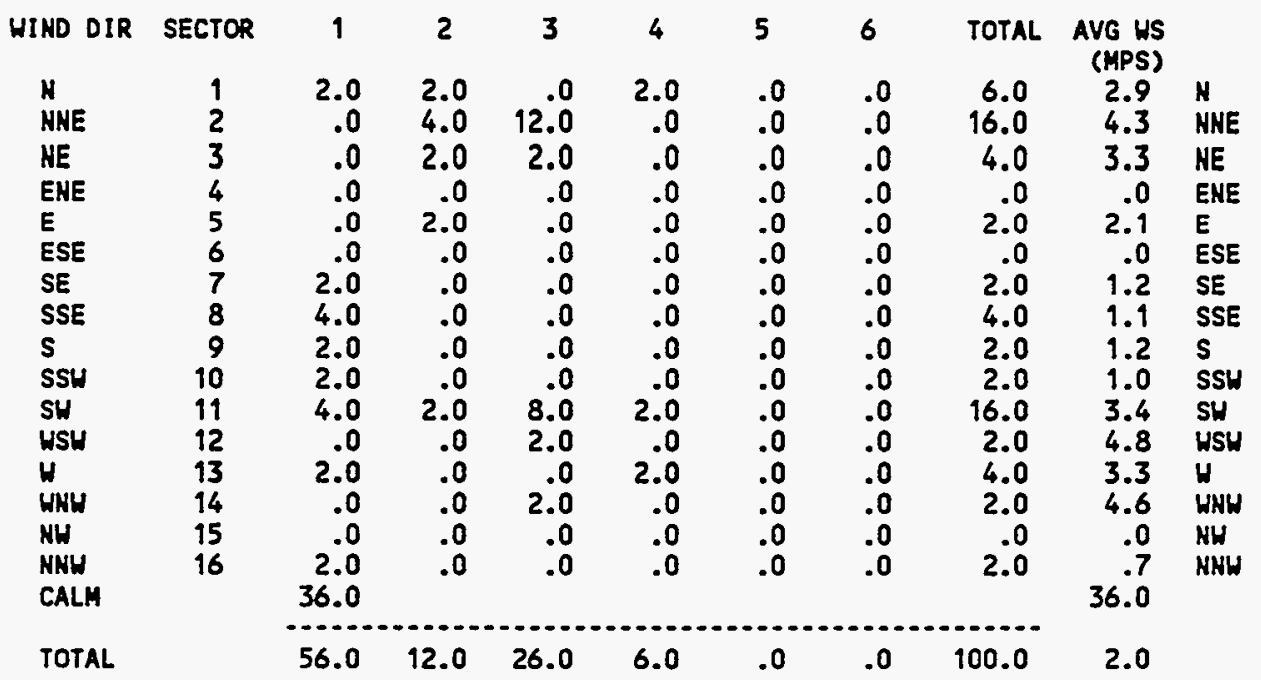
REPORTED ABOVE

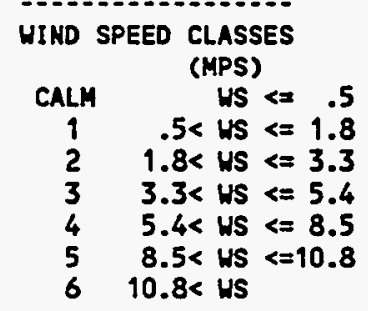


METEOROLOGICAL JOIHT FREQUENCY DISTRIBUTIOH (PERCENT OF VALID HOUR OBSERVATIONS) SPILL TEST FACILITY 24 METER TONER

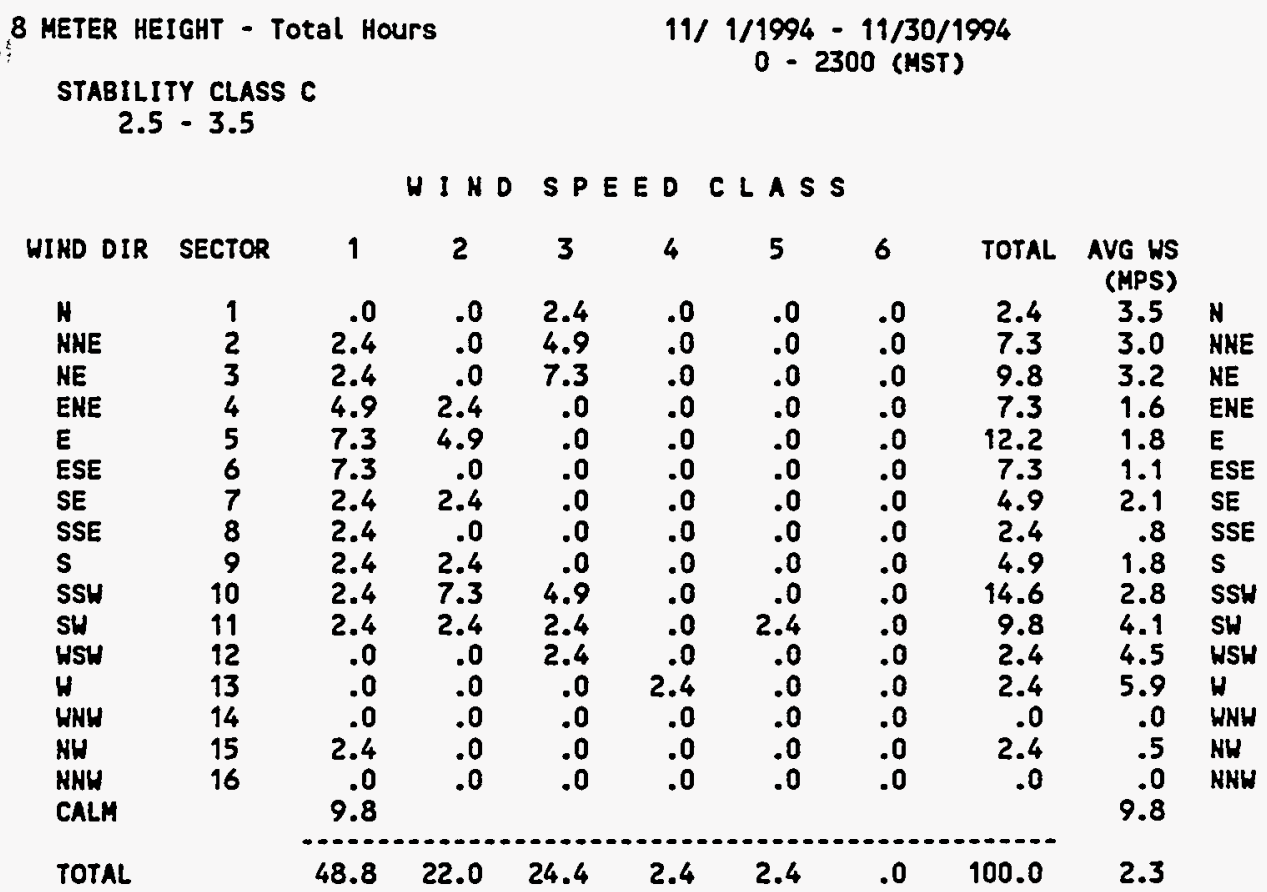

99.7\% DATA RECOVERED

$5.7 \%$ OF RECOVERED DATA REPORTED ABOVE

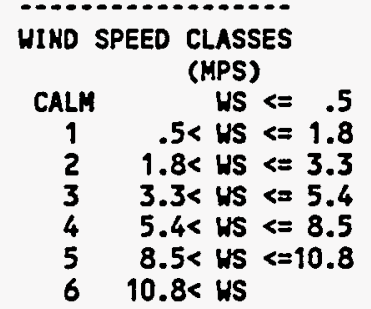


METEOROLOGICAL JOINT FREQUENCY DISTRIBUTION (PERCENT OF VALID HOUR OBSERVATIONS) SPILL TEST FACILITY 24 METER TOWER

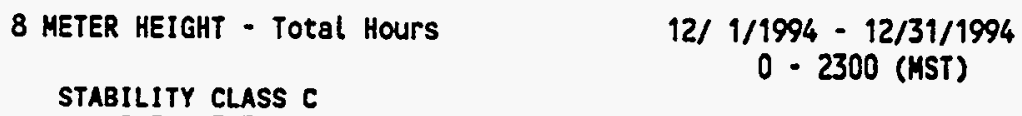

WIHD SPEED CLASS

\begin{tabular}{|c|c|c|c|c|c|c|c|c|c|c|}
\hline HIND DIR & SECTOR & 1 & 2 & 3 & 4 & 5 & 6 & TOTAL & $\begin{array}{c}\text { AVG US } \\
\text { (MPS) }\end{array}$ & \\
\hline N & $\begin{array}{l}1 \\
2\end{array}$ & $\begin{array}{r}6.7 \\
10.0\end{array}$ & .0 & .0 & .0 & .0 & .0 & 6.7 & 1.3 & $\mathrm{~N}$ \\
\hline $\begin{array}{l}\text { MNE } \\
\text { NE }\end{array}$ & $\frac{2}{3}$ & $\begin{array}{r}10.0 \\
.0\end{array}$ & $\begin{array}{r}.0 \\
3.3\end{array}$ & $\begin{array}{r}.0 \\
3.3\end{array}$ & $\begin{array}{l}.0 \\
.0\end{array}$ & .0 & $\begin{array}{l}.0 \\
.0\end{array}$ & $\begin{array}{r}10.0 \\
6.7\end{array}$ & $\begin{array}{r}.9 \\
3.4\end{array}$ & $\begin{array}{l}\text { NNE } \\
\text { NE }\end{array}$ \\
\hline ENE & 4 & 13.3 & .0 & .0 & .0 & .0 & .0 & 13.3 & 1.1 & ENE \\
\hline $\boldsymbol{E}$ & 5 & 6.7 & .0 & .0 & .0 & .0 & .0 & 6.7 & 1.1 & $E$ \\
\hline ESE & 6 & .0 & .0 & .0 & .0 & .0 & .0 & .0 & .0 & ESE \\
\hline SE & 7 & .0 & .0 & .0 & .0 & .0 & .0 & .0 & .0 & SE \\
\hline SSE & 8 & 3.3 & .0 & .0 & .0 & .0 & .0 & 3.3 & .8 & SSE \\
\hline $\mathbf{s}$ & 9 & 3.3 & .0 & .0 & .0 & .0 & .0 & 3.3 & .9 & $\mathbf{s}$ \\
\hline SSW & 10 & 13.3 & 6.7 & .0 & .0 & .0 & .0 & 20.0 & 1.4 & SSH \\
\hline SH & 11 & 10.0 & 3.3 & .0 & .0 & .0 & .0 & 13.3 & 1.7 & SW \\
\hline WSW & 12 & .0 & .0 & .0 & .0 & .0 & .0 & .0 & .0 & USW \\
\hline$H$ & 13 & 3.3 & .0 & .0 & .0 & .0 & .0 & 3.3 & .6 & $\mathbf{H}$ \\
\hline WNH & 14 & .0 & 3.3 & .0 & .0 & .0 & .0 & 3.3 & 1.8 & WHW \\
\hline HH & 15 & 3.3 & .0 & 3.3 & .0 & .0 & .0 & 6.7 & 2.7 & NH \\
\hline $\begin{array}{l}\text { NHW } \\
\text { CALM }\end{array}$ & 16 & $\stackrel{.0}{3.3}$ & .0 & .0 & .0 & .0 & .0 & .0 & $\begin{array}{r}.0 \\
3.3\end{array}$ & NHW \\
\hline & & & & & & & & & & \\
\hline AL. & & 76.7 & 16.7 & 6.7 & 0 & .0 & .0 & 100.0 & 1.4 & \\
\hline
\end{tabular}

65.1\% DATA RECOVERED

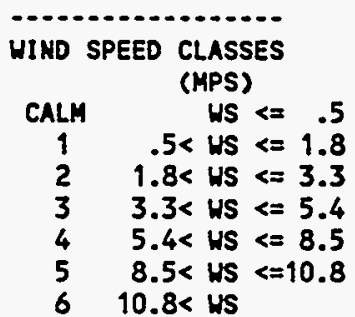


METEOROLOGICAL JOIHT FREQUENCY DISTRIQUTION (PERCENT OF VALID HOUR OBSERVATIONS) SPILL TEST FACILITY 24 METER TONER

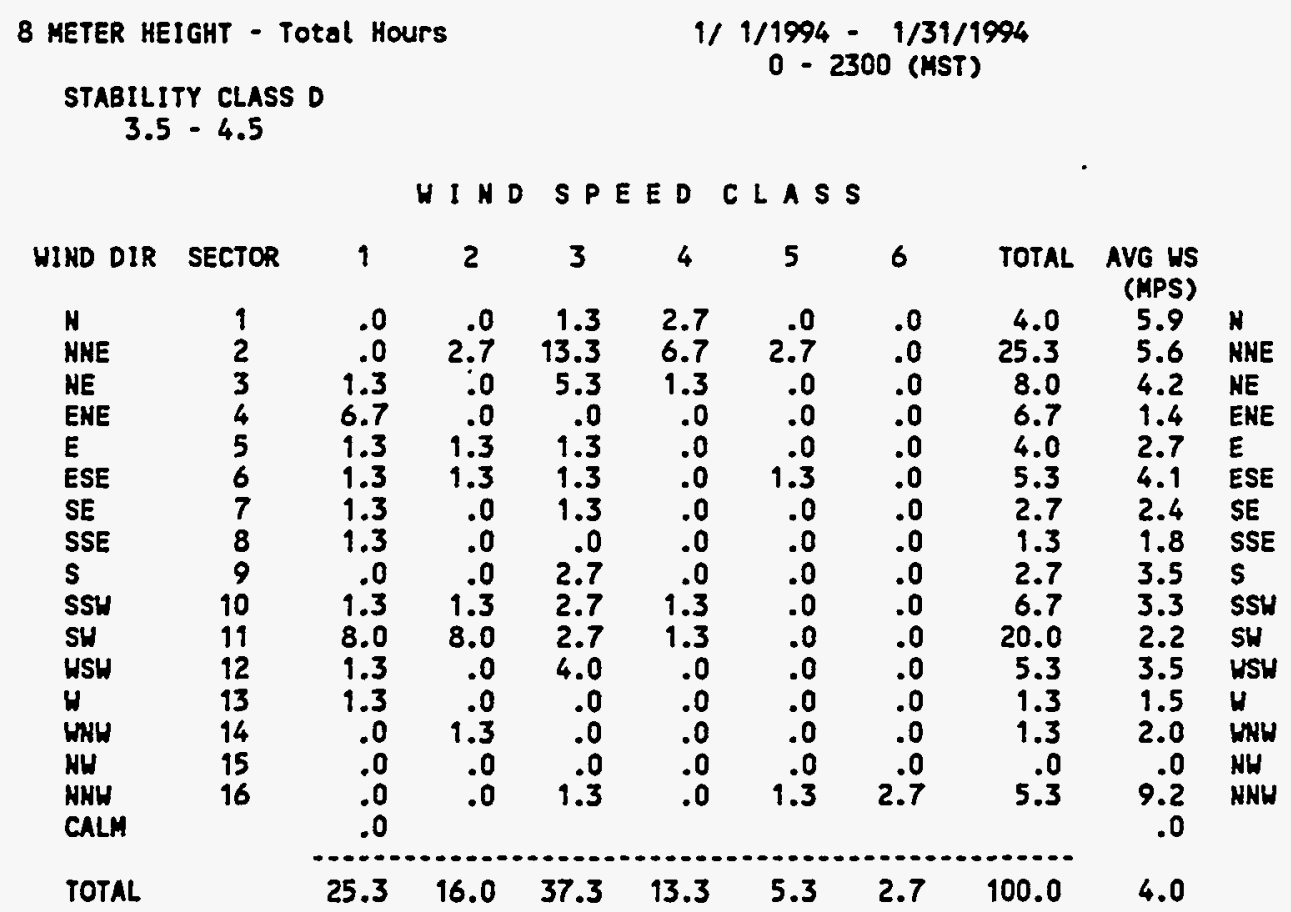

78.0\% DATA RECOVERED

12.9\% OF RECOVERED DATA REPORTED ABOVE

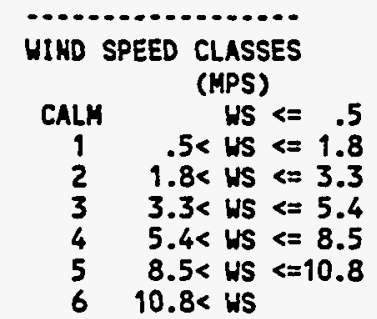


METEOROLOGICAL JOIHT FREQUENCY DISTRIBUTION (PERCENT OF VALID HQUR OBSERVATIONS) SPILL TEST FACILITY 24 METER TONER

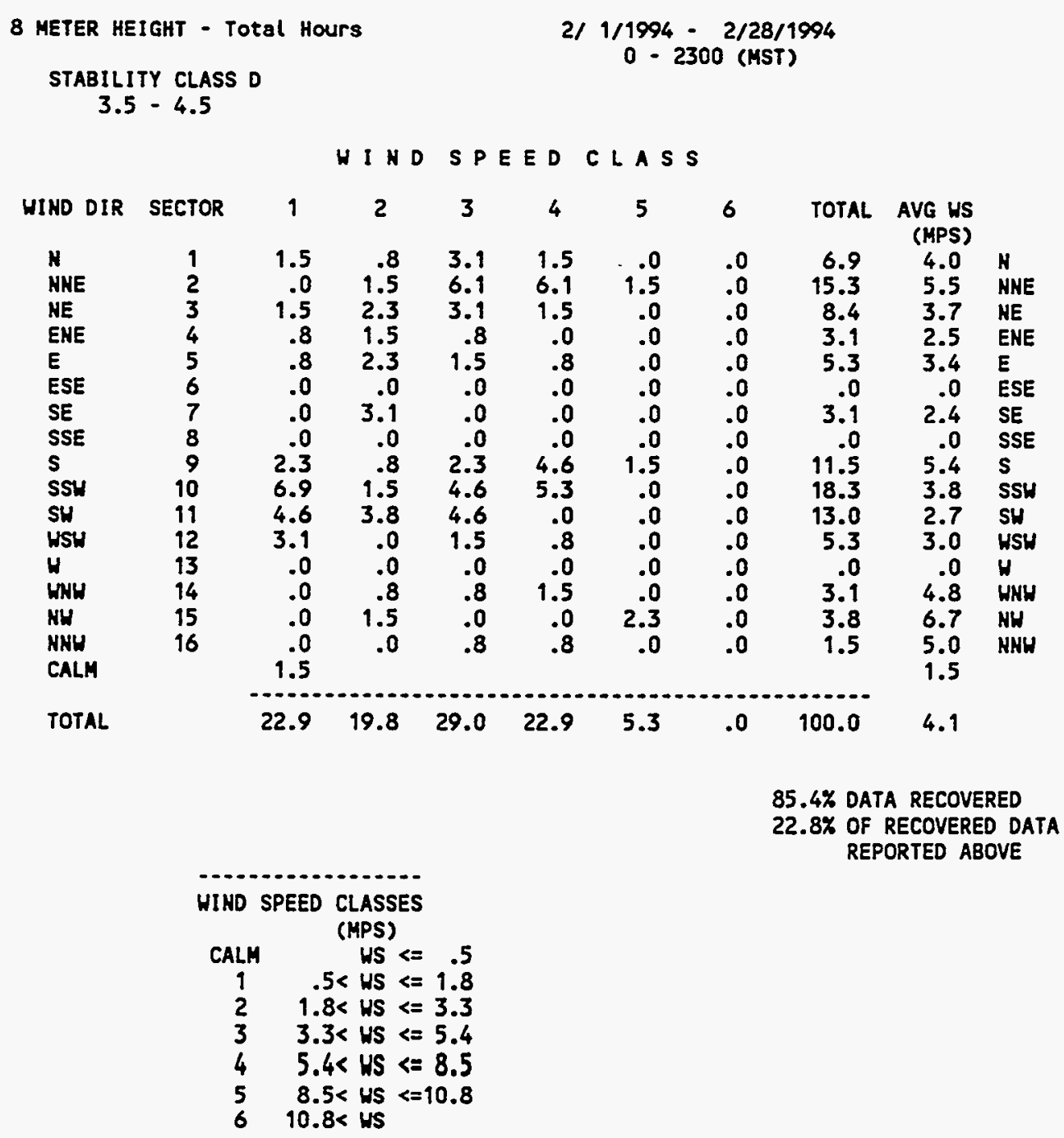


METEOROLOGICAL JOIHT FREQUENCY DISTRIBUTIOH (PERCENT OF VALID HOUR OBSERVATIONS)

SPILL TEST FACILITY 24 METER TONER

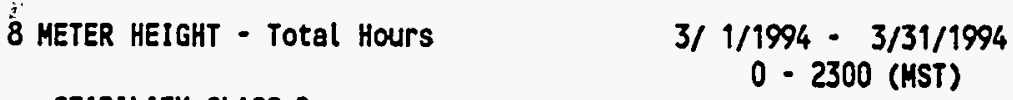

WIHD SPEEDCLASS

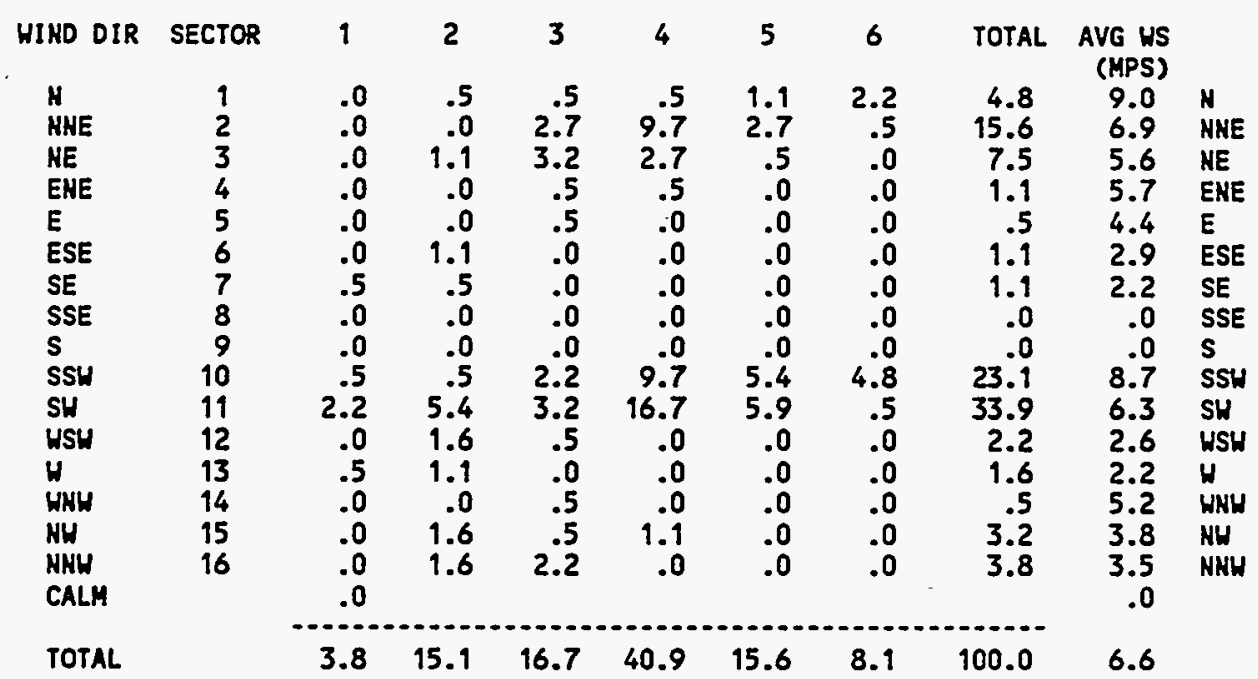

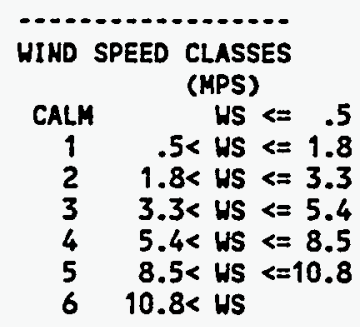


METEOROLOGICAL JOINT FREQUENCY DISTRIBUTION (PERCENT OF VALID HOUR OBSERVATIONS) SPILL TEST FACILITY 24 METER TOWER
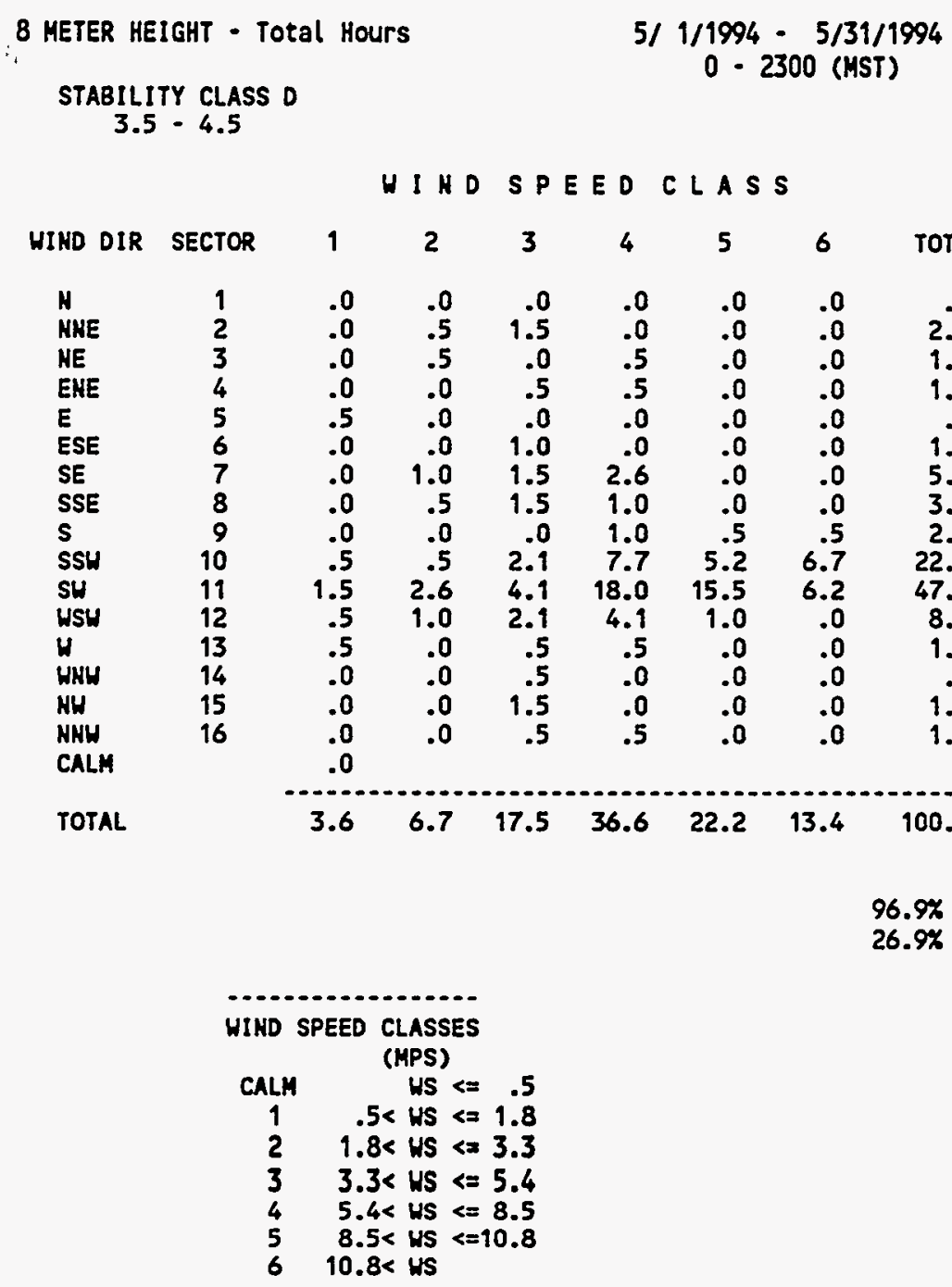
METEOROLOGICAL JOIHT FREQUENCY DISTRIBUTION (PERCENT OF VALID HOUR OBSERVATIONS)

SPILL TEST FACILITY 24 METER TONER

8 METER HEIGHT - Total Hours

6/ $1 / 1994-6 / 30 / 1994$

STABILITY CLASS D

$3.5 \cdot 4.5$

0 - 2300 (MST)

HINDSPEEDCLASS

\begin{tabular}{|c|c|c|c|c|c|c|c|c|c|c|}
\hline WIND DIR & SECTOR & 1 & 2 & 3 & 4 & 5 & 6 & TOTAL & $\begin{array}{l}\text { AVG US } \\
\text { (MPS) }\end{array}$ & \\
\hline $\begin{array}{l}N \\
\text { NHE }\end{array}$ & $\begin{array}{l}1 \\
2\end{array}$ & .0 & .0 & .0 & .0 & .0 & .0 & .0 & $\begin{array}{r}.0 \\
65\end{array}$ & N \\
\hline $\begin{array}{l}\text { NNE } \\
\text { ME }\end{array}$ & $\begin{array}{l}2 \\
3\end{array}$ & .0 & 1.0 & .0 & .0 & $\begin{array}{l}.0 \\
.0\end{array}$ & $\begin{array}{l}.0 \\
.0\end{array}$ & 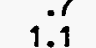 & $\begin{array}{l}6.5 \\
2.4\end{array}$ & $\begin{array}{l}\text { NME } \\
\text { NE }\end{array}$ \\
\hline ENE & 4 & .4 & .0 & .0 & .0 & .0 & .0 & .4 & 1.8 & ENE \\
\hline E & 5 & .0 & .4 & .0 & .0 & .0 & .0 & .4 & 2.1 & E \\
\hline ESE & 6 & .0 & .0 & .0 & .0 & .0 & .0 & .0 & .0 & ESE \\
\hline SE & 7 & .0 & .0 & .4 & .0 & .0 & .0 & .4 & 3.7 & SE \\
\hline SSE & 8 & .0 & .0 & .0 & .0 & .0 & .0 & .0 & .0 & SSE \\
\hline s & 9 & .0 & .0 & .0 & .0 & .0 & .0 & .0 & $\therefore$ & $s$ \\
\hline $\begin{array}{l}\text { SSW } \\
\text { SU }\end{array}$ & $\begin{array}{l}10 \\
19\end{array}$ & $\begin{array}{r}.0 \\
1.8\end{array}$ & $\begin{array}{r}.7 \\
2.6\end{array}$ & $\begin{array}{r}.4 \\
5.5\end{array}$ & $\begin{array}{r}4.4 \\
32.4\end{array}$ & $\begin{array}{r}4.4 \\
18.4\end{array}$ & $\begin{array}{l}1.1 \\
6.3\end{array}$ & $\begin{array}{l}11.0 \\
66.9\end{array}$ & 8.4 & $\begin{array}{l}\text { SSH } \\
\text { SH }\end{array}$ \\
\hline USW & 12 & .7 & .4 & 3.3 & 7.7 & 3.3 & .4 & 15.8 & 6.6 & WSH \\
\hline$H$ & 13 & .0 & .0 & .4 & .0 & .0 & .0 & .4 & 3.4 & $\boldsymbol{H}$ \\
\hline WWW & 14 & .4 & 1.1 & .7 & .0 & .0 & .0 & 2.2 & 3.1 & WNH \\
\hline NH & 15 & .0 & .4 & .4 & .0 & .0 & .0 & .7 & 3.2 & NH \\
\hline $\begin{array}{l}\text { NNH } \\
\text { CALH }\end{array}$ & 16 & $\begin{array}{l}.0 \\
.0\end{array}$ & .0 & .0 & .0 & .0 & .0 & .0 & .0 & NHW \\
\hline TOTAL & & 3.3 & 6.6 & 11.0 & 45.2 & 26.1 & 7.7 & 100.0 & 7.3 & \\
\hline
\end{tabular}

100.0\% DATA RECOVERED

37.8\% OF RECOVERED DATA REPORTED ABOVE

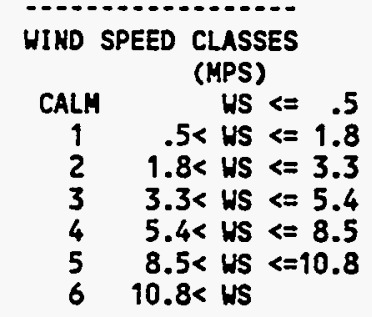


METEOROLOGICAL JOIHT FREQUENCY DISTRIBUTION (PERCENT OF VALID HOUR OBSERVATIONS)

SPILL TEST FACILITY 24 METER TOUER
- 8 METER HEIGHT - Total Hours
$7 / 1 / 1994-7 / 31 / 1994$
$0-2300$ (MST)

STABILITY CLASS D

$3.5 \cdot 4.5$

HI D SPEED CLASS

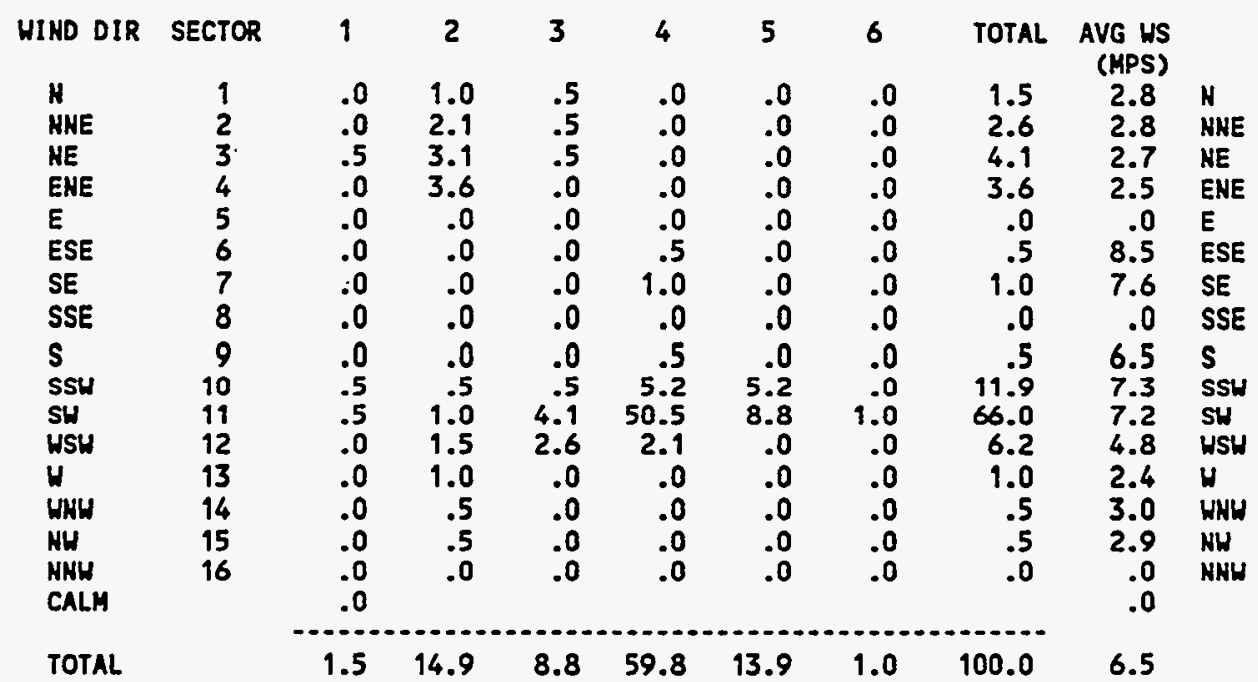

100.0\% DATA RECOVERED

26.1\% OF RECOVERED DATA REPORTED ABOVE

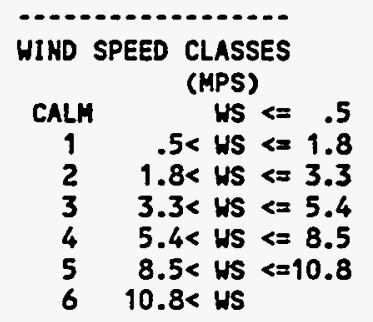


METEOROLOGICAL JOINT FREQUENCY DISTRIBUTION (PERCENT OF VALID HOUR OBSERVATIONS)

SPILL TEST FACILITY 24 METER TONER

8 METER HEIGHT - Total Hours

$8 / 1 / 1994-8 / 31 / 1994$

STABILITY CLASS D

o - 2300 (MST)

$3.5-4.5$

HINDSPEED CLASS

\begin{tabular}{|c|c|c|c|c|c|c|c|c|c|c|}
\hline WIND DIR & SECTOR & 1 & 2 & 3 & 4 & 5 & 6 & TOTAL & $\begin{array}{l}\text { AVG WS } \\
\text { (MPS) }\end{array}$ & \\
\hline H & 1 & .0 & .5 & 1.0 & .0 & .0 & .0 & 1.4 & 3.2 & $N$ \\
\hline NNE & 2 & .0 & 1.9 & 1.4 & .5 & .0 & .0 & 3.8 & 4.0 & NHE \\
\hline NE & 3 & .5 & 1.9 & .0 & .0 & .0 & .0 & 2.4 & 2.4 & NE \\
\hline ENE & 4 & .0 & 1.4 & .0 & .0 & .0 & .0 & 1.4 & 2.5 & ENE \\
\hline E & 5 & .5 & 1.0 & .5 & .0 & .0 & .0 & 1.9 & 2.7 & $E$ \\
\hline ESE & 6 & .0 & .5 & .0 & .0 & .0 & .0 & .5 & 3.3 & ESE \\
\hline $\begin{array}{l}\text { SE } \\
S S E\end{array}$ & $\begin{array}{l}7 \\
8\end{array}$ & $\begin{array}{l}.0 \\
0\end{array}$ & .5 & 1.4 & $\begin{array}{r}1.4 \\
5\end{array}$ & $\begin{array}{l}.0 \\
.0\end{array}$ & .0 & $\begin{array}{r}3.3 \\
.5\end{array}$ & $\begin{array}{l}5.3 \\
5.7\end{array}$ & $\begin{array}{l}\text { SE } \\
\text { SSE }\end{array}$ \\
\hline s & 9 & .0 & .5 & .0 & 2.9 & .0 & .0 & 3.3 & 6.5 & $S$ \\
\hline SSW & 10 & .0 & 1.0 & .5 & 9.0 & $\begin{array}{r}4.8 \\
25\end{array}$ & .0 & 15.2 & 7.4 & SSH \\
\hline $\begin{array}{l}\text { SH } \\
\text { WSW }\end{array}$ & $\begin{array}{l}11 \\
12\end{array}$ & $\begin{array}{l}.0 \\
.5\end{array}$ & $\begin{array}{l}1.9 \\
2.9\end{array}$ & $\begin{array}{l}1.9 \\
1.0\end{array}$ & $\begin{array}{r}33.3 \\
3.3\end{array}$ & $\begin{array}{r}15.2 \\
.0\end{array}$ & $\begin{array}{r}1.9 \\
.0\end{array}$ & $\begin{array}{r}54.3 \\
7.6\end{array}$ & $\begin{array}{l}7.8 \\
4.5\end{array}$ & $\begin{array}{l}\text { SH } \\
\text { WSH }\end{array}$ \\
\hline W & 13 & $\begin{array}{l}.0 \\
.0\end{array}$ & $\begin{array}{l}.5 \\
.5\end{array}$ & $\begin{array}{l}.0 \\
.0\end{array}$ & .0 & .0 & .0 & .5 & $\begin{array}{l}2.9 \\
2.9\end{array}$ & $\begin{array}{l}\text { H } \\
\text { WHW }\end{array}$ \\
\hline NW & 15 & .0 & .5 & .5 & .5 & .0 & .0 & 1.4 & 4.6 & $\mathrm{NH}$ \\
\hline HNH & 16 & .0 & 1.4 & .5 & .0 & .0 & .0 & 1.9 & 3.0 & NNW \\
\hline CALA & & & & & & & & & & \\
\hline TOTAL & & 1.4 & 16.7 & 8.6 & 51.4 & 20.0 & 1.9 & 100.0 & 6.6 & \\
\hline
\end{tabular}

100.0\% DATA RECOVERED

28.2\% OF RECOVERED DATA REPORTED ABOVE

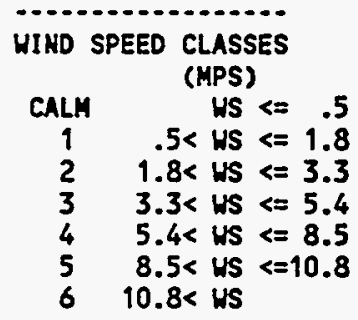


METEOROLOGICAL JOIHT FREQUENCY DISTRIBUTION (PERCENT OF VALID HOUR OBSERVATIONS)

SPILL TEST FACILITY 24 METER TOWER

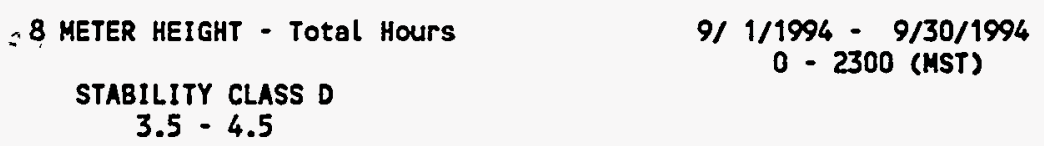

HINDSPEEDCLASS

\begin{tabular}{|c|c|c|c|c|c|c|c|c|c|c|}
\hline WIKD DIR & SECTOR & 1 & 2 & 3 & 4 & 5 & 6 & TOTAL & AVG WS & \\
\hline $\begin{array}{l}\text { N } \\
\text { NME }\end{array}$ & $\begin{array}{l}1 \\
2\end{array}$ & .0 & .5 & $\begin{array}{l}0 \\
0\end{array}$ & $\begin{array}{r}.5 \\
3.7\end{array}$ & .9 & $\begin{array}{l}.0 \\
0\end{array}$ & $\begin{array}{l}1.9 \\
5.1\end{array}$ & $\begin{array}{l}7.1 \\
5.3\end{array}$ & $\begin{array}{l}\text { N } \\
\text { NHE }\end{array}$ \\
\hline NE & 3 & .9 & .5 & .5 & .0 & .0 & .0 & 1.9 & 2.3 & $\mathrm{NE}$ \\
\hline ENE & 4 & .0 & .0 & .0 & .0 & .0 & .0 & .0 & .0 & ENE \\
\hline$E$ & 5 & .0 & .0 & .0 & .0 & .0 & .0 & .0 & .0 & $E$ \\
\hline ESE & 6 & .5 & .0 & .0 & .0 & .0 & .0 & .5 & 1.8 & ESE \\
\hline SE & 7 & .0 & .0 & .0 & .0 & .0 & .0 & .0 & .0 & SE \\
\hline SSE & 8 & .0 & .0 & .0 & .0 & .0 & .0 & .0 & .0 & SSE \\
\hline $\mathbf{s}$ & 9 & .0 & .5 & .5 & .5 & .0 & .0 & 1.4 & 4.5 & S \\
\hline SSW & 10 & 2.3 & 2.3 & .9 & 12.0 & 10.6 & 5.1 & 33.3 & 7.9 & SSH \\
\hline SW & 11 & 1.9 & 3.7 & 2.8 & 14.8 & 5.6 & 1.9 & 30.6 & 6.7 & SH \\
\hline USH & 12 & .0 & .5 & 2.3 & 4.2 & .0 & .0 & 6.9 & .8 & WSW \\
\hline $\boldsymbol{W}$ & 13 & .5 & .5 & .0 & .0 & .0 & .0 & .9 & 1.8 & $\boldsymbol{H}$ \\
\hline WNH & 14 & 1.4 & .5 & .5 & .0 & .0 & .0 & 2.3 & 1.7 & WNW \\
\hline NW & 15 & .0 & .5 & .0 & .5 & .0 & .0 & .9 & 4.1 & NH \\
\hline NHW & 16 & 11.9 & .0 & .5 & .5 & .9 & .0 & 2.8 & $\begin{array}{r}4.7 \\
11.6\end{array}$ & NNH \\
\hline TOTAL & & 20.8 & 9.7 & 7.9 & 36.6 & 18.1 & 6.9 & 100.0 & 5.8 & \\
\hline
\end{tabular}

99.2X DATA RECOVERED 30.3\% OF RECOVERED DATA REPORTED ABOVE

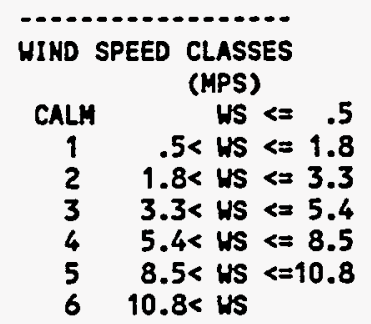




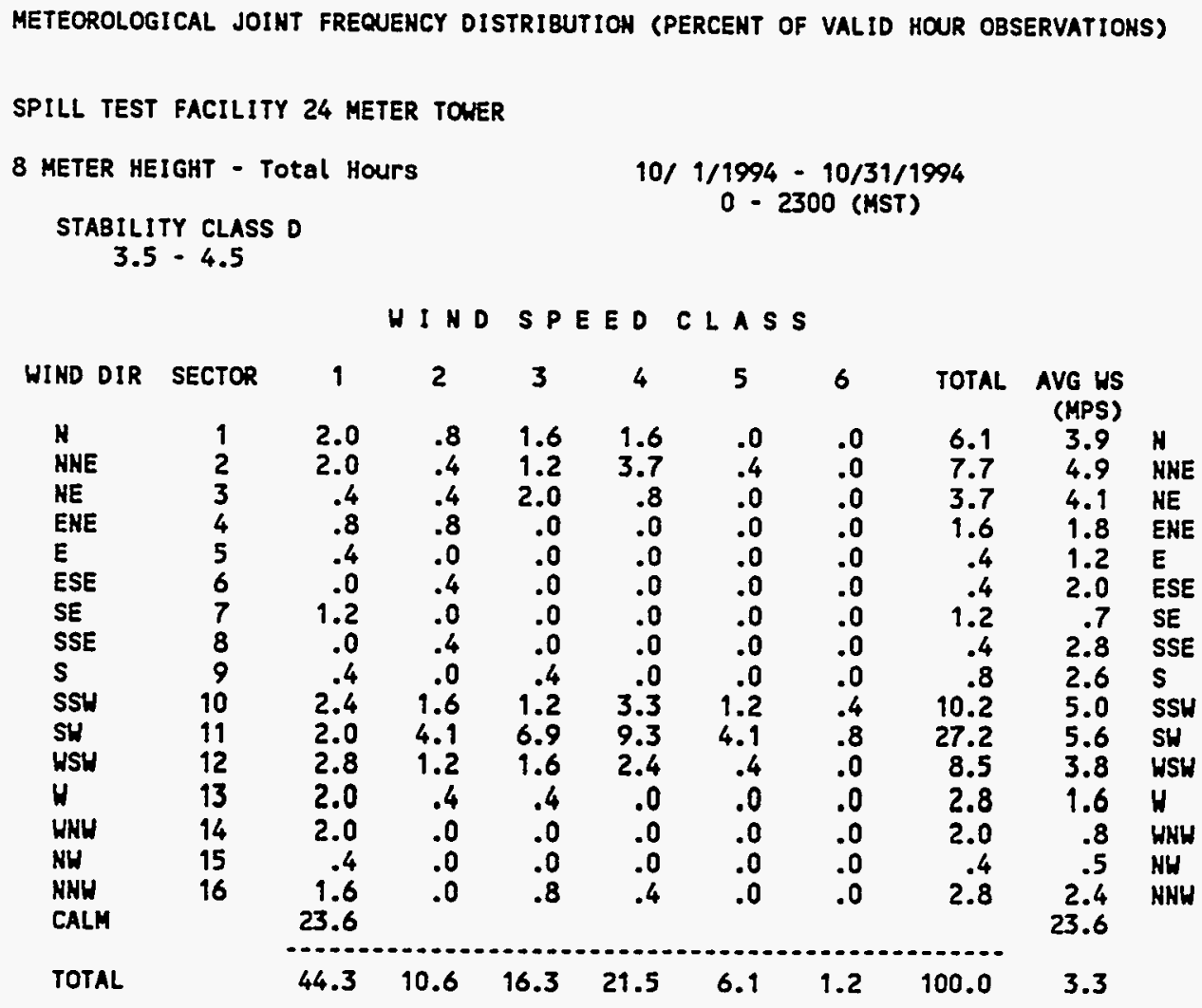

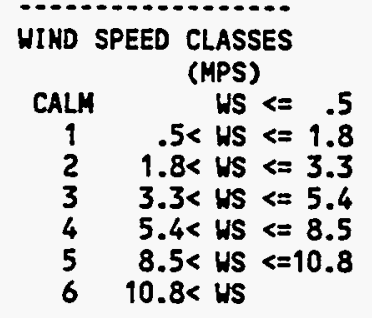




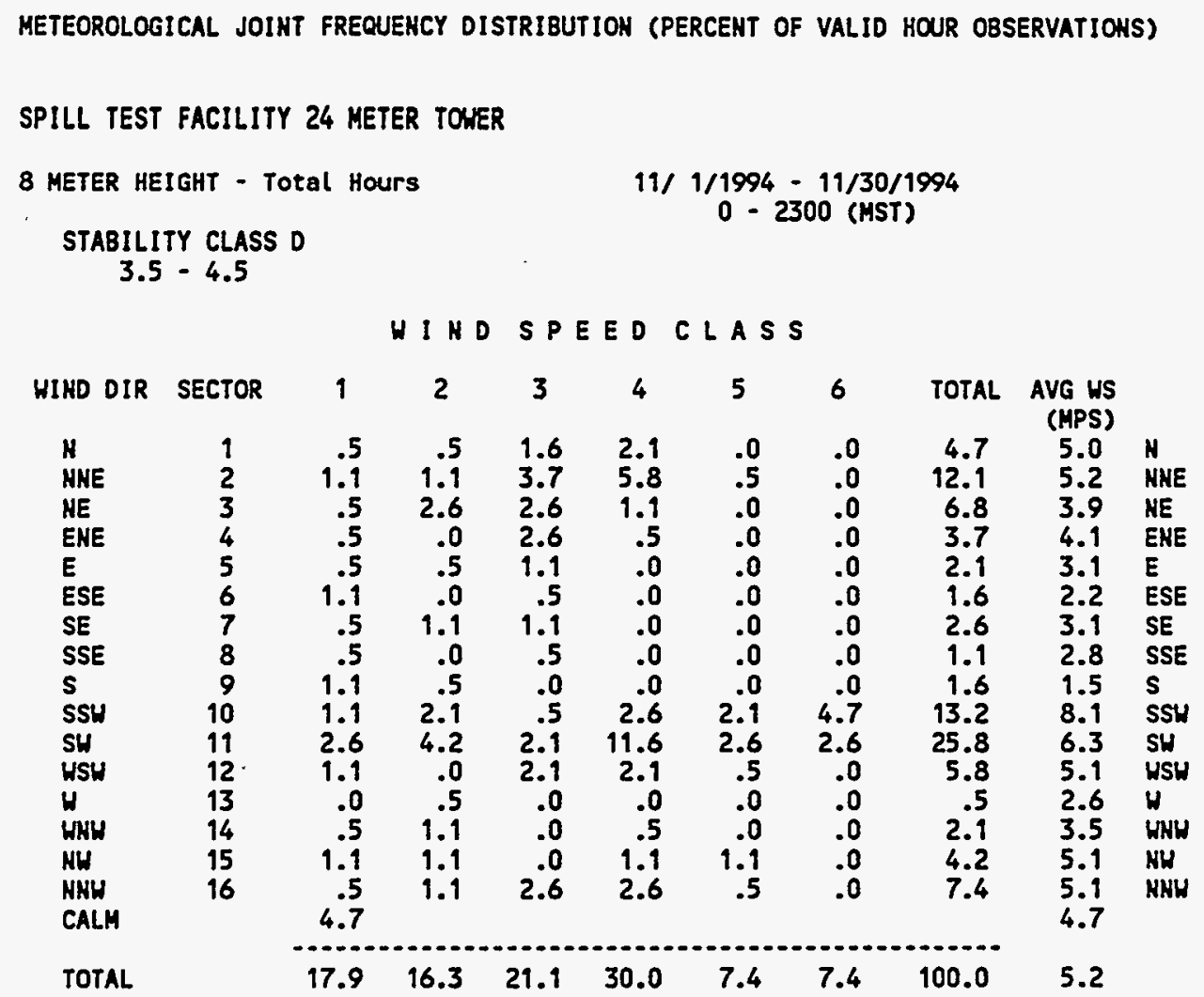
REPORTED ABOVE

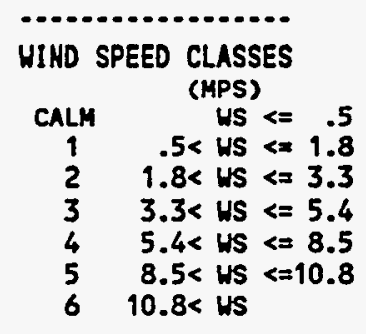


METEOROLOGICAL JOINT FREQUENCY DISTRIBUTION (PERCENT OF VALID HOUR OBSERVATIONS) SPILL TEST FACILITY 24 METER TOWER

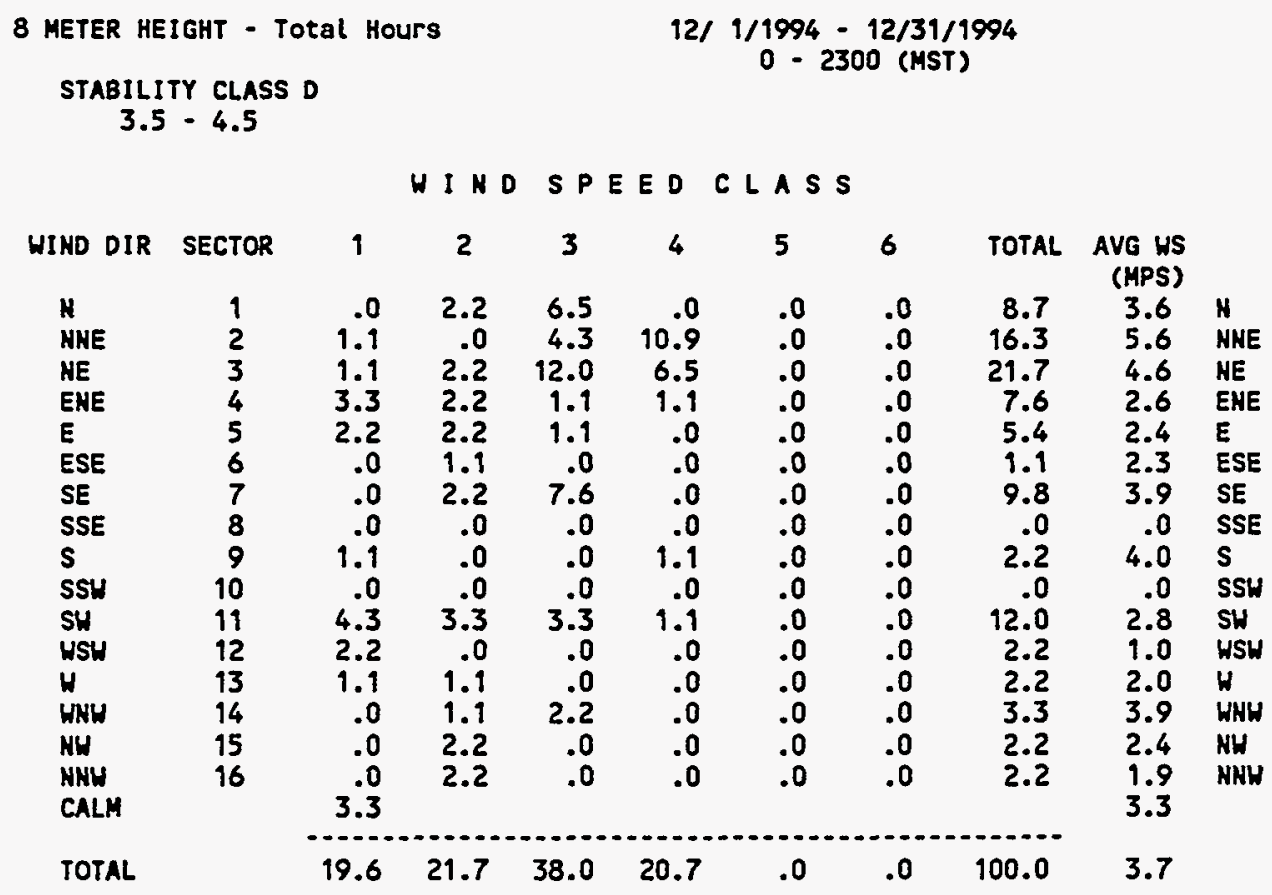

65.1\% DATA RECOVERED

19.0\% OF RECOVERED DATA REPORTED ABOVE

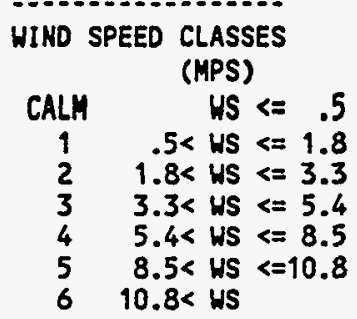


METEOROLOGICAL JOIHT FREQUENCY DISTRIBUTION (PERCENT OF VALID HOUR OBSERVATIONS) SPILL TEST FACILITY 24 METER TONER

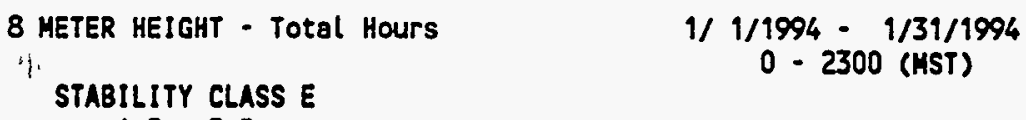

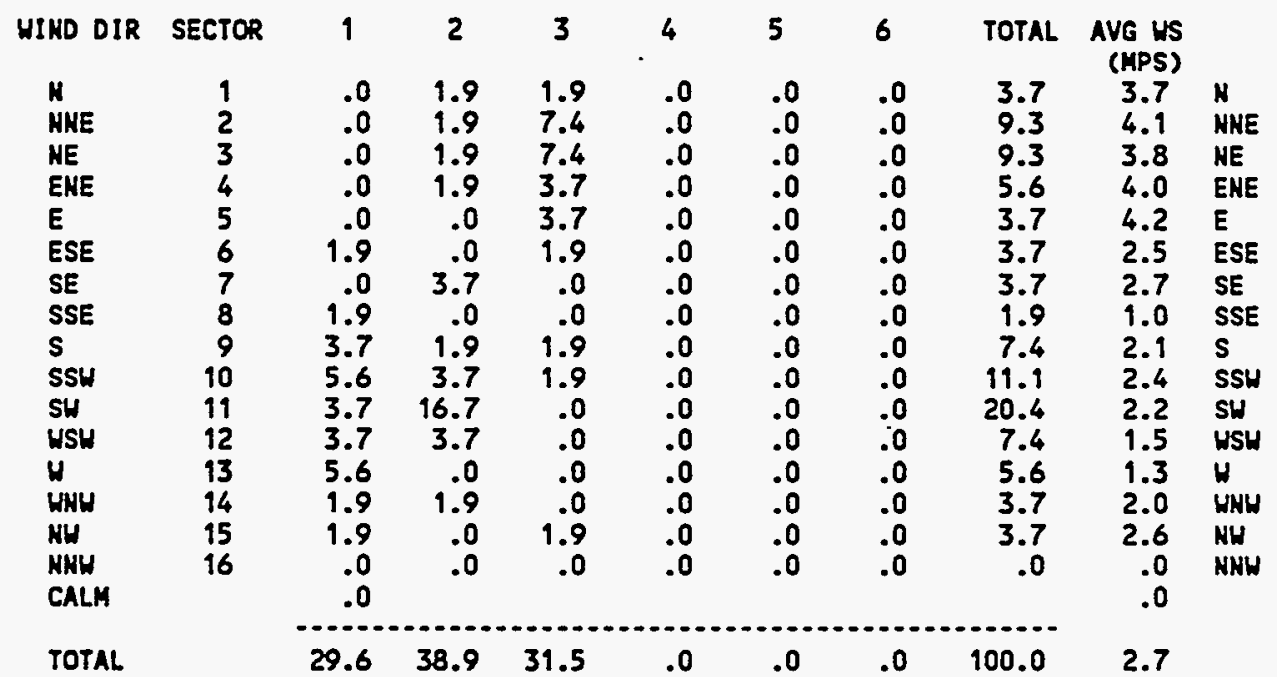

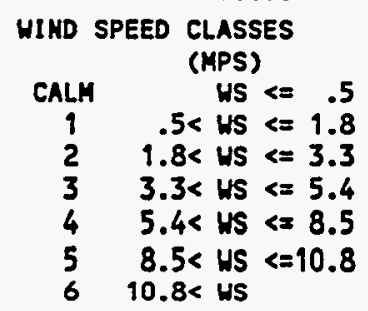


METEOROLOGICAL JOINT FREQUENCY DISTRIBUTION (PERCENT OF VALID HOUR OBSERVATIONS)

SPILL TEST FACILITY 24 METER TOWER

8 METER HEIGHT - Total Hours

2) 1/1994 - 2/28/1994

STABILITY CLASS E

$0-2300$ (MST)

$4.5 \cdot 5.5$

HI HD SPEEDCLASS

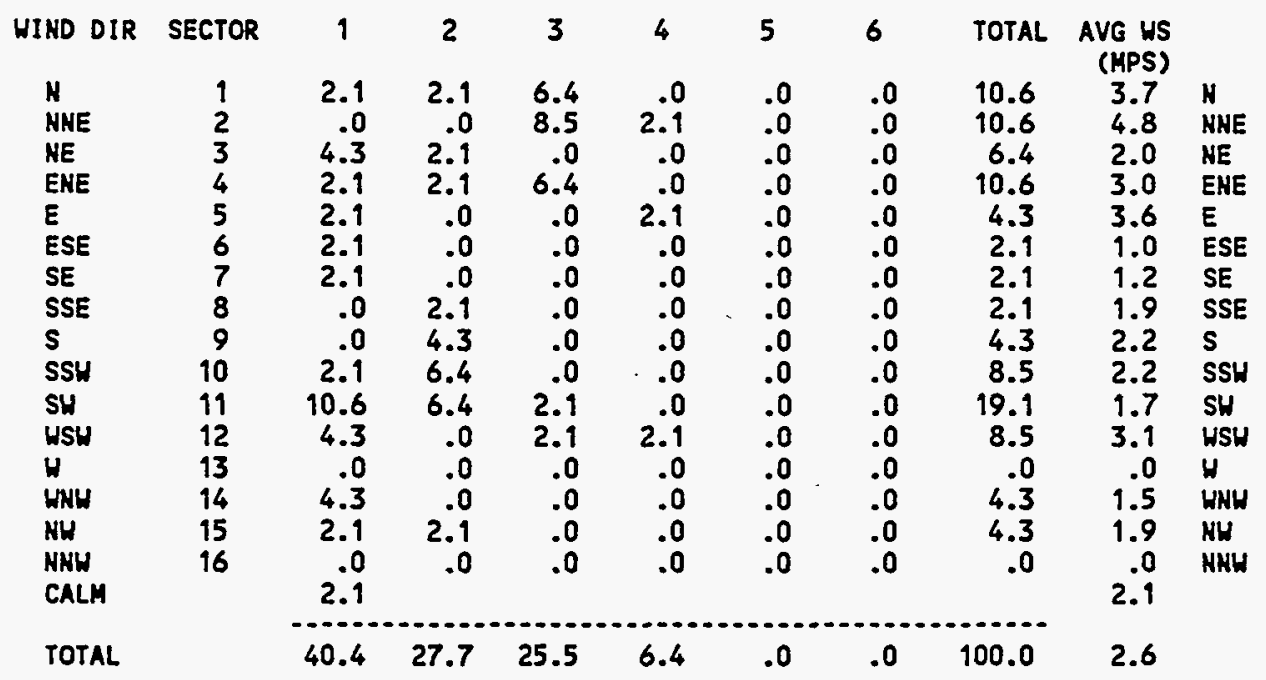

85.4\% DATA RECOVERED

8.2\% OF RECOVERED DATA REPORTED ABOVE

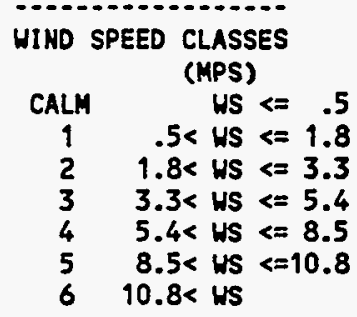


METEOROLOGICAL JOINT FREQUENCY DISTRIBUTION (PERCENT OF VALID HOUR OBSERVATIONS) SPILL TEST FACILITY 24 METER TOWER

8 METER HEIGHT - TOtal HOUrS

3/ $1 / 1994-3 / 31 / 1994$

STABILITY CLASS E

$0 \cdot 2300$ (MST)

$4.5 \cdot 5.5$

HIND SPEED CLASS

\begin{tabular}{|c|c|c|c|c|c|c|c|c|c|c|}
\hline HIHD DIR & SECTOR & 1 & 2 & 3 & 4 & 5 & 6 & TOTAL & $\begin{array}{l}\text { AVG US } \\
\text { (MPS) }\end{array}$ & \\
\hline H & 1 & 1.3 & .0 & 2.5 & .0 & .0 & .0 & 3.8 & 3.5 & N \\
\hline HHE & 2 & .0 & 3.8 & 5.1 & 2.5 & .0 & .0 & 11.4 & 4.0 & NNE \\
\hline NE & 3 & 1.3 & 5.1 & 5.1 & .0 & .0 & .0 & 11.4 & 3.5 & NE \\
\hline ENE & 4 & .0 & 2.5 & .0 & .0 & .0 & .0 & 2.5 & 2.8 & ENE \\
\hline E & 5 & .0 & .0 & .0 & .0 & .0 & .0 & .0 & .0 & $E$ \\
\hline ESE & 6 & .0 & 1.3 & .0 & .0 & .0 & .0 & 1.3 & 2.3 & ESE \\
\hline SE & 7 & .0 & 1.3 & .0 & .0 & .0 & .0 & 1.3 & 3.2 & SE \\
\hline SSE & 8 & .0 & .0 & .0 & .0 & .0 & .0 & .0 & .0 & SSE \\
\hline $\mathbf{S}$ & 9 & 1.3 & 2.5 & 1.3 & .0 & .0 & .0 & 5.1 & 2.5 & $\mathbf{S}$ \\
\hline SSH & 10 & 8.9 & 3.8 & 5.1 & .0 & .0 & .0 & 17.7 & 2.5 & SSW \\
\hline SH & 11 & 2.5 & 7.6 & 8.9 & .0 & .0 & .0 & 19.0 & 3.2 & SH \\
\hline $\begin{array}{l}\text { WSH } \\
\text { H }\end{array}$ & $\begin{array}{l}12 \\
13\end{array}$ & $\begin{array}{r}2.5 \\
.0\end{array}$ & $\begin{array}{l}3.8 \\
2.5\end{array}$ & $\begin{array}{r}2.5 \\
.0\end{array}$ & .0 & $\begin{array}{l}.0 \\
.0\end{array}$ & $\begin{array}{l}.0 \\
.0\end{array}$ & $\begin{array}{l}8.9 \\
2.5\end{array}$ & 2.5 & $\begin{array}{l}\text { WSH } \\
\text { W }\end{array}$ \\
\hline WHH & 14 & 2.5 & 1.3 & .0 & .0 & .0 & .0 & 3.8 & 1.7 & WNH \\
\hline WW & 15 & .0 & 2.5 & 1.3 & .0 & .0 & .0 & 3.8 & 3.0 & NW \\
\hline $\begin{array}{l}\text { NNH } \\
\text { CALM }\end{array}$ & 16 & $\begin{array}{l}2.5 \\
1.3\end{array}$ & 2.5 & 1.3 & .0 & .0 & .0 & 6.3 & $\begin{array}{l}2.7 \\
1.3\end{array}$ & NNW \\
\hline & & & & & & & & & & \\
\hline TOTAL & & 24.1 & 40.5 & 32.9 & 2.5 & .0 & .0 & 100.0 & 2.9 & \\
\hline
\end{tabular}

100.0\% DATA RECOVERED

10.6\% OF RECOVERED DATA REPORTED ABOVE

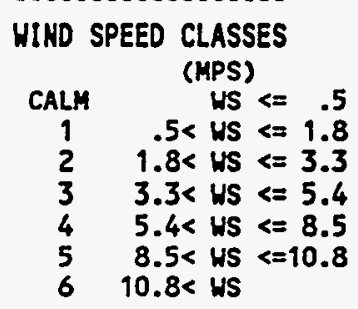


METEOROLOGICAL JOINT FREQUENCY OISTRIBUTION (PERCENT OF VALID HOUR OBSERVATIONS) SPILL TEST FACILITY 24 METER TONER

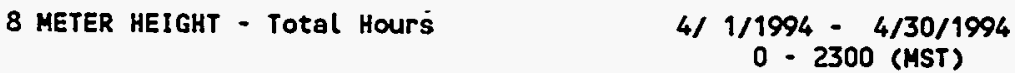

HINDSPEEDCLASS

\begin{tabular}{|c|c|c|c|c|c|c|c|c|c|c|}
\hline HIND DIR & SECTOR & 1 & 2 & 3 & 4 & 5 & 6 & TOTAL & $\begin{array}{r}\text { AVG US } \\
\text { (MPS) }\end{array}$ & \\
\hline N & 1 & .0 & .0 & .0 & .0 & .0 & .0 & .0 & .0 & H \\
\hline NNE & 2 & .0 & 1.6 & 1.6 & .0 & .0 & .0 & 3.3 & 3.9 & HAE \\
\hline NE & 3 & 1.6 & .0 & 4.9 & .0 & .0 & .0 & 6.6 & 3.5 & NE \\
\hline ENE & 4 & .0 & 1.6 & 1.6 & .0 & .0 & .0 & 3.3 & 3.3 & ENE \\
\hline$E$ & 5 & 1.6 & .0 & 1.6 & .0 & .0 & .0 & 3.3 & 2.8 & $E$ \\
\hline ESE & 6 & 3.3 & 1.6 & .0 & .0 & .0 & .0 & 4.9 & 1.8 & ESE \\
\hline SE & 7 & 1.6 & 1.6 & .0 & .0 & .0 & .0 & 3.3 & 2.0 & SE \\
\hline SSE & 8 & 3.3 & .0 & .0 & .0 & .0 & .0 & 3.3 & 1.5 & SSE \\
\hline s & 9 & 4.9 & 3.3 & .0 & .0 & .0 & .0 & 8.2 & 1.9 & $\mathbf{s}$ \\
\hline SSW & 10 & 4.9 & 6.6 & 1.6 & .0 & .0 & .0 & 13.1 & 2.3 & SSW \\
\hline SH & 11 & 3.3 & 8.2 & 6.6 & 4.9 & .0 & .0 & 23.0 & 3.5 & su \\
\hline WSW & 12 & 3.3 & 4.9 & 4.9 & .0 & .0 & .0 & 13.1 & 2.6 & WSW \\
\hline H & 13 & 1.6 & 1.6 & .0 & .0 & .0 & .0 & 3.3 & 2.3 & $H$ \\
\hline WWH & 14 & 1.6 & 1.6 & .0 & .0 & .0 & .0 & 3.3 & 9.6 & WWW \\
\hline NH & 15 & .0 & 1.6 & .0 & .0 & .0 & .0 & 1.6 & 2.8 & NH \\
\hline NNH & 16 & .0 & 3.3 & 1.6 & .0 & .0 & .0 & 4.9 & 3.1 & NNH \\
\hline $\mathrm{LH}$ & & & & & & & & & & \\
\hline TAL & & 32.8 & 37.7 & 24.6 & 4.9 & .0 & .0 & 100.0 & 2.7 & \\
\hline
\end{tabular}
REPORTED ABOVE

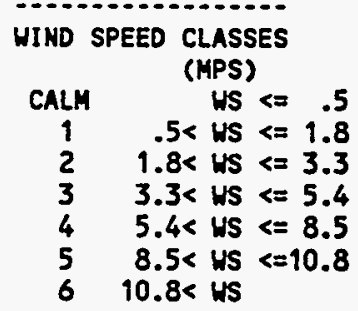




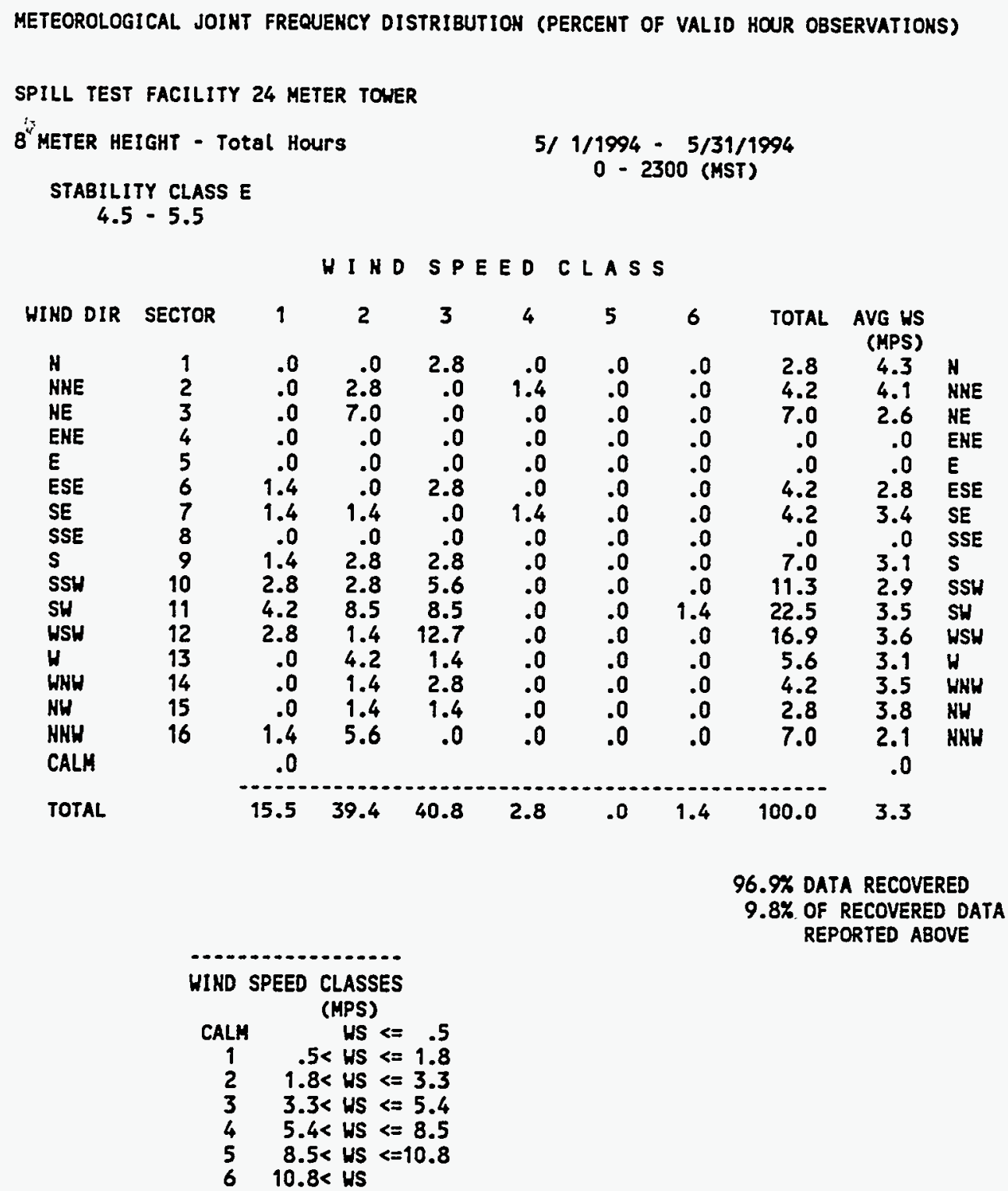


METEOROLOGICAL JOINT FREQUENCY DISTRIBUTION (PERCENT OF VALID HOUR OBSERVATIONS) SPILL TEST FACILITY 24 METER TOWER

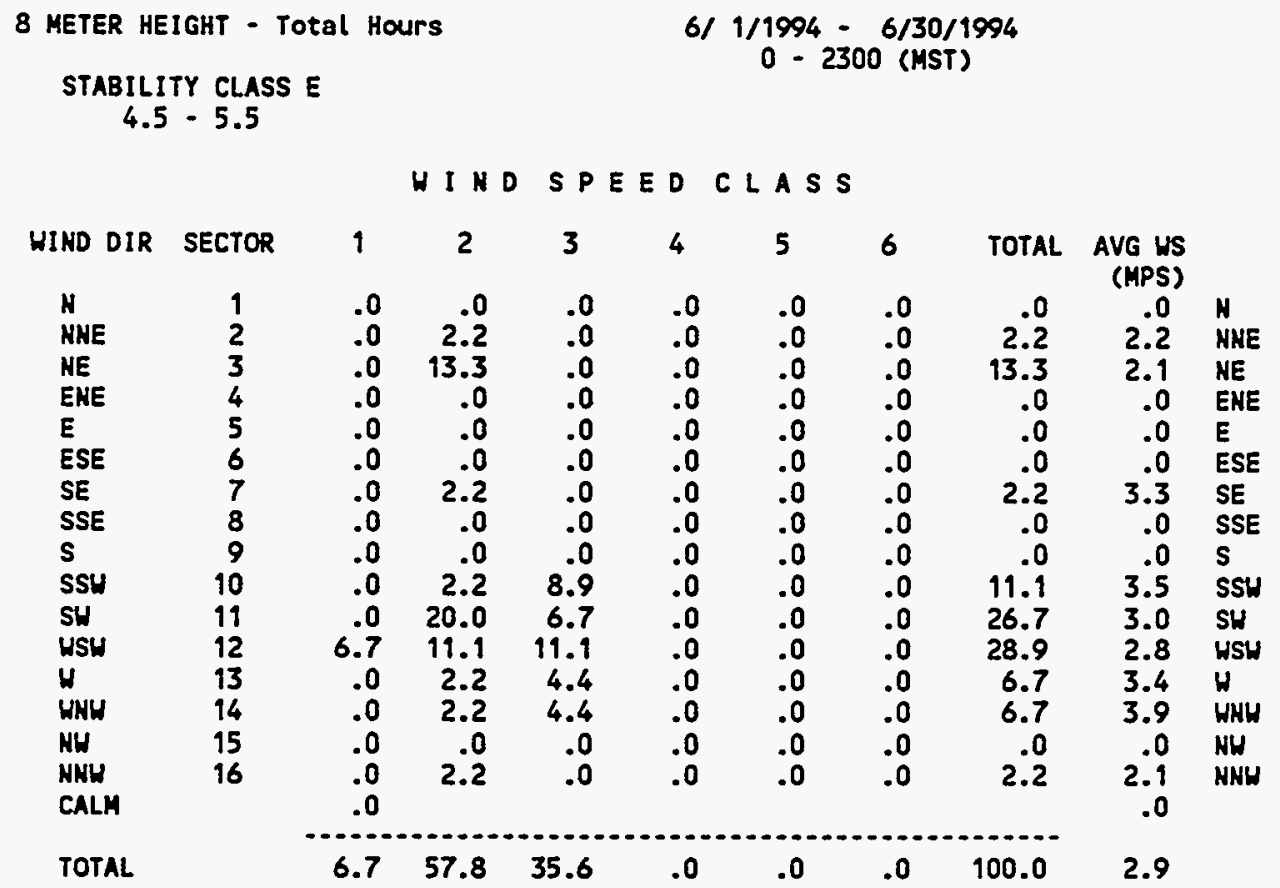

100.0\% DATA RECOVERED

6.3\% OF RECOVERED DATA REPORTED ABOVE

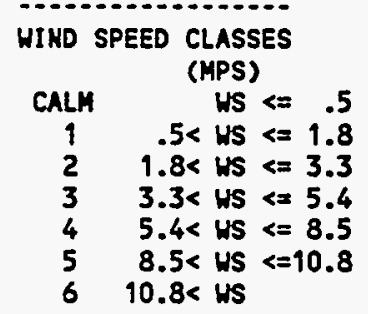


METEOROLOGICAL JOIHT FREQUENCY DISTRIBUTIOH (PERCENT OF VALID HOUR OBSERVATIONS)

SPILL TEST FACILITY 24 METER TONER

8 METER HEIGHT - Total Hours

$7 / 1 / 1994-7 / 31 / 1994$

STABILITY CLASS E

$4.5 \cdot 5.5$

HIND SPEED CLASS

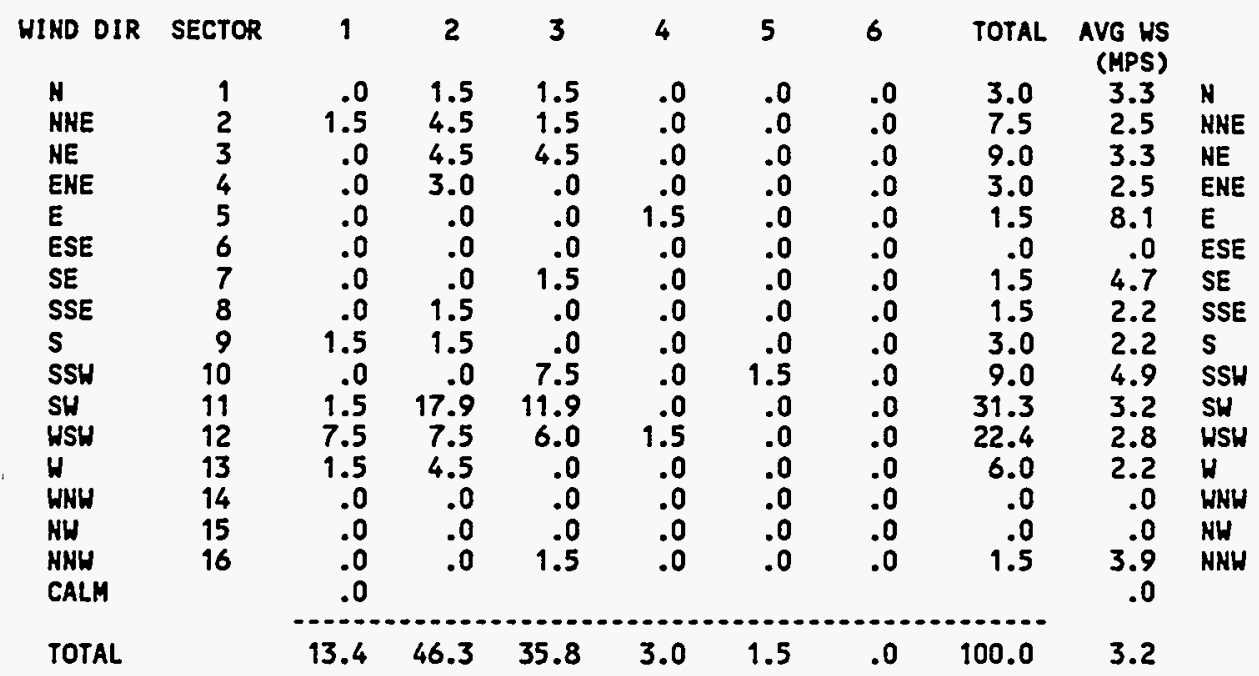

100.0\% DATA RECOVERED

9.0\% OF RECOVERED DATA REPORTED ABOVE

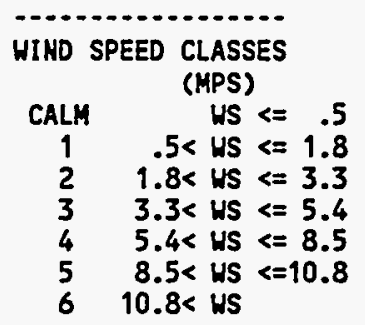


METEOROLOGICAL JOINT FREQUENCY OISTRIBUTION (PERCENT OF VALID HOUR OBSERVATIONS)

SPILL TEST FACILITY 24 METER TOMER
8 METER HEIGHT - Total Hours
$8 / 1 / 1994-8 / 31 / 1994$
$0-2300$ (MST)

STABILITY CLASS E

$4.5 \cdot 5.5$

WINDSPEEDCLASS

\begin{tabular}{|c|c|c|c|c|c|c|c|c|c|c|}
\hline HIKD DIR & SECTOR & 1 & 2 & 3 & 4 & 5 & 6 & TOTAL & $\begin{array}{l}\text { AVG WS } \\
\text { (MPS) }\end{array}$ & \\
\hline N & 1 & .0 & 1.5 & .0 & .0 & .0 & .0 & 1.5 & 3.0 & N \\
\hline NAE & 2 & .0 & 1.5 & 1.5 & .0 & .0 & .0 & 3.1 & 2.8 & HME \\
\hline NE & 3 & .0 & 6.2 & .0 & .0 & .0 & .0 & 6.2 & 2.5 & $\mathrm{NE}$ \\
\hline ENE & 4 & 1.5 & .0 & .0 & .0 & .0 & .0 & 1.5 & 1.6 & ENE \\
\hline $\mathbf{E}$ & 5 & .0 & .0 & 3.1 & .0 & .0 & .0 & 3.1 & 3.7 & $\mathbf{E}$ \\
\hline ESE & 6 & .0 & .0 & 1.5 & .0 & .0 & .0 & 1.5 & 3.8 & ESE \\
\hline SE & 7 & 1.5 & .0 & .0 & .0 & .0 & .0 & 1.5 & 1.6 & SE \\
\hline SSE & 8 & .0 & .0 & 4.6 & .0 & .0 & .0 & 4.6 & 4.2 & SSE \\
\hline s & 9 & 1.5 & 7.7 & 1.5 & .0 & .0 & .0 & 10.8 & 2.8 & $\mathbf{s}$ \\
\hline SSU & 10 & 1.5 & 1.5 & 7.7 & .0 & .0 & .0 & 10.8 & 3.8 & SSH \\
\hline SH & 11 & 6.2 & 6.2 & 13.8 & .0 & .0 & .0 & 26.2 & 3.2 & SH \\
\hline WSW & 12 & 4.6 & 1.5 & 7.7 & .0 & .0 & .0 & 13.8 & 3.1 & HSH \\
\hline W & 13 & .0 & 1.5 & .0 & .0 & .0 & .0 & 1.5 & 2.8 & 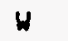 \\
\hline WWH & 14 & .0 & 1.5 & 1.5 & .0 & .0 & .0 & 3.1 & 3.8 & HHW \\
\hline NH & 15 & 0 & 4.6 & 1.5 & .0 & .0 & .0 & 6.2 & 3.0 & NW \\
\hline $\begin{array}{l}\text { NHH } \\
\text { CALY }\end{array}$ & 16 & $\begin{array}{r}3.1 \\
0\end{array}$ & 1.5 & .0 & .0 & .0 & .0 & & $\begin{array}{r}2.1 \\
.0\end{array}$ & NMH \\
\hline & & & & & & & & & & \\
\hline TOTAL & & 20.0 & 35.4 & 44.6 & .0 & .0 & .0 & 100.0 & 3.1 & \\
\hline
\end{tabular}

100.0\% DATA RECOVERED

8.7\% OF RECOVERED DATA REPORTED ABOVE

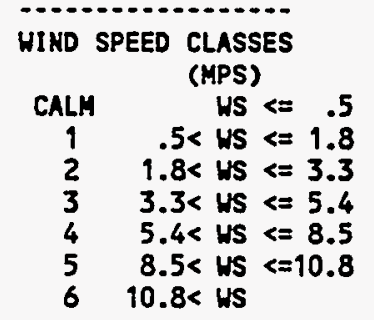


METEOROLOGICAL JOIHT FREQUENCY DISTRIBUTION (PERCENT OF VALID HOUR OBSERVATIONS)

SPILL TEST FACILITY 24 METER TOWER

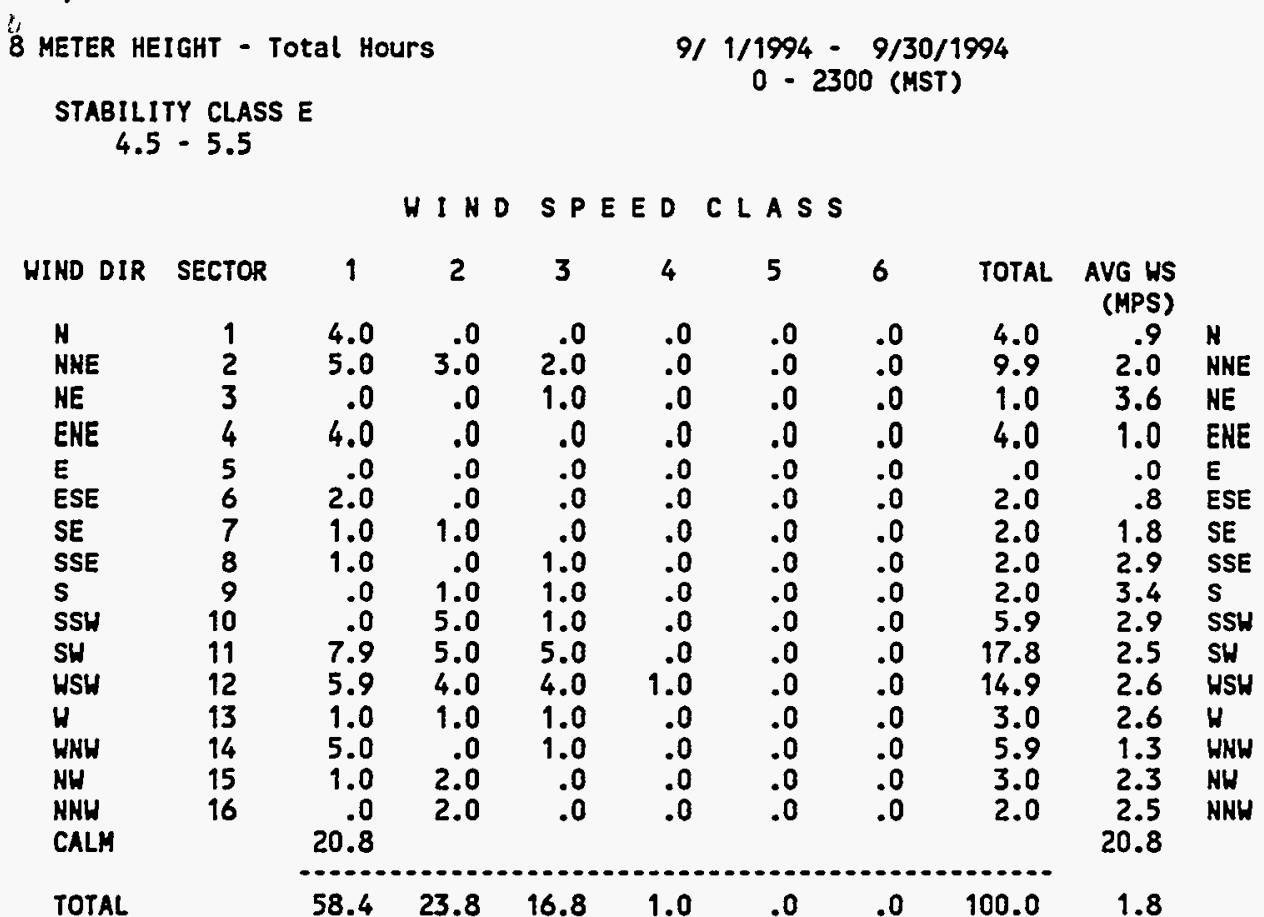

99.2\% DATA RECOVERED

14.1\% OF RECOVERED DATA REPORTED ABOVE

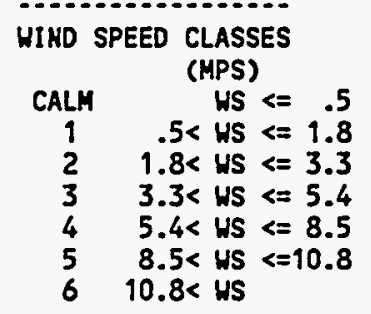


METEOROLOGICAL JOINT FREQUENCY DISTRIBUTION (PERCENT OF VALID HOUR OBSERVATIONS)

SPILL TEST FACILITY 24 METER TOWER

8 METER HEIGHT - TOtal HourS

10/ $1 / 1994 \cdot 10 / 31 / 1994$

STABILITY CLASS E

$0-2300$ (MST)

$4.5 \cdot 5.5$

HINDSPEED CLASS

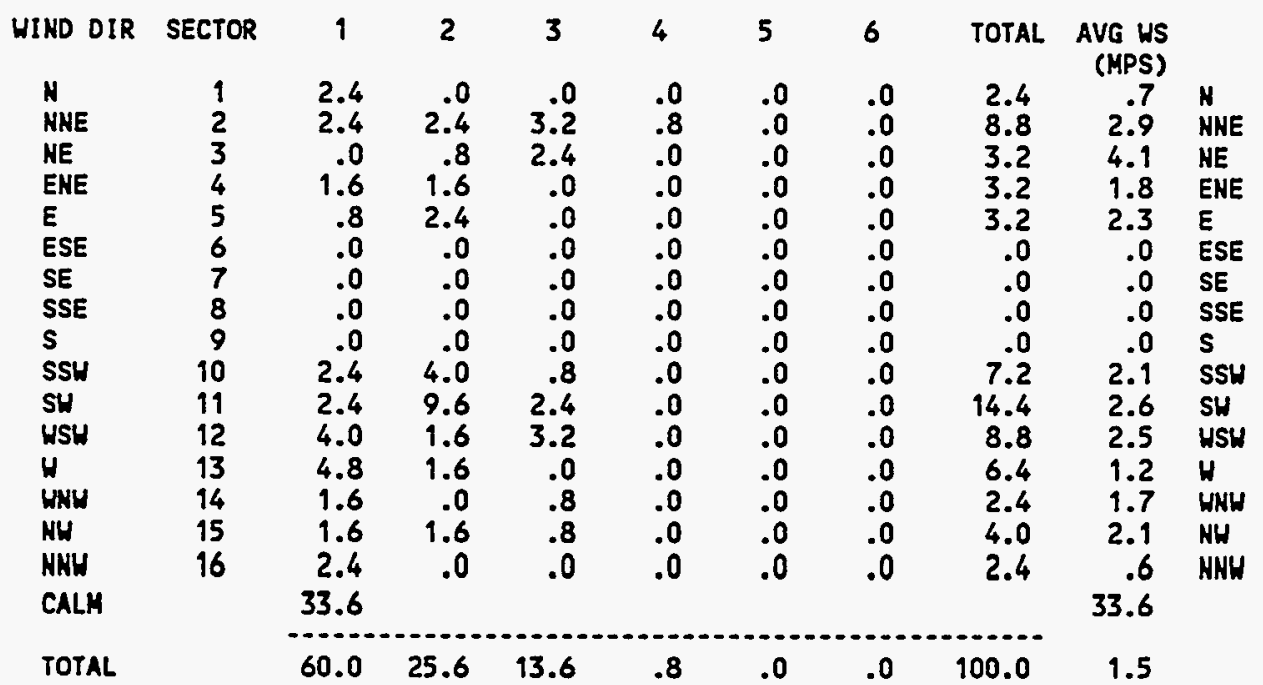

98.5\% DATA RECOVERED

17.1\% OF RECOVERED DATA REPORTED ABOVE

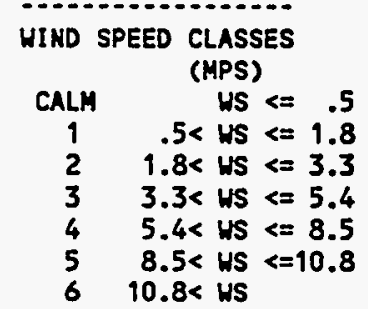


METEOROLOGICAL JOIHT FREQUENCY DISTRIBUTION (PERCENT OF VALID HOUR OBSERVATIONS)

SPILL TEST FACILITY 24 METER TONER

8 METER HEIGHT - TOtal HourS

$11 / 1 / 1994 \cdot 11 / 30 / 1994$

STABILITY CLASS E

0 - 2300 (MST)

$4.5-5.5$

HINDSPEED CLASS

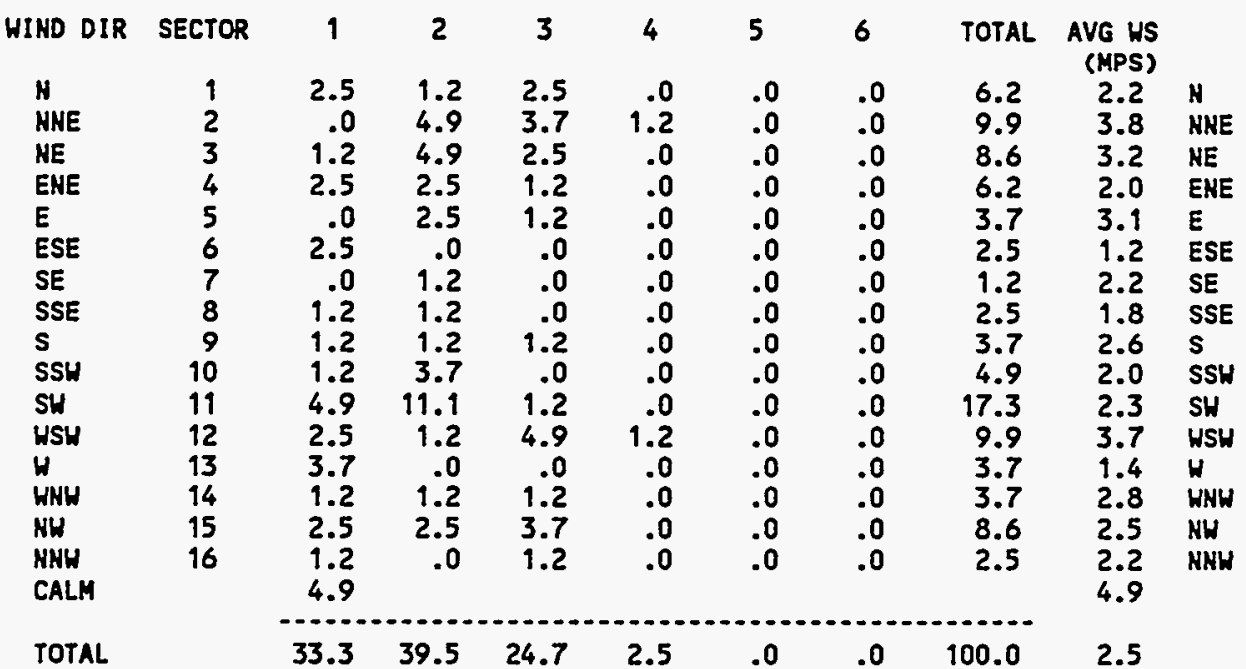

99.7X DATA RECOVERED

11.3\% OF RECOVERED DATA

REPORTED ABOVE

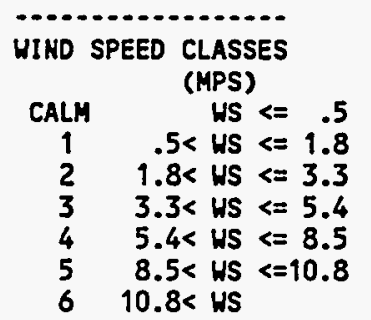


METEOROLOGICAL JOINT FREQUENCY DISTRIBUTION (PERCENT OF VALID HOUR OBSERVATIONS) SPILL TEST FACILITY 24 METER TOWER

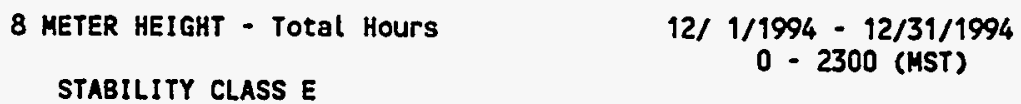

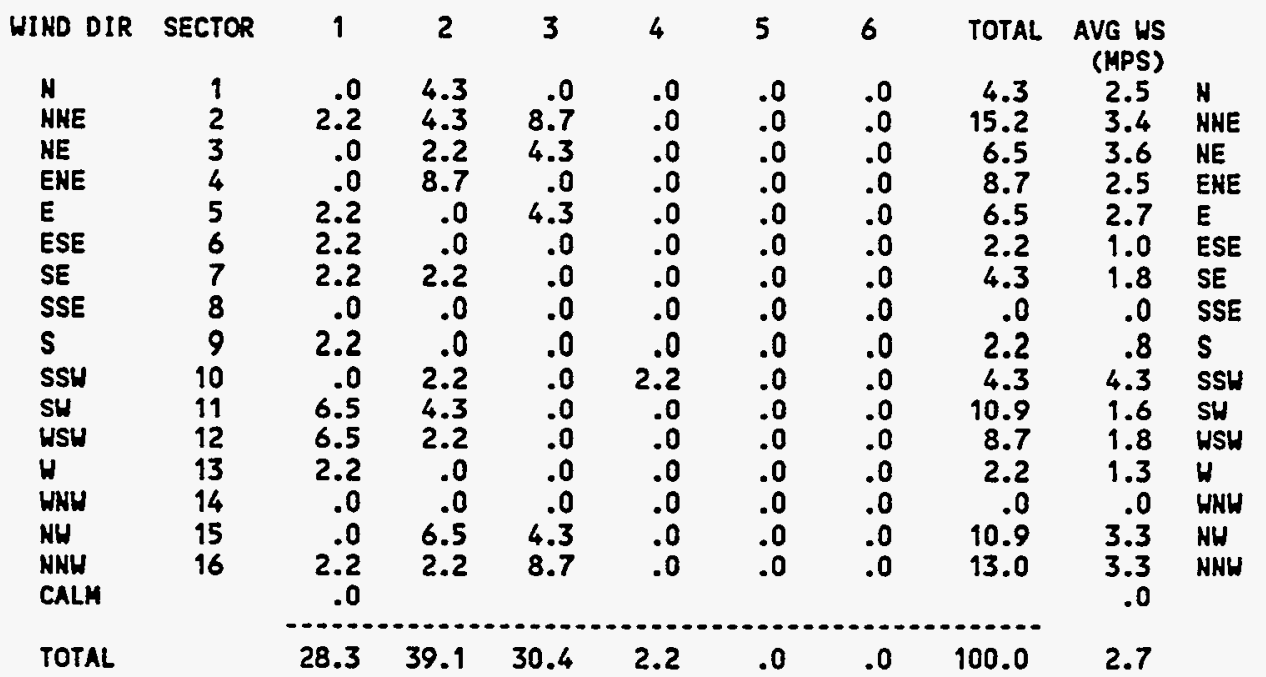

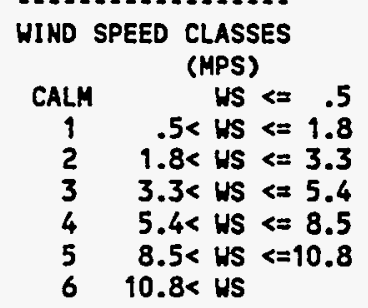


METEOROLOGICAL JOINT FREQUENCY OISTRIBUTION (PERCENT OF VALIO HOUR OBSERVATIOHS) SPILL TEST FACILITY 24 METER TONER

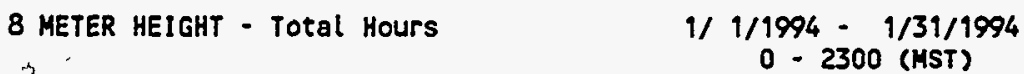

\begin{tabular}{|c|c|c|c|c|c|c|c|c|c|c|}
\hline HIKD DIR & SECTOR & 1 & 2 & 3 & 4 & 5 & 6 & TOTAL & $\begin{array}{l}\text { AVG US } \\
\text { (MPS) }\end{array}$ & \\
\hline $\mathrm{N}$ & 1 & .0 & .0 & .0 & .0 & .0 & .0 & .0 & .0 & $\mathrm{~N}$ \\
\hline HHE & 2 & .0 & .3 & .0 & .0 & .0 & .0 & .3 & 2.0 & MNE \\
\hline HE & 3 & .7 & .3 & .0 & .0 & .0 & .0 & 1.0 & 1.5 & $\mathrm{NE}$ \\
\hline EHE & 4 & .3 & 1.0 & .0 & .0 & .0 & .0 & 1.4 & 2.1 & inc \\
\hline E & 5 & 2.7 & 1.0 & .0 & .0 & .0 & .0 & 3.8 & 1.4 & \\
\hline ESE & 6 & 5.2 & .7 & .0 & .0 & .0 & .0 & 5.8 & 1.1 & ES \\
\hline SE & 7 & 4.8 & .3 & .0 & .0 & .0 & .0 & 5.2 & 1.1 & $\begin{array}{l}\text { SE } \\
\text { SS }\end{array}$ \\
\hline SSE & 8 & 6.5 & .7 & $\begin{array}{r}.0 \\
0\end{array}$ & .0 & .0 & .0 & 7.2 & 1.1 & $\begin{array}{l}\text { SS } \\
\text { S }\end{array}$ \\
\hline & $\begin{array}{r}9 \\
10\end{array}$ & $\begin{array}{l}13.4 \\
11.0\end{array}$ & $\begin{array}{l}1.0 \\
2.4\end{array}$ & $\begin{array}{l}.0 \\
.0\end{array}$ & $\begin{array}{l}.0 \\
.0\end{array}$ & $\begin{array}{l}.0 \\
.0\end{array}$ & $\begin{array}{l}.0 \\
.0\end{array}$ & $\begin{array}{l}14.4 \\
13.4\end{array}$ & $\begin{array}{l}1.1 \\
1.2\end{array}$ & $\begin{array}{l}\text { S } \\
\text { ss }\end{array}$ \\
\hline SW & 11 & 14.8 & 4.8 & .0 & .0 & .0 & .0 & 19.6 & 1.3 & St \\
\hline USW & 12 & 12.0 & .7 & .0 & .0 & .0 & .0 & 12.7 & 1.2 & $\begin{array}{l}\text { WS } \\
\text { W }\end{array}$ \\
\hline $\begin{array}{l}\text { W } \\
\text { WNW }\end{array}$ & $\begin{array}{l}13 \\
14\end{array}$ & $\begin{array}{l}4.5 \\
1.4\end{array}$ & 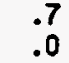 & $\begin{array}{l}.0 \\
.0\end{array}$ & $\begin{array}{l}.0 \\
.0\end{array}$ & $\begin{array}{l}.0 \\
.0\end{array}$ & $\begin{array}{l}.0 \\
.0\end{array}$ & $\begin{array}{l}5.2 \\
1.4\end{array}$ & $\begin{array}{l}1.3 \\
1.0\end{array}$ & $\begin{array}{l}\mathbf{H} \\
\mathbf{H}\end{array}$ \\
\hline NH & 15 & 1.7 & .3 & .0 & .0 & .0 & .0 & 2.1 & 9.7 & NH \\
\hline HWH & 16 & 3 & .3 & .0 & .0 & .0 & .0 & .7 & 1.5 & NNH \\
\hline CALAT & & $\cdots$ & & & & & & & & \\
\hline TOTAL & & 85.2 & 14.8 & .0 & .0 & .0 & .0 & 100.0 & 1.2 & \\
\hline
\end{tabular}

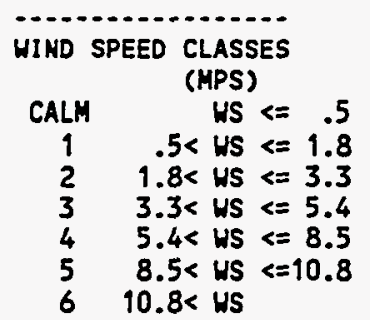


METEOROLOGICAL JOINT FREQUENCY DISTRIBUTION (PERCENT OF VALID HOUR OBSERVATIONS)

SPILL TEST FACILITY 24 METER TOWER

8 METER HEIGHT - Total Hours

2/ $1 / 1994-2 / 28 / 1994$

STABILITY CLASS F

$0 \cdot 2300$ (MST)

$$
5.5 \cdot 6.6
$$

HINDSPEEDCLASS

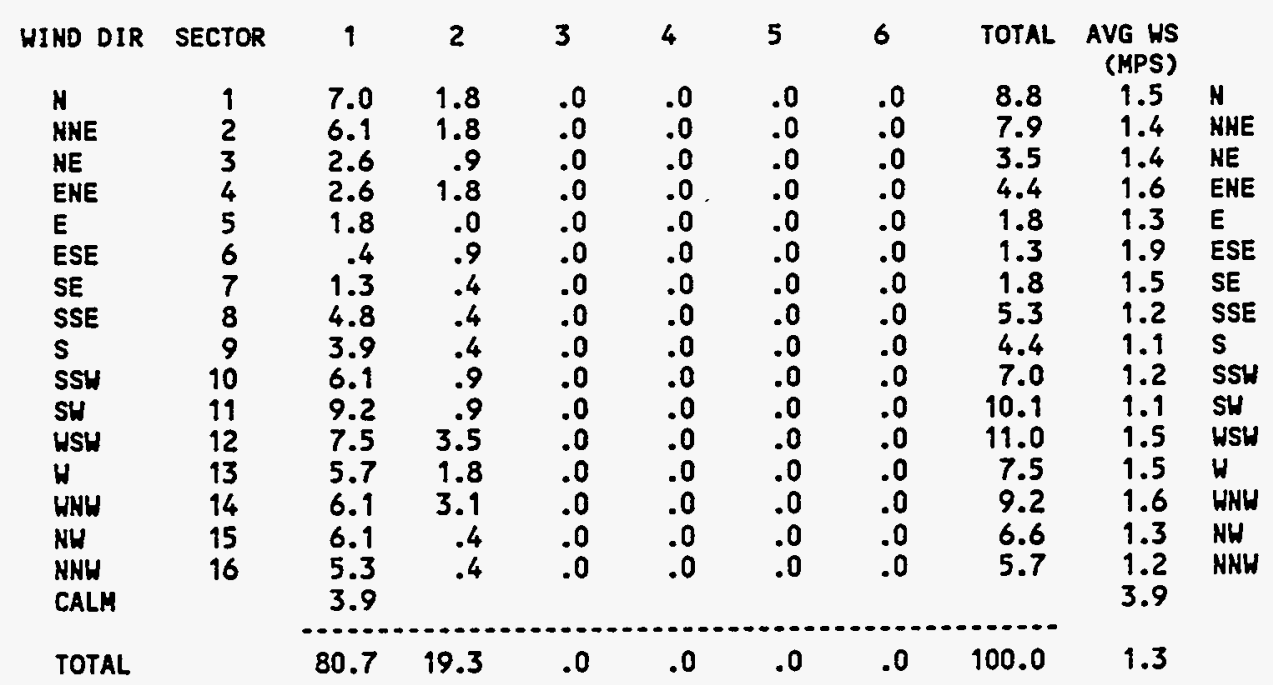

85.4\% DATA RECOVERED

39.7\% OF RECOVERED DATA REPORTED ABOVE

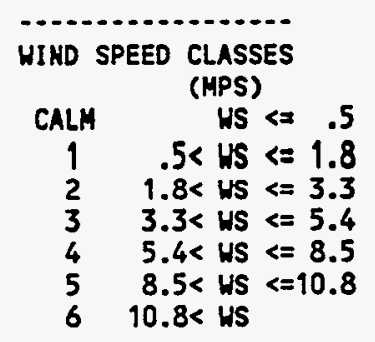


METEOROLOGICAL JOINT FREQUENCY DISTRIBUTION (PERCENT OF VALID HOUR OBSERVATIONS)

SPILL TEST FACILITY 24 METER TOWER
8 METER HEIGHT - Total Hours
$3 / 1 / 1994 \cdot 3 / 31 / 1994$
0 - 2300 (MST)

STABILITY CLASS F

WIND SPEED CLASS

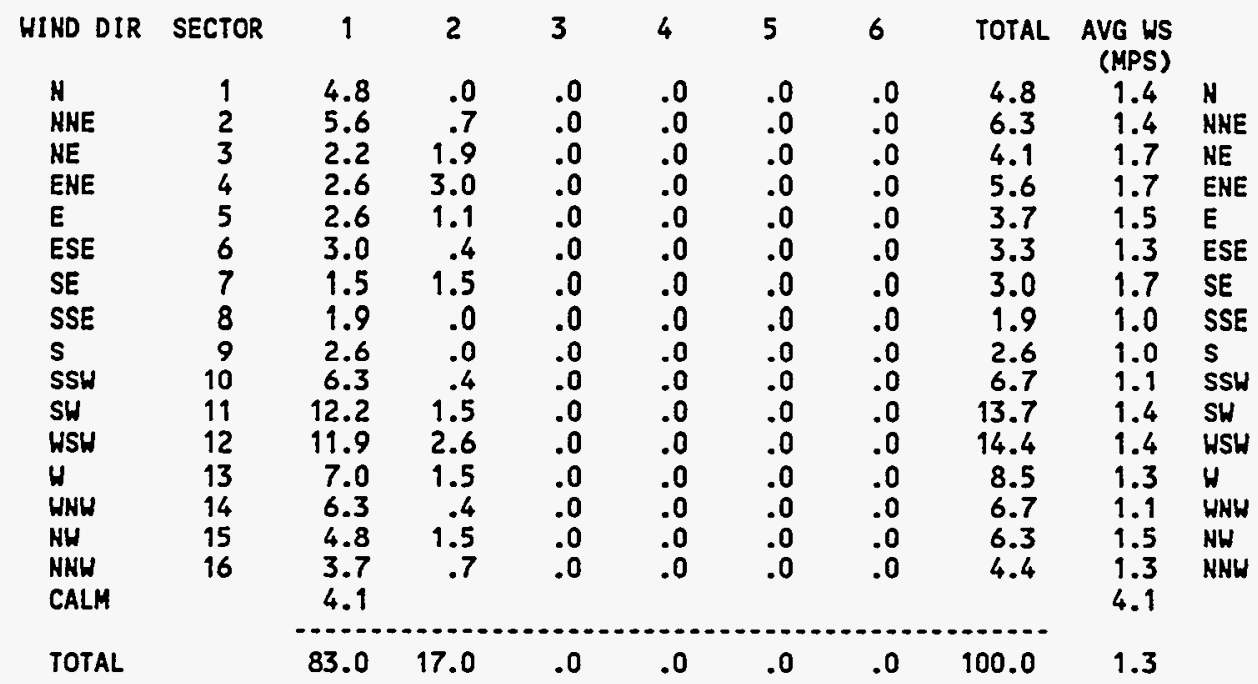

100.0\% DATA RECOVERED

36.3\% OF RECOVERED DATA REPORTED ABOVE

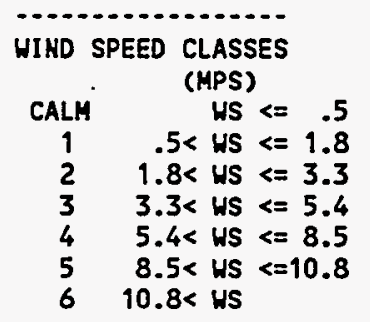


METEOROLOGICAL JOINT FREQUENCY DISTRIBUTIOH (PERCENT OF VALID HOUR OBSERVATIONS)

SPILL TEST FACILITY 24 METER TOWER
8 METER HEIGHT - Total Hours
4/ $1 / 1994 \cdot 4 / 30 / 1994$

$$
0-2300 \text { (MST) }
$$

STABILITY CLASS F

$5.5-6.6$

WI ND SPEED CLASS

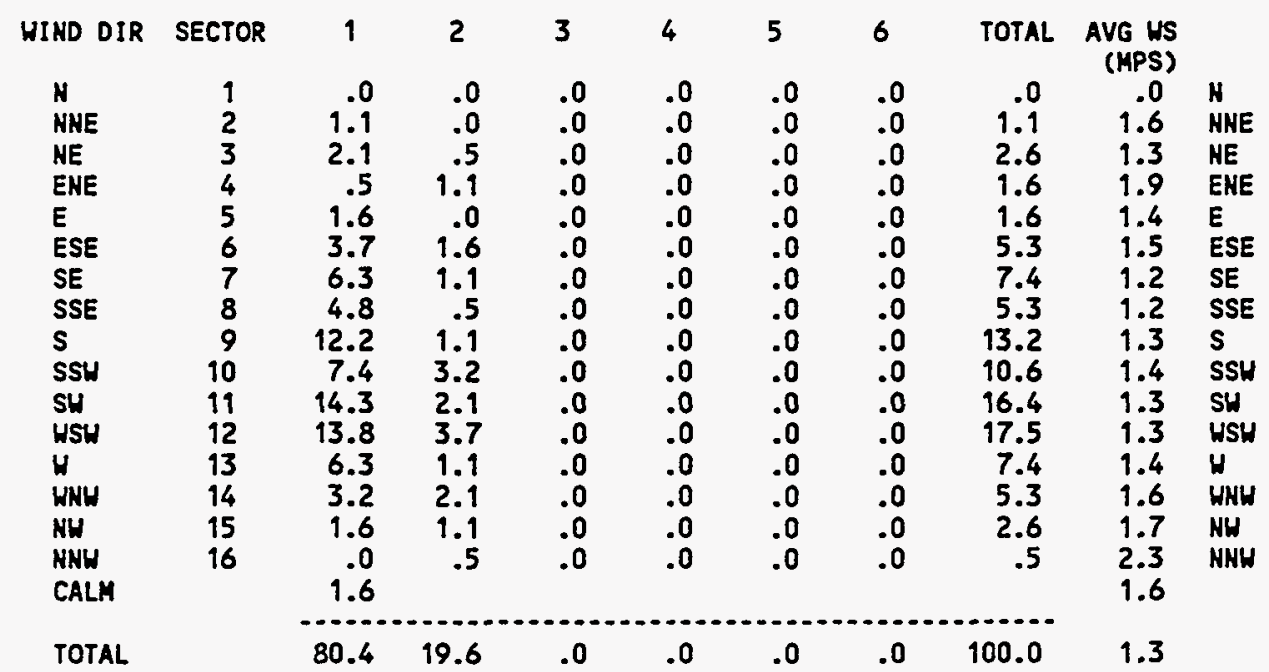

99.9\% OATA RECOVERED

26.3\% OF RECOVERED DATA REPORTED ABOVE

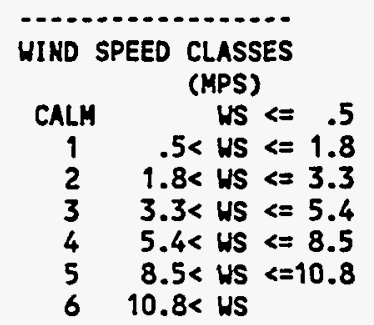


METEOROLOGICAL JOIHT FREQUENCY DISTRIBUTION (PERCENT OF VALID HOUR OBSERVATIONS) SPILL TEST FACILITY 24 METER TOWER

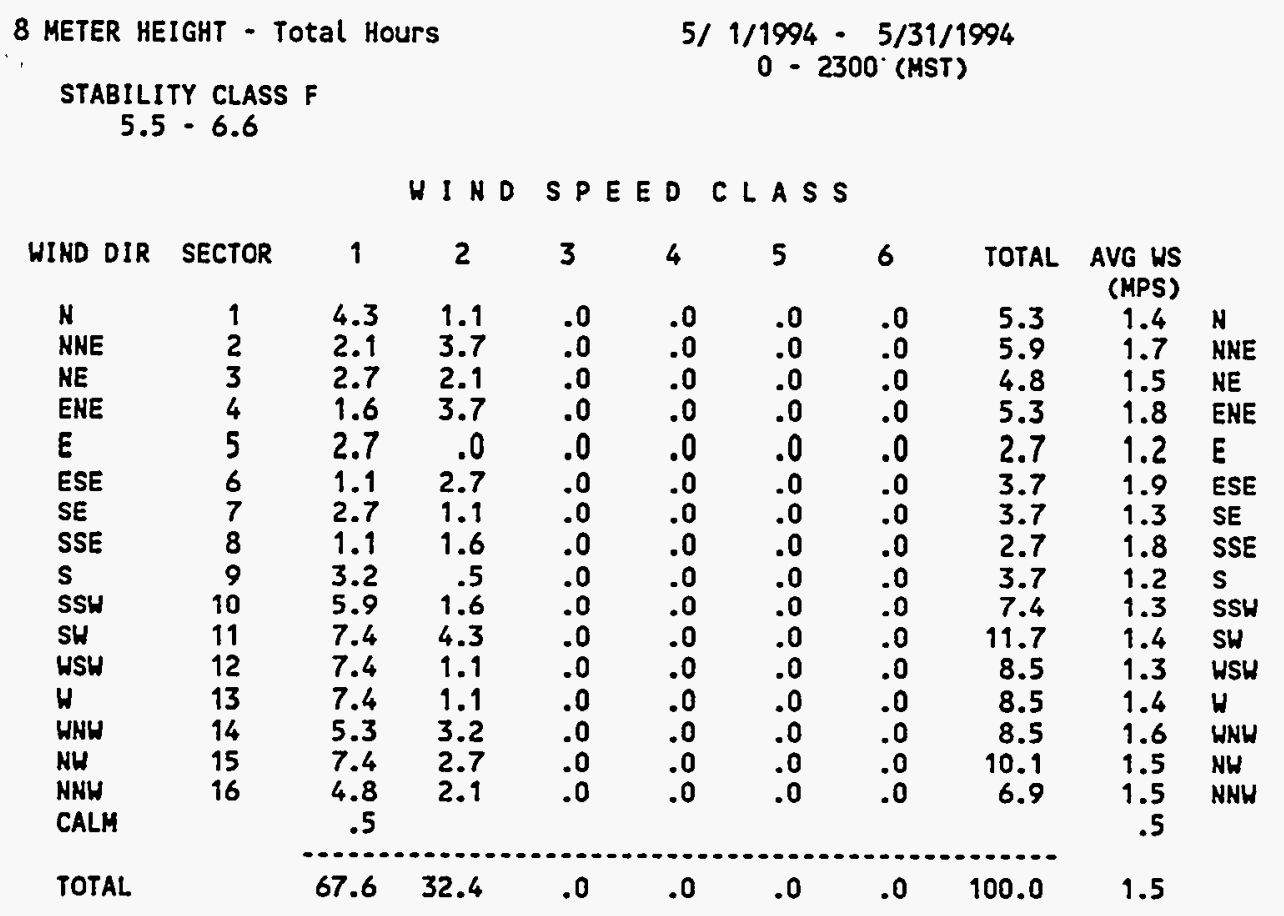

96.9\% DATA RECOVERED 26.1\% OF RECOVERED DATA REPORTED ABOVE

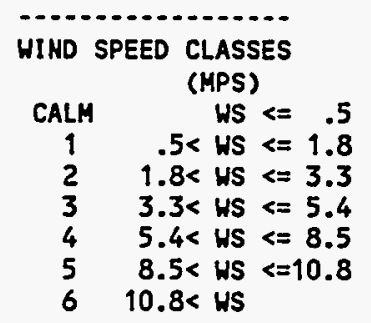


METEOROLOGICAL JOINT FREQUENCY DISTRIBUTIOH (PERCENT OF VALID HOUR OBSERVATIONS)

SPILL TEST FACILITY 24 METER TOWER

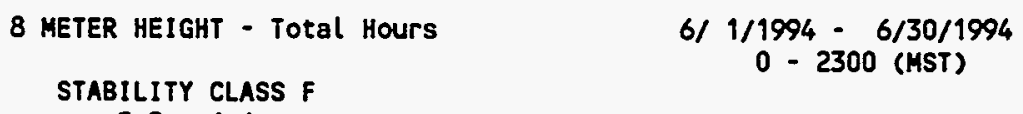

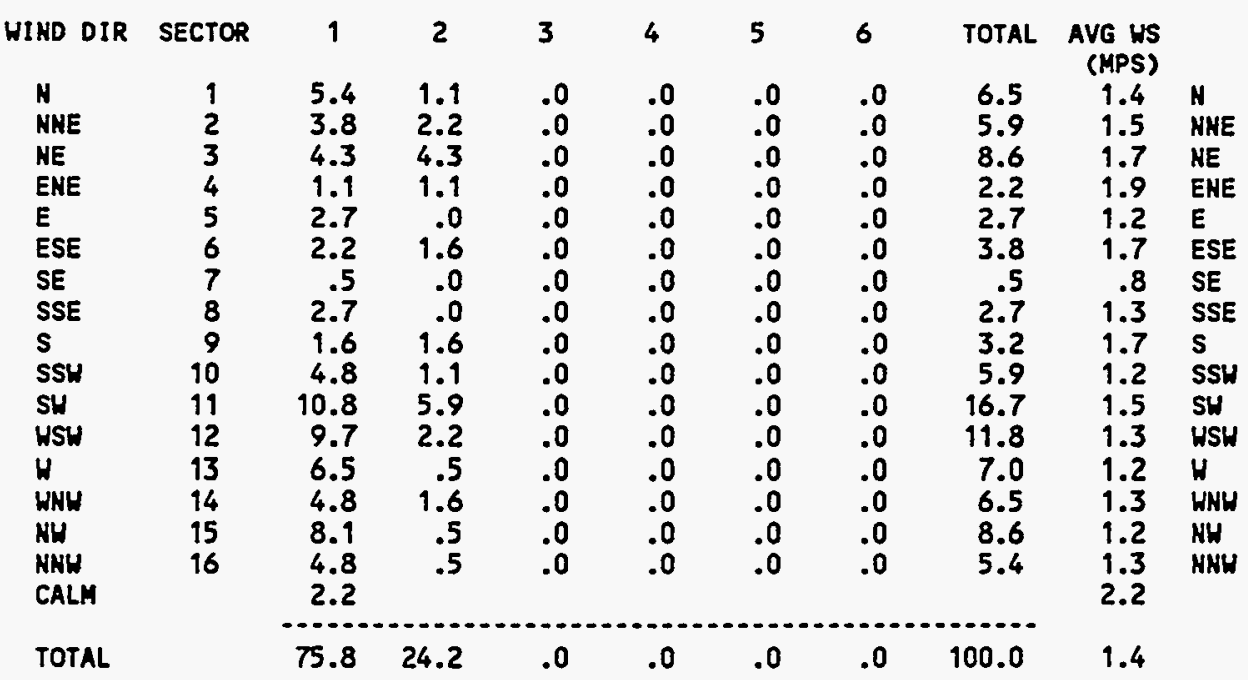
REPORTED ABOVE

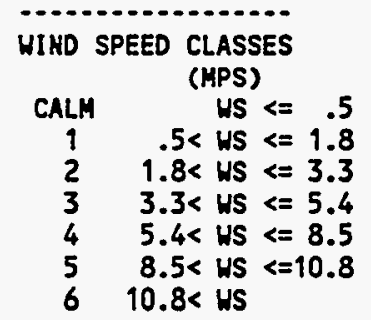


METEOROLOGICAL JOINT FREQUENCY OISTRIBUTION (PERCENT OF VALID HOUR OBSERVATIONS)

SPILL TEST FACILITY 24 METER TOWER
8 METER HEIGHT - TOtal Hours
$7 / 1 / 1994-7 / 31 / 1994$
$0-2300$ (MST)

STABILITY CLASS F

$5.5-6.6$

HIHD SPEED CLASS

\begin{tabular}{|c|c|c|c|c|c|c|c|c|c|c|}
\hline WIND DIR & SECTOR & 1 & 2 & 3 & 4 & 5 & 6 & TOTAL & $\begin{array}{l}\text { AVG WS } \\
\text { (MPS) }\end{array}$ & \\
\hline H & 1 & 6.3 & .5 & .0 & .0 & .0 & .0 & 6.8 & 1.3 & H \\
\hline HME & 2 & 7.8 & 1.0 & .0 & .0 & .0 & .0 & 8.7 & 1.4 & NME \\
\hline NE & 3 & 3.9 & 5.3 & .0 & .0 & .0 & .0 & 9.2 & 1.8 & NE \\
\hline ENE & 4 & 2.9 & 1.5 & .0 & .0 & .0 & .0 & 4.4 & 1.7 & ENE \\
\hline E & 5 & 2.9 & .5 & .0 & .0 & .0 & .0 & 3.4 & 1.4 & $E$ \\
\hline ESE & 6 & 3.9 & 1.0 & .0 & .0 & .0 & .0 & 4.9 & 1.3 & ESE \\
\hline SE & 7 & 1.0 & 1.0 & .0 & .0 & .0 & .0 & 1.9 & 1.7 & SE \\
\hline SSE & 8 & .0 & .0 & .0 & .0 & .0 & .0 & .0 & .0 & SSE \\
\hline $\mathbf{s}$ & 9 & 3.9 & .0 & .0 & 0 & .0 & .0 & 3.9 & 1.3 & s \\
\hline SSW & 10 & 4.9 & 1.9 & .0 & .0 & .0 & .0 & 6.8 & 1.6 & SSW \\
\hline SH & 11 & 10.2 & 1.9 & .0 & .0 & .0 & .0 & 12.1 & 1.3 & SH \\
\hline WSH & 12 & 8.3 & .5 & .0 & .0 & .0 & .0 & 8.7 & 1.2 & HSW \\
\hline$H$ & 13 & 6.8 & 1.0 & .0 & .0 & .0 & .0 & 7.8 & 1.4 & $H$ \\
\hline WHW & 14 & 5.8 & 1.5 & .0 & .0 & .0 & .0 & 7.3 & 1.3 & WNW \\
\hline NH & 15 & 4.4 & 2.4 & .0 & .0 & .0 & .0 & 6.8 & 1.5 & NH \\
\hline $\begin{array}{l}\text { NHW } \\
\text { CALM }\end{array}$ & 16 & $\begin{array}{l}4.4 \\
1.9\end{array}$ & 1.0 & .0 & .0 & .0 & .0 & 5.3 & $\begin{array}{l}1.4 \\
1.9\end{array}$ & NNW \\
\hline TOTAL & & 79.1 & 20.9 & .0 & .0 & .0 & .0 & 100.0 & 1.4 & \\
\hline
\end{tabular}

100.0\% DATA RECOVERED

27.7\% OF RECOVERED DATA

REPORTED ABOVE

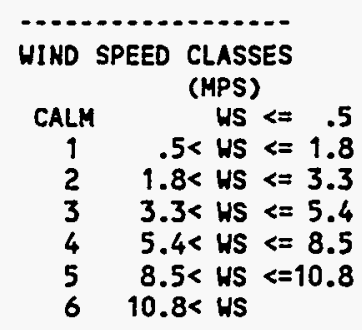


METEOROLOGICAL JOINT FREQUENCY DISTRIBUTION (PERCENT OF VALID HOUR OBSERVATIONS)

SPILL TEST FACILITY 24 METER TONER

8 METER HEIGHT - Total Hours

$8 / 1 / 1994-8 / 31 / 1994$

STABILITY CLASS F

0 - 2300 (MST)

$5.5 \cdot 6.6$

HIND SPEEDCLASS

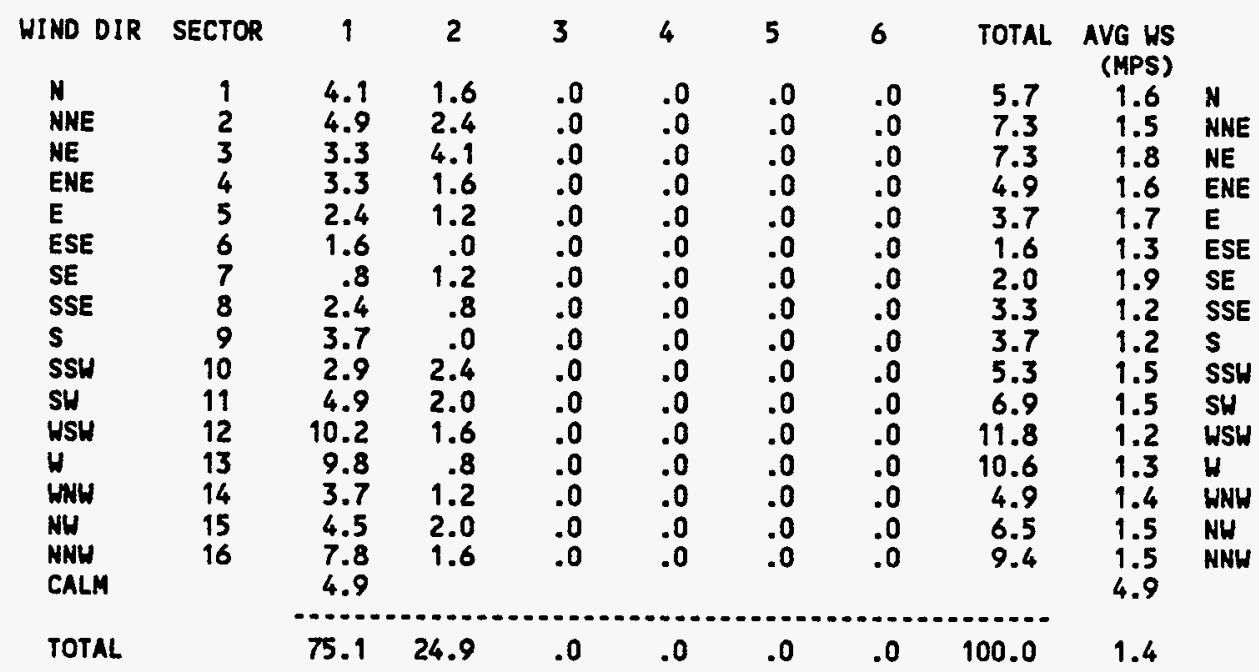

100.0\% DATA RECOVERED

32.9\% OF RECOVERED DATA REPORTED ABOVE

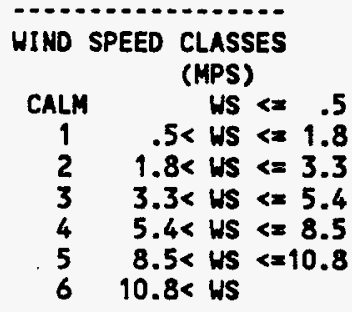


METEOROLOGICAL JOINT FREQUENCY DISTRIBUTION (PERCENT OF VALID HOUR OBSERVATIONS) SPILL TEST FACILITY 24 METER TOWER

8 METER HEIGHT - Total Hours

$9 / 1 / 1994 \cdot 9 / 30 / 1994$

STABILITY CLASS F

$0 \cdot 2300$ (MST)

$5.5 \cdot 6.6$

WINDSPEED CLASS

\begin{tabular}{|c|c|c|c|c|c|c|c|c|c|c|}
\hline WIND DIR & SECTOR & 1 & 2 & 3 & 4 & 5 & 6 & TOTAL & $\begin{array}{l}\text { AVG WS } \\
\text { (MPS) }\end{array}$ & \\
\hline$N$ & 1 & 9.1 & 1.1 & .0 & .0 & .0 & .0 & 10.2 & 1.2 & $N$ \\
\hline NNE & 2 & 3.2 & 1.1 & .0 & .0 & .0 & .0 & 4.3 & 1.5 & NHE \\
\hline NE & 3 & 7.5 & 3.8 & .0 & .0 & .0 & .0 & 11.3 & 1.4 & NE \\
\hline ENE & 4 & 2.7 & 1.6 & .0 & .0 & .0 & .0 & 4.3 & 1.8 & ENE \\
\hline $\begin{array}{l}E \\
\text { ESE }\end{array}$ & $\begin{array}{l}5 \\
6\end{array}$ & $\begin{array}{l}1.1 \\
1.6\end{array}$ & $\begin{array}{l}.0 \\
.0\end{array}$ & $\begin{array}{l}.0 \\
.0\end{array}$ & $\begin{array}{l}.0 \\
.0\end{array}$ & $\begin{array}{l}.0 \\
.0\end{array}$ & $\begin{array}{l}.0 \\
.0\end{array}$ & $\begin{array}{l}1.1 \\
1.6\end{array}$ & $\begin{array}{l}.8 \\
.9\end{array}$ & $\begin{array}{l}E \\
\text { ESE }\end{array}$ \\
\hline SE & 7 & $\begin{array}{l}.0 \\
.5\end{array}$ & .5 & .0 & .0 & .0 & .0 & 1.1 & 1.6 & SE \\
\hline $\begin{array}{l}\text { SSE } \\
\text { S }\end{array}$ & $\begin{array}{l}8 \\
9\end{array}$ & 4.5 & $\begin{array}{l}.0 \\
.5\end{array}$ & $\begin{array}{l}.0 \\
.0\end{array}$ & $\begin{array}{l}.0 \\
.0\end{array}$ & $\begin{array}{l}.0 \\
.0\end{array}$ & $\begin{array}{l}.0 \\
.0\end{array}$ & $\begin{array}{r}.5 \\
4.8\end{array}$ & .9 & $\begin{array}{l}\text { SSE } \\
\text { S }\end{array}$ \\
\hline SSH & 10 & $\begin{array}{l}4.3 \\
5.4\end{array}$ & .0 & .0 & .0 & .0 & .0 & $\begin{array}{l}4.0 \\
5.4\end{array}$ & 1.2 & SSW \\
\hline SW & 11 & 4.3 & 3.2 & .0 & .0 & .0 & .0 & 7.5 & 1.6 & SH \\
\hline WSW & 12 & 2.7 & 1.1 & .0 & .0 & .0 & .0 & 3.8 & 1.6 & WSW \\
\hline U & 13 & 7.0 & 1.1 & .0 & .0 & .0 & .0 & 8.1 & 1.2 & $H$ \\
\hline WNW & 14 & 5.9 & 1.6 & .0 & .0 & .0 & .0 & 7.5 & 1.3 & WNW \\
\hline NW & 15 & 2.7 & .5 & .0 & .0 & .0 & .0 & 3.2 & 1.1 & NW \\
\hline $\begin{array}{l}\text { NNW } \\
\text { CALLM }\end{array}$ & 16 & $\begin{array}{r}3.2 \\
22.0\end{array}$ & .0 & .0 & .0 & .0 & .0 & 3.2 & $\begin{array}{r}1.2 \\
22.0\end{array}$ & NNW \\
\hline TOTAL & & 83.9 & 16.1 & .0 & .0 & .0 & .0 & 100.0 & 1.0 & \\
\hline
\end{tabular}

$99.2 \%$ DATA RECOVERED

26.1\% OF RECOVERED DATA REPORTED ABOVE

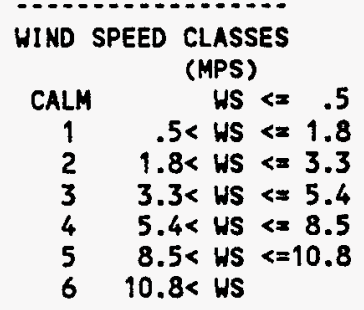


METEOROLOGICAL JOINT FREQUENCY DISTRIBUTION (PERCENT OF VALID HOUR OBSERVATIONS) SPILL TEST FACILITY 24 METER TOWER

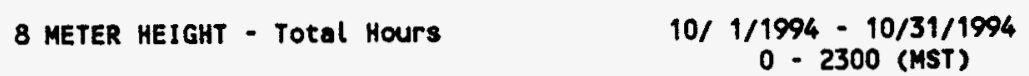

\begin{tabular}{|c|c|c|c|c|c|c|c|c|c|c|}
\hline WIND DIR & SECTOR & 1 & 2 & 3 & 4 & 5 & 6 & TOTAL & $\begin{array}{l}\text { AVG WS } \\
\text { (MPS) }\end{array}$ & \\
\hline $\begin{array}{l}\text { N } \\
\text { NNE } \\
\text { NE } \\
\text { ENE } \\
\text { E } \\
\text { ESE } \\
\text { SE } \\
\text { SSE } \\
\text { S } \\
\text { SSH } \\
\text { SH } \\
\text { WSH } \\
\text { W } \\
\text { HNW } \\
\text { HH } \\
\text { NHH } \\
\text { CALM }\end{array}$ & $\begin{array}{r}1 \\
2 \\
3 \\
4 \\
5 \\
6 \\
7 \\
8 \\
9 \\
10 \\
11 \\
12 \\
13 \\
14 \\
15 \\
16\end{array}$ & $\begin{array}{r}3.3 \\
2.0 \\
3.3 \\
4.0 \\
.7 \\
.7 \\
2.0 \\
2.7 \\
2.7 \\
3.3 \\
5.3 \\
4.7 \\
2.7 \\
5.3 \\
5.3 \\
5.3 \\
25.3\end{array}$ & $\begin{array}{r}2.0 \\
2.0 \\
1.3 \\
2.0 \\
.7 \\
1.3 \\
.0 \\
.0 \\
.7 \\
2.7 \\
4.0 \\
1.3 \\
.0 \\
.7 \\
.7 \\
2.0\end{array}$ & $\begin{array}{l}.0 \\
.0 \\
.0 \\
.0 \\
.0 \\
.0 \\
.0 \\
.0 \\
.0 \\
.0 \\
.0 \\
.0 \\
.0 \\
.0 \\
.0 \\
.0\end{array}$ & $\begin{array}{l}.0 \\
.0 \\
.0 \\
.0 \\
.0 \\
.0 \\
.0 \\
.0 \\
.0 \\
.0 \\
.0 \\
.0 \\
.0 \\
.0 \\
.0 \\
.0\end{array}$ & $\begin{array}{l}.0 \\
.0 \\
.0 \\
.0 \\
.0 \\
.0 \\
.0 \\
.0 \\
.0 \\
.0 \\
.0 \\
.0 \\
.0 \\
.0 \\
.0 \\
.0\end{array}$ & $\begin{array}{l}.0 \\
.0 \\
.0 \\
.0 \\
.0 \\
.0 \\
.0 \\
.0 \\
.0 \\
.0 \\
.0 \\
.0 \\
.0 \\
.0 \\
.0 \\
.0\end{array}$ & $\begin{array}{l}5.3 \\
4.0 \\
4.7 \\
6.0 \\
1.3 \\
2.0 \\
2.0 \\
2.7 \\
3.3 \\
6.0 \\
9.3 \\
6.0 \\
2.7 \\
6.0 \\
6.0 \\
7.3\end{array}$ & $\begin{array}{r}1.7 \\
1.4 \\
1.4 \\
1.3 \\
1.9 \\
1.8 \\
.8 \\
.8 \\
1.1 \\
1.6 \\
1.6 \\
1.3 \\
1.2 \\
1.2 \\
1.2 \\
1.6 \\
25.3\end{array}$ & $\begin{array}{l}\text { N } \\
\text { NNE } \\
\text { NE } \\
\text { ENE } \\
\text { E } \\
\text { ESE } \\
\text { SE } \\
\text { SSE } \\
\text { S } \\
\text { SSW } \\
\text { SW } \\
\text { WSW } \\
\text { W } \\
\text { WNW } \\
\text { HW } \\
\text { NNH }\end{array}$ \\
\hline TOTAL & & 78.7 & 21.3 & .0 & .0 & .0 & .0 & 100.0 & 1.0 & \\
\hline
\end{tabular}

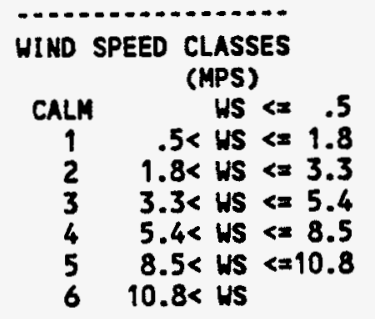




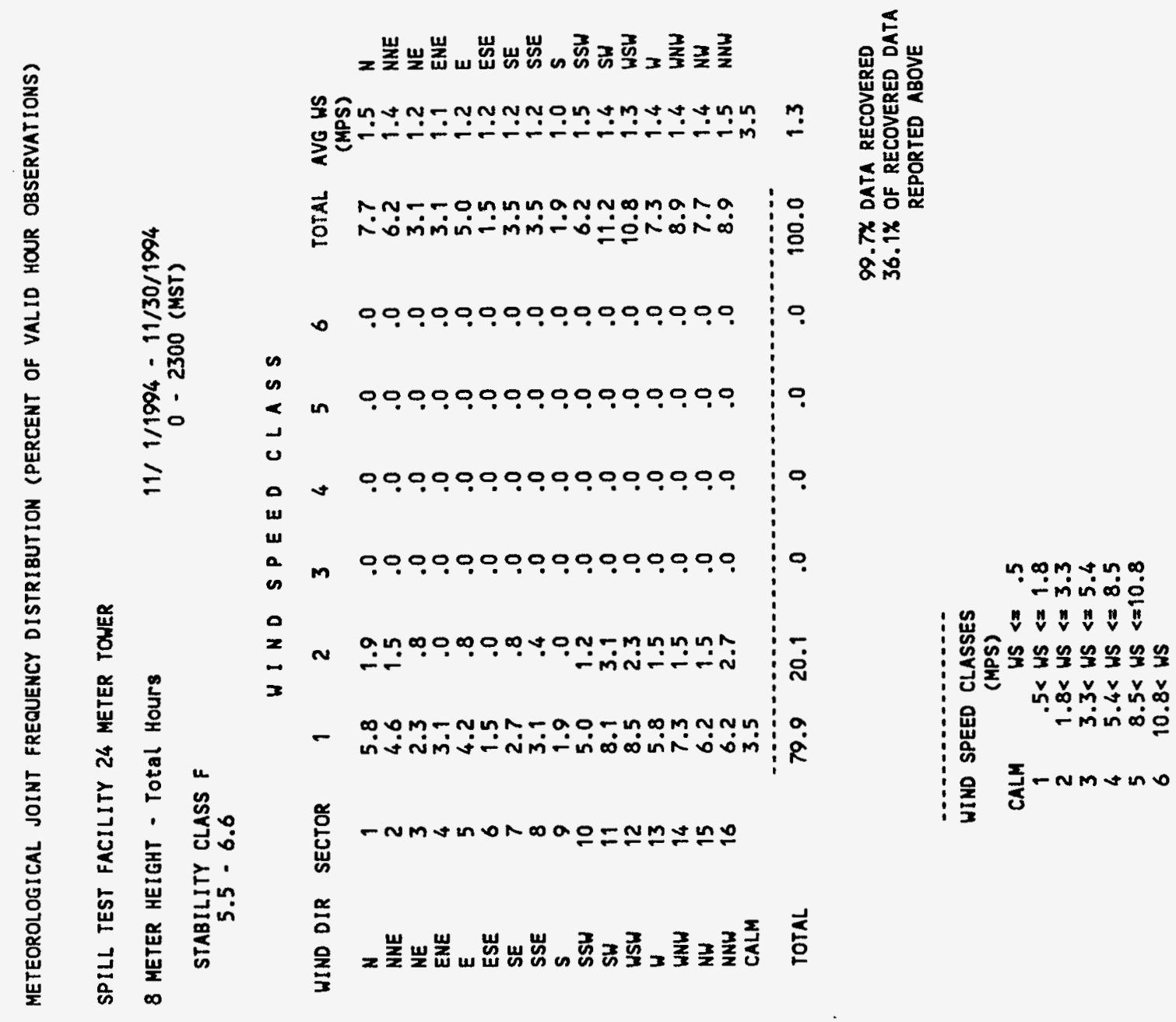


METEOROLOGICAL JOINT FREQUENCY DISTRIBUTION (PERCENT OF VALIO HOUR OBSERVATIONS) SPILL TEST FACILITY 24 METER TOWER

8 METER HEIGHT - Total Hours

$12 / 1 / 1994-12 / 31 / 1994$

STABILITY CLASS F

$0 \cdot 2300$ (MST)

$5.5-6.6$

WINDSPEEDCLASS

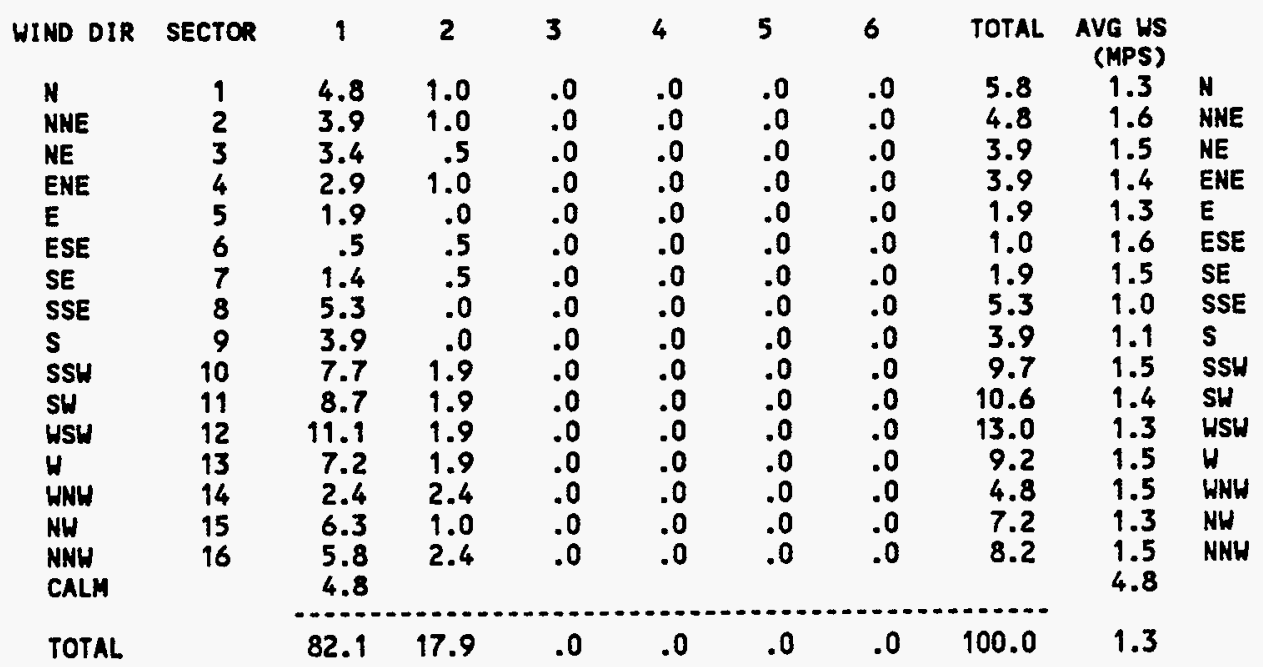

65.1\% DATA RECOVERED

42.8\% OF RECOVERED DATA REPORTED ABOVE

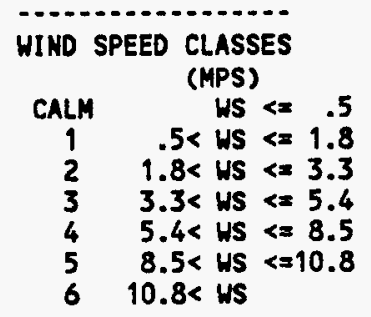




\section{APPENDIX D: TABULATED HOURLY RICHARDSON NUMBERS, MONIN- OBUKHOV LENGTHS ESTIMATED FROM RICHARDSON NUMBERS, TEMPERATURE DIFFERENCES TWO TO SIXTEEN METERS, AND SIGMA THETA STABILITY CLASSES}

Richardson Numbers

1-12 Richardson Number, One Quarter to Two Meter Layer, January-December, 1994

13-24 Richardson Number, One Half to Four Meter Layer, January-December, 1994

25-36 Richardson Number, Two to Sixteen Meter Layer, January-December, 1994

Monin-Obukhov Lengths Based on Richardson Numbers

37-48 Based on Richardson Number, One Quarter to Two Meter Layer, January-December, 1994

49-60 Based on Richardson Number, One Half to Four Meter Layer, January-December, 1994

61-72 Based on Richardson Number, Two to Sixteen Meter Layer, January-December, 1994

Temperature Differences Two to Sixteen Meters

73-84 Temperature Differences, Two to Sixteen Meter Layer, January-December, 1994

Sigma Theta Stability Classes

85-96 Eight Meter Sigma Theta Stability Class, January-December, 1994 


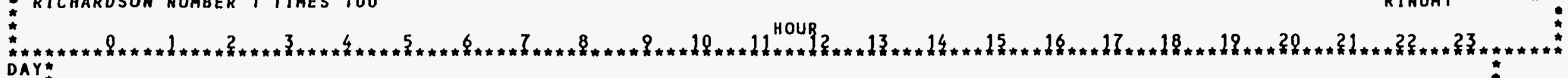

\begin{tabular}{|c|c|c|c|c|c|c|c|c|c|c|c|c|c|c|c|c|c|c|c|c|c|c|c|c|}
\hline 1 & 18 & 15 & 26 & 42 & 14 & 36 & -5 & -69 & -152 & -4 & -6 & -14 & -31 & -55 & -44 & -16 & -9 & 31 & 20 & 15 & 24 & 38 & 27 & 52 \\
\hline 2 & 103 & 31 & 108 & 20 & 14 & 23 & 20 & -14 & -103 & -177 & -94 & -157 & -249 & -248 & -89 & -54 & -7 & 28 & 123 & 43 & 42 & 15 & 13 & 30 \\
\hline 3 & 65 & 28 & 68 & 32 & 9 & 34 & 23 & 2 & 0 & -1 & -1 & -2 & -3 & -3 & -2 & -2 & -4 & 5 & 4 & 4 & 4 & 1 & 3 & 38 \\
\hline 4 & 51 & 16 & 27 & 23 & 15 & 31 & 3 & -44 & -48 & -42 & -33 & -102 & .66 & -3 & -2 & -1 & -1 & 1 & 3 & 5 & 8 & 28 & 19 & 19 \\
\hline 5 & 21 & 92 & 25 & 39 & 28 & 28 & -1 & -72 & 1482 & $\| \star * *$ & 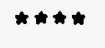 & 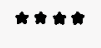 & $\hbar * \star \star *$ & 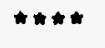 & -29 & -19 & -5 & 3 & 10 & 11 & 28 & 22 & 20 & 29 \\
\hline 6 & 30 & 54 & 30 & 14 & 4 & 9 & -23 & -23 & -24 & -31 & -234 & -160 & -110 & -115 & -9 & -4 & -2 & 2 & 49 & 13 & 4 & 4 & 2 & 9 \\
\hline 7 & 62 & 22 & 15 & 9 & 9 & 33 & -67 & -87 & -222 & -90 & -67 & -79 & -40 & -34 & -16 & -7 & -4 & 2 & 12 & 13 & 47 & 26 & 14 & 27 \\
\hline 8 & 14 & 30 & 7 & 24 & 13 & 27 & 6 & -4 & -10 & -15 & -26 & -51 & -9 & -4 & -2 & -1 & -1 & 0 & 1 & 1 & 1 & 1 & 2 & 2 \\
\hline 9 & 6 & 4 & 3 & 4 & 7 & 4 & 1 & 1 & 0 & 49 & -140 & -40 & -6 & -3 & -6 & -3 & 1 & 1 & 8 & 12 & 8 & 32 & 32 & 13 \\
\hline 10 & 10 & 19 & 23 & 19 & 27 & 21 & -11 & -160 & -17 & -5 & -7 & -4 & -6 & -3 & -3 & -2 & 0 & 0 & 1 & 2 & 2 & 4 & 6 & 6 \\
\hline 11 & 9 & 6 & 6 & .13 & 15 & 27 & 3 & -23 & -33 & -81 & -212 & -218 & -105 & -115 & -74 & .54 & -58 & 5 & 18 & 25 & 9 & 29 & 11 & 23 \\
\hline 12 & 19 & 35 & 14 & 30 & 28 & 14 & -5 & -36 & -908 & -352 & -658 & -186 & -56 & -32 & -18 & -17 & -3 & 3 & 16 & 31 & 15 & 29 & 35 & 42 \\
\hline 13 & 35 & 71 & 9 & 16 & 12 & -1 & -331 & $\cdots$ & -616 & -69 & -180 & -39 & -20 & -18 & -10 & -6 & -1 & 2 & 8 & 23 & 27 & 21 & 26 & 71 \\
\hline 14 & 83 & 22 & 13 & 11 & 5 & 8 & -7 & -99 & -483 & $\cdots$ & -159 & -104 & -123 & -32 & -20 & -11 & -2 & 37 & 22 & 26 & 48 & 9 & 12 & 14 \\
\hline 15 & 7 & 5 & 4 & 6 & 8 & 6 & 16 & -53 & -8 & -21 & -17 & -65 & -115 & -80 & -494 & -124 & -54 & 36 & 66 & 17 & 10 & 13 & 91 & 149 \\
\hline 16 & 157 & 69 & 20 & 52 & 48 & 10 & -108 & -110 & $\cdots$ & -100 & -156 & -62 & -24 & -22 & -9 & -5 & 1 & 15 & 66 & 32 & 12 & 17 & 38 & 13 \\
\hline 17 & 56 & 85 & 26 & 6 & 3 & 6 & -5 & -199 & $\cdots$ & $\cdots$ & -228 & -85 & -12 & -9 & -2 & -1 & 1 & 2 & 5 & 20 & 26 & 21 & 42 & 30 \\
\hline 18 & 13 & 18 & 35 & 24 & 50 & 19 & -33 & -40 & -314 & -188 & -241 & -91 & -13 & -91 & -23 & -25 & -9 & 4 & 11 & 16 & 41 & 42 & 25 & 32 \\
\hline 19 & 23 & 43 & 19 & 20 & 9 & 12 & $\ldots$ & 67 & -195 & $\cdots$ & $\cdots$ & -520 & -38 & -25 & -13 & -15 & -7 & 3 & 11 & 13 & 38 & 27 & 48 & 14 \\
\hline 20 & 14 & 23 & 84 & 59 & 28 & 39 & -46 & -225 & -796 & -944 & -227 & -50 & -10 & -6 & -4 & -4 & -1 & 2 & 8 & 24 & 18 & 51 & 82 & 24 \\
\hline 21 & 69 & 16 & 43 & 36 & 18 & 6 & -98 & -142 & -883 & -84 & -12 & -2 & -2 & -2 & -2 & -1 & -1 & 0 & 2 & 3 & 4 & 21 & 35 & 21 \\
\hline 22 & 8 & 4 & 7 & 51 & 112 & 13 & -2 & -18 & -113 & -33 & -23 & -19 & -6 & -3 & -2 & -2 & -2 & 0 & 6 & 4 & 36 & 22 & 115 & 4 \\
\hline 23 & 3 & 4 & 2 & 3 & 3 & 11 & 1 & -1 & -1 & -1 & -1 & -1 & -1 & -1 & -1 & -1 & 0 & 0 & 0 & 0 & 0 & 0 & 0 & 0 \\
\hline 24 & 0 & 1 & 0 & 2 & 8 & 2 & 0 & -1 & -3 & -4 & -5 & -9 & -13 & -13 & -9 & -7 & -3 & -2 & -2 & -1 & 19 & 8 & 15 & 7 \\
\hline 25 & 21 & 20 & 7 & 3 & 2 & 11 & -4 & -8 & -2 & -2 & -2 & -3 & -1 & -1 & -2 & -2 & 1 & 1 & 1 & 5 & 10 & 6 & 13 & 21 \\
\hline 26 & 21 & 16 & 0 & 3 & 4 & -4 & -67 & -151 & -726 & -223 & -135 & -21 & -6 & 1 & 0 & -3 & -2 & 0 & 3 & 6 & 22 & 22 & 4 & 2 \\
\hline 27 & 13 & 15 & -6 & -1 & 12 & 1 & -3 & -14 & -29 & -7 & -11 & -3 & -4 & -5 & -10 & -6 & -2 & -6 & 5 & 5 & 6 & 2 & 4 & 4 \\
\hline 28 & 4 & 2 & 8 & 7 & 6 & 4 & -15 & -69 & -681 & -78 & -13 & -67 & -17 & -6 & -6 & -18 & -35 & 3 & 11 & 30 & 14 & 6 & 14 & 26 \\
\hline 29 & 31 & 13 & 14 & 8 & 5 & 1 & -6 & -161 & -224 & -406 & -46 & -26 & -17 & -63 & -64 & -45 & -33 & -14 & 43 & 15 & 27 & 13 & 16 & 15 \\
\hline 30 & 42 & 18 & 39 & 18 & 14 & 9 & -10 & -81 & -456 & -334 & -103 & -33 & -11 & -4 & -2 & -1 & -1 & 4 & 14 & 23 & 32 & 29 & 36 & 13 \\
\hline
\end{tabular}




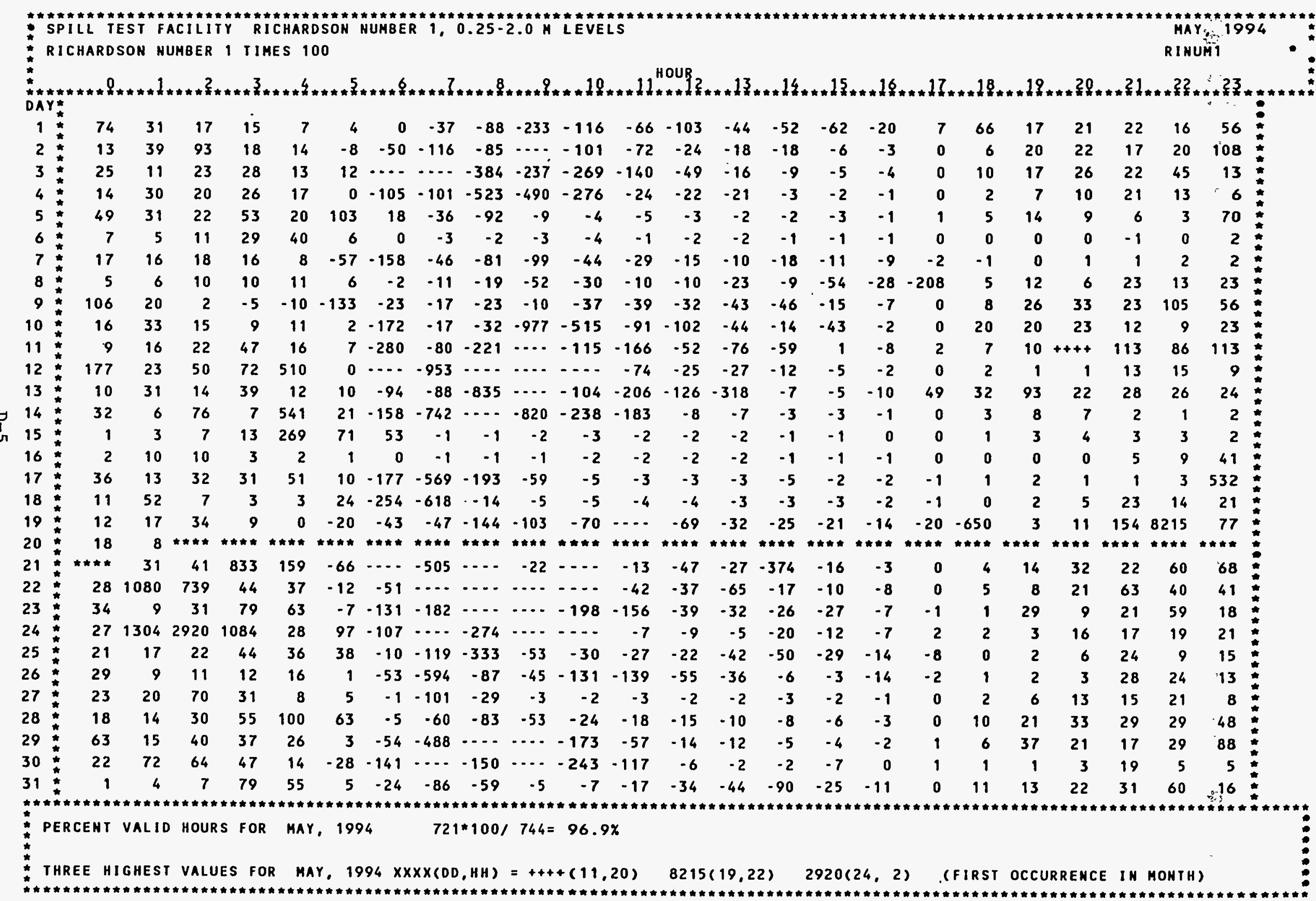




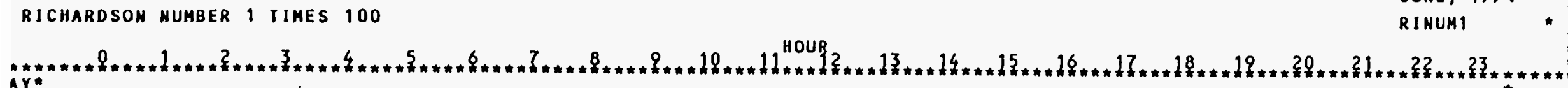

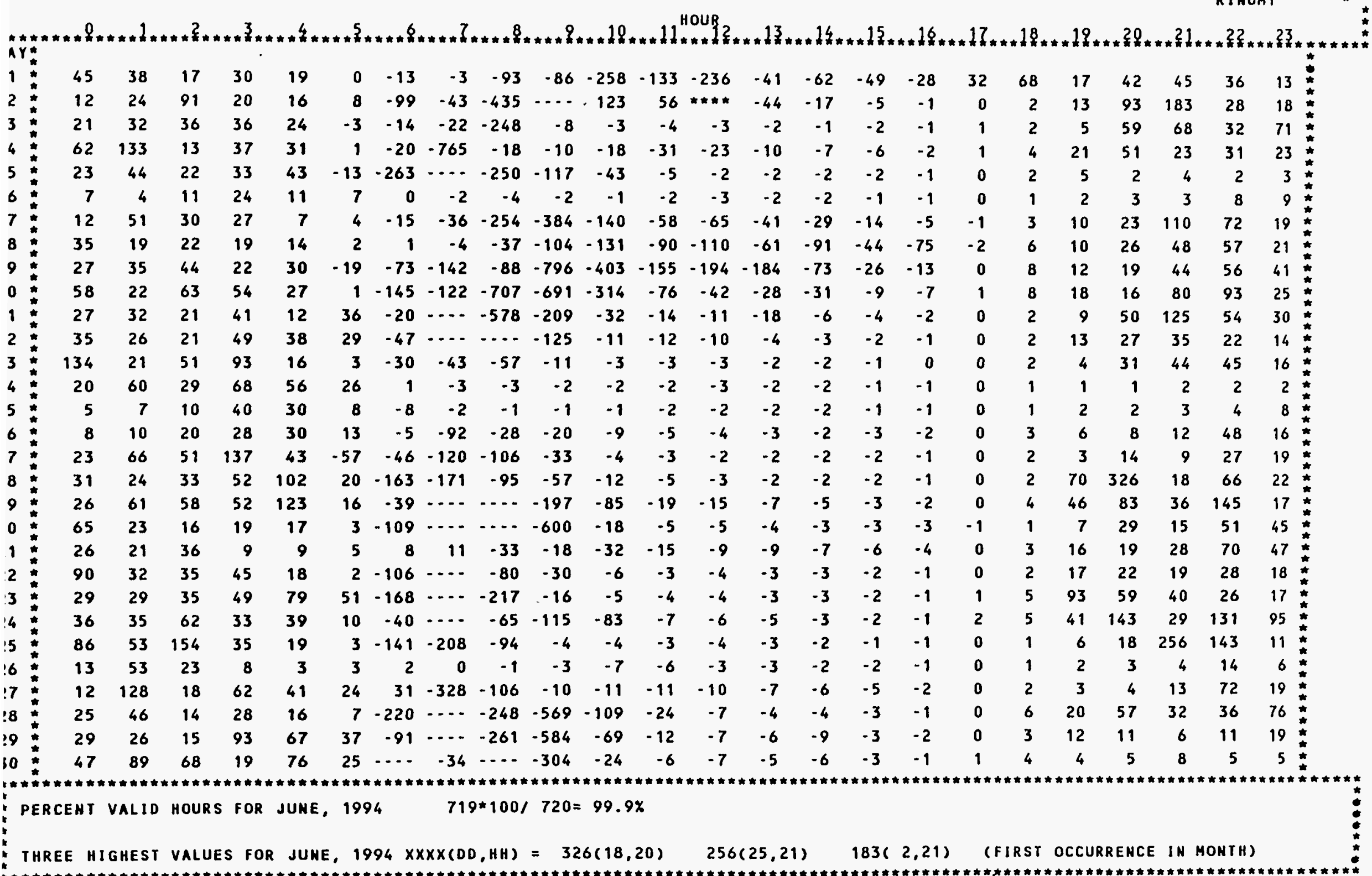




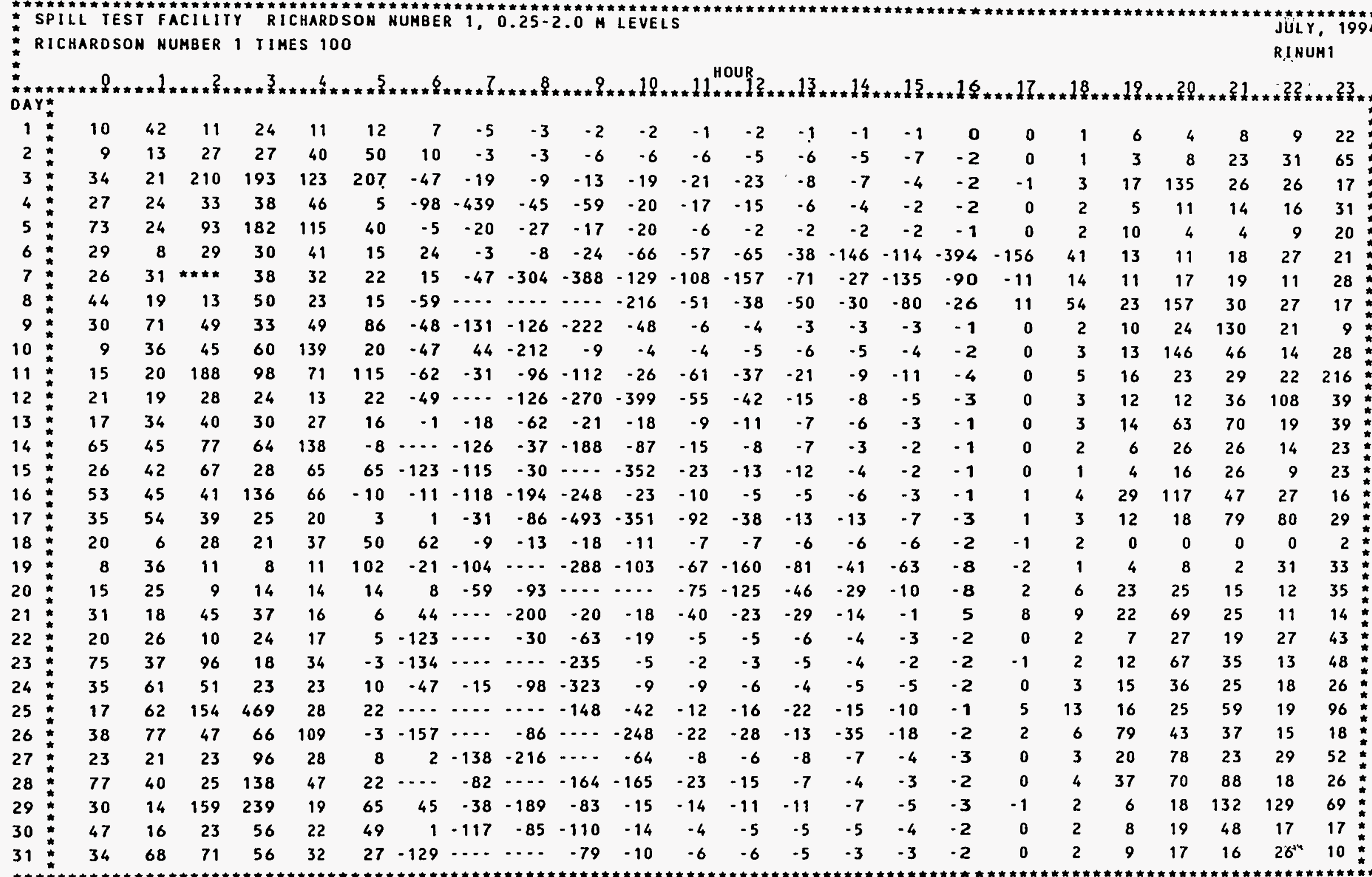

\footnotetext{
PERCENT VALID hOURS FOR JULY, $1994 \quad 743 * 100 / 744=99.9 \%$
}

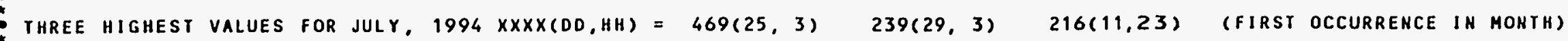




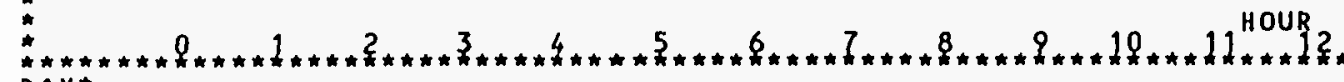
DAY*

\begin{tabular}{|c|c|c|c|c|c|c|c|c|c|c|c|c|c|c|c|c|c|}
\hline 1 & 11 & 72 & 23 & 48 & 19 & 24 & -26 & -260 & -185 & .71 & -4 & -4 & -5 & -4 & -3 & -2 & -1 \\
\hline 2 & 65 & 99 & 137 & 26 & 132 & 13 & -40 & $\cdots$ & $\cdots$ & -91 & -16 & -9 & -14 & -6 &.-7 & -7 & -4 \\
\hline 3 & 101 & 43 & 61 & 68 & 50 & 133 & 1161 & -285 & $\cdots$ & -226 & -236 & -227 & -28 & -16 & .5 & -2 & -1 \\
\hline 4 & 77 & 52 & 54 & 38 & 159 & 49 & -71 & -141 & -190 & $\cdots$ & -270 & -14 & -4 & -3 & -2 & -1 & -1 \\
\hline 5 & 73 & 212 & 48 & 106 & 40 & 45 & -171 & $\cdots$ & $\cdots$ & -268 & -8 & -3 & -3 & -3 & -2 & -1 & 0 \\
\hline 6 & 30 & 19 & 49 & 35 & 87 & 19 & 118 & -23 & -28 & -23 & -5 & -8 & -6 & -5 & -6 & -10 & -3 \\
\hline 7 & 32 & 72 & 60 & 96 & 138 & 69 & -74 & $\cdots$ & -42 & -40 & -10 & -8 & -13 & -6 & -5 & -2 & -3 \\
\hline 8 & 17 & 17 & 22 & 25 & 74 & 11 & 19 & 1 & -2 & 0 & 0 & 0 & -1 & -2 & -6 & -11 & -8 \\
\hline 9 & 10 & 124 & 13 & 18 & 132 & 19 & -2 & $\cdots$ & -187 & -18 & -7 & -6 & -7 & -11 & -21 & -5 & -2 \\
\hline 10 & 16 & 20 & 6 & 5 & 12 & 17 & -186 & $\cdots$ & -175 & -504 & -60 & -144 & -22 & -28 & -22 & -11 & -6 \\
\hline 11 & 8 & 9 & 7 & 27 & 45 & 21 & -90 & -96 & -196 & $\cdots$ & -219 & -363 & -48 & -29 & -16 & -12 & -6 \\
\hline 12 & 8 & 15 & 20 & 30 & 35 & 24 & 19 & -1 & -4 & 3 & -4 & .23 & -15 & -15 & -17 & -19 & -8 \\
\hline 13 & 28 & 33 & 7 & 23 & 7 & 5 & -1 & -18 & -247 & -516 & -111 & -133 & -59 & -119 & -4 & -4 & -10 \\
\hline 14 & 5 & 19 & 74 & 41 & 16 & 8 & -8 & -67 & $\cdots$ & $\cdots$ & -104 & -87 & -53 & -9 & -36 & -33 & -13 \\
\hline 15 & 30 & 19 & 20 & 24 & 43 & 32 & 21 & -50 & -106 & $\cdots$ & -285 & .102 & -39 & -16 & -11 & -10 & -5 \\
\hline 16 & 147 & 38 & 26 & 31 & 52 & 17 & -38 & -25 & $\cdots$ & $\cdots$ & -19 & -6 & -4 & -4 & -3 & -3 & -2 \\
\hline 17 & 38 & 20 & 60 & 55 & 50 & 58 & 23 & -64 & -228 & -10 & -2 & -2 & -2 & -1 & -1 & -1 & -1 \\
\hline 18 & 19 & 108 & 23 & 19 & 20 & 20 & 15 & -11 & -41 & -19 & -12 & -6 & -5 & -5 & -3 & -2 & -1 \\
\hline 19 & 11 & 9 & 5 & 3 & 19 & 16 & 8 & -26 & -32 & -24 & -29 & -20 & -22 & -52 & -30 & -17 & -24 \\
\hline 20 & 15 & 24 & 12 & 26 & 43 & 60 & -3 & -53 & $\cdots$ & -292 & -16 & -7 & -7 & -6 & -4 & -2 & -1 \\
\hline 21 & 14 & 29 & 33 & 115 & 120 & 110 & 8 & -30 & -46 & -5 & -2 & -2 & -2 & -2 & -3 & -2 & -1 \\
\hline 22 & 21 & 115 & 21 & 11 & 36 & 30 & 184 & 14 & -190 & -7 & -2 & -3 & -4 & -4 & -3 & -2 & -1 \\
\hline 23 & 15 & 27 & 65 & 42 & 31 & 11 & 81 & $\cdots$ & $\cdots$ & -178 & $\cdots$ & -124 & -15 & -8 & -4 & -3 & -1 \\
\hline 24 & 90 & 121 & 135 & 52 & 65 & 13 & -152 & -37 & -143 & -206 & -31 & -4 & -5 & -4 & -4 & -3 & -1 \\
\hline 25 & 86 & 79 & 177 & 43 & 49 & 58 & 13 & -54 & -62 & -2 & -2 & -3 & -3 & -3 & -3 & -2 & -1 \\
\hline 26 & 105 & 106 & 168 & 66 & 127 & 95 & -24 & $\cdots$ & -206 & -33 & -3 & -5 & -6 & -5 & -3 & -2 & 0 \\
\hline 27 & 10 & 35 & 13 & 12 & 3 & 5 & 2 & -1 & -9 & -42 & $\cdots$ & $\cdots$ & -147 & -293 & -77 & -54 & -13 \\
\hline 28 & 19 & 12 & 35 & 24 & 39 & 11 & -21 & -69 & -117 & -126 & -220 & -4 & -5 & -4 & -4 & -3 & -1 \\
\hline 29 & 23 & 78 & 46 & 55 & 41 & 41 & 96 & -240 & $\cdots$ & -180 & -83 & -26 & -17 & -10 & -8 & -6 & -2 \\
\hline 30 & 16 & 123 & 136 & 40 & 17 & 17 & -17 & $\cdots$ & -48 & -165 & -251 & -17 & -20 & -13 & -5 & -4 & -1 \\
\hline 31 & 37 & 109 & 109 & 192 & 27 & 44 & -21 & -224 & -193 & -203 & -162 & -6 & -3 & -2 & -2 & -2 & 0 \\
\hline
\end{tabular}




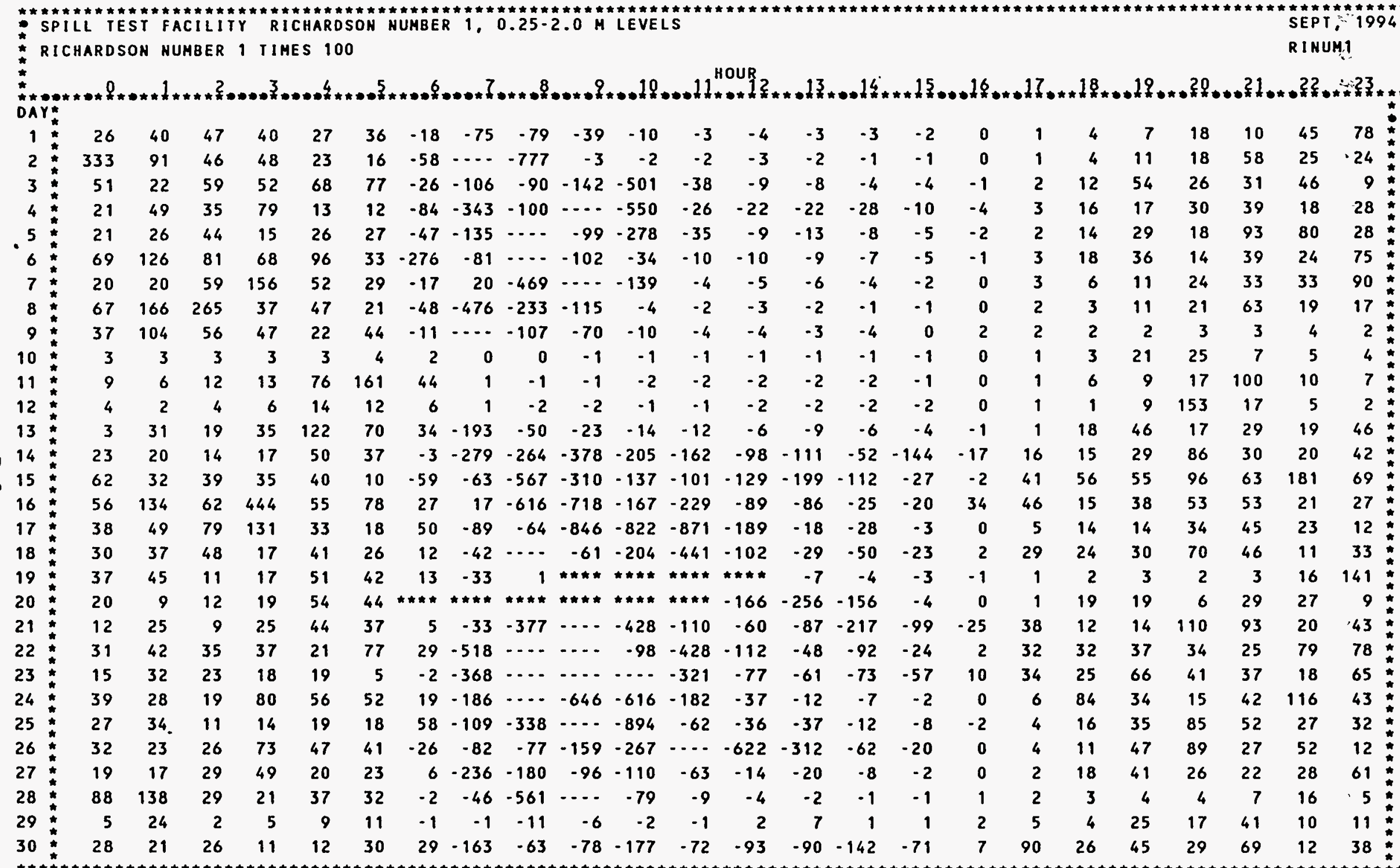

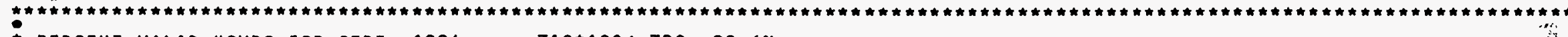

* PERCENT VALID HOURS FOR SEPT, $1994 \quad 710 * 100 / 720=98.6 \%$

THREE HIGHEST VALUES FOR SEPT, 1994 XXXX(DD,HH) a $444(16,3)$ 333( 2, 0) 265( 8 , 2 ) (FIRST OCCURREHCE IN MONTH) 


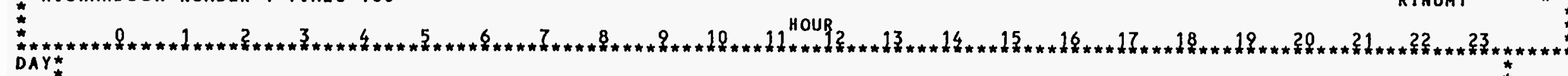

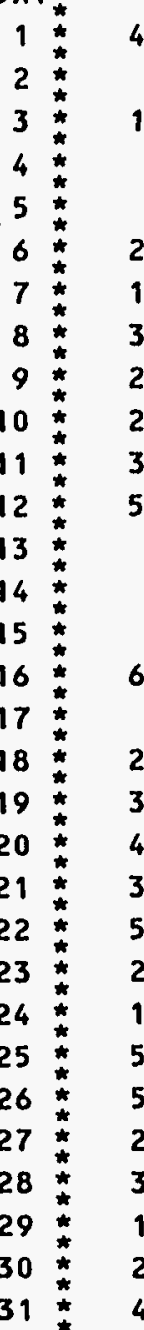

\begin{tabular}{|c|c|c|c|c|c|c|c|c|c|c|c|c|c|c|c|c|}
\hline 41 & 28 & 11 & 11 & 181 & 30 & 140 & -39 & -171 & -91 & -304 & -459 & -240 & -87 & -104 & -66 & -12 \\
\hline 7 & 42 & 56 & 31 & 50 & 19 & -11 & -179 & -493 & -382 & $\cdots$ & -20 & -7 & -6 & -4 & -2 & 1 \\
\hline 16 & 13 & 27 & 32 & 176 & 89 & 49 & 3 & 1 & 0 & -1 & -17 & -172 & -451 & -35 & -12 & 19 \\
\hline 2 & 3 & 33 & 22 & 15 & 13 & 30 & 0 & -1 & -1 & -2 & -2 & -1 & -1 & -1 & 0 & 0 \\
\hline 2 & 9 & 5 & 2 & 2 & 1 & 0 & -1 & -2 & -2 & -3 & -5 & -4 & -5 & -6 & -9 & -1 \\
\hline 24 & 20 & 8 & 12 & 9 & 41 & -31 & -107 & -180 & $\cdots$ & -225 & -319 & -150 & -220 & -65 & -42 & -4 \\
\hline 13 & 11 & 22 & 53 & 49 & 33 & 28 & -1 & -151 & -238 & -19 & -19 & -13 & -12 & -9 & -2 & 1 \\
\hline 37 & 7 & 16 & 62 & 39 & 31 & 43 & 2 & -6 & -24 & -30 & -97 & -277 & -154 & -261 & -332 & 7 \\
\hline 22 & 32 & 69 & 16 & 40 & 5 & 1 & -75 & -80 & $\ldots$ & -608 & -634 & -224 & -171 & -47 & -36 & 17 \\
\hline 24 & 52 & 44 & 37 & 30 & 31 & 8 & -177 & -226 & -109 & -567 & -46 & -4 & -5 & -3 & -1 & 2 \\
\hline 38 & 71 & 25 & 13 & 40 & 19 & 15 & -350 & -61 & -139 & -71 & -14 & -6 & -7 & -7 & -2 & 3 \\
\hline 55 & 16 & 13 & 19 & 16 & 34 & -10 & $\cdots$ & $\ldots$ & -101 & -44 & -23 & -4 & -2 & -1 & 0 & 1 \\
\hline 2 & 5 & 25 & 10 & 9 & 28 & 40 & -27 & -176 & -151 & -342 & -263 & -355 & -66 & -74 & -54 & 23 \\
\hline 5 & 11 & 10 & 16 & 33 & 52 & 19 & -114 & -509 & -293 & -181 & -28 & -8 & -6 & -4 & -1 & 0 \\
\hline 1 & 3 & 3 & 6 & 9 & 5 & 2 & -2 & -449 & -18 & -10 & -6 & -6 & -8 & -3 & -1 & 0 \\
\hline 68 & 44 & 29 & 17 & 6 & 6 & -12 & -426 & -132 & -184 & -143 & -34 & -19 & -29 & -16 & -12 & -1 \\
\hline 9 & 41 & 14 & 14 & -5 & -8 & -60 & -82 & -983 & $\cdots$ & -186 & -184 & -57 & -165 & -173 & -56 & 8 \\
\hline 20 & 21 & 19 & 14 & 20 & 26 & -44 & $\cdots$ & -152 & -46 & -246 & -88 & -23 & -18 & -10 & -4 & 3 \\
\hline 34 & 32 & 23 & 29 & 24 & 27 & -10 & -54 & $\cdots$ & -150 & $\cdots$ & -430 & -239 & -83 & -65 & -72 & 95 \\
\hline 41 & 40 & 93 & 85 & 64 & 28 & 6 & -330 & -279 & -200 & $\cdots$ & -101 & -145 & -20 & -26 & -10 & 9 \\
\hline 39 & 23 & 9 & 19 & 61 & 47 & 8 & -40 & -27 & -31 & $\cdots$ & $\cdots$ & -983 & -132 & -11 & -1 & 6 \\
\hline 52 & 21 & 175 & 22 & 12 & 15 & 31 & -303 & -71 & -620 & -284 & -344 & -147 & -42 & -5 & 1 & 9 \\
\hline 21 & 16 & 28 & 47 & 13 & 70 & 59 & -120 & $\cdots$ & -440 & -327 & 3 & -252 & -82 & -18 & -1 & 7 \\
\hline 13 & 18 & 23 & 19 & 27 & 13 & 17 & 1 & -70 & -107 & -229 & -112 & -167 & -180 & -100 & -14 & 23 \\
\hline 53 & 51. & 87 & 69 & 101 & 39 & 1 & -7 & -26 & -380 & -842 & $\cdots$ & -410 & -163 & -64 & 10 & 15 \\
\hline 50 & 52 & 89 & 46 & 75 & 25 & -8 & $\cdots$ & -6 & -60 & -401 & -140 & -597 & -325 & -155 & -4 & 5 \\
\hline 21 & 34 & 26 & 8 & 32 & 36 & 8 & -99 & -152 & -277 & 38 & -131 & -201 & -3 & -5 & 0 & 11 \\
\hline 36 & 24 & 13 & 41 & 51 & 10 & 5 & -177 & -15 & -6 & -972 & -149 & -198 & -176 & -46 & 1 & 7 \\
\hline 14 & 33 & 104 & 65 & 38 & 45 & 23 & 36 & -78 & -186 & -418 & -407 & -323 & -90 & -55 & -12 & 23 \\
\hline 23 & 23 & 19 & 13 & 22 & 23 & 20 & 19 & 1 & -7 & -16 & -6 & -9 & -6 & -5 & 1 & 9 \\
\hline 43 & 51 & 23 & 18 & 34 & 13 & -1 & -65 & -52 & -543 & $\cdots$ & -332 & - & -215 & $\cdots$ & 177 & 171 \\
\hline
\end{tabular}

$\begin{array}{rrrrrrr}20 & 18 & 19 & 104 & 117 & 18 & 60 \\ 5 & 16 & 52 & 16 & 31 & 31 & 33 \\ 24 & 29 & 55 & 17 & 52 & 17 & 2 \\ 1 & 7 & 4 & 2 & 1 & 5 & 1 \\ 6 & 5 & 11 & 38 & 60 & 37 & 40 \\ 13 & 9 & 14 & 50 & 19 & 25 & 20 \\ 7 & 12 & 13 & 17 & 91 & 40 & 35 \\ 16 & 19 & 31 & 22 & 22 & 37 & 36 \\ 36 & 22 & 11 & 26 & 42 & 47 & 23 \\ 11 & 231 & 128 & 50 & 81 & 45 & 78 \\ 14 & 87 & 35 & 40 & 22 & 30 & 36 \\ 3 & 6 & 8 & 16 & 3 & 2 & 3 \\ 49 & 30 & 12 & 14 & 3 & 1 & 6 \\ 1 & 1 & 2 & 1 & 1 & 0 & 0 \\ 6 & 36 & 18 & 39 & 15 & 9 & 12 \\ 4 & 11 & 8 & 45 & 51 & 23 & 11 \\ 12 & 10 & 27 & 9 & 98 & 47 & 23 \\ 21 & 97 & 40 & 24 & 26 & 17 & 32 \\ 20 & 33 & 16 & 24 & 13 & 16 & 29 \\ 12 & 14 & 31 & 66 & 38 & 118 & 16 \\ 17 & 15 & 23 & 40 & 36 & 38 & 17 \\ 21 & 24 & 32 & 46 & 35 & 154 & 40 \\ 24 & 30 & 27 & 43 & 51 & 26 & 48 \\ 12 & 42 & 129 & 45 & 25 & 31 & 95 \\ 11 & 84 & 143 & 37 & 39 & 62 & 65 \\ 13 & 17 & 41 & 46 & 117 & 21 & 57 \\ 30 & 58 & 83 & 33 & 20 & 105 & 79 \\ 11 & 64 & 59 & 35 & 42 & 116 & 47 \\ 18 & 72 & 18 & 31 & 50 & 17 & 24 \\ 12 & 29 & 38 & 96 & 27 & 80 & 51 \\ 27 & 20 & 33 & 75 & 379 & 30 & 27 \\ 13\end{array}$

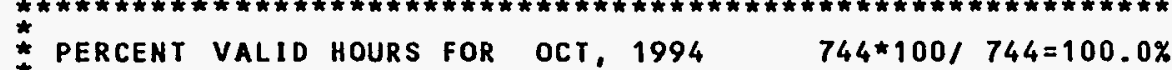




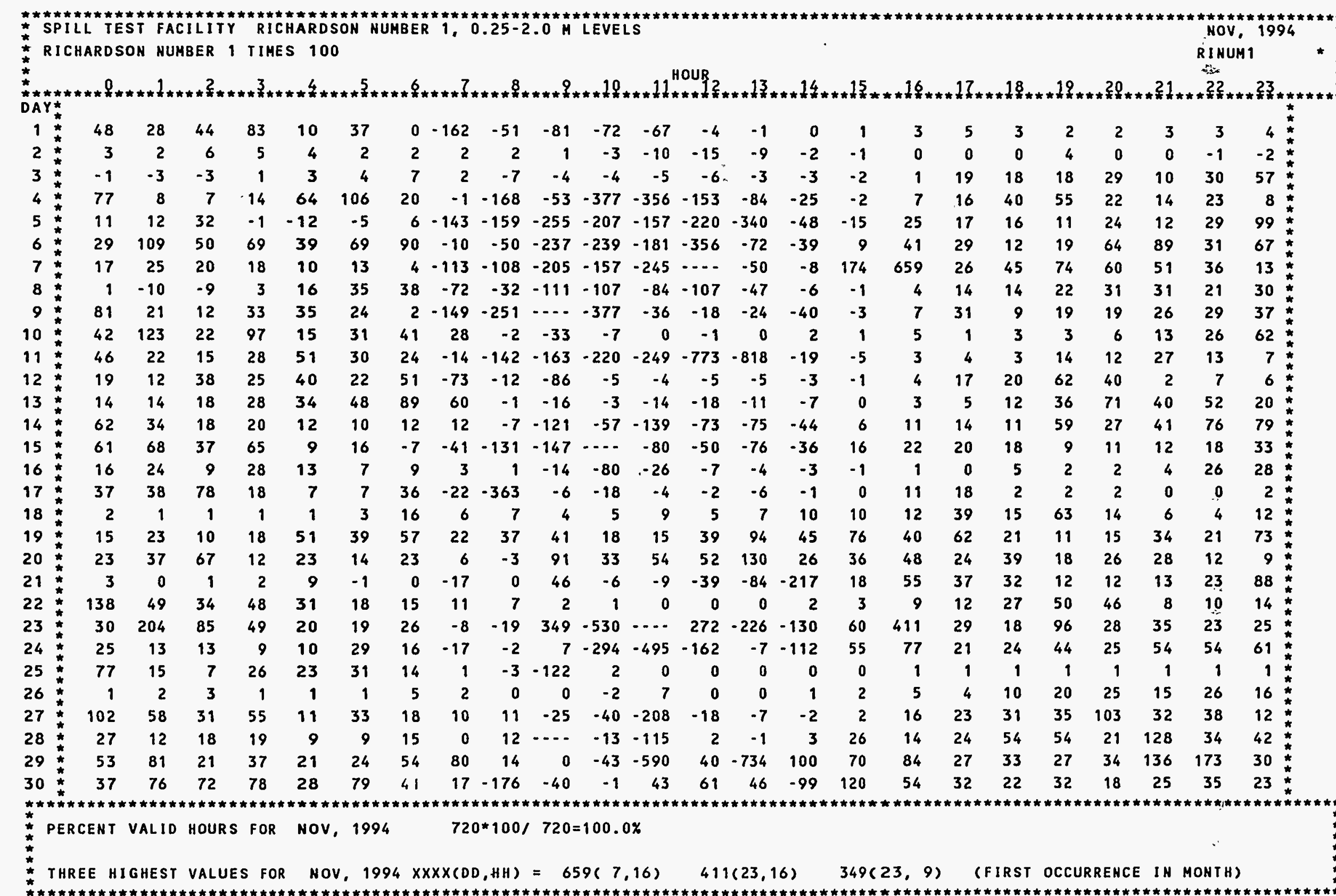




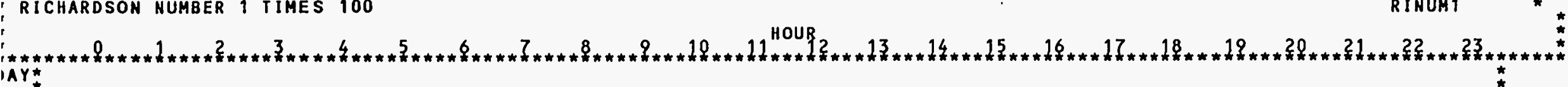

\begin{tabular}{|c|c|c|c|c|c|c|c|c|c|c|c|c|c|c|c|c|c|c|c|c|c|c|c|}
\hline 31 & 19 & 53 & 85 & 53 & 84 & 7 & 6 & 67 & 92 & $\cdots$ & -62 & 11 & 162 & 54 & 0 & 79 & 5 & 1 & 46 & 67 & 36 & 39 & \\
\hline 24 & 19 & 15 & 31 & 22 & 26 & 10 & -4 & 19 & -81 & $\cdots$ & -4 & -5 & 39 & 26 & 3 & 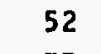 & 2 & 16 & 24 & 47 & 31 & 13 & \\
\hline 49 & 6 & ? & 4 & 0 & 0 & 68 & 51 & 20 & -50 & -62 & 25 & -22 & -7 & 20 & 22 & - & 20 & 21 & 19 & 32 & 41 & 20 & 2 \\
\hline 31 & 108 & 31 & 61 & 48 & 20 & -1 & -3 & 33 & -26 & -31 & -1 & -8 & 21 & 26 & 101 & 74 & 36 & 66 & 18 & 9 & 50 & 32 & \\
\hline 30 & 17 & 16 & 27 & 33 & 19 & 16 & 8 & -14 & -58 & -301 & 134 & -96 & -13 & -17 & 4 & 52 & 48 & 12 & 7 & 12 & 15 & 28 & 10 \\
\hline 18 & 19 & 17 & 60 & 17 & 4 & 10 & -6 & 04 & -73 & -305 & 04 & -9 & -28 & -8 & 2 & 5 & 16 & 47 & 24 & 35 & 24 & 26 & 31 \\
\hline 100 & 32 & 22 & 14 & 30 & 17 & 14 & -7 & -23 & -7 & -44 & -93 & 124 & -37 & -5 & 6 & 11 & 25 & 98 & 178 & 35 & 78 & 50 & 75 \\
\hline 58 & 93 & 31 & 67 & 32 & 20 & 22 & 12 & 2 & 0 & -1 & -2 & -2 & -3 & -1 & 5 & 18 & $\star \star * *$ & $\star \star \star \star$ & $\star \star \star \star ~$ & $* \star \star$ & $* * *$ & $* \star \star$ & \\
\hline$\star \star \star$ & $\star \star \star \star \star$ & $* \star *$ & $\star \star \star$ & $* * *$ & $* \star \star$ & * * & $\star \star \star \star \star$ & $* *$ & $* *$ & $\star \star \star \star \star$ & \#\#* & $\star \star \star \star$ & $\star \star \star$ & $* *$ & * * & $* * *$ & $\star \star \star \star$ & $\star \star \star \star *$ & $\star \star \star \star$ & $\star \star \star \star \star$ & $\star \star \star \star *$ & $\star$ & 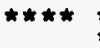 \\
\hline ** & $\star \star \star \star \star *$ & $* \pi$ & $* *$ & $* \neq$ & $\star \star \star \star \star$ & * * & $\star \star \star \star \star$ & $* \star \star$ & $\star \star \star \star \star$ & 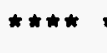 & $\star \star \star \star \star$ & $\star \star \star * \star$ & $\star \star \star \star$ & $\hbar *$ & & , & $\star$ & 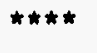 & ** & $\star \star \star \star$ & $*$ & 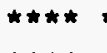 & \\
\hline 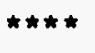 & $\star \star \star \star \star *$ & $\star \star *$ & $\star \star \star \star \star *$ & $\star * *$ & $\star * * \hbar$ & $\star \star * * *$ & $\star \star \star \star \star$ & $\star \star \star * \star$ & $\star \star \star \star \star *$ & $\star \star \star \star \star *$ & $\star \star \star \star \star$ & $\star \star \star \star \star$ & $\star \star \star \star$ & $\star \star \star *$ & $* *$ & $\star \star \star$ & $* * *$ & 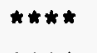 & $\star \star \star \star$ & 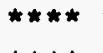 & $\star \star * *$ & 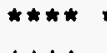 & * * \\
\hline$\star \star$ & $\hbar \star \star \star \star$ & $\star \star \star \star \star$ & $\star \star \star \star \star$ & $\star \star \star \star \star$ & $\star \star \star \star \star$ & ** & $\star \star \star \star \star$ & $\star \star \star *$ & 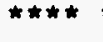 & $\star \star \star \star \star$ & $\star \star * \star \star *$ & 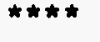 & $\star \star * \star *$ & **** & $\star \star \star \star \star$ & $\star \star \star \star \star *$ & $\star \star \star \star \star$ & $\star \star \star * \star \star$ & $\star \star$ & $\star \star \star$ & $\star \star \star \star \star$ & $\star \star \star \star$ & 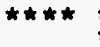 \\
\hline * & 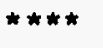 & $\star \star \star \star \star$ & $\star \star \star \star \star \star$ & $* *$ & $\star * * *$ & $\star *$ & $* *$ & $* *$ & $\star \star \star \star \star \star$ & $\star \star \star \star \star *$ & $\hbar * \star \star$ & $\star \star \star \star$ & $* \star$ & $\star \star *$ & $\star \star$ & ** & $\star \star$ & 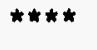 & $* \star$ & $\star \star \star \star \star$ & $\star \star \star \star \star$ & $* * x$ & $\star \star \star \star$ \\
\hline * * & $\star \star \star \star \star$ & $\star \star \star \star \star \star$ & 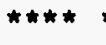 & 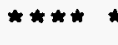 & $\star \star \star \star$ & 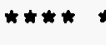 & 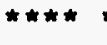 & $\star \star \star \star \star$ & $\star \star \star \star \star$ & $\star * \star * *$ & $\star \star \star \star \star$ & $\star \star \star \star$ & $\star \star * * \hbar$ & $\star \star \star \star \star$ & $\star \star \star * \star$ & 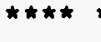 & $\star \star * * \star$ & $\star \star \star \star$ & $\star \star \star \star$ & $\star \star \star \star \star$ & $\star \star \star \star \star$ & $\star \star \star \star$ & $\star \star \star *$ \\
\hline$\star \star$ & $\star \star \star \star \star *$ & $\star * * *$ & $\star \star \star \star * *$ & $* *$ & $\star \star \star \star \star$ & $* *$ & 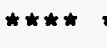 & $* *$ & 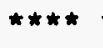 & $\star \star \star \star \star \star$ & $\star \star \star \star \star$ & $\star \star \star \star \star$ & $\star \star \star \star$ & $\star \star \star \star *$ & $\star$ & $\star \star \star \star \star *$ & * & 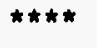 & 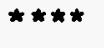 & $* * *$ & $* * *$ & $\star * * * *$ & 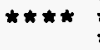 \\
\hline$\star \star \star$ & $\star \star \star \star \star$ & $* \star$ & $* \star$ & $* *$ & $\star \star \star \star \star *$ & $\star * * * *$ & * * & $* * *$ & $\star \star * * \star$ & $\star \star \star \star *$ & $\star * \star \star \star$ & $\star * \star * \star$ & $\star \star \star \star \star$ & $\star \star \star \star \star \star$ & & 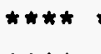 & $\star \star \star \star$ & * & $\star \star$ & $\star \star \star \star$ & $\star \star \star \star \star$ & $\star \star \star \star$ & 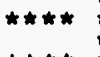 \\
\hline$\star \star \star$ & $\star \star \star \star \star$ & $* * * *$ & $\star \star \star \star \star \star$ & 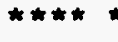 & $\star \star \star \star \star$ & $\star \star \star \star \star$ & $\star \star \star \star \star$ & $\star \star \star \star \star$ & $\star \star \star \star \star$ & $\star \star \star \star \star$ & 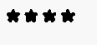 & $\star \star \star \star$ & 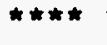 & $\star * * *$ & $\star \star \star \star \star$ & $\star \star \star \star \star *$ & $\star * * \star$ & 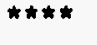 & $\star \star$ & 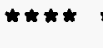 & $\star \star \star \star \star$ & 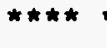 & 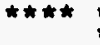 \\
\hline * * & $\star \star \star \star \star$ & $* * * *$ & $\star \star \star \star \star$ & $*$ & $\star \star \star \star \star$ & $\star * * * *$ & $* * * *$ & $* *$ & $* * * *$ & $\star \star \star * * *$ & $\star \star * \star *$ & $\star \star \star \star \star$ & $* *$ & * * & * * & $* *$ & * & 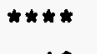 & ** & $* *$ & $* *$ & 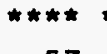 & 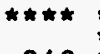 \\
\hline$\star *$ & $* * *$ & 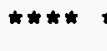 & $\star \star \star$ & & $\star \star \star \star \star$ & $\star \star \star \star \star$ & 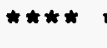 & $\star \star * * *$ & $\star \star \star \star \star$ & $\star * * *$ & $* \star \star * \star$ & $\star \star \star \star \star$ & $\star \star \star \star *$ & $\star * *$ & 114 & 77 & 75 & 40 & 80 & 42 & 34 & 57 & 240 \\
\hline 67 & 34 & 62 & 47 & 57 & 36 & 48 & 183 & 05 & 265 & 734 & 486 & 368 & 352 & 317 & 84 & 59 & 17 & 139 & 41 & 38 & 67 & 83 & 197 \\
\hline 135 & 72 & 34 & 36 & 67 & 33 & 124 & 5 & 104 & 146 & 435 & 136 & 438 & 143 & 223 & 131 & 232 & $y$ & 6 & 95 & 30 & 111 & 202 & 80 \\
\hline 83 & 41 & 45 & 22 & & 101 & 45 & 103 & 38 & 55 & 22 & 32 & 28 & 24 & 22 & 43 & 64 & 41 & 55 & 32 & 24 & 67 & 127 & 149 \\
\hline 45 & 23 & 8 & 12 & 31 & 60 & 29 & 45 & 57 & 225 & 143 & 113 & 476 & 124 & 197 & 50 & 45 & 57 & 122 & 13 & 10 & 31 & 48 & 40 \\
\hline 26 & 81 & 22 & 32 & 29 & 73 & 100 & 205 & 495 & 282 & 172 & 25 & 99 & 32 & 65 & 33 & 47 & 62 & 31 & 22 & 3 & 30 & 28 & 33 \\
\hline 42 & 36 & .48 & 5 & 12 & 11 & 16 & 46 & 27 & 29 & 7 & 10 & 63 & 6 & 10 & 19 & 10 & 11 & 8 & 4 & 8 & 46 & 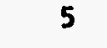 & 15 \\
\hline 45 & 16 & 15 & 19 & 13 & 38 & 86 & 6 & 9 & 6 & 4 & 6 & 0 & 12 & 22 & 16 & 14 & 7 & 65 & 44 & 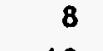 & 64 & 38 & 27 \\
\hline 17 & 83 & 41 & 26 & o & 4 & 48 & 49 & 79 & 125 & 367 & 153 & 1055 & 400 & 284 & 49 & 91 & 65 & 114 & 93 & 40 & 28 & 114 & 51 \\
\hline 97 & 44 & 75 & 86 & 39 & 39 & 57 & 31 & 30 & 100 & 166 & 134 & 21 & 12 & 143 & 39 & 62 & 36 & 107 & 4 & 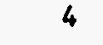 & 44 & 33 & 29 \\
\hline 22 & 13 & 8 & 10 & 57 & 52 & 36 & 29 & 94 & 85 & 93 & 120 & 4 & 2 & 6 & 15 & 139 & 74 & 47 & 29 & 47 & 16 & 25 & 16 \\
\hline 15 & 15 & 13 & 11 & 8 & 22 & 30 & 215 & 30 & 10 & 4 & 10 & 73 & 59 & 45 & 148 & 84 & 24 & 24 & 56 & 74 & 47 & 21 & 41 \\
\hline 33 & 64 & 11 & 34 & 12 & 85 & 22 & 55 & 65 & 125 & 77 & 38 & 87 & 281 & 186 & 88 & 70 & 73 & 28 & 39 & 29 & 54 & 53 & 87 \\
\hline
\end{tabular}

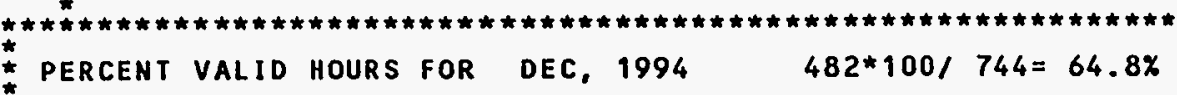




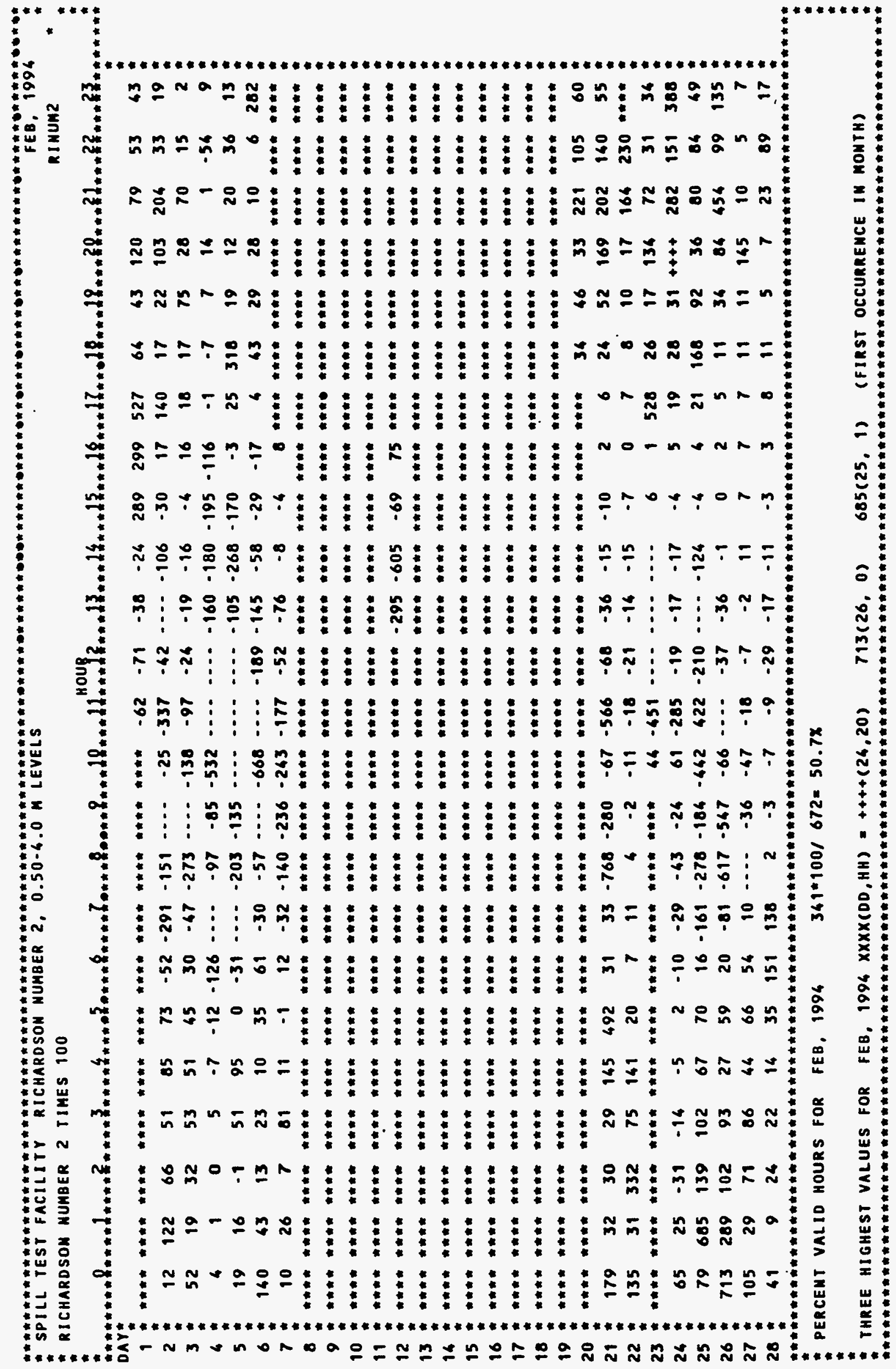




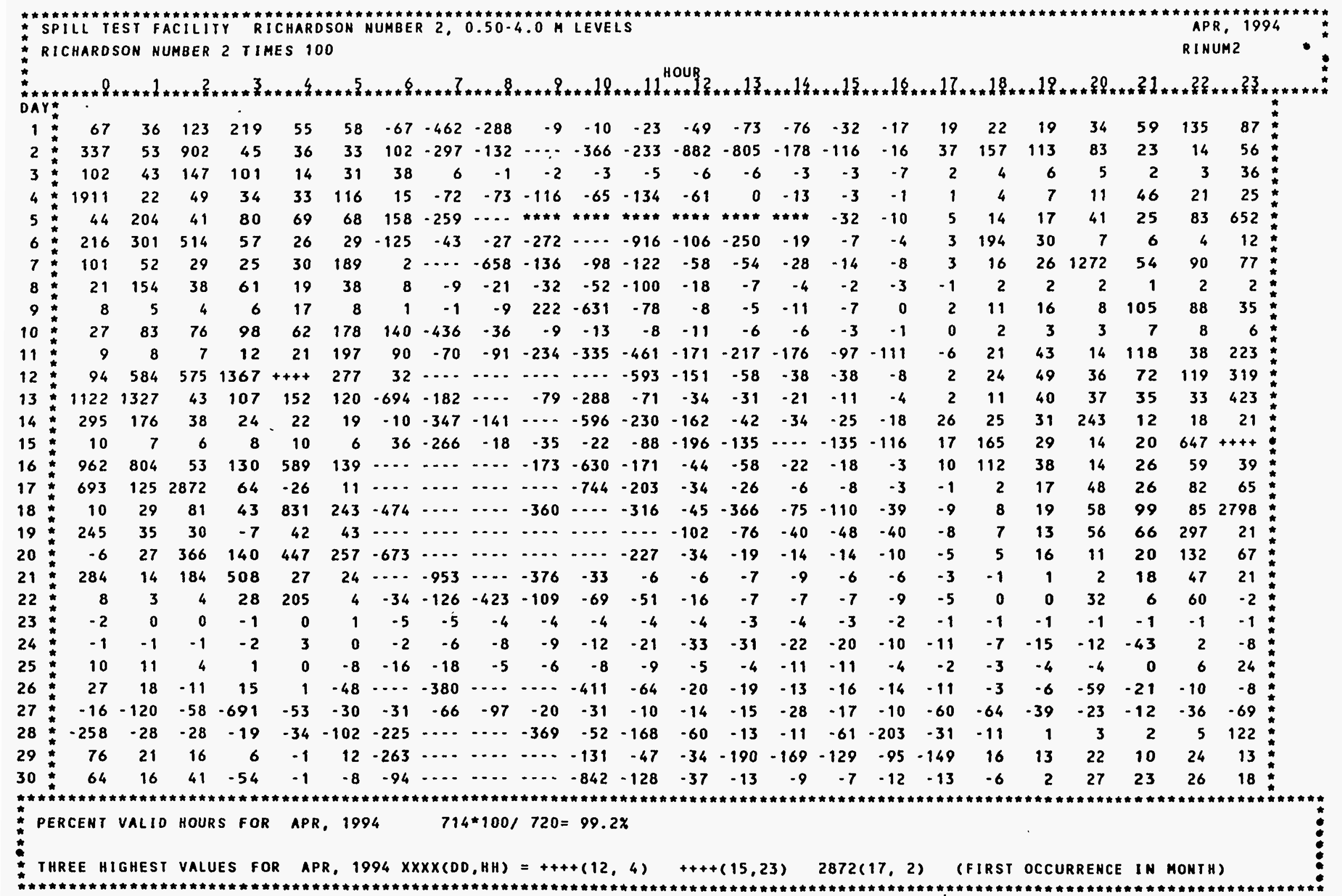




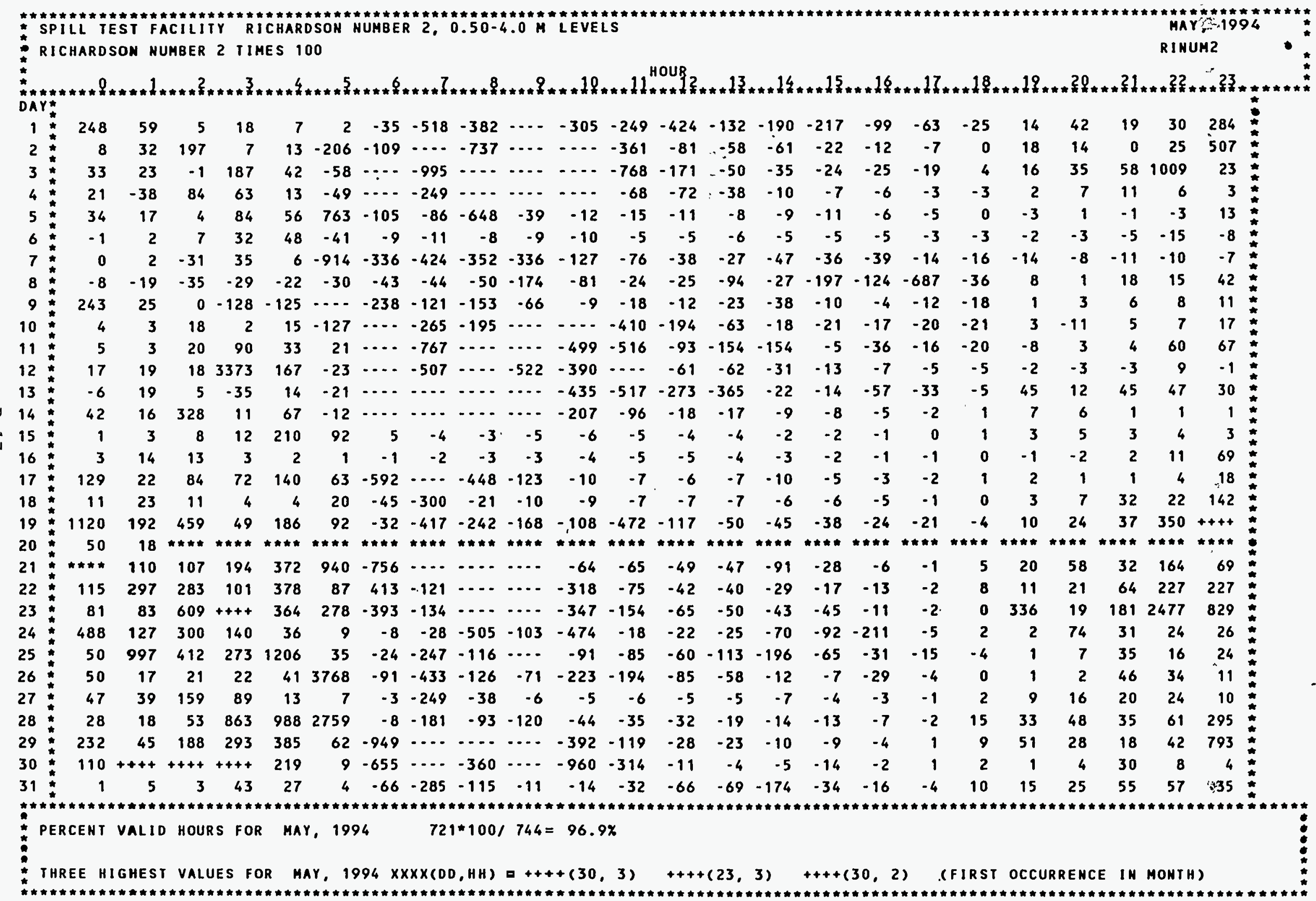




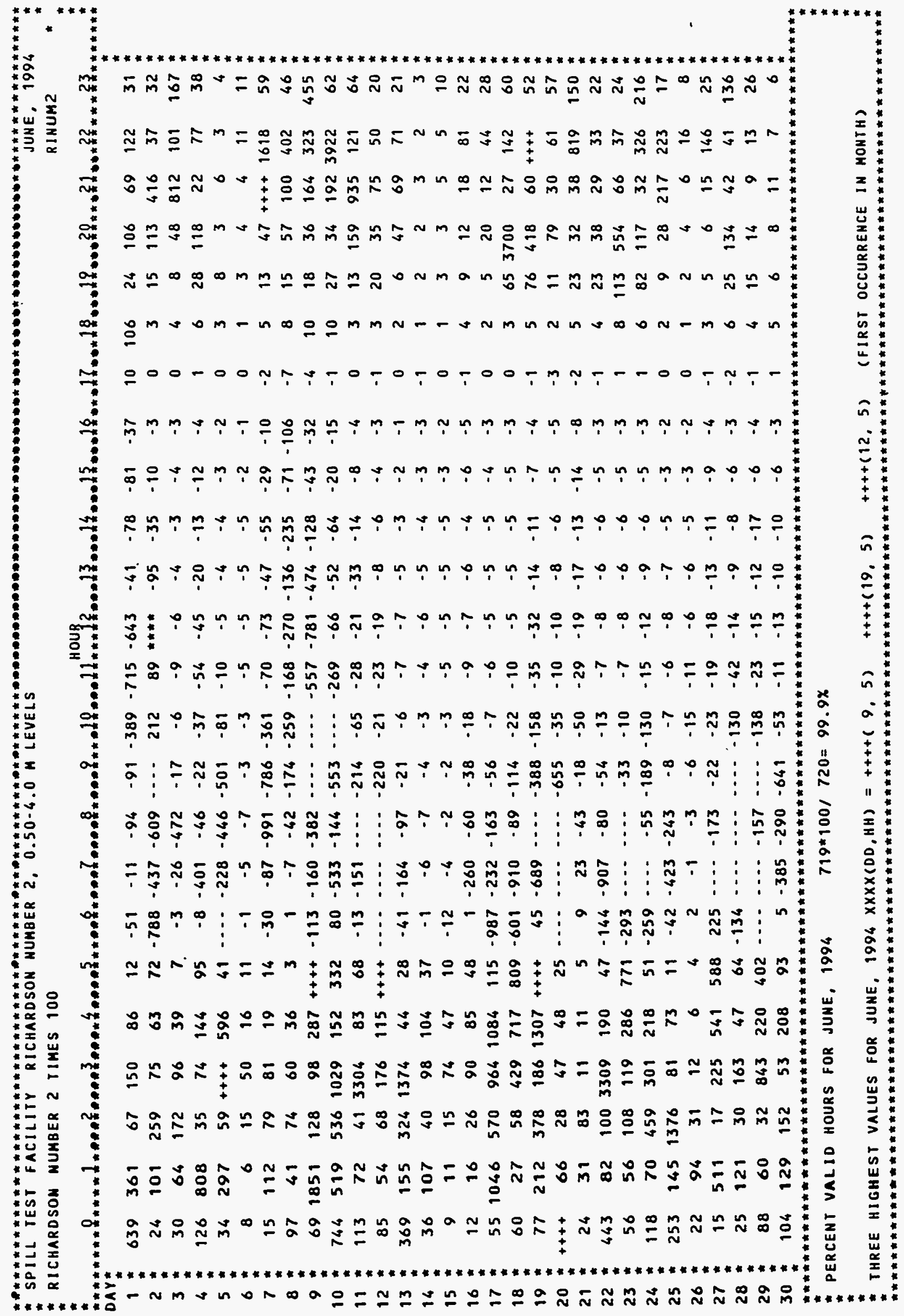




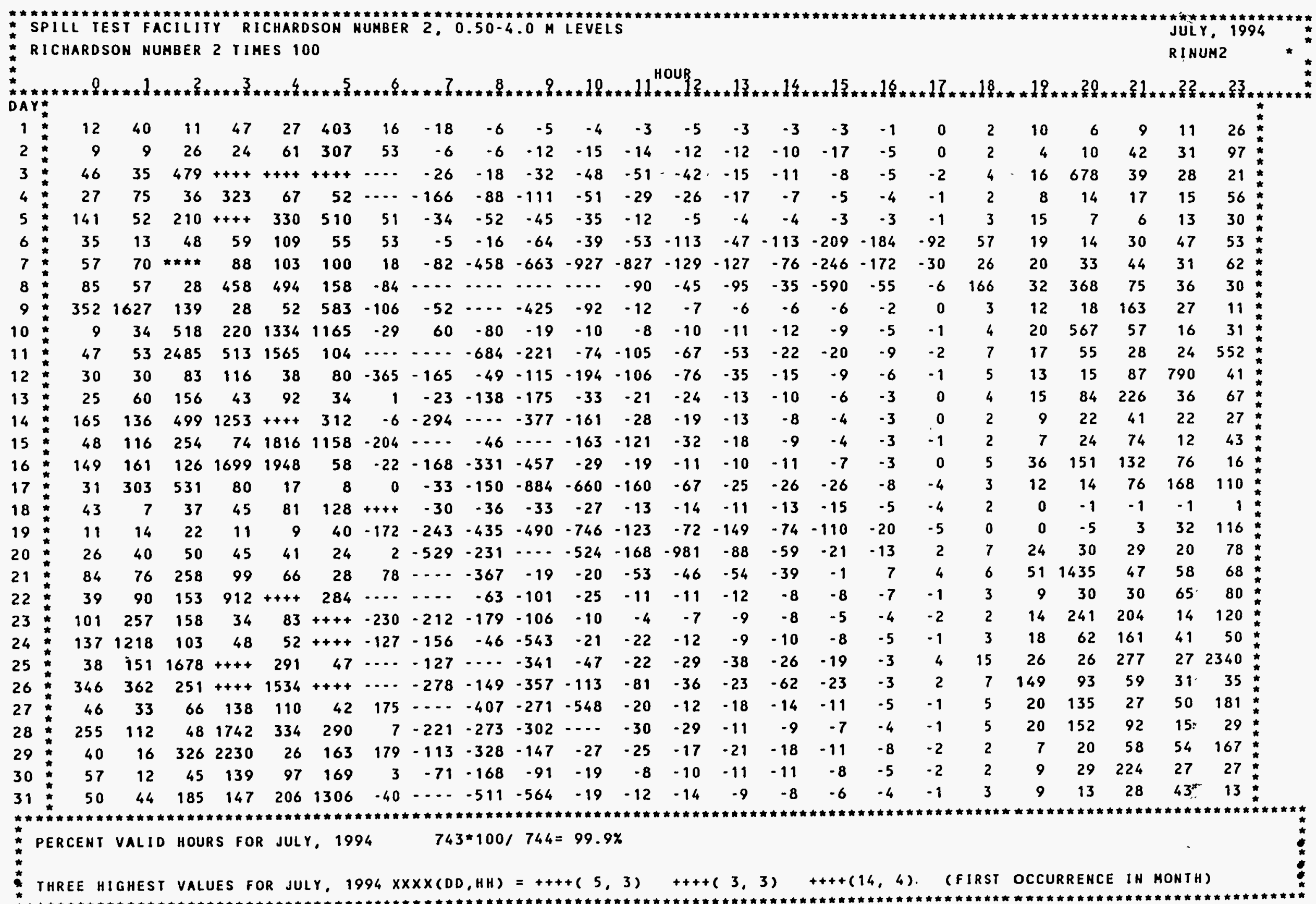




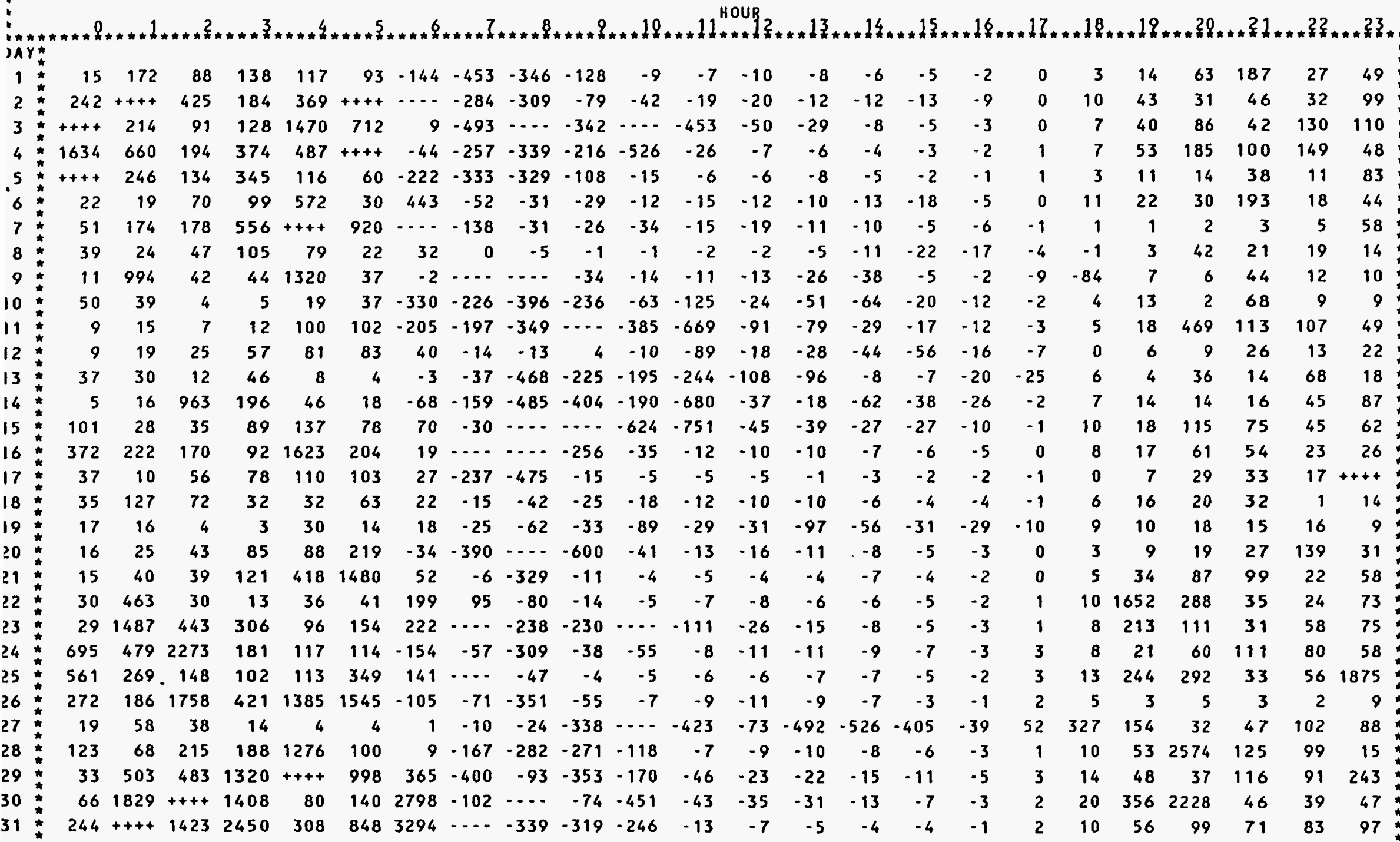

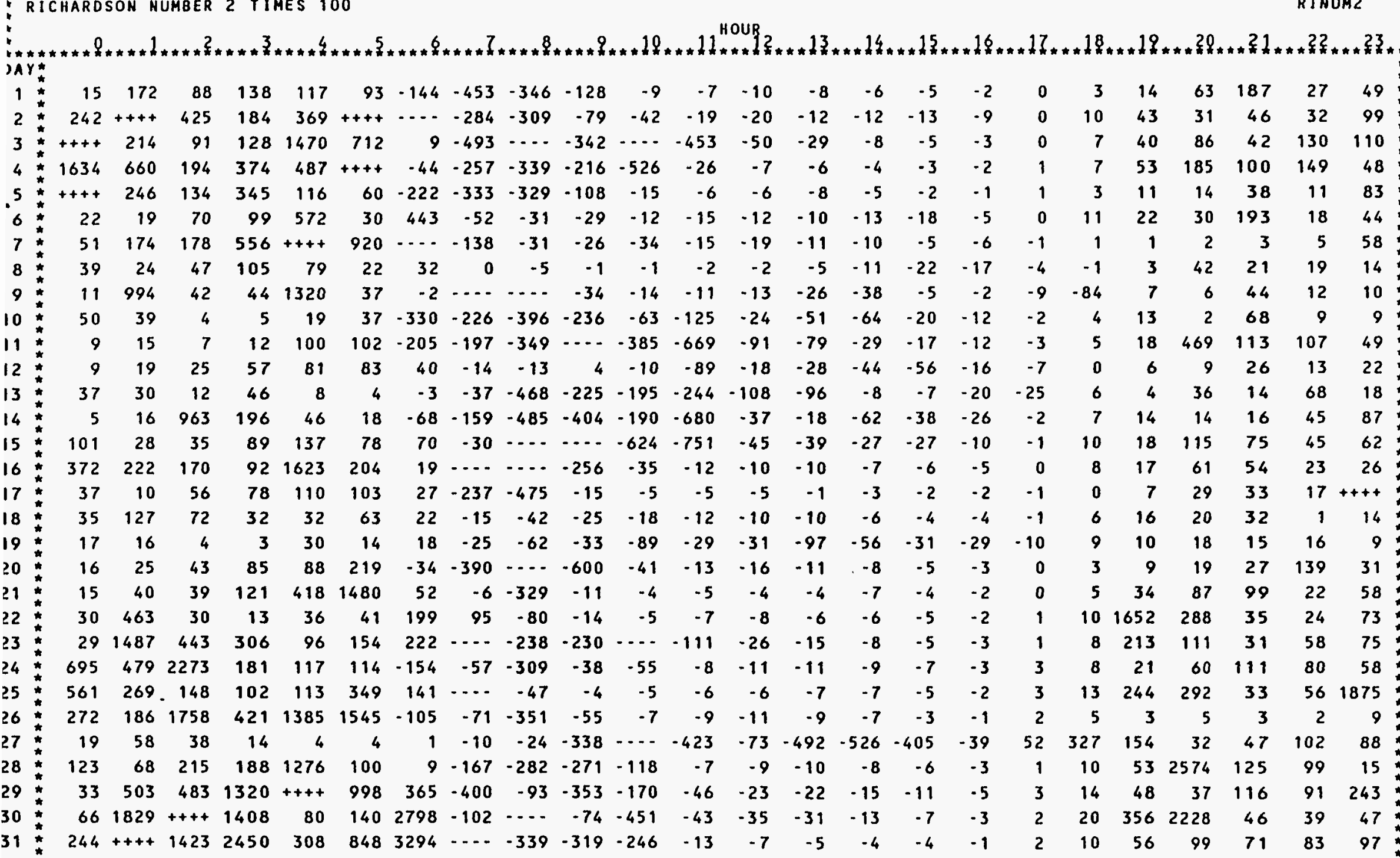

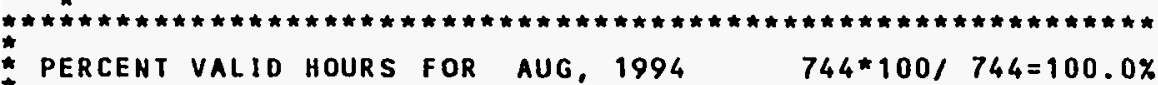




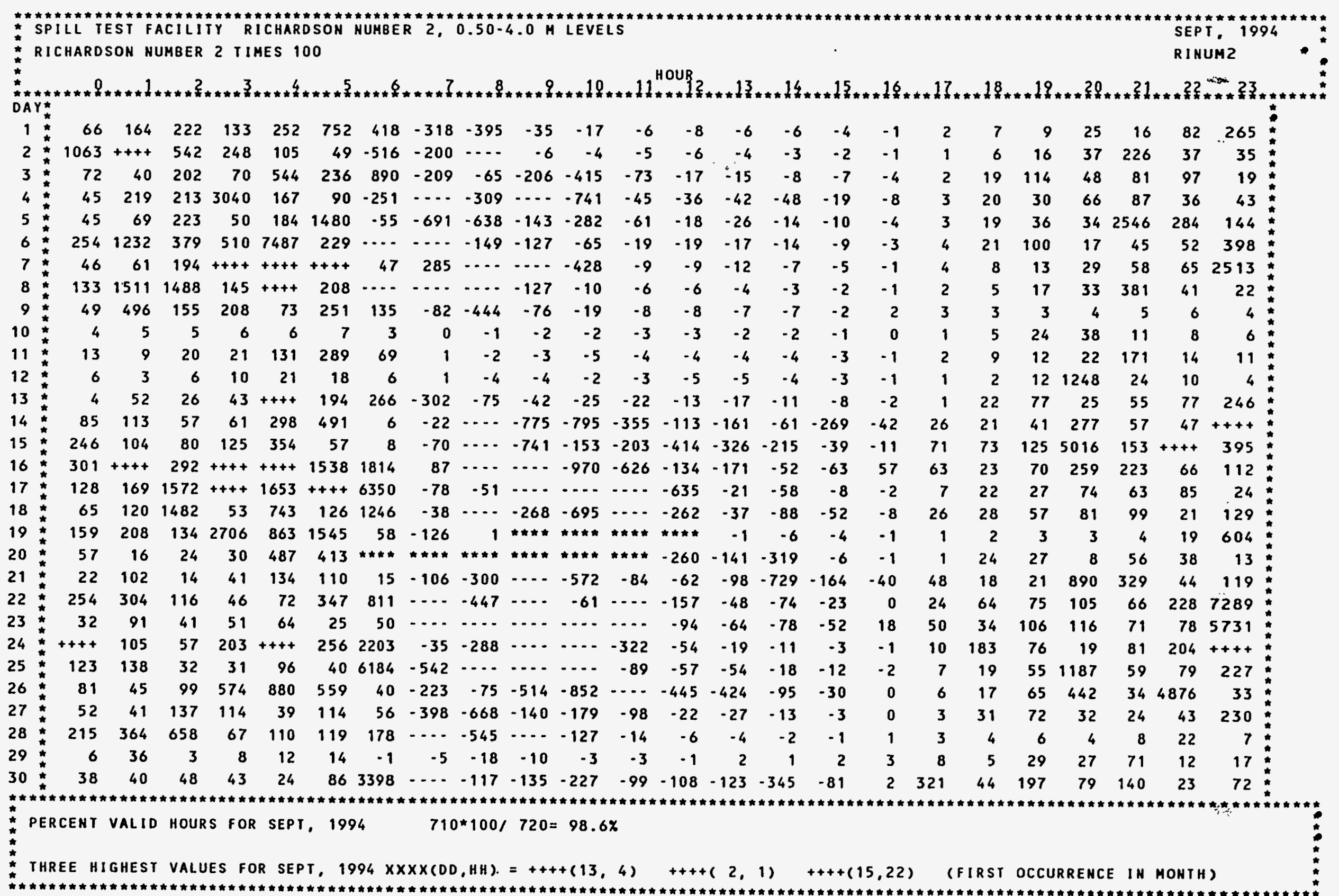




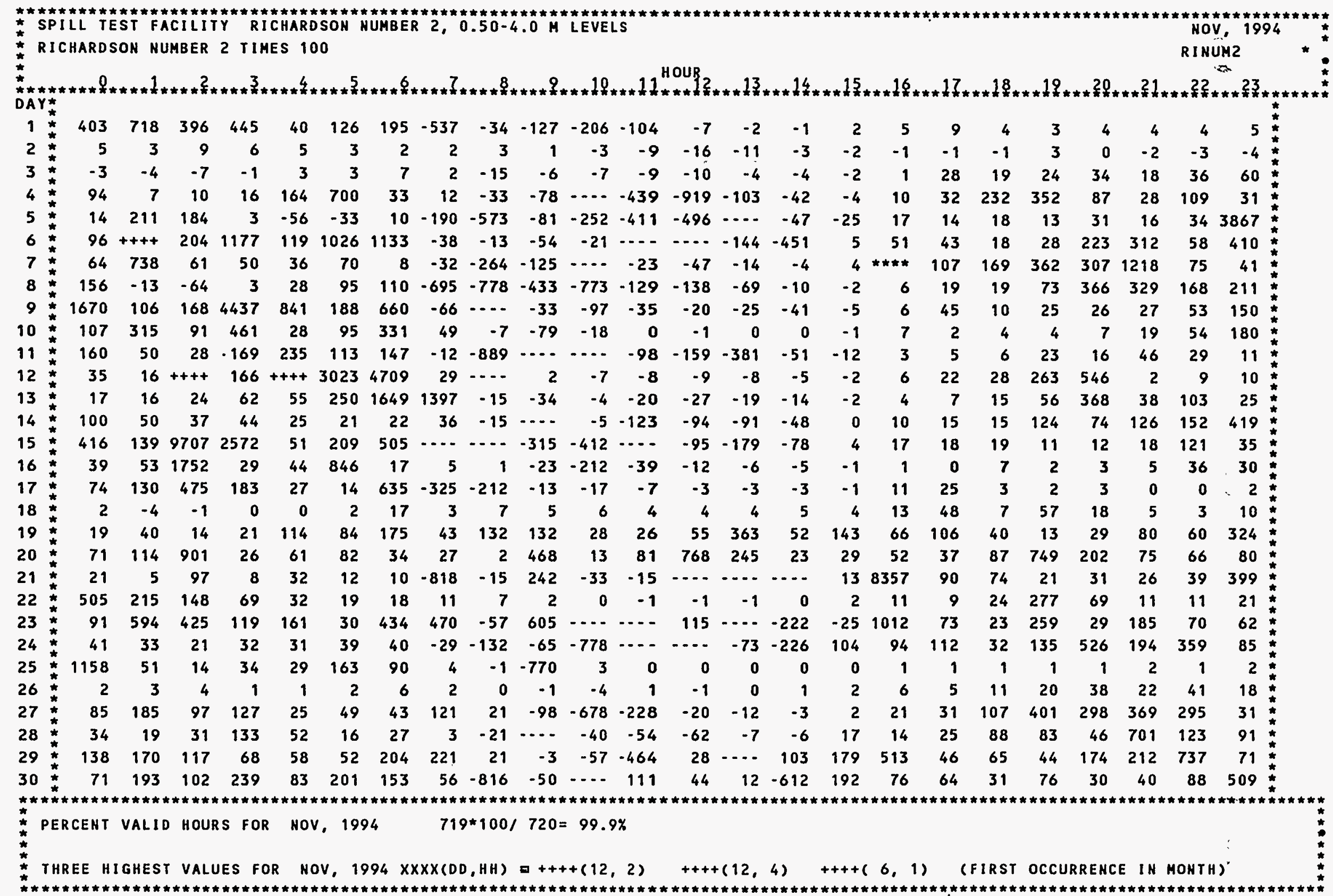




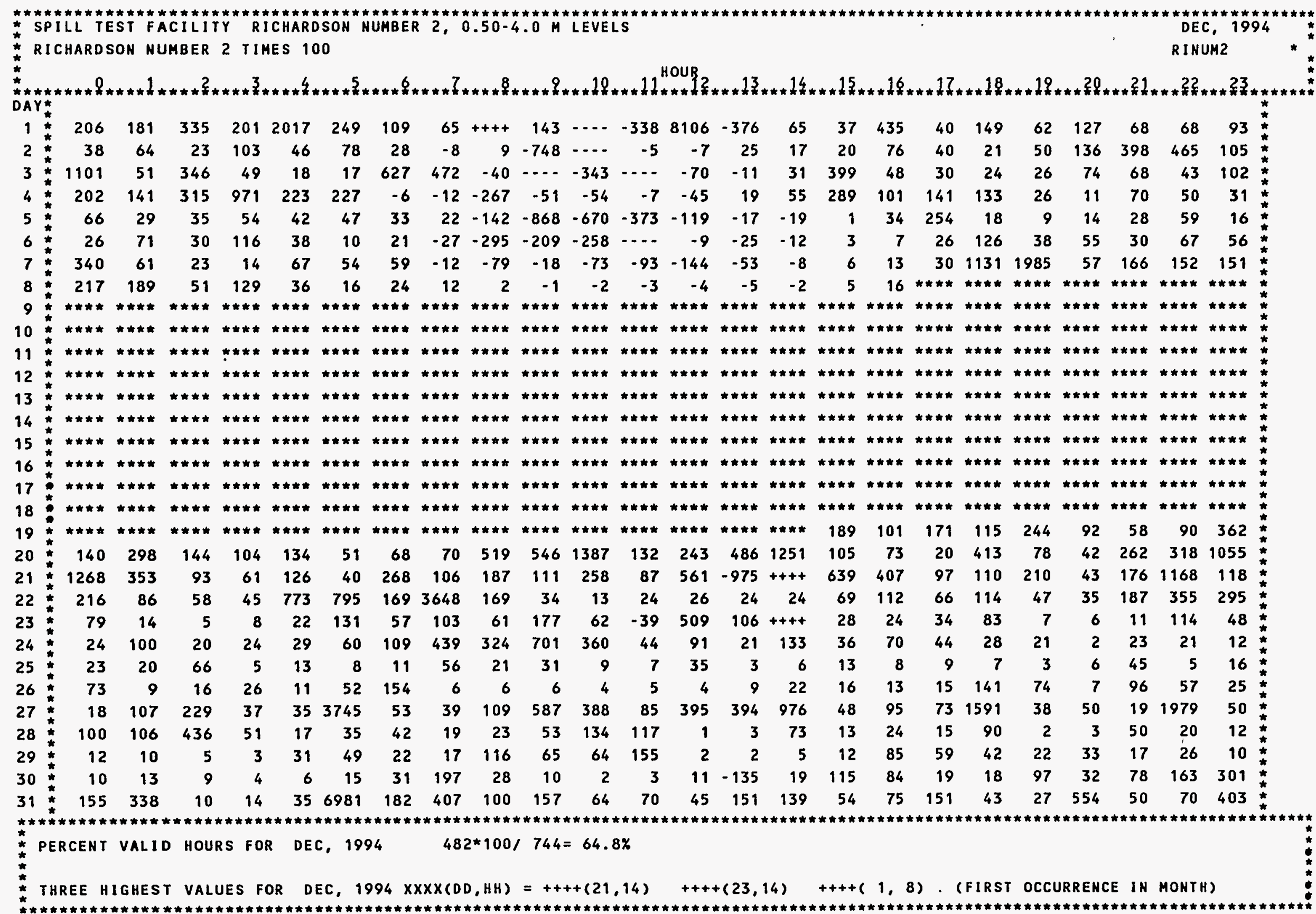




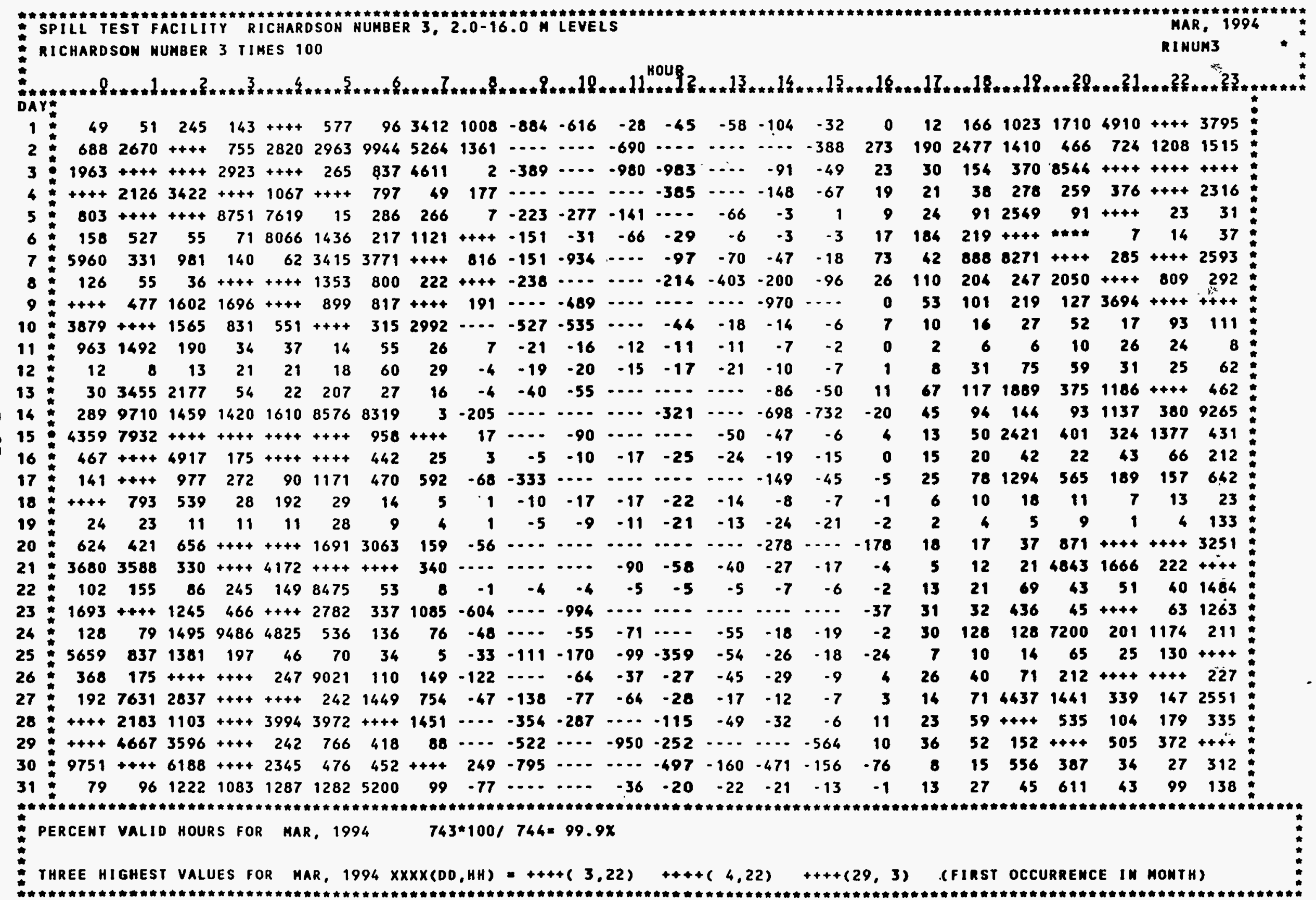




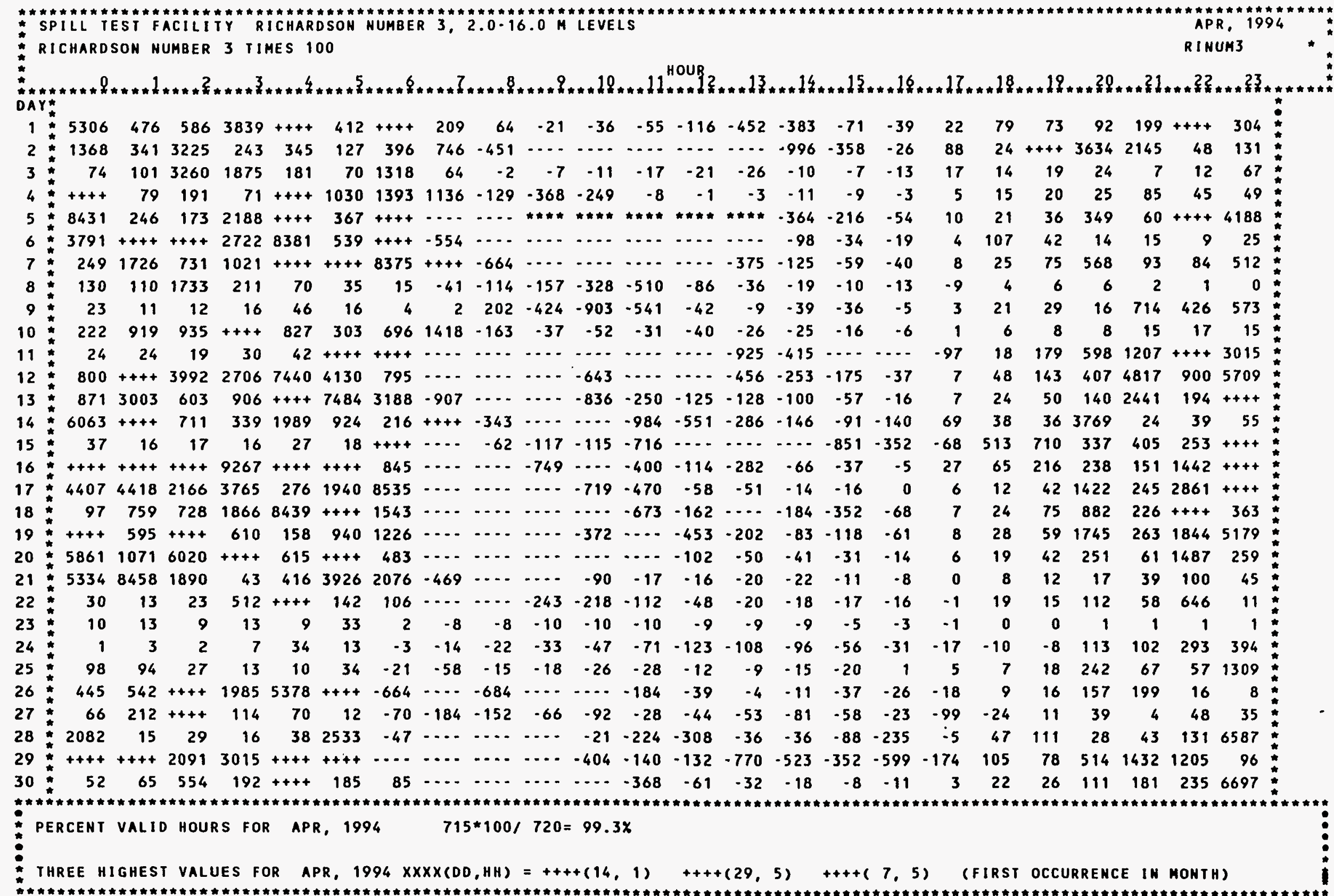




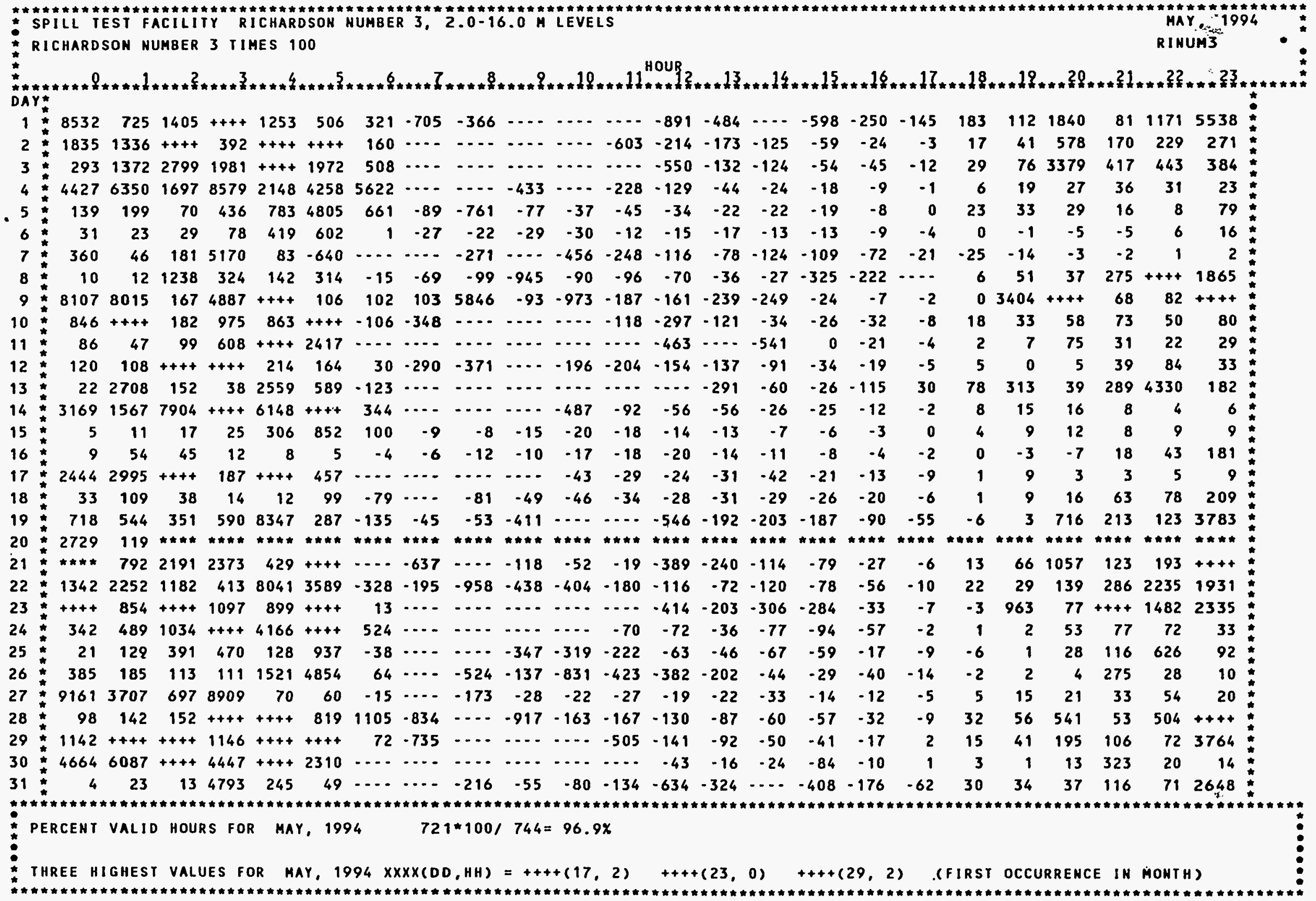




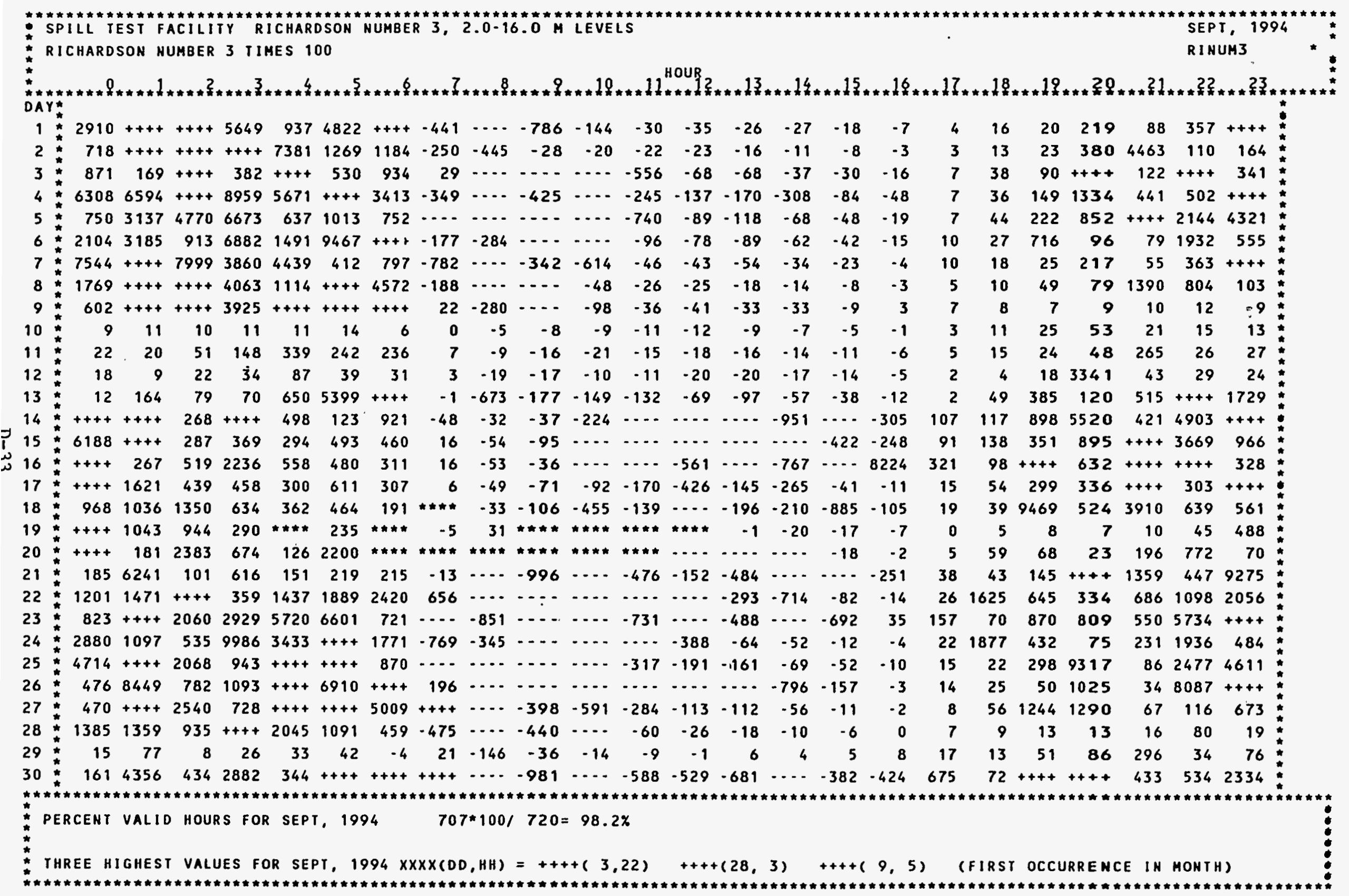




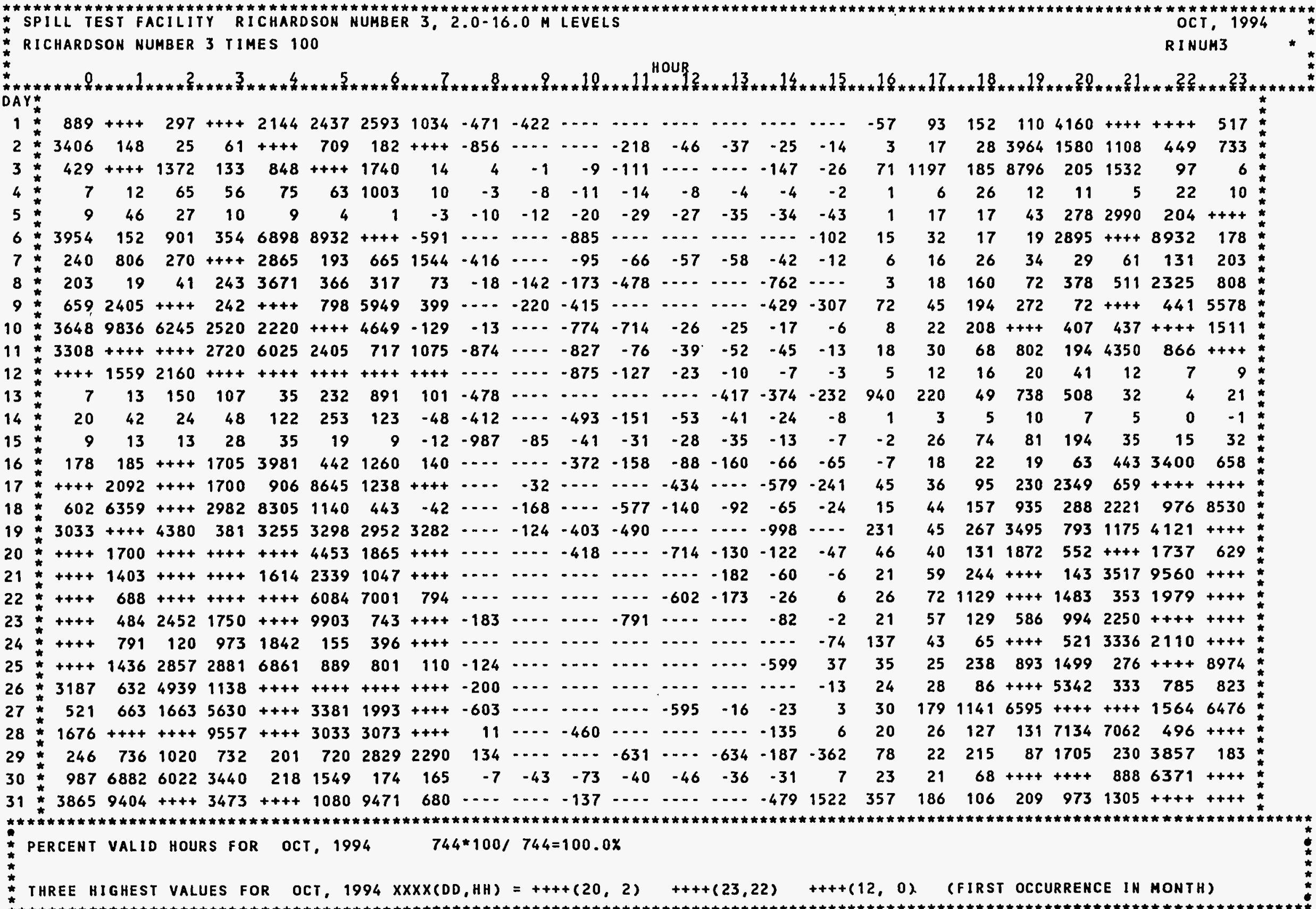




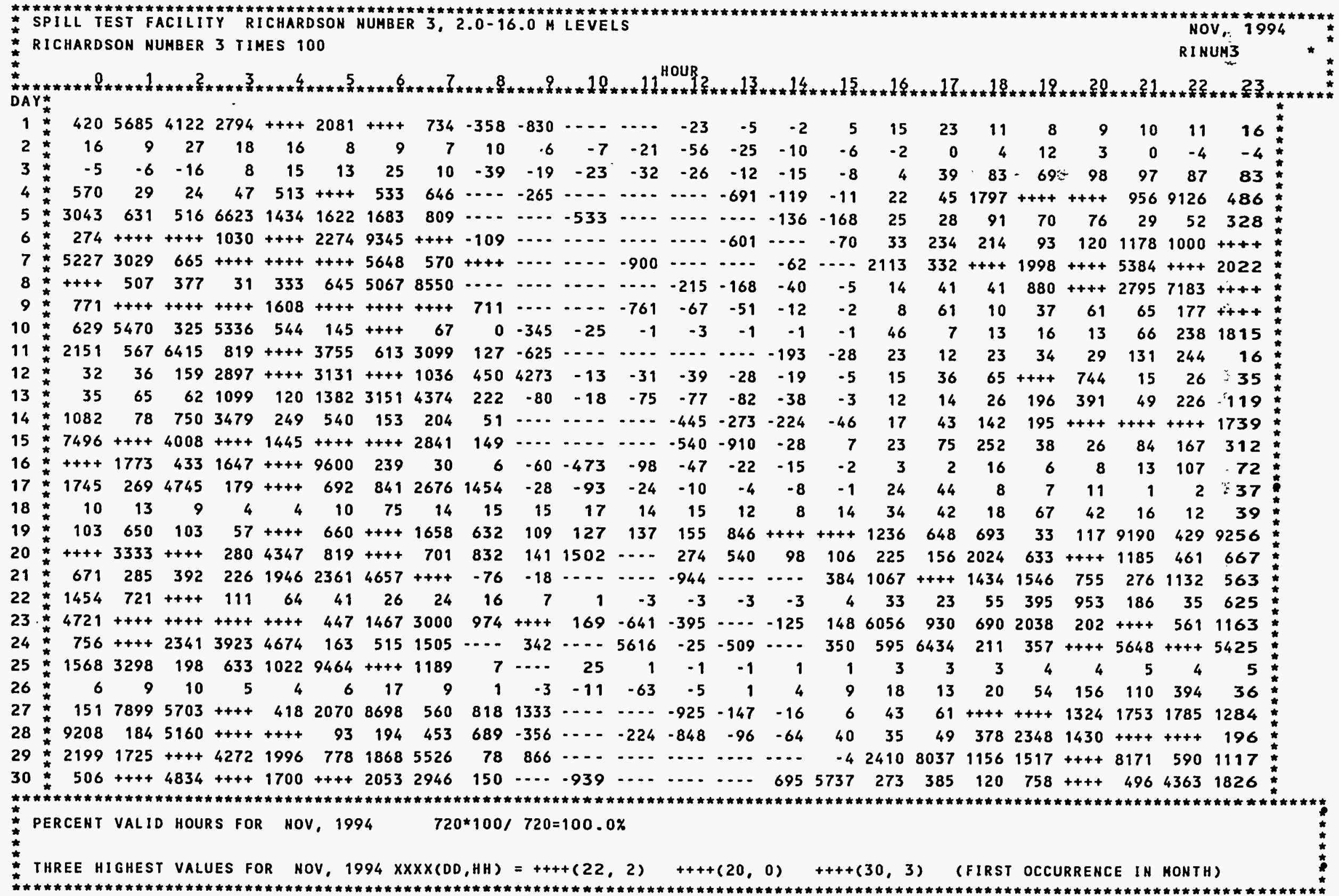




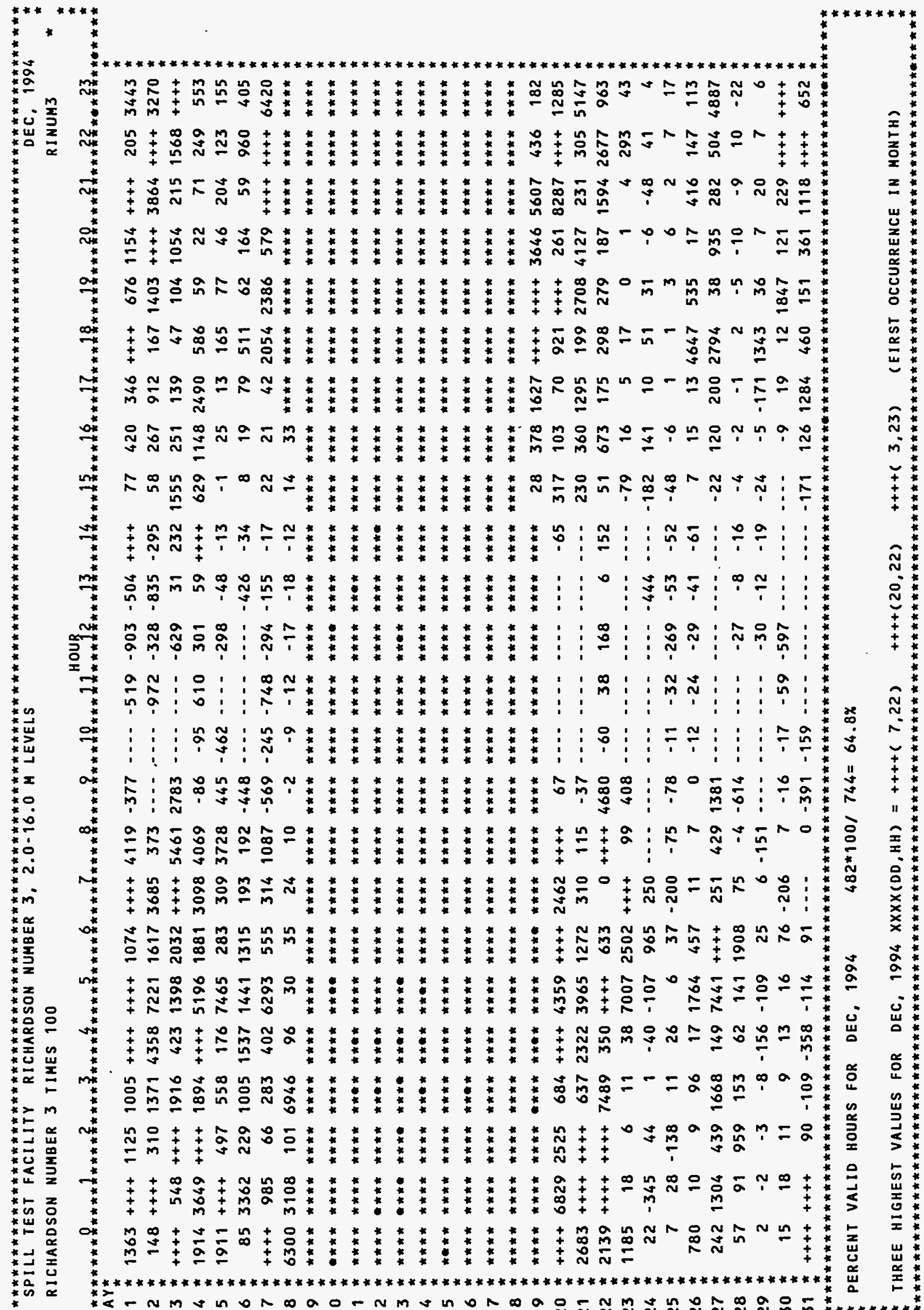




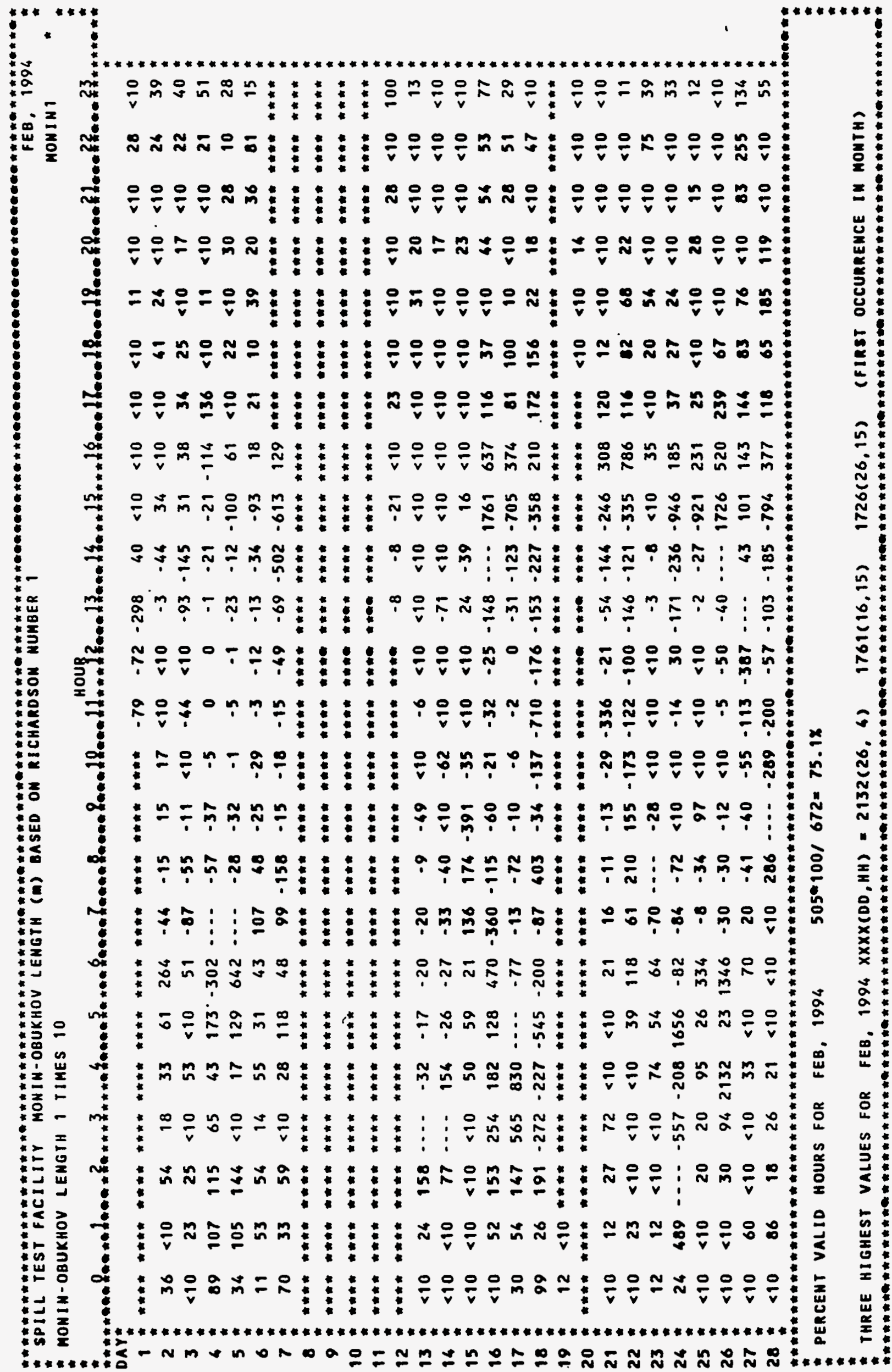




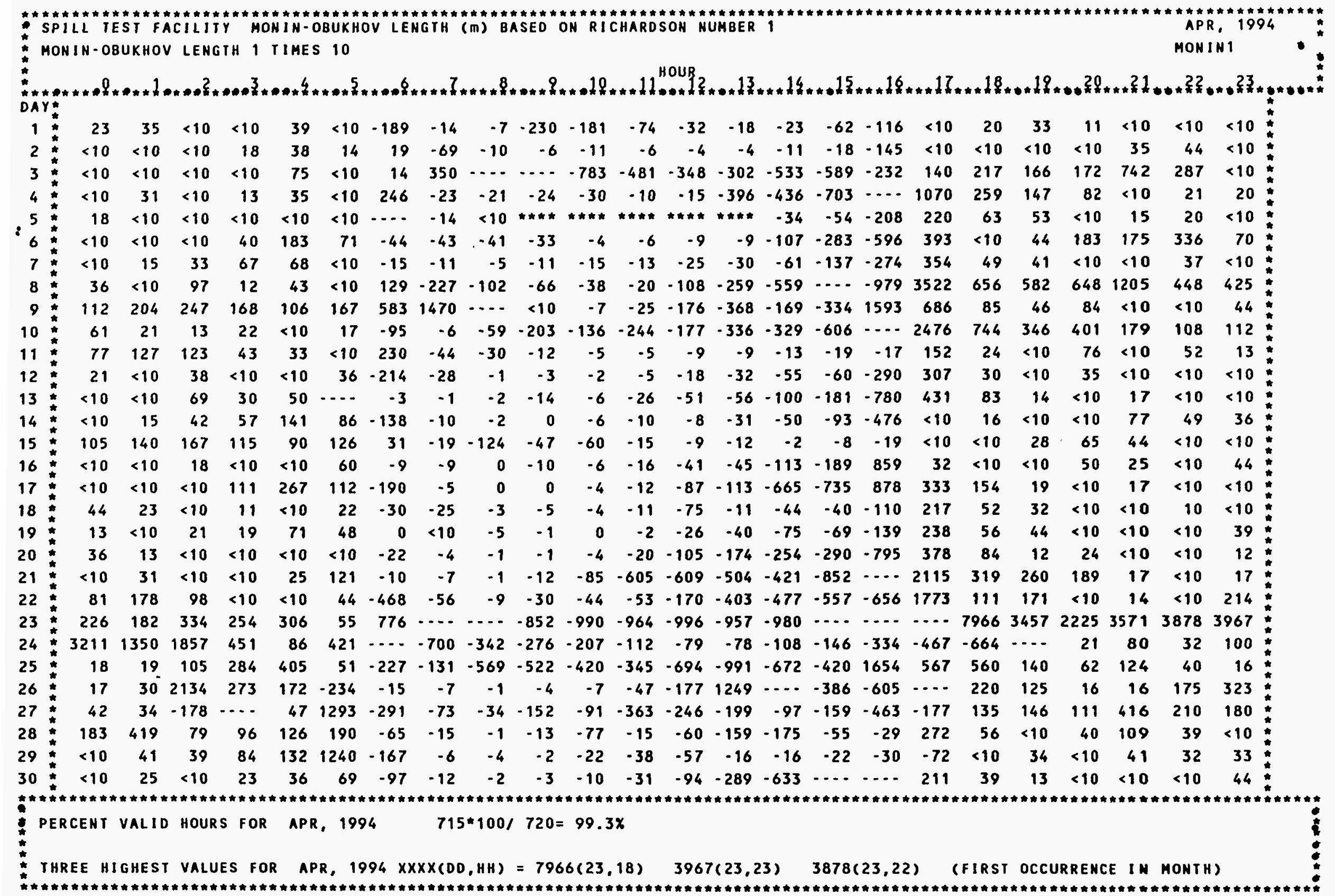




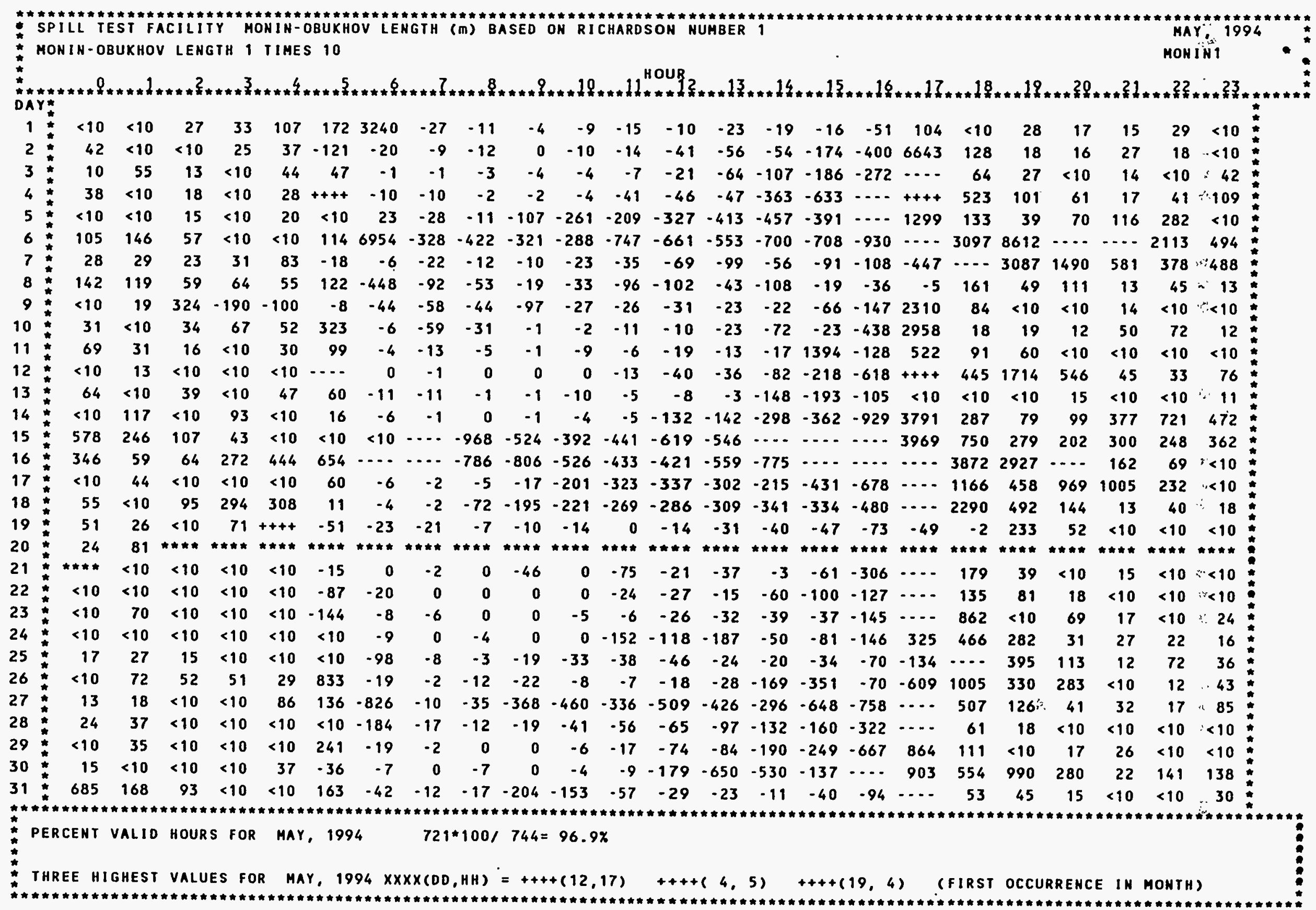




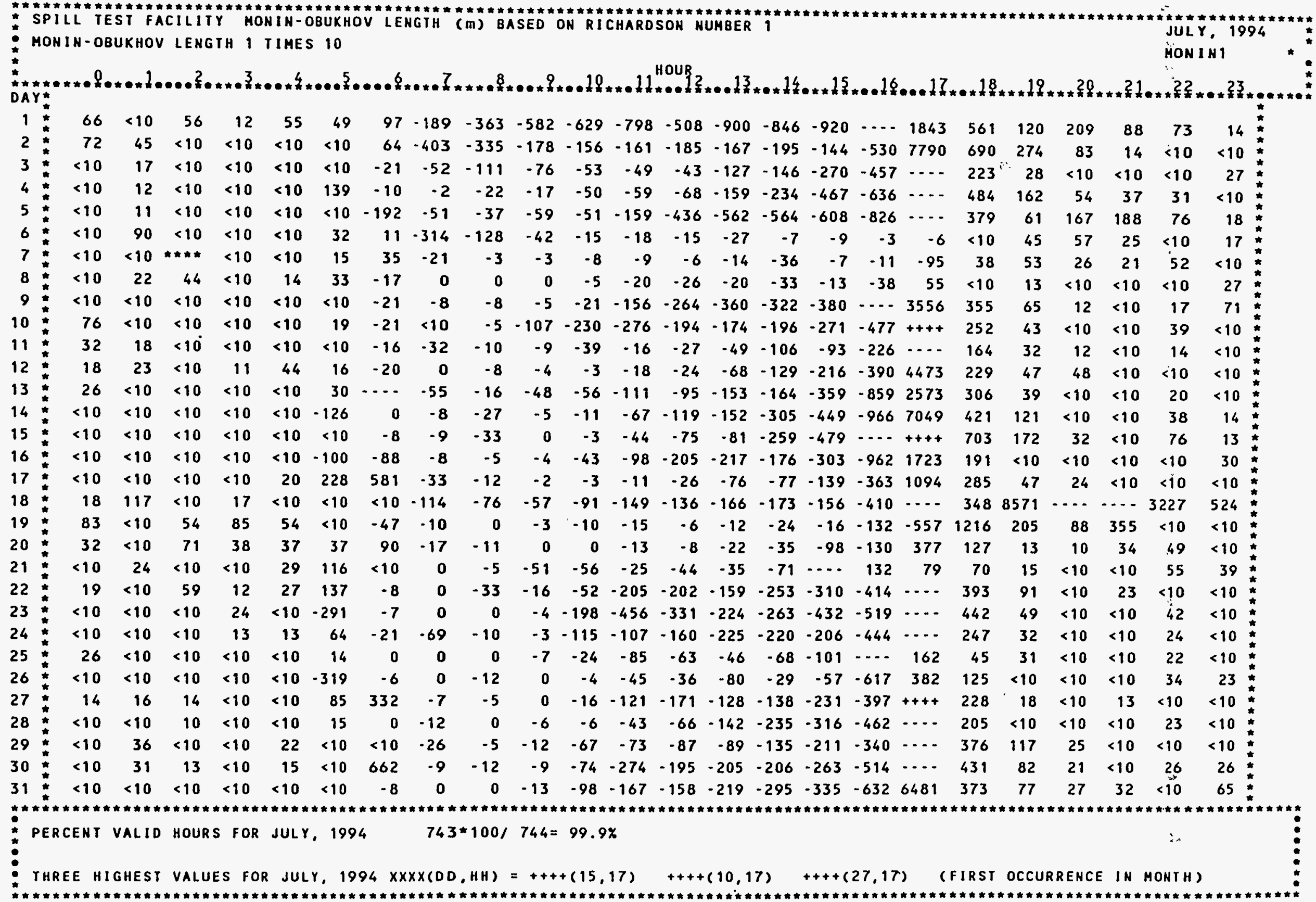




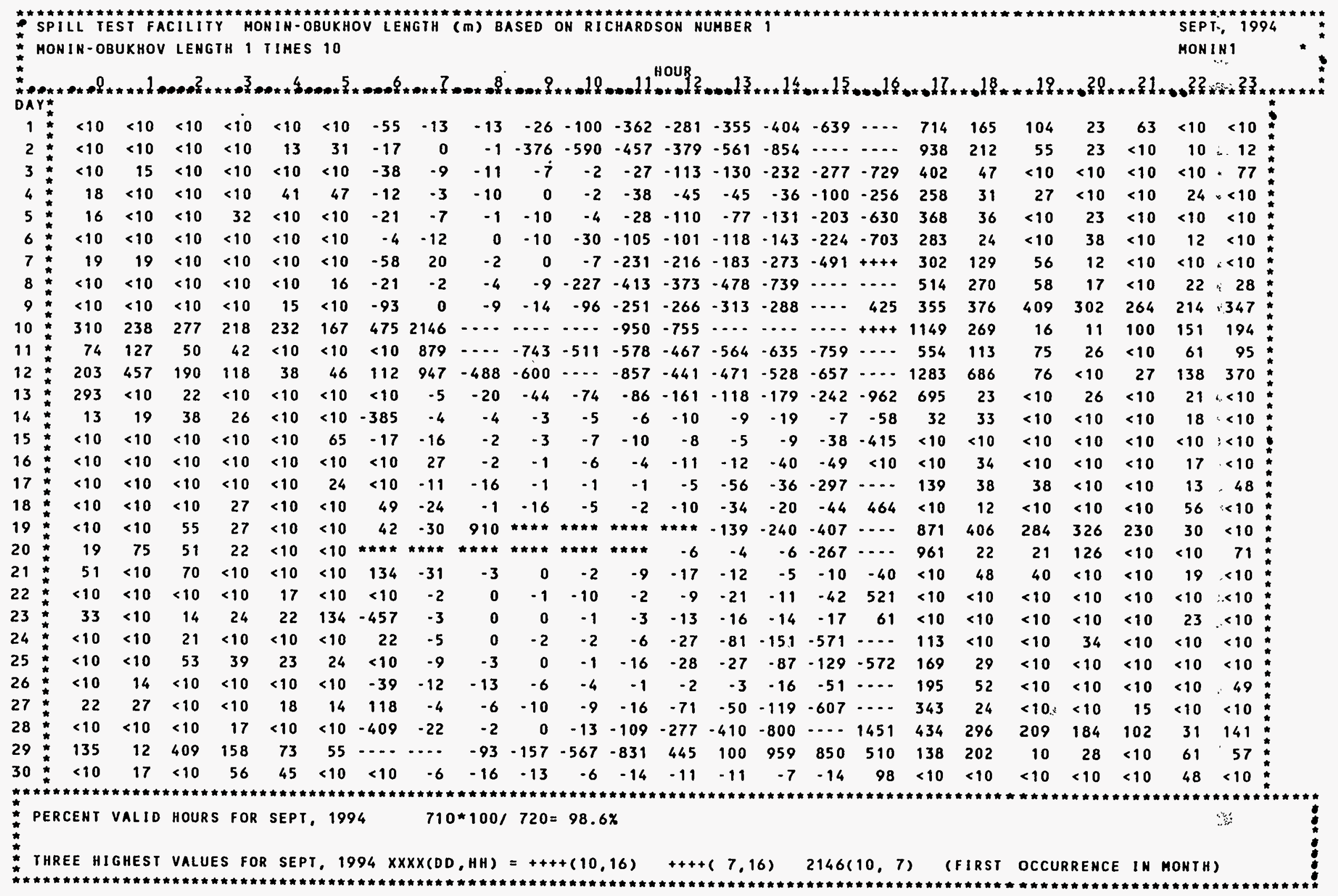




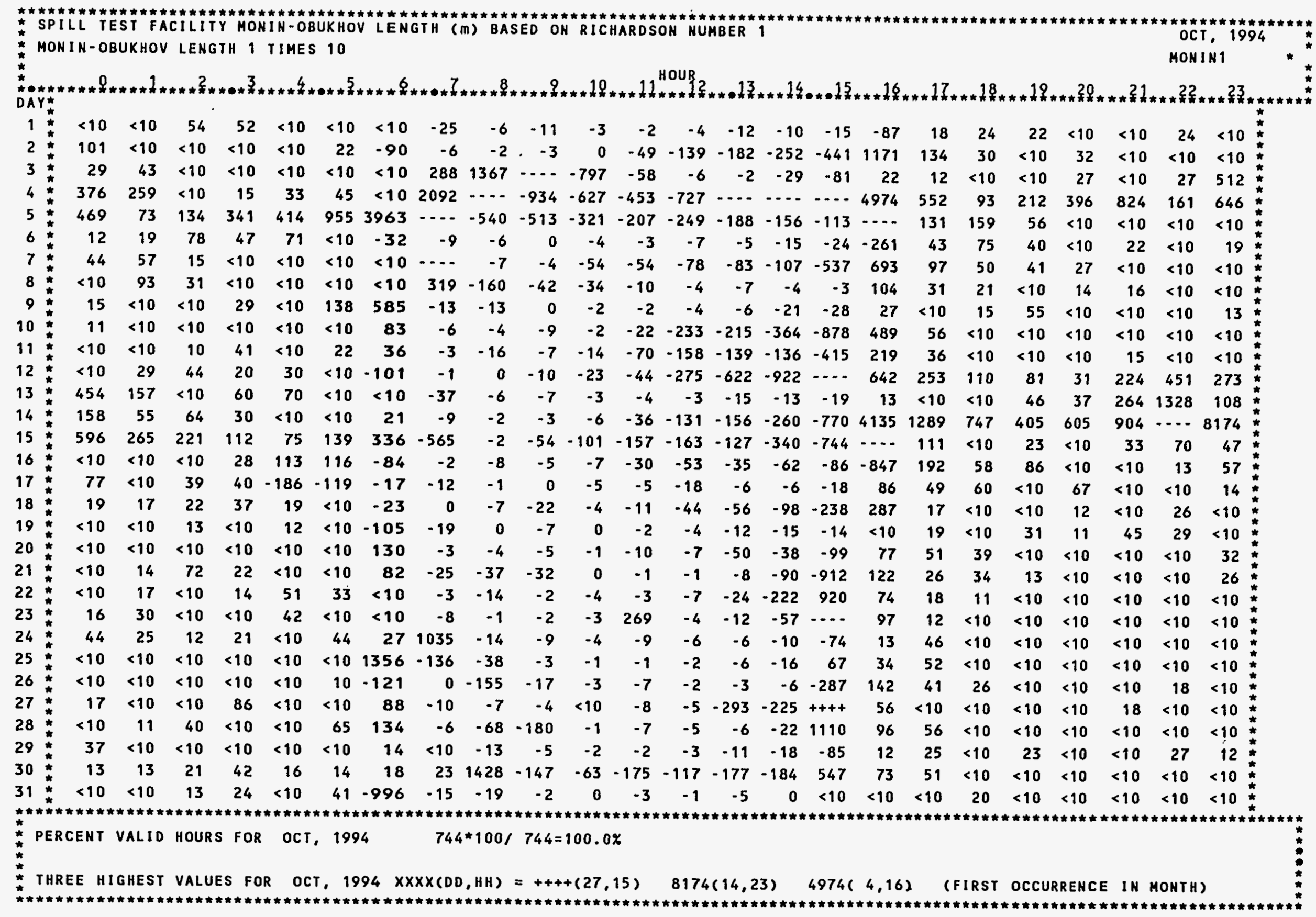




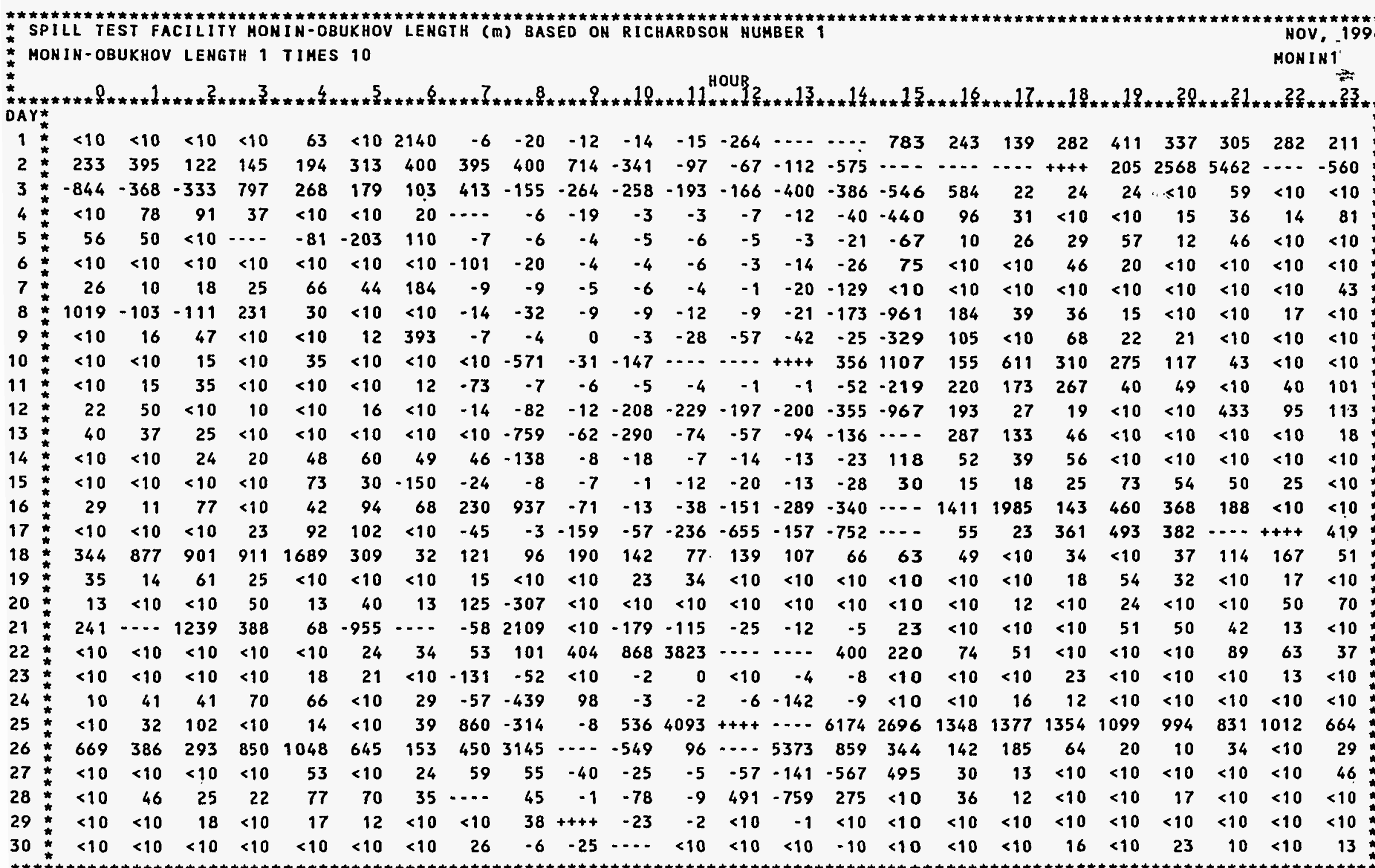

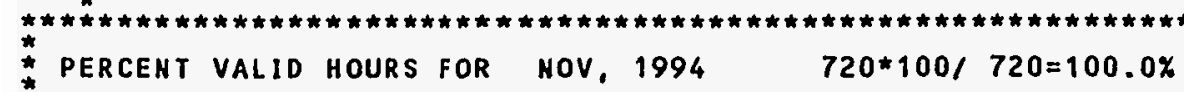

* THREE HIGHEST VALUES FOR NOV, $1994 \times X X X(D D, H H)=++++(25,12)++++2,18) \quad++++(17,22)$ (FIRST OCCURRENCE IN MONTH)

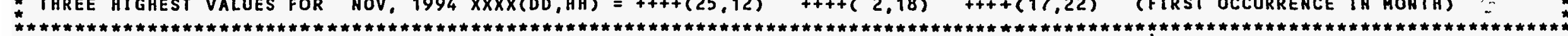




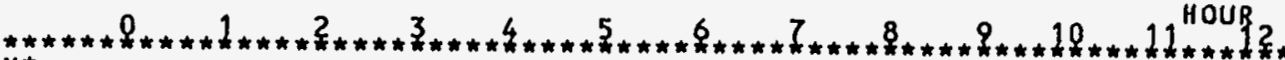




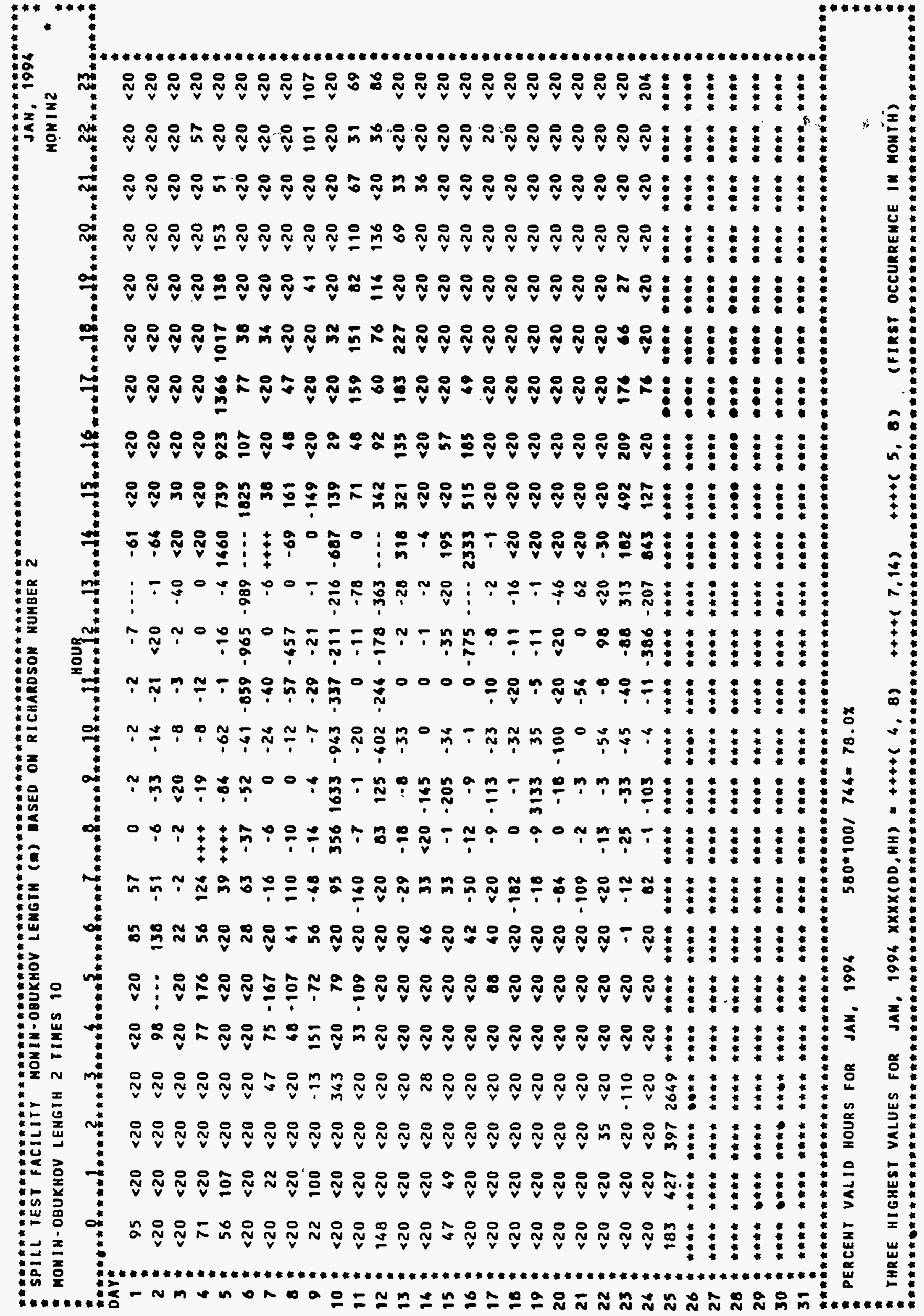




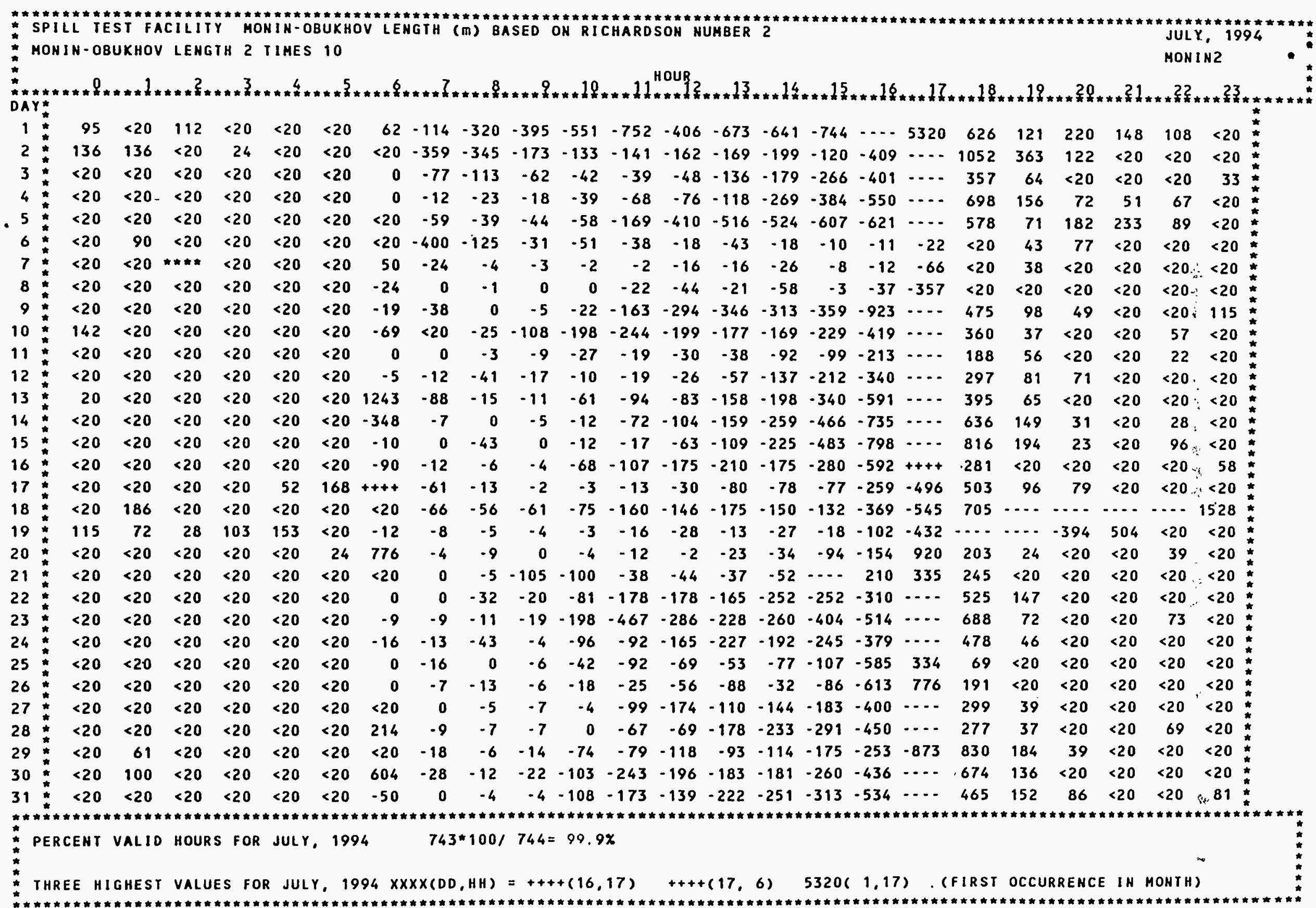




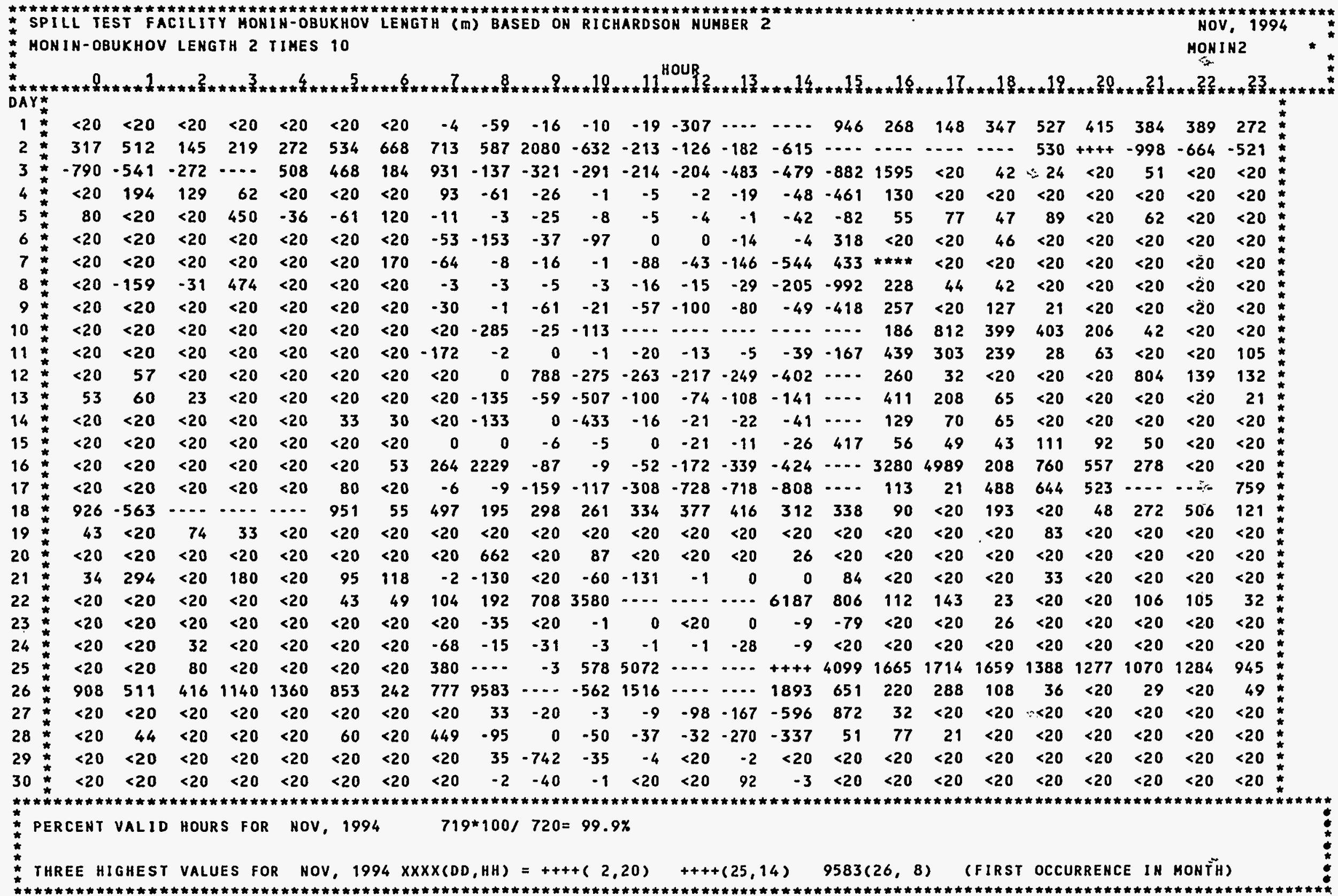




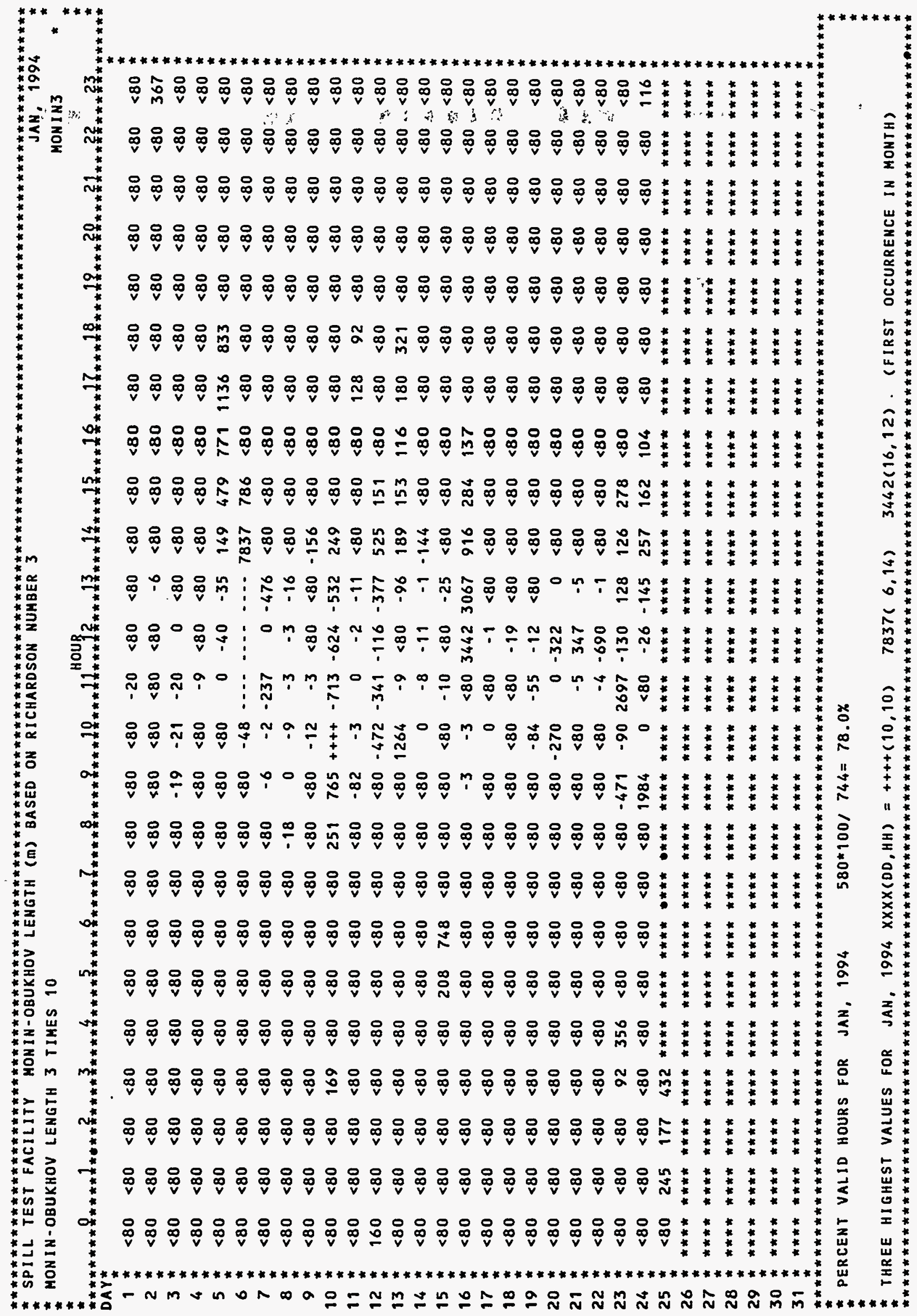




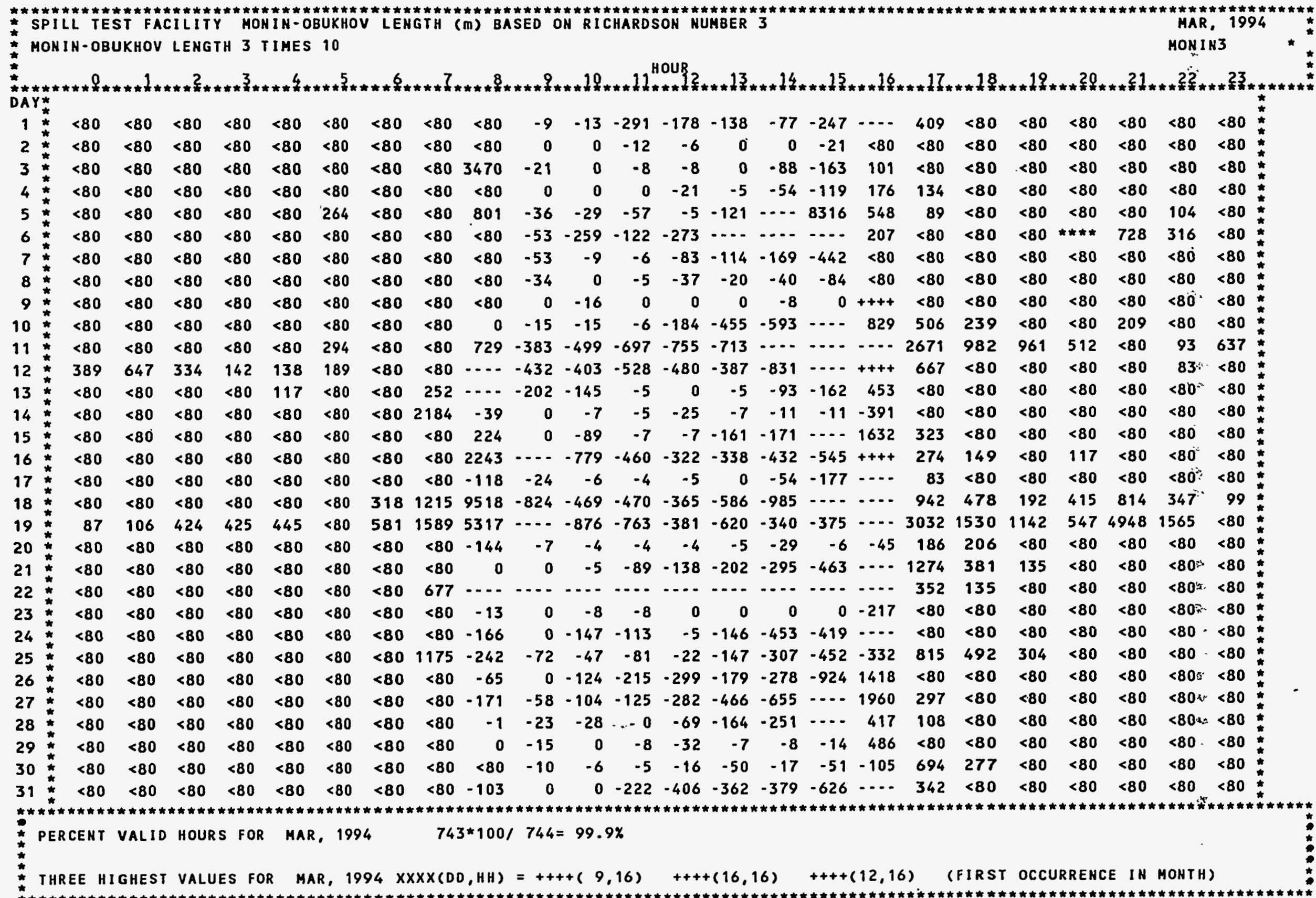




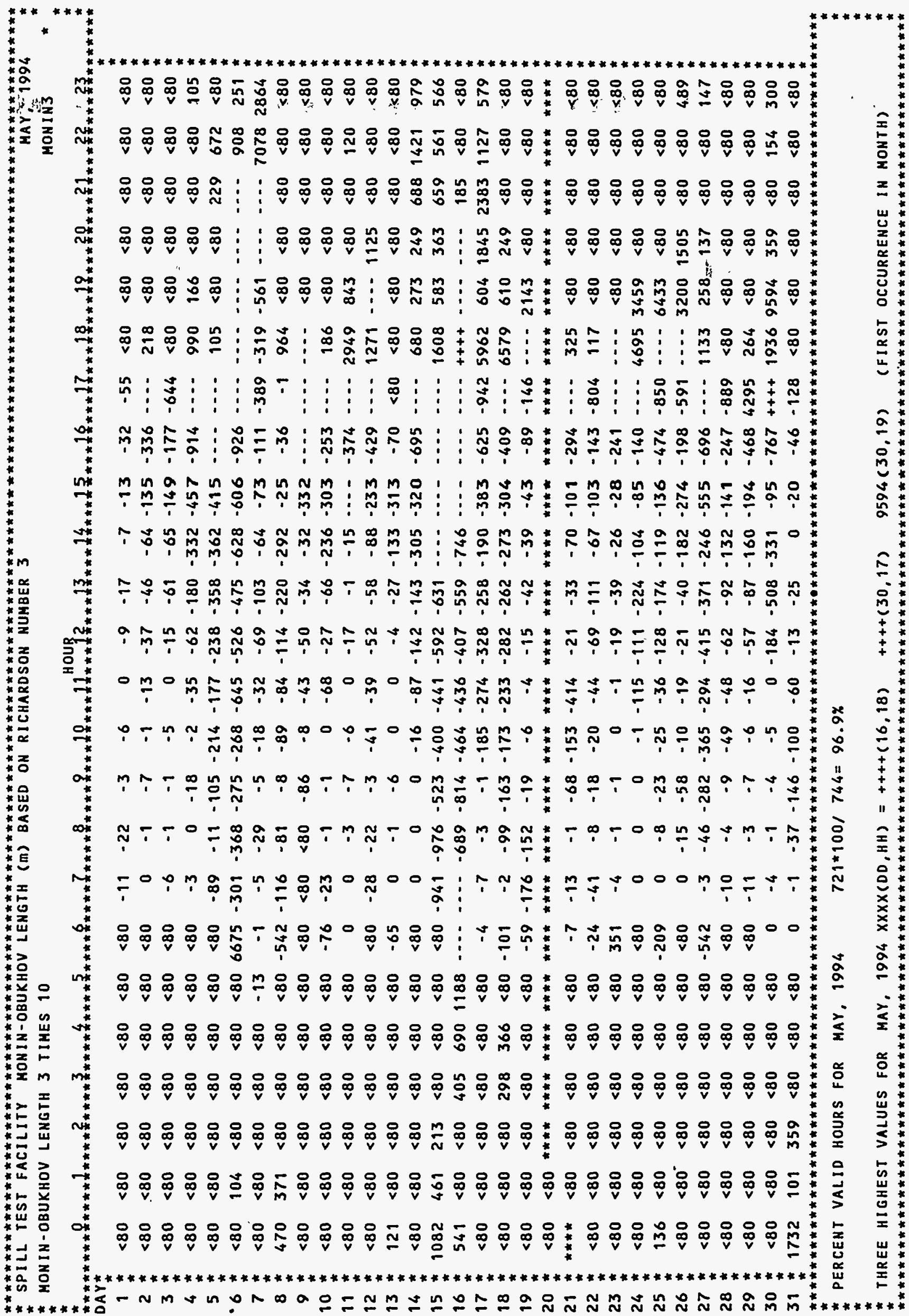




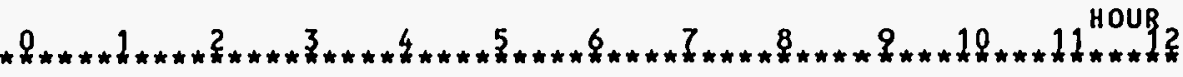

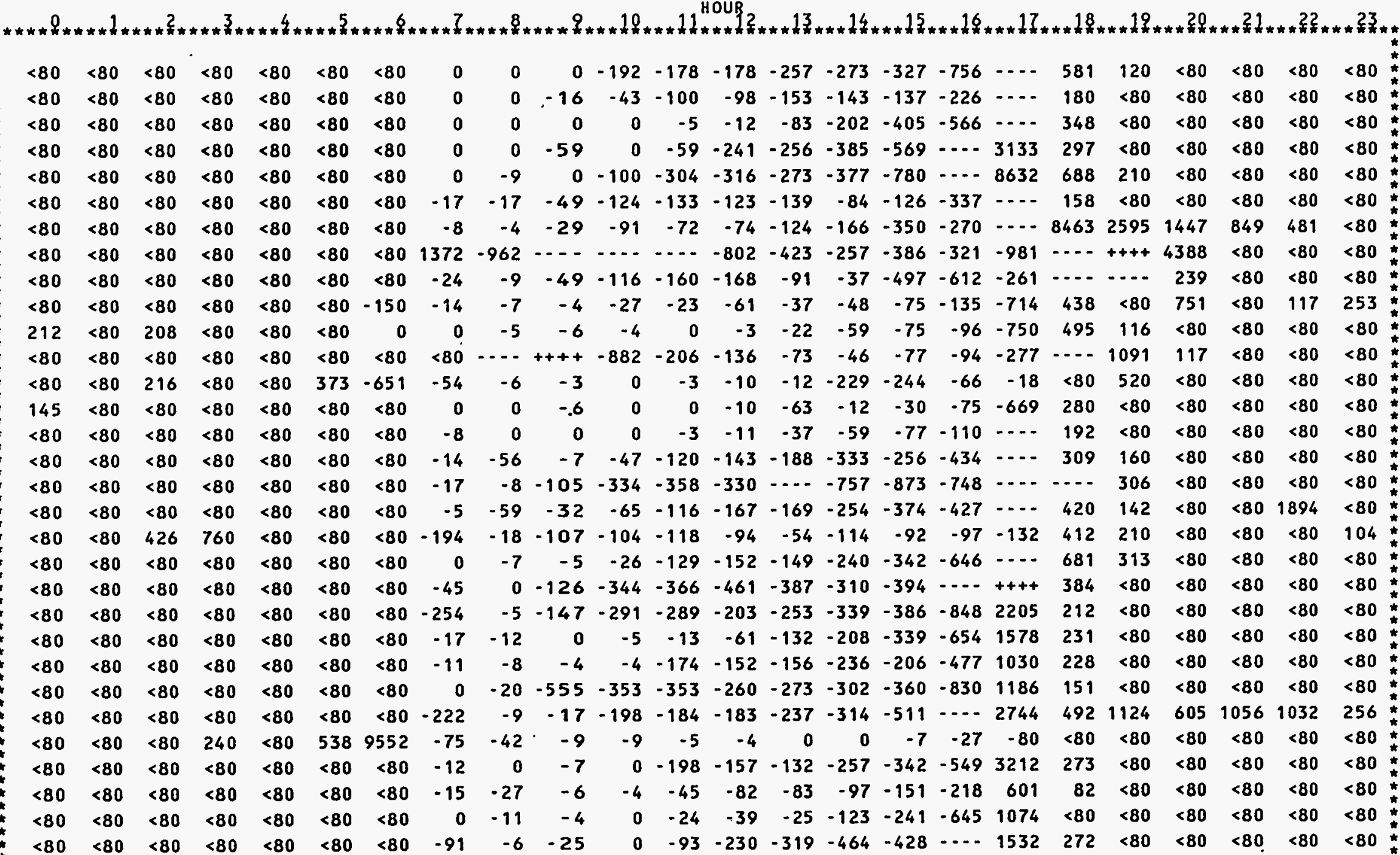

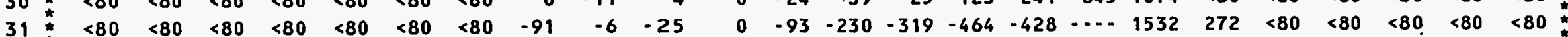

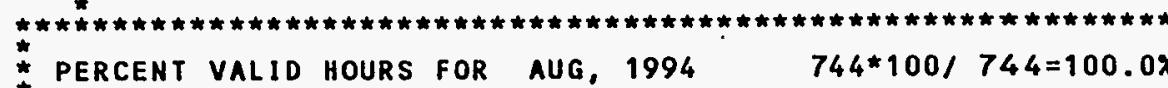
*

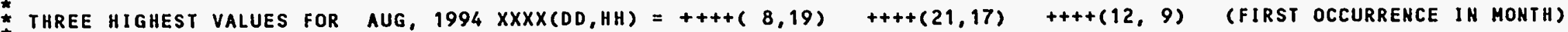




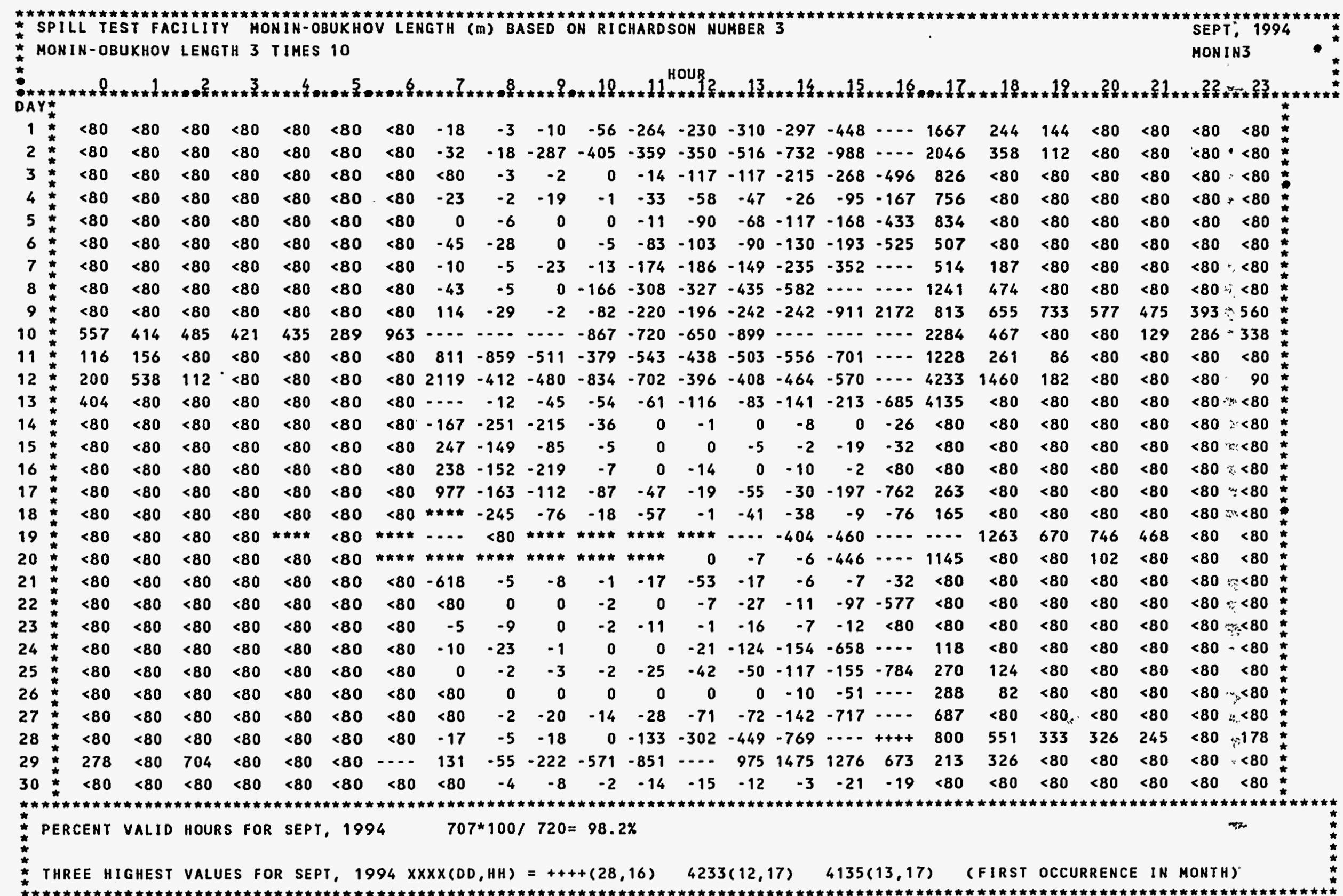




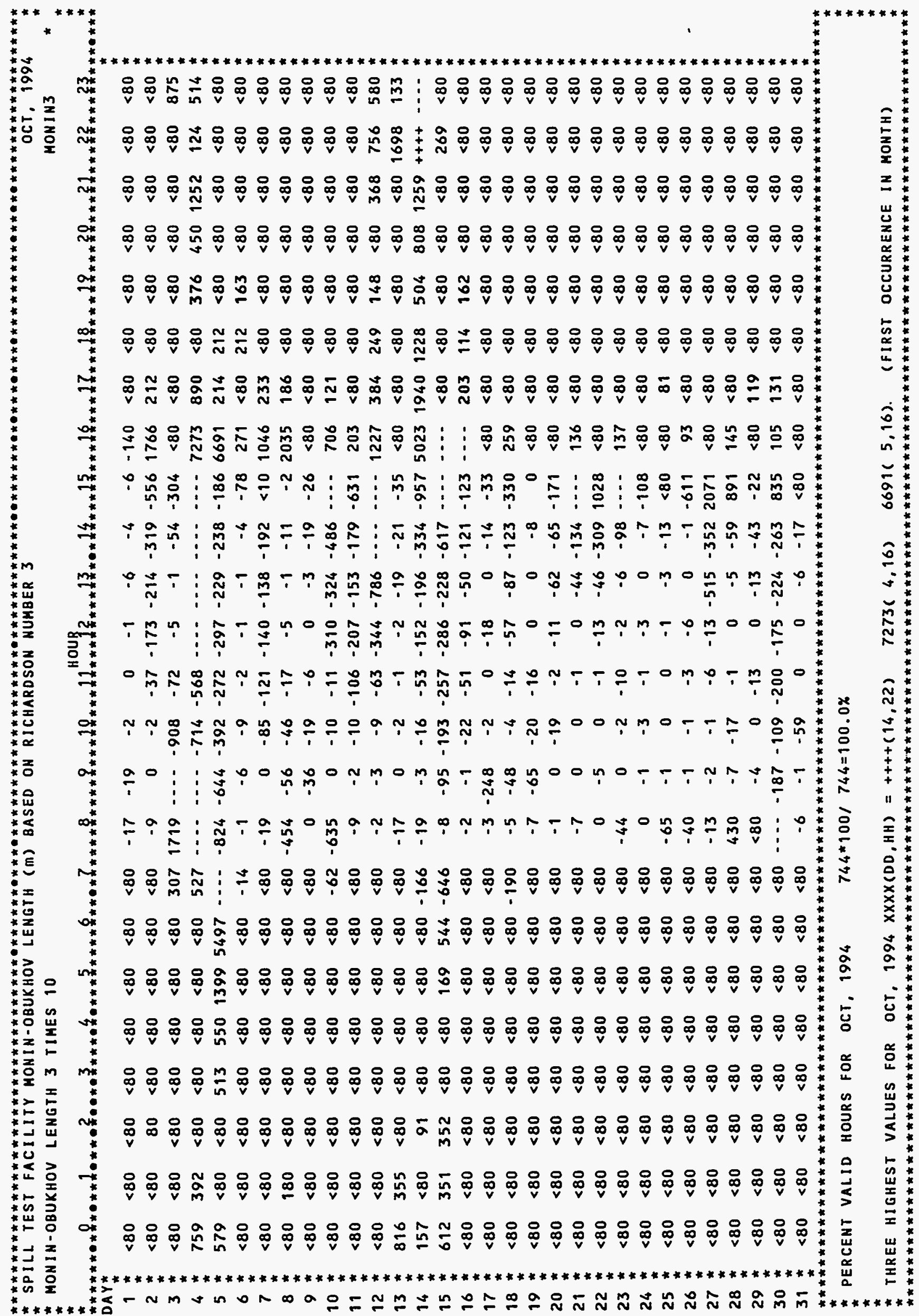




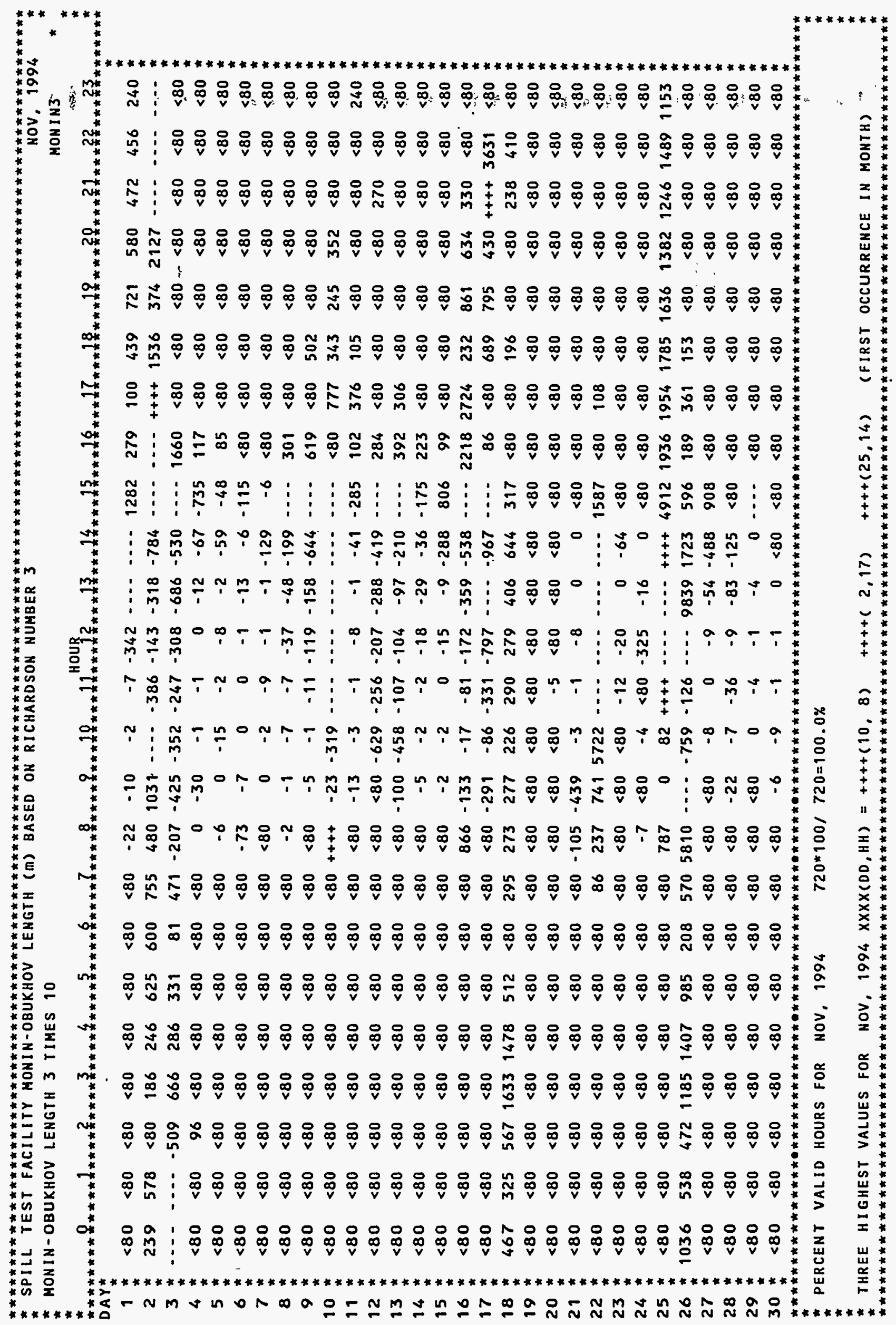




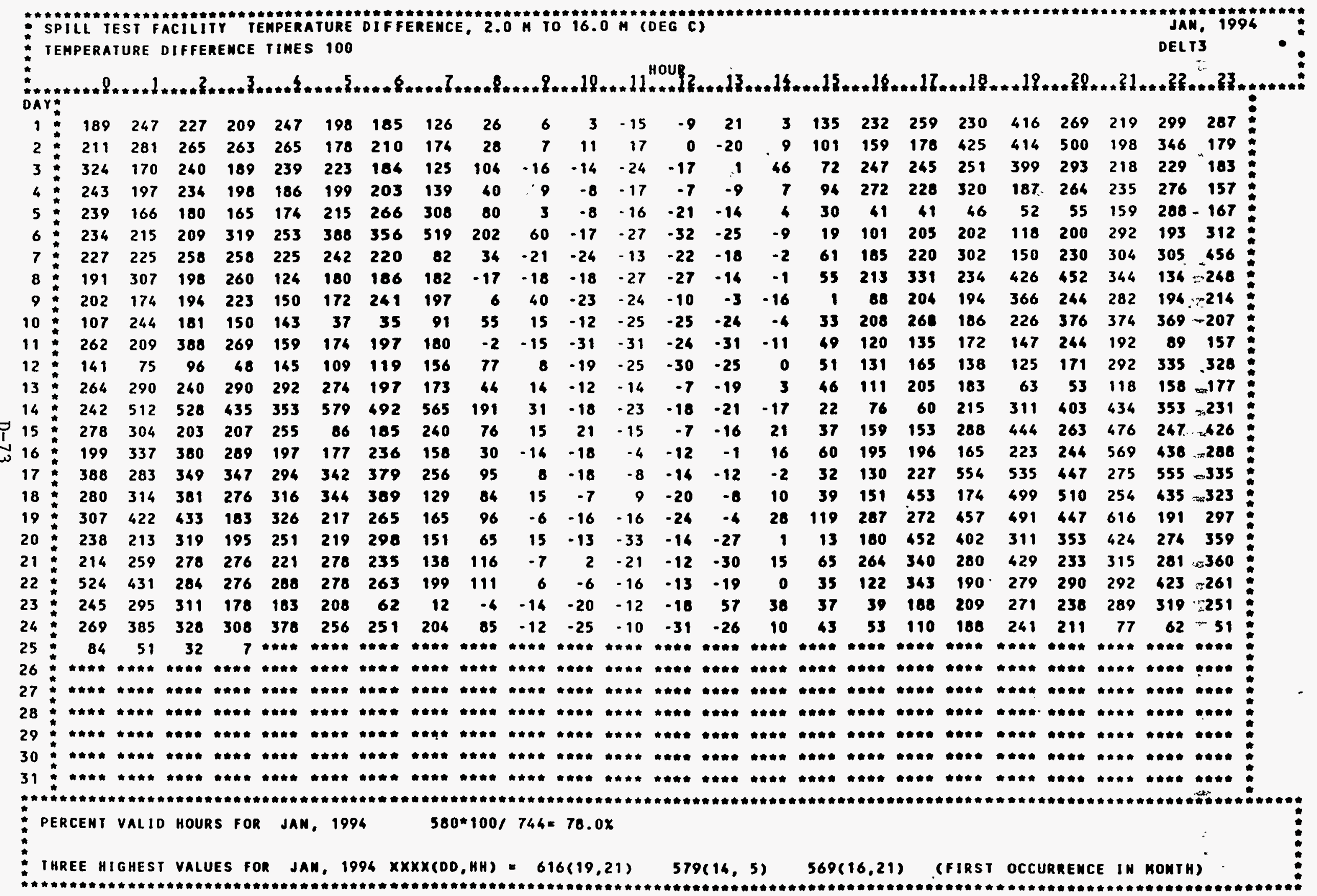




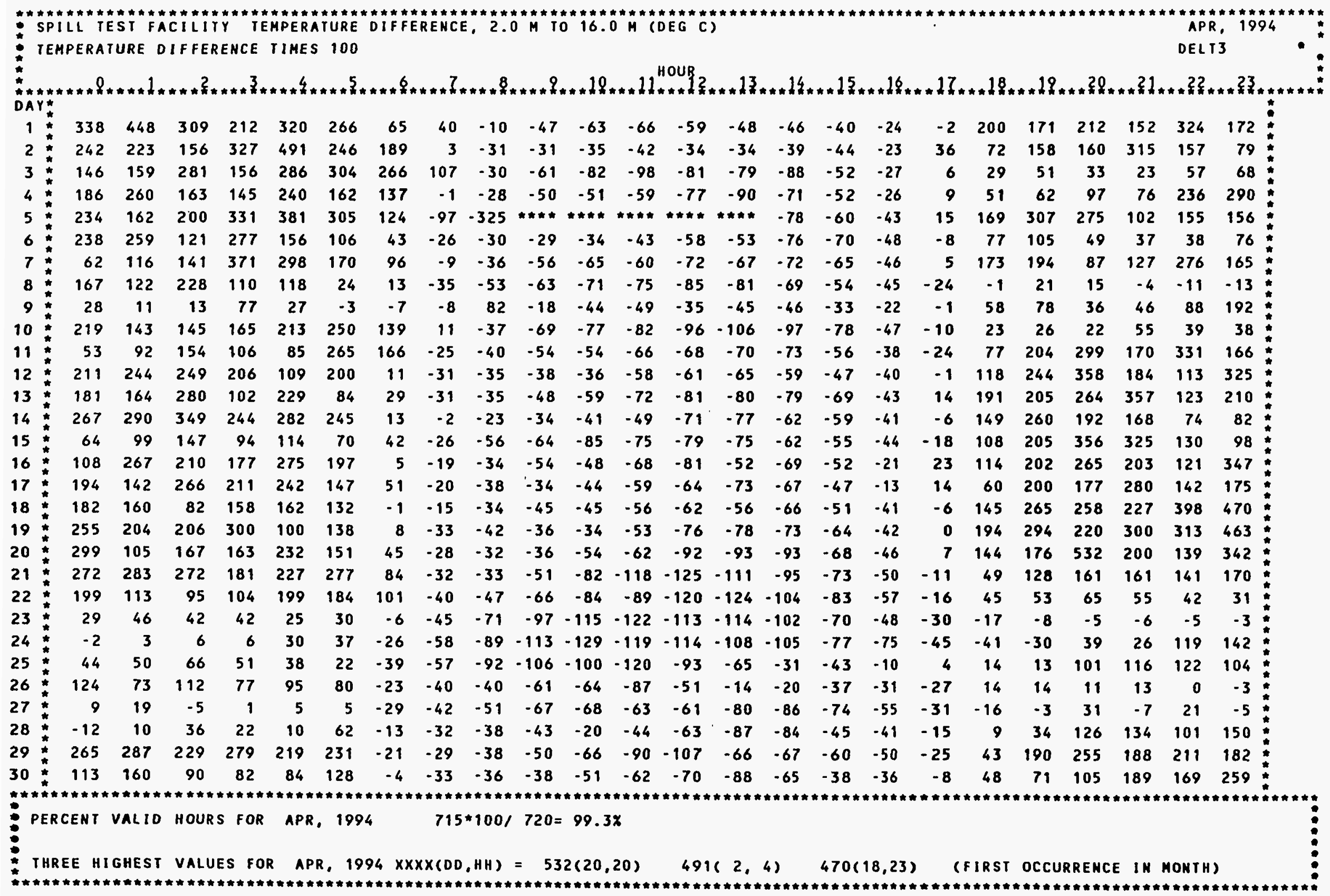




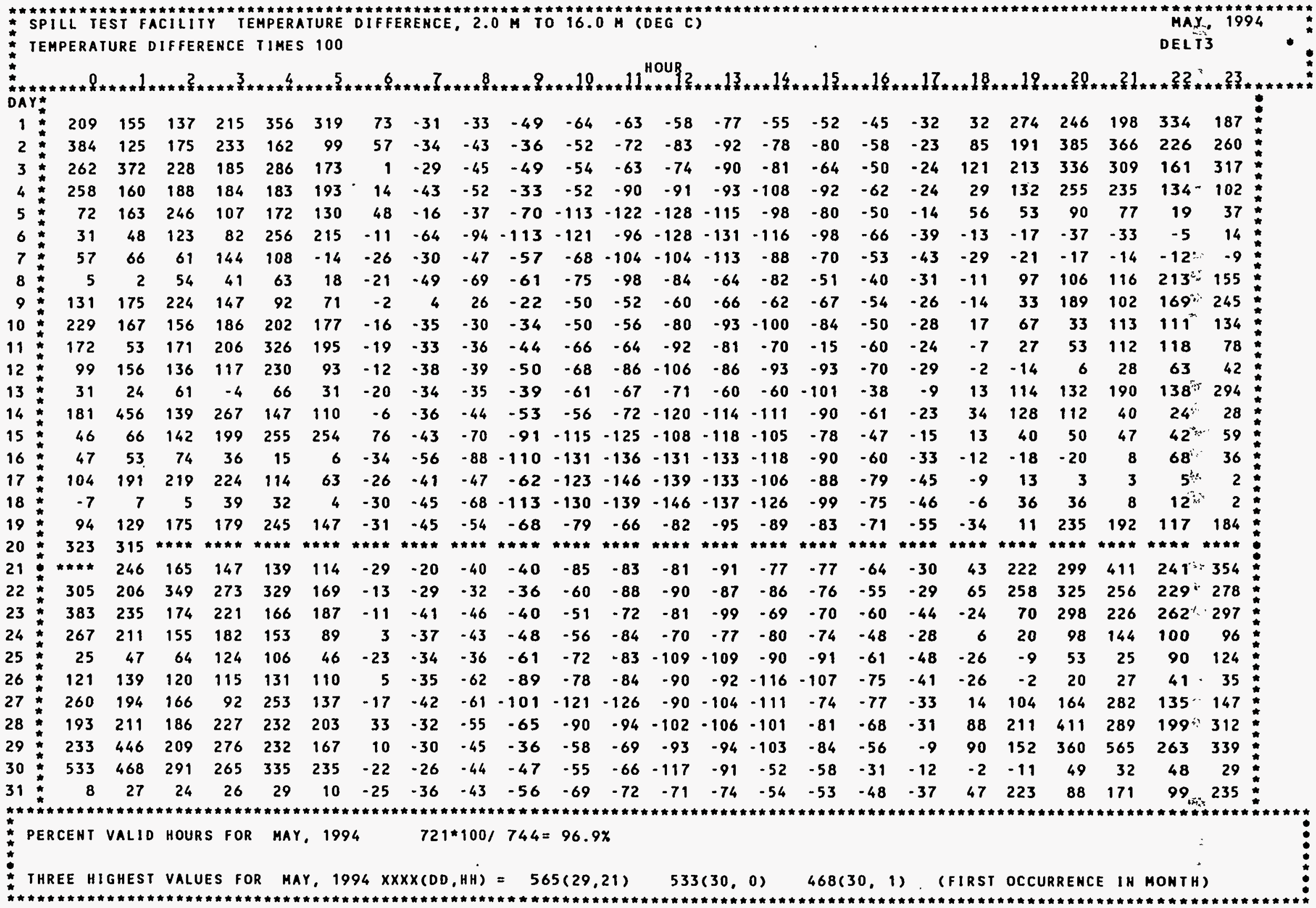




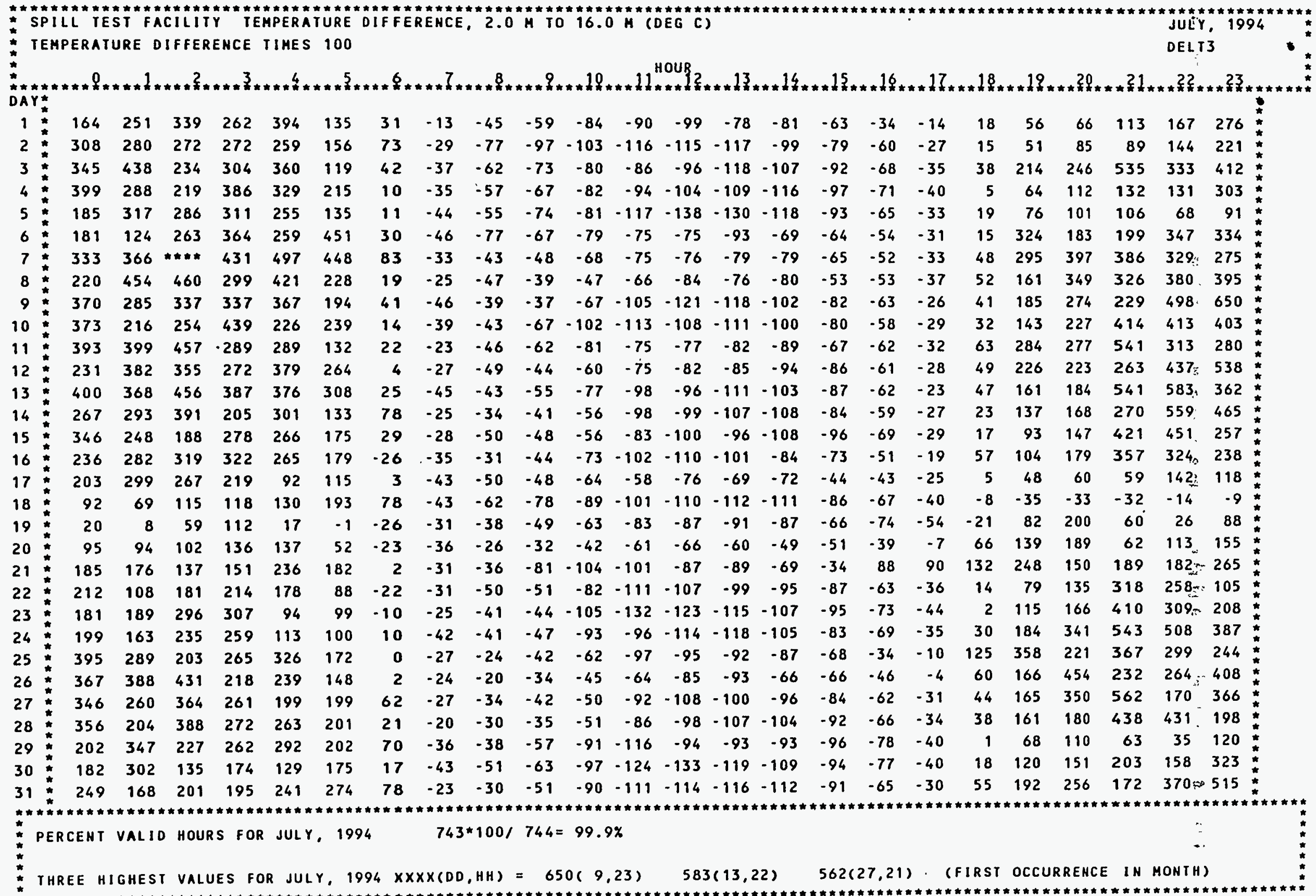



*

\begin{tabular}{|c|c|c|c|c|c|c|c|c|c|c|c|c|c|c|c|c|c|c|c|c|c|c|c|}
\hline 345 & 248 & 268 & 248 & 382 & 221 & -8 & -34 & -31 & -55 & -107 & -115 & -115 & -115 & -109 & -93 & -68 & -29 & 37 & 112 & 144 & 131 & 469 & 389 \\
\hline 188 & 199 & 272 & 236 & 259 & 221 & 24 & -25 & -37 & -58 & -80 & -102 & -104 & -109 & $: 95$ & -79 & -53 & -20 & 93 & 275 & 509 & 379 & 461 & 382 \\
\hline 231 & 276 & 243 & 297 & 226 & 186 & 34 & -33 & -38 & -50 & -51 & -50 & .76 & -92 & -104 & -90 & -60 & -18 & 43 & 149 & 261 & 380 & 342 & 361 \\
\hline 262 & 233 & 335 & 282 & 294 & 217 & 76 & -37 & -32 & -25 & -47 & -90 & -122 & -116 & -106 & -86 & -52 & -4 & 101 & 131 & 134 & 457 & 410 & 650 \\
\hline 215 & 256 & 229 & 211 & 200 & 298 & 0 & -37 & -33 & -46 & -78 & -115 & -111 & -110 & -95 & -66 & -41 & -8 & 37 & 173 & 333 & 436 & 655 & 328 \\
\hline 324 & 301 & 218 & 353 & 314 & 452 & 161 & -24 & -55 & -73 & -85 & -101 & -109 & -120 & -92 & -66 & -58 & -21 & 115 & 292 & 242 & 378 & 576 & 568 \\
\hline 291 & 302 & 296 & 302 & 249 & 178 & 40 & -36 & -53 & -69 & -85 & -105 & -103 & -108 & -103 & -89 & -69 & -32 & -9 & 4 & 13 & 34 & 31 & 142 \\
\hline 318 & 250 & 151 & 110 & 125 & 181 & 175 & -4 & -40 & -41 & -39 & -41 & -51 & -75 & -83 & -92 & -69 & -44 & -24 & -13 & -4 & -2 & 111 & 194 \\
\hline 175 & 105 & 202 & 172 & 123 & 145 & 18 & -20 & -33 & -71 & -112 & -125 & -120 & -110 & -91 & -117 & -63 & -47 & -19 & -16 & 9 & 29 & 20 & 23 \\
\hline 41 & 52 & 51 & 76 & 124 & 175 & -18 & -26 & -39 & -63 & -73 & -83 & -119 & -91 & -73 & -74 & -62 & -34 & 22 & 101 & 10 & 17 & 11 & 9 \\
\hline 5 & 16 & 41 & 53 & 96 & 29 & -19 & -33 & -52 & -44 & -54 & -64 & -81 & -87 & -90 & -74 & -61 & -38 & 31 & 113 & 197 & 341 & 248 & 229 \\
\hline 345 & 179 & 114 & 69 & 86 & 111 & 60 & 67 & -42 & -8 & -72 & -69 & -121 & -103 & -77 & -72 & -62 & -46 & -24 & 10 & 11 & 59 & 86 & 41 \\
\hline 59 & 28 & 17 & 66 & 75 & 25 & -26 & -43 & -44 & -65 & -66 & -75 & -89 & -75 & -64 & -72 & -57 & -23 & 10 & 0 & 11 & 62 & 30 & 68 \\
\hline 87 & 81 & 27 & 82 & 190 & 159 & -12 & -32 & -49 & -43 & -61 & -68 & -86 & -86 & -75 & -68 & -52 & -27 & 51 & 134 & 47 & 171 & 249 & 178 \\
\hline 211 & 170 & 179 & 148 & 236 & 135 & 136 & -36 & -35 & -43 & -58 & -68 & -82 & -92 & -92 & -73 & -55 & -26 & 104 & 261 & 211 & 267 & 303 & 345 \\
\hline 223 & 258 & 351 & 226 & 199 & 217 & 81 & -26 & -26 & -38 & -75 & -111 & -117 & -111 & -107 & -85 & -56 & -19 & 56 & 180 & 224 & 335 & 83 & 136 \\
\hline 210 & 241 & 311 & 338 & 154 & 237 & 120 & -24 & -36 & -75 & -120 & -127 & -121 & -40 & -91 & -80 & -67 & -40 & -14 & 12 & 64 & 155 & 98 & 79 \\
\hline 134 & 185 & 154 & 68 & 96 & 76 & 34 & -46 & -61 & -63 & -82 & -112 & -121 & -120 & -99 & -72 & -56 & .25 & 29 & 64 & 115 & 80 & 7 & 22 \\
\hline 53 & 37 & 42 & 2 & 29 & 94 & 35 & -21 & -54 & -94 & -98 & -110 & -107 & -96 & -91 & -84 & -60 & -36 & -7 & 17 & 7 & 51 & 76 & 59 \\
\hline 76 & 128 & 205 & 189 & 79 & 162 & 2 & -36 & -37 & -49 & -75 & -103 & -110 & -112 & -105 & -90 & -61 & -22 & 37 & 85 & 205 & 158 & 73 & 453 \\
\hline 351 & 139 & 250 & 175 & 228 & 182 & 94 & -29 & -40 & -83 & -116 & -124 & -126 & -118 & -97 & -79 & -50 & -11 & 47 & 140 & 161 & 240 & 215 & 219 \\
\hline 126 & 128 & 12 & 107 & 205 & 266 & 245 & -24 & -48 & -72 & -117 & -118 & -120 & -115 & -103 & -80 & -49 & -2 & 109 & 90 & 219 & 611 & 312 & 328 \\
\hline 572 & 260 & 289 & 282 & 337 & 300 & 28 & -23 & -28 & -38 & -50 & -69 & -87 & -100 & -100 & -78 & -47 & 5 & 117 & 117 & 582 & 296 & 297 & 385 \\
\hline 429 & 324 & 285 & 270 & 270 & 183 & 76 & -28 & -34 & -53 & -63 & -117 & -109 & -108 & -90 & -70 & -44 & 1 & 119 & 274 & 268 & 369 & 355 & 326 \\
\hline 419 & 384 & 369 & 371 & 321 & 177 & 75 & -23 & -47 & -68 & -99 & -113 & -113 & -109 & -100 & -74 & -45 & 5 & 148 & 223 & 530 & 610 & 412 & 254 \\
\hline 275 & 273 & 259 & 220 & 235 & 197 & 70 & -20 & -33 & -56 & -104 & -111 & -112 & -106 & -83 & -65 & -39 & 1 & 44 & 12 & 10 & 7 & 7 & 44 \\
\hline 49 & 20 & 38 & 29 & 3 & -6 & -12 & -22 & -29 & -32 & -32 & -50 & .61 & -42 & -54 & -41 & -40 & -16 & 58 & 96 & 299 & 325 & 81 & 159 \\
\hline 213 & 221 & 223 & 161 & 154 & 149 & 36 & -27 & -38 & -37 & -53 & -104 & -106 & -101 & -98 & -77 & -53 & -7 & 94 & 139 & 117 & 267 & 464 & 421 \\
\hline 222 & 282 & 337 & 228 & 273 & 160 & 39 & -24 & -39 & -45 & -62 & -77 & .92 & -91 & -80 & -72 & -43 & 10 & 228 & 324 & 430 & 379 & 480 & 418 \\
\hline 393 & 326 & 268 & 231 & 319 & 255 & 114 & -20 & -28 & -58 & -54 & -81 & -86 & -78 & .85 & -74 & -47 & 7 & 151 & 225 & 353 & 439 & 537 & 462 \\
\hline 257 & 185 & 277 & 221 & 312 & 270 & 47 & -29 & -40 & -41 & -49 & -83 & -108 & -94 & -79 & -64 & -36 & 9 & 118 & 186 & 488 & 221 & 428 & 299 \\
\hline
\end{tabular}
31
$\vdots$
$\vdots$
$*$
$\vdots$
0
$\vdots$
$\vdots$ Percent VAlio hours for aug, $1994 \quad 744 * 100 / 744=100.0 x$ 


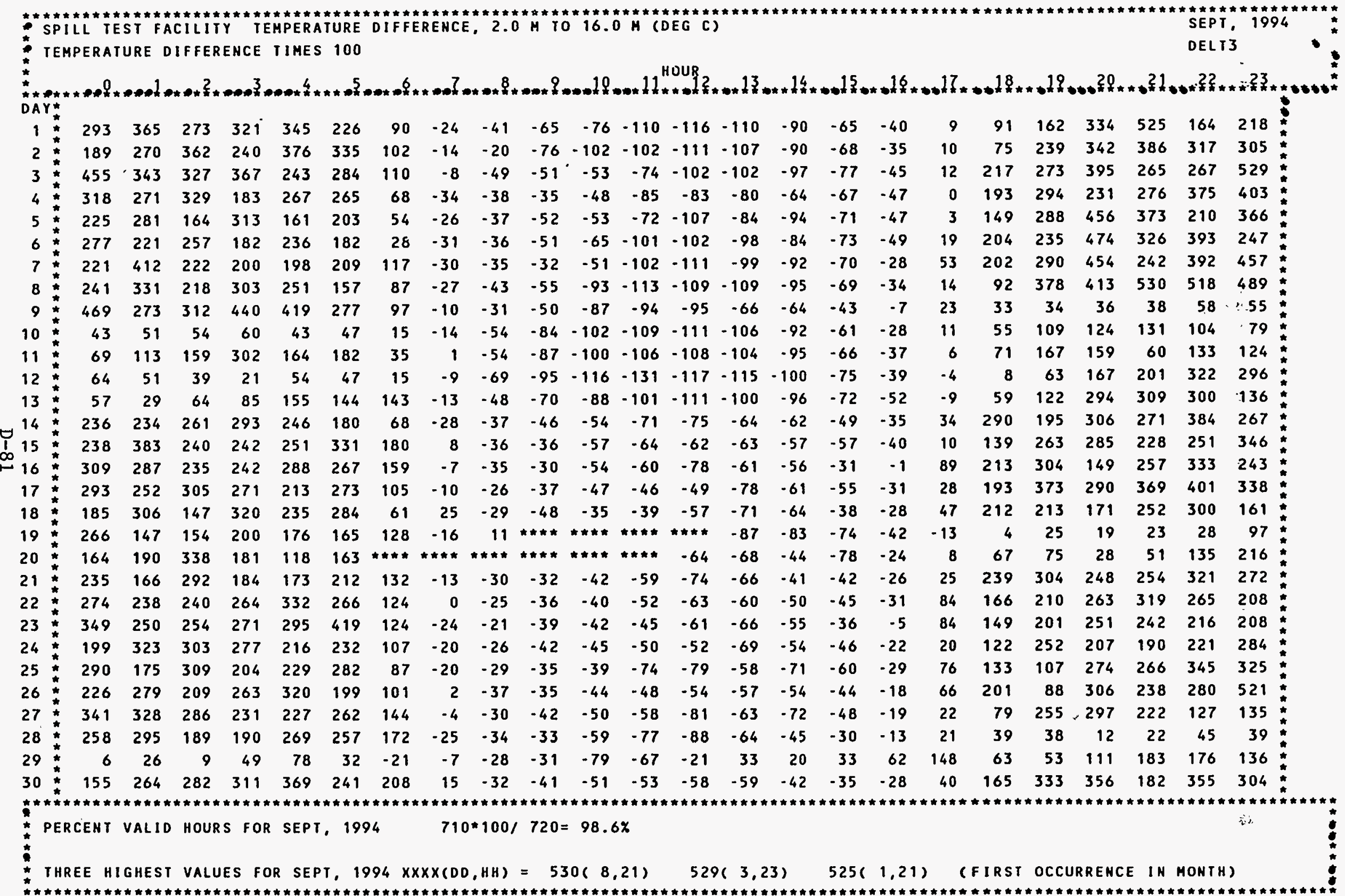




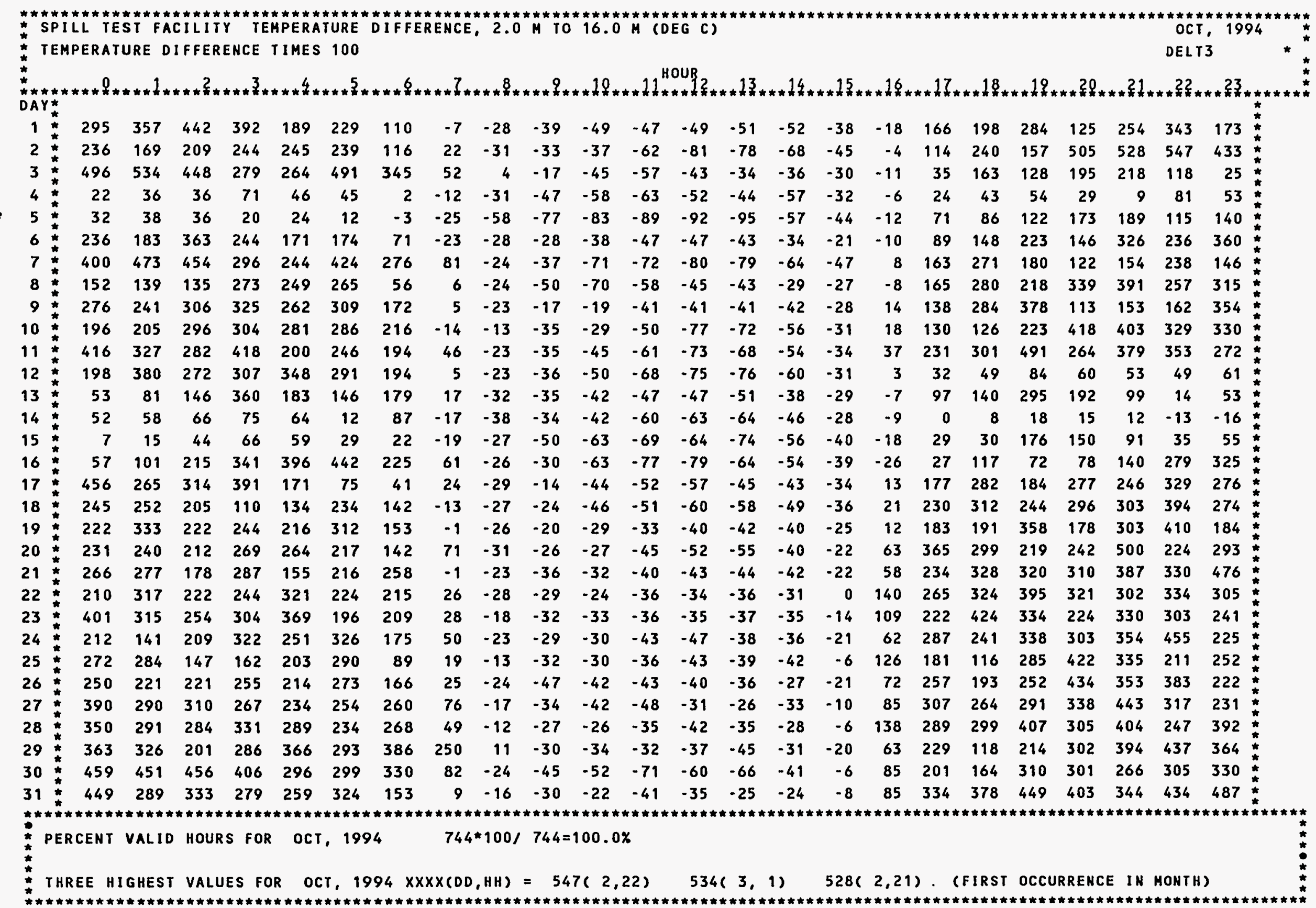




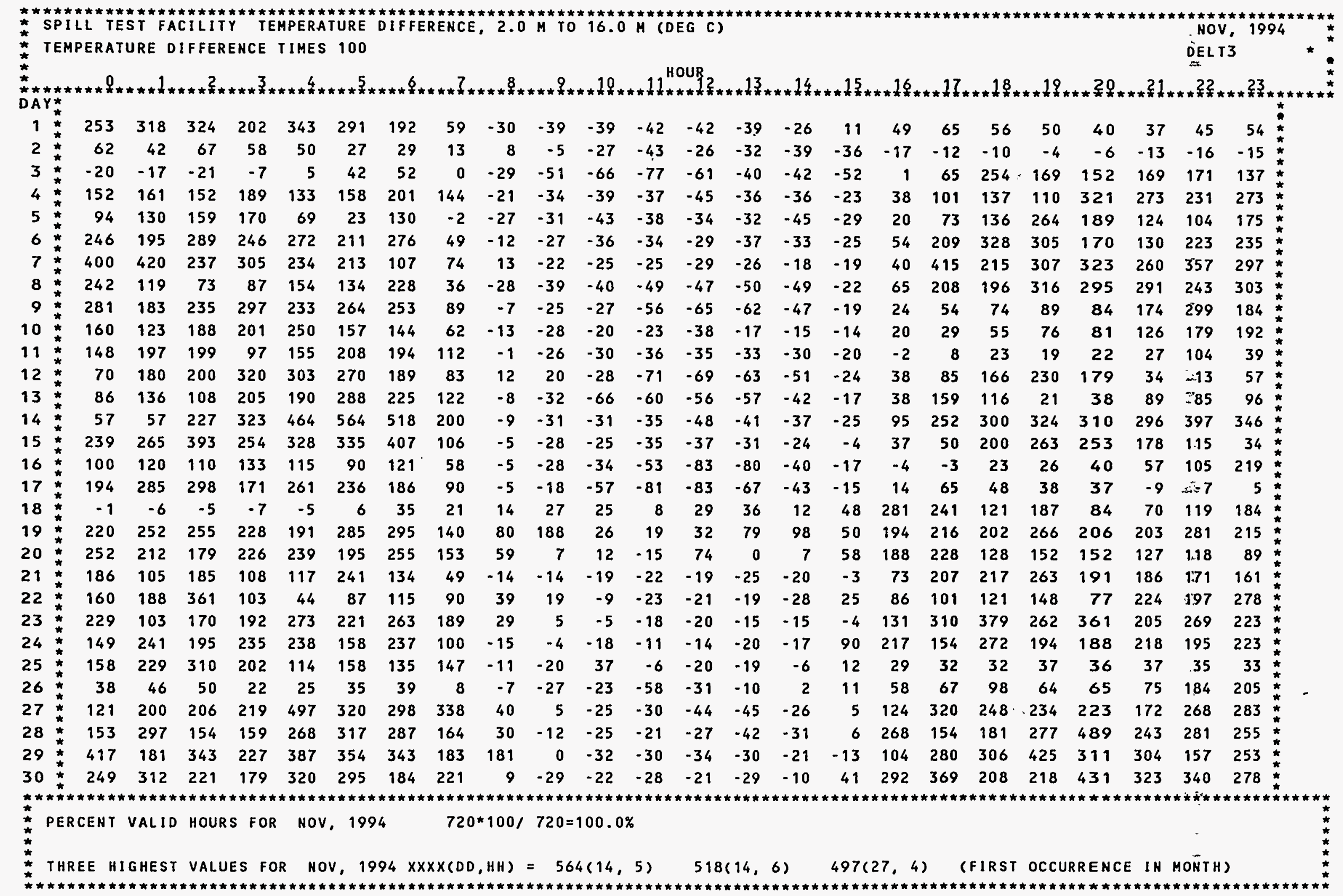




\begin{tabular}{|c|c|c|c|c|c|c|c|c|c|c|c|c|c|c|c|c|c|c|c|c|c|c|c|}
\hline 248 & 278 & 253 & 250 & 184 & 176 & 300 & 128 & 86 & -30 & -17 & -19 & -25 & -21 & -9 & 20 & 65 & 232 & 249 & 310 & 225 & 284 & 28 & 73 \\
\hline 175 & 345 & 364 & 251 & 300 & 247 & 283 & 145 & -9 & -23 & -36 & -38 & -45 & -35 & -28 & 85 & 238 & 305 & 387 & 133 & 270 & 239 & 199 & 251 \\
\hline 293 & 261 & 99 & 44 & 194 & 343 & 123 & 156 & 35 & 15 & -16 & -21 & -21 & -6 & 18 & 68 & 153 & 190 & 187 & 152 & 210 & 122 & 282 & 163 \\
\hline 268 & 186 & 15 & 235 & 248 & 297 & 175 & 61 & 13 & -17 & -18 & 30 & -1 & -8 & 18 & 49 & 122 & 176 & 90 & 117 & 144 & 79 & 146 & 87 \\
\hline 172 & 29 & 120 & 193 & 309 & 272 & 445 & 166 & 37 & -4 & -22 & -19 & -42 & -46 & -42 & -14 & 67 & 43 & 90 & 301 & 216 & 102 & 116 & 179 \\
\hline 116 & 153 & 258 & 140 & 249 & 150 & 246 & 108 & 1 & -20 & -37 & -26 & -40 & -47 & -27 & 10 & 77 & 140 & 157 & 171 & 137 & 112 & 243 & 234 \\
\hline 229 & 187 & 153 & 64 & 140 & 197 & 132 & 76 & 27 & -16 & -21 & -35 & -34 & -32 & -21 & 12 & 125 & 129 & 194 & 111 & 301 & 354 & 375 & 233 \\
\hline 355 & 223 & 249 & 459 & 344 & 142 & 182 & 96 & 22 & -17 & -39 & -57 & -51 & -46 & .33 & 15 & 199 & $\star \star \star * \star$ & $\star * * *$ & $\star \star \star \star \star$ & $\star * \star \star *$ & $\star \star \star \star \star *$ & $\star \star * \star$ & $\star * *$ \\
\hline$\star \star \star \star \star *$ & $\star \star *$ & $* \star \star$ & $\star \star \star \star$ & $\star \star \star \star$ & $* * \star *$ & $\star \star \star \star *$ & $\star \star \star \star$ & $\star \star \star \star$ & $\star \star \star \star$ & $\star \star \star \star$ & $* \star \star \star$ & $\hbar \star \star \star$ & $\star \star \star \star \star$ & $\star \star \star \star$ & $* \star \star$ & $\star \star \star \star$ & $\star \star \star \star \star$ & $\star \star \star \star \star$ & $\star \star \star \star$ & $\star \star \star \star$ & * * & 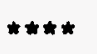 & $\star \star \star \star \star$ \\
\hline$* *^{*}$ & $* \star$ & $\star \star \star \star \star$ & $\star \star * * \star$ & 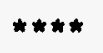 & $\star \star \star \star \star \star$ & $\star \star \star \star \star *$ & & $\star * * *$ & $\star \star \star \star \star$ & $\star * * \star$ & & & & $\star \star \# * *$ & & $\star \star \star \star$ & $\star \star \star \star \star$ & & & $\# \star \star \star$ & & & \\
\hline$* \star \star * *$ & $\star \star *$ & $\star \star \star \star \star *$ & $\star \star \star \star \star$ & $\star \star \star \star \star$ & $* \star \star$ & $\star \star \star \star \star$ & $\star \star \star \star \star *$ & $\star \star \star *$ & $\star \star \star \star \star$ & $* * *$ & $* \star \star *$ & $\star \star \star$ & $\star \star$ & $\star \star \star \star$ & 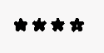 & 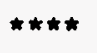 & $\star \star \star \star \star$ & $\star \star \star \star$ & $\star \star \star \star *$ & $\star \star \star \star$ & $\star \star \star \star \star *$ & $\star \star * *$ & $\star \star \star *$ \\
\hline$* * * *$ & $\# * * *$ & $\star * * *$ & $\star *$ & $\star \star$ & & $\star * * *$ & & & & & & & & 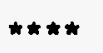 & & & & & & & & & \\
\hline 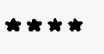 & $\star \star \star \star * *$ & $\star \star \star \star \star$ & 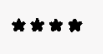 & $\star \star \star$ & * * & $* * *$ & $*$ & * & * * & $\star \star$ & $*$ & $\star \star$ & $\star \star$ & 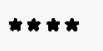 & 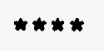 & 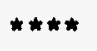 & $\star * * *$ & 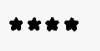 & $*$ & $\hbar * \star \star *$ & 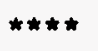 & & tro \\
\hline$\star * * * *$ & $\star * * *$ & $\star \star * \star *$ & $\star \star * \star *$ & $\star \star \star \star \star \star$ & $\star * \star * *$ & $\star * * *$ & 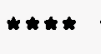 & $\hbar * \star *$ & $\star \star \star \star \star *$ & $\star \star * \star \star \star$ & $\star \star \star \star \star$ & $\star \star * * \star$ & $\star \star$ & $\star \star * \star \star \star *$ & $\star \star \star \star \star *$ & $\star \star \star \star \star$ & $\star \star \star \star$ & $\star \star \star \star \star \star *$ & * & $\star \star \star \star \star \star$ & $\star \star \star \star \star$ & $\star \star$ & $\star \star \star \star \star$ \\
\hline & $\star \star \star \star \star *$ & 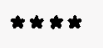 & & & & $* \star \star$ & & & & & & & & $* * \star *$ & & * & $\star$ & $\star$ & & $* * *$ & $\star$ & & \\
\hline 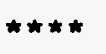 & 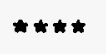 & $\hbar \hbar \hbar \star$ & $\star \star \star \star \star$ & $\star \star \star \star \star$ & $\star \star \star \star$ & $\hbar \star \star \star$ & $\star \star \star \star \star *$ & $\star \star \star \star *$ & $\star \star \star \star \star \star$ & $\star \star \star \star$ & $* \star \star$ & $* *$ & $\star \star$ & $\star \star \star \star \star$ & $\star \star * \star \star$ & $\star \star \star \star \star$ & $\star \star \star \star$ & $\star \star \star \star \star$ & $\star \star \star \star *$ & $\star * * \star$ & $\star \star \star \star *$ & $* *$ & $\hbar \star \star \star *$ \\
\hline$\pi \star \star \star \star *$ & $\# \star \star *$ & $\star \star \star \star * *$ & $\star * * * *$ & $\star \star \star \star \star *$ & $\star \star \star * *$ & $\star * * *$ & 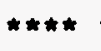 & $\star \star * * *$ & $\star \star \star * *$ & $\star \star * \star \star$ & $\star * * *$ & $\| \star * *$ & & $\star \star \star * \star$ & & $\star *$ & $\star \star \star \star \star$ & $* \hbar *$ & * & $\star \star$ & $\star \star$ & ** & $\star \star \star \star \star$ \\
\hline$\star \star \star \star \star$ & $\star \star \star \star$ & $\star \star \star \star \star$ & $\star \star$ & $* \star \star$ & $\hbar \star \star$ & $\star \star \star \star$ & * & * & & & & & & $\star \star \star \star$ & $* * *$ & $\star *$ & 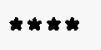 & $\star$ & & 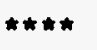 & $*$ & & \\
\hline$\star \star \star *$ & $\neq \star \star \star \star *$ & 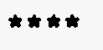 & $\star \star \star \star \star *$ & $* * * *$ & 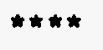 & 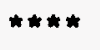 & $\star \star * * *$ & $* * * *$ & $\hbar \star \star \star * *$ & 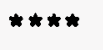 & $\hbar \hbar \hbar \star$ & $\star \star \star \star \star *$ & $\star \star \star \star \star$ & $\hbar \star \star \star \star$ & 4 & 172 & 185 & 358 & 521 & 499 & 34 & 17 & 131 \\
\hline 280 & 296 & 312 & 309 & 242 & 379 & 291 & 254 & 70 & 3 & -55 & & -62 & -52 & -25 & 131 & 216 & 380 & 342 & 510 & 543 & 278 & 37 & 276 \\
\hline 336 & 308 & 339 & 361 & 273 & 344 & 213 & 2 & 3 & -40 & -47 & 58 & 5 & -54 & -35 & 88 & 342 & 220 & 372 & 5 & & 165 & 255 & 205 \\
\hline 216 & 285 & 238 & 335 & 278 & 210 & 162 & 014 & 3 & 13 & -29 & 9 & 15 & -6 & 48 & 92 & 131 & 108 & 116 & 162 & 152 & 132 & 211 & 168 \\
\hline 184 & 93 & 67 & 86 & 113 & 133 & 82 & 142 & 17 & -4 & -48 & -57 & -53 & -49 & -47 & -42 & 33 & 7 & 5 & -12 & -9 & 2 & 18 & 9 \\
\hline 15 & -26 & 2 & -11 & -14 & -14 & 8 & -6 & 34 & -44 & -54 & -55 & -51 & -51 & -47 & -37 & 24 & 2 & 56 & 43 & -40 & -25 & 0 & -1 \\
\hline 4 & 21 & -29 & 17 & 26 & -6 & 19 & -38 & -72 & -103 & -39 & -42 & -59 & -55 & -55 & -45 & -25 & -9 & -10 & 8 & 22 & -10 & 51 & 65 \\
\hline 25 & 29 & -2 & 107 & 92 & 170 & 121 & 89 & 26 & -13 & -36 & -45 & -47 & -44 & -38 & 1 & 63 & 24 & 33 & 45 & 89 & 69 & 65 & 142 \\
\hline 124 & 109 & 137 & 146 & 107 & 58 & 120 & 43 & 31 & 28 & -37 & -56 & -50 & -55 & -47 & -18 & 67 & 144 & 34 & 101 & 112 & 158 & 97 & 37 \\
\hline 65 & 43 & 70 & 33 & 39 & 65 & 64 & 67 & -14 & -46 & -33 & -48 & -61 & -58 & -46 & -43 & -26 & -19 & -10 & -33 & -57 & -18 & -4 & -34 \\
\hline-8 & -17 & -25 & -37 & -42 & -25 & -2 & -4 & -35 & -45 & -47 & -48 & -49 & -48 & -42 & -33 & -16 & -17 & 24 & 16 & -3 & 15 & -7 & -3 \\
\hline 25 & 85 & 53 & 68 & 67 & 45 & 18 & -25 & -7 & -33 & -54 & -67 & -61 & -50 & -49 & -45 & -14 & 54 & 46 & 78 & 171 & 49 & 107 & 86 \\
\hline 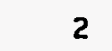 & 26 & -1 & -32 & -35 & -29 & -8 & -35 & -46 & -30 & -17 & -61 & -55 & -65 & -58 & -48 & 38 & 101 & 135 & 161 & 11 & 101 & 121 & 43 \\
\hline
\end{tabular}




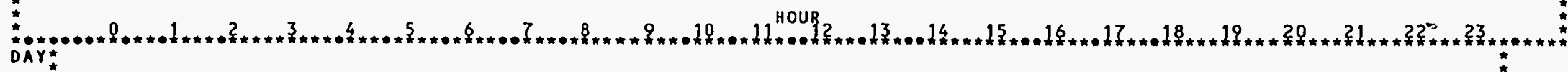




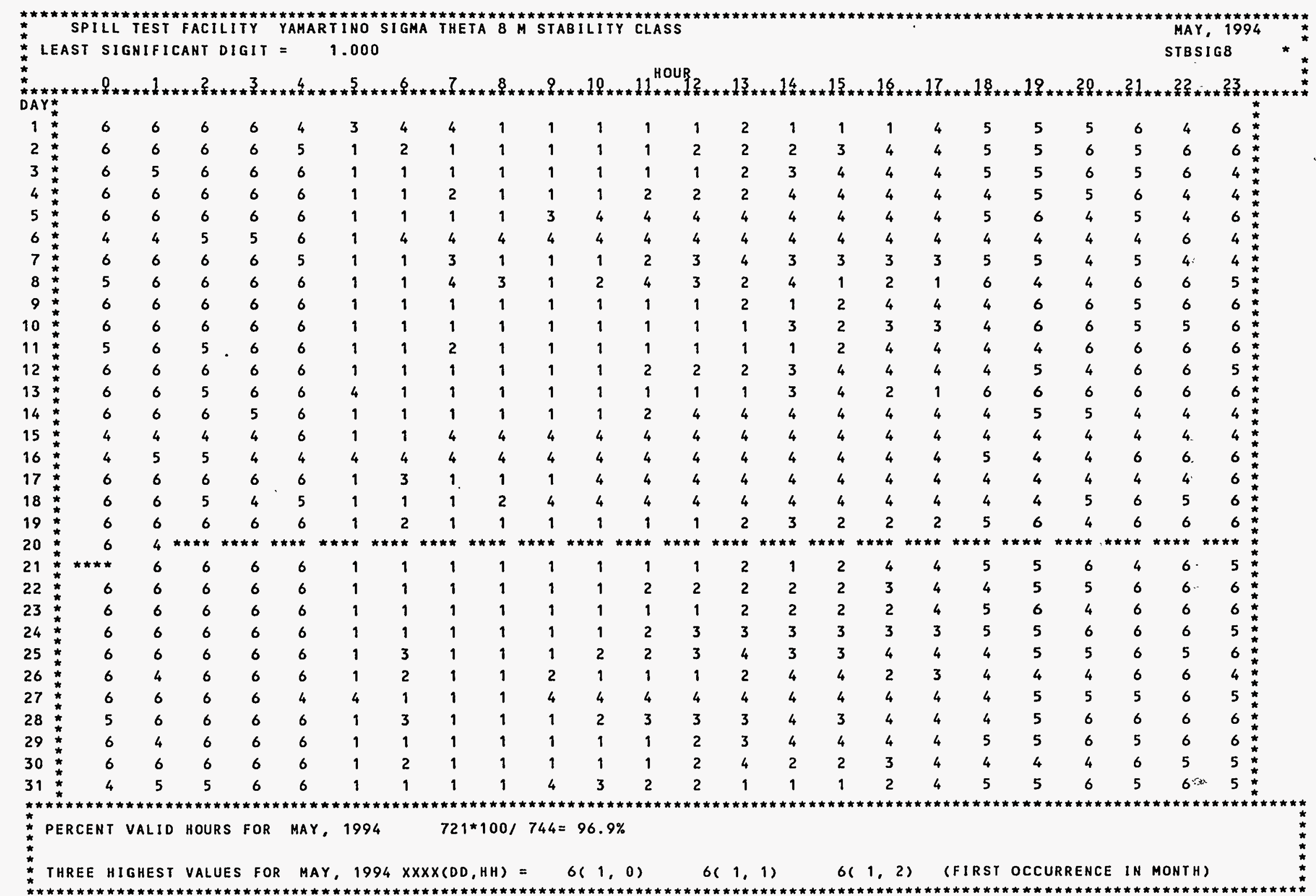


SPILL TEST FACILITY YAMARTINO SIGMA THETA 8 M STABILITY CLASS

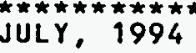

LEAST SIGNIFICANT DIGIT =

1.000

STBSIG8

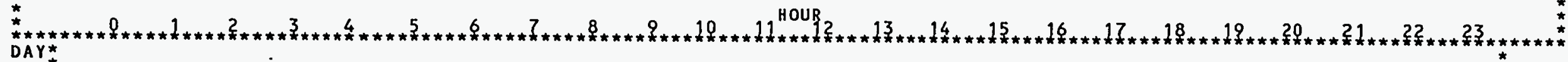

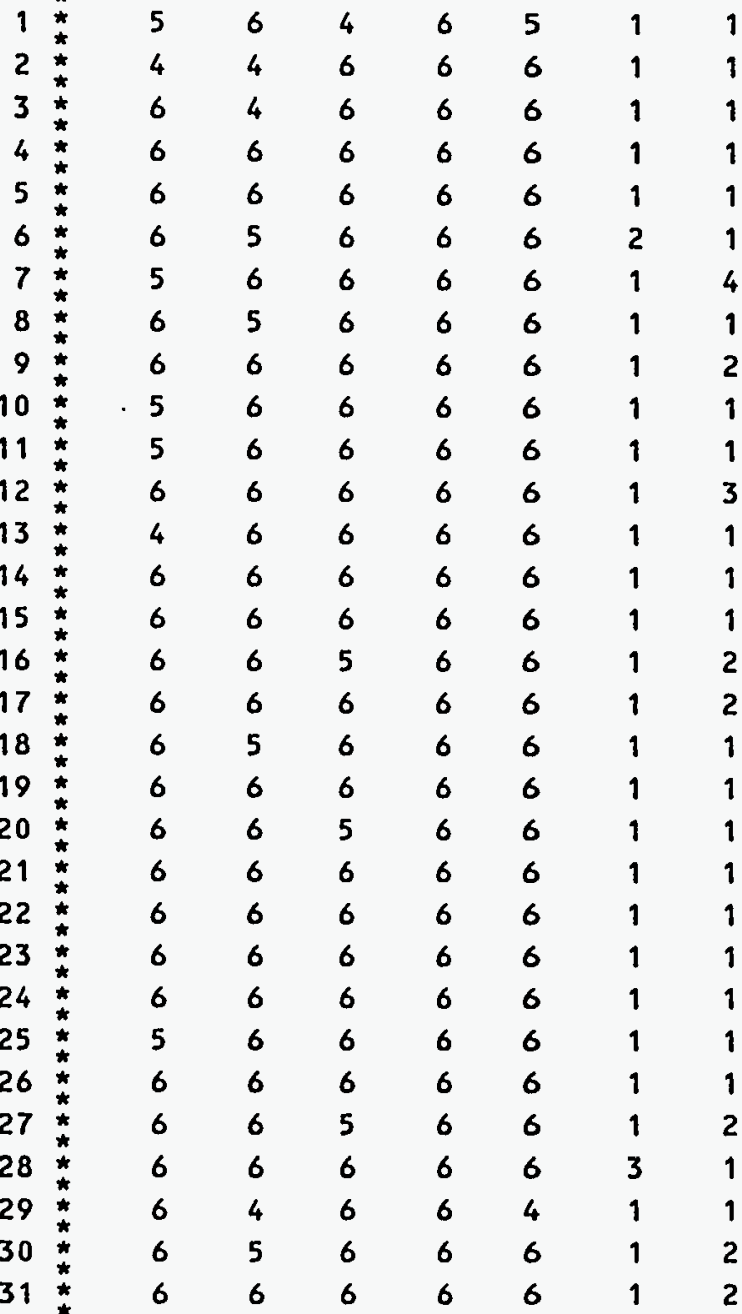




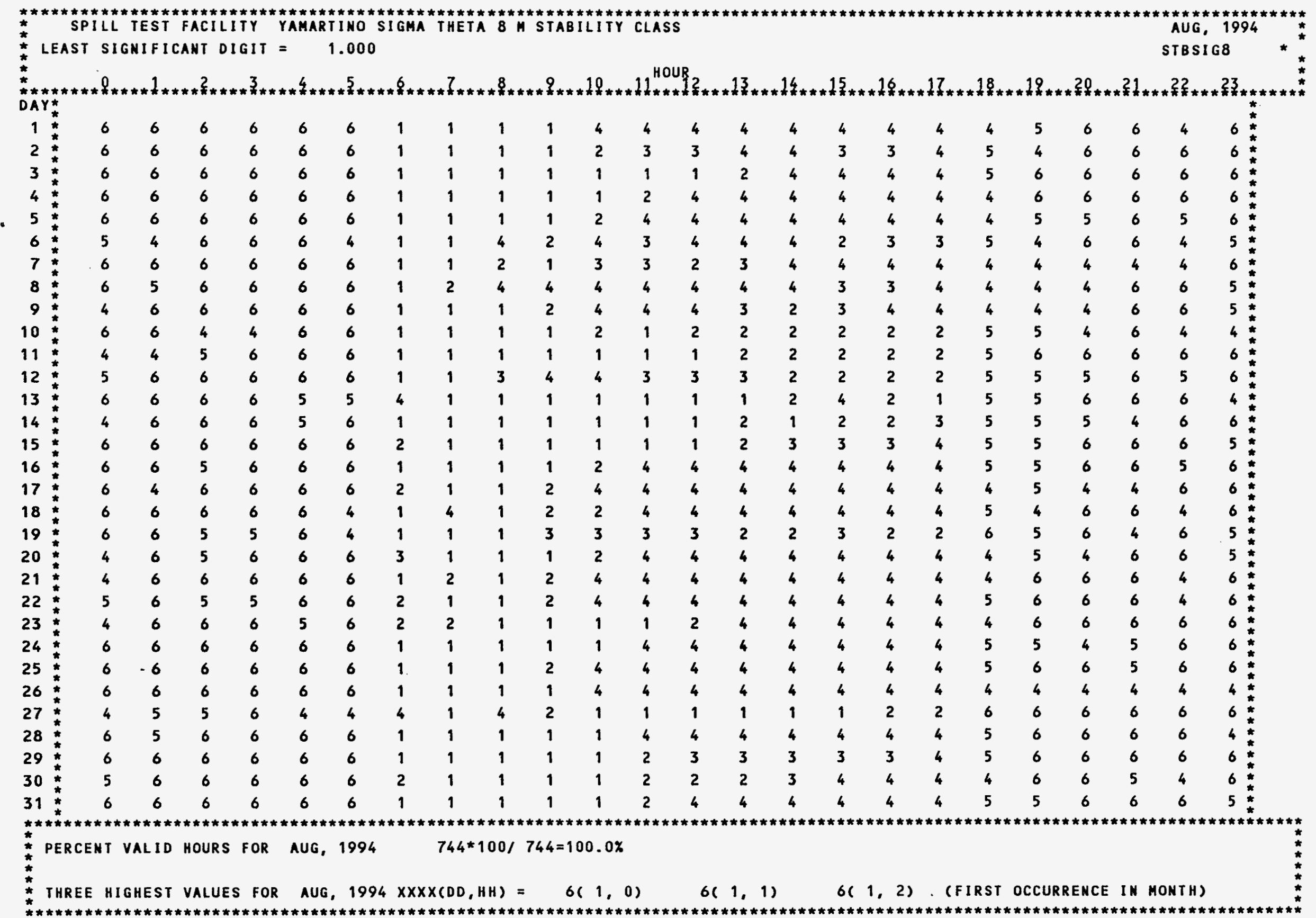


SPILL TEST FACILITY YAMARTINO SIGMA THETA 8 M MTABILITY CLASS

* LEAST SIGNIFICANT DIGIT $=1.000$

SEPT, 1994

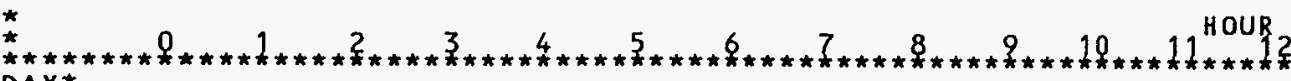

STBSIG 8

草

DAY*

$\begin{aligned} & 1 \star \\ & 2 \star \\ & 2 \star \\ & 3 \star \\ & 3 \star \\ & 4 \star \\ & 5 \star \\ & 5 \star \\ & 6 \star \\ & 6 \star \\ & 7 \star \\ & 8 \star \\ & 8 \star \\ & 9 \star \\ & 10 \star \\ & 10 \star \\ & 11 \star \\ & 12 \star \\ & 13 \star \\ & 13 \star \\ & 14 \star \\ & 15 \star \\ & 15 \star \\ & 16 \star \\ & 17 \star \\ & 18 \star \\ & 18 \star \\ & 19 \star \\ & 20 \star \\ & 20 \star \\ & 21 \star \\ & 22 \star \\ & 22 \star \\ & 23 \star \\ & 24 \star \\ & 24 \star \\ & 25 \star \\ & 26 \star \\ & 26 \star \\ & 27 \star \\ & 28 \star \\ & 29 \star \\ & 30 \star \\ & 30 \star \\ & 1 \star \\ & * \star \\ & *\end{aligned}$

$\begin{array}{lll}6 & 6 & 6 \\ 6 & 6 & 6 \\ 6 & 6 & 5 \\ 6 & 5 & 4 \\ 4 & 6 & 5 \\ 6 & 6 & 4 \\ 6 & 4 & 6 \\ 6 & 6 & 6 \\ 6 & 6 & 6 \\ 4 & 4 & 4 \\ 4 & 4 & 4 \\ 4 & 4 & 4 \\ 5 & 6 & 6 \\ 5 & 6 & 6 \\ 5 & 6 & 6 \\ 5 & 6 & 4 \\ 5 & 6 & 6 \\ 6 & 4 & 4 \\ 6 & 6 & 4 \\ 6 & 4 & 4 \\ 6 & 5 & 5 \\ 6 & 6 & 5 \\ 6 & 6 & 6 \\ 6 & 6 & 6 \\ 5 & 6 & 5 \\ 6 & 6 & 5 \\ 6 & 5 & 6 \\ 6 & 6 & 6 \\ 5 & 6 & 5 \\ 6 & 6 & 6 \\ 4 x & 44 & 6\end{array}$

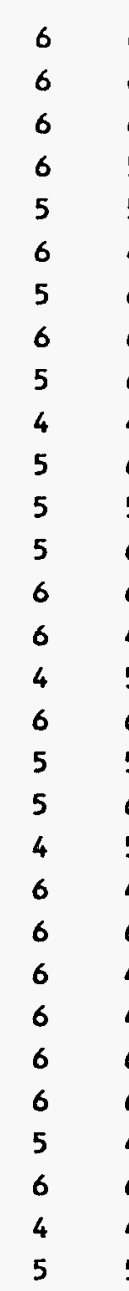

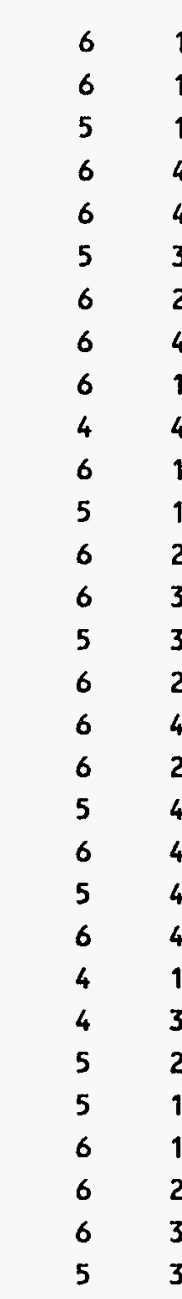

* PERCENT VALID HOURS FOR SEPT, 1994

$720 * 100 / 720=100.0 \%$

* THREE HIGHEST VAlUeS FOR SEPT, $1994 \times x \times x \times(D D, H H)=6(1,0)$

$6(1,1)$ 


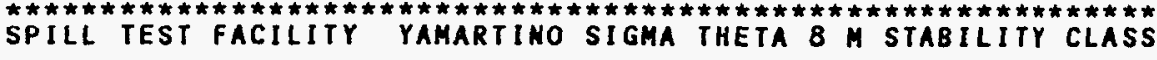

* Least SIghificant digit = 1.000

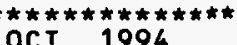

STBSIG8

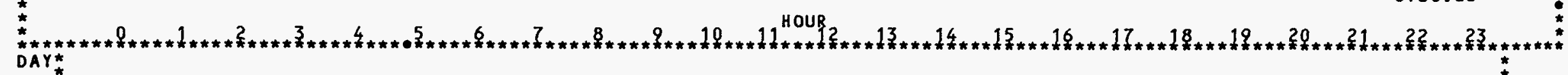

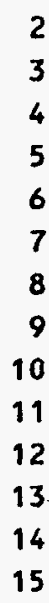

$20 *$

21

22

23

25

\begin{tabular}{|c|c|c|c|c|c|c|}
\hline 6 & 4 & 5 & 6 & 4 & 3 & 3 \\
\hline 5 & 6 & 6 & 4 & 5 & 3 & 4 \\
\hline 4 & 6 & 6 & 6 & 6 & 3 & 4 \\
\hline 4 & 6 & 4 & 5 & 4 & 1 & 1 \\
\hline 5 & 4 & 4 & 4 & 4 & 4 & 4 \\
\hline 5 & 4 & 4 & 4 & 4 & 4 & 4 \\
\hline 5 & 4 & 5 & 4 & 6 & 1 & 1 \\
\hline 5 & 5 & 6 & 6 & 6 & 1 & 1 \\
\hline 6 & 5 & 4 & 4 & 4 & $\star \star \star \star \star$ & 4 \\
\hline 5 & 5 & 6 & 6 & 6 & $\star \star \star \star \star *$ & 4 \\
\hline 6 & 5 & 6 & 6 & 4 & 4 & 4 \\
\hline 4 & 4 & 6 & 6 & 4 & 4 & 4 \\
\hline 4 & 6 & 4 & 5 & 5 & 1 & 4 \\
\hline 4 & 4 & 6 & 6 & 6 & 2 & 3 \\
\hline 4 & 5 & 4 & 6 & 4 & 4 & 3 \\
\hline 6 & 6 & 4 & 5 & 5 & 1 & 1 \\
\hline 6 & 4 & 5 & 5 & 5 & 4 & 4 \\
\hline 5 & 4 & 5 & 4 & 5 & 1 & 4 \\
\hline 4 & 4 & 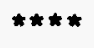 & 6 & 5 & 4 & 4 \\
\hline 5 & 5 & 6 & 6 & 5 & 3 & 3 \\
\hline 6 & 6 & 4 & $\star \star \star \star \star$ & 6 & 4 & 4 \\
\hline 5 & 6 & 5 & 4 & 6 & 4 & 4 \\
\hline 5 & 5 & 5 & 5 & 5 & 4 & 4 \\
\hline 6 & 6 & 6 & 6 & 5 & 1 & 4 \\
\hline 5 & $\star \star \star \star *$ & 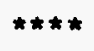 & 5 & $\star * * * *$ & 2 & $\star \star \star \star * \star$ \\
\hline & $\star \star \star * *$ & $\star \star \star * \star *$ & 6 & 4 & 4 & 4 \\
\hline 4 & 4 & 6 & 4 & 6 & 4 & 4 \\
\hline 6 & 6 & 5 & 5 & 6 & 4 & 3 \\
\hline 6 & 6 & 6 & 6 & 6 & 3 & 1 \\
\hline 6 & 6 & 6 & 5 & 6 & 1 & 1 \\
\hline 6 & 6 & 6 & 6 & 6 & 4 & 3 \\
\hline
\end{tabular}

$\begin{array}{ll}3 & 3 \\ 4 & 2 \\ 4 & 4 \\ 4 & 4 \\ 4 & 4 \\ 3 & 4 \\ 4 & 1 \\ 1 & 1 \\ 4 & 4 \\ 2 & 1 \\ 3 & 1 \\ 4 & 4 \\ 3 & 1 \\ 3 & 2 \\ 1 & 2 \\ 4 & 2 \\ 2 & 1 \\ 3 & 1 \\ 3 & 1 \\ 4 & 3 \\ 1 & 3 \\ 4 & 4 \\ 2 & 2 \\ 2 & 3 \\ 4 & 1 \\ 4 & 2 \\ 4 & 3 \\ 4 & 1 \\ 4 & 1 \\ 3 & 3 \\ 1 & 1\end{array}$




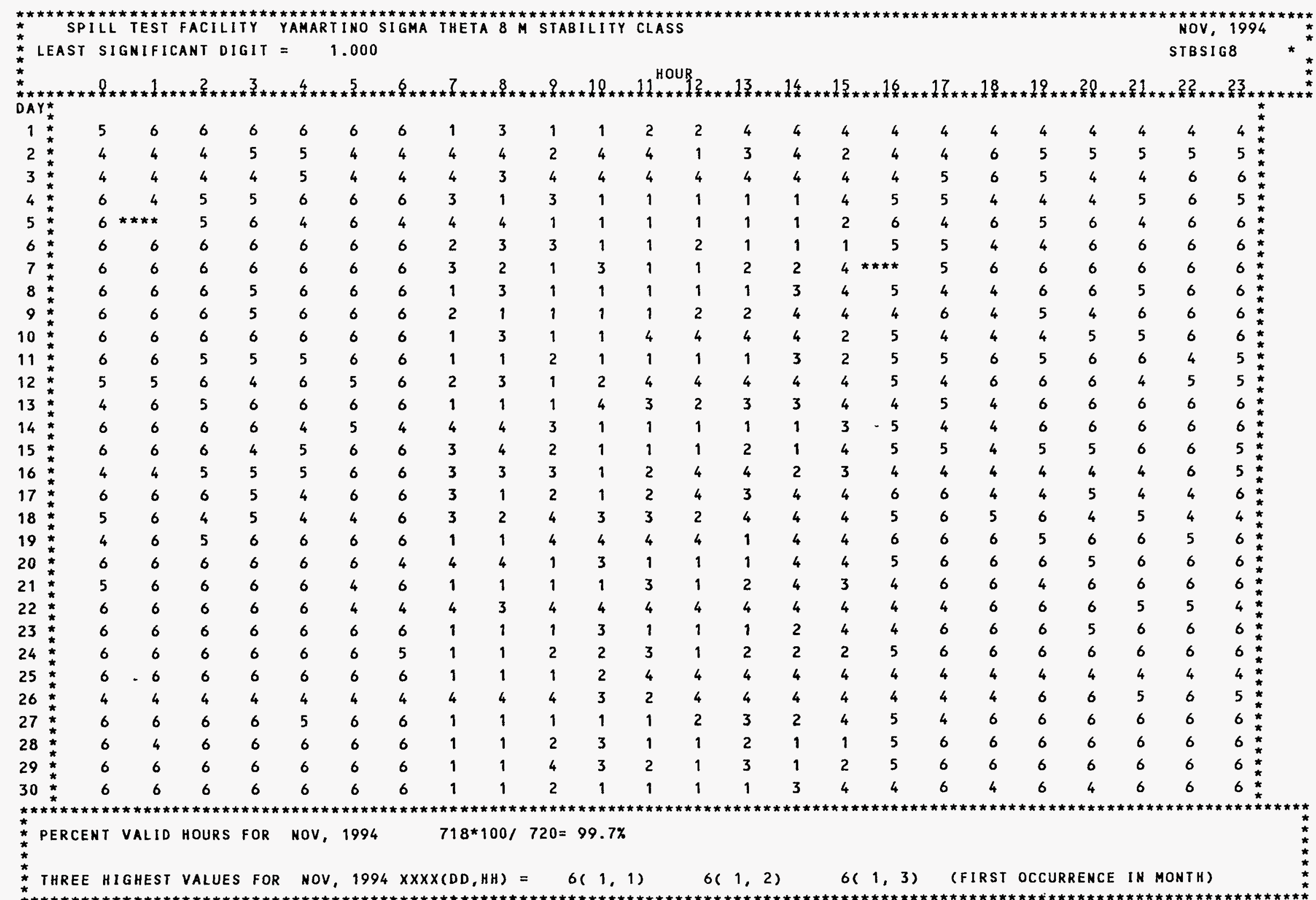


SPILL TESTFACILITY YAMARTINO SIGMA THETA B M STABILITY CLASS Least Significant digit $=\mathbf{1 . 0 0 0}$

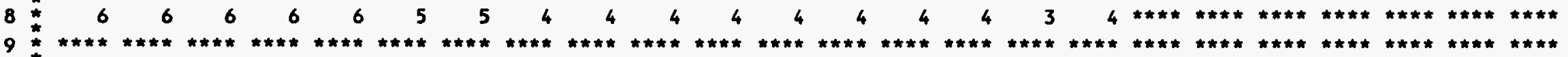

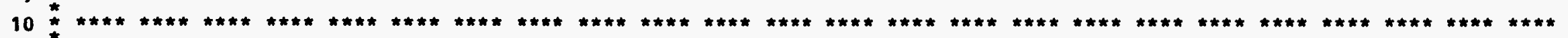

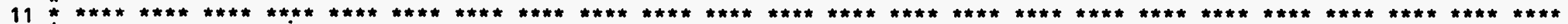

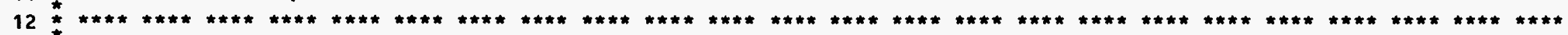

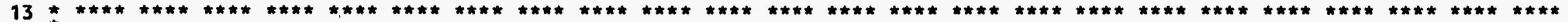

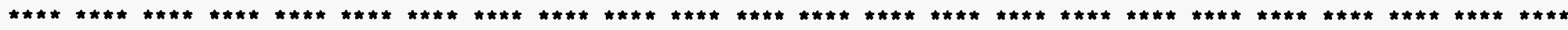

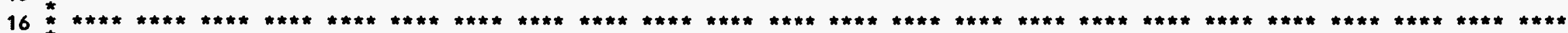

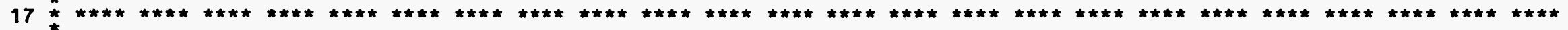

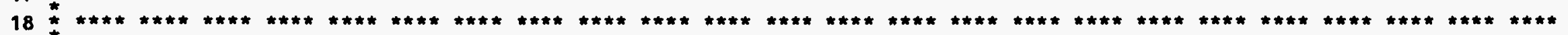

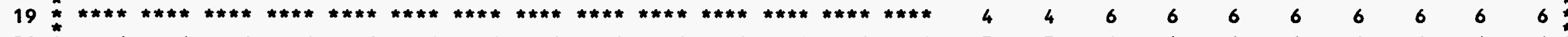

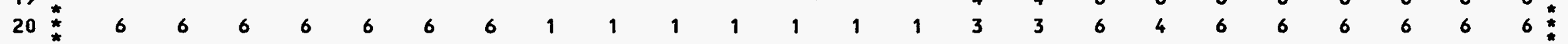

